Fuertes Prieto, María Natividad

Estudio tecnológico de las industrias líticas del Paleolítico Superior y del Epipaleolítico de la Cuenca del Duero [Recurso electrónico] / $\mathrm{M}^{\mathrm{a}}$ Natividad Fuertes Prieto. -- [León] : Universidad de León, Área de Publicaciones, 2010

1 disco compacto (CD-ROM) : il., graf., fot. ; $12 \mathrm{~cm}$

Tesis-Universidad de León, 2004. - Bibliogr. - Datos. -- Fecha de defensa, 26$11-2004$

ISBN 978-84-9773-533-9

1. Universidad de León-Tesis y disertaciones académicas-2004. 2. Utensilios de piedra-España-Duero, Cuenca del. 3. Excavaciones (Arqueología)-España-Duero, Cuenca del. 4. El Expertín (León, España). 5. Paleolítico-España-Duero, Cuenca del. I. Título. II. Universidad de León. Área de Publicaciones

903.21"6325”(282.246.24)(043.2)

903.21”6328”(282.246.24)(043.2)

Tesis defendida con fecha 26/11/2004

\title{
TRIBUNAL:
}

González Morales Manuel R. (presidente)

Neira Campos, Ana (secretario)

Alonso Herrero, Eduardo (vocal)

Valdeyrón, Nicolás (vocal)

Fernández Rodríguez, Carlos (vocal)

(C) Universidad de León

I.S.B.N. 978-84-9773-533-9

Depósito Legal: LE-1118-2010 


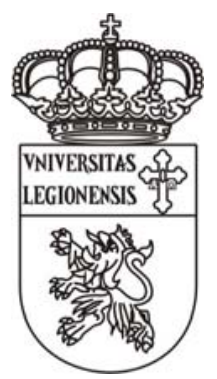

UNIVERSIDAD DE LEÓN

FACULTAD DE FILOSOFÍA Y LETRAS

DEPARTAMENTO DE ESTUDIOS CLÁSICOS

ESTUdIO TECNOLÓGICO DE LAS INDUSTRIAS LÍTICAS Del Paleolítico SuPerior y DeL Epipaleolítico de la Cuenca del Duero

$M^{\mathrm{a}}$ Natividad Fuertes Prieto

León, 2004 



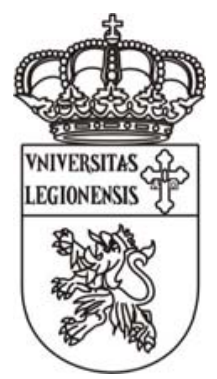

UNIVERSIDAD DE LEÓN

FACULTAD DE FILOSOFÍA Y LETRAS

DEPARTAMENTO DE ESTUDIOS CLÁSICOS

\section{ESTUDIO TECNOLÓGICO DE LAS INDUSTRIAS LÍTICAS Del Paleolítico SuPerior y DeL Epipaleolítico de la Cuenca del Duero}

Memoria presentada para optar al Grado de Doctor por

$M^{\mathrm{a}}$ Natividad Fuertes Prieto

León, 2004 



\section{AGRADECIMIENTOS}

Quisiera agradecer en estas primeras líneas a aquellas personas que me han prestado su apoyo a lo largo de la realización de esta tesis.

En primer lugar al Dr. F. Bernaldo de Quirós, Catedrático de Prehistoria de la Universidad de León por aceptar dirigir este trabajo. A la Dra. A. Neira Campos, Profesora Titular en la misma Universidad, quien, al lado del anterior, me animó a emprender el estudio de la tecnología lítica. Sus consejos y la colaboración con ambos han sido determinantes no solo en el desarrollo de esta tesis, sino en mi formación de tipo más amplio dentro de la Prehistoria.

A mis compañeros en el Área de Prehistoria de la Universidad de León: al Dr. C. Fernández Rodríguez, por su tiempo, por sus prácticas sugerencias y pacientes consejos; y a Dña. L. Pérez Ortiz, compañera en el proceso de realización de esta tesis.

Al Dr. J. M. Maíllo Fernández, amigo y compañero, por las conversaciones, consultas, recomendaciones y apoyo que me ha ofrecido en todo momento.

A los miembros de la sección de Archéologie et Technologie de la Maison d'Archéologie et Ethnologie de la Université Paris-X-Nanterre, por habernos acogido tan formidablemente en la estancia allí desarrollada; especialmente a J. Pelegrin y E. Boëda, quienes amablemente fueron nuestros tutores en nuestra formación sobre la tecnología lítica. A C. Karlin, por atender nuestras dudas sobre la "cadena operativa”; a P. Bodu y a J.-M. Geneste, por recibirnos en sus clases. Queremos expresar también un agradecimiento muy especial a J. Tixier, por atendernos tan amablemente y aconsejarnos sobre los problemas del vocabulario en tecnología lítica. También a J. Féblot-Agustins, quien nos asesoró en el reconocimiento de las materias primas, y también nos facilitó una plantilla para sistematizar este tipo de analítica. Sin olvidar tampoco a la directora del departamento, V. Roux, quien facilitó nuestra estancia allí.

A los miembros de la Université de Paris-I, N. Pigeot y B. Valentin, que nos recibieron y permitieron asistir a sus clases. Especialmente agradecemos el habernos facilitado la estancia en el Étage de Etiolles. 
A la Dra. V. Cabrera Valdés, por acogernos en el equipo de la Cueva de El Castillo, las excavaciones allí han sido muy importantes para nuestra formación.

Asimismo, al resto de los directores de las excavaciones de las que he formado parte, especialmente a los Dres. J. González Echegaray y L. G. Freeman, quienes amablemente nos permitieron formar parte del equipo de la Cueva del Juyo. También al Dr. A. Turq, que nos facilitó nuestra incorporación a la excavación de la cueva de Isturitz.

A la Dra. N. Cazals, por invitarnos al Project Collectif de Recherche (P.C.R.), Midi-Pyrénées “Comportements techiques et économiques des sociétés au Paléolithique Supérieur dans le contexte Pyrénéen. Apports de la technologie lithique”, proyecto en el que hemos sido acogidos y que nos ha facilitado el contacto con un amplio grupo de prehistoriadores. La colaboración, los consejos y los debates en este foro han sido esenciales para el desarrollo de este trabajo y, en general, para concretar de forma más eficaz y práctica nuestras ideas respecto a la tecnología lítica.

A los miembros de este P.C.R.: F. Bon, X. Terradas, J.-P. Bracco, I. Ortega, D. Ortega, J.E. González Urquijo, X. Mangado, A. Tarriño, etc.

Al Dr. E. Alonso Herrero, geólogo de la Universidad de León, por haberme ayudado con el tema de las materias primas, especialmente en la localización de los afloramientos de chert y radiolarita.

A R. Ma Yágüez por la realización de algunos de los dibujos.

A J. M. Fuertes Prieto, por su ayuda en la elaboración de las figuras y esquemas, así como en otros problemas de tipo informático; además de la impresión de la presente memoria. 
Finalmente, quiero dejar constancia de un agradecimiento muy especial hacia aquéllos a quien dedico este trabajo:

A mis padres, Laurentino y $M^{a}$ Luisa, y hermanos, José Miguel, Ana y Alejandro.

Tampoco quiero olvidar en estos agradecimientos a Sagrario Prieto y a mis amigos y amigas en general; todos ellos me han apoyado pacientemente a lo largo de estos años, brindándome en todo momento su ánimo, comprensión y cariño.

Y a la memoria de Natividad Santiago Francisco, su inteligencia práctica y cotidiana ha sido y es un ejemplo que sigue presente. 



\section{ÍNDICE}

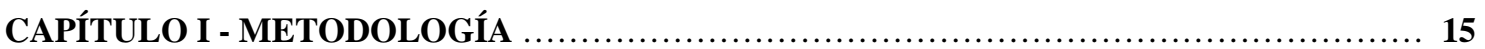

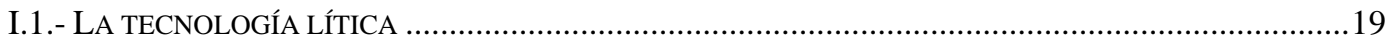

I.1.1.- Tecnología y técnica .........................................................................................19

I.1.2.- La tecnología lítica en Prehistoria ..........................................................................27

I.2. MÉTODO DE ANÁLISIS TECNOLÓGICO APLICADO .....................................................................4

I.2.1.- Niveles de análisis: esquema técnico, operativo y conceptual ...................................41

I.2.2.- Estructura ideal de una cadena operativa de débitage laminar.................................43

I.2.3.- Reconstrucción del esquema técnico: análisis empírico del material lítico ...............50

I.2.4.- Reconstrucción de los esquemas operativos...............................................................92

I.2.5.- Reconstrucción de la cadena operativa .....................................................................94

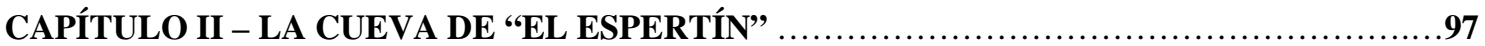

II. 1- CARACTERÍSTICAS GENERALES DE LA CUEVA: UBICACIÓN, PLANTA Y ESTRATIGRAFÍA. ............99

II. 2.- ESTUDIOS PREVIOS Y CARACTERIZACIÓN CULTURAL DE “EL ESPERTÍN” ................................102

II. 3.- “EL ESPERTÍ́”” EN SU MARCO TERRITORIAL: ......................................................................104

II.3.1.- Contexto geológico........................................................................................104

II.3.2.- Recursos líticos silíceos potenciales en el entorno de El Espertín...........................113

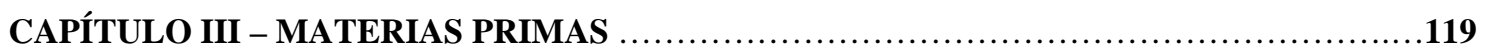

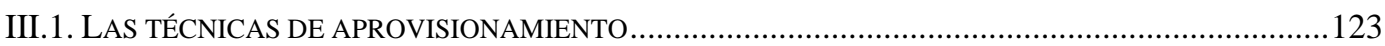

III.2. POSIBILIDADES Y LÍMITES DE UN ANÁLISIS DE TÉCNICAS DE APROVISIONAMIENTO EN EL

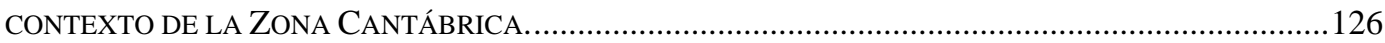

III.3. CARACTERIZACIÓN MACROSCÓPICA DEL MATERIAL ARQUEOLÓGICO: METODOLOGÍA

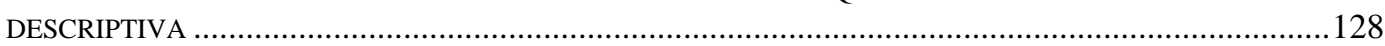

III.4. DESCRIPCIÓN DEL GRUPO LITOLÓGICO DE LA FAMILIA DE LOS SÍLEX.......................................131

III.4.1. El grupo del sílex negro (SN) ...........................................................................131

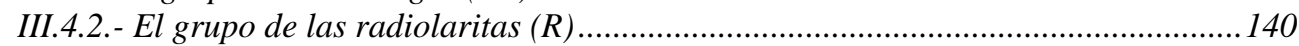

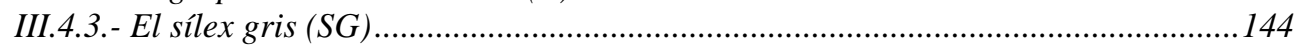

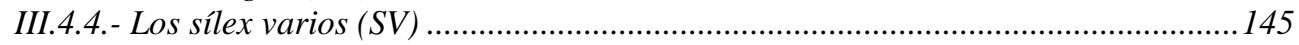

II.5. ORIGEN POTENCIAL DE LOS PRINCIPALES GRUPOS SILÍCEOS ..................................................151

III.5.1.- El sílex/chert negro ................................................................................153

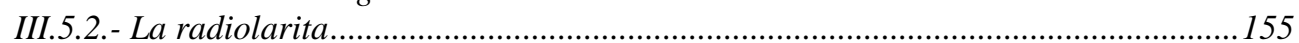

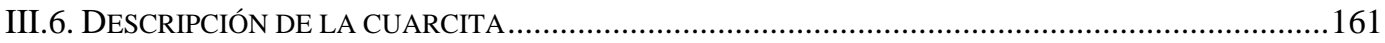

III.6.1. Cuarcita genérica (C) ................................................................................162

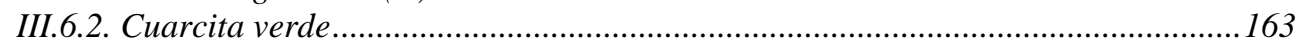

III.6.3. Cuarcita blanca-rosácea .................................................................................164

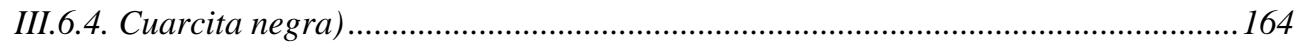

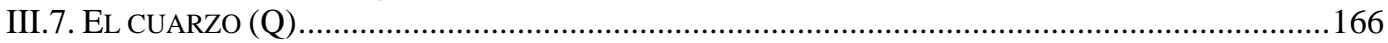




\section{CAPÍTULO IV - ANÁLISIS TECNOLÓGICO DEL CONJUNTO LÍTICO DE EL ESPERTÍN}

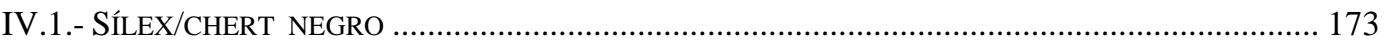

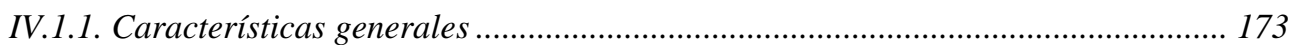

IV.1.2. Núcleos: síntesis de los esquemas técnicos.......................................................... 205

IV.1.3. Productos de acondicionamiento...................................................................... 236

IV.1.4. Soportes: lascas, hojas y hojitas....................................................................... 245

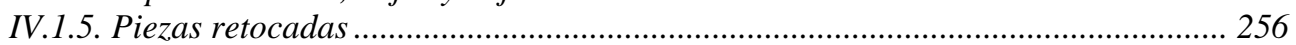

IV.1.6. Cadenas operativas.................................................................................... 274

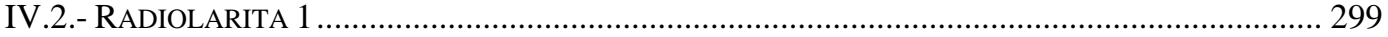

IV.2.1.- Características generales ............................................................................. 299

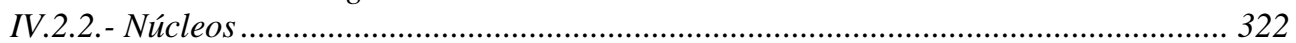

IV.2.3.- Productos de acondicionamiento ...................................................................... 335

IV.2.4.- Soportes: lascas, hojas y hojitas..................................................................... 340

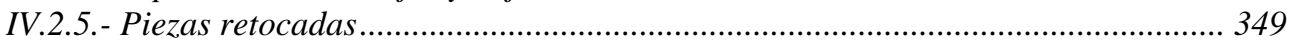

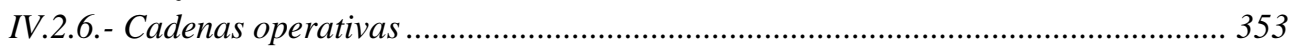

IV.3.- RADIOLARITA TIPO B (O RADIOLARITA-2)..................................................................... 365

IV.3.1.- Características generales ............................................................................. 365

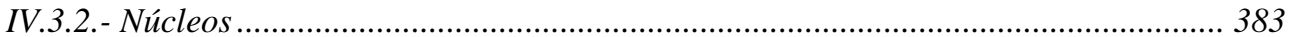

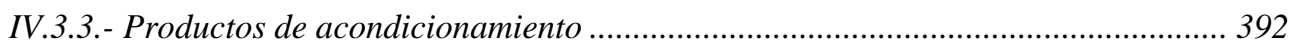

IV.3.4.- Soportes: lascas, hojas y hojitas....................................................................... 393

IV.3.5.- Piezas retocadas ........................................................................................... 399

IV.3.6.- Cadena operativa .......................................................................................... 402

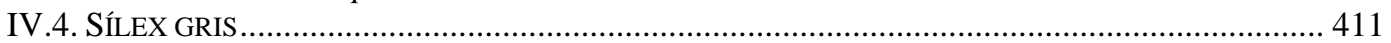

IV.4.1. Características generales ................................................................................. 411

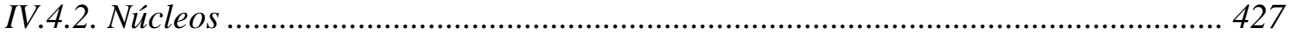

IV.4.3. Productos de acondicionamiento....................................................................... 432

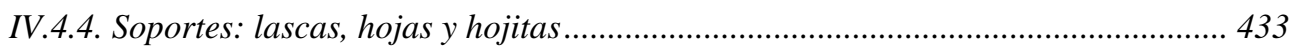

IV.4.5. Piezas retocadas …………………………………………………………….... 439

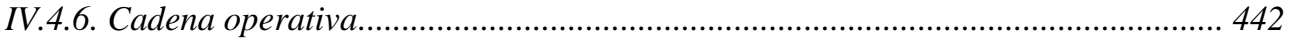

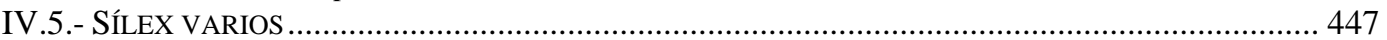

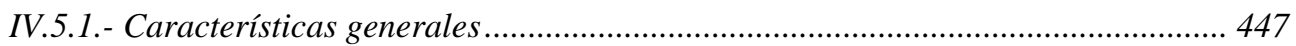

IV.5.2.- Núcleos ........................................................................................................... 460

IV.5.3.- Soportes: hojas y hojitas............................................................................... 462

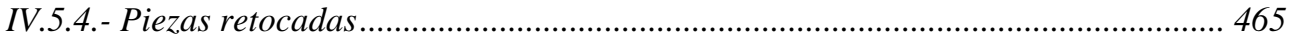

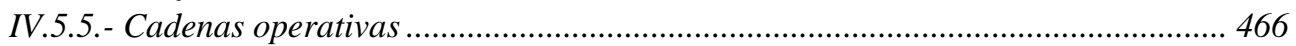

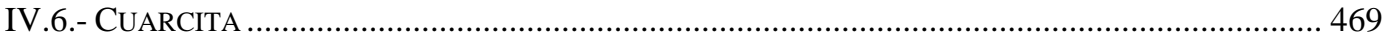

IV.6.1.- Características generales ............................................................................. 469

IV.6.2.- Núcleos ......................................................................................... 488

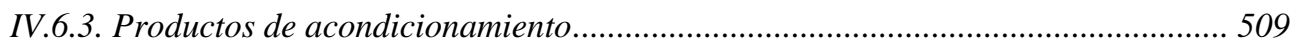

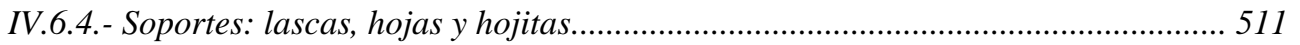

IV.6.5.- Piezas retocadas ......................................................................................... 517

IV.6.6.- Cadenas operativas ...................................................................................... 521

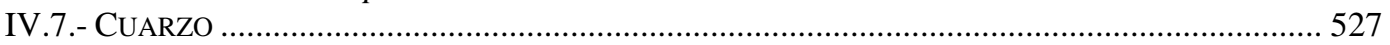

IV.7.1.- Características generales .............................................................................. 527

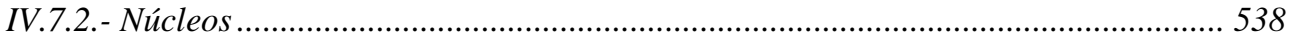

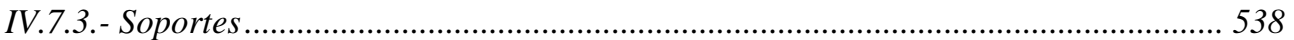

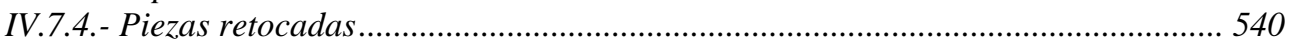

IV.7.5.- Cadenas operativas ..................................................................................... 540 
CAPÍTULO V - EL PROCESO DE TALLA PRESENTE EN “EL ESPERTÍN”. .543

V.1.- ESTRATEGIAS DE APROVISIONAMIENTO Y REPRESENTACIÓN DEL PROCESO TÉCNICO ............545

V.1.1.- Disponibilidad de materias primas y representación de las distintas materias .....545

V.1.2.- Dimensiones de las materias primas ...................................................................547

V.1.3.- Representación del proceso operativo...................................................................550

V.1.4.- Roturas e intensidad del proceso de talla ...............................................................555

V.1.5.- Estrategia de explotación de las materias primas ...............................................559

V.2.- LAS DIFICULTADES DE LAS MATERIAS PRIMAS Y LOS MODOS DE TALLA ...............................562

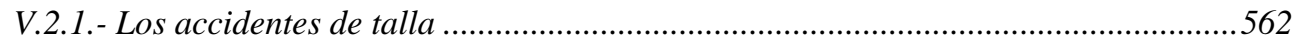

V.2.2.- El modo de talla................................................................................................564

V.3.- LOS OBJETIVOS DEL DÉBITAGE: LOS SOPORTES EXTRAÍDOS Y LAS PIEZAS RETOCADAS ...........574

V.3.1.- Proceso de débitage: representación de los grupos tecnológicos ...........................574

V.3.2.- Las piezas retocadas.........................................................................................5.

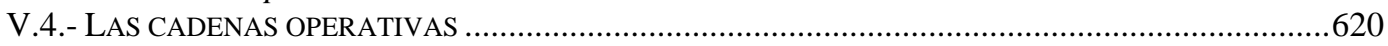

V.4.1.- Cadena de concepción prismática .....................................................................623

V.4.2.- Cadena operativa tipo nódulo-placa ...............................................................636

V.4.3.- Cadena operativa centrípeta ...............................................................................638

V.4.4.- Relación de las cadenas operativas presentes en "El Espertín” con otros procesos

operativos.

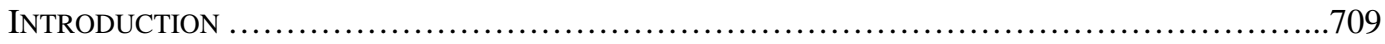

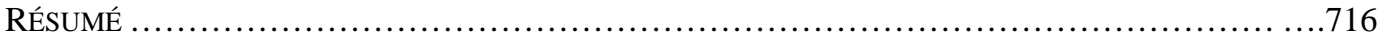

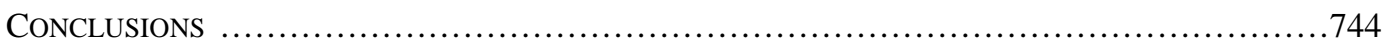


INTRODUCCIÓN 

El principal objetivo de este trabajo es la elaboración de un análisis tecnológico del material lítico de un yacimiento prehistórico. Tal objetivo se concreta en la determinación de las estructuras operativas básicas desarrolladas por el grupo prehistórico concreto, con las implicaciones que éstas conllevan respecto a ámbitos socio-económicos, y en definitiva culturales, por ejemplo las estrategias de explotación del material lítico del entorno.

El presente estudio se encuadró en un principio dentro de un marco de análisis más extenso, relacionado con el material lítico de yacimientos de finales del Paleolítico Superior-Epipaleolítico en la cuenca del Duero. Este proyecto inicial hubo de reacondicionarse a unos objetivos más concretos y específicos debido a razones de índole metodológica. El tipo de análisis que se quería desarrollar con cada serie lítica era de tipo tecnológico, lo cual significaba que teníamos que tener en cuenta, necesariamente, todo el conjunto de elementos líticos tallados procedente de cada yacimiento arqueológico. Esta labor analítica, como es lógico, debe completarse en cada caso con una síntesis del proceso técnico desarrollado por el grupo prehistórico sobre el material lítico.

Debido a estas necesidades metodológicas y a que contábamos, dentro de este marco geográfico de estudio, con un único yacimiento que reunía las condiciones idóneas para acometer tal analítica decidimos centrar nuestro estudio en el yacimiento de El Espertín. Desde un punto de vista geográfico, esta pequeña cueva se sitúa en la cuenca del Duero. Sin embargo debemos tener en cuenta su ubicación en un entorno de montaña, a las puertas de Picos de Europa y muy cerca de la divisoria de vertientes; lo que corresponde con un área marginal de la citada cuenca, caracterizada por un relieve predominantemente llano. El yacimiento resulta excepcional, no solo por su propia posición geográfica, a una altitud que supera los 1200 metros y que indica una relación con la vertiente septentrional de la Cornisa Cantábrica; sino porque el periodo al que pertenece, el Mesolítico, está muy mal conocido en este entorno. La elección, en consecuencia, no ha resultado aleatoria, sino que estas circunstancias justificaban el centrarnos plenamente en su estudio. 
POR QUÉ UN ESTUDIO DE TIPO TECNOLÓGICO

El principal interés al iniciar el presente trabajo radicaba en la elaboración de un estudio de tipo tecnológico sobre el material lítico prehistórico. Se intentaba de este modo abordar este tipo de materia, esencial en todo contexto paleolítico, desde un punto de vista que se estaba extendiendo en gran medida a lo largo de las dos últimas décadas en otras regiones europeas. Este tipo de acercamiento responde al intento constante por extraer la mayor información posible, desde distintos ángulos, a unos datos materiales que se han tratado tradicionalmente desde perspectivas más inmediatas (tipológicas fundamentalmente).

Hoy en día este tipo de análisis se considera muy útil para diferentes objetivos (de tipo económico, espacial, cognitivo, etc.) y especialmente para contribuir a una mejor caracterización de los modelos económicos utilizados por los diferentes grupos humanos, así como para un acercamiento a sus rasgos culturales más inmediatos. Este tipo de estudios tecnológicos se enmarca, por tanto, en conjunción con el resto de análisis interdisciplinares, dentro de una perspectiva de estudio del material lítico que pretende aportar síntesis económico-estratégicas, las cuales nos permitirán entender los grupos prehistóricos en relación tanto al contexto medioambiental, como a sus características culturales.

\section{LA CUEVA DE “EL ESPERTÍN”}

Como hemos señalado, comenzamos a aplicar este tipo de análisis tecnológico al conjunto de un yacimiento excavado en la montaña del noreste de León, la cueva de El Espertín, yacimiento interesante por dos motivos principales:

i) su peculiar situación geográfica, ya remarcada

ii) las características arqueológicas del mismo yacimiento, con un único período representado, apto por tanto para aplicar la analítica de tipo tecnológico 
El Espertín, en un valle secundario de la cabecera del río Esla a más de 1200 m de altitud, constituye uno de los escasos yacimientos conocidos en el interior de la Cordillera Cantábrica a tan elevada altitud. Las únicas excepciones son la cueva de La Uña (Burón, León), situada muy cerca de El Espertín a una altitud similar y con un nivel Aziliense (Neira et al., 1997) y el abrigo de La Mina (Dobarganes, Vega de Liébana, Cantabria), a 1000 metros altitud, enclavado en el interior de Picos de Europa, en un valle no muy lejano de El Espertín y con un yacimiento mesolítico (Arias, 1996). Por tanto nuestro yacimiento aporta datos para el conocimiento tanto del territorio frecuentado por los grupos prehistóricos, como de la comunicación entre la vertiente septentrional y meridional de la Cordillera. Durante las primeras fases de su excavación y en función del material lítico recuperado, se planteó la posibilidad de que se tratara de un yacimiento del Paleolítico Superior; pero análisis posteriores han permitido comprobar su adscripción a momentos del Mesolítico. En consecuencia es interesante para la valoración del territorio frecuentado por grupos holocenos en este contexto montañoso.

A este respecto, parece que la relación del grupo ocupacional del yacimiento se establece con la vertiente norte de la cordillera, dentro de la tradición de los grupos paleolíticos que poblaron la zona asturiana y de forma paralela al Asturiense. Habrá que poner el acento por tanto en la presencia de estos grupos mesolíticos tanto en el litoral, como en contextos montañosos, llegando incluso hacia la vertiente meridional de la Cornisa Cantábrica. Estos contactos en la vía norte-sur, a través de las redes hidrográficas, son muy interesantes, pero también habrá que valorar la vinculación de tales grupos con el eje este-oeste.

Otro aspecto interesante que tiene El Espertín, para desarrollar un análisis tecnológico, es que se trata de un yacimiento con un único periodo representado, el Mesolítico, al menos su industria lítica tallada se puede tratar como un conjunto unitario en cuanto a su tradición cultural, procedente de este único momento. Es cierto, no obstante, que hay alguna remoción posterior en el yacimiento (escorrentías, alteraciones antrópicas más recientes, etc.) que ha provocado que la situación espacial de los objetos líticos ha sido alterada en algunas partes de la cueva; lo que, por otra parte, no impide 
una adscripción del mismo a un conjunto unitario. Esta característica hace posible que desarrollemos de forma extensa el análisis de tipo tecnológico.

En consecuencia decidimos centrar el análisis tecnológico sobre este yacimiento e intentar concretar los procesos técnicos realizados por el grupo o grupos mesolíticos que habitaron la cueva. Habrá que valorar también posteriormente el significado de tales procesos dentro de la tradición paleolítica de la Cornisa Cantábrica y en relación a los posibles cambios respecto al momento medioambiental en que se desarrollan y a la ampliación del territorio frecuentado durante el Holoceno.

\section{ESTRUCTURA DEL TRABAJO}

Este trabajo se estructura en seis capítulos, el primer capítulo se centra en la metodología aplicada, con dos partes principales:

i) Una exposición global de los principios generales de la tecnología dentro de las “Ciencias Humanas” y, más en concreto, aplicada a la Prehistoria y a la industria lítica. En este apartado se dedicará una especial atención a los conceptos más generales, básicos en los análisis tecnológicos con el fin de delimitar su significado; especialmente en los términos siguientes: cadena operativa (/esquema conceptual), esquema operativo y esquema técnico.

ii) Una exposición de la metodología concreta empleada para el estudio analítico del material (con los distintos atributos contemplados). Se describe el examen concreto de cada elemento lítico, a partir del cual se van a ir sintetizando los esquemas técnicos, operativos $\mathrm{y}$, por último, conceptuales presentes. Se seguirá un discurso expositivo que va de lo más general a lo más particular, partiendo de los conceptos más amplios (cadena operativa laminar) hasta los más concretos (por ejemplo la denominación de algunos soportes como las piezas con cresta).

Se elige como cadena operativa ideal una de estructura laminar, ya que la producción de hojas y hojitas es la que predomina en el conjunto lítico. 
Esta cadena operativa se divide en las distintas fases y procesos técnicos en que se insertan los sucesivos elementos líticos. Para estructurar este proceso será muy útil tanto la clasificación de estos elementos en los tipos de soportes técnicos (por ejemplo lasca cortical, hoja de encetadura, lasca-laminar de segundo orden, semitableta de núcleo, etc.), como, sobre todo, la agrupación de tales soportes en "grupos tecnológicos” más amplios, los cuales resumen de forma inmediata el proceso operativo de un conjunto lítico (el grupo 1 corresponde a las lascas, el 2 de las hojas/hojitas, el 3 a los productos de acondicionamiento, el 4 a los núcleos, el 5 a los chunks y en general soportes informes y, por último, el 6 reúne a los debris).

En el segundo capítulo se expone la procedencia del material examinado, que es el conjunto lítico de El Espertín, con una contextualización de tal material desde dos puntos de vista:

i) Punto de vista arqueológico. Se describe la ubicación del yacimiento, su excavación y las características de los materiales recuperados (fauna, industria ósea, carbones, etc.).

ii) Punto de vista geográfico. Se dedica una extensa atención al contexto geológico en el que se encuentra esta cueva, con el fin de hacer una relación, posteriormente, de los niveles litológicos que potencialmente pueden contener fuentes de las materias que se emplean en este conjunto.

El análisis concreto del material se estructura a partir de las distintas materias, por lo que el tercer capítulo se centra en la descripción de las diversas materias líticas que hay en el conjunto, estructurándose en dos partes:

i) Descripción del material lítico estableciendo los principales grupos de sílex, cuarcitas y cuarzos. Aunque esta descripción es de tipo macroscópico, consideramos que es muy útil y necesaria para conocer qué tipo de materia se ha utilizado. 
ii) Relación entre las materias presentes en el conjunto lítico y los niveles litológicos existentes en el contexto geológico de la cueva, que potencialmente pueden contener los principales grupos líticos reconocidos: el chert negro y la radiolarita. En esta relación se observa que estas dos variedades de rocas silíceas se encuentran, efectivamente, en un entorno más o menos cercano a la cueva.

En el capítulo cuarto se desarrolla el análisis tecnológico concreto de las distintas materias primas (el sílex /chert negro, las dos variedades de radiolarita, el sílex gris, los sílex varios, la cuarcita y el cuarzo) a partir del esquema tecnológico establecido en la metodología, con el examen de los distintos atributos especificados. Tales atributos se van a resumir en una serie de cuadros y gráficos diferenciando los grupos tecnológicos, para intentar constatar variaciones a lo largo del proceso operativo desarrollado en cada materia. En primer lugar se realizará una exposición de las características más generales del conjunto lítico (por ejemplo la presencia de córtex, las dimensiones, los tipos de talón, las roturas, etc.); en segundo término se analizarán las distintas categorías de soportes para extraer las líneas técnicas básicas del proceso (núcleos, productos de acondicionamiento); seguidamente se examinarán también los soportes extraídos, tanto los de carácter secundario (las lascas en general) como aquellos de "primera intención” (hojas, hojitas). A continuación se expondrán las piezas retocadas, intentando determinar si hay algún tipo de preferencia en los soportes seleccionados. Como paso último, se describirán las cadenas operativas presentes en la materia, con sus peculiaridades.

El capítulo cinco es la síntesis del proceso operativo total desarrollado en el conjunto lítico tallado de El Espertín, empleando para ello los distintos atributos observados. A partir de estos datos sintéticos se puede llegar a varias categorías de conclusiones, por ejemplo:

- las estrategias de aprovisionamiento y los objetivos de producción en las distintas materias

- la influencia de las características de las diferentes materias al aplicar los procesos de débitage 
- el grado de definición en la utilización de soportes concretos, es decir si existen soportes especializados en determinados tipos de útiles o si hay soportes de utilidad más amplia

- las cadenas operativas genéricas y sus esquemas operativos particulares desarrollados

Sin duda alguna, estas cadenas constituyen uno de los objetivos básicos de todo este trabajo. A este respecto, se intentará relacionar tales estructuras con las definidas en otros contextos culturales. Incluso se abre la posibilidad de que alguno de estos esquemas se pueda considerar a modo de arquetipos, es decir, formas de tallar un nódulo de una manera sencilla, manera que puede aparecer en distintos contextos culturales y que puede ser consecuencia de un fenómeno de convergencia técnica.

Por último, el capítulo seis corresponde a las conclusiones más genéricas de todo este análisis tecnológico, en el cual se intentará esquematizar las características más importantes de la industria lítica. 
CAPÍTULO I -

METODOLOGÍA 

En este capítulo se van a presentar las bases metodológicas que sustentan la realización de esta tesis, cuyo objetivo final consiste en un análisis tecnológico de la industria lítica de la cueva de El Espertín. Se trata de identificar las modalidades técnicas presentes y definir, en la medida de lo posible, el/los esquemas conceptuales desarrollados en este conjunto. El objetivo último sería encontrar patrones de "comportamiento" determinados (por ejemplo aspectos como métodos aplicados en diferentes materias primas) que nos permitan acceder a otras esferas interpretativas del conjunto arqueológico. En efecto, no podemos olvidar que la finalidad esencial, como en todo trabajo sobre cualquier aspecto de la Prehistoria, es intentar determinar y explicar las características definitorias del grupo en cuestión. Por tanto trataremos de deducir, a partir de la actividad técnica ejecutada, rasgos más generales, quizás extrapolables a tendencias comportamentales del grupo mesolítico que es objeto de estudio.

El marco metodológico y teórico de referencia en el que se inserta este tipo de objetivo es una concepción sistémica de los grupos humanos (Clarke, 1984) en la que la tecnología sería un subsistema en correlación con otros subsistemas como el social, económico, etc. La industria lítica sería a su vez uno de los subsistemas de la tecnología, en interacción directa con los otros conjuntos técnicos (óseo, vegetal, etc.). De acuerdo con esta perspectiva, a partir del análisis de la industria se pretende caracterizar un aspecto concreto desarrollado por el grupo, e intentar acceder así a otras esferas de dicha sociedad.

La metodología empleada para definir los conocimientos técnicos parte de un análisis directo sobre el material lítico, de modo que este examen empírico va estructurando los objetos líticos en sus distintas fases y secuencias para reconstruir la cadena operativa; y por último acceder a niveles de composición más amplios y alcanzar, al fin, una síntesis de los conceptos, variedades y modalidades desarrolladas en los esquemas técnicos ejecutados. Pero todo este planteamiento se imbrica dentro de un contexto teórico sobre la tecnología lítica arqueológica, desarrollado en buena parte por diversos autores franceses (Tixier, 1978; Balfet, 1991; Boëda, 1991a; Karlin, 1991a, 1991c; Pelegrin, 1991; Tixier et al., 1980; Inizian et al., 1995; etc.) a partir de concepciones etnológico-estructuralistas elaboradas, entre otros, por M. Mauss, A. 
Leroi-Gourhan, y A. G. Haudricourt (Lemonnier, 1976: 10; Sigaut, 1985: 4). Vamos a intentar describir paso por paso lo que sería el esqueleto de este marco conceptual, desde lo más genérico a lo más concreto, relacionando los términos y conceptos sobre los que basamos todo nuestro trabajo. 


\section{I.1.- LA TECNOLOGÍA LÍTICA}

El análisis de la tecnología es, desde hace un par de décadas al menos, una de las perspectivas más frecuentemente adoptadas sobre las industrias líticas. El interés de los prehistoriadores por la tecnología lítica no es novedoso, podemos decir que está presente casi desde los inicios de la disciplina prehistórica en el siglo XIX, cuando ya hay varios autores que se preocupan por el modo como se habrían realizado los útiles líticos. No obstante se podría decir que había otras prioridades dentro de la Prehistoria, tales como el establecimiento de un cuadro cronológico-cultural de las distintas culturas o conjuntos paleolíticos, a los que se podía contribuir mejor desde otras perspectivas del conjunto lítico como la tipología (Pelegrin, 1995: 11-18). El desarrollo de los estudios de tecnología lítica, tal y como ha acontecido en las dos últimas décadas (restringiéndonos al contexto europeo), se produce a partir de un enfoque de raíz etnológica francesa que se impulsa sobre todo a partir de 1980 (Cahen, Karlin, Keeley et Van Noten, 1980; Tixier, 1980a; Tixier, Inizian et Roche, 1980). Para el desarrollo de estos estudios tecnológicos el concepto de cadena operativa será un vector muy importante (Pelegrin, Karlin et Bodu, 1988; Desrosiers, 1991; Karlin, 1991a). El tipo de trabajo que realizaremos es subsidiario de la estructuración metodológico-conceptual elaborada por estos prehistoriadores (-tecnólogos) franceses.

\section{I.1.1.- TECNOLOGÍA Y TÉCNICA}

\section{I.1.1.1.- LA TECNOLOGÍA COMO TECNOLOGÍA CULTURAL Y DENTRO DE LA TEORÍA DE SISTEMAS}

En este primer apartado, se va a comenzar clarificando el sentido y límites con que empleamos cada término, empezando por lo más general, incluso desde el mismo concepto de tecnología. A este respecto, podríamos matizar la propia ubicación de este tipo de analítica, en el ámbito de la categoría científica a la que pertenece, adoptando por tanto un punto de vista propio de los filósofos de la ciencia. La Tecnología tendría una doble vertiente (Sigaut, 1985: 4), por un lado una "Tecnología normativa", aquella 
que se encarga de aplicar la teoría (científica) a la técnica (Sanmartín, 1990: 39), con el fin de mejorarla e incrementar su eficacia. En esta "Tecnología normativa" se encuentran todas las "tecnologías" que, por otro lado, tanto desarrollo tienen hoy en día dentro de la ciencia "más pura", como son, por ejemplo, la tecnología industrial, aeronáutica, informática, etc. Por otra parte está la "Tecnología objetiva", la cual tendría a "las técnicas" como objeto de observación, bien para elaborar una historia de las mismas, o bien para desarrollar una etnología de las técnicas (o tecnología cultural). En este caso la Tecnología se encuentra en el terreno de las "ciencias humanas", ubicación postulada ya por Hadricourt en 1964 (Inizian et al., 1995: 13).

La definición de tecnología más ampliamente aceptada por los prehistoriadores ha sido realmente importada del campo de la Etnología (de la mano, fundamentalmente, de M. Mauss, Haudricourt y A. Leroi-Gourhan). De este modo, Tixier et al. (1980: 7) definen tecnología de la siguiente manera:

"Es el estudio del conjunto de procedimientos empleados para producir un útil o un arma".

Parece sin embargo que la definición es un poco vaga. Si recurrimos al campo de la etnología, Creswell (1996: 692-695) define la tecnología como:

"Estudio de las actividades emprendidas por los hombres para adquirir y transformar los elementos orgánicos e inorgánicos del mundo natural. Estas actividades abarcan tanto los conocimientos y habilidades como los gestos y las herramientas, y se disponen según relaciones que son a la vez técnicas y sociales".

En esta definición se encuentran todas las claves del sentido con que los prehistoriadores han tomado los estudios tecnológicos, al menos aquellos que se han ocupado de una conceptualización y desarrollo de este tipo de análisis. De aquí que no sólo se tomen en consideración los objetos o útiles, sino también los conocimientos, las herramientas, los gestos, las habilidades, toda una serie de aspectos que remiten no sólo a cuestiones socio-económicas de la sociedad analizada, sino que incluso llegan a afectar al nivel cognitivo del individuo. 
Por tanto la tecnología prehistórica tiene por objeto el análisis de las técnicas ${ }^{1}$ (Sigaut, 1985) desarrolladas por un grupo prehistórico. El concepto de técnica se toma desde una perspectiva muy amplia del término; en este uso "la técnica” abarcaría un amplio abanico de actividades, todas aquellas que suponen una transformación o manipulación de las materias (de todo tipo: líticas, vegetales, animales, etc.) de la naturaleza para satisfacer las distintas necesidades del grupo. La tecnología es, por tanto, la ciencia que estudia las técnicas. El primer término pertenece a la parte del prehistoriador y el segundo se refiere al grupo estudiado, a las acciones analizadas. Según este esquema, la industria lítica sería el testimonio del conjunto de técnicas aplicadas por el grupo humano prehistórico sobre la materia lítica, en tanto que el prehistoriador realiza los estudios tecnológicos para acceder a esas técnicas. Para salvar la distancia entre ambos polos la tecnología ha creado un entramado teórico para manipular los restos arqueológicos.

Hay que concretar además que esta perspectiva se imbrica, como ya hemos mencionado, dentro de una concepción sistémica de las sociedades. El sistema técnico del grupo prehistórico está constituido por varios subsistemas: lítico, óseo, etc. Dado que estas distintas partes del sistema están interconectadas, será posible acceder a conclusiones más allá de los "datos materiales"; y es así como se pretende llegar a estudios de carácter económico, social, etc. El sistema operativo que podemos reconstruir pretende ser el reflejo del sistema técnico prehistórico.

Este tipo de enfoque sistémico de nuestra disciplina se ha desarrollado extensamente en el mundo anglosajón (Clarke, 1984) vinculado a la Arqueología procesual. No obstante, la aplicación de los sistemas en los estudios tecnológicos se produce tanto en el ámbito anglosajón como en el europeo continental, llegándose por tanto a la concepción de sistemas desde dos trayectorias distintas (Sellet, 1993). En el mundo anglosajón de la mano de la Arqueología procesual, como se ha apuntado (Collins, 1975 por ejemplo), y en el ámbito europeo, y más concretamente francés, a

\footnotetext{
${ }^{1}$ A veces se ha considerado la “tecnología” y la "técnica” como sinónimos (Pelegrin, 1988). En este sentido, se considera a la técnica como un todo, y la tecnología como el fenómeno antropológico (Basalla, 1994) que define esa relación entre el grupo humano y la materia. Así se puede hablar tanto de la tecnología "científica” que surge a raíz de la Revolución Industrial, como de la tecnología característica de cualquier cultura que se estudie.
} 
partir de la Etnología de raigambre estructural (Lemonnier, 1976, 1983). Por tanto, aunque ambas tendencias van a converger en una postura sistémica respecto al análisis de la técnica, el origen dispar de ambas trayectorias metodológico-conceptuales de la tecnología lítica explica las diferencias entre ambas, diferencias palpables desde el mismo planteamiento de los problemas. Las connotaciones cognitivas son uno de los aspectos más peculiares dentro de la línea francesa. También difieren en el grado de detalle con que se estudian las colecciones líticas, intentando llegar casi hasta el gesto mínimo en la perspectiva francesa. No obstante la convergencia en las posturas es visible por ejemplo en la existencia de unos conceptos analíticos (hasta cierto punto) similares: la "chaîne operatoire" francesa, la "behavioral chain" de Schiffer (1972 [Sellet, 1993]), la "lithic reduction sequence" (Bradley, 1975), y los "reductive steps" (Collins, 1975).

\section{I.1.1.2.- ¿QUÉ ES LA TÉCNICA?}

La definición de lo que es una técnica no es sencilla porque es un término polisémico y se ha utilizado en contextos dispares. En Prehistoria existen dos acepciones principales respecto a la técnica (Boëda, 1997: 33) cuya diferencia está en que el mismo término se utiliza para denominar a categorías de hechos distintos, dependiendo de que adoptemos un punto de vista genérico o más concreto. Desde la óptica de lo genérico, hablaríamos de técnicas como las actividades desarrolladas por un grupo para alcanzar un objetivo. En este caso, el término técnica no designa una cosa precisa dentro del proceso ("processus") operatorio. El otro punto de vista tendría un sentido más restringido que incide sobre el acto de transformación de un objeto material. Corresponde a la acción y al medio necesario para ejecutar cualquier procedimiento de talla (de un núcleo, una pieza bifacial o un útil retocado). La acción puede ser una percusión o una presión, directa o indirecta; siendo el medio la utilización de un percutor: mineral, vegetal o animal. 


\section{I.1.1.3.- TÉCNICA EN SENTIDO RESTRINGIDO: TÉCNICA AL NIVEL DE “MODO DE} TALLA"

En el apartado anterior se ha desarrollado el sentido de técnica en tanto que el conjunto de actividades realizadas sobre la materia, desde una perspectiva muy amplia. Vamos a centrarnos en el uso concreto del término técnicas, el cual ha sido frecuentemente adoptado en la tecnología lítica. Para ello se va a tomar la definición elaborada desde la Etnología, ya que se podrá entender perfectamente su relación con la técnica “en sentido restringido”. Para Lemonnier (1996: 601) técnica es:

"Una acción socializada sobre la materia, poniendo en acción las leyes del mundo físico. Toda técnica es un pensamiento objetivado y tendría cuatro elementos, que forman un sistema: la materia sobre la que actúa, los objetos (herramientas, medios de trabajo, artefactos), los gestos o fuentes de energía, y las representaciones particulares que subyacen a los gestos técnicos".

Esta definición etnológica estructura perfectamente todos los elementos implicados en la técnica; el problema radica en que esta visión, que resulta más o menos accesible desde la Etnología, no lo es tanto desde la Prehistoria, ya que de los cuatro elementos que conforman el sistema técnico contamos solamente con uno de manera clara y directa: la materia (los objetos líticos en sí, o la industria lítica en conjunto). Los objetos utilizados para desarrollar la técnica (las herramientas) no siempre están presentes (percutores, cinceles, yunques) y en cuanto a las fuentes de energía (percusión y presión en el caso de la industria lítica), se puede acceder de forma indirecta, como también en el caso de algunas herramientas. De hecho estos dos elementos están estrechamente relacionados, de modo que a partir de las huellas y características físicas y técnicas presentes en los objetos tallados (tamaño del bulbo, presencia del punto de impacto, de labio, de una preparación cuidadosa de la cornisa, etc.) se puede deducir a veces tanto el útil empleado, como la forma de aplicación de la fuerza (percusión directa con percutor duro, con percutor blando, presión, etc.). Esta deducción es un actualismo basado en la analogía existente entre los experimentos de talla y el registro arqueológico. 
Respecto a "las representaciones que subyacen a los gestos técnicos”, el último de los elementos definidos por Lemonnier, es un aspecto difícil de abordar, ya que se refiere a los conocimientos implicados en esas actividades. Además, hay que tener en cuenta que existen dos tipos de conocimientos implícitos: i) el conocimiento (connaissance) de tipo cultural, y ii) la habilidad manual requerida (savoir-faire). Estos elementos no dejan unas huellas más o menos claras en el registro arqueológico; no obstante, sí se han desarrollado estudios que ahondan en este ámbito de lo cognitivo, sobre todo en conjuntos con unas condiciones de conservación especiales y por medio de análisis intra-espaciales. En ellos se abordan aspectos relativos a las relaciones o estructura social, los procesos de aprendizaje, la organización de la talla en el yacimiento, etc. (Pigeot, 1987, 1988; Olive 1988; Ploux 1991; etc.)

Y es así por tanto como llegamos al sentido limitado que tiene muchas veces la “técnica” en la tecnología lítica, centrada realmente en los elementos de la "técnica en sentido amplio" a los que se puede acceder a partir de las huellas existentes en el registro lítico, fundamentalmente el tipo de percutor (duro o blando) y la forma de aplicar la fuerza (percusión, presión). Desde este punto de vista sería preferible utilizar (en lugar del término “técnica”) otras expresiones como el modo de ejecución de la talla de Pelegrin (1995:20) (las modalidades de talla, según Tixier [1967, citado por Pelegrin 1995]), que hacen referencia al útil de que nos servimos, al gesto y a una cierta posición del cuerpo. Newcomer (1975a: 97-98) propone el término “modo” (“mode”) para la combinación de dos caracteres: el modo de aplicación de la fuerza y la naturaleza del útil de talla (percutor duro, percutor blando y presión), y prefiere reservar el término técnica para la definición completa, incluyendo la posición del cuerpo y la pieza a tallar y el empleo eventual de complementos de útiles, afirmando que llegar a definir verdaderas técnicas en Prehistoria es prácticamente imposible.

Siguiendo este último punto de vista y para evitar la confusión respecto al empleo de “técnica”, en este trabajo se utilizará el término “modo de talla” para referirnos a esos aspectos más materiales y físicos de la acción descrita (la herramienta utilizada para ejecutar la acción y la manera de aplicar la fuerza). Sólo nos faltaría por especificar los modos de talla que se han determinado en Prehistoria: la percusión directa con percutor de piedra dura o blanda, con percutor blando, la presión y la 
percusión indirecta. Existe una extensa bibliografía sobre esta cuestión en la que se especifica de forma muy detallada las características de cada una de ellas ${ }^{2}$.

\section{I.1.1.4.- TÉCNICA EN SENTIDO AMPLIO: PROCESO, MÉTODO DE TALLA, ESQUEMAS,}

ETC.

Como ya hemos indicado es muy difícil desde la Prehistoria llegar a saber cómo serían las técnicas (en sentido amplio, al menos tal y como se define en la Etnología) desarrolladas por los grupos prehistóricos ${ }^{3}$. Esta dificultad es una traba intrínseca a la propia ciencia prehistórica, que tiene que lidiar con la restricción impuesta por las características ("evidentes" y "latentes") propias de los datos arqueológicos. Esta limitación inevitable en el acceso directo a todos los elementos que estructuran la técnica, puede ser la explicación del uso polisémico y amplio del propio término de técnica. Por otro lado, para abordar el aspecto amplio de la técnica, es decir el conjunto de las acciones desarrolladas sobre la materia, con todas las implicaciones que conlleva, desde la propia organización del objeto a tallar, la sucesión de secuencias de talla (con el/los modos de talla adecuados en cada momento), hasta las implicaciones cognitivas implícitas; se han desarrollado otros conceptos en la tecnología lítica: método de talla, proceso, esquema, ... etc. En los apartados siguientes se intentará concretar estos términos.

La cuestión que late en el fondo es el problema de cómo podemos acceder al análisis de los grupos prehistóricos (que es el objetivo de la Prehistoria) a partir de los restos arqueológicos que tenemos, concretamente de la industria lítica. Hay que tener en cuenta no sólo las peculiaridades de los datos arqueológicos, sino también las características del propio yacimiento en el cual se inscribe el conjunto lítico, las cuales van a delimitar la potencialidad de información de tal conjunto. De este modo en un

${ }^{2}$ Para la percusión directa con percutor duro y blando: Bordes, 1947, 1961; Bordes et Crabtree, 1969; Inizian et al, 1995. Para la percusión directa con percutor de piedra blanda: Pelegrin, 2000. Para la presión: Crabtree, 1968; Binder, 1984; Pelegrin, 1988a; etc. Para la percusión indirecta: Poplin, 1979; Pelegrin, 1991b.

${ }^{3}$ Desde esta perspectiva amplia, la técnica propia de los grupos prehistóricos paleolíticos en su manipulación de los recursos líticos es la TALLA (frente al pulimento a partir del neolítico por ejemplo). En consecuencia "talla" es un término muy genérico (Tixier et al., 1980: 104), que engloba toda aquella acción de fraccionamiento intencional de las rocas duras. A efectos prácticos, es un término que emplearemos repetidamente, siempre en este sentido tan amplio y por tanto flexible. 
yacimiento in situ en el que se conserve un suelo de ocupación, en muchos casos será posible acceder a un nivel de análisis relativo a la estructuración social, a aspectos cognitivos, etc. Por el contrario un conjunto que proceda de un nivel producto de un palimpsesto tendrá más delimitado el grado de acceso a elementos cognitivos o sociales. Sobre ambos tipos de yacimientos se podrá realizar un estudio tecnológico, sin embargo los enfoques, perspectivas o grados de análisis van a variar en una amplia gama de posibilidades que dependen fundamentalmente, como hemos indicado, de la propia potencialidad que marca el yacimiento arqueológico al que pertenezca el conjunto lítico.

Para centrar esta problemática, hemos de recordar que todo este entramado metodológico-teórico no trata sino de resolver la dicotomía que hemos apuntado en este apartado: la comprensión de las técnicas aplicadas por los grupos prehistóricos a partir de un análisis tecnológico actual realizado por el prehistoriador. Se trata de analizar y explicar de forma comprensible el subsistema técnico de un conjunto prehistórico determinado, a partir de unos criterios o parámetros establecidos; pero la industria lítica concreta y peculiar va a delimitar las posibilidades del propio estudio tecnológico. Es decir existe casi siempre un juego bipolar entre el análisis técnico (estudio directo y empírico del material) y las conclusiones tecnológicas, y ambos aspectos se van influyendo entre sí.

Teniendo en cuenta esta dicotomía, creemos que es importante determinar cada uno de estos polos:

- los objetos líticos que vamos a analizar (la industria lítica)

- los esquemas elaborados para estructurar esa información (las cadenas operativas, los esquemas operativos, métodos de talla, modalidades, preferencias, etc).

Para tratar con detenimiento el primer aspecto, el de los objetos líticos en sí, reservamos el segundo apartado de este capítulo, en el que expondremos de forma detallada la metodología y terminología utilizada para el análisis directo del material así como los atributos analizados. Respecto al segundo aspecto, se seguirá repasando a continuación el entramado conceptual para la elaboración de un análisis tecnológico. 


\section{I.1.2.- LA TECNOLOGÍA LÍTICA EN PREHISTORIA}

\section{I.1.2.1.- ANÁLISIS TECNOLÓGICO: POSIBILIDADES}

Ya se ha apuntado que los análisis tecnológicos en Prehistoria se van a desarrollar en gran medida a partir de los años 80, pero a partir de un enfoque que deriva de la Etnología estructural francesa (que desde mediados de los años 50 está trabajando el estudio de las técnicas sobre el análisis de procesos). Va a ser A. LeroiGourhan uno de los artífices de la influencia de esta corriente etnológica en la Prehistoria.

Asimismo, se ha repetido también que la tecnología tiene por objeto el estudio de las acciones realizadas por el grupo humano sobre la materia, es decir las técnicas en sentido amplio. A este respecto es paradigmático el título del libro de Leroi-Gourhan: L’Homme et la Matière (1943, $1^{\text {a }}$ ed.). En toda acción de este tipo (es decir, aquella que afecta a "la materia”) están ya implícitos varios tipos de conocimientos (ya sean de tipo motor, cultural o práctico inmediato) por parte del grupo humano, desde la materia seleccionada para ejecutar la talla por ejemplo, hasta la manera de sujetar el nódulo, el percutor apto, etc. (Inizian et al., 1995; Pelegrin, 1995). Desde esta perspectiva holística y sistémica, la tecnología va estructurando los tipos de actividades y conocimientos a lo largo de toda una secuencia teórica lógica de acciones que irían desde la adquisición de la materia prima (cualquiera que sea) hasta su abandono, pasando por el transporte, transformación y uso del objeto realizado con tal materia. En este sentido algunos autores dicen que las actividades técnicas se dividen en cuatro grandes esferas: las técnicas de adquisición, de fabricación, de montaje y de consumo (Geneste, 1991a: 3; Creswell, 1996: 694). Cada uno de estos pasos puede desarrollarse y diversificarse de forma específica y muy detallada desde distintas ramas dentro de la Prehistoria, tal y como apuntamos en el esquema del cuadro I.1. Aparecen así, por ejemplo, los análisis territoriales para determinar las fuentes de materia prima y la lejanía de estos puntos al yacimiento arqueológico (Geneste, 1991a, Morala et Turq, 1991; etc). Se desarrollan también estudios de economía o gestión de la materia prima (Perlès, 1980, 1991; Lenoir, 1980; Binder, 1986), que tratan de determinar en qué medida las características de la materia pesan en determinadas cadenas operativas y, en último término, en el 
comportamiento de los grupos humanos en tanto que se producen desplazamientos en busca de una determinada roca. Los estudios de economía del débitage 4 (Perlès, 1980, 1991) se centran en determinar si hay diferentes cadenas operativas con relación a soportes determinados y en último término a útiles concretos. Estas dos posibles variaciones, en la gestión del débitage y de la materia prima, se definen también como estrategias económicas (Geneste, 1991b: 15-16), es decir variantes del sistema determinadas por factores económicos. La gestión del débitage estaría plenamente centrada en la fase de transformación de la materia y es la perspectiva de análisis más ampliamente aplicada a los conjuntos líticos a partir de la tendencia tecnológica. La gestión del débitage (Pigeot, 1987: 25) consiste en explicar el proceso de talla desarrollado y la función de ese procedimiento. De aquí se derivan las conclusiones tecno-económicas (y si es posible sociales) factibles sobre los conjuntos líticos, es decir el "cómo" tallaban y quizás a veces el "por qué" (siempre que esta pregunta se pueda contestar en términos, por ejemplo, de preferencias de una materia prima sobre otra, la elección de unos soportes para unos útiles determinados, o incluso aspectos de ámbito más social).

Los análisis que abordan el ámbito de lo mental tratan de acercarse a los conocimientos del grupo prehistórico estudiado, al "saber hacer" ("savoir-faire”) y al saber decir (“savoir-dire”) (Karlin, 1991a; Pelegrin, 1991a) y determinar las preferencias e intenciones de las cadenas operativas así como la tradición del grupo en que se inscriben (Pelegrin, 1995). Este tipo de análisis incluso intenta llegar al individuo concreto en estudios que diferencian talladores expertos de otros inexpertos o

${ }^{4}$ El término débitage, así como el de façonnage, lo vamos a conservar en su grafía francesa. Ambos términos pertenecen al grupo de las “operaciones de talla” (Pelegrin, 1995: 21) genéricas que se pueden dar sobre la materia y cuya diferencia está en el objetivo final que se persigue: extraer varios soportes en el caso del débitage y conformar un único objeto o útil en el caso del façonnage. "Débitage" no solo denomina al proceso de talla genérico, sino también al conjunto de elementos líticos resultantes de dicho proceso (es decir, lascas, hojas, productos de acondicionamiento, debris, ...), exceptuando el núcleo, que, en conjunto, son los "productos de débitage" (Tixier et al., 1980: 40). Se ha decidido conservar el término galo por dos razones esencialmente: i) no hay consenso para su traducción en castellano, "lascado" podría ser una posibilidad, pero resultaría un tanto redundante decir por ejemplo "un esquema de lascado de lascas"; en cuanto a "desbastado" no tiene el mismo significado semántico que el término francés ya que equivaldría a una conformación o bosquejo inicial del bloque (sería la traducción de "degrossissage") y no a una producción de soportes; ii) tanto débitage como façonnage están perfectamente definidos y delimitados en la tecnología lítica, por lo que es preferible importar el término original con la carga semántica que conlleva, al menos hasta que encontremos términos que sean capaces de aportar tal significación. 
aprendices (Pigeot, 1987, 1988; Olive, 1988; Ploux, 1991). En este punto se aborda no sólo el análisis técnico estricto de aprendizaje de los distintos pasos para tallar, sino las implicaciones sociales que ello conlleva.

\begin{tabular}{|l|l|}
\hline FASES & ANÁLISIS POTENCIALES \\
\hline Adquisición de la materia prima & $\begin{array}{l}\text { Técnicas de aprovisionamiento: estrategias de adquisición, } \\
\text { selección de la materia prima, prácticas de extracción de la } \\
\text { materia, minería, etc. }\end{array}$ \\
\hline Transporte & \begin{tabular}{l} 
Implicaciones respecto a territorio, intercambios, etc. \\
\hline Transformación
\end{tabular} \\
\hline Uso & $\begin{array}{l}\text { Análisis tecno-económico: esquemas conceptuales, } \\
\text { métodos, esquemas operativos. Economía o gestión de la } \\
\text { materia prima o del débitage. Modos de talla. } \\
\text { Implicaciones sociales y cognitivas. } \\
\text { Tipología: objetivos que guían la talla: útiles concretos. }\end{array}$ \\
\hline Abandono & Funcionalidad de los útiles: Traceología \\
\hline & $\begin{array}{l}\text { Análisis espaciales (intra-site): organización del } \\
\text { yacimiento e implicaciones sociales, funcionales, etc. }\end{array}$ \\
\hline
\end{tabular}

Cuadro I.1: fases teóricas de un análisis tecnológico y potencialidad de líneas de investigación de cada una de ellas.

Como hemos señalado, a lo largo de estos últimos años los análisis tecnológicos aplicados se han interesado sobre todo en la fase de transformación de la materia, centrándose por tanto en aspectos tecno-económicos (el "cómo") y económico-sociales (el "por qué") cuando es posible. Quedarían muchos aspectos aún por abordar y desarrollar en torno a las posibilidades esbozadas en torno a la tecnología (Boëda, 1997), sobre todo centradas en responder las preguntas respecto al "para qué" (la problemática de los análisis traceológicos) de esos objetos líticos.

Parece claro que en toda esta concepción de la tecnología prima una metodología de análisis en la que se pretende una ordenación secuencial del conjunto lítico, lo cual ha dado lugar a la definición de procesos, secuencias, fases técnicas, modalidades, preferencias, etc., ocasionando una multiplicación de términos. En este contexto se desarrolla también el concepto de cadena operativa, el cual se puede aplicar a los distintos niveles de análisis. 
El cuadro sobre las posibilidades de desarrollo de la tecnología (Cuadro I.1) sería un esquema de análisis técnico global en el que estarían integrados la mayoría de los puntos de vista adoptados a la hora de enfrentarnos a un conjunto lítico; y aún faltarían las implicaciones de tipo cognitivo. Parece lógico pensar que es muy difícil realizar un estudio que incluya la totalidad de este proceso, de hecho no siempre están presentes todas las fases (el transporte, por ejemplo, puede estar ausente si analizamos un taller lítico al lado de una fuente de materia prima). A lo largo de esta secuencia tecnológica teórica, las distintas fases pueden tener también significados diferentes respecto a los vectores de espacio y tiempo. En fin, un análisis tecnológico integral es, a efectos prácticos, muy difícil. En este trabajo nos centramos fundamentalmente en el segmento de transformación de los bloques líticos, aunque haremos también algunas indicaciones sobre la adquisición de las materias primas.

\section{I.1.2.2.- LÍMITES DE LA TECNOLOGÍA LÍTICA}

Además de esta imposibilidad práctica de analizar de forma global la tecnología de una materia, hay otro límite esencial en los estudios tecnológicos, límite que en realidad determina el tipo de analítica que se puede desarrollar sobre cualquier material dado. Se trata de que las características del conjunto lítico a analizar delimitan directamente la potencialidad de información que podemos obtener de la industria en cuestión. Y estas características de la industria lítica están determinadas por el tipo de yacimiento en el que se inscribe, la presencia e intensidad de los procesos postdeposicionales y la funcionalidad del propio yacimiento. Es necesario por tanto valorar en su justa medida el tipo de datos que se van a tratar.

Otro problema respecto al análisis tecnológico, en parte como consecuencia de lo anterior, radica en la dificultad, sobre todo cuando se inicia un acercamiento a este tipo de estudios, ocasionada por la multiplicidad de términos, esquematizaciones y definiciones respecto a la tecnología lítica elaboradas por distintos autores. El problema surge debido a que existen muchos conceptos cuyo significado se solapa entre sí o porque un mismo término se utiliza con significados distintos, así por ejemplo: el proceso técnico, el método de talla, la secuencia operativa, la cadena operativa, la estructura técnica, etc. Parece que la causa de este problema está en el límite anterior, el 
impuesto por las características peculiares de cada conjunto lítico concreto, de modo que muchas de estas esquematizaciones surgen a partir de la resolución y explicación de conjuntos concretos.

De todas formas se ha intentado extraer un factor común a la variedad de términos empleados por los distintos autores, ya que tal diversidad responde, por un lado, a las características del propio yacimiento y, por otro, al nivel de análisis que se aplique al conjunto dado, aparte de las preferencias propias de cada autor. Se podría establecer tres categorías o niveles de análisis de un conjunto: i) nivel de los objetos (análisis empírico inmediato), ii) nivel de los métodos, y iii) nivel conceptual.

\section{I.1.2.3.- NIVELES DE ANÁLISIS-SÍNTESIS DE UN CONJUNTO LÍTICO: MÉTODOS, MODALIDADES, ESQUEMAS O CONCEPTOS OPERATIVOS}

Como se ha apuntado en el párrafo anterior en ocasiones los distintos prehistoriadores(-tecnólogos) han adoptado diferentes puntos de vista para analizar conjuntos líticos concretos. Como consecuencia de ello, los términos, conceptos o esquemas varían de unos a otros. No obstante hemos intentado realizar una esquematización en tres niveles de los tipos de análisis (o síntesis) tecnológicos (Cuadro I.2). Se trata de un resumen quizás muy simplista de todos estos conceptos, pero el espíritu de tal esquema no es ahondar en las connotaciones, matices y sutilezas de cada uno de los enfoques, sino un propósito meramente práctico.

Para realizar esta esquematización se ha partido del trabajo teórico de C. Karlin (1991) sobre la cadena operativa, ya que estructura las distintas fases accesibles a partir del análisis tecnológico. De este artículo he tomado las denominaciones de las tres entidades globales: un nivel empírico, otro estructural y un último nivel conceptual. Se han ordenado estas tres categorías de lo concreto a lo genérico:

1.- Nivel empírico. Sería el más inmediato, centrado en lo concreto, el análisis directo de los datos. En términos tecnológicos, para saber cómo se ha transformado un bloque concreto, lo ideal sería reconstruir tal nódulo a través de un remontage total, pero lamentablemente son muy pocos los yacimientos en los que podemos realizar esta operación. Esto se refleja en el cuadro adjunto en la escasez de conceptos que recogen 
este tipo de esquematización. Karlin denomina "esquema operativo” al esquema creado a partir de la cadena operativa de un núcleo tallado. No obstante, en revisiones posteriores esta misma autora (Karlin, 1999) y en colaboración con S. Ploux (Ploux et Karlin, 1993) prefiere denominar "séquence” a la cadena operativa de un riñón.

\begin{tabular}{|c|c|c|c|}
\hline $\begin{array}{l}\text { NIVEL EMPÍRICO } \\
\text { (análisis directo del material, } \\
\text { reconstrucción de cada bloque) }\end{array}$ & $\begin{array}{l}\text { NIVEL ESTRUCTURAL } \\
\text { (esquematización de variantes) }\end{array}$ & $\begin{array}{l}\text { NIVEL CONCEPTUAL } \\
\text { (estructura básica } \\
\text { que rige la talla) }\end{array}$ & BIBLIOGRAFÍA \\
\hline $\begin{array}{l}\text { Cadena operativa } \\
\text { Esquema operativo }\end{array}$ & Esquema técnico & $\begin{array}{l}\text { Esquema conceptual } \\
\text { Proceso técnico }\end{array}$ & Karlin, 1991a \\
\hline \multirow[t]{6}{*}{ Séquence (de un riñón) } & Schéma & Schème & $\begin{array}{l}\text { Ploux \& Karlin, } 1993 \\
\text { Karlin, } 1999\end{array}$ \\
\hline & $\begin{array}{l}\text { Modalidad técnica } \\
\text { (preferencias y variantes) }\end{array}$ & $\begin{array}{l}\text { Esquema operativo } \\
\text { conceptual }\end{array}$ & Pelegrin, 1995 \\
\hline & Métodos & $\begin{array}{l}\text { Estructura / } \\
\text { Cadena operativa / } \\
\text { Concepto }\end{array}$ & Boëda, 1991a \\
\hline & $\begin{array}{l}\text { Método o } \\
\text { modalidades de aplicación }\end{array}$ & $\begin{array}{l}\text { Concepto operativo }= \\
\text { Cadena operativa }= \\
\text { Esquema operativo }\end{array}$ & $\begin{array}{l}\text { Boëda, Geneste \& } \\
\text { Meignen, } 1990\end{array}$ \\
\hline & Esquemas operativos & Esquema conceptual & Valentin, 1995 \\
\hline & Método & Estilo & Tixier, 1978 \\
\hline \multicolumn{2}{|c|}{ Objetos } & Tendencias & $\begin{array}{l}\text { Leroi-Gourhan, } \\
\text { 1971b }\end{array}$ \\
\hline
\end{tabular}

Cuadro I.2: esquema-resumen de los distintos términos utilizados por los principales autores a la hora de conceptualizar las distintos niveles de análisis tecnológicos.

En este nivel de análisis se instalaría el examen directo del material, a partir de cual se puedan reconstruir posteriormente esquemas (más o menos teóricos; modelos) sintéticos de los bloques tallados en el yacimiento. Para ello es necesario el examen detallado de cada elemento del conjunto, teniendo en cuenta no solo sus atributos métricos básicos, sino también los técnicos (por ejemplo el tipo de soporte de que se trate y su posición en la cadena operativa). También nos ayudaremos de las lecturas diacríticas sobre las piezas que más información técnica aportan, fundamentalmente los núcleos y los productos de acondicionamiento, además de los remontages. Dentro de este paso algunos autores nos proponen una "lista tecnológica" (a la manera de los listados tipológicos clásicos) de modo que cada tipo tecnológico se sitúa en su secuencia 
y fase correspondiente (por ejemplo: Chadelle 1983: 28; Geneste 1991a: 21; Lloret 1995). Así se obtiene una visión genérica de las características tecnológicas del conjunto lítico correspondiente.

2.- Nivel estructural. El segundo nivel de análisis sería una esquematización del anterior, una estructuración operativa inicial, que colocaría los distintos artefactos líticos a lo largo de la cadena operativa. En esta primera esquematización se aprecian normalmente las similitudes y variantes en secuencias o fases de talla concretas y también, en general, en procesos más o menos unificadores. En esta categoría analítica, en la que se elaborarían los “esquemas” técnicos según C. Karlin, se ubicarían conceptos ampliamente utilizados en la Prehistoria, tales como "método" o “modalidad”. Para Pelegrin (1995) con las “modalidades” entran en juego las preferencias de un grupo concreto por utilizar un procedimiento dado.

Asimismo, en esta categoría estarían los métodos tal y como los denomina Boëda (1991a), en tanto que variantes de un concepto estructural (por ejemplo el método recurrente unipolar o el de lasca preferencial serían métodos del concepto Levallois). Y Boëda, Geneste et Meignen (1990) utilizan de nuevo la palabra método en este sentido (variantes dentro de un esquema conceptual genérico) como sinónimo de modalidad de aplicación.

El término método es un concepto tradicionalmente empleado con un sentido muy general y teórico en el estudio de las industrias líticas y ha sido muy utilizado para el análisis y descripción de las industrias del Paleolítico ${ }^{5}$. No obstante es muy interesante esta delimitación de su significado dentro de un lenguaje tecnológico estricto.

${ }^{5}$ El método es: “l'agencement, suivant une marche raisonnée d'un certain nombre de gestes liés chacun grâce à une technique" (Tixier et al. 1980: 92); Lo que podríamos traducir como: "una disposición que sigue un camino razonado de un cierto número de gestos unidos cada uno gracias a una técnica”. Podemos añadir que estos pasos se dirigen hacia la obtención de un objetivo (Inizian et al. 1995: 151). La noción de método está muy cercana a la de cadena operativa, ya que implica una organización "metódica” de varios pasos técnicos con el fin de conseguir un objetivo. No obstante la "cadena operativa” aporta una connotación mucho más estructurada del proceso técnico y unas posibilidades de análisis directo del material más flexibles y amplias que el "método". Respecto al "método" sucede algo parecido a lo que pasaba con "técnica"; desde un punto de vista genérico tendría un significado amplio, muy válido y muy frecuente en el lenguaje de tecnología paleolítica. Desde un punto de vista tecnológico más concreto, Boëda por ejemplo propone su uso como una variante dentro de un concepto-estructura de talla. 
3.- Nivel conceptual. Por último, el tercer nivel sería el de síntesis global, esquemático, el proceso subyacente básico en todo el proceso de talla. Este nivel estaría en la línea de concepto que guía toda la talla. Sería el “concepto” desde un punto vista volumétrico o estructural, si tomamos la terminología de Boëda (1991), quien considera que sería también sinónimo de cadena operativa. Se trata del esquema básico que después se irá diversificando en variantes, modalidades o métodos, dependiendo de diversos factores. Karlin (1991) lo denomina "esquema conceptual” o "proceso técnico", de modo muy similar a Pelegrin (1995) con su "esquema operativo conceptual”. Sería lo que Karlin denomina después como “schème” (Ploux et Karlin 1993). Como ejemplo de esta categoría técnica tendríamos el “Concepto Levallois” con sus distintos métodos (Boëda, 1994), métodos que estarían en el nivel anterior, el estructural; o también el “esquema conceptual” de los grupos magdalenienses de la Cuenca de París, que a su vez tienen una serie de esquemas operativos peculiares dependiendo de los distintos (Valentin, 1995: 141).

La ordenación de estos tres niveles desde un punto de vista analítico-inductivo es meramente práctica. Al enfrentarnos a un conjunto lítico normalmente se puede ver el/los esquemas conceptuales básicos que han dirigido la talla, es decir el tercer nivel o nivel conceptual; por ejemplo si se trata de un débitage de lascas o de hojas. En efecto, sería dentro de esta “categoría conceptual” en la que se diferenciarían en primer lugar los grandes procedimientos de talla: débitage y façonnage y, centrándonos en el débitage, el de lascas por un lado, y el laminar, por otro. Estos esquemas conceptuales son muy claros desde un punto de vista tan básico y amplio. Del mismo modo parece que se puede diferenciar a este nivel (conceptual o estructural-volumétrico básico) un esquema/débitage achelense de un débitage quina y de un esquema/débitage de lascas discoide; o también parece que puede hablarse de distintos esquemas/débitages laminares en el Auriñaciense, Gravetiense y Magdaleniense. Ahora bien, la dificultad aparece frecuentemente en determinar hasta qué punto un esquema de talla puede ser diferente de otro en el ámbito conceptual, o bien puede tratarse de una variante del mismo, pasando a ser por tanto un método o modalidad. Aquí estaría por ejemplo la controversia en torno al débitage/esquema discoide frente al método Levallois recurrente centrípeto (Boëda, 1991a). Y también la cuestión de si el débitage laminar es 
un esquema conceptual (en el ámbito estructural) único con variantes, o bien tales variantes se pueden erigir como estructuras volumétricas diferenciadas (Boëda, 1997).

Diferenciar y concretar estos niveles de síntesis de los procesos técnicos presentes en un conjunto lítico es una labor primordial en su análisis tecnológico. Centrándonos en el conjunto objeto de nuestro análisis, en los momentos finales del Paleolítico y en el Mesolítico los esquemas de talla que aparecen son cadenas de débitage laminar mayoritariamente, aunque también hay producción de lascas. Dentro de los esquemas laminares, deberíamos determinar si hay un esquema laminar diferente de uno microlaminar o si por el contrario se trata de una producción integrada (Cazals, 1998). También deberíamos concretar si hay varios esquemas laminares o si se trata de un esquema con variantes o modalidades distintas, es decir que responda a un solo esquema laminar unívoco.

Para la caracterización tecnológica de un conjunto lítico, estos tres niveles se pueden concretar en los dos últimos. Habría por tanto que mostrar en primer lugar, siguiendo ahora un principio deductivo, los esquemas genéricos de talla, es decir, a escala conceptual o estructural. Si volvemos al cuadro, los términos que encontramos en este nivel serían, fundamentalmente, el de esquema conceptual (Karlin, 1991a; Pelegrin, 1995) y concepto (operativo) (Böeda, Geneste et Meignen, 1990; Boëda, 1991a).

En segundo lugar habría que especificar las variantes de cada uno de los esquemas, es decir los "métodos” (Boëda, 1991a) o “modalidades de aplicación” (Pelegrin, 1995). Tales variantes dependen de diversos factores, que pueden ser de tipo económico, social, limitaciones de la propia materia, etc. Por ejemplo, la preferencia por la fabricación de unos soportes de un módulo determinado, lo cual definiría una “gestión de los soportes” concreta; o bien la aparición de una materia concreta para ciertos soportes (en lo que se ha denominado como gestión de la materia prima). Habría que valorar la transcendencia de tales preferencias, si están relacionadas con el interés por fabricar unos útiles concretos, por ejemplo, o bien con un utillaje menos especializado, o responden a unas necesidades inmediatas porque se encuentren en sitios especializados. 
Las variantes se pueden producir también por factores que afectan estrictamente al individuo, a su habilidad técnica o a procesos de aprendizaje (Olive, 1988; Pigeot, 1988; Roux, 1991). Es en este sentido como Karlin habla de los “schémas” (Ploux y Karlin, 1993; Karlin, 1999).

En fin, estos dos niveles del “concepto y sus variantes”, dejando aparte los términos que adoptemos y centrándonos en su significado esencial, los podríamos colocar en la misma línea que el "estilo y el método" de Tixier (1978) o incluso, dentro de una perspectiva muy global, en la línea de "las tendencias” y "los objetos” de LeroiGourhan (1971b:27). Según este último autor, la línea subyacente de las tendencias (con su carga cultural implícita) está contrarrestada por los objetos en sí, es decir las posibilidades marcadas por la materia, por la función del útil, etc.

Quedan abiertos muchos caminos para interpretar el significado de los esquemas técnicos deducidos de un grupo, por ejemplo, entre los métodos (al nivel de modalidades o variantes) y los conceptos: ¿cuál de estas categorías tienen una carga cultural definitoria?. También habría que delimitar en qué medida las variantes son marcadores culturales que impliquen alguna tendencia de índole sincrónica o diacrónica; o si, por el contrario, esas variantes son producto de factores de otra índole (las características de los recursos locales, las limitaciones de la propia materia o de la función de un objeto determinado), etc. Para abordar estas cuestiones es necesario tomar en consideración todos los datos conocidos del grupo en cuestión, el resto de artefactos arqueológicos, el contexto medioambiental en que se encuentran, etc.

\section{I.1.2.4.- EL CONCEPTO DE CADENA OPERATIVA}

Uno de los conceptos más ampliamente utilizados a la hora de aplicar los análisis tecnológicos a las industrias líticas es el de “cadena operativa”. Se trata de un término que articula frecuentemente incluso las fases genéricas del estudio tecnológico tal y como lo hemos expuesto en el cuadro anterior; en este sentido, es un término muy útil porque es muy práctico.

El concepto de cadena operativa se fragua (Desrosiers, 1991: 21) a principios de los años 50 del siglo XX, dentro de la Etnología francesa (M. Mauss, M. Maget), tal y 
como se ha señalado, en el contexto del análisis de las técnicas (o el "hecho técnico”) en tanto que procesos con operaciones o fases distintas, articuladas entre sí. A. LeroiGourhan introduce tal concepto dentro del análisis tecnológico, apuntando su viabilidad como útil analítico y da una primera definición de cadena operativa en "El Gesto y la Palabra” (1964) ${ }^{6}$.

El origen del concepto está más o menos claro, pero no lo está tanto su translación al campo de la tecnología prehistórica. Se puede decir que la aplicación de tal término se produce de una forma un tanto confusa. Y esto es debido a que la manera de integrarlo dentro de la familia de los conceptos pertenecientes al grupo de los hechos (sociales) técnicos (considerados como procesos a lo largo de fases) en tecnología varía según los autores y también en función de los estudios específicos. Esta circunstancia se produce entre los mismos etnólogos, por lo que no es extraño que la exportación de este concepto a otra disciplina provoque situaciones equívocas. Asimismo una de las principales razones de la variedad de aplicaciones de tal término es su adaptabilidad a distintas perspectivas analíticas. De hecho, A. Leroi-Gourhan utiliza el concepto de “cadena operativa” desde el ángulo de la evolución, para resaltar la relación entre técnica y lenguaje y, por otra parte, para abordar la noción de innovación a través de la realización de cadenas operativas (en relación con lo que denominan como cadenas operativas maquinales) (Desrosiers, 1991: 25).

Desde el mundo de la Etnología la cadena operativa se define como una serie de operaciones que transforman una materia en un producto; teniendo en cuenta las acciones sobre la materia, las fases de preparación, presentes o no, los tiempos muertos, necesarios o no, ..., hasta la obtención del resultado técnico deseado. Sería un término más restringido que el de “processus” técnico (Lemonnier, 1976: 106). La tecnología prehistórica va a utilizar este término como una guía de lectura de los datos arqueológicos, adaptando este concepto etnológico a las peculiaridades propias de los datos arqueológicos (Pelegrin, Karlin et Bodu, 1988; Karlin, Bodu et Pelegrin, 1991).

6 "La noción de cadena operatoria [...] es necesario evocarla aquí para comprender el vínculo que existe entre técnica y lenguaje. La técnica es a la vez gesto y útil, organizados en cadenas por una verdadera sintaxis que da a las series operatorias a la vez su fijeza y su flexibilidad" (Leroi-Gourhan, 1971a: 116). 
Precisamente la base de la extrapolación de este término a la Prehistoria está inspirada en el artículo del etnólogo francés P. Lemonnier (1976), al que ya se ha aludido, en el que expone que la base del análisis de los procesos técnicos se fundamenta en tres órdenes de fenómenos:

1. Los objetos: entre los que se incluirían no solo los útiles retocados sino también todos los productos y desechos que se producen a lo largo del proceso de talla.

2. Los procesos técnicos: es decir las series de gestos u operaciones, las cuales se pueden descomponer en cadenas operativas (que a su vez agrupan varias secuencias gestuales).

3. Los conocimientos: implicados en todas estas acciones. Habría distintos tipos de conocimientos, con consecuencias directas sobre el esquema conceptual existente en el grupo prehistórico; desde el manejo de las limitaciones impuestas por la propia materia, hasta el juego de preferencias que puede imponer una determinada tendencia cultural.

C. Karlin (1991: 109) define la cadena operativa como un útil conceptual que proporciona un camino de lectura de los restos arqueológicos y obliga al prehistoriador a organizar de forma coherente los elementos conocidos y también los no conocidos. Se trata por tanto esencialmente de un útil metodológico y teórico de ordenamiento de elementos y de conceptos, que pone en evidencia la lógica interna de una actividad. La cadena operativa es un encadenamiento de actos, gestos e instrumentos que constituyen un proceso técnico con unas etapas generales más o menos previsibles. Dentro de este concepto se asume tanto el orden (dentro de la óptica de un proyecto técnico) de las fases técnicas en serie; como el camino técnico seguido por un objeto desde su estado de materia prima hasta que es un producto acabado. A escala empírica, la cadena operativa es el conjunto de operaciones, agrupadas o no en secuencias, que se encaminan a la consecución de un único objetivo. A escala estructural es una combinación de factores técnicos a partir de una fórmula de concretización y convergencia que se denomina esquema técnico. 
La cadena operativa se encuentra en un paso incierto entre el lado de los “objetos” y el de los “conceptos”. Lo más importante es que se trata de un término que se refiere sobre todo a la suma de secuencias y operaciones. Como consecuencia es un concepto muy útil a la hora de examinar el objeto concreto, porque lo sitúa dentro de una fase; por ejemplo las hojas en una fase de débitage pleno, las lascas corticales en una fase inicial de preparación, una tableta de núcleo dentro de una fase de pleno débitage en una secuencia de reforma del plano de percusión, etc. La clave de la utilidad práctica de la “cadena operativa” está en dos aspectos:

1) Aporta un esquema ideal estructurado que permite colocar cada artefacto lítico dentro de una de las fases del proceso técnico, con las implicaciones espacio-temporales que esto conlleva.

2) Es un concepto muy flexible, que ha sido aplicado en distintos niveles o categorías de análisis, desde la talla de un único núcleo, al proceso técnico que resume la talla de hojas, lascas, etc.

Esta flexibilidad es muy útil y efectiva, de hecho no es raro, como se puede observar en el cuadro I.2, que algunos autores prefieran denominar como cadena operativa a los distintos niveles de análisis que hemos descrito. No obstante, esta variabilidad en la aplicación del término es apta siempre que determinemos en qué nivel de análisis nos encontramos o delimitemos el sentido en que utilizamos tanto éste, como el resto de los términos (Lemonnier, 1983: 12).

En resumen, la cadena operativa es un útil metodológico de primera magnitud que impone un orden al conjunto lítico. A través de ella el prehistoriador trata de distinguir cómo los seres humanos organizaban las operaciones técnicas, sopesando el juego de elecciones constantes que tiene que realizar el tallador, el cual ha de equilibrar los objetivos e intenciones que pretende alcanzar (dentro de las posibilidades del esquema operativo-cultural en el que se encuentra), con las limitaciones impuestas por la propia materia (las leyes mecánicas de fractura de las rocas y el tipo de materia concreta).

El empleo de los distintos términos que hemos esbozado aquí va a depender muchas veces del tipo de análisis que se desarrolle, de las características del conjunto lítico y hasta de las propias preferencias del autor en concreto. Como en todos los casos, 
las características del conjunto lítico son determinantes a la hora de aplicar unas metodologías de análisis u otras (posibilidad de realizar remontages por ejemplo). A este respecto, en el siguiente apartado, se va a delimitar el uso que de estos distintos términos se va a realizar en este trabajo, uso que está basado en el cuadro-resumen expuesto en el cuadro I.2. 


\section{I.2. MÉTODO DE ANÁLISIS TECNOLÓGICO APLICADO}

\section{I.2.1.- NIVELES DE ANÁLISIS: ESQUEMA TÉCNICO, OPERATIVO Y CONCEPTUAL}

Para estructurar el análisis tecnológico de un conjunto lítico, hemos optado por utilizar la terminología propuesta por los diferentes autores, pero teniendo en cuenta que el sentido y significado con que entendemos los principales conceptos es el siguiente:

- ESQUEMA TÉCNICO: es aquél desarrollado sobre un núcleo. El análisis de cada núcleo aportará un esquema técnico básico.

- ESQUEMA OPERATIVO: las similitudes entre varios esquemas técnicos definirán los esquemas operativos, que pueden ser modalidades o preferencias dentro de un mismo esquema conceptual amplio.

- ESQUEMA CONCEPTUAL: esquema estructural básico y teórico que subyace en el desarrollo de un proceso de talla. Este término encierra una idea concreta del volumen del núcleo; la aplicación práctica de este esquema cognitivo puede dar lugar a la aparición de uno o varios esquemas operativos (que son las variantes de ese “núcleo ideal”: modalidades o preferencias).

- CADENA OPERATIVA: se utilizará este término en un sentido amplio, al nivel del esquema conceptual, sería el desarrollo del esquema o estructura básica a lo largo de sus distintas etapas teóricas.

- MÉTODO: utilizaremos este término en sentido restringido para denominar fases o secuencias concretas que pueden variar dentro de la cadena operativa. Por ejemplo un esquema de débitage puede tener varios métodos de preparación o iniciación (dependientes sobre todo del bloque seleccionado para tallar o bien de los métodos de obtención de dicho nódulo a partir de otro bloque mayor por ejemplo). 
- MODO DE TALLA: en el sentido del modo de ejecución de la talla, centrado esencialmente en el tipo de percutor empleado y la forma como se aplica la fuerza. Los modos de talla son: la percusión directa con percutor duro o blando, la percusión indirecta y la presión.

\begin{tabular}{|l|l|l|}
\hline NIVEL EMPÍRICO & NIVEL ESTRUCTURAL & NIVEL CONCEPTUAL \\
\hline $\begin{array}{l}\text { Esquema técnico } \\
\text { (el desarrollado sobre un núcleo) }\end{array}$ & $\begin{array}{l}\text { Esquema operativo } \\
\text { (el esquema-resumen de varios } \\
\text { esquemas técnicos con } \\
\text { características comunes) }\end{array}$ & $\begin{array}{l}\text { Esquema conceptual: } \\
\text { CADENA OPERATIVA } \\
\text { (estructura de base que guía un } \\
\text { proceso de talla, agrupando uno o } \\
\text { varios esquemas operativos) }\end{array}$ \\
\hline
\end{tabular}

Cuadro I.3: propuesta del significado con que se emplean los términos para la descripción de los distintos niveles de análisis de los procesos técnicos. Elaborado a partir de las referencias del cuadro I.2.

\begin{tabular}{|l|l|}
\hline CADENAS OPERATIVAS BÁSICAS \\
\hline DÉBITAGE & $\begin{array}{l}\text { DE LASCAS } \\
\text { LAMINAR }\end{array}$ \\
\hline FAÇONNAGE \\
\hline
\end{tabular}

Cuadro I.4: cadenas operativas básicas a nivel genérico.

En el cuadro I.3 se esquematizan los tres niveles de análisis con los términos asignados para cada uno. El análisis de los esquemas técnicos de los núcleos, así como también del resto de los artefactos líticos del conjunto, permitirá definir las cadenas operativas presentes en un yacimiento. Habrá que determinar por último si estas últimas pertenecen a un solo esquema conceptual, siendo variantes de él, o a más de uno. El término de “cadena operativa” se reservará para la categoría más amplia, en un ámbito conceptual-estructural que definiría todo el proceso que rige el desarrollo de dicho esquema conceptual; dicho esquema puede sufrir variaciones o adaptaciones, que se manifestarán en los esquemas operativos. Desde este punto de vista se describen en el cuadro I.4 las cadenas operativas básicas en todo proceso de talla, que estarían determinadas por los objetivos esenciales de los procesos de talla: las cadenas de débitage frente a las de façonnage. Y dentro de las primeras, normalmente las cadenas laminares pueden diferenciarse, en este nivel conceptual, de las cadenas de lascas. 
En todo caso, el adjetivo “conceptual” o “cognitivo” (ya sea esquema, estructura, etc.) atañe siempre al ámbito del tercer nivel que hemos expuesto, es decir el que definiría el esquema básico subyacente al proceso de talla. Por el contrario el adjetivo "técnico" estaría vinculado al primer nivel de análisis, en un sentido más empírico y directo de contacto con los artefactos. Por su parte el adjetivo "operativo" se aplica al nivel intermedio de análisis, y será importante en esta categoría determinar si las diferencias o variaciones entre los esquemas responden a factores relativos a la materia prima o bien a preferencias de índole cultural.

\section{I.2.2.- ESTRUCTURA IDEAL DE UNA CADENA OPERATIVA DE DÉBITAGE}

\section{LAMINAR}

Dado que el conjunto lítico examinado pertenece a un nivel adscrito al Mesolítico, adoptaremos como esquema básico de análisis el propio de una cadena operativa laminar, ya que la obtención de soportes tipo hoja/hojita es el principal objetivo de este tipo de conjuntos.

Toda cadena operativa se puede dividir en segmentos menores cuyo número y complejidad puede variar. La primera división de la cadena es en amplias fases, concretamente se pueden distinguir cinco (las cuales son la plasmación concreta de las fases teóricas de todo proceso tecnológico; ver cuadro I.1): fase de adquisición de la materia prima, fase de preparación o conformación del nódulo, fase de transformación o producción propiamente dicha, fase de uso y por último la fase de abandono. Cada fase, a su vez, se puede subdividir en secuencias y éstas en procedimientos, llegando casi a los gestos ejecutados, que sería la unidad mínima. Pero estos gestos en Prehistoria son difícilmente accesibles. 


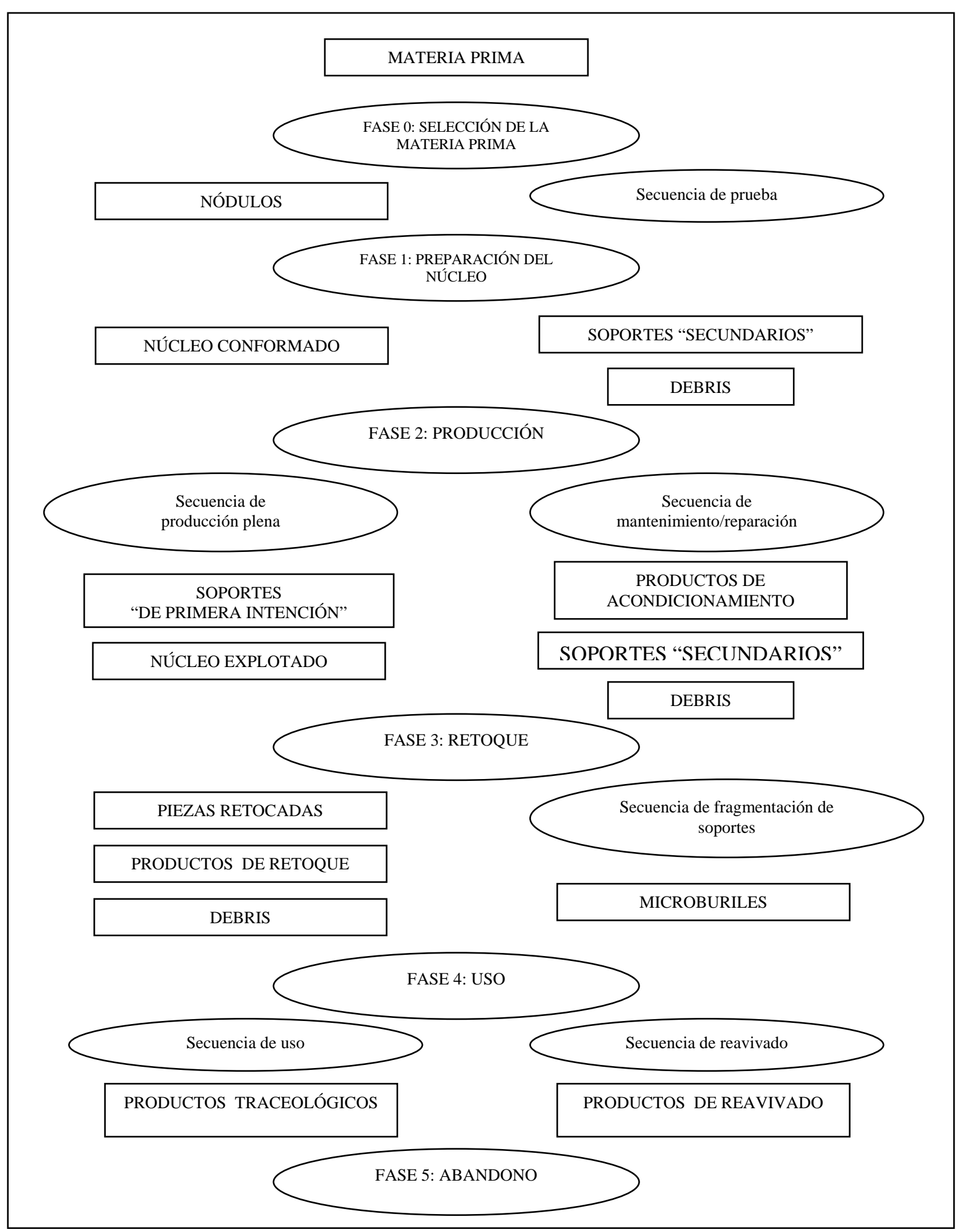

Cuadro I.5: diagrama ideal de una cadena operativa laminar. En rectángulos están los soportes líticos que aparecen a lo largo de cada fase y secuencia; en óvalos las fases y secuencias propiamente dichas. Basado en: I. Ortega (Boëda, 1997: fig.3). 


\begin{tabular}{|c|c|c|c|}
\hline FASE & SECUENCIA & PROCEDIMIENTO & SOPORTES \\
\hline $\begin{array}{l}\text { 0: Adquisición } \\
\text { materia prima }\end{array}$ & $\begin{array}{l}\text { Selección de bloques } \\
\text { Prueba }\end{array}$ & & $\begin{array}{l}\text { Nódulos sin tallar } \\
\text { Nódulos fragmentados }\end{array}$ \\
\hline \multirow{4}{*}{$\begin{array}{l}\text { 1: Preparación (mise } \\
\text { en forme) }\end{array}$} & Conformación inicial & $\begin{array}{l}\text { Desbaste (degrossissage) } \\
\text { Cadrage } \\
\text { Regularización }\end{array}$ & $\begin{array}{l}\text { Lascas corticales y } \\
\text { parcialmente corticales de } \\
\text { gran tamaño } \\
\text { Lascas de tercer orden } \\
\end{array}$ \\
\hline & \multirow{3}{*}{ Iniciación } & Hoja de encetadura (“de entame”) & $\begin{array}{l}\text { Hoja cortical } \\
\text { Hoja cortical con arista } \\
\text { natural }\end{array}$ \\
\hline & & Cresta anterior & Hoja con cresta \\
\hline & & Serie de hojas de inicio & $\begin{array}{l}\text { Hojas corticales (quizás con } \\
\text { arista natural) } \\
\text { Hojas semicorticales } \\
\text { Hojas de tercer orden }\end{array}$ \\
\hline \multirow{7}{*}{ 2: Producción } & $\begin{array}{l}\text { “Producción plena” } \\
\text { de hojas }\end{array}$ & $\begin{array}{l}\text { Preparación } \\
\text { Extracción propiamente dicha } \\
\text { Serie de extracciones continuas }\end{array}$ & $\begin{array}{l}\text { Soportes con talón facetado, } \\
\text { abrasión, talón con espolón } \\
\text { (“en éperon”) } \\
\text { Hojas de tercer orden }\end{array}$ \\
\hline & \multirow{4}{*}{$\begin{array}{l}\text { Reparación / conservación / } \\
\text { mantenimiento } \\
\text { (entretien, mantien) } \\
\text { de la superficie de } \\
\text { extracciones }\end{array}$} & Extracciones axiales & $\begin{array}{l}\text { Flancos de núcleo } \\
\text { longitudinales y opuestos } \\
\text { Lascas laminares } \\
\text { “Hojas con flanco” } \\
\text { Hojas semicorticales } \\
\end{array}$ \\
\hline & & Extracciones transversales & Flancos transversales \\
\hline & & $\begin{array}{l}\text { Regularización a partir de } \\
\text { crestas laterales }\end{array}$ & $\begin{array}{l}\text { Hojas con neo-cresta } \\
\text { Lascas pequeñas }\end{array}$ \\
\hline & & $\begin{array}{l}\text { Desde la base del núcleo: } \\
\text { cresta inferior, } \\
\text { segundo plano de percusión }\end{array}$ & $\begin{array}{l}\text { Hojas con negativos bipolares } \\
\text { Lascas pequeñas }\end{array}$ \\
\hline & $\begin{array}{l}\text { Reparación / mantenimiento } \\
\text { del plano de percusión }\end{array}$ & & $\begin{array}{l}\text { Tabletas } \\
\text { Semitabletas } \\
\text { Lascas de reavivado del frente }\end{array}$ \\
\hline & $\begin{array}{l}\text { Reparación/mantenimiento } \\
\text { de otras partes del núcleo }\end{array}$ & $\begin{array}{l}\text { De la base del núcleo } \\
\text { De los bordes laterales o posterior (puede } \\
\text { que mediante crestas) }\end{array}$ & $\begin{array}{l}\text { Base de núcleo } \\
\text { Lascas corticales } \\
\text { Lascas de tercer orden }\end{array}$ \\
\hline \multirow[b]{2}{*}{ Fase 3: retoque } & Selección del soporte & Retoque & \multirow{2}{*}{$\begin{array}{l}\text { Pieza retocada } \\
\text { Lasquitas de retoque } \\
\text { Golpe de buril } \\
\text { Microburil }\end{array}$} \\
\hline & Rotura de un soporte & $\begin{array}{l}\text { “Técnica” de microburil } \\
\text { “Técnica” de rotura transversal }\end{array}$ & \\
\hline Fase 4: uso & $\begin{array}{l}\text { Uso del útil } \\
\text { Reavivado }\end{array}$ & & $\begin{array}{l}\text { Frente de raspador } \\
\text { Golpe de buril }\end{array}$ \\
\hline Fase 5: abandono & & & \\
\hline
\end{tabular}

Cuadro I.6: modelo hipotético de una cadena operativa laminar con las secuencias y procedimientos en que se puede dividir y las piezas líticas que corresponderían a cada segmento. El cuadro se ha realizado (especialmente la fase de conformación) a partir de B. Valentin (1995). 
En el cuadro I.5 se expone un diagrama-modelo de desarrollo de una cadena operativa de débitage laminar. Se trata de una esquematización ideal en la que no sólo se estructuran las diferentes fases y secuencias, sino que se señalan los soportes o huellas que pueden dejar en el conjunto lítico. Este diagrama se completa con el cuadro I.6, en el que se especifica, también de forma ideal, el progreso de una cadena de débitage laminar de manera más detallada, incluyendo procedimientos dentro de las secuencias. Este último esquema tiene un desarrollo de procedimientos hipotéticos que pueden estar presentes o no. Se indica también en este cuadro tanto los términos franceses que se han traducido al castellano, como aquéllos para los que no encontramos una palabra adecuada para su traducción en este contexto (por ejemplo el cadrage). Todos estos cuadros de esquematización y síntesis de una cadena operativa se han elaborado a partir de los trabajos de varios autores (por ejemplo Geneste, 1988; Turq, 1990, 1992), especialmente aquellos que han abordado los problemas de las cadenas operativas del Paleolítico Superior (Chadelle, 1983; Pigeot, 1987; Pelegrin, 1995; Valentin, 1995; Lloret, 2001, etc.).

Se especifican a continuación las distintas fases y secuencias estructuradas en los cuadros I.5 y I.6. Entre paréntesis se señalan los soportes del conjunto lítico que podrían adscribirse a dichos segmentos de la cadena.

$\triangleright$ FASE 0: adquisición de la materia prima:

- Selección de nódulos (nódulos seleccionados)

- Secuencia de prueba de dichos nódulos (fragmentos de nódulos probados y desechados).

$\triangleright$ FASE 1: preparación del núcleo (mise en forme):

Esta fase puede prolongarse más o menos dependiendo de las características de los nódulos seleccionados o de los requisitos impuestos por el proceso aplicado. Las distintas secuencias y procedimientos se han tomado del análisis realizado por B. Valentin (1995) sobre los conjuntos del Tardiglaciar de la Cuenca de París, y el significado de cada una se especifica en el cuadro I.7. En este cuadro se exponen un buen número de secuencias factibles en una cadena laminar; pero, como es lógico, es difícil que se encuentren la totalidad de ellas, especialmente cuando se utilizan 
métodos rápidos de preparación, con un aprovechamiento de las características morfotécnicas de los nódulos de origen (como es el caso de El Espertín).

- Secuencia de conformación o bosquejo inicial (degrossissage): se centra en la preparación del volumen del núcleo, fundamentalmente en la colocación de la superficie de extracciones y el plano de percusión.

- Secuencia de iniciación: con varios procedimientos para abrir el débitage de la superficie de extracciones (por ejemplo las hojas o lascas "de encetadura" ${ }^{7}$ [de entame], la extracción de una cresta anterior, etc.).

\begin{tabular}{|l|l|}
\hline $\begin{array}{l}\text { Conformación inicial } \\
\text { (mise en forme) }\end{array}$ & $\begin{array}{l}\text { Preparación del núcleo para los objetivos del débitage que se quieren } \\
\text { desarrollar. Bosquejo del volumen con la instalación de las superficies } \\
\text { principales (plano de percusión y superficie de extracciones) y de la } \\
\text { carena y la cintra }\end{array}$ \\
\hline $\begin{array}{l}\text { Desbaste } \\
\text { (Degrossissage) }\end{array}$ & $\begin{array}{l}\text { suprimir irregularidades en bloques informes, definir volumen con } \\
\text { instalación del plano de percusión y superficie de extracciones }\end{array}$ \\
\hline Cadrage & acondicionamiento cuidadoso de las convexidades (carena y cintra)
\end{tabular}

Cuadro I.7: Procedimientos y secuencias posibles en la fase de preparación (fase 1). Elaborado a partir de B. Valentin (1995).

7 "Encetar" (o encentar), significa (DRAE, 2001) comenzar y tiene un uso específico relativo al comienzo de alguna cosa comestible (como una hogaza de pan, queso, etc.). Su sustantivo, “encetadura”, que significaría el comienzo, extremo, etc.; es la traducción de entame, término francés que tiene también el mismo significado y uso específico que el señalado en castellano (Diccionario Larousse, 1991). 
$\triangleright$ FASE 2: producción

- Secuencia de producción (/débitage) plena: extracción de los soportes (hojas, hojitas) propiamente dichos.

- Procedimiento de preparación del frente de talla o del punto de impacto en concreto (abrasión de la cornisa de los núcleos, talones preparados). Este gesto suele producirse de forma previa a la secuencia de extracción anterior.

- Secuencia de reparación/acondicionamiento (entretien/mantien) del plano de percusión (tabletas, semitabletas, lasquitas de reavivado).

- Secuencia de reparación/acondicionamiento de la superficie de extracciones:

- Desde los laterales de dicha superficie (flancos de núcleo transversales, procedimiento de cresta lateral o inferior, etc.).

- Según el eje axial (flancos longitudinales, “hojas con flanco”,...).

$\gg$ FASE 3: retoque, realización del útil

- Selección del soporte.

- Secuencia de acondicionamiento del soporte (por ejemplo la realización de una truncadura previa a un golpe de buril).

- Procedimiento de rotura del soporte: de forma directa (fragmento desechado del soporte, que es prácticamente imposible de reconocer entre otros soportes rotos), mediante la “técnica del microburil” (microburil).

- Retoque propiamente dicho para realizar el útil (útil retocado propiamente dicho, lasquitas de retoque, golpes de buril).

$\triangleright$ FASE 4: uso

- Uso del útil realizado; los que se han denominado como "productos traceológicos” son las huellas que eventualmente pueden quedar de dicho uso: pseudorretoques, micro-huellas traceológicas, roturas, etc.

- Secuencia de reavivados, afilado de la parte activa del útil (golpes de buril de segunda generación y posteriores, reavivado del frente de un raspador, lasquitas de retoque, etc.). 
FASE 5: abandono

La disposición y ubicación de los restos líticos permitirían eventualmente la realización de análisis espaciales (determinación de zonas de talla, por ejemplo).

Pueden aparece también, por ejemplo, ciertos patrones de roturas como consecuencia de procesos postdeposicionales.

Como se puede comprobar en estos cuadros, hay algunos soportes del conjunto lítico que se pueden ubicar sin problemas a lo largo de esta cadena y, más concretamente, dentro de secuencias concretas:

- Los nódulos o sus fragmentos pertenecen a la fase 0

- $\quad$ Los núcleos conformados a la fase 1

- Las hojas de primer orden (totalmente corticales) pueden ser hojas de encetadura, de la fase 1 en una secuencia de iniciación

- Las hojas-hojitas (que serían los soportes de primera intención) a la fase 2 en una secuencia de producción plena

- $\quad$ Los núcleos explotados a la fase 2

- Los productos de acondicionamiento (tabletas, semitabletas, flancos de núcleo) a la fase 2 en una secuencia de reparación/mantenimiento

- $\quad$ Los útiles retocados a la fase 3-4

- $\quad$ Los golpes de buril de primera generación a la fase 3

- $\quad$ Los frentes de raspador y golpes de buril reavivados, a la fase 4

En cambio hay otra serie de soportes presentes en el conjunto lítico que no tienen una correspondencia unívoca con una fase o secuencia concreta:

- Los que se han denominado como "soportes secundarios" o "soportes de segunda intención” agrupan esencialmente al conjunto de lascas, de todos los órdenes, las cuales pueden aparecer en las dos primeras fases. Las lascas corticales suelen producirse en la fase de preparación, pero si el esquema aplicado es muy somero, pueden extraerse también a lo largo de la fase de explotación plena, en secuencias de reparación del núcleo

- Los debris pueden aparecer a lo largo de toda la cadena operativa 
Hay que tener en cuenta también que el desarrollo de la cadena operativa, tal y como se ha presentado en estos cuadros, no es un esquema rígido, de forma que las distintas fases y secuencias no siempre están presentes. Es muy frecuente, sobre todo en conjuntos mesolíticos como el que es objeto de nuestro estudio, que la fase de preparación sea muy somera, produciéndose entonces un acercamiento entre la fase de selección de la materia prima, de preparación e inicio del débitage. Esto sucede sobre todo cuando la morfología inicial del nódulo tiene unas características que se acercan a la conformación ideal del esquema a desarrollar.

Otro aspecto a considerar es que dicha cadena tampoco tiene un sentido unidireccional estricto, es decir las secuencias se pueden repetir, o volver a fases anteriores; por ejemplo un núcleo de hojas en fase de producción que haya sufrido un accidente, puede bien repararse, o bien volver a realizar una conformación (fase 1) total del núcleo para seguir con la producción de soportes. Esta flexibilidad de la cadena es la razón que explica la ausencia de líneas en el diagrama del cuadro I.5, ya que el sentido del proceso de talla no tiene una dirección única y obligatoria, sino que está sometido al juego constante entre los objetivos que se persiguen, los límites de la materia y la propia habilidad de la persona que ejecuta el débitage.

\section{I.2.3.- RECONSTRUCCIÓN DEL ESQUEMA TÉCNICO: ANÁLISIS EMPÍRICO DEL MATERIAL LÍTICO}

En este apartado se va a exponer la metodología explícita aplicada para el análisis tecnológico realizado en El Espertín. Si bien nuestro objetivo será concretar los esquemas conceptuales presentes en los procesos técnicos del conjunto analizado, con sus variantes, modalidades o particularidades concretas, partiremos desde la base del análisis directo, empírico de los elementos líticos, para ir sintetizando posteriormente los esquemas operativos.

Esta primera fase consiste en un análisis del conjunto lítico, anotando los distintos atributos que hemos tenido en cuenta para su estructuración en las distintas fases de la cadena operativa. El paso previo al análisis técnico del conjunto lítico ha sido una clasificación de las distintas materias primas, labor que hemos realizado en un 
capítulo específico dedicado a lo que serían las "técnicas de aprovisionamiento" o al menos lo que podemos decir de ellas desde el tipo de análisis tecnológico que hemos realizado. Nos centraremos en la descripción de los atributos genéricos y técnicos analizados en el material lítico, atributos sobre los cuales se van a derivar todas las esquematizaciones realizadas sobre el conjunto.

\section{I.2.3.1.-ATRIBUTOS BÁSICOS}

El análisis tecnológico implica como hemos indicado, necesariamente, la consideración de todo el conjunto lítico existente en el yacimiento, tanto los útiles retocados como los núcleos, lascas y otros restos de talla. Hemos tenido en cuenta por tanto todos estos elementos, tomando una serie de variables cuantitativas y cualitativas de cada uno de ellos. En todas las piezas líticas se han recogido unos datos básicos en una ficha. Para la elección de estos atributos se ha tomado como punto de partida el protocolo de análisis propuesto por Bernaldo de Quirós et al. (1981), además de incluir también algunos de los atributos de tipo más técnico propuestos por M. Lloret (2001).

$\gg$ sigla: año, cuadro, sector, nivel, bolsa, $\mathrm{n}^{\circ}$ de inventario.

$\triangleright$ tipo de materia prima, tal y como la hemos descrito en el capítulo dedicado a este tema

- SN: sílex/chert negro

- $\quad \mathrm{R}$ : radiolarita

- C: cuarcita

- SG: sílex gris

- C: cuarcita

- Q: cuarzo

$\triangleright$ Datos métricos: las medidas se han tomado todas en milímetros, y a partir de su eje técnico; en caso de que éste no pueda ser determinado, se recurre al eje tipológico o morfológico.

- L: longitud, según el eje técnico de la pieza

- A: anchura, perpendicular a la anterior 
- G: grosor, en la mitad de la pieza

$>$ el tipo de soporte de que se trata, que puede ser, siguiendo su orden según la cadena operativa:

- PL: placa

- CR: canto rodado

- L: lasca

- L-H: lasca laminar

- H: hoja

- H-FN: hoja con flanco (Figura I.11)

- HT: hojita

- LC: lasca u hoja con cresta

- LCP: lasca/hoja con cresta parcial

- LC1: lasca/hoja con neo-cresta, es decir las extracciones de la cresta sólo van hacia una de las vertientes (Figura I.9).

- LC1P: lasca/hoja con neo-cresta parcial (Figura I.11)

- LC2: lasca/hoja con subcresta, es decir con restos de extracciones perpendiculares al eje de la pieza, lo que indicaría la realización de una cresta, pero sin que esta pieza porte los contrabulbos de dicha cresta (Figura I.10).

- TN: tableta de núcleo (Figura I.13).

- $\mathrm{SN}$ : semitableta de núcleo (Figura I.13).

- FN: flanco de núcleo (Figura I.12).

- FNL: flanco longitudinal extraído desde misma dirección que las últimas extracciones.

- FNLO: flanco longitudinal extraído desde plano opuesto a las últimas extracciones

- FNT: flanco transversal a la superficie de extracciones, y se podría concretar incluso desde qué lateral del núcleo ha sido extraído (según la orientación del núcleo)

- AN: arista de núcleo en el ámbito genérico, sin que se pueda concretar si es una cresta, una cornisa, etc. 
- PA: producto de acondicionamiento genérico, sin que se pueda determinar exactamente qué tipo producto es.

- $\quad$ BN: base de núcleo.

- P1: Núcleo prismático con un plano de percusión.

- P2: Núcleo prismático con dos planos de percusión.

- P2O: Núcleo prismático con dos planos opuestos y una misma superficie de extracciones

- P2A: Núcleo prismático con dos planos opuestos y con superficies alternas (por ejemplo una en la cara anterior y la otra sobre un lateral o posterior).

- LN: Núcleo sobre lasca

- NG: Núcleo globuloso

- $\quad$ RN: Resto de núcleo

- GB: Golpe de buril

- LT: Lasquita de talla

- AT: Astilla de talla

- $\mathrm{CH}$ : Chunk

- IT: Indeterminado

$\gg$ La presencia de córtex:

- 1: totalmente cortical

- 2: parcialmente cortical

- 3: sin córtex

$\triangleright$ Accidentes:

- RF: reflejado

- SP: sobrepasado

- PB: pseudoburil de Siret

- DB: doble bulbo

- LG: lengüeta

- PN: presencia de planos naturales que hayan dificultado la talla de la pieza.

Presencia de la rotura, con su causa:

- F: flexión 
- P: percusión

- I: indeterminada

$\gg$ Situación de la rotura:

- PX: proximal

- DS: distal

- LT: lateral

- PD: proximal-distal

- DL: distal-lateral

- PL: proximal-lateral

- BL: bilateral

- DP: proximal, distal, lateral (rotura por todos los lados)

Tipo de talón:

- C: cortical

- L: liso

- D: diedro

- F: facetado

- P: puntiforme

- S: suprimido

- O: sin talón

Respecto al talón también se tendrán en cuenta sus dimensiones métricas: el espesor y la longitud (Figura I.1):

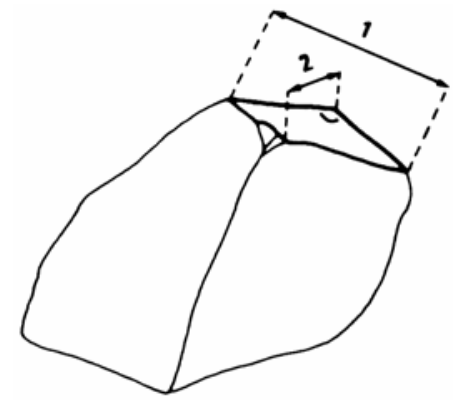

Figura I.1: Atributos métricos del talón. 1: longitud (distancia entre los bordes laterales de la lasca). 2: anchura (espesor del talón, distancia entre la cara superior y la inferior). A partir de: Pelegrin, 1995: p. 66. 
$\triangleright$ Anchura del talón, respecto al espesor de la pieza (distancia desde la cara inferior a la superior). Esta medida, y la siguiente se toman en milímetros con un decimal.

$\gg$ Longitud del talón (distancia entre los bordes laterales del soporte), perpendicular al anterior.

$\triangleright$ Preparación de la extracción en el anverso:

- R: retoque, sería análogo a un retoque simple o escamoso en torno a la cornisa y hacia la cara superior

- E: esquirlado, similar al esquirlado del retoque

- A: abrasión: acción de frotamiento más o menos intensa que deja en torno al talón un efecto de pulido de baja intensidad

Estas tres variables pueden corresponder a una variación en la intensidad del gesto de preparación del frente de percusión, la abrasión sería reflejo de una preparación intensa de todo el frente; el retoque y el esquirlado pueden ser testimonio, bien de una abrasión de menor entidad, o bien de gestos más puntuales para la eliminación de irregularidades de la cornisa (en la figura I.2 se muestra un ejemplo de una serie de operaciones de preparación de la cornisa).

La combinación de estas variables se señala separando cada letra con un punto:

- R.E: retoque y esquirlado

- R.A: retoque y abrasión

- E.A: esquirlado y abrasión

Se puede anotar en ocasiones la intensidad de dicha preparación o también la escasez de ésta con los signos "+" y "-", por ejemplo:

- $\quad \mathrm{R}+$ : retoque acusado

- E-: esquirlado leve 


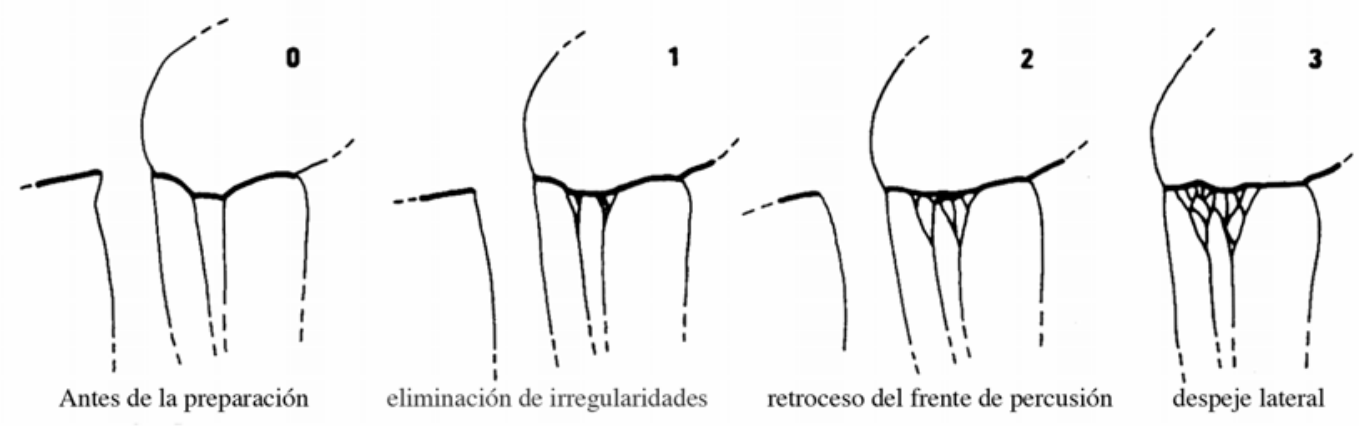

Figura I.2: Ejemplo de operaciones de preparación de la extracción laminar, mediante un retoque en 1 y 2 y esquirlado en 3 . Con las operaciones 1 y 2 se obtienen talones lisos o lineales, con la 3, talones puntiformes (a partir de: Pelegrin, 1995: 104).

$>$ El ángulo de percusión se ha tomado en sus dos posibilidades (figura I.3):

- Ángulo 1: el ángulo de lascado (angle d'eclatement), el más interno, el existente entre el talón y la cara inferior

- Ángulo 2: el ángulo del frente de talla (angle de chasse), el externo, entre el talón y la cara superior, equivalente al ángulo existente entre el plano de percusión y la superficie de extracciones. Este ángulo sería inferior o igual a $90^{\circ}$ según las reglas de la percusión intencional.

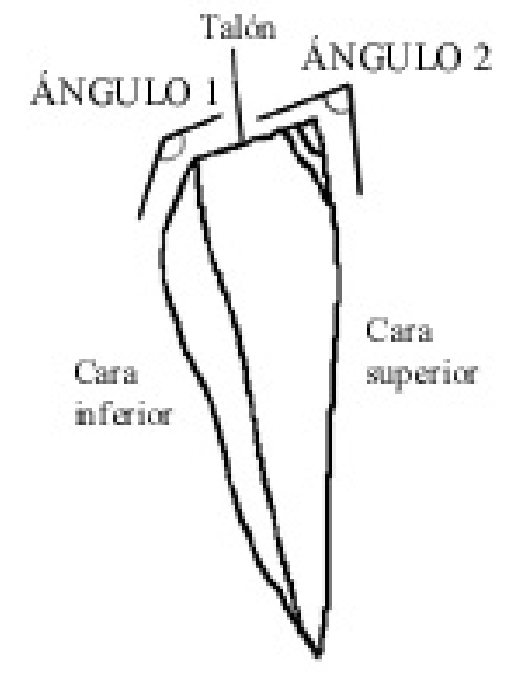

Figura I.3: ángulos del talón. Ángulo 1 (ángulo de lascado): situado entre el talón y la cara inferior. Ángulo 2 (ángulo del frente de talla o débitage; o de la cornisa): entre el talón y la cara superior. 
Se presentan los datos relativos a la combinación de ambos ángulos para constatar si hay alguna tendencia peculiar respecto a estos atributos y relativamente a los distintos grupos tecnológicos. En la combinación de ambos ángulos parece que se produce una cierta complementariedad entre ambos, de modo que un frente de talla con ángulo cerrado (por ejemplo inferior a $70^{\circ}$ ) tiene un ángulo interno abierto (a partir de $110^{\circ}$ ); mientras que un frente de talla con ángulo abierto (80-90 por ejemplo), tiene un ángulo de talla más cerrado; en este último caso ambos ángulos se acercarían al ángulo recto.

La medición de estos ángulos se ha realizado poniendo el soporte de perfil sobre una plantilla milimetrada que tiene el desarrollo de ángulos de 0 a $180^{\circ}$. Se ha dividido dicha plantilla en sectores de $20^{\circ}$ que se nombran por una letra mayúscula (de "A" a “I”), comenzando por la derecha. Cada sector se divide a su vez en dos subsectores, que se nombran con letras minúsculas (“a” y “b”).

Alteraciones:

- Q: quemado

- $\quad \mathrm{R}$ : redondeamiento

- DS: desilificación o deshidratación

$\gg \mathrm{N}^{\mathrm{o}}$ de nervaduras: para las piezas laminares

$\gg$ Dirección de los negativos: para las piezas laminares

- PD: proximal-distal es decir el mismo sentido y dirección que la propia hoja (unipolar)

- DP: distal-proximal, es decir en sentido opuesto a la de la hoja.

- DI: en dirección transversal al eje de la hoja, desde la izquierda a la derecha.

- ID: en dirección transversal al eje de la hoja, desde la derecha a la izquierda.

- CD: en dirección transversal al eje de la hoja, pero partiendo desde el centro de la cara superior, es decir desde una nervadura, por lo que se trataría de una pieza con cresta o con pequeños restos de ella.

- CI: como la anterior pero desde la nervadura a la izquierda. 
Sección en sentido longitudinal (para los productos laminares):

- cn: cóncava

- cx: convexa

- $\quad$ R: recta

- $\mathrm{T}$ : torse (alabeada) ${ }^{8}$

$\triangleright$ Sección en sentido transversal (para los productos laminares):

- TR: triangular

- TZ: trapezoide

$>$ Indice de Regularidad (para los productos laminares), se trata de una medida cualitativa, determinada a partir de las características de la hoja, su rectitud, equilibrio, etc.

- 0: mala

- 1: regular

- 2: buena

Hemos tomado también a veces estadios intermedios:

- $\quad$ 0-1: regular tendente a mala

- 1-2: regular tendente a buena

Modo de talla. No siempre se puede anotar este atributo, hemos tomado como referencia los criterios respecto a las características en torno al talón y el bulbo: tamaño del bulbo, presencia de labio, del punto de impacto, tamaño del talón, etc.

- PDP: percusión directa con percutor duro.

- PDB: percusión directa con percutor blando.

- PDPB: percusión directa con percutor de piedra blanda.

En este último caso se han tenido en cuenta una serie de piezas que tienen las características de lo que parece ser la piedra blanda, en especial la presencia del astillado del bulbo (esquillement du bulb, Pelegrin, 2000).

${ }^{8}$ El término francés torse, hace referencia a una curva longitudinal inclinada tanto en el eje longitudinal como transversal, en un movimiento más o menos helicoidal. No estamos seguros respecto a su traducción correcta en castellano, probablemente el adjetivo "alabeado" sea posible; no obstante, se conserva la inicial de torse (“T”) para la anotación de esta variante dentro de este atributo. 
$\triangleright$ Tipología: tipo de útil retocado

$\triangleright$ Por último se ha reservado un apartado para las observaciones que no se han podido insertar en los anteriores apartados. Aquí se ha consignado por ejemplo la presencia de pseudorretoques, con la localización y descripción somera de tales alteraciones en algunas piezas.

Se ha incluido también dos atributos de carácter estrictamente técnico, encaminados a caracterizar el conjunto lítico a lo largo de la cadena operativa (los cuadros I.8 y I.9 ponen en relación estas categorías tecnológicas con los tipos de soportes definidos):

$\triangleright \mathrm{N}^{\mathrm{o}}$ en lista tecnológica:

Se trata de la lista tecnológica que hemos creado, a partir del tipo de soporte y de la presencia de córtex. El orden que se ha establecido, al igual que otras listas tecnológicas, es el que marcaría la ejecución de la cadena operativa, empezando por los bloques sin tallar, hasta los debris. No obstante no se trataría de un orden cronológico estricto.

- $\quad$ 0: nódulo sin tallar o fragmentado

- 1 : lasca cortical

- 2: lasca parcialmente cortical

- 2-5: lasca laminar de segundo orden

- 3: lasca sin córtex, de tercer orden

- 3-6: lasca laminar de tercer orden

- 4: Hoja de primer orden o totalmente cortical

- 5: Hoja de segundo orden

- 5b: Hoja de segundo orden "con flanco"

- 6: Hoja de tercer orden

- 6b: Hoja de tercer orden "con flanco"

- 7: Hojita de segundo orden

- 8: Hojita de tercer orden

- 9: lasca u hoja con cresta

- 10: Tableta de núcleo 
- 11: Semitableta de núcleo

- 12: Flanco de núcleo

- 13: Arista de núcleo, base de núcleo y otros productos de acondicionamiento indeterminados

- 14: Núcleo P1

- 15: Núcleo P2

- 16: Núcleo sobre lasca

- 17: Núcleo globuloso

- 18: Resto de núcleo

- 19: Golpe de buril

- 20: Microburil/picante triédrico

- 21: Lasquita de retoque

- 22: Lasquita de talla

- 23: Astilla de talla

- 24: Chunk

- 25: Indeterminado

$\triangleright$ Grupo tecnológico: estos distintos tipos tecnológicos se agrupan en siete categorías amplias, las cuales se pueden relacionar grosso modo con las distintas secuencias a lo largo de la cadena operativa:

- Grupo 0: fase de adquisición-selección de la materia prima, se incluirían los nódulos sin tallar o los nódulos fragmentados o probados

- Grupo 1: agrupa los soportes que se pueden asignar a las primeras fases de la talla: descortezado, conformación inicial y la talla en sentido amplio. Se incluirían aquí las lascas corticales, las de segundo y tercer orden, las lascas laminares con córtex y las hojas de primer orden.

- Grupo 2: secuencia de producción plena, dado que el conjunto que estudiamos es un proceso de talla laminar, se considera el inicio de la fase de producción a partir de que comenzamos a extraer hojas de segundo orden y también lascas laminares sin córtex; pero los soportes más importantes de este grupo son los productos laminares estrictos: hojas y hojitas, que serían los “soportes de primera intención”. 
- Grupo 3: los productos de acondicionamiento (piezas con cresta, flancos, tabletas, etc.), que pertenecerían también a la fase de producción, en secuencias de arreglo del núcleo, etc. Este grupo de piezas nos va a dar mucha información técnica sobre el proceso de talla desarrollado en la colección.

- Grupo 4: los núcleos, que pertenecerían también a la fase global de producción plena, constituyen, junto con el grupo anterior los elementos que nos van a dar una mayor información sobre el proceso de talla ejecutado.

- Grupo 5: piezas indeterminadas, es decir los chunks, astillas y otros fragmentos más o menos informes o de lectura técnica difícil.

- Grupo 6: debris, el conjunto de piezas menores a un centímetro, que pueden ser tanto lasquitas de talla, de retoque, fragmentos de lascas mayores o astillas de talla.

- Grupo 7: piezas que pertenecen a la fase de retoque o de ciertas secuencias de fabricación de útiles, se han recogido fundamentalmente los golpes de buril.

Este atributo del grupo tecnológico resume los distintos soportes que se producen a lo largo de la cadena técnica en siete grupos tecnológicos amplios y básicos. Tales grupos reúnen los soportes en categorías que en algunos casos se pueden asimilar a secuencias y fases de la cadena operativa propiamente dicha (Cuadro I.5), por lo que proporciona una visión rápida de la constitución del conjunto lítico. Dado que todo proceso de talla es un encadenamiento de secuencias dirigidas a la consecución de una finalidad última, se puede realizar agrupaciones de los productos de este proceso a lo largo del progreso diacrónico de dicho proceso de talla. No obstante los procesos de talla son sumamente dinámicos, hay un juego constante de equilibrio entre las intenciones culturales del esquema que se quiere realizar por un lado, y las características de la propia materia a tallar, por otro. Esta dicotomía entre las intenciones técnicas culturales y las limitaciones físicas y mecánicas de la materia hace que el proceso de talla pueda presentarse bien como un esquema lineal resuelto de forma clara; o bien como una serie de secuencias encaminadas a un fin que se puede intuir pero al que no se puede acceder demasiado bien. 


\begin{tabular}{|c|c|c|c|}
\hline GRUPO TECNOLÓGICO & $\mathrm{N}^{\mathrm{o}}$ TEC. & & TIPO SOPORTE \\
\hline GRUPO 0 & 0 & PL, CR & Bloque: plaqueta, canto rodado, \\
\hline \multirow[t]{4}{*}{ GRUPO 1} & 1 & L1 & Lasca de primer orden \\
\hline & 2 & $\mathrm{~L} 2$ & Lasca de segundo orden \\
\hline & 3 & L3 & Lasca de tercer orden \\
\hline & 4 & H1 & Hoja de primer orden \\
\hline \multirow[t]{6}{*}{ GRUPO 2} & 5 & $\mathrm{H} 2$ & Hoja de segundo orden \\
\hline & $5 b$ & H-FN2 & Hoja con flanco de segundo orden \\
\hline & 6 & H3 & Hoja de tercer orden \\
\hline & $6 b$ & H-FN3 & Hoja con flanco de tercer orden \\
\hline & 7 & HT2 & Hojita de segundo orden \\
\hline & 8 & HT3 & Hojita sin córtex \\
\hline \multirow[t]{6}{*}{ GRUPO 3} & 9 & $\mathrm{LC}$ & Lasca o pieza con cresta \\
\hline & 10 & $\mathrm{TN}$ & Tableta de núcleo \\
\hline & 11 & SN & Semitableta de núcleo \\
\hline & 12 & FN & Flanco de núcleo \\
\hline & 13 & AN, PA & Arista de núcleo y otros reavivados \\
\hline & 13 & $\mathrm{BN}$ & Base de núcleo \\
\hline \multirow[t]{7}{*}{ GRUPO 4} & 14 & P1 & Prismático con un plano de percusión \\
\hline & 15 & P2 & Núcleo prismático con dos planos \\
\hline & 16 & $\mathrm{LN}$ & Núcleo sobre lasca \\
\hline & 17 & NG & Núcleo globuloso \\
\hline & 17 & CT & Centrípeto \\
\hline & 17 & $\mathrm{AM}$ & Núcleo amorfo, sin organización concreta \\
\hline & 18 & RN & Resto de núcleo \\
\hline GRUPO 7 & 19 & GB & Golpe de buril \\
\hline \multirow[t]{2}{*}{ GRUPO 6} & 22 & LT & Lasquita de talla \\
\hline & 23 & AT & Astilla de talla \\
\hline \multirow[t]{2}{*}{ GRUPO 5} & 24 & $\mathrm{CH}$ & Chunk \\
\hline & 25 & IT & Indeterminado \\
\hline
\end{tabular}

Cuadro I.8: tipos de soportes según su número técnico y sus agrupaciones correspondientes en los grupos técnicos más amplios. 


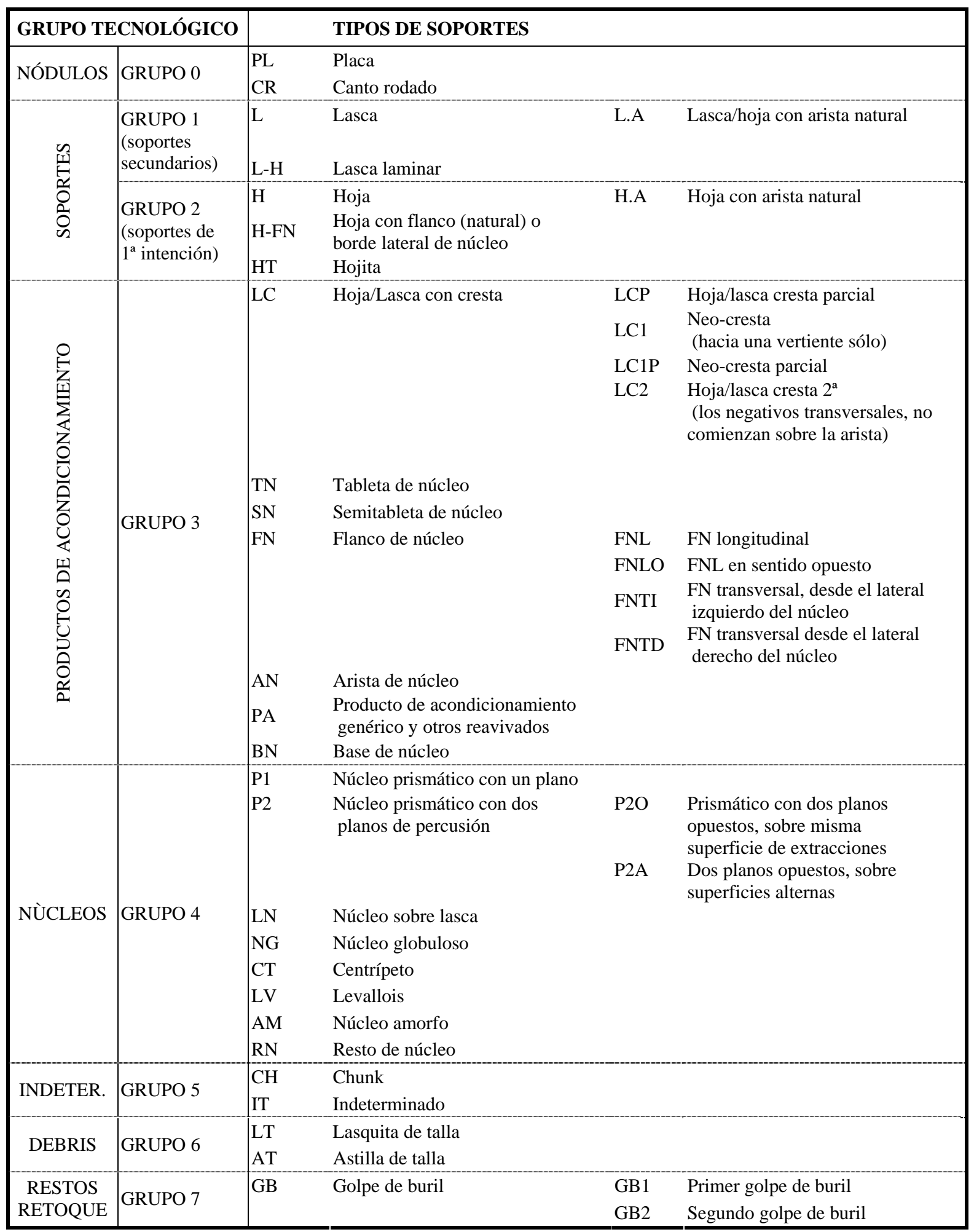

Cuadro I.9: tipos de soportes y grupos tecnológicos. 
Los grupos tecnológicos aquí definidos tienen la finalidad práctica de agrupar los soportes característicos de algunas secuencias de débitage, fundamentalmente los soportes “de primera intención”, los productos de acondicionamiento y los núcleos. Los grupos tecnológicos 2, 3 y 4 reunirían los soportes característicos de la segunda fase de la cadena operativa, la de producción propiamente dicha. Por el contrario, el grupo 1 incluye el conjunto de las lascas (de todos lo órdenes), lascas laminares y hojas de primer orden. Este conjunto de soportes pertenece a la fase de preparación pero también pueden incluir elementos producidos a lo largo de la fase de producción plena. En todo caso el número de lascas, lascas-laminares, etc., en general los soportes que podríamos tildar de más "genéricos", es indicativo de la presencia de la primera fase de la cadena, además de la intensidad del proceso de talla ejecutado en el conjunto dado. El grupo 6 reúne las lasquitas de talla, de retoque, fragmentos pequeños y astilla de talla que se producen prácticamente a lo largo de todo el proceso de talla, desde la fase prueba y preparación a la de retoque y reavivado. Este grupo es indicativo también de la intensidad del proceso de talla efectuada en el yacimiento.

La exposición del conjunto lítico a partir de estos grupos tecnológicos va a ser muy útil tanto para presentar la composición de cada tipo de materia, como para la presentación de los distintos atributos, con el fin de comprobar si hay diferencias técnicas a lo largo del proceso de talla.

Una vez presentada la composición global del material lítico de cada materia, se expondrá un análisis más pormenorizado según los tipos de soportes, prestando una atención especial a las piezas que mayor información técnica nos pueden ofrecer. Comenzaremos por los núcleos y los productos de acondicionamiento, para cuyo análisis se han teniendo en cuenta otro tipo de atributos tanto descriptivos como técnicos, que nos ayudarán a definir el proceso técnico desarrollado. 


\section{I.2.3.2.-NÚCLEOS}

Para el análisis y descripción de los núcleos partiremos de la propuesta elaborada por Pelegrin (1995: 111-117) y Pigeot (1987: 22-23) (figuras I.4 y I.5 respectivamente). Para su descripción hay que tener en cuenta que en la orientación convencional del núcleo la superficie de extracciones o tabla ${ }^{8}$ laminar se coloca como vista principal, con el plano de percusión principal hacia arriba. A partir de él encontraríamos, siguiendo esta orientación convencional y a partir de las reglas del dibujo, el lateral derecho, el izquierdo, base, etc.

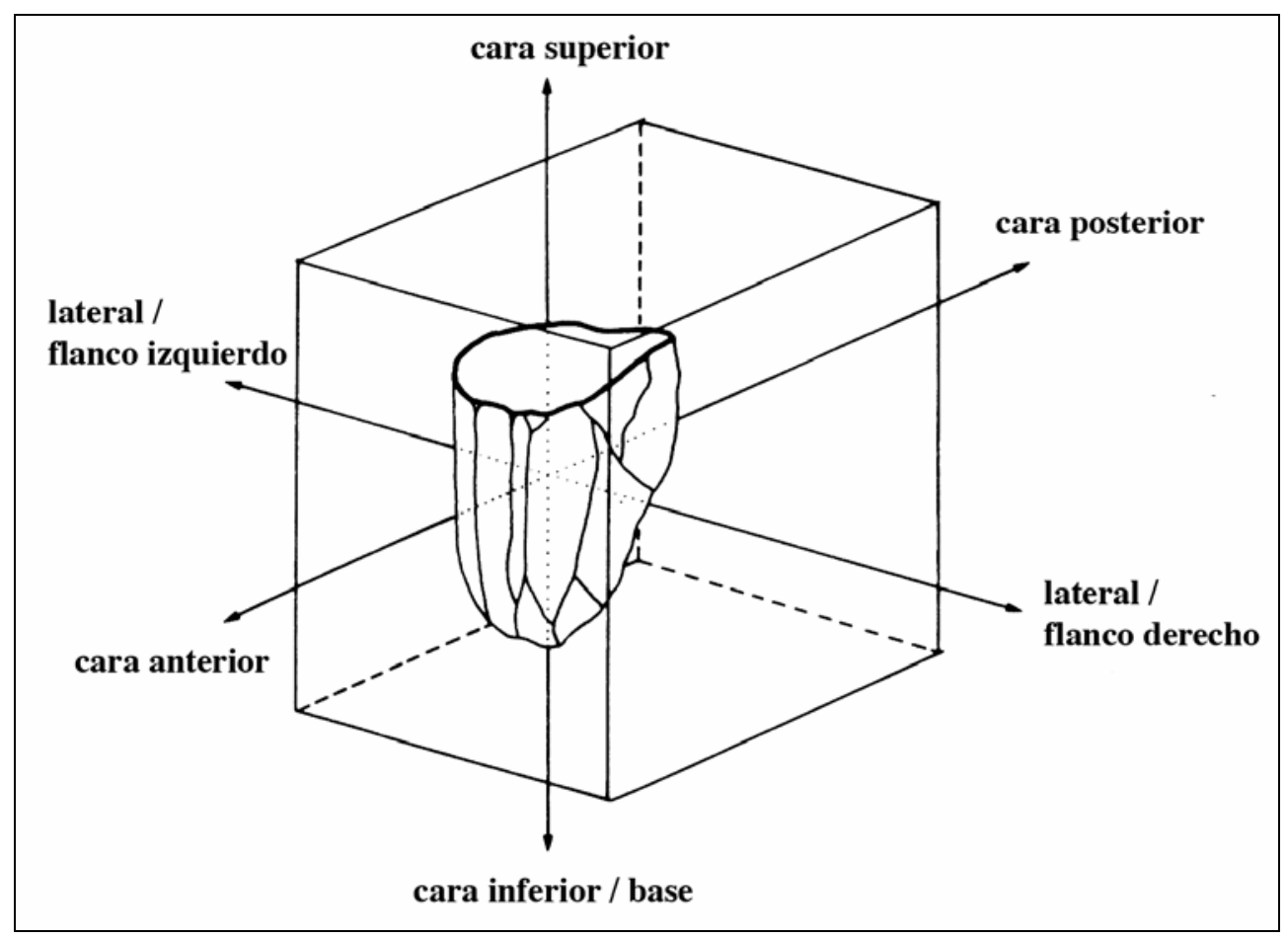

Figura I.4: Descripción del núcleo. Según: Pelegrin, 1995: 112.

\footnotetext{
${ }^{8}$ La denominación de "tabla" para la superficie de extracciones es una traslación directa de la "table" en francés; si bien es cierto que existe en castellano la traducción por "tabla" con el mismo significado que en francés, es una acepción hoy en día en desuso (DRAE, 2001). Se trata de un término que se utiliza para denominar la superficie de extracciones de núcleos laminares (Pigeot 1987: 23). B. Valentin (1995) utiliza este término para denominar las secuencias de extracciones laminares dentro de una superficie de extracciones más amplia (Figura I.7).
} 


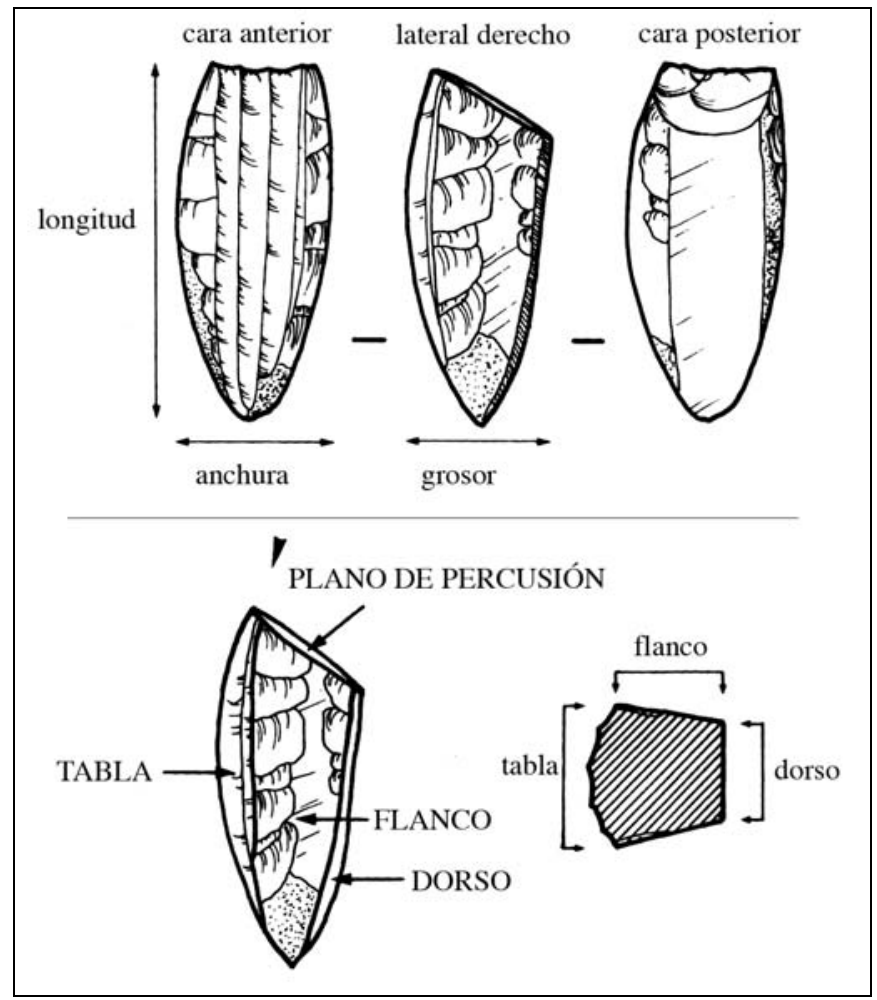

Figura I.5: descripción del núcleo. Según Pigeot, 1987: 22.

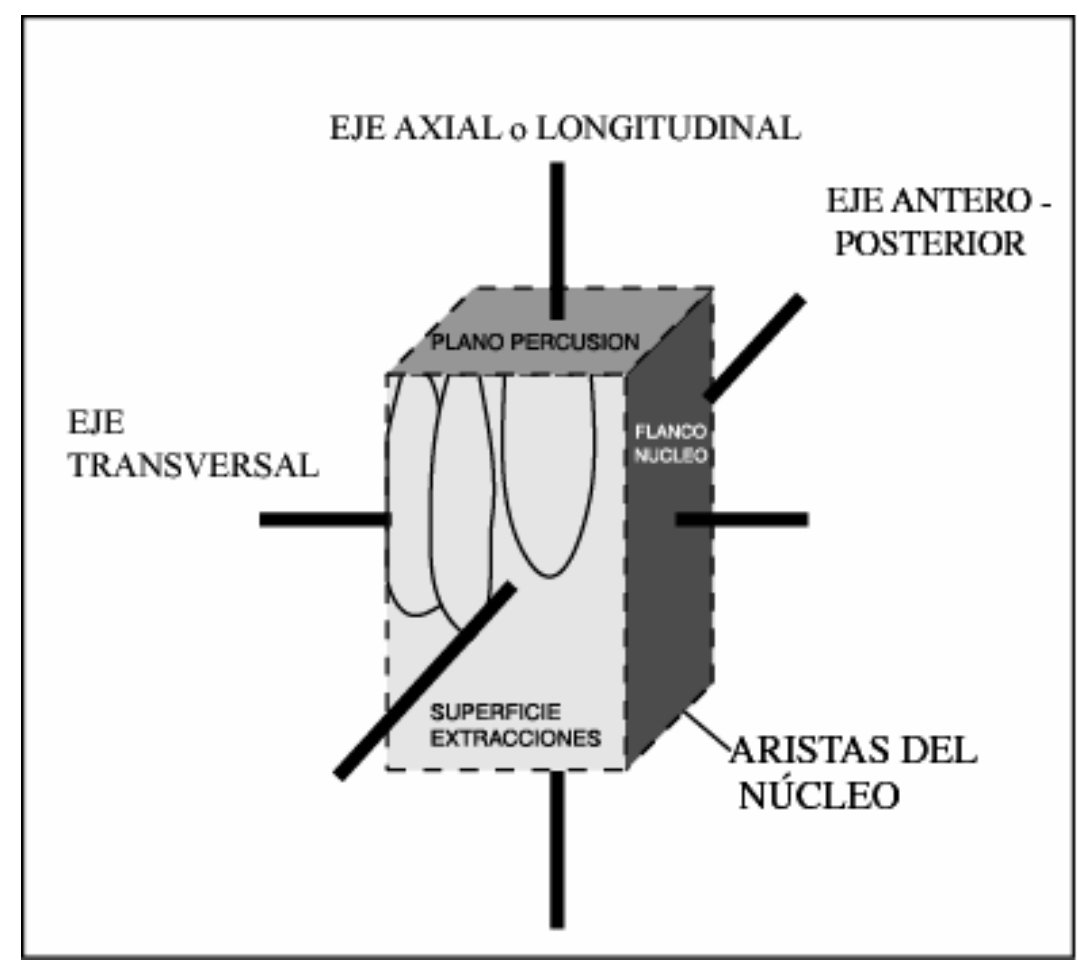

Figura I.6: descripción y ejes del núcleo. 


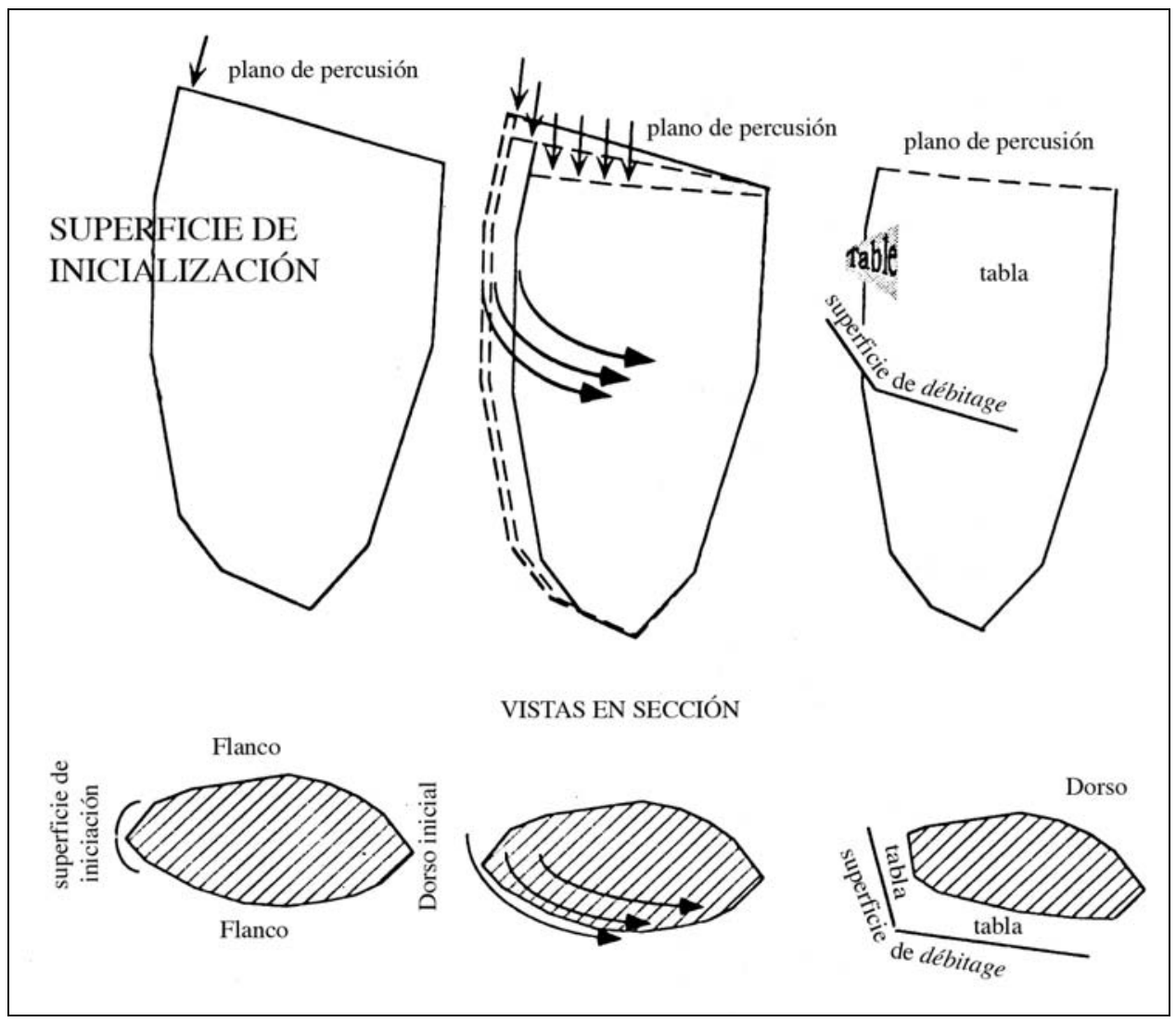

Figura I.7: avance del débitage en tablas a través de la superficie de extracciones. Según Valentin, 1995: anexos, p.4.

Respecto a la orientación de los núcleos y su descripción morfológica tendremos en cuenta los siguientes matices (figura I.6):

- Las extracciones orientadas desde la cara superior a la inferior o a la inversa las denominaremos "longitudinales", "axiales" o "de eje"; mientras que las perpendiculares a éstas son "transversales". Respecto a la dirección axial, denominaremos longitudinal a las extracciones con dirección superiorinferior, correspondiendo la parte superior al plano principal; "opuesto" lo reservaremos para las extracciones en sentido inferior-superior, desde un plano secundario, si existe, en la parte inferior o base del núcleo.

- Los bordes laterales del núcleo también se denominan flancos;

- Para la cara o superficie posterior del núcleo (opuesta a la superficie de extracciones o tabla) se ha utilizado a veces el término "dorso" (sobre todo 
cuando se trata de una superficie plana, ver figura I.5 [Pigeot 1987: 23; Olive 1988: 66]), pero en este trabajo no vamos a utilizar esta palabra para evitar confusiones ${ }^{9}$.

- La "arista (del núcleo)" es un término general de morfología: es el diedro delimitado por la intersección de las distintas superficies de un núcleo (o de un útil nuclear, un bifaz por ejemplo) (Tixier et al. 1980: 73). Se trata de un término descriptivo con un sentido muy amplio, de modo que una arista de núcleo es tanto la cornisa del núcleo (unión entre el plano de percusión y la superficie de extracciones), como una cresta anterior, posterior o lateral; o también la unión entre la tabla y la base del núcleo, del tipo que sea; o entre un flanco y una cara posterior cortical. Desde esta perspectiva, "arista" incluiría tanto las semitabletas de núcleo como las crestas y también las aristas naturales. Por su parte, las crestas, frentes de talla, etc., serán aristas del núcleo con una posición técnica y funcional más concreta. En la descripción de un núcleo estas distintas aristas se diferencian perfectamente, pero no sucede así cuando nos encontramos “piezas con aristas” en el conjunto lítico. En esta circunstancia, hay muchas veces en las se puede determinar si se trata de una semitableta, una pieza con cresta o neo-cresta, y por tanto se interpreta en relación con una acción concreta realizada sobre las distintas partes del núcleo (por ejemplo reavivado del plano de percusión en el caso de las semitabletas, o iniciación de la fase de producción de hojas en la lámina con cresta). Pero hay otras veces en las que no podemos determinar el carácter técnico concreto de una "arista", en estos casos denominaremos a la pieza con su correspondiente genérico: "arista de núcleo".

- Una “cresta” es (Tixier et al. 1980: 82-83): “una forma de preparación de un núcleo para el débitage de hojas (u hojitas). Se trata de crear una arista a partir de extracciones, lo más frecuentemente bifaciales, quedando

${ }^{9}$ El término "dorso" tiene un significado muy concreto en el vocabulario tipológico, el dorso de una pieza es un borde lateral perpendicular a las caras superior e inferior de tal soporte. El dorso más frecuente es el constituido por un retoque abrupto (que caracterizaría el grupo de las "piezas con dorso"). Este término no obstante se ha utilizado también desde un punto de vista tecnológico: para denominar a la cara superior de una lasca (en sentido genérico); pero el significado más extendido y aceptado hoy en día es el tipológico (Tixier et al. 1980: 86). 
limitada así por dos series de contrabulbos. Esta arista permitirá dirigir, guiándola, la extracción de una primera hoja: la lámina de cresta, que tendrá una sección triangular, siendo las dos vertientes de su cara superior la parte eliminada de la cresta”. Se trata por tanto de un procedimiento de preparación de un núcleo laminar, cuya función es, concretamente, acondicionar una arista para guiar el inicio del débitage. Este procedimiento es además muy típico del Paleolítico Superior, e incluso se ha hablado muy frecuentemente de la "técnica de la lámina cresta” para calificar este método. No obstante, también se han denominado como crestas a otras aristas conformadas de la misma manera, pero que su función técnica no está vinculada a la iniciación de la talla, sino a otras funciones, fundamentalmente dos:

i) Facilitar la preparación o reparaciones de la superficie de extracciones o el plano de percusión desde una zona lateral, posterior (Hahn \& Owen, 1985: 73) o inferior del núcleo, denominándose entonces cresta posterior, postero-lateral o inferior. Un ejemplo del uso de crestas laterales para la conformación de la superficie de extracciones (pero sin ser la arista de inicio de la misma) lo tenemos en los núcleos “tipo livres de beurre” del Grand-Pressigny, del Neolítico Final (Mohen, 1988), y quizás también podríamos apuntar a los núcleos Levallois.

ii) Función ergonómica: facilitar la prensión del núcleo a tallar. En este sentido la cresta se acerca mucho a la "arista" genérica. A este respecto Pigeot (1987: 23) concreta que la lámina cresta es un plano de percusión, por tanto un "diedro bastante cerrado $\left(\leq 90^{\circ}\right)$, mientras que la arista es un diedro que puede ser bastante abierto (cuando está formado por las nervaduras o acondicionamientos, más o menos alineados, de nervaduras), o también cerrado como una cresta (cuando se trata de una arista constituida por la intersección de dos grandes superficies planas, naturales o no)”. 
De todas formas podemos resumir, subrayando lo descrito anteriormente, que una cresta es una arista, pero no toda arista es una cresta. Y consideramos que es bastante interesante diferenciar tanto los tipos de crestas que pueden darse en la conformación de un núcleo, como si hay “crestas verdaderas” desde un punto de vista funcional (las encaminadas a la apertura de la tabla) o si por el contrario no hay procedimientos de conformación o preparación del núcleo (mise en forme) que impliquen el recurso de las crestas.

El análisis de los núcleos tiene por objetivo la determinación de su esquema técnico, para lo cual se van a tener en cuenta una serie de atributos que describen tanto la conformación genérica del volumen, como las características de sus distintas partes. Lo ideal sería llegar a determinar qué tipo de bloques se seleccionaban, el método de conformación del núcleo y su producción. El núcleo es una de las piezas que mayor información técnica contiene, ya que en él está resumido el proceso de talla aplicado sobre un bloque, aunque la validez y alcance de su análisis siempre va a depender del estado de agotamiento en que se encuentre, de los accidentes que hay sufrido, etc.

Uno de los atributos más importantes es la definición del tipo de núcleo propiamente dicho (prismático, piramidal, centrípeto, etc.), ya que en ella quedaría sintetizada su estructura volumétrica, con las implicaciones que ello conlleva en cuanto a los tipos de soportes obtenidos. En el conjunto analizado se desarrolla fundamentalmente una talla laminar a partir de núcleos de tipo prismático básicamente. Como consecuencia directa de ello se ha tomado, como base para su caracterización, el modelo de un núcleo prismático. Sobre dicho núcleo prismático-básico, se describirá la organización del volumen, centrándonos en la caracterización de la superficie de extracciones y del plano de percusión, su interrelación y cómo se gestiona el núcleo para mantener tales superficies.

Dentro de cada materia prima se van a especificar los distintos atributos que caracterizan cada núcleo, para lo cual se van a agrupar dichos atributos en tres cuadros. En el primer cuadro se realiza una presentación genérica de los núcleos, el segundo se centrará en las características de la superficie de extracciones y el tercero en el plano de percusión. 
Presentación genérica de los núcleos (Cuadro I.10):

$\triangleright \mathbf{N}^{\mathbf{0}}$ identificador de cada núcleo, es un número-clave que permitirá eliminar la sigla completa en los cuadros siguientes

$\gg$ Sigla: con el año, cuadro, sector, bolsa, etc. como en la ficha de los soportes

$\triangleright$ Tipo de núcleo: se trataría de una descripción sintética del esquema técnico desarrollado: prismático (con uno o dos planos), piramidal, centrípeto, etc.

$\triangleright$ Datos métricos (longitud, anchura y grosor) en milímetros, tal y como se ha descrito para los tipos de soportes

Tipo de soporte o bloque seleccionado, igual que para los tipos de soportes

- CR: canto rodado

- RÑ: riñón más o menos informe

- PL: plaqueta o placa

- L: lasca

- BL: bloque prismático

$\triangleright$ Córtex y su situación. Para indicar la zona exacta del núcleo se utilizarán las claves descriptivas a partir de la orientación convencional de los núcleos prismáticos (Pelegrin, 1995; Lloret, 2001), esquematizadas en el cuadro I.10.

$>$ Descripción de la superficie de extracciones. Este atributo consta de dos partes:

i) situación de la superficie sobre el núcleo (a partir de las mismas claves descriptivas que para describir la situación del córtex), por ejemplo:

- ALD: antero-lateral derecho

- A: anterior

- AP: antero-posterior

- Etc.

ii) avance de la talla (frontal, semi-envolvente o envolvente) 
Este campo se rellenará separando ambas características con un guión, por ejemplo:

- A-FNT: anterior, frontal

- ALI-SENV: antero-lateral izquierdo, semi-envolvente.

Es interesante la situación de la superficie de extracciones respecto al nódulo original para comprobar qué tipo de superficie se prefieren en el volumen de partida. La explotación de una superficie ancha o estrecha va a implicar que a lo largo de la fase de producción se necesiten más o menos recursos para el propio mantenimiento (entretien) de las características técnicas de la superficie de extracciones. Sobre una superficie estrecha se puede dar un auto-mantenimiento de la propia tabla, ya que ésta está constreñida entre los laterales del núcleo; serán frecuentes entonces los soportes que hemos denominado como "con flanco", es decir las lascas u hojas que portan en uno de sus bordes laterales el flanco del núcleo original, siendo éste prácticamente perpendicular a la cara superior del soporte. En el caso de una tabla de extracciones sobre una superficie ancha del núcleo, los recursos para el mantenimiento de las condiciones idóneas de talla serán normalmente más complejos, con flancos de núcleos axiales o transversales, neo-crestas, etc.

Respecto al avance de la talla, se refiere a cómo se suceden las extracciones sobre la superficie de extracciones, es decir el desarrollo de la fase de explotación del núcleo respecto al volumen potencial. Este avance tendría dos variantes esenciales en los núcleos de concepción laminar prismática: frontal y semi-envolvente (semitournante). En una talla frontal la tabla laminar está totalmente constreñida por los flancos del núcleo, mientras que en una talla semi-envolvente la extracción laminar avanza hacia los laterales. El débitage frontal es, como consecuencia de las propias delimitaciones técnicas de su definición, más frecuente cuando el núcleo es estrecho, mientras que el débitage semi-envolvente es más propio de los núcleos anchos. Asimismo en el primer caso los productos son generalmente más gruesos y hay menos hojas en cada secuencia de explotación, mientras que en el segundo las hojas son más finas y más abundantes (Pigeot, 1987: 50-51). Habría una tercera posibilidad: la envolvente (tournante) que no es tan frecuente en momentos paleolíticos como las anteriores y sería más propia de procesos de débitage donde hay modos de talla como la percusión indirecta y la presión, dando lugar a los 
núcleos "de tendencia envolvente" típicos, como son los núcleos "en bala de fusil" y "en mitra". No obstante en El Espertín se han constatado casos de un avance de la talla de tipo envolvente, tanto en un débitage laminar de tipo prismático, como en débitage de lascas. En esos casos, este avance envolvente tiene unas peculiaridades que se describirán convenientemente.

$>$ Preparación de otras superficies en la conformación del volumen del núcleo: por ejemplo presencia de un segundo plano de percusión, preparación de los laterales, de la base del núcleo, crestas, aprovechamiento de aristas naturales, etc. Como en los atributos anteriores, para la localización de las distintas partes del núcleo se utilizarán las claves descriptivas especificadas en el cuadro I.10.

Si hay varias superficies del núcleo preparadas, se indicarán separándolas por un guión, por ejemplo:

- BN-LD: preparación de la base del núcleo y del lateral derecho

A veces se puede concretar el tipo de preparación, en este caso se anotará dicho método de preparación entre paréntesis, por ejemplo:

- BN(CR-AP): preparación de la base del núcleo mediante una cresta anteroposterior

Tipos de soportes extraídos: lascas, lascas-laminares, hojas, hojitas

Causa del abandono: agotado, accidentes (reflejado, sobrepasado, etc.)

La combinación de varios de estos estados se indicará separándolos con un guión, por ejemplo:

- $\quad$ RF-PN: reflejados y planos naturales

- AG-RF: agotamiento y últimas extracciones reflejadas

- RF-CAR: reflejados y carena con curvatura inadecuada

La causa de abandono del núcleo es un aspecto bastante subjetivo, pero teniendo en cuenta las características técnicas básicas que hemos expuesto, hay ocasiones en las que podemos presumir los motivos del abandono del bloque. A veces el núcleo ha llegado a un estado de agotamiento bastante evidente, otras veces parece que hay 
alguna pérdida en las características técnicas necesarias para la continuación de su explotación, como puede ser por ejemplo que la carena o la cintra no sean adecuadas. Uno de los motivos más frecuentes de la pérdida de una buena carena son los accidentes reflejados; y éstos a su vez pueden ser como consecuencia de una falta de curvatura adecuada (aunque también pueden estar ocasionados por otro tipo de causas, por ejemplo que la persona que ha tallado el núcleo en cuestión no tenga mucha habilidad técnica, errando quizás el ángulo, la intensidad o cualquier otro gesto de la acción).

En el segundo cuadro se describirá de forma detallada las características relativas a la superficie de extracciones (Cuadro I.11):

$\gg$ Características genéricas de la superficie de extracciones, respecto a tres aspectos:

- morfología: rectangular, cuadrangular o triangular

- anchura

- longitud relativa

Este atributo se presentará combinando las tres características definidas, separando cada estado de atributo por un guión, por ejemplo:

- R-A-L: rectangular, ancha, larga

- P-E-C: piramidal, estrecha, corta

- CD-A-C: cuadrangular ancha corta

La descripción de la morfología de la superficie de extracciones mediante una forma geométrica (cuadrada, rectangular, triangular; ancha o estrecha; corta o larga) proporciona una visión rápida de las características básicas de conformación de la tabla y de los recursos que será necesario utilizar. Por ejemplo en una superficie cuadrada ancha, lo más probable es que se utilice un segundo plano de percusión para el mantenimiento de la carena; por el contrario, una superficie triangular nos está marcando un núcleo piramidal, con un único plano de percusión.

Datos métricos de la superficie de extracciones, en milímetros: la longitud y anchura 
$\gg$ Preparación de la superficie de extracciones, respecto a la conformación o reparación de dicha superficie para la talla, se señalará la existencia de restos de alguna cresta, flancos de núcleo, etc.

En la tabla se pueden ver, a veces, restos de la conformación inicial de tal superficie, así como de las reparaciones o re-acondicionamientos sufridos a lo largo de la fase de producción propiamente dicha. Por ejemplo pueden quedar restos de crestas, en forma de negativos transversales, ya sean de una cresta anterior (de iniciación de la talla) o lateral. También se pueden ver a veces negativos de extracciones de flancos de núcleo, o crestas y neo-crestas. Los motivos de la necesidad de una reparación de la tabla se deben a la pérdida de las condiciones técnicas adecuadas para el progreso de la talla, por ejemplo cuando la carena o la cintra no tienen una curvatura adecuada, o cuando se produce algún accidente.

$>$ Preparación de las extracciones respecto al punto de impacto, en torno al frente de talla y sobre la superficie de extracciones: abrasión, retoque o esquirlado.

En todos los estados se puede hacer una indicación sobre la intensidad de la preparación (igual que en los soportes), con el símbolo "+" o "-", según sea intenso o débil, por ejemplo:

- $\mathrm{R}+$ : retoque intenso

- E-: abrasión débil

En caso de que haya combinación de estos estados de atributo, se separarán por un punto, por ejemplo:

- $\quad \mathrm{R}+\mathrm{A}$ : retoque intenso y abrasión

$\triangleright$ Carena (carène o carenage) o curvatura longitudinal: recta, convexa, oblicua

$\triangleright$ Cintra (cintre o cintrage) o curvatura transversal: recto, en diedro, convexo

La carena y la cintra son las curvaturas técnicas esenciales de la superficie de extracciones y tales curvaturas constituyen, junto con el ángulo necesario para la talla (menor o igual a $90^{\circ}$ ), las condiciones técnicas básicas en todo proceso de talla. Estos tres criterios son los elementos que continuamente están en juego y que 
muchas veces explican las limitaciones en cuanto a modalidades posibles, la necesidad de reparaciones de carácter técnico, etc.

$>$ Dirección de las extracciones: sentido de los negativos realizados: unipolar, bipolar, etc.

$\triangleright$ Indice de regularidad: como para los soportes laminares

$>$ Última extracción, dimensión, tanto en longitud como en anchura, en milímetros, aunque frecuentemente no es posible conseguir ambas medidas, siendo la anchura la más habitual.

Por último en el tercer cuadro se describen las características del plano de percusión (Cuadro I.12):

$\triangleright$ Características genéricas, respecto a:

- la superficie elegida (plano natural, cortical) o preparación de la misma (liso, facetado)

- la morfología del plano en visión lateral (recto [cercano a los 90º , oblicuo, cóncavo)

Para rellenar este apartado se separa cada estado de atributo con un guión, y siempre irán en primer lugar las características de la superficie elegida como plano de percusión (liso, cortical, facetado, etc.), por ejemplo:

- L-O: liso oblicuo

- F-CN: facetado, cóncavo

Cuando hay un segundo plano de percusión se pueden indicar las características genéricas para ambos señalando entre paréntesis la localización de cada uno, por ejemplo:

- $\quad$ L-O(S)/F-R(I): plano superior liso-oblicuo, plano inferior facetado-recto

Esta descripción del plano de percusión (cortical, liso, oblicuo, recto, etc.) está relacionada directamente con los tipos de talón de los soportes extraídos, además de implicar un mayor o menor cuidado en su instalación en la fase de preparación del núcleo. Si se elige una superficie cortical o un plano natural se habrá optado por un 
procedimiento mucho más rápido que si hay que realizar una limpieza del plano de percusión para dejarlo liso o facetado.

$\triangleright$ Preparación del plano de percusión, respecto a su conformación o reforma: tabletas de núcleo, semitabletas, lasquitas de reavivado

$\triangleright$ Preparación de las extracciones, huellas de la preparación del punto de impacto: abrasión, retoque o esquirlado sobre la cornisa

$\triangleright$ Cornisa, hay que describir si su morfología es continua o más irregular; en el primer caso se habría producido una preparación de la cornisa para eliminar las irregularidades del frente de talla, en el segundo quedarían los negativos de los contrabulbos.

La cornisa o frente de talla es la arista delimitada por la intersección entre el plano de percusión y la superficie de extracciones, es la zona donde mejor se van a observar algunas de las características del modo de talla empleado. Si su morfología es continua se ha realizado, normalmente, una preparación más o menos intensa del frente de talla ${ }^{10}$. Este atributo estaría en correlación directa con las huellas de preparación que pueden verse sobre la tabla y sobre el plano y está también determinado por el modo de talla empleado. Como tendencia general, sabemos por ejemplo que la percusión directa con un percutor blando necesita una preparación previa del frente para eliminar sus irregularidades. También hay que tener en cuenta si se trata de una percusión interior o tangencial; esta última necesita (sea un percutor duro o blando) igualmente una preparación (/abrasión) cuidadosa de la cornisa.

${ }^{10}$ El gesto de preparación del frente de talla se suele denominar como una “abrasión”, la cual puede tener distintos grados de intensidad (Pelegrin, 1995: 104). Dicho gesto se realiza con percutores adecuados realizando un movimiento transversal sobre la cornisa y eventualmente pequeños golpes sobre la superficie de extracciones o sobre el plano de percusión. Tales gestos dejan huellas tanto en torno a la cornisa como en los talones de los soportes extraídos. Sobre estos últimos se distinguieron tres variantes de huellas preparación, que se pueden extender también a las huellas que quedan en torno a la cornisa: retoque, esquirlado y abrasión; esta última se correspondería con un gesto de preparación más intenso. Asimismo un gesto de preparación del punto de impacto aún más cuidadoso sería la realización de un espolón (éperon), lo cual daría como resultado los talones con espolón. 
$>$ Ángulo: según las claves de medida utilizadas, que se pueden traducir en grados.

El ángulo del frente de talla tiene normalmente el límite máximo en los $90^{\circ}$ para que se pueda lograr una talla intencional. Dependiendo de si el avance de talla se produce a partir de un ángulo de percusión abierto o cerrado se necesitarán más o menos reajustes en ese progreso del débitage así como reavivados del frente de talla (tabletas y semitabletas). B. Valentin en su análisis de la tecnología de los grupos tardiglaciares de la Cuenca de París (1995: anexos, p. 16), establece que si el modo de talla impone la explotación de un ángulo cerrado (en torno a los $70^{\circ}$ ), dicho ángulo necesitará ser reavivado a lo largo del progreso del débitage (que suele ser frontal). Si el modo de talla permite la explotación de un ángulo más abierto (cercano a los $90^{\circ}$ ), no habrá necesidad de un reavivado tan frecuente del frente de percusión, ya que la talla se puede auto-mantener y expandirse de forma semienvolvente (Figura I.8).

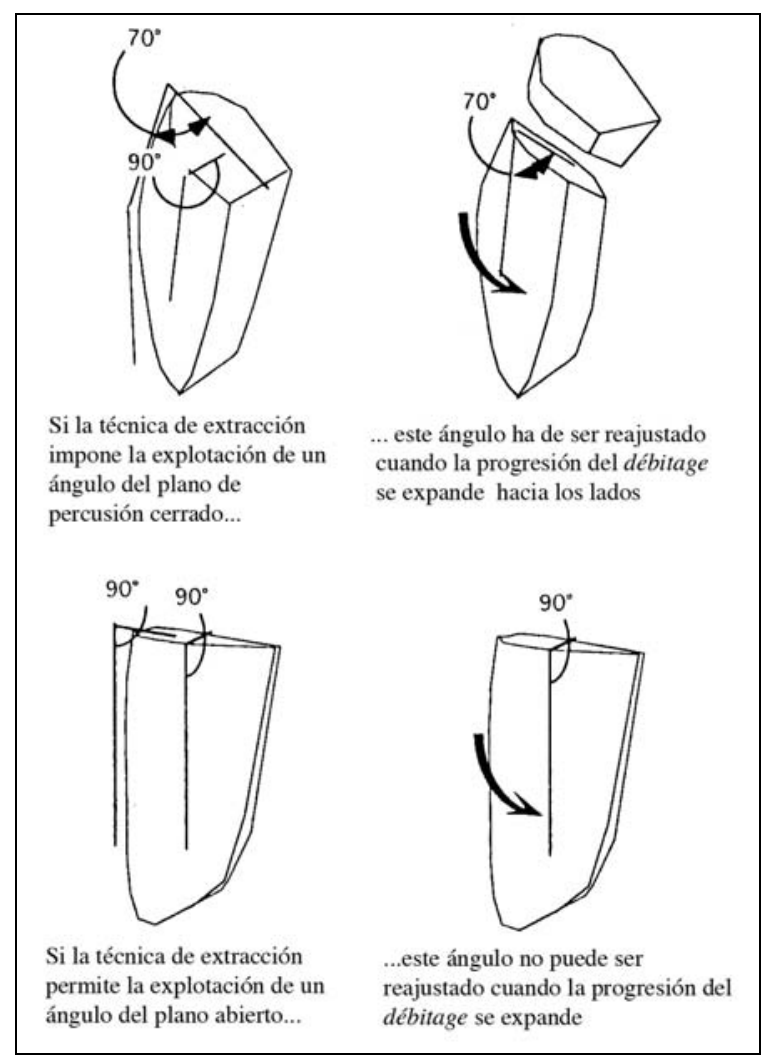

Figura I.8: relación entre el ángulo de percusión y los reavivados del frente de talla. Según Valentin, 1995: anexos, p.16. 
$>$ Modo de talla: percutor duro, blando, etc. No siempre se puede describir este atributo.

Estos atributos se han recogido y almacenado en una tabla de datos distinta a la ficha básica. Hay que hacer constar que no en todos los núcleos se ha podido tomar la totalidad de los campos descritos. 


\section{CARACTERÍSTICAS GENERALES DE LOS NÚCLEOS}

\begin{tabular}{|llll|}
\hline TIPO DE NÚCLEO & & \\
\hline P1 & Núcleo prismático con un plano de percusión & & \\
P2 & Núcleo prismático con dos planos de percusión & P2O & $\begin{array}{l}\text { Prismático con dos planos opuestos, } \\
\text { sobre misma superficie de extracciones } \\
\text { dos planos, sobre superficies alternas }\end{array}$ \\
PM & Piramidal & P2A & \\
LN & Lasca núcleo & \\
NG & Núcleo globuloso & \\
CT & Centrípeto & \\
AM & Núcleo amorfo, sin organización concreta & \\
RN & Resto de núcleo & \\
UP-P1 & Unipolar con tendencia a prismático & \\
N-PL & Núcleo sobre placa: débitage periférico & SA-P1 & Núcleo de superficie ancha unipolar \\
SA & Núcleo que explota superficie ancha & SA-P2 & Núcleo de superficie ancha bipolar \\
\hline
\end{tabular}

\begin{tabular}{|llll|}
\hline \multicolumn{4}{|c|}{ DESCRIPCIÓN DE LAS PARTES DEL NÚCLEO } \\
\hline A & Anterior, frontal & AP & Antero-posterior \\
P & Posterior & AS & Antero-superior \\
S & Superior & AI & Antero-inferior \\
I & Inferior & ALD/ALI & Antero-lateral derecho/izquierdo \\
LD & Lateral derecho & ABL & Antero-bilateral \\
LI & Lateral izquierdo & CB-P & Cubriente menos en posterior \\
BL & Bilateral & CB-I & Cubriente menos en inferior \\
CB & cubriente & & \\
\hline
\end{tabular}

\begin{tabular}{|ll|}
\hline AVANCE DEL DÉBITAGE \\
\hline FNT & Frontal \\
SENV & Semi-envolvente (semi-tournante) \\
ENV & Envolvente (tournante) \\
\hline
\end{tabular}

\begin{tabular}{|ll|}
\hline $\begin{array}{l}\text { PREPARACIÓN DE OTRAS SUPERFICIES } \\
\text { (en la conformación del volumen del núcleo) }\end{array}$ \\
\hline 2PO & segundo plano de percusión opuesto \\
2SE & segunda superficie de extracciones \\
LD & preparación en el lateral derecho, \\
& por ejemplo por una cresta postero-lateral \\
LI & preparación en el lateral izquierdo \\
CR & cresta \\
AN & Arista natural \\
BN & preparación de la base del núcleo \\
\hline
\end{tabular}

\begin{tabular}{|llll|}
\hline CAUSA DEL ABANDONO & & \\
\hline RF & Reflejados & ANG & Ángulo del frente de percusión inadecuado \\
SP & Sobrepasados & CAR & Carena inadecuada \\
PN & Planos naturales & COR & Cornisa o frente de percusión inadecuado \\
AG & Agotado & & \\
\hline
\end{tabular}

Cuadro I.10: atributos para la descripción de las características genéricas de los núcleos. 


\section{SUPERFICIE DE EXTRACCIONES}

\begin{tabular}{|ll|ll|ll|}
\hline \multicolumn{4}{|l|}{ SUPERFICIE DE EXTRACCIONES: CARACTERÍSTICAS } & GENÉRICAS \\
\hline MORFOLOGÍA GENERAL & \multicolumn{2}{|l|}{ ANCHURA RELATIVA } & LONGITUD RELATIVA \\
\hline R & Rectangular & A & Ancha & L & Largo \\
CD & Cuadrangular & E & estrecha & C & corto \\
TR & Triangular & & & & \\
\hline
\end{tabular}

\begin{tabular}{|c|c|c|}
\hline \multicolumn{3}{|c|}{$\begin{array}{l}\text { PREPARACIÓN DE LA SUPERFICIE DE EXTRACCIONES } \\
\end{array}$} \\
\hline \multicolumn{2}{|c|}{ CONFORMACIÓN SUPERFICIE } & PPARACION EXTRACCIONES \\
\hline & restos de cresta & Retoque \\
\hline FN & restos de flancos de núcleo & Esquirlado \\
\hline AN & Arista natural para inicio de talla & abrasión \\
\hline HRT & $\begin{array}{l}\text { Hoja de recintrado lateral: } \\
\text { hoja o lasca con flanco }\end{array}$ & \\
\hline & Base del núcleo acondicionada & \\
\hline
\end{tabular}

\begin{tabular}{|ll|ll|}
\hline \multicolumn{2}{|l|}{ CURVATURAS DE LA SUPERFICIE DE EXTRACCIONES } \\
\hline CINTRA & CARENA \\
\hline $\mathrm{R}$ & Recta, plana & $\mathrm{R}$ & Recta \\
$\mathrm{CX}$ & Convexa & $\mathrm{CX}$ & Convexa \\
$\mathrm{CN}$ & Cóncava & $\mathrm{CN}$ & Cóncava \\
$\mathrm{D}$ & En diedro & $\mathrm{O}$ & oblicua \\
\hline
\end{tabular}

\begin{tabular}{|c|c|c|c|c|}
\hline \multicolumn{5}{|c|}{ SOPORTES EXTRAÍDOS } \\
\hline \multicolumn{2}{|c|}{ DIRECCIÓN } & TIP & DE SOPORTES & REGULARIDAD (H, HT) \\
\hline UP & Unipolar & & Lascas & mala regularidad \\
\hline UPcvg & Unipolar convergente & & Hojas & regular \\
\hline UPalt & Unipolar alterna & & hojitas & 2 buena \\
\hline $\mathrm{BP}$ & bipolar & L-H & Lasca-laminar & \\
\hline CT & centrípeta & & & \\
\hline MD & multidireccional & & & \\
\hline
\end{tabular}

Cuadro I.11: atributos para la descripción de la superficie de extracciones.

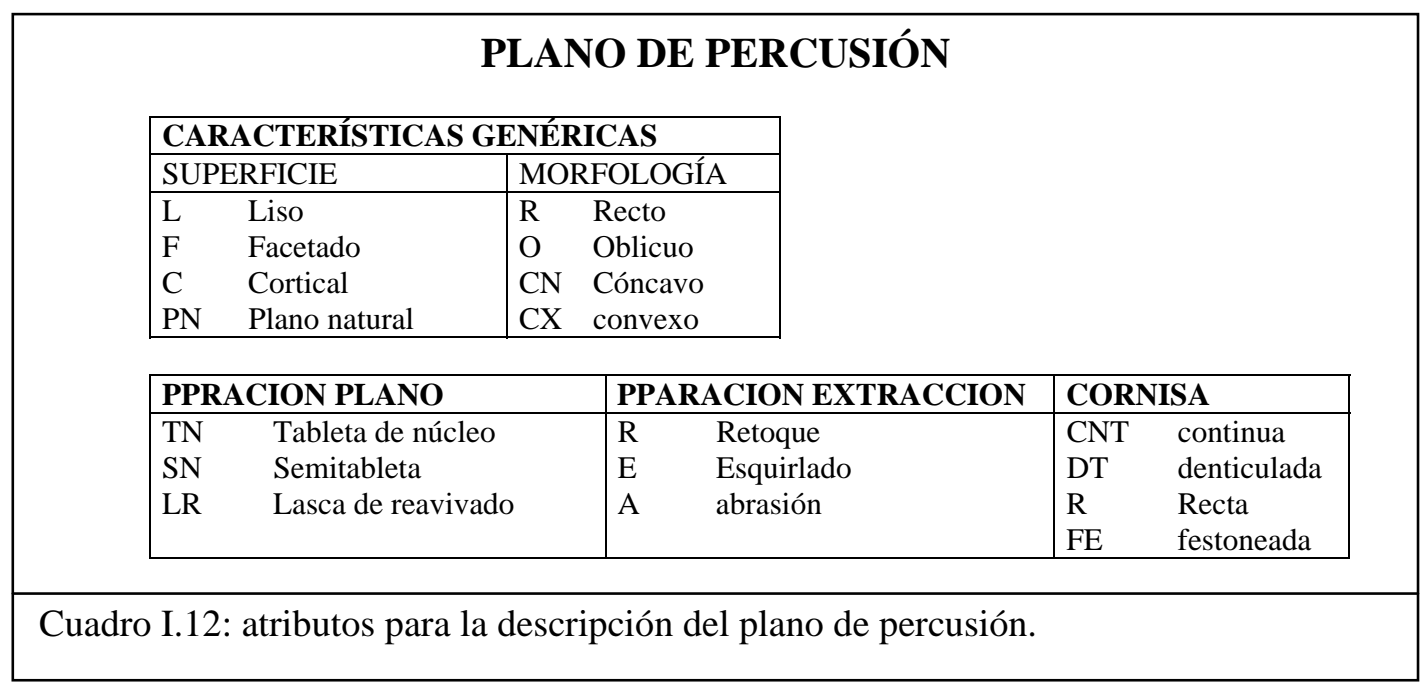




\section{I.2.3.3.- ProduCtos DE ACONDICIONAMIENTO}

Una vez descritos los núcleos ya tenemos una parte importante de las características técnicas del proceso de talla desarrollado en la materia prima en cuestión. Dicha parte no obstante se verá completada con el grupo de piezas pertenecientes a los productos de acondicionamiento o aquellas que son susceptibles de aportarnos datos sobre los actos y gestos técnicos propios del proceso aplicado sobre la materia prima tratada. Vamos a especificar cómo denominados a este grupo de los "productos de acondicionamiento", es decir el conjunto de piezas que no consideramos como soportes buscados en sí mismos, sino como elementos relacionados con el mantenimiento del núcleo para poder continuar la talla.

Los productos de acondicionamiento, en conjunto, son piezas que se caracterizan morfológicamente por tener secciones gruesas, que extraen una parte importante de la masa del núcleo, ya que su función es reparar ciertas partes de éste. Vamos a tratar de sistematizar todas las definiciones expuestas hasta ahora para concretar la terminología existente.

\section{LAS PIEZAS CON CRESTA Y LAS ARISTAS DE NÚCLEO}

La lámina con cresta (lame à crête) es la hoja (desde un punto de vista métrico) que se obtiene como consecuencia de la extracción de la cresta de un núcleo, con la función de iniciar el proceso de producción laminar en el débitage de dicho núcleo (Tixier et al., 1980: 82-83). Como ya hemos indicado, la cresta es un procedimiento de preparación de un núcleo de hojas u hojitas con la función de facilitar el inicio de la talla, y, tanto las hojas con cresta como, el método en sí se reconocen perfectamente desde principios del siglo XX (Cheynier et Barnes, 1934).

Lo ideal sería por tanto que reserváramos este término de lámina (o pieza en general) con cresta para los soportes que funcionalmente se relacionan con la apertura de la tabla de extracciones en un débitage laminar, así serían marcadores sintomáticos del uso de este método de preparación e inicio de una talla de hojas-hojitas en un conjunto en concreto. Según este supuesto, no habría que confundir la lámina de cresta con otros productos de acondicionamiento que porten crestas que realicen una función 
diferente dentro del núcleo (ya hemos descrito las crestas laterales, posteriores, etc.). En este caso estas piezas procederían de la eliminación de un borde o arista de núcleo (tal y como la hemos definido más arriba). Además pueden aparecer en cualquier tipo de núcleo y en distintos periodos cronológicos, por ejemplo los productos que eliminan el borde de un núcleo Levallois u otros característicos del Paleolítico Medio.

Podemos resumir diciendo que una lámina de cresta es una arista, pero no toda arista es una lámina de cresta. A este respecto tenemos que llamar la atención en la necesidad de no igualar los significados de ambos términos, y no llamar cresta a una semitableta de núcleo por ejemplo; siempre que sea posible realizar la diferencia funcional de la pieza. De hecho, el término arista de núcleo lo asignaremos a cualquier pieza que porte un borde de un núcleo, sin que podamos determinar de qué parte del núcleo se trata o la función de realiza. Conservaría por tanto “arista” el sentido amplio, de descripción morfológica.

Sin embargo en lo relativo a la lámina de cresta, a pesar de insistir en intentar determinar lo que es una verdadera cresta de iniciación de débitage laminar, el procedimiento de la cresta es un recurso que se utiliza bastante, aparte de la conformación inicial del núcleo. Vamos a tratar de concretar la variabilidad que se produce dentro de dicho concepto, para relacionarla con las posibles funciones que desempeñan a lo largo del débitage. Basándonos en la noción de “productos de cresta” expresada por Pigeot (1987: 23) proponemos la siguiente diferenciación (figura I.11):

- Lámina u hoja de cresta propiamente dicha, tal y como se ha definido, correspondiente a la apertura de la tabla laminar. Un dato interesante quizás para individualizar estas piezas, sea el criterio del ángulo $\left(\leq\right.$ a $\left.90^{\circ}\right)$ de la cresta mencionado por (Pigeot, 1987).

- Cresta parcial: la confección de la cresta (con las extracciones bidireccionales) no se extiende a lo largo de toda la arista central. Las crestas parciales pueden ser crestas desde un punto de vista funcional, pero la propia morfología inicial del bloque permita que la cresta no se extienda a lo largo de la arista.

- Neo-cresta (neo-crête) o semi-cresta (figura I.9): la confección de la cresta es unidireccional, es decir las extracciones transversales que parten de la arista 
central se dirigen a una sola de las vertientes. Pigeot propone también el término de “cresta simple”, haciendo alusión a Cheynier y Barnes (1936). La neo-cresta parece corresponder a un procedimiento de reparación de la tabla laminar en la fase de producción plena, con la función de rectificar la carena o la cintra, enderezando de este modo el curso de la talla (Pelegrin, 1995: 140).

- Cresta segunda o sub-cresta (figura I.10): lámina con fragmentos residuales de cresta que son los soportes extraídos a continuación de la lámina cresta a lo largo de la tabla de extracciones. Su superficie se caracteriza por tener al menos un negativo de un levantamiento anterior longitudinal al eje mientras que la otra vertiente conserva aún los restos de las extracciones de la preparación de la cresta, negativos perpendiculares al eje de talla, pero no portan los contrabulbos de los mismos (ya que son los que caracterizan a la lámina de cresta).

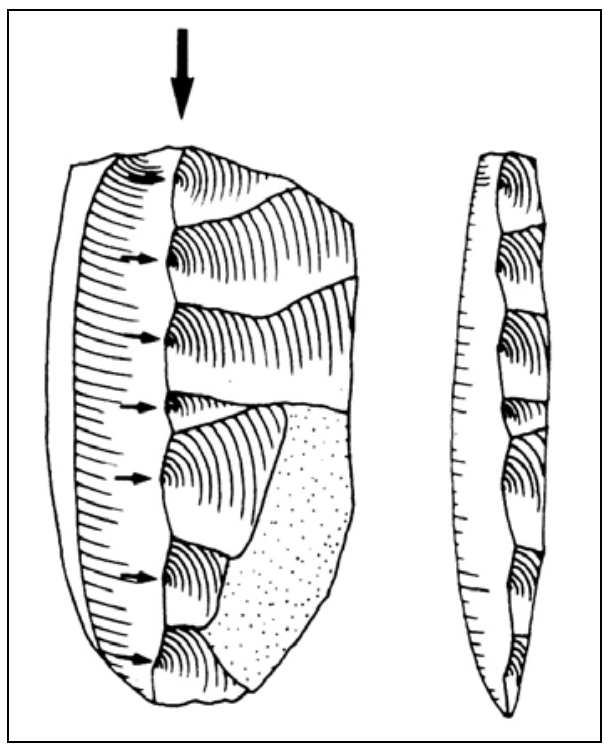

Figura I.9: neo-cresta. Reavivado de la cintra del núcleo a partir de extracciones transversales antero-posterioes (cresta), con la extracción de la neo-cresta. Según: Pelegrin, 1995: p. 140. 


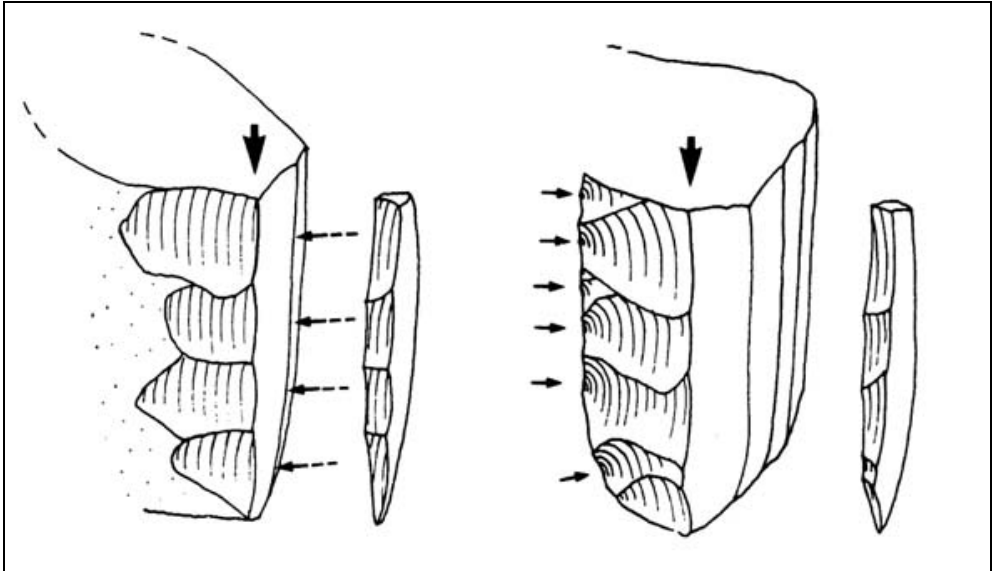

Figura I.10: sub-cresta o cresta $2^{\mathrm{a}}$, anterior (izquierda) y posterior (derecha). Según: Pelegrin, 1995: p. 139.
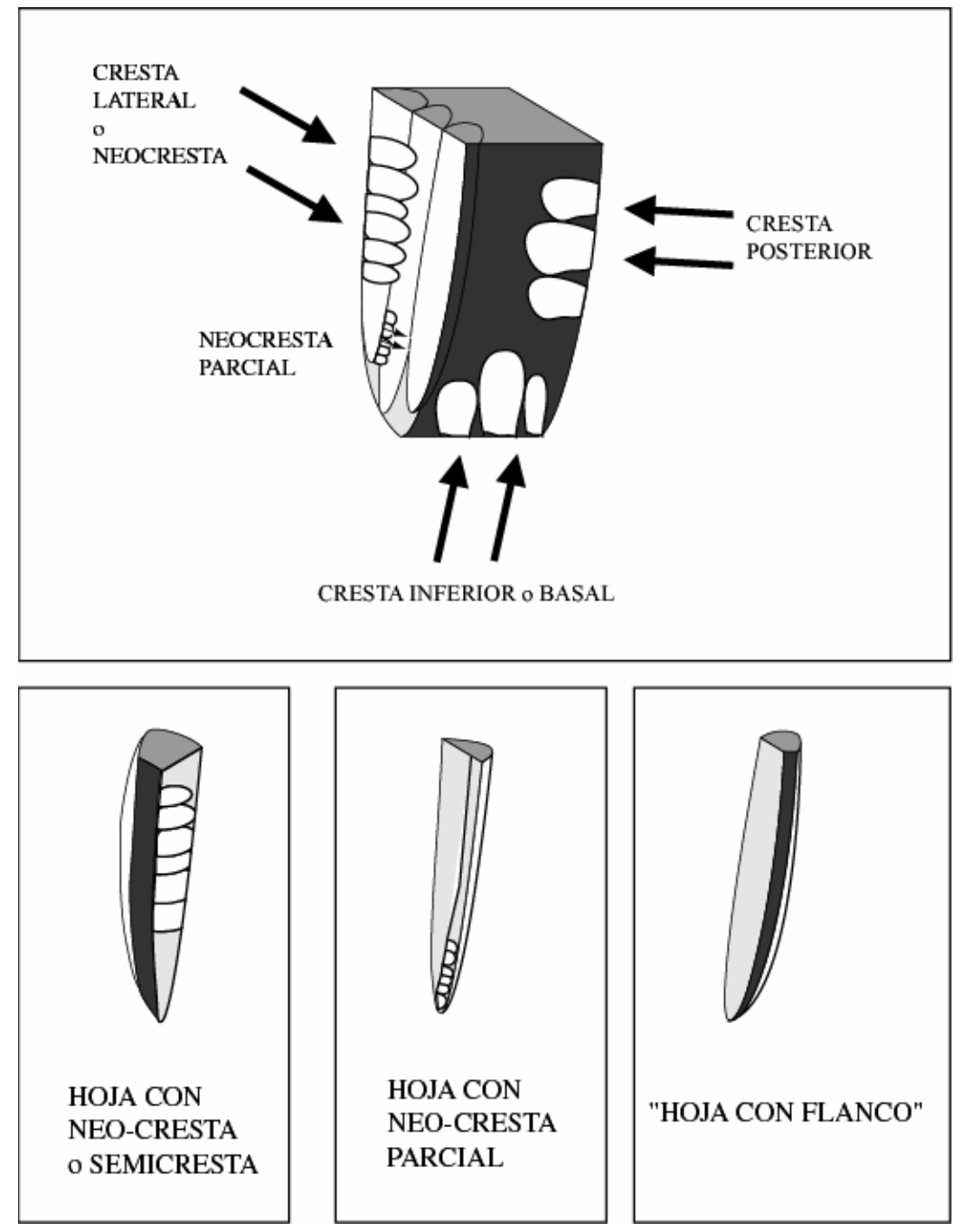

Figura I.11: crestas sobre el núcleo, hojas con neo-cresta, con neo-cresta parcial y hojas con flanco. 


\section{LOS FLANCOS DE NÚCLEO}

Son piezas que están perfectamente definidas al menos desde 1932, cuando E. G. Gobert y R. Vaufrey hablan ya de flancos de núcleo (Brézillon, 1977: 96). Con este término haremos referencia a los soportes que se llevan una parte importante de la superficie de extracciones, además de una parte del frente de percusión. Los motivos para realizar esta extracción pueden ser varios, por ejemplo:

- presencia de accidentes en la tabla laminar, sobre todo los reflejados

- carena o especialmente cintra inadecuada
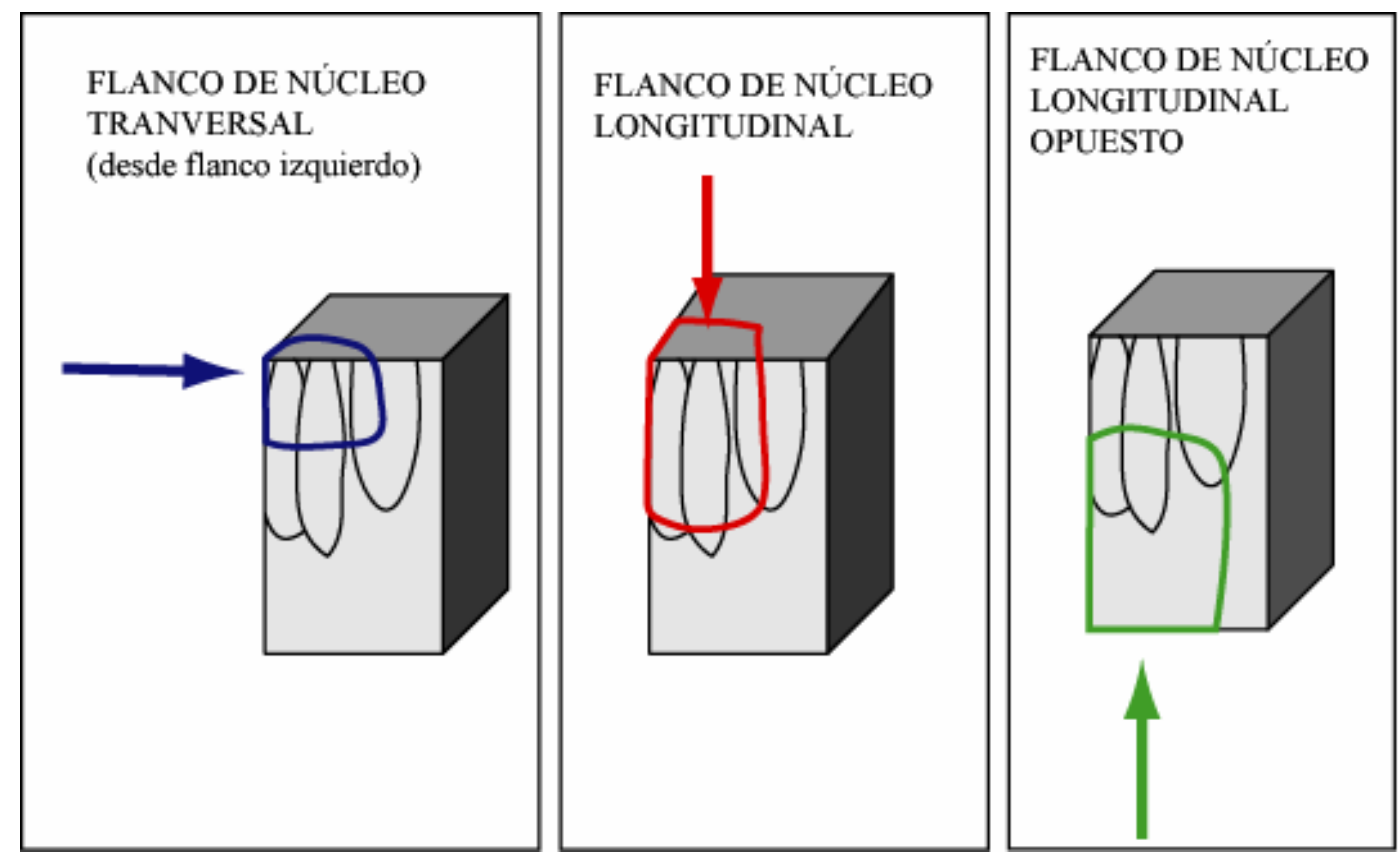

Figura I.12: procesos de arreglo de la superficie de extracciones: los flancos de núcleo.

Los flancos por tanto van a reavivar y limpiar la tabla de extracciones, eliminando irregularidades o enderezando las curvaturas de la misma. Y esto se puede realizar de dos formas, bien en una dirección axial desde el plano de percusión principal o desde un plano opuesto secundario; o bien desde una dirección transversal, a partir de los laterales del núcleo. Atendiendo a esta dirección de la extracción, tendremos entonces (figura I.12): 
- Flanco longitudinal: desde el plano de percusión principal, siguiendo el mismo sentido que las hojas extraídas.

- Flanco longitudinal opuesto: desde el plano de percusión secundario, en sentido contrario a las extracciones laminares.

- Flanco transversal: desde los laterales del núcleo. En este caso la parte de la cornisa del núcleo que se llevan suele ser bastante importante.

\section{LAS TABLETAS Y SEMITABLETAS}

Las tabletas y semitabletas de núcleo son las piezas correspondientes al reavivado del plano de percusión y, por tanto, del frente de talla (figura I.13). Sus características se han descrito desde hace ya mucho tiempo y no nos detendremos en ello (Tixier et al.,1980; Brézillon, 1977).

- Tableta de núcleo: se llevaría todo el plano de percusión, portando en todo su contorno el frente de percusión.

- Semitableta de núcleo: tan solo una parte de la tableta, es decir, en uno de los laterales contiene una pequeña porción del frente de talla además de parte del plano de percusión. En oposición a los flancos de núcleo, la semitableta se lleva una amplia parte del plano de percusión, mientras que el flanco elimina buena parte de la tabla de extracciones. Las semitabletas son mucho más frecuentes que las tabletas completas. Hay que tener en cuenta también que en los métodos de débitage laminar del Paleolítico Superior, normalmente la superficie de extracciones es frontal o semi-envolvente, raramente afecta a todo el contorno del núcleo; como consecuencia, el frente de talla está restringido a una zona del bloque, por lo que el reavivado de ese plano de percusión producirá más soportes del tipo de las semitabletas.

- Lascas de reavivado: en los planos de percusión de los núcleos se puede observar con bastante frecuencia el recurso a la extracción de pequeñas lascas a modo de semitabletas, pero sin afectar completamente al frente de percusión. Este procedimiento se da también en secuencias de preparación 
del punto de impacto de la hoja a extraer, ocasionando a veces el talón facetado en tales soportes. De todos modos estas lascas no se distinguen bien del resto de las lascas del conjunto lítico, ya que no se llevan una parte importante y evidente del frente de percusión. El empleo de este procedimiento se constata mejor sobre las huellas que dejan en los planos de percusión.

Las tabletas y semitabletas tienen por finalidad el reavivado del plano de percusión, volviendo a componer el ángulo adecuado para proseguir el débitage. Éste puede perderse por varios motivos, fundamentalmente en la preparación del frente de percusión, cuando se somete a la cornisa a un gesto de frotamiento o abrasión para eliminar las irregularidades de los contrabulbos. Pero sobre todo si la preparación del punto de impacto es muy acusada, por ejemplo un talón en espolón (en éperon), el ángulo se pierde más rápidamente. Por tanto el mantenimiento del frente de talla adecuado va a depender sobre todo del modo de talla que se utilice.

A partir del análisis técnico tanto de los núcleos como de los productos de acondicionamiento vamos a tener las características técnicas básicas desarrollas sobre la materia prima analizada. Sabremos cómo construían los núcleos, qué tipo de superficie de extracciones preparaban, sus dimensiones, la preparación del plano de percusión, la existencia o no de preparación de la cornisa y del punto de impacto de las extracciones, cómo avanza sobre el núcleo la talla, el ritmo de los levantamientos, la intensidad de explotación, cómo se repara el núcleo en el curso del proceso de talla, los motivos del abandono, etc. 

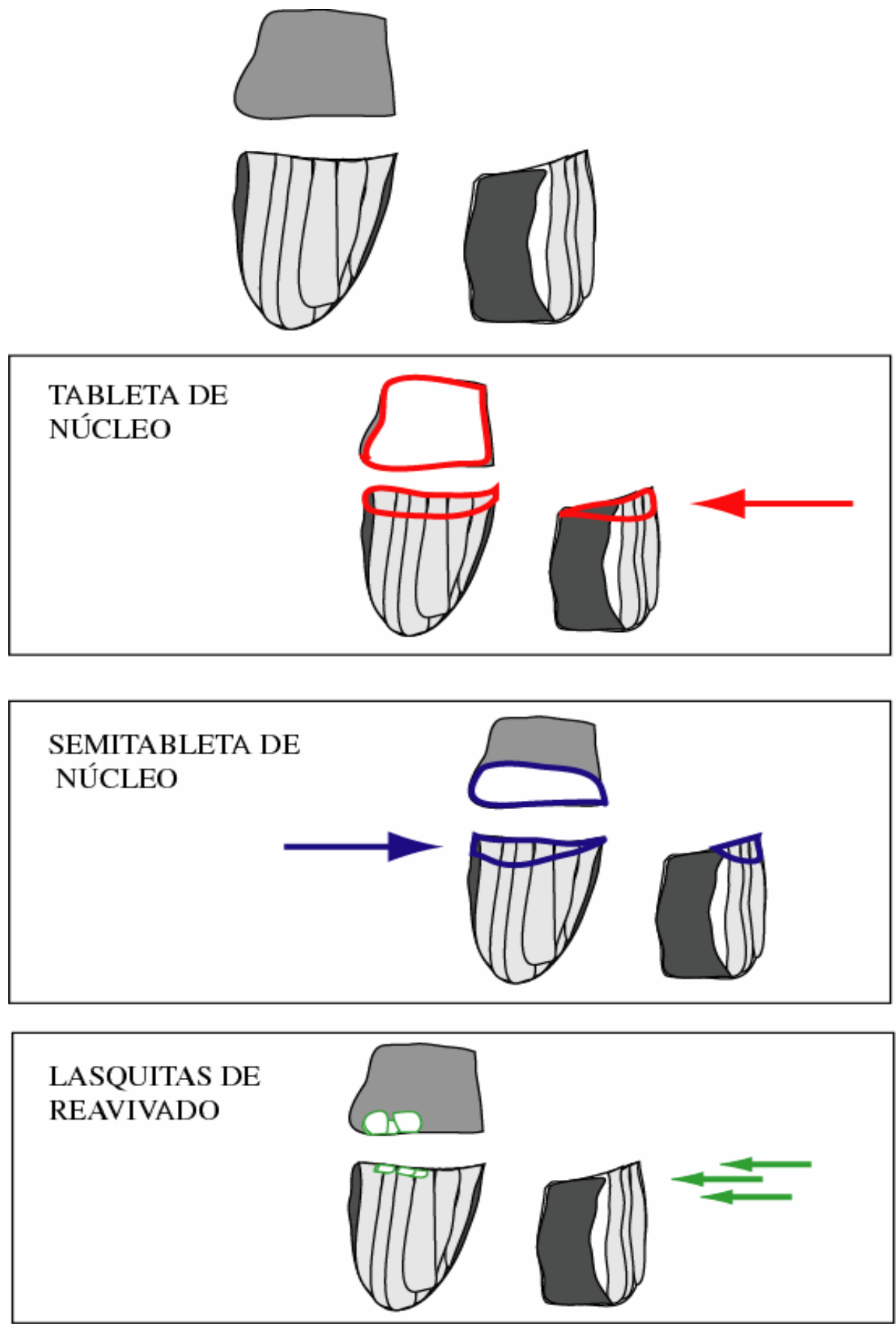

Figura I.13: procedimientos de reforma / acondicionamiento del plano de percusión. 


\section{I.2.3.4.- SOPORTES}

El término “soporte” es, como otros muchos dentro de la bibliografía paleolítica, muy amplio, polivalente y flexible. Tiene, por un lado, un sentido muy genérico en tanto que se refiere a todo objeto lítico sea cual sea (una lasca, una hoja, un núcleo, etc., todos son soportes). Por otro lado con el término "soporte" también se puede hacer referencia al tipo de pieza utilizada para retocar, conformar o tallar otra; así por ejemplo el soporte de un núcleo puede ser un canto rodado, un riñón, una plaqueta, etc.; una hoja como soporte de un raspador; o una lasca como soporte de un bifaz. Puede utilizarse también el término “soporte” en el sentido de piezas potencialmente utilizables o supuestamente buscadas en un proceso de débitage. En este último sentido es como se ha utilizado aquí, es decir serían los objetos líticos buscados en un proceso de débitage: lascas u hojas. Quedarían excluidos los núcleos y los productos de acondicionamiento, ya que, estos últimos al menos, no son piezas “teóricamente buscadas”, sino elementos funcionales subsidiarios de los métodos empleados para producir los soportes deseados. Ello no quiere decir que no se hallan podido utilizar, tan solo realizamos esta diferencia dentro de la fase de transformación de la materia para ver la finalidad del propio proceso de talla.

Los elementos de un conjunto lítico que no son ni núcleos ni productos de acondicionamiento son las lascas, las hojas u hojitas y los debris. Dependiendo del tipo del objetivo del débitage, los soportes deseados pueden ser cualquiera de los tres primeros. No obstante en un débitage laminar se van a producir también lascas y lascas laminares. Por tanto se podrían distinguir aún dentro de estos soportes, aquellos que son de primera intención, es decir los que pertenecerían a la “fase de producción plena” de la cadena operativa: lascas, hojas u hojitas, dependiendo del objetivo de talla. Como nos encontramos en procesos laminares, serían las hojas u hojitas, incluyendo también las hojas de segundo orden. Por otro lado estarían los "soportes secundarios”, los cuales pertenecerían a la fase de preparación o de reparación del núcleo. 


\section{SOPORTES SECUNDARIOS}

Serían las lascas corticales y en general las piezas de preparación y reparación. Estarían ubicados tanto en la fase de preparación del núcleo como en secuencias de reparación dentro de la fase de producción plena. En un proceso laminar serían:

- las lascas, de cualquier orden

- $\quad$ las hojas totalmente corticales

- lascas laminares

- las piezas con “arista natural”, es decir aquellas lascas u hojas corticales que portan un diedro o esquina natural del nódulo de origen. Este tipo de piezas, sobre todo las hojas, es importante que las tengamos en cuenta ya que son testimonio de un recurso que funcionalmente sería análogo a la lámina cresta, pero ejecutado de una forma muy rápida, inmediata y totalmente adaptada a las condiciones de la materia. Nos fijaremos por tanto en estos elementos para establecer métodos de preparación o iniciación del débitage

- Las "hojas o lascas con flanco" (Valentin, 1995): son aquellas piezas que portan un lateral del núcleo (figura I.11). Estarían a medio camino entre un soporte propiamente dicho y un producto de acondicionamiento, pero creemos que encajarían mejor dentro de los soportes buscados (las lascas con flanco se asimilarían a las lascas y las hojas con flanco a las hojas de segundo orden), ya que parece que pueden pertenecer a procesos de débitage que utilizan un auto-mantenimiento de la tabla de extracciones a partir de este avance sobre el núcleo.

\section{SOPORTES “DE PRIMERA INTENCIÓN”}

Como nos encontramos en procesos laminares, serían las hojas u hojitas, incluyendo también las hojas de segundo orden. En cuanto a la diferencia entre hojas y hojitas, es un carácter subjetivo, hemos tomado como límite la anchura de $10 \mathrm{~mm}$. 
Para ver las características de estos supuestos productos de primera intención, tendremos en cuenta una serie de características para comprobar su calidad técnica, resumida en la regularidad de estas piezas laminares.

\section{I.2.4.- RECONSTRUCCIÓN DE LOS ESQUEMAS OPERATIVOS}

Aparte de los datos recogidos en la ficha básica, en los que ya se anotan los datos básicos para la interpretación de los elementos líticos (básicamente los datos métricos y técnicos: presencia de córtex, tipo de soporte, de talón, índice de regularidad, etc.) nos ayudamos de dos métodos para reconstruir el esquema técnico de las piezas: el esquema diacrítico y los remontages.

\section{I.2.4.1.- EL ESQUEMA O DIBUJO DIACRÍTICO}

Este tipo dibujo esquemático (Dauvois, 1976) es esencial para la lectura tecnológica sobre todo de los elementos que tienen un contenido importante de información técnica, es decir los núcleos y los productos de acondicionamiento. Es en este tipo de soportes en el que se mostrará preferentemente de modo gráfico su lectura diacrítica. No obstante, para el análisis de cada elemento lítico se puede realizar su examen diacrítico, de hecho este tipo de análisis se realiza de forma efectiva sobre cada elemento, desde el momento que examinamos la pieza, la colocamos en su posición técnica y "leemos" cuál es la dirección de los negativos de su cara superior. Esta lectura tecnológica de los objetos líticos (Tixier et al., 1980) es una interpretación de la historia particular de la pieza, situándola de modo más o menos inmediato en el lugar que ocuparía a lo largo de la cadena operativa.

\section{I.2.4.2.- LOS REMONTAGES: EL REMONTAGE MENTAL Y LOS "RACCORDS" PARCIALES}

El remontage sería el método de análisis ideal para reconstruir de modo efectivo y directo el proceso técnico aplicado sobre un conjunto lítico. Pero este tipo de analítica no siempre es posible, y es de hecho muy raro que se lleguen a obtener lo que se consideran como "remontages totales", que son aquellos en los que se recompone todo un bloque tallado. Tixier (1980) distingue entre "remontage" y "raccord": 
- "Remontage": reconstrucción de un bloque tallado a partir de la yuxtaposición de todos (o la mayoría de sus elementos).

- "Raccord": remontage parcial y habría dos tipos de raccords:

a) Dos piezas que "remontan" porque son elementos consecutivos en la secuencia de talla (por ejemplo una lasca sobre su correspondiente negativo del núcleo). Serían "remontages parciales", bien de dos o más piezas o de secuencias más o menos cortas dentro del proceso de talla.

b) Dos fragmentos que "pegan" porque se trata de una misma pieza que está rota. Dicha rotura puede ser intencional o por otras causas, incluyendo factores postdeposicionales.

Sin duda alguna, tenemos un problema terminológico a la hora de traducir estas variedades de "remontages". Normalmente se ha traducido el término "remontage" directamente por su equivalente al castellano: “remontaje”, pero surgen dos problemas. El primero sería estrictamente terminológico, ya que el término "remontaje" en castellano no existe ${ }^{11}$. El segundo problema se relaciona más con el significado propiamente dicho y, sobre todo, en cómo diferenciar las variantes señaladas en el esquema anterior. El término remontage se ha venido utilizando tanto para los remontages totales propiamente dichos, como para los "raccords tipo a" es decir los remontages parciales. Respecto al término "raccord” no encontramos una traducción válida que nos convenza, aunque se ha propuesto “enlace” (Lloret, 2001) y “adaptación” (Merino, 1994).

De todas formas, dado que el término remontage tiene un empleo bastante extendido en la literatura tecnológica y su significado es muy claro, vamos a utilizarlo también en castellano, pero conservando esta grafía francesa debido a que es difícil encontrar una traducción adecuada en castellano. Respecto al problema de los

${ }^{11}$ En castellano "remontar" significa (DRAE, 2001): superar algún obstáculo o dificultad; subir; elevar por el aire o navegar aguas arriba; ahuyentar, espantar (la caza);...; también echar suelas nuevas al calzado. Como vemos, nada de esto encajaría en el significado "tecnológico" conque se aplica el término en nuestro contexto. Ni tampoco existe en castellano el sustantivo equivalente al propio término remontage, ya que el sustantivo y participio correspondientes a remontar son: "remonta" y "remontado", los cuales toman la última acepción a que se ha hecho referencia, es decir al efecto de remontar el calzado. Ante esta situación, optamos (como para el caso de débitage y façonnage) por importar el término francés directamente con toda su carga semántica. No obstante algunos autores han intentado traducir esta palabra, así por ejemplo, J.M. Merino (1994: 437-440) propone el término “acoplamiento”. 
"raccords" o remontages parciales, utilizaremos también el término remontage en este sentido más restringido. Ya se ha indicado que realizar remontages verdaderos es muy difícil, y lo más común son remontages parciales. El término remontage por tanto se utilizará tanto en sentido amplio como parcial, haciendo valer por tanto el remontage en su sentido técnico: reconstrucción de un bloque de forma total, de una secuencia de talla o sólo de dos o tres elementos consecutivos.

En El Espertín no hemos podido realizar remontages completos, tan solo remontages parciales, normalmente dos o tres piezas, reflejando una acción o gesto dentro de secuencias de talla. Las características de la cueva delimitan este tipo de metodología, hay que recordar que tiene un único nivel fértil que ha sido erosionado y removido en gran parte de la cavidad, por lo que muchas de las piezas líticas se han perdido o están desplazadas hacia la galería inferior o al exterior. Esta característica imposibilita la realización de otro tipo de tratamiento de los remontages (Hofman \& Enloe, 1992), como son los análisis espaciales intra-site a partir de los remontages existentes; o aspectos relativos a la productividad económica de los núcleos.

Atendiendo a las características del yacimiento del que procede el conjunto lítico, la validez de los remontages realizados es estrictamente técnica, nos servirán para ver tan solo pequeñas secuencias de talla. Para reconstruir los esquemas operativos de forma completa nos ayudaremos tanto de estas pequeñas partes del proceso, como de lo que Pelegrin (1995) denomina "remontage mental", que sería una suerte de esquematización teórica deducida tanto de la lectura diacrítica de las piezas, como de los remontages con que nos podamos ayudar.

\section{I.2.5.- RECONSTRUCCIÓN DE LA CADENA OPERATIVA}

Una vez analizadas todas las características técnicas tanto del conjunto de los soportes como de los núcleos y productos de acondicionamiento, se ha llegado normalmente a una esquematización de los esquemas operativos desarrollados sobre cada una de las materias primas. De hecho al describir el tipo de núcleo se realiza una síntesis del esquema técnico de dicho núcleo y, por afinidad entre estos tipos de núcleos, se van obteniendo los esquemas operativos más genéricos. Las características 
detalladas de los núcleos, así como los productos de acondicionamiento y el resto de los atributos del conjunto lítico, aportan datos sobre las distintas fases de la cadena operativa, sobre métodos concretos a lo largo de ella (por ejemplo los métodos de conformación o de iniciación), los objetivos del débitage, etc. El último paso será por tanto intentar sintetizar toda esta información en la/s cadenas operativas presentes, señalando las modalidades o variantes dentro de ellas y las causas de esta variación. Se trata por tanto de establecer las secuencias tal y como se han desarrollado en el conjunto analizado, basándonos para ello en los cuadros I.5 y I.6, donde se esquematizaba una cadena operativa laminar ideal. 
CAPÍTULO II -

LA CUEVA DE “EL ESPERTÍN” 



\section{1- CARACTERÍSTICAS GENERALES DE LA CUEVA: UBICACIÓN, PLANTA Y ESTRATIGRAFÍA.}

La cueva de "El Espertín” es una pequeña cavidad situada en el noreste de la provincia de León, en los valles altos del río Esla, junto a los Picos de Europa (Figura II.1). Se ubica a media ladera en un afloramiento calizo en la margen derecha del valle de un afluente del Esla: el río Orza. Está orientada al sureste y su altitud sobre el nivel del mar es de 1260 metros, a una cota de 20 metros sobre el actual nivel del río. Tiene una excelente ubicación en cuanto a las comunicaciones con el norte, cerca de la vía natural de conexión con Asturias. A menos de 10 kilómetros se encuentra el Puerto de El Pontón, en la divisoria hidrográfica con el río Sella, que da acceso a la vertiente septentrional. De hecho, siguiendo el Sella a través del desfiladero de los Beyos río abajo, nos encontramos con una serie de yacimientos magdalenienses y azilienses: Collubil (Amieba, Asturias) y el conjunto de yacimientos de Cangas de Onís: los Azules, la Cueva del Buxu y la Cueva de la Güelga (Bernaldo de Quirós y Neira 1993: 21).

En planta, la cueva tiene un vestíbulo de $24 \mathrm{~m}^{2}$ ante el cual se abre una terraza de unos $18 \mathrm{~m}^{2}$ apta para ampliar la zona de hábitat. Hacia el interior, en el centro de la pared norte se abre una galería estrecha descendente (Figura II.2). La cueva presenta una erosión en dirección Este-Oeste y hacia el interior, de forma que parte del nivel fértil está en superficie, e incluso ha desaparecido en algunas zonas. Además está localmente alterado por crioturbaciones y también hay retazos de brechificación (Bernaldo de Quirós y Neira 1993: 19). La superficie presenta una pendiente a partir de la zona central y hacia el fondo, en dirección a la galería, de modo que la erosión ha arrastrado parte del nivel fértil hacia el fondo.

La estratigrafía de la cueva presenta un único nivel arqueológicamente fértil. La extensión de este nivel varía, encontrándose la parte donde mejor conservada en la pared este, siendo el perfil que se dibuja sobre ella en el eje norte-sur el más completo. El nivel superficial (que cubre al fértil) está en parte erosionado por un flujo de agua 
que sigue una dirección desde la parte izquierda hacia el fondo, arrastrando parte del mismo hacia la galería de la pared norte de la covacha. Por esta razón no sólo el nivel de superficie, sino también el nivel fértil se pierde en ocasiones (especialmente en la zona izquierda y central). En el comienzo de la galería la estratigrafía está revuelta debido a esta erosión y a la pendiente del terreno a la que aludimos anteriormente. La zona más intacta es la que se encuentra hacia la entrada y la pared oriental. 


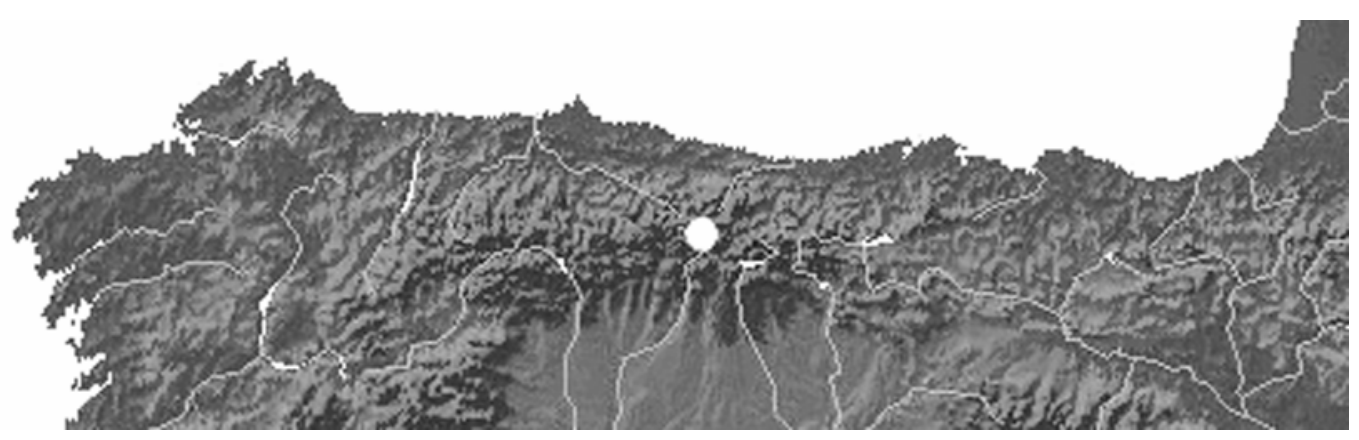

Figura II.1: situación geográfica de El Espertín.

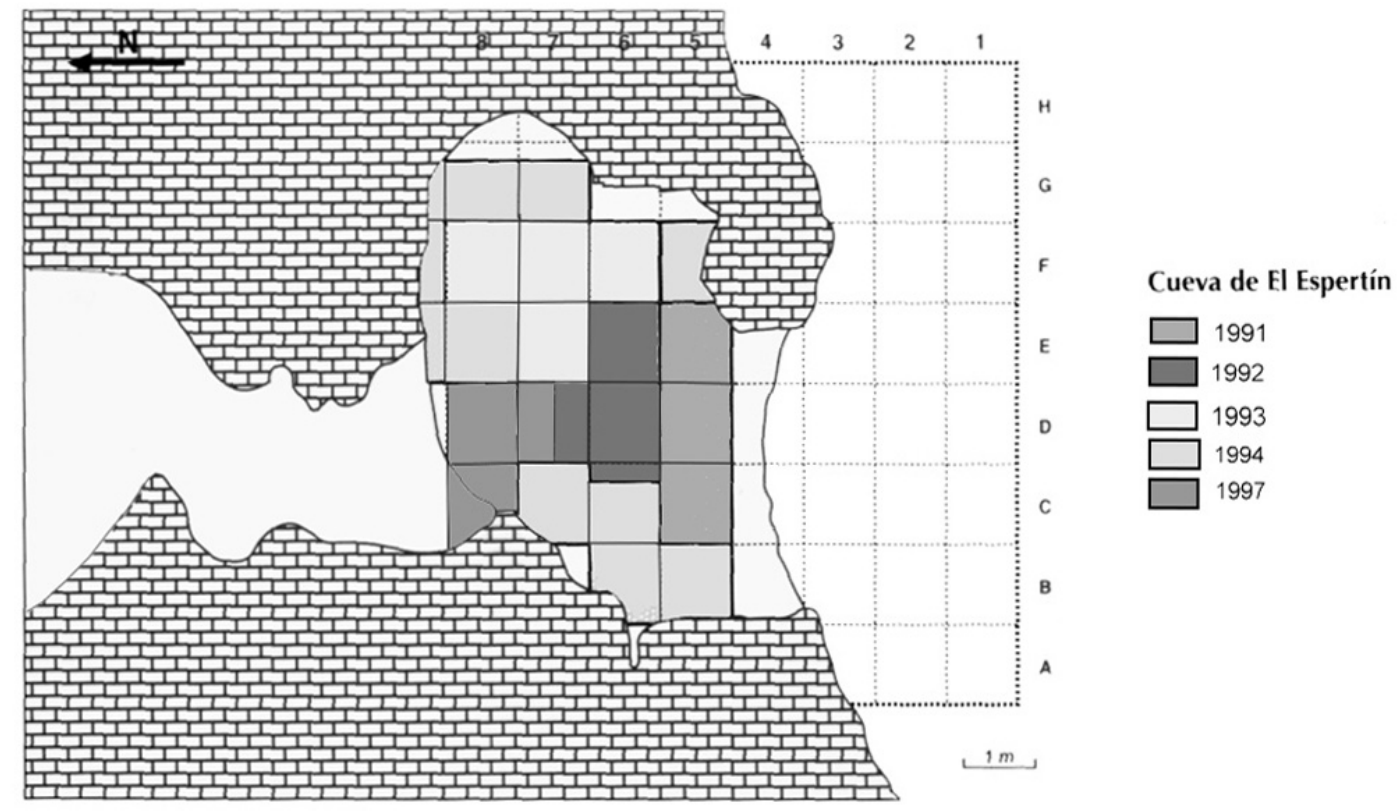

Figura II.2: planta de la cueva de El Espertín. 


\section{2.- ESTUDIOS PREVIOS Y CARACTERIZACIÓN CULTURAL DE “EL ESPERTÍN”}

La cueva fue descubierta por Carlos Piñel. El material de superficie fue estudiado por la Dra. A. Neira, de la Universidad de León en la elaboración de su trabajo de licenciatura sobre el Paleolítico en la provincia de León (Neira 1985, 1987). Posteriormente comenzaron una serie de campañas de excavación dirigidas por A. Neira y F. Bernaldo de Quirós de los años 1991 a 1994 y en 1997.

En un principio se encuadró esta cueva en algún momento de finales del Paleolítico Superior (Neira 1985, 1987; Bernaldo de Quirós y Neira 1992, 1993a, 1993b; Neira y Bernaldo de Quirós 1996). Esta adscripción respondía a las primeras características tanto tipológicas como tecnológicas observadas en la industria lítica (por ejemplo los raspadores unguiformes o la abundancia de la industria sobre hojas). Sin embargo han aparecido nuevos datos para la caracterización cronológico-cultural del yacimiento. Por una parte el cribado del sedimento de la cueva en el laboratorio ha proporcionado material lítico novedoso, principalmente los microlitos geométricos. Las pequeñas dimensiones de estas piezas hacen que tan sólo se puedan recuperar de forma sistemática durante el trabajo posterior a la excavación. Además, su hallazgo se vincula a la última campaña de excavación, cuando se procedió a excavar la zona más intacta del nivel fértil de la cueva. Por otra parte, la datación radiocarbónica sobre una muestra ósea ha ofrecido una fecha de $7790 \pm 120$ BP (Gif-10053). Estas características llevaron a desechar aquella primera definición del Espertín dentro de los momentos finales del Magdaleniense, para otorgarle un encuadre cronológico-cultural posterior, en el Mesolítico (Neira 1997: 75-80; Bernaldo de Quirós y Neira, 1999: 54; Neira et al., e.p.). Los estudios de otros aspectos del registro del Espertín vienen a confirmar esta caracterización cultural, así por ejemplo la fauna parece que apunta hacia un mundo holocénico más que de finales del Pleistoceno.

Con relación a los análisis especializados realizados sobre el material de "El Espertín”, la fauna (que está en proceso de estudio a cargo del Dr. C. Fernández 
Rodríguez) indica que las especie más cazadas eran los pequeños bóvidos, esto es, rebeco (Rupicapra rupicapra) y cabra (Capra ibex); seguidas por el jabalí (Sus scropha). También hay restos de ciervo (Cervus elaphus), liebre (Lepus sp.), y más anecdóticos de grandes bóvidos, uro (Bos primigenius) y corzo (Capreolus capreolus). Hay asimismo restos de carnívoros, que probablemente serían cazados para aprovechar la piel. Se ha constatado la presencia de oso pardo (Ursus arctos) y gato montés (Felis silvestris), etre otros.

El análisis antracológico de los carbones recuperados en el yacimiento (cuyo estudio está a cargo de la Dra. P. Uzquiano) ha dado como resultado la presencia de avellanos, castaños, pinos silvestres, dos especies de robles, madroños y enebros. Estos datos indican una flora diferente a la actual, compuesta por bosques de robles en las zonas de solana, hayas en la umbría y sin pinos. (Neira 1997: 79; Neira y Bernaldo de Quirós 1996: 23; Bernaldo de Quirós y Neira 1993: 19). 


\section{3.- “EL ESPERTÍN” EN SU MARCO TERRITORIAL}

\section{II.3.1.- CONTEXTO GEOLÓGICO}

El yacimiento de “El Espertín” está situado, dentro de la Cordillera Cantábrica, en la Montaña Oriental leonesa, en los valles altos del río Esla, a las puertas de los Picos de Europa. En este apartado nos centraremos en las características geográficas y geológicas, prestando especial atención a la denominada "Zona Cantábrica”, en la que se encontraría nuestro yacimiento. Para elaborarlo nos hemos basado fundamentalmente en los mapas geológico disponibles para este entorno (Suárez et al., 1994; Heredia et al., 1991; Alonso Herrero, 1995).

Los rasgos generales de la Cordillera Cantábrica son su alineación Este-Oeste, constituyendo una prolongación de los Pirineos, y su disimetría en las vertientes NorteSur: la parte septentrional presenta un fuerte desnivel desde la divisoria hasta la costa marina, que está muy cercana, mientras que la parte meridional tiene un escalonamiento no tan acusado, en su descenso hacia la meseta. Otra característica esencial de la Cordillera Cantábrica es su disimetría en el eje Este-Oeste desde un punto de vista geológico (Figura II.3). La parte occidental pertenece al Macizo Hercínico, con litologías predominantemente paleozoicas, mientras que la centro-oriental (la zona vasco-cantábrica), tiene una composición meso-terciaria (Gutiérrez Elorza, 1994). El límite entre ambas estaría situado en la parte occidental de Cantabria. Estas diferencias litológicas y también estructurales (el sustrato hespérico está totalmente condicionado por las líneas maestras producidas en la orogenia hercínica), van a determinar los rasgos característicos de cada zona una vez que la orogenia alpina afecte durante el terciario al zócalo hespérico occidental y a la cuenca mesozoica oriental, con el efecto de la elevación de la Cordillera Cantábrica (Martín Serrano, 1994: 25; Marquínez, 1992: 145). Estos condicionantes explican las diferencias geomorfológicas de ambas zonas y la presencia en la parte occidental, más concretamente en la Zona Cantábrica, de las alturas mayores de toda la Cornisa (superando los 2.500 metros de altitud), además de un relieve sumamente complejo. 
Las características morfoestructurales del sustrato hespérico en la Cordillera Cantábrica están determinadas por la presencia de la "Rodilla Astúrica”, estructura de sedimentos precámbricos y paleozoicos plegada en un arco de rumbo general NO-SE durante la orogenia herciniana. En el Mesozoico tal estructura fue arrasada y en el Terciario se verá afectada por la orogenia alpina, que provoca la fracturación y levantamiento de bloques, conformando la Cordillera Cantábrica, como hemos indicado (Águeda et al., 1983: 449). A este arco geológico se circunscriben tres de las cinco zonas geológicas en que se divide el Macizo Hespérico: la Zona Cantábrica, la Zona Asturoccidental-Leonesa, y la Zona Centroibérica (Martín-Serrano, 1994: 26). Las tres están presentes en la provincia leonesa, quedando las últimas fuera del marco de nuestro estudio (Figura II.4). El arco montañoso situado al norte y noroeste de la provincia leonesa está integrado en las dos primeras zonas, la Cantábrica y la AsturoccidentalLeonesa. La diferencia entre ambas es de carácter estructural y litológico, siendo eminentemente silícea la segunda, y más heterogénea la Zona Cantábrica (pero abundando las calizas) (Rodríguez Fernández, 1994: 9).

La “Zona Cantábrica” es el contexto geológico en el que se inscribe El Espertín, y es interesante centrarnos en esta unidad geológica y geográfica ya que constituye una amplia área con unas características geológicas básicas que definirán el marco de recursos (litológicos) potenciales en una zona bastante amplia, plenamente integrada en un contexto cantábrico. Los principales elementos que definen esta zona son el componente calizo predominante, las elevadas altitudes (Picos de Europa) y un relieve muy compartimentado en valles encajados como consecuencia de la erosión diferencial (Rodríguez Fernández, 1994: 9). Desde un punto de vista geográfico, esta zona abarcaría el norte de la provincia leonesa, la parte centro-oriental de Asturias y el extremo occidental cántabro (Figura II.4). El arco que enmarca por occidente la Zona Cantábrica partiría de un punto ligeramente al oeste de Cabo Peñas (aproximadamente en torno a la ría de Pravia) con rumbo NE-SO abarcando la zona central de Asturias con rumbo N-S, hasta llegar a la altura de Villablino donde cambiaría a rumbo O-E. Desde un punto de vista estructural este límite estaría marcado por el cabalgamiento del Narcea, que constituye el contacto con la Zona Astur-occidental leonesa. El límite meridional estaría determinado por la banda de afloramientos cretácicos que discurre en una estrecha franja que limita la Cordillera con la meseta; dicha banda pasa 
aproximadamente por La Robla, Boñar y Cistierna en la provincia leonesa y seguiría hasta Guardo y Cervera de Pisuerga en Palencia. El límite oriental de la Zona Cantábrica se adentra en la parte occidental cántabra, sobre todo por los Picos de Europa. Los límites oriental y meridional desaparece bajo los sedimentos mesozoicos y terciarios de las cuencas vasco-cantábrica y del Duero respectivamente (Heredia et al., 1994: 106).

La “Zona Cantábrica” es por tanto una unidad geológica, y en muchas partes geomorfológica, que constituye un amplio marco geográfico de estudio enclavado en la parte occidental-central de la Cordillera Cantábrica y abarca tanto la vertiente septentrional como meridional de la Cordillera. Es por tanto un marco útil como punto de partida para analizar las características geográficas, sobre todo porque permite integrar la circulación potencial entre ambas vertientes. A este respecto, se puede esbozar un esquema de las unidades de relieve que se desarrollan en esta zona. Al este de Cabo Peñas hay una serie de cordones de serranías y surcos intermedios que se presentan en bandas paralelas a la costa, siguiendo la orientación según el eje E-O (genérica en la Cordillera Cantábrica). La sucesión de cordones y serranías sería, de forma resumida, la siguiente a partir de la costa: la Rasa costera, las sierras Litorales (Cuera, Sueve), el Surco Prelitoral (Oviedo, Cangas de Onís, Panes), las Cadenas Prelitorales (Picos de Europa), las Cuencas interiores (Sajambre, Valdeón, Liébana), hasta llegar a las Montañas o Sierras de la Divisoria (Sierra de Cebolleda, Sierra Mediana) (Alvargonzález, 1997: 9).

Esta alternancia de cordones montañosos y surcos paralelos a la costa cambia totalmente hacia el oeste de Cabo Peñas, cuando se avanza hacia la Zona Asturoccidental Leonesa, donde tan solo la rasa litoral sigue esta dirección. La presencia de la Rodilla Astúrica es la causante de un cambio en la estructura de esta zona, de modo que los cordales montañosos y los valles (Narcea, Navia y Eo) tienen una dirección N-S hasta las Sierras de la Divisoria, donde retoman el rumbo E-O. Este ordenamiento continúa hacia el sur, entroncando con la zona oriental anteriormente descrita, en las Cuencas intramontañosas (Laciana, Babia, Riaño), la Alineación Intermedia, una serie de valles y cuencas (Valle de Gordón, Cuenca de Omaña), alineación meridional hasta llegar por último al piedemonte castellano. 
La cueva de “El Espertín” se localiza en la vertiente sur de la Cordillera Cantábrica, en el límite de las vertientes hidrográficas que vierten al sur (afluentes de la cabecera del Esla) y al norte (Cares y Sella), en el lado meridional del cordal (Sierra de Cebolleda) que limita la Cuenca Interior de Valdeón. De hecho a partir de la ubicación de la cueva y siguiendo río arriba el cauce del río Tuerto (afluente del Orza) y a unos 10 Km, se encuentra el puerto del Pontón, vía natural de comunicación con Asturias, a través del cual se accede inmediatamente a la cabecera del Sella.

Desde un punto de vista tectónico, las estructuras más importantes de la Zona Cantábrica son una serie de unidades cabalgantes (mantos de corrimiento) que han acortado de modo importante la primitiva cuenca de sedimentación paleozoica y dan lugar a la superposición y repetición de su sucesión litológica (Figura II.5). Dichos mantos aparecen plegados posteriormente, formando grandes unidades. Todo esto explica el relieve tan complejo de esta zona de la Cornisa Cantábrica con abruptas alineaciones montañosas calizas junto a valles excavados en materiales erosionables (pizarras y areniscas). Las unidades o mantos que se distinguen dentro de la Zona Cantábrica, a partir de estos criterios, son: Unidad de Somiedo-Correcilla, Unidad del Esla-Valsurvio, Unidad de la Sobia-Bodón, Unidad de la Cuenca Carbonífera Central, Unidad del Manto del Ponga, Unidad de Picos de Europa y Unidad del PisuergaCarrión. Esta última es la que nos interesa, el entorno donde está ubicado "El Espertín” (Heredia et al., 1994: 106).

Desde un punto de vista litológico las rocas que constituyen la "Zona Cantábrica” son fundamentalmente de edad Paleozoica (del Cámbrico al Carbonífero). De forma más concreta abundan las calizas cámbricas, devónicas y carboníferas; las cuarcitas ordovícicas; las pizarras y areniscas devónicas y los afloramientos de pizarras carboníferas.

La historia geológica de esta zona comienza en el Paleozoico. En esta área el sustrato rocoso está compuesto por materiales con edades comprendidas del Cámbrico al Carbonífero Superior. El Paleozoico Inferior está peor representado que en la zona Asturoccidental Leonesa, acuñándose hacia la parte interior del arco que constituye esta zona Cantábrica. Existe así una importante laguna estratigráfica precarbonífera, que se 
acusa hacia la parte interior del arco, de modo que hay zonas donde el lapsus temporal abarca parte del Ordovícico, Silúrico y Devónico (Rodríguez Fernández, 1991: 8).

El Carbonífero se caracteriza por la acumulación de depósitos sinorogénicos Hercínicos, es decir el ciclo sedimentario es paralelo a la Orogenia Hercínica. Con el levantamiento de la Cordillera Hercínica se origina una cuenca de antepaís de carácter marino que se va a rellenar principalmente por los aportes del área elevada o traspaís. Cerca del borde orógeno la cuenca tiene un gran surco que es donde se va a alcanzar un mayor espesor de sedimentos (detríticos). La zona de la cuenca de antepaís más alejada tiene una mayor estabilidad que permitirá la existencia de acumulaciones de carbonatos y/o series condensadas. El Carbonífero es un período que tiene mucha representación en esta área, constituyendo numerosas formaciones. En particular, para la unidad del Pisuerga-Carrión y más concretamente en la zona donde se ubica el yacimiento son importantes una serie de formaciones de edad Westfaliense compuestas por conglomerados, areniscas, calizas y lutitas en diferentes grupos. Tenemos que reseñar, especialmente para nuestro ámbito de estudio, el grupo Pando con sus distintas formaciones: Pandetrave (con areniscas, lutitas y brechas calcáreas), Panda (con calizas y calizas brechoides), Vegacerneja (con areniscas y lutitas) y Lechada (con conglomerados silíceos, calizas, areniscas y lutitas) (Heredia et al., 1991; Suárez et al., 1994).

Las siguientes fases geológicas no tienen mucha representación en la zona que nos interesa. La orogenia alpina llega en el Terciario inferior (Eoceno-Oligoceno), lo que dará lugar al rejuvenecimiento del Macizo Hercínico con una serie de fracturaciones y cabalgamientos que provocan el levantamiento de la Cordillera Cantábrica tal y como la conocemos hoy, con sus elevados macizos calizos. La elevación de esta Cadena se debe a la convergencia de las placas Europea e Ibérica, con subducción de la primera bajo la segunda. Al sur de esta Cordillera se forma la cuenca de antepaís de carácter continental, que es la Cuenca del Duero, la cual será rellenada por sedimentos terciarios y cuaternarios.

Desde un punto de vista geomorfológico la Cordillera Cantábrica en la provincia leonesa se presenta como un conjunto de bloques tectónicos progresivamente levantados hacia la Meseta, que aparecen desdibujados por erosión diferencial. 
Constituye un relieve muy compartimentado en macizos y depresiones de orientación este-oeste, surcados a su vez por otros de dirección norte-sur. Los Picos de Europa son un macizo calcáreo espectacular, el techo de la cordillera, modelado intensamente por las acciones del glaciarismo y la karstificación. El relieve de la Zona Cantábrica se ha conformado a partir de la alternancia de litologías calcáreas y litologías silíceas “duras” (cuarcitas, areniscas y conglomerados) y silíceas “blandas” (pizarras). Esta alternancia origina un relieve diferencial de tipo apalachiense complejo, por la geometría de los mantos y cabalgamientos (Relieve Diferencial Apalachiense Complejo). En varias ocasiones la tectónica superpone litologías iguales mediante apilamientos de cabalgamientos que conforman grandes macizos calcáreos (Alonso Herrero, 1995: 15). Todo este conjunto orográfico aparece surcado por profundas gargantas correspondientes a la red fluvial meseteña del Duero, constituida por los ríos Luna (Órbigo), Bernesga, Torío, Curueño, Porma, Esla, Cea y Carrión (ya en Palencia). Las únicas excepciones corresponden al Valle de Valdeón y Sajambre, surcados por los ríos Cares y Sella, que pertenecen a la vertiente cantábrica. Los grandes relieves compactos son debidos a las formaciones carbonatadas carboníferas de la "Caliza de Montaña" (formaciones Barcaliente y Valdeteja) y las “calizas de Picos de Europa” (Nozal, 1994: 83-84).

Como síntesis, “El Espertín” se encuentra, dentro de la Cordillera Cantábrica, en la denominada Zona Cantábrica, que es una parte del Macizo Hespérico antiguo. Más concretamente se ubica al sur de la divisoria Cantábro-Atlántica. Geológicamente los materiales pertenecen al Paleozoico (del Cámbrico al Carbonífero), predominando las calizas, pizarras y areniscas. Las diferencias litológicas, las características estructurales (con la existencia de la rodilla astúrica) y el juego de plegamientos, cabalgamientos y fallas, son las causantes de un relieve complejo y compartimentado, con una disposición general de los cordones en una dirección Este-Oeste y un encajamiento fluvial aprovechando los materiales erosionables. 


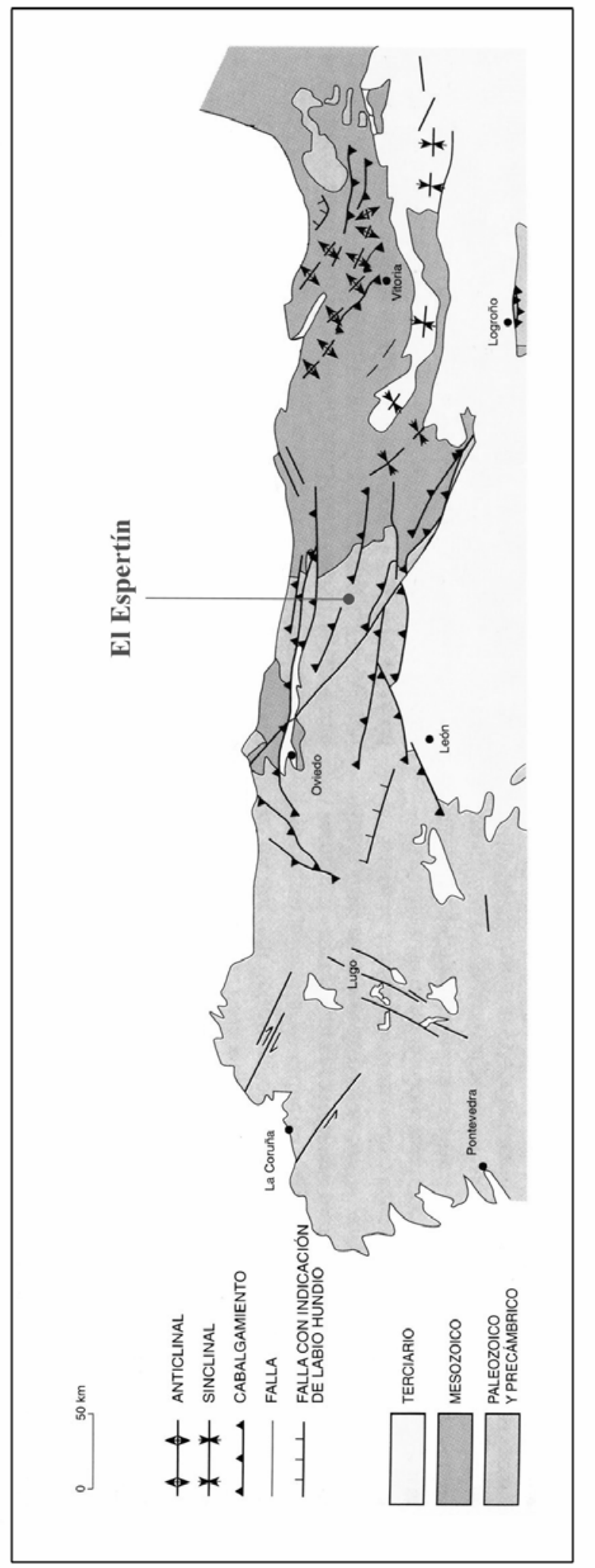

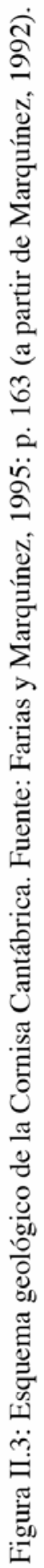




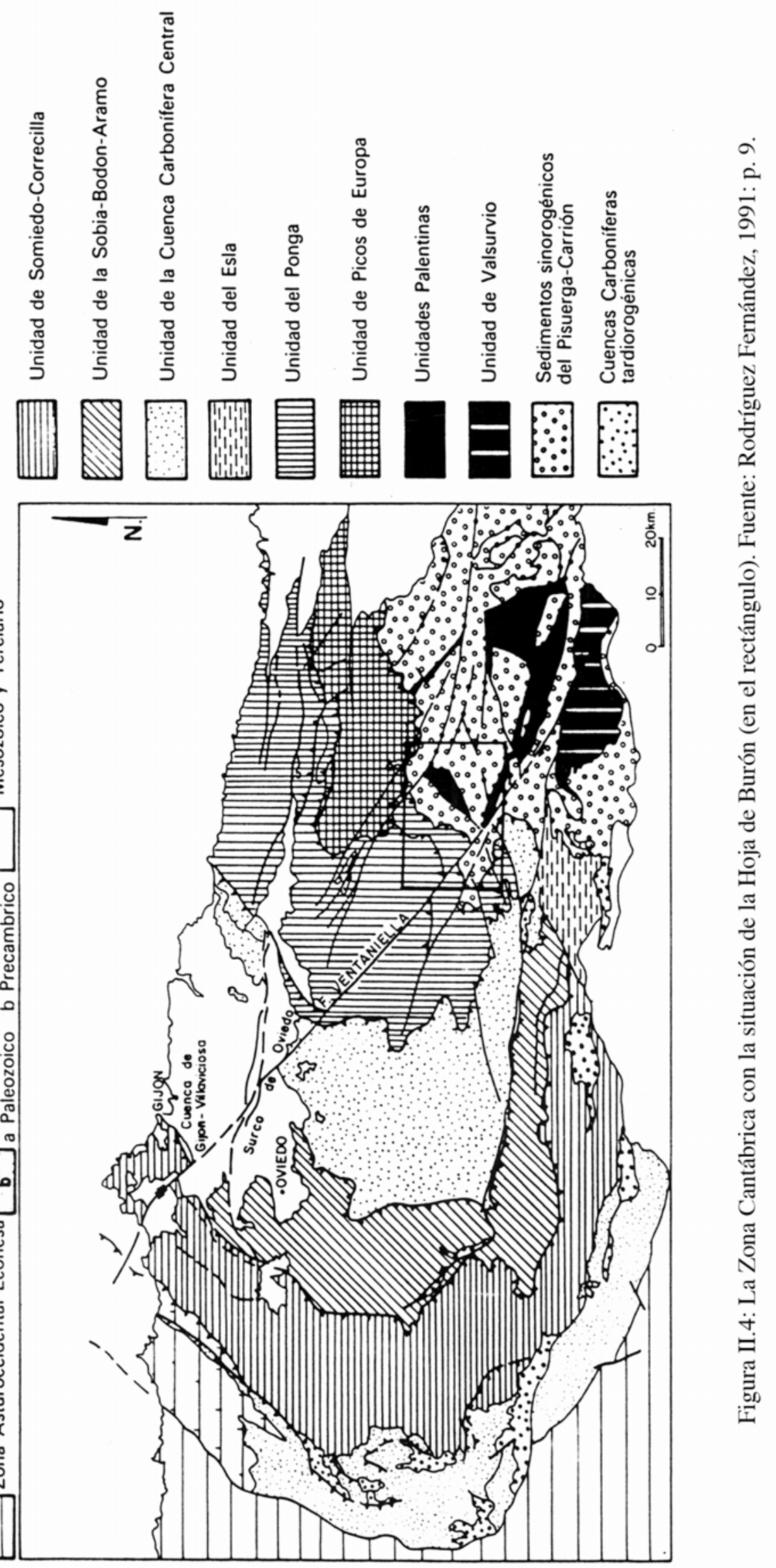



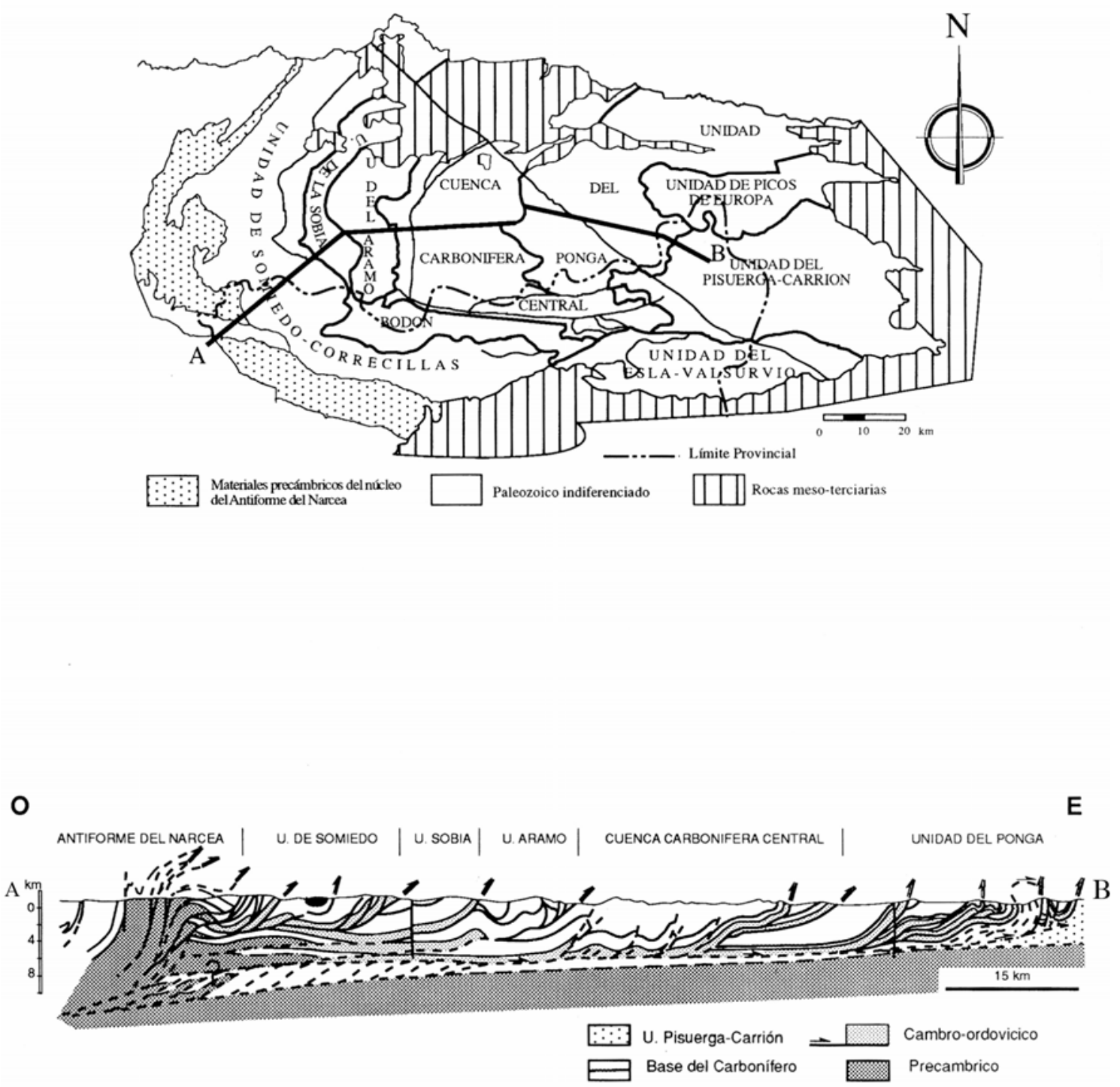

Figura II.5: Esquema de las unidades geológicas de la Zona Cantábrica y corte geológico a través de ellas. Fuente: Heredia et al., 1994: p. 108.. 


\section{II.3.2.- RECURSOS LÍTICOS SILÍCEOS POTENCIALES EN EL ENTORNO DE EL ESPERTÍN}

Las características geológicas de una zona geográfica concreta nos proporcionan por tanto una radiografía de los recursos que potencialmente pueden haberse explotado, siempre con las limitaciones y problemáticas que hemos mencionado. En el caso de El Espertín, situado en el extremo nororiental de la provincia de León, se encuentra localizado plenamente en la Zona Cantábrica, pero no está lejos del límite oriental de esta unidad geológica, pasando a la denominada unidad peri-asturiana (Montañas de Cantabria y norte de Burgos), dentro de los Montes Vasco-Cantábricos (Ugarte, 1994). Esta cercanía marca un cambio importante a escala litológica debido al sustrato mesozoico y terciario, frente al paleozoico de la Zona Cantábrica (Figura II.3).

Ya se han comentado las características genéricas del entorno de El Espertín, centrándonos especialmente en la unidad geográfica de la Zona Cantábrica. Su litología característica se resume fundamentalmente en la presencia de potentes series carbonatadas carboníferas (Calizas de Montaña, Calizas de la Unidad Picos de Europa), que resaltan en el paisaje, al lado de areniscas, lutitas y conglomerados.

A continuación se expondrán los niveles o formaciones geológicas en los que pueden aparecer rocas silíceas (fundamentalmente chert y radiolarita) susceptibles de haber sido utilizadas. Nos basamos fundamentalmente para ello en el mapa geológico de la provincia de León a escala 1:200.000 (Suárez et al., 1994) y en la memoria de la hoja de Burón (de escala 1:50.000 [Barba et al., 1991]).

\section{II.3.2.1.- EL CHERT}

Hay varios niveles geológicos en los que se cita la aparición de nódulos de chert, sobre todo dentro de series carbonatadas, en las calizas del Carbonífero Inferior y, más aún, en el Carbonífero Medio-Superior. Además de las series carbonatadas, el chert también se menciona en series siliciclásticas de grano fino como lutitas y pizarras. 
En estas series siliciclásticas hay presencia de chert en las siguientes formaciones:

- FORMACIÓN VEGAMIÁN (Carbonífero Inferior: Tournasiense Medio-Superior), que tiene una composición litológica de pizarras y limolitas con nódulos de fosfato, manganeso y chert

- FORMACIÓN RICACABIELLO, que está formada por pizarras del Carbonífero Medio-Superior. Se ha localizado de hecho un afloramiento de chert dentro de esta última formación en el valle de Valdosín ${ }^{12}$ (Burón, León). Esta situación es muy interesante ya que dicho valle se encuentra en las inmediaciones de la cueva de la Uña y da acceso, en la cabecera del Esla, al puerto de Ventaniella, paso natural hacia Asturias.

En las series carbonatadas aparece chert en las siguientes formaciones:

- En la CALIZA DE MontaÑa (Carbonífero Inferior: Namuriense), dentro de la Formación Barcaliente, el chert se presenta en bandas entre las calizas grisoscuro tableadas características de esta formación.

- En las CAlizas de la Formación Picos de EUROPA (Carbonífero MedioSuperior: Westfaliense) aparecen niveles de chert y pizarras tanto en la caliza oscura tableada del miembro inferior, como en las calizas masivas rosadasblancas del miembro superior.

- Dentro del la FORMACIÓN LOIS-CigUERA (Carbonífero Medio-Superior) se cita una gran cantidad de nódulos de chert en las calizas tableadas del Miembro Bachende (de edad Moscoviense, dentro del Westfaliense).

Debemos hacer mención también a la FORMACIÓN ESCALADA (Carbonífero Medio-Superior: Moscoviense), una serie con gruesos bancos calcáreos masivos, que si bien en la Hoja de Burón no se cita la presencia de chert, en cambio sí se constata en la parte asturiana (Arias 1991b), y precisamente en esta formación se ha localizado ${ }^{13}$ un afloramiento que contiene nódulos de chert.

${ }^{12}$ La localización de este afloramiento en el valle de Valdosín ha sido realizada por el Dr. E. Alonso Herrero.

${ }^{13}$ La localización de este afloramiento de chert negro, así como el de radiolarita que se describe en el apartado siguiente, se enmarca dentro del proyecto: "La Gestión de los Materiales silíceos en las sociedades cazadoras-recolectoras de la provincia de León", Ref. ULE-2002-14, dirigido por la Dra. A. Neira Campos. 


\section{II.3.2.2.- LA RADIOLARITA}

Respecto a la radiolarita se encuentra perfectamente localizada dentro de la FORMACIÓN ALBA (o Genicera), de edad Viseense (Carbonífero Inferior). Esta formación se compone de calizas rojas tableadas nodulosas, en una facies muy característica que se extiende por toda la Zona Cantábrica. Se ha denominado también como caliza griotte, mármol griotte o Griotte de Puente de Alba (por la localidad leonesa homónima donde se describe la formación). El color rojizo característico se debe a condiciones oxidantes en su formación. La formación Alba tiene una potencia media de unos 30 m y está compuesta por tres miembros que tienen un tránsito gradual entre sí. De base a techo son:

- Miembro basal (Gete o Gorgera, potencia de 1 a 2,8 m), con lutitas rojas o verdosas y calizas.

- Miembro medio (Valdehuesa o Lavandera, potencia de 1 a 16 m), con lutitas calcáreas o silíceas rojas, radiolaritas y/o calizas silicificadas.

- Miembro superior (La Venta o Canalón, potencia de 13 a 40 m), con calizas rojas o verdosas y lutitas rojas, grises o verdosas.

En esta descripción de la secuencia de la formación Alba, la radiolarita se encuentra en el miembro intermedio, presentándose en forma de potente banco entre dos series de calizas rojas griotte. Esta formación aparece de manera muy uniforme en bandas más o menos amplias a lo largo de la Zona Cantábrica (Figura 6). En la parte leonesa, se puede seguir en distintos tramos en la Unidad Picos de Europa, en el extremo occidental de la unidad Carrión y siguiendo hacia el oeste, a lo largo de la Cuenca Carbonífera Central.

Además de esta localización potencial y efectiva (y también efectiva, ya que se han localizado sendos afloramientos de ambas variedades silíceas dentro de las formaciones citadas, que se describirán en el capítulo sobre las materias primas) de chert y radiolarita en posición primaria (es decir en el lugar de su formación geológica), también se ha constatado la presencia de ambas rocas en posición derivada tanto en los sedimentos fluviales cercanos como en terrazas más alejadas. Así en las terrazas del 
Esla, por ejemplo en la comarca de $\operatorname{los}$ Oteros $^{14}$, son abundantes los cantos rodados aluviales de chert negro y radiolarita en sus dos variedades (roja y verde).

${ }^{14}$ Dentro del proyecto: "Prospección intensiva de la Primera Edad del Hierro en la comarca de Los Oteros en León", dirigido por A. Neira Campos, C. Fernández Rodríguez y L. Pérez Ortiz; financiado por la Junta de Castilla y León; se ha comprobado la presencia de estas materias en posición derivada. 


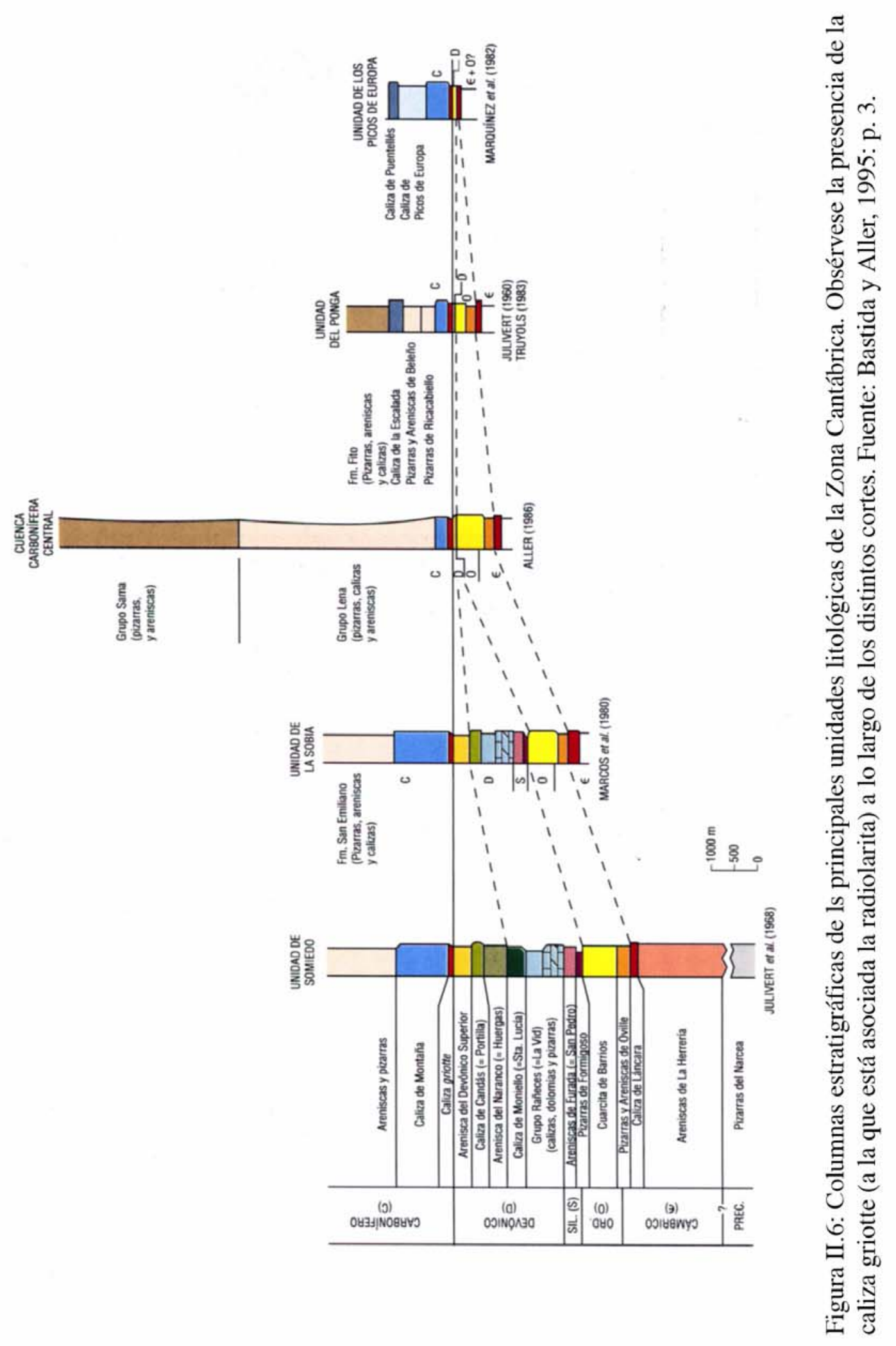


CAPÍTULO III -

MATERIAS PRIMAS 

Las materias primas utilizadas para elaborar la industria lítica de El Espertín se han clasificado y determinado a partir de sus características macroscópicas (aspecto, color, textura, etc.). Somos conscientes de que una caracterización correcta de las rocas pasaría por la realización de un análisis petrográfico (lámina delgada) o físico-químico, pero ante la ausencia de éstos, optamos por realizar una descripción que permita reconocer e identificar de modo adecuado, rápido y eficaz las variedades de materias utilizadas.

Hay dos grandes familias de rocas talladas en El Espertín: el sílex y la cuarcita, además de una presencia prácticamente testimonial de cuarzo. Vamos a centrarnos fundamentalmente en la descripción de los distintos tipos de sílex presentes en nuestro yacimiento.

Respecto al término "sílex", no vamos a ahondar en el controvertido tema del uso o abuso que de tal concepto se viene realizando desde el campo de la prehistoria ${ }^{15}$. Somos conscientes de que la determinación adecuada de las rocas talladas, desde un punto de vista geológico, dista a veces de las clasificaciones intuitivas y macroscópicas que se realizan por parte de los prehistoriadores. Por esto queremos incidir en el sentido en que utilizaremos este término para evitar errores ulteriores. Dado que este trabajo se basa en un análisis tecnológico del conjunto industrial lítico de El Espertín, estamos instalados en un punto de vista plenamente prehistórico, que no geológico; es decir, las rocas utilizadas por los grupos prehistóricos responden a unas necesidades y/o intencionalidades determinadas, explicables dentro de las características culturales del grupo dado. Desde esta perspectiva nos van a interesar más las características físicas (dureza y fragilidad) y mecánicas (fractura concoidea) de las materias seleccionadas por los grupos prehistóricos para confeccionar su industria lítica; que las características mineralógicas y petrológicas propiamente dichas. Consideramos que éste es un punto de partida válido para el tipo de análisis que desarrollamos aquí, no obstante reiteramos la ausencia de estudios mineralógicos y petrológicos estrictos que definan y caractericen las distintas variedades de afloramientos existentes en la Zona Cantábrica y que

${ }^{15}$ Así por ejemplo, desde un punto de vista geológico, muchos autores restringen el término “sílex" a una variedad criptocristalina granulada del cuarzo (al lado del jaspe), que se presenta en forma de nódulos en terrenos cretácicos (Klein \& Hurlbult, 1997:587; Mollfulleda, 1999:226). 
facilitarían una correlación entre las materias explotadas en los yacimientos prehistóricos y las potenciales fuentes de aprovisionamiento.

Tomando como punto de partida esta perspectiva prehistórica de las rocas talladas, queda justificado el hecho de que utilicemos el término "sílex" con un sentido muy amplio, al menos en un primer momento al acercarnos al conjunto industrial y para hacer agrupaciones genéricas (por ejemplo cuarcita frente a sílex). En un segundo momento intentaremos definir mejor las distintas variantes de sílex presentes, al menos la radiolarita y el sílex/chert negro con la intención de acercarnos más a la caracterización geológica de tales variantes y determinar posibles fuentes de aprovisionamiento.

Al utilizar el término "sílex" en su sentido más amplio no se pretende tampoco abordar problemáticas que pertenecen a otras disciplinas, pero aceptaremos muy gustosamente las correcciones e indicaciones que procedan de ellas. Vamos a seguir en este aspecto a A. Tarriño (1998), de modo que con el término "sílex" se hace referencia al conjunto de rocas silíceas sedimentarias diagenéticas, cuyo rasgo esencial es que tengan una composición de mineral de la sílice criptocristalina (cuarzo u ópalo, minerales del grupo de $\mathrm{Si} \mathrm{O}_{2}$ amorfo) mayor del 50\%. Este grupo es muy amplio e incluye rocas de variada apariencia y características, desde el cuarzo en sus distintas variedades cristalinas hasta los distintos sílex. Su terminología es muy diversa dependiendo del tipo de afloramiento del que procedan (silexita, lidita), de la presencia de organismos con caparazón silíceo en su formación (radiolarita, diatomita, especulita), del contenido en impurezas (por ejemplo el jaspe tiene óxidos de hierro y las variedades negras materia orgánica) o de la composición mineralógica (la calcedonia sería la variedad fibrosa del cuarzo, el ágata y el ónice serían variantes de la calcedonia). 


\section{III.1. LAS TÉCNICAS DE APROVISIONAMIENTO}

El interés por las materias primas utilizadas en las industrias líticas está presente prácticamente desde el principio del estudio del material prehistórico. Desde hace algunas décadas este tipo análisis se integrarían, dentro una perspectiva tecnológica (Cuadro I.1), en las denominadas técnicas o sistemas de aprovisionamiento (Geneste, 1991a), centradas en el primer paso de la cadena técnica: la selección y recogida de la materia deseada, con las distintas implicaciones que dicha actividad puede acarrear, tanto de tipo cultural (preferencias por materias concretas más o menos "exóticas", territorios recorridos o frecuentados, intercambios, etc.) como técnica (límites y posibilidades de los distintos tipos de rocas, dificultades en su "extracción" o recogida, etc.).

Los análisis de materias primas y las técnicas de aprovisionamiento han tenido gran predicamento en las últimas décadas en el contexto europeo a lo largo de distintos momentos del Paleolítico (Demars, 1982; Geneste, 1985; Seronie-Viven \& SeronieViven, 1987; Turq, 1992; Flébot-Augustins, 1997, etc.) y queda patente también en la celebración de varios congresos (las diversas reuniones del Flint Symposium como ejemplo más representativo, o también se puede citar la más reciente tabla redonda sobre "les matières premières lithiques en Préhitoire” [VVAA, 2003]). En el ámbito español el interés por esta temática se hace patente desde hace algunos años, palpable en la realización de algunas reuniones especializadas, por ejemplo la $1^{\mathrm{a}}$ y $2^{\mathrm{a}}$ Reunión de Trabajo sobre Aprovisionamiento de Recursos Líticos en la Prehistoria celebradas en Valencia en 1994 (Bernabeu, Orozco y Terradas, 1998) y en Gavá en 1997 (Bosch, Terradas y Orozco, 1998) respectivamente. En estos foros se han especificado la situación de este tipo de estudios en nuestro país así como sus problemas y límites (Terradas, 1998b). Más recientemente han aparecido algunas tesis doctorales sobre esta temática en la parte norte peninsular, concretamente en Cataluña (Mangado, 2002), País Vasco (Tarriño, 2001) y Cantabria (Sarabia Rogina, 2000).

En la interpretación correcta del uso o gestión de las distintas materias primas es esencial la determinación del origen de las rocas utilizadas, al menos si se trata de una 
materia local, foránea o "exótica", sin ahondar en este punto en los límites de definición entre una y otra categoría. Esta labor tendría un doble enfoque: por un lado analizar y caracterizar las materias existentes en un yacimiento; por otro, disponer de una muestra comparativa de los afloramientos de las materias que potencialmente pueden haber sido las fuentes de aprovisionamiento (lo ideal sería una litoteca). Estos dos tipos de datos (los materiales arqueológicos y las muestras de los afloramientos localizados) habrían de ser analizados a partir de los mismos criterios y métodos, con el fin de que fuera factible una comparación entre ambos. De esta manera se podría determinar de dónde proceden los tipos de rocas utilizadas.

Los problemas implicados en este planteamiento son múltiples, y los podríamos reducir esencialmente a dos:

a) Es muy difícil determinar las fuentes de materias primas potenciales existentes en épocas prehistóricas, tanto porque las condiciones de visibilidad y accesibilidad han variado con el tiempo, como porque pueden haber existido afloramientos que hayan desaparecido hoy en día o que no seamos capaces de identificar. En este aspecto han influido de manera notable los diferentes ciclos erosivos (ciclos $\mathrm{K}$ ) ocurridos a lo largo del Cuaternario.

b) Las características y apariencia de un tipo de materia prima dentro de una litología pueden variar dentro de un mismo afloramiento, a lo largo de sus distintos tramos; y esta circunstancia se acentúa si dicha materia se ve afectada por procesos estructurales de plegamiento o fracturación. De la misma manera, unos procesos semejantes pueden ocasionar materias de aspecto análogo en lugares distintos, por un fenómeno de convergencia.

El resultado de toda esta problemática es que resulta bastante complicado establecer el origen exacto de un tipo de materia concreta utilizada en un yacimiento arqueológico. Desde un punto de vista geológico lo que sí es posible es la determinación de una facies, formación o nivel geológico que pueden proporcionar potencialmente una materia análoga a la arqueológica. Por tanto, más que de puntos exactos de adquisición 
de la materia prima, se debería intentar especificar formaciones o unidades potenciales de explotación, en las que afloran los niveles geológicos que contienen la materia.

Para poder realizar una aproximación a las distintas materias susceptibles de ser explotadas en una zona en concreto, hay que tener en cuenta las características geográficas de dicho entorno, ya que su historia geológico-estructural condiciona las características y posibilidades de los afloramientos silíceos, es decir la potencialidad de recursos líticos. La Cordillera Cantábrica es una zona geográfica continua, pero con una diferencia geológica neta entre su mitad oriental (mesozoica y terciaria) y occidental (paleozoica, excepto la parte litoral y prelitoral del este de Asturias; ver Figura II.3), siendo esta última de una mayor complejidad geomorfológica (Marín Ramos et al., 1997: 457-458). Los depósitos secundarios y terciarios de la parte vasco-cantábrica, incluida por ejemplo la formación de la serie de Flysch (roca típica paleógena, que se puede seguir tanto en la zona vasca como su continuación por el golfo de Vizcaya hacia el litoral e interior francés [Marín Ramos, 1997: 447]), constituyen un marco potencial de formación de rocas silíceas que no existe en la Zona Cantábrica. Como ejemplo a efectos prácticos de esta diferencia podemos citar el sílex terciario de Treviño y de Urbasa, o el sílex de las calizas cretácicas del País Vasco (Tarriño, 2001) frente al chert/sílex de las calizas carboníferas (fracturado, plegado y elevado de nuevo por la orogenia alpina) de la Zona Cantábrica.

Como consecuencia de todos estos factores, fundamentalmente la ausencia de análisis mineralógicos y petrológicos y la complejidad geológica intrínseca de la Cordillera Cantábrica, tan solo se pretende realizar una descripción macroscópica de las materias existentes en el yacimiento, así como una revisión del contexto geológico en el que se ubica el yacimiento. De este modo, nos centraríamos en un acercamiento indirecto a las técnicas de aprovisionamiento, con la intención de señalar formaciones o unidades geológicas que sean susceptibles de contener posibles fuentes explotables, dentro de un territorio más o menos cercano. 


\section{III.2. POSIBILIDADES Y LÍMITES DE UN ANÁLISIS DE TÉCNICAS DE APROVISIONAMIENTO EN EL CONTEXTO DE LA ZONA CANTÁBRICA.}

El reconocimiento y caracterización de las rocas talladas se ha realizado tradicionalmente desde una perspectiva muy genérica, clasificando las materias de forma laxa y realizando grupos amplios como la cuarcita, el sílex, arenisca, etc. Esta es una práctica muy extendida de hecho en toda la Cordillera y a lo largo de los distintos periodos cronológicos analizados. Asimismo la caracterización como materia local o foránea también es muy frecuente y si bien no tiene por qué ser incorrecta, conlleva la limitación de que se trata habitualmente de una asignación intuitiva más que analítica ni contrastada por métodos objetivos.

Hay que hacer la salvedad de algún análisis petrológico como por ejemplo el realizado sobre el material de La Riera (Straus et al., 1986), pero lo más frecuente es una clasificación genérica y macroscópica de las rocas, faltando a veces incluso esta descripción preliminar.

Centrándonos en el estudio y análisis inmediato del material de nuestro yacimiento, podemos concretar en una serie de puntos los límites de tal caracterización:

- Se trata de una caracterización macroscópica y por tanto el factor subjetivo está siempre latente.

- Escasez de análisis y descripciones que permitan relacionar las materias de este yacimiento con otros. En este apartado hay que hacer la excepción del análisis petrográfico de La Riera (Straus et al., 1986), así como la descripción de ciertas rocas, en especial la radiolarita, materia que se reconoce con cierta facilidad. No obstante hay numerosas colecciones de las que ni siquiera disponemos de una descripción macroscópica genérica que nos sirva a modo de guía. 
Asimismo, los siguientes puntos pueden concretar la validez o posibilidades de dicho estudio:

- el contexto geológico alberga fuentes de materia prima potenciales, las cuales pueden haberse explotado

- localización de dos fuentes análogas a los tipos de rocas principales de El Espertín: chert/sílex negro y radiolarita.

- A efectos prácticos, nuestro objetivo se centra en los siguientes pasos:

- recopilar las referencias, dentro del entorno geológico, relativas a la presencia de rocas silíceas ${ }^{16}$

- descripción macroscópica del conjunto lítico

- $\quad$ ensayo de correlación entre las materias y el entorno

Lo ideal sería calificar las materias como “locales”, “foráneas” o “exóticas” y, además, matizar estas categorías a partir de criterios técnicos. Es decir poner en relación las materias que se localizan en el contexto geológico del yacimiento con el tipo de proceso técnico presente, para comprobar si se cumple la hipótesis de que a mayor cercanía del afloramiento de la materia, mayor representación de las distintas fases de la cadena operativa.

${ }^{16}$ Este aspecto se ha realizado, dentro del capítulo correspondiente al yacimiento de El Espertín (capítulo II, pp. 113-117), en el apartado II.3.2: "Recursos líticos silíceos potenciales en el entorno de El Espertín”. 


\section{III.3. CARACTERIZACIÓN MACROSCÓPICA DEL MATERIAL ARQUEOLÓGICO: METODOLOGÍA DESCRIPTIVA}

El método de descripción que emplearemos es una caracterización macroscópica de las rocas. Si bien este tipo de analítica tiene un componente muy alto de subjetividad, a falta de análisis microscópicos, petrológicos o geo-químicos intentaremos ofrecer los datos necesarios para la identificación correcta de las materias. Nos basaremos para ello en la propuesta descriptiva elaborada por J. Féblot-Agunstins ${ }^{17}$, teniendo en cuenta los siguientes atributos (ver esquema en Cuadro II.1):

En primer lugar para la descripción de la roca en sí misma:

$\gg$ Color: Caracterización genérica y referencia al código Cailleux (1948).

$>$ Trama: Respecto a la manera en que se presentan los colores, que puede ser uniforme cuando el color se presenta de forma homogénea, o no uniforme. En este último caso puede haber una disposición de los colores en bandeado, punteado, moteado, marmoriforme, etc.

$>$ Fábrica: Relativo a la existencia de partes de la roca en las que varíe la composición interna de la misma; por ejemplo puede haber zonas con menos composición en chert, o con un aspecto menos compacto, rotura más irregular, menos concoidea, etc. También pueden existir vacuolas, poros o grietas en la roca, las cuales pueden afectar en mayor o menor grado a las características técnicas de la roca. En este apartado también se hará referencia a la presencia de planos de diaclasa internos que dificulten la talla, irregularidades, etc. A partir de estas características la materia puede ser homogénea o heterogénea, y este atributo puede tomarse relativo a un solo bloque de materia o respecto al conjunto de nódulos tallados de un tipo de roca.

$\triangleright$ Apariencia (externa de la roca): respecto al brillo: mate, brillante, y con distintos grados o características de dicho brillo: semibrillante, con brillo graso, vitroso, 
metálico, etc. Por otra parte también se hará referencia a la transparencia de la materia: opaco o translúcido, normalmente este atributo se observa relativo a la transparencia en el filo, y se señalará convenientemente si dicha transparencia se extiende hacia la parte más interna de una lasca o bloque.

Tamaño del grano: es un atributo estimativo al que le otorgaremos un valor relativo: fino, medio, grueso.

En segundo lugar hay que describir también el córtex o superficie externa de la materia prima:

$\triangleright$ Fábrica: fresco (con aspecto "tizoso" o rugoso por ejemplo), rodado (superficie alisada, suave al tacto), aluvial.

$\triangleright$ Espesor: fino (menor $1 \mathrm{~mm}$ ), medio (2-3 mm), grueso (mayor $4 \mathrm{~mm}$ ).

A partir de las características del córtex y de los bloques de cada materia prima se puede intentar hacer también una aproximación a la morfología de los nódulos originales llevados al yacimiento.

Por último se puede realizar una estimación subjetiva (con un valor por tanto relativo y no concluyente) respecto a la calidad para la talla desde un punto de vista técnico a partir de las características descritas de la roca, sobre todo el tamaño de grano, el aspecto de la materia, el tipo de fractura, la presencia de irregularidades, etc.

Los principales tipos de materias primas talladas en El Espertín son las rocas silíceas, en sus distintas variantes, seguida por la cuarcita. Dentro de las primeras, la materia preferida es el chert negro, con presencia de una gran gama de variantes, heterogénea respecto a su calidad. Después estaría la radiolarita, con dos tipos: la radiolarita roja-granate y la verde. A continuación estaría el sílex gris y por último los que hemos denominado como sílex "varios" que se trata de un conjunto de distintas materias que aparecen en un número muy reducido de elementos dentro de cada tipo de

17 Agradezco a la profesora J. Féblot-Agustins su amabilidad al atender nuestras dudas y cuestiones y sobre todo el habernos proporcionado y explicado esta guía de análisis macroscópico de las materias primas. 
roca. Entre ellos destacan un conjunto de sílex afectados por desilificación, el que hemos denominado como sílex vario 1, 2 y 3. Por último estaría la cuarcita y el cuarzo.

\section{DESCRIPCIÓN MACROSCÓPICA DE LAS MATERIAS PRIMAS}

Descripción de la roca en sí misma:

$\triangleright$ Color

$\triangleright$ Trama:

- uniforme color de forma homogénea

- no uniforme: bandeado, punteado, moteado, marmoriforme, etc.

$\triangleright$ Fábrica (respecto a un bloque o a un afloramiento):

- Homogénea

- Heterogénea: aspecto más o menos compacto, rotura más o menos irregular, menos concoidea, etc.; presencia de vacuolas, poros o grietas en la roca, planos de diaclasado interno en los bloques que dificulten la talla, irregularidades, etc.

Apariencia:

- brillo: mate, brillante; y con distintos grados y matices: semibrillante, con brillo graso, vitroso, metálico, etc.

- transparencia: opaco o translúcido

$\triangleright$ Tamaño del grano: fino, medio, grueso.

El córtex o superficie externa de la materia prima:

$\triangleright$ Aspecto: fresco (con aspecto “tizoso” por ejemplo), rodado (superficie alisada, suave al tacto), aluvial.

Espesor: fino (menor $1 \mathrm{~mm})$, medio (2-3 mm), grueso (mayor 4mm).

Cuadro III.1: plantilla para la descripción macroscópica de las materias primas. A partir de esquema proporcionado por J. Féblot-Agustins. 


\section{III.4. DESCRIPCIÓN DEL GRUPO LITOLÓGICO DE LA FAMILIA DE LOS SÍLEX}

En un primer momento se adoptó una perspectiva muy amplia del término sílex, de modo que a partir de una identificación macroscópica de las rocas que conforman la industria lítica del yacimiento se han ido haciendo grupos de materias con características similares, grupos que posteriormente se han reunido en categorías más amplias, al comprobar cómo las primeras separaciones se debían a diferencias que pueden encajar en la variabilidad propia de un mismo tipo de roca. Esta dificultad, ocasionada por la heterogeneidad del aspecto de la materia, ha sido más acusada en el que hemos denominado como "sílex/chert negro". Una vez solventada esta traba, se ha agrupado el grupo de los sílex presentes en El Espertín en cuatro conjuntos: el sílex/chert negro, la radiolarita (con dos subconjuntos: roja y verde), el sílex gris y los sílex "varios". Todos ellos serán descritos a partir de la plantilla propuesta en el Cuadro III.1, y al final del capítulo, algunos de los atributos observados se esquematizan en el Cuadro III.2.

\section{III.4.1. EL GRUPO DEL SÍLEX NEGRO}

Dentro de este amplio grupo hemos incluido el mayor conjunto de rocas de este yacimiento. Como se ha indicado, en una primera aproximación a las materias presentes en el yacimiento se realizó una clasificación de este grupo en tres subconjuntos de sílex: el sílex negro, el sílex negro-marrón y el sílex gris-negro (a su vez con dos variantes: 1 y 2). A ellos habría que añadir un sílex negro brillante, que probablemente se diferencie del resto del chert negro, pero que a efectos prácticos lo hemos incluido en el amplio grupo del sílex negro. Los tres primeros en cambio sí parecen responder a una gama muy heterogénea de una misma roca. Sucede de hecho que, por ejemplo, el sílex negro (genérico) parece diferente al sílex gris-negro-1, pero éste, se acerca al sílex negromarrón, cuyas características en cambio convergen con las del "sílex negro genérico”. El resultado es que hay pasos intermedios entre las distintas variantes de lo que parece una misma roca y al comprobar esta relación indirecta entre los distintos subconjuntos se ha decidido englobarlos bajo un mismo grupo. De hecho todas estas variantes se 
relacionan entre sí de modo que las características macroscópicas del sílex negro se solapan con las del sílex negro-marrón, y éste a su vez tiene una gama de variación que lo acerca a las distintas variantes del sílex gris-negro. Creemos por tanto factible que tales grupos iniciales responden a una variación de una misma materia, muy típica por otro lado en la formación de los sílex. Se van a presentar no obstante las características detalladas de cada uno de los subtipos de sílex negro que se diferenciaron en un primer momento; de este modo quedaría descrita esta materia en las distintas variantes que aparecen en el yacimiento.

\section{SíLEX/CHERT NEGRO (GENÉRICO) (SN)}

El que hemos calificado como sílex negro parece corresponder a lo que en la bibliografía litológica se denomina como chert $^{18}$, en nuestro caso de color negro mate que constituye la materia prima más abundante del yacimiento. Sus características macroscópicas son las siguientes:

$>$ Color: negro o gris oscuro (dominando el T31, a veces T73, y S31 en zonas más claras).

$>$ Trama: uniforme, excepto por la presencia de un punteado rojo-anaranjado, presente con mayor o menor intensidad en todos los bloques. Con una lupa de 8 aumentos se observa que estos puntitos son en realidad poros huecos existentes en la materia, teñidos de ese rojo-anaranjado como consecuencia de una alteración.

$>$ Fábrica: varía mucho dependiendo de los bloques. En todos se observan abundantes planos de rotura y diaclasado naturales, visibles en forma de líneas en la superficie de la materia o bien desarrollándose a lo largo de planos irregulares, quizás de apariencia esquistosa o rugosa, los cuales se ven afectados a veces por distintas alteraciones que les da unos tonos rojos o anaranjados.

${ }^{18}$ En los mapas geológicos consultados de la zona aparece la denominación de "chert” para este tipo de materia; por esta razón, se utilizará este término como sinónimo del genérico "sílex", utilizado normalmente en Prehistoria. Por tanto sílex negro y chert negro se emplearán indistintamente en este trabajo, como sinónimos. 
La composición de los bloques de chert negro varía mucho, hay bloques con un aspecto muy homogéneo, los cuales tienen el córtex muy fino, que es prácticamente continuidad de la materia interna. Por el contrario hay otros nódulos más heterogéneos, con el córtex más rugoso y poco compacto respecto al chert interno, con aspecto esquistoso o irregular y, frecuentemente es más grueso que en el caso anterior, es como si el bloque perdiera la composición en chert conforme nos acercamos a la superficie externa. Hay también una serie muy amplia de bloques de chert negro que tienen una estructura interna y un córtex de apariencia esquistosa y de rotura astillosa, no demasiado concoidea.

$\triangleright$ Apariencia: semi-brillante y opaca.

$\gg$ Grano: fino.

$\gg$ Córtex: hay variedad en las características del córtex, del mismo modo que en las características internas del chert, existiendo tanto córtex rodado como fresco. Hay un grupo muy amplio de nódulos que tienen un córtex liso y rodado, a veces del mismo color que la materia interna y más frecuentemente con tonalidades tendentes a negro-azulado o blanquecino (N31), con una apariencia frecuentemente brillante y a veces más mate. En algunos ejemplos tiene un grosor fino, llegando en algunos casos a parecer una película muy delgada, perfectamente delimitada con el interior, del mismo color que el chert y con brillo graso. En otros bloques el córtex es más grueso, y la delimitación con el interior no tan clara, con unos tonos tendentes a pardos. En este último caso el córtex y la parte interna inmediatamente adyacente a él, tiene una estructura menos compacta, con fractura más astillosa e irregular. Ya hemos indicado en el apartado anterior que se trata de nódulos de composición heterogénea, y el córtex parece seguir los planos de fractura natural o superficies de diaclasado interno de la roca, lo cual ocasiona que tales bloques tengan una morfología de tendencia prismática.

Pero por otro lado hay también otros nódulos con córtex de aspecto “fresco", es decir, es una superficie que no está rodada, de grosor medio, con una estructura menos compacta que el chert interno, rotura irregular y color rojo o amarillento. 
Respecto a la morfología de la materia prima, hay por una parte nódulos con una forma subredondeada que recuerdan a cantos fluviales (por ejemplo el núcleo ESP97/D8/S11/N3b/B2.5). Por otra parte son mucho más abundantes los bloques de morfología prismática, delimitados por superficies corticales planas, que parecen seguir superficies de rotura natural de la roca, con abundantes aristas naturales más o menos redondeadas. La abundante presencia de planos de diaclasado interno y superficies de rotura natural en el interior de este tipo de roca, plantea la posibilidad de que muchos de los nódulos a los que tuvieran acceso los grupos prehistóricos, estuvieran conformados a partir de estas delimitaciones estructurales de la roca, dando lugar a bloques más o menos prismáticos y a bloques tipo placa o plaqueta más o menos estrechos. A veces es complicado diferenciar si una superficie natural en el exterior de un núcleo es original o como consecuencia de la talla, normalmente se diferencia por la presencia del rodamiento. Por último los nódulos con córtex “fresco” parecen tener morfologías arriñonadas.

El aspecto del córtex, así como la forma en que aparecen los bloques, está relacionado y determinado, lógicamente, por el lugar de formación y de adquisición de los nódulos de chert. Aunque como hemos visto hay una cierta variabilidad en la forma en que se presenta el córtex en los distintos bloques, en muchos casos se trata de una superficie rodada (aspecto alisado, el cual puede haber sido ocasionado por distintos grados de rodamiento) y con presencia de aristas y planos de diaclasado naturales.

Teniendo en cuenta estas características, lo que podemos decir respecto al origen del chert negro, a modo de hipótesis, es que pueden plantearse varios lugares de adquisición de dicho chert.

$\triangleright$ El chert con el córtex de morfología subesférica podría proceder de un origen aluvial, quizás del río que corre al lado de la cueva, pero no parece en todo caso que haya sido sometido a un proceso de transporte demasiado acusado, al menos así lo permite suponer la apariencia del propio córtex.

$\triangleright$ Los nódulos de chert de forma prismática y aristas más o menos redondeadas, pueden vincularse a las condiciones naturales de su afloramiento, quizás en bancos delimitados por grandes planos de diaclasado o bien en forma de riñones encajados 
en una roca madre que les conforma esa morfología. A este respecto, hay que recordar que los bloques de chert de composición más heterogénea, tienen una estructura interna característica, con un aspecto mucho menos compacto conforme nos acercamos a la corteza. Este fenómeno lo hemos constatado en algún afloramiento de chert negro en riñones dentro de la roca caliza.

$\gg$ Los nódulos arriñonados, con córtex "fresco" han de proceder de un yacimiento en posición primaria, sin que podamos precisar más a este respecto.

Calidad para la talla: depende de los nódulos, al ser el chert negro un conjunto heterogéneo respecto a la formación silícea interna de cada bloque y sobre todo también de la presencia más o menos intensa de las superficies irregulares internas. La calidad varía de aceptable en los bloques homogéneos a regular-mala en los heterogéneos.

Origen del chert negro: la fuente concreta es desconocida, pero vamos a retener algunas características que quizás nos pueden acercar esta roca a aquellas localizadas en el contexto geológico de la zona.

$\triangleright$ La gran abundancia de planos de rotura y de diaclasado internos, lo cual puede apuntar a que la roca tenga un origen geológico de edad antigua (paleozoico) que explicaría la abundancia de procesos de fractura, a la que se ha visto sometido.

$\triangleright$ La abundancia de sílex negro en el yacimiento permite establecer la hipótesis de que se trata de una roca que puede encontrarse en un entorno no demasiado alejado de la cueva.

\section{SÍLEX NEGRO-MARRÓN (SN-M)}

El que hemos denominado sílex negro-marrón es un chert con muchos planos de rotura natural que dificultan la talla y unos colores tendentes a marrón-grisáceo. Pensamos que puede pertenecer a la gama de variación normal de una roca, con nódulos de distinta calidad y homogeneidad interna, tal y como apuntábamos en el apartado anterior. 
$\gg$ Color: negro o gris oscuro-marrón (P31 normalmente, a veces P73 y cuando es más oscuro R31 ó S73).

$\triangleright$ Trama: predomina un bandeado fino horizontal (de líneas de un grosor en torno a 0,6 mm) alternando tonos grises con los marrones. En otras zonas esta estructura lineal se pierde, quedando una trama marrón-grisácea con un veteado blanco. Aparece también el punteado rojizo que corresponde a poros dentro de la roca teñidos por una alteración, como en el chert negro anterior.

$\triangleright$ Fábrica: un tanto heterogénea porque está afectado por multitud de planos de rotura natural, con superficies muy rugosas e irregulares, tomando frecuentemente un tono rojizo como consecuencia de alteraciones.

$\triangleright$ Apariencia: mate/semibrillante y opaco

$\triangleright$ Grano: fino

$\triangleright$ Córtex: parece que la superficie externa de los nódulos corresponde a planos de rotura natural de la roca, con morfología más o menos prismática con las arista redondeadas, aunque otras veces se presenta en forma de cantos ovalados similares a los fluviales. Es un córtex muy fino respecto a su grosor, con aspecto rodado (superficie alisada)y una delimitación neta con el interior de la roca.

$>$ Calidad para la talla: regular debido a la heterogeneidad de los bloques, con los abundantes planos de rotura, con una fractura exfoliante que dificulta la ejecución de la talla intencional.

Este tipo de roca silícea parece corresponder, como ya hemos indicado, al grupo del chert negro anterior, el dominante en el conjunto lítico. La apariencia, el córtex, y sobre todo la presencia de los poros en la superficie, que se observan como puntitos rojos, son características comunes y significativas en ambos tipos de rocas. Tan sólo el color y la trama interna de éste son lo que diferencia aparentemente a esta materia de la anterior. En consecuencia este "sílex negro-marrón" sería a lo sumo una variante de calidad mediocre dentro de la gama de nódulos que puede ofrecer el chert negro. 


\section{SíLEX GRIS-NEGRO (SG-N)}

$\triangleright$ Color: gris oscuro-negro (R73), con zonas que tienden a veces a un gris más claro.

$\triangleright$ Trama: uniforme aunque a veces hay un bandeado en líneas finas de tonos grises más o menos oscuros. También hay un punteado negro de puntos muy pequeños y dispersos y la presencia del punteado naranja que corresponde a pequeños poros rellenos de alteración, como ya se ha visto para otros tipos de rocas.

$\triangleright$ Fábrica: homogéneo excepto por la presencia de abundantes planos de diaclasa los cuales a veces tienen una superficie rugosa.

Apariencia: brillo graso y translúcido en filo.

$\triangleright$ Grano: fino.

$\triangleright$ Córtex: color marrón, aspecto fresco, espesor fino (0,5 mm aproximadamente) y delimitación neta.

$\triangleright$ Morfología de los nódulos:

$\triangleright$ Calidad para la talla: buena

\section{SÍLEX GRIS-NEGRO 1 (SG-N.1)}

$\triangleright$ Color: Gris con distintas tonalidades oscuras tendente a negro (S31, T31)

$\triangleright$ Trama: No uniforme con un color gris oscuro variando en sus tonos por zonas, y también hay un bandeado horizontal.

$\triangleright$ Fábrica: Homogéneo excepto por la presencia de planos de diaclasas que tienen frecuentemente un color anaranjado, como afectados por una oxidación.

Apariencia: brillo graso y translúcido en filo.

$>$ Grano: fino 
$>$ Córtex: aspecto rodado con apariencia esquistosa, de espesor fino (en torno a 0,5 mm.) y delimitación neta.

$>$ Morfología de los nódulos:

$>$ Calidad para la talla: buena excepto por las diaclasas.

\section{SíLEX GRIS-NEGRO 2 (SG-N.2)}

$>$ Color: gris-azulado tendente bien a negro o bien a tonos más claros (S31 cuando es gris oscuro, R73 cuando es gris más claro).

$>$ Trama: No uniforme, variando el color por zonas entre gris más oscuro o claro tendente incluso a veces a blanquecino; a veces estos tonos más claros hacen un veteado. En otras piezas se aprecia un bandeado en líneas finas horizontales.

$>$ Fábrica: Heterogéneo en cuanto a la caracterización de los mismos bloques, con partes con un aspecto no tan compacto, más rugoso y de fractura no tan concoidea sino más irregular. Es como si la composición en chert no fuera igual en todas las zonas, esta apariencia menos homogénea se produce sobre todo cerca del córtex. Hay también abundantes planos de rotura internos de color naranja-rojizo de brillo metálico. Con la lupa de ocho aumentos se aprecia un punteado oscuro así como el punteado anarajado correspondiente a porosidades que vemos repetirse en otras rocas. Estos poros a veces son mayores, conformando grietas en las piezas.

$>$ Apariencia: varía por piezas y bloques de mate a semibrillante de brillo metálico.

$>$ Grano: fino

$>$ Córtex: Se aprecian dos tipos de córtex, el primero sería un córtex fresco, irregular, de aspecto mate y rugoso y cuyo espesor varía de fino a medio. En dos bloques se observa como son nódulos de aspecto arriñonado. En segundo lugar hay un córtex rodado, de espesor mucho más fino, parece que sigue planos de rotura natural de los bloques y con un aspecto igual al interior de la roca pero más brillante. 
$\triangleright$ Morfología de los nódulos: una parte de los nódulos de este tipo de roca serían arriñonados de morfologías ovaladas aunque variarían.

$\triangleright$ Calidad para la talla: media-mala

Todos estas variantes silíceas que hemos descrito hasta ahora (sílex negro, sílex gris-negro, sílex negro-marrón) parecen corresponder a una misma variedad de roca: el chert negro. A este respecto hay que decir que hemos localizado un afloramiento chert negro, en el cual se ha podido constatar la gran heterogeneidad que presenta esta materia dentro del mismo lugar de aprovisionamiento. En dicho lugar hay rocas que nos recuerdan tanto el sílex negro como el sílex negro-marrón y el sílex gris-negro.

No obstante hay una parte del sílex negro, el que tiene una composición y un córtex de rotura más astillosa y aspecto más esquistoso, del que no hay equivalente en el afloramiento localizado. Se plantea entonces la posibilidad de que dicha variante corresponda a un lugar de captación local, quizás entre los afloramientos de lutitaspizarrosas.

\section{SíLEX NEGRO BRILLANTE (SNB)}

$\triangleright$ Color: Marrón oscuro (S51) a gris oscuro o casi negro (T31).

$\triangleright$ Trama: No uniforme variando los tonos más oscuros y más claros por zonas a modo de grandes masas que se entrelazan sin trama fija. En algunas piezas se aprecian tonos más pardos.

$>$ Fábrica: Heterogéneo con la presencia de zonas no demasiado compactas en algunos bloques, con un aspecto más mate, irregular y de fractura no tan concoidea. Hay también abundantes planos de rotura y diaclasas de pequeño tamaño. Se aprecia por último un punteado anaranjado de puntos muy pequeños y no demasiado abundantes, que corresponden a porosidades en la materia.

$\triangleright$ Apariencia: Brillo vítreo genérico y hay que señalar también la presencia de unos puntos de brillo metálico. Es una roca translúcida en filo. No obstante algunas piezas son mates. 
$\triangleright$ Grano: medio, más grueso que en el resto de las rocas.

$\triangleright$ Córtex: Fresco con aspecto arriñodado irregular y mate, con un espesor que varía de fino a medio, delimitación difusa y de color rojizo.

$\gg$ Morfología de los nódulos: arriñonada, ovalar a irregular.

$\triangleright$ Calidad para la talla: buena.

\section{III.4.2.- EL GRUPO DE LAS RADIOLARITAS}

La radiolarita o sílex de radiolarios es una roca bastante común en El Espertín y también en otros yacimientos asturianos de la vertiente norte. En el apartado sobre el entorno geológico de El Espertín se han descrito ya su origen geológico y la formación a la que está vinculada esta roca de origen orgánico. Hay dos variedades, la primera es la más común, de color rojo-granate; la segunda es menos frecuente y es de tono verdoso. A la primera la hemos denominado "radiolarita-1" o simplemente “radiolarita”; a la segunda, “radiolarita-2”, aunque a veces también puede aparecer como "radiolarita-B".

\section{RADIOLARITA 1 (R, R1)}

> Color: rojo-granate-marrón (T30 sería el más común, así como S30; los bloques más oscuros serían T51, y otros más claros P30)

$\triangleright$ Trama: hay normalmente un punteado por toda la superficie en forma de puntitos transparentes y otros puntos anaranjados. El punteado anaranjado es bastante intenso en algunas zonas, siendo en ocasiones los puntos de un cierto tamaño (de 0.2 a 0.5 $\mathrm{mm}$.). Hay bloques en los que se aprecia un bandeado horizontal muy fino (por ejemplo en el núcleo ESP94/F9/S13/n²49) con líneas más oscuras sobre el fondo granate-marrón. En otros bloques el bandeado no es horizontal, sino que las líneas dibujan ondas amplias. Hay también a veces un veteado negro o grisáceo (P92) a modo de una inclusión dentro de la roca, que en ocasiones se convierte en una banda irregular. 
Fábrica: heterogéneo debido sobre todo a las abundantes diaclasas, las cuales se desarrollan en forma de planos mates con una superficie rugosa o esquistosa. A veces estos planos se engrosan a lo largo de algunos milímetros, proporcionando una zona heterogénea y que dificulta la talla.

$\gg$ Apariencia: mate y opaca.

$>$ Grano: fino

$>$ Córtex: la superficie externa de los bloques parece estar conformada por los planos de sedimentación natural de la roca y por planos de diaclasado. El córtex entonces es similar al interior de la roca pero con una estructura menos compacta, apariencia más mate, rodada (muy alisada y suave al tacto), de grosor fino y rotura exfoliante. En algunos bloques esta superficie externa se introduce ligeramente hacia el interior, sin que exista una diferencia neta entre el córtex y la radiolarita interna.

$>$ Morfología de los nódulos: a partir de los restos de córtex en algunos núcleos y fragmentos se puede constatar que los bloques tendrían un volumen en paralelepípedo, con forma quizás a veces prismática delimitada a partir de aristas bastante agudas. Dichas aristas, que corresponden a la unión entre los planos de sedimentación y las superficies de diaclasado, van a ser muy útiles a la hora de iniciar la talla.

$>$ Calidad para la talla: regular-aceptable, aunque la presencia de los abundantes planos de rotura dificulta la ejecución de la talla, determinando en gran medida la instalación volumétrica de los núcleos, empleando frecuentemente los planos de rotura natural como plano de percusión.

Respecto al origen de la radiolarita, contamos con la existencia de referencias a presencia de radiolaritas dentro de la caliza de edad Griotte, cerca de la ubicación de El Espertín. Si bien no sabemos si la radiolarita presente en nuestro yacimiento procede "efectivamente" de este entorno, parece bastante probable que así sea. En el mapa geológico (Heredia et al., 1991) hay dos bandas principales en que aparece la serie Griotte, se encuentran a unos $10 \mathrm{~km}$. aproximadamente de El Espertín. Por tanto 
podemos plantear como hipótesis que la radiolarita proceda de esta zona, que sería "autóctona" dentro de una zona de captación más amplia que el entorno inmediato.

\section{RADIOLARITA 2 O RADIOLARITA TIPO-B (R2, R-B)}

La materia que en un principio denominamos como sílex gris-radiolarita, por su cercanía aparente a la radiolarita, se trata efectivamente de otra variedad de radiolarita de color verde aceituna-grisácea, con una gran gama de variantes en cuanto a su color y trama. De hecho en principio intentamos una clasificación separando estas variantes internas, pero tal separación respondería casi a la heterogeneidad típica entre bloques dentro un mismo tipo de roca.

$\triangleright$ Color: La radiolarita B es una roca que abarca una amplia gama de tonos o variantes, que dependen al parecer de los distintos bloques. El color predominante, presente en casi todas las variantes es un tono gris-verde aceituna (R92 el más habitual, siendo S92 o T92 en las zonas más oscuras). Otros bloques presentan un color más tendente a marrón, acercándose a la radiolarita roja (S51, P71 y P51). Por último en otras piezas se aprecia un bandeado en el que alternan colores grises más oscuros (N71, P71, R92) y claros (M91).

$\triangleright$ Trama: Es heterogénea variando tanto de unos bloques a otros como dentro de las mismas piezas. Hay algunos bloques que son más homogéneos pero existe normalmente un bandeado horizontal formado por líneas de distinto grosor en tonos grises o marrones oscuros y otras bandas más claras. En algunos bloques se puede apreciar que estas bandas más claras tienen una composición un tanto "polvorienta", a base de una especie de arenillas de trama más compacta en unas zonas y más disgregada en otras. A veces esta trama de color claro se extiende por la mayor parte del bloque, siendo entonces predominante. Además del bandeado aparece también un punteado negro, con puntos de pequeño tamaño y un punteado más importante en forma de punteado-moteado de color naranja-amarillento, el cual está presente en casi todas los ejemplares de esta roca, variando tanto en el tamaño de los puntos como en la intensidad con que aparecen. Por último se pueden observar a veces un 
veteado negro (o grisáceo más claro en ejemplares con predominio de tonos claros) de brillo vitroso en forma de líneas quebradas irregulares.

$\triangleright$ Fábrica: heterogénea debido a los abundantes planos de rotura natural que se cortan entre sí, observándose frecuentemente líneas de diaclasas discontinuas a modo de pequeñas fallas internas. Hay también vacuolas irregulares tanto en morfología como en tamaño a lo largo de algunas piezas de esta roca, son como poros huecos que en esta roca (a diferencia del sílex negro) no se han rellenado por ninguna alteración. A veces estos poros se desarrollan de modo más amplio en forma de grietas huecas.

$\triangleright$ Apariencia: mate y opaca tanto en el interior como en los bordes.

$\triangleright$ Grano: Fino

$\triangleright$ Córtex: la superficie externa de los bloques de este tipo de radiolarita responde posiblemente de nuevo a la superficie de sedimentación y a planos naturales que delimitan la fracturación de la roca. Se trata de una superficie rugosa y poco compacta, frecuentemente de un color más claro que el interior, mate, con rotura esquistosa y apariencia irregular. Su espesor suele ser fino, aunque en ocasiones la zona cortical se extiende hacia el interior del bloque, sin que exista una delimitación neta entre el córtex y el interior de la roca.

$\triangleright$ Morfología de los nódulos: parece que los bloques estarían delimitados por planos de sedimentación de la roca o bien por zonas diaclasadas en la roca madre, los cuales delimitarían la compartimentación de los distintos bloques en el lugar de formación. Se pueden observar en algunos ejemplos estos planos y la intersección perpendicular entre ellos, en forma de prismas o paralelepípedos. Se observará también el aprovechamiento de estas aristas naturales para la talla.

$\triangleright$ Calidad para la talla: regular-aceptable.

En cuanto al origen sería el mismo que la radiolarita anterior ya que hemos podido comprobar cómo en su lugar de formación geológica la radiolarita tiene tonalidades cercanas a esta variante. Las diferencias de color de las radiolaritas (rojas y 
verdes) presentes en los afloramientos de esta zona se deben al estado de oxidación del hierro $\left(\mathrm{Fe}^{+3}\right.$ y Fe ${ }^{+2}$ ) presente en la composición de los minerales arcillosos de esta roca.

\section{III.4.3.- EL SÍLEX GRIS (SG)}

El que hemos denominado sílex gris es una roca silícea con las siguientes características:

$\triangleright$ Color: gris-verdoso (R73) o gris-azulado (R31), a veces con tonalidades tendentes a verde aceituna (P91).

$\triangleright$ Trama: fondo gris con bandas muy finas (en torno al milímetro como máximo) o más bien líneas de distinto grosor, dispuestas horizontalmente. Estas bandas y líneas varían en su coloración, desde un gris más claro, tendente a amarillento, hasta negro. Hay también a veces zonas con puntitos de pequeño tamaño, dispersos, de color negro o rojo.

$\triangleright$ Fábrica: Sílex homogéneo pero abundan los planos de rotura natural en la roca. Dichos planos tienen una superficie mate, a veces afectada por alteraciones lo que les da una coloración anaranjada o rojiza y un aspecto más irregular. En ocasiones los planos se extienden a lo largo de algunos milímetros, constituyendo bandas más gruesas en ciertas zonas del sílex.

$\gg$ Apariencia: semibrillante y translúcido en los bordes.

$\gg$ Granulometría: Fina.

En este tipo de roca no tenemos ejemplares con córtex, además al no saber el lugar de origen de esta materia no podemos saber cuál es la forma en que se presenta el sílex gris. Puede que incluso la morfología con la que aparece esta roca externamente esté delimitada por los planos de rotura que afectan a la roca. A este respecto, desde un punto de vista técnico veremos cómo en los núcleos se van a aprovechar estos planos bien como planos de percusión, o bien en la conformación global del núcleo. 
Estos planos de rotura son planos de diaclasa de la roca, observables a lo largo del sílex como líneas de color rojizo. Como ya hemos indicado pueden verse afectados en distinto grado por alteraciones que les van a dar una coloración rojiza o amarillenta, una apariencia heterogénea y mate, con morfología rugosa en ocasiones, y una fractura irregular.

Respecto a la calidad para la talla, podemos calificarla de buena, en virtud de la composición del sílex, con el grano muy fino y homogéneo, con fractura concoidea en la que se pueden ver perfectamente los estigmas diagnósticos de la talla intencional, con las ondas de percusión muy marcadas. El único problema para la talla del sílex gris es la presencia de esos abundantes planos de rotura.

Origen: No sabemos las fuentes de aprovisionamiento de este tipo de sílex pero parece que pueden existir fuentes de este tipo de roca en la zona Cantábrica, al menos en la cabecera del río Esla, ya que hemos constatado la presencia de cantos rodados de este tipo de roca en las terrazas de este río, en la comarca de los Oteros. Por tanto de confirmarse esta vinculación, se trataría de una roca más o menos "local".

\section{III.4.4.- LOS SÍLEX VARIOS}

\section{SÍLEX DESILIFICADO (SDS)}

Es un sílex afectado por esta alteración de forma muy intensa, de modo que no podemos saber cómo era el sílex en su origen. Esta alteración ha vuelto el sílex totalmente blanco e incluso en algunas zonas presenta un aspecto poroso y tizoso.

$\triangleright$ Color: blanco (K31, K51), como consecuencia de la alteración, aunque en algunas piezas se observa un núcleo de la roca de un tono gris claro-azulado.

$\triangleright$ Trama: Uniforme excepto en algunas piezas en que hay un punteado de pequeños puntos. Hay 5-6 lascas en las que este punteado es más grande en intenso constituyendo quizás piezas de otro bloque. 
$\gg$ Fábrica: Homogéneo excepto por los planos de rotura natural que tienen un color rojizo en las piezas con el punteado negro, así como por los distintos grados de deshidratación.

$\triangleright$ Apariencia: mate predominante, hay un par de piezas con un brillo graso. Opaco.

$\triangleright$ Grano: muy fino

$\triangleright$ Córtex: el córtex aparece solo en las piezas que son las excepcionales dentro del conjunto de esta roca, por lo que no podemos extraer características concluyentes, máxime cuando hay dos tipos de córtex totalmente distintos. En primer lugar hay dos piezas corticales en las rocas con punteado negro, el córtex tienen un aspecto fresco, "tizoso" e irregular, con un grosor medio y una delimitación difusa. Hay también una hoja de sílex deshidratado de brillo graso con córtex rodado (superficie alisada), espesor fino y delimitación neta.

$\triangleright$ Morfología de los nódulos: indeterminada

$\triangleright$ Calidad para la talla: buena

\section{SíLEX VARIO 1 (SV.1)}

$\triangleright$ Color y trama: Se trata de un sílex de muy buena calidad de color amarillento (M90), con una trama en bandas circulares de tono gris claro (M92) delimitadas por líneas rojizas (N11). Hay también un moteado blanco.

$\gg$ Fábrica: Homogéneo

$\triangleright$ Apariencia: semibrillante y translúcido en filo

$\triangleright$ Grano: muy fino

$\triangleright$ Córtex: sólo hay una lasca cortical (ESP93/F8/S8/nº41). Se trata de un córtex de aspecto fresco, "tizoso", de espesor medio y delimitación difusa

$\triangleright$ Morfología de los nódulos: quizás arriñonada, pero no lo podemos saber. 
$\gg$ Alteración: deshidratación débil.

$\triangleright$ Calidad para la talla: muy buena

\section{SÍLEX VARIO 2 (SV.2)}

Sílex de muy buena calidad, similar al anterior.

$>$ Color y trama: disposición en bandas amplias, sin llegar a la delineación circular como el anterior, más bien hay una disposición en amplias zonas de color marrónrojizo (P30) y gris rosáceo (M51). Hay también un moteado de color oscuro.

$\gg$ Fábrica: Homogéneo

$\triangleright$ Apariencia: Semibrillante y opaca en filos.

$\triangleright$ Grano: muy fino

$\triangleright$ Córtex: aspecto fresco, de textura arenosa y color claro (M53=gris-rosa), con un espesor medio (casi $3 \mathrm{~mm}$ en alguna pieza) y una delimitación difusa.

$\triangleright$ Morfología de los nódulos: indeterminada, pero quizás arriñonada.

$\triangleright$ Calidad para la talla: muy buena

\section{SÍLEX VARIO 2B (SV.2B)}

Es un sílex de muy buena calidad que está presente en un número muy pequeño de ejemplares, siendo casi todos hojitas de dorso. Sus características macroscópicas son bastantes cercanas tanto al sílex vario1 como al sílex vario2.

$\triangleright$ Color y trama: trama en líneas horizontales de color gris claro (L31) o rosáceo (L30) y gris más oscuro (N71)

Fábrica: Homogénea excepto por la presencia de líneas de planos de fractura que presentan una alteración anaranjada. 
$\triangleright$ Apariencia: Semibrillante-mate, translúcido en filo

$\triangleright$ Grano: muy fino

$\triangleright$ Córtex: ausente

$\triangleright$ Calidad para la talla: muy buena

\section{SÍLEX VARIO 3 (SV.3)}

$\gg$ Color: gris claro (P31), transparente

$>$ Trama: Uniforme, excepto en alguna zona (sólo en una lasca: ESP92/E6/S14/N2/B2) que hay un punteado naranja que en realidad corresponde a poros rellenos de una alteración.

$\triangleright$ Fábrica: Homogéneo excepto por la existencia de algunas superficies de rotura natural que se manifiestan en líneas finas o planos de apariencia mate y rugosa con un tono anaranjado, por lo que parece que están afectados por la misma alteración que los pequeños poros que comentamos en el apartado anterior.

$\triangleright$ Apariencia: Brillante, grasa y translúcido no solo en los bordes sino más al interior del bloque

$\triangleright$ Grano: muy fino

$\triangleright$ Córtex: no hay

$\gg$ Morfología de los nódulos: indeterminada

$\gg$ Calidad para la talla: muy buena 


\section{SÍLEX VARIO 4 (SV.4)}

Hay muy pocas piezas, en esta variedad, destacando una punta de dorso entre ellas.

$\gg$ Color: Beige. Alteración blanca de la deshidratación.

$\triangleright$ Trama: homogéneo

$\gg$ Fábrica: uniforme

$\triangleright$ Apariencia: semibrillante. Transparente en filo e interior.

$>$ Grano: fino

$\gg$ Córtex: no hay

$\triangleright$ Morfología de los nódulos: no sabemos

$\triangleright$ Calidad para la talla: muy buena porque no tiene diaclasado interno, etc.,

\section{SíLEX VARIO 5 (SV.5)}

Es una variedad que cuenta con muy pocos ejemplares, y que recuerda al sílex vario 3.

$\triangleright$ Color: gris rosáceo (domina el N51, siendo N31 en las partes más grises)

$\triangleright$ Trama: líneas horizontales alterando los tonos grises y gris-rosáceos. Hay un punteado blanco que puede ser una alteración (deshidratación). Hay también un punteado naranja que corresponde, como en otras rocas anteriores, a una serie de poros rellenos por algún tipo de alteración. 
Fábrica: Homogéneo excepto por la presencia de planos de rotura natural que se presentan a modo de grietas anaranjadas, afectadas posiblemente por la misma alteración que los poros anteriores.

$>$ Apariencia: Mate, con tacto "rugoso" en las zonas del punteado (porosidad) naranja. Translúcido en bordes y más al interior.

$>$ Grano: muy fino

$\triangleright$ Córtex: no hay

$\triangleright$ Morfología de los nódulos: indeterminada

$\triangleright$ Calidad para la talla: buena

\section{SíLEX VARIO 6 (SV.6)}

$\triangleright$ Color: gris pardo (P70)

$\gg$ Trama: bandeado horizontal en líneas gris oscuro, gris y blancuzo.

$\gg$ Fábrica: homogénea

$\triangleright$ Apariencia: brillante. Translúcido en filo.

$\triangleright$ Grano: Fino

$\gg$ Córtex: no hay

$\triangleright$ Morfología de los nódulos: no sabemos

$\triangleright$ Calidad para la talla: Buena 


\section{II.5. ORIGEN POTENCIAL DE LOS PRINCIPALES GRUPOS SILÍCEOS}

El origen las rocas utilizadas en la industria lítica de un yacimiento es una labor esencial a la hora de abordar las técnicas de adquisición de las materias primas así como aspectos relativos muchas veces al comportamiento y organización social de los grupos prehistóricos, al menos en aquello que atañe a las zonas de circulación, territorialidad, preferencias por una determinada materia o estrategia de explotación, con los distintos condicionantes socio-culturales que dirijan tal explotación.

Ya hemos expuesto las características geomorfológicas básicas del entorno amplio en el que se ubica El Espertín (la Zona Cantábrica): una orografía difícil, modelada sobre una litología antigua (Carbonífera predominantemente), con un relieve diferencial muy complejo, compartimentado y sometido a intensos procesos de fracturación y plegamiento; y retocado en último término por procesos glaciares, karstificación y erosión de la red fluvial. Ya se ha comentado también que este relieve complejo se estructura en distintas unidades y mantos desarrollados a lo largo de toda esta unidad geológica, abarcando no solo el norte de León sino la parte oriental asturiana y occidental cántabra. Es muy interesante por tanto constatar que el marco geográfico delimitado por la unidad geomorfológica de la Zona Cantábrica podemos considerarlo como una unidad básica geográfica, sobre la que comprobar los recursos potenciales existentes en dicho marco.

El mayor inconveniente a la hora de abordar el análisis de las materias primas de la Cornisa Cantábrica es la propia complejidad geológico-estructural de la misma (Figura II.5). Se ha explicado cómo su litología antigua ha sido afectada por procesos muy intensos de plegamientos y fallas, además de la orogenia alpina. Todo esto ha provocado que las rocas existentes en la Zona Cantábrica estén fuertemente fracturadas. Si a estos procesos de fracturación interna les sumamos la heterogeneidad típica en la composición de una fuente de materia prima, tenemos como resultado unos afloramientos de materias potencialmente explotables, dentro del contexto geológico, 
que son sumamente variados tanto en la composición de la roca silícea, variando por tramos y zonas del afloramiento, como en la manera en que tales afloramientos se presentan.

Estas características estructurales tan complejas de la Cornisa Cantábrica van a dificultar la localización y definición de las fuentes de aprovisionamiento y su eventual relación con los materiales arqueológicos. En la zona Cantábrica hay potencialmente la posibilidad de encontrar diversas fuentes de materias silíceas, en forma de chert nodulares, chert de Caliza de Montaña, etc., tal y como hemos mostrado en el apartado sobre la potencialidad del entorno geológico del Espertín.

Hay dos grupos principales de rocas existentes en el entorno geológico de El Espertín, que parecen corresponder a las principales rocas silíceas utilizadas en el yacimiento: el chert y la radiolarita. Se van a describir a continuación las muestras recogidas en dos afloramientos ${ }^{19}$ de ambas rocas para constatar que podemos considerarlos como muestras análogas a la materia utilizada en el yacimiento (en la Lámina 1 se muestra una parte del mapa geológico a escala 1:200.000 en torno a El Espertín. Se constata la complejidad geoestructural de la zona, con la repetición de series de formaciones. También se han señalado los puntos de procedencia de las muestras encontradas, las formaciones a las que están adscritas se suceden y repiten a lo largo de toda el área, especialmente hacia el oeste y noroeste de El Espertín).

En la literatura arqueológica sobre yacimientos de la Región Cantábrica, parecen ocasionalmente referencias a ciertas denominaciones de sílex o rocas silíceas en general. Nos interesan sobre todo las que se refieren a zonas más o menos cercanas al lugar donde se localiza El Espertín, sobre todo en la vertiente norte de la Cornisa y en especial tendremos en cuenta las referencias geológicas que marcan tales formaciones.

Un material que aparece frecuentemente en los yacimientos asturianos es el denominado "chert/sílex” de la "Caliza de Montaña". Según P. Arias (1990: 450) el “chert de Pendueles” es una de las tres variantes principales de sílex utilizado en esta

${ }^{19}$ La localización de estos afloramientos se enmarca dentro del proyecto: "La Gestión de los Materiales silíceos en las sociedades cazadoras-recolectoras de la provincia de León", Ref. ULE-2002-14, dirigido por la Dra. A. Neira Campos. 
zona (las otras dos son la radiolarita y un sílex negro que aparece en Cabrales). Dicho chert se encuentra en una formación westfaliense localizada sobre la costa de Llanes y aparece en la formación “Caliza de Montaña” namuriense. Asimismo uno de los sílex más utilizados en La Riera, el tipo B, vendría de los nódulos que se forman en la Caliza de Montaña de edad Carbonífera, esta materia aparece en posición derivada en forma de cantos rodados, que por transporte fluvial, llegan a las playas de esta zona asturiana (Straus et al., 1986: 191-204). Este sílex tipo B de La Riera es blanco o gris muy claro, por lo que en principio parece que no correspondería con el chert negro que está presente en El Espertín.

Hay más referencias al sílex de "Caliza de Montaña" para la zona de Cantabria, donde de nuevo aparece el sílex en la caliza del Namuriense medio (Sarabia Rogina, 1990: 142), se trata de un sílex gris que se presenta en riñones de 7 a $10 \mathrm{~cm}$ de máxima dimensión, de grano fino, opaco y córtex poroso y de grosor medio.

Por tanto el chert/sílex de "Caliza de Montaña" a que se refieren estas citas es una roca que aparece en las Calizas de Montaña del Carbonífero Medio (Namuriense y Westfaliense). En su lugar de formación se presentan en forma de riñones, pero también se puede encontrar en posición derivada a lo largo de los cursos fluviales y en las playas, en forma de cantos rodados, transportados por los ríos que han erosionado las rocas-madre de donde origen. Es muy factible por tanto plantear que el chert negro que aparece en El Espertín (o al menos un conjunto amplio de esta variedad) proceda de afloramientos análogos a los que originan la materia explotada en los yacimientos asturianos.

\section{III.5.1.- EL SÍLEX/CHERT NEGRO}

El chert negro que aparece en El Espertín engloba un conjunto muy amplio de bloques heterogéneos, sería una roca silícea de color negro-gris oscuro, con tonalidades que van de marrones a gris; con una trama a veces homogénea en cuanto a la presencia de dichos colores, y otras veces bandeada. Su composición es muy heterogénea sobre todo debido a la presencia bastante intensa de planos de diaclasado interno, lo que será una traba bastante importante respecto a su calidad técnica para la talla. Un rasgo 
característico de este tipo de chert es que tiene unos poros de pequeño tamaño, frecuentemente afectados por una alteración que los tiñe de rojo o naranja. La apariencia macroscópica de tales poros es en forma de puntos de pequeño tamaño de color rojo o naranja.

Se ha localizado un afloramiento de chert negro que tienen unas características que pueden considerarse análogas a la materia que aparece en El Espertín y que se describirá a continuación, se trata del “chert de Gobezanes”.

\section{CHERT DE GOBEZANES}

Se trata de una fuente de materia prima en posición primaria localizada a partir de una referencia de Calderón (1910: 268-269). Se localiza en la sierra de Gobezanes, concejo de Caso (Asturias), al lado del río Orle (afluente del Nalón por su vertiente derecha, [Hoja 54, Rioseco, E. 1:50.000, 1945]). Se trata de un chert en caliza carbonífera que se encuentra en la formación Escalada (de edad Westfaliense). El chert se presenta en forma de riñones de morfología variada (ovoide, formas alargadas más irregulares, etc.), en una banda de unos 40 metros dentro de la caliza (Lámina 2.2).

$\triangleright$ Color: gris oscuro, con varias tonalidades más claras, a negro. Predomina el P92 (gris) (también el R92, N71, N73), y el T31 cuando es más oscuro.

$\triangleright$ Trama: no uniforme, bloques heterogéneos. Hay bloques de chert color negro uniforme, brillante, recordando incluso a veces al sílex negro brillante. Otros bloques tienen una trama lineal horizontal, de tonos más claros (P92), similar al sílex negro-marrón, con un veteado blanco.

$\triangleright$ Fábrica: heterogénea, con abundantes planos de diaclasa, aunque varía dentro de la variedad de los bloques de chert. Aquellos que recuerdan al sílex negro-marrón tienen poros y vacuolas en la superficie frecuentemente con una morfología y tamaño variado, lo cual parece relacionarlos con fósiles.

$\triangleright$ Apariencia: brillante (como el sílex negro) y opaco, aunque hay bloques que tienen a veces una transparencia en el filo.

$\triangleright$ Grano: fino 
$\triangleright$ Córtex: varía, a veces tiene un aspecto fresco, otras está más rodado.

$\triangleright$ Morfología de los nódulos: riñones de forma variada: ovoides, alargados, más irregulares, etc.

$\triangleright$ Calidad para la talla: regular.

A partir de esta descripción, en la que también se puede observar una gran heterogeneidad dentro del mismo lugar de formación litológica del chert, se puede confirmar que hay una analogía entre el material descrito como chert de Gobezanes y algunas variedades de rocas que hemos incluido dentro de nuestro chert negro; tanto el sílex negro genérico, como el sílex negro-marrón y el sílex gris-negro. Es de suponer que debido a la amplia distribución de la formación "Caliza de Escalada" en el contexto cercano y lejano de la cueva "El Espertín", existan una serie de posibles yacimientos de chert negro con las mismas características pero en zonas más próximas que Gobezanes.

\section{III.5.2.- LA RADIOLARITA}

Las radiolaritas son frecuentes en yacimientos de la parte oriental de Asturias como Los Canes (Arias 1990: 450; 1991b: 38), Las Caldas (Corchón y Hoyos ${ }^{20}$, $1972-$ 73: 46) o La Riera (sería el sílex tipo A [Straus et al., 1986: 191-204]), y también aparecen en Cantabria (Cabrera Valdés, 1984; Sarabia Rogina, 2002). El origen de este tipo de roca está en la formación Alba (en el miembro Valdehuesa o Lavandera), de edad Viseense dentro del Carbonífero Inferior. Esta formación se localiza en áreas no muy alejadas de la ubicación de la cueva, tanto hacia el oeste-noroeste como hacia el noreste. Se puede llegar a ellas siguiendo río arriba el curso del río Tuerto, a través del Puerto del Pontón, o bien remontando el $\operatorname{Esla}^{21}$ (Heredia et al. 1991; Suárez et al., 1994).

${ }^{20}$ Lo que estos autores denominan como "silecita”, parece corresponder a la radiolarita, ya que aparece descrita como un sílex de baja calidad, con color rojizo o marrón-oscuro, con aspecto más opaco y menos vítreo que el sílex común. También afirman que es una materia de origen local, de fácil acceso y relativamente abundante, presente en varios yacimientos magdalenienses asturianos como La Lloseta, Balmori y Collubil además de Las Caldas y Sofoxó.

${ }^{21}$ Respecto a la vía de la cabecera del Esla, el Dr. E. Alonso Herrero (com. Per.) ha localizado un afloramiento de radiolaritas en el valle de Valdosín (valle por el que se accede al puerto de Ventaniella, paso natural hacia Asturias). Dicho afloramiento no está demasiado distante de la cueva de La Uña. 
La radiolarita que aparece asociada a la caliza Griotte en la Formación Alba, se presenta como un estrato subyacente a las calizas rosas, en bancos de unos 15-20 metros de espesor. Es una roca que se presenta en forma tableada, con grandes superficies de sedimentación y abundantes planos de diaclasado interno, que se intersecan entre sí de forma perpendicular. Las líneas de fractura internas son muy abundantes y son testimonio de la intensidad y cantidad de fuerzas a las que ha estado sometida dicha roca. En consecuencia esta materia proporciona en su lugar de formación bloques delimitados por los planos de sedimentación y las líneas de fractura, bloques de forma prismática, con aristas naturales muy agudas. El córtex correspondería a los planos de sedimentación, que tienen una estructura menos compacta que la radiolarita interna, con aspecto irregular, esquistoso y rotura exfoliante. Conforme nos acercamos al límite con la caliza Griotte esta superficie cortical es más gruesa.

No obstante, como en el caso del chert/sílex de la Caliza de Montaña, la radiolarita aparece también en posición derivada en forma de cantos rodados transportados por los ríos cuya cabecera atraviesa las formaciones en las que se origina. En varios yacimientos del noreste asturiano se ha constatado un aprovisionamiento de este tipo de acumulaciones de cantos de radiolarita en posición derivada (Arias, 1990; Straus et al., 1986). A este respecto, hay que recordar que las materias en posición derivada suelen ser de una calidad aceptable debido a que habrían sufrido ya una selección en los procesos erosivos, abrasivos y de transporte a los que han estado sometidas.

Si se presta atención a la forma en que se presenta el afloramiento de radiolarita (Lámina 2.1), a lo largo del banco de la formación litológica se puede ver una gran variación en su composición, con unas zonas sometidas a fracturas de mayor intensidad, otras con una composición en radiolarita más heterogénea, con mayor desarrollo de los planos de sedimentación, etc. Y también se puede constatar variedad en cuanto a los colores o tonos, desde rojo-granate a marrón, con diversos matices, hasta llegar a una variante de tono verde-aceituna, análogo a la roca que hemos denominado como Radiolarita B o radiolarita-2; colores que resultan del estado de oxidación de los minerales con hierro. 
Se ha tomado una muestra de radiolarita localizada en un afloramiento de la Formación Alba, al lado de la caliza griotte. Se trata de un corte de la carretera que conduce a Oseja de Sajambre, una zona no muy alejada de El Espertín, y ya en la cabecera del Sella ${ }^{22}$ (Lámina 2.1). Las características macroscópicas de esta muestra son las siguientes:

$\gg$ Color: rojo-marrón (R30 el más frecuente y también S30) predominante, aunque también con tonos verdosos (N91: oliva pálido).

$\triangleright$ Trama: a veces el color es uniforme, pero en otros bloques tiene una trama lineal horizontal en líneas paralelas a las superficies de sedimentación. A veces hay un punteado-moteado de distinto tamaño e intensidad, variando según los bloques. El color no es contante, como ya hemos indicado, variando en los distintos tonos descritos tanto hacia marrón oscuro, como hacia verdoso. Hay que reseñar la presencia de fósiles.

$>$ Fábrica: heterogénea debido a los abundantes planos de diaclasa que afectan el interior de esta roca. Estos planos son superficies rugosas, mates, afectados muchas veces por alteraciones. En algunos bloques tales planos dejan espacios dentro de la materia (hasta de $1 \mathrm{~mm}$ de grosor).

$\gg$ Apariencia: mate y opaca.

$>$ Grano: fino.

$\triangleright$ Córtex: se correspondería con los planos de sedimentación o de crecimiento de la roca. Es una superficie esquistosa, del mismo color rojizo que el interior, pero mate, con aspecto menos compacto, a veces escamoso y rotura exfoliante. Estos planos delimitan de forma paralela las distintas bandas de formación de la roca.

$\triangleright$ Morfología de los nódulos: está determinada por las características estructurales de la formación de la radiolarita en bancos tabulares con varias líneas de crecimiento. Se forman así bloques cuyos volúmenes son paralelepípedos, con marcadas aristas

${ }^{22}$ Aquí se localiza perfectamente un tramo de una de las bandas de la formación Alba con la radiolarita pegada a la caliza Griotte. Tales bandas son relativamente frecuentes en la Zona Cantábrica. 
naturales agudas, determinadas por la intersección prácticamente perpendicular entre los planos de sedimentación y los abundantes planos de rotura. No obstante ya indicamos que la radiolarita puede aparecer también en forma de cantos rodados en posición derivada en los lechos de ríos que han erosionado y cortado el lugar de formación de la roca.

$>$ Calidad para la talla: en la muestra de este afloramiento la podemos calificar de regular-mala debido a la fracturación tan intensa que ha sufrido la roca en su lugar de formación. La muestra que hemos tomado es de una calidad muy baja, siendo imposible casi conseguir una extracción intencional, ya que la roca rompe siguiendo las líneas de rotura internas. Hay que tener en cuenta que la muestra puede estar mucho más alterada debido a la propia realización del corte de la carretera.

Esta muestra se puede considerar totalmente análoga a la radiolarita que aparece en nuestro yacimiento. Con esto no afirmamos que proceda del lugar exacto de la recogida de la muestra, si no que la formación geológica sí se puede corresponder con un lugar de potencial aprovisionamiento de radiolarita. A este respecto, la Formación Alba aparece en bandas más o menos frecuentes en la Zona Cantábrica (Figura II.6). 


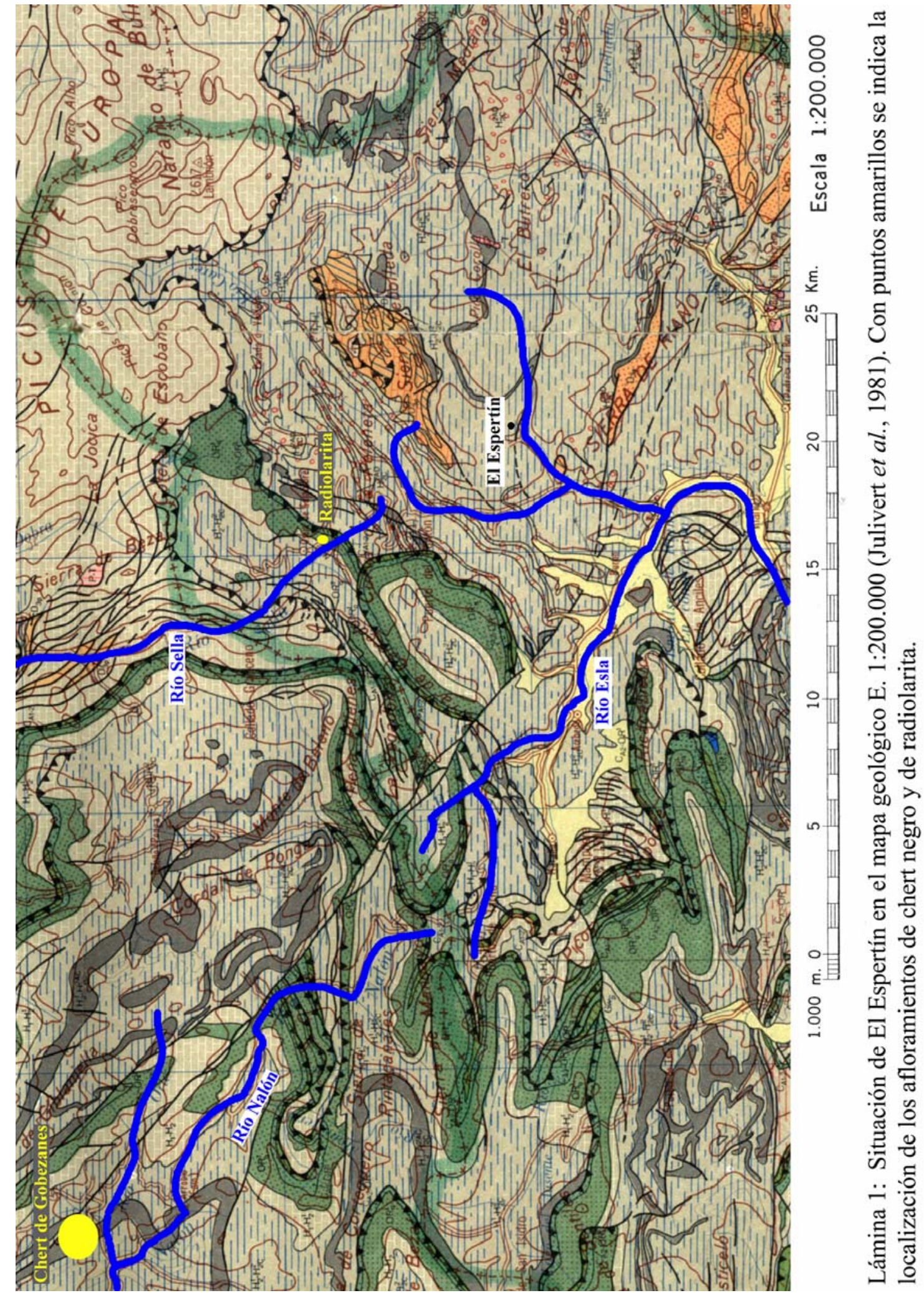



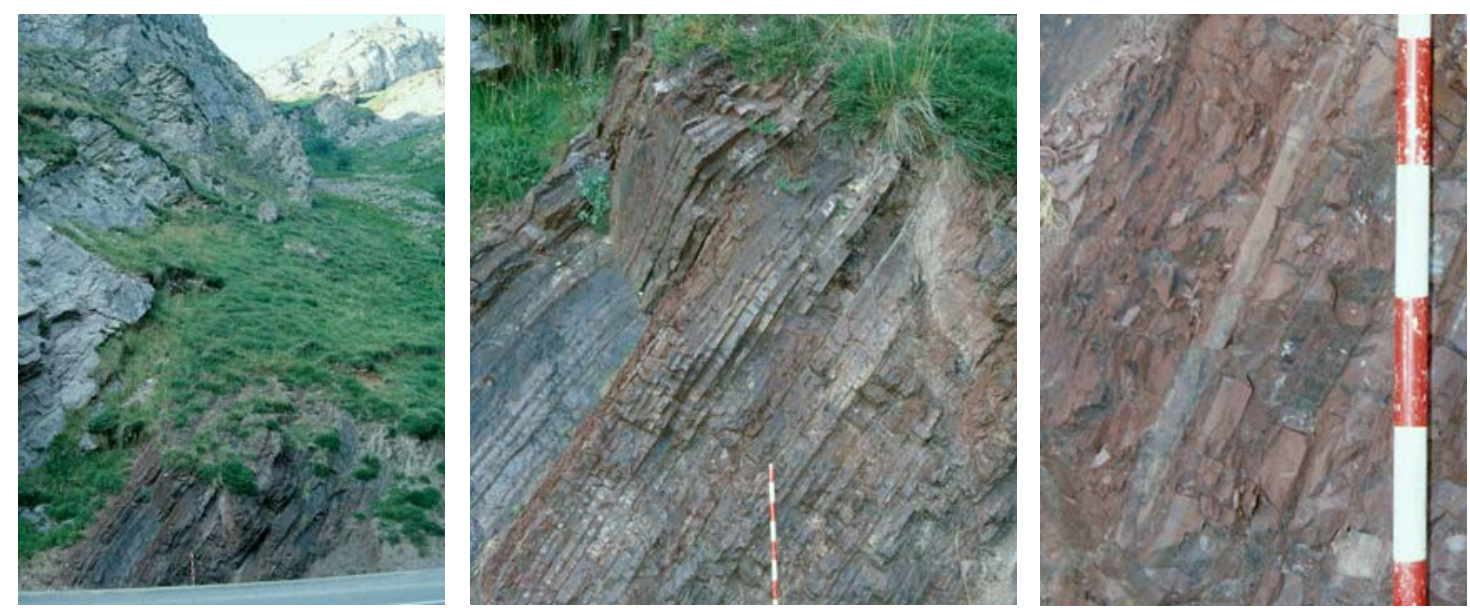

Lámina 2.1: Afloramiento de radiolarita en la Formación Alba. El miembro de radiolarita se presenta de forma masiva, con la caliza Griotte a la izquierda. En las fotos central y derecha se pueden observar en detalle las bandas de radiolarita delimitadas por las líneas de sedimentación; así como el cambio de coloración a lo largo del afloramiento. Fotos: E. Alonso Herrero.
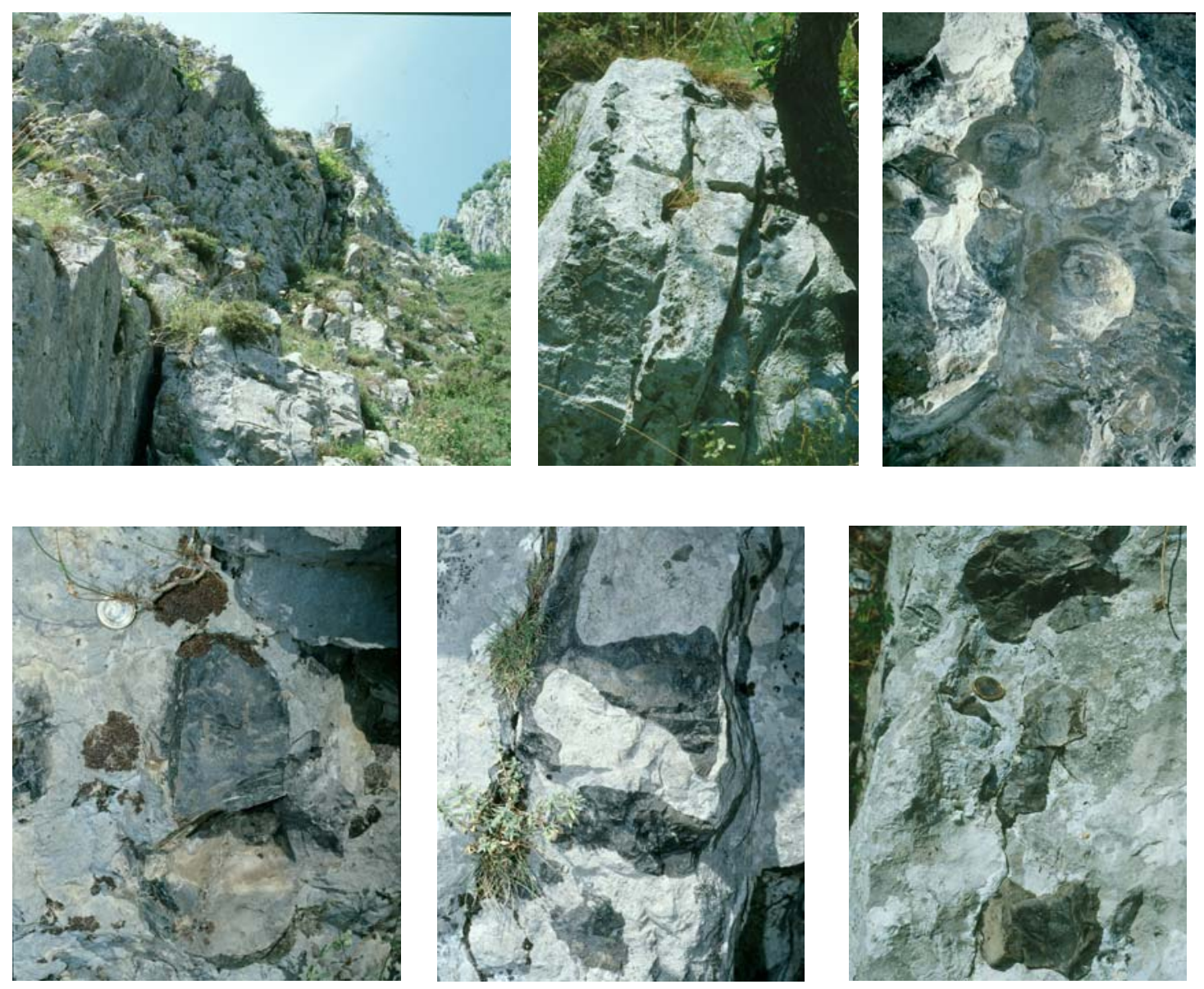

Lámina 2.2:: Afloramiento de chert de Gobezanes, dentro de la caliza de la Formación Escalada, que es su roca madre. Se presenta en nódulos ovalares,o riñones de morfología más o menos caprichosas. Fotos: E. Alonso Herrero. 


\section{III.6. DESCRIPCIÓN DE LA CUARCITA}

La cuarcita es una roca con una presencia relativamente importante en El Espertín. La caracterización de este tipo de materia resulta a veces complicada debido a la heterogeneidad de los distintos bloques, sobre todo respecto a la variedad de color. No obstante se intentará realizar también una descripción a partir de los mismos criterios que en el caso del grupo de los sílex. Hay que decir que un rasgo común a todas las variantes de cuarcitas presentes en el yacimiento es que los nódulos de partida son siempre cantos rodados, aluviales. A este respecto, en el contexto geológico donde se ubica el yacimiento existen posibles fuentes donde se pueda recoger cuarcita, por un lado hay formaciones con conglomerados; por otro, el transporte fluvial y fluvio-glacial arrastran cantos rodados de cuarcita que se acumulan a lo largo de los ríos de la cabecera del Esla.

La cuarcita es una materia bastante utilizada en la Cornisa Cantábrica a lo largo del Paleolítico (Bernaldo de Quirós \& Cabrera Valdés, 1996). En el contexto geológico hay bastantes formaciones geológicas con cuarcita, que aparece tanto de forma masiva como dentro de conglomerados. En la parte occidental, sobre todo, es muy habitual, tal y como se pone de manifiesto en la mayoría de los yacimientos asturianos (González Sainz, 1989, 1991; Corchón Rodríguez, 1995; Straus, 2002). Hay de hecho en la Cornisa una variedad de cuarcita de grano muy fino que tiene unas características muy adecuadas para la talla.

La mayoría de la cuarcita presente en El Espertín puede adscribirse a un mismo tipo, que sería la que hemos denominado como cuarcita genérica (C1). Aquí se incluiría un amplio número de elementos con una cierta variedad interna, con colores de gris genérico a gris oscuro, con tonos amarillentos, gris más claro, variantes rojizas, etc. A parte de este grupo se pueden individualizar otros tres tipos de cuarcita, que agruparían un número menor de elementos, los cuales en algún caso (la cuarcita verde) puede tratarse incluso de una muestra perteneciente a unos pocos bloques. No obstante tan solo retendremos esta división en grandes grupos de cuarcita en este apartado de materias primas, donde se describirá de forma detallada sus características 
macroscópicas. Por el contrario, al tratar el proceso técnico desarrollado sobre esta materia se englobarán a todas las variantes en un mismo grupo (el de la cuarcita) sin distinción.

\section{III.6.1. CUARCITA GENÉRICA (C, C1)}

$\triangleright$ Color: gris predominante, en sus diversas tonalidades, desde oscuro a claroblancuzco, con matices a veces amarillentos; también hay bloques con un tono rojizo-granate y otros que tienden a negro. Colores grises, de distinta intensidad: P31, N31, M31

$>$ Trama: en la mayoría de los casos es uniforme, pero en otros no lo es, con distintas posibilidades, a veces hay alguna banda o zona de color distinto (blanquecina en los bloques rojizos por ejemplo), otras veces el bloque tiene dos colores totalmente distintos (por ejemplo negro y granate), sin que exista ninguna solución de continuidad.

$\gg$ Fábrica: varía también dependiendo de los bloques. La mayoría son bloques homogéneos excepto por la presencia de alguna línea de fractura interna. En algunos casos hay bloques que son más heterogéneos, con presencia de zonas irregulares y escamosas.

$\triangleright$ Apariencia: brillante-semibrillante, a veces con brillo graso.

$>$ Grano: medio-fino. Los ejemplos con grano más fino suelen tener un brillo menor, mientras que los que tienen un grano medio tienen un brillo graso (son muy abundantes en tono gris claro).

Córtex: rodado, aluvial.

$\triangleright$ Calidad para la talla: media-buena, dependiendo de nuevo de los bloques, pero en general tiene una rotura concoidea adecuada.

Dentro de esta cuarcita genérica (C) se pueden diferenciar algunas variantes: 
$\triangleright$ C10: cuarcita gris con zonas amarillentas, con grano fino. A esta variante pertenece un núcleo prismático y varias hojas. Color L73 (blanco) a P73 (gris).

$\triangleright$ C11: cuarcita gris-granate con brillo vítreo (S11 [rojo oscuro]-P11 [rojo claro]) y aspecto heterogéneo porque tiene zonas escamosas y poros (como motas de color claro) o huecos de cierto tamaño (a veces oxidados). Tamaño del grano medio. Respecto a la calidad técnica sería media-mala debido sobre todo a las escamaciones de la materia que impide una fractura regular.

$>$ C12: cuarcita gris-roja o gris-rosácea (M11: rojo pálido), con un punteado negro y un aspecto no muy homogéneo sobre todo cerca del córtex.

$\triangleright$ C13: cuarcita gris oscura marrón "opaca” de trama uniforme normalmente aunque a veces tiene bandas de color marrón-rojizo cercanas al córtex, haciendo entonces que el córtex tenga tonos rojos. Color P31 (gris), N31 (gris-rosa). Tiene un punteado naranja y un moteado blanco que frecuentemente se escama. Tamaño del grano medio. Fractura concoidea adecuada para la talla. Algunas de las piezas de este subtipo se acercan a la cuarcita blanca-rosácea, que describiremos más abajo, sobre todo en las variantes más rosáceas.

$\triangleright$ C14: cuarcita gris clara y gris muy claro-blanca, brillante. Color M91 (gris claro).

$\gg$ C15: cuarcita verde-marrón.

\section{III.6.2. CUARCITA VERDE (C2)}

A este tipo pertenece un pequeño grupo de piezas, incluido un percutor. Quizás pertenezcan todas a un mismo bloque o nódulo.

Color y trama: verde oscuro con zonas negras a modo de manchas y un punteado negro. Color S 91 (gris oliva). Hay también un moteado blancuzco y un punteado anaranjado. Este último corresponde a poros y es frecuente que tales poros sean de mayor tamaño, conformando huecos a veces de tamaño importante. 
$\gg$ Fábrica: heterogéneo por la presencia de zonas menos compactas, irregulares y escamosas, sobre todo cerca del córtex.

$\gg$ Apariencia: brillante.

$\triangleright$ Grano: medio

$\triangleright$ Córtex: rodado.

$\triangleright$ Calidad para la talla: media

\section{III.6.3. CUARCITA BLANCA-ROSÁCEA (C3)}

$\triangleright$ Color y trama: blanco-sucio, blanco-rosáceo, a veces con tendencia a gris claro. Colores K92 para el blanco y M11 para el rojizo (rojo pálido). Hay un punteadomoteado negro.

$\triangleright$ Fábrica: homogénea excepto por la presencia de algún plano natural. A veces hay inclusiones a modo de pequeños puntos negros o rojizos que salta en forma de pequeñas escamas.

$\triangleright$ Apariencia: mate y opaca.

$>$ Grano: medio.

$>$ Córtex: rodado.

$\triangleright$ Calidad para la talla: media-buena, cuando la superficie está afectada por las escamas que hemos indicado la fractura no es tan limpia.

\section{III.6.4. CUARCITA NEGRA (C4)}

$\triangleright$ Color: gris oscuro-negro (T31: gris oscuro), con pequeños granos blancuzcos.

$\triangleright$ Trama: uniforme

$\triangleright$ Fábrica: Homogéneo excepto por la presencia de diaclasas internas. 
$\gg$ Apariencia: brillante.

$\triangleright$ Grano: medio-grueso

$\gg$ Córtex: fluvial

$\triangleright$ Calidad para la talla: media-mediocre, sobre todo teniendo en cuenta la talla se ve dificultada por la abundancia de planos internos de rotura, la textura rugosa debido al tamaño del grano y que la rotura no es demasiado concoidea. 


\section{III.7. EL CUARZO (Q)}

La última materia prima que se ha tallado en El Espertín es el cuarzo, pero su presencia es muy escasa, constituyendo un grupo muy reducido elementos. Tampoco se va a incidir en el aspecto de la presencia de este tipo de roca de grano grueso, ya que tanto el cuarzo, como la cuarcita y otros materiales son rocas de sobre conocidas desde el Paleolítico Inferior (Bracco, 1997), y empleadas de forma recurrente en la Cornisa Cantábrica (Bernaldo de Quirós \& Cabrera Valdés, 1996).

Respecto al tipo de cuarzo que se ha seleccionado, no podemos ahondar demasiado debido al reducido número de la muestra y a que se trata en casi todos los casos de piezas de tercer orden. Se trata en general de un cuarzo lechoso de color blanco a veces con un veteado negro. Otras veces el cuarzo es más transparente, acercándose al cristal de roca, incluso hay alguna pieza cortical, en la que se puede observar las caras del prisma, típico del cuarzo hialino. Asimismo se puede apreciar en estas escasas piezas el procedimiento de talla peculiar que esta variedad necesita, es decir una talla en planos oblicuos al ápice del prisma (Ramil Soneira y Ramil Rego, 1997).

Se puede plantear la hipótesis de que existan dos variedades de cuarzo, por una parte un cuarzo lechoso del que no conocemos demasiado bien sus características debido al escaso número de elementos con los que contamos. Por otro lado hay algunas piezas que pueden proceder de prismas de cuarzo hialino, pero su número es muy reducido. Lamentablemente no podemos se puede decir nada concreto acerca de su lugar de adquisición. De nuevo, como en las cuarcitas, hay que recordar que en el contexto geológico de la cueva hay tanto formaciones de conglomerados, como acumulaciones aluviales e incluso fluvio-glaciares, que bien pudieran contener este tipo de materia. 


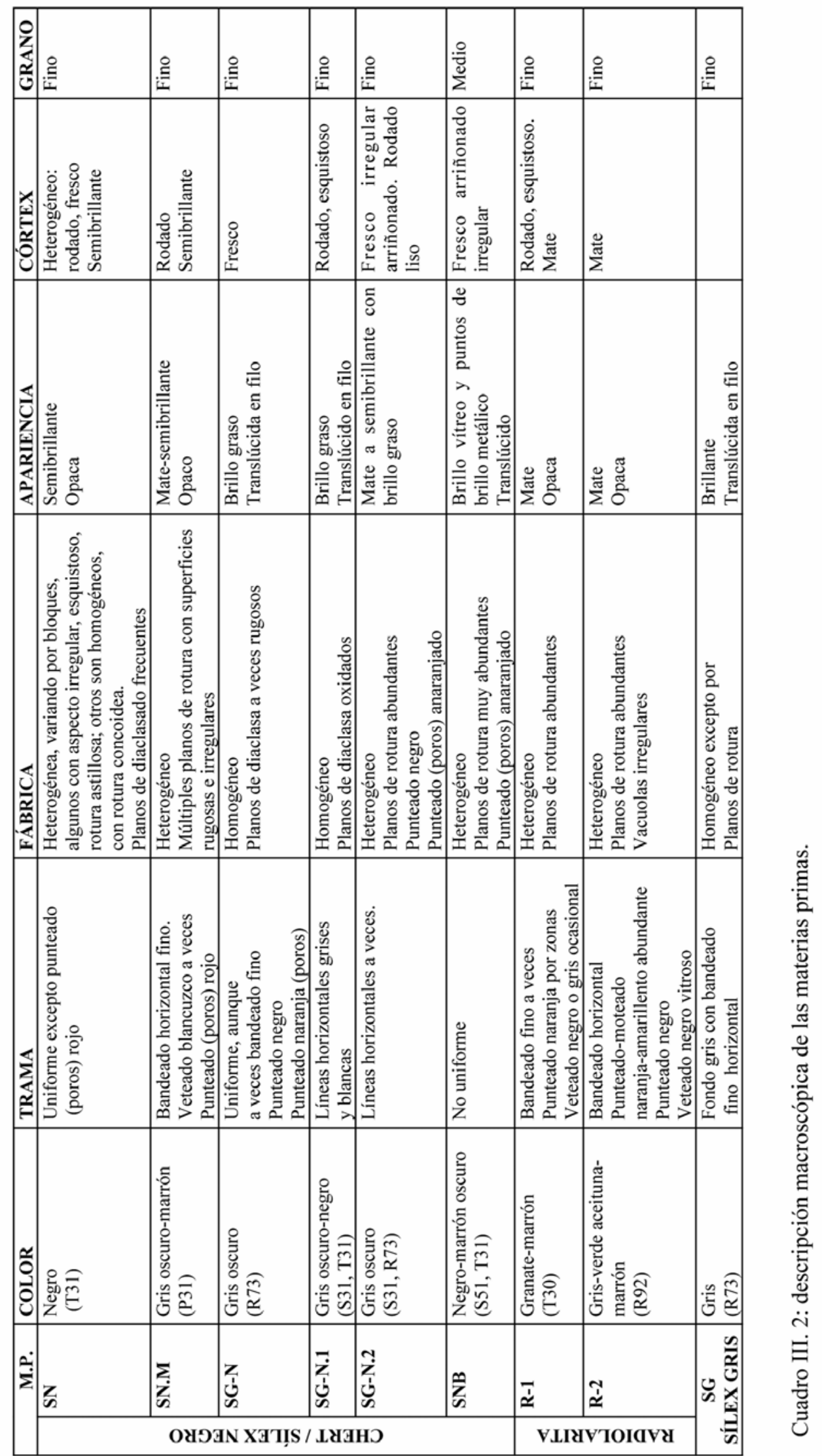




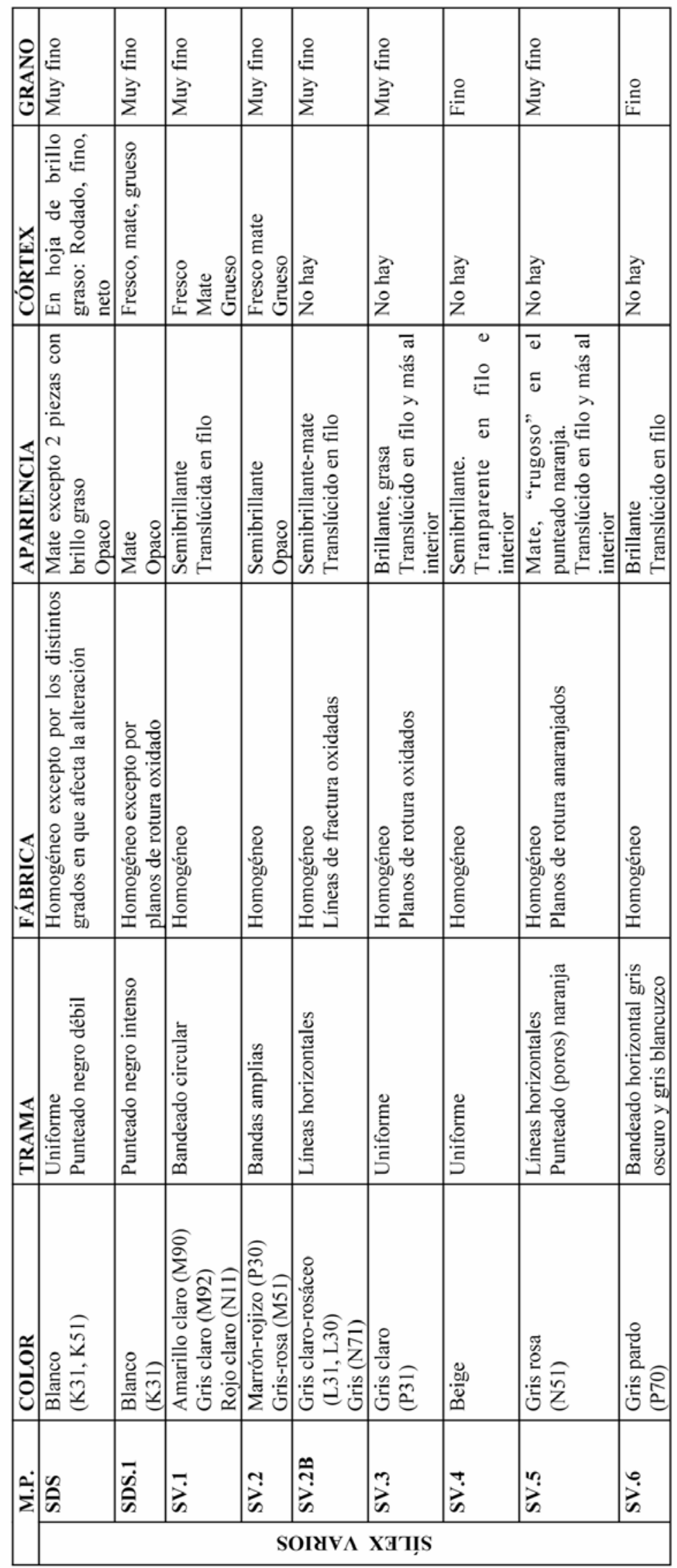

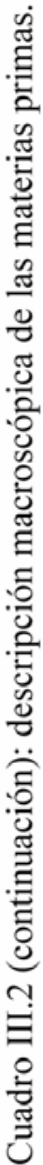




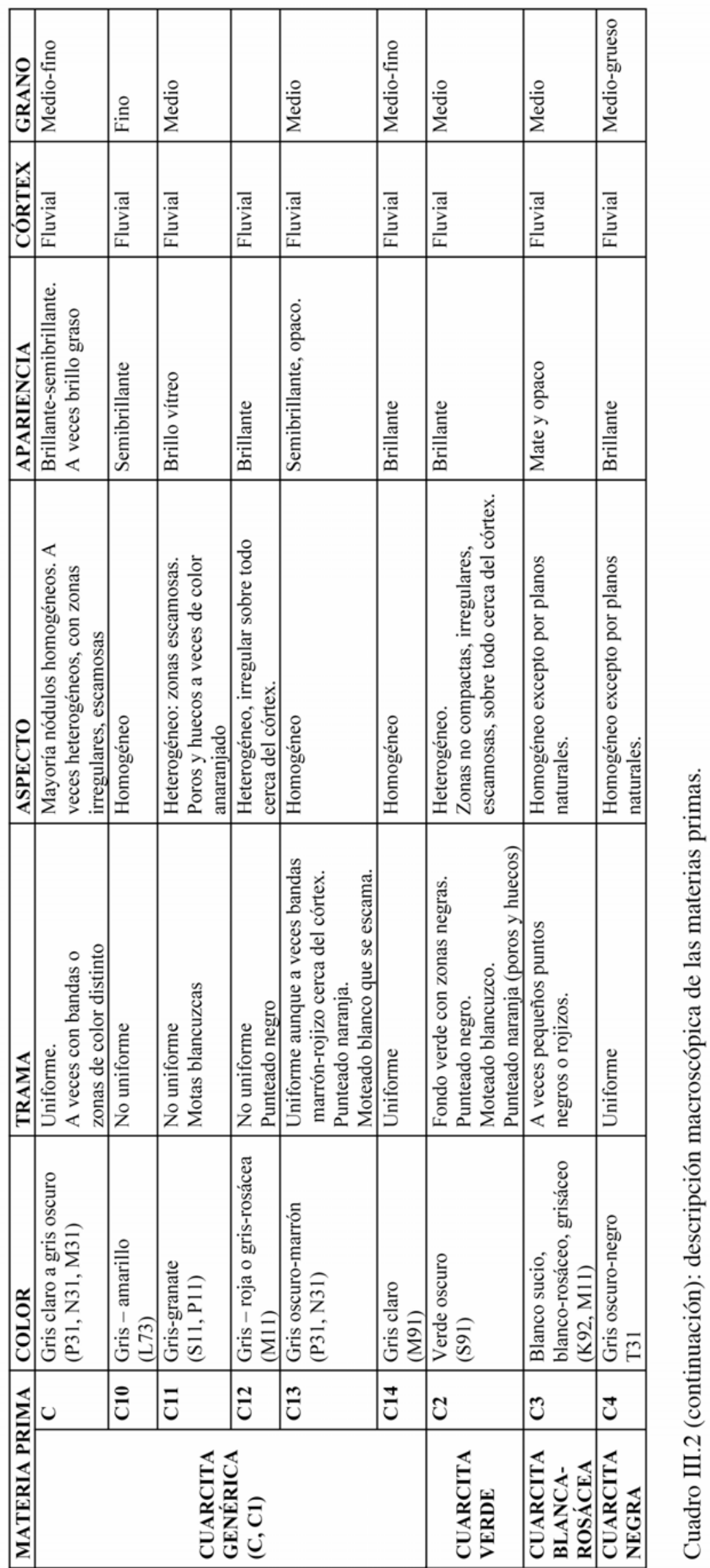




\section{CAPÍTULO IV -}

ANÁLISIS TECNOLÓGICO

DEL CONJUNTO LÍTICO

DE “EL ESPERTÍN” 



\section{IV.1.- SÍLEX/CHERT NEGRO}

El chert o sílex negro es la materia más abundante de El Espertín (n=8238), constituyendo el 64\% del conjunto lítico total. Es la materia que más variedad de soportes contiene y, entre ellos, destaca el elevado porcentaje de núcleos y productos de acondicionamiento. Ya se ha indicado cómo el sílex negro parece proceder del entorno del yacimiento, cosa que estaría apoyada por este alto porcentaje de elementos dentro del conjunto, incluidos varios fragmentos de nódulos, es decir bloques con algún levantamiento, o simplemente bloques rotos, de calidad mediocre para la talla. La cercanía de la/s fuente/s de adquisición de esta materia explicaría tanto el elevado volumen de material presente en el yacimiento como el hecho de que se transporten bloques brutos que tras ser probados resultan desechados. Asimismo esta disponibilidad de materia prima, permite el desarrollo de diversos métodos de talla en la explotación de los nódulos, en función de su variada morfología y tamaño. Y es así como nos encontramos en este tipo de roca con la mayor variedad de esquemas aplicados, tanto para la obtención de hojas y hojitas como de lascas.

\section{IV.1.1. CARACTERÍSTICAS GENERALES}

En el capítulo sobre las materias primas se abordan los aspectos relativos a lo que constituiría la fase 0 o de aprovisionamiento del chert negro, especialmente las características macroscópicas de esta materia prima y la forma como se selecciona. El presente apartado se centra en las características de ámbito más amplio sobre el sílex negro, las cuales servirán para hacer una presentación del conjunto.

\section{IV.1.1.1. LISTA TECNOLÓGICA}

En el cuadro SN.1 se presenta la lista tecnológica del sílex negro, tanto el número de elementos como su porcentaje relativo. 


\begin{tabular}{|c|c|c|c|c|}
\hline \begin{tabular}{|l|} 
GRUPO \\
TECNOLÓGICO \\
\end{tabular} & $\mathbf{N}^{\circ}$ TEC. & SOPORTE & $\mathbf{N}$ & $\%$ \\
\hline \begin{tabular}{|l|}
$\begin{array}{l}\text { GRUPO } 0 \\
\text { (nódulos) }\end{array}$ \\
\end{tabular} & 0 & Nódulo & 14 & 0,17 \\
\hline \multirow{6}{*}{$\begin{array}{l}\text { GRUPO } 1 \\
\text { (lascas) }\end{array}$} & 1 & Lasca de primer orden & 175 & 2,12 \\
\hline & 2 & Lasca de segundo orden & 452 & 5,49 \\
\hline & $2-5$ & Lasca laminar de segundo orden & 9 & 0,11 \\
\hline & 3 & Lasca de tercer orden & 2926 & 35,52 \\
\hline & 3-6 & Lasca laminar & 125 & 1,52 \\
\hline & 4 & Hoja de primer orden & 9 & 0,11 \\
\hline \multirow{5}{*}{$\begin{array}{l}\text { GRUPO } 2 \\
\text { (soportes laminares) }\end{array}$} & 5 & Hoja de segundo orden & 73 & 0,89 \\
\hline & 6 & Hoja de tercer orden & 366 & 4,44 \\
\hline & 6-FN & Hoja de tercer orden con flanco & 8 & 0,10 \\
\hline & 7 & Hojita de segundo orden & 29 & 0,35 \\
\hline & 8 & Hojita de tercer orden & 477 & 5,79 \\
\hline \multirow{5}{*}{$\begin{array}{l}\text { GRUPO } 3 \\
\text { (productos de } \\
\text { acondicionamiento) }\end{array}$} & 9 & Lámina cresta & 64 & 0,78 \\
\hline & 10 & Tableta de núcleo & 3 & 0,04 \\
\hline & 11 & Semitableta de núcleo & 22 & 0,27 \\
\hline & 12 & Flanco de núcleo & 58 & 0,70 \\
\hline & 13 & Arista de núcleo y otros & 28 & 0,34 \\
\hline \multirow{5}{*}{$\begin{array}{l}\text { GRUPO } 4 \\
\text { (núcleos) }\end{array}$} & 14 & Núcleo prismático con un plano & 12 & 0,15 \\
\hline & 15 & Núcleo prismático con dos planos & 9 & 0,11 \\
\hline & 16 & Núcleo sobre lasca & 6 & 0,07 \\
\hline & 17 & Núcleo globuloso & 3 & 0,04 \\
\hline & 18 & Resto de núcleo & 8 & 0,10 \\
\hline \begin{tabular}{|l|}
$\begin{array}{l}\text { GRUPO } 7 \\
\text { (golpes buril) }\end{array}$ \\
\end{tabular} & 19 & Golpe de buril & 30 & 0,36 \\
\hline \multirow{3}{*}{$\begin{array}{l}\text { GRUPO } 5 \\
\text { (indeterminados) }\end{array}$} & 23 & Astilla de talla & 251 & 3,05 \\
\hline & 24 & Chunk & 90 & 1,09 \\
\hline & 25 & Indeterminado & 132 & 1,60 \\
\hline \multirow{2}{*}{$\begin{array}{l}\text { GRUPO } 6 \\
\text { (debris) }\end{array}$} & DEB-LT & Debris: lasquita & 2485 & 30,17 \\
\hline & DEB-AT & Debris: astilla e indeterminados & 374 & 4,54 \\
\hline & & & 8238 & 100 \\
\hline
\end{tabular}

Cuadro SN.1: lista tecnológica del sílex negro.

\begin{tabular}{|lrr|}
\hline GRUPOS TEC. & $\mathbf{N}$ & $\mathbf{\%}$ \\
\hline 0 & 14 & 0,17 \\
1 & 3697 & 44,88 \\
2 & 953 & 11,57 \\
3 & 175 & 2,12 \\
4 & 37 & 0,45 \\
5 & 473 & 5,74 \\
6 & 2859 & 34,71 \\
7 & 30 & 0,36 \\
\hline & 8238 & 100 \\
\hline
\end{tabular}

Cuadro SN.2: grupos tecnológicos del sílex negro. 


\begin{tabular}{|c|c|c|c|c|}
\hline GRUPO TECNOLÓGICO & $\mathrm{N}^{\circ}$ TEC. & SOPORTE & $\mathbf{N}$ & $\%$ \\
\hline GRUPO 0 (nódulos) & 0 & Nódulo & 3 & 0,39 \\
\hline \multirow{6}{*}{$\begin{array}{l}\text { GRUPO } 1 \\
\text { (lascas) }\end{array}$} & 1 & Lasca de primer orden & 12 & 1,55 \\
\hline & 2 & Lasca de segundo orden & 68 & 8,76 \\
\hline & $2-5$ & Lasca laminar de segundo orden & 2 & 0,26 \\
\hline & 3 & Lasca de tercer orden & 271 & 34,92 \\
\hline & $3-6$ & Lasca laminar & 29 & 3,74 \\
\hline & 4 & Hoja de primer orden & 2 & 0,26 \\
\hline \multirow{5}{*}{$\begin{array}{l}\text { GRUPO } 2 \\
\text { (soportes laminares) }\end{array}$} & 5 & Hoja de segundo orden & 38 & 4,90 \\
\hline & 6 & Hoja de tercer orden & 153 & 19,72 \\
\hline & 6-FN & Hoja de tercer orden con flanco & 7 & 0,90 \\
\hline & 7 & Hojita de segundo orden & 2 & 0,26 \\
\hline & 8 & Hojita de tercer orden & 117 & 15,08 \\
\hline \multirow{5}{*}{$\begin{array}{l}\text { GRUPO } 3 \text { (productos de } \\
\text { acondicionamiento) }\end{array}$} & 9 & Lámina cresta & 9 & 1,16 \\
\hline & 10 & Tableta de núcleo & 0 & 0,00 \\
\hline & 11 & Semitableta de núcleo & 3 & 0,39 \\
\hline & 12 & Flanco de núcleo & 24 & 3,09 \\
\hline & 13 & Arista de núcleo y otros & 4 & 0,52 \\
\hline \multirow{5}{*}{$\begin{array}{l}\text { GRUPO } 4 \\
\text { (núcleos) }\end{array}$} & 14 & Núcleo prismático con un plano & 0 & 0,00 \\
\hline & 15 & Núcleo prismático con dos planos & 0 & 0,00 \\
\hline & 16 & Núcleo sobre lasca & 1 & 0,13 \\
\hline & 17 & Núcleo globuloso & 0 & 0,00 \\
\hline & 18 & Resto de núcleo & 0 & 0,00 \\
\hline $\begin{array}{l}\text { GRUPO } 7 \\
\text { (golpes buril) }\end{array}$ & 19 & Golpe de buril & 2 & 0,26 \\
\hline \multirow{3}{*}{$\begin{array}{l}\text { GRUPO } 5 \\
\text { (indeterminados) }\end{array}$} & 23 & Astilla de talla & 4 & 0,52 \\
\hline & 24 & Chunk & 7 & 0,90 \\
\hline & 25 & Indeterminado & 3 & 0,39 \\
\hline \multirow{2}{*}{$\begin{array}{l}\text { GRUPO } 6 \\
\text { (debris) }\end{array}$} & DEB-LT & Debris: lasquita & 15 & 1,93 \\
\hline & DEB-AT & Debris: astilla e indeterminados & 0 & 0,00 \\
\hline & & & 776 & 100 \\
\hline
\end{tabular}

Cuadro SN.3: lista tecnológica de los soportes retocados de sílex negro.

\begin{tabular}{|lcc|}
\hline GRUPOS TEC. & $\mathbf{N}$ & $\mathbf{~ \% ~}$ \\
\hline 0 & 3 & 0,39 \\
1 & 384 & 49,48 \\
2 & 317 & 40,85 \\
3 & 40 & 5,15 \\
4 & 1 & 0,13 \\
5 & 14 & 1,80 \\
6 & 15 & 1,93 \\
7 & 2 & 0,26 \\
\hline & 776 & 100 \\
\hline
\end{tabular}

Cuadro SN.4: grupos tecnológicos del sílex negro en las piezas retocadas. 
El tipo de soporte más abundante es la lasca de tercer orden (35\%), seguido por las lasquitas de los debris (30\%); los siguientes tipos serían las lascas semicorticales, las hojitas y hojas de tercer orden, los cuales bajan a un 5-6\% de representación. El resto de los tipos de soportes tienen una presencia muy pequeña, inferior al 3\%.

Es quizás más claro el cuadro que agrupa los soportes en los grupos tecnológicos amplios (cuadro SN.2), al menos se puede ver de forma más rápida la representación de secuencias amplias dentro del proceso de talla. Así se observa cómo el grupo que predomina ampliamente es el primero (las lascas), con un 45\%, seguido por los debris con un 35\% y los soportes laminares (grupo 2), con un 12\%; con un 6\% están a continuación los soportes indeterminados (grupo 5), y con porcentajes inferiores al 3\% se encuentran los productos de acondicionamiento (grupo 3), los núcleos (grupo 4), los golpes de buril (grupo 7) y los nódulos o fragmentos de materia que han sido probados; estos dos últimos grupos tienen una presencia muy pequeña.

Esta representación del conjunto lítico de sílex negro; con un neto predominio del grupo tecnológico 1 y 6, es decir los soportes procedentes de la fase de preparación y las lascas en general por un lado, y los debris por otro, suponiendo ambos el 80\% del conjunto lítico; indica que esta materia ha sido sometida a un proceso de talla bastante intenso en el yacimiento. Las hojas-hojitas son testimonio de un débitage laminar, al que también se adscriben un buen número de productos de acondicionamiento y núcleos; lo cual indica que se pueden considerar como soportes intencionalmente buscados por una buena parte del proceso técnico desarrollado sobre el sílex negro.

En los cuadros siguientes se muestra la distribución tanto por tipos de soportes como por grupos tecnológicos de las piezas retocadas y se ve un cambio patente en la representación de los distintos soportes: siguen predominando las lascas de tercer orden, con el 35\% de las piezas retocadas, pero están seguidas por las hojas (con un 20\%) y las hojitas de tercer orden (con un 15\%), quedando el resto de soportes en porcentajes inferiores al 10\%. En el cuadro de distribución de los grupos tecnológicos se ve resumido este incremento de la importancia de los elementos laminares a la hora seleccionar los soportes para retocar. 
En el siguiente cuadro (cuadro SN. 3) se presenta el porcentaje de los tipos de soportes relativamente al número de soportes existentes en el conjunto lítico, se pretende ver así preferencias por soportes concretos en la fase de retoque. Se observa claramente que los soportes elegidos pertenecen sobre todo al grupo tecnológico 2, el de las hojas-hojitas. En este grupo se retocan más del 40\% de las hojas, estando retocadas casi todas las hojas con flanco, sorprende en cambio que del conjunto de las hojitas sólo se retoquen aproximadamente la cuarta parte de ellas, lo cual puede estar relacionado con el índice de fragmentación elevado de éstas. Con porcentajes superiores al 20\% destacan también como soportes seleccionados las lascas laminares y las hojas totalmente corticales. Ambos tipos, aunque pertenecerían al grupo 1, señalarían quizás una preferencia por los soportes de tendencia alargada. En el cuadro de los grupos técnicos (Cuadro SN.3 y Cuadro SN.5) se observa de modo resumido la preferencia que hay por retocar los soportes laminares (grupo 2), con un 33\%, seguido por el grupo de los productos de acondicionamiento (con un 23\%) y el de las lascas (con tan sólo un $10 \%$ respecto al número de lascas disponibles); el grupo 0 tiene un elevado porcentaje, pero es un dato desvirtuado por el escaso número de este tipo de piezas.

\begin{tabular}{|l|r|rr|}
\hline \multirow{2}{*}{ GRUPO TEC. } & \multirow{2}{*}{ TOTAL } & \multicolumn{2}{|c|}{ RETOCADAS } \\
\cline { 3 - 4 } & & $\mathrm{N}$ & $\%$ \\
\hline 0 & 14 & 3 & 21,43 \\
1 & 3697 & 384 & 10,39 \\
2 & 953 & 317 & 33,26 \\
3 & 175 & 40 & 22,86 \\
4 & 37 & 1 & 2,63 \\
5 & 473 & 14 & 2,96 \\
6 & 2859 & 15 & 0,56 \\
7 & 30 & 2 & 6,67 \\
\hline & 8238 & 776 & 9,42 \\
\hline
\end{tabular}

Cuadro SN.5: piezas retocadas relativamente al total de las disponibles y según los distintos grupos tecnológicos.

Teniendo en cuenta estos cuadros, se puede afirmar que existe, a la hora de elegir los soportes para retocar, una preferencia marcada hacia los soportes del grupo 2 y 3 ya que, aunque porcentualmente no son demasiado numéricos en el conjunto lítico de sílex negro, su representación entre las piezas retocadas es muy alta. 


\section{IV.1.1.2. ROTURAS}

\section{IV.1.1.2.1. TIPOS DE SOPORTES ROTOS}

Además de la distribución en los tipos de soportes técnicos, hay que señalar que el sílex negro es una materia que tiene un índice de fragmentación bastante elevado, tan solo el 36\% de las piezas están completas (cuadro SN.6). Los elementos del grupo técnico 1 (lascas, lascas laminares, hojas de primer orden) tienen en torno a un 50\% de piezas rotas, lo mismo que ocurre en las hojas con flanco, las piezas con cresta y los golpes de buril. En el grupo técnico 2 el número de piezas rotas se incrementa ligeramente, de forma que las hojas tienen un $60 \%$ de elementos rotos, de forma parecida a las lascas laminares. Dentro de este grupo el soporte que cuenta con más roturas son las hojitas de tercer orden, de las que casi el 90\% están rotas. Esta última tendencia a un incremento de los soportes rotos en los productos laminares, parece estar relacionada con las roturas existentes en los soportes retocados, las hojitas de dorso rotas explicarían entonces el alto porcentaje de hojitas rotas.

\begin{tabular}{|c|c|c|c|c|c|c|c|}
\hline \multirow{2}{*}{$\begin{array}{l}\text { GRUPO } \\
\text { TEC. }\end{array}$} & \multirow{2}{*}{ TIPO TEC. } & \multirow{2}{*}{ COMPLETOS } & \multicolumn{4}{|c|}{ FRAGMENTADOS } & \multirow{2}{*}{$\mathbf{N}$} \\
\hline & & & Distal & Mesial & Proximal & Roto & \\
\hline 0 & L-PL & & & & & 14 & 14 \\
\hline \multirow{3}{*}{1} & $\mathrm{~L}$ & 1371 & 643 & 255 & 564 & 720 & 3553 \\
\hline & L-H & 42 & 29 & 25 & 37 & 2 & 135 \\
\hline & $\mathrm{H}$ & 2 & 3 & 4 & & & 9 \\
\hline \multirow{2}{*}{2} & $\mathrm{H}$ & 176 & 277 & 286 & 193 & 10 & 942 \\
\hline & H-FN & 7 & 2 & & 2 & & 11 \\
\hline \multirow{5}{*}{3} & LC & 15 & 26 & 15 & 8 & & 64 \\
\hline & $\mathrm{TN}$ & 3 & & & & & 3 \\
\hline & $\mathrm{SN}$ & 18 & 3 & & 1 & & 22 \\
\hline & FN & 42 & 13 & & 3 & & 58 \\
\hline & AN & 20 & 2 & 1 & 2 & 3 & 28 \\
\hline 4 & $\mathrm{~N}$ & 29 & & & & 8 & 37 \\
\hline 5 & IT & & & & & 473 & 473 \\
\hline \multirow{2}{*}{6} & LT & 1176 & 344 & 153 & 212 & 600 & 2485 \\
\hline & IT & & & & & 374 & 374 \\
\hline \multirow[t]{2}{*}{7} & GB & 12 & 7 & 5 & 5 & 1 & 30 \\
\hline & & 2934 (35,61\%) & \multicolumn{4}{|c|}{$5304(64,38 \%)$} & 8238 \\
\hline
\end{tabular}

Cuadro SN.6: representación de los tipos de soportes enteros y fragmentados de sílex negro, teniendo en cuenta la totalidad de las piezas.

Dentro de los soportes rotos, se muestra en el Cuadro SN.6 los tipos de fragmentos de cada tipo de soporte. En este caso se han resumido algunos tipos en 
grupos más amplios (bajo la denominación de "lascas" se agrupan a las lascas de los distintos ordenes, con y sin córtex; las hojas incluyen todos los soportes laminares, hojas y hojitas; etc.) y en las categorías de fragmentación se especifican los fragmentos distales, mesiales, proximales y los rotos. Estas categorías serán útiles al analizar más detalladamente los distintos tipos soporte, sobre todo para calcular los datos métricos, ya que para la longitud sólo se tendrán en cuenta las piezas completas, en cambio para la anchura también se contabilizarán los fragmentos distales, mesiales y proximales. Lo mismo sucede cuando analicemos los atributos relativos al talón, la preparación del punto de impacto, etc., donde se tendrán en cuenta tanto los soportes completos como los fragmentos proximales.

\section{IV.1.1.2.2. TIPOS DE ROTURAS}

En el tipo de rotura que afecta a las piezas (cuadro SN.7) predominan las distales (23\%), seguidas por las piezas rotas por todas partes (19\%), las próximo-distales (16\%), las proximales (15\%), las distales-laterales (10\%), y con menores porcentajes el resto de las variantes. Las proximales, distales y próximo-distales aparecen en todos los tipos de soportes; en cambio las bilaterales y las roturas totales (DP) son propias sobre todo de los soportes del grupo 1 (lascas) y 6 (debris).

\begin{tabular}{|l|cccccccc|r|}
\hline & BL & DL & DP & DS & LT & PD & PL & PX & N \\
\hline GR.1:L & 34 & 346 & 552 & 593 & 206 & 316 & 382 & 425 & 2854 \\
GR.2:H & & 12 & 10 & 228 & 9 & 304 & 12 & 252 & 827 \\
GR.3:P.A. & & 6 & 1 & 23 & 9 & 17 & 7 & 43 & 106 \\
GR.6:DEB & 22 & 167 & 442 & 362 & 112 & 201 & 7 & 43 & 1356 \\
GR.7:GB & & & & 6 & & 6 & 1 & 10 & 23 \\
\hline N & 56 & 531 & 1005 & 1212 & 336 & 844 & 409 & 773 & 5166 \\
$\%$ & 1,08 & 10,26 & 19,42 & 23,42 & 6,49 & 16,39 & 7,92 & 15,00 & 100 \\
\hline
\end{tabular}

Cuadro SN.7: tipos de roturas en los distintos grupos tecnológicos. BL: bilateral, DL: distallateral, DP: distal-lateral-proximal, DS: distal, LT: lateral, PD: proximal-distal, PL: proximallateral, PX: proximal. 


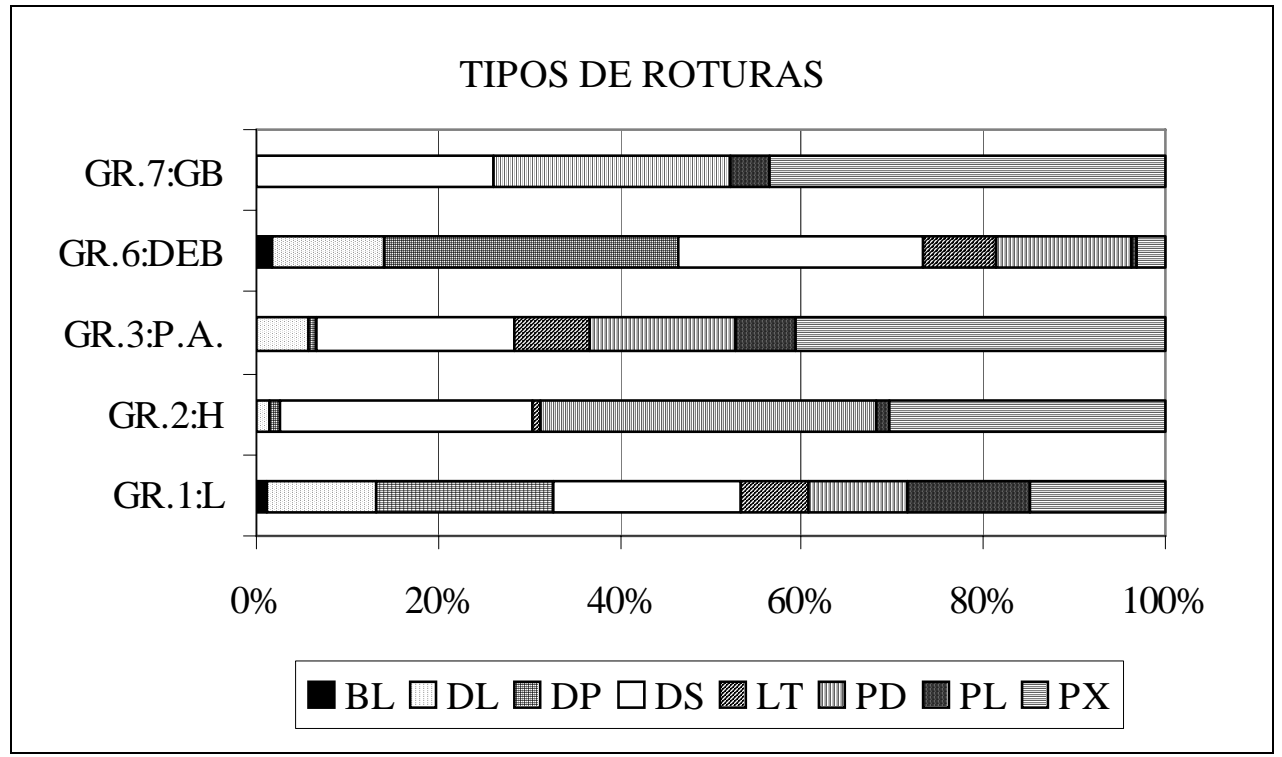

Gráfico SN.1: porcentaje de los tipos de roturas por grupos tecnológicos. Tipos de roturas: BL: bilateral, DL: distal-lateral, DP: distal-proximal-lateral, LT: lateral, PD: proximal-distal, PL: proximal-lateral, PX: proximal.

Si observamos el gráfico SN.1 se pueden identificar dos patrones de comportamiento en los tipos de roturas presentes en los distintos grupos tecnológicos:

a) En el grupo 1 y 6 (las lascas y los debris) están representados todos los estados del atributo analizado, los elementos líticos están rotos de una forma más o menos anárquica, sin que se pueda marcar ninguna tendencia especial, tan solo cabe señalar que en los debris hay una tercera parte de ellos que están rotos por todos lados. Es posible que este tipo de representación sea característico de la pauta de rotura de un conjunto lítico afectado por roturas ajenas a factores humanos intencionales. Las roturas pueden ser consecuencia del propio proceso de talla, o bien de procesos postdeposicionales que hayan incidido sobre el registro.

b) En el grupo de los soportes laminares la representación de los tipos de roturas se polariza hacia las fracturas que afectan de forma transversal (las roturas distales, proximales y próximo-distales). Esta circunstancia puede deberse por un lado a la propia clasificación de este tipo de soportes, en los cuales se suele poner un especial cuidado en definir correctamente, por lo que los fragmentos laterales o con roturas que impidan reconocer eficazmente a las hojas-hojitas no se suelen considerar como tales. Por otro 
lado puede deberse también a que muchos de ellos corresponden a piezas retocadas, piezas que pueden tener quizás alguna rotura intencional dirigida para obtener por ejemplo una longitud determinada de hojitas de dorso. Esta última posibilidad, que haría recaer la explicación de esta segunda pauta de rotura a un factor de tipo cultural, habrá que valorarla al examinar los soportes seleccionados para retocar.

Los productos de acondicionamiento y los golpes de buril tienen también un predominio de las roturas que afectan de forma transversal a las piezas. En el caso de los primeros hay muchos de ellos que están retocados, por lo que se plantea la hipótesis, apuntada en el párrafo anterior sobre su relación con los tipos de piezas retocadas.

\section{IV.1.1.2.3. CAUSA DE LA ROTURA}

En la causa de las roturas (cuadro SN.8), la flexión y las fracturas indeterminadas tienen un porcentaje equilibrado (39 y 38\%), mientras que la rotura por percusión tiene una menor representación (22\%). El grupo tecnológico en el que más aparece la flexión es el de los soportes laminares. Las causas de las roturas según sus distintos tipos y por grupos tecnológicos (gráfico SN.2) tienen una presencia dispar, sin que se puedan ver pautas claras predominantes.

\begin{tabular}{|l|cccc|cc|}
\hline & GR.1 & GR.2 & GR.3 & GR.6 & N & $\%$ \\
\hline Flexión & 1058 & 405 & 42 & 694 & 2199 & 39,3 \\
Indeterminada & 1097 & 172 & 38 & 818 & 2125 & 38,0 \\
Percusión & 687 & 249 & 26 & 308 & 1270 & 22,7 \\
\cline { 5 - 7 } & & & & & &
\end{tabular}

Cuadro SN.8: causa rotura en los distintos grupos tecnológicos. 

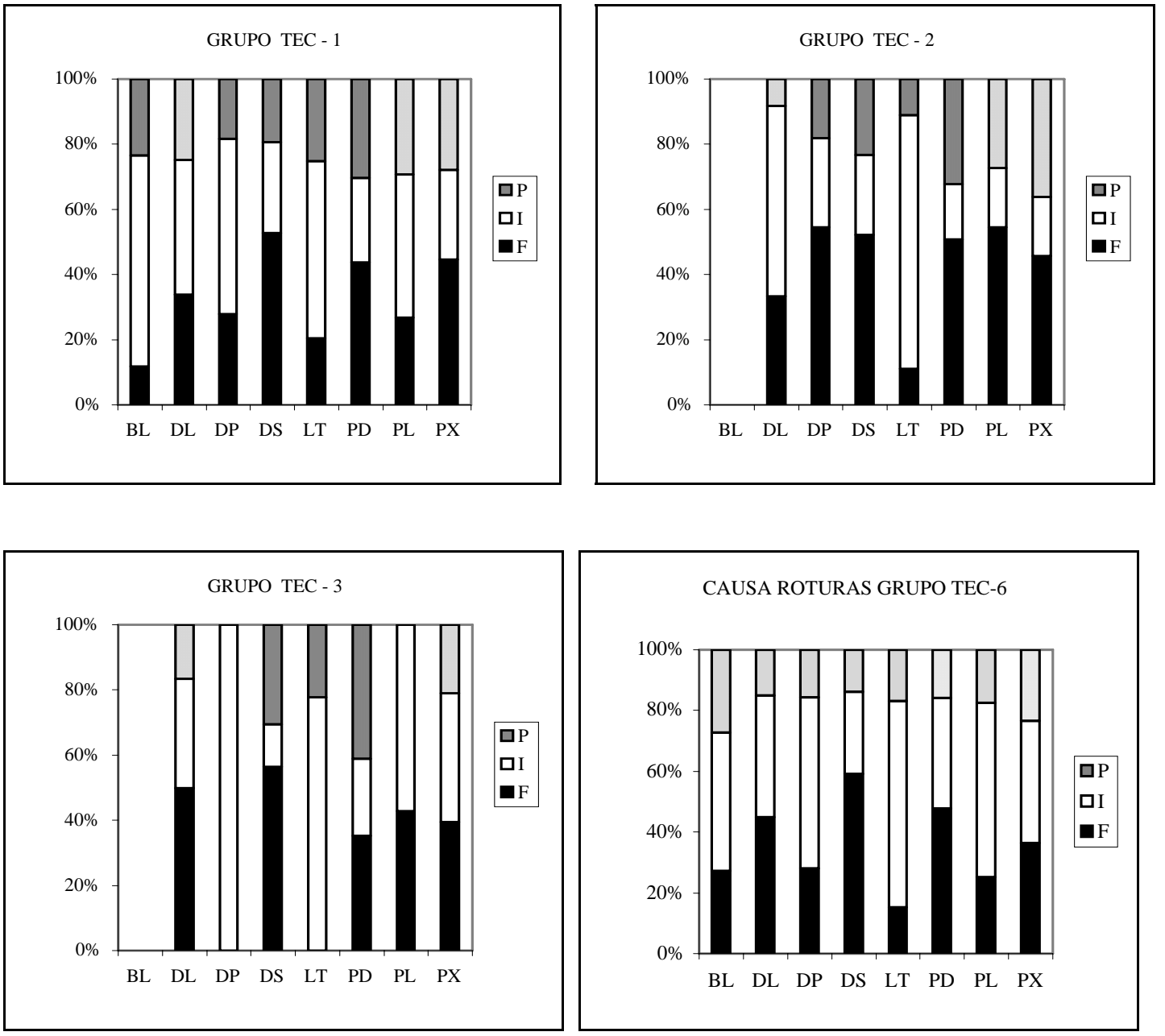

Gráfico SN.2: porcentaje de representación de las causas de la rotura según los distintos tipos de fracturas y por grupos tecnológicos. En el eje de abscisas se colocan los tipos de roturas: BL: bilateral, DL: distal-lateral, DP: distal-proximal-lateral, LT: lateral, PD: proximal-distal, PL: proximal-lateral, PX: proximal. En el eje de ordenadas se sitúa el porcentaje de las causas de las roturas: P: percusión, I: indeterminada, F: por flexión.

\section{IV.1.1.3. CÓRTEX}

La presencia de córtex no es muy abundante (cuadro SN.9), tan solo el 14\% de las piezas tienen restos de corteza, siendo además este tipo de materia donde más aparece la superficie cortical. Son los productos de acondicionamiento, los núcleos y las "hojas con flanco" los soportes que más córtex tienen, pero siempre en porcentajes bastante reducidos. 


\begin{tabular}{|l|rrrrrr|r|}
\hline & \multicolumn{7}{|c|}{ CÓRTEX } \\
\hline L & 1 & $\%$ & 2 & $\%$ & 3 & $\%$ & \\
L-H & 186 & 5,24 & 456 & 12,85 & 2907 & 81,91 & 3549 \\
H & & & 11 & 8,21 & 124 & 92,54 & 134 \\
H-FN & 9 & 2,01 & 77 & 17,19 & 362 & 80,80 & 448 \\
HT & & & 4 & 33,33 & 8 & 66,67 & 12 \\
LC & 2 & 0,40 & 28 & 5,53 & 476 & 94,07 & 506 \\
TN & 1 & 1,56 & 12 & 18,75 & 51 & 79,69 & 64 \\
SN & & & 0 & 0,00 & 3 & 100,00 & 3 \\
FN & & & 3 & 13,64 & 19 & 86,36 & 22 \\
AN & & & 14 & 24,14 & 44 & 75,86 & 58 \\
Nuc. & 1 & 4,76 & 7 & 33,33 & 20 & 95,24 & 21 \\
GB & & & 15 & 40,54 & 22 & 59,46 & 37 \\
IT & 1 & 3,33 & 8 & 26,67 & 21 & 70,00 & 30 \\
DEB:LT & 14 & 2,96 & 44 & 9,30 & 415 & 87,74 & 473 \\
DEB:IT & 84 & 3,38 & 103 & 4,14 & 2298 & 92,47 & 2485 \\
\hline TOTAL & 12 & 3,21 & 22 & 5,88 & 340 & 90,91 & 374 \\
\hline
\end{tabular}

Cuadro SN.9: presencia de córtex en los principales tipos tecnológicos, con sus respectivos porcentajes.

\section{IV.1.1.4. DATOS MÉTRICOS}

Para presentar las dimensiones de los elementos de sílex negro se ha optado por separarlos según grupos y tipos técnicos, intentando así dar una visión lo más fidedigna posible de los productos presentes en el conjunto lítico. Asimismo se presentan a la vez las dimensiones de los distintos tipos sin retocar y retocados (cuadro SN.10) para ver si se puede determinar alguna preferencia respecto a las dimensiones a la hora de seleccionar los soportes para retocar.

\section{IV.1.1.4.1. TIPOS DE SOPORTES}

Se especifican los datos relativos a las dimensiones medias de la longitud, anchura y grosor, con la media aritmética, el número de elementos sobre los que se han establecido estos cálculos, así como el rango y la desviación típica de cada media. En casi todos los casos las desviaciones son muy amplias, lo cual muestra la amplia dispersión de muchos de estas medidas. El grosor, como es lógico sería el dato que tiene una desviación menor. El número de elementos tenidos en cuenta para las distintas medidas varía debido a que no es posible tomar cada uno de estos datos en todas las piezas estudiadas, a este respecto hay que recordar el alto porcentaje de elementos rotos 
en el conjunto. Para la longitud sólo se han considerado las piezas completas, para la anchura también se han incluido en los cálculos los fragmentos distales, mesiales y proximales; y para el grosor el total de las piezas de un tipo. En el caso del grupo tecnológico 5, relativo a los chunks y piezas indeterminadas, se muestran las medidas del total de las piezas, ya que en la propia clasificación de estos elementos queda implícito su carácter de elementos informes; su dimensión es representativa de esta condición.

Para calcular las dimensiones medias no solo se han separado los grupos tecnológicos, sino que, dentro de algunos de los grupos tecnológicos, se han individualizado ciertos tipos soportes para poder comprobar de forma más detallada las dimensiones de los distintos productos, así como sus implicaciones respecto a la evolución de las secuencias del proceso de talla. Así en el grupo 1 se han separado las lascas, las lascas laminares y las hojas totalmente corticales (hojas de encetadura). Estas últimas son muy interesantes para valorar los métodos de iniciación del débitage laminar sobre todo en lo relativo a la longitud inicial de la superficie seleccionada para instalar la superficie de extracciones. En el grupo 2 se han diferenciado, por un lado el conjunto de los soportes laminares (hojas y hojitas) y, por otro, las "hojas con flanco"23.

La mayor dimensión de los elementos de sílex negro no llega a los $10 \mathrm{~cm}$, la mayor longitud está en un núcleo de $98 \mathrm{~mm}$, seguido por un flanco de núcleo que alcanza los $84 \mathrm{~mm}$. Cabe pensar entonces que los bloques seleccionados de chert, o al menos la superficie seleccionada de dichos bloques para instalar la superficie de extracciones es inferior a $10 \mathrm{~cm}$, lo cual definiría el límite máximo en la longitud de las extracciones. Es de suponer que esta medida máxima es un límite impuesto por las dimensiones originales de los bloques de materia prima, al menos para un tipo de débitage laminar.

23 Todos estos criterios, tanto los datos estadísticos calculados como la presentación de los distintos tipos de soportes y el número de elementos observados en cada medida, son válidos tanto para el sílex negro como para el resto de las materias primas. 


\begin{tabular}{|c|c|c|c|c|c|c|c|}
\hline SIN RETOCAR & & & & RETOCADAS & & & \\
\hline GR-0 & $\mathbf{L}$ & A & G & GR-0 & $\mathbf{L}$ & $\mathbf{A}$ & G \\
\hline $\mathrm{N}$ & 11 & 11 & 11 & $\mathrm{~N}$ & 3 & 3 & 3 \\
\hline Rango & $13-62$ & $18-53$ & 3-29 & Rango & $46-57$ & $25-35$ & $6-14$ \\
\hline Media & 43,82 & 34,09 & 11,91 & Media & 50,67 & 28,33 & 11 \\
\hline Desviación & 14,06 & 10,65 & 7,47 & Desviación & 5,69 & 1,56 & 4,36 \\
\hline GR1:L & $\mathbf{L}$ & A & G & GR1:L & $\mathbf{L}$ & A & G \\
\hline $\mathrm{N}$ & 1218 & 2518 & 3206 & $\mathrm{~N}$ & 153 & 310 & 351 \\
\hline Rango & $5-79$ & $3-62$ & $0,4-26$ & Rango & $12-94$ & $6-76$ & $1-24$ \\
\hline Media & 16,65 & 14,88 & 3,52 & Media & 29,92 & 23,02 & 6,19 \\
\hline Desviación & 9,09 & 7,17 & 2,55 & Desviación & 14,31 & 10,39 & 3,67 \\
\hline GR1:L-H & $\mathbf{L}$ & A & G & GR1:L-H & $\mathbf{L}$ & A & G \\
\hline $\mathrm{N}$ & 31 & 102 & 104 & $\mathrm{~N}$ & 10 & 32 & 32 \\
\hline Rango & $10-58$ & $5-31$ & $1-8$ & Rango & $19-62$ & $9-30$ & $2-10$ \\
\hline Media & 20,32 & 13,54 & 2,77 & Media & 30,70 & 17,32 & 4,04 \\
\hline Desviación & 10,16 & 4,41 & 1,41 & Desviación & 12,71 & 4,41 & 1,69 \\
\hline GR1:H & $\mathbf{L}$ & A & G & GR1:H & $\mathbf{L}$ & A & G \\
\hline $\mathrm{N}$ & 1 & 7 & 7 & $\mathrm{~N}$ & 1 & 2 & 2 \\
\hline Rango & & $8-22$ & $1-10$ & Rango & & $12-25$ & 3-8 \\
\hline Media & 69 & 13,28 & 4,71 & Media & 62 & & \\
\hline Desviación & & 4,53 & 3,04 & Desviación & & & \\
\hline GR2:H & $\mathbf{L}$ & A & G & GR2:H & $\mathbf{L}$ & A & G \\
\hline $\mathrm{N}$ & 113 & 624 & 632 & $\mathrm{~N}$ & 63 & 128 & 310 \\
\hline Rango & $8-77$ & $4-30$ & $0,5-11$ & Rango & $13-64$ & $4-26$ & $1-11$ \\
\hline Media & 24,79 & 9,54 & 2,46 & Media & 35,89 & 13 & 3,27 \\
\hline Desviación & 13,29 & 3,65 & 1,43 & Desviación & 12,97 & 5,61 & 1,54 \\
\hline GR2:H-FN & $\mathbf{L}$ & A & G & GR2:H-FN & $\mathbf{L}$ & A & G \\
\hline $\mathrm{N}$ & 4 & 4 & 4 & $\mathrm{~N}$ & 3 & 7 & 7 \\
\hline Rango & $18-45$ & 7-12 & $3-5$ & Rango & $46-60$ & $12-36$ & 3-8 \\
\hline Media & 28 & 9,25 & 4 & Media & 52,67 & 19,86 & 5,08 \\
\hline Desviación & 12,30 & 2,06 & 0,81 & Desviación & 7,02 & 7,99 & 1,91 \\
\hline GR3:P.A. & $\mathbf{L}$ & A & G & GR3:P.A. & $\mathbf{L}$ & A & G \\
\hline $\mathrm{N}$ & 129 & 132 & 135 & $\mathrm{~N}$ & 27 & 40 & 40 \\
\hline Rango & $7-84$ & $6-55$ & $1-31$ & Rango & $16-73$ & $10-46$ & $2-22$ \\
\hline Media & 28,02 & 18,36 & 7,88 & Media & 36,11 & 22,72 & 8,7 \\
\hline Desviación & 14,63 & 9,21 & 4,75 & Desviación & 16,54 & 8,70 & 4,59 \\
\hline GR4:N & $\mathbf{L}$ & A & G & GR4:N & $\mathbf{L}$ & A & G \\
\hline $\mathrm{N}$ & 37 & 37 & 37 & $\mathrm{~N}$ & - & - & - \\
\hline Rango & $16-98$ & $13-62$ & $12-55$ & Rango & & & \\
\hline Media & 46,43 & 35,70 & 25,22 & Media & & & \\
\hline Desviación & 16,57 & 11,25 & 10,08 & Desviación & & & \\
\hline GR5:IT & $\mathbf{L}$ & A & G & GR5:IT & $\mathbf{L}$ & A & G \\
\hline $\mathrm{N}$ & 459 & 459 & 459 & $\mathrm{~N}$ & 14 & 14 & 14 \\
\hline Rango & $9-55$ & 3-33 & $0,5-37$ & Rango & $12-39$ & $5-31$ & $2,7-18$ \\
\hline Media & 16,51 & 9,65 & 4,81 & Media & 24,57 & 15,36 & 7,83 \\
\hline Desviación & 6,30 & 5,08 & 3,54 & Desviación & 9,66 & 8,05 & 5,10 \\
\hline GR6:DEB & $\mathbf{L}$ & A & G & GR6:DEB & $\mathbf{L}$ & A & G \\
\hline $\mathrm{N}$ & 2844 & 2844 & 2844 & $\mathrm{~N}$ & 15 & 15 & 15 \\
\hline Rango & $1-10$ & $0,6-10$ & $0,1-9$ & Rango & $6-10$ & $4-10$ & $1-5$ \\
\hline Media & 7,55 & 7,04 & 1,71 & Media & 8,63 & 7,93 & 2,11 \\
\hline Desviación & 1,76 & 1,92 & 1,04 & Desviación & 1,47 & 1,75 & 1,07 \\
\hline
\end{tabular}

Cuadro SN.10: datos métricos del sílex negro. N: número de elementos. L: longitud, A: anchura, G: grosor. 
Las lascas tienen unas dimensiones medias que no son demasiado amplias: $\mathrm{L}=17, \mathrm{~A}=15, \mathrm{G}=4 \mathrm{~mm}$; estas medidas definirían unos productos cuadrangulares o rectangulares de un grosor medio, pero la amplia desviación de estos datos dan una idea de la variedad de dimensiones que incluyen. Las lascas laminares están compuestas por soportes más alargados y estrechos que los anteriores: $\mathrm{L}=20, \mathrm{~A}=14, \mathrm{G}=3$; encontrándose a medio camino entre las lascas y las hojas. De las "hojas de encetadura" solo hay una donde podemos observar su longitud (69 mm), teniendo el resto de las piezas una anchura de $13 \mathrm{~mm}$ y un grosor de 5; en consecuencia serían piezas más características de la fase de preparación que de producción propiamente dicha, sobre todo por su grosor.

Los soportes laminares tienen unas medias de: $\mathrm{L}=25, \mathrm{~A}=10, \mathrm{G}=3 \mathrm{~mm}$. Las "hojas con flanco" ( $\mathrm{L}=28, \mathrm{~A}=9, \mathrm{G}=4)$ tan solo se individualizan, respecto a las hojashojitas, de una forma clara en su grosor; y en la longitud se acercan también a los productos de acondicionamiento.

Los productos de acondicionamiento ( $\mathrm{L}=28, \mathrm{~A}=18, \mathrm{G}=8 \mathrm{~mm}$ ) son piezas bastante alargadas (su longitud les acerca más a los soportes laminares que a las lascas), anchas y gruesas, dimensiones que concuerdan con su función de mantener y reparar el núcleo. En el apartado dedicado específicamente a este tipo de soportes se individualizarán los distintos tipos productos de acondicionamiento, y podrá verse de forma más clara las diferentes dimensiones de las piezas procedentes de reparaciones de la superficie de extracciones (flancos de núcleo, piezas con cresta) en oposición a las del plano de percusión (tabletas y semitabletas). En el caso de los flancos de núcleo, su longitud se acerca más a las de la superficie de extracciones de los núcleos, y en el caso de las tabletas y semitabletas a las de las lascas.

Los núcleos tienen unas dimensiones de: $\mathrm{L}=46, \mathrm{~A}=37, \mathrm{G}=25 \mathrm{~mm}$; nos indicarían unos volúmenes tendentes a ser alargados y no demasiado gruesos, pero habrá que separarlos a partir de sus distintos esquemas técnicos para poder valorar mejor las dimensiones de cada uno y los soportes que aportan. Las medias de los fragmentos de nódulos incluidos en el grupo 0 se acercan mucho a las de los núcleos ( $\mathrm{L}=44, \mathrm{~A}=34$, $\mathrm{G}=12 \mathrm{~mm}$ ). 
Los chunks y soportes indeterminados tienen unas dimensiones que los acercan a las lascas: $L=17, A=10, G=5$; excepto porque tienden a ser más estrechos y algo más gruesos. Por último el conjunto de los debris; que reúne tanto las lasquitas de talla y de retoque como los fragmentos de lascas y otros soportes más o menos indeterminados, todos ellos inferiores a $10 \mathrm{~mm}$; tienen unas dimensiones de: $\mathrm{L}=8, \mathrm{~A}=7, \mathrm{G}=2 \mathrm{~mm}$. Serían por tanto lasquitas cuadrangulares, cuyo tamaño estaría cercano al límite impuesto en la individualización del grupo $(10 \mathrm{~mm})$.

Para valorar de una forma sintética y clara las dimensiones de estas piezas se pueden retener los principales grupos tecnológicos:

- Grupo tecnológico 1 (lascas): $\mathrm{L}=17, \mathrm{~A}=15, \mathrm{G}=4 \mathrm{~mm}$

- Grupo 2 (soportes laminares): $L=25, A=10, G=3 \mathrm{~mm}$

- Grupo 3 (productos de acondicionamiento): L=28, A=18, G=8 mm

- Grupo 4 (núcleos): L=46, A=37, G=25 mm

El resto de los soportes presentan características intermedias entre uno y otro de estos soportes, indicativas de pasos intercalados a lo largo de las secuencias del proceso de talla.

Al comparar las medias de las distintas medidas con las piezas retocadas, se puede constatar un incremento de los valores de forma generalizada, hay una tendencia a seleccionar los soportes más grandes en todos los grupos tecnológicos a la hora de elegir aquellos que se van a retocar.

IV.1.1.4.2. TALÓN

Respecto a la dimensión del talón, se presenta la longitud y la anchura de los distintos grupos tecnológicos. Estas medidas (sobre todo la anchura) serán importantes a la hora de valorar el modo de talla aplicado. Como para las dimensiones totales de los soportes, no se ha podido tomar los datos relativos al tamaño del talón más que en los soportes enteros o los fragmentos proximales (Cuadro SN.11). Se aprecia claramente la relación existente entre los tipos de soportes y el tamaño del talón, de modo que es 
mucho más reducido en las hojas y hojitas $(L=5,22 ; A=1,93)$ que en las lascas $(L=8,92$; $\mathrm{A}=2,99)$ y productos de acondicionamiento $(\mathrm{L}=11,07 ; \mathrm{A}=4,21)$.

\begin{tabular}{|c|c|c|c|c|c|}
\hline \multicolumn{3}{|l|}{ SIN RETOCAR } & \multicolumn{3}{|l|}{ RETOCADAS } \\
\hline GR1:L & $\mathbf{L}$ & A & GR1:L & $\mathbf{L}$ & A \\
\hline $\mathrm{N}$ & 787 & 1063 & $\mathrm{~N}$ & 120 & 158 \\
\hline Rango & $0,9-45$ & $0,2-17$ & Rango & $1-39,1$ & $0,5-24$ \\
\hline Media & 8,92 & 2,99 & Media & 14,06 & 4,74 \\
\hline Desviación & 5,65 & 2,34 & Desviación & 7,73 & 3,53 \\
\hline GR1:L-H & $\mathbf{L}$ & A & GR1:L-H & $\mathbf{L}$ & A \\
\hline $\mathrm{N}$ & 42 & 47 & $\mathrm{~N}$ & 11 & 12 \\
\hline Rango & $1-15$ & $0,3-6,7$ & Rango & $0,9-20,8$ & $1,22-5,2$ \\
\hline Media & 7,25 & 2,27 & Media & 7,14 & 2,47 \\
\hline Desviación & 2,96 & 1,30 & Desviación & 5,54 & 1,24 \\
\hline GR1:H & $\mathbf{L}$ & A & GR1:H & $\mathbf{L}$ & $\mathbf{A}$ \\
\hline $\mathrm{N}$ & - & - & $\mathrm{N}$ & 1 & 1 \\
\hline Rango & & & Rango & & \\
\hline Media & & & Media & 24,3 & 2,3 \\
\hline Desviación & & & Desviación & & \\
\hline GR2:H & $\mathbf{L}$ & A & GR2:H & $\mathbf{L}$ & A \\
\hline $\mathrm{N}$ & 123 & 144 & $\mathrm{~N}$ & 75 & 80 \\
\hline Rango & $1-12,6$ & $0,2-8$ & Rango & 1,3-20,5 & $0,3-7,5$ \\
\hline Media & 5,22 & 1,93 & Media & 7,26 & 2,39 \\
\hline Desviación & 2,38 & 1,22 & Desviación & 3,87 & 1,58 \\
\hline GR2:H-FN & $\mathbf{L}$ & A & GR2:H-FN & $\mathbf{L}$ & A \\
\hline $\mathrm{N}$ & 2 & 2 & $\mathrm{~N}$ & 4 & 5 \\
\hline Rango & $3,7-4$ & $1,3-3$ & Rango & 5,5-21 & $3,3-7$ \\
\hline Media & & & Media & 12,82 & 4,7 \\
\hline Desviación & & & Desviación & 7,29 & 1,52 \\
\hline GR3:P.A. & $\mathbf{L}$ & A & GR3:P.A. & $\mathbf{L}$ & A \\
\hline $\mathrm{N}$ & 39 & 51 & $\mathrm{~N}$ & 13 & 18 \\
\hline Rango & $2-26$ & $0,5-11$ & Rango & $3,5-24$ & $1,2-12$ \\
\hline Media & 11,07 & 4,21 & Media & 12,21 & 4,54 \\
\hline Desviación & 6,70 & 2,80 & Desviación & 6,22 & 2,99 \\
\hline GR6:DEB & $\mathbf{L}$ & A & GR6:DEB & $\mathbf{L}$ & A \\
\hline $\mathrm{N}$ & 482 & 615 & $\mathrm{~N}$ & - & - \\
\hline Rango & $0,7-10$ & $0,2-6,6$ & Rango & & \\
\hline Media & 5,01 & 1,61 & Media & & \\
\hline Desviación & 1,99 & 0,98 & Desviación & & \\
\hline
\end{tabular}

Cuadro SN.11: medidas del talón de las piezas de sílex negro. L: longitud. A: anchura. 
En casi todos los casos estas dimensiones muestran talones alargados y estrechos, que en los soportes laminares se suelen convertir en talones de aspecto lineal y en los debris ( $\mathrm{L}=5 ; \mathrm{A}=1,61 \mathrm{~mm}$ ) puntiformes. Una anchura del talón grande (como los $3 \mathrm{~mm}$ de las lascas y los 4 de los productos de acondicionamiento) puede implicar una percusión interna en el plano de percusión. Este tipo de percusión puede relacionarse con una percusión directa con percutor duro, lo cual es muy habitual en las primeras fases del proceso de talla y en secuencias de acondicionamiento. Por el contrario, una anchura menor del talón (en el caso de las hojas-hojitas es menor a $2 \mathrm{~mm}$ ) implicaría un tipo de percusión tangencial, la cual podría relacionarse también con una percusión con percutor blando, o al menos algún cambio en los gestos aplicados en la percusión. Estas diferencias en la dimensión de los talones pueden indicar diferencias en los procedimientos empleados en la extracción de los distintos soportes, hay que valorar sobre más atributos (preparación del frente de percusión, ángulo de talla, modo de talla identificado) el modo de talla empleado así como los cambios a lo largo del proceso de talla.

Las piezas retocadas tienen la misma tendencia a seleccionar las piezas con dimensiones mayores, de igual manera que ocurría en el caso del tamaño de los soportes. Esta selección de los soportes más grandes es muy marcada en el caso de las lascas $(\mathrm{L}=14 ; A=4,74 \mathrm{~mm})$ y en menor grado en los soportes laminares $(L=7,26$; $\mathrm{A}=2,39 \mathrm{~mm}$ ). También tenemos una media para las "hojas con flanco", de las que no disponíamos datos para las piezas sin retocar ( $L=12,82 ; A=4,7)$, mostrando un tipo de soportes con talón bastante “robusto", más cercano a los productos de acondicionamiento que a las hojas.

\section{IV.1.1.5. ACCIDENTES}

El accidente más frecuente en el chert negro es el reflejado, que afecta a la mitad de las piezas y de una forma similar a los distintos soportes (cuadro SN.12, gráfico SN.3). A continuación está el pseudoburil de Siret, que afecta al 22\% de los soportes, siendo más abundantes en los grupos 1 y 6. El hecho de aparecer de forma más abundante en el conjunto de lascas y el de los debris puede estar relacionado con el 
modo de talla, en el sentido de que parece que hay una relación entre un modo de talla con percusión dura, con un impacto fuerte, con la aparición de este accidente. Los planos de rotura natural presentes en la materia prima afectan también de un modo genérico a los distintos soportes del proceso de débitage de estos núcleos.

\begin{tabular}{|l|cccccc|r|}
\hline & DB & LG & PB & RF & SP & PN & N \\
\hline GR.1 & 17 & 38 & 252 & 506 & 40 & 192 & 1045 \\
GR.2 & 1 & 27 & 15 & 133 & 23 & 28 & 227 \\
GR.3 & 1 & 1 & 1 & 17 & 14 & 18 & 52 \\
GR.6 & 1 & 10 & 137 & 257 & 8 & 52 & 465 \\
GR.7 & 0 & 0 & 0 & 4 & 0 & 2 & 6 \\
\hline N & 20 & 76 & 405 & 917 & 85 & 292 & 1795 \\
$\%$ & 1,11 & 4,23 & 22,56 & 51,09 & 4,74 & 16,27 & 100 \\
\hline
\end{tabular}

Cuadro SN.12: accidentes de talla según los distintos grupos tecnológicos. DB: doble bulbo, LG: fragmento en lengüeta, PB: pseudoburil de Siret, RF: reflejado, SP: sobrepasado, PN: plano natural.

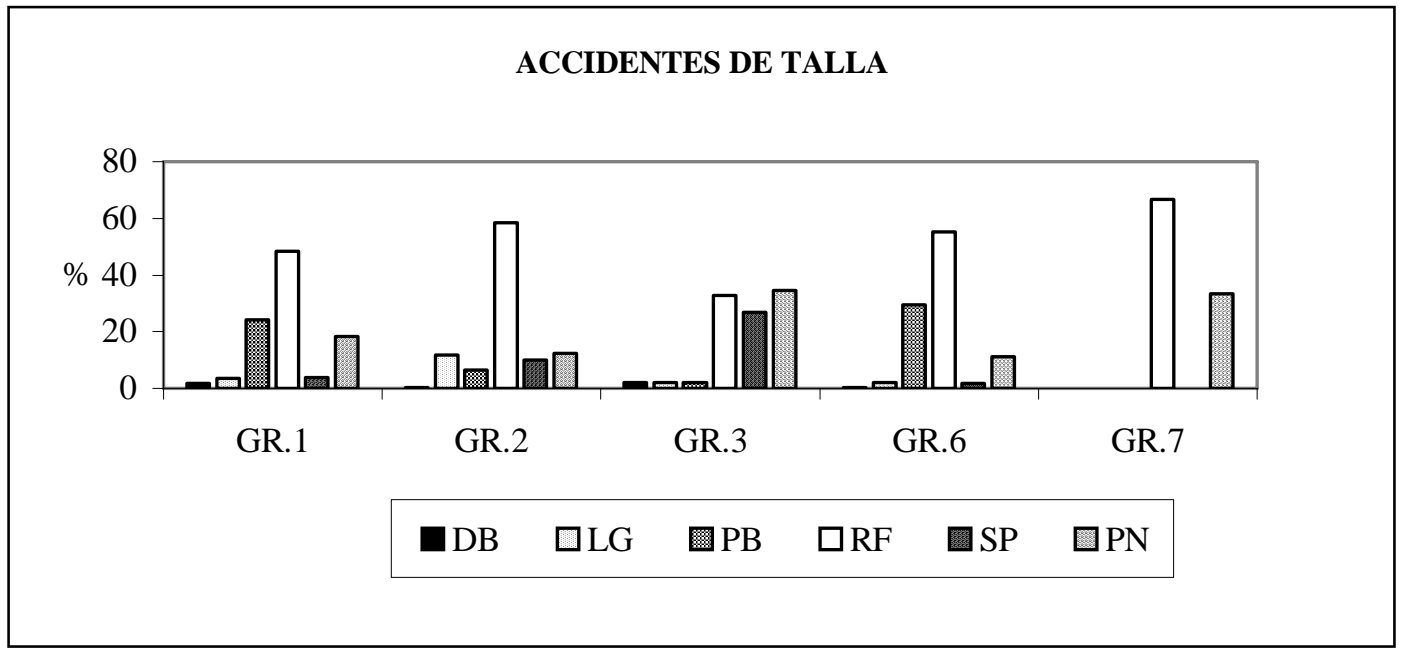

Gráfico SN.3: accidentes de talla por grupos tecnológicos. DB: doble bulbo, LG: fragmento en lengüeta, PB: pseudoburil de Siret, RF: reflejado, SP: sobrepasado, PN: plano natural.

El resto de los accidentes aparecen de forma minoritaria, inferior al 5\% del conjunto; los fragmentos en lengüeta se presentan sobre todo en el grupo de las hojashojitas, indicando quizás alguna relación con el modo de talla aplicado en la secuencia de débitage pleno propiamente dicha. Los sobrepasados aparecen de forma más abundante en el grupo 2 y sobre todo en el grupo de los productos de acondicionamiento, por lo que de nuevo puede que estén relacionados con los métodos 
adoptados en la fase de producción. Por último el doble bulbo aparece tan solo en un 1\% de las piezas, y en este caso está prácticamente centrado en las piezas del grupo 1. La aparición del doble bulbo es debida al contacto de dos puntos del percutor sobre el plano de percusión, y el hecho de que se localice especialmente sobre el grupo tecnológico que agrupa las piezas de la primera fase y en general las lascas menos específicas, puede apuntar a la presencia, en la extracción de este tipo de piezas, de un modo de talla distinto al empleado en la fase de producción plena, quizás una percusión directa con percutor duro.

En los tipos de accidentes presentes en el conjunto lítico del sílex negro y su representación a lo largo de los distintos grupos tecnológicos surgen dos conjuntos de soportes que coinciden con las fases 1 y 2 del proceso operativo genérico. Estas agrupaciones estarían relacionadas sobre todo con los modos de talla adoptados en estas fases genéricas de la cadena operativa (fase de preparación y de producción plena).

a) Por un lado están los soportes del grupo 1, el que reúne a los elementos de la primera fase del proceso de talla y a las lascas en general; en ellos es donde mayor representación hay de los pseudoburiles de Siret y del doble bulbo. Ambos son accidentes que se producen en la zona del talón, relacionados directamente con el tipo de percusión ejecutada, apuntando probablemente a una percusión directa con percutor duro. El pseudoburil se relaciona con un impulso bastante intenso, por lo que es muy probable que se produzca en las primeras secuencias de talla, en la preparación del núcleo, en momentos en los que se produce una conformación del bloque, obteniendo grandes lascas corticales o semicorticales por ejemplo. El doble bulbo es debido a que el percutor deja dos puntos de impacto, y de nuevo este tipo de accidente parece apuntar a una percusión dura: normalmente es el percutor duro el que deja el punto de impacto muy marcado, la existencia de un doble bulbo se explica porque el contacto entre el percutor y el plano de percusión se produce en una superficie relativamente amplia y de forma que el percutor tenga más de un punto de contacto con el talón; no obstante este tipo de accidente puede deberse también a un deterioro de las condiciones del percutor. 
b) Por otro lado los soportes del grupo 2 (hojas-hojitas) y 3 (productos de acondicionamiento), tienen una mayor presencia de sobrepasados y, en los soportes laminares, de fracturas en lengüeta. Estos dos accidentes; frente a los anteriores que aparecen justo en el momento de la percusión; se producen a lo largo de la extracción de la pieza. La causa de tales accidentes por tanto puede estar relacionada con un modo de talla en el que más que el impulso de la percusión, sean importantes otros gestos asociados (el ángulo, la colocación del núcleo, las curvaturas técnicas adecuadas, etc.) necesarios para la obtención exitosa de los soportes. En este caso, se relaciona con los soportes laminares, y en general con los obtenidos en la fase de producción plena.

Los reflejados afectan de una forma muy abundante al conjunto de los soportes, sin que se pueda apreciar diferencias netas entre los distintos grupos tecnológicos. En cuanto al grupo de los debris, dado que contiene un buen número de fragmentos de lascas y otros restos de talla, tiene rasgos que lo acercan, sobre todo por el elevado porcentaje de los pseudoburiles de Siret, al grupo tecnológico 1.

\section{IV.1.1.6.- TIPOS DE TALÓN}

Debido al elevado porcentaje de roturas casi la mitad de las piezas de sílex negro carecen de la parte proximal (cuadro SN.6 y SN.14), por lo que no podemos saber su tipo de talón, esta circunstancia es máxima en el caso de los soportes laminares, los cuales tienen más del 60\% de las piezas sin talón. Los talones lisos están en un 20\% de las piezas (cuadro SN.13), seguidos por los rotos (11\%) y los puntiformes (8\%); en porcentajes inferiores al 5\% están los facetados, diedros y corticales.

Si nos fijamos en la representación de los distintos tipos de talones según los grupos tecnológicos (gráfico SN.4), en todos hay un predominio de los talones lisos (aparte de las piezas sin talón) a excepción de los golpes de buril, donde son los rotos los más abundantes. Los corticales y los diedros aparecen sobre todo en los grupos 1 y 3, mientras los suprimidos son más característicos de los soportes de la fase producción 
(grupos 2 y 3). Los rotos son más abundantes en las lascas, los debris y los golpes de buril. Los puntiformes no tienen mucha representación, a excepción de los debris.

\begin{tabular}{|l|cccccccc|r|}
\hline & $\mathrm{C}$ & $\mathrm{D}$ & $\mathrm{F}$ & $\mathrm{L}$ & $\mathrm{O}$ & $\mathrm{P}$ & $\mathrm{R}$ & $\mathrm{S}$ & $\mathrm{N}$ \\
\hline GR.1 & 113 & 172 & 229 & 764 & 1709 & 237 & 395 & 37 & 3656 \\
GR.2 & 11 & 24 & 54 & 142 & 591 & 51 & 54 & 26 & 953 \\
GR.3 & 11 & 11 & 18 & 36 & 78 & 5 & 9 & 7 & 175 \\
GR.6 & 41 & 63 & 55 & 482 & 1171 & 314 & 357 & 2 & 2485 \\
GR.7 & 0 & & 2 & 2 & 17 & 3 & 8 & 0 & 32 \\
\hline TOTAL & 176 & 270 & 358 & 1426 & 3566 & 610 & 823 & 72 & 7301 \\
$\%$ & 2,41 & 3,70 & 4,90 & 19,53 & 48,84 & 8,36 & 11,27 & 0,99 & 100 \\
\hline
\end{tabular}

Cuadro SN.13: tipos de talón por grupos tecnológicos. C: cortical, D: diedro, F: facetado, L: liso, O: sin talón, P: puntiforme, R: roto, S: suprimido.

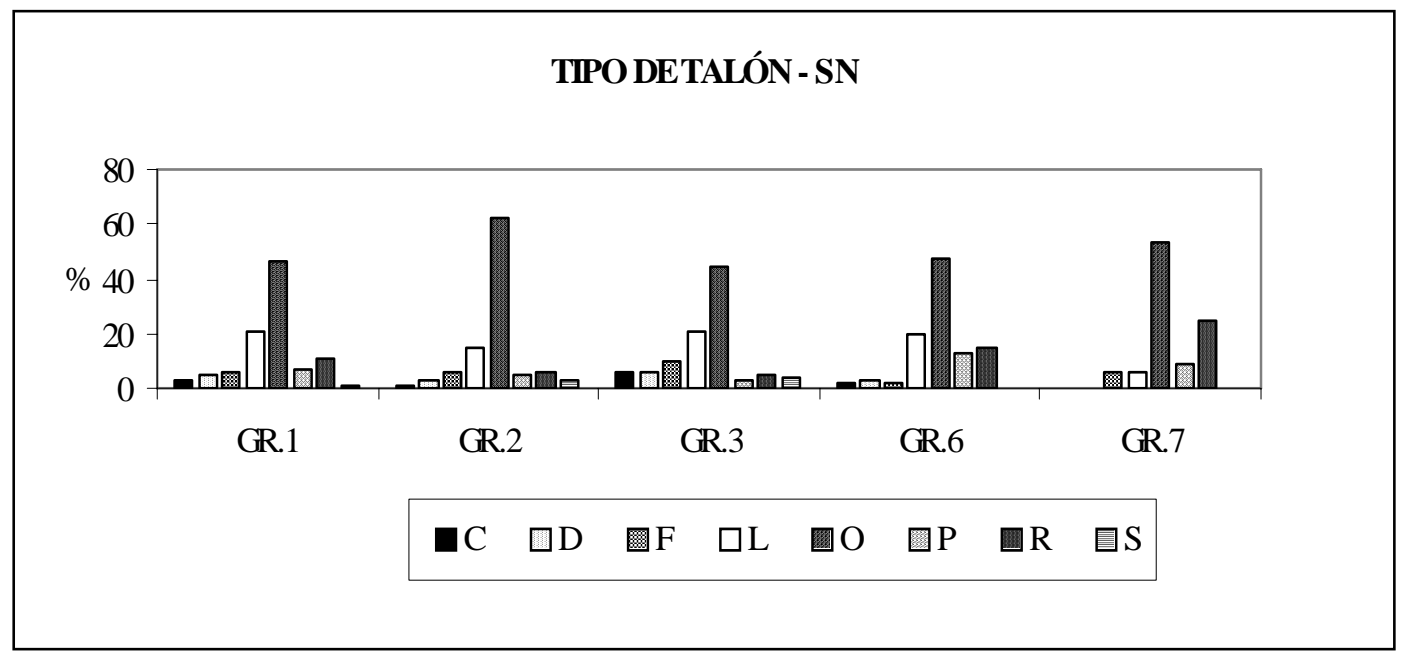

Gráfico SN.4: tipos de talón por grupos tecnológicos. C: cortical, D: diedro, F: facetado, L: liso, O: sin talón, P: puntiforme, R: roto, S: suprimido.

Se pueden resumir las características de los talones en los siguientes puntos:

- la gran mayoría de las piezas están sin talón

- de los soportes en los que el talón es legible, la mitad de ellos (en torno al 20\%) aproximadamente tienen un talón liso

- el resto de los tipos de talón (diedros, facetados, puntiformes) tienen una presencia porcentual mucho menor, inferior casi siempre al 10\%

- Algunos tipos de talón son más abundantes (de manera muy relativa) en ciertos soportes: los corticales en el grupo 1 y 3, los suprimidos en el 2 y 3; pero puede tratarse de aspectos puntuales 
- los debris se separan un poco de la tendencia general, al predominar en ellos de forma muy clara los talones puntiformes a continuación de los lisos

Hay por tanto una tendencia muy clara al predominio de los talones lisos, las variantes en los tipos de talón parecen corresponder a aspectos muy puntuales y bastante lógicos con relación a los soportes sobre los que afecta: el talón cortical sobre las lascas y productos de acondicionamiento, el suprimido en los soportes laminares y productos de acondicionamiento, que son las piezas más retocadas; por último, la abundancia de los puntiformes en los debris es una circunstancia que está totalmente de acuerdo con el pequeño tamaño de las lasquitas de talla.

\section{IV.1.1.7.- PREPARACIÓN DEL PUNTO DE IMPACTO}

Para valorar la preparación de la cornisa del frente de talla examinaremos dos cuadros. En primer lugar, el cuadro SN.14 muestra las piezas preparadas relativamente al número de elementos disponibles con talón, en él se puede observar cómo los soportes laminares son los más preparados, ya que la mitad de los que disponen talón presentan algún tipo de acondicionamiento. A continuación está el grupo 1, el de las lascas (con un 40\%), después el de los productos de acondicionamiento (31\%) y por último las lasquitas de los debris (27\%). Es bastante coherente que sean los soportes laminares, que teóricamente son los de “primera intención”, los que presenten una preparación mayor, ya que habrá un cuidado especial en que la extracción de estos soportes se produzca de forma adecuada.

\begin{tabular}{|c|c|cc|cc|}
\hline & \multirow{2}{*}{$\mathrm{N}$} & \multicolumn{2}{|c|}{ PIEZAS CON TALÓN } & \multicolumn{2}{c|}{ PIEZAS PREPARADAS } \\
\cline { 3 - 6 } & & $\mathrm{N}$ & $\%$ & $\mathrm{~N}$ & $\%$ \\
\hline GR-1 & 3697 & 2016 & 54,5 & 804 & 39,9 \\
GR-2 & 953 & 378 & 39,7 & 199 & 52,6 \\
GR-3 & 175 & 112 & 64,0 & 35 & 31,3 \\
GR-6 & 2485 & 1388 & 55,9 & 378 & 27,2 \\
\hline & 7310 & 3894 & 53,3 & 1416 & 36,4 \\
\hline
\end{tabular}

Cuadro SN.14: piezas con talón y preparación relativa dentro de los distintos grupos tecnológicos. 
En los tipos de preparación que se han observado, predomina de forma genérica el esquirlado para la los distintos grupos tecnológicos excepto para los soportes laminares, que es más abundante la abrasión (cuadro SN.15). El retoque tiene una presencia moderada en los distintos grupos tecnológicos, siendo menos frecuente en el grupo 2. Respecto a los tipos de talones preparados (cuadro SN.16), hay predominio de los lisos, seguidos por los puntiformes y en menor grado por los facetados, diedros, corticales y suprimidos.

\begin{tabular}{|l|cccc|cc|}
\hline & \multirow{2}{*}{ GR-1 } & \multirow{2}{*}{ GR-2 } & \multirow{2}{*}{ GR-3 } & \multirow{2}{*}{ GR-6 } & \multicolumn{2}{|c|}{ TOTAL } \\
\cline { 6 - 7 } & & & & & $\mathrm{N}$ & $\%$ \\
\hline Facetado & 85 & 13 & 5 & 10 & 113 & 8,0 \\
Abrasión & 107 & 78 & 3 & 123 & 311 & 22,0 \\
Esquirlado & 368 & 69 & 16 & 136 & 589 & 41,6 \\
Retoque & 244 & 39 & 11 & 109 & 403 & 28,4 \\
\hline & 804 & 199 & 35 & 378 & 1416 & 100 \\
\hline
\end{tabular}

Cuadro SN.15: tipos de preparación según los distintos grupos tecnológicos.

\begin{tabular}{|l|cccccc|}
\hline & $\mathrm{C}$ & $\mathrm{D}$ & $\mathrm{F}$ & $\mathrm{L}$ & $\mathrm{P}$ & $\mathrm{R}$ \\
\hline Facetado & 7 & 12 & 75 & 17 & 0 & 2 \\
Abrasión & 13 & 17 & 22 & 173 & 78 & 8 \\
Esquirlado & 24 & 41 & 62 & 227 & 173 & 62 \\
Retoque & 28 & 54 & 38 & 229 & 45 & 9 \\
\hline $\mathrm{N}$ & 72 & 124 & 197 & 646 & 296 & 81 \\
$\%$ & 5,1 & 8,8 & 13,9 & 45,6 & 20,9 & 5,7 \\
\hline
\end{tabular}

Cuadro SN.16: tipos de preparación sobre los distintos tipos de talón. C: cortical, D: diedro, F: facetado, L: liso, O: sin talón, P: puntiforme, R: roto, S: suprimido.

\begin{tabular}{|l|cccccc|}
\hline & $\mathrm{C}$ & $\mathrm{D}$ & $\mathrm{F}$ & $\mathrm{L}$ & $\mathrm{P}$ & $\mathrm{R}$ \\
\hline PIEZAS CON TALÓN & 176 & 270 & 358 & 1426 & 610 & 823 \\
\hline PIEZAS PREPARADAS & 72 & 124 & 197 & 646 & 296 & 81 \\
$\%$ & 40,9 & 45,9 & 55,0 & 45,3 & 48,5 & 9,8 \\
\hline
\end{tabular}

Cuadro SN.17: porcentaje de preparación en los distintos tipos de talón disponibles. C: cortical, D: diedro, F: facetado, L: liso, O: sin talón, P: puntiforme, R: roto, S: suprimido.

No obstante, si tenemos en cuenta la preparación que tiene cada uno de los tipos de talones (cuadro SN.17), los porcentajes se equilibran, de forma que los facetados son lo talones que más preparación presentan, pero los lisos y diedros tienen también casi la 
mitad de las piezas preparadas. En consecuencia, el hecho de que predomine la preparación de los talones lisos de forma absoluta se debe a la mayor abundancia de los talones lisos, no a una preferencia por preparar este tipo de talón en concreto.

En el cuadro SN.18 se muestran cuatro cuadros (uno por cada grupo tecnológico) donde se presenta el porcentaje de los distintos tipos de preparación según los distintos talones. En el grupo 1, el de las lascas en general, el tipo de retoque que predomina es el esquirlado sobre talones lisos. En el grupo 2, el tipo de preparación que predomina es la abrasión en los talones lisos. En el grupo 3 predomina el esquirlado en los talones lisos. En el grupo 6 (las lasquitas recogidas en los debris) hay una preparación similar de abrasión y retoque en los talones lisos por un lado, y esquirlado en los puntiformes.

\begin{tabular}{|l|cccccc|}
\hline TEC-1 & $\mathrm{C}$ & $\mathrm{D}$ & $\mathrm{F}$ & $\mathrm{L}$ & $\mathrm{P}$ & $\mathrm{R}$ \\
\hline Facetado & 0,9 & 1,4 & 6,2 & 1,9 & & 0,2 \\
Abrasión & 0,9 & 0,9 & 1,4 & 7,8 & 1,9 & 0,5 \\
Esquirlado & 2,6 & 4,2 & 5,8 & $\mathbf{1 8 , 0}$ & 11,6 & 3,5 \\
Retoque & 2,5 & 4,6 & 3,4 & 16,9 & 2,4 & 0,6 \\
\hline
\end{tabular}

\begin{tabular}{|l|cccccc|}
\hline TEC-2 & C & D & F & L & P & R \\
\hline Facetado & & & 6,0 & 0,5 & & \\
Abrasión & 1,0 & 2,5 & 4,0 & $\mathbf{2 3 , 1}$ & 8,0 & 0,5 \\
Esquirlado & 0,5 & 1,0 & 4,0 & 18,1 & 7,0 & 4,0 \\
Retoque & 1,5 & 1,5 & 3,5 & 9,5 & 3,0 & 0,5 \\
\hline
\end{tabular}

\begin{tabular}{|l|cccccc|}
\hline TEC-3 & C & D & F & L & P & R \\
\hline Facetado & & 2,9 & 11,4 & & & \\
Abrasión & & & 2,9 & 2,9 & 2,9 & \\
Esquirlado & & 8,6 & 0,0 & $\mathbf{2 2 , 9}$ & 8,6 & 5,7 \\
Retoque & 11,4 & 2,9 & 5,7 & 11,4 & 0,0 & \\
\hline
\end{tabular}

\begin{tabular}{|l|cccccc|}
\hline TEC-6 & $\mathrm{C}$ & $\mathrm{D}$ & $\mathrm{F}$ & $\mathrm{L}$ & $\mathrm{P}$ & $\mathrm{R}$ \\
\hline Facetado & & & 2,4 & 0,3 & & \\
Abrasión & 1,1 & 1,3 & 0,5 & 16,7 & 12,2 & 0,8 \\
Esquirlado & 0,5 & 0,5 & 1,9 & 10,1 & 16,7 & 6,3 \\
Retoque & 0,3 & 3,4 & 0,5 & $\mathbf{1 8 , 5}$ & 5,3 & 0,8 \\
\hline
\end{tabular}

Cuadro SN.18: porcentaje de tipo de preparación por tipos de talón separando por grupos tecnológicos. C: cortical, D: diedro, F: facetado, L: liso, O: sin talón, P: puntiforme, R: roto, S: suprimido.

Los rasgos reseñables de estos cuadros son los siguientes: 
- Los talones lisos son los más preparados en el conjunto de elementos, lo cual resulta bastante lógico teniendo en cuenta que es el tipo de talón más abundante prácticamente en todos los grupos tecnológicos

- Hay una preparación más específica en los soportes de la fase de producción genérica (secuencia de producción de soportes y secuencia de productos de acondicionamiento), se produce el mayor porcentaje de preparación (23\%) en un solo método, la abrasión para las hojas y hojitas y el esquirlado para los productos de acondicionamiento. Por el contrario, en las lascas y los debris los tipos de preparación están más diversificados.

- La abrasión sólo alcanza porcentajes reseñables en los soportes laminares (donde es máximo este índice de representación) y en menor número en los debris.

- En los tres primeros grupos hay un punto central que concentra el mayor número de elementos preparados (los talones lisos esquirlados en el grupo 1 y 3; los lisos abrasionados en el grupo 2), en cambio en el grupo de los debris no hay ninguna tendencia clara, los talones lisos con retoque o abrasión y los puntiformes con esquirlado tienen una representación similar.

- Si se considera que el retoque, el esquirlado y la abrasión son grados distintos de la intensidad de preparación de la cornisa, se puede afirmar que, dentro de una misma tendencia en el mantenimiento del núcleo (con preferencia por el talón liso) el mayor cuidado en la preparación del frente de percusión se produce en las hojas-hojitas.

Por tanto en este atributo de la preparación, los soportes laminares no solo son las piezas que más se han preparado, sino que también son las que más cuidado se ha tenido en este acondicionamiento del frente de percusión.

\section{IV.1.1.8.- ÁNGULO DE PERCUSIÓN}

En el cuadro SN.19 se puede observar la gran variedad de combinaciones que pueden darse relativas al ángulo de percusión, no obstante la mayoría de ellas se dan en muy pocas piezas, mientras que hay unas pocas que son las más abundantes. En los 
cuatro cuadros se expone cómo se manifiestan ambos ángulos en los distintos grupos tecnológicos. En todos aparecen dos pares de combinaciones donde se agrupan la mayoría de las piezas, la primera en $\mathrm{Fa} / \mathrm{Db}\left(100-110^{\circ} / 70-80^{\circ}\right)$, es decir un frente cerrado, la segunda en Eb/Ea (en torno a 90º), es decir un ángulo abierto. Difiere en cierto grado cuál de los dos pares predomina, en el grupo 1 el más abundante es el frente más abierto (Eb/Ea), en el grupo 2 y 6 predomina más el frente cerrado ( $\mathrm{Fa} / \mathrm{Db})$, mientras que en el grupo 3 hay un equilibrio entre ambos.

Si nos fijamos más específicamente en el ángulo del frente de percusión (ángulo 2), predomina siempre un ángulo de tipo medio ( $\mathrm{Db}: 70-80^{\circ}$ ) excepto en el grupo de las lascas, donde es el ángulo abierto el más abundante (Ea: 80-90²). En los otros grupos tecnológicos el aspecto que varía es el ángulo que seguiría en importancia al predominante, que en todos los casos es el más abierto (Ea, es decir 80-90), excepto en los debris, que el frente tiende a ser más cerrado (Da: 60-70²).

A partir de estos datos es difícil establecer pautas concretas respecto a los ángulos de percusión y es quizás más claro un acercamiento a este aspecto fijándonos en el ángulo externo (el de la cornisa o ángulo 2). En dicho ángulo hay un predominio genérico de un ángulo de tipo medio tendente a abierto, con dos variantes en función de los grupos tecnológicos: en el grupo de las lascas predomina el ángulo casi recto (no el ángulo de tipo medio), mientras que en los debris el predominante es el ángulo medio, pero con tendencia a ser más cerrado. Las implicaciones de estos datos a lo largo del proceso operativo o el modo de talla no son demasiado claras. Parece que se dibuja una tendencia en el sentido de que en las primeras fases el ángulo del frente de percusión es más abierto y en las últimas más cerrado; o quizás tenga relación más específicamente con el tipo de soportes extraídos, de modo que las lascas (en sentido general) se obtienen con ángulos más rectos $\left(80-90^{\circ}\right)$, las hojas-hojitas con ángulos de tipo medio (70-80 $)$ tendente a recto y los debris con ángulo de tipo medio pero tendente a cerrado. Los productos de acondicionamiento serían similares a los soportes laminares, pero se acercan bastante al grupo de las lascas. Quizás haya que valorar la influencia de otros atributos como el tamaño de la extracción o su grosor en relación con el ángulo. De hecho parece que se explica mejor estas pequeñas variaciones en el tipo de ángulo tomando en consideración el grosor de los distintos grupos tecnológicos. 


\begin{tabular}{|c|c|c|c|c|c|c|c|c|c|c|c|}
\hline & & & & & & JGUI & $\mathrm{LO} 2$ & & & & \\
\hline & GR.1 & - & $\mathrm{Bb}$ & $\mathrm{Ca}$ & $\mathrm{Cb}$ & $\mathrm{Da}$ & $\mathrm{Db}$ & $\mathrm{Ea}$ & $\mathrm{Eb}$ & $\mathrm{Fa}$ & $\mathrm{N}$ \\
\hline & - & & & & & & & & & & \\
\hline & $\mathrm{Ca}$ & & & & 1 & & & & & & 1 \\
\hline & $\mathrm{Cb}$ & & & & & & & & & & \\
\hline & Da & & & & & & 1 & & 1 & & 2 \\
\hline-1 & $\mathrm{Db}$ & & & & 1 & & & & & & \\
\hline 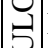 & Ea & 1 & & & & & & 1 & 5 & & 7 \\
\hline (2) & $\mathrm{Eb}$ & 6 & & & & 15 & 37 & 243 & 1 & & 302 \\
\hline 4 & $\mathrm{Fa}$ & 28 & & 3 & 12 & 131 & 222 & 68 & 6 & & 470 \\
\hline & $\mathrm{Fb}$ & 16 & & 4 & 26 & 115 & 57 & 22 & & & 240 \\
\hline & Ga & 5 & 2 & 11 & 29 & 32 & 9 & 2 & & 1 & 92 \\
\hline & Gb & & & 5 & 2 & 2 & & 1 & & & 10 \\
\hline & На & 1 & & 1 & & & & & & & 2 \\
\hline & $\mathrm{N}$ & 57 & 2 & 24 & 71 & 295 & 326 & 337 & 14 & 1 & 1127 \\
\hline
\end{tabular}

\begin{tabular}{|c|c|c|c|c|c|c|c|c|}
\hline & \multirow[b]{2}{*}{ GR.2 } & \multicolumn{6}{|c|}{ ANGULO 2} & \\
\hline & & - $\mathrm{BbCa}$ & $\mathrm{Cb}$ & $\mathrm{Da}$ & $\mathrm{Db}$ & $\mathrm{Ea}$ & $\mathrm{Eb} \mathrm{Fa}$ & $\mathrm{N}$ \\
\hline & - & & & & 1 & 3 & & 4 \\
\hline & $\mathrm{Ca}$ & & & & & & & \\
\hline & Cb & & & & & & & \\
\hline & Da & & & & & & & \\
\hline-1 & $\mathrm{Db}$ & & & & & & & \\
\hline 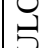 & Ea & & & & & & 1 & 1 \\
\hline 0 & $\mathrm{~Eb}$ & & & 1 & 6 & 41 & & 48 \\
\hline \& & $\mathrm{Fa}$ & & & 15 & 53 & 15 & & 83 \\
\hline & $\mathrm{Fb}$ & & 1 & 19 & 12 & 1 & & 33 \\
\hline & $\mathrm{Ga}$ & & 4 & 6 & 3 & 1 & & 14 \\
\hline & Gb & 1 & 2 & & & & & 3 \\
\hline & На & & & & & & & \\
\hline & $\mathrm{N}$ & 1 & 7 & 41 & 75 & 61 & 1 & 186 \\
\hline
\end{tabular}

Cuadro SN.19: ángulo externo o de la cornisa (ángulo 2) e interno (ángulo 1) según los distintos grupos tecnológicos. $\mathrm{Bb}=30-40^{\circ}, \mathrm{Ca}=40-50^{\circ}, \mathrm{Cb}=50-60^{\circ}, \mathrm{Da}=60-70^{\circ}, \mathrm{Db}=70-80^{\circ}, \mathrm{Ea}=80-$ $90^{\circ}, \mathrm{Eb}=90-100^{\circ}, \mathrm{Fa}=110-120^{\circ}, \mathrm{Fb}=120-130, \mathrm{Ga}=130-140^{\circ}, \mathrm{Gb}=140-150^{\circ}, \mathrm{Ha}=150-160^{\circ}$. 

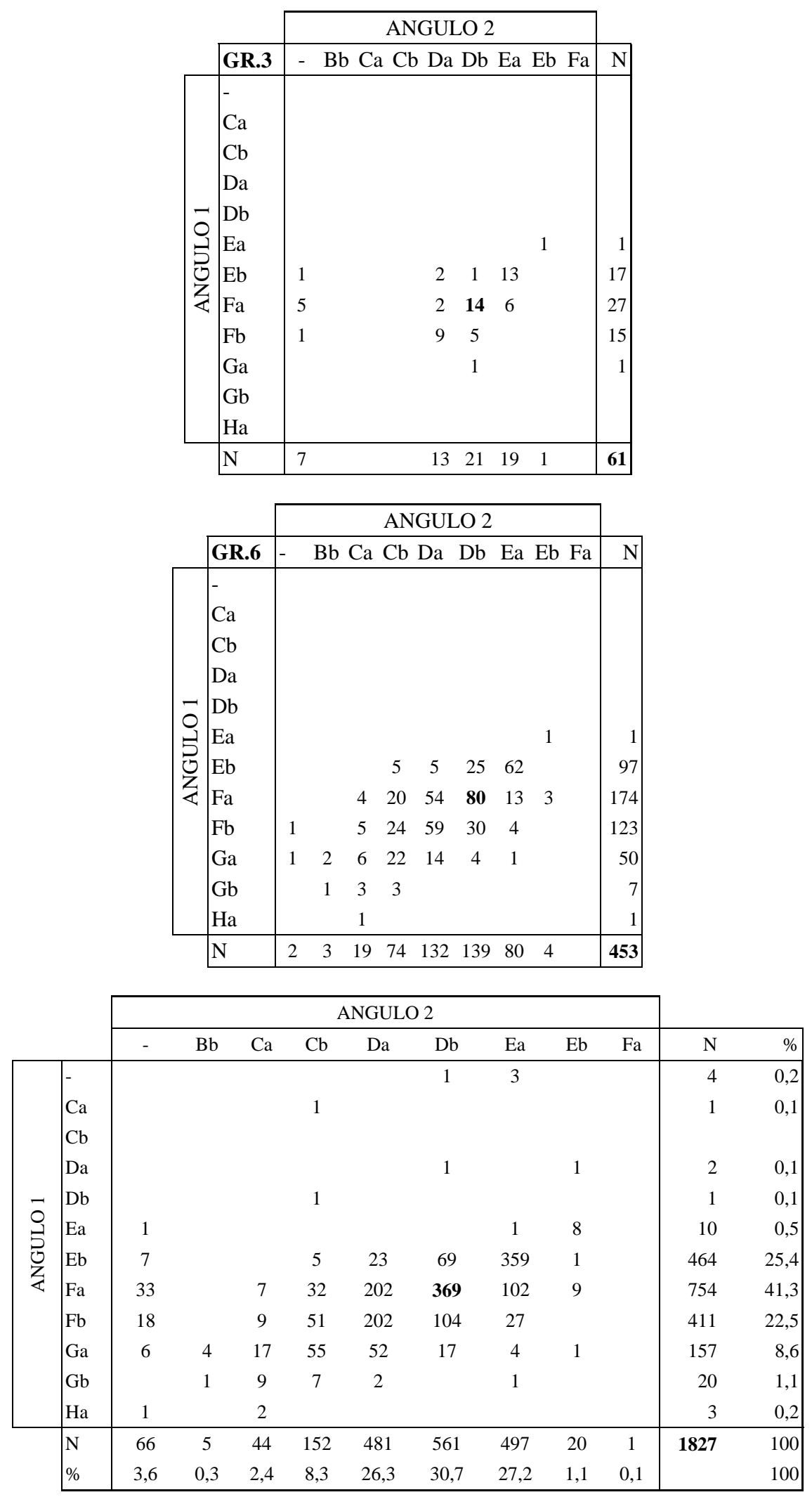

Cuadro SN.19 (continuación): ángulo externo o de la cornisa (ángulo 2) e interno (ángulo 1) según los distintos grupos tecnológicos. 


\section{IV.1.1.9.- AlTERACIONES}

El sílex negro no está demasiado afectado por alteraciones (cuadro SN.20), predominan las piezas quemadas y las rodadas, existiendo también algún ejemplo de doble pátina y desilificación.

\begin{tabular}{|l|cccc|r|}
\hline & DP & DS & Q & R & N \\
\hline $\mathrm{N}$ & 5 & 1 & 56 & 22 & 84 \\
$\%$ & 6,0 & 1,2 & 66,7 & 26,2 & 100 \\
\hline
\end{tabular}

Cuadro SN.20: alteraciones presentes en el conjunto. DP: doble pátina, DS: desilificación, Q: quemado, R: redondeamiento.

\section{IV.1.1.10. MODO DE TALLA}

El modo de talla es un aspecto un poco difícil de aprehender y no nos atrevemos demasiado a establecer un diagnóstico fijo sobre la mayoría de los soportes. Esta cautela ha hecho que sólo realicemos una valoración de este atributo en unos pocos ejemplos, aquellos que presentan las características típicamente diagnósticas de alguno de los modos de talla más conocidos. En el cuadro 21 se ve que son muy pocas las piezas sobre las que se ha determinado el modo de talla; de todas maneras, al diferenciar según grupos tecnológicos se ve un claro predominio de la percusión blanda en los soportes procedentes de la secuencia de débitage pleno (las hojas-hojitas). En el grupo de las lascas y productos de acondicionamiento hay más piezas de percusión directa con percutor duro.

\begin{tabular}{|l|ccc|r|}
\hline & PDD & PDDB & PDB & $\mathrm{N}$ \\
\hline GR.1 & 46 & 17 & 9 & 72 \\
GR.2 & 1 & 16 & 14 & 31 \\
GR.3 & 2 & 1 & & 3 \\
GR.6 & 4 & 1 & 9 & 14 \\
\hline
\end{tabular}

Cuadro SN.21: modo de talla por grupos tecnológicos. PDD: percusión directa con percutor duro; PDDB: percusión directa con percutor de piedra blando; PDB: percusión directa con percutor blando. 
Es un comportamiento bastante extendido el hecho de que en la fase de producción plena se utilicen percutores blandos. Es de sobra conocida la ventaja que otorgan estos percutores en relación con la longitud del soporte deseado y el grosor fino del mismo. Por tanto es bastante lógico que los modos de talla que se han podido identificar sean sobre todo de percutores tanto blandos estrictamente como de piedra blanda. Respecto a los percutores blandos, se ha observado en varias hojas-hojitas las características típicas de este modo de talla: el labio marcado, la ausencia de bulbo y de punto de impacto; además podríamos recordar aspectos como la abrasión frecuente del talón sobre este tipo de soportes así como su pequeño grosor; todo lo cual nos llevaría a una percusión tangencial muy característica de este modo de talla. Pero también hemos encontrado soportes con características que, por una parte son propias de la percusión blanda (la abrasión del frente de talla, la percusión tangencial) y por otra nos remiten al aprovechamiento de estas ventajas de la percusión blanda pero mediante un percutor de piedra. Este modo de talla se ha identificado sobre todo en piezas que portan una característica bastante diagnóstica del mismo: la presencia del "esquirlado del bulbo" (esquillement du bulb, Pelegrin, 2000). En consecuencia, a pesar del pequeño número de piezas sobre las que se ha realizado un diagnóstico directo del modo de talla, se puede establecer la hipótesis del empleo de una percusión blanda en la fase de producción plena, con el uso muy posible de piedra blanda en muchos casos. Puede que sea éste incluso el modo de talla empleado en toda la fase, ya que la piedra blanda comparte con los percutores blandos propiamente dichos muchas de sus características.

Un aspecto importante a valorar respecto al modo de talla y, desde un punto de vista más amplio, en general los gestos asociados a la acción propiamente dicha de la talla intencional, es que se puede afirmar, a partir de una serie de indicios, la existencia de un cambio en dichos gestos en las distintas secuencias del proceso de talla, al menos en los esquemas laminares. En dichos gestos no están incluidos solamente los percutores y el modo de aplicar la fuerza, sino también el ángulo con el que se ejecuta la percusión, el impulso o efecto que se da a dicha percusión, la necesidad de que el frente esté bien preparado, etc. Todos estos elementos son factores que influyen en la manifestación del "modo de talla" tal y como se aprecia en las huellas que deja. Por tanto aunque es un poco complicado observar y realizar un diagnóstico directo sobre los soportes aislados acerca del modo de talla utilizado, sí es posible, a partir de otra serie 
de datos, intuir algún tipo de cambio en los gestos con que se extraen distintos tipos de soportes. Son las hojas y hojitas, y también los productos de acondicionamiento, las piezas sobre las que se puede observar a veces ciertas variaciones. Se puede resumir del modo que sigue los principales factores sobre los que afirmar un cambio de modo de talla

En el grupo 1 (lascas en general):

- el tamaño del talón es relativamente grande (3 mm de anchura media), señalando una percusión interna

- Entre los accidentes, están presentes aquellos que se producen en la zona del punto de impacto, relacionados con el momento de la percusión misma: el pseudoburil de Siret y el doble bulbo

- es el grupo donde hay más piezas con percusión directa con percutor duro

El grupo 2 (hojas-hojitas):

- La dimensión del talón es menor (en torno a 2 mm de anchura media), por lo que la percusión sería más tangencial

- Entre los accidentes está presente la fractura en lengüeta, la cual se produce no tanto en momento del impacto, sino a lo largo de la extracción

- Las hojas-hojitas son los soportes que más se han preparado (más del 50\%) y además aquellos sobre los que se ha procurado una mayor intensidad y cuidado en tal preparación (predominio de los talones lisos abrasionados en este grupo)

- Se ha diagnosticado sobre todo percusión blanda, destacando el posible uso de la piedra blanda.

En cuanto al grupo de los productos de acondicionamiento, tiene características que los acercan al grupo de las lascas:

- Talón bastante grueso (4 mm de anchura media), mayor que las lascas

- La preparación del talón es incluso inferior a la de las lascas (sólo el 31\% de los productos de acondicionamiento están preparados, mientras que en el caso de las lascas el porcentaje asciende al 40\%) 
- En el modo de talla diagnosticado en los productos de acondicionamiento hay más percutor duro que blando

Como consecuencia de todos estos aspectos, se puede afirmar la presencia de un cambio en el modo de talla, o en los gestos vinculados a éste, en las secuencias de débitage pleno laminar, con la posibilidad de una percusión blanda mediante piedra blanda. Para los procesos de débitage de lascas y en las secuencias de preparación y arreglo dentro de los procesos laminares el modo de talla sea posiblemente la percusión dura. 


\section{IV.1.2. NÚCLEOS: SÍNTESIS DE LOS ESQUEMAS TÉCNICOS}

Hay 37 núcleos de chert negro, que según la clasificación más convencional se distribuirían como se indica en el cuadro de la lista tecnológica (cuadro SN.1): 12 núcleos prismáticos con un plano de percusión, 9 con dos planos, 6 sobre lasca, 3 globulosos y 8 restos de núcleo. De forma preliminar, por tanto, predominan los núcleos prismáticos, por lo que habría una tendencia a una mayor presencia de los núcleos “clásicos” laminares o microlaminares de tendencia prismática. No obstante, al realizar el análisis diacrítico y tecnológico de los mismos, se han clasificado atendiendo a parámetros más tecnológicos, intentando concretar las características puramente “técnicas” que rigen la construcción estructural de los núcleos en su explotación.

En un primer momento se han realizado agrupaciones amplias siguiendo estas características técnicas genéricas analizadas en cada núcleo. Se han realizado de este modo cinco grupos (cuadro SN.22) que describiremos detalladamente para concretar los esquemas operativos.

\begin{tabular}{|l|c|cc|}
\cline { 2 - 4 } \multicolumn{1}{c|}{} & TOTAL & SN & SNB \\
\hline Prismáticos & 16 & 14 & 2 \\
Superficie ancha & 7 & 7 & \\
Unipolar-prismático & 2 & 2 & \\
Nódulo-placa & 1 & 1 & \\
Indeterminados & 11 & 6 & 5 \\
\hline TOTAL & 37 & 30 & 7 \\
\hline
\end{tabular}

Cuadro SN.22: núcleos sílex negro, grupos generales.

Los esquemas técnicos de cada núcleo se han esquematizado en tres cuadros, el primero sobre sus características más genéricas (Cuadro SN.24), el segundo sobre la superficie de extracciones (Cuadro SN.25) y el último sobre el plano de percusión (Cuadro SN.26). En el primer cuadro se especifica la sigla de cada uno de ellos, con la referencia a un número de identificación único (ID) válido para identificarlo en el resto de los cuadros y las figuras. 


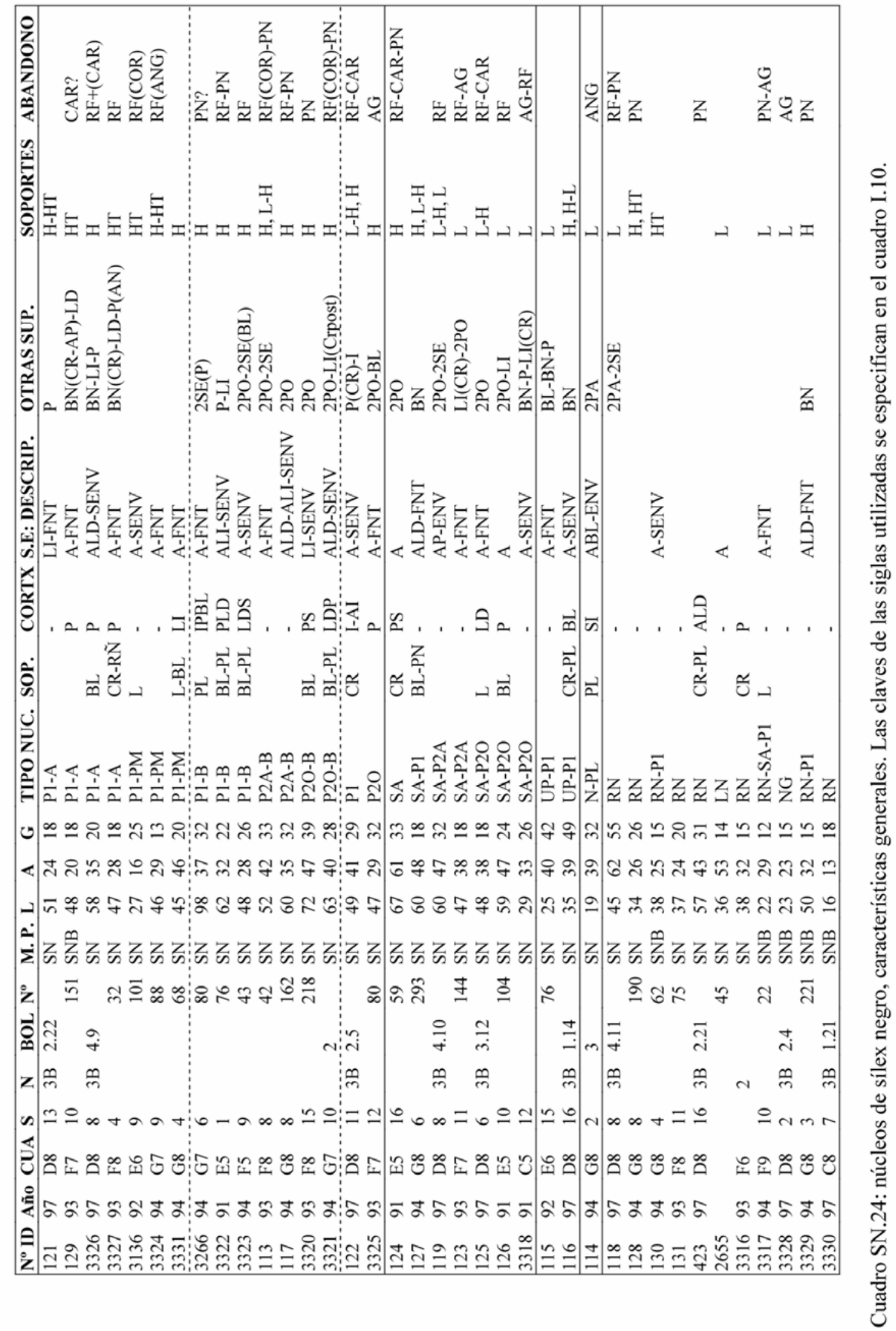




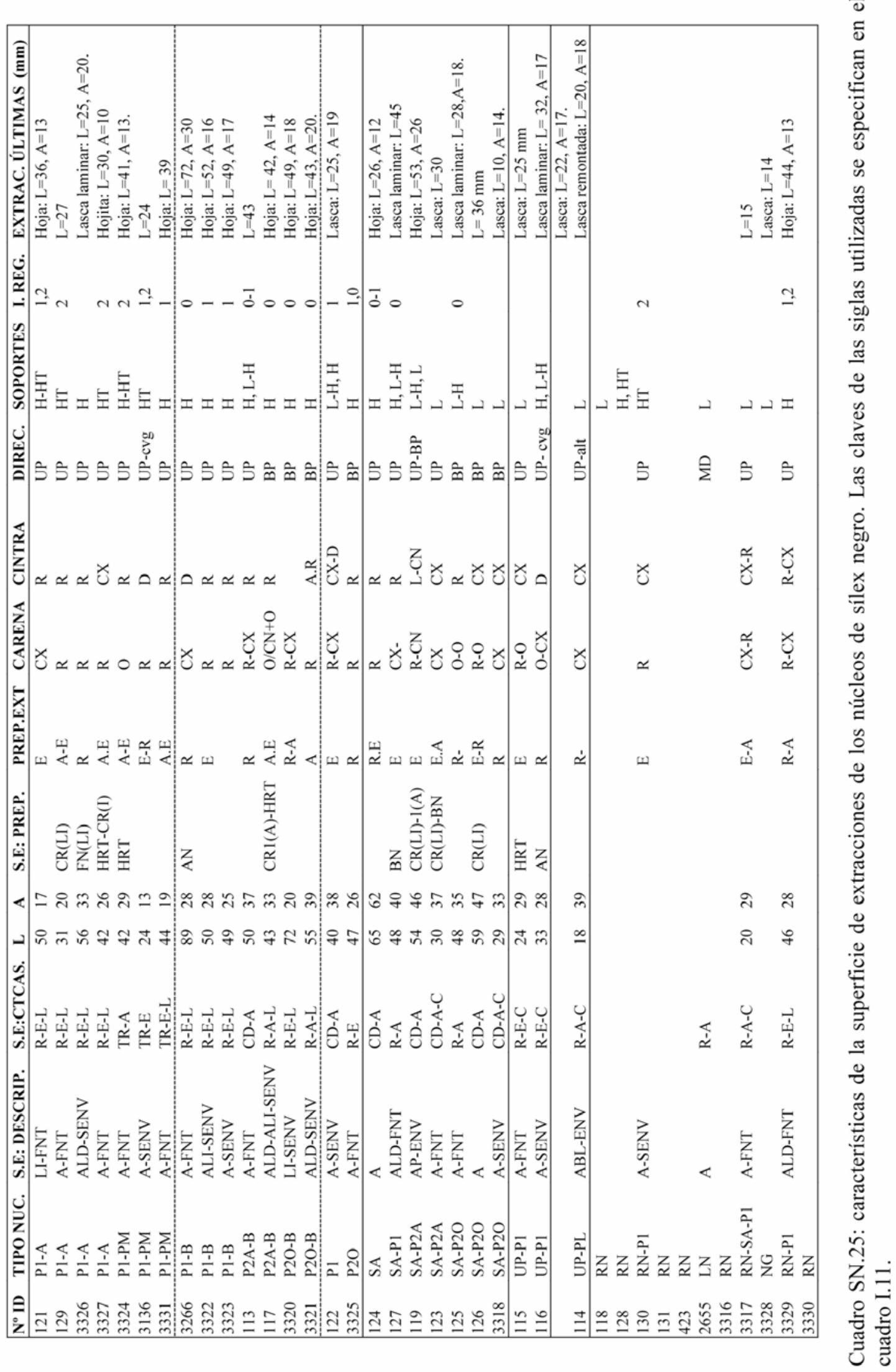




\begin{tabular}{|c|c|c|c|c|c|c|c|}
\hline $\mathbf{N}^{0}$ ID & TIPO NUCLEO & PLANO: CTCAS & PLANO: PREP. & PREP. EXT. & CORNISA & ANGULO & $\begin{array}{l}\text { MODO } \\
\text { TALLA }\end{array}$ \\
\hline 121 & P1-A & $\mathrm{L}-\mathrm{O}$ & TN & & $\mathrm{R}$ & $\mathrm{Db}$ & \\
\hline 129 & P1-A & $\mathrm{L}-\mathrm{O}$ & $\mathrm{TN}$ & & DT & $\mathrm{Da}$ & \\
\hline 3326 & P1-A & L-R & LR & & DT & $\mathrm{Da}-\mathrm{Db}$ & \\
\hline 3327 & P1-A & L-O & LR & $\mathrm{R}$ & CNT & $\mathrm{Db}$ & \\
\hline 3136 & P1-PM & $\mathrm{L}-\mathrm{CN}$ & & & CNT & Ea-Db & \\
\hline 3324 & P1-PM & $\mathrm{L}$ & & & CNT & & \\
\hline 3331 & $\mathrm{P} 1-\mathrm{PM}$ & L-CN & $\mathrm{TN}$ & & CNT & $\mathrm{Da}$ & \\
\hline 3266 & P1-B & $\mathrm{L}-\mathrm{O}$ & $\mathrm{TN}$ & & $\mathrm{FE}$ & $\mathrm{Da}$ & \\
\hline 3322 & P1-B & L-CN-O & $\mathrm{TN}$ & & DT & $\mathrm{Da}$ & \\
\hline 3323 & P1-B & L-CN & SN-LR & A & DT & & \\
\hline 113 & P2A-B & F-R & & R-E & CNT-DT & $\mathrm{Ea}$ & \\
\hline 117 & P2A-B & $\mathrm{L}-\mathrm{O}$ & SN & & CNT & $\mathrm{Da}$ & \\
\hline 3320 & P2O-B & L(I)/L-O-CN(S) & SN & & CNT & $\mathrm{Ea}$ & \\
\hline 3321 & P2O-B & $\mathrm{D}-\mathrm{R}(\mathrm{S}) / \mathrm{L}-\mathrm{O}(\mathrm{I})$ & SN & $\mathrm{R}$ & DT & Db-Da & \\
\hline 122 & $\mathrm{P} 1$ & $\mathrm{~F}-\mathrm{O}$ & $\mathrm{LR}$ & $\bar{E}$ & $\mathrm{DT}$ & $\mathrm{Ea}$ & \\
\hline 3325 & $\mathrm{P} 2 \mathrm{O}$ & $\mathrm{L}-\mathrm{O}$ & & & DT & $\mathrm{Db}$ & \\
\hline 124 & SA & $\mathrm{F}-\mathrm{O}$ & SN & $E$ & DT & $\mathrm{Da}$ & \\
\hline 127 & SA-P1 & $\mathrm{F}-\mathrm{O}$ & SN & $\mathrm{R}$ & DT & $\mathrm{Db}$ & \\
\hline 119 & SA-P2A & L-R(S)/L-O-2(I) & LR & $\mathrm{R}$ & CNT(S)-DT & Db-Ea & \\
\hline 123 & SA-P2A & $\mathrm{L}-\mathrm{O}$ & SN & $\mathrm{R}$ & DT & $\mathrm{Da}$ & \\
\hline 125 & SA-P2O & $\mathrm{L}-\mathrm{O}(\mathrm{S}) / \mathrm{F}-\mathrm{CN}(\mathrm{I})$ & LR & & DT & $\mathrm{Da}(\mathrm{S}) / \mathrm{Db}(\mathrm{I})$ & \\
\hline 126 & SA-P2O & D-O & LR & & DT & $\mathrm{Db}$ & \\
\hline 3318 & SA-P2O & L-CN & $\mathrm{TN}$ & $\mathrm{R}$ & DT & $\mathrm{Db}$ & \\
\hline 115 & UP-P1 & L-CN & & & DT & Db-Ea & PDD \\
\hline 116 & UP-P1 & L-CN-O & & & & Db-Ea & \\
\hline 114 & UP-PL & PN-R & & & $\mathrm{Fe}$ & $\mathrm{Cb}$ & \\
\hline 118 & RN & & & & & & PDD \\
\hline 128 & $\mathrm{RN}$ & & & & & & \\
\hline 130 & RN-P1 & $\mathrm{F}-\mathrm{O}$ & SN & $\mathrm{R}$ & DT & $\mathrm{Db}$ & \\
\hline 131 & $\mathrm{RN}$ & & & & & & \\
\hline 423 & $\mathrm{RN}$ & & & & & & PDD \\
\hline 2655 & LN & & & & & & \\
\hline 3316 & $\mathrm{RN}$ & & & & & & \\
\hline 3317 & RN-SA-P1 & $\mathrm{F}-\mathrm{O}$ & LR & A & CNT & $\mathrm{Da}-\mathrm{Db}$ & \\
\hline 3328 & NG & & & & & & \\
\hline 3329 & RN-P1 & $\mathrm{F}-\mathrm{O}$ & LR & & CNT & $\mathrm{Da}\left(60^{\circ}\right)$ & \\
\hline 3330 & $\mathrm{RN}$ & & & & & $\mathrm{Cb}\left(60^{\circ}\right)$ & \\
\hline
\end{tabular}

Cuadro SN.26: características planos de percusión de núcleos de sílex negro. Las claves de las siglas utilizadas se especifican en el cuadro I.12. Para los ángulos: $\mathrm{Cb}=50-60^{\circ}, \mathrm{Da}=60-70^{\circ}, \mathrm{Db}=$ $70-80^{\circ}, \mathrm{Ea}=80-90^{\circ}$. 


\section{IV.1.2.1. ATRIBUTOS BÁSICOS}

En el cuadro SN.23 se exponen las características genéricas básicas de cada uno de ellos. Se ha concretado también el tipo de chert de que se trata (sílex negro genérico y sílex negro-brillante). A continuación se especifica el tipo de núcleo, siendo este atributo el que rige el orden de presentación del conjunto: los núcleos prismáticos (según el método $\mathrm{A}$ y el $\mathrm{B}$ ), los núcleos que explotan una superficie ancha, los unipolares, el núcleo tipo-placa y por último los restos de núcleo.

\section{TIPO DE NÚCLEO}

Se pueden distinguir, por tanto, cinco categorías básicas: los prismáticos, los que explotan una superficie ancha (que siguen teniendo una tendencia prismática), los unipolares-prismáticos, los núcleos “tipo-placa” y por último aquellos en los que no se ha podido determinar un tipo de explotación concreto, que serían los indeterminados.

\begin{tabular}{|l|l|l|rrc|}
\cline { 3 - 6 } \multicolumn{2}{l|}{} & TOTAL & SN & SNB \\
\hline \multirow{3}{*}{ Prismáticos } & Grupo A & P1-A & 7 & 6 & 1 \\
& Grupo B & P1, P2B & 7 & 7 & \\
& Otros & P1, P2 & 2 & 1 & 1 \\
\hline \multirow{2}{*}{ Superficie ancha (SA) } & Unipolar & SA-P1 & 3 & 3 & \\
& Bipolar & SA-P2 & 4 & 4 & \\
\hline Unipolar-prismático & & UP-P1 & 2 & 2 & \\
\hline Núcleo-placa & & N-PL & 1 & 1 & \\
\hline \multirow{3}{*}{ Indeterminados } & Lasca-núcleo & LN & 1 & 1 & \\
& Globuloso & NG & 1 & & 1 \\
& Resto de núcleo & RN & 9 & 5 & 4 \\
\hline
\end{tabular}

Cuadro SN.23: núcleos sílex negro, grupos generales. P1: prismático con un plano de percusión. P1-A: prismático con un plano de percusión, grupo A dentro de la cadena prismática amplia. P2: prismático con dos planos de percusión. P2B: prismático con dos planos de percusión, perteneciente al grupo B de la cadena prismática amplia. SA: esquema de superficie ancha. SAP1: superficie ancha unipolar. SA-P2: superficie ancha bipolar. UP-P1: núcleo unipolar con tendencia a prismático. N-PL: núcleo-placa. LN: lasca-núcleo. NG: núcleo globuloso. RN: resto de núcleo.

Aún se pueden hacer divisiones dentro de estos grupos amplios (cuadro SN.23), así dentro de los núcleos prismáticos distinguimos dos subgrupos (A y B), que pueden corresponder, como veremos, a métodos de producción específicos. El grupo A incluye 
solo núcleos prismáticos unipolares, muchas veces con tendencia a ser piramidales. El grupo B incluye núcleos prismáticos tanto unipolares como bipolares. Por último hay otros dos núcleos prismáticos que no encajan demasiado bien en las dos anteriores subdivisiones. En los núcleos de superficie ancha también diferenciamos los núcleos unipolares y bipolares. Por último, dentro de los indeterminados hay un núcleo globuloso, otro sobre lasca y nueve restos de núcleo, que en su mayoría se trata de núcleos prácticamente agotados o aveces fragmentados, sobre los que no se puede leer bien el sistema de explotación. De hecho en dos casos se podrían incluir dentro de los núcleos prismáticos con un plano de percusión y otro entre los de explotación de superficie ancha.

Estos tipos de núcleos en cuatro grupos genéricos (exceptuando por tanto los indeterminados) podrían considerarse como esquemas operativos que se han sintetizado a partir del análisis de cada esquema técnico (correspondiente a cada núcleo). Se han reunido así los núcleos con características similares, que se han tallado a partir de procesos análogos. Cuando analicemos más detalladamente las características de cada uno de los grupos en sus distintas fases tendremos una mejor caracterización de cada grupo, e intentaremos saber posteriormente la relación que existe entre estos distintos esquemas operativos, sobre todo si pertenecen a una misma cadena operativa o hay varias.

\section{DATOS MÉTRICOS}

Las dimensiones medias de los núcleos son (cuadro SN.10): 46 mm de longitud, 36 de anchura y 25 de grosor, no obstante hay que tomar estos valores con mucha cautela ya que las desviaciones de estos cálculos son muy amplias, además, tal y como se ha comentado al tratar las dimensiones, va a ser más representativo el tamaño de los núcleos separándolos según los esquemas operativos establecidos. La mayoría se sitúan entre los 20-70 mm de longitud, 20-50 mm de anchura y 15-35 mm de grosor. En cuanto a los tipos de núcleos se aprecia la tendencia de los núcleos prismáticos a ser más largos y estrechos, frente a los de superficie ancha, no obstante ambos tipos de núcleos se yuxtaponen en su dispersión y no es posible individualizarlos estrictamente. 
Los unipolares y el nódulo-placa tienen una longitud escasa, en torno a $30 \mathrm{~mm}$, y una anchura media de $40 \mathrm{~mm}$ y por último los restos de núcleo se distribuyen de forma más o menos anárquica, pero sin sobrepasar los $60 \mathrm{~mm}$ de longitud. Los núcleos de tipo unipolar-prismático destacan también por su grosor, ya que son los únicos (además de un resto de núcleo) que sobrepasan los $40 \mathrm{~mm}$.

\section{CÓRTEX}

Hay 18 núcleos que tienen restos de la superficie cortical, seis de los cuales son núcleos prismáticos con el córtex en la superficie posterior, opuesta a la superficie de extracciones. El resto de las piezas que tienen córtex lo presenta de forma más desigual, sobre los laterales, cara posterior o inferior.

\section{TIPO DE SOPORTE UTILIZADO COMO NÚCLEO}

El córtex de todos estos núcleos es fino y liso, algunos parecen corresponder a cantos rodados fluviales, de morfología esferoide (por ejemplo los núcleos Id. $\mathrm{n}^{0} 122$, 3327), mientras otros corresponden más a bloques prismáticos, con aristas naturales marcadas (Id. 3266, 126). Precisamente estas aristas serán utilizadas para la iniciación de la explotación de los bloques. Hay que reseñar también que hay tres lascas que se han utilizado como soportes de núcleo.

\section{SUPERFICIE DE EXTRACCIONES: DESCRIPCIÓN}

Este es un atributo meramente ilustrativo de la ubicación y desarrollo del débitage. Por razones de convencionalismos descriptivos la superficie de extracciones suele ser la cara anterior. Lo que sí varía es el progreso de la talla (frontal, semienvolvente o envolvente) y este atributo va a depender de factores que analizaremos en el apartado sobre la fase de producción de los esquemas, fundamentalmente asociados con los métodos de iniciación de la explotación del núcleo y los procedimientos de reparación o mantenimiento dentro de la fase de explotación plena de los núcleos. 


\section{PREPARACIÓN EN OTRAS PARTES DE LOS NÚCLEOS}

En el estado de abandono de los núcleos hay un buen número de ellos en los que se constata un acondicionamiento sobre los flancos u otras superficies (cuadro SN.27). La aparición de un segundo plano de percusión se produce con mucha frecuencia en los núcleos prismáticos del subgrupo $\mathrm{B}$ y también en los núcleos de superficie ancha. La preparación de los laterales del núcleo, con distintos procedimientos (crestas laterales, flancos de núcleos, etc.) es bastante frecuente también en general en todos los grupos de núcleos que hemos definido. En cambio una preparación de la base del núcleo sí parece ser característica de los núcleos prismáticos del subgrupo A y de los núcleos unipolares. Como veremos al analizar detalladamente ambos esquemas, en el primer caso es muy típico el procedimiento de una base con una arista más o menos ortogonal a la superficie de extracciones, lo cual va a provocar la tendencia a la morfología piramidal de este esquema. En los núcleos unipolares la base del núcleo va a ser una superficie más o menos paralela al plano de percusión. Por último el acondicionamiento de la superficie posterior va a producirse sobre todo en los núcleos prismáticos del tipo A.

\begin{tabular}{|l|cccc|}
\cline { 2 - 5 } \multicolumn{1}{c|}{} & $2^{\circ}$ PLANO & FLANCOS & BASE NÚCLEO & POSTERIOR \\
\hline Prismáticos - A & & 3 & 3 & 3 \\
Prismáticos - B & 6 & 4 & & 1 \\
Superficie ancha & 5 & 3 & 2 & 1 \\
Unipolar-prismático & 1 & 1 & 2 & \\
Núcleo-placa & & & 1 & 1 \\
Indeterminados & 1 & & & \\
\hline
\end{tabular}

Cuadro SN.27: preparación o acondicionamiento de otras superficies del núcleo.

Esta preparación de las distintas superficies del núcleo proporciona unas pautas características de los distintos tipos de núcleo:

- Empleo de un segundo plano de percusión (acompañado frecuentemente de la apertura de una segunda superficie de extracciones) en los núcleos prismáticos del tipo B y en los que explotan una superficie ancha.

- En los núcleos prismáticos tipo A no existe el recurso a un segundo plano de percusión de forma estricta, lo que sí aparece en la base del núcleo en una arista perpendicular a la superficie de extracciones. Dicha arista puede ser el asiento de una cresta inferior, que servirá bien para corregir la carena desde 
la base (en un procedimiento muy cercano al del segundo plano de percusión), o bien para controlar los flancos o la superficie posterior.

- Los núcleos tipo unipolar-prismático tienen un acondicionamiento de la base del núcleo peculiar y específico, ya que se trata de una superficie paralela al plano de percusión, como si esta parte inferior se truncara.

- La preparación de los flancos del núcleo no es un procedimiento peculiar de ninguno de los grupos de núcleos que se han diferenciado, por el contrario, en la mayoría de las piezas se pueden encontrar acondicionamientos más o menos acusados, circunstancia que es lógica en todo proceso de talla.

\section{SOPORTES EXTRAÍDOS}

En los núcleos prismáticos se han obtenido hojas y hojitas, en cambio en los núcleos de superficie ancha hay obtención de lascas así como hojas o lascas laminares. En cuanto a los núcleos unipolares, en uno de ellos parece que hay una intención laminar, pero en el otro los últimos productos son lascas. Por último en el núcleo-placa hay una producción muy clara e intencional de lascas. Respecto a los restos de núcleo, hay muchos que sus características no permiten reconocer el tipo de soportes que se habrían extraído, en otros en cambio hay negativos tanto de lascas como de hojas y hojitas.

Es interesante por tanto resaltar que los procesos de talla aplicados sobre los bloques de sílex negro están encaminados tanto a la producción de hojas y hojitas, como de lascas e incluso quizás podamos diferenciar una producción de lascas-laminares.

\section{ABANDONO}

En la mayoría de los casos parece que el abandono está relacionado con algún accidente de talla, sobre todo los reflejados, bien en la superficie de extracciones (por problemas relativos quizás a una carena incorrecta) o bien en la zona de la cornisa (relacionado entonces más con el mismo momento de la aplicación de la fuerza de la percusión, por ejemplo un ángulo inadecuado o un impulso incorrecto). En estos casos habrá que valorar el esquema operativo ejecutado, la validez de los procedimientos para 
la reforma o mantenimiento de las condiciones técnicas adecuadas. La aparición de los inconvenientes de la materia en forma de planos naturales de fractura es también muy frecuente y es una limitación, la impuesta por la materia (tal y como se ha insistido en el capítulo sobre las materias primas), muy importante a la hora de valorar los esquemas aplicados y los procedimientos con los que se resuelven esas trabas. Por último hay también núcleos en los que se ha llegado a un agotamiento del bloque.

\section{IV.1.2.2. CARACTERÍSTICAS DE LA SUPERFICIE DE EXTRACCIONES}

En el cuadro sobre las características de la superficie de extracciones (cuadro SN.25) se repiten los atributos del tipo de núcleo y la descripción de dicha superficie.

\section{DATOS MÉTRICOS}

En la dispersión de la longitud y anchura de la superficie de extracciones se puede observar las características de los distintos tipos de núcleos, con la tendencia de los prismáticos a ser más largos y estrechos que los de superficie ancha. Ambos grupos se diferencian sobre todo en la anchura, distribuyéndose los primeros entre los 13 y 39 mm y los segundos entre 33 y 62, por tanto estos núcleos se solapan en el intervalo de los 30-40 mm. En cuanto a la longitud, la mayoría de los prismáticos se sitúan entre 40 y 60 mm; y los de superficie ancha entre 30 y 60, con una distribución más dispersa. Estas dimensiones de la superficie de extracciones están relacionadas, lógicamente, con los soportes que se van a producir. De los núcleos más alargados se van a obtener hojas y hojitas, mientras que los núcleos de superficie ancha aportan soportes más anchos, lascas y lascas-laminares. Los dos núcleos de tipo unipolar-prismático son bastante cortos (24-33 mm), pero su anchura (28-29) los coloca más hacia los núcleos prismáticos. Ya se ha visto cómo en los soportes obtenidos de estos núcleos uno aportaría lascas, pero el otro hojas o lascas laminares. Parece que estos núcleos hay que ubicarlos más en la línea de los prismáticos, como veremos al abordar su esquema operativo. En cuanto al núcleo-placa, su escasa longitud (18 mm) y mayor anchura (39 $\mathrm{mm}$ ) lo colocan hacia la zona de los soportes tipo lasca, más cortos y anchos. 


\section{CARACTERÍSTICAS MORFOLÓGICAS DE LA SUPERFICIE DE EXTRACCIONES}

En el cuadro SN.28 se muestra la distribución de las variantes de este atributo en los distintos esquemas operativos. En el grupo de los prismáticos son casi todos rectangulares, estrechos y alargados; con dos tendencias marcadas en los subgrupos que hemos definido; en los prismáticos tipo-A hay tres con forma triangular, mientras en los tipo-B hay otros dos rectangulares anchos. Estas dos morfologías resumen los distintos procedimientos aplicados en ambos subgrupos, con una tendencia a núcleos piramidales en el primer caso y a núcleos más anchos en el segundo.

\begin{tabular}{|l|ccccccccc|}
\cline { 2 - 8 } \multicolumn{1}{c|}{} & CD-A & CD-A-C & R-A & R-A-C & R-A-L & R-E & R-E-C & R-E-L & TR \\
\hline Prismáticos - A & 1 & & & & & & & 4 & 3 \\
Prismáticos - B & 1 & & & & 2 & 1 & & 4 \\
$\begin{array}{l}\text { Superficie ancha } \\
\text { Unipolar-prismático }\end{array}$ & 3 & 2 & 2 & & & & & \\
Núcleo-placa & & & & 1 & & & 1 & \\
Indeterminados & & & & 1 & & & & \\
\hline
\end{tabular}

Cuadro SN.28: características morfológicas de la superficie de extracciones. CD-A: cuadrangular, ancha. CD-A-C: cuadrangular, ancha, corta. R-A: rectangular, ancha. R-A-C: rectangular, ancha, corta. R-A-L: rectangular, ancha, larga. R-E: rectangular, estrecha. R-E-C: rectangular, estrecha, corta. R-E-L: rectangular, estrecha, larga. TR: triangular.

\section{SUPERFICIE DE EXTRACCIONES: PREPARACIÓN/MANTENIMIENTO}

Se trata del atributo relativo a la presencia fundamentalmente de procedimientos de reparación, acondicionamiento y mantenimiento del ritmo de talla. En ocasiones estos procedimientos pueden ser subsidiarios de aquellos empleados en la fase de preparación del núcleo, pero en la mayoría de los casos se refieren a la fase de producción plena. Hay que tener en cuenta que hay métodos de producción que utilizan procedimientos de reparación visibles y más o menos complejos, pero hay otros en los que el propio esquema aplicado permite un auto-mantenimiento del ritmo de talla. Esta última posibilidad la tendremos que valorar al analizar la fase de producción plena de estos esquemas.

En el cuadro SN.29 se muestra cómo se distribuyen los distintos procedimientos de preparación sobre los tipos de núcleos. El empleo de una arista natural inicial es un 
recurso que se intuye en dos núcleos, si bien puede haberse empleado en otros más, sin que se pueda constatar debido a que los núcleos se encuentran en un estado de explotación avanzada.

\begin{tabular}{|l|cccccc|}
\cline { 2 - 7 } \multicolumn{1}{c|}{} & AN & BN & CR & HRT & FN & 2PO \\
\hline Prismáticos - A & & & 1 & 2 & 1 & 1 \\
Prismáticos - B & 1 & & 2 & & & \\
Superficie ancha & & 2 & 3 & & & \\
Unipolar-prismático & 1 & & & 1 & & \\
Núcleo-placa & & & & & & \\
Indeterminados & & & & & & \\
\hline
\end{tabular}

Cuadro SN.29: preparación/reparación/mantenimiento de la superficie de extracciones. AN: posible arista natural, BN: mantenimiento sobre la base del núcleo, CR: resto de cresta; HRT: hoja/extracción de recintrado sobre lateral, FN: flancos de núcleo. 2PO: uso de un segundo plano de percusión opuesto para corregir la carena.

El arreglo de la base del núcleo a lo largo del débitage se constata en dos núcleos de superficie ancha, se trata de conformar la base de forma paralela al plano de percusión, a partir de una extracción desde la superficie posterior del núcleo. Parece que este recurso al mantenimiento de la base del núcleo ortogonal a la superficie de extracciones se relaciona con un control de la carena de la misma.

Restos de crestas laterales los tenemos sobre todo en los núcleos de superficie ancha, los prismáticos tipo-B y un caso en el prismático tipo-A. El empleo de extracciones perpendiculares a la superficie de extracciones desde los flancos del núcleo es un procedimiento muy básico en el mantenimiento de dicha superficie, sobre todo la cintra o convexidad transversal. Es interesante retener este dato que apunta a un uso más extendido en los núcleos de superficie ancha y los prismáticos tipo-B, ya que puede ser un indicio de la relación entre ambos esquemas.

Las que hemos denominado como restos de hojas (u otros productos) de recintrado lateral son extracciones axiales sobre el límite entre la superficie de extracciones y el flanco del núcleo, estarían en cierto modo a medio camino entre una hoja (o el soporte que se produce en esa superficie) y un flanco de núcleo, y se producen a lo largo del débitage pleno de los soportes. Parecen corresponder dichas piezas a un método de avance de la talla a lo largo de la fase de producción plena que integra un auto-mantenimiento de las características técnicas de la superficie de extracciones. 
Mediante este abordamiento del flanco de la tabla se produce un mantenimiento sobre todo de la cintra de dicha superficie. Así se lograría un doble objetivo, por un lado la obtención de un producto similar a los que se extraen de la superficie de extracciones, tan solo tendría una arista quizás un poco más marcada y sería algo más grueso, soporte perfectamente utilizable; y por otro lado se consigue la reparación del núcleo sin recurrir a procedimientos (como las crestas laterales) que alargarían las secuencias de talla. Se puede caracterizar este método por tanto como un procedimiento rápido y eficaz.

Estos productos de recintrado lateral los podemos observar en dos núcleos prismáticos tipo-A (3327, 3324), en las extracciones que se producen hacia los laterales de los mismos. Asimismo en uno de los núcleos unipolares (115). Es interesante también retener este dato sobre la aparición de este procedimiento en el primer tipo de núcleos para examinar su esquema operativo.

Por último, el empleo de un segundo plano de percusión opuesto al plano principal lo tenemos en un núcleo prismático tipo-A (3327). Este procedimiento es uno de los más habituales para corregir la carena, no obstante no se utiliza demasiado en el conjunto lítico de El Espertín. En este punto se puede plantear el problema de si un segundo plano de percusión opuesto a un plano principal tiene la función de corregir la superficie de extracciones desde la base, o bien es un plano tan productivo como el opuesto. A este respecto, hay tres núcleos de superficie ancha que se han considerado bipolares, es decir los soportes se extraen desde ambos planos y el propio esquema operativo parece imponer una explotación de la superficie de extracciones de forma bipolar.

\section{CARENA}

La carena o curvatura longitudinal de la superficie de extracciones se presenta en el cuadro SN.30 según los distintos tipos de núcleos. Hay que tener en cuenta que se está valorando la apariencia de este atributo sobre núcleos abandonados, por lo que las características de los mismos no son las mismas que en la fase de producción plena. Hay predominio de las carenas tendentes a rectas en casi todos los tipos, cosa que puede 
ser consecuencia del estado de abandono de los núcleos, pero que quizás sea sintomática de una preferencia o necesidad concreta vinculada a las técnicas aplicadas sobre estos núcleos. De hecho esta tendencia a conservar la carena recta es muy acusada en los núcleos prismáticos, sobre todo los tipo-B. En cambio en los núcleos de superficie ancha hay tantos ejemplos de carenas rectas como convexas. Por último las carena oblicuas aparecen minoritariamente en todos los tipos de núcleos.

\begin{tabular}{|l|ccc|ccc|ccc|}
\cline { 2 - 9 } \multicolumn{1}{c|}{} & \multicolumn{3}{c|}{ CARENA } & \multicolumn{3}{c|}{ CINTRA } & \multicolumn{3}{c|}{ DIRECCIÓN } \\
\cline { 2 - 10 } \multicolumn{1}{c|}{} & $\mathrm{CX}$ & $\mathrm{O}$ & $\mathrm{R}$ & $\mathrm{CX}$ & $\mathrm{D}$ & $\mathrm{R}$ & $\mathrm{UP}$ & $\mathrm{BP}$ & $\mathrm{MD}$ \\
\hline Prismáticos - A & 2 & 1 & 6 & 2 & 1 & 5 & 8 & & \\
Prismáticos - B & & 1 & 6 & & 1 & 6 & 4 & 4 & \\
Superficie ancha & 3 & 1 & 3 & 3 & & 4 & 4 & 3 & \\
Unipolar-prismático & 1 & 1 & 1 & 1 & 1 & & 2 & & \\
Núcleo-placa & & & & 1 & & & 1 & & 1 \\
Indeterminados & 1 & & 2 & 2 & & & 3 & & 1 \\
\hline
\end{tabular}

Cuadro SN.30: carena, cintra y dirección de las extracciones en los núcleos de sílex negro. CX: convexa, O: oblicua, R: recta, aplanada, D: en diedro. UP: unipolar, BP: bipolar, MD: multidireccional.

\section{CINTRA}

La cintra es un atributo difícil de valorar y de hecho los estados de atributo que hemos contemplado no parecen discriminar los distintos esquemas operativos entre sí (cuadro SN.30). La cintra aplanada o recta es el predominante, sería característica de secuencias de avance del débitage frontal. La cintra convexa es menos frecuente de modo genérico, pero dentro de los núcleos de superficie ancha es bastante importante. Por último la cintra en diedro es prácticamente testimonial.

\section{DIRECCIÓN DE LAS EXTRACCIONES}

La dirección de los negativos ha sido ya indicada en la propia definición de los distintos tipos de núcleos. Tan solo habría que resaltar el predominio de la explotación unipolar de los núcleos y sobre todo el hecho de que la talla bipolar aparece en los núcleos prismáticos tipo-B y en los de superficie ancha (cuadro SN.30). Hay que reseñar que una explotación bipolar es aquella en la que la explotación de una superficie de extracciones se produce desde dos planos de percusión opuestos. Aquellos núcleos 
con dos planos pero que explotan superficies distintas no serían bipolares estrictos, sino unipolares alternos.

\section{PREPARACIÓN DE LAS EXTRACCIONES}

Esta preparación se manifiesta sobre la cornisa aparece en forma de huellas más o menos intensas. Un gesto de frotación intenso del frente de talla provoca un efecto abrasivo que se ha identificado con la abrasión. A veces este gesto no es una frotación tan intensa o se trata de pequeñas extracciones sobre la superficie de extracciones, apareciendo entonces tales huellas en forma de un esquirlado o retoque. En el cuadro SN.31 se presenta la aparición de estas distintas categorías según los tipos de núcleos. La abrasión (y la combinación de abrasión y esquirlado) aparece sobre todo en los núcleos prismáticos tipo-A. El esquirlado y retoque se presenta en el resto de los tipos. Hay que reseñar que en prácticamente todos los núcleos del grupo de los prismáticos se constata la preparación del frente de talla, más en forma de retoque en el tipo-B y más abrasión en tipo-A. En los núcleos de superficie ancha se produce también una preparación de las extracciones, pero es más común en forma de retoque y esquirlado.

\begin{tabular}{|c|c|c|c|c|c|c|c|c|c|}
\hline & \multicolumn{4}{|c|}{$\begin{array}{c}\text { PPARACION } \\
\text { EXTRACCIONES }\end{array}$} & \multicolumn{5}{|c|}{$\begin{array}{l}\text { INDICE REGULARIDAD } \\
\text { LAMINAR }\end{array}$} \\
\hline & A & A-E & $E$ & $\mathrm{R}$ & 0 & $0-1$ & 1 & $1-2$ & 2 \\
\hline Prismáticos - A & & 4 & 3 & 1 & & 1 & 2 & 2 & 3 \\
\hline Prismáticos - B & 1 & 1 & 1 & 4 & 4 & & 4 & & \\
\hline Superficie ancha & & & 4 & 3 & 2 & 1 & & & \\
\hline Unipolar-prismático & & & 1 & 1 & & & & & \\
\hline Núcleo-placa & & & & 1 & & & & & \\
\hline Indeterminados & & & 2 & 1 & & & & 1 & 1 \\
\hline
\end{tabular}

Cuadro SN.31: preparación de las extracciones visible sobre la superficie de extracciones (sobre la cornsisa) e índice de regularidad de los negativos laminares. A: abrasión. E: esquirlado. R: retoque. 0 : regularidad mala, 1 : media, 2 : buena.

\section{EL ÍNDICE DE REGULARIDAD}

El índice de regularidad se ha establecido en aquellos núcleos laminares en los que se ha podido hacer una estimación de este atributo, estimación, que como se ha insistido en el capítulo sobre la metodología, es un tanto subjetiva. Sobre los núcleos se 
valoran los negativos laminares presentes en la superficie de extracciones: su rectitud respecto a la carena, el paralelismo de las nervaduras, etc. A pesar de esta subjetividad, es éste un atributo que sintetiza muchas de las características de los núcleos y establece una valoración sobre su potencialidad para la calidad de la producción de hojas/hojitas. A este respecto el cuadro SN.31. Muestra unas tendencias más o menos marcadas en los distintos esquemas operativos que representan los tipos de núcleos. Los núcleos que aportarían hojas con mayor regularidad son los prismáticos tipo-A, seguido por el tipoB. Los núcleos de superficie ancha en cambio tienen unas características bastante mediocres respecto a la regularidad. Los dos núcleos indeterminados de buena calidad son fragmentos de núcleos de sílex negro brillante que parecen proceder de núcleos prismáticos.

\section{ÚLTIMAS EXTRACCIONES}

Este es un dato que a veces se ha utilizado para valorar el aprovechamiento de los núcleos y también las implicaciones económicas que tendría el tamaño de los últimos negativos de los soportes extraídos, en el sentido de que los núcleos se explotaría hasta conseguir un tamaño mínimo de los soportes. Esta evaluación es un poco complicada como para aplicarla en un conjunto con las características de El Espertín ya que se trata de una industria que aprovecha bastante la materia prima, hallándonos además en un contexto cultural (el Mesolítico) caracterizado por una estrategia de explotación intensiva del entorno. Aparte de esta consideración previa respecto al propio carácter e implicaciones del sistema cultural que produce este conjunto, hay una limitación de base para llevar a cabo una valoración económica del aprovechamiento de estos núcleos y son las propias características del conjunto lítico, ya que no disponemos de una muestra suficientemente amplia de los bloques tallados.

No obstante se aportan los datos sobre las últimas extracciones de los núcleos. Las hojitas tienen un tamaño de 12 a $36 \mathrm{~mm}$ de longitud ( $\mathrm{n}=8)$ y una anchura de $10 \mathrm{~mm}$ $(\mathrm{n}=4)$; las hojas, entre 18 y $72 \mathrm{~mm}$ de longitud $(\mathrm{n}=16)$ y 10-30 mm de anchura; las lascas laminares, 25-45 mm de anchura $(\mathrm{n}=3)$ y $20 \mathrm{~mm}$ de anchura $(\mathrm{n}=2)$; y por último las lascas, 15-36 mm de longitud $(n=12)$ y 14-30 de anchura $(n=9)$. 
Respecto a la longitud de las últimas extracciones se ha intentado determinar si es posible establecer un tamaño mínimo de explotación de los distintos de núcleos, en relación con el tipo de soportes que se obtienen de dichos esquemas. Para ello, se ha tenido en cuenta solamente aquellos núcleos cuyos últimos negativos se desarrollan a todo lo largo de la superficie de extracciones, eliminando así los negativos reflejados o fallidos en general, que se presenta en el cuadro SN.32.

\begin{tabular}{|c|c|c|c|c|}
\hline & & $\mathrm{N}^{0}$ ID & SOPORTE & Long. ultima extracción \\
\hline \multirow{4}{*}{ Prismáticos - A } & P1-A & 129 & HT & 27 \\
\hline & P1-PM & 3324 & $\mathrm{H}$ & 41 \\
\hline & P1-PM & 3136 & HT & 24 \\
\hline & P1-PM & 3331 & $\mathrm{H}$ & 39 \\
\hline \multirow{3}{*}{ Prismáticos - B } & $\mathrm{P} 1-\mathrm{B}$ & 3322 & $\mathrm{H}$ & 52 \\
\hline & P1-B & 3323 & $\mathrm{H}$ & 49 \\
\hline & P2A-B & 117 & $\mathrm{H}$ & 42 \\
\hline \multirow{3}{*}{ Superficie ancha } & SA-P1 & 127 & L-H & 45 \\
\hline & SA-P2A & 123 & $\mathrm{~L}$ & 30 \\
\hline & SA-P2A & 119 & $\mathrm{H}, \mathrm{L}-\mathrm{H}$ & 53 \\
\hline \multirow{2}{*}{ Unipolar-prismático } & & 115 & $\mathrm{~L}$ & 25 \\
\hline & & 116 & L-H & 32 \\
\hline Nódulo-placa & & 114 & $\mathrm{~L}$ & 22 \\
\hline
\end{tabular}

Cuadro SN.32: longitud de las últimas extracciones en los núcleos que se ha aprovechado toda la longitud de la superficie de extracciones en el estado de abandono.

En dicho cuadro llama la atención el hecho de que la longitud de los distintos negativos se agrupan entre los distintos tipos de núcleos de la manera siguiente:

- Los núcleos prismáticos tipo-A tienen negativos de hojas-hojitas de 24 a 41 mm de longitud

- Los núcleos prismáticos tipo-B tienen negativos de hojas de 42 a 52 mm

- Los núcleos de superficie ancha de hojas y lascas laminares tienen negativos de 45-53 mm de longitud

- Los núcleos tipo unipolar-prismático entre 25 y 32 mm

- El núcleo placa proporciona lascas de $22 \mathrm{~mm}$

Parece dibujarse tres grupos de soportes según su longitud y tipos de esquemas:

i) Hojas-hojitas de 2 a $4 \mathrm{~cm}$ de longitud a partir de los núcleos prismáticos tipo-A 
ii) Hojas y lascas laminares de 4-5 cm a partir de núcleos prismáticos tipo-B y núcleos de superficie ancha

iii) Lascas de 2-3 cm de longitud sobre los esquemas unipolares y tipo-placa.

Se plantea como hipótesis la existencia real de estos tres grupos de soportes deducidos sobre las longitudes de los últimos negativos, habrá que valorar sobre otros parámetros si estas tres categorías tienen una entidad real e implican esquemas operativos distintos.

\section{IV.1.2.3. CARACTERÍSTICAS DEL PLANO DE PERCUSIÓN}

Los atributos definidos para describir el plano de percusión de los núcleos se resumen en el cuadro SN.26.

\section{PlANO: CARACTERÍSTICAS GENÉRICAS}

Esta característica está relacionada tanto con la elección de la superficie donde se coloca el plano de percusión en la fase de preparación del núcleo (planos corticales o con plano natural) como con las secuencias de acondicionamiento y reparación del mismo a lo largo de la fase de producción. Asimismo se especifica la disposición del plano de percusión respecto a la superficie de extracciones, si es un plano oblicuo, recto o cóncavo.

En el cuadro SN. 33 se muestra la distribución de estas características en los distintos tipos de núcleos. La mayoría de ellos tienen planos lisos-cóncavos y lisosoblicuos, sin que se pueda observar ninguna tendencia clara.

\begin{tabular}{|l|ccccccccc|}
\cline { 2 - 9 } \multicolumn{1}{c|}{} & D-O & D-R & F-O & F-R & L & L-CN & L-O & L-R & PN-R \\
\hline Prismáticos - A & & & 1 & & 1 & 2 & 3 & 1 & \\
Prismáticos - B & & & & 1 & 1 & 2 & 3 & & \\
Superficie ancha & 1 & 1 & 2 & & & 1 & 2 & 1 & \\
Unipolar-prismático & & & & & & 2 & & & \\
Núcleo-placa & & & & & & & & & 1 \\
Indeterminados & & & 3 & & & & & & \\
\hline
\end{tabular}

Cuadro SN.33: características del plano de percusión de los núcleos de sílex negro. D: diedro, O: oblicuo, F: facetado, L: liso, CN: cóncavo, R: recto, PN: plano natural. 


\section{REPARACIÓN/ACONDICIONAMIENTO DEL PLANO DE PERCUSIÓN}

Es un atributo en el que se producen tendencias más marcadas, tal y como se puede ver en el cuadro SN.34. Las lasquitas de reavivado del frente de percusión es un procedimiento muy utilizado en los núcleos prismáticos tipo-A y en los de superficie ancha; las semitabletas de núcleo en los prismáticos tipo-B y de nuevo en los de superficie ancha; por último las tabletas de núcleo son características de los núcleos prismáticos en sus dos subgrupos.

\begin{tabular}{|l|ccc|ccc|ccc|}
\cline { 2 - 10 } \multicolumn{1}{c|}{} & \multicolumn{2}{c|}{\begin{tabular}{c} 
REPARACIÓN DEL \\
\multicolumn{1}{c|}{}
\end{tabular}} & \multicolumn{3}{c|}{$\begin{array}{c}\text { PPARACION } \\
\text { PLANO }\end{array}$} & \multicolumn{3}{c|}{ CORNISA } \\
\cline { 2 - 10 } & LR & SN & TN & A & E & R & CNT & DT & FE \\
\hline Prismáticos - A & 3 & & 3 & & 1 & 1 & 4 & 5 & \\
Prismáticos - B & & 4 & 2 & 1 & & 2 & 3 & 2 & 1 \\
Superficie ancha & 3 & 3 & 1 & & 1 & 4 & 1 & 6 & \\
Unipolar-prismático & & & & & & & & 1 & 1 \\
Núcleo-placa & & & & & & & & & \\
Indeterminados & 2 & 3 & & & 1 & 1 & 2 & 1 & \\
\hline
\end{tabular}

Cuadro SN.34: reparación / acondicionamiento del plano de percusión, preparación del frente de percusión morfología de la cornisa. LR: lasquitas de reavivado del frente de percusión. SN: semitabletas de núcleo. TN: tabletas de núcleo. A: abrasión, E: esquirlado, R: retoque. CNT: cornisa continua, DT: denticulada, FE: festoneada.

En las secuencias de reparación del plano de percusión, los tres estados de atributo que se han contemplado no dejan de ser variantes en la intensidad como se afecta sobre dicho plano, de manera que la tableta de núcleo implica una eliminación total del plano de percusión y las lasquitas de reavivado tan solo una reforma parcial de dicho plano, estando por tanto las semitabletas en un estado intermedio. La elección de uno u otro gesto depende del modo de talla que se utilice en el débitage del núcleo, unido a los gestos implícitos en dicho modo, relativos al ángulo de percusión adecuado, la intensidad del golpe, etc. Asimismo otro factor importante en este punto es la preparación a que se someta el frente de percusión, lo cual va a determinar la duración de un plano de percusión en condiciones óptimas.

Teniendo en cuenta estos factores, se podrían agrupar los núcleos de sílex negro en dos grupos, los núcleos prismáticos tipo-A y los de superficie ancha. En los primeros se repara el plano de percusión de modo puntual, en forma de lasquitas de reavivado, o 
bien se elimina directamente el plano mediante una tableta de núcleo. En los segundos se recurre más a los re-acondicionamientos localizados, tanto en forma de lasquitas de reavivado como de semitabletas. Los núcleos prismáticos tipo-B tendrían unas características a medio camino entre los dos grupos anteriores.

Se puede plantear la hipótesis de que en los núcleos prismáticos tipo-A el modo de talla aplicado o las necesidades del débitage laminar implican un mantenimiento del frente de percusión específico, el cual no se soluciona solamente con acondicionamientos de tipo medio como son las semitabletas de núcleo; en caso de que no se pueda solucionar con lasquitas de reavivado se recurre directamente a la eliminación del plano de percusión, con el consiguiente reavivado del frente de talla. Hay que recordar que en los restos de preparación del frente de percusión sobre la superficie de extracciones, eran los núcleos prismáticos tipo-A los que tenían una abrasión más intensa de la cornisa. Quizás estas necesidades específicas de preparación intensa del frente de talla impliquen un mantenimiento más rígido del plano de percusión. En los núcleos de superficie ancha, por el contrario, el recurso al reavivado total del plano de percusión parece ser mínimo; quizás las necesidades del débitage de los soportes no sean tan severas como en el caso anterior.

\section{PREPARACIÓN DEL FRENTE DE TALLA}

No se constata demasiado la preparación sobre el plano de percusión, se ve mejor en la zona de la cornisa, como se ha mostrado al tratar la superficie de extracciones. La abrasión sólo se puede ver en dos núcleos, uno prismático tipo-B y otro fragmento de un posible núcleo prismático (cuadro SN.34). El esquirlado en un núcleo prismático tipo-A y otro de superficie ancha. El retoque aparece sobre todo en los núcleos de superficie ancha.

\section{CORNISA}

La cornisa es denticulada en la mayoría de los casos, sobre todo en los núcleos de superficie ancha (cuadro SN.34). Los núcleos prismáticos tienen cornisas más continuas, relacionadas probablemente con la preparación del frente de percusión. 
ÁNGULO

El ángulo del frente de talla se encuentra en la mayoría de los núcleos entre 60$70^{\circ}$, se podría considerar como un ángulo relativamente cerrado (cuadro SN.35). Los núcleos con ángulos más abiertos, cercanos a los $90^{\circ}$ son los prismáticos. Asimismo, los unipolares tienen un ángulo también abierto, en torno a los $80^{\circ}$.

\begin{tabular}{|l|cccc|}
\cline { 2 - 5 } \multicolumn{1}{c|}{} & $\mathrm{Cb}\left(50-60^{\circ}\right)$ & $\mathrm{Da}\left(60-70^{\circ}\right)$ & $\mathrm{Db}\left(70-80^{\circ}\right)$ & $\mathrm{Ea}\left(80-90^{\circ}\right)$ \\
\hline Prismáticos - A & & 3 & & 2 \\
Prismáticos - B & & 3 & 1 & 2 \\
Superficie ancha & & 3 & 1 & \\
Unipolar-prismático & & & 2 & \\
Núcleo-placa & 1 & & & \\
Indeterminados & 1 & 2 & & \\
\hline
\end{tabular}

Cuadro SN.35: ángulo del frente de talla de los núcleos de sílex negro.

Sobre las características de los esquemas técnicos de cada núcleo se han obtenido una serie de tendencias más o menos marcadas en los distintos tipos de núcleos, tendencias ya intuidas en la propia caracterización de los núcleos y que se concretarán al examinar el resto de las piezas. 

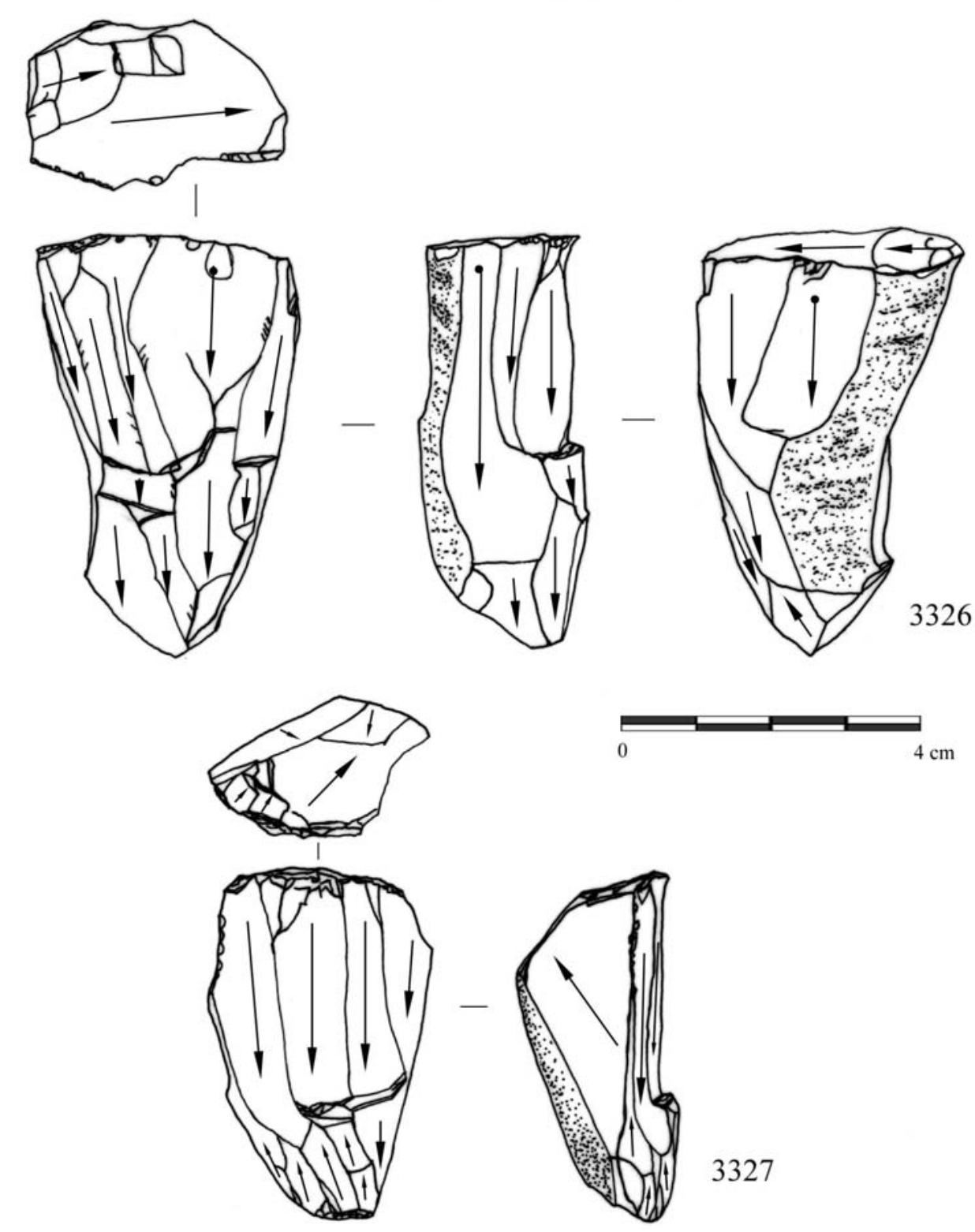

3327
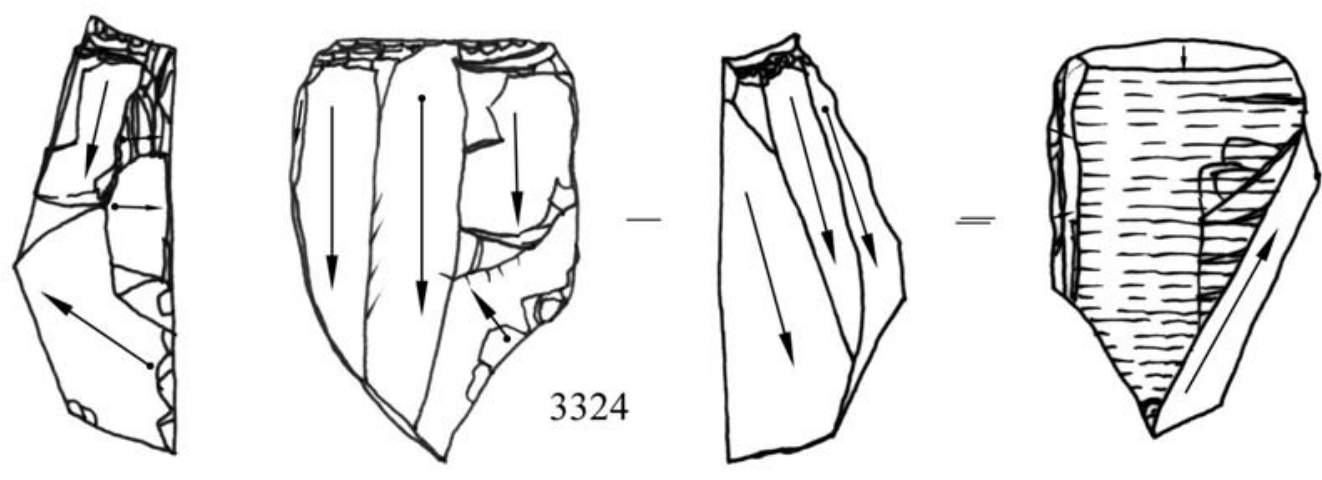

Figura SN.1: núcleos de sílex negro a partir del esquema prismático “clásico” tipo A (prismático unipolar-A). 


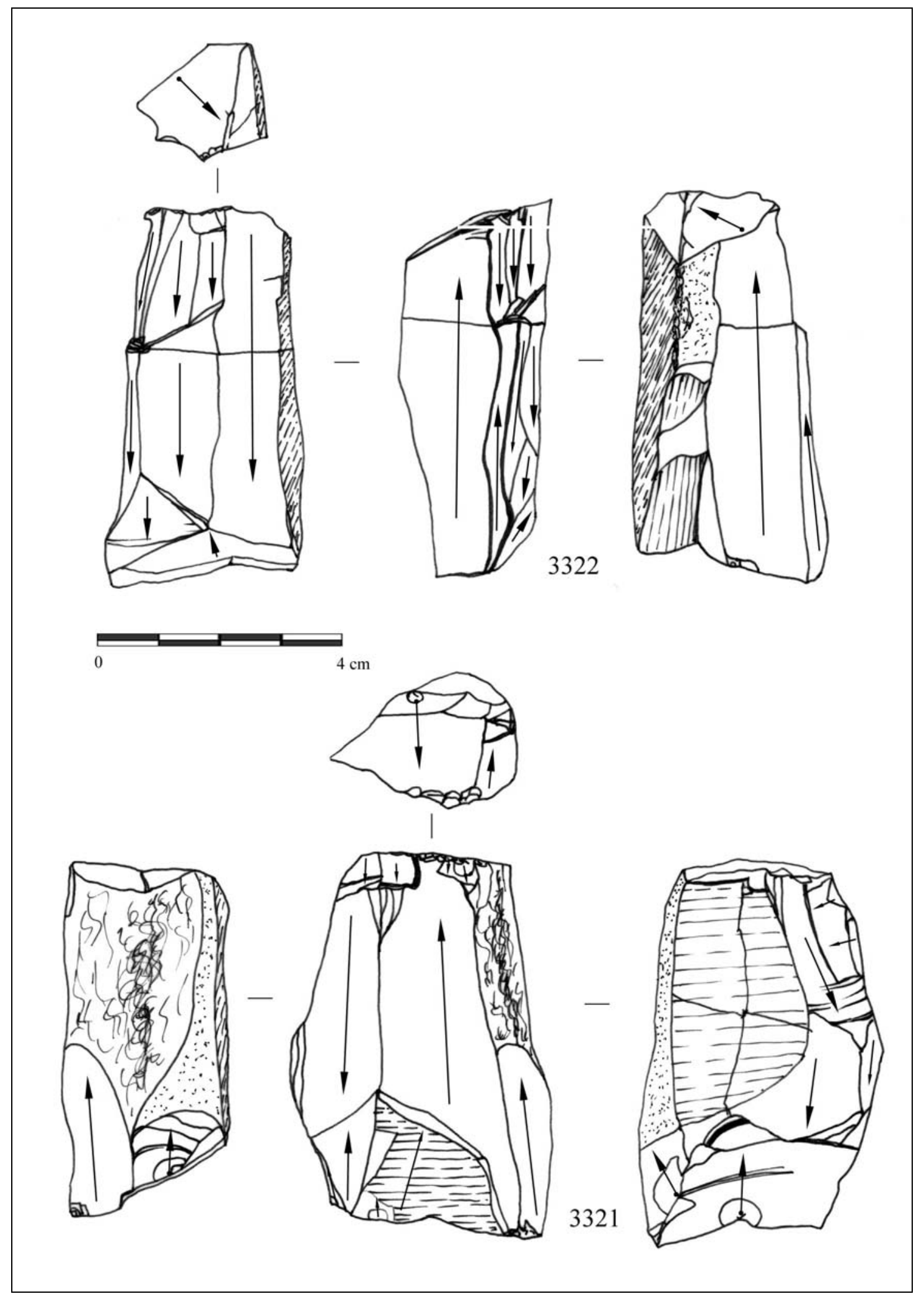

Figura SN.2: núcleos de sílex negro a partir del esquema prismático tipo-B. 


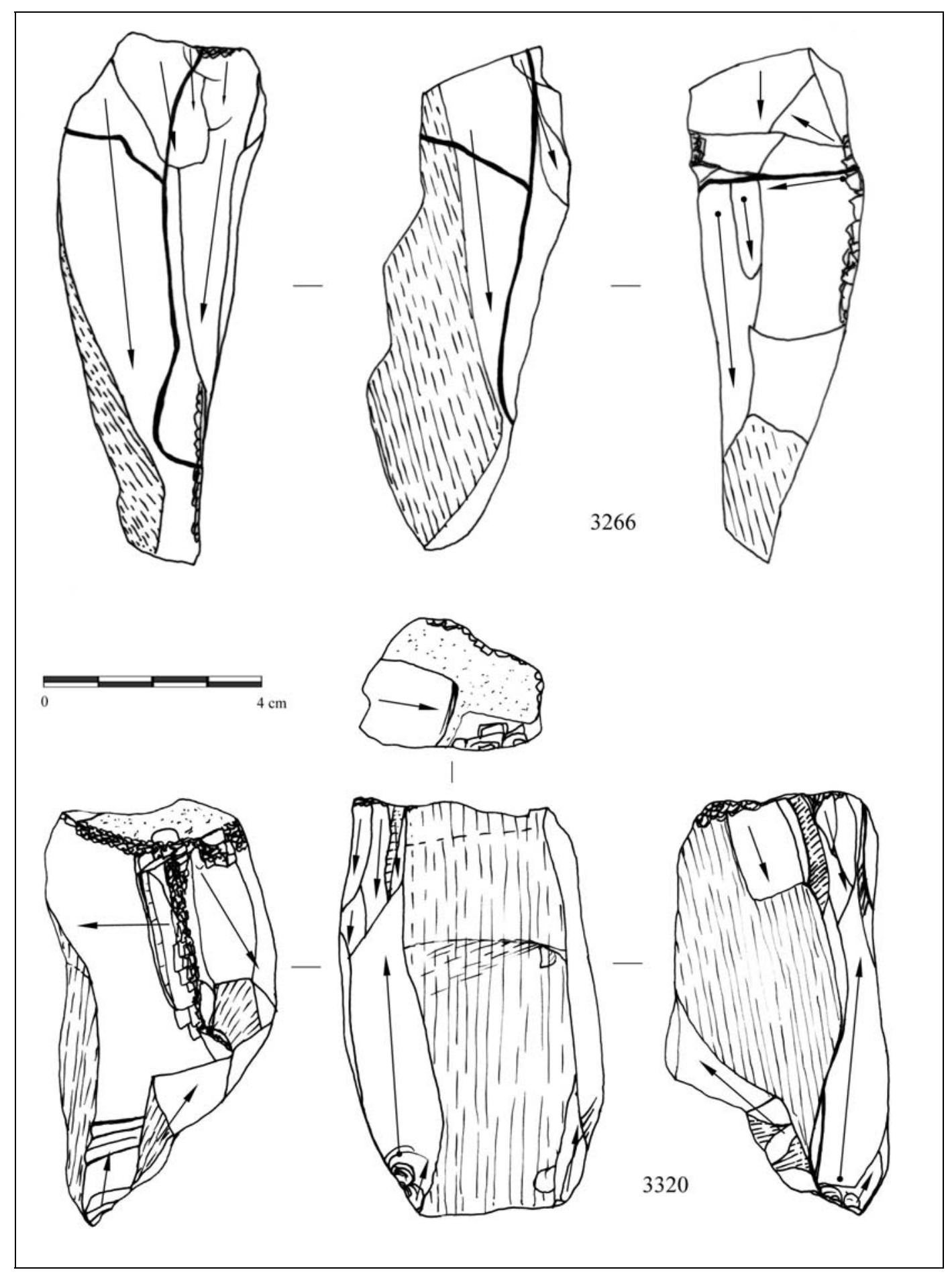

Figura SN. 3: núcleos de sílex negro, a partir del esquema prismático tipo-B. El primer núcleo tiene un remontage de tres piezas: el núcleo (que tiene un aprovechamiento de la superficie opuesta a la superficie de extracciones inicial), una hoja con arista natural y una tableta de núcleo que ha eliminado buena parte de la zona superior del primitivo núcleo, permitiendo el aprovechamiento de la superficie posterior. 


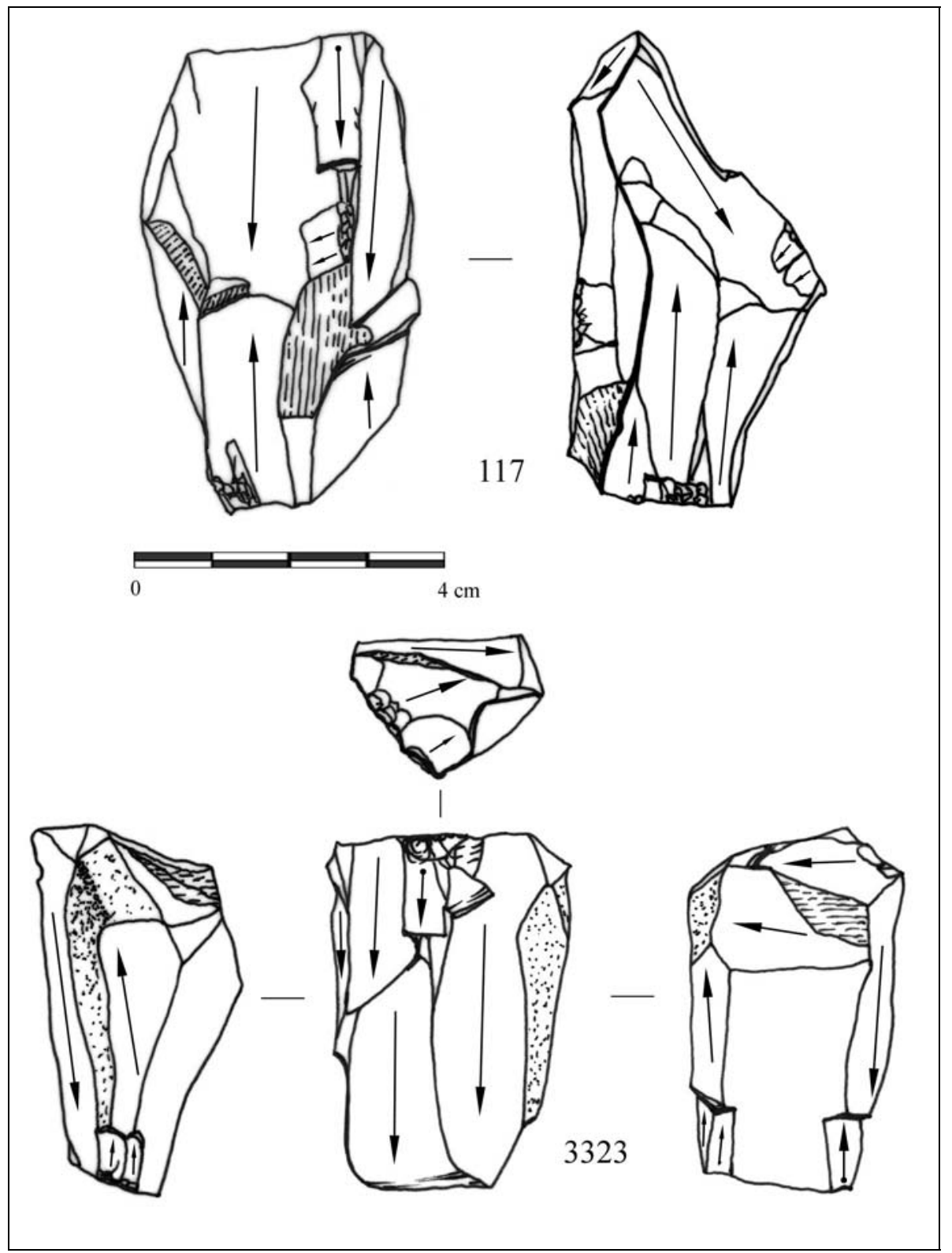

Figura SN.4: núcleos de sílex negro a partir del esquema prismático tipo-B. 


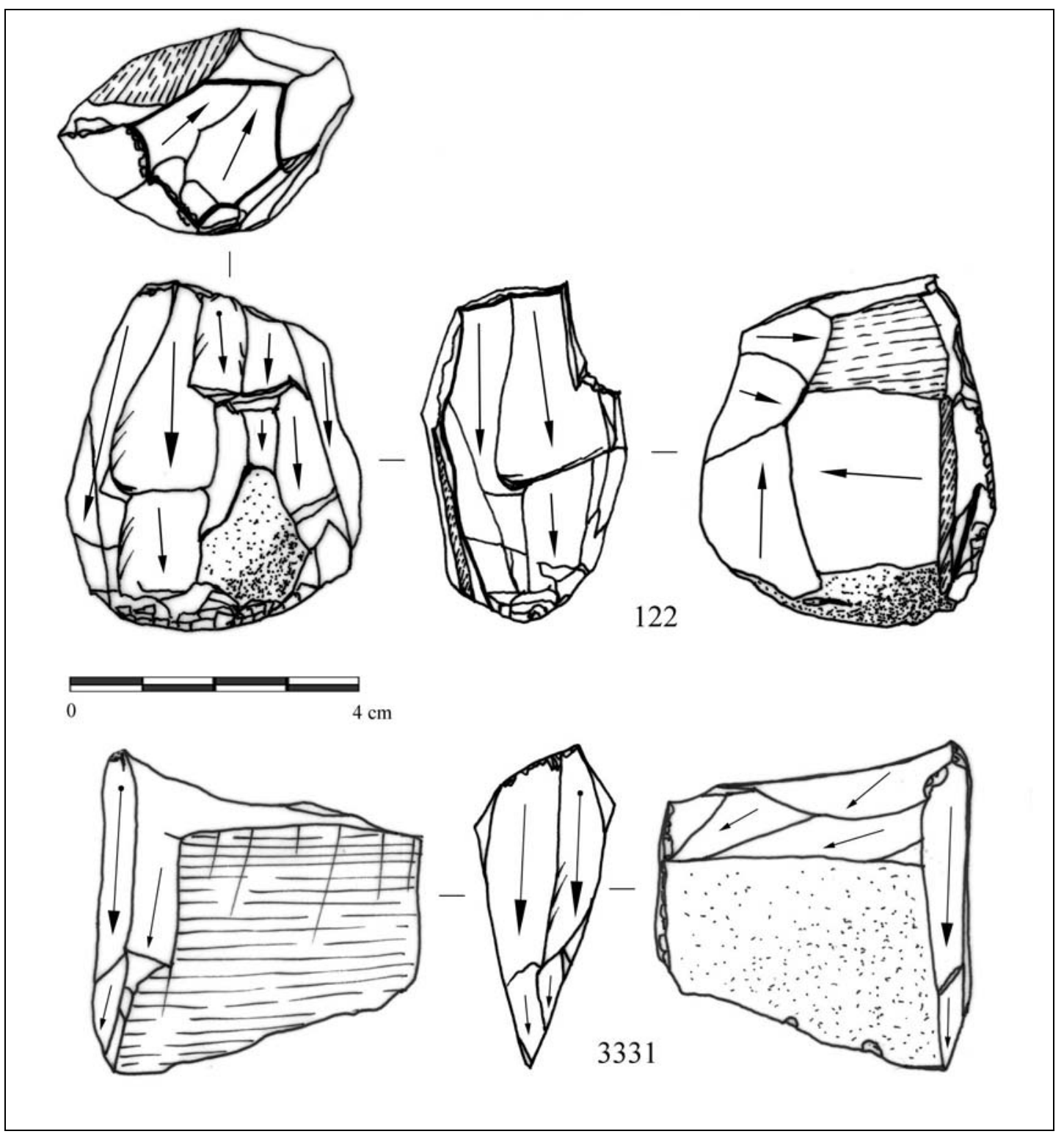

Figura SN.5: núcleos de sílex negro, a partir del esquema prismático genérico el superior (ID nº 122), y prismático tipo-A el inferior (ID nº 3331). Este último tiene por soporte una lasca. 


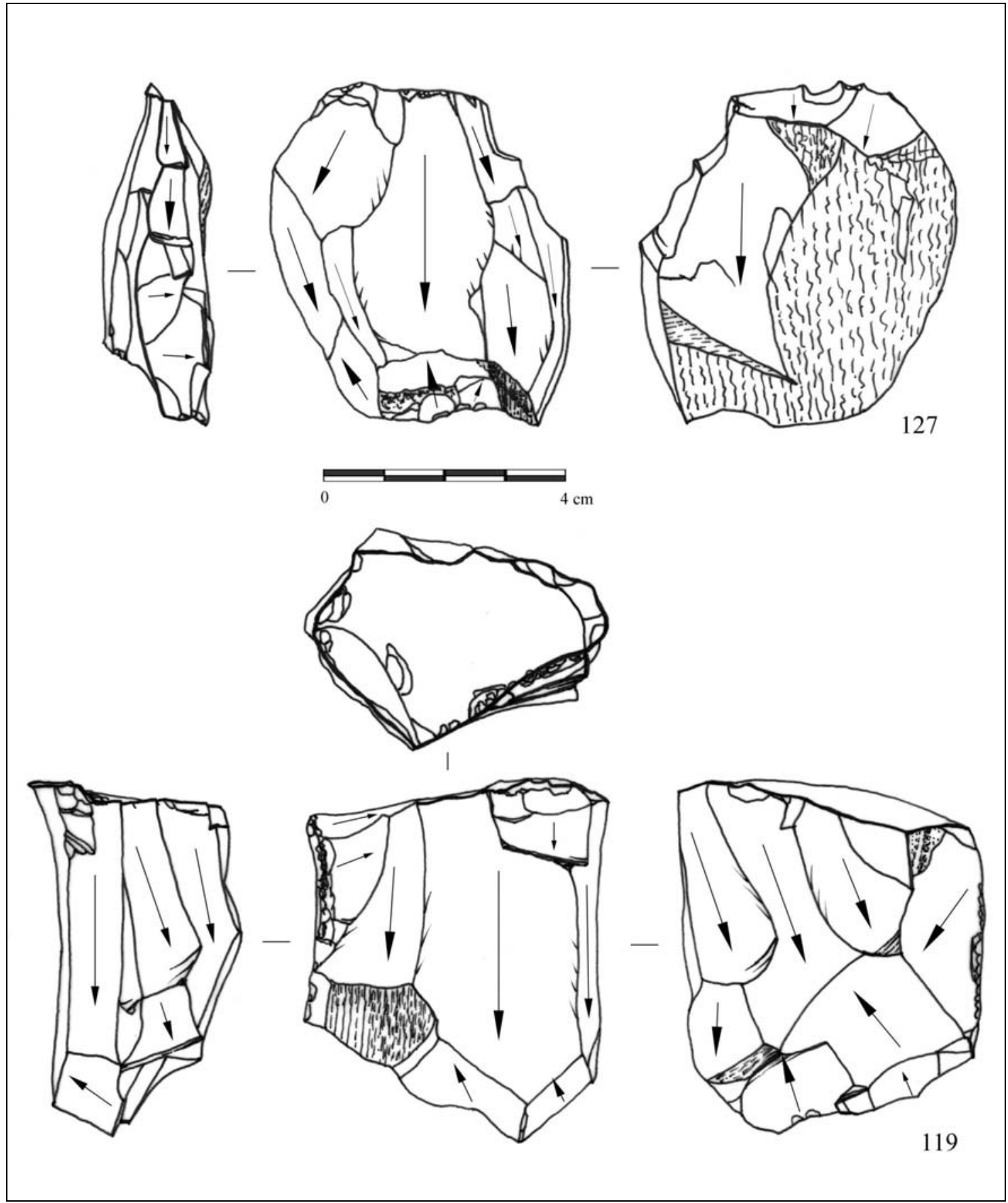

Figura SN.6: núcleos de sílex negro, a partir del esquema prismático de superficie ancha, con método unipolar 


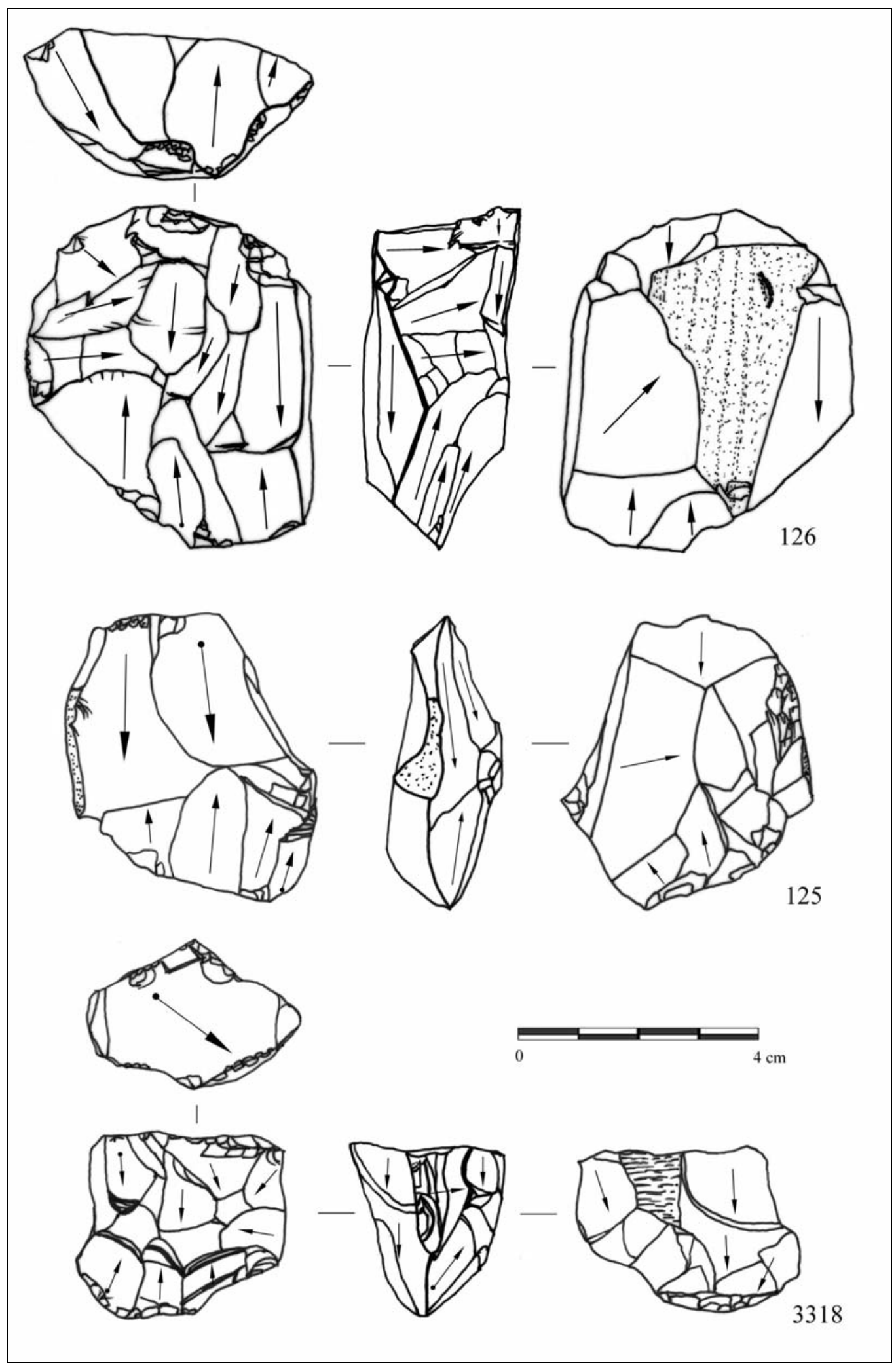

Figura SN.7: núcleos de sílex negro, a partir del esquema prismático de superficie ancha, con método bipolar. El segundo utiliza la cara inferior de una lasca. . 


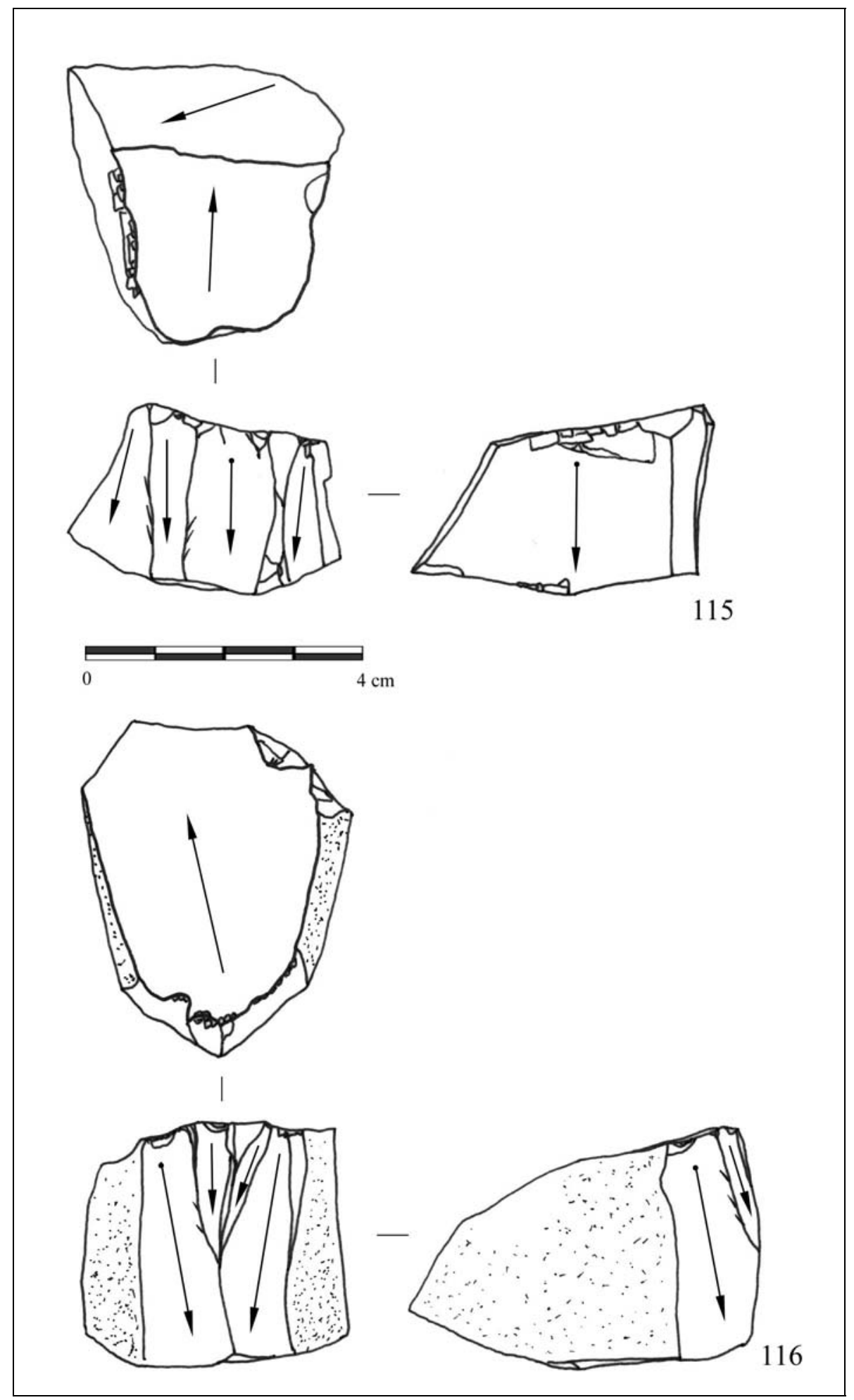

Figura SN.8: núcleos de sílex negro, a partir del esquema unipolar - prismático. 

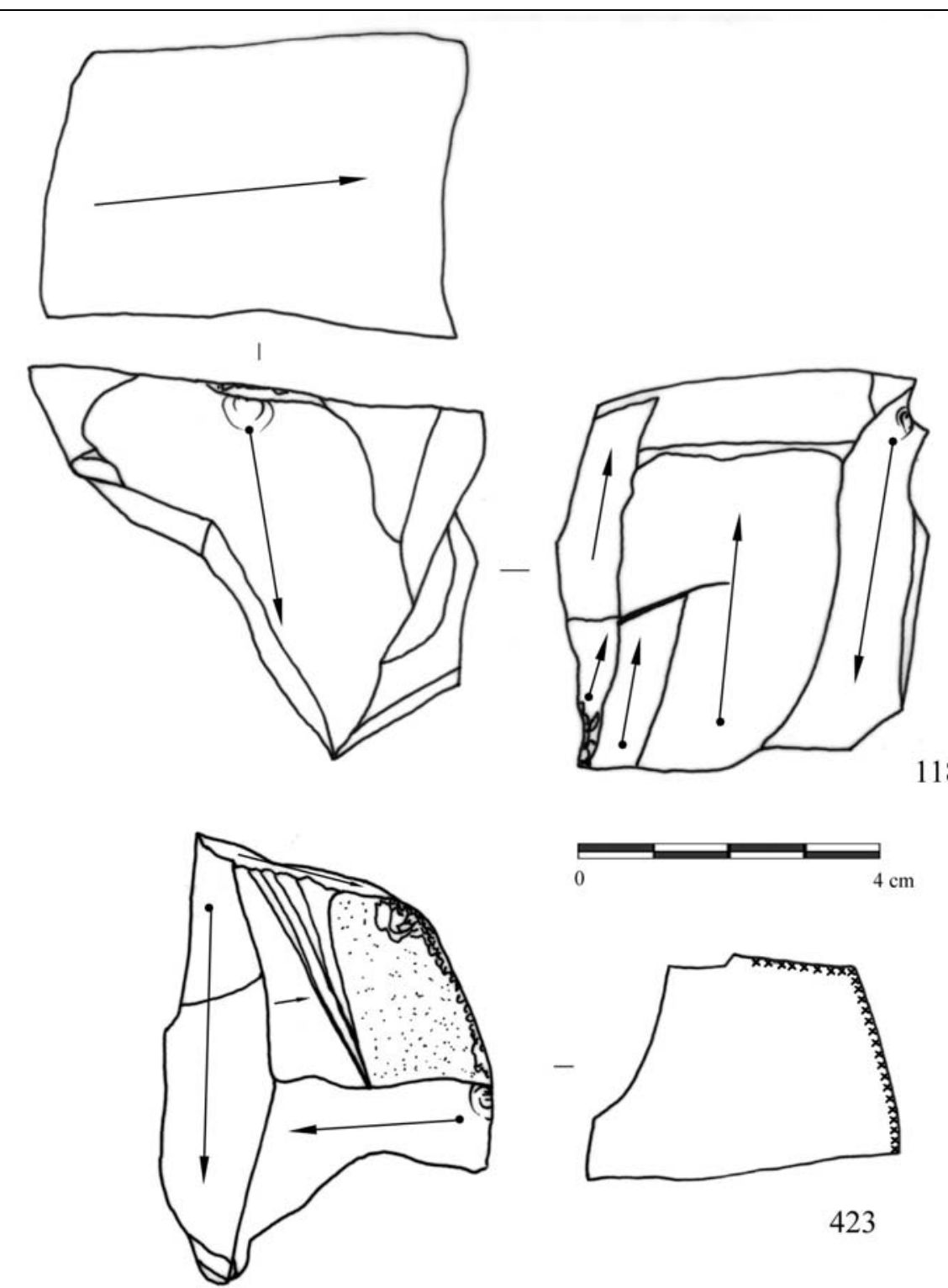

423

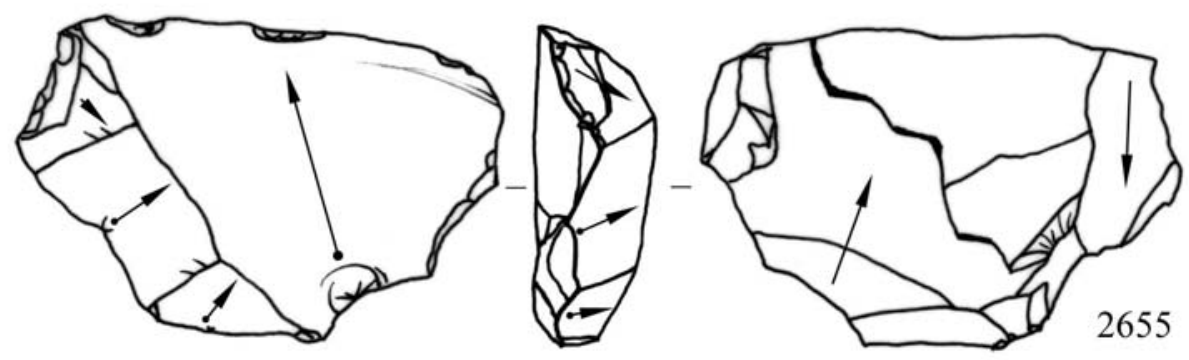

Figura SN.9: núcleos de sílex negro, esquemas no estandarizados. El último es una lasca. 


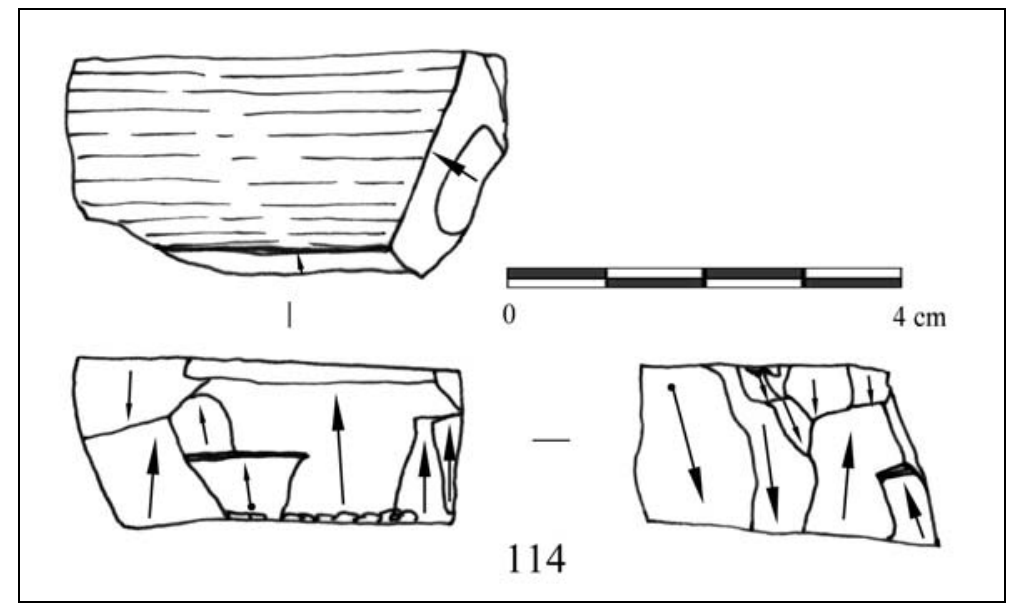

Figura SN.10: núcleo de sílex negro, a partir del esquema tipo "nódulo-placa”. 


\section{IV.1.3. PRODUCTOS DE ACONDICIONAMIENTO}

Hay 175 piezas que hemos considerado como productos de acondicionamiento o reparación del núcleo (Cuadro SN.2). Serían soportes que se obtienen sobre todo a lo largo de la fase de producción plena y aportan información sobre los procedimientos adoptados en el propio proceso de débitage. Se pueden distinguir los soportes que proceden del acondicionamiento de la superficie de extracciones y los del plano de percusión.

\section{IV.1.3.1. PIEZAS CON CRESTA}

Hay 64 soportes con algún resto del procedimiento de cresta sobre su cara superior. Dicho procedimiento consiste en realizar una serie de extracciones de forma transversal al eje de débitage y puede tener varias funciones (apertura de la superficie de extracciones, reparación de dicha superficie desde un lateral, etc.). Se ha indicado en el capítulo sobre metodología la dificultad que tiene en ocasiones determinar la función de dichas piezas cuando están de forma aislada sin conexión con el núcleo.

Hay un último tipo de piezas con cresta que no da demasiada información técnica: las hojas con cresta segunda, las cuales pueden proceder de las dos funciones mencionadas anteriormente.

\begin{tabular}{|l|cc|r|}
\cline { 2 - 4 } \multicolumn{1}{c|}{} & CRESTA COMPLETA & CRESTA PARCIAL & TOTAL \\
\hline LC (hoja/lasca con cresta) & 15 & 9 & 24 \\
LC1 (hoja/lasca con neo-cresta) & 18 & 18 & 36 \\
\hline
\end{tabular}

Cuadro SN.36 : piezas con cresta.

En el sílex negro hay 24 piezas con cresta, 36 con neo-cresta y 4 con cresta segunda. En el cuadro SN.36 se presenta para las dos primeras categorías si la cresta se desarrolla a lo largo de toda la longitud del soporte o sólo de un modo parcial. En el caso de las piezas con neo-cresta hay tantos elementos con la cresta total como parcial, lo cual puede ser indicio de que se trata de procedimientos centrados en partes concretas 
de la superficie de extracciones. El mayor número de neo-crestas es indicativo de un empleo abundante de procedimientos de reforma de la superficie de extracciones en el curso del débitage pleno, con la finalidad de abrir la superficie de extracciones hacia un flanco o bien enderezar la carena o la cintra. Las piezas con cresta propiamente dichas son hojas y también lascas, en ambos casos pueden tratarse de piezas que pertenecerían al inicio del débitage, pero también pueden corresponder a otras partes del núcleo, en el proceso de talla.

En el caso de las neo-crestas hay muchas de ellas que se realizan sobre lo que serían flancos corticales del núcleo, tienen en la zona donde se realiza la neo-cresta un mayor grosor, en la sección se aprecia cómo la disposición de este mayor grosor se desequilibra hacia el flanco de la superficie de extracciones. Son piezas que se producen a lo largo del débitage pleno en el que se avanza sobre un flanco del núcleo. Suele tratarse de núcleos en los que se instala la superficie de extracciones entre sendos flancos más o menos ortogonales, dichos flancos pueden ser corticales (sobre un nódulo con forma de placa por ejemplo) o acondicionados por extracciones. Esta forma de construir el núcleo permite un avance del débitage relativamente rápido y continuo cuando la superficie de extracciones es estrecha, ya que la cintra se va manteniendo a lo largo del débitage gracias al avance paulatino y controlado sobre los flancos. Como producto de este avance se puede obtener estas neo-crestas cuando es necesario acondicionar dicho lateral, pero también se pueden extraer hojas semicorticales, o las que hemos denominado como "hojas con flanco"; todos estos soportes tendrían la misma función técnica. La ventaja de este método de débitage es que en el mismo avance de la talla, de forma intercalada a las hojas-hojitas, se produce un mantenimiento del débitage mediante la extracción de estos soportes del flanco en forma de hojas con neo-cresta que son piezas alargadas, aptas para su eventual utilización. Ya se ha visto asimismo cómo en los núcleos prismáticos grupo-A, cuyos objetivos son esencialmente hojas-hojitas, hay restos de estas “hojas de recintrado” del núcleo.

En el cuadro SN.37 Se muestran las dimensiones de las piezas con cresta, se trata de soportes bastante largos $(43 \mathrm{~mm})$ y anchos $(14 \mathrm{~mm})$ aunque de un grosor también amplio (7 mm). La longitud las acerca a la media obtenida para los núcleos, por lo que son indicativas de la longitud de la superficie de extracciones. Son por tanto 
piezas robustas, que al parecer se han aprovechado posteriormente también para utilizar la longitud de los bordes laterales ya que tipológicamente hay varias piezas con retoque continuo o huellas de uso.

\begin{tabular}{|l|ccc|ccc|}
\cline { 2 - 7 } \multicolumn{1}{c|}{} & \multicolumn{3}{c|}{ PIEZAS CON CRESTA } & \multicolumn{3}{c|}{ TABLETAS Y SEMITABLETAS } \\
\cline { 2 - 7 } \multicolumn{1}{c|}{} & $\mathrm{L}$ & $\mathrm{A}$ & $\mathrm{G}$ & $\mathrm{L}$ & $\mathrm{A}$ & $\mathrm{G}$ \\
\hline $\mathrm{N}$ & 11 & 60 & 60 & 21 & 25 & 25 \\
Rango & $21-58$ & $6-28$ & $2-20$ & $7-38$ & $9-35$ & $1-26$ \\
Media & $\mathbf{4 3 , 2}$ & $\mathbf{1 4 , 5}$ & $\mathbf{7 , 1}$ & $\mathbf{2 2 , 5}$ & $\mathbf{1 9 , 8}$ & $\mathbf{6 , 4}$ \\
Desviación & 12,1 & 6,5 & 3,8 & 9,4 & 7,3 & 5,8 \\
\hline
\end{tabular}

Cuadro SN.37: datos métricos de las piezas con cresta y de las tabletas y semitabletas de núcleo. L: longitud, A: anchura, G: grosor.

\section{IV.1.3.2. TABLETAS Y SEMITABLETAS DE NÚCLEO}

Hay tres tabletas de núcleo y veintidós semitabletas, en el cuadro SN.37 se muestran los datos métricos, donde se comprueba que son piezas de morfología cuadrangular, con una longitud media de $22 \mathrm{~mm}, 20$ de anchura y 6 de grosor; estos datos las acerca a las características métricas de las lascas, pero son mayores que éstas.

\section{IV.1.3.3. FLANCOS DE NÚCLEO}

Hay 58 piezas que se han clasificado como flancos de núcleo, y dentro de ellos pueden diferenciarse a veces los flancos de núcleo longitudinales (al menos en 27 piezas) y los transversales (16 elementos). Las medidas de los flancos (cuadro SN.38) indican una dispersión que encaja dentro de los parámetros vistos para las medidas de la superficie de extracciones de los núcleos. La longitud de los flancos de núcleo longitudinales sería indicio de la longitud de la superficie de extracciones del núcleo del que proceden, su amplia dispersión (19-84 mm) es similar a la de los núcleos prismáticos. Para la anchura, podemos tomar en consideración los flancos transversales, los cuales marcan una dispersión entre 19 y $57 \mathrm{~mm}$ de anchura de la superficie de extracciones, sobrepasando por tanto la anchura media de los núcleos prismáticos en su fase de abandono, en consecuencia pueden pertenecer a cualquiera de los esquemas técnicos vistos en los núcleos. 
Las medidas de la superficie de extracciones otorgada por los flancos son indicios de las dimensiones de los núcleos explotados a lo largo de todo el proceso técnico; si los núcleos portan la superficie de extracciones en su estadio final, los flancos muestran los distintos reavivados de dicha superficie a lo largo de la explotación del mismo. Si tuviéramos el esquema técnico de uno de estos núcleos, con el remontage de todos sus elementos, podríamos comprobar cómo se va gestionando y reduciendo la superficie de extracciones, la relación entre dicha explotación y la pérdida de masa por los productos de acondicionamiento, el número de soportes en cada secuencia de explotación plena, etc., así podríamos realizar una valoración sobre la explotación y "rentabilidad" de un núcleo. Como no tenemos remontages completos de los núcleos, tan solo podemos constatar algunos aspectos relativos a las características recogidas para los núcleos. Lo ideal sería que fuéramos capaces de identificar los productos de acondicionamiento característicos de los distintos tipos de núcleo, pero no siempre es posible. Los flancos de núcleo longitudinales parecen proceder en su mayoría de los núcleos prismáticos, su longitud encaja de hecho dentro de este grupo. Los flancos de núcleo transversales en cambio pueden proceder prácticamente de cualquier tipo de núcleo del conjunto, y la anchura así parece indicarlo.

\begin{tabular}{|l|ccc|ccc|}
\cline { 2 - 7 } \multicolumn{1}{c|}{} & \multicolumn{3}{c|}{ FLANCOS DE NÚCLEO } & \multicolumn{3}{c|}{ FLANCOS DE NÚCLEO } \\
\cline { 2 - 7 } \multicolumn{1}{c|}{} & $\mathrm{L}$ & $\mathrm{A}$ & $\mathrm{G}$ & $\mathrm{L}$ & $\mathrm{A}$ & $\mathrm{G}$ \\
\hline $\mathrm{N}$ & 41 & 57 & 57 & 18 & 27 & 27 \\
Rango & $17-84$ & $10-55$ & $2-31$ & $19-84$ & $12-46$ & $4-22$ \\
Media & $\mathbf{4 0 , 3}$ & $\mathbf{2 5 , 7}$ & $\mathbf{9 , 3}$ & $\mathbf{4 8 , 6}$ & $\mathbf{2 6 , 2}$ & $\mathbf{9 , 3}$ \\
Desviación & 17,2 & 9,9 & 5,1 & 18,1 & 9,4 & 3,9 \\
\hline
\end{tabular}

Cuadro SN.38: datos métricos de los flancos de núcleo.

\section{IV.1.3.4. ARISTAS DE NÚCLEO Y OTROS PRODUCTOS DE ACONDICIONAMIENTO}

Hay por último 28 piezas que se han clasificado como aristas de núcleo y productos de acondicionamiento genéricos, sin que se pueda concretar más a qué parte del núcleo o qué función cumplirían dentro del proceso técnico. En dos casos podrían corresponder a bases del núcleo. La eliminación de la base del núcleo de forma transversal al eje de talla puede interpretarse como un procedimiento que reaviva la 
carena de la superficie de extracciones, aunque también acorta la longitud de la misma. En relación con este recurso, se ha visto en los esquemas técnicos de los núcleos que en algunos de ellos la base del núcleo se coloca de forma transversal a la superficie de extracciones, concretamente en algunos de los núcleos de superficie anca y en los núcleos tipo unipolar-prismático. 


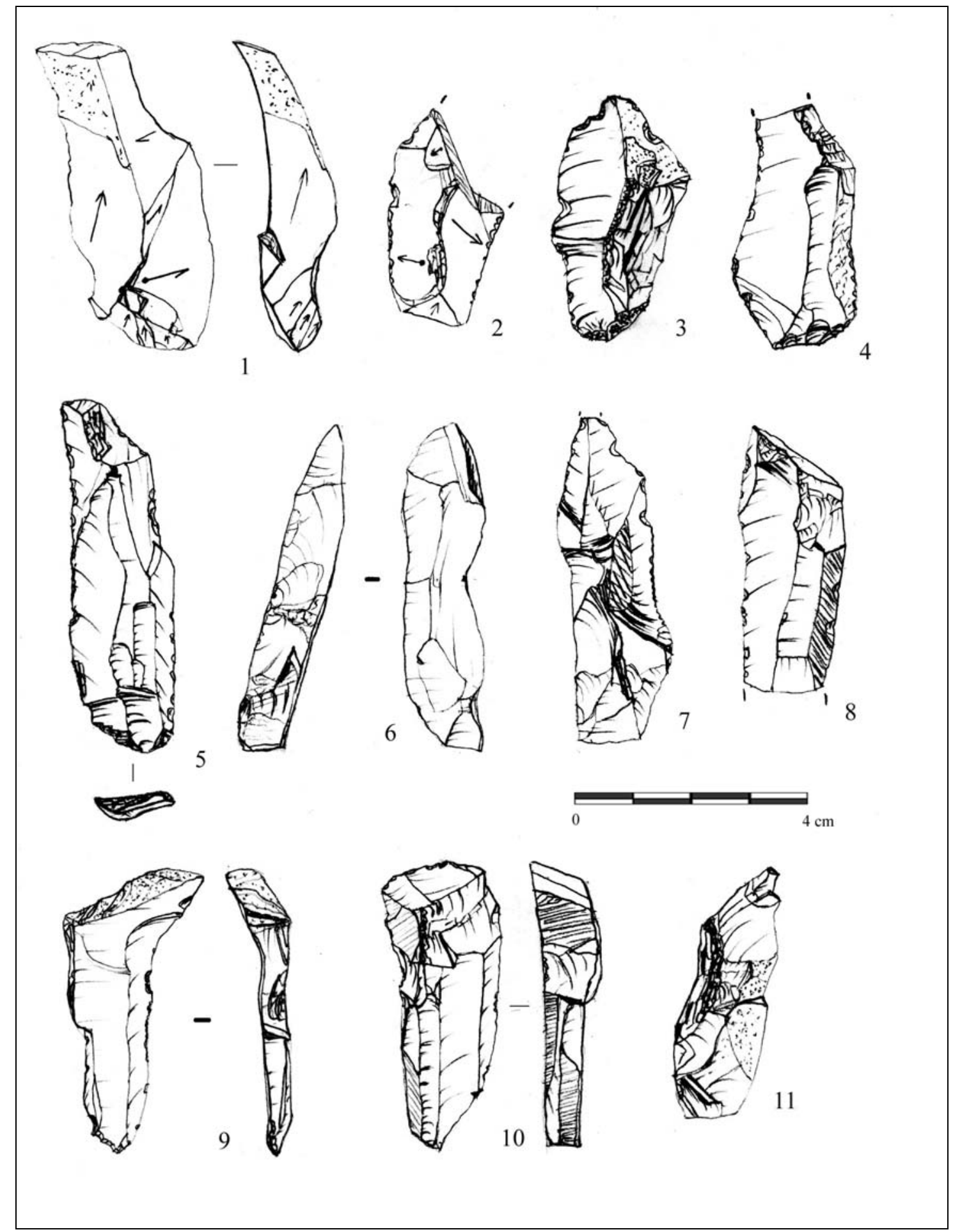

Figura SN.11: productos de acondicionamiento de sílex negro. Hojas con cresta. Hoja con cresta (“total”): $n^{\circ}$ 2. Neo-cresta: $n^{\circ} 3,6$. Neo-cresta parcial: $1,4,5,8,10,11$. La $n^{\circ} 9$ es una neocresta parcial y también una "hoja con flanco". La ${ }^{\circ}$ 7: es una arista con negativos en dirección centrípeta. 

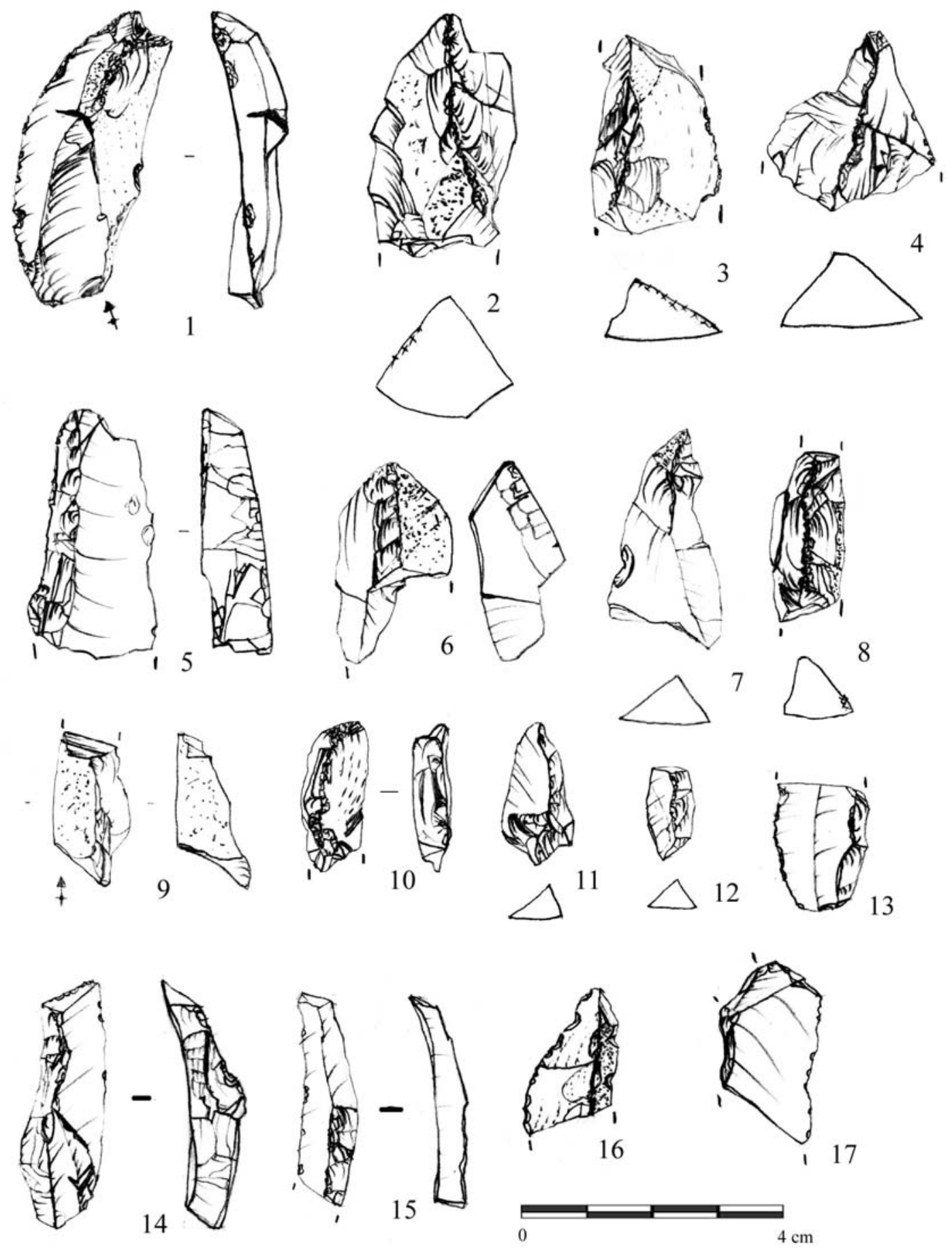

13

Figura SN.12: productos de acondicionamiento de sílex negro: piezas con cresta. Lascas y hojas con cresta: $\mathrm{n}^{\circ}$ 2, 3, 4, 8, 10, 16. Cresta parcial: 1, 7. Neo-cresta: 5, 6, 9, 11, 12, 13, 14, 17. Neocresta parcial: 15 . 


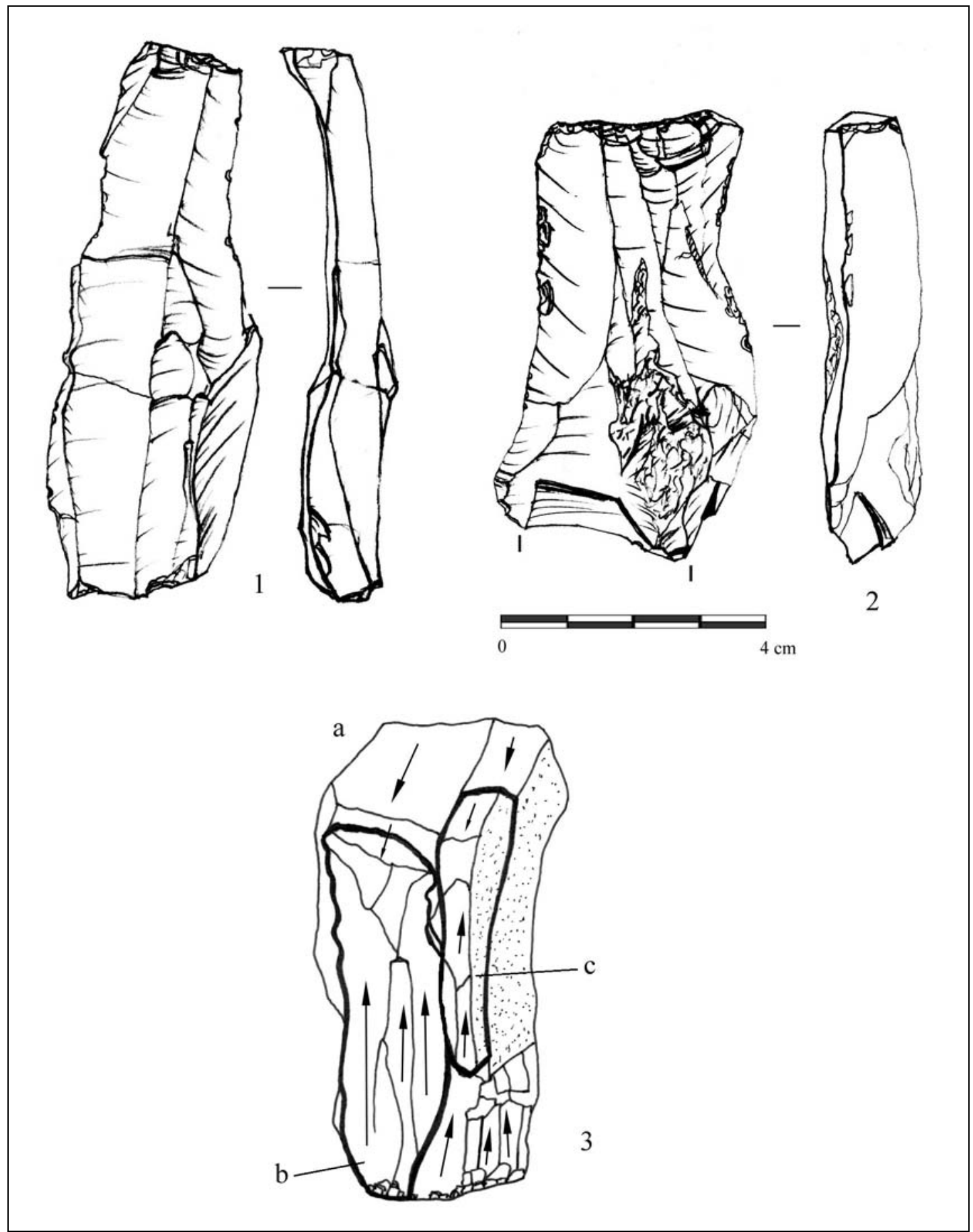

Figura SN.13: productos de acondicionamiento de sílex negro: flancos de núcleo, de tipo longitudinal opuesto. $\mathrm{El} \mathrm{n}^{\circ} 3$ tiene un remontage de una secuencia de tres piezas, a: flanco de núcleo; b: hoja de tercer orden (con retoque continuo-festoneado sobre ambos bordes laterales [ver Figura SN.24: $\mathrm{n}^{\circ}$ 2]); c: hoja de segundo orden (extraída después de la hoja anterior, se avanza así hacia el flanco cortical). 

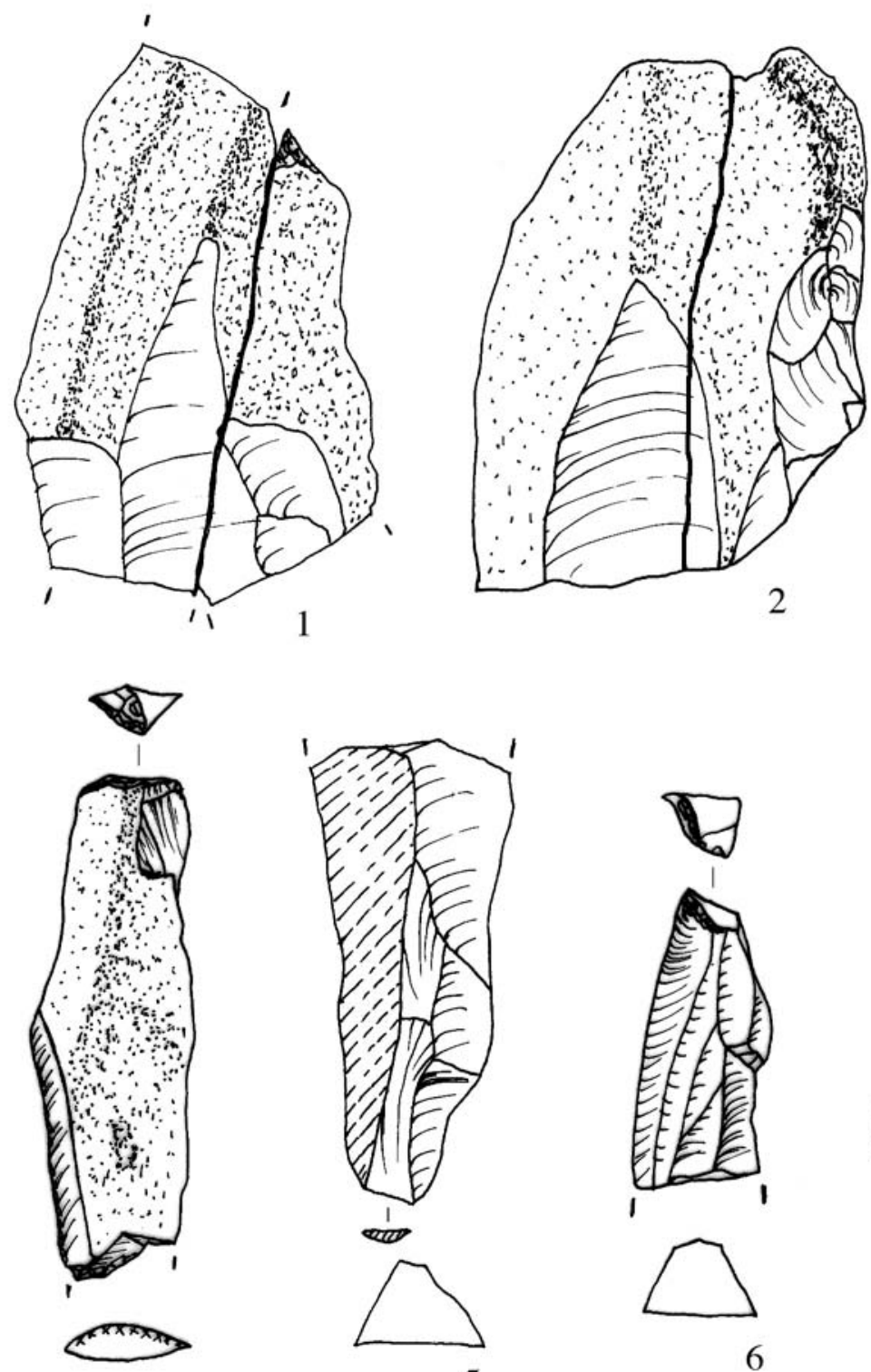

4

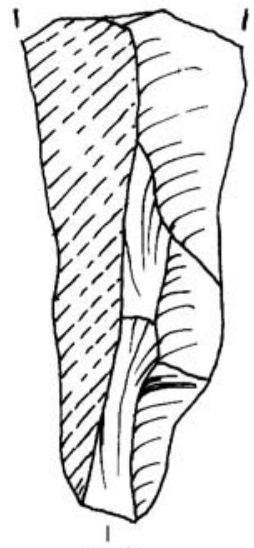

(ख)

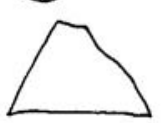

5
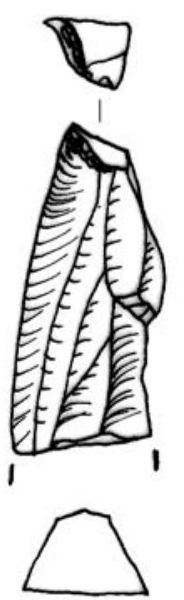

6
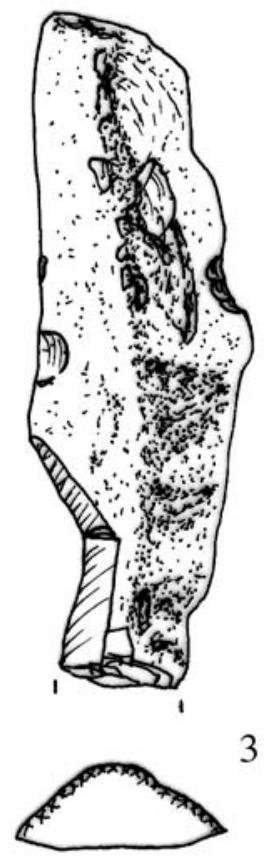

3
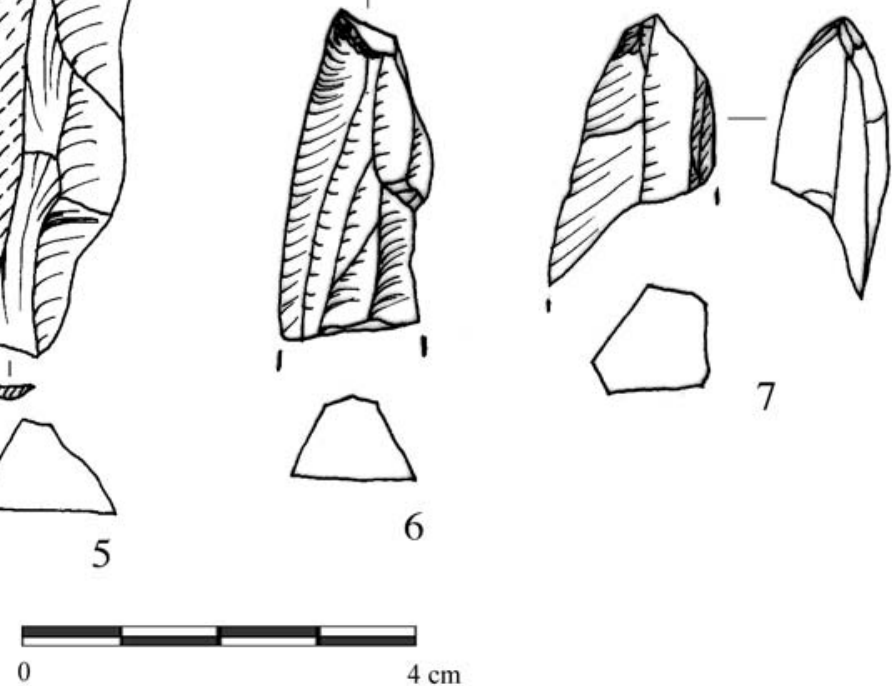

Figura SN.14: Piezas de encetadura (1 a 4), hoja con subcresta (5) y productos de acondicionamiento indeterminados, con una arista estrecha marcada (6 y 7). $\mathrm{N}^{\mathrm{o}} 1$ y 2 son hojas y lascas corticales “de encetadura”, con aristas naturales marcadas (en el $\mathrm{n}^{0} 2$ se refuerza dicha arista por una cresta parcial); en ambos casos hay un remontage parcial, de dos soportes. $\mathrm{N}^{\circ} 3$ y 4 son hojas de encetadura totalmente corticales. 


\section{IV.1.4. SOPORTES: LASCAS, HOJAS Y HOJITAS}

\section{IV.1.4.1. LASCAS}

En los primeros cuadros sobre la composición de la lista tecnológica del sílex negro se puede comprobar cómo el grueso del conjunto lítico está constituido por las piezas que hemos incluido en el grupo 1: lascas de todos los órdenes, y lascas laminares, sumando así casi la mitad de los elementos de chert. Por su parte, los soportes laminares suponen en torno al 11\% del conjunto, incluyendo en él también las “hojas con flanco”. La razón de esta abundancia de lascas frente a hojas-hojitas se debe a dos motivos:

i) en todo proceso de débitage laminar existe una importante producción de lascas procedentes sobre todo de la fase de preparación del núcleo y también de secuencias de acondicionamiento en la fase de producción

ii) en el sílex negro de El Espertín existe una producción de lascas independiente de los procesos laminares, y también hay esquemas de tendencia laminar en los que se obtienen lascas laminares

El conjunto de lascas existente en este yacimiento pertenece por tanto a estos dos procesos, y es complicado diferenciar las lascas supuestamente intencionales, características de los esquemas específicos de lascas, del resto. En el caso del esquema del núcleo-placa hay un débitage de lascas cuadrangulares de un tamaño pequeño $(3 \mathrm{~cm}$ de longitud por 2 de anchura), contamos como ejemplo de este esquema con el remontage de dos de estas lascas sobre el núcleo. En otras ocasiones hay núcleos en un estado de explotación muy avanzado, cuyas últimas extracciones son lascas también de pequeño tamaño.

Respecto al tamaño de los elementos de este grupo (cuadro SN.10) las lascas tienen una medias de: $17 \mathrm{~mm}$ de longitud, 15 de anchura y 3,5 de grosor; las lascaslaminares por su parte: 20 mm de longitud, 13 de anchura y 2,8 de grosor. No obstante hay una amplia dispersión, que se puede comprobar de forma más clara en los gráficos SN.5 y SN.6, se trata de gráficos de barras con la longitud y anchura tanto de las piezas 
sin retocar como retocadas. En la longitud hay un máximo muy claro que se sitúa por debajo de la media, en los 11-12 mm. En la anchura el máximo se sitúa en el mismo intervalo (11-12 mm), pero en este caso, hay un mayor número de elementos entre los 7 y $18 \mathrm{~mm}$. En cuanto a las piezas retocadas, se comprueba la tendencia, ya constatada al examinar las dimensiones medias, a retocar las de mayor dimensión. 


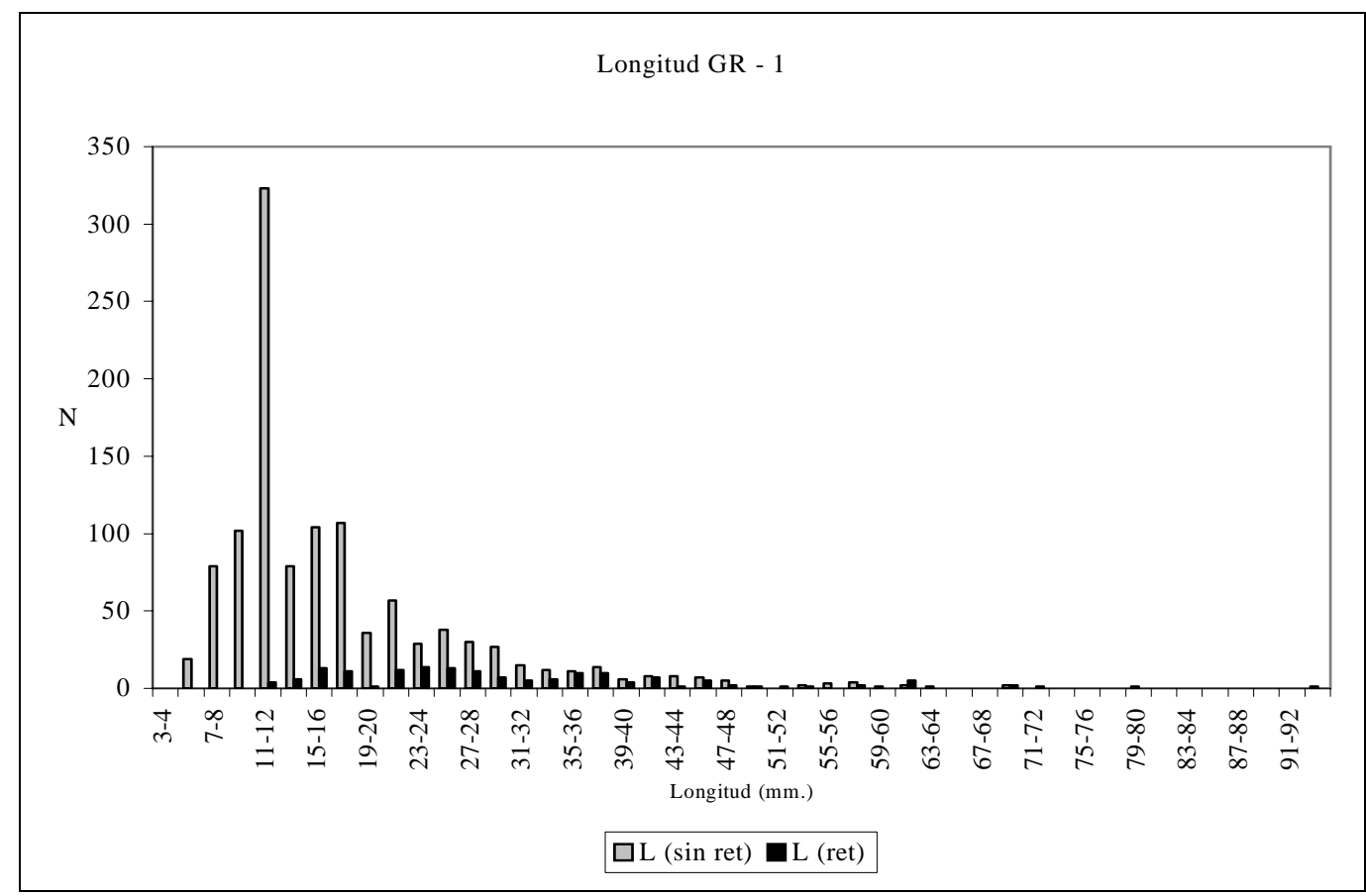

Gráfico SN.5: longitud de los soportes del grupo tecnológio 1 (lascas, lascas laminares). Sin retocar: $\mathrm{n}=1134$. Retocados: $\mathrm{n}=155$.

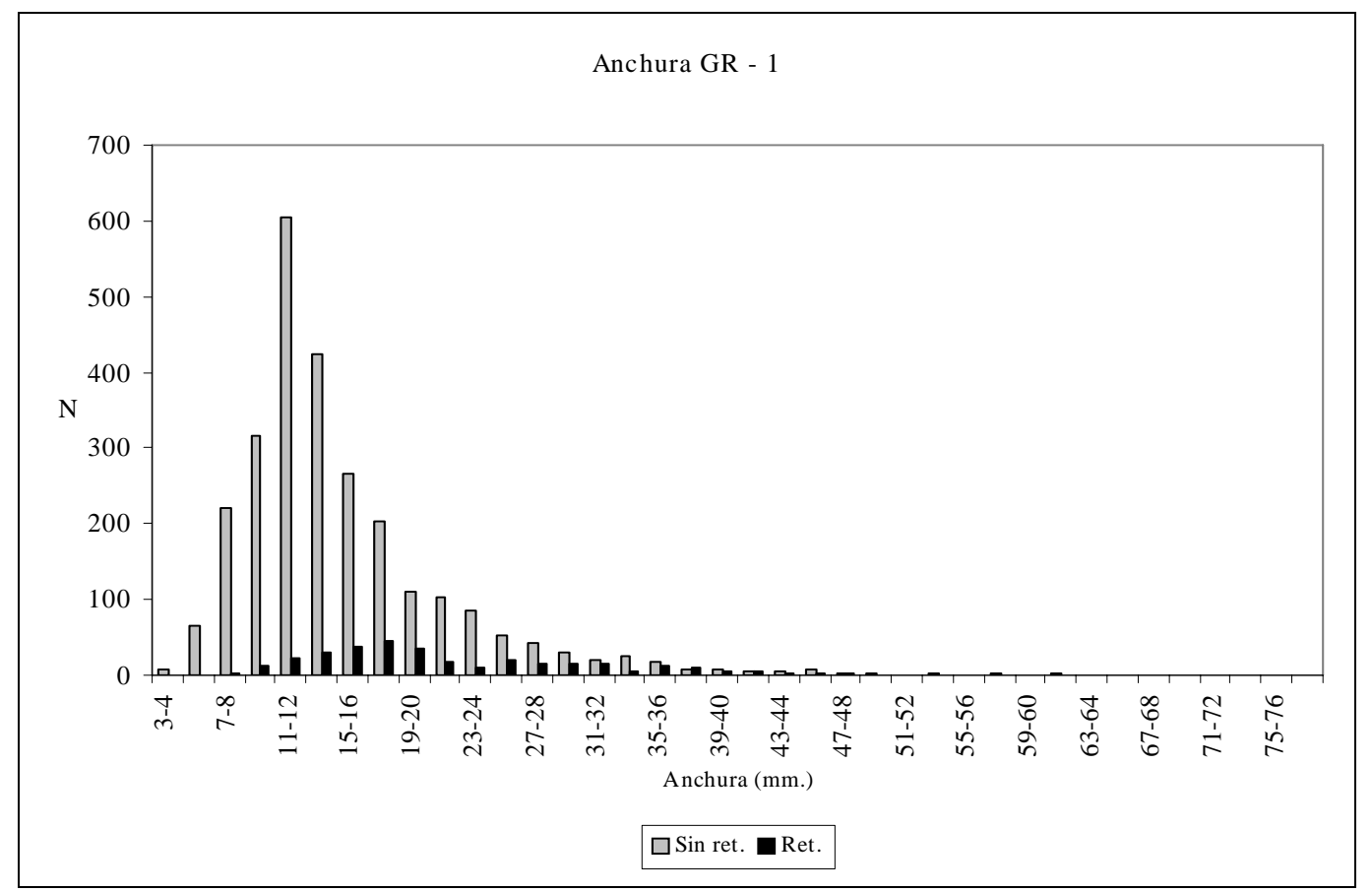

Gráfico SN.6: anchura de los soportes del grupo tecnológio 1 (lascas, lascas laminares). Sin retocar: $\mathrm{n}=2646$. Retocados: $\mathrm{n}=329$. 


\section{IV.1.4.2. Piezas CON ARISTA NATURAL: “HOJAS DE ENCETADURA”}

Otro aspecto interesante respecto a las primeras fases del débitage y en relación con los métodos de iniciación de la producción laminar propiamente dicha, son las piezas corticales que portan restos de una arista natural del nódulo, es decir una esquina natural o una convexidad adecuada en la morfología inicial de bloque seleccionado (cuadro SN.39). Las lascas de primer orden que tienen una arista natural en su cara superior suponen el $23 \%$ de las lascas totalmente corticales y, de las nueve hojas corticales que se han diferenciado, siete de ellas tienen una arista natural. Además hay ocasionalmente restos de aristas naturales aprovechadas en los nódulos de sílex negro en piezas de segundo orden. En consecuencia se puede afirmar que hay un aprovechamiento de las ventajas otorgadas por la morfología inicial de los nódulos, y en especial hay que remarcar la presencia de esas hojas corticales con arista natural, las cuales vienen a confirmar el uso del método de iniciación mediante las "hojas de encetadura” de la superficie de extracciones como procedimiento de apertura de la misma.

\begin{tabular}{|l|c|cc|}
\cline { 2 - 4 } \multicolumn{1}{c|}{} & \multirow{2}{*}{ TOTAL } & \multicolumn{2}{c|}{ CON ARISTA NATURAL } \\
\cline { 2 - 4 } \multicolumn{1}{c|}{} & & $\mathrm{N}$ & $\%$ \\
\hline Lasca de primer orden & 175 & 41 & 23,4 \\
Lasca de segundo orden & 448 & 34 & 7,6 \\
Lasca-laminar de segundo orden & 9 & 1 & 11,1 \\
Lasca de tercer orden & 2929 & 10 & 0,3 \\
Hoja de primer orden & 9 & 7 & 77,8 \\
\hline Hoja de segundo orden & 73 & 10 & 15,9 \\
Hojita de segundo orden & 29 & 1 & 3,6 \\
\hline Flanco de núcleo & 58 & 2 & 3,4 \\
\hline Golpe de buril & 30 & 5 & 16,7 \\
\hline
\end{tabular}

Cuadro SN.39: representación de piezas con arista natural

\section{IV.1.4.3. SOPORTES LAMINARES: HOJAS Y HOJITAS}

La producción laminar del sílex negro se cifra en torno al 12\% del conjunto, no es un porcentaje demasiado elevado, pero hay que tener en cuenta la producción de lascas dentro de la misma materia, lo que hace difícil diferenciar entre las lascas propias de ambos procesos técnicos; asimismo hay un número elevado de núcleos, restos de 
núcleos y nódulos desechados en la primera fase de prueba, este intenso tratamiento del sílex negro en la cueva hace el número elevado de piezas del conjunto desdibuje un tanto la producción propiamente laminar.

Respecto a la producción de soportes laminares existe el problema de si se trata de una producción de hojas y hojitas de forma diferenciada o bien es una producción integrada en un mismo proceso, de modo que a medida que disminuye el núcleo laminar se obtienen hojitas. A este respecto se van a analizar varios atributos, tanto métricos como morfológicos.

\section{IV.1.4.3.1. DATOS MÉTRICOS: LONGITUD Y ANCHURA}

En el cuadro SN.10 se han presentado las dimensiones medias de los soportes laminares. En los gráficos SN.7 y SN.8 se presentan los gráficos de barras relativos a la distribución tanto de la anchura como de la longitud en intervalos de dos milímetros, en ambos casos se muestran dos series: la de los soportes sin retocar y la de los retocados. Como en el grupo 1, las piezas retocadas tienen mayor dimensión.

En la longitud de las hojas-hojitas sin retocar, el mayor número de piezas se encuentra entre 11 y $30 \mathrm{~mm}$, con un máximo en los 15-16 mm, distribuyéndose de forma decreciente hasta los $50 \mathrm{~mm}$. Las piezas retocadas tienen una distribución más homogénea desde los 15-16 mm hasta 57, con un máximo en los 33-34 mm.

Las piezas sin retocar tienen una anchura con un máximo muy marcado entre 6 y $9 \mathrm{~mm}$, descendiendo bruscamente hasta los $20 \mathrm{~mm}$; las piezas retocadas, por su parte, tienen una distribución más homogénea, con una abundancia de elementos entre los 6 y $13 \mathrm{~mm}$, descendiendo paulatinamente hasta los $26 \mathrm{~mm}$. Las retocadas incluyen todos los soportes laminares, por tanto hay muchas piezas (los dorsos) cuya anchura ha sido rebajada por el retoque. Este hecho marca una tendencia muy clara a la selección de los soportes más anchos para ser terminados por retoque, llegando a la circunstancia de que a partir de los $16 \mathrm{~mm}$ de anchura hay más hojas retocadas que sin retocar. 


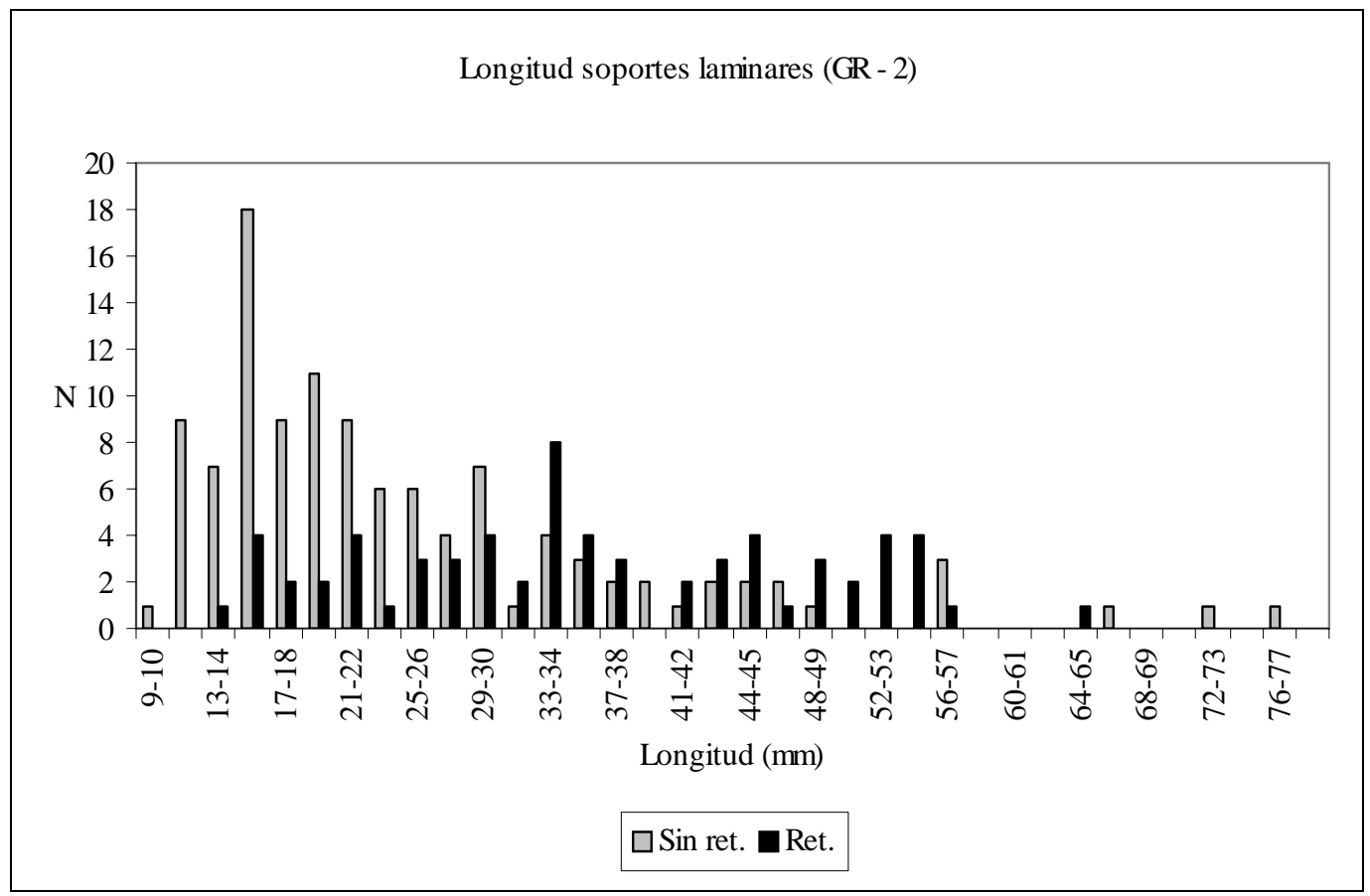

Gráfico SN.7: longitud de los soportes del grupo tecnológico 2 (hojas, hojitas). Sin retocar: $n=$ 113. Retocados: $\mathrm{n}=66$.

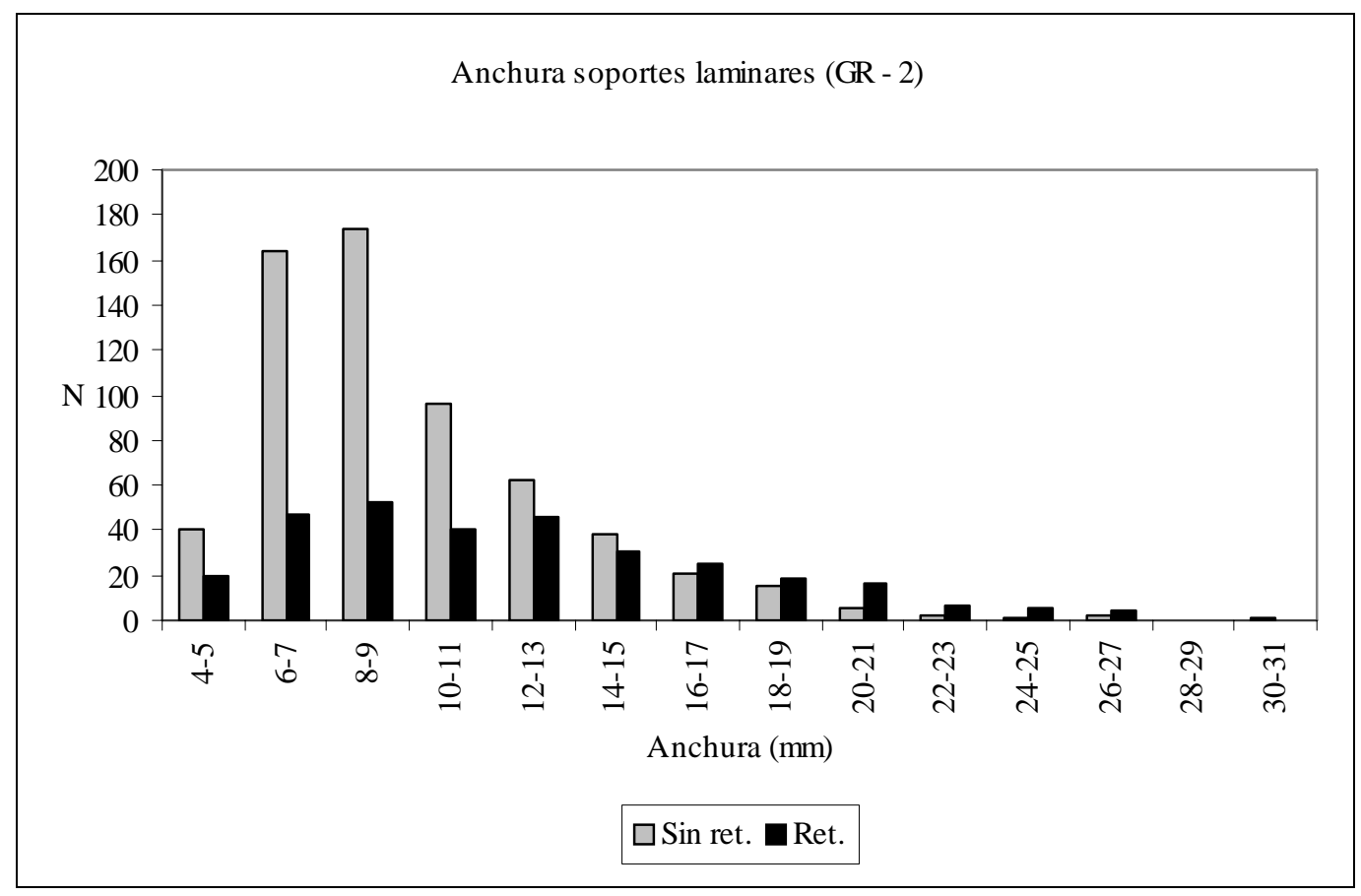

Gráfico SN.8: anchura de los soportes del grupo tecnológico 2 (hojas, hojitas). Sin retocar: $\mathrm{n}=621$. Retocados: $\mathrm{n}=313$. 


\section{IV.1.4.3.2. ATRIBUTOS TÉCNICOS}

Los atributos técnicos de los soportes laminares que se van a tratar a continuación estarán resumidos en cierto modo en el “índice de regularidad” de los soportes laminares. Este último atributo tiene un carácter subjetivo en tanto que se trata de una valoración estimativa de la “calidad” de la hoja-hojita en función de su apariencia, rectitud de las nervaduras, equilibrio general de la pieza, etc. No obstante, es evidente que dicho índice es indicativo de la calidad del débitage laminar desarrollado en el conjunto lítico. En este sentido unas hojas de una calidad buena se obtendrán de unos núcleos bien preparados, con una superficie de extracciones bien calibrada, sobre la que se ejecuta un proceso de débitage laminar exitoso. Es importante por tanto valorar los indicios técnicos de dichas hojas-hojitas que nos puedan remitir a las características de los núcleos de los que proceden, así por ejemplo la dirección de los negativos nos indicará el ritmo de avance de la talla ejecutado; o su sección longitudinal remitirá a la curvatura de la carena de los núcleos. Es interesante por tanto constatar este tipo de información procedente de las hojas-hojitas, tanto de modo relativo a las piezas retocadas como sin retocar, a fin de intentar comprobar tanto características técnicas en el proceso de talla, como preferencias a la hora de seleccionar los soportes a retocar.

\section{$N^{o}$ nervaduras/negativos}

\begin{tabular}{|l|l|cccccc|r|}
\hline \multicolumn{2}{|c|}{} & 0 & 1 & 2 & 3 & 4 & 5 & TOTAL \\
\hline \multirow{2}{*}{ SIN RET } & $\mathrm{N}$ & 2 & 266 & 245 & 77 & 12 & 2 & 604 \\
& $\%$ & 0,33 & 44,0 & 40,6 & 12,7 & 1,99 & 0,33 & 100 \\
\hline \multirow{2}{*}{ RETOC } & $\mathrm{N}$ & 18 & 90 & 120 & 62 & 16 & 4 & 310 \\
& $\%$ & 5,8 & 29,0 & 38,7 & 20,0 & 5,2 & 1,3 & 100 \\
\hline
\end{tabular}

Cuadro SN.40: $\mathrm{N}^{\mathrm{o}}$ de nervaduras en los soportes laminares

En los soportes laminares sin retocar la mayoría de las piezas (el 85\%) tienen uno o dos nervaduras y en menor grado se presentan aquellas que tienen tres o más nervaduras. En las piezas retocadas de nuevo la mayoría tienen uno o dos nervaduras, pero en un porcentaje inferior (el 70\%), existiendo más hojas-hojitas con tres y más nervaduras. Esta mayor presencia relativa de soportes laminares con más nervaduras 
entre las piezas retocadas puede estar relacionada con la tendencia ya observada de una mayor anchura de dichos elementos.

\section{Dirección negativos}

En la dirección de los negativos de la cara superior de las hojas-hojitas no tiene demasiada relevancia la diferenciación entre piezas retocadas y sin retocar. Sí es más interesante en cambio el conjunto de estas piezas en relación con la dirección del débitage general del proceso de talla. En este sentido la mayoría de los soportes laminares proceden de un ritmo de talla predominantemente unipolar, en torno al $80 \%$ de dichos soportes tienen los negativos anteriores en el mismo sentido y dirección en que han sido extraídos. Esto concordaría con el hecho del predominio de un débitage unipolar a partir de un plano de percusión principal, tal y como se ha visto al examinar los núcleos. Existe también un 18\% de las hojas-hojitas que tienen los negativos en dirección opuesta o bipolar, esto vendría también a corresponder con lo observado sobre los núcleos, en los cuales aparecía ocasionalmente el recurso a un segundo plano de percusión opuesto al plano principal con la función de rectificar la superficie de extracciones a lo largo de la fase de producción, sobre todo cuidando la curvatura de la carena. Los soportes laminares con los negativos en sentido opuesto al de la extracción misma serían posiblemente un testimonio de este tipo de mantenimiento de la superficie de extracciones.

\begin{tabular}{|l|cc|cc|}
\cline { 2 - 5 } \multicolumn{1}{c|}{} & \multicolumn{2}{c|}{ SIN RET } & \multicolumn{2}{c|}{ RET } \\
\cline { 2 - 5 } \multicolumn{1}{c|}{} & $\mathrm{N}$ & $\%$ & $\mathrm{~N}$ & $\%$ \\
\hline DI & 1 & 0,2 & 2 & 0,7 \\
DP & 6 & 1,2 & 3 & 1,0 \\
ID & 3 & 0,6 & 1 & 0,3 \\
PD & 393 & 78,3 & 217 & 75,6 \\
PD-ID & 1 & 0,2 & 0 & 0,0 \\
PD-CD & 5 & 1,0 & 0 & 0,0 \\
PD-CD-CI & 1 & 0,2 & 1 & 0,3 \\
PD-DI & 4 & 0,8 & 4 & 1,4 \\
PD-DP & 82 & 16,3 & 52 & 18,1 \\
PD-ID & 5 & 1,0 & 7 & 2,4 \\
PD-CI & 1 & 0,2 & 0 & 0,0 \\
\hline
\end{tabular}

Cuadro SN.41: dirección de los negativos de los soportes laminares. DI: distal-izquierda (trasnversal al eje técnico); DP: distal-proximal (opuesta al sentido de la extracción); ID: izquierda-distal (trasnversal al eje técnico); PD: proximal-distal (unipolar); PD-ID: proximaldistal y transversal en sentido izquierdo-distal; PD-CD: proximal-distal y restos de neo-cresta hacia la derecha; PD-CD-CI: proximal-distal y restos de cresta hacia ambas vertientes; PD-DI: 
proximal-distal y transversal en sentido hacia la izquierda; PD-DP: proximal-distal y distalproximal (bipolar).

\section{Sección}

La sección al igual que la dirección de los negativos es un atributo que no es demasiado relevante al diferenciarlo por piezas retocadas y sin retocar, en cambio sí es interesante en relación con la superficie de extracciones de los núcleos de los que procede. En la sección longitudinal de las hojas-hojitas hay un predominio de una sección curva (el 50\%) sobre rectilínea (en torno al 40\%). Este hecho es por una parte lógico desde un punto de vista meramente técnico, ya que dicha curvatura se correspondería con la curva (técnicamente necesaria) de la carena de la superficie de extracciones, pero no sabemos si también puede ser intencionado. Quizás lo que se debería de calibrar es precisamente la relación que existe entre los soportes curvos y los rectilíneos, y en qué medida unos y otros son consecuencia bien de las "leyes mecánicas” de la fractura intencional de las rocas, o bien de unas "leyes técnicas” más intencionales y relacionadas con unas necesidades culturales. Estas últimas "leyes” son las regidas directamente por el tallador en cuestión, el cual a partir de la preparación cuidadosa del núcleo, la disposición del plano de percusión y de la superficie de extracciones, el modo de talla empleado y su propia habilidad técnica puede conseguir soportes más rectilíneos a partir de un control de la carena ${ }^{24}$.

\begin{tabular}{|l|l|ccccc|r|}
\cline { 3 - 8 } \multicolumn{2}{l|}{} & Cn & Cx & R & S & T & TOTAL \\
\hline \multirow{2}{*}{ SIN RET } & $\mathrm{N}$ & 196 & 30 & 157 & 12 & 9 & 404 \\
& $\%$ & 48,5 & 7,4 & 38,9 & 3,0 & 2,2 & 100 \\
\hline \multirow{2}{*}{ RET } & $\mathrm{N}$ & 128 & 9 & 106 & 2 & 10 & 255 \\
& $\%$ & 50,2 & 3,5 & 41,6 & 0,8 & 3,9 & 100 \\
\hline
\end{tabular}

Cuadro SN.42: perfil longitudinal de los soportes laminares. Cn: cóncavo, curvo; Cx: convexo; R: rectilíneo; S: sinuoso (cóncavo-convexo); T: torse (alabeado).

No disponemos de mucha información relativa a este aspecto, por lo que no es posible valorar la pertinencia de la relación entre soportes rectilíneos (40\%) y curvos (50\%) presente en el sílex negro. Sí hemos visto en los núcleos cómo hay una tendencia a la presencia de una carena recta sobre todo en los núcleos prismáticos, que son de los 
cuales procederían precisamente estos soportes laminares. El resto de los soportes laminares tienen una sección que se reparte entre convexa, sinuosa y alabeada.

Respecto a la sección transversal, predomina ampliamente la sección triangular sobre el trapezoide, con una relación de 70 a 30\% aproximadamente. Este hecho está en relación directa con el número de nervaduras presentes en la cara superior de la hojahojita, con su grosor y su anchura. En este sentido a pesar de contar en el conjunto con un buen número de elementos laminares que tienen dos nervaduras, parece que la anchura de los mismos no es lo suficiente como para dibujar una sección trapezoide.

\begin{tabular}{|l|l|ccc|r|}
\cline { 3 - 6 } \multicolumn{2}{c|}{} & Bi-cX & TR & TZ & TOTAL \\
\hline \multirow{2}{*}{ SIN RET } & $\mathrm{N}$ & 4 & 423 & 148 & 575 \\
& $\%$ & 0,7 & 73,6 & 25,7 & 100 \\
\hline \multirow{2}{*}{ RET } & $\mathrm{N}$ & & 209 & 92 & 301 \\
& $\%$ & & 69,4 & 30,6 & 100 \\
\hline
\end{tabular}

Cuadro SN.43: sección transversal de los soportes laminares. Bi-cx: biconvexa; TR: triangular; TZ: trapezoidal.

\section{Indice de Regularidad}

Como ya se ha indicado el índice de regularidad de las hojas-hojitas es un atributo que por una parte tiene un carácter sintético de los atributos anteriores (relativos a aspectos técnicos del débitage laminar) y, por otra parte, un carácter subjetivo, en tanto que reproduce una valoración estimativa de la "calidad" de los soportes en cuestión. Para este atributo sí es interesante la diferencia entre las piezas retocadas y sin retocar ya que se constata una tendencia a seleccionar los soportes de una mejor calidad (los caracterizados con una regularidad de “2” y “1-2”). De hecho a pesar de que la mayoría de las hojas-hojitas retocadas tienen una calidad que podríamos tildar de media (índice “1”), en cambio es en los retocados donde vamos a encontrar la mayoría de los soportes de "buena" calidad del conjunto lítico (hay más hojas-hojitas retocadas de calidad “1-2” y "2”, que sin retocar). En consecuencia se puede afirmar que hay una preferencia, lógica por otro lado, por los soportes de mayor calidad.

${ }^{24}$ Así sucede por ejemplo en los yacimientos azilienses de la Cuenca de París, mediante un método de débitage bipolar (Valentin, 1995). 


\begin{tabular}{|l|l|ccccc|r|}
\cline { 3 - 8 } \multicolumn{2}{l|}{} & 0 & $0-1$ & 1 & $1-2$ & 2 & TOTAL \\
\hline \multirow{2}{*}{ SIN RET. } & $\mathrm{N}$ & 100 & 34 & 256 & 104 & 37 & 531 \\
& $\%$ & 18,8 & 6,4 & 48,2 & 19,6 & 7,0 & 100 \\
\hline \multirow{2}{*}{ RET. } & $\mathrm{N}$ & 39 & 37 & 104 & 77 & 29 & 286 \\
& $\%$ & 13,6 & 12,9 & 36,4 & 26,9 & 10,1 & 100 \\
\hline
\end{tabular}

Cuadro SN.44: índice de regularidad de los soportes laminares. 0: mala calidad; 1: calidad media, aceptable; 2: buena calidad.

\section{IV.1.4.4. "HOJAS CON FLANCO"}

Hay una serie de soportes laminares que se han clasificado como "hojas con flanco", son hojas que han sido extraídas en el mismo proceso de débitage en el borde de la superficie de extracciones, en torno al límite con el flanco correspondiente. Sería una pieza a medio camino entre un producto laminar $\mathrm{y}$ un producto de acondicionamiento. Ya hemos indicado que en muchos casos tendrían la misma categoría funcional que las hojas con neo-cresta y algunas hojas semicorticales, y se corresponderían también con los negativos visibles sobre los núcleos que hemos denominado como “hojas o piezas de recintrado". 


\section{IV.1.5. PIEZAS RETOCADAS}

Hay en sílex negro un buen número de piezas con algún tipo de retoque, se han contabilizado un total de 776 elementos, incluyendo tanto los tipos retocados clásicos, como los soportes con algún tipo de retoque pero que realmente pertenecen a una fase previa a la secuencia de realización del tipo concreto (los microburiles, picantes triédricos y piezas con escotadura al lado de una rotura), así como también las piezas con retoque marginal, que podrían corresponder a piezas con huellas de uso.

En los soportes seleccionados para la realización de los útiles retocados hay un predominio del primer grupo tecnológico, es decir el de las lascas y lascas laminares, constituyendo la mitad del utillaje retocado. Con un $40 \%$ le sigue el grupo de los soportes laminares, siendo minoritarios el resto de los soportes del conjunto. A pesar de este predominio de las lascas en el conjunto retocado de sílex negro, si tenemos en cuenta el tipo de soportes seleccionados relativamente a la abundancia de éstos en el conjunto total de chert, la perspectiva en cuanto al tipo de soportes preferidos varía, ya que los soportes más seleccionados, dentro de los posibles, son los laminares: un tercio de las hojas-hojitas existentes en el total del conjunto se han retocado, el siguiente grupo es el de los productos de acondicionamiento, de los cuales el 23\% se han retocado, y por último, con un $10 \%$, se encontrarían las lascas. A pesar de este menor porcentaje relativo de retoque en los soportes del grupo tecnológico primero, el número de lascas retocadas es muy alto porque también son muchos los soportes de este grupo existentes en el conjunto de sílex negro. Ya hemos indicado cómo además de las lascas, lascaslaminares, etc. que se producen en un proceso laminar, hay esquemas propiamente de lascas. 


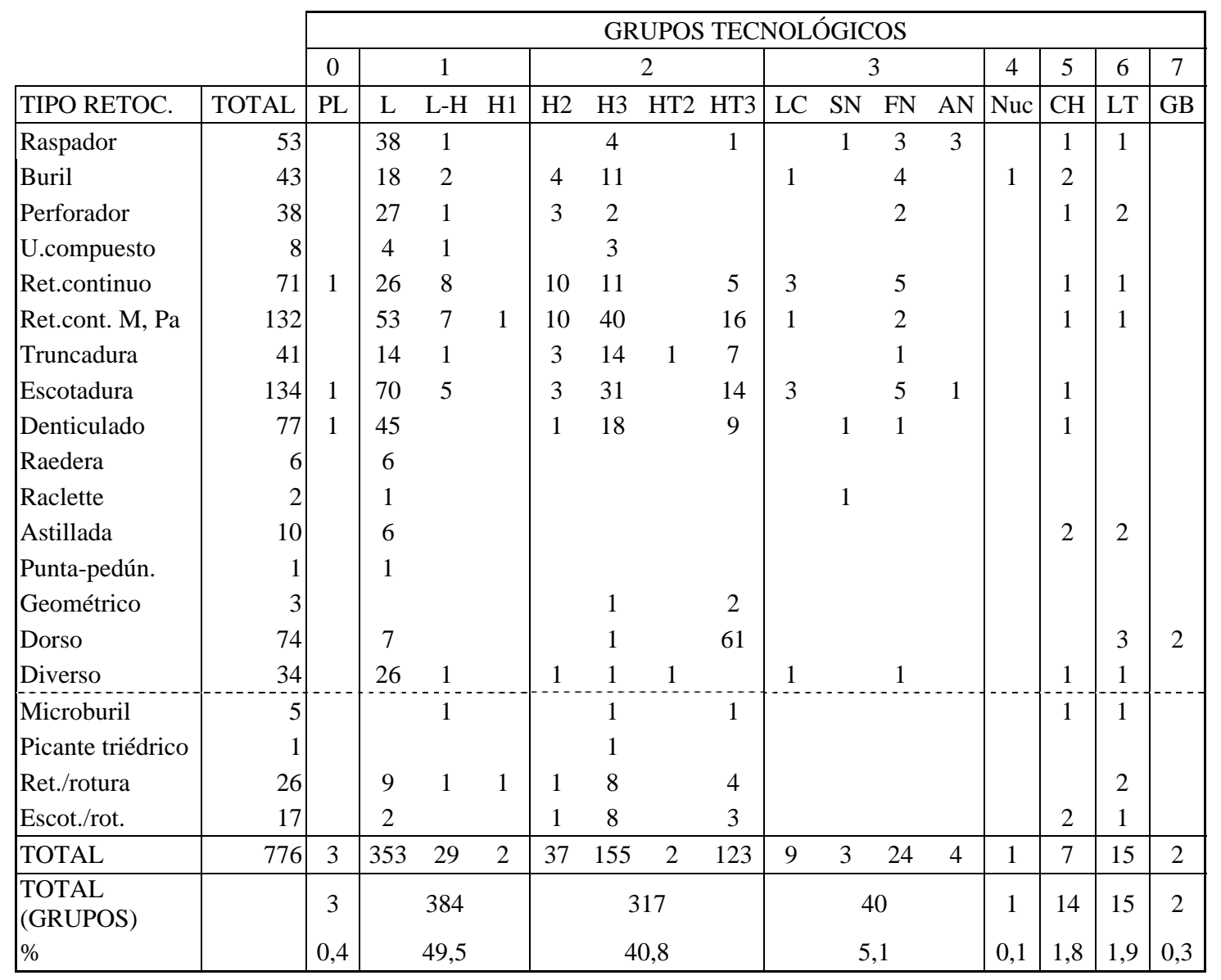

Cuadro SN.45: piezas retocadas de sílex negro, por tipos de soporte y por grupos tecnológicos.

En el cuadro SN.45 se especifican los soportes seleccionados para la realización de los principales grupos tipológicos. En los siguientes puntos se esquematiza dentro de cada soporte el tipo retocado realizado, se intentará determinar si hay soportes con uso específico para determinados tipos:

- Los fragmentos de nódulos se han utilizado ocasionalmente en tres piezas: una escotadura, un denticulado y un retoque continuo.

- Las lascas se han utilizado sobre todo para escotaduras y denticulados (suponiendo un tercio de las lascas), después para las piezas con retoque continuo (22\%), raspadores (10\%), perforadores y buriles.

- Las lascas laminares tienen un uso más específico para los retoques continuos (el 50\%) y en menor medida para escotaduras (17\%), buriles (7\%) 
$\mathrm{y}$, con porcentajes en torno al 3\%, para raspadores, perforadores y útiles compuestos.

- Las hojas semicorticales tienen también un uso específico como las anteriores en los retoques continuos (el 54\%) y en menor medida para buriles (10\%), así como perforadores, escotaduras y truncaduras.

- Las hojas de tercer orden tienen un uso más diversificado, un tercio de ellas tienen retoque continuo, que es el grupo tipológico más abundante, igual que los soportes anteriores, pero en este caso el número de escotaduras es mayor (20\%), existiendo también otro $10 \%$ de hojas con una rotura o escotadura al lado de una rotura; en el 11\% se han identificado denticulados y también se han utilizado para la confección de buriles (7\%) y algún raspador.

- Las hojitas de tercer orden tienen un uso específico para la realización de piezas de dorso (el 50\%), también hay hojitas con retoque continuo y marginal (17\%), con escotaduras (11\%) y denticulados (7\%), y en porcentajes menores hay restos del procedimiento de fractura intencional de las mismas, microburiles y geométricos.

- Las piezas con cresta aparecen sobre todo en los retoques continuos (el 44\%) y las escotaduras (33\%).

- Las semitabletas de núcleos retocadas son tres, con uso diversificado: un raspador, un denticulado y una raclette.

- Los flancos de núcleo aparecen en piezas con retoque continuo (30\%), escotaduras (20\%), buriles (16\%) y raspadores.

- Las aristas de núcleo o productos de acondicionamiento indeterminado se utilizan específicamente en raspadores.

- Los soportes indeterminados y chunks aparecen de forma bastante diversificada en distintos tipos retocados.

- Las lasquitas de talla o fragmentos de lascas incluidos en los debris aparecen sobre todo en algún dorso, y es destacable el hecho de que algunos tipos se presentan aquí de forma microlítica: raspadores, perforadores y astilladas.

- Respecto a los dos golpes de buril retocados, son ambos piezas con dorso. 
A partir de este análisis parece que hay una preferencia de unos soportes concretos para unos tipos retocados concretos también. Se podría considerar que hay una gestión específica de un soporte determinado cuando al menos en torno a la mitad de un tipo de soporte se ha utilizado para un tipo retocado concreto, así sucede en los dos siguientes casos:

- Las hojitas y los golpes de buril para los dorsos

- Las lascas laminares y hojas semicorticales para las piezas con retoque continuo

El resto de los soportes tienen una gestión más diversificada, es decir se han utilizado para realizar más variedad de tipos. No obstante hay algunos soportes que tienen ciertas preferencias hacia tipos concretos:

- las lascas para las escotaduras

- Las hojas de tercer orden, las piezas con cresta y los flancos de núcleo para las piezas con retoque continuo. 

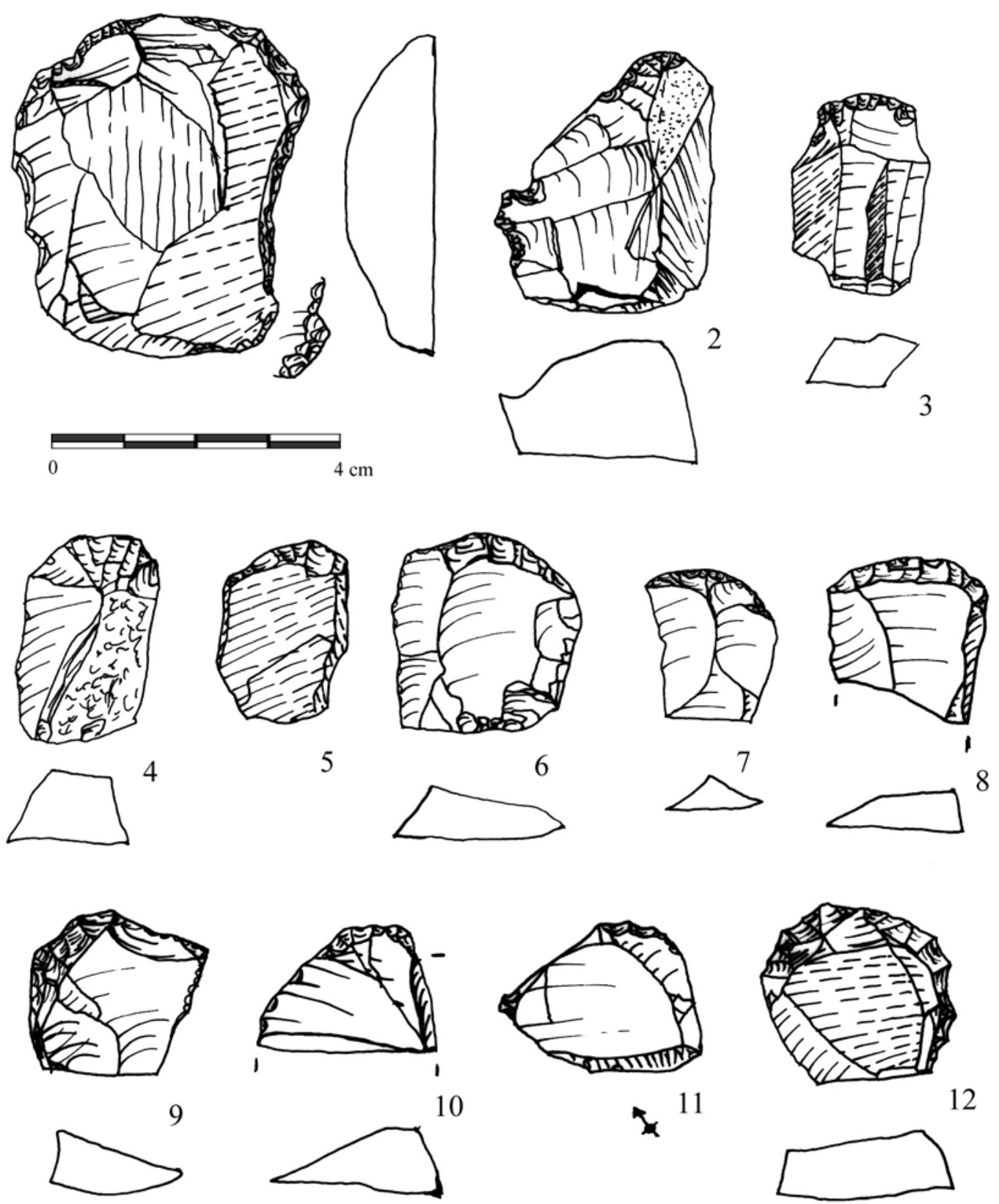

Figura SN.15: Piezas retocadas de sílex negro: raspadores. 


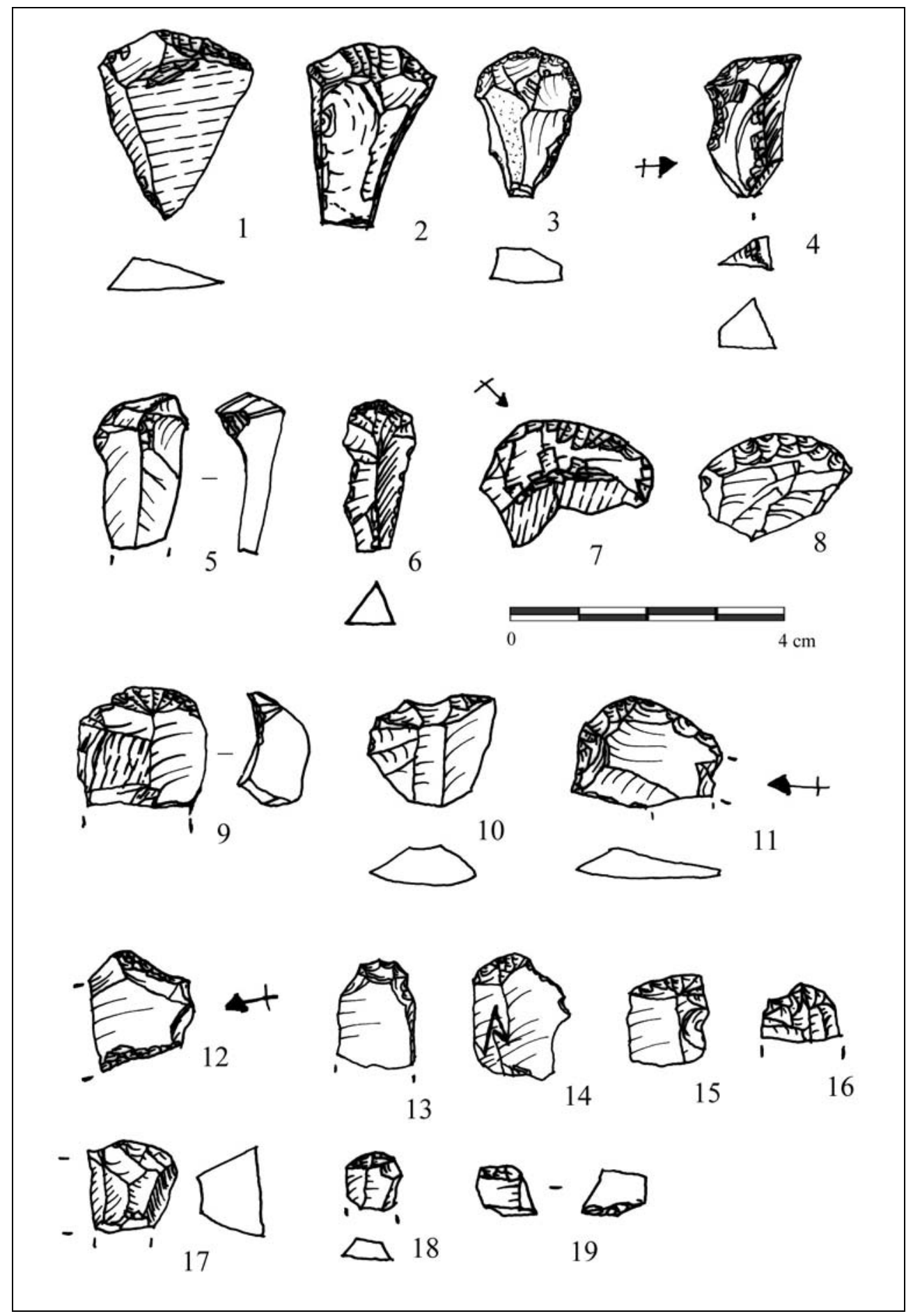

Figura SN.16: Piezas retocadas de sílex negro: raspadores. 


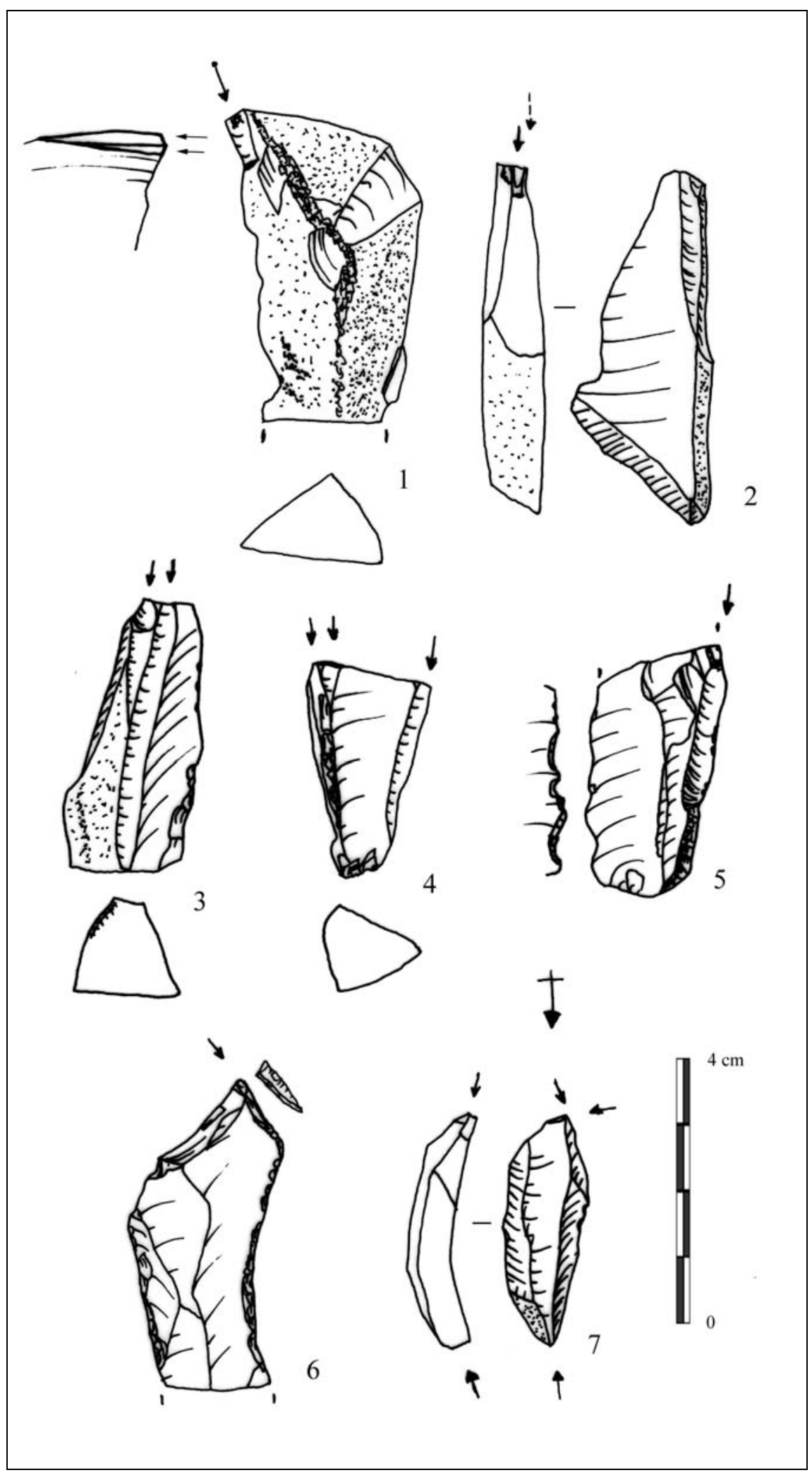

Figura SN.17: piezas retocadas de sílex negro: buriles. El n ${ }^{\circ} 1$ es una lasca cortical con arista natural (lasca de encetadura). 


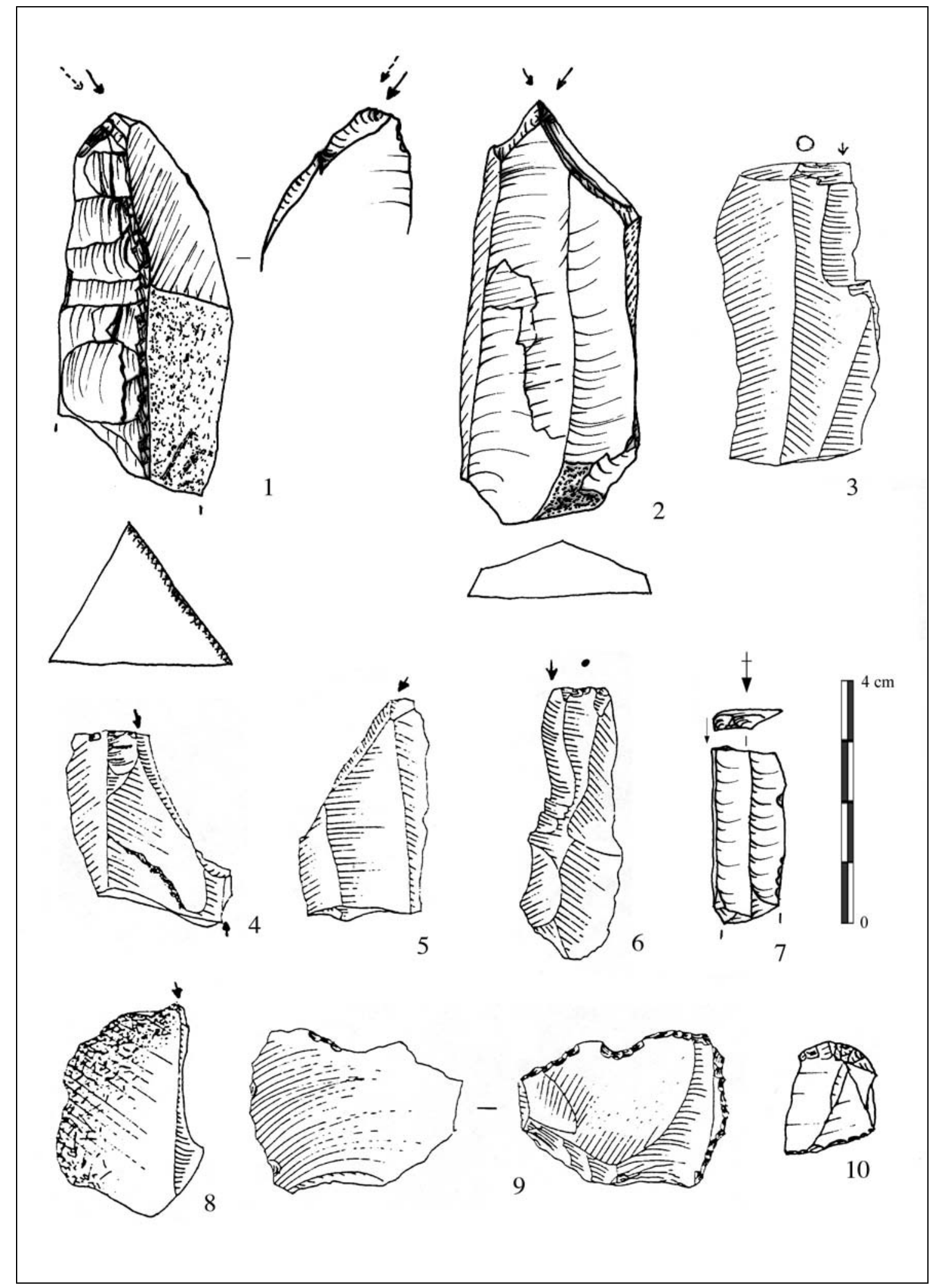

Figura SN.18: Piezas retocadas de sílex negro: Buriles (1 a 8), raclette (9) y útil compuesto (raspador-truncadura [10]). Dibujos 3 a 6, 8 y 9 realizados por R. Mª Yágüez. 


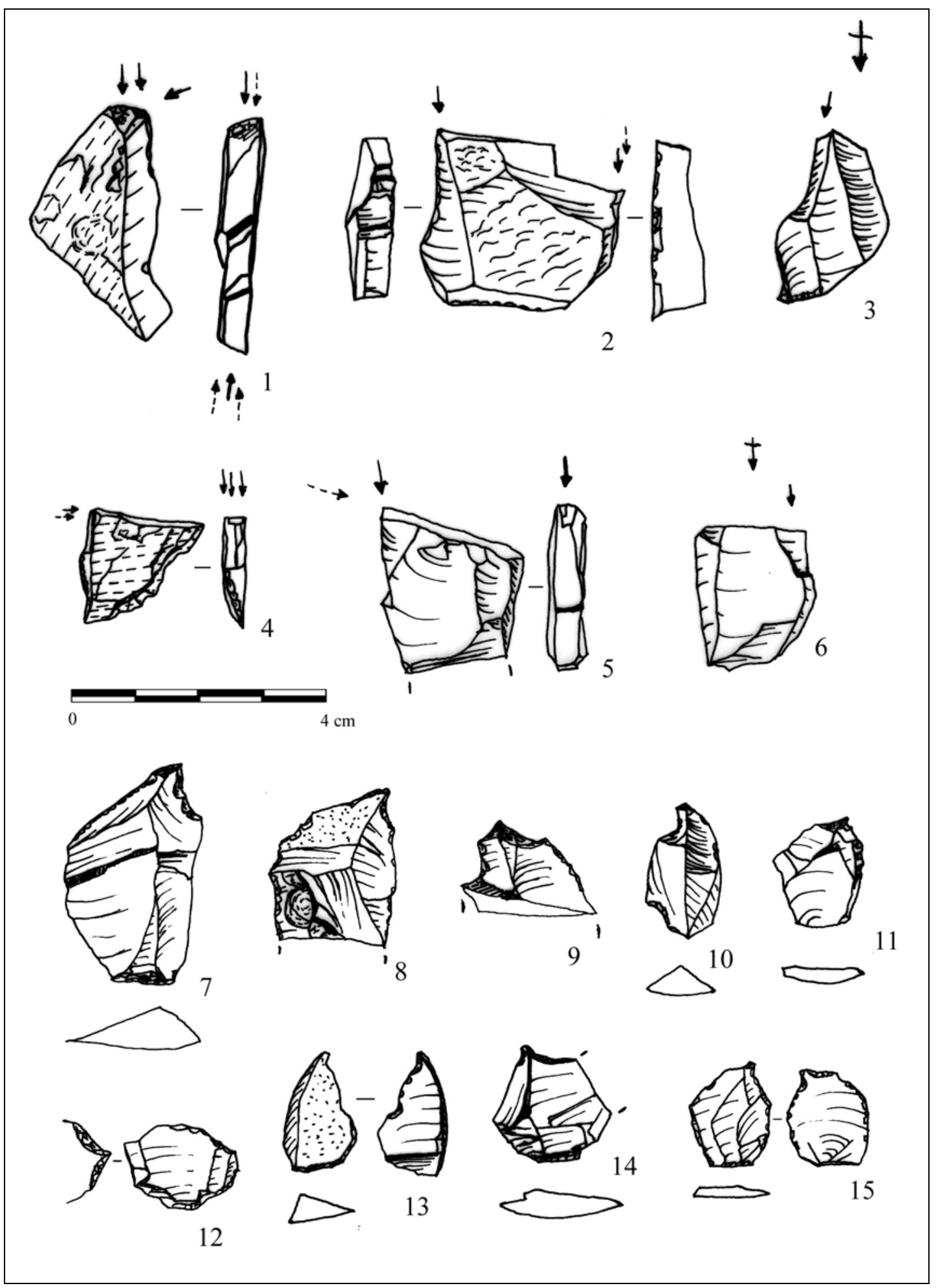

Figura SN.19: Piezas retocadas de sílex negro: buriles ( 1 a 6 ) y perforadores ( 7 a 15 ; microperforadores de 10 a 15). Para el $\mathrm{n}^{0} 1,2$ y 4 se aprovechan fragmentos de lascas con roturas en placa. El n ${ }^{\circ} 3$ y 5 son flancos de núcleo (longitudinal opuesto). 


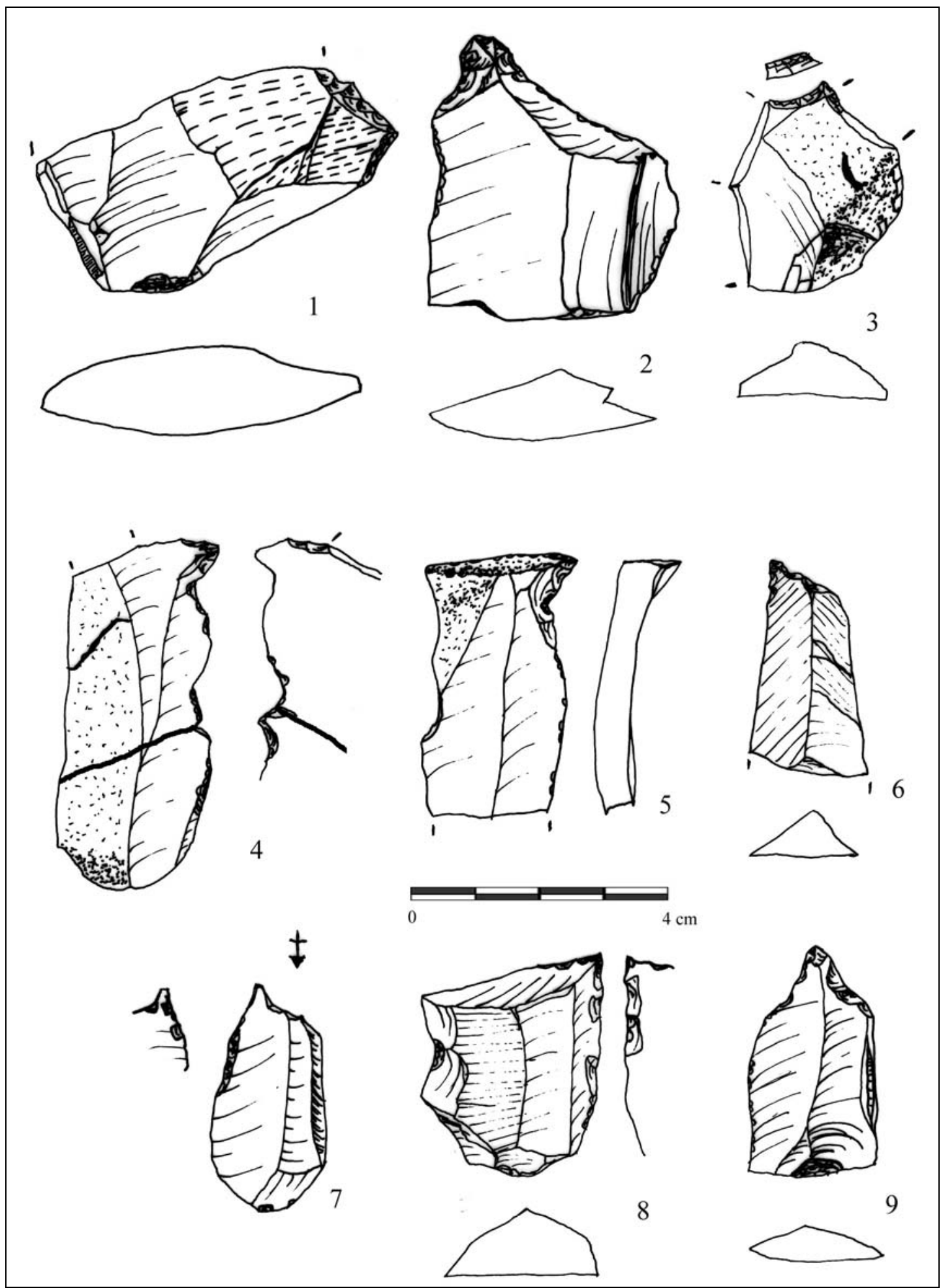

Figura SN.20: Piezas retocadas de sílex negro: perforadores. Del 4 al 8 aprovechan una esquina distal para confeccionar el perforador. El $n^{0} 4$ tiene un denticulado en el borde derecho y está roto en dos; la parte proximal tiene también un perforador sobre la zona distal-derecha. 


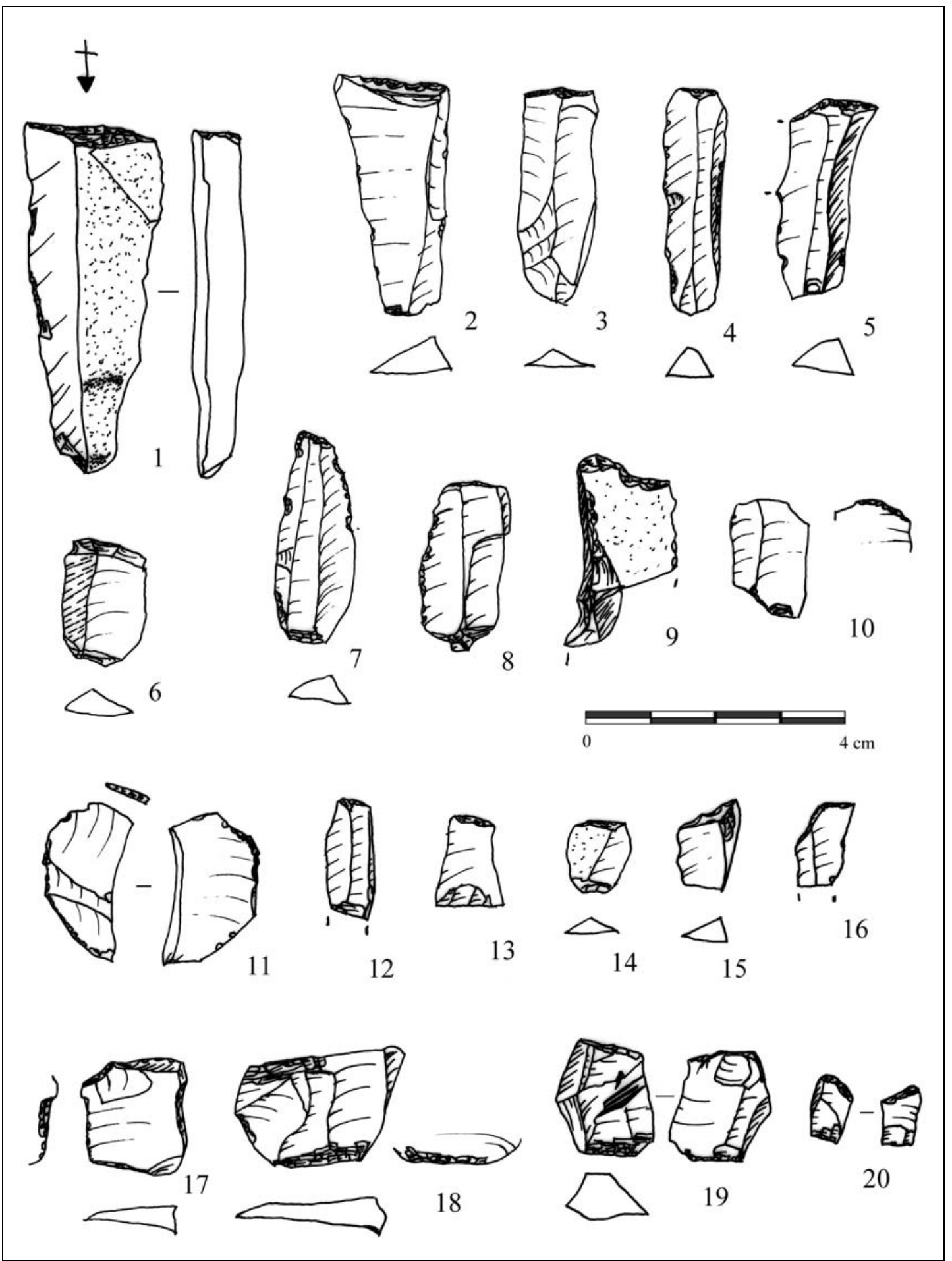

Figura SN.21: Piezas retocadas de sílex negro. Truncaduras (1 a 11 sobre hoja/lasca; 12 a 16 sobre hojita), raclette (17) y astilladas (18 y 19 sobre lasca, 20 sobre lasquita). 

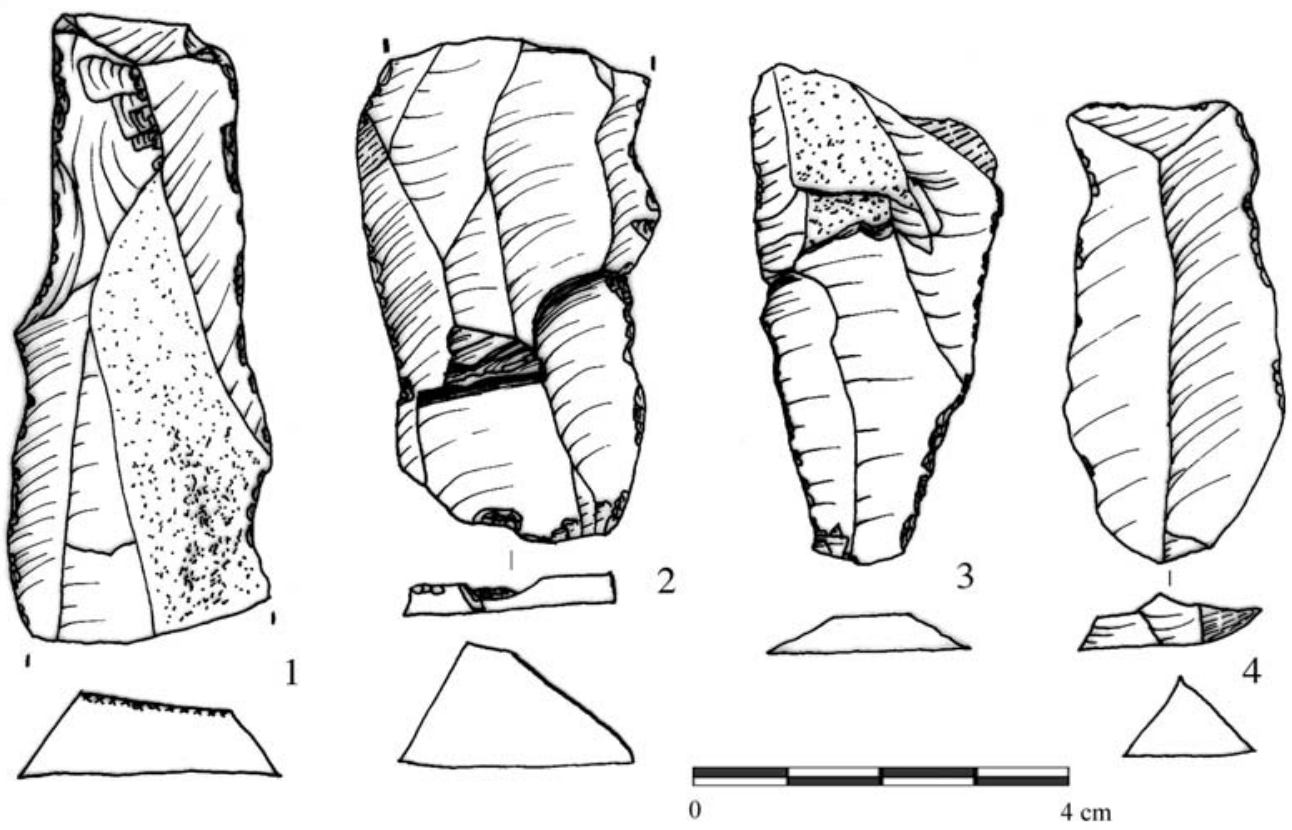
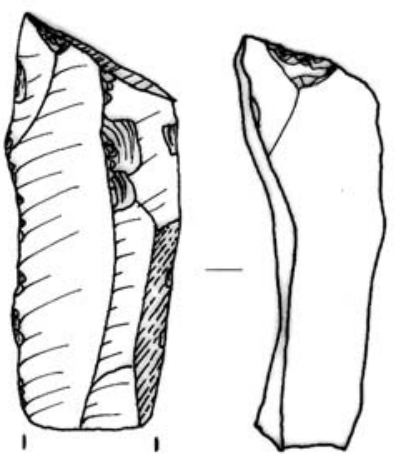

5

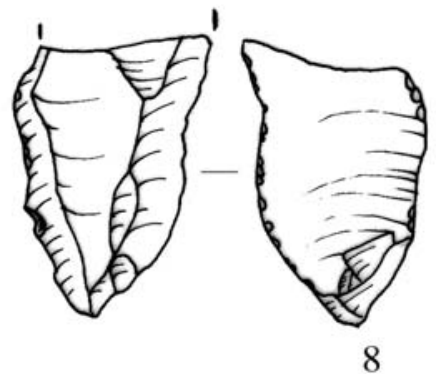

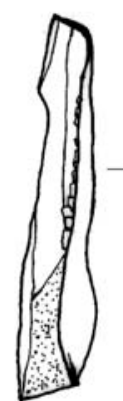

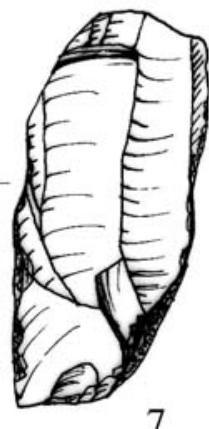

7

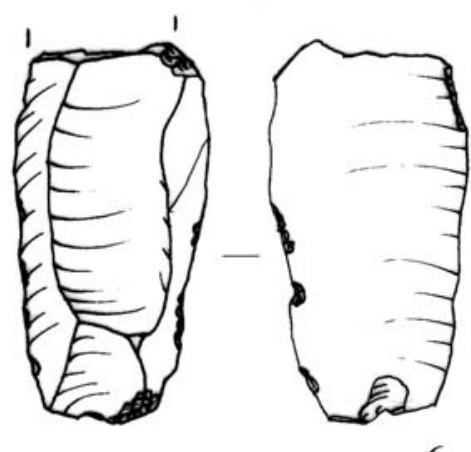

6
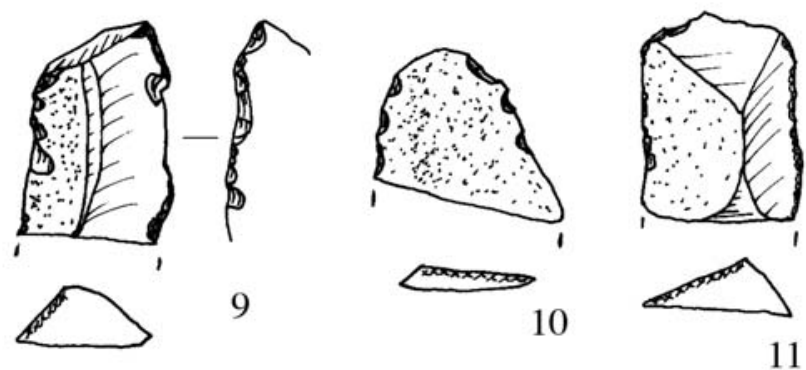

Figura SN.22: Piezas retocadas de sílex negro. Retoque continuo marginal: 3, 4, 6, 8. Retoque continuo marginal festoneado o irregular: $1 . \mathrm{El} \mathrm{n}^{\circ} 2$ está entre retoque continuo y denticulado. Retoque continuo (de amplitud normal): 9, 10, 11. Piezas con pseudorretoques: 5 y 6. Soportes: neocresta parcial $(1,5)$, flanco de núcleo $(2)$, lasca laminar $(3,6)$, lasca laminar "con flanco" (7), hoja $(4,9)$ y lascas $(8,10,11)$. 

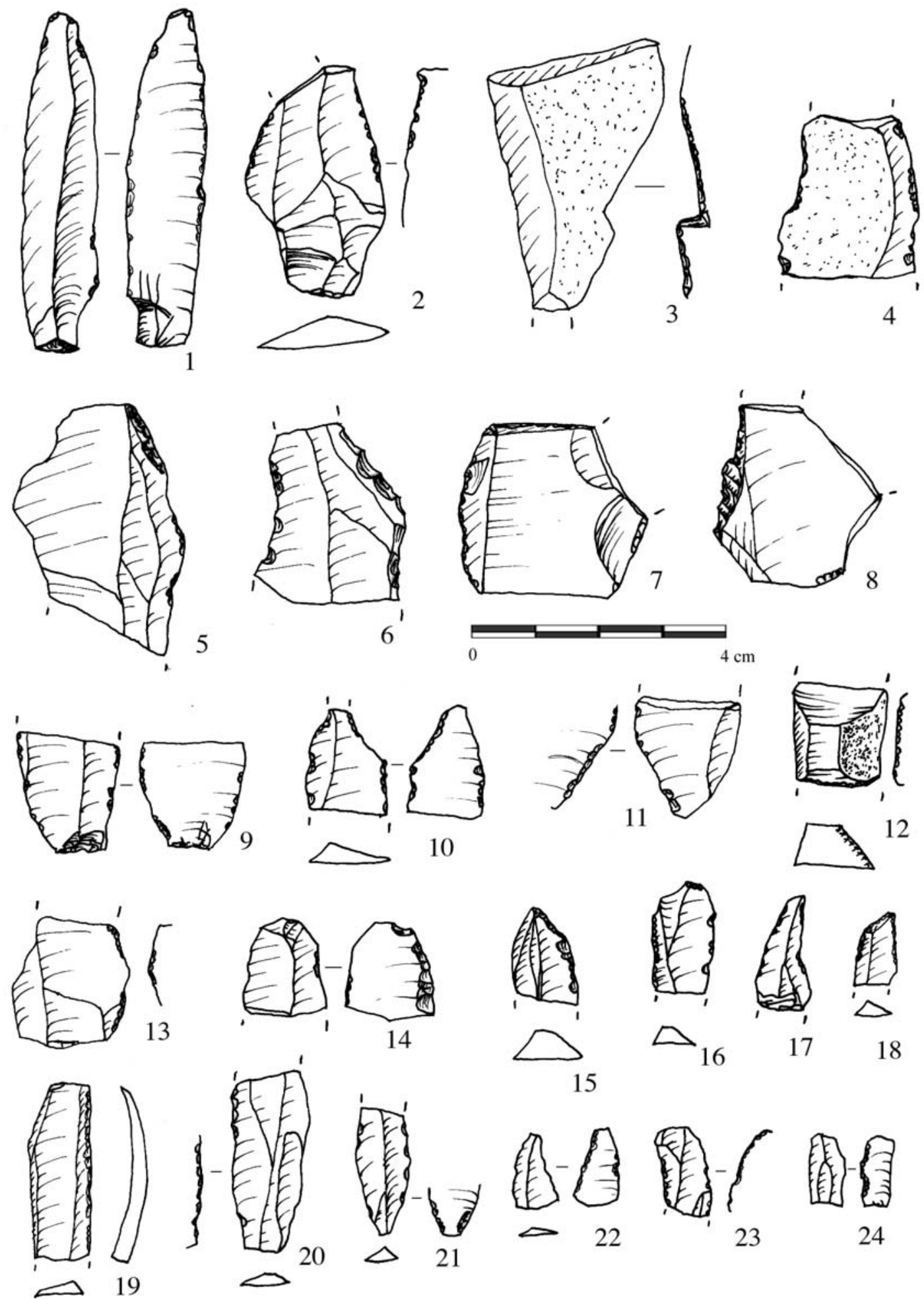

15
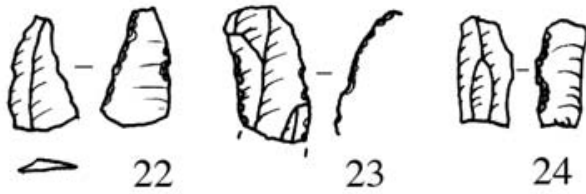

Figura SN.23: Piezas retocadas de sílex negro. Retoque continuo marginal (1, 2, 7, 9 a 13, 16, 18, 19, 22, 23). Retoque continuo (de amplitud normal): 3 a 6, 8, 14, 15, 17, 20, 21, 24. No 21 y 24 con morfología microdenticulada. Soportes: hojas (1, 16, 19, 20), hojitas (17, 18, 21 a 24) lascas-laminares $(9,10,14)$ y lascas $(2$ a 8,11 a 13,15$)$. 


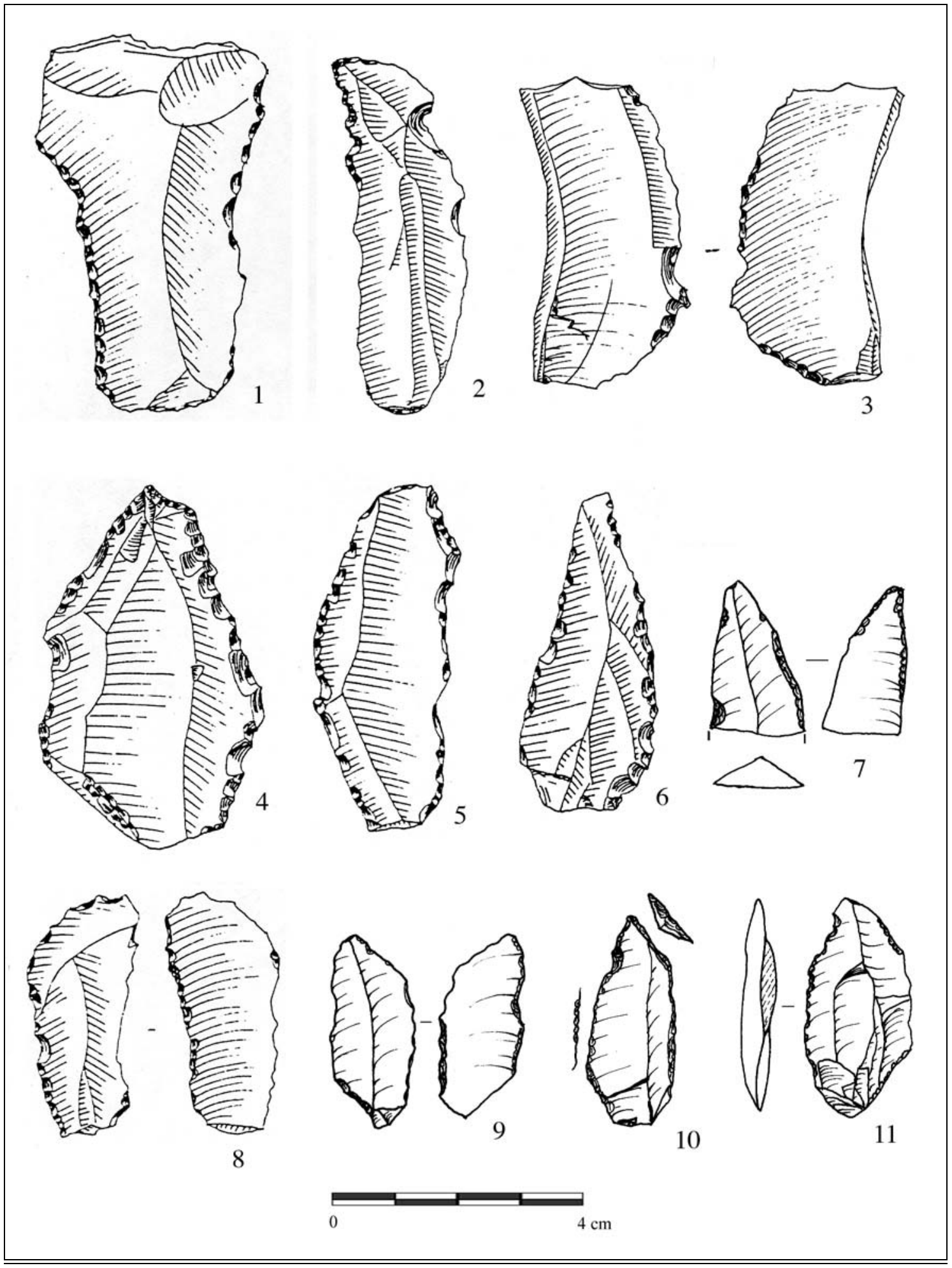

Figura SN.24: Piezas retocadas de sílex negro. Piezas de retoque continuo. $\mathrm{N}^{\circ}$ 4, 5, 8, 9 y 10: piezas con retoque continuo y truncadura. $\mathrm{N}^{\circ} 6$ y 7: hojas apuntadas. Dibujos 1 a 6 y 8 realizados por R. M ${ }^{\mathrm{a}}$ Yágüez. 

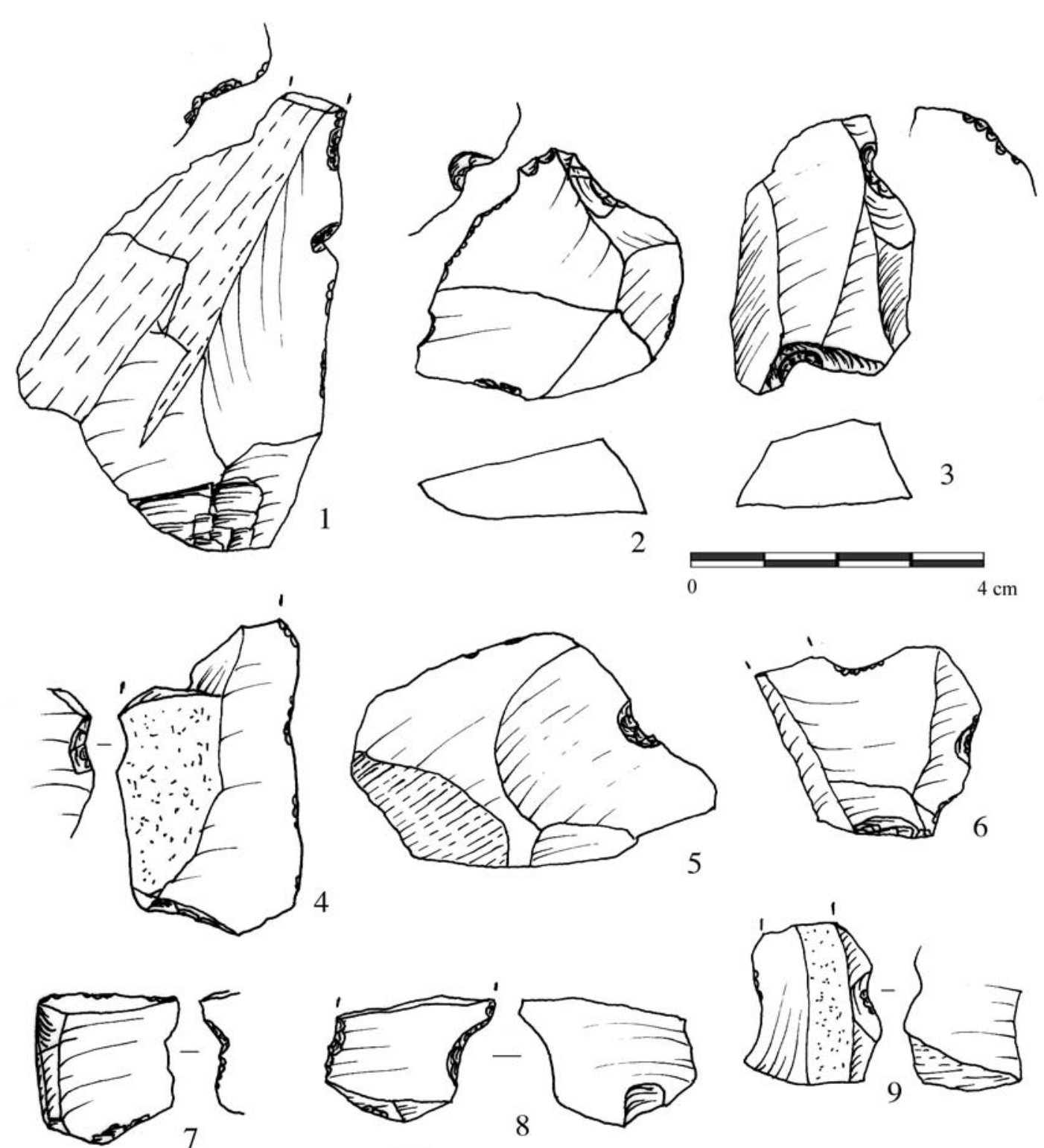

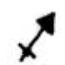
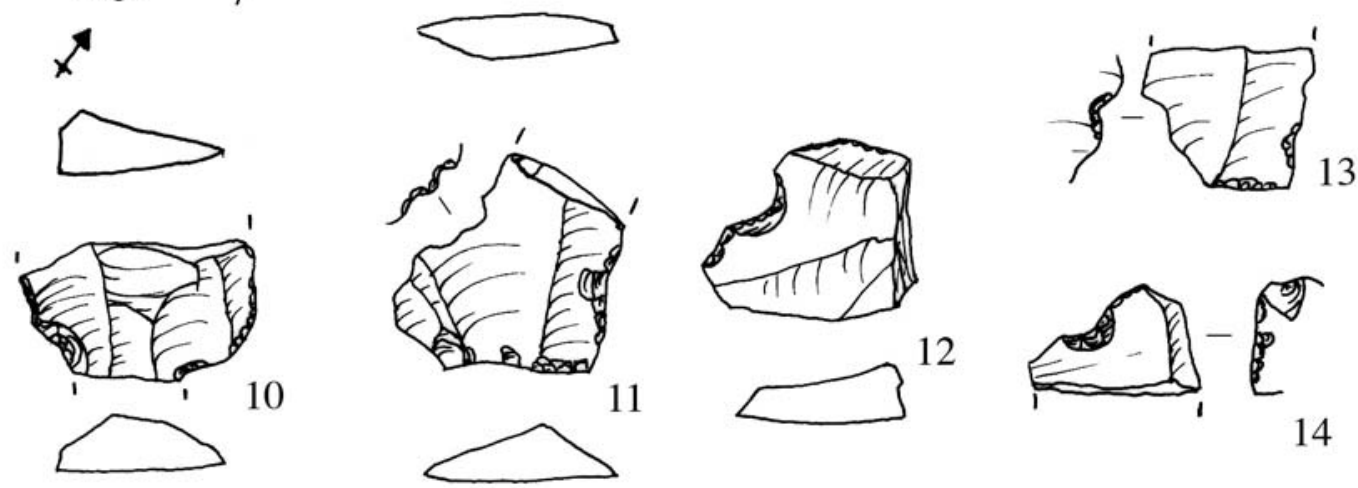

Figura SN.25: Piezas retocadas de sílex negro: escotaduras sobre soporte tipo-lasca. 


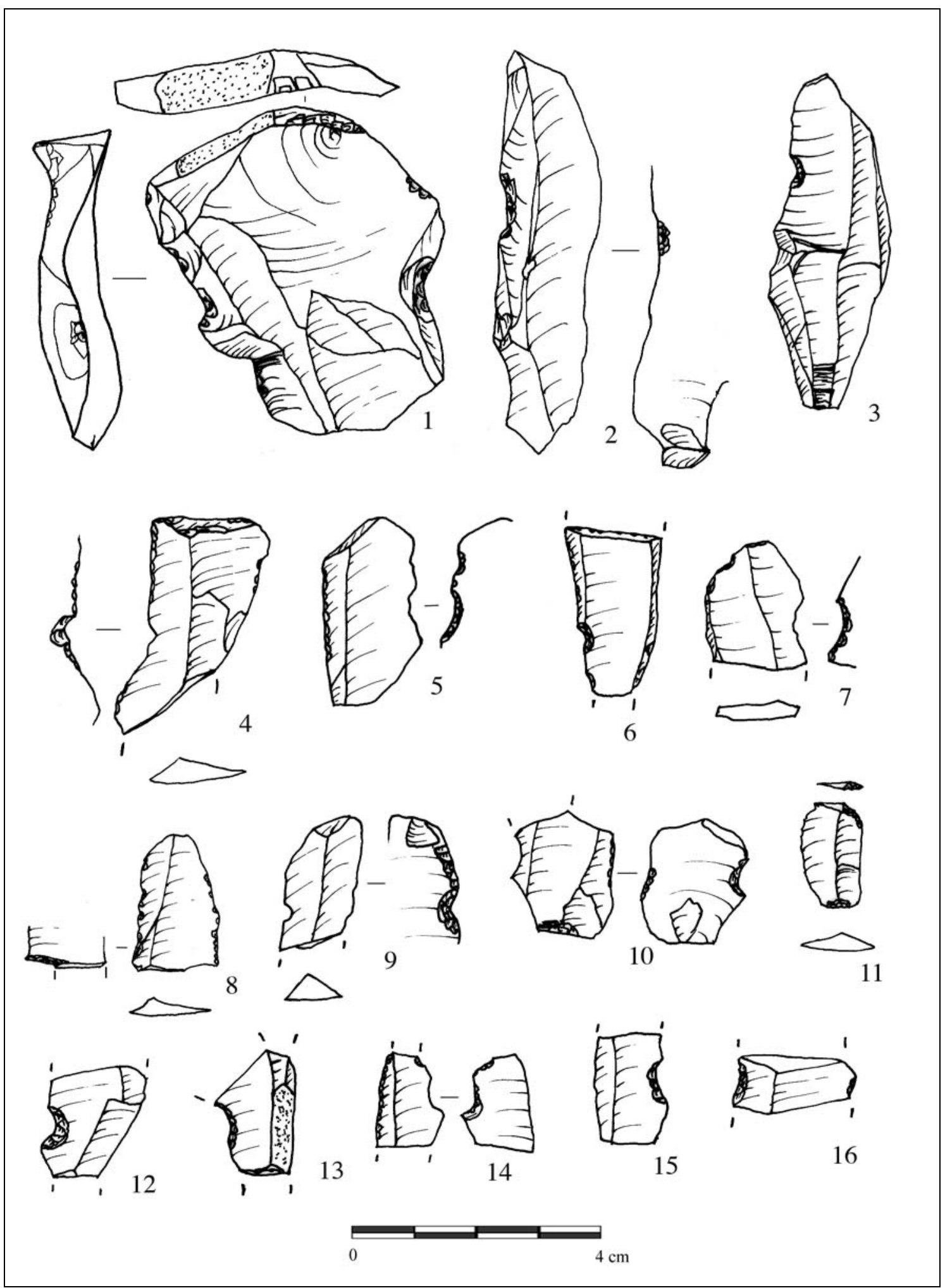

Figura SN.26: Piezas retocadas de sílex negro: escotaduras sobre soporte laminar, excepto el $\mathrm{n}^{\circ}$ 1 , que es un flanco de núcleo longitudinal opuesto. 


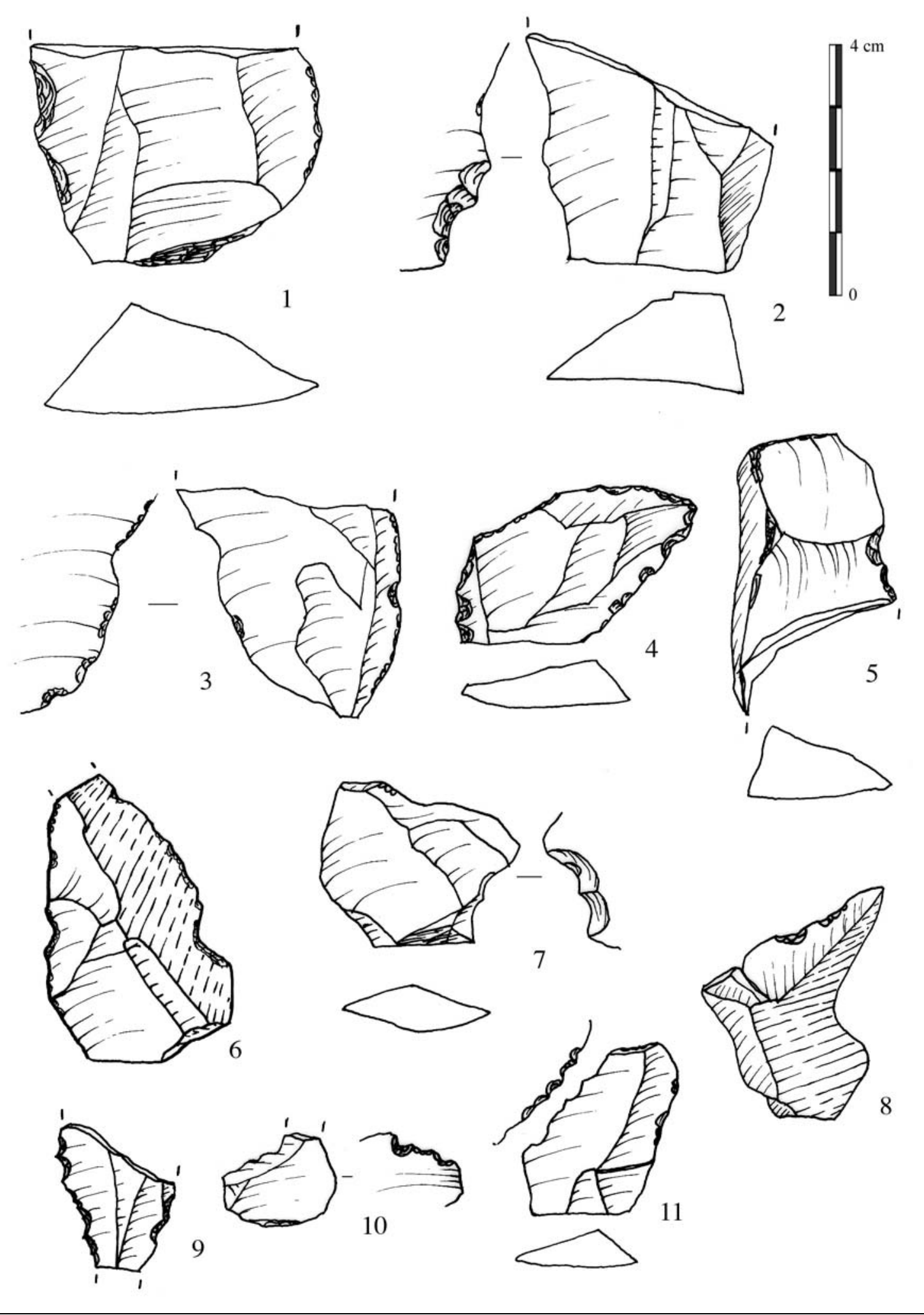

Figura SN.27: Piezas retocadas de sílex negro: denticulados sobre soporte tipo-lasca. 

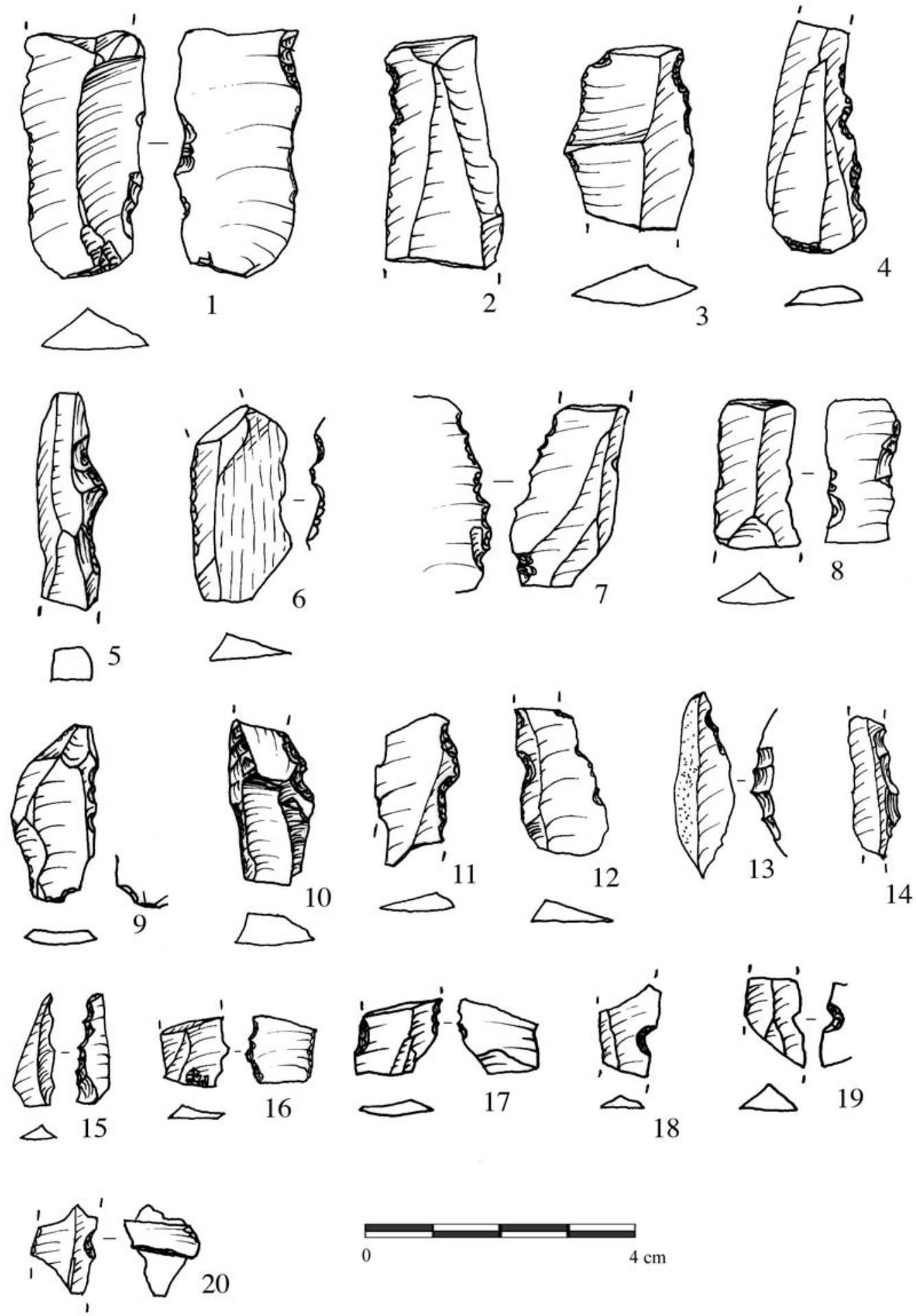

Figura SN.28: Piezas retocadas de sílex negro: denticulados sobre soporte laminar y microlaminar (1 a 17) y fragmentos mesiales de hojitas con escotadura (18 a 20). 


\section{IV.1.6. CADENAS OPERATIVAS}

En este apartado realizaremos un resumen de todas las características descritas hasta ahora. A partir de ellas consideramos que se pueden hacer dos amplios grupos de cadenas que tienen objetivos distintos:

i) la cadena operativa de concepción prismática-unipolar, que está encaminada a la obtención de soportes laminares y en general alargados, aunque en algunos esquemas se obtienen también lascas

ii) la cadena del nódulo tipo-placa, cuyo objetivo son lascas

Se podría añadir una tercera cadena, de carácter indeterminado, que incluiría tanto las cadenas oportunistas para una producción rápida de lascas, como aquellos esquemas poco estandarizados o difíciles de encajar en alguno de los esquemas definidos. Estos últimos podrían corresponder a una sobre-explotación de alguno de los esquemas operativos descritos, o bien a procesos de talla anárquicos encaminados, quizás, a buscar un manejo con las técnicas de talla y la materia.

Al examinar los esquemas técnicos de los núcleos y a la hora de clasificarlos en tipos de núcleos genéricos (cuadros SN.22 y SN.23) se realizó un esbozo de los principales esquemas operativos existentes en el sílex negro. Tales esquemas pueden quedar agrupados en estas tres cadenas tal y como se describe en el cuadro SN.46.

\begin{tabular}{|l|l|l|l|c|}
\hline CADENAS OPERATIVAS & \multicolumn{2}{|l|}{ ESQUEMAS OPERATIVOS } & ESQUEMAS TÉCNICOS & TOTAL \\
\hline \multirow{4}{*}{\begin{tabular}{l} 
DE CONCEPCIÓN \\
\multirow{2}{*}{ PRISMÁTICA - UNIPOLAR }
\end{tabular}} & \multirow{2}{*}{ Prismático } & Tipo A & P1 - A & 7 \\
& & Tipo B & P1, P2 -B & 7 \\
& \multirow{2}{*}{ Superficie ancha } & Genérico & P1, P2 & 2 \\
\cline { 2 - 5 } & Unipolar & SA-P1 & 3 \\
\cline { 2 - 5 } & Bipolar & SA-P2 & 4 \\
\hline NÓDULO-PLACA & & UP-P1 & 2 \\
\hline NO ESTANDARIZnático & & N-PL & 1 \\
\hline
\end{tabular}

Cuadro SN.46: cadenas operativa y esquemas operativos presentes en el sílex negro.

La cadena operativa de concepción prismática-unipolar es el esquema conceptual predominante en el sílex negro $(n=25)$, mientras que la del nódulo-placa 
tiene un solo núcleo como representante. Este desequilibrio marca la importancia de la obtención de productos alargados, ya sea hojas, hojitas o lascas-laminares.

Un rasgo común, presente en todos los esquemas es el aprovechamiento de la morfología inicial de los nódulos de origen, tanto su forma volumétrica como sus aristas naturales.

\section{IV.1.6.1. CADENA OPERATIVA DE CONCEPCIÓN PRISMÁTICA-UNIPOLAR}

Bajo esta denominación incluimos aquellos esquemas organizados a partir de los núcleos que tienen una estructura volumétrica de tendencia prismática alargada. La construcción del núcleo prima una configuración del mismo cercana a la de un prisma tetraedro, en el que el plano de percusión va a ser una superficie más o menos perpendicular a la superficie de extracciones; y la superficie de extracciones frecuentemente va a estar también constreñida entre dos planos (más o menos ortogonales) que son los flancos laterales del núcleo. La superficie de extracciones es bastante larga, de hecho va a ser muy frecuente el inicio del débitage a partir de una arista natural, mediante hojas de encetadura y sobre una cara alargada del núcleo. Esta construcción volumétrica ideal, en forma de parlelepípedo tiene las siguientes ventajas para el débitage laminar:

- muchos de los nódulos disponibles tienen una morfología en paralelepípedo, por lo que la conformación del núcleo está prácticamente realizada

- la orientación de un núcleo de modo que el plano de percusión sea una superficie más o menos ortogonal a una superficie de extracciones alargada es el procedimiento más sencillo para la obtención de hojas

- la delimitación de la superficie de extracciones por flancos laterales más o menos ortogonales, con tendencia a construir el volumen prismático, va a beneficiar el débitage laminar porque el control de la anchura de la superficie de extracciones permitirá el mantenimiento de la cintra

Este volumen-modelo sería una esquematización teórica de las características técnicas comunes examinadas para varios esquemas operativos desarrollados en El Espertín. La aplicación de este modelo se realiza en estos esquemas operativos de 
diferentes maneras, cada una responde a problemáticas diferentes, sobre todo la adecuación a la morfología inicial de los nódulos disponibles y también al tamaño de los soportes que se pretenden extraer. Las variantes de los esquemas prismáticos que se han identificado aquí corresponden a los esquemas operativos deducidos del análisis técnico de los núcleos:

1) Los núcleos prismáticos propiamente dichos, con dos sub-grupos:

- Prismáticos unipolares con tendencia a ser piramidales. Son los núcleos de mejor calidad para la extracción de hojas y hojitas, los que tienen una construcción prismática más alargada y más “clásica”. En este grupo hay siete núcleos.

- Prismáticos unipolares y bipolares sobre bloques gruesos, frecuentemente utilizando aristas naturales; con siete núcleos.

2) Núcleos con explotación de superficie ancha, en ellos la superficie de extracciones es más ancha que en los anteriores y los soportes son a menudo lascas-laminares.

3) Unipolares-prismáticos, con dos núcleos

\section{IV.1.6.1.1. ESQUEMA OPERATIVO DE LOS NÚCLEOS PRISMÁTICOS SUBGRUPO A}

Este primer esquema de núcleos prismáticos está muy bien desarrollado, con núcleos bien construidos, serían los núcleos prismáticos de hojas y hojitas más “clásicos”, y se incluirían aquí los mejores núcleos de la colección.

\section{Fase 0: selección de nódulos}

Los criterios para la selección de los nódulos sobre los que se desarrollará este tipo de esquema operativo no están demasiado claros. Lo más probable es que exista, como en todos los casos, un aprovechamiento de las características morfo-técnicas de los bloques de origen. Pero, a partir de los núcleos presentes, quizás haya también otros criterios como la calidad de la materia o al menos la homogeneidad interna del chert del nódulo en cuestión, sobre todo que no contenga demasiados planos de diaclasado internos. También quizás exista una selección de la dimensión del nódulo, pero 
probablemente sea más decisivo el factor anterior relativo a la calidad de la materia prima.

\section{Fase 1: preparación}

La construcción de estos núcleos se acercaría bastante al esquema volumétrico prismático “ideal” que se ha esbozado para el conjunto de los núcleos de tendencia prismática. De hecho estos núcleos se inscribirían en un prisma alargado en el cual el plano de percusión es más o menos perpendicular a la superficie de extracciones y ésta, a su vez, es ortogonal a los flancos del núcleo. Este esquema se va a conseguir en el conjunto lítico de El Espertín a partir de dos métodos, los cuales difieren entre sí por el tipo de soporte elegido como núcleo.

1) Método de preparación sobre nódulo

La superficie de extracciones se instala sobre una superficie rectangular estrecha y alargada; en la distribución de las dimensiones de las superficies de extracciones se comprobó cómo estos núcleos serían los más alargados. Dicha superficie está constreñida entre los flancos laterales del núcleo, los cuales van a facilitar el mantenimiento de la cintra de dicha superficie. El plano de percusión se instala sobre una superficie pequeña del nódulo y posiblemente a partir de una gran lasca extraída desde la superficie de extracciones. La base del núcleo suele tener una arista perpendicular u oblicua a la superficie de extracciones.

Tenemos los datos sobre la instalación de la superficie de extracciones a partir del estado de abandono de estos núcleos, pero no sabemos a ciencia cierta los métodos de iniciación que se utilizarían. Cabe la posibilidad de que se recurriera al procedimiento de la cresta anterior, sobre todo si tenemos en cuenta que son núcleos muy bien construidos, en los que la superficie de extracciones tiene unas características técnicas bastante bien acondicionadas. También cabe a posibilidad de un aprovechamiento de las aristas naturales para facilitar la apertura de la superficie de extracciones. 
2) Método de preparación sobre lasca

Hay otro método para la preparación de un núcleo con el fin de explotarlo según este esquema de talla a partir de la selección de una lasca como soporte del núcleo. Sobre dicha lasca la superficie de extracciones se instala en uno de los bordes laterales (en el ejemplo que tenemos se sitúa sobre el borde transversal), la morfología de dicha superficie es triangular, con los flancos ortogonales (tal y como se ha descrito en la conformación ideal de los núcleos prismáticos) perfectamente delimitados por lo que sería la cara superior e inferior de la primitiva lasca. El plano de percusión se coloca sobre otro de los bordes del núcleo, mediante unas pocas lascas para su acondicionamiento. La explotación de un núcleo sobre lasca así conformado, sería de "tipo-buril".

\section{Fase 2: producción}

En estos núcleos se extraen soportes microlaminares de forma unipolar. La preparación de las extracciones es muy cuidadosa, con una abrasión del frente de percusión visible en la cornisa de los núcleos de este tipo. En muchos de los soportes laminares se puede observar asimismo una abrasión de la zona del talón. El plano de percusión suele ser liso y oblicuo, lo cual daría talones lisos también (los predominantes en el conjunto de soportes). La superficie de extracciones tiene una carena bastante rectilínea y una cintra también tendente a recta. El avance del débitage sobre ella se produce de forma frontal aunque aveces se vuelve semi-envolvente. Al ser una superficie de extracciones alargada pero estrecha se puede producir a lo largo del proceso de producción un auto-mantenimiento de la cintra ya que la anchura, estaría controlada por los flancos del núcleo, que tienden a ser más o menos ortogonales; de hecho al abordar dichos laterales de los núcleos se pueden producir las "piezas del flanco" en forma de hojas semicorticales, "hojas con flanco" propiamente dichas o bien hojas con neo-cresta. En cuanto al control de la carena, cuando los núcleos no tienen demasiada longitud se puede producir un mantenimiento en el curso del débitage laminar pleno, mediante la aplicación de los gestos adecuados en la manipulación del núcleo. No obstante es necesario a veces, sobre todo cuando los núcleos son de mayor longitud o cuando ha ocurrido algún accidente en el proceso de débitage (reflejados sobre todo), recurrir a secuencias de arreglo de la carena, procedimiento que se realiza a 
partir de la base del núcleo. Para este cometido, en varios núcleos de este tipo se constata la presencia de una arista en la base, arista que tiene una orientación perpendicular u oblicua a la superficie de extracciones. Sobre esta arista, que se utilizará como una cresta inferior, se realizan pequeñas extracciones sobre la superficie de extracciones, opuestas al sentido del débitage. Estas secuencias de extracciones desde la arista inferior del núcleo se enmarcan en procedimientos de arreglo del mismo (bien de la superficie de extracciones o bien de los flancos), no responden a un débitage bipolar propiamente dicho.

La presencia de esta arista (en el caso del núcleo sobre lasca es una arista natural que correspondería con uno de los bordes laterales de la lasca) o cresta inferior explica que en muchas ocasiones el débitage de este tipo de núcleos tenga una tendencia piramidal, con una morfología de la superficie de extracciones triangular y un avance del débitage que a veces es convergente. Esta morfología viene a reforzar las ventajas (respecto a la conservación de la carena y cintra correctas) a lo largo de la explotación de este tipo de núcleos a partir de un avance del débitage frontal (eventualmente semienvolvente), sobre una superficie de extracciones estrecha, cuya carena y cintra tienden a ser rectas. La propia habilidad del tallador, con el cuidado en los gestos aplicados en este avance de la producción plena, permite una gestión eficaz del núcleo, con un automantenimiento de las condiciones técnicas requeridas.

Se pueden establecer los siguientes puntos básicos en este esquema:

- Superficie de extracciones estrechas, de morfología triangular o rectangular estrecha.

- Secuencia de débitage unipolar con una preparación del frente de talla muy cuidadosa, con huellas frecuentes de abrasión.

- Base del núcleo con una arista ortogonal a la superficie de extracciones. Dicha arista es natural (por ejemplo el borde de una lasca) o una cresta inferior.

- Los soportes que se extraen son hojitas de buena regularidad, podrían relacionarse también con la preparación cuidadosa del frente de percusión, ya se ha visto cómo en el conjunto de soportes, son los laminares los que tienen una abrasión más intensa. 
El modo de talla aplicado estaría determinado por las siguientes características: i) el ángulo de percusión no es demasiado claro, hay ejemplo tanto de núcleos con ángulo abierto como cerrado; ii) preparación cuidadosa del frente por abrasión, cuya reparación implica un reavivado total del plano de percusión. Quizás se utilice algún tipo de percutor blando, sobre todo en relación con lo que sucede en los soportes laminares, que son los soportes en los que se constatan indicios del empleo de este tipo de percutor. Si tenemos en cuenta también el hecho de que la carena de estos núcleos tiende a ser rectilínea, quizás encaje también la posible utilización de los percutores de piedra blanda, ya que dentro de los soportes laminares se ha constatado el uso probable de este modo de talla.

Las secuencias de reparación de este tipo de esquemas son bastante variadas a pesar de que el propio avance del débitage permite un cierto auto-mantenimiento de las condiciones técnicas.

Reparación del plano de percusión: se produce sobre todo en forma de tabletas que reavivan completamente el frente de talla, por tanto se prefiere reavivar totalmente el plano de percusión a realizar extracciones más pequeñas, de acondicionamientos puntuales. Hay que recordar que sobre estos núcleos se aprecia una intensidad importante de la abrasión. Este cuidado en la preparación del punto de impacto necesitará probablemente planos despejados.

Para la reparación y acondicionamiento de la superficie de extracciones hay varios soportes reconocibles en el conjunto lítico:

- Los flancos de núcleo longitudinales podrían proceder tanto de este esquema prismático grupo-A, como del grupo-B. Hay algunos flancos cuya longitud nos remite a una dimensión de la superficie de extracciones considerable, así como a métodos bipolares que no se constatan en este tipo de esquemas. Consideramos por tanto que pueden ser los flancos longitudinales unipolares los más característicos de estos núcleos prismáticos. No obstante hay que tener siempre en cuenta que los núcleos pertenecen al estado de abandono del proceso técnico, y que a lo largo de dicho proceso se pueden haber producido algún cambio en el método de explotación de la superficie de 
extracciones, con secuencias de un ritmo bipolar por ejemplo entre otras de sentido unipolar preferente.

- Crestas laterales para adecuar la carena o cintra de la superficie de extracciones. Dicho procedimiento es visible tanto en los núcleos, como en las hojas con semicresta o neo-cresta del conjunto.

- Las "hojas con flanco" también se pueden haber extraído en el curso del débitage pleno, al avanzar sobre uno de los laterales del núcleo. Es importante en este tipo esquemas el mantenimiento de los flancos de forma más o menos perpendicular a la superficie de extracciones

- Las extracciones desde la cresta inferior son visibles en los núcleos, no tanto en el conjunto lítico, cuyos testimonios serían lasquitas u hojitas con una dirección bipolar en los negativos de su cara superior

Los procedimientos para la reparación de los núcleos son variados e inciden en el mantenimiento de unas condiciones técnicas adecuadas para el desarrollo del proceso de talla. Este tipo de esquema tiene de hecho unos requerimientos y métodos de reparación que permitirían definir este esquema como el más "exigente" de todos los desarrollados sobre el sílex negro. A este respecto, el modo de talla parece ser el más cuidadoso en función de la abrasión del frente y el reavivado completo del plano; se plantea la hipótesis de que el modo de talla en la fase de producción plena sea la percusión directa con percutor blando.

El abandono de estos núcleos se produce en algunos casos por la presencia de accidentes, sobre todo reflejados, que han estropeado la superficie de extracciones. En otros casos en cambio no hay constancia de presencia de accidentes que imposibiliten el débitage, pero la explotación del núcleo ha sido detenida por razones más difíciles de concretar. Quizás porque la carena no tenga unas condiciones adecuadas, o puede que el tamaño sea también determinante. 


\section{IV.1.6.1.2. ESQUEMA OPERATIVO DE NÚCLEOS PRISMÁTICOS SUBGRUPO B}

Este tipo de núcleos tendría un tipo de explotación muy cercana a los anteriores, la diferencia está sobre todo en el tipo de nódulos que se seleccionan, que suelen ser bloques con morfología de prisma alargado, nódulos cuya forma exterior está enmarcada por superficies que delimitan este tipo de volumen. En el capítulo sobre la materia prima hemos visto cómo el chert negro se presenta tanto en forma de cantos rodados como en bloques de morfología en paralelepípedo. Esta forma es sumamente útil para la instalación de un débitage prismático tal y como se ha descrito. No obstante, a veces este tipo de nódulos tienen el problema, frente a los núcleos anteriores, de que la materia prima no es muy homogénea, con la presencia tanto de planos de rotura natural como de zonas, dentro del nódulo, en las que la composición del chert no es demasiado compacta. Sobre unos nódulos de estas características entonces el tipo de esquema que se puede aplicar tiene que estar más adaptado a los condicionantes de la materia, habría un aprovechamiento de las condiciones naturales del soporte, el cual tiene una conformación natural casi apta para un inicio rápido del débitage; pero dicho aprovechamiento se ve imposibilitado asimismo porque dichas características suponen unos límites para el propio avance del débitage de la talla.

\section{Fase 0: selección}

Ya se ha indicado que la fase de selección es la que va a condicionar la aplicación de esta variante del esquema prismático. Los nódulos que se escogen en este caso son bloques prismáticos, el córtex de los mismos son superficies aplanadas o bien planos de rotura de la materia, los cuales suelen unirse entre sí de forma perpendicular, formando aristas agudas en su intersección. Dichas aristas serán óptimas para el inicio del débitage mediante piezas de encetadura.

\section{Fase 1: preparación}

La fase de preparación está muy cercana tanto a la de selección como al inicio del débitage propiamente dicho. Los nódulos seleccionados en este caso, tal y como 
hemos indicado, tienen una morfología prismática, por lo que el propio volumen original del nódulo proporciona ya una conformación somera del núcleo. La superficie de extracciones se colocará sobre una superficie rectangular estrecha del nódulo, la cual normalmente tiene sendos flancos de núcleo ortogonales a la anterior. El plano de percusión se coloca sobre una superficie perpendicular a las anteriores, que sino existe se forma natural, se acondiciona de forma rápida.

La iniciación del débitage se produce por tanto de una forma bastante rápida, apenas si es necesario un acondicionamiento del núcleo; el método para abrir el débitage es a partir de una de las aristas que unen la superficie de extracciones y uno de los flancos de núcleo. Ya hemos visto que en los nódulos seleccionados estas aristas son los diedros que unen, de forma ortogonal aproximadamente, las superficies que conforman el volumen prismático original. Por tanto a partir de una de estas aristas naturales es posible abrir la superficie de débitage sobre uno de los laterales de dicha superficie mediante hojas de encetadura.

En el conjunto lítico hay varios ejemplos que núcleos prismáticos cuya morfología está determinada, bien por superficies naturales o bien por superficies de diaclasado interno que han dado como resultado de alguna prueba del nódulo, un volumen prismático tal y como venimos describiendo. En varios de ellos se puede constatar esta conformación somera de los mismos, así como el inicio del débitage sobre una de las aristas laterales, pero no se ha podido realizar una explotación demasiado exhaustiva de ellos debido sobre todo a la escasa calidad de la materia prima.

\section{Fase 2: producción}

Sobre este tipo de núcleos se desarrolla una explotación esencialmente unipolar de la superficie de extracciones a partir de uno de sus laterales. Los soportes extraídos son hojas de longitud considerable en algunos casos y a veces de calidad técnica bastante aceptable. En algunos de estos núcleos se puede ver la preparación del frente de talla, en la que hay más huellas de retoques y esquirlados que de abrasión propiamente dicha. También hay que destacar la presencia de más semitabletas y 
lasquitas de reavivado del plano de percusión que en el caso de los núcleos prismáticos tipo-A.

Respecto a la forma como avanza el débitage y el sentido de las extracciones, hay dos métodos: unipolar estricto y unipolar alterno.

1) Método de explotación unipolar

El avance de talla frontal es el más común, para su mantenimiento los laterales se reavivan mediante "hojas con flanco" o flancos de núcleos. No obstante también puede darse un avance de tipo semi-envolvente, en ambos casos la carena suele conservarse bastante recta.

2) Método de explotación unipolar-alterno

Hay algunos núcleos cuya superficie de extracciones tiene una anchura considerable, la cual hace que sea difícil un avance del débitage laminar unipolar de forma continuada sin recurrir a procedimientos de mantenimiento de las condiciones técnicas. La solución con que se resuelve esta circunstancia consiste en la explotación de la superficie de extracciones desde un plano de percusión opuesto al anterior; pero más que desarrollar un ritmo de débitage bipolar, el segundo plano de percusión abre la superficie de extracciones hacia la arista del flanco menos explotado. En consecuencia el ritmo de talla, aunque sea bipolar opuesto, podría considerarse más bien como unipolar alternante desde planos opuestos, cada uno de los cuales acomete la explotación de la superficie de extracciones desde las aristas de sendos laterales. Mediante esta solución se consigue que la dimensión de los soportes a extraer sea la mayor posible respecto a la longitud de la superficie de extracciones. Además se abre un plano opuesto desde el cual se puede arreglar la superficie explotada desde el plano anterior, en caso de que hayan producido accidentes o una pérdida de las condiciones técnicas correctas.

3) Métodos de reparación/mantenimiento

Las secuencias de reparación del plano de percusión y de la superficie de extracciones son similares al esquema operativo anterior. Hay que destacar que para el 
plano de percusión la reparación se centra en la obtención de lasquitas de reavivado y semitabletas, más que de tabletas propiamente dichas. Quizás el modo de talla empleado en este esquema no sea tan exigente respecto a las características del plano de percusión, además parece que no se someten a una abrasión tan intensa como en los núcleos unipolares tipo-A.

Respecto a la reparación de la superficie de extracciones los procedimientos son muy similares al esquema anterior:

- Los flancos de núcleo longitudinales, tanto unipolares como bipolares; estos últimos encajarían mejor en este esquema que en el anterior. Además hay ejemplos de estos flancos bipolares con una longitud considerable, la cual encajaría en la mayor dimensión de estos núcleos.

- Las "hojas con flanco", o bien hojas semicorticales que se extraen al avanzar sobre un flanco cortical. Hay un ejemplo de un flanco de núcleo con una hoja de buena calidad remontada, en el que también remonta una hoja cortical extraída después de la hoja anterior.

- Las crestas laterales, visibles tanto en los núcleos como en las piezas con neo-cresta

- El empleo del plano opuesto para reparar la superficie de extracciones puede ser tanto un procedimiento de arreglo de la misma como una solución para la explotación de dicha superficie.

Los recursos para el mantenimiento/arreglo de este esquema son prácticamente los mismos que para el esquema anterior. Tan solo se pueden ver diferencias en los siguientes aspectos:

- La longitud de los núcleos son mayor que para el esquema anterior

- Las carenas de las superficies de extracciones son tanto rectas como convexas, por lo que la intención sería obtener hojas lo más regulares posible, siempre en correlación con las posibilidades de la materia

- La preparación del plano de percusión y del frente de talla parece ser menos exigente que en el caso anterior, pero hay variaciones entre los núcleos de este esquema 
Respecto al modo de talla aplicado, no podemos decir mucho, tan solo apuntaríamos la posibilidad de una percusión blanda como en el caso anterior (de nuevo quedaría abierta la posibilidad de que sea percutor blando o piedra blanda).

\subsubsection{Esquemas operativos de los núcleos de superficie ancha}

Las características básicas de este esquema son las siguientes:

- Núcleos bastante gruesos

- Superficie de extracciones muy ancha y larga normalmente, con una morfología tendente a cuadrangular o rectangular ancha.

\section{FASE 0-1: Selección de nódulos e instalación de superficie de extracciones}

A partir de los núcleos analizados se pueden distinguir tres tipos de nódulos sobre los que se va a desarrollar el esquema de la superficie ancha:

1) Sobre bloques prismáticos gruesos (los núcleos más voluminosos, por ejemplo ID $n^{\circ}$ 119)

2) Sobre fragmentos de nódulos del estilo anterior. Hay un ejemplo de un resto de núcleo (ID no 124) que es un nódulo de morfología en paralelepípedo partido en dos; la superficie de extracciones se coloca sobre el plano de rotura del bloque.

3) Sobre una lasca gruesa, con la instalación de la superficie de extracciones en la cara inferior (ID n $\left.{ }^{\circ} 125\right)$.

La instalación de la superficie de extracciones se produce por tanto sobre una superficie grande y ancha, cualquiera que sea el tipo de nódulo seleccionado. Para el plano de percusión se suele aprovechar alguna superficie natural o bien se acondiciona mediante la extracción de varias lascas.

Respecto al método de iniciación, en todos los casos parece que se produce la apertura del débitage aprovechando la arista entre el plano que será la superficie de extracciones y un lateral. 


\section{FASE 2: Métodos de producción}

Para la fase de producción, se han diferenciado varios métodos en función de la dirección y sentido del débitage: unipolar, bipolar y una última variante que combina las dos previas, que se ha calificado como mixta.

\section{1) Unipolar}

En este método de producción hay una explotación de toda la longitud de la superficie de extracciones. Es frecuente que la base del núcleo sea ortogonal a las caras anterior y posterior, posiblemente para controlar la carena y optimizar así la extracción de la superficie de extracciones en toda su longitud.

Las extracciones son largas y relativamente anchas, serían lascas laminares además de alguna hoja propiamente dicha.

El avance de la talla suele adoptar un ritmo semi-envolvente, avanzando sobre uno de los laterales del núcleo, con lo que se producirían lascas con flanco. Además este tipo de avance es una solución técnica para acometer una superficie tan ancha sin el recurso del plano opuesto para controlar la carena. En este caso el avance del débitage de forma envolvente permite controlar la carena y la cintra ya que fragmenta las secuencias de producción plena en segmentos de superficie de extracciones de menor anchura (unos ubicados sobre la superficie de extracciones propiamente dicha y otros sobre el flanco sobre el que se avanza).

El avance del débitage se puede producir a su vez mediante dos procedimientos:

- A partir de un plano de percusión (SA-P1)

- Con dos planos alternos (SA-P2A): dos planos de percusión que pueden ser opuestos, pero explotan superficies distintas

\section{2) Bipolar}

En este segundo método, la explotación de la superficie de extracciones se produce mediante dos planos opuestos. La dimensión de las extracciones que se van a producir así es menor que en el método anterior, ya que no se consigue alcanzar toda la 
longitud desde ninguno de los dos planos. A partir de cada uno de ellos se llega hasta la mitad de la superficie de extracciones aproximadamente, por lo que la longitud de los soportes no se corresponde con el máximo potencial de la longitud de la superficie de extracciones. Los últimos negativos de estos núcleos son lascas o lascas laminares cortas. Parece que el avance del débitage se produce alternando las secuencias de extracciones desde ambas planos. Una característica típica de este tipo de explotación es una carena convexa o "en diedro" como consecuencia de la intersección de las dos carenas oblicuas a partir de cada plano de percusión. Al mismo tiempo, este tipo de explotación bipolar alternante permite el auto-mantenimiento tanto de la carena como de la cintra. De todas formas se recurre también a una cresta lateral para reparar ocasionalmente la cintra.

3) Mixto: unipolar y bipolar

Hay un ejemplo de un núcleo (ID n¹19) que se ha explotado mediante los dos métodos anteriores, sobre la cara anterior hay una explotación unipolar, y sobre la superficie posterior bipolar.

\section{IV.1.6.1.3. ESQUEMA OPERATIVO DE LOS NÚCLEOS UNIPOLARES-PRISMÁTICOS}

Lo más característico de este esquema es la conformación volumétrica del mismo:

- Plano de percusión y base del núcleo paralelos o prácticamente paralelos (excepto por la inclinación requerida por el ángulo del frente de talla), la superficie inferior está totalmente truncada.

- Superficie de extracciones corta (24 y 33 mm en cada uno de los núcleos) enmarcada entre el plano de percusión y la base del núcleo; situada en una parte estrecha del volumen (la superficie posterior es más ancha que la anterior). Probablemente se elija una arista (natural o conformada) como apertura de la tabla de extracciones.

- Los flancos del núcleo son superficies que enmarcan la tabla de extracciones, tendiendo a converger de forma ortogonal con ella

- Son núcleos muy gruesos, con relación a su longitud 


\section{Fase 0-1: selección - preparación}

Estas características volumétricas se van a conseguir bien aprovechando las condiciones del bloque de partida o bien mediante una serie de gestos de conformación. De la primera alternativa es ejemplo el núcleo ID $n^{0} 116$, en él los flancos son corticales y los restos del bloque original, con la presencia de aristas naturales, permiten intuir la posible presencia de una arista natural en el inicio de la superficie de extracciones. En este núcleo la fase de preparación habría necesitado conformar tan solo el plano de percusión y la base del núcleo mediante sendas extracciones de grandes lascas transversales.

En el segundo núcleo (ID n ${ }^{0}$ 115) además de la conformación del plano y la base, se necesita también un acondicionamiento de los flancos a partir de extracciones de eje sobre los laterales, ortogonales a la superficie de extracciones. Dichas extracciones serían del estilo de los flancos longitudinales.

Por tanto, dependiendo de las condiciones del bloque de origen, la fase de preparación y conformación volumétrica de este tipo de núcleos puede constar de más o menos gestos, existiendo siempre la posibilidad de adaptación de las características naturales del bloque a las condiciones técnicas del método.

\section{Fase 2: producción}

En la fase de producción propiamente dicha, hay que decir que la superficie de extracciones delimitada por el volumen descrito es corta, por lo que las extracciones potenciales están totalmente constreñidas a una longitud que ronda los $3 \mathrm{~cm}$ como máximo. Se trataría por tanto de lascas o lascas laminares, puede que de posibles hojitas con esa longitud máxima.

Las condiciones técnicas de los núcleos construidos según este método comparten algunas características con el esquema del nódulo-placa, especialmente la delimitación del eje axial de la superficie de extracciones en una estrecha franja entre dos superficies más o menos paralelas; esta circunstancia va a favorecer un control de la carena. Asimismo las extracciones se desarrollan a todo lo largo de la superficie de 
extracciones, parece que tienden a sobrepasarse, portando en su borde transversal parte de la base del núcleo, por tanto la zona distal de las mismas tendría una morfología cuadrangular.

Por el contrario, una diferencia esencial con el método del nódulo-placa, es que la superficie de extracciones es frontal y está encuadrada en un borde estrecho del núcleo. Esta circunstancia conlleva que se necesiten unos requerimientos técnicos específicos sobre los flancos del núcleo, a partir de los cuales se va a conservar las características técnicas de la superficie de extracciones. Los laterales del núcleo son perpendiculares a la superficie posterior y tienden también a ser ortogonales respecto a la superficie de extracciones. En uno de los núcleos estos flancos son corticales y no se reforman a lo largo del curso del débitage, con lo que hay una pérdida de la cintra al avanzar la talla sobre los laterales. En el otro núcleo sí se observan sendas extracciones “tipo flanco longitudinal” sobre los laterales que enmarcan la superficie de extracciones.

El ritmo de talla es unipolar frontal en el primer núcleo y unipolar convergente semi-envolvente, avanzando hacia ambos laterales, en el segundo núcleo. Este último deja, como consecuencia de esta dirección convergente, una arista marcada en la zona más anterior del bloque.

En cuanto al modo de talla, hay restos de preparación sobre uno de los núcleos en forma de esquirlado sobre una parte de la cornisa, haciéndola continua. Sí parece que se podría constatar una preparación cuidadosa del punto de impacto, con un pequeño facetado sobre la parte más anterior del frente de talla. Este núcleo es el que tiene extracciones más alargadas, por lo que es factible relacionar esta preparación cuidadosa (sin que podamos constatar una abrasión intensa) con una intención laminar. En el otro la cornisa es denticulada, pero al no seguir con la extracción de soportes, no sabemos el tipo de preparación que se hubiera ejecutado. El ángulo de talla ronda en ambos casos los $80^{\circ}$. Para el primer núcleo las características de los contrabulbos encajarían con las de percusión directa con percutor duro. Para el segundo, quizás la preparación cuidadosa de las extracciones, así como el ritmo de talla convergente, y la rectitud de los negativos, podrían apuntar quizás al uso de un percutor más blando. 
En un primer momento no sabíamos si este esquema encajaba en la cadena operativa de concepción prismática, ya que difiere en cierto grado de los esquemas prismáticos más clásicos, pero las características que lo acercan a esta cadena se pueden resumir en las siguientes:

- La conformación volumétrica del núcleo comparte la morfología geométrica de los núcleos prismáticos: se inscribe en un prisma, con la superficie de extracciones aproximadamente perpendicular al plano de percusión, a los flancos del núcleo y, en este caso, también a la base del mismo

- fase de preparación que necesita al menos la instalación del plano de percusión y la base del núcleo

- superficie de extracciones sobre una superficie concreta del bloque, estrecha, aprovechando las aristas naturales para la apertura de la talla

- avance del débitage de forma frontal o semi-envolvente, con la necesidad del mantenimiento de este tipo de débitage

En consecuencia, el esquema desarrollado en estos núcleos parece situarse en la línea de los esquemas prismáticos anteriores, los motivos de sus peculiaridades son difíciles de determinar. En los dos núcleos con que contamos no se observan superficies naturales o zonas irregulares en la materia que hallan delimitado la morfología inicial de los bloques, así que parece que hay una intencionalidad respecto a la conformación volumétrica de los mismos. Por otro lado no puede descartarse la posibilidad de que se tratarse de un aprovechamiento de bloques fragmentados o de elementos producto de la conformación de otros núcleos para la obtención de soportes de unos dos o tres centímetros de longitud.

\section{IV.1.6.1.4. LOS SOPORTES OBTENIDOS EN LOS ESQUEMAS PRISMÁTICOS}

En los puntos anteriores se han expuesto los esquemas operativos que se pueden adscribir a una estructura prismática, basándonos fundamentalmente en el análisis técnico de los núcleos. Los productos que se obtienen a lo largo de la explotación de este tipo de núcleos los encontramos también en el conjunto lítico, tanto los soportes "intencionales", como los que se obtienen a lo largo del proceso de talla. Respecto a 
estos últimos hay varios soportes que se pueden ubicar en distintos momentos de las secuencias de explotación de los núcleos y que estarían en correlación con los distintos métodos adoptados en dichos esquemas. Tal y como se ha ido viendo a lo largo de la descripción de estos esquemas, hay métodos recurrentes en varios de ellos, por ejemplo el recurso a la extracción de aristas naturales (con la función de "hojas de encetadura" como método de apertura de la superficie de extracciones) está presente en casi todos los esquemas; bien es cierto que es más característico por ejemplo de los núcleos prismáticos grupo-B.

Las hojas corticales, así como las lascas en general que portan en su cara superior restos de una arista natural, serían testimonio de la utilización del aprovechamiento de dichas aristas y convexidades naturales como método de iniciación del débitage. En el caso de las hojas corticales, se ha visto como la mayoría portan una arista natural, por lo que serían "hojas de encetadura" de la superficie de extracciones. Este método se ha utilizado tanto en los núcleos prismáticos grupo-B, como en los unipolares-prismáticos. A este respecto, la longitud de dichas hojas de encetadura es bastante considerable (una de estas hojas alcanza prácticamente los $7 \mathrm{~cm}$ ), dándonos una idea de la longitud inicial de la superficie de extracciones.

Muchas de las lascas laminares pueden ser también testimonio de estas secuencias de iniciación del débitage, con la función de ser una secuencia de conformación inicial de la superficie de extracciones.

Respecto a los soportes característicos de la fase de producción, habría varias categorías, dependiendo de la secuencia concreta a la que pertenezcan. Los soportes intencionales, es decir los que pertenecen a las secuencias de débitage pleno, son hojas y hojitas y también lascas-laminares. Es en los soportes intencionales donde parece que se puede ver un comportamiento más específico de los distintos esquemas:

- Los núcleos prismáticos grupo-A producen hojitas de una calidad bastante buena, a juzgar por los negativos presentes en las superficies de extracciones. Asimismo es importante constatar que en este tipo de núcleos se ha observado una preparación del frente de percusión muy cuidadosa, dato que podría relacionarse con el hecho de que los soportes laminares tienen una 
preparación del talón que es también muy cuidadosa: la abrasión sólo aparece de una forma abundante en las hojas y hojitas.

- Los núcleos prismáticos del grupo-B tienen unos negativos laminares de mayor longitud, por lo que pueden haber sido el origen de las hojas de mayor calibre de la colección. Al examinar los soportes retocados, se ha comprobado cómo había una preferencia por este tipo de piezas de un módulo robusto, para confeccionar por ejemplo los buriles.

- Los núcleos de superficie ancha van a producir lascas-laminares de calibre relativamente grande y lascas de menor longitud (las procedentes de los métodos bipolares). En este caso no hay una producción laminar demasiado clara, pero al examinar el conjunto de soportes se pudo comprobar cómo el porcentaje de lascas era muy elevado y éstas procederían tanto de las fases de acondicionamiento de los núcleos anteriores como de este tipo de núcleos.

- Los núcleos unipolares-prismáticos tienen una producción con una longitud restringida $(2-3 \mathrm{~cm})$, debido a las características de dicho esquema, de ellos se van a extraer lascas, y también hojas-hojitas.

\section{IV.1.6.2. CADENA OPERATIVA TIPO NÓDULO-PLACA}

Este esquema de núcleo sobre placa es una cadena de débitage de lascas oportunista, tenemos un solo núcleo en sílex negro (ID n ${ }^{\circ} 114$ ), el cual tiene dos lascas remontadas.

\section{Fase 0-1: selección/preparación}

Aprovechamiento/selección de un nódulo en forma de placa, delimitado por sendos planos (en este caso superficies naturales de diaclasado), que se utilizarán como planos de percusión, de forma alterna.

La superficie enmarcada por los planos naturales va a ser la superficie de extracciones, que será explotada a partir de su eje corto en una dirección de talla que va de un plano al otro. En consecuencia la superficie potencial de extracciones es corta y envolvente. 
Esta primera fase sería muy rápida, se reduce tan solo a la selección de un bloque con las características especificadas, a una calibración de los planos de percusión, eliminando alguna irregularidad en los bordes para adecuar el ángulo adecuado de talla como gesto máximo destacable en la preparación

\section{Fase 2: explotación}

Los soportes que se pueden extraer de este tipo de núcleos son lascas cortas y cuadrangulares, enmarcadas por los planos naturales que delimitan el volumen. En el núcleo con que contamos la longitud de la superficie de extracciones es de $18 \mathrm{~mm}$, y dos lascas remontadas miden 20 y $22 \mathrm{~mm}$ respectivamente. Al ser una superficie tan corta, las extracciones llegan hasta el plano inferior, con tendencia a sobrepasarse, de forma que el borde distal de las lascas es transversal, portando la parte de la base del núcleo correspondiente.

Estas lascas cortas constituyen el objetivo del débitage de estos núcleos, son piezas que no tienen demasiadas complicaciones, como tampoco la tiene este esquema en general.

Las condiciones técnicas del débitage (esencialmente las curvaturas y el ángulo) se consiguen fácilmente sobre el bloque presentado. La carena se puede mantener en un soporte tan corto, tan solo habría que tener cuidado en no provocar reflejados. En cuanto a la cintra, se puede perder la curvatura transversal al ir avanzando de forma envolvente, pero esto se soluciona por el cambio de plano de percusión.

Para el inicio de la talla tan solo sería necesaria la apertura de un ángulo adecuado, cosa que se puede conseguir rápidamente sobre uno de los bordes del nódulo, activando un frente de percusión a partir de una preparación sencilla. El débitage comenzaría sobre uno de los bordes del núcleo de forma semi-envolvente, avanzando sobre el contorno del nódulo, al menos hasta que las condiciones de la cintra lo permitan; cosa que va a depender de las características del propio bloque así como del avance de la talla. Si no se puede seguir sobre ese borde, hay un cambio de plano de percusión, rotando el núcleo y realizando la misma operación semi-envolvente sobre otra porción de la superficie explotable. Se produce así un ritmo de talla en series o 
secuencias cortas de lascas, con un avance del débitage envolvente, con alternancia del plano de percusión y siguiendo la misma superficie de extracciones a lo largo del contorno del bloque.

Se trata de un esquema conceptual de débitage poco exigente ya que los soportes son de un módulo pequeño y se utiliza un método rápido de talla. No es necesario recurrir a reparaciones de la superficie de extracciones ya que el propio avance de la talla, encuadrando totalmente de forma axial las extracciones, permite un mantenimiento de las condiciones técnicas básicas; teniendo la posibilidad además de adoptar un ritmo alterno del débitage para continuar la misma superficie de extracciones.

En cuanto a la preparación de las extracciones tampoco es demasiado cuidadosa. Se constata algún gesto de acondicionamiento sobre la cornisa, con la eliminación de sus irregularidades en forma de pequeñas extracciones en esquirlado. No hay una abrasión intensa del frente de percusión, ya que éste permanece con una morfología irregular. De todas formas en las lascas remontadas sí se observa una preparación más cuidada de lo que se podría deducir del núcleo, con un redondeamiento de la zona del talón a partir de un gesto que ha dejado unas huellas en pequeño esquirlado. El ángulo de talla empleado es bastante cerrado, cosa que se constata tanto en el núcleo (con un ángulo de $\left.50-60^{\circ}\right)$ como en una de las lascas remontadas (110-120 de ángulo de lascado). La percusión es interior (grosor del talón de 4,5 mm) y las características del bulbo, con el punto de impacto visible, así como de los contrabulbos del núcleo, serían propias de la percusión directa con percutor duro.

Esta cadena se puede resumir en los siguientes puntos:

- Esquema muy sencillo, basado en el aprovechamiento de un volumen aplanado, delimitado por sendos planos naturales, los cuales enmarcan una superficie de extracciones corta, pero que se extiende por todo el contorno del bloque.

- Los planos adoptan el rol de plano de percusión y base de núcleo, sin que ambas funciones necesiten una conformación específica (no existe ningún acondicionamiento de uno de las superficies naturales como plano de 
percusión). El criterio para determinar cuál de las superficies será el plano de percusión estaría determinado por la adecuación de uno de los bordes de un plano con el ángulo apto para el inicio de la talla. Esta ausencia de conformación específica del plano de percusión, permitirá intercambiar la función de ambos en la fase de producción plena de soportes.

- La superficie de extracciones se explota a partir del eje corto del volumen, siguiendo la dirección entre los dos planos.

- Los soportes son lascas cortas y cuadrangulares, su longitud abarca toda la superficie de extracciones, incluyendo la base del núcleo en el borde transversal.

- El modo de talla aplicado probablemente sea la percusión directa con percutor duro, con percusión interna y ángulo cerrado.

- La preparación de las extracciones se centra en eliminar de forma somera las irregularidades de la cornisa y preparar sucintamente el punto de impacto.

- Avance de la talla de forma envolvente por el contorno del volumen-placa, con un sentido circular.

- Las características del volumen, perfectamente delimitado para desgajar las lascas a lo largo de su contorno, permiten el desarrollo de un débitage rápido, sin complicaciones técnicas ni necesidad de secuencias de preparación.

- Si el débitage se entorpece por algún accidente o limitación del bloque, se procede a rotar el núcleo, invirtiendo así las funciones de plano de percusión y base de núcleo.

Se trata de un método muy sencillo que aprovecha al máximo las características de la materia prima para obtener lascas pequeñas. Los criterios técnicos de talla básicos se controlan prácticamente por las propias características del volumen, sin necesidad de operaciones o gestos extras. La carena se puede controlar bastante bien debido al pequeño tamaño de las lascas y la cintra se mantiene también en el propio ritmo de talla así como por la posibilidad de la alternancia de planos de percusión. En consecuencia estos dos criterios básicos de la talla se auto-mantienen a lo largo de la explotación plena, de modo que hay una extracción de lascas sin que haya necesidad de secuencias 
de reparación, con la obtención de productos de acondicionamiento. Habría que tener cuidado tan solo en el ángulo de talla y en el gesto técnico con que se extraen las lascas para evitar reflejados o pérdida del frente de talla.

Este método se podría calificar de simple (no complejo) en el sentido de que tiene una cadena operativa corta. Es un método muy eficaz y rápido pero está limitado y condicionado por las características del volumen explotado, de modo que solo se pueden extraer lascas de tamaño pequeño. Si ahondamos en este aspecto, una explotación de este estilo puede tener dos lecturas:

i) La calidad mediocre de la materia limita el tamaño de los productos. El método es simple, con una cadena operativa corta y no hay evidencia de una gran maestría técnica; los límites de la materia prima condicionarían el esquema aplicado

ii) Hay un aprovechamiento máximo de las condiciones en que se presenta la materia prima, de modo que se adopta un esquema de débitage adaptado a unos bloques con unas características determinadas para obtener un tipo de soportes concreto; es decir se trataría de un método flexible, adatado a los condicionantes de la materia

Desde mi punto de vista me inclino más hacia la segunda explicación, en el sentido de que habría una adaptación eficaz y rápida a las potencialidades que ofrece la materia prima disponible. Este método aprovecha las limitaciones de la materia prima (es decir la existencia de irregularidades y planos de diaclasado naturales que originan nódulos estrechos), mediante la aplicación de un método de talla que aprovecha al máximo las características técnicas del bloque, de modo que hay una economía de gestos de preparación o reparación, centrándose el grueso del proceso de talla en la extracción de los soportes potencialmente utilizables. El inconveniente de este método es que no permite obtener soportes de mayor tamaño, pero no sabemos hasta qué punto esto se puede interpretar como un inconveniente, o bien, simplemente, como un modo de obtener un conjunto de lascas de un tamaño regular y más o menos constante. 


\section{IV.2.- RADIOLARITA 1}

La radiolarita es una materia que se presenta en dos variantes, la que se ha denominado como radiolarita-1 es de color rojo-granate y es la más abundante. La segunda variedad, de un color verde-aceituna muy característico, tiene una menor representación. En el capítulo sobre las materias primas se indicó cómo esta segunda variante responde a cambios en la coloración de la roca debido a variaciones en la oxidación de hierro. En dicho capítulo se describió extensamente cómo este tipo de materia se encuentra localizada en un nivel geológico concreto (la Formación Alba), asociada a la caliza Griotte. Asimismo se expusieron las características de los afloramientos de radiolarita, que aparece de forma masiva, en bandas delimitadas por planos de sedimentación y con abundantes planos de diaclasado interno. Esto va a provocar que en los afloramientos in situ, la radiolarita se presente en forma de nódulos delimitados por dichos planos naturales, con morfologías prismáticas muy frecuentes. Estas características tan concretas de la radiolarita respecto a la forma como se presenta, van a ser determinantes respecto a los esquemas aplicados, ya que serán aprovechadas al máximo las ventajas de esta conformación natural en prisma, para realizar un débitage laminar. Pero, si la morfología inicial de los nódulos va a ser sumamente ventajosa para el desarrollo de esquemas laminares, en cambio la abundancia de planos naturales, así como el hecho de que a veces los bloques no tengan una composición homogénea, van a dificultar en gran medida el progreso de la talla. Serán así muy abundantes los accidentes provocados por la presencia de planos internos de rotura, los cuales distorsionan la fracturación intencional de esta materia.

\section{IV.2.1.- CARACTERÍSTICAS GENERALES}

\section{IV.2.1.1.- LISTA TECNOLÓGICA, GRUPOS TECNOLÓGICOS}

El número de piezas de la primera variedad de radiolarita no es muy elevado ( $\mathrm{n}=1533$ ), sería el tercer tipo de materia explotada, después del sílex negro y la cuarcita, 
con un 12\% del conjunto lítico. En el cuadro R1.1 se presenta la lista tecnológica, con sus porcentajes relativos.

\begin{tabular}{|c|c|c|c|c|}
\hline GRUPO TECNOLÓGICO & $\mathrm{N}^{\circ}$ TEC & SOPORTE & $\mathbf{N}$ & $\%$ \\
\hline GRUPO 0 (nódulos) & 0 & Nódulo & & \\
\hline \multirow{6}{*}{$\begin{array}{l}\text { GRUPO } 1 \\
\text { (lascas) }\end{array}$} & 1 & Lasca de primer orden & 8 & 0,52 \\
\hline & 2 & Lasca de segundo orden & 15 & 0,98 \\
\hline & $2-5$ & Lasca laminar de segundo orden & 2 & 0,13 \\
\hline & 3 & Lasca de tercer orden & 543 & 35,42 \\
\hline & $3-6$ & Lasca laminar & 41 & 2,67 \\
\hline & 4 & Hoja de primer orden & & \\
\hline \multirow{5}{*}{$\begin{array}{l}\text { GRUPO } 2 \\
\text { (soportes laminares) }\end{array}$} & 5 & Hoja de segundo orden & 2 & 0,13 \\
\hline & 6 & Hoja de tercer orden & 122 & 7,96 \\
\hline & $6-\mathrm{FN}$ & Hoja con flanco & 2 & 0,13 \\
\hline & 7 & Hojita de segundo orden & 9 & 0,59 \\
\hline & 8 & Hojita de tercer orden & 172 & 11,22 \\
\hline \multirow{5}{*}{$\begin{array}{l}\text { GRUPO } 3 \text { (productos de } \\
\text { acondicionamiento) }\end{array}$} & 9 & Lámina cresta & 13 & 0,85 \\
\hline & 10 & Tableta de núcleo & & \\
\hline & 11 & Semitableta de núcleo & 9 & 0,59 \\
\hline & 12 & Flanco de núcleo & 28 & 1,83 \\
\hline & 13 & Arista de núcleo y otros prod. de acon. & 9 & 0,59 \\
\hline \multirow{5}{*}{$\begin{array}{l}\text { GRUPO } 4 \\
\text { (núcleos) }\end{array}$} & 14 & Núcleo prismático con un plano & 3 & 0,20 \\
\hline & 15 & Núcleo prismático con dos planos & 3 & 0,20 \\
\hline & 16 & Núcleo sobre lasca & & \\
\hline & 17 & Núcleo globuloso & & \\
\hline & 18 & Resto de núcleo & 4 & 0,26 \\
\hline $\begin{array}{l}\text { GRUPO } 7 \\
\text { (golpes buril) }\end{array}$ & 19 & Golpe de buril & 1 & 0,07 \\
\hline \multirow{3}{*}{ GRUPO 5 (indeterminados) } & 23 & Astilla de talla & 18 & 1,17 \\
\hline & 24 & Chunk & 18 & 1,17 \\
\hline & 25 & Indeterminado & 27 & 1,76 \\
\hline \multirow{2}{*}{$\begin{array}{l}\text { GRUPO } 6 \\
\text { (debris) }\end{array}$} & DEB-LT & Debris: lasquita & 438 & 28,57 \\
\hline & DEB-AT & Debris: astilla e indeterminados & 46 & 3,00 \\
\hline & & & 1533 & 100 \\
\hline
\end{tabular}

Cuadro R1.1: lista tecnológica de radiolarita.

\begin{tabular}{|l|cc|}
\hline GRUPOS TEC. & $\mathbf{N}$ & $\mathbf{\%}$ \\
\hline 1 & 609 & 39,7 \\
2 & 307 & 20,0 \\
3 & 59 & 3,8 \\
4 & 10 & 0,7 \\
5 & 63 & 4,1 \\
6 & 484 & 31,6 \\
7 & 1 & 0,1 \\
\hline
\end{tabular}

Cuadro R1.2: grupos tecnológicos de radiolarita. 


\begin{tabular}{|c|c|c|c|c|}
\hline \begin{tabular}{|l|} 
GRUPO \\
TECNOLÓGICO \\
\end{tabular} & $\mathbf{N}^{\circ}$ TEC & SOPORTE & $\mathbf{N}$ & $\%$ \\
\hline \begin{tabular}{|l|} 
GRUPO 0 \\
(nódulos)
\end{tabular} & 0 & Nódulo & & \\
\hline \multirow{6}{*}{$\begin{array}{l}\text { GRUPO } 1 \\
\text { (lascas) }\end{array}$} & 1 & Lasca de primer orden & & \\
\hline & 2 & Lasca de segundo orden & 4 & 2,5 \\
\hline & $2-5$ & Lasca laminar de segundo orden & 35 & 21,9 \\
\hline & 3 & Lasca de tercer orden & & \\
\hline & $3-6$ & Lasca laminar & 4 & 2,5 \\
\hline & 4 & Hoja de primer orden & & \\
\hline \multirow{5}{*}{$\begin{array}{l}\text { GRUPO } 2 \\
\text { (soportes laminares) }\end{array}$} & 5 & Hoja de segundo orden & & \\
\hline & 6 & Hoja de tercer orden & 49 & 30,6 \\
\hline & 6-FN & Hoja con flanco & 1 & 0,6 \\
\hline & 7 & Hojita de segundo orden & 1 & 0,6 \\
\hline & 8 & Hojita de tercer orden & 49 & 30,6 \\
\hline \multirow{5}{*}{$\begin{array}{l}\text { GRUPO } 3 \text { (productos } \\
\text { de acondicionamiento) }\end{array}$} & 9 & Lámina cresta & 3 & 1,9 \\
\hline & 10 & Tableta de núcleo & & \\
\hline & 11 & Semitableta de núcleo & & \\
\hline & 12 & Flanco de núcleo & 5 & 3,1 \\
\hline & 13 & Arista de núcleo y otros prod. de acon. & 1 & 0,6 \\
\hline \multirow{5}{*}{$\begin{array}{l}\text { GRUPO } 4 \\
\text { (núcleos) }\end{array}$} & 14 & Núcleo prismático con un plano & 1 & 0,6 \\
\hline & 15 & Núcleo prismático con dos planos & & \\
\hline & 16 & Núcleo sobre lasca & & \\
\hline & 17 & Núcleo globuloso & & \\
\hline & 18 & Resto de núcleo & & \\
\hline \begin{tabular}{|l|} 
GRUPO 7 \\
(golpes buril)
\end{tabular} & 19 & Golpe de buril & & \\
\hline \multirow{3}{*}{$\begin{array}{l}\text { GRUPO } 5 \\
\text { (indeterminados) }\end{array}$} & 23 & Astilla de talla & & \\
\hline & 24 & Chunk & & \\
\hline & 25 & Indeterminado & & \\
\hline \multirow{2}{*}{\begin{tabular}{|l}
$\begin{array}{l}\text { GRUPO } 6 \\
\text { (debris) }\end{array}$ \\
\end{tabular}} & DEB-LT & Debris: lasquita & 7 & 4,4 \\
\hline & DEB-AT & Debris: astilla e indeterminados & & \\
\hline & & & 160 & 100 \\
\hline
\end{tabular}

Cuadro R1.3: lista tecnológica de los soportes retocados de radiolarita.

\begin{tabular}{|l|cc|}
\hline GRUPOS TEC. & $\mathbf{N}$ & $\mathbf{\%}$ \\
\hline 1 & 43 & 26,9 \\
2 & 100 & 62,5 \\
3 & 9 & 5,6 \\
4 & 1 & 0,6 \\
5 & & \\
6 & 7 & 4,4 \\
7 & & 100 \\
\hline
\end{tabular}

Cuadro R1.4: grupos tecnológicos de radiolarita en las piezas retocadas. 
Las piezas más abundantes son las lascas de tercer orden (35\%) y las lasquitas de los debris (29\%), seguidos por las hojitas de tercer orden, con un 11\% y las hojas, con un 8\%; el reto de los soportes tienen un porcentaje inferior al 3\%. Este primer acercamiento a la representación interna de los tipos de soportes presentes, se aprecia mejor en el resumen por grupos tecnológicos (cuadro R1.2), en el cual se observa el predominio claro del primer grupo (lascas en general), con un $40 \%$ de las piezas, seguido por el 30\% de los debris; por su parte el grupo de los soportes laminares, con un 20\% de piezas marcaría una tendencia clara en los objetivos del débitage.

\begin{tabular}{|l|c|cc|}
\hline \multirow{2}{*}{ GRUPO TEC. } & \multirow{2}{*}{ TOTAL } & \multicolumn{2}{|c|}{ RETOCADAS } \\
\cline { 3 - 4 } & & $\mathrm{N}$ & $\%$ \\
\hline 0 & & & \\
1 & 609 & 43 & 7,1 \\
2 & 307 & 100 & 32,6 \\
3 & 59 & 9 & 15,3 \\
4 & 10 & 1 & 10,0 \\
5 & 63 & & \\
6 & 484 & 7 & 1,4 \\
7 & 1 & & \\
\hline & 1533 & 160 & 10,4 \\
\hline
\end{tabular}

Cuadro R1.5: piezas retocadas relativamente al total de las disponibles en los distintos grupos tecnológicos.

Respecto a los tipos de soportes retocados (cuadro R1.3), no hay una variedad de soportes tan elevada como la que veíamos para el sílex negro negro. La tendencia hacia el objetivo laminar que se apreciaba en la representación total de la radiolarita se acusa claramente en las piezas retocadas, ya que hay una elección predominante de los soportes laminares, suponiendo el 60\% de las piezas retocadas (cuadro R1.4), seguidas por el grupo 1, con un 27\%, y de forma muy minoritaria estarían los productos de acondicionamiento y el resto de soportes. No obstante si tenemos en cuenta las piezas retocas relativamente a las piezas disponibles en el conjunto, estos porcentajes se matizan ligeramente (cuadro R1.5): los soportes laminares siguen siendo los soportes que se seleccionan mayoritariamente (se retocan el 32\% de las hojas-hojitas disponibles), pero estarían seguidos por los productos de acondicionamiento (de los que se retocan el 15\%) en lugar de las lascas (con un 7\% de selección para ser retocadas). En conjunto se puede afirmar que hay sobre la radiolarita, respecto a la elección de 
soportes para ser retocados, un comportamiento de tipo más selectivo que en el sílex negro, ya que hay un predominio neto de los soportes laminares.

\section{IV.2.1.2.- ROTURAS}

Sobre la radiolarita hay un porcentaje muy elevado de roturas, superando el 75\% de las piezas. Para explicar este escaso número de piezas completas quizás haya que tener en cuenta las características de la propia materia, cuya calidad para la talla se ve afectada por la presencia de los abundantes planos que provocan accidentes y roturas a lo largo del proceso de talla.

\section{IV.2.1.2.1.- TIPOS DE SOPORTES ROTOS}

En el cuadro R1.6 se especifica el estado de fragmentación en que se encuentran los principales tipos de soportes.

\begin{tabular}{|c|c|c|c|c|c|c|c|}
\hline \multirow{2}{*}{$\begin{array}{c}\text { GRUPO } \\
\text { TEC. }\end{array}$} & \multirow{2}{*}{ TIPO TEC. } & \multirow{2}{*}{ COMPLETOS } & \multicolumn{4}{|c|}{ FRAGMENTADOS } & \multirow{2}{*}{ TOTAL } \\
\hline & & & Distal & Mesial & Proximal & Rota & \\
\hline \multirow[b]{2}{*}{1} & $\mathrm{~L}$ & 157 & 118 & 50 & 142 & 99 & 566 \\
\hline & $\begin{array}{c}\mathrm{L}-\mathrm{H} \\
\mathrm{H}\end{array}$ & 8 & 7 & 12 & 16 & & 43 \\
\hline \multirow{3}{*}{2} & $\mathrm{H}$ & 16 & 23 & 43 & 39 & 3 & 124 \\
\hline & $\mathrm{H}-\mathrm{FN}$ & 1 & & & 1 & & 2 \\
\hline & HT & 15 & 50 & 62 & 53 & 1 & 181 \\
\hline \multirow{4}{*}{3} & $\begin{array}{l}\mathrm{LC} \\
\mathrm{TN}\end{array}$ & 5 & 6 & 1 & 1 & & 13 \\
\hline & $\mathrm{SN}$ & 4 & & 1 & 4 & & 9 \\
\hline & FN & 17 & 9 & 2 & & & 28 \\
\hline & AN & 3 & 2 & & 2 & 2 & 9 \\
\hline 4 & $\mathrm{~N}$ & 10 & & & & & 10 \\
\hline 5 & IT & & & & & 63 & 63 \\
\hline \multirow{2}{*}{6} & LT & 142 & 92 & 26 & 76 & 102 & 438 \\
\hline & IT & & & & & 46 & 46 \\
\hline \multirow[t]{2}{*}{1} & GB & & & 1 & & & 1 \\
\hline & & 378 & 307 & 198 & 334 & 316 & 1533 \\
\hline
\end{tabular}

Cuadro R1.6: representación de los tipos de soportes enteros y fragmentados de radiolarita, teniendo en cuanta la totalidad de las piezas. 


\section{IV.2.1.2.2.- TIPOS DE ROTURAS}

En los tipos de roturas predominan (cuadro R1.7) las distales (25\%), seguidas por las proximales (18\%), las proximales-distales (17\%), las rotas por todos los lados (16\%), las próximo-laterales (11\%), las distales-laterales (8\%), las laterales (5\%) y, por último las bilaterales $(0,3 \%)$.

\begin{tabular}{|l|cccccccc|r|}
\hline & BL & DL & DP & DS & LT & PD & PL & PX & TOTAL \\
\hline GR.1:L & 2 & 46 & 81 & 95 & 31 & 55 & 70 & 61 & 441 \\
GR.2:H & & 7 & 3 & 94 & & 102 & 3 & 65 & 274 \\
GR.3:P.A. & & 2 & 1 & 8 & 3 & 4 & 1 & 16 & 35 \\
GR.6:DEB & 1 & 34 & 90 & 77 & 17 & 34 & 50 & 60 & 1 \\
GR.7:GB & & & & & & 1 & & & 363 \\
\hline N & 3 & 89 & 175 & 274 & 51 & 195 & 124 & 202 & 1113 \\
$\%$ & 0,3 & 8,0 & 15,7 & 24,6 & 4,6 & 17,5 & 11,1 & 18,1 & 100 \\
\hline
\end{tabular}

Cuadro R1.7: tipos de roturas en los distintos grupos tecnológicos. BL: bilateral, DL: distallateral, DP: distal-lateral-proximal, DS: distal, LT: lateral, PD: proximal-distal, PL: proximallateral, PX: proximal.

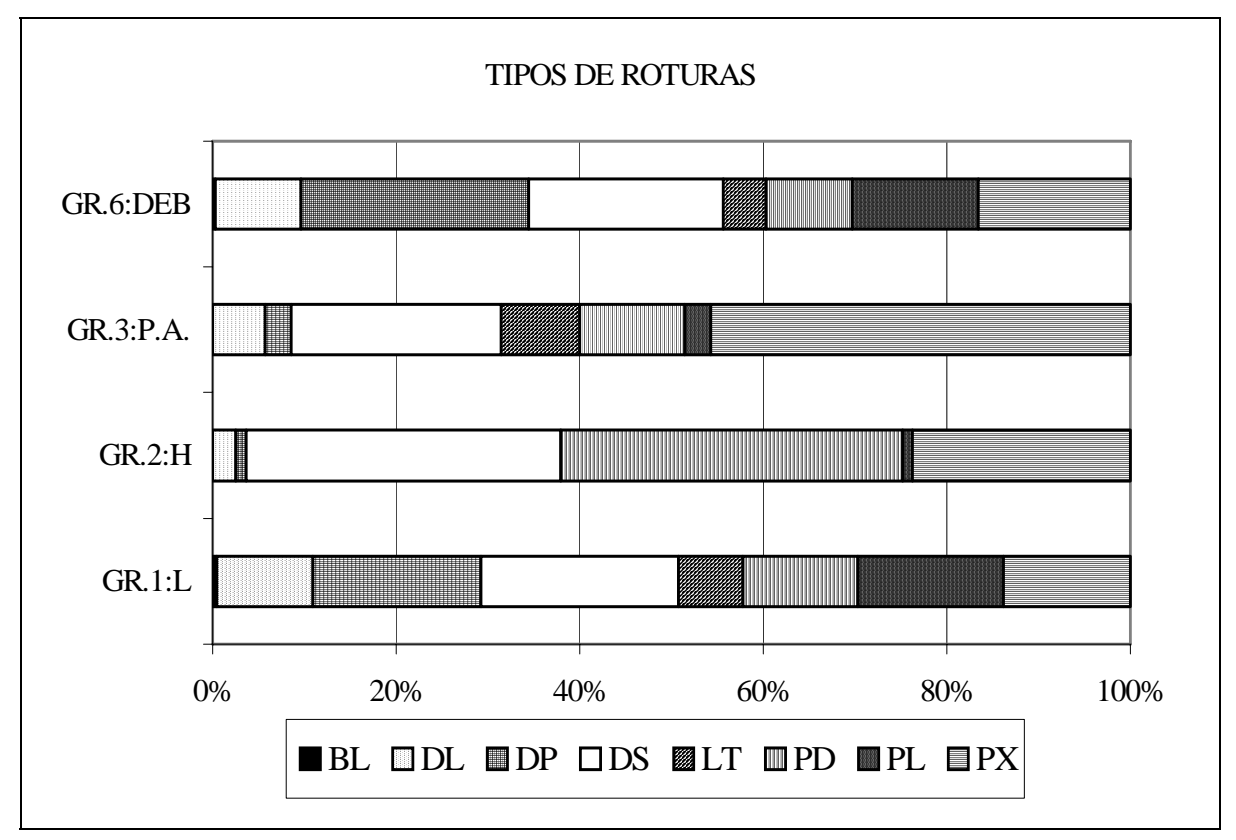

Gráfico R1.1: porcentaje de los tipos de roturas por grupos tecnológicos. Tipos de roturas: BL: bilateral, DL: distal-lateral, DP: distal-proximal-lateral, LT: lateral, PD: proximal-distal, PL: proximal-lateral, PX: proximal. 
Si se toma en consideración esta representación según los distintos grupos tecnológicos (Gráfico R1.1) se pueden diferenciar dos tendencias, de forma parecida a como sucedía en el sílex negro:

a) en el grupo tecnológico 1 (lascas) y 6 (debris) están presentes todos los tipos de roturas, sin que haya un predominio claro de unos sobre otros, a excepción quizás del mayor número de piezas rotas por todas partes (DP) que hay en los debris

b) En el grupo tecnológico 2 (soportes laminares) y 3 (productos de acondicionamiento) hay un predominio neto de las roturas que afectan de forma transversal a los soportes: las roturas distales, proximales y próximodistales.

Esta tendencia ya se había observado para el sílex negro, y de nuevo planteamos la duda respecto al hecho de que si sobre las hojas-hojitas hay más fragmentos distales, proximales y mesiales que en los grupos 1 y 6, puede deberse a un sesgo en la caracterización de tales soportes, o bien responde a un hecho intencional, relacionado con el retoque y uso de dichas piezas.

\section{IV.2.1.2.3.- CAUSA DE LA ROTURA}

Las roturas por flexión y las indeterminadas tienen una presencia similar, en torno al $40 \%$ de las piezas, mientras la percusión se encuentra en un $17 \%$ de las piezas (cuadro R1.8). El elevado número de piezas con roturas indeterminadas puede estar en relación, de nuevo, con la abundancia de planos de diaclasado interno de la materia.

\begin{tabular}{|l|cccc|cc|}
\hline & GR.1 & GR.2 & GR.3 & GR.6 & N & $\%$ \\
\hline Flexión & 166 & 136 & 13 & 152 & 467 & 42,0 \\
Indeterminada & 208 & 74 & 12 & 158 & 452 & 40,6 \\
Percusión & 67 & 64 & 10 & 53 & 194 & 17,4 \\
\hline
\end{tabular}

Cuadro R1.8: causa rotura en los distintos grupos tecnológicos. 

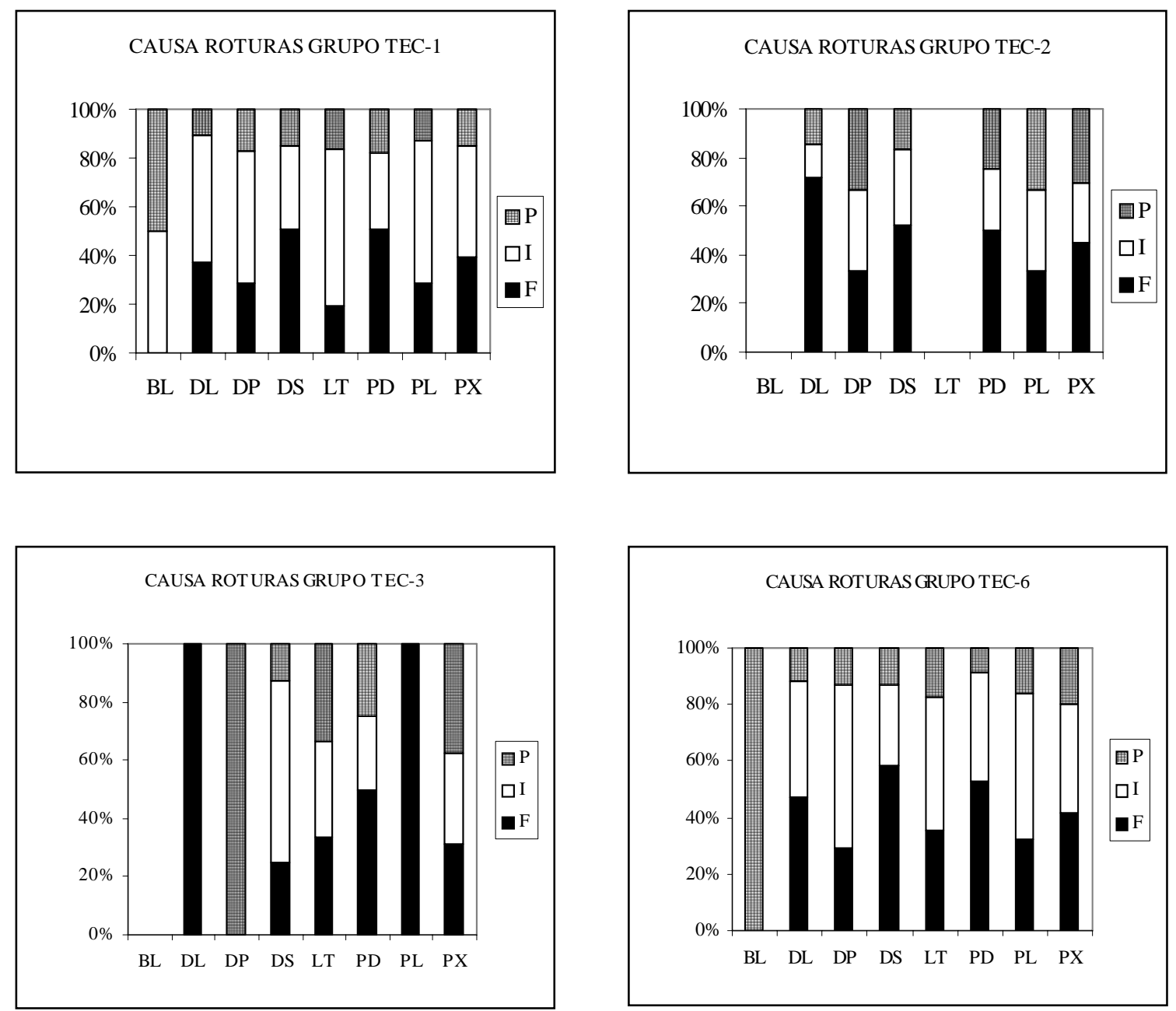

Gráfico R1.2: gráficos por grupos tecnológicos que representan porcentualmente las causas de la rotura según los distintos tipos de fracturas. En el eje de abscisas los tipos de fracturas: BL: bilateral, DL: distal-lateral, DP: distal-proximal-lateral, LT: lateral, PD: proximal-distal, PL: proximal-lateral, PX: proximal. En el eje de ordenadas se sitúa el porcentaje de los tipos de roturas: P: percusión, I: indeterminada, F: por flexión.

Si observamos la representación de la causa de la rotura diferenciando los distintos grupos tecnológicos (Gráfico R1.2), hay mayor representación de las roturas indeterminadas en los grupos 1 y 6 que en el 2 y 3, aunque habría que hacer la excepción de que las roturas distales en los productos de acondicionamiento son la mayoría indeterminadas 


\section{IV.2.1.3.- CÓRTEX}

La presencia de córtex no es muy abundante en la radiolarita, tan solo está presente en torno al 4\% de las piezas (cuadro R1.9). Esto es debido fundamentalmente a las características de la propia materia. Ya hemos indicado que lo que sería la superficie exterior de los nódulos de radiolarita se corresponde con los planos de sedimentación de la roca en su lugar de formación, pero su apariencia es muy cercana a la de los abundantes planos de diaclasado interno que afectan a esta materia. En consecuencia muchas veces no es posible determinar si tales superficies pertenecen a lo que habría sido el córtex o no.

\begin{tabular}{|c|c|c|c|c|c|c|c|}
\hline & \multicolumn{6}{|c|}{ CÓRTEX } & \multirow[t]{2}{*}{ TOTAL } \\
\hline & 1 & $\%$ & 2 & $\%$ & 3 & $\%$ & \\
\hline $\mathrm{L}$ & 8 & 1,4 & 15 & 2,7 & 543 & 95,9 & 566 \\
\hline L-H & & & 2 & 4,7 & 41 & 95,3 & 43 \\
\hline $\mathrm{H}$ & & & 2 & 1,6 & 122 & 98,4 & 124 \\
\hline H-FN & & & & & 2 & 100,0 & 2 \\
\hline HT & & & 9 & 5,0 & 172 & 95,0 & 181 \\
\hline LC & & & & & 13 & 100,0 & 13 \\
\hline TN & & & & & & & \\
\hline SN & & & 1 & 11,1 & 8 & 88,9 & 9 \\
\hline FN & & & 3 & 10,7 & 25 & 89,3 & 28 \\
\hline AN & & & 2 & 22,2 & 7 & 77,8 & 9 \\
\hline Nuc. & & & 5 & 50,0 & 5 & 50,0 & 10 \\
\hline GB & & & & & 1 & 100,0 & 1 \\
\hline IT & 1 & 1,6 & 1 & 1,6 & 61 & 96,8 & 63 \\
\hline DEB:LT & & & 5 & 1,1 & 433 & 98,9 & 438 \\
\hline DEB:IT & & & & & 46 & 100,0 & 46 \\
\hline TOTAL & 9 & 0,6 & 45 & 2,9 & 1479 & 96,5 & 1533 \\
\hline
\end{tabular}

Cuadro R1.9: presencia de córtex en los principales tipos tecnológicos, con sus respectivos porcentajes

De todas formas, dadas las circunstancias como se presenta la radiolarita en su lugar de afloramiento, no es demasiado pertinente la presencia o no de córtex. Es más interesante en cambio el hecho de que se trata de una materia cuyos nódulos tienen una conformación natural con unas características totalmente aptas para el desarrollo de un débitage laminar aprovechando las aristas naturales formadas en la intersección de las superficies de diaclasado y de sedimentación. Dichos planos serán aprovechados también para la conformación inicial de los núcleos, ya que sobre ellos se puede instalar el plano de percusión u otras superficies estructurales del núcleo. 


\section{IV.2.1.4.- DATOS MÉTRICOS}

En el cuadro R1.10 se presentan las medidas medias de los tipos de soportes principales dentro de los grupos técnicos amplios, tanto para las piezas sin retocar como las retocadas. En conjunto, la radiolarita está compuesta por elementos de dimensión que podemos caracterizar de "moderada”. Las medidas de las piezas de radiolarita son menores que las de sílex negro, es de suponer por tanto que los bloques de origen sean también inferiores. El mayor tamaño se encuentra entre los núcleos: uno de ellos llega a los 54 mm de longitud y otro a 59 de anchura. Por tanto el límite mayor del conjunto de radiolarita se encuentra en los $6 \mathrm{~cm}$. Esta dimensión está totalmente delimitada por el tamaño de los bloques de origen, los cuales están constreñidos por la forma en como se presentan: entre planos de sedimentación y de diaclasado que restringen en gran medida las posibilidades de obtención de nódulos de tamaño importante.

\section{IV.2.1.4.1.- TIPOS DE SOPORTES}

En el grupo 1, las lascas tienen unas dimensiones medias de: $L=15, A=14, G=3$ mm, es decir serían piezas de morfología cuadrangular en torno a 1,5 cm de dimensión. Las lascas laminares tienen una mayor longitud: $L=19, A=12, G=3 \mathrm{~mm}$; pero siguen sin alcanzar apenas los $2 \mathrm{~cm}$ de longitud media, al que sí se llegan en cambio en los soportes laminares: $\mathrm{L}=20, \mathrm{~A}=9, \mathrm{G}=2 \mathrm{~mm}$. Los productos de acondicionamiento siguen esta tendencia a incrementar el tamaño, siendo piezas más "robustas” que las anteriores: $\mathrm{L}=27, \mathrm{~A}=18, \mathrm{G}=6$. Los núcleos son, como es natural, las piezas de mayores dimensiones, si bien hay gran variación interna: $L=35, A=27, G=20$. Las piezas indeterminadas tienen unas dimensiones que se acercan en longitud a las lascas, pero son más estrechas y gruesas: $\mathrm{L}=16, \mathrm{~A}=11, \mathrm{G}=5 \mathrm{~mm}$. Por último los debris, tendrían una morfología cuadrangular en torno a los $7 \mathrm{~mm}$ : L=8, A=7, G=2mm.

En todos los tipos de soportes hay una tendencia muy clara a retocar las piezas mayores, incluso en algunos de ellos el rango de la distribución es mayor (caso de los productos de acondicionamiento, en los que hay una pieza retocada de $54 \mathrm{~mm}$ de longitud). 


\begin{tabular}{|c|c|c|c|c|c|c|c|}
\hline \multicolumn{4}{|l|}{ SIN RETOCAR } & \multicolumn{4}{|l|}{ RETOCADAS } \\
\hline GR1:L & $\mathbf{L}$ & A & G & GR1:L & $\mathbf{L}$ & A & G \\
\hline $\mathrm{N}$ & 142 & 428 & 527 & $\mathrm{~N}$ & 14 & 39 & 39 \\
\hline Rango & $7-37$ & $3-43$ & $0,6-15$ & Rango & $14-30$ & 8-39 & $1,6-14$ \\
\hline Media & 15,47 & 13,87 & 3,29 & Media & 22 & 18,15 & 4,96 \\
\hline Desviación & 6,13 & 5,23 & 1,93 & Desviación & 6,08 & 6,79 & 2,45 \\
\hline GR1:L-H & $\mathbf{L}$ & A & G & GR1:L-H & $\mathbf{L}$ & A & G \\
\hline $\mathrm{N}$ & 7 & 39 & 39 & $\mathrm{~N}$ & 1 & 4 & 4 \\
\hline Rango & $11-32$ & $5-20$ & $0,5-5$ & Rango & 24 & $7-20$ & $1,8-5,5$ \\
\hline Media & 19,21 & 12,09 & 2,85 & Media & & 14,62 & 3,4 \\
\hline Desviación & 7,66 & 3,03 & 1,12 & Desviación & & 5,73 & 1,69 \\
\hline GR2:H & $\mathbf{L}$ & $\mathbf{A}$ & G & GR2:H & $\mathbf{L}$ & A & G \\
\hline $\mathrm{N}$ & 25 & 203 & 206 & $\mathrm{~N}$ & 6 & 98 & 99 \\
\hline Rango & $9-34$ & $3-18$ & $0,5-6,5$ & Rango & $12-34$ & $3-22$ & $1-6,4$ \\
\hline Media & 20,42 & 8,80 & 2,35 & Media & 25 & 9,79 & 2,54 \\
\hline Desviación & 7,77 & 2,81 & 1,14 & Desviación & 7,82 & 3,55 & 1,02 \\
\hline GR2:H-FN & $\mathbf{L}$ & A & G & GR2:H-FN & $\mathbf{L}$ & A & G \\
\hline $\mathrm{N}$ & - & 1 & 1 & $\mathrm{~N}$ & 1 & 1 & 1 \\
\hline Rango & & 16 & 5 & Rango & 34 & 10 & 6,5 \\
\hline Media & & & & Media & & & \\
\hline Desviación & & & & Desviación & & & \\
\hline GR3:P.A. & $\mathbf{L}$ & $\mathbf{A}$ & G & GR3:P.A. & $\mathbf{L}$ & A & G \\
\hline $\mathrm{N}$ & 21 & 49 & 50 & $\mathrm{~N}$ & 8 & 9 & 9 \\
\hline Rango & $12-46$ & $5-40$ & $1-13$ & Rango & $22-54$ & $10-33$ & $4-9,5$ \\
\hline Media & 27,05 & 17,89 & 6,46 & Media & 40 & 19,76 & 7,56 \\
\hline Desviación & 9,81 & 8,79 & 2,80 & Desviación & 10,72 & 7,58 & 1,65 \\
\hline GR4:N & $\mathbf{L}$ & $\mathbf{A}$ & G & GR4:N & $\mathbf{L}$ & A & G \\
\hline $\mathrm{N}$ & 10 & 10 & 10 & $\mathrm{~N}$ & 1 & 1 & 1 \\
\hline Rango & $21-54$ & $12-59$ & $11-35$ & Rango & 26 & 18 & 12 \\
\hline Media & 35,30 & 27,10 & 20,70 & Media & & & \\
\hline Desviación & 10,99 & 12,51 & 7,45 & Desviación & & & \\
\hline GR5:IT & $\mathbf{L}$ & $\mathbf{A}$ & G & GR5:IT & $\mathbf{L}$ & A & G \\
\hline $\mathrm{N}$ & 63 & 63 & 63 & $\mathrm{~N}$ & - & - & - \\
\hline Rango & $11-32$ & $4-27$ & $1,3-14$ & Rango & & & \\
\hline Media & 16 & 10,18 & 5,0 & Media & & & \\
\hline Desviación & 5,39 & 5,38 & 2,66 & Desviación & & & \\
\hline GR6:DEB & $\mathbf{L}$ & A & G & GR6:DEB & $\mathbf{L}$ & A & G \\
\hline $\mathrm{N}$ & 477 & 477 & 477 & $\mathrm{~N}$ & - & 5 & 7 \\
\hline Rango & $2-10$ & $1-10$ & $0,2-7$ & Rango & & $6-10$ & $1,5-4$ \\
\hline Media & 7,66 & 7,24 & 1,76 & Media & & $\mathbf{8 , 8 4}$ & 2,51 \\
\hline Desviación & 1,71 & 1,91 & 0,97 & Desviación & & 1,71 & 0,92 \\
\hline
\end{tabular}

Cuadro R1.10: datos métricos de la radiolarita, por grupos tecnológicos. $\mathrm{N}$ : número de elementos. L: longitud, A: anchura, G: grosor. 


\section{IV.2.1.4.2.- TALÓN}

Las dimensiones del talón (cuadro R1.11) están en correspondencia con el tamaño y grosor de los distintos tipos de soportes, siendo los talones mayores, lógicamente, los de los productos de acondicionamiento ( $\mathrm{L}=10,3 \mathrm{~A}=4,3 \mathrm{~mm}$ ) y las lascas $(\mathrm{L}=9,3 \mathrm{~A}=2,8 \mathrm{~mm})$.

\begin{tabular}{|c|c|c|c|c|c|}
\hline SIN RETOCAR & & & RETOCADAS & & \\
\hline GR1:L & $\mathbf{L}$ & $\mathbf{A}$ & GR1:L & $\mathbf{L}$ & $\mathbf{A}$ \\
\hline $\mathrm{N}$ & 152 & 198 & $\mathrm{~N}$ & 14 & 16 \\
\hline Rango & $1-34,5$ & $0,2-11$ & Rango & $5,5-20$ & $1-6$ \\
\hline Media & 9,32 & 2,83 & Media & 10,94 & 3,19 \\
\hline Desviación & 4,80 & 1,82 & Desviación & 4,77 & 1,32 \\
\hline GR1:L-H & $\mathbf{L}$ & A & GR1:L-H & $\mathbf{L}$ & A \\
\hline $\mathrm{N}$ & 15 & 16 & $\mathrm{~N}$ & 2 & 2 \\
\hline Rango & $4-14,6$ & $1,2-4,2$ & Rango & $6,8-7$ & $2-2,8$ \\
\hline Media & 8,23 & 2,42 & Media & & \\
\hline Desviación & 2,92 & 0,91 & Desviación & & \\
\hline GR2:H & $\mathbf{L}$ & $\mathbf{A}$ & GR2:H & $\mathbf{L}$ & $\mathbf{A}$ \\
\hline $\mathrm{N}$ & 7 & 7 & $\mathrm{~N}$ & 18 & 20 \\
\hline Rango & $4,7-10$ & $0,3-2$ & Rango & $2,4-15$ & $0,7-6,4$ \\
\hline Media & 7,46 & 1,1 & Media & 7,82 & 2,44 \\
\hline Desviación & 2,05 & 0,51 & Desviación & 3,0 & 1,30 \\
\hline GR2:H-FN & $\mathbf{L}$ & A & GR2:H-FN & $\mathbf{L}$ & A \\
\hline $\mathrm{N}$ & - & - & $\mathrm{N}$ & 1 & 1 \\
\hline Rango & & & Rango & 1,3 & 0,5 \\
\hline Media & & & Media & & \\
\hline Desviación & & & Desviación & & \\
\hline GR3:P.A. & $\mathbf{L}$ & A & GR3:P.A. & $\mathbf{L}$ & A \\
\hline $\mathrm{N}$ & 15 & 20 & $\mathrm{~N}$ & 7 & 7 \\
\hline Rango & 3-38 & $1,2-15$ & Rango & $3,3-19$ & $1,3-5,5$ \\
\hline Media & 10,27 & 4,27 & Media & 7,5 & 2,78 \\
\hline Desviación & 8,49 & 3,28 & Desviación & 3,27 & 1,43 \\
\hline GR6:DEB & $\mathbf{L}$ & A & GR6:DEB & $\mathbf{L}$ & A \\
\hline $\mathrm{N}$ & 96 & 135 & $\mathrm{~N}$ & - & 1 \\
\hline Rango & $1,4-10$ & $0,2-3,6$ & Rango & & 7,4 \\
\hline Media & 4,81 & 1,40 & Media & & \\
\hline Desviación & 1,97 & 0,77 & Desviación & & \\
\hline
\end{tabular}

Cuadro R1.11: datos métricos del talón de radiolarita 
Las lascas laminares tienen un talón ligeramente menor a las lascas $(\mathrm{L}=8,2$ $\mathrm{A}=2,4 \mathrm{~mm}$ ) y las hojas-hojitas tienen un talón prácticamente lineal ( $\mathrm{L}=7,5 \mathrm{~A}=1,1 \mathrm{~mm})$. Sorprende el hecho de que la anchura de los soportes laminares sea incluso inferior a la de los debris ( $\mathrm{L}=4,8 \mathrm{~A}=1,4 \mathrm{~mm}$ ), si bien el dato de las hojas-hojitas puede estar desvirtuado debido al escaso número de piezas sobre las que se ha podido tomar esta medida $(n=7)$. No obstante es interesante retener este dato a la hora de valorar el modo de talla ejecutado en la fase de producción laminar plena y en relación también con la intensidad de preparación del talón de las hojas.

De nuevo en los soportes retocados se puede observar el incremento del tamaño de estas piezas, reflejando soportes de un módulo considerablemente mayor, a excepción de los productos de acondicionamiento, cuyo talón es menor ( $\mathrm{L}=7,5 \mathrm{~A}=2,8)$. Aunque no obstante, este dato puede estar falseado por el pequeño número de elementos sobre los que se ha tomado la medida $(\mathrm{n}=7)$. Sorprenden también las dimensiones de las hojas-hojitas retocadas $(\mathrm{L}=7,8 \mathrm{~A}=2,4 \mathrm{~mm})$, cuya anchura se acercaría a las de las lascas sin retocar, y pondría en entredicho quizás la intensidad de la preparación de este tipo de soportes.

\section{IV.2.1.5.- ACCIDENTES}

En los accidentes producidos a lo largo de la talla (cuadro R1.12) predominan los provocados por la presencia de los planos de rotura natural (casi el 50\%), seguidos por los reflejados (29\%) y en porcentajes inferiores los pseudoburiles de Siret (10\%), los

Respecto a la representación de estos accidentes relativamente a los grupos tecnológicos (gráfico R1.3), en todos predomina el ocasionado por los planos naturales, excepto en los debris, donde los planos naturales están equilibrados con los reflejados. A continuación están los reflejados, menos en los productos de acondicionamiento, que el segundo accidente más frecuente son los sobrepasados. Los pseudoburiles de Siret aparecen en el grupo 1, 3 y 6, siendo anecdóticos en las hojas-hojitas. Las fracturas en lengüeta aparecen de forma muy escasa en el grupo 1, 2 y 6 . El doble bulbo aparece 
también en estos tres grupos, pero en un número muy escaso (5 ejemplos en el grupo de las lascas y 3 en el de los soportes laminares y debris).

\begin{tabular}{|l|cccccc|r|}
\hline & DB & LG & PB & RF & SP & PN & TOTAL \\
\hline GR.1 & 5 & 5 & 29 & 79 & 16 & 149 & 283 \\
GR.2 & 3 & 3 & 1 & 20 & 11 & 42 & 80 \\
GR.3 & 0 & 0 & 1 & 3 & 7 & 11 & 22 \\
GR.6 & 3 & 3 & 20 & 42 & 1 & 43 & 112 \\
\hline TOTAL & 11 & 11 & 51 & 144 & 35 & 245 & 497 \\
$\%$ & 2,21 & 2,21 & 10,26 & 28,97 & 7,04 & 49,30 & 100 \\
\hline
\end{tabular}

Cuadro R1.12: accidentes de talla según los distintos grupos tecnológicos. DB: dobre bulbo, LG: fragmento en lengüeta, PB: pseudoburil de Siret, RF: reflejado, SP: sobrepasado, PN: plano natural.

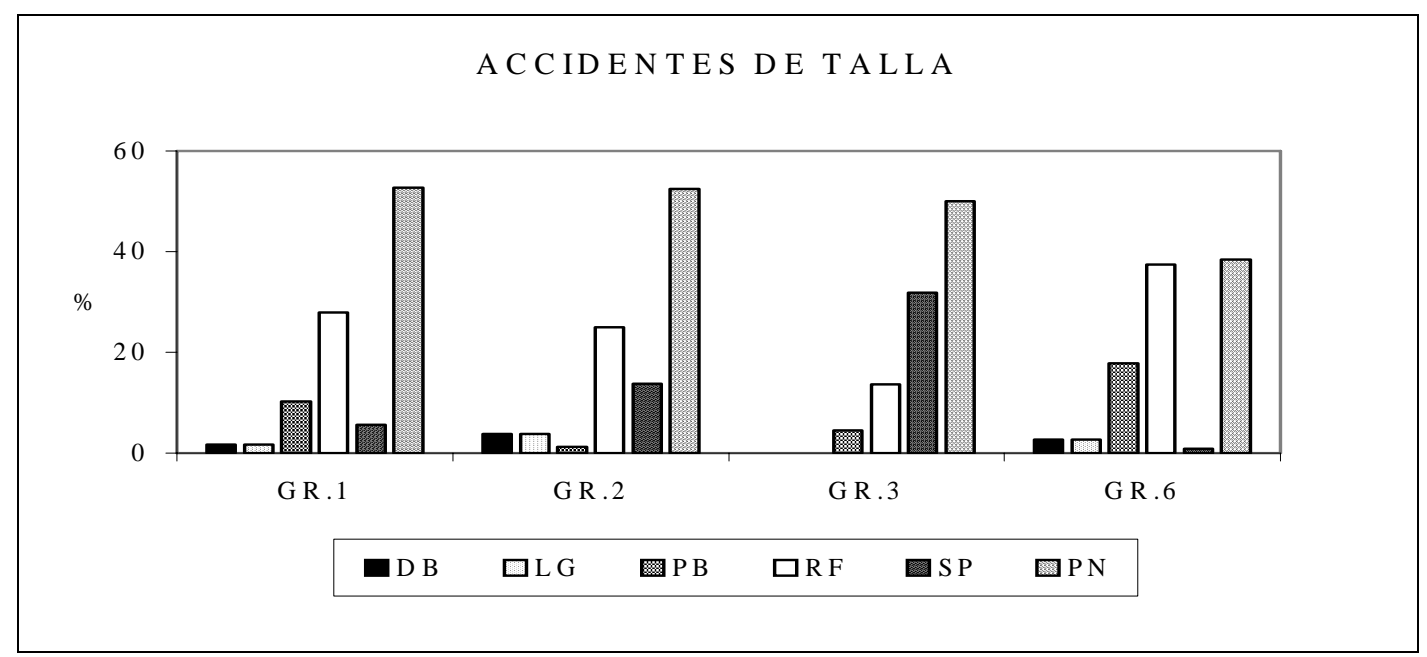

Gráfico R1.3: accidentes de talla por grupos tecnológicos. DB: dobre bulbo, LG: fragmento en lengüeta, PB: pseudoburil de Siret, RF: reflejado, SP: sobrepasado, PN: plano natural

En la radiolarita no se ven tan claramente las tendencias que se apreciaban en el sílex negro, sobre todo por el pequeño número de elementos que hay en algunos de estos accidentes, por lo que la muestra no sería demasiado fiable. De todos modos hay dos tendencias que coinciden con lo que sucedía en el sílex negro:

- $\quad$ el pseudoburil de Siret aparece casi exclusivamente en el grupo de las lascas y de los debris 
- los sobrepasados tienen una mayor representación en los soportes de la fase de producción, tanto las hojas-hojitas como los productos de acondicionamiento

Se puede esbozar de nuevo la hipótesis relativa al pseudoburil de Siret, dado que se trata de un accidente que se produce en el mismo momento de la percusión, en la zona del talón, se puede plantear la relación con un modo de talla más intenso y duro, quizás percusión directa con percutor duro o en general un modo de talla ligeramente distinto a aquel propio de la producción plena propiamente dicha. Los productos de acondicionamiento tendrían también un modo de talla más cercano al de las lascas de la primera fase, aspecto que concordaría con el módulo mayor de estos soportes.

\section{IV.2.1.6.- TIPOS DE TALÓN}

En los atributos relativos a la zona del talón (tipo de talón, preparación, ángulo) hay que tener en cuenta el elevado porcentaje de roturas de la radiolarita (cuadro R1.14), que provoca que en torno al 50\% de las piezas carezcan de la parte proximal. Como consecuencia de este elevado porcentaje de roturas en los tipos de talón predominan los soportes sin talón, sobre todo en las hojas-hojitas (cuadro R1.13). Entre las piezas con talón, predominan los lisos, suponiendo el 20\% del conjunto lítico; con un 9\% le siguen los talones facetados, a continuación están los rotos (7\%), los puntiformes y diedros (con un 5\%) y por último los corticales, que tienen una presencia meramente testimonial $(0,1 \%)$.

\begin{tabular}{|l|cccccccc|r|}
\hline & $\mathrm{C}$ & $\mathrm{D}$ & $\mathrm{F}$ & $\mathrm{L}$ & $\mathrm{O}$ & $\mathrm{P}$ & $\mathrm{R}$ & $\mathrm{S}$ & TOTAL \\
\hline GR.1 & 1 & 33 & 77 & 123 & 281 & 24 & 57 & 13 & 609 \\
GR.2 & & 16 & 22 & 61 & 185 & 14 & 6 & 3 & 307 \\
GR.3 & & 5 & 12 & 13 & 22 & 2 & 3 & 2 & 59 \\
GR.6 & 1 & 14 & 22 & 101 & 279 & 35 & 30 & 2 & 484 \\
\hline TOTAL & 2 & 68 & 133 & 298 & 767 & 75 & 96 & 20 & 1459 \\
$\%$ & 0,14 & 4,66 & 9,12 & 20,42 & 52,57 & 5,14 & 6,58 & 1,37 & 100 \\
\hline
\end{tabular}

Cuadro R1.13: tipos de talón por grupos tecnológicos. C: cortical, D: diedro, F: facetado, L: liso, O: sin talón, P: puntiforme, R: roto, S: suprimido. 
La representación de los distintos tipos de talón respecto a los distintos grupos técnicos (gráfico R1.4) sigue las tendencias esbozadas en el párrafo anterior, pero se pueden observar algunas matices, por ejemplo, dentro de los productos de acondicionamiento los talones facetados tienen tanta representación como los lisos, y los diedros son también más abundantes que en el resto de los grupos. Estos talones diedros y facetados serían el resultado de unos gestos de preparación del punto de impacto que inciden de forma acusada sobre el plano de percusión. Tal método quizás se acerque a un procedimiento del estilo de los talones "en espolón" ${ }^{24}$. Los puntiformes tienen una mayor importancia relativa en el grupo de los debris, lo cual estaría en concordancia con el pequeño tamaño de estas lasquitas. Los suprimidos no tienen una pauta demasiado marcada, no se puede realizar ninguna asociación con un grupo tecnológico concreto como para el sílex negro.

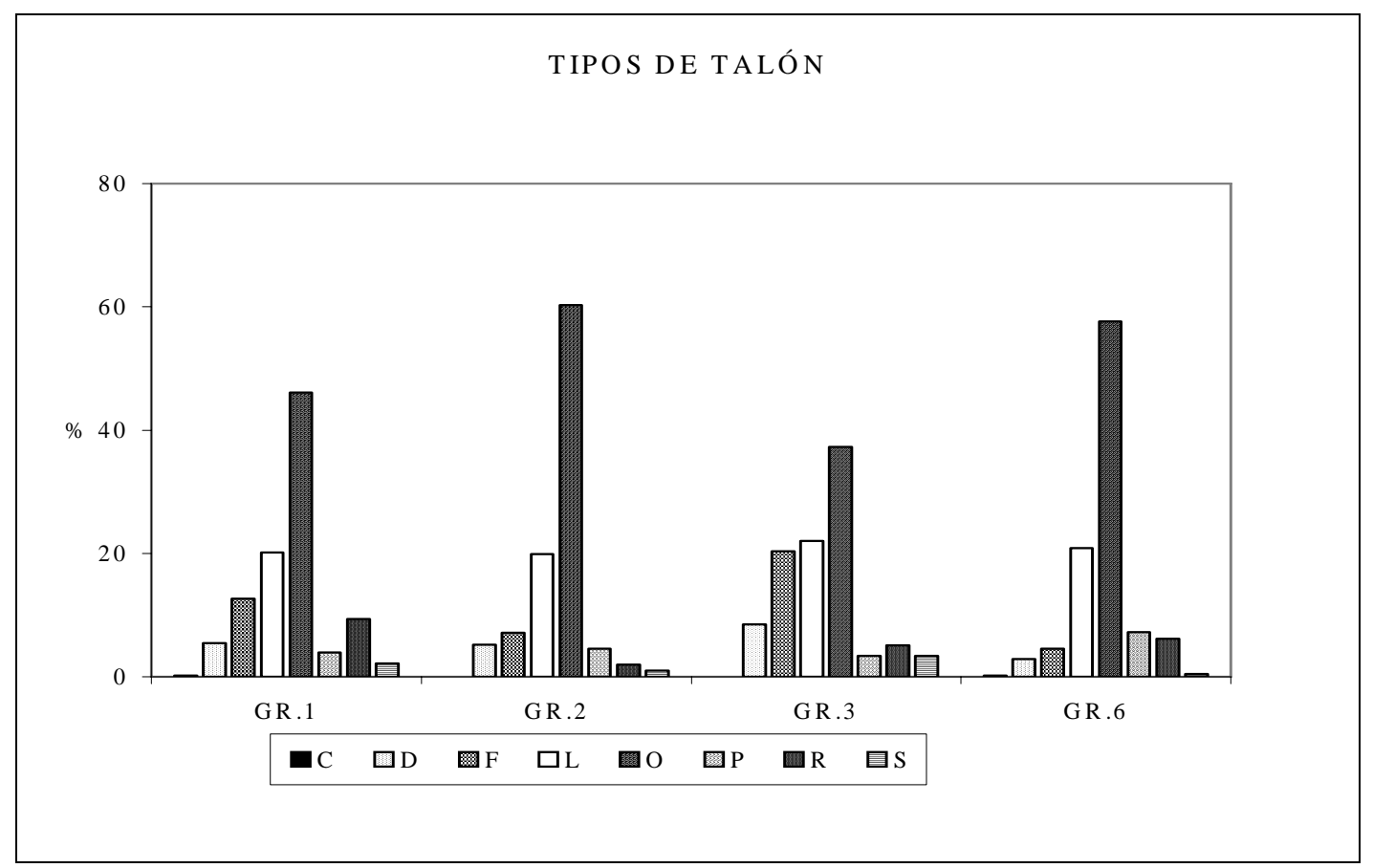

Gráfico R1.4: tipos de talón por grupos tecnológicos. C: cortical, D: diedro, F: facetado, L: liso, O: sin talón, P: puntiforme, R: roto, S: suprimido.

${ }^{24}$ Talón "en espolón" (en éperon): la preparación sobre la cornisa incide sobre el plano de percusión de forma que el punto de impacto se delimita mediante sendas concavidades a ambos lados del futuro talón. 
Respecto al talón se pueden resumir los siguientes puntos:

- El talón sólo se puede observar en un porcentaje de piezas que oscila entre el $40 \%$ para las hojas-hojitas y el $60 \%$ para los productos de acondicionamiento

- De las piezas con talón, predomina el liso, con un 20\%; a continuación, bajando hasta el 9\%, se situarían los facetados

- En los productos de acondicionamiento hay un porcentaje relativo elevado de facetados y diedros, indicando un posible procedimiento de preparación del punto de impacto sobre el plano de percusión que podría estar en la línea de los "talones en espolón"

- Los puntiformes tienen una mayor importancia relativa en los debris

\section{IV.2.1.7.- PREPARACIÓN DEL PUNTO DE IMPACTO}

Para valorar la preparación del punto de impacto de las extracciones hay que tener en cuenta el número de piezas que tienen restos de preparación en función de aquellos soportes sobre los que se puede observar dicho atributo, es decir, aquellos que tienen talón. En el cuadro R1.14 se muestra el porcentaje de preparaciones relativamente a los soportes con talón, y en él se ve claramente cómo son los soportes laminares los que tienen una mayor preparación del punto de impacto (un 64\%), a continuación estaría el grupo 1, con un 46\%, y por último los debris y productos de acondicionamiento (los cuales se prepararan en un tercio de los casos).

\begin{tabular}{|c|c|cc|cc|}
\hline & \multirow{2}{*}{ TOTAL } & \multicolumn{2}{|c|}{ PIEZAS CON TALÓN } & \multicolumn{2}{c|}{ PIEZAS PREPARADAS } \\
\cline { 3 - 6 } & & $\mathrm{N}$ & $\%$ & $\mathrm{~N}$ & $\%$ \\
\hline GR-1 & 609 & 323 & 53,0 & 148 & 45,8 \\
GR-2 & 307 & 125 & 40,7 & 80 & 64,0 \\
GR-3 & 59 & 36 & 61,0 & 11 & 30,6 \\
GR-6 & 484 & 218 & 45,0 & 68 & 31,2 \\
\hline & 1459 & 702 & 48,1 & 307 & 43,7 \\
\hline
\end{tabular}

Cuadro R1.14: piezas con talón y preparación relativa dentro de los distintos grupos tecnológicos 
En cuanto al tipo de preparación ejecutada, predomina el retoque (con un 43\%), seguido por el esquirlado (con un 27\%), la abrasión (17\%) y el facetado (13\%). La abrasión es más frecuente en los soportes del grupo 2, 3 y 6 que en el 1 (gráfico R1.15).

\begin{tabular}{|l|cccc|cc|}
\hline & \multirow{2}{*}{ GR-1 } & \multirow{2}{*}{ GR-2 } & \multirow{2}{*}{ GR-3 } & \multirow{2}{*}{ GR-6 } & \multicolumn{2}{|c|}{ TOTAL } \\
\cline { 6 - 7 } & & & & & $\mathrm{N}$ & $\%$ \\
\hline Facetado & 22 & 9 & 2 & 5 & 38 & 12,6 \\
Abrasión & 17 & 19 & 3 & 13 & 52 & 17,2 \\
Esquirlado & 39 & 22 & 2 & 18 & 81 & 26,8 \\
Retoque & 67 & 28 & 4 & 32 & 131 & 43,4 \\
\hline & 145 & 78 & 11 & 68 & 302 & 100 \\
\hline
\end{tabular}

Cuadro R1.15: tipos de preparación según los grupos tecnológicos.

Respecto al modo como afecta la preparación sobre los distintos tipos de talón (Cuadro R1.16) se cumple el porcentaje genérico en torno a la mitad de las piezas preparadas, exceptuando aquellos tipos de talón que no se pueden “leer” adecuadamente (es decir los rotos o suprimidos). Los talones más preparados son los facetados (57\%), seguidos por los puntiformes (49\%) y los lisos (48\%) y, por último, los diedros (44\%). El elevado porcentaje de los corticales no es significativo porque sólo hay dos piezas.

\begin{tabular}{|l|cccccccc|}
\hline & $\mathrm{C}$ & $\mathrm{D}$ & $\mathrm{F}$ & $\mathrm{L}$ & $\mathrm{P}$ & $\mathrm{R}$ & $\mathrm{S}$ & $\mathrm{O}$ \\
\hline PIEZAS CON TALÓN & 2 & 68 & 133 & 298 & 75 & 96 & 20 & 767 \\
\hline PIEZAS PREPARADAS & 1 & 30 & 76 & 142 & 37 & 16 & 3 & 2 \\
$\%$ & 50,0 & 44,1 & 57,1 & 47,7 & 49,3 & 16,7 & 15,0 & 0,3 \\
\hline
\end{tabular}

Cuadro R1.16: porcentaje de preparación en los distintos tipos de talón disponibles. C: cortical, D: diedro, F: facetado, L: liso, O: sin talón, P: puntiforme, R: roto, S: suprimido.

\begin{tabular}{|l|cccccccc|}
\hline & $\mathrm{C}$ & $\mathrm{D}$ & $\mathrm{F}$ & $\mathrm{L}$ & $\mathrm{P}$ & $\mathrm{R}$ & $\mathrm{S}$ & $\mathrm{O}$ \\
\hline Facetado & & 3 & 29 & 6 & & & & \\
Abrasión & & 5 & 7 & 31 & 8 & 1 & & 1 \\
Esquirlado & & 7 & 11 & 42 & 10 & 11 & 2 & \\
Retoque & 1 & 15 & 29 & 63 & 19 & 4 & 1 & 1 \\
\hline TOTAL & 1 & 30 & 76 & 142 & 37 & 16 & 3 & 2 \\
$\%$ & 0,3 & 9,8 & 24,8 & 46,3 & 12,1 & 5,2 & 1,0 & 0,7 \\
\hline
\end{tabular}

Cuadro R1.17: tipos de preparación sobre los distintos tipos de talón. C: cortical, D: diedro, F: facetado, L: liso, O: sin talón, P: puntiforme, R: roto, S: suprimido. 
En los distintos tipos de talones también se cumple el orden de predominio de mayor a menor frecuencia (cuadro R1.17): retoque-esquirlado-abrasión, excepto para los facetados en los que predomina la preparación sobre el plano de percusión, y sin tomar en consideración los rotos y suprimidos por su presencia meramente anecdótica.

En el cuadro R1.18 se presentan los tipos de talón y su correspondiente preparación, separando por grupos tecnológicos. En los grupos 1, 2 y 6 se pueden apreciar una misma tendencia, el mayor porcentaje se sitúa en los talones lisos preparados por retoque. Tan solo los productos de acondicionamiento se separan de esta tendencia genérica en la radiolarita. De hecho el grupo 3 tiene una representación un tanto anómala, que puede ser debida a que el número de piezas con las que contamos es muy escaso (tan solo hay 11 talones preparados en los productos de acondicionamiento). Por tanto lo más razonable es considerar que el cuadro correspondiente al grupo 3 no es representativo.

\begin{tabular}{|l|cccccccc|}
\hline TEC-1 & $\mathrm{C}$ & $\mathrm{D}$ & $\mathrm{F}$ & $\mathrm{L}$ & $\mathrm{P}$ & $\mathrm{R}$ & $\mathrm{S}$ & $\mathrm{O}$ \\
\hline Facetado & & 1,4 & 12,4 & 1,4 & & & & \\
Abrasión & & 2,8 & 1,4 & 6,2 & 0,7 & 0,7 & & \\
Esquirlado & & 2,1 & 4,1 & 13,1 & 2,8 & 4,8 & 0,7 & \\
Retoque & 0,7 & 4,8 & 13,1 & $\mathbf{2 0 , 7}$ & 5,5 & 1,4 & 0,7 & 0,7 \\
\hline
\end{tabular}

\begin{tabular}{|l|cccccccc|}
\hline TEC-2 & $\mathrm{C}$ & $\mathrm{D}$ & $\mathrm{F}$ & $\mathrm{L}$ & $\mathrm{P}$ & $\mathrm{R}$ & $\mathrm{S}$ & $\mathrm{O}$ \\
\hline Facetado & & & 7,7 & 3,8 & & & & \\
Abrasión & & 1,3 & 5,1 & 14,1 & 3,8 & & & 1,3 \\
Esquirlado & & 5,1 & 2,6 & 14,1 & 5,1 & 1,3 & 1,3 & \\
Retoque & & 6,4 & 3,8 & $\mathbf{1 7 , 9}$ & 5,1 & 2,6 & & \\
\hline
\end{tabular}

\begin{tabular}{|l|cccccccc|}
\hline TEC-3 & C & D & F & L & P & R & S & O \\
\hline Facetado & & & 18,2 & & & & & \\
Abrasión & & & & 27 & & & & \\
Esquirlado & & & & 9,1 & & 9,1 & & \\
Retoque & & 9,1 & $\mathbf{2 7 , 3}$ & & & & & \\
\hline
\end{tabular}

\begin{tabular}{|l|cccccccc|}
\hline TEC-6 & C & D & F & L & P & R & S & O \\
\hline Facetado & & 1,5 & 4,4 & 1,5 & & & & \\
Abrasión & & & 1,5 & 11,8 & 5,9 & & & \\
Esquirlado & & & 4,4 & 16,2 & 2,9 & 2,9 & & \\
Retoque & & 2,9 & 5,9 & $\mathbf{2 7 , 9}$ & 10,3 & & & \\
\hline
\end{tabular}

Cuadro R1.18: porcentaje de tipo de preparación en los distintos tipos de talón y separando los grupos tecnológicos. C: cortical, D: diedro, F: facetado, L: liso, O: sin talón, P: puntiforme, R: roto, S: suprimido. 
Lo que sí es reseñable es el hecho de constatarse una misma tendencia en los tipos de talones y su preparación para el conjunto de los distintos soportes de radiolarita. A partir de este aspecto se podría afirmar que hay un tratamiento bastante homogéneo en los distintos esquemas que se han desarrollado sobre esta materia prima.

\section{IV.2.1.8.- ÁNGULO DE PERCUSIÓN}

En los ángulos del talón no hay tantas combinaciones como en el sílex negro (cuadro R1.19). Respecto a la combinación de los ángulos según los grupos tecnológicos, en los grupos 1 y 2 predominan un frente de percusión abierto (Eb/Ea), mientras que en el 6 es ligeramente más abundante un frente más cerrado (Fa/Db). El grupo 3 tiene una representación un tanto anómala y distinta al resto del conjunto, de nuevo el motivo puede ser el escaso número de piezas con que contamos en este grupo $(n=26)$.

Si nos fijamos más específicamente en el ángulo 2 (ángulo de la cornisa), cada uno de los grupos difiere ligeramente del otro. En el grupo 2 y en el 3 predomina un ángulo abierto $\left(\mathrm{Ea}=80-90^{\circ}\right)$, en el grupo 6 por su parte es más abundante un ángulo de tipo medio $\left(\mathrm{Db}=70-80^{\circ}\right)$ y en el grupo 1 estas dos categorías de ángulos están equilibradas. Hay por tanto en radiolarita un predominio general hacia los frentes de talla abiertos, cercanos a los $90^{\circ}$, el único grupo donde aparece una tendencia hacia frentes más cerrados es en los debris, circunstancia que también sucedía en el sílex negro. 

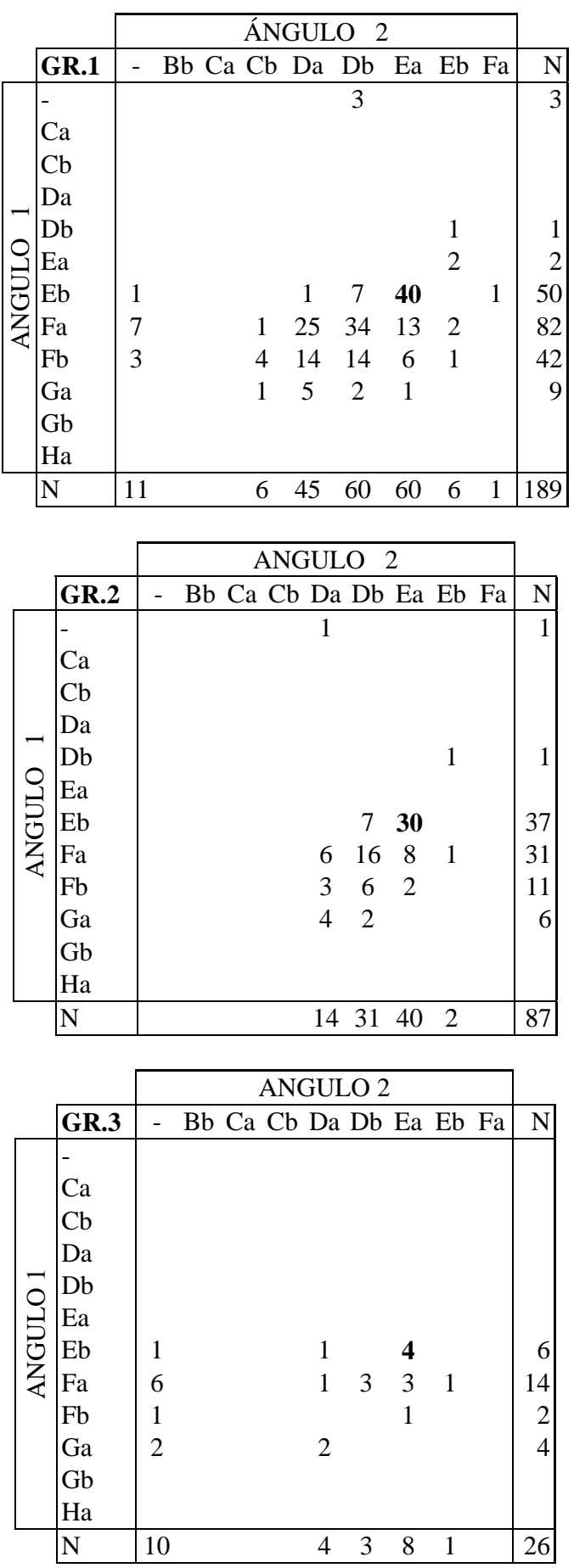

Cuadro R1.19: ángulos de percusión según los distintos grupos tecnológicos en los cuatro primeros cuadros y en total en el último cuadro. Angulo 1: ángulo interno (entre talón y el bulbo). Angulo 2: ángulo externo o de la cornisa (entre talón y la cara superior). $\mathrm{Bb}=30-40^{\circ}$, $\mathrm{Ca}=40-50^{\circ}, \mathrm{Cb}=50-60^{\circ}, \mathrm{Da}=60-70^{\circ}, \mathrm{Db}=70-80^{\circ}, \mathrm{Ea}=80-90^{\circ}, \mathrm{Eb}=90-100^{\circ}, \mathrm{Fa}=100-110^{\circ}$, $\mathrm{Fb}=110-120^{\circ}, \mathrm{Ga}=120-130^{\circ}, \mathrm{Gb}=130-140^{\circ}, \mathrm{Ha}=140-150^{\circ}$. 

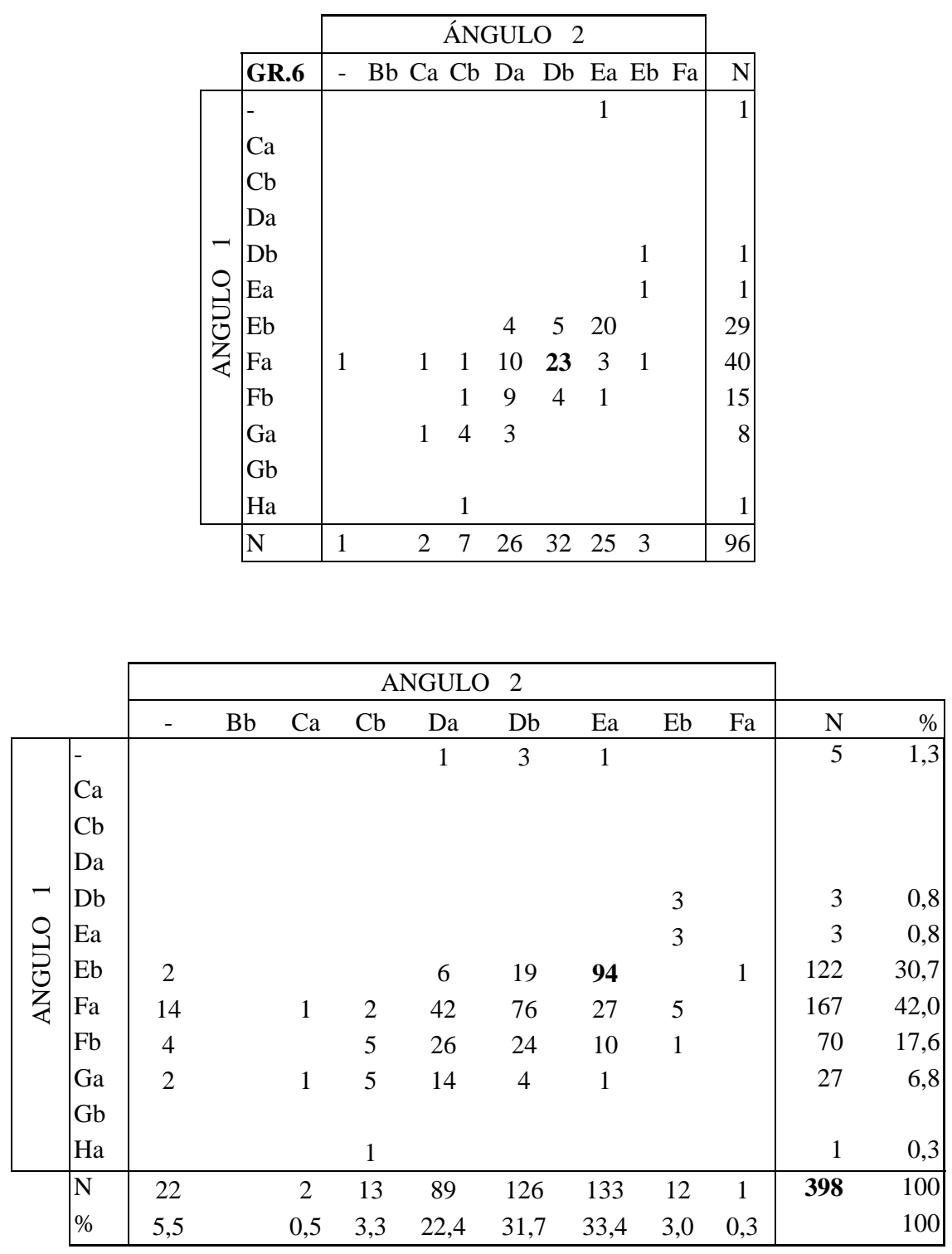

Cuadro R1.19 (continuación): ángulos de percusión según los distintos grupos tecnológicos en los cuatro primeros cuadros y en total en el último cuadro. Angulo 1 es el ángulo interno (entre talón y el bulbo). Angulo 2 es el ángulo externo o la cornisa (entre talón y la cara superior). $\mathrm{Bb}=30-40^{\circ}, \mathrm{Ca}=40-50^{\circ}, \mathrm{Cb}=50-60^{\circ}, \mathrm{Da}=60-70^{\circ}, \mathrm{Db}=70-80^{\circ}, \mathrm{Ea}=80-90^{\circ}, \mathrm{Eb}=90-100^{\circ}, \mathrm{Fa}=100-$ $110^{\circ}, \mathrm{Fb}=110-120^{\circ}, \mathrm{Ga}=120-130^{\circ}, \mathrm{Gb}=130-140^{\circ}, \mathrm{Ha}=140-150^{\circ}$. 


\section{IV.2.1.9.- AlteracioneS}

La radiolarita no está afectada por demasiadas alteraciones, tan solo se constatan algunas piezas quemadas y una con rodamiento.

\begin{tabular}{|l|lllll|r|}
\hline & DP & DS & PA & Q & R & TOTAL \\
\hline $\mathrm{N}$ & & & & 17 & 1 & 18 \\
$\%$ & & & & & & \\
\hline
\end{tabular}

Cuadro R1.20: alteraciones presentes en el conjunto. DP: doble pátina, DS: desilificación, PA:, Q: quemado, R: redondeamiento.

\section{IV.2.1.10.- MODO DE TALLA}

En el modo de talla diagnosticado sobre el material, son muy pocas las piezas sobre las que se ha consignado este atributo. A pesar de ello se constata la tendencia general a una aparición de la percusión directa con percutor duro en los soportes propios del grupo tecnológico 1; mientras que huellas de percusión blanda la encontramos de forma más frecuente en los soportes laminares.

\begin{tabular}{|l|ccc|r|}
\hline & PDD & PDDB & PDB & TOTAL \\
\hline GR.1 & 3 & & 2 & 5 \\
GR.2 & & & 4 & 4 \\
GR.3 & & & 1 & 1 \\
GR.6 & & & 1 & 1 \\
\hline
\end{tabular}

Cuadro R1.21: modo de talla por grupos tecnológicos. . PDD: percusión directa con percutor duro; PDDB: percusión directa con percutor de piedra blando; PDB: percusión directa con percutor blando. 


\section{IV.2.2.- NÚCLEOS}

Hay 10 núcleos en radiolarita: dos prismáticos unipolares de hojas, otros dos prismáticos de hojitas (uno unipolar y el otro unipolar alterno, con dos planos de percusión opuesto pero sobre otra superficie), dos núcleos de pequeño tamaño con una explotación de hojitas sobre un borde estrecho, otros dos restos de núcleo y por último un núcleo con una explotación muy somera de tipo unipolar.

\section{IV.2.2.1.- ATRIBUTOS BÁsICos}

En el cuadro R1.22 se han resumido las características básicas de los núcleos de radiolarita. Se han ordenado a partir de los tipos de núcleo diferenciados, los cuales reúnen aquéllos con esquemas técnicos similares.

\section{Tipos de núcleos}

P1 (de hojas): dos núcleos prismáticos unipolares, de hojas, con unas dimensiones aproximadas de $50 \mathrm{~mm}$ de longitud y 30 de anchura ( ${ }^{\circ} 1542$ y 967). El primero tiene una explotación envolvente prácticamente total de todo el contorno, obteniendo hojas posiblemente de una calidad bastante buena.

P1 (de hojitas): dos núcleos prismáticos también, pero de hojitas, con una longitud menor (30 mm) y anchura igual a los anteriores (30 mm). Uno de ellos es unipolar con negativos de hojitas de buena calidad ( $\left.n^{\circ} 1544\right)$. El segundo $\left(n^{\circ} 964\right)$ tiene una explotación unipolar predominante, pero las extracciones son lascas además de hojitas, de una calidad mediocre en este estado de abandono. Se recurre entonces a un segundo plano de percusión opuesto pero para explotar, no la superficie de extracciones anterior, sino la superficie opuesta a partir del flanco izquierdo. Sería por tanto un núcleo bipolar alterno (P2A), pero no se caracterizaría el tipo de explotación como bipolar estricta.

El siguiente grupo (P2O) estaría formado por dos núcleos ( ${ }^{\circ} 1543$ y 966) de pequeño tamaño (21-27 mm de longitud por 18-22 de anchura respecto a la cara mayor), 
de morfología cuadrangular y escaso grosor $(12 \mathrm{~mm})$. La superficie más estrecha del núcleo es la superficie de extracciones principal, para la obtención de hojitas de forma bipolar, si bien sobre las caras mayores hay también extracciones en sentido axial.

- El primer núcleo $\left(n^{\circ}\right.$ 1543) es de tamaño sumamente reducido (es un pequeño bloque cuadrado en vista frontal, de $22 \mathrm{~mm}$ de lado por 12 de grosor) y ha sido explotado hasta un estado de agotamiento que resulta casi inverosímil, con una explotación de los dos bordes estrechos en sentido bipolar y la base del núcleo perpendicular al plano de percusión. Éste ha llegado a unas dimensiones mínimas como consecuencia de la intensidad de extracciones y gestos de preparación en abrasión a que ha sido sometida la cornisa.

- El otro núcleo ( $n^{\circ}$ 966) tiene también una explotación del borde estrecho de forma bipolar, pero el plano preferente es el superior. A diferencia del anterior, la base de este núcleo es una arista ortogonal a la superficie de extracciones estrecha. Dicha arista tiene un esquirlado sobre una de las superficies (el flanco derecho del núcleo), por lo que este núcleo puede haber sido utilizado como una pieza astillada. De hecho el otro núcleo que podemos incluir en este grupo, y que en principio se había clasificado como un resto de núcleo ( $n^{\circ}$ 1020), tiene también una posible superficie de extracciones sobre una cara estrecha, siendo la base del núcleo también ortogonal a ella. Sobre dicha arista hay un esquirlado bifacial, y esta pieza se ha incluido entre las retocadas. En consecuencia, cabe la posibilidad de que estos dos núcleos fueran utilizados como piezas astilladas, para lo cual se habrían seleccionado estas piezas de morfología cuadrangular, con el plano de percusión opuesto a una arista que es la que recibe el efecto de esquirlado. Incluso las extracciones bipolares, en forma de hojitas de uno de los bordes estrechos puede ser consecuencia también de la acción ejecutada con este tipo de piezas. 
Por último estarían dos restos de núcleo y un núcleo que se ha clasificado como unipolar.

- El núcleo $n^{0} 1545$ tiene la superficie de extracciones estropeada como consecuencia de la presencia de un plano de diaclasado interno, que provoca una gran rotura sobre la cara anterior. Es destacable en este núcleo la conformación de su volumen, con una cresta posterior que continúa hacia una de las aristas infero-laterales y también hacia la cara superior, ayudando a situar el plano de percusión; y otra sobre el flanco izquierdo. De nuevo (como en el núcleo $n^{\circ}$ 1543) sorprende esta intensidad en la preparación de un volumen tan pequeño ( $3 \mathrm{~cm}$ de longitud por 2 de anchura y otros 2 de grosor).

- El núcleo $n^{\circ} 965$ tiene una conformación volumétrica que recuerda bastante al núcleo prismático unipolar de hojitas y de hecho puede que pertenezca a este esquema operativo, ya que se trata de un núcleo con una conformación del volumen de tendencia prismática, con un plano de percusión oblicuo opuesto a una base que en este caso también es oblicua, con los flancos delimitados por planos naturales. La superficie de extracciones iniciaría su explotación a partir del flanco izquierdo, donde hay restos de extracciones en sentido bipolar, pero el plano de percusión superior sería el preferente. En un momento dado se procede a actuar sobre el flanco derecho con una extracción axial y ortogonal a la superficie de extracciones. Se trataría de un flanco de núcleo que reavivaría ese lateral, facilitando un cintrado correcto a la superficie de extracciones. Pero tal extracción resulta demasiado intensa, a juzgar por la acusada concavidad del contrabulbo, posiblemente el modo de talla aplicado fuera percutor duro, con la creación de una concavidad en el flanco y en la superficie adyacente que impide la continuación de la explotación del núcleo.

El que se ha denominado como núcleo unipolar (UP) (n 1059) es un núcleo grande (aproximadamente $4 \mathrm{~cm}$ de longitud, 6 de anchura y 4 de grosor), se trata de una de las piezas mayores del conjunto, y su eje mayor corresponde a una superficie de sedimentación de la radiolarita, la cual se ha utilizado como plano de percusión. El 
flanco derecho es también una superficie natural (un plano de diaclasado interno en este caso), siendo en general muy abundantes tales planos en este núcleo y, en consecuencia, las dificultades para su talla. Al mismo tiempo se constata de nuevo la flexibilidad del tallador para solucionar las dificultades de este bloque, ya que se ha adoptado un esquema de talla bastante expeditivo. A partir del plano de percusión se abre la superficie de extracciones desde una arista lateral natural, a partir de la cual se explota una superficie rectangular ancha. Se producen una serie de extracciones de lascas (son visibles 3 negativos) grandes y posiblemente bastante gruesas a juzgar por el perfil oblicuo y cóncavo de la carena. Se trataría posiblemente de una solución rápida para aprovechar un bloque fragmentado, con múltiples planos naturales, para obtener una serie de lascas grandes.

\section{Dimensiones}

La mayoría se encuentran entre los 2-3 cm de anchura, exceptuando el "núcleo unipolar”, que llega casi a los $6 \mathrm{~cm}$. Este hecho vendría confirmar el carácter expeditivo del esquema adoptado sobre este núcleo, ya que se separa totalmente de la pauta más global del resto. Parece que en este núcleo su orientación misma difiere de la tónica general, ya que la máxima longitud se ha tomado para orientar la anchura de la superficie de extracciones en lugar de su longitud.

Los núcleos laminares mejor conformados, es decir, los prismáticos de los dos primeros grupos se sitúan todos en una anchura que ronda los $3 \mathrm{~cm}$, la única diferencia entre estos 4 núcleos es su longitud, que viene a determinar también el carácter laminar o microlaminar de sus extracciones. Los núcleos de hojas tienen una longitud ligeramente superior a $5 \mathrm{~cm}$, mientras los de hojitas rondan $\operatorname{los} 3 \mathrm{~cm}$.

Los tres núcleos que tienen una explotación de un borde estrecho tienen unas dimensiones reducidas (2,5 cm de longitud por 2 de anchura), con morfología cuadrangular. No obstante ya se ha indicado que este grupo tiene unas características peculiares, con un núcleo sumamente agotado y otros dos con restos de esquirlado.

Por último, en los dos restos de núcleo, el que corresponde posiblemente con un esquema de hojitas tiene unas dimensiones similares a los núcleos prismáticos de 
hojitas, por lo que se vendría a confirmar esta adscripción. En cuanto al núcleo con preparación de una cresta posterior, encaja más con los núcleos “anómalos” de pequeño tamaño, por lo que viene también a reforzar este carácter peculiar de todos estos núcleos.

\section{Córtex}

La presencia de córtex no es muy abundante y puede que se trate de planos naturales de morfología irregular.

\section{Descripción de la superficie de extracciones}

En la situación de la superficie de extracciones, destaca en la radiolarita la tendencia a expandirse hacia los laterales de forma semi-envolvente e incluso envolvente, afectando a todo el contorno del núcleo. Este avance de la talla en sentido envolvente ocurre sobre todo en los núcleos prismáticos laminares, y parece ser que sucede, no tanto de una manera continua sino mediante tablas yuxtapuestas, a través de series de extracciones consecutivas en sentido frontal.

\section{Preparación en otras partes de los núcleos}

En la preparación del núcleo se presta bastante cuidado en la base del mismo y, a veces, también en la superficie posterior. Casi todos los núcleos prismáticos tienen la base paralela al plano de percusión, conformada normalmente desde uno de los laterales o la cara posterior. Esta preparación puede estar relacionada, como se ha indicado para el sílex negro, con un control de la carena de la superficie de extracciones.

\section{Soportes extraídos}

En la gran mayoría de los núcleos los últimos productos extraídos son laminares, por lo que en la radiolarita se puede afirmar la existencia de un objetivo de talla claramente especializado en la producción de hojas y hojitas. Tan solo el núcleo que se ha clasificado como “unipolar” hay una extracción clara de lascas grandes, pero hay que recordar el carácter expeditivo de este ejemplo y un tanto discordante con el resto de los núcleos. 


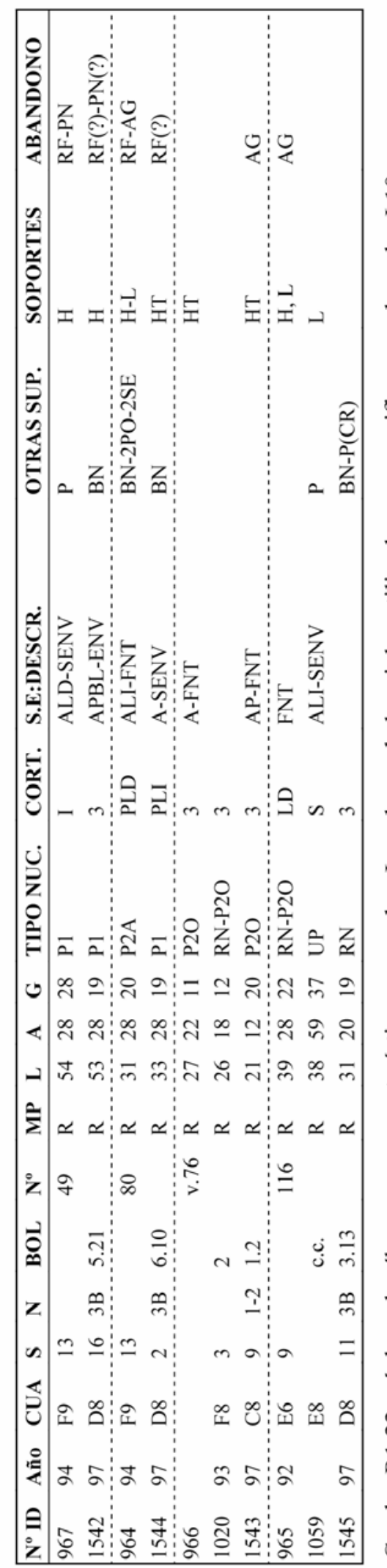

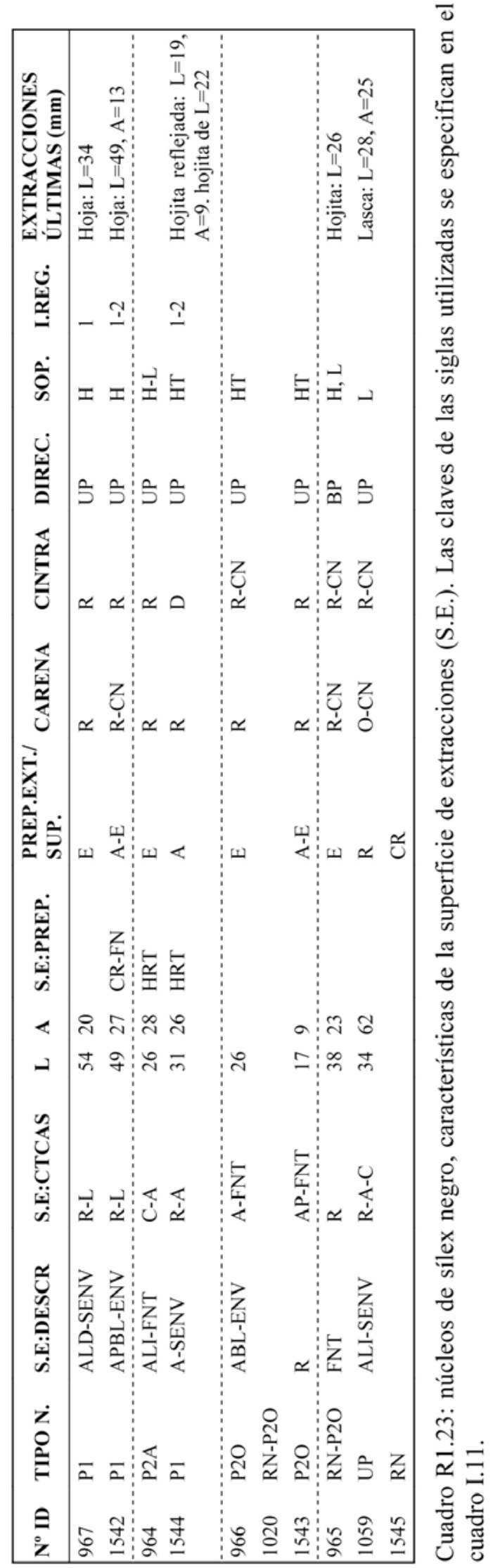




\section{Causa del abandono}

Los motivos del abandono de los núcleos son siempre un poco difíciles de valorar. En la radiolarita hay una serie de ellos que han llegado a un estado de agotamiento claro. Incluso dicho agotamiento resulta hasta "excesivo" en el caso del núcleo $\mathrm{n}^{\circ} 1543$, como se ha indicado. En los otros núcleos ha habido accidentes reflejados, bastante frecuentes; y también son muy abundantes la presencia de los planos de rotura internos que dificultan el curso de la talla.

\section{IV.2.2.2.- CARACTERÍSTICAS DE LA SUPERFICIE DE EXTRACCIONES}

En este apartado se analizará más específicamente las características de la superficie de extracciones esquematizadas en el cuadro R1.23.

\section{Morfología de la superficie de extracciones}

Casi todos los núcleos tienen una superficie de extracciones de forma rectangular alargada, los prismáticos de hojas serían más largos, los de hojitas más cortos y anchos. En radiolarita no hay ningún núcleo prismático que tenga una morfología de esta superficie tendente a triangular como sucedía en el sílex negro.

\section{Medidas}

Las medidas de la superficie de extracciones se ubican, como en el caso de las medidas de los núcleos en general, en torno a los $3 \mathrm{~cm}$ de anchura en los núcleos prismáticos. La longitud de los núcleos de hojitas está aproximadamente en los $3 \mathrm{~cm}$, y de las hojas en los 5 . De esta tendencia general se separa uno de los núcleos pequeños $\left(n^{\circ} 1543\right)$ y el “unipolar” de lascas ( $\left.{ }^{\circ} 1059\right)$.

\section{Preparación de la superficie de extracciones}

Para la preparación/reparación de la superficie de extracciones, en los núcleos prismáticos aparecen los procedimientos típicos de un esquema prismático unipolar. En el primer núcleo hay una cresta sobre uno de los laterales, que hace la función de 
enderezar la carena y matizar la arista sobre la que se realiza para servir de guía de esa extracción. Hay también un negativo, del que se ha encontrado el remontage de su lasca correspondiente, que se puede considerar como un flanco de núcleo en sentido longitudinal, se trata de una lasca sobre la cara anterior del núcleo, que porta los negativos de las extracciones laminares.

En los núcleos prismáticos de hojitas se constata el empleo de "hojitas de recintrado" u "hojas con flanco", es decir piezas que abordan los laterales del núcleo con el fin de posibilitar un avance y mantenimiento del ritmo de talla.

\section{Preparación de las extracciones}

En casi todos los núcleos de radiolarita hay restos de una preparación del frente de percusión, en forma de esquirlado o abrasión de la cornisa. Este cuidado de dicho frente está presente en todos los núcleos prismáticos.

\section{Carena}

La carena de la práctica totalidad de los núcleos de radiolarita es recta, la única excepción es el núcleo unipolar de lascas, con una carena muy oblicua y cóncava.

\section{Cintra}

$\mathrm{Al}$ igual que la carena, la curvatura transversal de los núcleos es tendente a recta, reflejando por tanto la estructura prismática de los núcleos, con el encuadre de la superficie de extracciones entre los flancos laterales.

\section{Dirección de las extracciones}

La dirección del débitage es unipolar en los núcleos prismáticos, y sólo en los núcleos pequeños hay una dirección bipolar. 


\section{Indice de regularidad}

El índice de regularidad se ha establecido solo para los núcleos prismáticos, y en general tiene negativos de extracciones de una regularidad aceptable e incluso bastante buena.

\section{Últimas extracciones}

Las últimas extracciones están acordes con la dimensión de los núcleos. Los núcleos de hojas tienen negativos de soportes que alcanza los 49 y 34 mm de longitud; mientras que en los de hojitas hay un ejemplo de $19 \mathrm{~mm}$ de longitud.

\section{IV.2.2.3.- CARACTERÍSTICAS DEL PLANO DE PERCUSIÓN}

En el cuadro R1.24 se esquematizan las características de los planos de percusión.

\section{Las características genéricas}

En este atributo hay más variedad que en los anteriores, pero predomina el plano liso oblicuo en la mayoría. En los núcleos prismáticos solo habría la excepción del núcleo con débitage envolvente, que tiene el plano más recto.

\section{Preparación del plano de percusión}

En los núcleos prismáticos, a la hora de arreglar el plano de percusión, hay un predominio del procedimiento de la tableta de núcleo, con reavivado total del frente de percusión, aunque también se recurre a las semitabletas. En el resto de los núcleos hay más abundancia de las lasquitas de reavivado.

\section{Preparación de las extracciones}

Sobre el plano de percusión quedan también restos de la preparación del frente de percusión, en forma de abrasión y esquirlado en los núcleos prismáticos y en retoque en los restos de núcleo. Habría por tanto una preparación de las extracciones bastante 
intensa, lo suficiente como para que queden restos tanto en torno a la cornisa como en el plano de percusión.

\section{Cornisa}

La morfología de la cornisa no se ha tomado en todos los casos y no sigue una pauta demasiado fija. Teniendo en cuenta la preparación del frente de percusión, lo más coherente es una cornisa continua, aunque si el núcleo se ha abandonado después de realizar alguna extracción, quedaría con una cornisa más denticulada.

\begin{tabular}{|c|c|c|c|c|c|c|}
\hline $\mathbf{N}^{0}$ ID & $\begin{array}{l}\text { TIPO } \\
\text { Nuc. }\end{array}$ & $\begin{array}{l}\text { PLANO: } \\
\text { CTCAS }\end{array}$ & $\begin{array}{l}\text { PLANO: } \\
\text { PREP. }\end{array}$ & PREP. EXT. & CORNISA ANGULO & $\begin{array}{l}\text { MODO } \\
\text { TALLA }\end{array}$ \\
\hline 967 & P1 & $\mathrm{L}-\mathrm{O}$ & $\mathrm{TN}$ & $\mathrm{E}$ & CNT & \\
\hline 1542 & P1 & L-R & TN-SN & A & DT & \\
\hline 964 & P2A & $\mathrm{D}-\mathrm{O}$ & $\mathrm{SN}$ & & CNT & \\
\hline 1544 & P1 & $\mathrm{L}-\mathrm{O}$ & TN & $E$ & & \\
\hline 966 & $\mathrm{P} 2 \mathrm{O}$ & F-R & LR & $\mathrm{E}$ & & \\
\hline 1020 & $\mathrm{RN}-\mathrm{P} 2 \mathrm{O}$ & L-R & & & & \\
\hline 1543 & $\mathrm{P} 2 \mathrm{O}$ & $\mathrm{L}-\mathrm{O}$ & & & & \\
\hline 965 & $\mathrm{RN}-\mathrm{P} 2 \mathrm{O}$ & $\mathrm{F}-\mathrm{O}$ & TN-LR & $\mathrm{R}-\mathrm{A}$ & CNT & \\
\hline 1059 & UP & PN-R & & $\mathrm{R}$ & DT & PDD \\
\hline 1545 & $\mathrm{RN}$ & F-O & LR & & & \\
\hline
\end{tabular}

Cuadro R1.24: características de los planos de percusión de núcleos de radiolarita. Las claves de las siglas utilizadas se especifican en el cuadro 12. 


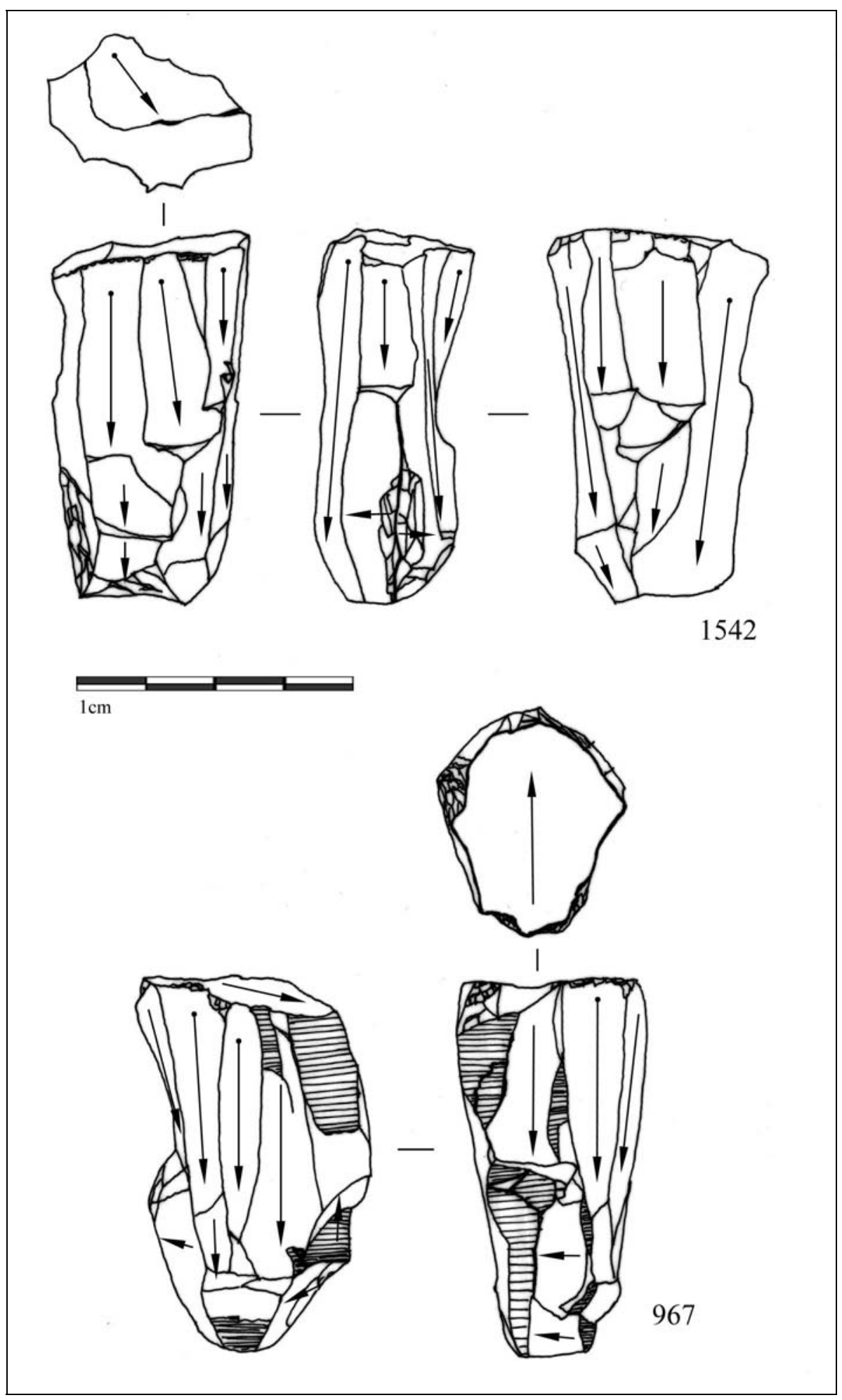

Figura R1.1: núcleos de hojas de radiolarita-1, a partir del esquema prismático tipo-B, unipolar. 


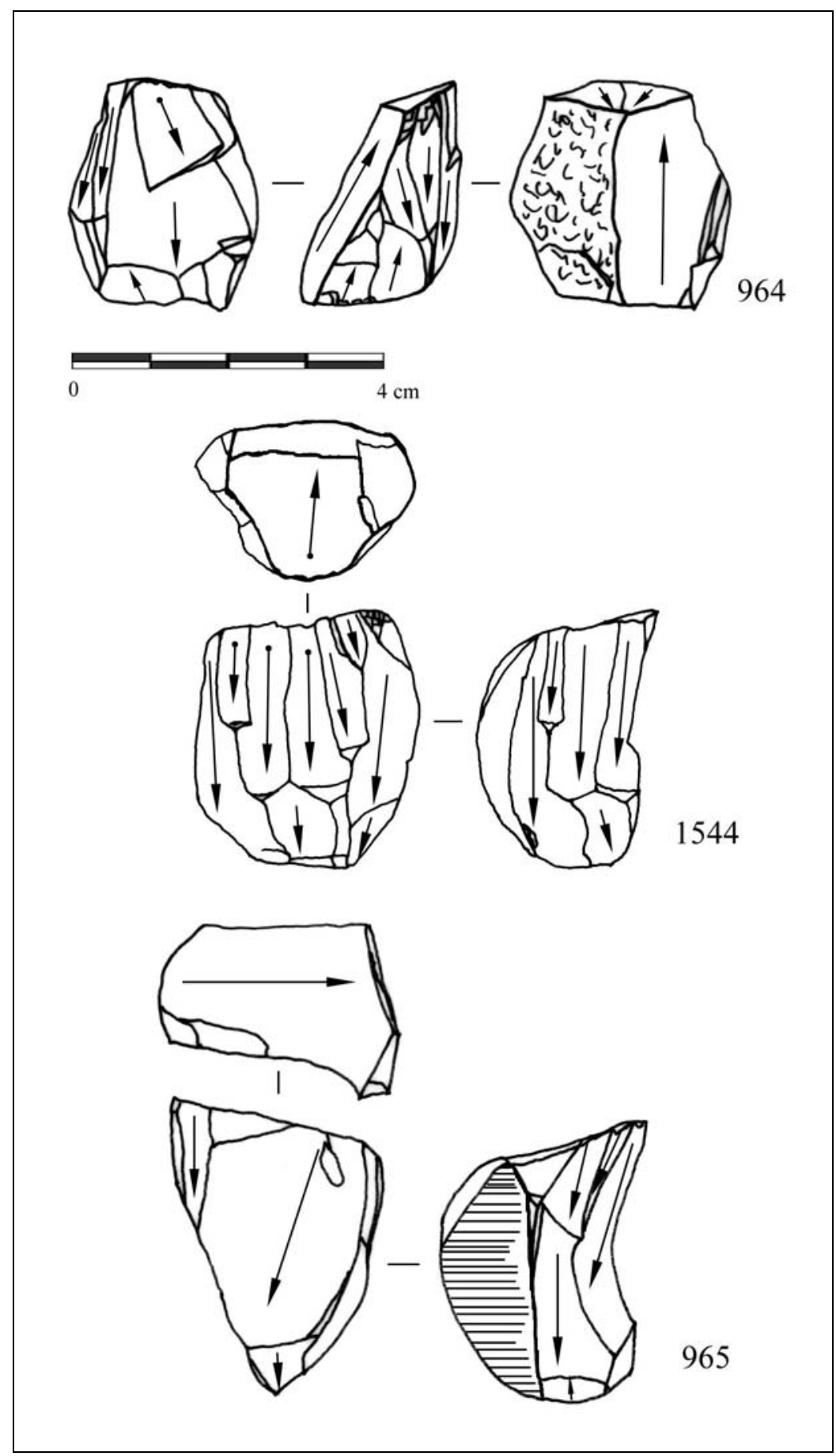

Figura R1.2: Núcleos de hojitas de radiolarita-1. N 964 y 1544 a partir de un esquema prismático unipolar. № 965 es un resto de núcleo que podría incluirse también dentro de este mismo esquema. 


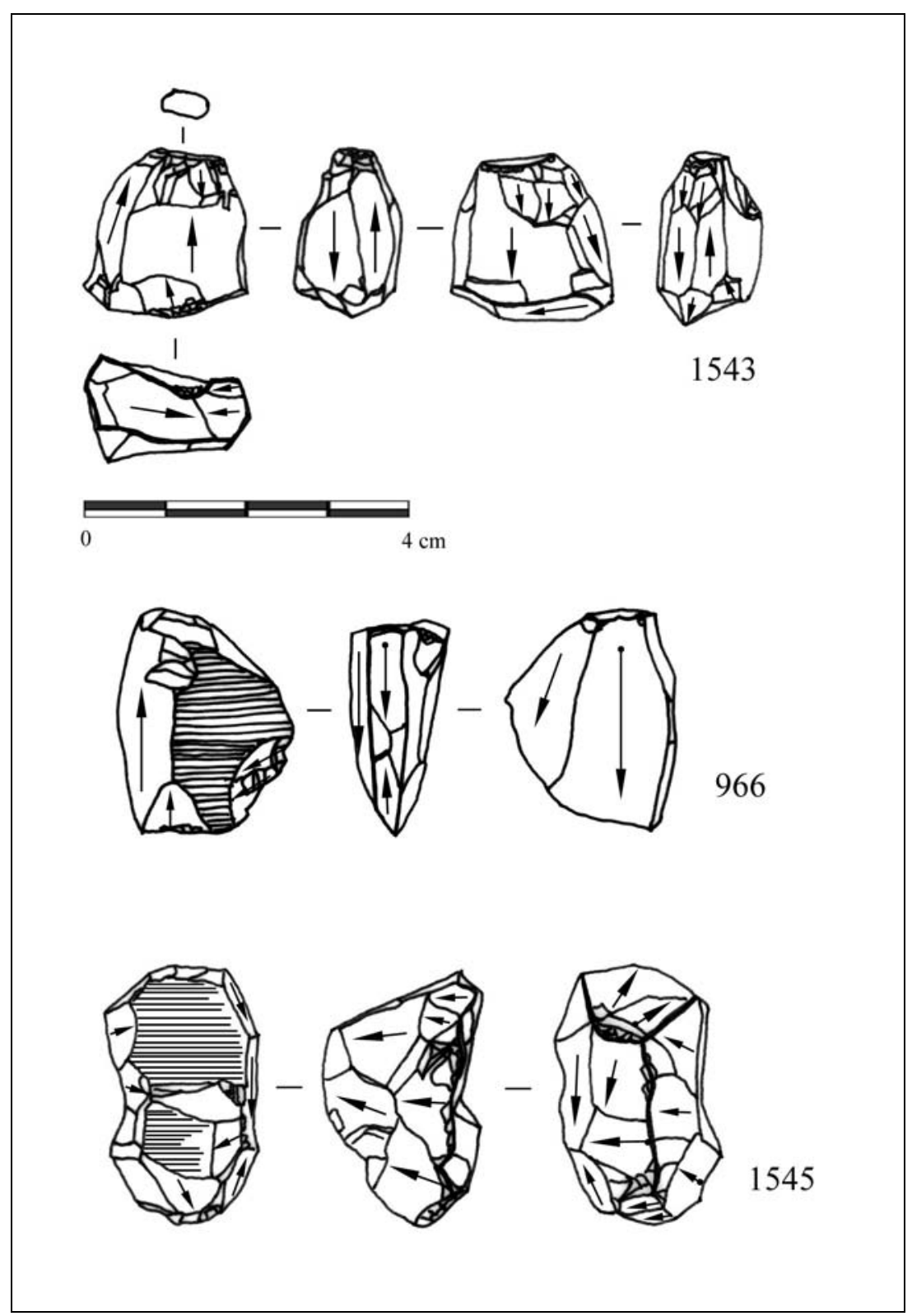

Figura R1.3: Núcleos de hojitas de radiolarita-1. El nº 1543 y 966 son prismáticos bipolares; el $\mathrm{n}^{\circ} 1545$ es un resto de núcleo de difícil lectura debido a que tiene un plano de diaclasado natural que afecta por completo a la superficie de extracciones. 


\section{IV.2.3.- PRODUCTOS DE ACONDICIONAMIENTO}

\section{IV.2.3.1. PIEZAS CON CRESTA}

Hay 13 piezas con cresta, 11 con cresta o neo-cresta y 2 con cresta segunda. Tres serían piezas con cresa hacia las dos vertientes (pero solo en un caso dicha cresta afecta a la totalidad de la hoja) y 8 son hojas con neo-cresta, es decir con extracciones transversales hacia una vertiente solamente (Figura R1.4: $\mathrm{n}^{\mathrm{o}} 1$ a 4). En este último caso hay más ejemplares de neo-crestas totales (cinco casos en concreto) que parciales (cuadro R1.25). Esto podría relacionarse con el empleo del procedimiento de la cresta sobre el borde lateral para avanzar sobre él de forma frontal, y encajaría en los esquemas técnicos que se han visto para los núcleos. En cuanto a las piezas con cresta total, suelen proceder de secuencias del inicio del débitage pleno, para la apertura de la superficie de extracciones; no obstante podrían también situarse a lo largo del débitage pleno, tal y como se ha visto en el caso del núcleo sobre el que se observa la cresta sobre uno de sus laterales.

\begin{tabular}{|l|cc|r|}
\hline & CRESTA COMPLETA & CRESTA PARCIAL & TOTAL \\
\hline LC & 1 & 2 & 3 \\
LC1 & 5 & 3 & 8 \\
\hline
\end{tabular}

Cuadro R1.25 : piezas con cresta. LC: hoja o lasca con cresta hacia las dos vertientes. LC1: hoja/lasca con neo-cresta.

\begin{tabular}{|l|ccc|ccc|}
\cline { 2 - 7 } \multicolumn{1}{c|}{} & \multicolumn{3}{c|}{ PIEZAS CON CRESTA } & \multicolumn{3}{c|}{ SEMITABLETAS DE NÚCLEO } \\
\cline { 2 - 7 } \multicolumn{1}{c|}{} & $\mathrm{L}$ & $\mathrm{A}$ & $\mathrm{G}$ & $\mathrm{L}$ & $\mathrm{A}$ & $\mathrm{G}$ \\
\hline $\mathrm{N}$ & 5 & 12 & 13 & 4 & 9 & 9 \\
Rango & $25-43$ & $5-19$ & $3-10$ & $12-31$ & $7-28$ & $2-8$ \\
Media & $\mathbf{3 4 , 8 0}$ & $\mathbf{1 1 , 1 5}$ & $\mathbf{5 , 4 2}$ & $\mathbf{1 9 , 7 5}$ & $\mathbf{1 7 , 0}$ & $\mathbf{4 , 6 0}$ \\
Desviación & 8,20 & 3,49 & 2,19 & 8,18 & 7,66 & 1,90 \\
\hline
\end{tabular}

Cuadro R1.26: datos métricos de las piezas con cresta. L: longitud, A: anchura, G: grosor. 
En las dimensiones de las piezas con cresta (cuadro R1.26) se puede observar que su longitud media (35 mm) se acercaría a la media de los núcleos, y encajaría plenamente en los núcleos prismáticos de la colección.

\section{IV.2.3.2. TABLETAS Y SEMITABLETAS DE NÚCLEO}

Hay nueve semitabletas de núcleo, sus dimensiones son mayores (cuadro R1.26) que la media de las lascas y su función técnica se explica por la preparación del frente de percusión (Figura R1.4: $n^{\circ} 5$ a 7).

\section{IV.2.3.3. FLANCOS DE NÚCLEO}

Hay 28 flancos de núcleo, 9 transversales y 14 longitudinales (Figura R1.5). De estos últimos, cinco se han extraído desde la misma dirección y sentido que la dirección general de talla y nueve desde un plano opuesto (cuadro R1.27) .

\begin{tabular}{|l|c|}
\hline FLANCOS - R1 & N \\
\hline FN longitudinal-unipolar & 5 \\
FN longitudinal-bipolar & 9 \\
FN transversal & 9 \\
FN genérico & 5 \\
\hline
\end{tabular}

Cuadro R1.27: tipos de flancos de núcleo.

\begin{tabular}{|l|ccc|ccc|}
\cline { 2 - 7 } \multicolumn{1}{c|}{} & \multicolumn{3}{c|}{ FLANCOS LONGITUDINALES } & \multicolumn{3}{c|}{ FLANCOS TRANSVERSALES } \\
\cline { 2 - 7 } \multicolumn{1}{c|}{} & $\mathrm{L}$ & $\mathrm{A}$ & $\mathrm{G}$ & $\mathrm{L}$ & $\mathrm{A}$ & $\mathrm{G}$ \\
\hline $\mathrm{N}$ & 7 & 14 & 14 & 8 & 9 & 9 \\
Rango & $22-46$ & $10-39$ & $1-13$ & $20-54$ & $13-33$ & $3-12$ \\
Media & $\mathbf{3 4 , 4 3}$ & $\mathbf{2 3 , 8 4}$ & $\mathbf{7 , 5}$ & $\mathbf{3 0 , 1 3}$ & $\mathbf{2 0 , 3 3}$ & $\mathbf{6 , 7}$ \\
Desviación & 8,90 & 9,31 & 3,12 & 11,42 & 6,67 & 2,65 \\
\hline
\end{tabular}

Cuadro R1.28: datos métricos de los flancos de núcleo.

Teniendo en cuenta el hecho de que la dirección de débitage predominante es unipolar, sorprende un poco el elevado número de flancos en dirección opuesta. Además en los núcleos unipolares se ha constatado un empleo preferente de los procedimientos de arreglo del núcleo de dirección unipolar, estando ausente tanto el empleo de un segundo plano de percusión opuesto (a excepción de un núcleo de hojitas 
con plano alterno) como una cresta inferior; de hecho la base del núcleo tiende a mantenerse perpendicular a la superficie de extracciones. Quizás estos flancos bipolares correspondan a secuencias de la explotación del núcleo que no se constatan en el estado de abandono de los mismos.

La longitud media (Cuadro R1.28) de los flancos longitudinales (34 mm) sería similar a las piezas con cresta, y encajaría totalmente en proceso operativo de los núcleos prismáticos.

\section{IV.2.3.4. ARISTAS DE NÚCLEO Y OTROS PRODUCTOS DE ACONDICIONAMIENTO}

Por último hay nueve piezas que se han clasificado como aristas de núcleo sin que se pueda especificar una función concreta en la gestión del núcleo. Algunas parecen fragmentos de cornisas, otras pertenecerían más a aristas del núcleo pero sin poder determinar si se trata de frentes de percusión o bien crestas laterales, inferiores, etc. 


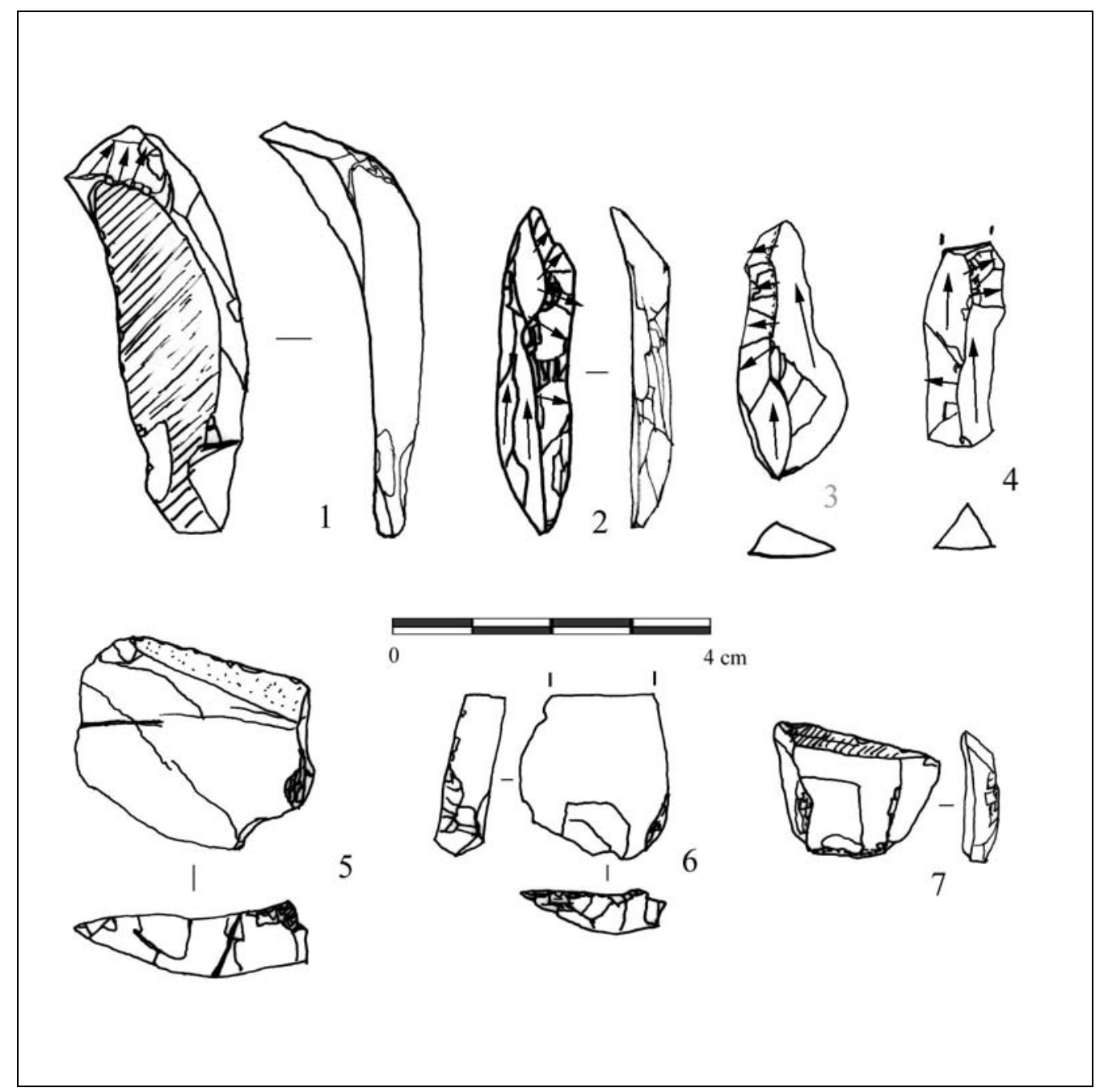

Figura R1.4: productos de acondicionamiento de radiolarita-1. Hojas con neo-cresta parcial: $1 \mathrm{a}$ 4.. Semitabletas de núcleo: 5 a 7. 

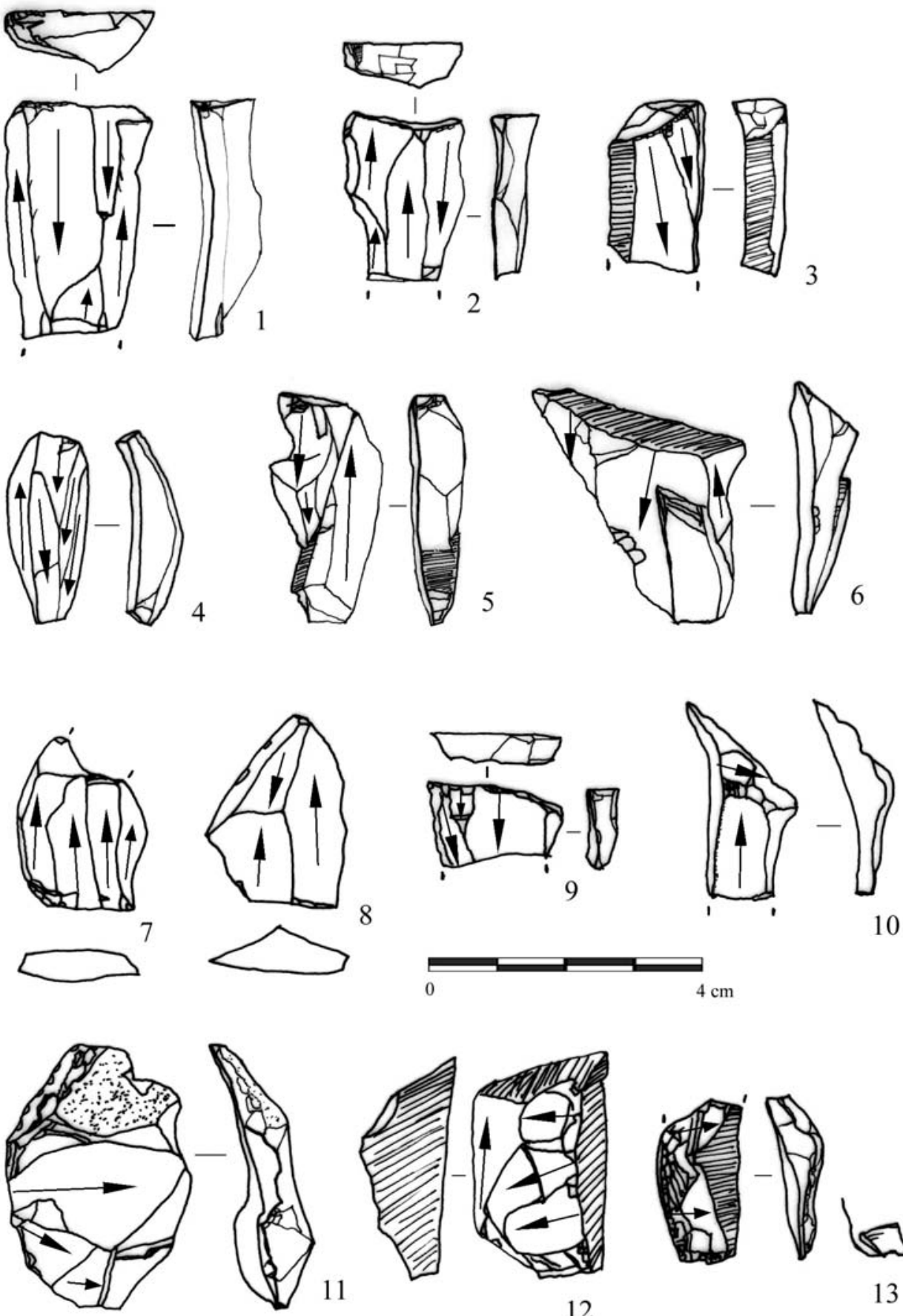

12

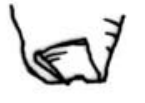

Figura R1.5: flancos de núcleo de radiolarita-1. Flanco longitudinal opuesto: 1, 2, 3, 4, 5, 6, 9. Flanco longitudinal: 6, 8. Flanco transversal: 10 a 13 . El no 7 es una lasca laminar con negativos de hojitas, cuya función es "limpiar" la tabla laminar. El n ${ }^{\circ} 13$ tiene en la zona del bulbo un astillado que recuerda al esquillement du bulb típico de la percusión con piedra blanda. En 1, 2, 4 y 10 hay restos de abrasión en torno a la cornisa. 


\section{IV.2.4.- SOPORTES: LASCAS, HOJAS Y HOJITAS}

El conjunto de lascas y hojas de radiolarita pertenecen fundamentalmente a un proceso de débitage laminar, tan solo hay un núcleo (el unipolar) que tiene una explotación de lascas. En torno al 40\% de las piezas de radiolarita se inscribirían en el grupo tecnológico 1, es decir el que reúne a las lascas, lascas laminares y hojas corticales. Este porcentaje es ya un poco más reducido que en el caso del sílex negro, que tiene un 50\% de elementos en este grupo, ya que también hay una producción de lascas específica.

\section{IV.2.4.1.- LASCAS}

El 37\% del conjunto de la radiolarita son lascas $(n=566)$, la mayoría de las cuales están rotas, como se ha indicado. Sus dimensiones no son demasiado amplias, con una media de 15 mm de longitud, 14 de anchura y 3 de grosor; sugiriendo por tanto lascas cuadrangulares de 1,5 cm de lado. En el gráfico de barras de la distribución de la longitud y anchura de las piezas del grupo 1, (gráfico R1.5) se puede ver el número de piezas a lo largo de las distintas medidas, matizándose ligeramente los valores medios. La longitud tiene una media de $15 \mathrm{~mm}$, pero hay un mayor número de las lascas en los 11-12 mm, y en menor grado entre los 13 -16. En cuanto a las retocadas, se constata la preferencia a seleccionar las lascas más grandes, a partir de los 13-14 mm.

En el gráfico de barras de la anchura de las lascas (gráfico R1.6), hay un máximo en los 11-12 mm, siendo también muy abundantes en los 13-14 mm. Para las piezas retocadas también hay una tendencia a elegir las piezas de mayor anchura, aunque en este atributo no es tan claro como en la longitud. 


\section{Longitud GR - 1}

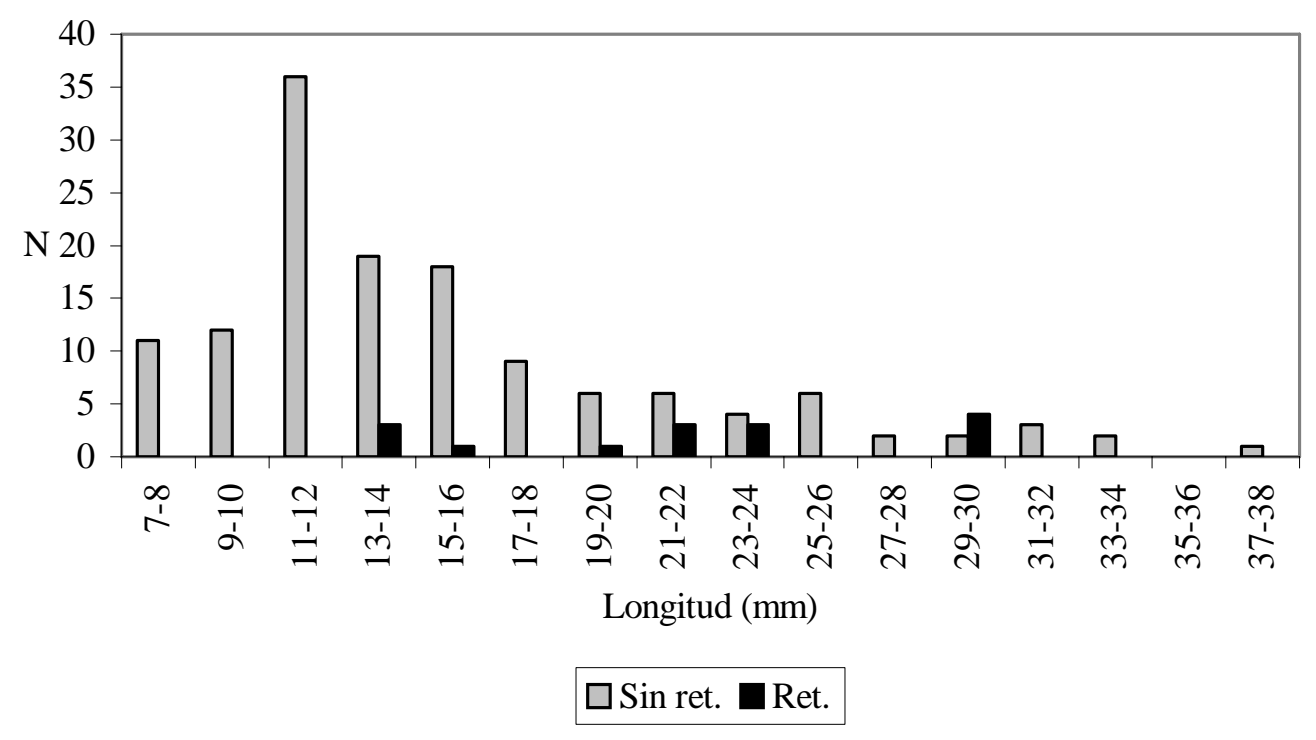

Gráfico R1.5 : longitud de los soportes de radiolarita-1 del grupo tecnológio 1 (lascas, lascas laminares). Sin retocar: $n=137$. Retocados: $n=15$.

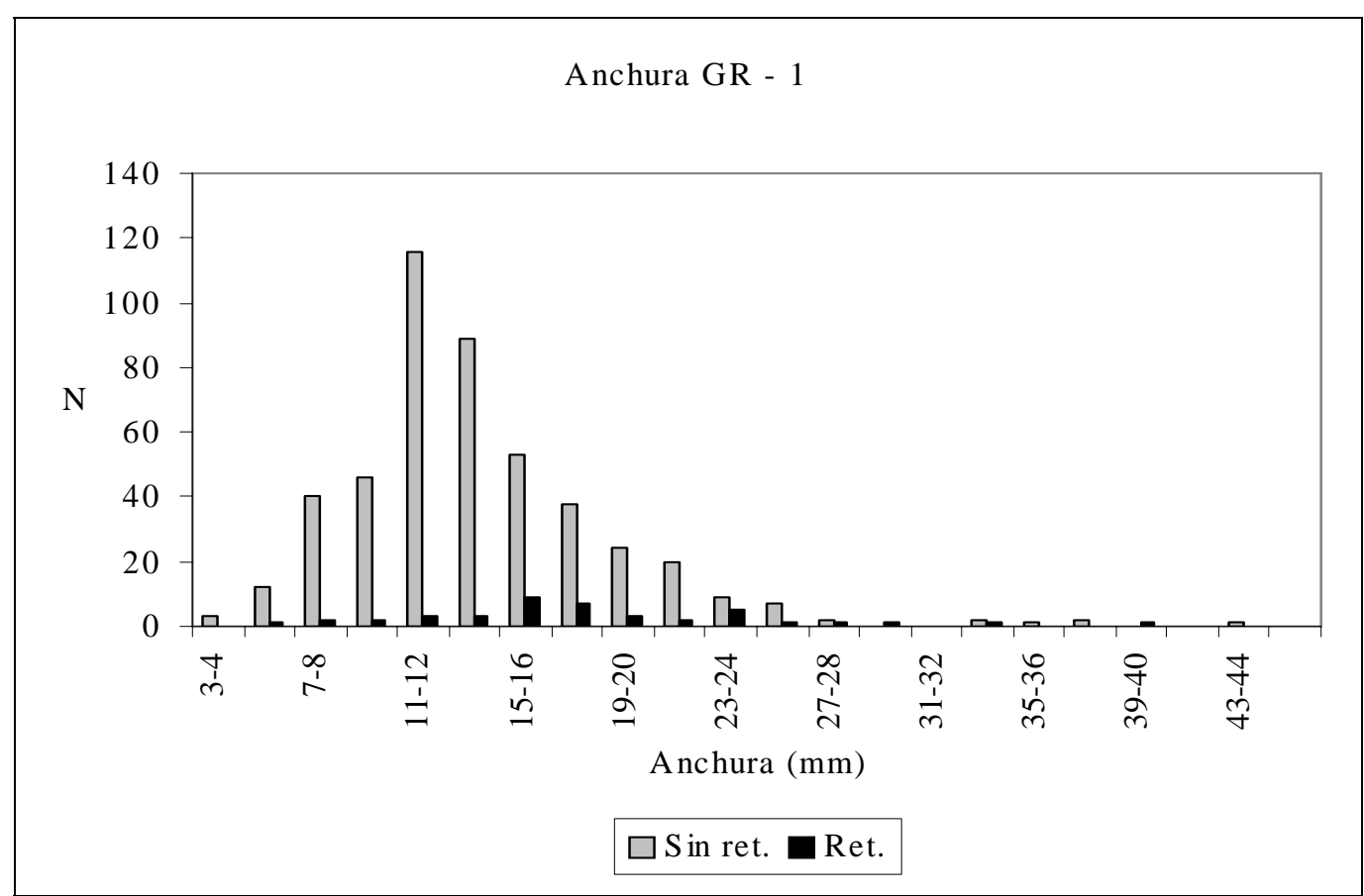

Gráfico R1.6: anchura de los soportes de radiolarita-1del grupo tecnológio 1 (lascas, lascas laminares). Sin retocar: $n=465$. Retocados: $n=42$. 


\section{IV.2.4.2.- SOPORTES LAMINARES: HOJAS Y HOJITAS}

Los soportes laminares (grupo tecnológico 2) representan el 20\% del conjunto de radiolarita, por lo que el objetivo laminar de proceso de débitage aplicado sobre esta materia es más claro que en el caso del sílex negro (en el que el grupo 2 tenía el 11\% de representación).

\section{IV.2.4.2.1.- DATOS MÉTRICOS: LONGITUD Y ANCHURA}

El valor medio de las dimensiones de las hojas-hojitas es (cuadro R1.10): $20 \mathrm{~mm}$ de longitud, 9 de anchura y 2 de grosor. Dicho valor se incrementa en las piezas retocadas: $25 \mathrm{~mm}$ de longitud, 10 de anchura y 2,5 de grosor. Se puede observar la representatividad de estas medidas en los gráficos de barras correspondientes. Para la longitud de los soportes (gráfico R1.7) hay una distribución más o menos continua entre 11 y 35 mm, sin que existan picos relevantes, excepto un ligero incremento en los 15-16 mm y los 23-24. En las retocadas sí se constata también la tendencia a seleccionar aquellos soportes laminares de mayor longitud, sobre todo a partir de $2 \mathrm{~cm}$.

Para la anchura (gráfico R1.8), hay una distribución de las piezas bastante homogénea, la mayoría de las hojas-hojitas se encuentran entre los 5 y $12 \mathrm{~mm}$ de longitud, con un máximo en los 7-8. Respecto a las piezas retocadas, la distribución es similar a las anteriores, pero, teniendo en cuenta que hay muchas de ellas que son hojitas de dorso, habría una tendencia a seleccionar aquellas más anchas. De hecho a partir de los $13 \mathrm{~mm}$ de anchura hay más hojas retocadas que sin retocar. 


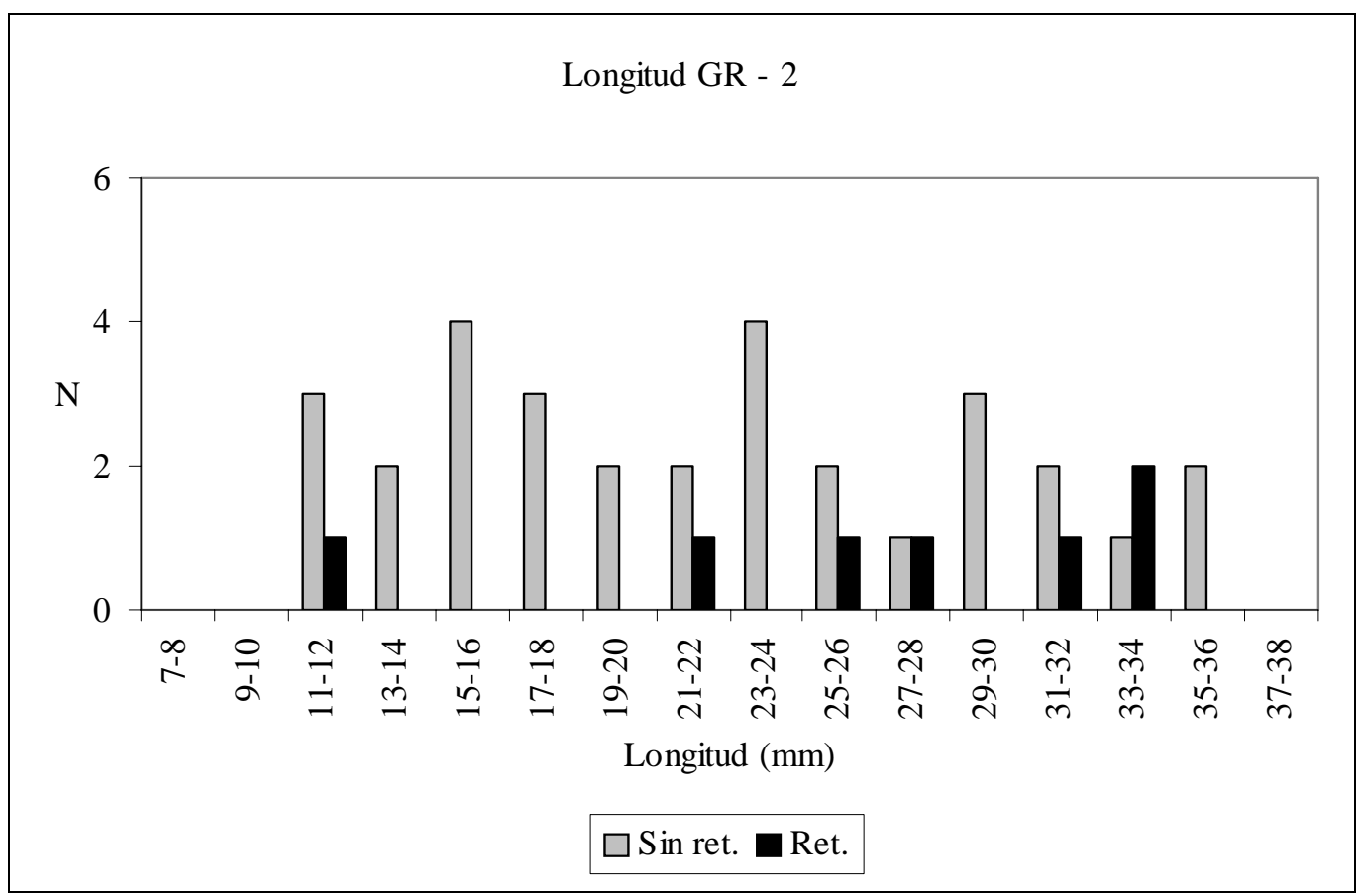

Gráfico R1.7: longitud de los soportes del grupo tecnológio 2 (hojas, hojitas). Sin retocar: $n=31$. Retocados: $\mathrm{n}=7$.

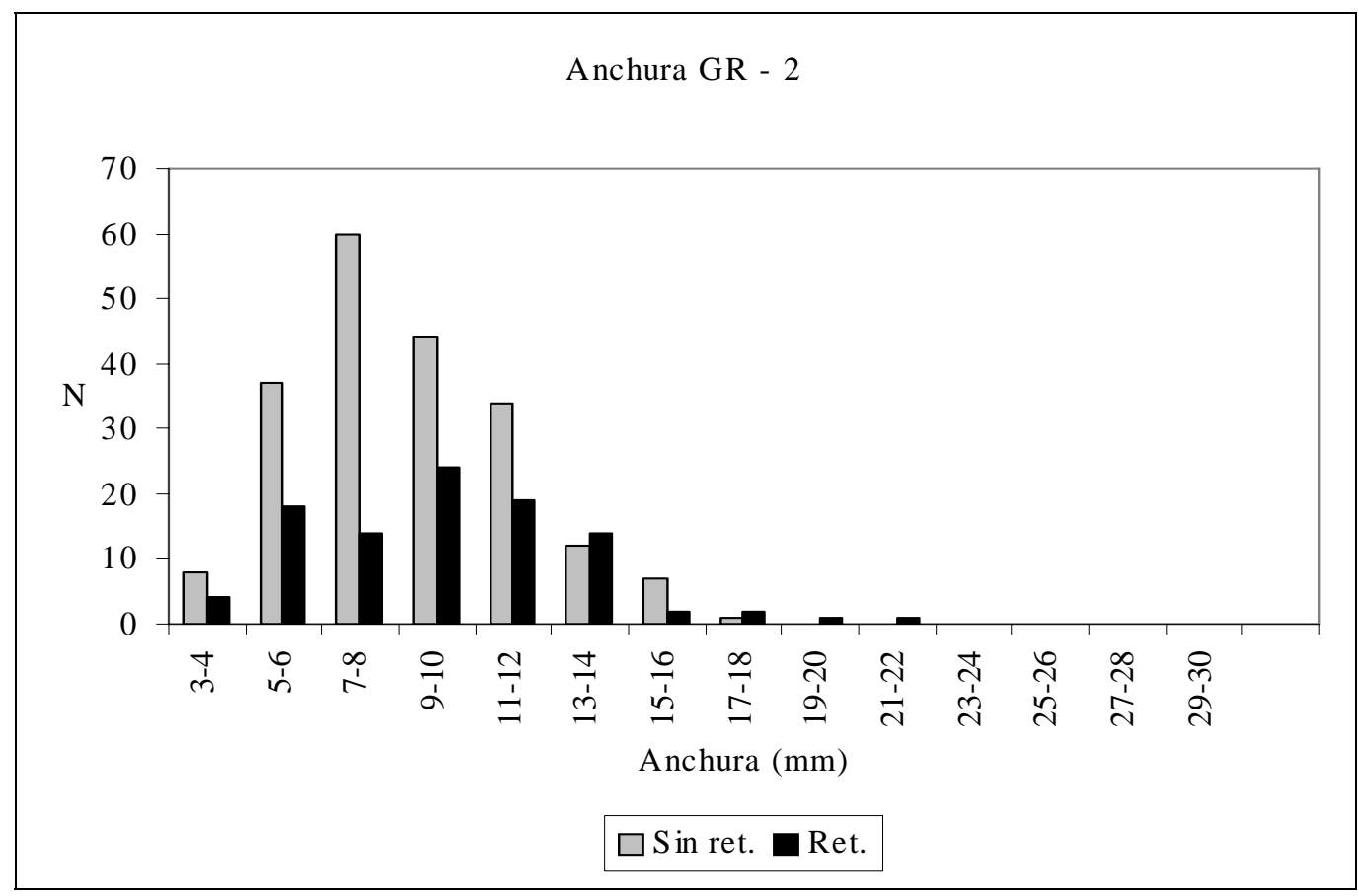

Gráfico R1.8: anchura de los soportes del grupo tecnológio 2 (hojas, hojitas). Sin retocar: $n=203$. Retocados: $n=99$. 


\section{IV.2.4.2.2.- ATRIBUTOS TÉCNICOS}

\section{$N^{o}$ nervaduras/negativos}

La mayoría de los soportes laminares (con o sin retoque) tienen una nervadura, lo cual dibujaría secciones transversales de morfología triangular.

\begin{tabular}{|l|l|cccccc|r|}
\hline \multicolumn{2}{|c|}{} & 0 & 1 & 2 & 3 & 4 & $5+$ & TOTAL \\
\hline \multirow{2}{*}{ SIN RET } & $\mathrm{N}$ & 3 & 94 & 74 & 27 & 8 & 1 & 207 \\
& $\%$ & 1,4 & 45,4 & 35,7 & 13,0 & 3,9 & 0,5 & \\
\hline \multirow{2}{*}{ RETOC } & $\mathrm{N}$ & 8 & 49 & 33 & 10 & & & 100 \\
& $\%$ & 8,0 & 49,0 & 33,0 & 10,0 & & & \\
\hline
\end{tabular}

Cuadro R1.29: $\mathrm{N}^{\circ}$ de nervaduras en los soportes laminares.

\section{Dirección negativos}

El 90\% de las hojas-hojitas tienen una dirección de los negativos en sentido unipolar, lo cual está acorde con la dirección unipolar genérica del proceso de talla aplicado sobre la radiolarita; tan solo el 9\% de este tipo de soportes tienen una dirección bipolar.

\begin{tabular}{|l|cc|cc|}
\hline \multirow{2}{*}{} & \multicolumn{2}{|c|}{ SIN RET } & \multicolumn{2}{c|}{ RET } \\
\cline { 2 - 5 } & $\mathrm{N}$ & $\%$ & $\mathrm{~N}$ & $\%$ \\
\hline ID & 1 & 0,6 & 1 & 1,1 \\
PD & 145 & 89,5 & 78 & 89,7 \\
PD-CI & 1 & 0,6 & & \\
PD-DP & 15 & 9,3 & 8 & 9,2 \\
\hline
\end{tabular}

Cuadro R1.30: dirección de los negativos de los soportes laminares, según el número de nervaduras en su cara superior. ID: izquierda-distal (trasnversal al eje técnico); PD: proximaldistal (unipolar); PD-CI: proximal-distal y restos de neo-cresta hacia la izquierda; PD-DP: proximal-distal y distal-proximal (bipolar). 


\section{Sección}

En la sección longitudinal de los soportes laminares sí hay una variación entre las piezas sin retocar y las retocadas. En las primeras, más del 50\% tienen una sección curva, mientras el 34\% la tienen rectilínea. En cambio en las retocadas los porcentajes se invierten: el 50\% de ellas tienen una sección longitudinal rectilínea, frente al 38\% curva. Este atributo se correspondería con la carena de los núcleos, en los cuales se comprobó cómo había una tendencia (al menos en las últimas secuencias de producción plena, sobre los negativos de las últimas extracciones antes del abandono del núcleo) hacia una carena rectilínea. Precisamente los soportes más rectos son los seleccionados para retocar.

\begin{tabular}{|l|l|ccccc|r|}
\hline \multicolumn{2}{|c|}{} & $\mathrm{Cn}$ & $\mathrm{Cx}$ & $\mathrm{R}$ & $\mathrm{S}$ & $\mathrm{T}$ & TOTAL \\
\hline \multirow{2}{*}{ SIN RET } & $\mathrm{N}$ & 74 & 9 & 46 & 4 & 2 & 135 \\
& $\%$ & 54,8 & 6,7 & 34,1 & 3,0 & 1,5 & \\
\hline \multirow{2}{*}{ RET } & $\mathrm{N}$ & 26 & 6 & 34 & 2 & & 68 \\
& $\%$ & 38,2 & 8,8 & 50,0 & 2,9 & & \\
\hline
\end{tabular}

Cuadro R1.31: perfil longitudinal de los soportes laminares. Cn: cóncavo, curvo; Cx: convexo; R: rectilíneo; S: sinuoso (cóncavo-convexo); T: torse (alabeado).

En la sección transversal, tienen un amplio predominio los soportes con sección triangular (casi el 80\% de las hojas-hojitas sin retocar, y el 85\% de las retocadas), sobre los de sección trapezoide. Esto se corresponde totalmente con el número de nervaduras presentes sobre la cara superior, que en la mayoría de los casos se reducía a una. En las piezas retocadas hay más soportes de sección triangular que trapezoide, frente a lo que sucedía en el sílex negro, donde los soportes con sección trapezoide se habían seleccionado mayoritariamente para ser retocados.

\begin{tabular}{|l|l|ccr|}
\hline \multicolumn{2}{|c|}{} & TR & TZ & TOTAL \\
\hline \multirow{2}{*}{ SIN RET } & $\mathrm{N}$ & 150 & 39 & 189 \\
& $\%$ & 79,4 & 20,6 & \\
\hline \multirow{2}{*}{ RET } & $\mathrm{N}$ & 81 & 14 & 95 \\
& $\%$ & 85,3 & 14,7 & \\
\hline
\end{tabular}

Cuadro R1.32: sección transversal de los soportes laminares. TR: triangular; TZ: trapezoidal. 


\section{Indice de Regularidad}

Por último respecto al índice de regularidad, hay una tendencia a seleccionar las hojas-hojitas de mayor calidad (índice “1-2” y “2”), dentro de las posibilidades que ofrece las hojas producidas.

\begin{tabular}{|l|l|ccccc|r|}
\hline \multicolumn{2}{|c|}{} & 0 & $0-1$ & 1 & $1-2$ & 2 & TOTAL \\
\hline \multirow{2}{*}{ SIN RET } & $\mathrm{N}$ & 52 & 9 & 82 & 28 & 6 & 177 \\
& $\%$ & 29,4 & 5,1 & 46,3 & 15,8 & 3,4 & \\
\hline \multirow{2}{*}{ RET } & $\mathrm{N}$ & 5 & 7 & 43 & 23 & 9 & 87 \\
& $\%$ & 5,7 & 8,0 & 49,4 & 26,4 & 10,3 & \\
\hline
\end{tabular}

Cuadro R1.33: índice de regularidad de los soportes laminares. 0: mala calidad; 1: calidad media, aceptable; 2: buena calidad.

Como conclusión de todos estos atributos se puede decir que la mayoría de las piezas laminares producidas en radiolarita tienen una dirección de talla unipolar, con una nervadura sobre su cara superior, dando por tanto una sección transversal; respecto a la sección longitudinal es mayoritariamente curva, pero con un buen número de piezas con sección rectilínea y un índice de regularidad mayoritariamente bueno. Entre ellas se seleccionan aquellas con una sección más recta y regularidad mayor.

\section{IV.2.4.3.- "HOJAS CON FLANCO"}

De las denominadas "hojas con flanco", se han clasificado dos piezas en radiolarita, constándose por tanto la presencia de un procedimiento coherente con los esquemas prismáticos unipolares que se han visto en los núcleos. Estas piezas podrían poner en relación con sus negativos correspondientes sobre los núcleos, en los que se han denominado como "hojas de recintrado" que quedan sobre hacia los flancos. 


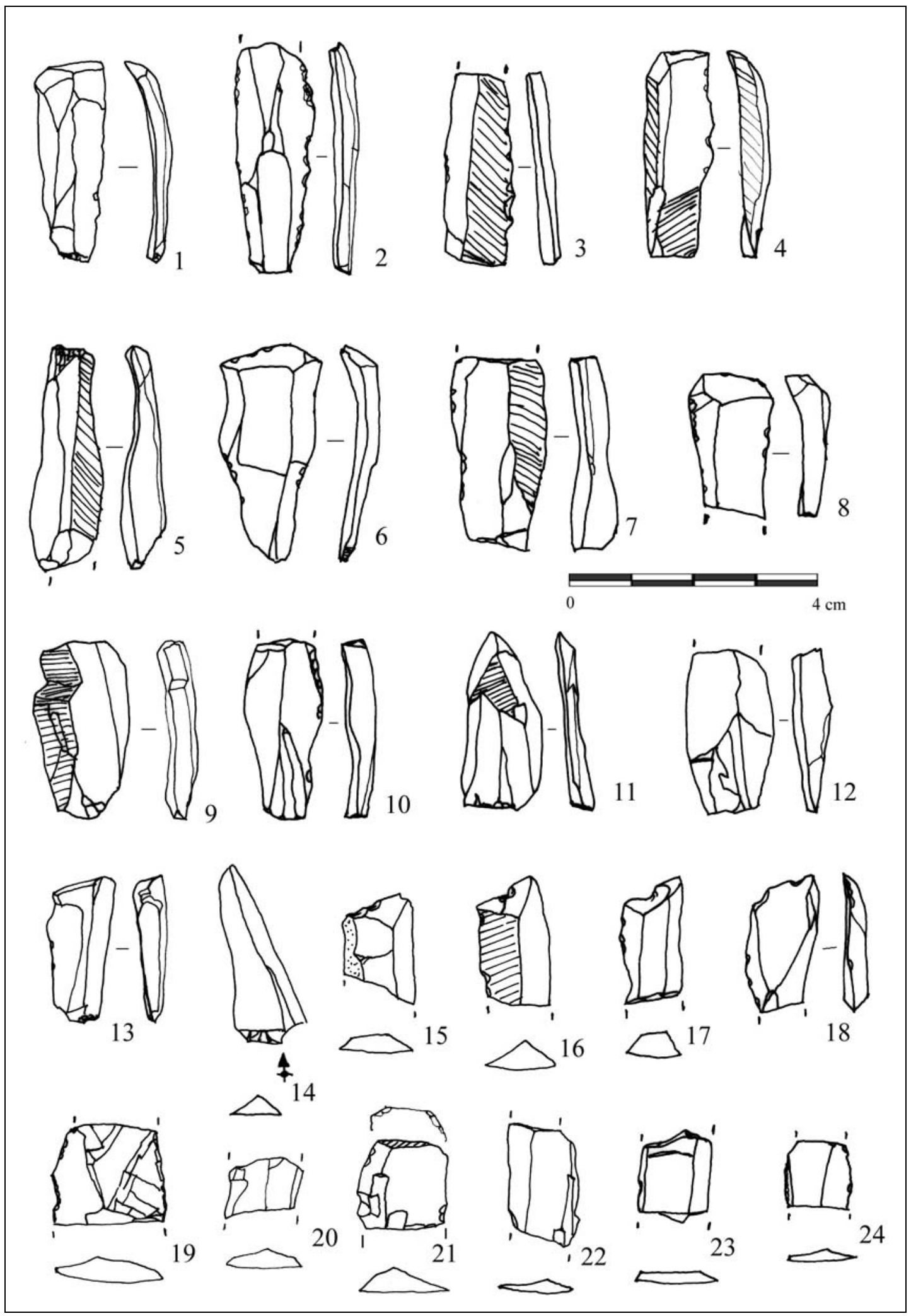

Figura R1.6: hojas de radiolarita-1. Hojas completas o prácticamente completas: 1 a 7, 9 a 14. Fragmento distal: 8, 15 a 18. Fragmento mesial: 19 a 24. 

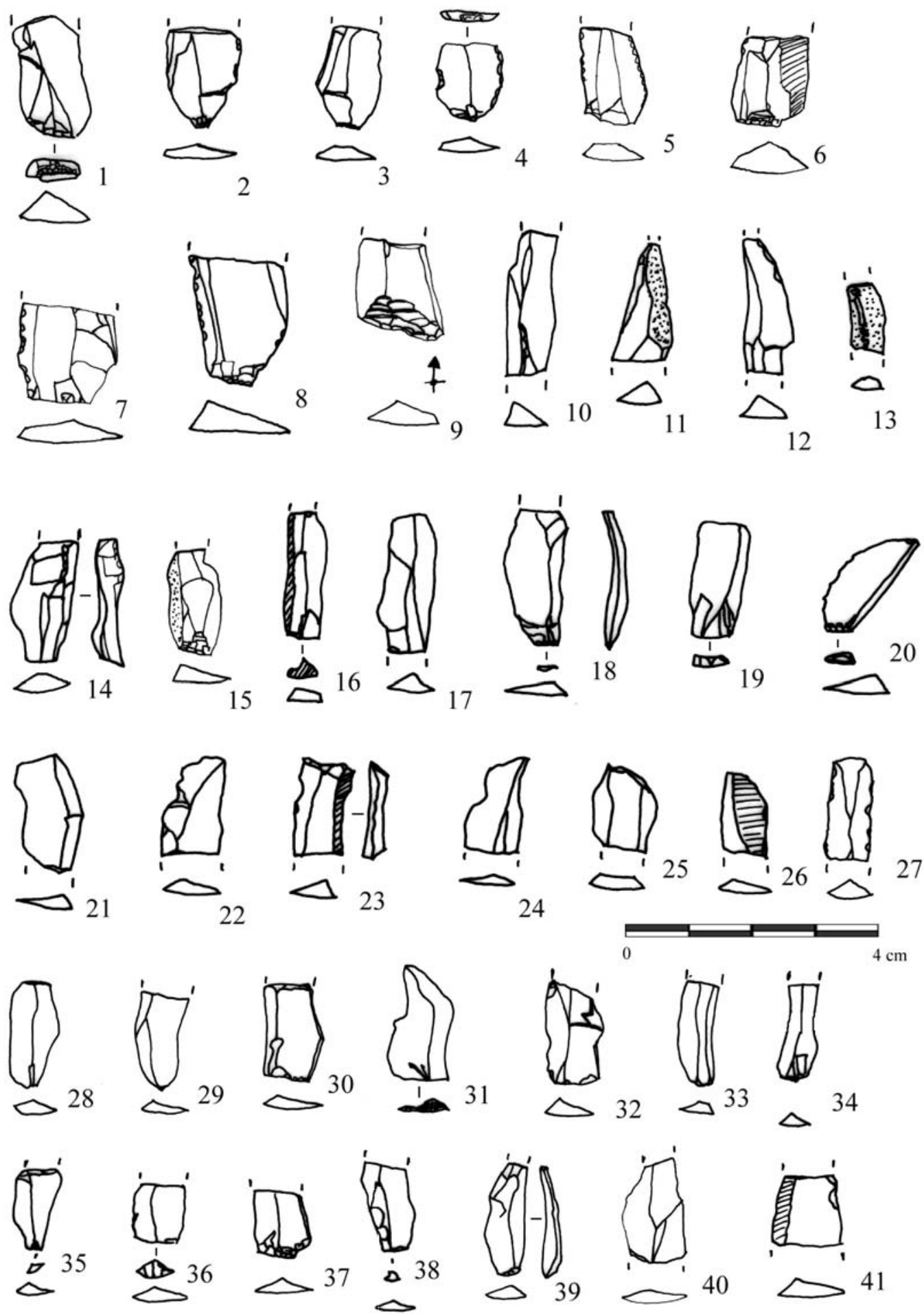

Figura R1.7: Hojas y hojitas fragmentadas de radiolarita-1. Fragmento proximal: 1 a 9, 14 a 16, 18, 29, 30, 32 a 39. Fragmento mesial: 10, 13, 40, 41. Fragmento distal: 11, 12, 17, 21 a 27. Hojitas completas: 19, 20, 28,31. $\mathrm{N}^{\mathrm{o}} 13$ es una hojita de primer orden con arista natural (hojita de encetadura). 


\section{IV.2.5.- PIEZAS RETOCADAS}

El $62 \%$ de las piezas retocadas se realizan sobre soportes laminares (cuadro R1.4). Hay una preferencia neta a seleccionar las hojas-hojitas para realizar las piezas con retoque (cuadro R1.5): un tercio de los soportes laminares existentes se han retocado, seguido por los productos de acondicionamiento, de los que se han seleccionado el 15\% de los productos existentes; de las lascas y soportes del grupo tecnológico 1 sólo se han retocado el 7\%.

\begin{tabular}{|c|c|c|c|c|c|c|c|c|c|c|c|c|c|}
\hline \multirow[b]{3}{*}{ TIPO RETOC. } & & & \multicolumn{11}{|c|}{ GRUPOS TECNOLÓGICOS } \\
\hline & \multicolumn{2}{|c|}{ TOTAL } & \multicolumn{2}{|c|}{1} & \multicolumn{4}{|c|}{2} & \multicolumn{3}{|l|}{3} & \multirow{2}{*}{\begin{tabular}{|c|}
4 \\
Nuc
\end{tabular}} & \multirow{2}{*}{$\begin{array}{c}6 \\
\text { LT }\end{array}$} \\
\hline & $\mathrm{N}$ & $\%$ & $\mathrm{~L}$ & L-H & $\mathrm{H} 2$ & H3 & HT2 & HT3 & LC & FN & AN & & \\
\hline Raspador & 11 & 6,9 & 9 & & & 1 & & & & & & & 1 \\
\hline Buril & 7 & 4,4 & 3 & & & 4 & & & & & & & \\
\hline Perforador & 3 & 1,9 & 1 & & & 1 & & & 1 & & & & \\
\hline U.compuesto & 2 & 1,3 & 1 & & & & & & 1 & & & & \\
\hline Ret.continuo & 11 & 6,9 & 4 & 1 & & 3 & & 1 & 1 & 1 & & & \\
\hline Ret.cont. M, Pa & 11 & 6,9 & 2 & & & 6 & & & & 1 & 1 & & 1 \\
\hline Truncadura & 6 & 3,8 & & & & 3 & & & & 2 & & & 1 \\
\hline Escotadura & 23 & 14,4 & 6 & 1 & & 8 & 1 & 7 & & & & & \\
\hline Denticulado & 3 & 1,9 & 2 & & & 1 & & & & & & & \\
\hline Astillada & 1 & 0,6 & & & & & & & & & & 1 & \\
\hline Geométrico & 12 & 7,5 & & & & 6 & & 5 & & & & & 1 \\
\hline Dorso & 35 & 21,9 & 4 & & & 4 & & 27 & & & & & \\
\hline Diverso & 6 & 3,8 & 4 & & & & & & & 1 & & & 1 \\
\hline Microburil & 10 & 6,3 & 1 & 2 & & 3 & & 3 & & & & & 1 \\
\hline Picante triédrico & 5 & 3,1 & & & & 2 & & 2 & & & & & 1 \\
\hline Ret./rotura & 3 & 1,9 & & & & 2 & & 1 & & & & & \\
\hline Escot./rot. & 11 & 6,9 & 2 & & & 6 & & 3 & & & & & \\
\hline TOTAL & 160 & 100,0 & 39 & 4 & & 50 & 1 & 49 & 3 & 5 & 1 & 1 & 7 \\
\hline
\end{tabular}

Cuadro R1.34: piezas retocadas por tipos de soportes.

Respecto al tipo de piezas que se fabrican (cuadro R1.34), el 22\% de las piezas retocadas son dorsos, seguidos por las escotaduras y denticulados, con el 16\%; las piezas con retoque continuo, con el 14\%; los raspadores y geométricos, con el 7\%; los buriles, con el 5\%; y el resto de las piezas retocadas con porcentajes inferiores. El conjunto de las piezas que se han considerado como desechos de un procedimiento de rotura de un soporte, previo al retoque (microburiles, picantes triédricos, hojas con 
retoque al lado de una rotura, etc.) suponen el 18\% del conjunto, por lo que este tipo de procedimientos alcanza una importancia reseñable en la radiolarita, lo cual está en correlación directa con el número de geométricos presentes en este tipo de materia, que es donde más aparecen estos tipos.

El uso de los distintos tipos de soportes de radiolarita se resumiría en los siguientes puntos:

- Las lascas tienen un uso más o menos diversificado, pero se seleccionan especialmente para fabricar raspadores, escotaduras y denticulados.

- Las hojas tienen también un empleo diversificado, pero aparecen sobre todo en escotaduras, piezas de retoque continuo, geométricos, buriles y una cuarta parte de ellas en forma de desechos de procedimientos de fractura de los soportes (microburiles, escotaduras al lado de una rotura, etc.). Puede que algunas de las escotaduras pertenezcan también a estos procedimientos de rotura intencional de los soportes en relación con la fabricación de los geométricos. En consecuencia las hojas tendrían dos usos principales:

i) Para la fabricación de geométricos (aparecen tanto los geométricos como los restos de su fabricación)

ii) Para piezas de retoque continuo, se aprovecharía en este caso la longitud del/los filos de los bordes laterales como parte activa del útil

- Las hojitas tienen un uso totalmente específico para la fabricación de piezas con dorso (más de la mitad de las hojitas se han utilizado para este fin). El resto de las hojitas se han utilizado también en la fabricación de geométricos (tanto los geométricos propiamente dichos como los desechos de su factura), así como de escotaduras, las cuales pueden estar relacionadas con los anteriores.

- Las lascas laminares tienen un empleo muy similar al de las hojas (retoque continuo y restos de la rotura de soportes, así como una escotadura), aunque el pequeño número de piezas no permite llegar a conclusiones muy tajantes.

- Los productos de acondicionamiento se han utilizado para varios tipos retocados, sin que se pueda establecer un patrón demasiado marcado debido al escaso número de piezas con las que contamos. 
A partir de estos puntos se puede afirmar que la radiolarita es una materia que ha tenido una gestión específica de los productos obtenidos:

- Se ha seleccionado mayoritariamente los soportes laminares para retocar.

- Las hojitas de han utilizado para las piezas de dorso (este grupo tipológico supone más de la mitad del utillaje retocado).

- Se han fabricado, sobre hojas, varios microlitos geométricos, constándose tanto los geométricos propiamente dichos como los restos de su fabricación (microburiles, etc.).

- Las hojas se han utilizado también para las piezas de retoque continuo y para los buriles.

- Los raspadores se han fabricado prácticamente todos sobre lascas. 


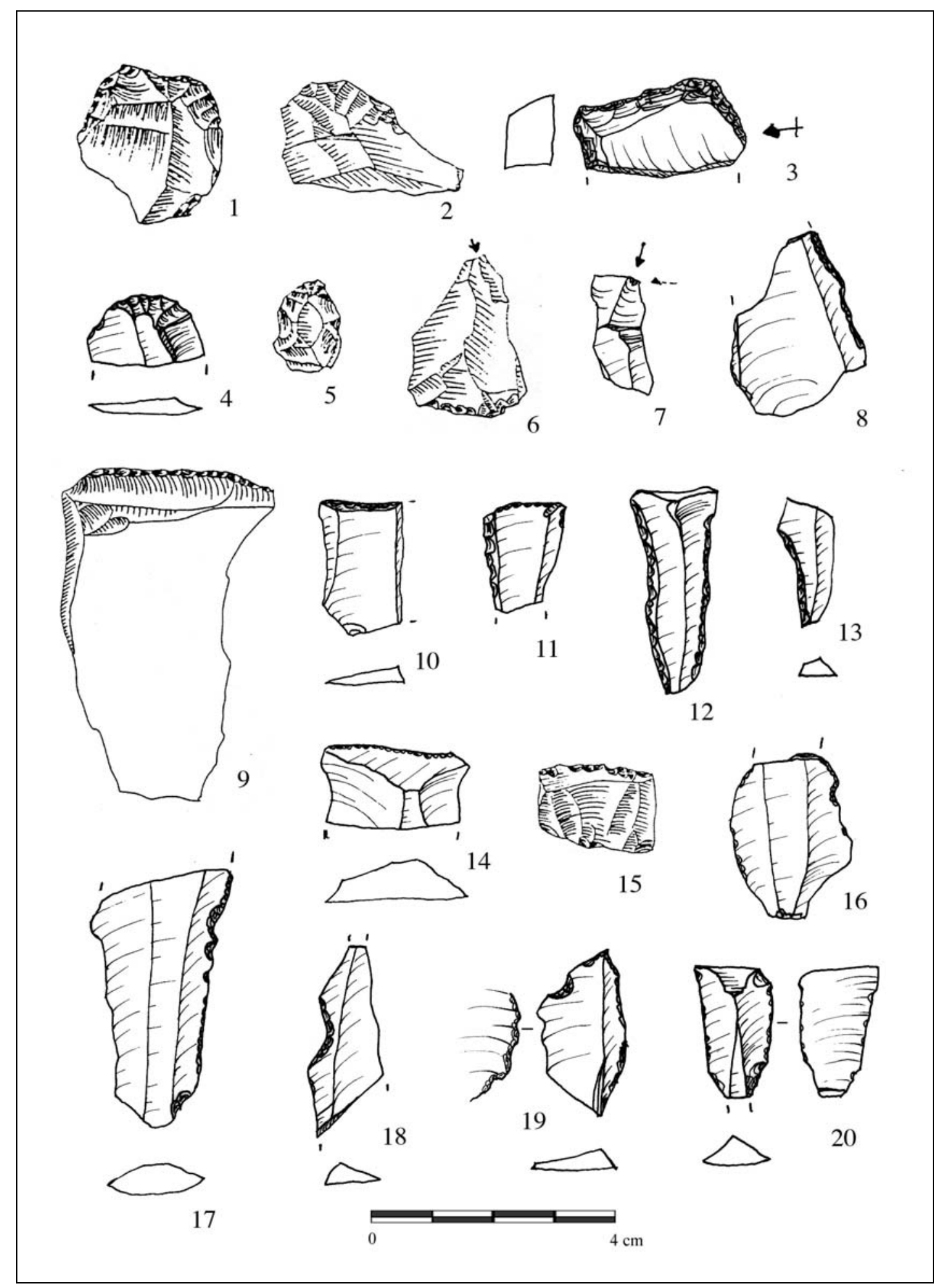

Figura R1.8: Piezas retocadas de radiolarita-1. Raspadores (1 a 5), útil compuesto (buriltruncadura [6]), buril (7), piezas con dorso $(8,12,13)$, truncaduras (9 a 11), piezas con retoque continuo (sobre el borde transversal: 14, 15) y denticulados-escotaduras (16 a 20). Soportes: flanco de núcleo transversal (9), hojas (10 a 13, 17, 18 y 20) y lascas (el resto). Dibujos 1, 2, 5, 6, 9 y 15 realizados por R. Ma Yágüez. 


\section{IV.2.6.- CADENAS OPERATIVAS}

Para la radiolarita hay una cadena operativa básica desarrollada en El Espertín, que es el esquema prismático para la obtención de soportes laminares y microlaminares. Habría otro esquema mucho más expeditivo, representado por el núcleo que se ha denominado como “unipolar”, sobre el que, mediante una técnica rápida, se obtienen lascas. Las piezas que se han clasificado como resto de núcleo, se acercan a los esquemas operativos prismáticos en alguna de sus modalidades, no obstante el estado en que se han abandonado no permiten realizar una lectura correcta de su esquema técnico, ya que han estado sometidos frecuentemente a un aprovechamiento y sobre-explotación que quizás responda a aspectos relacionados con factores sociales (aprendizaje, prácticas con técnicas de talla y materias, etc.).

\section{IV.2.6.1.- CADENA OPERATIVA PRISMÁTICA: ESQUEMA CONCEPTUAL BÁSICO}

Este esquema prismático para la obtención de soportes laminares se adapta bastante bien al tipo de nódulos en que se presenta la materia prima, ya que en muchos casos estos bloques tienen una morfología prismática casi perfecta, delimitada por planos naturales. Las características de la radiolarita por tanto van a favorecer un tipo de organización de los núcleos para el débitage laminar de forma muy rápida, la fase de preparación del núcleo está muy cercana a la de la misma selección del nódulo a tallar.

Las variantes de este esquema se traducen en tres grupos o esquemas operativos:

1) Núcleos de hojas

2) Núcleos de hojitas

3) Núcleos de hojitas sobre superficie estrecha

Los dos primeros traducen un esquema muy similar, la diferencia entre ambos está en el tamaño de los soportes que se van a obtener (hojas u hojitas). En los núcleos de hojas la superficie de extracciones se sitúa sobre una superficie estrecha, y se va expandiendo hacia los laterales de forma envolvente. En los núcleos de hojitas dicha 
superficie suele ser más ancha, avanzando el débitage de forma semi-envolvente, sin llegar a afectar a todo el contorno.

En el tercer grupo, el esquema técnico de estos núcleos recordaría más a los núcleos de hojitas que utilizan una lasca como soporte, situando la superficie de extracciones sobre uno de los bordes laterales, a la manera de los núcleos-tipo buril. Pero en el caso de la radiolarita el soporte no parece ser una lasca, sino un nódulo o fragmento de forma prismática pequeño y estrecho.

\section{FASE 0-1: SELECCIÓN Y PREPARACIÓN DE LOS NÚCLEOS}

La fase de adquisición de la materia prima estaría muy cercana a la de la propia conformación del núcleo. La estructura básica de dicho núcleo es un prisma alargado, con el plano de percusión sobre la superficie superior (para el que se puede aprovechar una superficie natural preexistente) y la superficie de extracciones orientada según el eje de mayor longitud del nódulo. Los flancos y la base del núcleo tienden a ser ortogonales a la superficie de extracciones. La base se sigue manteniendo ortogonal a lo largo del débitage del núcleo; en cambio los flancos laterales tienden a aveces a debilitar esta ortogonalidad al avanzar la talla de forma semi-envolvente. La morfología original de los nódulos de radiolarita es la característica esencial de esta materia prima y la que condiciona los esquemas aplicados.

La iniciación del débitage se produce aprovechando una de las aristas naturales de unión entre la superficie de extracciones y los flancos del núcleo. No hay constancia de la creación de una cresta de apertura de la superficie de extracciones, aunque sí se utilizará este recurso de la cresta a lo largo del débitage.

\section{FASE 2: PRODUCCIÓN}

\section{Secuencias de débitage pleno}

Las extracciones laminares se producen de forma unipolar, en secuencias que van avanzando de forma frontal, pero yuxtapuestas, dando como resultado un avance semi-envolvente, e incluso envolvente. Este avance en secuencias de extracciones 
frontales, tiende a mantener la estructura prismática del núcleo, en especial el hecho de que la superficie de extracciones y los flancos sean perpendiculares. La carena tiende a ser recta, y la preparación del frente de percusión es cuidadosa, constatándose la abrasión de la cornisa.

Un aspecto a reseñar de esta secuencia es el mantenimiento de la base del núcleo perpendicular a la superficie de extracciones, lo cual se consigue, bien porque dicha base es un plano natural de la materia; o bien mediante una conformación de esta zona. Esta construcción del núcleo, por una parte, permite controlar la curvatura de la carena, aunque exige una ejecución correcta en la destreza del gesto de percusión, con el fin de que las extracciones alcancen toda su longitud. Por otro lado, la zona distal de los soportes tiende a ser cuadrangular, si llega hasta dicha base.

Como producto de estas secuencias se obtiene las hojas y hojitas, con un tamaño que oscila entre 10 y 35 mm de longitud; 5-12 mm de anchura y 2 mm de grosor. En muchas de ellas se observan los restos de la preparación sobre el talón (que suele ser liso), y se ha comprobado también cómo hay una tendencia a seleccionar aquellos soportes más rectilíneos para ser retocados.

En el tamaño de las hojas hay una cosa que sobresale: el hecho de que los núcleos, los negativos presentes en ellos y los productos de acondicionamiento tienen unas longitudes potenciales que sobrepasan los $5 \mathrm{~cm}$, en cambio, en el conjunto lítico, los soportes laminares completos no llegan a los $4 \mathrm{~cm}$ de longitud. La explicación de este desequilibrio, con la ausencia de las hojas de mayor longitud, puede ser que dichas hojas se rompan, de hecho la mayoría de las hojas están rotas, además dentro de la fase de retoque de la radiolarita está presente una secuencia de rotura de las hojas, previa a su retoque. Hay que indicar también que dentro de las hojas rotas, hay 4 piezas (una es un buril y otra tiene una escotadura) cuya longitud sobrepasa el límite mayor de las hojas completas, situándose entre los 35 y $42 \mathrm{~mm}$. Por tanto las hojas de mayor longitud lo más probable es que hayan sido rotas, bien de forma intencional, para obtener fragmentos con los que fabricar otros útiles, o bien de forma fortuita, como consecuencia quizás de su uso. 


\section{Reparación/mantenimiento de la superficie de extracciones}

El avance del débitage descrito, permite un auto-mantenimiento de la carena y la cintra a lo largo del débitage pleno, ya que se va produciendo el avance de la talla sobre los laterales, manteniendo éstos de forma perpendicular a la superficie de extracciones. En este tipo de avance se producen las "hojas con flanco", o las hojas de recintrado, cuyos negativos quedan en los laterales de los núcleos.

Con la misma función de control de los laterales, se recurre también a las crestas o neo-crestas laterales, y sus correspondientes hojas con neo-cresta, que son relativamente abundantes en el conjunto lítico.

También aparecen los procedimientos que "limpian” la superficie de extracciones de forma axial, desde el mismo plano donde se produce el débitage pleno, en forma de lascas laminares y flancos longitudinales. En el conjunto de flancos que aparecen en el conjunto lítico, llama la atención el hecho de que hay un buen número de flancos extraídos desde una superficie opuesta al plano principal, mientras que, por el contrario, sobre los núcleos prismáticos de hojas y hojitas hay un débitage unipolar preferente. La explicación de este desajuste quizás radique en que los flancos pertenecen a secuencias del débitage en las que hay un empleo del plano opuesto para reformar o rectificar la superficie de extracciones, sin que quede constancia de tal hecho en los núcleos en estado de abandono. De hecho en los núcleos abandonados destaca la presencia de la base del núcleo paralela al plano de percusión, pero sin que se recurra demasiado a un segundo plano de percusión. Este tipo de procedimiento se ha constatado también en el sílex negro, concretamente en el esquema operativo prismático tipo-B.

Hay en el conjunto lítico asimismo flancos transversales, que pueden proceder probablemente de las primeras secuencias de talla.

\section{Reparación/mantenimiento del plano de percusión}

Se produce en forma fundamentalmente de semitabletas de núcleo extraídas desde la superficie de extracciones, se limpia así el frente de percusión, dejando el plano de percusión liso y oblicuo. 


\section{FASE 3: RETOQUE}

En esta fase se tienden a seleccionar como norma general los soportes de mayor tamaño y hay una gestión específica de los soportes laminares: se eligen las hojas y hojitas más rectilíneas y de mejor calidad.

Las hojitas se utilizan fundamentalmente para la realización de hojitas de dorso. Las hojas se utilizan para piezas con retoque continuo, aprovechando por tanto el potencial de la longitud de sus bordes laterales como parte activa del útil. Al ser soportes largos y relativamente robustos se han utilizado también para realizar algún buril; y destaca la fabricación de geométricos. Este grupo tipológico, aunque es reducido (12 ejemplares en radiolarita), es destacable su presencia, no tanto por el número, como sí por estar todo el proceso de su preparación, tanto el esquema laminar para obtener las hojas, como la secuencia de rotura de los soportes seleccionados y los mismos microlitos retocados, incluso hay varias piezas que parecen corresponder a microlitos fallidos o en fase de retoque.

\section{IV.2.6.2.- ESQUEMA OPERATIVO DE LOS NÚCLEOS DE HOJAS}

La variación del esquema del primer grupo de núcleos de radiolarita radica en el tamaño del núcleo, el cual va a determinar unos soportes laminares de mayor longitud: hojas de hasta $5 \mathrm{~cm}$ de longitud; y también un método concreto de gestión del núcleo en la fase de producción.

\section{FASE 0-1: SELECCIÓN - PREPARACIÓN DEL NÚCLEO}

Esta fase no tiene ninguna variación respecto al esquema conceptual prismático que se acaba de esbozar. Tan solo habría que decir que se escogen en este caso nódulos con una longitud original que es difícil de deducir porque en radiolarita no hay nódulos o bloques sin tallar en el yacimiento; en todo caso el abandono de los núcleos se produce en los 5-6 cm de longitud, por lo que sería el tamaño mínimo. 
FASE 2:PRODUCCIÓN

\section{Secuencia de producción plena: método de avance frontal-envolvente}

En esta fase hay que destacar el método aplicado en la producción plena de los soportes, que es un método de débitage laminar en secuencias de extracciones de forma frontal-envolvente, de manera que dichas secuencias se van yuxtaponiendo entre sí avanzando por el contorno del núcleo. De esta forma en primer lugar se procede a extraer una serie de hojas en la superficie anterior por ejemplo; acto seguido se mueve ligeramente el núcleo para realizar una secuencia similar sobre lo que sería el flanco derecho del núcleo; y así se continuaría avanzando sobre el contorno del núcleo, llegando a afectar totalmente las superficies de dicho núcleo. El resultado sería un núcleo con extracciones por todo el contorno, como aparece en el núcleo $n^{\circ} 1542$, con un avance de la talla de forma totalmente envolvente, pero conservando los límites de las distintas caras del núcleo de forma perpendicular entre sí.

Este núcleo representa una destreza técnica (savoir-faire) destacable, ya que normalmente el método más cómodo de avance de un débitage laminar unipolar es el frontal o semi-envolvente, que es el más frecuente por otro lado en el propio conjunto de El Espertín. Este método envolvente limita las opciones para reparar la superficie de extracciones desde los laterales, ya que la superficie de extracciones es realmente una superficie continua. También impone unos límites al reavivado del plano de percusión, ya que no se puede extraer una tableta demasiado oblicua (cosa que suele ser lo más habitual), puesto que estropearía una zona del frente de percusión. Por el contrario, tiene la ventaja de que se explota al máximo la longitud del núcleo, a lo largo de todo su contorno.

Los métodos de avance del débitage de tipo envolvente son relativamente frecuentes vinculados a modos de talla complejos: la percusión indirecta y la presión. En estos casos, no obstante, los núcleos típicos como los de "mitra” o "en bala de fusil” tienen un avance totalmente circular, no en secuencias frontales yuxtapuestas, como es el núcleo de El Espertín. La conservación de la estructura prismática a lo largo de la gestión del volumen, puede estar provocada por el modo de talla que se está aplicando. 
En todo caso no hay en este núcleo rasgos que apunten a una percusión indirecta o presión, como sería por ejemplo una regularidad muy acusada entre las nervaduras.

El otro núcleo de hojas (Fig. R1.1: $\mathrm{n}^{\circ}$ 967) tiene un método frontal semienvolvente, con el plano de percusión muy oblicuo. No es posible saber si el hecho de no presentarse aquí un avance envolvente se debe a una intención concreta o a que no es posible adoptarlo por las dificultades que presenta la materia y los accidentes de talla. Me inclino a que son los límites de la materia los que imponen el método de avance adoptado.

\section{Secuencia de reparación/mantenimiento}

En estas secuencias de arreglo de la superficie de extracciones o del plano de percusión no habría variaciones respecto a lo que se ha apuntado para el esquema conceptual genérico.

\section{IV.2.6.3.- ESQUEMA OPERATIVO DE LOS NÚCLEOS DE HOJITAS}

La variante de los núcleos de hojitas, respecto al esquema conceptual genérico, es el tamaño de los núcleos cuya longitud está en torno a los $3 \mathrm{~cm}$., por lo demás el método de avance del débitage es frontal semi-envolvente, con un auto-mantenimiento de la carena y la cintra favorecido por este tipo de avance, que abarca los laterales del núcleo de forma axial, con la obtención también de "hojas con flanco". En uno de los núcleos (Figura R.1.2: $\mathrm{n}^{\circ}$ 964) se produce el empleo de un segundo plano de percusión, hacia uno de los laterales y la cara posterior, pero es un intento fallido porque las extracciones se reflejan en la zona de la cornisa.

Este procedimiento del segundo plano de percusión aparece en otro núcleo (Figura R1.2: $n^{\circ}$ 965), que se acerca a estos núcleos de hojitas, y en él se aprecia sobre la superficie de extracciones un método bipolar, que sería el único núcleo donde está presente. Este ejemplo explique quizás la presencia de estas secuencias de débitage bipolar que se han visto en varios flancos longitudinales. 


\section{IV.2.6.4.- ESQUEMA OPERATIVO DE LOS NÚCLEOS DE HOJITAS DE SUPERFICIE DE EXTRACCIONES ESTRECHA}

Por último estarían los tres núcleos de pequeño tamaño $(2 \mathrm{~cm})$ sobre los que se han extraído hojitas, frecuentemente de forma bipolar, tomando como superficie de extracciones un borde estrecho del núcleo. Estos núcleos tienen las siguientes peculiaridades:

- $\quad$ dos de ellos tienen restos de esquirlado (n 966 [Figura R1.3] y 1020)

- el otro está sumamente agotado (Figura R1.3: nº 1543)

El esquema de obtención de hojitas sobre un borde estrecho del núcleo, aparece también en el sílex negro, pero en ningún caso hay núcleos de tamaño tan pequeño a como se llega en la radiolarita. En el caso del núcleo agotado, hay una explotación bipolar de la superficie de extracciones y en uno de los planos de percusión se llega a una intensidad de preparación (esquirlado y abrasión) que, teniendo en cuenta el tamaño del núcleo, no se explica demasiado bien.

Los núcleos que tienen un esquirlado en uno de sus bordes, quizás se hallan seleccionado para la acción relacionada con dicho esquirlado, eligiendo soportes cuadrangulares y robustos, con un borde estrecho (sobre el que se produce el esquirlado) opuesto a una superficie más amplia (la del plano de percusión). 


\section{IV.2.6.5.- CADENA OPERATIVA EXPEDITIVA PARA LA OBTENCIÓN DE LASCAS}

Hay un núcleo de radiolarita representa una cadena operativa sencilla, a partir de la que se obtienen lascas de forma rápida ( $\left.\mathrm{n}^{\circ} 1059\right)$.

\section{IV.2.6.5.1. FASE 1: PREPARACIÓN}

Como en el esquema anterior, las características del bloque, con la presencia de los planos naturales, se van a aprovechar en la conformación del núcleo. La mayor diferencia con la cadena operativa prismática laminar anterior está en la orientación del nódulo de origen, en este caso la superficie de extracciones se toma a partir de su eje menor, al contrario del caso anterior que primaba la mayor longitud. La superficie de extracciones está delimitada así por dos superficies naturales del nódulo: aquella sobre la que se coloca el plano de percusión, y la base del núcleo.

\section{IV.2.6.5.2. FASE 2: PRODUCCIÓN}

La superficie de extracciones se ha colocado sobre una superficie ancha y relativamente corta. El eje de débitage está totalmente encuadrado por sendos planos paralelos (plano de percusión y base del núcleo), de forma que se puede avanzar en las extracciones de forma bastante rápida, ya que la carena está controlada por este encuadre de la superficie de extracciones. El inicio del débitage se produce sobre uno de los bordes del núcleo, utilizando las aristas naturales que proporcionan los planos naturales tan abundantes en la radiolarita. Las extracciones son grandes lascas que llegan hasta la base del núcleo, dejando carenas muy oblicuas y cóncavas, y contrabulbos muy marcados. Lo más probable es que se utilice como modo de talla el percutor duro. Precisamente esta concavidad de la carena es lo que más estropea las condiciones del núcleo para seguir su débitage. 


\section{IV.2.6.6.- CONCLUSIONES SOBRE LA RADIOLARITA}

Una vez analizada la radiolarita, se pueden resumir sus aspectos más importantes en los siguientes puntos:

- La materia prima se aporta una vez seleccionada en el lugar de adquisición, no se transportan nódulos o bloques, sino que se llevan los núcleos una vez que han sido probados y probablemente conformados. Como consecuencia, se plantea la hipótesis de que el lugar de adquisición no esté inmediatamente adyacente a la cueva, sino que se encuentre algo más alejado que el sílex negro.

- La forma como se presentan los nódulos de radiolarita determina totalmente los esquemas aplicados, favoreciendo una producción laminar sobre la superficie más larga de los bloques, pero limitando dicha producción por los abundantes planos naturales.

- Hay una cadena operativa dominante de tipo prismática unipolar para la obtención de hojas y hojitas.

- Destaca en este esquema conceptual el sentido unipolar de las extracciones, con la base de los núcleos paralela al plano de percusión.

- En dicha cadena se pueden diferenciar tres esquemas operativos: de hojas, de hojitas y de hojitas a partir de una superficie estrecha.

- El esquema de hojas encaja en el esquema prismático tipo-B definido en el sílex negro, incluyendo en este esquema los métodos de arreglo por flancos de núcleo longitudinales que limpian la tabla bien desde el plano de percusión principal o bien desde el opuesto. De estos últimos métodos han quedado los flancos existentes en el conjunto lítico, no tanto en los núcleos propiamente dichos.

- Hay una producción diferenciada de hojas y hojitas, basada fundamentalmente en el tamaño de los núcleos.

- El esquema de hojitas sobre superficie estrecha es el que más variantes presenta respecto a la cadena genérica. Sus peculiaridades quizás sean debidas bien a una intención de agotar al máximo la potencialidad del núcleo o bien a algún tipo de uso (piezas con esquirlado). 
- El método de producción plena es de tipo unipolar frontal, avanzando de forma semi-envolvente en los núcleos de hojitas y frontal-envolvente en los de hojas.

- Producción específica de hojitas para fabricar sobre todo piezas de dorso.

- Producción de hojas para un uso más diversificado, destacando la fabricación de geométricos.

- Selección de los soportes laminares de mayor regularidad y rectitud para ser retocados.

- Al lado de la cadena operativa prismática hay otra de tipo más oportunista, consistente en la extracción de lascas de forma rápida y expeditiva. 


\section{IV.3.- RADIOLARITA TIPO B (R2)}

La segunda variedad de radiolarita, de color verde-aceituna, tiene unas características muy cercanas a la radiolarita roja genérica, si bien su representación es menor $(n=367)$.

\section{IV.3.1.- CARACTERÍSTICAS GENERALES}

\section{IV.3.1.1.- LISTA TECNOLÓGICA, GRUPOS TECNOLÓGICOS}

El tipo de soporte más abundante (cuadro R2.1) son las lascas de tercer orden (38\%) seguidas por lasquitas de talla (26\%), las hojitas (14\%) y hojas (6\%) de tercer orden; el resto de los soportes de la lista tecnológica tienen una representación que no supera apenas el $1 \%$.

Respecto a la representación por grupos tecnológicos (cuadro R2.2) predomina el primer grupo (43\%), seguido por el grupo de los debris (28\%) y en tercer lugar el de los soportes laminares (21\%). La representación de este último grupo es prácticamente igual a la de la radiolarita genérica.

En las piezas retocadas (cuadro R2.3) no hay, al igual que la radiolarita roja, mucha variedad de soportes; predominan las lascas (28\%), seguidas por las hojitas (27\%) y las hojas (19\%) de tercer orden. En la representación por grupos tecnológicos (cuadro R2.4) se puede comprobar el predominio de los soportes laminares (51\%), pero, frente a lo que sucedía en la radiolarita roja, el grupo de las lascas es también relativamente abundante (34\%). 


\begin{tabular}{|c|c|c|c|c|}
\hline \begin{tabular}{|l} 
GRUPO \\
TECNOLÓGICO \\
\end{tabular} & $\mathbf{N}^{\circ}$ TEC. & SOPORTE & $\mathbf{N}$ & $\%$ \\
\hline \begin{tabular}{|l}
$\begin{array}{l}\text { GRUPO } 0 \\
\text { (nódulos) }\end{array}$ \\
\end{tabular} & 0 & Nódulo & & \\
\hline \multirow{6}{*}{$\begin{array}{l}\text { GRUPO } 1 \\
\text { (lascas) }\end{array}$} & 1 & Lasca de primer orden & 1 & 0,27 \\
\hline & 2 & Lasca de segundo orden & 2 & 0,54 \\
\hline & $2-5$ & Lasca laminar de segundo orden & & \\
\hline & 3 & Lasca de tercer orden & 140 & 38,15 \\
\hline & 3-6 & Lasca laminar & 17 & 4,63 \\
\hline & 4 & Hoja de primer orden & & \\
\hline \multirow{5}{*}{$\begin{array}{l}\text { GRUPO } 2 \\
\text { (soportes laminares) }\end{array}$} & 5 & Hoja de segundo orden & 1 & 0,27 \\
\hline & 6 & Hoja de tercer orden & 23 & 6,27 \\
\hline & 6-FN & Hoja de tercer orden con flanco & 2 & 0,54 \\
\hline & 7 & Hojita de segundo orden & 2 & 0,54 \\
\hline & 8 & Hojita de tercer orden & 50 & 13,62 \\
\hline \multirow{5}{*}{$\begin{array}{l}\text { GRUPO } 3 \\
\text { (productos de } \\
\text { acondicionamiento) }\end{array}$} & 9 & Lámina cresta & 7 & 1,91 \\
\hline & 10 & Tableta de núcleo & & \\
\hline & 11 & Semitableta de núcleo & & \\
\hline & 12 & Flanco de núcleo & 4 & 1,09 \\
\hline & 13 & Arista de núcleo y otros & 1 & 0,27 \\
\hline \multirow{5}{*}{$\begin{array}{l}\text { GRUPO } 4 \\
\text { (núcleos) }\end{array}$} & 14 & Núcleo prismático con un plano & 2 & 0,54 \\
\hline & 15 & Núcleo prismático con dos planos & & \\
\hline & 16 & Núcleo sobre lasca & 1 & 0,27 \\
\hline & 17 & Núcleo globuloso & & \\
\hline & 18 & Resto de núcleo & 1 & 0,27 \\
\hline \begin{tabular}{|l|}
$\begin{array}{l}\text { GRUPO } 7 \\
\text { (golpes buril) }\end{array}$ \\
\end{tabular} & 19 & Golpe de buril & 1 & 0,27 \\
\hline \multirow{3}{*}{$\begin{array}{l}\text { GRUPO } 5 \\
\text { (indeterminados) }\end{array}$} & 23 & Astilla de talla & 3 & 0,82 \\
\hline & 24 & Chunk & 6 & 1,63 \\
\hline & 25 & Indeterminado & 1 & 0,27 \\
\hline \multirow{2}{*}{\begin{tabular}{|l} 
GRUPO 6 \\
(debris)
\end{tabular}} & DEB-LT & Debris: lasquita & 97 & 26,43 \\
\hline & DEB-AT & Debris: astilla e indeterminados & 5 & 1,36 \\
\hline & & & 367 & 100 \\
\hline
\end{tabular}

Cuadro R2.1: lista tecnológica de radiolarita tipo-B.

\begin{tabular}{|lcc|}
\hline GRUPOS TEC. & $\mathbf{N}$ & $\mathbf{\%}$ \\
\hline 0 & & \\
1 & 160 & 43,6 \\
2 & 78 & 21,3 \\
3 & 12 & 3,3 \\
4 & 4 & 1,1 \\
5 & 10 & 2,7 \\
6 & 102 & 27,8 \\
7 & 1 & 0,3 \\
\hline & 367 & 100 \\
\hline
\end{tabular}

Cuadro R2.2: grupos tecnológicos de radiolarita tipo-B. 


\begin{tabular}{|c|c|c|c|c|}
\hline $\begin{array}{l}\text { GRUPO } \\
\text { TECNOLÓGICO }\end{array}$ & $N^{o}$ TEC. & SOPORTE & $\mathbf{N}$ & $\%$ \\
\hline $\begin{array}{l}\text { GRUPO } 0 \\
\text { (nódulos) }\end{array}$ & 0 & Nódulo & & \\
\hline $\begin{array}{l}\text { GRUPO } 1 \\
\text { (lascas) }\end{array}$ & $\begin{array}{l}1 \\
2 \\
2-5 \\
3 \\
3-6 \\
4\end{array}$ & $\begin{array}{l}\text { Lasca de primer orden } \\
\text { Lasca de segundo orden } \\
\text { Lasca laminar de segundo orden } \\
\text { Lasca de tercer orden } \\
\text { Lasca laminar } \\
\text { Hoja de primer orden }\end{array}$ & $\begin{array}{r}19 \\
4\end{array}$ & $\begin{array}{r}28,4 \\
6,0\end{array}$ \\
\hline $\begin{array}{l}\text { GRUPO } 2 \\
\text { (soportes laminares) }\end{array}$ & $\begin{array}{l}5 \\
6 \\
6-\mathrm{FN} \\
7 \\
8\end{array}$ & $\begin{array}{l}\text { Hoja de segundo orden } \\
\text { Hoja de tercer orden } \\
\text { Hoja de tercer orden con flanco } \\
\text { Hojita de segundo orden } \\
\text { Hojita de tercer orden }\end{array}$ & $\begin{array}{r}13 \\
2 \\
1 \\
18\end{array}$ & $\begin{array}{r}19,4 \\
3,0 \\
1,5 \\
26,9\end{array}$ \\
\hline $\begin{array}{l}\text { GRUPO } 3 \text { (productos } \\
\text { de } \\
\text { acondicionamiento) }\end{array}$ & $\begin{array}{l}9 \\
10 \\
11 \\
12 \\
13\end{array}$ & $\begin{array}{l}\text { Lámina cresta } \\
\text { Tableta de núcleo } \\
\text { Semitableta de núcleo } \\
\text { Flanco de núcleo } \\
\text { Arista de núcleo y otros }\end{array}$ & $\begin{array}{l}3 \\
1\end{array}$ & $\begin{array}{l}4,5 \\
1,5\end{array}$ \\
\hline $\begin{array}{l}\text { GRUPO } 4 \\
\text { (núcleos) }\end{array}$ & $\begin{array}{l}14 \\
15 \\
16 \\
17 \\
18\end{array}$ & $\begin{array}{l}\text { Núcleo prismático con un plano } \\
\text { Núcleo prismático con dos planos } \\
\text { Núcleo sobre lasca } \\
\text { Núcleo globuloso } \\
\text { Resto de núcleo }\end{array}$ & & \\
\hline $\begin{array}{l}\text { GRUPO } 7 \\
\text { (golpes buril) }\end{array}$ & 19 & Golpe de buril & & \\
\hline $\begin{array}{l}\text { GRUPO } 5 \\
\text { (indeterminados) }\end{array}$ & $\begin{array}{l}23 \\
24 \\
25\end{array}$ & $\begin{array}{l}\text { Astilla de talla } \\
\text { Chunk } \\
\text { Indeterminado }\end{array}$ & & \\
\hline $\begin{array}{l}\text { GRUPO } 6 \\
\text { (debris) }\end{array}$ & $\begin{array}{l}\text { DEB-LT } \\
\text { DEB-AT }\end{array}$ & $\begin{array}{l}\text { Debris: lasquita } \\
\text { Debris: astilla e indeterminados }\end{array}$ & 1 & 1,5 \\
\hline & & & 67 & 100 \\
\hline
\end{tabular}

Cuadro R2.3: lista tecnológica de los soportes retocados de sílex negro.

\begin{tabular}{|lcc|}
\hline GRUPOS TEC. & N & \% \\
\hline 0 & & \\
1 & 23 & 34,3 \\
2 & 34 & 50,7 \\
3 & 9 & 13,4 \\
4 & & \\
5 & & \\
6 & 1 & 1,5 \\
7 & & \\
\hline & 67 & 100 \\
\hline
\end{tabular}

Cuadro R2.4: grupos tecnológicos del sílex negro en las piezas retocadas. 
En el porcentaje de la utilización de los soportes en función de los elementos disponibles (cuadro R2.5) se pone de manifiesto el alto porcentaje de retoque presente en esta materia (18\%), ya que no sólo se retocan casi la mitad de las hojas y hojitas disponibles, sino que también se aprovechan las tres cuartas partes de los productos de acondicionamiento; incluso se utiliza un porcentaje de lascas más elevado (el 14\%) que en el sílex negro y la radiolarita roja. Hay, por tanto, un incremento del aprovechamiento de este tipo de materia, destacando la preferencia por los soportes laminares.

\begin{tabular}{|l|c|cc|}
\hline \multirow{2}{*}{ GRUPO TEC. } & \multirow{2}{*}{ TOTAL } & \multicolumn{2}{|c|}{ RETOCADAS } \\
\cline { 3 - 4 } & & $\mathrm{N}$ & $\%$ \\
\hline 0 & 160 & 23 & 14,4 \\
1 & 78 & 34 & 43,6 \\
2 & 12 & 9 & 75,0 \\
3 & 4 & & \\
4 & 10 & & \\
5 & 102 & 1 & 1,0 \\
6 & 1 & & \\
7 & 367 & 67 & 18,3 \\
\hline
\end{tabular}

Cuadro R2.5: piezas retocadas relativamente al total de las disponibles y según los distintos grupos tecnológicos.

\section{IV.3.1.2.- ROTURAS}

El porcentaje de roturas presentes en la radiolarita-B es también similar a la radiolarita genérica, suponiendo en torno al 74\% del conjunto (cuadro R2.6). 


\begin{tabular}{|c|c|c|c|c|c|c|c|}
\hline \multirow{2}{*}{$\begin{array}{l}\text { GRUPO } \\
\text { TEC. }\end{array}$} & \multirow{2}{*}{ TIPO TEC. } & \multirow{2}{*}{ COMPLETOS } & \multicolumn{4}{|c|}{ FRAGMENTADOS } & \multirow{2}{*}{ TOTAL } \\
\hline & & & Distal & Mesial & Proximal & Rota & \\
\hline \multirow[b]{2}{*}{1} & $\mathrm{~L}$ & 37 & 22 & 16 & 39 & 29 & 143 \\
\hline & $\begin{array}{l}\mathrm{L}-\mathrm{H} \\
\mathrm{H}\end{array}$ & 2 & 1 & 6 & 8 & & 17 \\
\hline \multirow{3}{*}{2} & $\mathrm{H}$ & 7 & 8 & 4 & 5 & & 24 \\
\hline & H-FN & 1 & 1 & & & & 2 \\
\hline & $\mathrm{HT}$ & 3 & 17 & 11 & 20 & 1 & 52 \\
\hline \multirow{5}{*}{3} & $\mathrm{LC}$ & 3 & 2 & 2 & & & 7 \\
\hline & $\mathrm{TN}$ & & & & & & \\
\hline & SN & & & & & & \\
\hline & FN & 2 & & & 2 & & 4 \\
\hline & AN & & 1 & & & & 1 \\
\hline 4 & $\mathrm{~N}$ & 4 & & & & & 4 \\
\hline 5 & IT & & & & & 10 & 10 \\
\hline \multirow{2}{*}{6} & $\mathrm{LT}$ & 36 & 15 & 5 & 22 & 19 & 97 \\
\hline & IT & & & & & 5 & 5 \\
\hline \multirow[t]{3}{*}{7} & GB & 1 & & & & & 1 \\
\hline & & & 67 & 44 & 96 & 64 & 367 \\
\hline & & $96(26,2 \%)$ & \multicolumn{4}{|c|}{$271(73,8 \%)$} & \\
\hline
\end{tabular}

Cuadro R2.6: representación de los tipos de soportes enteros y fragmentados de radiolarita, teniendo en cuenta la totalidad de las piezas.

\section{IV.3.1.2.1.- TIPOS DE ROTURAS}

Las roturas que inciden de forma transversal a los soportes son las que más afectan a este tipo de materia: las distales (36\%), las proximal-distales (21\%) y las proximales (16\%) (cuadro R2.7).

\begin{tabular}{|l|cccccccc|r|}
\hline & BL & DL & DP & DS & LT & PD & PL & PX & TOTAL \\
\hline GR.1: $\mathrm{L}$ & 1 & 8 & 18 & 48 & 2 & 27 & 15 & 13 & 132 \\
GR.2: $\mathrm{H}$ & & & 1 & 25 & & 19 & 1 & 19 & 65 \\
GR.3: P.A. & & & & 4 & & 3 & & 2 & 9 \\
GR.6: DEB & & 6 & 15 & 23 & 3 & 10 & 8 & 10 & 75 \\
\hline N & 1 & 14 & 34 & 100 & 5 & 59 & 24 & 44 & 281 \\
$\%$ & 0,4 & 5,0 & 12,1 & 35,6 & 1,8 & 21,0 & 8,5 & 15,7 & 100 \\
\hline
\end{tabular}

Cuadro R2.7:tipos de roturas en los distintos grupos tecnológicos. BL: bilateral, DL: distallateral, DP: distal-lateral-proximal, DS: distal, LT: lateral, PD: proximal-distal, PL: proximallateral, PX: proximal. 


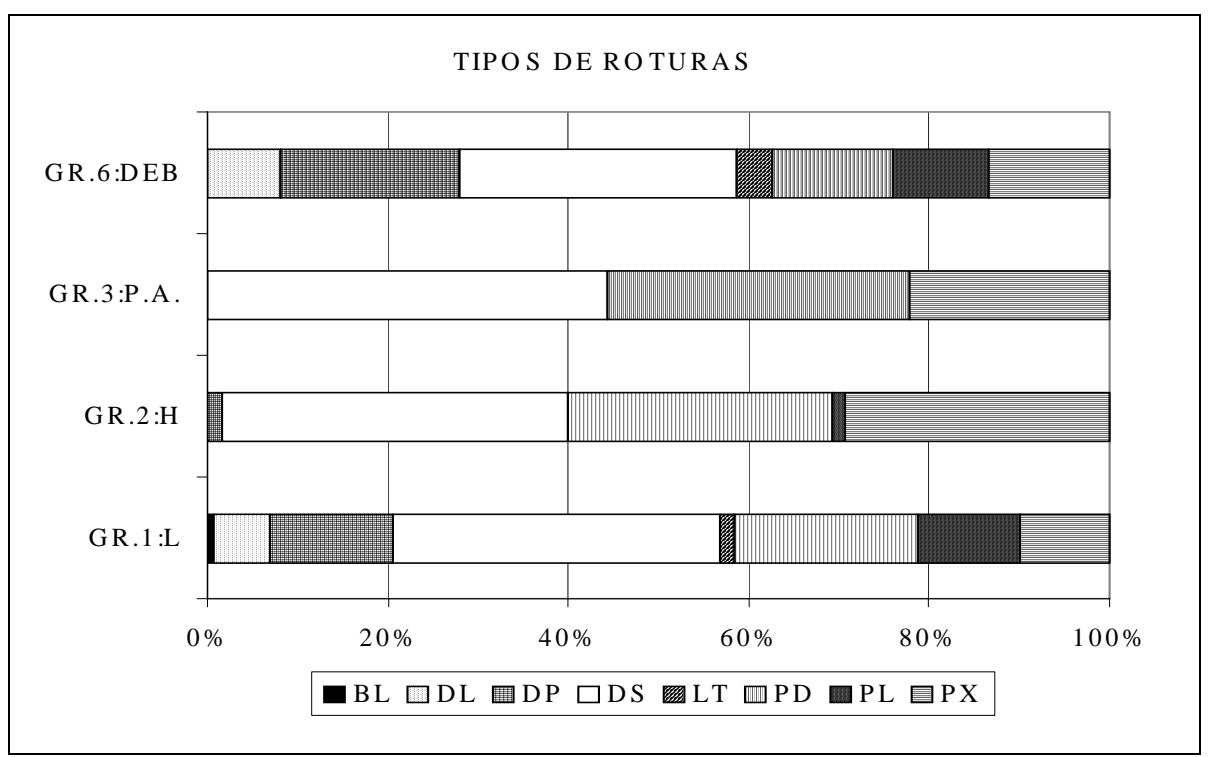

Gráfico R2.1: porcentaje de los tipos de roturas por grupos tecnológicos. Tipos de roturas: BL: bilateral, DL: distal-lateral, DP: distal-proximal-lateral, LT: lateral, PD: proximal-distal, PL: proximal-lateral, PX: proximal.

\section{IV.3.1.2.2.- CAUSA DE LA ROTURA}

La causa más frecuente (cuadro R2.8) es la flexión (42\%) y la rotura indeterminada (40\%), estando la percusión menos representada (17\%). Atendiendo a la forma como afecta a los distintos tipos de roturas, se puede observar (gráfico R2.2), cómo en los grupos 1 y 6 hay una representación bastante similar, pero con una mayor presencia de la flexión en el grupo 1 frente al incremento de las roturas indeterminadas en el grupo 6. Los grupos 2 y 3 son más difíciles de valorar debido al pequeño número de elementos representados. 

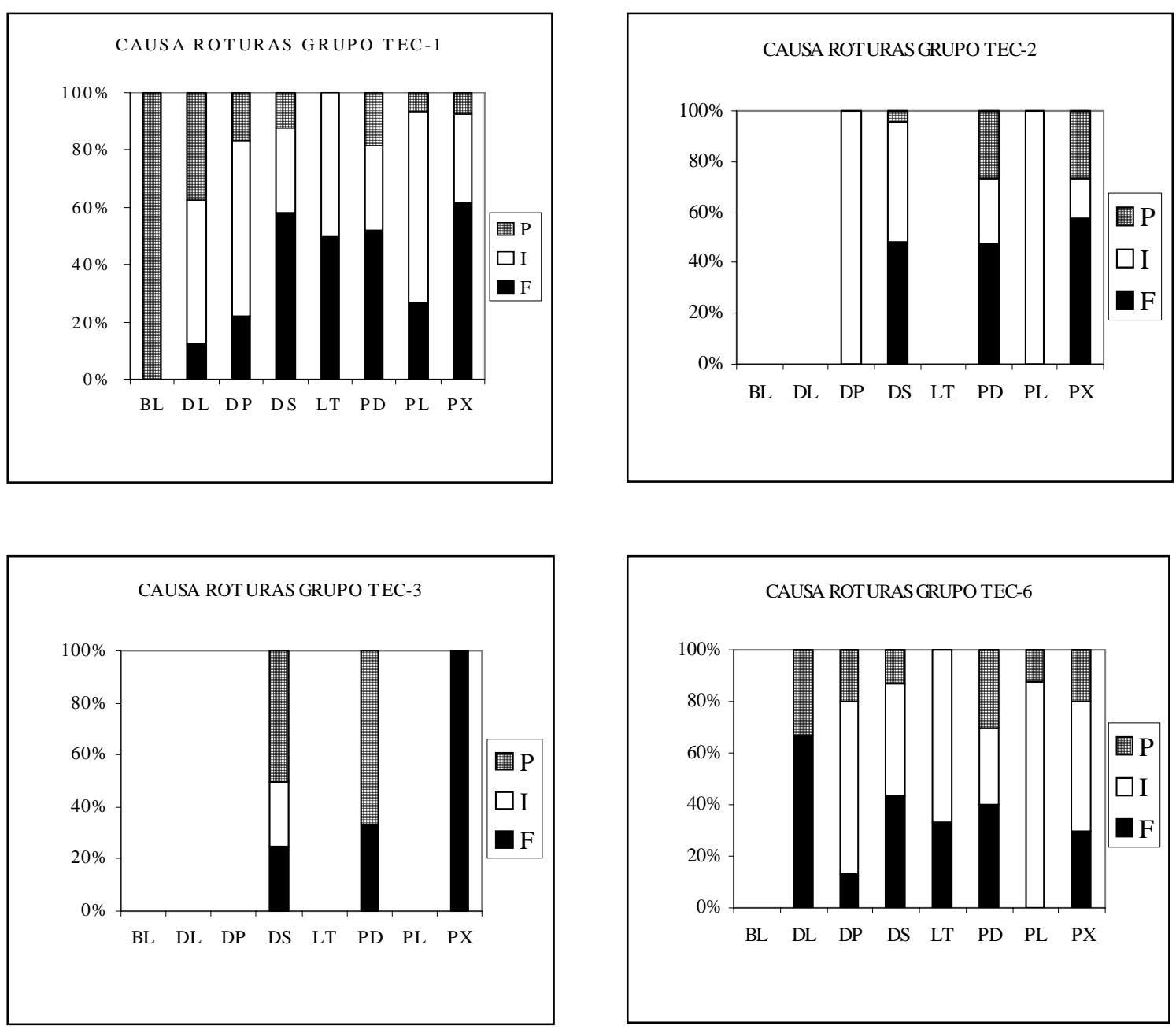

Gráfico R2.2: porcentaje de representación de las causas de la rotura según los distintos tipos de fracturas y según los grupos tecnológicos. En el eje de abscisas los tipos de fracturas: BL: bilateral, DL: distal-lateral, DP: distal-proximal-lateral, LT: lateral, PD: proximal-distal, PL: proximal-lateral, PX: proximal. En el eje de ordenadas se sitúa el porcentaje de los tipos de roturas: P: percusión, I: indeterminada, F: por flexión.

\begin{tabular}{|l|cccc|cc|}
\hline & GR.1 & GR.2 & GR.3 & GR.6 & N & $\%$ \\
\hline Flexión & 60 & 32 & 4 & 24 & 120 & 42,7 \\
Indeterminada & 52 & 22 & 1 & 37 & 112 & 39,9 \\
Percusión & 20 & 11 & 4 & 14 & 49 & 17,4 \\
\hline
\end{tabular}

Cuadro R2.8: causa rotura en los distintos grupos tecnológicos. 


\section{IV.3.1.3.- CÓRTEX}

Hay muy pocas piezas con córtex en la radiolarita tipo-B (cuadro R2.9), las cuales representan tan solo el $2 \%$ del conjunto.

\begin{tabular}{|c|c|c|c|c|c|c|c|}
\hline & \multicolumn{6}{|c|}{ CÓRTEX } & \multirow[t]{2}{*}{ TOTAL } \\
\hline & 1 & $\%$ & 2 & $\%$ & 3 & $\%$ & \\
\hline $\mathrm{L}$ & 1 & & 2 & & 140 & & 143 \\
\hline L-H & & & & & 17 & & 17 \\
\hline $\mathrm{H}$ & & & 1 & & 23 & & 24 \\
\hline H-FN & & & & & 2 & & 2 \\
\hline HT & & & 2 & & 50 & & 52 \\
\hline LC & & & & & 7 & & 7 \\
\hline $\mathrm{TN}$ & & & & & & & \\
\hline SN & & & & & & & \\
\hline FN & & & & & 4 & & 4 \\
\hline AN & & & & & 1 & & 1 \\
\hline Nuc. & & & & & 4 & & 4 \\
\hline GB & & & & & 1 & & 1 \\
\hline IT & & & & & 10 & & 10 \\
\hline DEB:LT & & & & & 97 & & 97 \\
\hline DEB:IT & & & & & 5 & & 5 \\
\hline TOTAL & 1 & 0,3 & 5 & 1,4 & 361 & 98,3 & 367 \\
\hline
\end{tabular}

Cuadro R2.9: presencia de córtex en los principales tipos tecnológicos, con sus respectivos porcentajes.

\section{IV.3.1.4.- DATOS MÉTRICOS}

\section{IV.3.1.4.1.- TIPOS DE SOPORTES}

Las lascas incluidas en el grupo 1 tienen unas dimensiones de $15 \mathrm{~mm}$ de longitud, 13 de anchura y 3,4 de grosor (cuadro R2.10). Las lascas laminares incrementan la anchura a 14 mm y también el grosor a 3,9 mm.

Los soportes laminares tienen unas medias de: $30 \mathrm{~mm}$ de longitud, 8 de anchura y 2,5 de grosor. Si separamos las hojas y hojitas, las primeras incrementan estos datos a $37 \mathrm{~mm}$ de longitud (con una dispersión que se extiende desde los 27 hasta los $67 \mathrm{~mm}$ ), 12 de anchura y 3,9 de grosor. Por su parte, las hojitas tienen unas medias de $19 \mathrm{~mm}$ de longitud (pero hay alguna hojita rota que llega a los $26 \mathrm{~mm}$ ), 7 de anchura y 2 de grosor. Es destacable por tanto el grosor de las hojas, que, con sus casi $4 \mathrm{~mm}$, son equiparables a las lascas laminares. 


\begin{tabular}{|c|c|c|c|c|c|c|c|}
\hline \multicolumn{4}{|l|}{ SIN RETOCAR } & \multicolumn{4}{|l|}{ RETOCADAS } \\
\hline GR1:L & $\mathbf{L}$ & A & G & GR1:L & $\mathbf{L}$ & A & G \\
\hline $\mathrm{N}$ & 32 & 91 & 116 & $\mathrm{~N}$ & 4 & 15 & 19 \\
\hline Rango & $9-33$ & $5-29$ & $1-11$ & Rango & $15-34$ & $8-36$ & $1,5-11$ \\
\hline Media & 14,97 & 13,29 & 3,40 & Media & 24,50 & 19,20 & 5,39 \\
\hline Desviación & 5,20 & 4,30 & 1,82 & Desviación & 7,85 & 8,12 & 2,51 \\
\hline GR1:L-H & $\mathbf{L}$ & $\mathbf{A}$ & $\mathbf{G}$ & GR1:L-H & $\mathbf{L}$ & A & G \\
\hline $\mathrm{N}$ & - & 14 & 14 & $\mathrm{~N}$ & 2 & 4 & 4 \\
\hline Rango & & $9-20$ & $2-10$ & Rango & 22 & $11-14$ & $2-5$ \\
\hline Media & & 14,27 & 3,88 & Media & & 12,53 & 3,4 \\
\hline Desviación & & 3,13 & 1,93 & Desviación & & 1,23 & 0,91 \\
\hline GR2:H & $\mathrm{L}$ & A & G & GR2:H & $\mathbf{L}$ & A & G \\
\hline $\mathrm{N}$ & - & - & - & $\mathrm{N}$ & 3 & 31 & 32 \\
\hline Rango & & & & Rango & $34-42$ & $4-18$ & $2-6$ \\
\hline Media & & & & Media & 38,33 & 9,18 & 2,81 \\
\hline Desviación & & & & Desviación & 4,04 & 4,68 & 1,20 \\
\hline GR2:H-FN & $\mathrm{L}$ & A & G & GR2:H-FN & $\mathbf{L}$ & A & G \\
\hline $\mathrm{N}$ & - & - & - & $\mathrm{N}$ & 1 & 2 & 2 \\
\hline Rango & & & & Rango & 48 & $12-23$ & $4-7$ \\
\hline Media & & & & Media & & & \\
\hline Desviación & & & & Desviación & & & \\
\hline GR3:P.A. & $\mathbf{L}$ & A & G & GR3:P.A. & $\mathbf{L}$ & A & G \\
\hline $\mathrm{N}$ & 3 & 4 & 4 & $\mathrm{~N}$ & 2 & 8 & 8 \\
\hline Rango & $18-47$ & $8-20$ & $3-7$ & Rango & $25-62$ & $10-28$ & $6-11$ \\
\hline Media & 29,33 & 15,5 & 4,75 & Media & & 17,0 & 8,83 \\
\hline Desviación & 15,50 & 5,20 & 1,71 & Desviación & & 5,98 & 1,61 \\
\hline GR4:N & $\mathbf{L}$ & A & G & GR4:N & $\mathrm{L}$ & A & G \\
\hline $\mathrm{N}$ & 4 & 4 & 4 & $\mathrm{~N}$ & - & - & - \\
\hline Rango & $23-37$ & $22-40$ & $15-20$ & Rango & & & \\
\hline Media & 29,50 & 30,25 & 16,88 & Media & & & \\
\hline Desviación & 5,80 & 7,41 & 2,32 & Desviación & & & \\
\hline GR5:IT & $\mathbf{L}$ & A & G & GR5:IT & $\mathrm{L}$ & A & G \\
\hline $\mathrm{N}$ & 10 & 10 & 10 & $\mathrm{~N}$ & - & - & - \\
\hline Rango & $11-34$ & $4-23$ & $2-13$ & Rango & & & \\
\hline Media & 16,60 & 11,85 & 6,36 & Media & & & \\
\hline Desviación & 6,64 & 5,63 & 3,34 & Desviación & & & \\
\hline GR6:DEB & $\mathbf{L}$ & A & G & GR6:DEB & $\mathbf{L}$ & A & G \\
\hline $\mathrm{N}$ & 94 & 94 & 94 & $\mathrm{~N}$ & 1 & 1 & 1 \\
\hline Rango & $5-10$ & $4-10$ & $1-5$ & Rango & 10 & 9 & 2 \\
\hline Media & 7,77 & 8,06 & 1,85 & Media & & & \\
\hline Desviación & 1,42 & 1,48 & 0,93 & Desviación & & & \\
\hline
\end{tabular}

Cuadro R2.10: datos métricos de la radiolarita, por grupos tecnológicos. $\mathrm{N}$ : número de elementos. L: longitud, A: anchura, G: grosor. 
Los productos de acondicionamiento tienen una longitud de $29 \mathrm{~mm}$, una anchura de 15 y grosor de 4,7. Destaca la escasa longitud de estos soportes respecto a los productos laminares. Asimismo los núcleos alcanzan una longitud media similar a los productos de acondicionamiento (29 $\mathrm{mm})$, y una anchura $(30 \mathrm{~mm})$ y grosor $(16,9 \mathrm{~mm})$ bastante reducidos. Los productos indeterminados representan unas piezas alargadas y relativamente gruesas (con una longitud de $17 \mathrm{~mm}$, anchura de 12 y grosor de 6,4) y por último los debris tienen unas medias que dibujan pequeñas piezas cuadrangulares de 8 mm de lado y 1,8 de grosor.

Respecto a estos datos métricos hay que hacer notar los siguientes aspectos:

- Las hojas tienen una longitud media muy elevada (30 mm), constituyendo la mayor media de las materias vistas hasta ahora (mayor incluso que el sílex negro), además la dispersión de esta medida llega hasta los $67 \mathrm{~mm}$, siendo la hoja que alcanza esta longitud, la pieza de mayor dimensión de todo el conjunto de la radiolarita-2.

- Los productos de acondicionamiento son también mayores que los núcleos, alcanzando en la dispersión de su longitud los 47 mm (un centímetro más que los núcleos).

El hecho de que los elementos de mayor longitud se encuentren en el grupo de los soportes laminares y, de forma secundaria, en los productos de acondicionamiento, es una circunstancia que no ocurre ni en la radiolarita genérica ni en el sílex negro. La explicación de esta circunstancia puede radicar en que la radiolarita tipo-B no haya sido sometida a un proceso de talla tan intenso como las materias anteriores, y que dicho proceso no se haya realizado de forma completa en el yacimiento. Se plantea por tanto la posibilidad de la existencia de una ruptura espacial en el débitage de la radiolarita tipo-B, de forma que las primeras secuencias de talla se habrían producido fuera del yacimiento, en el lugar de adquisición posiblemente. Esto explicaría la ausencia tanto de lascas grandes como de productos de acondicionamiento de tamaño también considerable, los cuales indicaran la progresiva disminución del tamaño de los núcleos. Se seleccionarían por tanto los soportes “de primera intención” de mayor longitud para llevar al yacimiento, así como los núcleos que se pueden continuar explotando, los 
cuales están ya preparados y listos para seguir una explotación de hojitas; son éstos precisamente los que aparecen en nuestro yacimiento.

\section{IV.3.1.4.2.- TALÓN}

Las dimensiones del talón (cuadro R2.11) son, como siempre, correlativas al tamaño y al tipo de soportes a que pertenecen, siendo las hojas y hojitas las piezas con talones más pequeños $(\mathrm{L}=4,5 \mathrm{~mm} ; \mathrm{A}=1,5)$.

\begin{tabular}{|c|c|c|c|c|c|}
\hline SIN RETOCAR & & & RETOCADAS & & \\
\hline GR1:L & $\mathbf{L}$ & A & GR1:L & $\mathbf{L}$ & $\mathbf{A}$ \\
\hline $\mathrm{N}$ & 39 & 49 & $\mathrm{~N}$ & 5 & 5 \\
\hline Rango & $4-21$ & $0,4-8$ & Rango & $3,5-15$ & $1,3-5$ \\
\hline Media & 8,07 & 2,75 & Media & 8,10 & 2,34 \\
\hline Desviación & 3,86 & 1,72 & Desviación & 4,77 & 1,52 \\
\hline GR1:L-H & $\mathbf{L}$ & $\mathbf{A}$ & GR1:L-H & $\mathbf{L}$ & $\mathbf{A}$ \\
\hline $\mathrm{N}$ & 5 & 5 & $\mathrm{~N}$ & 2 & 2 \\
\hline Rango & $7,6-8,5$ & $1,8-2$ & Rango & $6,5-8,5$ & $0,4-2$ \\
\hline Media & 8,04 & 2,36 & Media & & \\
\hline Desviación & 0,36 & 0,38 & Desviación & & \\
\hline GR2:H & $\mathbf{L}$ & $\mathbf{A}$ & GR2:H & $\mathbf{L}$ & $\mathbf{A}$ \\
\hline $\mathrm{N}$ & 21 & 21 & $\mathrm{~N}$ & 4 & 5 \\
\hline Rango & $2-7,6$ & $0,4-3,5$ & Rango & $4,7-8,2$ & $1,3-5,2$ \\
\hline Media & 4,50 & 1,50 & Media & 6,35 & 2,38 \\
\hline Desviación & 1,68 & 0,89 & Desviación & 1,56 & 1,61 \\
\hline GR3:P.A. & $\mathbf{L}$ & $\mathbf{A}$ & GR3:P.A. & $\mathbf{L}$ & $\mathbf{A}$ \\
\hline $\mathrm{N}$ & 2 & 3 & $\mathrm{~N}$ & 2 & 2 \\
\hline Rango & $3-9$ & $2,1-3,5$ & Rango & $8-10$ & $3,4-3,5$ \\
\hline Media & & 2,70 & Media & & \\
\hline Desviación & & 0,72 & Desviación & & \\
\hline GR6:DEB & $\mathbf{L}$ & $\mathbf{A}$ & GR6:DEB & $\mathbf{L}$ & $\mathbf{A}$ \\
\hline $\mathrm{N}$ & 14 & 21 & $\mathrm{~N}$ & - & - \\
\hline Rango & $1,8-8,7$ & $0,2-3,7$ & Rango & & \\
\hline Media & 4,93 & 1,29 & Media & & \\
\hline Desviación & 2,03 & 0,89 & Desviación & & \\
\hline
\end{tabular}

Cuadro R2.11: datos métricos de los talones de radiolarita tipo-B, por grupos tecnológicos. N: número de elementos. L: longitud, A: anchura, G: grosor. 


\section{IV.3.1.5.- ACCIDENTES}

En la representación de los accidentes de talla (cuadro R2.12), el comportamiento de esta materia es prácticamente igual a la radiolarita genérica. Predomina ampliamente los accidentes ocasionados por la presencia de los abundantes planos naturales (39\%) y de diaclasado interno propios de este tipo de materia. A continuación están los reflejados (29\%) y los pseudoburiles de Siret (19\%) y, en porcentajes inferiores, el doble bulbo, los sobrepasados y la fractura en lengüeta.

\begin{tabular}{|l|cccccc|r|}
\hline & DB & LG & PB & RF & SP & PN & TOTAL \\
\hline GR.1 & 4 & 3 & 13 & 14 & 1 & 25 & 60 \\
GR.2 & 1 & & 1 & 7 & 2 & 8 & 19 \\
GR.3 & & & & & & 1 & 1 \\
GR.6 & & & 5 & 8 & 1 & 5 & 19 \\
\hline TOTAL & 5 & 3 & 19 & 29 & 4 & 39 & 99 \\
$\%$ & 5,05 & 3,03 & 19,19 & 29,29 & 4,04 & 39,39 & 100 \\
\hline
\end{tabular}

Cuadro R2.12: accidentes de talla según los distintos grupos tecnológicos. DB: dobre bulbo, LG: fragmento en lengüeta, PB: pseudoburil de Siret, RF: reflejado, SP: sobrepasado, PN: plano natural.

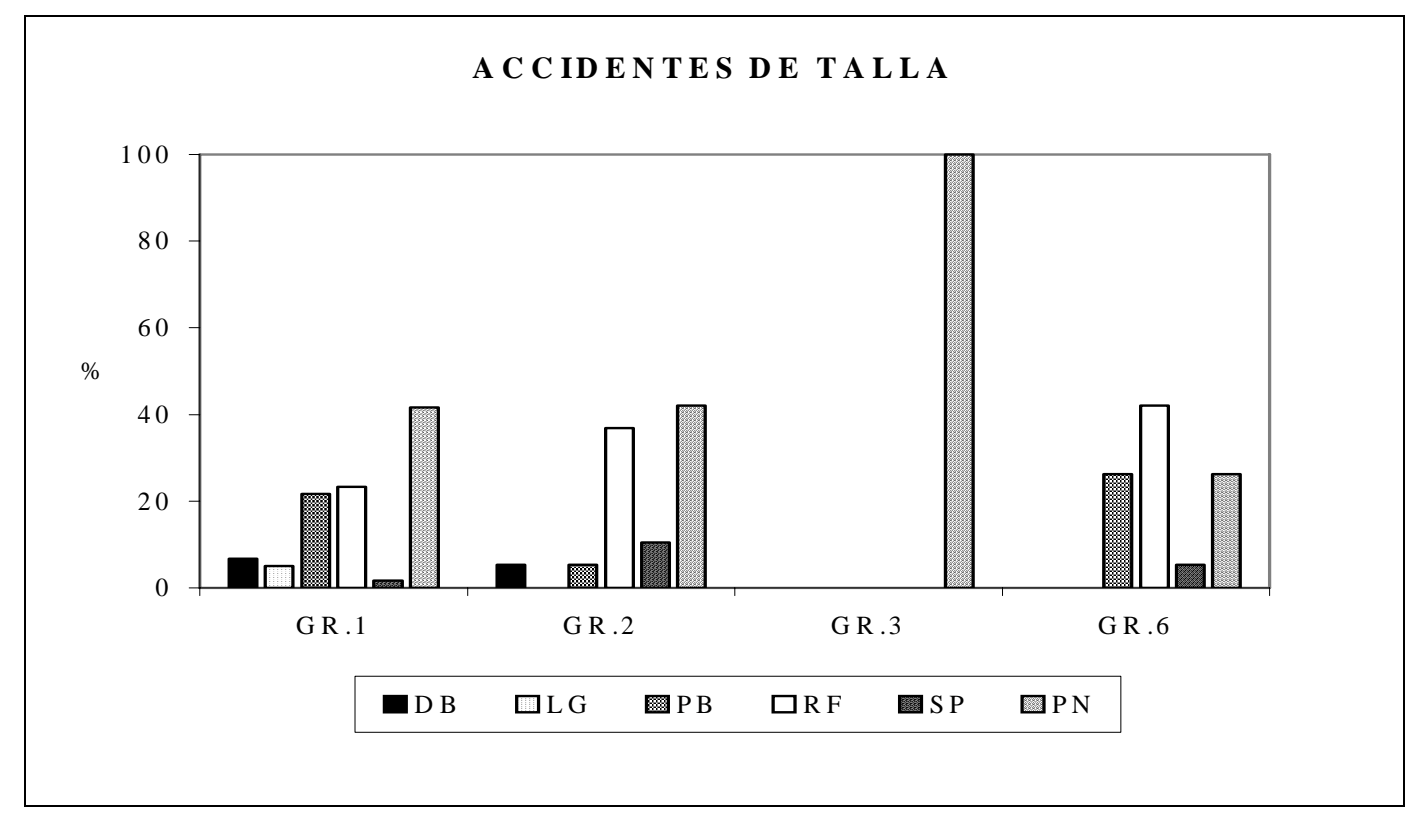

Gráfico R2.3: accidentes de talla por grupos tecnológicos. DB: dobre bulbo, LG: fragmento en lengüeta, PB: pseudoburil de Siret, RF: reflejado, SP: sobrepasado, PN: plano natural.

Si analizamos a representación de estos distintos accidentes según los grupos tecnológicos (gráfico R2.3), los planos naturales predominan en todos, excepto en los 
debris, que están más afectados por reflejados. El doble bulbo, por su parte, es más frecuente en los soportes del grupo 1; y el pseudoburil es también más abundante en el grupo 1 y 6. De este modo, en los grupos tecnológicos de las lascas y los debris es donde más aparecen los accidentes situados en torno al punto de impacto, vinculados posiblemente a algún gesto inherente al modo de talla; tal y como sucedía también en el caso del sílex negro, para el que se comentó la posibilidad de la percusión directa con percutor duro.

\section{IV.3.1.6.- TIPOS DE TALÓN}

\begin{tabular}{|l|cccccccc|r|}
\hline & $\mathrm{C}$ & $\mathrm{D}$ & $\mathrm{F}$ & $\mathrm{L}$ & $\mathrm{O}$ & $\mathrm{P}$ & $\mathrm{R}$ & $\mathrm{S}$ & TOTAL \\
\hline GR.1 & & 8 & 16 & 37 & 73 & 7 & 13 & 6 & 160 \\
GR.2 & & 9 & 4 & 15 & 41 & 4 & 1 & 4 & 78 \\
GR.3 & & 1 & 2 & 3 & 5 & & 1 & & 12 \\
GR.6 & 1 & 1 & 5 & 16 & 47 & 21 & 11 & & 102 \\
\hline TOTAL & 1 & 19 & 27 & 71 & 166 & 32 & 26 & 10 & 352 \\
$\%$ & 0,28 & 5,40 & 7,67 & 20,17 & 47,16 & 9,09 & 7,39 & 2,84 & 100 \\
\hline
\end{tabular}

Cuadro R2.13 tipos de talón por grupos tecnológicos. C: cortical, D: diedro, F: facetado, L: liso, O: sin talón, P: puntiforme, R: roto, S: suprimido.

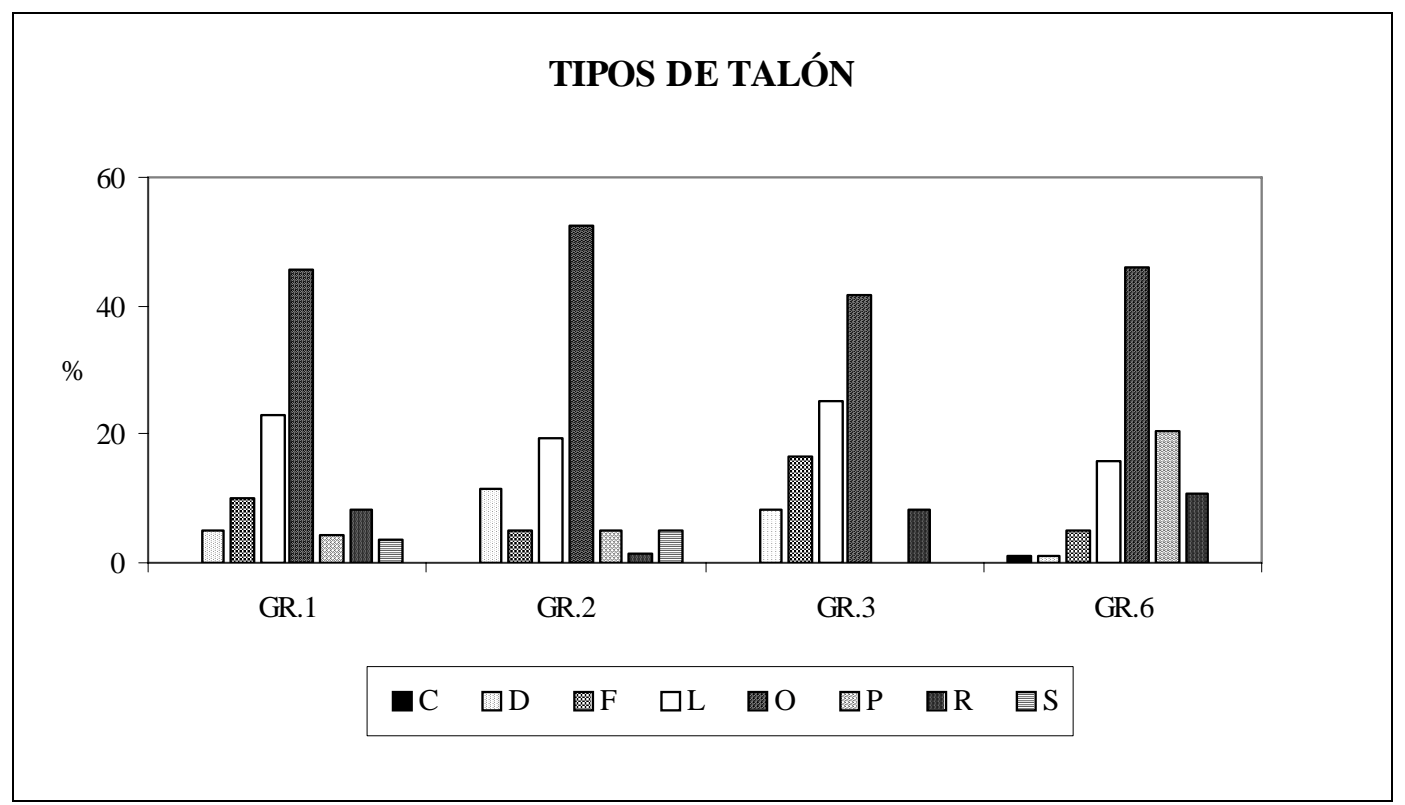

Gráfico R2.4: tipos de talón por grupos tecnológicos. C: cortical, D: diedro, F: facetado, L: liso, O: sin talón, P: puntiforme, R: roto, S: suprimido. 
$\mathrm{Al}$ igual que en las materias analizadas anteriormente, predominan las piezas sin talón (cuadro R2.6) debido a que prácticamente la mitad de los elementos tienen la zona proximal rota (cuadro R2.6). De nuevo también, después de los “sin talón”, son los talones lisos los más abundantes (20\%), seguidos, en menor proporción por los puntiformes, los facetados, los rotos, los diedros, los suprimidos y por último los corticales. La representación de los distintos tipos de talones según los grupos tecnológicos (gráfico R2.4) no tiene, en general, demasiadas variaciones, tan solo habría que señalar que los debris es el grupo en el que mayor importancia alcanzan los puntiformes.

\section{IV.3.1.7.- PREPARACIÓN DEL PUNTO DE IMPACTO}

En la preparación del punto de impacto, siguiendo la tónica general vista hasta ahora, es el grupo de las hojas-hojitas el que cuenta con un porcentaje de preparación más intenso (el 53\% de este tipo de soportes presentan preparación) (cuadro R2.14).

\begin{tabular}{|c|c|cc|cc|}
\hline \multirow{2}{*}{ TOTAL } & \multicolumn{2}{|c|}{ PIEZAS CON TALÓN } & \multicolumn{2}{c|}{ PIEZAS PREPARADAS } \\
\cline { 3 - 6 } & & $\mathrm{N}$ & $\%$ & $\mathrm{~N}$ & $\%$ \\
\hline GR-1 & 160 & 86 & 53,8 & 19 & 22,1 \\
GR-2 & 78 & 36 & 46,2 & 19 & 52,8 \\
GR-3 & 12 & 7 & 58,3 & 2 & 28,6 \\
GR-6 & 102 & 58 & 56,9 & 22 & 37,9 \\
\hline & 352 & 187 & 53,1 & 62 & 33,2 \\
\hline
\end{tabular}

Cuadro R2.14: piezas con talón y preparación relativa dentro de los distintos grupos tecnológicos

\begin{tabular}{|l|cccc|cc|}
\hline & \multirow{2}{*}{ GR-1 } & \multirow{2}{*}{ GR-2 } & \multirow{2}{*}{ GR-3 } & \multirow{2}{*}{ GR-6 } & \multicolumn{2}{|c|}{ TOTAL } \\
\cline { 6 - 8 } & & & & & N & $\%$ \\
\hline Facetado & 5 & & 1 & & 6 & 7,8 \\
Abrasión & 3 & 4 & & 7 & 14 & 18,2 \\
Esquirlado & 10 & 9 & 1 & 8 & 28 & 36,4 \\
Retoque & 16 & 6 & & 7 & 29 & 37,7 \\
\hline & 34 & 19 & 2 & 22 & 77 & 100 \\
\hline
\end{tabular}

Cuadro R2.15: tipos de preparación según los distintos grupos tecnológicos.

En cuanto al tipo de preparación concreta efectuada sobre el talón, el esquirlado y el retoque alcanzan porcentajes similares (en torno al 37\%), por delante de la abrasión 
(18\%) y el facetado (cuadro R2.15). Atendiendo a los distintos grupos tecnológicos la abrasión, aunque no llega a predominar, es más abundante entre las hojas-hojitas y los debris.

Respecto a los tipos de talones preparados, son los lisos y los facetados los que han sido más preparados (cuadro R2.16). En el tipo de preparación concreta de estos distintos talones (cuadro R2.17), el esquirlado predomina sobre los talones diedros, puntiformes y rotos; mientras que el retoque es más frecuente sobre los lisos. La abrasión no alcanza nunca una presencia demasiado marcada.

\begin{tabular}{|l|cccccccc|}
\hline & $\mathrm{C}$ & $\mathrm{D}$ & $\mathrm{F}$ & $\mathrm{L}$ & $\mathrm{P}$ & $\mathrm{R}$ & $\mathrm{S}$ & $\mathrm{O}$ \\
\hline PIEZAS CON TALÓN & 1 & 19 & 27 & 71 & 166 & 32 & 26 & 10 \\
\hline PIEZAS PREPARADAS & & 7 & 15 & 37 & 13 & 4 & 1 & \\
$\%$ & & 36,8 & 55,6 & 52,1 & 7,83 & 12,5 & 3,85 & \\
\hline
\end{tabular}

Cuadro R2.16: porcentaje de preparación en los distintos tipos de talón disponibles. C: cortical, D: diedro, F: facetado, L: liso, P: puntiforme, R: roto, S: suprimido, O: sin talón.

\begin{tabular}{|l|cccccccc|}
\hline & $\mathrm{C}$ & $\mathrm{D}$ & $\mathrm{F}$ & $\mathrm{L}$ & $\mathrm{P}$ & $\mathrm{R}$ & $\mathrm{S}$ & $\mathrm{O}$ \\
\hline Facetado & & 0 & 6 & & & & & \\
Abrasión & & 2 & 0 & 7 & 4 & 1 & & \\
Esquirlado & & 3 & 5 & 11 & 6 & 2 & 1 & \\
Retoque & & 2 & 4 & 19 & 3 & 1 & & \\
\hline TOTAL & & 7 & 15 & 37 & 13 & 4 & 1 & \\
$\%$ & & 9,1 & 19,5 & 48,1 & 16,9 & 5,2 & 1,3 & \\
\hline
\end{tabular}

Cuadro R2.17: tipos de preparación sobre los distintos tipos de talón. C: cortical, D: diedro, F: facetado, L: liso, P: puntiforme, R: roto, S: suprimido, O: sin talón.

En el tipo de preparación según los distintos tipos de talón y separando también por grupos tecnológicos (cuadro R2.18) las tendencias que aparecen son:

- en el grupo tecnológico 1 un tercio de las piezas tienen los talones lisos preparados por retoque

- en el grupo 2 predomina la preparación de los talones lisos, mediante todas sus variantes (abrasión, esquirlado y retoque), sin que ninguna de ellas predomine claramente 
- el grupo de los productos de acondicionamiento apenas cuenta con elementos sobre los que se pueda valorar estos atributos

- en el grupo de los debris predominan los talones puntiformes preparados por esquirlado y abrasión; y los lisos por abrasión y retoque

\begin{tabular}{|l|cccccccc|}
\hline TEC-1 & C & D & F & L & P & R & S & O \\
\hline Facetado & & & 14,7 & & & & & \\
Abrasión & & 5,9 & & 2,9 & & & & \\
Esquirlado & & 2,9 & 8,8 & 14,7 & 2,9 & & & \\
Retoque & & 2,9 & 8,8 & $\mathbf{3 5 , 3}$ & & 2,9 & & \\
\hline
\end{tabular}

\begin{tabular}{|l|cccccccc|}
\hline TEC-2 & C & D & F & L & P & R & S & O \\
\hline Facetado & & & & & & & & \\
Abrasión & & & & 15,8 & 5,3 & & & \\
Esquirlado & & 10,5 & 5,3 & $\mathbf{2 1 , 1}$ & 5,3 & & 5,3 & \\
Retoque & & 5,3 & 5,3 & 15,8 & 5,3 & & & \\
\hline
\end{tabular}

\begin{tabular}{|l|cccccccc|}
\hline TEC-3 & C & D & F & L & P & R & S & O \\
\hline Facetado & & & 50,0 & & & & & \\
Abrasión & & & & & & & & \\
Esquirlado & & & & & & 50,0 & & \\
Retoque & & & & & & & & \\
\hline
\end{tabular}

\begin{tabular}{|c|c|c|c|c|c|c|c|c|}
\hline TEC-6 & $\mathrm{C}$ & $\mathrm{D}$ & $\bar{F}$ & $\bar{L}$ & $P$ & $\mathrm{R}$ & $\mathrm{S}$ & $\bar{O}$ \\
\hline \multicolumn{9}{|l|}{ Facetado } \\
\hline Abrasión & & & & 13,6 & 13,6 & 4,5 & & \\
\hline Esquirlado & & & 4,5 & 9,1 & 9,1 & 4,5 & & \\
\hline Retoque & & & 4,5 & 8,2 & 8,2 & & & \\
\hline
\end{tabular}

Cuadro R1.18: porcentaje de tipo de preparación en los distintos tipos de talón, según grupos tecnológicos. C: cortical, D: diedro, F: facetado, L: liso, P: puntiforme, R: roto, S: suprimido, O: sin talón.

\section{IV.3.1.8.- ÁNGULO DE PERCUSIÓN}

Respecto a la combinación de los ángulos del talón (cuadro R2.19), en todos los grupos tecnológicos predomina un frente de talla abierto (Eb/Ea, cercano al ángulo recto), excepto en los debris, donde habría un frente más cerrado (Fb/Da). Si observamos el ángulo 2 en el total de los elementos del conjunto, el ángulo abierto $\left(\mathrm{Ea}=80-90^{\circ}\right)$ representa casi la mitad de los elementos. 

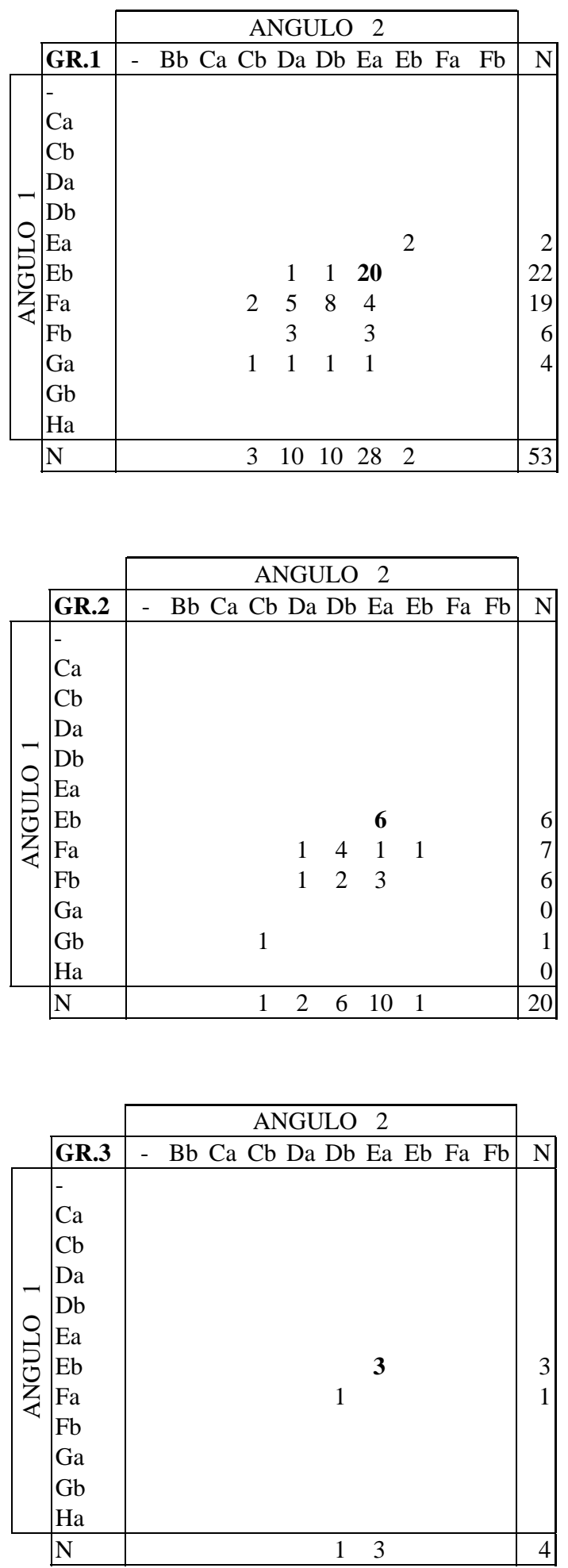

Cuadro R2.19: ángulos de percusión según los distintos grupos tecnológicos. Angulo 1: ángulo interno (entre talón y el bulbo). Angulo 2: ángulo externo o de la cornisa (entre talón y la cara superior). $\mathrm{Bb}=30-40^{\circ}, \mathrm{Ca}=40-50^{\circ}, \mathrm{Cb}=50-60^{\circ}, \mathrm{Da}=60-70^{\circ}, \mathrm{Db}=70-80^{\circ}, \mathrm{Ea}=80-90^{\circ}, \mathrm{Eb}=90-100^{\circ}$, $\mathrm{Fa}=100-110^{\circ}, \mathrm{Fb}=110-120^{\circ}, \mathrm{Ga}=120-130^{\circ}, \mathrm{Gb}=130-140^{\circ}, \mathrm{Ha}=140-150^{\circ}$. 

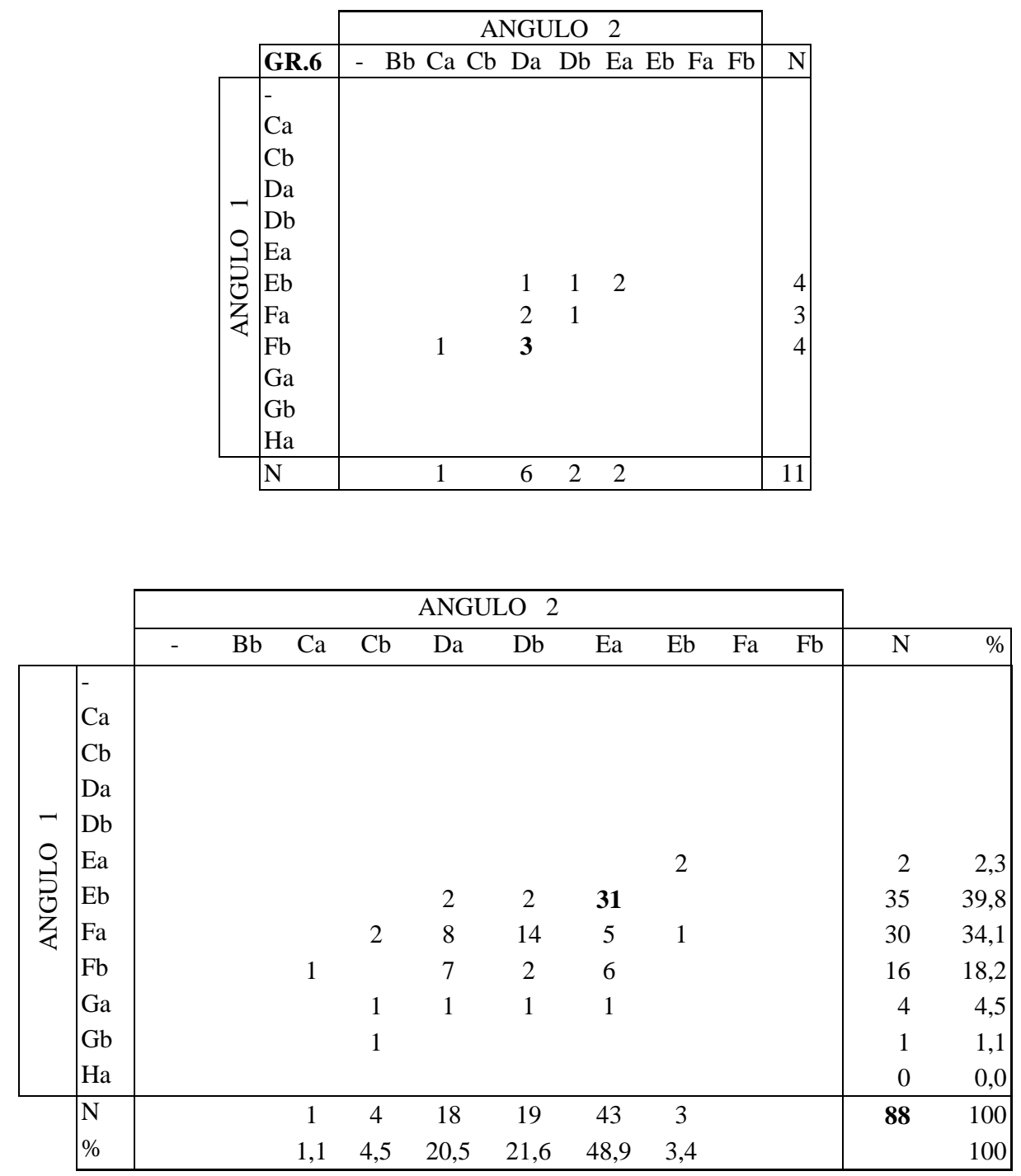

Cuadro R2.19 (continuación): ángulos de percusión en el grupo tecnológico 6 y en total en el último cuadro. Angulo 1: ángulo interno (entre talón y el bulbo). Angulo 2: ángulo externo o de la cornisa (entre talón y la cara superior). $\mathrm{Bb}=30-40^{\circ}, \mathrm{Ca}=40-50^{\circ}, \mathrm{Cb}=50-60^{\circ}, \mathrm{Da}=60-70^{\circ}$, $\mathrm{Db}=70-80^{\circ}, \mathrm{Ea}=80-90^{\circ}, \mathrm{Eb}=90-100^{\circ}, \mathrm{Fa}=100-110^{\circ}, \mathrm{Fb}=110-120^{\circ}, \mathrm{Ga}=120-130^{\circ}, \mathrm{Gb}=130-140^{\circ}$, $\mathrm{Ha}=140-150^{\circ}$.

\section{IV.3.1.9.- AlTERACIONES}

Tan solo hay una pieza en la radiolarita tipo-B que presenta algún tipo de alteración, en concreto de tipo térmico. 


\section{IV.3.1.10.- MODO DE TALLA}

Sobre la radiolarita tipo-B no se ha podido constatar el modo de talla de forma directa sobre ninguna pieza. De todas formas, a partir de la preparación del punto de impacto, se observa un cambio en los gestos vinculados al modo de talla sobre los soportes laminares. La extracción de este tipo de piezas se prepara más que el resto de los soportes, además el tipo de preparación que se produce es mucho más cuidadoso que para el resto. A esto hay que añadir el hecho de que los talones tienen unas dimensiones muy reducidas, lo cual conduce a un tipo de percusión tangencial.

\section{IV.3.2.- NÚCLEOS}

Como en el resto de las materias primas, las características de los esquemas técnicos de los núcleos se esquematizan en tres cuadros: R2.20 para las características genéricas, R2.21 para la superficie de extracciones y R2.22 para el plano de percusión.

\section{IV.3.2.1.- AtRIBUtos BÁsICOS}

\section{Tipo de núcleos}

Hay cuatro núcleos de radiolarita tipo-B, dos prismáticos unipolares, uno piramidal y un resto de núcleo. Hay una última pieza (ESP97/C8/S10/N2-3/B1.4), clasificada como chunk, que puede corresponder a un resto de núcleo del tipo de los bipolares con esquirlado opuesto, esquema que ya se ha visto en la radiolarita genérica.

El piramidal es un núcleo de hojitas con una explotación frontal (ID n ${ }^{\circ} 249$ ). El esquema esbozado en este núcleo es similar al esquema operativo prismático tipo-A definido para el chert negro. Las características más significativas de este tipo de núcleo es la morfología triangular de la tabla de extracciones, con un avance del débitage de tipo frontal. El mantenimiento de este tipo de débitage, en especial la cintra, es posible a lo largo del mismo ritmo de explotación laminar, ya que se procura que los laterales del núcleo converjan con la superficie de extracciones de forma ortogonal aproximadamente. La base del núcleo además es una arista perpendicular a la tabla, 
provocando unas extracciones de sentido convergente y modelando por tanto esa estructura piramidal. Al mismo tiempo esta solución en la base del núcleo permite un control de la carena, propiciada asimismo por la escasa longitud del núcleo.

El primer núcleo clasificado como prismático (ID $n^{\circ}$ 248) encaja también en el mismo esquema operativo que el anterior; está fabricado sobre una lasca, de la que se selecciona un borde sobre el que abrir la superficie de extracciones. Ésta es estrecha y alargada, con la base del núcleo ortogonal a ella, como en el caso anterior. Sobre este núcleo se produce una explotación bipolar de hojitas. Sería un esquema de núcleo tipoburil.

El segundo núcleo prismático (ID n² 247) pertenece al esquema operativo de los núcleos de superficie ancha, determinado en el sílex negro. En este caso se explota de forma semi-envolvente y unipolar una superficie bastante ancha con relación a su longitud para la extracción de hojas y lascas-laminares. La base del núcleo no es ortogonal como en los casos anteriores, más bien parece que se ha preferido una base paralela al plano de percusión, si bien en el momento de abandono del núcleo una de las últimas extracciones se ha sobrepasado. La carena y la cintra se mantienen a partir de las aristas de los bordes laterales, mediante crestas laterales.

El último núcleo (ID $n^{0}$ 237) es en realidad un fragmento en el que se puede observar un plano de percusión amplio y una cornisa sobre uno de sus bordes, sin que sea posible deducir un esquema técnico concreto en el mismo.

\section{Dimensiones}

Las dimensiones medias de los núcleos de radiolarita dan idea del tamaño reducido de los núcleos de radiolarita, ya que tanto su longitud como su anchura se sitúan en torno a los $3 \mathrm{~cm}$ y su grosor no llega a los $2 \mathrm{~cm}$ (cuadro R2.10). En los tres primeros núcleos no se llega a sobrepasar los tres centímetros de longitud. La anchura es más variable debido a que se han explotado según dos esquemas operativos distintos, siendo el último el que tiene una mayor anchura $(4 \mathrm{~cm})$. Por el contrario el resto de núcleo tiene unas dimensiones relativamente amplias, mayores que los núcleos 
anteriores, con lo que se correspondería con un fragmento eliminado en un momento del débitage del núcleo en plena fase de explotación.

El tamaño reducido de los núcleos puede relacionarse con el hecho de que se lleven al yacimiento los bloques una vez conformados, preparados para llevar a cabo las últimas secuencias de la fase de producción plena, centrada en la obtención de hojitas sobre todo. Se habría desarrollado por tanto un tipo de explotación intensiva sobre unos bloques seleccionados y preparados en un contexto diferente al yacimiento, posiblemente el lugar de aprovisionamiento de este tipo de radiolarita.

\section{Córtex}

En todos los casos se trata de núcleos sin restos de córtex, si bien hay que señalar que se constata en el núcleo piramidal la presencia de un plano de diaclasado interno de la materia que ha sido utilizado como cara posterior. Hay que recordar que la radiolarita se presenta en su fuente de origen de forma masiva y tableada, con líneas de sedimentación a lo largo del nivel afloramiento así como abundantes planos de diaclasado interno. En el caso de la radiolarita rojiza se había constatado el empleo de estos planos de sedimentación y de diaclasado a la hora de conformar el núcleo, reservándolos para instalar alguna de las superficies estructurales del núcleo (el plano de percusión, la superficie posterior o alguno de los flancos). En el caso de la radiolarita verde se constata en un solo núcleo, pero, teniendo en cuenta que el número de núcleos de esta variedad es muy pequeño, se puede afirmar que el comportamiento en ambos tipos de radiolarita es análogo.

\section{Descripción de la superficie de extracciones}

Las superficies de extracciones se instalan sobre la cara anterior y el avance del débitage se produce de forma frontal en el caso del núcleo piramidal y semi-envolvente en los otros dos núcleos. El caso del avance frontal parece ser característico del esquema operativo desarrollado en ese núcleo concreto. 


\section{Preparación en otras partes de los núcleos}

En los tres núcleos sobre los que se han podido determinar los esquemas técnicos hay constancia de una preparación más o menos cuidadosa del bloque antes de la fase de producción plena. En el núcleo piramidal y el prismático de hojitas sobre lasca hay una conformación de la base del núcleo específica, ésta es una arista perpendicular a la superficie de extracciones. Cuando se analizaron los núcleos de sílex negro se vio ya el empleo de este recurso en núcleos prismáticos de tendencia piramidal. Dicho método permite una construcción del núcleo de forma que la superficie de extracciones sea ortogonal a los flancos del núcleo, favoreciendo un avance del débitage frontal. La cintra se controla por la disposición de los flancos, la carena se puede mantener en el proceso de extracciones debido a que la longitud del núcleo no es excesiva. Esto explica también que este tipo de método aparezca en núcleos de hojitas. Al mismo tiempo la base del núcleo permite controlar los flancos y produce una tendencia a que las extracciones sean convergentes.

El núcleo que explota una superficie ancha tiene también una preparación del volumen previa a su fase de producción. En este caso la construcción del núcleo difiere sobre todo en que la base es una superficie paralela al plano de percusión y los bordes laterales se van a aprovechar mediante crestas para acondicionar la superficie de extracciones (cintra y carena).

\section{Soportes extraídos}

Los negativos presentes en los núcleos de la radiolarita-B son laminares, en el caso del núcleo piramidal y el prismático sobre lasca se obtienen hojitas, en el núcleo de superficie ancha se extraen hojas y lascas-laminares.

\section{Causa del abandono}

Prácticamente en los tres núcleos hay un agotamiento de la explotación del mismo, con la aparición de reflejados o también pérdida de la carena, por ejemplo en el núcleo de superficie ancha. 

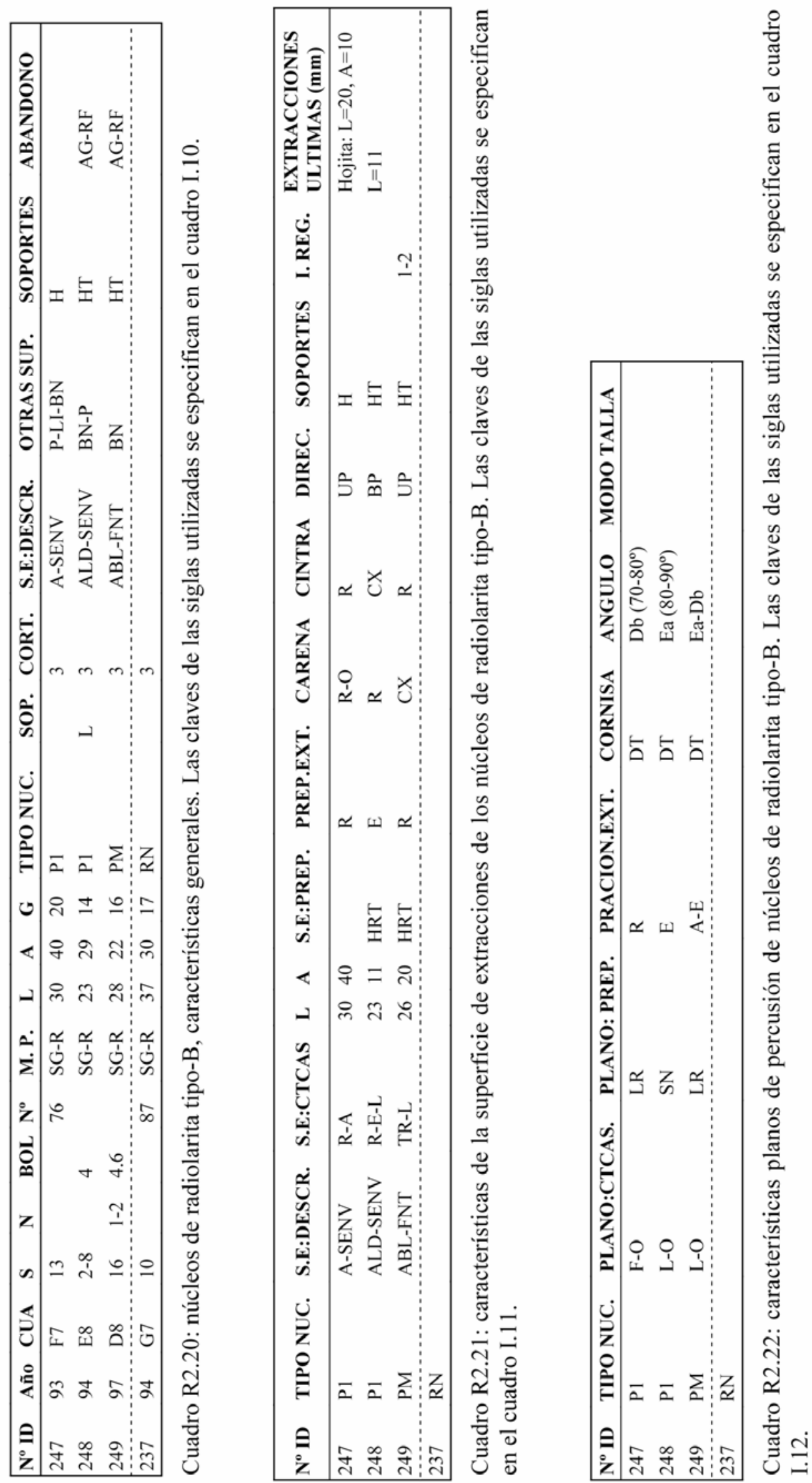


\section{IV.3.2.2.- CARACTERÍSTICAS DE LA SUPERFICIE DE EXTRACCIONES}

\section{Morfología de la superficie de extracciones}

La morfología de la superficie de extracciones refleja los distintos esquemas operativos a que se adscriben los tres núcleos:

- rectangular estrecha alargada en el caso del núcleo de hojitas sobre lasca, el cual aprovecha un borde de dicha lasca para ser explotado

- triangular alargada en el núcleo piramidal

- rectangular ancha para el último núcleo, asimilable asimismo a los núcleos de superficie ancha de chert negro

\section{Medidas}

Las medidas de las superficies reflejan la morfología anterior, siendo los núcleos más alargados los dos primeros (en torno a 2,5 cm de longitud en ambos casos, la anchura es de $2 \mathrm{~cm}$ en el núcleo prismático y $1 \mathrm{~cm}$ en el otro), mientras el último sería más ancho que largo (3 cm de longitud por $4 \mathrm{~cm}$ de anchura).

\section{Preparación de las extracciones}

En todos se constata una preparación del punto de impacto en la zona de la cornisa, en forma de esquirlado en el núcleo de hojitas sobre lasca y en retoque en los otros dos.

\section{Carena}

La carena tan solo presenta una curvatura que podría ser adecuada en el núcleo piramidal, pero el tamaño del núcleo y su estado de agotamiento han provocado probablemente el reflejado de las extracciones. En los otros dos núcleos la carena es demasiado recta e incluso oblicua, por lo que la ausencia de esta curva longitudinal impide seguir el débitage. 


\section{Cintra}

La cintra presenta una curvatura que podría ser adecuada en el núcleo de hojitas sobre lasca, mientras en los otros dos dibuja una curva transversal demasiado aplanada.

\section{Dirección de las extracciones}

El sentido de la explotación es unipolar en casi todos los núcleos excepto en el núcleo de hojitas sobre lasca, donde es bipolar. En este último caso incluso parece que el sentido principal es unipolar, mientras que el recurso a un segundo plano sobre la arista basal, sería un método de control de la carena y los flancos.

\section{Indice de regularidad}

Es difícil calibrar la calidad de los negativos laminares extraídos de estos núcleos, tan solo se puede decir que en el núcleo piramidal hay una regularidad bastante buena de las hojitas.

\section{Últimas extracciones}

Hay alguna hojita de $2 \mathrm{~cm}$ de longitud y $1 \mathrm{~cm}$ de anchura, pero el estado de agotamiento de los núcleos y los accidentes reflejados desdibujan las últimas extracciones.

\section{IV.3.2.3.- CARACTERÍSTICAS DEL PLANO DE PERCUSIÓN}

\section{Las características genéricas}

El núcleo de superficie ancha tiene un plano de percusión facetado, mientras que los otros dos lo tienen liso; en los tres casos dicho plano es bastante oblicuo. 


\section{Preparación del plano de percusión}

Los restos evidentes de la preparación/reparación del plano de percusión se producen en forma de semitabletas de núcleo en el núcleo sobre lasca y mediante lasquitas de reavivado del frente de percusión en los otros dos núcleos.

\section{Preparación de las extracciones}

Se observan restos de la preparación del frente de percusión en los tres núcleos, tanto en forma de esquirlado como de retoque, incluso restos de una abrasión más intensa en el núcleo piramidal.

\section{Cornisa}

A pesar de los restos de preparación que han quedado sobre la cornisa, ésta presenta una morfología denticulada. Seguramente el estado de agotamiento de los núcleos, que se han abandonado después de unas últimas extracciones, a veces fallidas, impide ver la morfología que habrían tenido si se hubiera preparado la cornisa una vez más para proseguir su explotación.

El ángulo del frente de talla tiende a ser abierto, en torno a los 80-90 (Ea), aunque con tendencia también a cerrarse hacia los 70-80 (Db). 


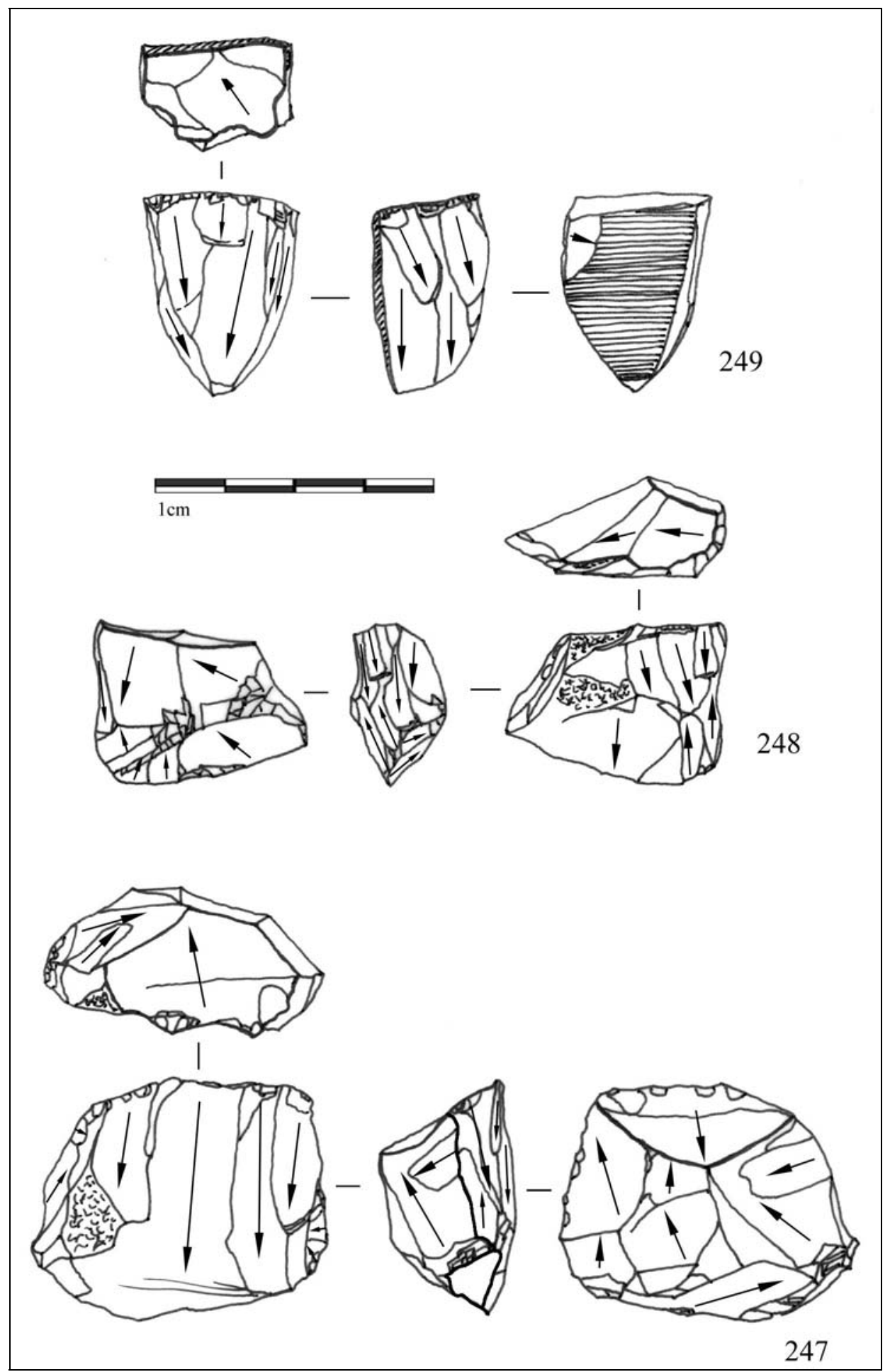

Figura R2.1: núcleos de radiolarita-2. Esquema prismático tipo-A (unipolar convergente): 249 y 248. Esquema prismático de superficie ancha (unipolar): 247. 


\section{IV.3.3.- PRODUCTOS DE ACONDICIONAMIENTO}

Hay doce piezas clasificadas como productos de acondicionamiento: 7 láminas con cresta, 4 flancos de núcleo y una arista de núcleo. No se ha localizado ninguna tableta o semitableta, quizás porque el procedimiento más habitual sea el de las lasquitas de reavivado del frente de percusión, tal y como se ha visto al analizar los núcleos.

\section{IV.3.3.1.- PIEZAS CON CRESTA}

De las siete piezas con cresta hay sólo una con cresta hacia ambas vertientes, cuatro son neo-crestas (de las cuales tres son parciales) y las dos últimas son piezas con cresta segunda. Las neo-crestas se relacionarían con procedimientos de reparación de la superficie de extracciones realizadas sobre todo a partir de los flancos laterales. Las longitudes de las piezas con cresta superan en tres casos la longitud de los núcleos de esta variedad de radiolarita, lo cual implicaría, bien que se ha producido en el yacimiento un proceso de débitage en varias secuencias, decreciendo el tamaño del núcleo paulatinamente, o bien que alguna de dichas piezas más largas se hayan traído de un primer lugar donde se habría explotado el núcleo.

\section{IV.3.3.2.- FLANCOS DE NÚCLEO}

De los cuatro flancos de núcleo, tres son transversales, es decir han "limpiado" la superficie de extracciones a partir de un borde lateral del núcleo, y uno es longitudinal, extraído desde un plano de percusión opuesto al plano principal. Si bien el tamaño reducido de los núcleos y el estado de agotamiento a que han llegado no permiten leer demasiado bien el proceso de débitage ejecutado de los mismos excepto en el último momento antes de su abandono, no obstante las características generales de éstos permiten decir que los flancos transversales pueden haberse extraído en secuencias anteriores de su explotación. En el caso del flanco longitudinal, podría corresponder a un reavivado de la superficie por ejemplo del núcleo piramidal, pero en este último no hay un plano opuesto, de todos modos podría corresponder a una fase anterior de la 
explotación del mismo. La longitud de esta pieza (37 mm), teniendo en cuenta además que está rota, de nuevo supera las longitudes de los núcleos presentes en el yacimiento. Se podría plantear la posibilidad de que su extracción se hubiera ejecutado fuera del yacimiento y posteriormente se hubiera traído aquí. Esta hipótesis se vería reforzada por el hecho de que sobre dicha pieza se ha realizado un buril múltiple sobre paño natural.

\section{IV.3.4.- SOPORTES: LASCAS, HOJAS Y HOJITAS}

Los soportes “de primera intención” de esta variedad de radiolarita son laminares fundamentalmente, así se puede deducir al menos de los esquemas técnicos determinados en los núcleos y de los soportes propiamente dichos presentes en el conjunto. A pesar de que las hojas-hojitas no representan mas que un $21 \%$ de este tipo de materia, el resto del conjunto lítico se correspondería con elementos que se extraen a lo largo de un débitage laminar (lascas, productos de acondicionamiento, debris).

En el conjunto de radiolarita-B hay alguna pieza cortical, pero no se ha localizado ninguna que se pueda definir como típicamente “de encetadura”, utilizando una arista natural. De hecho este tipo de procedimiento sería muy apropiado para este tipo de materia, habida cuenta de las características peculiares de su origen litológico. De nuevo la explicación de esta ausencia estaría posiblemente en la ruptura aparente que hay en la cadena operativa de esta variedad de radiolarita, la fase de preparación y posiblemente las primeras fases de producción se han desarrollado en un lugar distinto al yacimiento.

\section{IV.3.4.1.- LASCAS}

Al calcular el tamaño medio de los distintos grupos de soportes (cuadro R2.10) se expuso que las lascas tenían unas dimensiones de $15 \mathrm{~mm}$ de longitud por $13 \mathrm{~mm}$ de anchura y 3 de grosor. Respecto a la longitud hay un máximo en torno a los 11-12 mm y también hay otro pico en los 15-16 mm (Gráfico R2.5); en cuanto a la anchura, la mayoría de las piezas se encuentran entre los 11-14 mm (Gráfico R2.6). Se trata por tanto, en general, de lascas de morfología rectangular corta de un centímetro y medio de 
longitud por uno de anchura. Como para el resto de las materias, se prefieren las lascas mayores para ser retocadas, en la longitud, todas excepto una miden más de dos centímetros. Respecto a la anchura sucede algo parecido, el mayor número de piezas retocadas se encuentra en el intervalo de $13-14 \mathrm{~mm}$, y el resto se distribuyen paulatinamente en intervalos de mayor anchura, hasta los 35-36 mm.

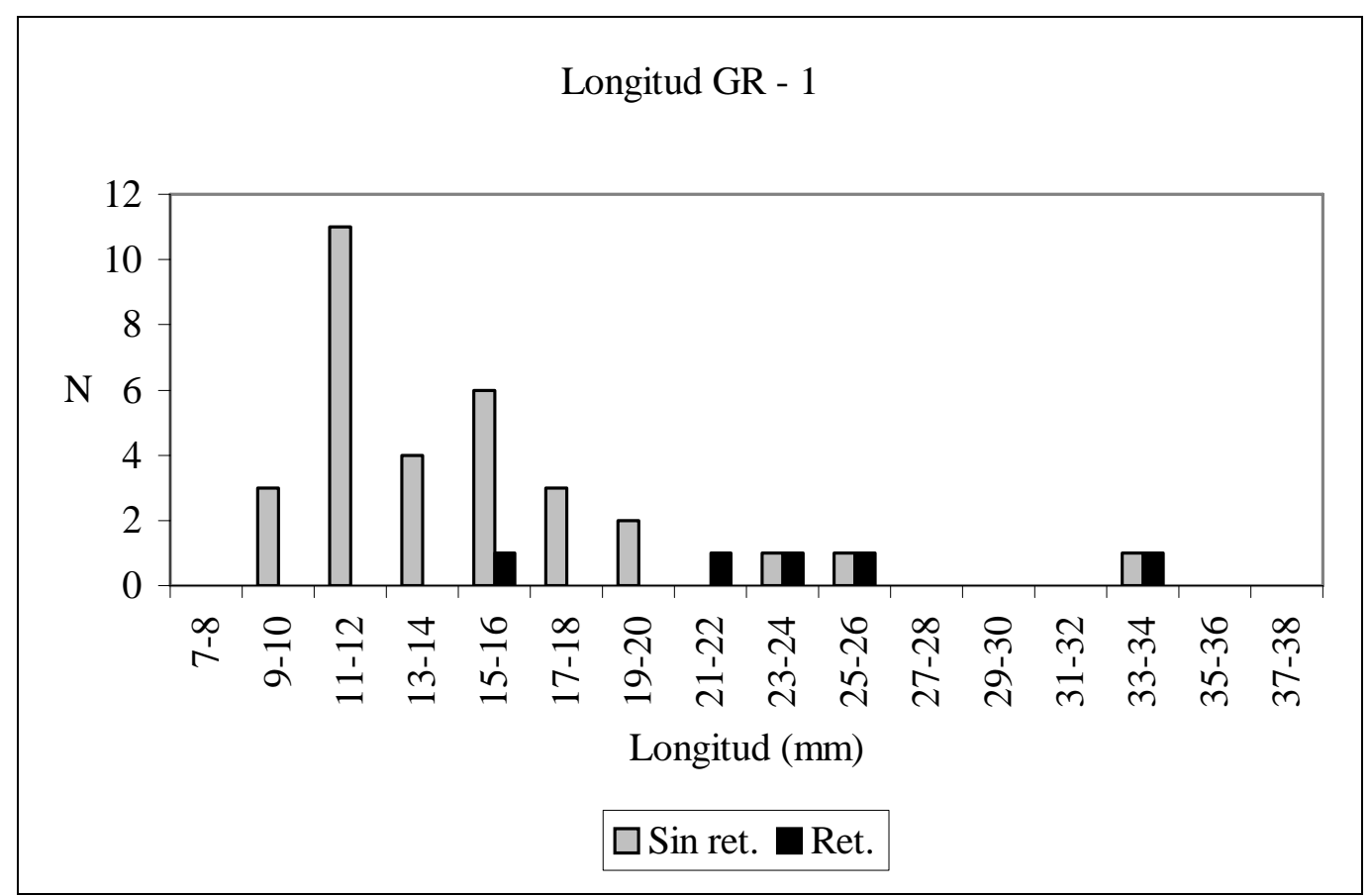

Gráfico R2.5 : longitud de los soportes de radiolarita-1 del grupo tecnológio 1 (lascas, lascas laminares). Sin retocar: $n=32$. Retocados: $n=5$. 


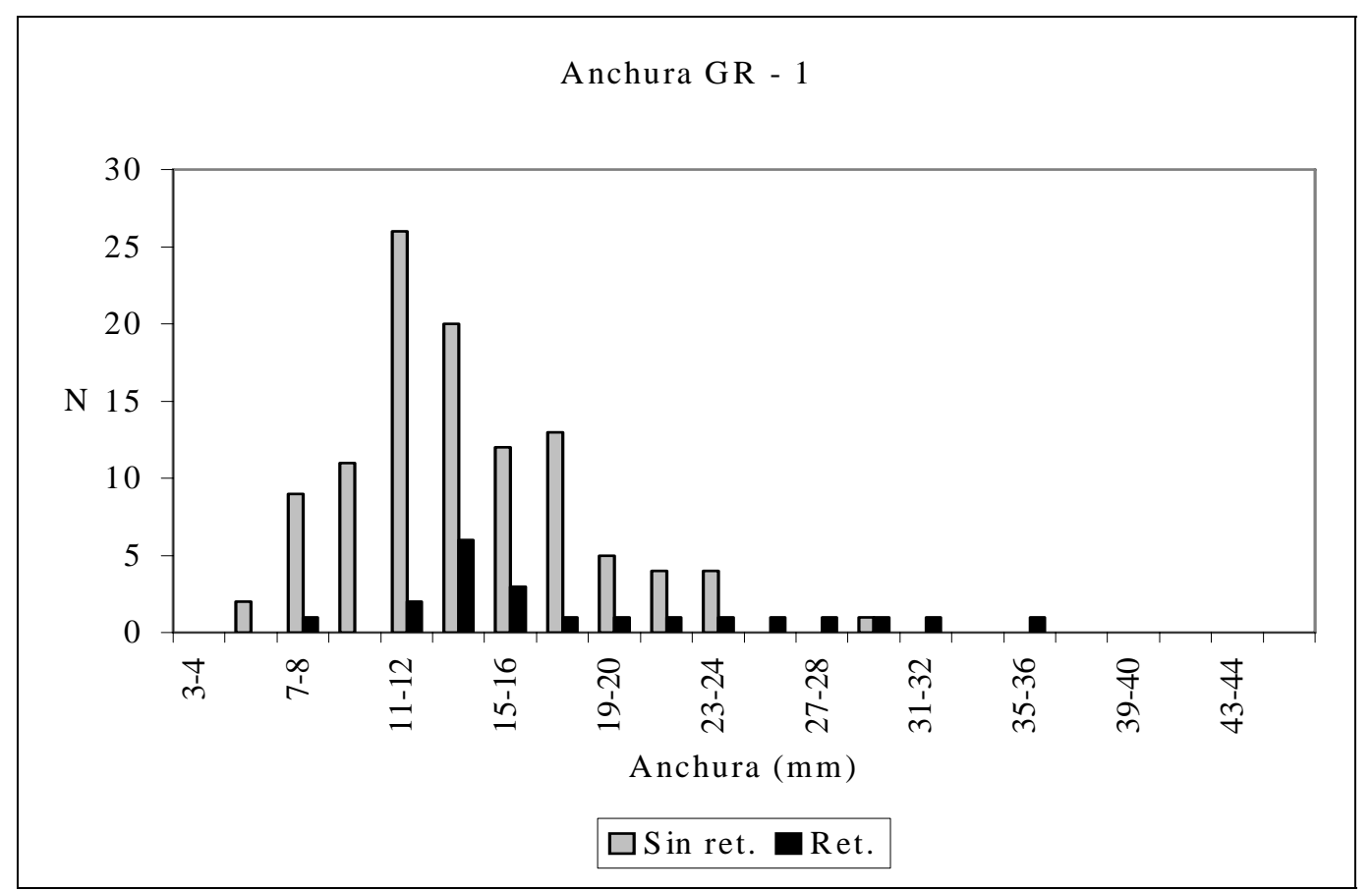

Gráfico R2.6: anchura de los soportes de radiolarita-1del grupo tecnológio 1 (lascas, lascas laminares). Sin retocar: $n=107$. Retocados: $n=21$.

\section{IV.3.4.2.- SOPORTES LAMINARES: HOJAS Y HOJITAS}

Las hojas-hojitas son los soportes buscados al explotar la radiolarita tipo-B, especialmente parece que son las hojitas los elementos preferidos en este tipo de materia, ya que hay el doble que de hojas (52 frente a 26), no obstante también es cierto que las hojitas están más fracturadas que las hojas (cuadro R2.6).

\section{IV.3.4.2.1.- DATOS MÉTRICOS: LONGITUD Y ANCHURA}

La longitud de los soportes laminares sin retocar tiene una media de $3 \mathrm{~cm}$ (cuadro R2.10), pero son muy pocas las piezas completas con las que contamos como para valorar tal dato, de hecho de las seis piezas completas, cinco de ellas no llegan a esos tres centímetros, y tan solo una mide casi $7 \mathrm{~cm}$ (gráfico R2.7). Esta última desentona totalmente con el tamaño observado no solo para el resto de los soportes, sino también en los núcleos y los productos de acondicionamiento, e incluso entre las piezas retocadas en estos últimos no llegan a los $5 \mathrm{~cm}$ de longitud. 
En cuanto a la anchura, hay una mayor concordancia entre las hojas-hojitas sin retocar y las retocadas, con la salvedad de que estas últimas son mayores que las primeras, es decir se seleccionarían los soportes de mayor tamaño para ser retocados (gráfico R2.8). Hay que tener en cuenta además que la mayoría de las hojitas retocadas lo están en forma de piezas con dorso, por lo que la anchura de los soportes habría sido unos milímetros mayor. La anchura media de los soportes sin retocar es de $8 \mathrm{~mm}$ (cuadro R2.10), mientras que la de las piezas retocadas es de $9 \mathrm{~mm}$. En el gráfico de barras se puede observar cómo la mayoría de las piezas sin retocar están entre los 5-8 mm, pero hasta los 11-12 mm hay un buen número de soportes. Las retocadas por su parte tienen un máximo en los 5-6 mm (recordemos que se trata de hojitas de dorso) y existen un buen número de ellas en los intervalos de 9-12 mm y 15-18 mm. Este último intervalo, relativo a hojas de anchura superior a los $15 \mathrm{~mm}$ no parece tener su correspondencia en las piezas sin retocar. De nuevo puede surgir la hipótesis de que estas hojas de mayor dimensión se hallan obtenido en secuencias de producción ejecutadas fuera del yacimiento, aunque también habría la posibilidad de que dichas hojas de mayor anchura hubieran sido todas retocadas. 


\section{Longitud GR - 2}

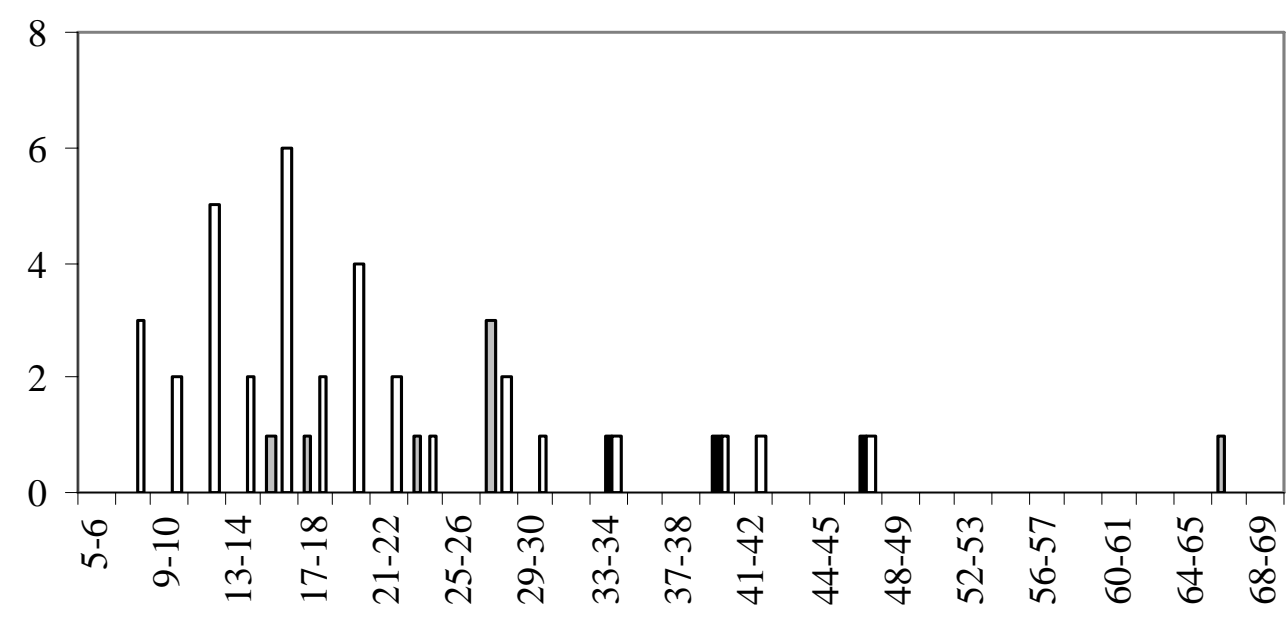

$\square$ Sin ret. $\square$ Ret. $\square$ Ret (rotas incluidas)

Gráfico R2.7: longitud de los soportes del grupo tecnológio 2 (hojas, hojitas). Sin retocar: $n=6$. Retocados: $n=3$. Retocadas, incluyendo las piezas rotas, $n=34$.

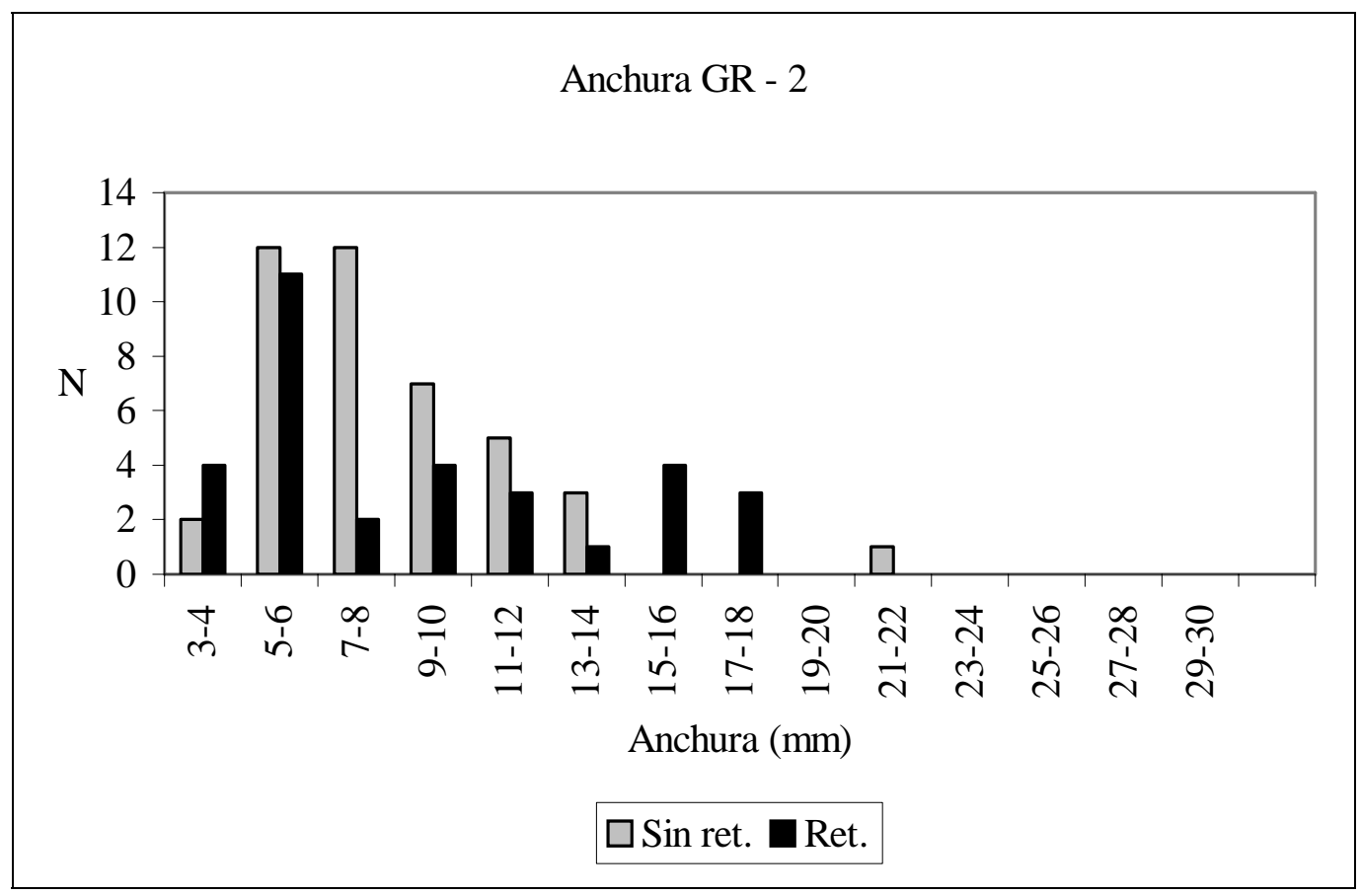

Gráfico R2.8: anchura de los soportes del grupo tecnológio 2 (hojas, hojitas). Sin retocar: $n=42$. Retocados: $\mathrm{n}=32$. 


\section{IV.3.4.2.2.- DATOS TÉCNICOS}

La mayoría de los soportes laminares tienen dos nervaduras (cuadro R2.23) y una sección transversal de forma triangular (cuadro R2.26), por lo que dichas nervaduras no están demasiado separadas entre sí (ya que en este último caso producirían secciones de tipo más trapezoide). La orientación de los negativos es en la mayoría de los casos unipolar, siendo muy pocas las piezas que tienen extracciones en sentido opuesto (cuadro R2.24).

\begin{tabular}{|l|l|cccccc|r|}
\hline \multicolumn{2}{|c|}{} & 0 & 1 & 2 & 3 & 4 & 5 & TOTAL \\
\hline \multirow{2}{*}{ SIN RET } & $\mathrm{N}$ & & 11 & 22 & 7 & 1 & 1 & 42 \\
& $\%$ & & 26,2 & 52,4 & 16,7 & 2,4 & 2,4 & 100,0 \\
\hline \multirow{2}{*}{ RETOC } & $\mathrm{N}$ & 3 & 5 & 17 & 3 & 7 & & 35 \\
& $\%$ & 8,6 & 14,3 & 48,6 & 8,6 & 20,0 & & 100,0 \\
\hline
\end{tabular}

Cuadro R2.23: $\mathrm{N}^{\circ}$ de nervaduras en los soportes laminares.

\begin{tabular}{|l|cc|cc|}
\hline \multirow{2}{*}{} & \multicolumn{2}{|c|}{ SIN RET } & \multicolumn{2}{c|}{ RET } \\
\cline { 2 - 5 } & $\mathrm{N}$ & $\%$ & $\mathrm{~N}$ & $\%$ \\
\hline DP & 1 & 2,9 & & \\
PD & 30 & 85,7 & 24 & 75,0 \\
PD-DP & 4 & 11,4 & 8 & 25,0 \\
\hline
\end{tabular}

Cuadro R2.24: dirección de los negativos de los soportes laminares. DP: distal-proximal (opuesta); PD: proximal-distal (unipolar); PD-DP: proximal-distal y distal-proximal (bipolar).

Respecto a la sección longitudinal (cuadro R2.25), en las piezas sin retocar es la sección cóncava la predominante sobre la rectilínea. En cambio, en las piezas retocadas las secciones cóncavas y rectilíneas alcanzan la misma representación, por lo que habría una selección de los soportes rectilíneos para ser retocados.

\begin{tabular}{|l|l|ccccc|r|}
\hline \multicolumn{2}{|c|}{} & $\mathrm{Cn}$ & $\mathrm{Cx}$ & $\mathrm{R}$ & $\mathrm{S}$ & $\mathrm{T}$ & TOTAL \\
\hline \multirow{2}{*}{ SIN RET } & $\mathrm{N}$ & 34 & 2 & 11 & 2 & & 49 \\
& $\%$ & 69,4 & 4,1 & 22,4 & 4,1 & & 100,0 \\
\hline \multirow{2}{*}{ RET } & $\mathrm{N}$ & 13 & 3 & 13 & 1 & 1 & 31 \\
& $\%$ & 41,9 & 9,7 & 41,9 & 3,2 & 3,2 & 100,0 \\
\hline
\end{tabular}

Cuadro R2.25: perfil longitudinal de los soportes laminares. Cn: cóncavo, curvo; Cx: convexo; R: rectilíneo; S: sinuoso (cóncavo-convexo); T: torse (alabeado). 
Por último, en el índice de regularidad de los soportes laminares de la radiolarita-B la mayoría de las piezas tendrían una calidad media, pero se habrían seleccionado aquellos soportes de mejor calidad para ser retocados (cuadro R2.27).

\begin{tabular}{|l|l|cccr|}
\hline \multicolumn{2}{|c|}{} & Bi-cx & TR & TZ & TOTAL \\
\hline \multirow{2}{*}{ SIN RET } & $\mathrm{N}$ & & 35 & 4 & 39 \\
& $\%$ & & 89,7 & 10,3 & 100 \\
\hline \multirow{2}{*}{ RET } & $\mathrm{N}$ & & 23 & 8 & 31 \\
& $\%$ & 74,2 & 25,8 & 100 \\
\hline
\end{tabular}

Cuadro R2.26: sección transversal de los soportes laminares. Bi-cx: biconvexa; TR: triangular; TZ: trapezoidal.

\begin{tabular}{|l|l|ccccc|r|}
\hline \multicolumn{2}{|c|}{} & 0 & $0-1$ & 1 & $1-2$ & 2 & TOTAL \\
\hline \multirow{2}{*}{ SIN RET } & $\mathrm{N}$ & 8 & 8 & 15 & 3 & 2 & 36 \\
& $\%$ & 22,2 & 22,2 & 41,7 & 8,3 & 5,6 & 100 \\
\hline \multirow{2}{*}{ RET } & $\mathrm{N}$ & 2 & 5 & 10 & 8 & 3 & 28 \\
& $\%$ & 7,1 & 17,9 & 35,7 & 28,6 & 10,7 & 100 \\
\hline
\end{tabular}

Cuadro R2.27: índice de regularidad de los soportes laminares. 0: mala calidad; 1: calidad media, aceptable; 2: buena calidad.

\section{IV.3.5.- PIEZAS RETOCADAS}

Hay un total de 67 piezas con algún tipo de retoque en la radiolarita verde. En ellas se constata, como ya se ha indicado, una selección de los soportes laminares para ser retocados, la mitad de estas piezas se han realizado sobre hojas y sobre todo hojitas (cuadros R2.3 y R2.4). Estas últimas se utilizan especialmente para la confección de hojitas de dorso, que constituyen el 21\% del conjunto retocado (cuadro R2.28).

Las pautas de retoque de los distintos tipos de soportes se pueden resumir en los siguientes puntos:

- Las lascas tienen un uso diversificado, se emplean sobre todo en la realización de útiles de fondo común: escotaduras y denticulados, buriles, raspadores, etc.

- de las lascas laminares solo contamos con cuatro ejemplos, dos para retoques continuos, un buril y una escotadura 
- las hojas tienen un uso preferente para las piezas con retoque continuo, aunque también aparecen en un raspador, una truncadura y tres piezas relacionadas con la confección de geométricos (una punta triangular, un microburil y una escotadura con rotura adyacente)

- las hojitas tienen un uso específico para las hojitas de dorso, apareciendo también en dos truncaduras y dos retoques continuos

- los productos de acondicionamiento tienen un uso diversificado, si bien destaca el empleo de las hojas con cresta de una forma similar a las hojas y las lascas laminares, en piezas con retoque continuo; primaría por tanto la morfología alargada de todos estos soportes

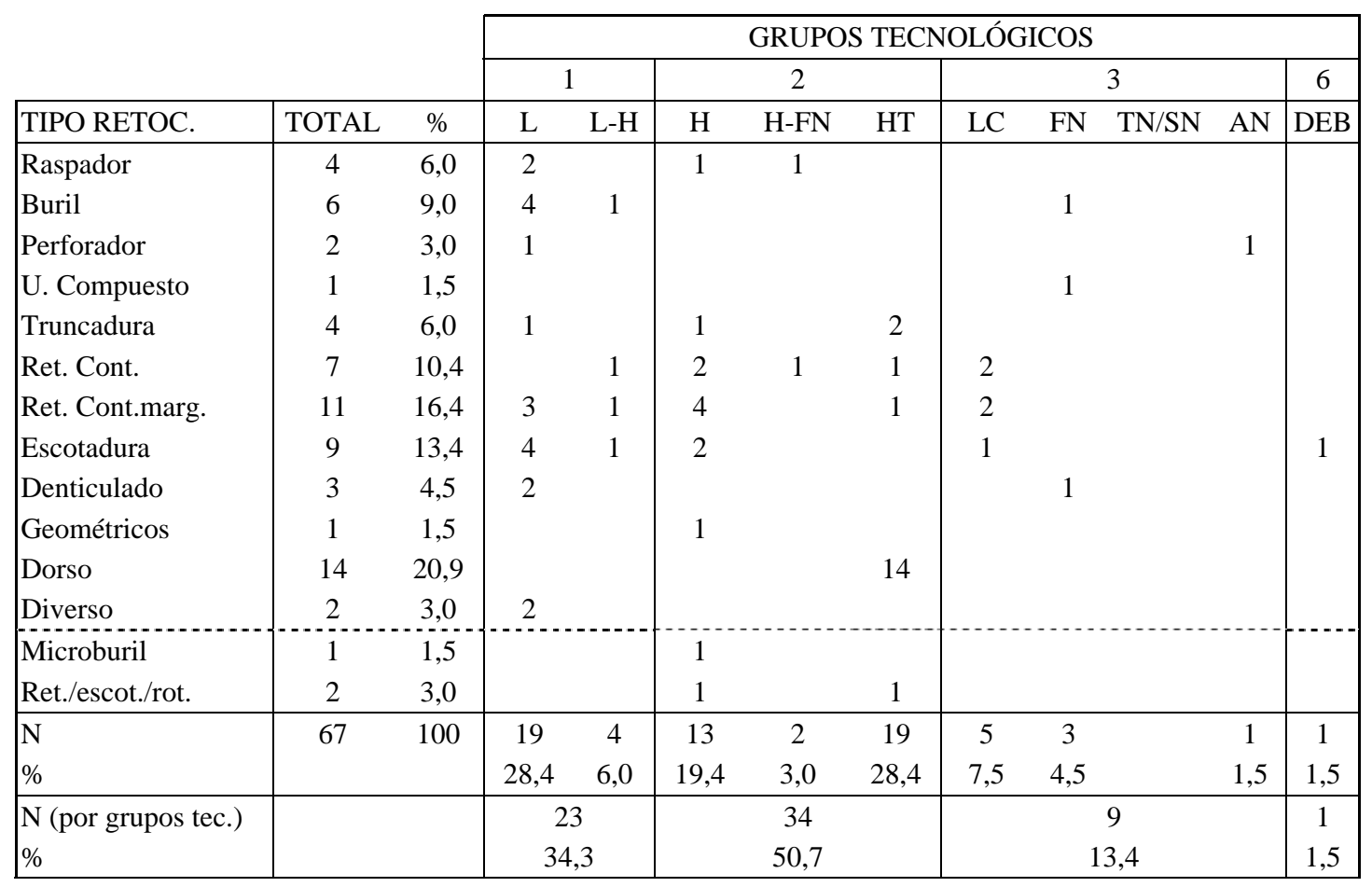

Cuadro R2.28: piezas retocadas por tipos de soportes. 

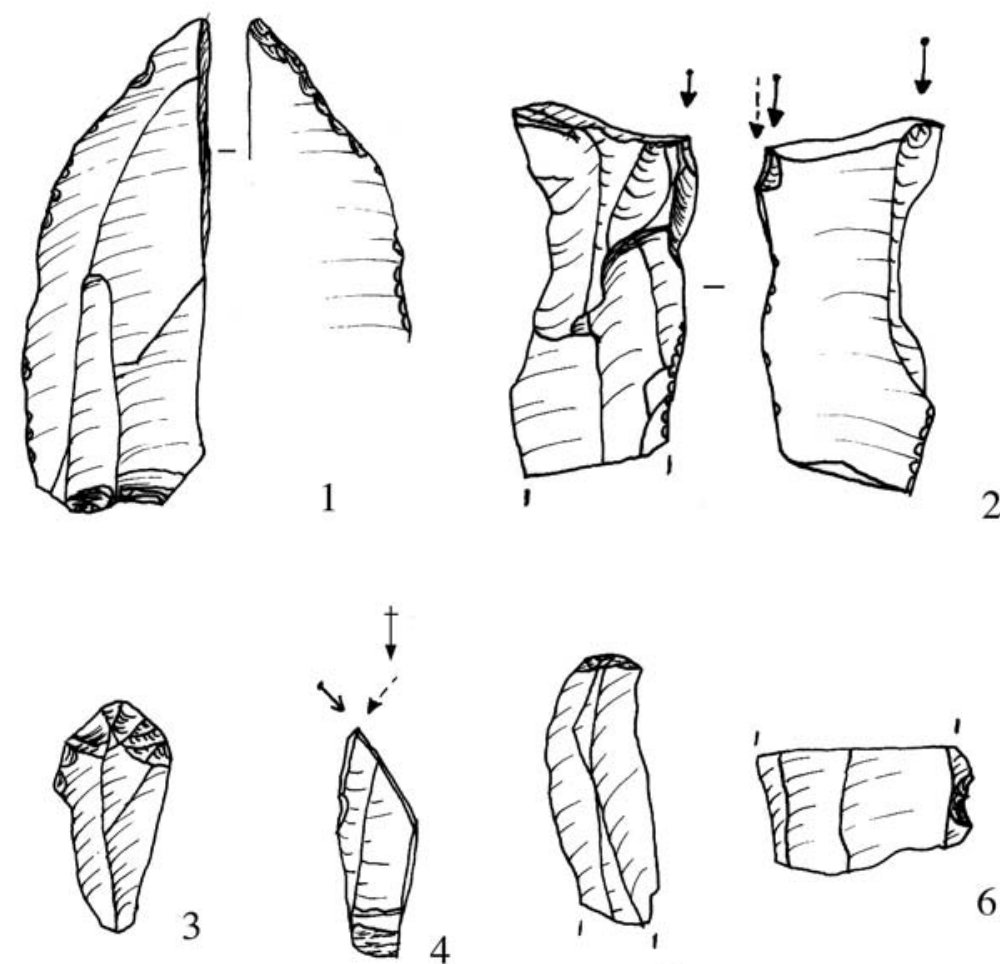

5
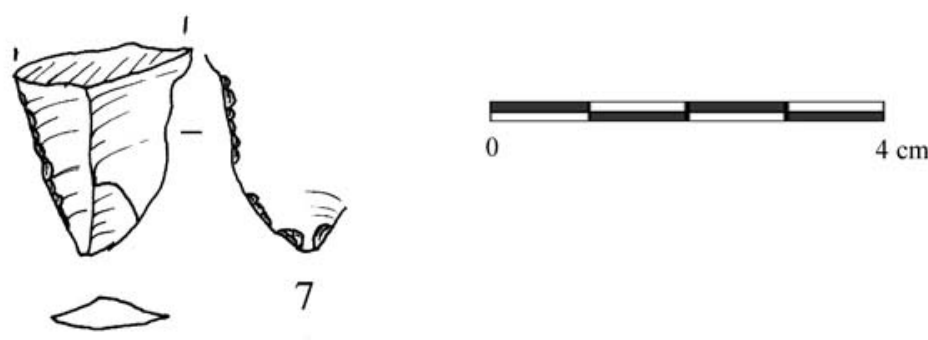

Figura R2.2: Piezas retocadas de radiolarita-2. Piezas con retoque continuo (1, 7), buriles $(2,4)$, raspador (3), truncadura (5), escotadura (6). $\mathrm{N}^{\mathrm{o}} 1$ : hoja con retoque continuo sobr ambos bordes, apuntada. Soportes: hojas-hojitas (1, 3, 5), lasca-laminar (6), flanco de núcleo opuesto (2) y lascas $(4,7)$. 


\section{IV.3.6.- CADENA OPERATIVA}

En la radiolarita tipo-B los esquemas técnicos presentes encajarían en la cadena operativa prismática genérica que se ha examinado en las materias anteriores, sobre todo para el sílex negro. Se podrían identificar dos de los esquemas operativos analizados en el chert negro:

- Esquema operativo prismático tipo-A, es decir los núcleos prismáticos laminares con tendencia a ser piramidales, con dos métodos en la fase de preparación del núcleo (sobre nódulo y sobre lasca).

- Esquema operativo de los núcleos de superficie ancha, más concretamente según el método unipolar.

En ambos casos lo que se puede decir de la fase de adquisición de la materia prima es lo mismo ya que se trata de una materia que no se ha llevado de forma completa al yacimiento, sino que los núcleos han sido preparados y, en este caso, parece que explotados en una primera fase fuera de El Espertín.

\section{IV.3.6.1.- FASE 0: ADQUISICIÓN DE LA MATERIA PRIMA}

Sobre esta fase no se puede decir gran cosa, tan solo se puede recordar que la radiolarita verde es una variante de la radiolarita genérica, que aparece eventualmente en los mismos afloramientos que ésta y, por tanto, el lugar de adquisición estaría unido a ella. La forma en que se presenta la radiolarita es en paralelepípedos delimitados por las superficies de sedimentación y los planos de diaclasado interno, con aristas agudas en la unión de dichas superficies. Dicha morfología natural favorece por tanto una explotación de tipo prismática. No podemos decir mucho acerca de qué tipo de nódulos se habrían seleccionado ya que no contamos en la colección ni con bloques fragmentados desechados ni con soportes de las primeras secuencias de talla. Los núcleos son de pequeño tamaño, pero no por ello se habrían seleccionado solamente nódulos pequeños. De hecho hay constancia en la colección tanto de hojas como de productos de acondicionamiento de tamaño mayor al representado por el conjunto presente en la colección, por lo que se habrían seleccionado nódulos de buen tamaño. 


\section{IV.3.6.2.- ESQUEMA OPERATIVO DE NÚCLEOS PRISMÁTICOS TIPO-A}

Aquí se incluirían los dos primeros núcleos (el piramidal y el que está sobre lasca), los cuales se caracterizan por ser núcleos de hojitas encajados en una estructura prismática en la que la superficie de extracciones está enmarcada de forma ortogonal por los flancos del núcleo y la base del núcleo no es una superficie paralela al plano de percusión, sino que se trata de una arista perpendicular a la superficie de extracciones y a la cara posterior del núcleo.

\section{IV.3.6.2.1- FASE 1: PREPARACIÓN DEL NÚCLEO}

Lo que podemos decir de esta fase, a partir de los dos núcleos presentes en el conjunto que disponemos, es que hay dos tipos de preparación, que difieren en el momento de elegir el soporte seleccionado como núcleo.

\section{1.- Método de preparación sobre nódulo}

El primer núcleo (ID $\mathrm{n}^{\circ}$ 249), con tendencia a ser piramidal, habría sido preparado sobre un nódulo o un fragmento de nódulo, utilizando las superficies naturales para la construcción del núcleo, así la superficie posterior es un plano de diaclasado interno, mientras que el plano de percusión se ha instalado también sobre una superficie afectada por las irregularidades de la materia. Estas superficies naturales son parte integrante de la construcción volumétrica del núcleo, lo cual va a ser ventajoso en especial en este tipo de esquema operativo, que es bastante exigente en la configuración de dicho volumen.

\section{2.- Método de preparación sobre lasca}

En el segundo núcleo (ID n ${ }^{\circ} 248$ ) se ha seleccionado una lasca gruesa de la que se ha eliminado el talón, instalando en esa parte proximal el plano de percusión y sobre el borde derecho de la primitiva lasca, la superficie de extracciones. Se consigue de este modo la estructura perseguida, con la superficie de extracciones sobre una superficie estrecha, la cual está enmarcada por unos flancos ortogonales (que corresponderían con la superficie superior y bulbar de la lasca) y la base del núcleo en arista natural (que no 
es sino el borde transversal de la lasca-soporte). De esta forma el núcleo está preparado para la obtención de hojitas a partir de uno de los bordes de una lasca, del tipo por tanto de los núcleos tipo-buril.

Las superficies laterales del núcleo, así como la posterior, son sometidas a arreglos y acondicionamientos a lo largo del curso de la talla.

\section{IV.3.6.2.2- FASE 2: EXPLOTACIÓN DEL NÚCLEO}

Hay constancia de lo que serían las últimas secuencias de la fase de explotación plena de los núcleos. En ellas se revela una explotación de tipo unipolar fundamentalmente, con preparación del frente de percusión mediante una abrasión de la zona de la cornisa y un ángulo bastante abierto (cercano a los $90^{\circ}$ ). La cornisa tiene una curvatura que no es demasiado acusada y la cintra es también aplanada. La superficie de extracciones está preparada así para la obtención de soportes microlaminares con un perfil longitudinal de tendencia rectilínea. El débitage avanza de forma frontal preferentemente, si bien en el núcleo sobre lasca se convierte en semi-envolvente al progresar hacia el lateral izquierdo. Este cambio posiblemente sea debido a la escasa anchura de la superficie de extracciones otorgada por el borde la lasca primitiva. El sentido de las extracciones es unipolar, con tendencia a converger en la base. No obstante en el núcleo sobre lasca hay extracciones opuestas, pero estarían requeridas por necesidades de acondicionamiento del avance del débitage.

En el mantenimiento de la explotación de estos núcleos habría por un lado un auto-mantenimiento de las condiciones de talla debido a la estructura volumétrica de los flancos del núcleo (que ayudan a controlar la cintra) y de la base del mismo (que controlaría la carena), que favorece este tipo de explotación unipolar frontal de hojitas rectilíneas. Por otro lado existirían dos tipos de recursos para conservar las características de la talla:

- Reparación / acondicionamiento de los flancos del núcleo para mantenerlos más o menos perpendiculares a la superficie de extracciones, desde el plano de percusión y de forma longitudinal. Este recurso puede dar lugar a flancos de núcleo longitudinales, “hojas con flanco”, o lascas (difíciles de reconocer 
en conjunto lítico) de reavivado de dichos flancos. En el núcleo piramidal son visibles los negativos de extracciones que podrían ser flancos longitudinales o piezas “con flanco” (portarían parte del plano natural de la superficie posterior del núcleo) en ambos laterales del núcleo. En el núcleo sobre lasca son visibles también los negativos de lascas desde el plano de percusión para el acondicionamiento de los laterales.

- Reparación / acondicionamiento de la superficie de extracciones desde la arista inferior del núcleo. Este recurso se emplea sólo en el núcleo sobre lasca y, en este caso, la arista que configura la base del núcleo se utiliza como una cresta infero-lateral sobre la que se producen extracciones en sentido opuesto al principal en la superficie de extracciones y también hacia el flanco izquierdo del núcleo. Con estas extracciones se persigue, al parecer, una rectificación y acondicionamiento de la carena; también se adecua el flanco izquierdo para progresar el débitage sobre él, de forma semienvolvente.

El plano de percusión se repara a partir de semitabletas o pequeña lasca, mientras que sobre el núcleo piramidal se prefiere un reavivado total del frente de percusión, más reparaciones puntuales.

El resultado de este tipo de esquema es la obtención de hojitas de talón liso y preparado, con los negativos anteriores unipolares, quizás convergentes, con una longitud máxima de unos $3 \mathrm{~cm}$ y una anchura difícil de valorar, pero que se encontraría entre los 7-11 mm. El núcleo piramidal proporcionaría hojitas de mayor anchura y perfil más curvo, mientras que el núcleo sobre lasca aportaría hojitas muy estrechas y rectas.

El abandono de los núcleos se produce sobre todo por accidentes (reflejados), ocasionados seguramente por agotamiento del núcleo, de forma que éste pierde las condiciones ideales de talla. 


\section{IV.3.6.3.- ESQUEMA OPERATIVO DE NÚCLEOS DE SUPERFICIE ANCHA}

El tercer núcleo de la radiolarita verde (ID $n^{\circ}$ 247) tiene una estructura similar a la de los núcleos de sílex negro que explotaban una superficie de extracciones bastante ancha.

\section{IV.3.6.3.1- FASE 1: PREPARACIÓN DEL NÚCLEO}

La preparación de este núcleo ha requerido más extracciones que en el caso anterior sobre la superficie posterior, laterales e inferior. La superficie de extracciones queda instalada finalmente sobre una superficie más ancha que larga, el plano de percusión es bastante oblicuo y la base del núcleo es una superficie más o menos paralela al plano de percusión; con la presencia e unas extracciones desde dicha base hacia la superficie posterior que pueden haber sido restos de una conformación anterior del núcleo, o bien una parte de su preparación actual. La conformación de este esquema no tiene tantos condicionantes estructurales como en el esquema anterior, pero esta flexibilidad relativa tiene que ajustarse mediante reformas más frecuentes.

\section{IV.3.6.3.2- FASE 2: EXPLOTACIÓN DEL NÚCLEO}

La explotación de este núcleo se produce de forma unipolar semi-envolvente, avanzando hacia ambos laterales. Se constata una preparación del frente de talla a partir de un gesto que no parece tan intenso como la abrasión del esquema anterior. El ángulo de talla es más cerrado también que en el caso anterior $\left(70-80^{\circ}\right)$. La carena y la cintra no realizan una curvatura muy acusada, son de hecho incluso demasiado aplanadas, la carena dibuja (si se observa la vista lateral) una línea oblicua que no es demasiado adecuada para la talla, pero probablemente esté ocasionada porque se trata de los restos de la última secuencia de extracciones y no es posible continuar el débitage.

El mantenimiento de este tipo de explotación se produce gracias al propio avance del débitage, las extracciones comienzan apoyándose sobre una arista lateral, y se continúan en dirección al otro flanco. La carena se puede mantener de forma más o menos adecuada debido a que se trata de un núcleo de escasa longitud, de todos modos la superficie inferior (paralela al plano de percusión) también contribuiría a controlar la 
carena de una superficie tan ancha. La cintra por su parte tendrá que ser controlada a partir de las aristas laterales, que servirán de apoyo a eventuales crestas que, mediante extracciones transversales, permiten el mantenimiento de la superficie de extracciones. El avance del débitage hacia estos flancos puede producir la extracción de estas aristas en forma de neo-crestas.

El resultado de este tipo de explotación serán hojas, hojitas y también lascas laminares, de una longitud de $3 \mathrm{~cm}$ y una anchura probablemente superior a $1 \mathrm{~cm}$.

\section{IV.3.6.4.- FASE 3-4: FASE DE RETOQUE}

En esta fase hay un empleo preferente de los soportes producidos en las secuencias de explotación plena del núcleo: los soportes “de primera intención” (hojashojitas) así como también los productos de acondicionamiento que se producen en secuencias intercaladas a las de producción plena.

Las lascas se emplean de forma mayoritaria en la fabricación de los “útiles de fondo común”: buriles, escotaduras, denticulados y raspadores, también en piezas con retoque continuo. Las lascas-laminares no son muy abundantes y tienen un uso diversificado similar al de las lascas. Las hojas se utilizan sobre todo en piezas con retoque continuo, frecuentemente marginal, por lo que este retoque puede ser testimonio indirecto del uso de tales piezas, seguramente debido a la longitud del filo útil que proporcionan. Las hojitas tienen un uso específico para la realización de hojitas de dorso y también aparecen, en menor número, en hojitas con truncadura y con retoque continuo. Las piezas con cresta tienen un uso similar a las hojas, aprovechando seguramente la longitud del filo de tales soportes en las piezas de retoque continuo. Los flancos de núcleo en cambio se utilizan de forma más similar a las lascas.

Hay también en esta variedad de radiolarita un geométrico, se trata de un triángulo o punta triangular fabricado sobre el fragmento distal de una hoja a partir de la que hemos denominado como "técnica de fractura transversal” (Fuertes, 2000-2001). No obstante hay también en el conjunto lítico testimonio de la presencia de la "técnica de microburil” en forma de un microburil proximal, así como otras dos piezas que 
pueden corresponder con una ejecución errónea de dicha técnica, ya que se trata de soportes con una escotadura o un retoque parcial adyacente a una rotura.

Se constata por tanto un patrón de empleo de los soportes para ser retocados/usados bastante similar a la radiolarita genérica, con un uso específico de las hojitas para las hojitas de dorso, las hojas sobre todo en piezas de retoque continuo y las lascas para los útiles “del fondo común” (raspadores, denticulados, escotaduras). Se realizan también las “técnicas” de fractura de una hoja en las dos variantes que se han constatado en el conjunto lítico.

\section{IV.3.6.5.- RUPTURA EN LA CADENA OPERATIVA DE LA RADIOLARITA-B}

Un último aspecto que resta por tratar respecto a la radiolarita-2 es que parece existir una ruptura espacio-temporal en su cadena operativa. Los datos sobre los que nos apoyamos para sustentar esta hipótesis son los siguientes:

- Las hojas tienen una longitud media muy elevada (30 mm), constituyendo la mayor media de las materias vistas hasta ahora (mayor incluso que el sílex negro), además la dispersión de esta medida llega hasta los $67 \mathrm{~mm}$. Esta última medida pertenece a una hoja que es la pieza de mayor longitud de todo el conjunto de la radiolarita-2. No obstante la media es un dato equívoco ya que la muestra de hojas completas es muy escasa y la mayoría no alcanzan los $3 \mathrm{~cm}$; es por tanto la hoja de casi $7 \mathrm{~cm}$ la que desentona totalmente en el conjunto.

- En la anchura de las hojas hay una serie de piezas retocadas de una dimensión mayor a $15 \mathrm{~mm}$, sin que existan en el conjunto hojas sin retocar de tales medidas.

- Los productos de acondicionamiento son también mayores que los núcleos, alcanzando en la dispersión de su longitud los 47 mm (un centímetro más que los núcleos)

- Existen entre estos productos de acondicionamiento indicios también de que proceden de secuencias de débitage anteriores a las presentes en nuestro yacimiento, al menos así lo atestiguaría un flanco de núcleo longitudinal opuesto (que está roto en la zona proximal pero aún así mide 37 mm de 
longitud) sobre el que se ha fabricado un buril múltiple. Por tanto dicho soporte se habría llevado al yacimiento porque se trata de un útil.

Se plantea como hipótesis para explicar estos datos que exista una ruptura espacio-temporal en la explotación de la radiolarita tipo-B. En un lugar fuera de El Espertín (probablemente en el lugar de adquisición de esta materia) se produce una primera explotación de los núcleos, obteniéndose hojas de longitud considerable. En la cueva hay una segunda secuencia de explotación de esta materia, pero sobre núcleos de pequeño tamaño, de que en sus últimas fases se han extraído hojitas. Se habría producido por tanto una selección de la materia a transportar a la cueva, estando ausentes los grandes núcleos, nódulos y lascas de las primeras fases de explotación.

La explicación de este comportamiento respecto a la radiolarita tipo-B puede radicar en el hecho de que se trate de una materia cuyo origen se encuentre quizás más alejado que la radiolarita genérica. Así los bloques se tallan en un primer momento y solo se llevan al yacimiento los soportes laminares obtenidos en esta primera explotación, además de los núcleos ya conformados para la obtención de hojitas. El conjunto de radiolarita tipo-B presente en el yacimiento representa por tanto la segunda fase de explotación más los soportes obtenidos de la primera.

La otra explicación que podríamos encontrar para este comportamiento es que la radiolarita verde no sea muy abundante y que cuando se ha encontrado algún afloramiento de esta variedad, al lado de la radiolarita roja genérica, se haya explotado más intensamente en el lugar de adquisición, mientras que para el resto de la radiolarita se haya preferido reducir las secuencias de talla realizadas en dicho lugar a la primera fase y realizar el resto del proceso de débitage en el yacimiento. 


\section{IV.4. SÍLEX GRIS}

\section{IV.4.1. CARACTERÍSTICAS GENERALES}

El sílex gris no es muy abundante, contamos tan sólo con 234 elementos, de los cuales más del 30\% pertenecerían a la categoría de los debris (menores de un centímetro). Ya se han comentado las características de este sílex gris, y su calidad bastante aceptable para la talla.

\section{IV.4.1.1. LISTA TECNOLÓGICA, GRUPOS TECNOLÓGICOS}

El sílex gris no cuenta con demasiada variedad de tipos de soportes, los más abundantes son los debris, seguidos por las lascas y las hojitas de tercer orden (cuadro SG.1). Por grupos tecnológicos (cuadro SG.2) predomina el grupo 6 (34\%), seguido por el grupo 1 (26\%) y, muy cerca de este último, el grupo de los soportes laminares (23\%).

En las piezas retocadas (cuadro SG.3) hay un predominio evidente de los soportes laminares, especialmente las hojitas (42\%), aspecto que se ve más claramente en la distribución por grupos tecnológicos (cuadro SG.4), donde supera el $60 \%$ del conjunto. 


\begin{tabular}{|c|c|c|c|c|}
\hline GRUPO TECNOLÓGICO & $\mathrm{N}^{\circ}$ TEC. & SOPORTE & $\mathbf{N}$ & $\%$ \\
\hline GRUPO 0 (nódulos) & 0 & Nódulo & & \\
\hline \multirow{6}{*}{$\begin{array}{l}\text { GRUPO } 1 \\
\text { (lascas) }\end{array}$} & 1 & Lasca de primer orden & & \\
\hline & 2 & Lasca de segundo orden & 1 & 0,43 \\
\hline & $2-5$ & Lasca laminar de segundo orden & & \\
\hline & 3 & Lasca de tercer orden & 56 & 23,93 \\
\hline & 3-6 & Lasca laminar & 4 & 1,71 \\
\hline & 4 & Hoja de primer orden & & \\
\hline \multirow{5}{*}{$\begin{array}{l}\text { GRUPO } 2 \\
\text { (soportes laminares) }\end{array}$} & 5 & Hoja de segundo orden & & \\
\hline & 6 & Hoja de tercer orden & 16 & 6,84 \\
\hline & 6-FN & Hoja de tercer orden con flanco & 9 & 3,85 \\
\hline & 7 & Hojita de segundo orden & & \\
\hline & 8 & Hojita de tercer orden & 30 & 12,82 \\
\hline \multirow{5}{*}{$\begin{array}{l}\text { GRUPO } 3 \text { (productos de } \\
\text { acondicionamiento) }\end{array}$} & 9 & Lámina cresta & 5 & 2,14 \\
\hline & 10 & Tableta de núcleo & & \\
\hline & 11 & Semitableta de núcleo & 1 & 0,43 \\
\hline & 12 & Flanco de núcleo & 5 & 2,14 \\
\hline & 13 & Arista de núcleo y otros & 3 & 1,28 \\
\hline \multirow{5}{*}{$\begin{array}{l}\text { GRUPO } 4 \\
\text { (núcleos) }\end{array}$} & 14 & Núcleo prismático con un plano & 3 & 1,28 \\
\hline & 15 & Núcleo prismático con dos planos & & \\
\hline & 16 & Núcleo sobre lasca & & \\
\hline & 17 & Núcleo globuloso & & \\
\hline & 18 & Resto de núcleo & & \\
\hline GRUPO 7 (golpes buril) & 19 & Golpe de buril & 1 & 0,43 \\
\hline \multirow{3}{*}{$\begin{array}{l}\text { GRUPO } 5 \\
\text { (indeterminados) }\end{array}$} & 23 & Astilla de talla & & \\
\hline & 24 & Chunk & 4 & 1,71 \\
\hline & 25 & Indeterminado & 16 & 6,84 \\
\hline \multirow{2}{*}{$\begin{array}{l}\text { GRUPO } 6 \\
\text { (debris) }\end{array}$} & DEB-LT & Debris: lasquita & 74 & 31,62 \\
\hline & DEB-AT & Debris: astilla e indeterminados & 6 & 2,56 \\
\hline & & & 234 & 100 \\
\hline
\end{tabular}

Cuadro SG.1: lista tecnológica de sílex gris.

\begin{tabular}{|lrr|}
\hline GRUPOS TEC. & N & \% \\
\hline 0 & & \\
1 & 61 & 26,1 \\
2 & 55 & 23,5 \\
3 & 14 & 6,0 \\
4 & 3 & 1,3 \\
5 & 20 & 8,5 \\
6 & 80 & 34,2 \\
7 & 1 & 0,4 \\
\hline & 234 & 100 \\
\hline
\end{tabular}

Cuadro SG.2: grupos tecnológicos de sílex gris. 


\begin{tabular}{|c|c|c|c|c|}
\hline GRUPO TEC. & $N^{o}$ TEC. & SOPORTE & $\mathbf{N}$ & $\%$ \\
\hline $\begin{array}{l}\text { GRUPO } 1 \\
\text { (lascas) }\end{array}$ & $\begin{array}{l}1 \\
2 \\
2-5 \\
3 \\
3-6 \\
4\end{array}$ & $\begin{array}{l}\text { Lasca de primer orden } \\
\text { Lasca de segundo orden } \\
\text { Lasca laminar de segundo orden } \\
\text { Lasca de tercer orden } \\
\text { Lasca laminar } \\
\text { Hoja de primer orden }\end{array}$ & 4 & 10,53 \\
\hline $\begin{array}{l}\text { GRUPO } 2 \\
\text { (soportes laminares) }\end{array}$ & $\begin{array}{l}5 \\
6 \\
6-\mathrm{FN} \\
7 \\
8\end{array}$ & $\begin{array}{l}\text { Hoja de segundo orden } \\
\text { Hoja de tercer orden } \\
\text { Hoja de tercer orden con flanco } \\
\text { Hojita de segundo orden } \\
\text { Hojita de tercer orden }\end{array}$ & $\begin{array}{l}3 \\
6\end{array}$ & $\begin{array}{r}7,89 \\
15,79 \\
42,11\end{array}$ \\
\hline $\begin{array}{l}\text { GRUPO } 3 \text { (productos de } \\
\text { acondicionamiento) }\end{array}$ & $\begin{array}{l}9 \\
10 \\
11 \\
12 \\
13\end{array}$ & $\begin{array}{l}\text { Lámina cresta } \\
\text { Tableta de núcleo } \\
\text { Semitableta de núcleo } \\
\text { Flanco de núcleo } \\
\text { Arista de núcleo y otros }\end{array}$ & $\begin{array}{l}1 \\
1\end{array}$ & 2,63 \\
\hline $\begin{array}{l}\text { GRUPO } 4 \\
\text { (núcleos) }\end{array}$ & $\begin{array}{l}14 \\
15 \\
16 \\
17 \\
18\end{array}$ & $\begin{array}{l}\text { Núcleo prismático con un plano } \\
\text { Núcleo prismático con dos planos } \\
\text { Núcleo sobre lasca } \\
\text { Núcleo globuloso } \\
\text { Resto de núcleo }\end{array}$ & & \\
\hline GRUPO 7 (golpes buril) & 19 & Golpe de buril & 1 & 2,63 \\
\hline $\begin{array}{l}\text { GRUPO } 5 \\
\text { (indeterminados) }\end{array}$ & $\begin{array}{l}23 \\
24 \\
25\end{array}$ & \begin{tabular}{|l|} 
Astilla de talla \\
Chunk \\
Indeterminado
\end{tabular} & 2 & 5,26 \\
\hline $\begin{array}{l}\text { GRUPO } 6 \\
\text { (debris) }\end{array}$ & $\begin{array}{l}\text { DEB-LT } \\
\text { DEB-AT }\end{array}$ & $\begin{array}{l}\text { Debris: lasquita } \\
\text { Debris: astilla e indeterminados }\end{array}$ & 4 & 10,53 \\
\hline & & & 38 & 100 \\
\hline
\end{tabular}

Cuadro SG.3: lista tecnológica de los soportes retocados de sílex gris.

\begin{tabular}{|lrr|}
\hline GRUPOS TEC. & N & \% \\
\hline 0 & & \\
1 & 4 & 10,5 \\
2 & 25 & 65,8 \\
3 & 2 & 5,3 \\
4 & & \\
5 & 2 & 5,3 \\
6 & 4 & 10,5 \\
7 & 1 & 2,6 \\
\hline & 38 & 100 \\
\hline
\end{tabular}

Cuadro SG.4: grupos tecnológicos del sílex gris en las piezas retocadas. 
En el uso de los distintos tipos de soportes para ser retocados también se observa claramente el aprovechamiento de las hojitas, de las que casi la mitad están retocadas (cuadro SG.5).

\begin{tabular}{|l|c|cc|}
\hline \multirow{2}{*}{ GRUPO TEC. } & \multirow{2}{*}{ TOTAL } & \multicolumn{2}{|c|}{ RETOCADAS } \\
\cline { 3 - 4 } & & N & $\%$ \\
\hline 0 & 61 & 4 & 6,6 \\
1 & 55 & 25 & 45,5 \\
2 & 14 & 2 & 14,3 \\
3 & 3 & & \\
4 & 20 & 2 & 10,0 \\
5 & 80 & 4 & 5,0 \\
6 & 1 & 1 & 100,0 \\
7 & 234 & 38 & 16,2 \\
\hline
\end{tabular}

Cuadro SG2.5: piezas retocadas relativamente al total de las disponibles y según los distintos grupos tecnológicos.

\section{IV.4.1.2. ROTURAS}

\section{IV.4.1.2.1.- TIPOS DE ROTURAS}

El sílex gris tiene un porcentaje de roturas muy elevado, alcanzando casi el 70\% de las piezas (cuadro SG.6). Este índice es representativo de todos los grupos tecnológicos mayoritarios, es decir lascas y los soportes laminares. Destaca el alto porcentaje de roturas entre estos últimos, de los que tan sólo siete están enteros. En cuanto a los productos indeterminados, su propia definición ya hacer referencia a piezas rotas de carácter indeterminado. Los debris tienen también un porcentaje elevado de roturas debido a que entre éstos hay gran número de piezas rotas y astillas de talla inferiores a un centímetro. 


\begin{tabular}{|c|c|c|c|c|c|c|c|}
\hline \multirow{2}{*}{$\begin{array}{l}\text { GRUPO } \\
\text { TEC. }\end{array}$} & \multirow{2}{*}{ TIPO TEC. } & \multirow{2}{*}{ COMPLETOS } & \multicolumn{4}{|c|}{ FRAGMENTADOS } & \multirow{2}{*}{ TOTAL } \\
\hline & & & Distal & Mesial & Proximal & Rota & \\
\hline \multirow[b]{2}{*}{1} & $\mathrm{~L}$ & 14 & 19 & 2 & 11 & 11 & 57 \\
\hline & $\begin{array}{l}\mathrm{L}-\mathrm{H} \\
\mathrm{H}\end{array}$ & & 1 & & 3 & & 4 \\
\hline \multirow{3}{*}{2} & $\mathrm{H}$ & & 6 & 6 & 4 & & 16 \\
\hline & $\mathrm{H}-\mathrm{FN}$ & 1 & 3 & 3 & 2 & & 9 \\
\hline & HT & 7 & 7 & 12 & 4 & & 30 \\
\hline \multirow{4}{*}{3} & LC & 3 & 2 & & & & 5 \\
\hline & SN & 1 & & & & & 1 \\
\hline & FN & 3 & 1 & 1 & & & 5 \\
\hline & AN & 3 & & & & & 3 \\
\hline 4 & $\mathrm{~N}$ & 3 & & & & & 3 \\
\hline 5 & IT & & & & & 20 & 20 \\
\hline \multirow{2}{*}{6} & $\mathrm{LT}$ & 36 & 8 & 5 & 8 & 17 & 74 \\
\hline & IT & & & & & 6 & 6 \\
\hline \multirow[t]{3}{*}{7} & GB & & & 1 & & & 1 \\
\hline & & & 47 & 30 & 32 & 54 & 234 \\
\hline & & $71(30,3 \%)$ & \multicolumn{4}{|c|}{$163(69,7 \%)$} & \\
\hline
\end{tabular}

Cuadro SG.6: representación de los tipos de soportes enteros y fragmentados de sílex gris, teniendo en cuenta la totalidad de las piezas.

\section{IV.4.1.2.2. TIPOS DE ROTURAS}

En los tipos de roturas, predominan las que afectan a las piezas de forma transversal (cuadro SG.7), es decir las distales (24\%) y proximales (19\%), a las que seguirían las roturas por todos los lados (18\%). En la representación de los tipos de roturas en los distintos grupos tecnológicos (gráfico SG.1), se repite la pauta que se ha visto en las anteriores materias, en el grupo de las lascas y los debris están presentes todos los tipos de roturas, mientras que en los soportes laminares predominan las roturas transversales; por su parte, en los productos de acondicionamiento hay una representación más dispar de los distintos tipos de roturas.

\begin{tabular}{|l|cccccccc|r|}
\hline & BL & DL & DP & DS & LT & PD & PL & PX & TOTAL \\
\hline GR.1:L & & 2 & 7 & 11 & 2 & 2 & 11 & 7 & 42 \\
GR.2:H & 2 & & 9 & & 13 & & 7 & 31 \\
GR.3:P.A. & & & & 2 & 1 & & 1 & 3 & 7 \\
GR.6:DEB & 7 & 16 & 9 & 2 & 6 & 3 & 8 & 51 \\
\hline $\mathrm{N}$ & & 11 & 23 & 31 & 5 & 21 & 15 & 25 & 131 \\
$\%$ & & 8,4 & 17,6 & 23,7 & 3,8 & 16,0 & 11,5 & 19,1 & 100 \\
\hline
\end{tabular}

Cuadro SG.7: tipos de roturas en los distintos grupos tecnológicos. BL: bilateral, DL: distallateral, DP: distal-proximal-lateral, LT: lateral, PD: proximal-distal, PL: proximal-lateral, PX: proximal. 


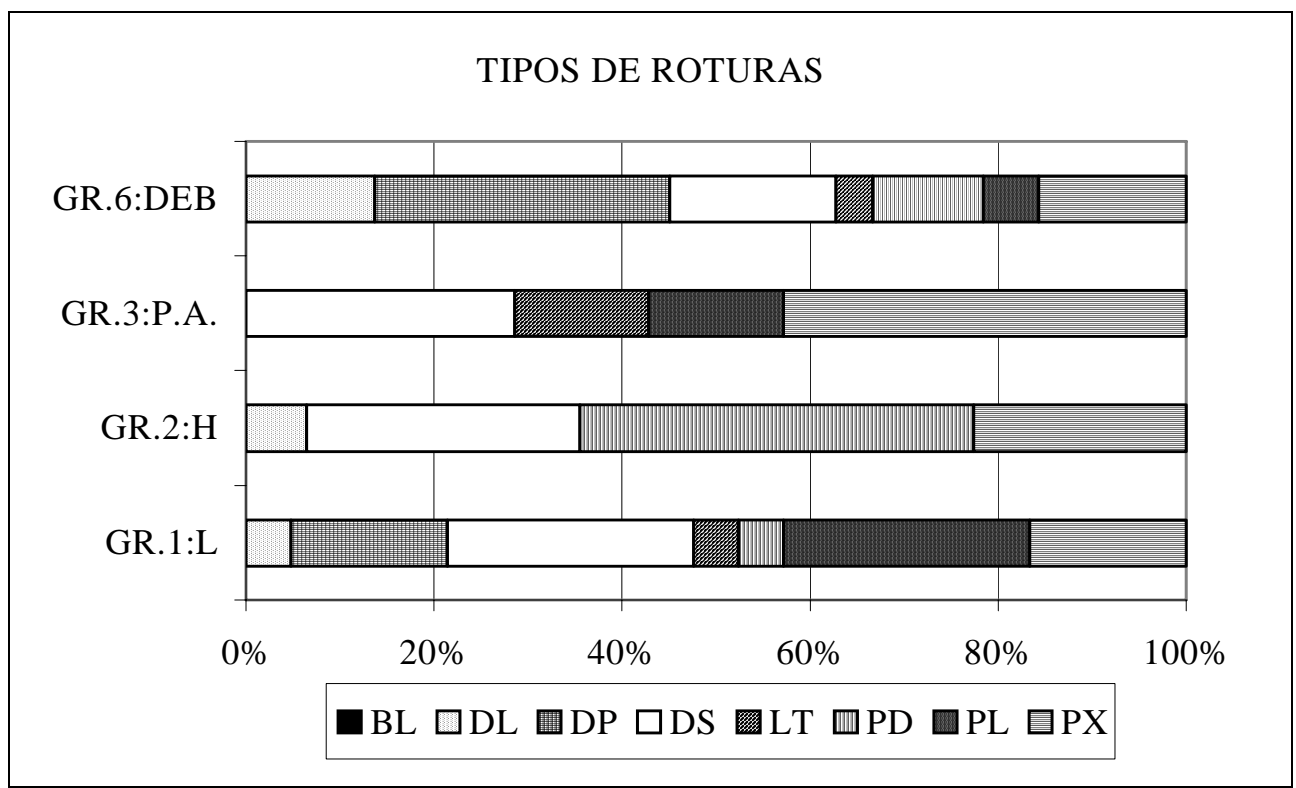

Gráfico SG.1: porcentaje de los tipos de roturas por grupos tecnológicos. Tipos de roturas: BL: bilateral, DL: distal-lateral, DP: distal-proximal-lateral, LT: lateral, PD: proximal-distal, PL: proximal-lateral, PX: proximal.

\section{IV.4.1.2.3. CAUSA DE LA ROTURA}

En este atributo predomina la flexión (58\%) sobre la percusión (16\%) y las roturas de causa indeterminada (25\%) (cuadro SG.8). Según los distintos tipos de rotura esta relación de predominio de la flexión se cumple, excepto en las piezas con rotura lateral (gráfico SG.2).

\begin{tabular}{|l|cccc|cc|}
\hline & GR.1 & GR.2 & GR.3 & GR.6 & N & $\%$ \\
\hline Flexión & 27 & 33 & 4 & 30 & 94 & 58,4 \\
Indeterminada & 9 & 11 & 2 & 19 & 41 & 25,5 \\
Percusión & 10 & 10 & 2 & 4 & 26 & 16,1 \\
\hline
\end{tabular}

Cuadro SG.8: causa rotura en los distintos grupos tecnológicos. 

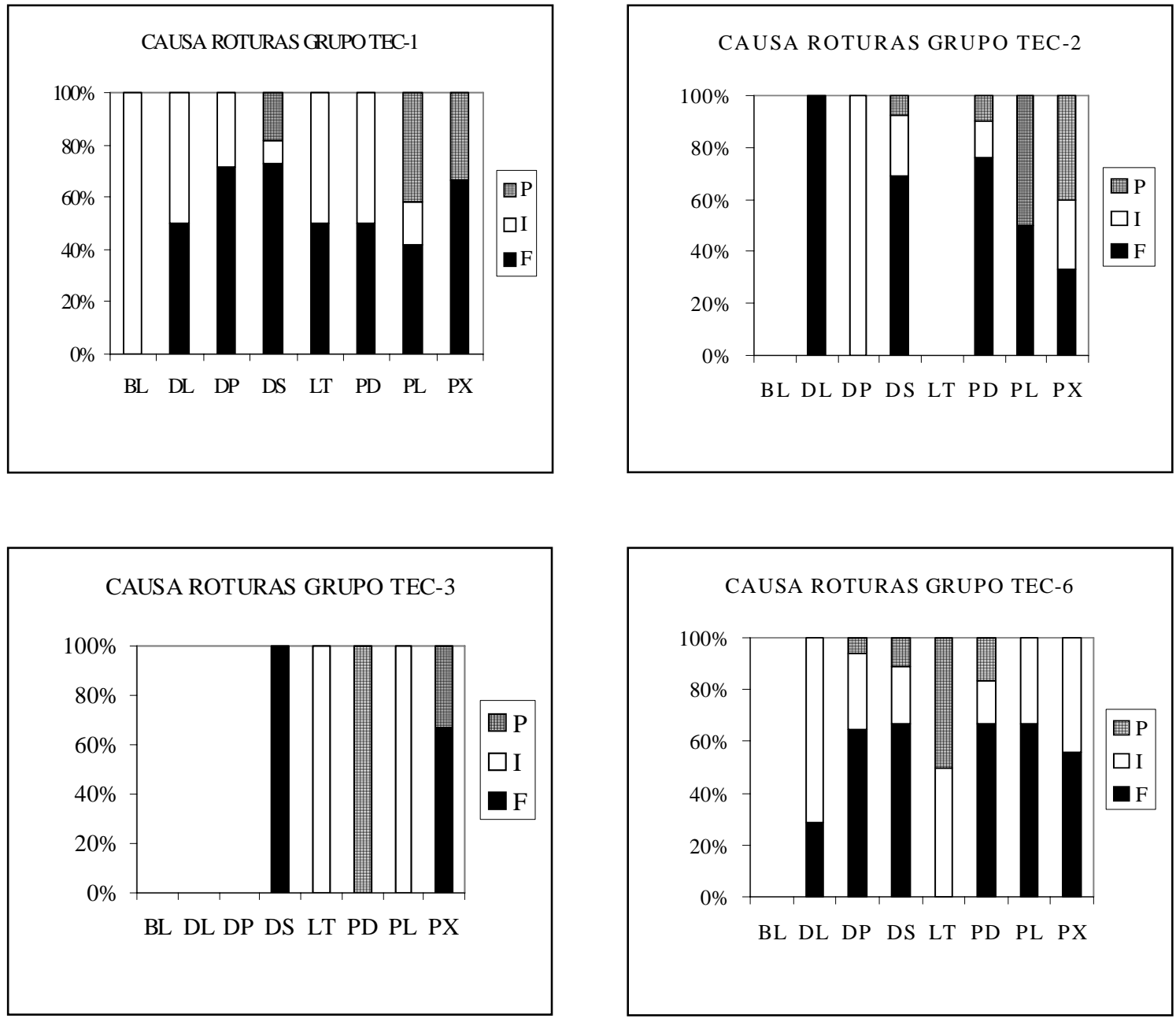

Gráfico SG.2: porcentaje de representación de las causas de la rotura según los distintos tipos de fracturas y según los grupos tecnológicos. En el eje de abscisas los tipos de fracturas: BL: bilateral, DL: distal-lateral, DP: distal-proximal-lateral, LT: lateral, PD: proximal-distal, PL: proximal-lateral, PX: proximal. En el eje de ordenadas se sitúa el porcentaje de los tipos de roturas: P: percusión, I: indeterminada, F: por flexión.

\section{IV.4.1.3. CÓRTEX}

La representación de superficie cortical es muy escasa en sílex gris, tan solo se puede apreciar algún resto de córtex en dos piezas. Hay que recordar que se trata de una materia de la que no conocemos cómo se presenta en su lugar de adquisición. La abundancia de planos de diaclasado interno presente están relacionados con la forma como se presenta la radiolarita, y puede que esta variedad silícea proceda también de una formación similar. 


\section{IV.4.1.4. DATOS MÉTRICOS}

El conjunto de restos de sílex gris tiene un tamaño bastante pequeño. La longitud máxima alcanza sólo en algún caso los cuatro centímetros y la anchura apenas llega a los tres; se trata por tanto de un conjunto de dimensiones muy reducidas. Este tamaño reducido de los objetos que componen este conjunto puede ser como consecuencia, bien del tamaño inicial de los nódulos, o bien de una explotación intensiva sobre esta materia. A este respecto, recordemos que al analizar las características de esta roca se comprobó que era una materia de una calidad bastante buena; $y$, si observamos las tablas de distribución de los tipos de soportes que aparecen en sílex gris, hay un predominio neto de los productos procedentes de la fase de explotación plena, con abundantes piezas retocadas y sin presencia apenas de piezas corticales. En consecuencia puede que el sílex gris encaje en un modelo de explotación de la materia típico, aplicado a rocas que no proceden del entorno inmediato de la cueva, en el que los núcleos habrían sido llevados una vez conformados en su lugar de adquisición. Estas rocas foráneas se suelen aprovechar de una forma muy intensiva, llegando a un nivel de explotación que agotaría prácticamente la roca disponible.

\section{IV.4.1.4.1. TIPOS DE SOPORTES}

Se ha calculado las dimensiones medias de los distintos grupos de soportes (cuadro SG.9), aunque estos datos estadísticos tienen un valor muy reducido debido al tamaño reducido de la muestra, y en todo caso buscamos una función sobre todo descriptiva de los datos analizados para presentar la muestra.

Los núcleos son las piezas mayores y también las que tienen una desviación típica más amplia. De hecho no se puede tener demasiado en cuenta este tipo de soporte ya que tan sólo contamos con tres ejemplares. Como es lógico las piezas que le seguirían en tamaño son los soportes indeterminados y los chunks, los cuales también cuentan con una desviación bastante amplia debido a las propias características de estos productos. A continuación se sitúan las lascas y los productos laminares. Las lascas tienen unas dimensiones medias de $13 \mathrm{~mm}$ de longitud, 11 de anchura y 3 de grosor. Las hojas/hojitas por su parte: 14 mm de longitud, 9 de anchura y 2 de grosor. 


\begin{tabular}{|c|c|c|c|c|c|c|c|}
\hline \multicolumn{4}{|l|}{ SIN RETOCAR } & \multicolumn{4}{|l|}{ RETOCADAS } \\
\hline GR1:L & $\mathbf{L}$ & A & G & GR1:L & $\mathbf{L}$ & A & G \\
\hline $\mathrm{N}$ & 14 & 44 & 53 & $\mathrm{~N}$ & - & 2 & 4 \\
\hline Rango & $5-25$ & $5-33$ & $1-8$ & Rango & & $17-23$ & $2-10$ \\
\hline Media & 13,14 & 11,19 & 3,45 & Media & & & 6,25 \\
\hline Desviación & 5,22 & 5,13 & 1,72 & Desviación & & & 3,30 \\
\hline GR1:L-H & $\mathbf{L}$ & A & G & GR1:L-H & $\mathbf{L}$ & A & G \\
\hline $\mathrm{N}$ & - & 4 & 4 & $\mathrm{~N}$ & - & - & - \\
\hline Rango & & $12-18$ & $3-5$ & Rango & & & \\
\hline Media & & 11,19 & 3,45 & Media & & & \\
\hline Desviación & & 5,13 & 1,72 & Desviación & & & \\
\hline GR2:H & $\mathbf{L}$ & A & G & GR2:H & $\mathbf{L}$ & A & G \\
\hline $\mathrm{N}$ & 5 & 26 & 26 & $\mathrm{~N}$ & 2 & 19 & 19 \\
\hline Rango & $12-18$ & 5-13 & $1-4$ & Rango & $13-14$ & $4-10$ & $0,7-3,2$ \\
\hline Media & 14,4 & 8,96 & 2,37 & Media & & 6,41 & 2,08 \\
\hline Desviación & 2,30 & 2,18 & 0,84 & Desviación & & 1,73 & 0,68 \\
\hline GR2:H-FN & $\mathbf{L}$ & A & G & GR2:H-FN & $\mathbf{L}$ & A & G \\
\hline $\mathrm{N}$ & - & 4 & 4 & $\mathrm{~N}$ & 1 & 6 & 6 \\
\hline Rango & & 5-16 & $2-6$ & Rango & 22 & $7-15$ & $4-8$ \\
\hline Media & & 11,50 & 3,63 & Media & & 10,58 & 5,27 \\
\hline Desviación & & 4,65 & 1,49 & Desviación & & 3,23 & 1,49 \\
\hline GR3:P.A. & $\mathbf{L}$ & $\mathbf{A}$ & G & GR3:P.A. & $\mathbf{L}$ & A & G \\
\hline $\mathrm{N}$ & 9 & 12 & 12 & $\mathrm{~N}$ & 1 & 2 & 2 \\
\hline Rango & $7-41$ & $7-17$ & $4-10$ & Rango & 16 & 5-19 & $3,5-4$ \\
\hline Media & 23,67 & 11,42 & 6,19 & Media & & & \\
\hline Desviación & 11,36 & 3,63 & 1,79 & Desviación & & & \\
\hline GR4:N & $\mathbf{L}$ & A & $\mathbf{G}$ & GR4:N & $\mathbf{L}$ & A & G \\
\hline $\mathrm{N}$ & 3 & 3 & 3 & $\mathrm{~N}$ & - & - & - \\
\hline Rango & $30-39$ & $18-27$ & 9-18 & Rango & & & \\
\hline Media & 33,67 & 22,0 & 12,33 & Media & & & \\
\hline Desviación & 4,73 & 4,58 & 4,93 & Desviación & & & \\
\hline GR5:IT & $\mathbf{L}$ & A & G & GR5:IT & $\mathbf{L}$ & A & G \\
\hline $\mathrm{N}$ & 18 & 18 & 18 & $\mathrm{~N}$ & 2 & 2 & 2 \\
\hline Rango & $8-37$ & $4-24$ & $1,8-11$ & Rango & $17-29$ & $19-27$ & $11-14$ \\
\hline Media & 16,67 & 9,89 & 4,80 & Media & & & \\
\hline Desviación & 6,89 & 5,09 & 2,53 & Desviación & & & \\
\hline GR6:DEB & $\mathbf{L}$ & A & G & GR6:DEB & $\mathbf{L}$ & A & G \\
\hline $\mathrm{N}$ & 76 & 76 & 76 & $\mathrm{~N}$ & 4 & 4 & 4 \\
\hline Rango & $2-10$ & $3-10$ & $0,3-5$ & Rango & $9-9$ & $6-8$ & $1-3$ \\
\hline Media & 7,65 & 6,78 & 1,89 & Media & 9,0 & 7,0 & 2,13 \\
\hline Desviación & 1,98 & 1,74 & 1,07 & Desviación & 0 & 0,82 & 0,83 \\
\hline
\end{tabular}

Cuadro SG.9: datos métricos de los talones de radiolarita tipo-B, por grupos tecnológicos. N: número de elementos. L: longitud, A: anchura, G: grosor. 
IV.4.1.4.2. TALÓN

En la dimensión del talón (cuadro SG.10) se ve también una relación entre el tipo de soporte y el tamaño del talón, de modo que es mayor en las lascas ( $\mathrm{L}=7,9 \mathrm{~mm}$ y $\mathrm{A}=2,7$ ) y productos de acondicionamiento (con una media de 7,1 mm de longitud y 3,7 de anchura) que en los soportes laminares $(L=4,1 \mathrm{~mm}$ y $A=1,8)$. Estas dimensiones están relacionadas con el modo de talla empleado y, sobre todo si nos fijamos en la anchura, es una dimensión que se reduce por la preparación en el anverso de la extracción. En las hojas se puede apreciar una reducción del talón y, por tanto, de la superficie que está en contacto con el percutor (no llega a los $2 \mathrm{~mm}$ ), apuntando a una percusión de tipo tangencial.

\begin{tabular}{|c|c|c|c|c|c|}
\hline SIN RETOCAR & & & RETOCADAS & & \\
\hline GR1:L & $\mathbf{L}$ & A & GR1:L & $\mathbf{L}$ & A \\
\hline $\mathrm{N}$ & 13 & 17 & $\mathrm{~N}$ & - & - \\
\hline Rango & $2,7-23$ & $1-6,8$ & Rango & & \\
\hline Media & 7,89 & 2,69 & Media & & \\
\hline Desviación & 5,69 & 1,60 & Desviación & & \\
\hline GR1:L-H & $\mathbf{L}$ & A & GR1:L-H & $\mathbf{L}$ & A \\
\hline $\mathrm{N}$ & 3 & 3 & $\mathrm{~N}$ & - & - \\
\hline Rango & $8-11,8$ & $2,2-2,8$ & Rango & & \\
\hline Media & 9,33 & 2,53 & Media & & \\
\hline Desviación & 2,14 & 0,31 & Desviación & & \\
\hline GR2:H & $\mathbf{L}$ & A & GR2:H & $\mathbf{L}$ & A \\
\hline $\mathrm{N}$ & 5 & 6 & $\mathrm{~N}$ & 3 & 3 \\
\hline Rango & $3-6$ & $0,5-1,8$ & Rango & $0,8-6,5$ & $0,8-1$ \\
\hline Media & 4,06 & 1,17 & Media & 4,03 & 1,37 \\
\hline Desviación & 1,15 & 0,49 & Desviación & 2,93 & 0,81 \\
\hline GR3:P.A. & $\mathbf{L}$ & A & GR3:P.A. & $\mathbf{L}$ & A \\
\hline $\mathrm{N}$ & 5 & 5 & $\mathrm{~N}$ & 1 & 1 \\
\hline Rango & $3,3-13$ & $1,5-6$ & Rango & 10 & 2,5 \\
\hline Media & 7,08 & 3,66 & Media & & \\
\hline Desviación & 3,76 & 1,75 & Desviación & & \\
\hline GR6:DEB & $\mathbf{L}$ & A & GR6:DEB & $\mathbf{L}$ & A \\
\hline $\mathrm{N}$ & 12 & 18 & $\mathrm{~N}$ & & \\
\hline Rango & $0,7-6$ & $0,4-3,2$ & Rango & & \\
\hline Media & 3,48 & 1,26 & Media & & \\
\hline Desviación & 1,61 & 0,74 & Desviación & & \\
\hline
\end{tabular}

Cuadro SG.10: datos métricos de los talones de radiolarita tipo-B, por grupos tecnológicos. N: número de elementos. L: longitud, A: anchura, G: grosor. 


\section{IV.4.1.5. ACCIDENTES}

No hay muchos accidentes ( $\mathrm{n}=60$ ), pero destaca la abundancia de planos naturales (30\%) que han dificultado de algún modo la talla correcta de los soportes (especialmente se ve en las piezas indeterminadas), que serían tan importantes como los reflejados (30\%). A continuación está el pseudoburil de Siret (22\%) y los sobrepasados (15\%); por último, las fracturas en lengüeta y el doble bulbo tienen una presencia muy puntual (cuadro SG.11). Respecto a la manera como afectan los distintos accidentes a los distintos grupos tecnológicos, el reflejado predomina de forma clara en los soportes laminares, mientras que los sobrepasados lo hacen en los productos de acondicionamiento (gráfico SG.3).

\begin{tabular}{|l|cccccc|r|}
\hline & DB & LG & PB & RF & SP & PN & TOTAL \\
\hline GR.1 & 1 & & 4 & 8 & 1 & 8 & 22 \\
GR.2 & & & 1 & 3 & 1 & 1 & 6 \\
GR.3 & & & 2 & 1 & 7 & 2 & 12 \\
GR.6 & & 1 & 6 & 6 & & 7 & 20 \\
\hline TOTAL & 1 & 1 & 13 & 18 & 9 & 18 & 60 \\
$\%$ & 1,67 & 1,67 & 21,67 & 30,00 & 15,00 & 30,00 & 100 \\
\hline
\end{tabular}

Cuadro SG.11: accidentes de talla por grupos tecnológicos. DB: doble bulbo, LG: fragmento en lengüeta, PB: pseudoburil de Siret, RF: reflejado, SP: sobrepasado, PN: plano natural.

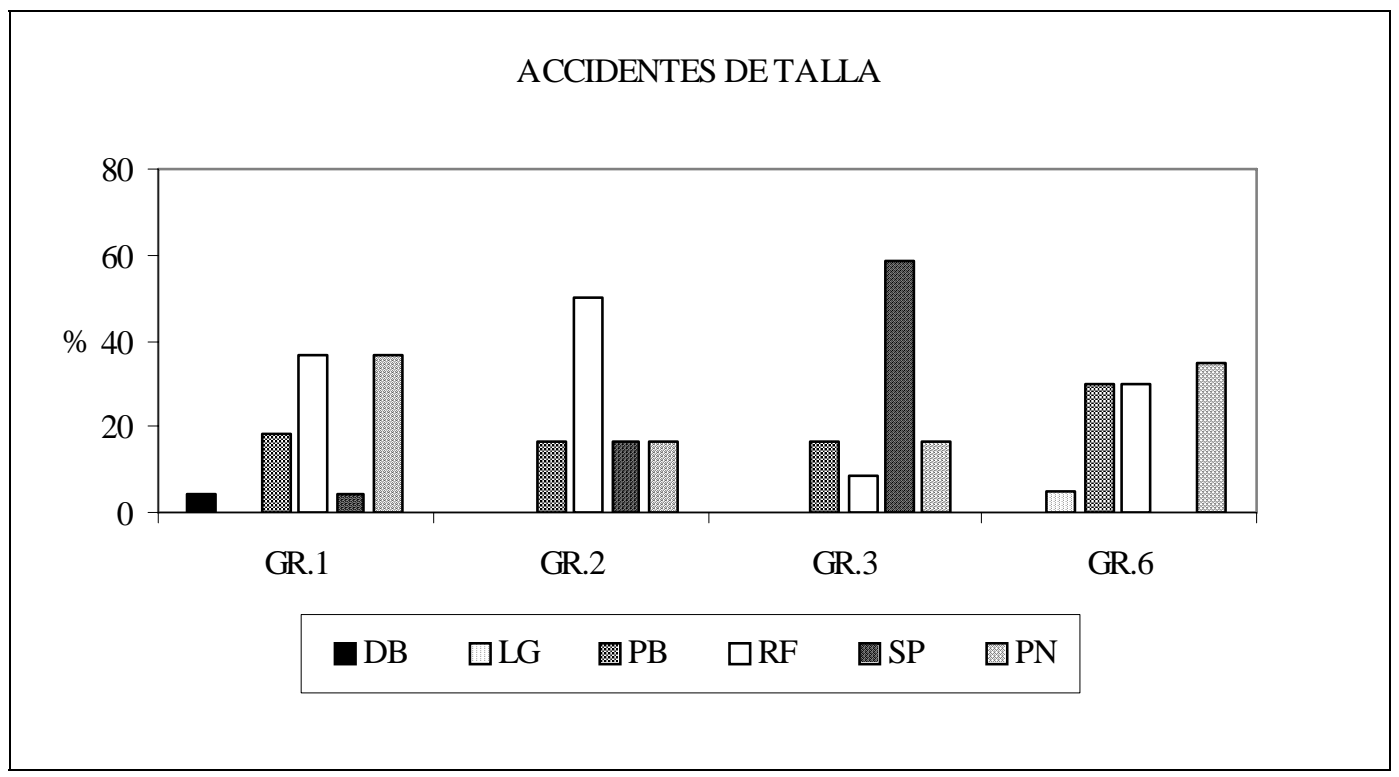

Gráfico SG.3: accidentes de talla por grupos tecnológicos. DB: dobre bulbo, LG: fragmento en lengüeta, PB: pseudoburil de Siret, RF: reflejado, SP: sobrepasado, PN: plano natural. 


\section{IV.4.1.6.- TIPOS DE TALÓN}

Hay más de un 50\% de piezas en el que no podemos observar este atributo, lo cual está relacionado también con el elevado porcentaje de roturas. Del resto, la mayoría tienen el talón liso (19\%) (hay que tener en cuenta que dentro de esta categoría se han incluido también aquellos talones que aprovechan un plano natural). Después se encontrarían los talones puntiformes (9\%), los rotos (8\%), los facetados (7\%) y, con un porcentaje en torno al 2\%, los diedros y los suprimidos (cuadro SG.12). Esta representación genérica de los distintos tipos de talón es válida en los distintos tipos de soportes (gráfico SG.4).

\begin{tabular}{|l|rccccccc|r|}
\hline & $\mathrm{C}$ & $\mathrm{D}$ & $\mathrm{F}$ & $\mathrm{L}$ & $\mathrm{O}$ & $\mathrm{P}$ & $\mathrm{R}$ & $\mathrm{S}$ & TOTAL \\
\hline GR.1 & & 2 & 6 & 11 & 30 & 3 & 1 & & 53 \\
GR.2 & & 1 & 2 & 5 & 20 & 3 & 1 & 2 & 34 \\
GR.3 & & & 2 & 3 & 4 & & 2 & 1 & 12 \\
GR.6 & & 1 & 3 & 15 & 37 & 10 & 10 & & 76 \\
\hline TOTAL & & 4 & 13 & 34 & 91 & 16 & 14 & 3 & 175 \\
$\%$ & & 2,29 & 7,43 & 19,43 & 52,00 & 9,14 & 8,00 & 1,71 & 100 \\
\hline
\end{tabular}

Cuadro SG.12: tipos de talón por grupos tecnológicos. C: cortical, D: diedro, F: facetado, L: liso, O: sin talón, P: puntiforme, R: roto, S: suprimido.

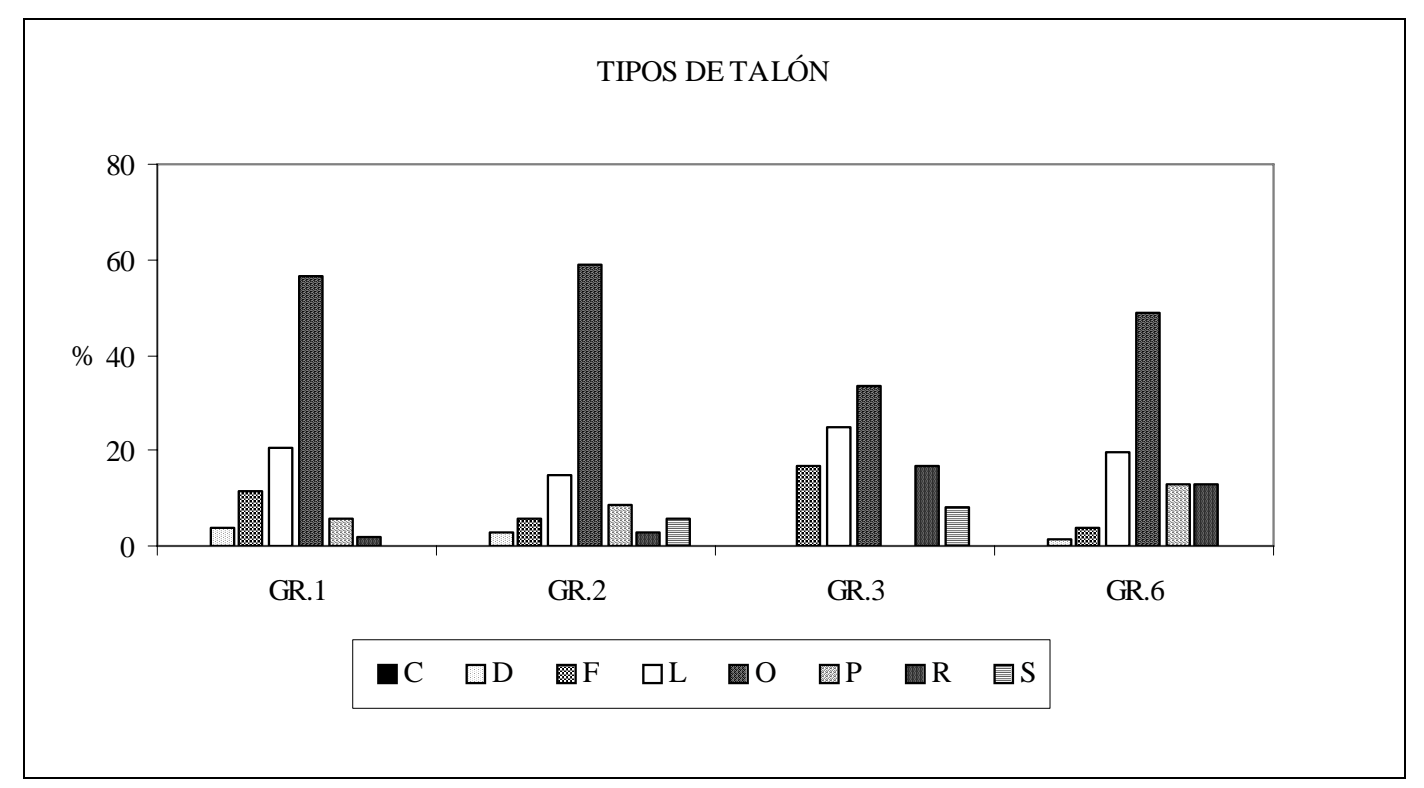

Gráfico SG.4: tipos de talón por grupos tecnológicos. C: cortical, D: diedro, F: facetado, L: liso, O: sin talón, P: puntiforme, R: roto, S: suprimido. 


\section{IV.4.1.7.- PREPARACIÓN DEL PUNTO DE IMPACTO}

La preparación del punto de impacto en las piezas que tienen talón se cifra en torno al 30\%, siendo en este caso ligeramente más abundante en las lasquitas presentes en los debris (36\%) que en los soportes laminares (33\%); las lascas y productos de acondicionamiento presentan en torno a un 20\% de preparación (cuadro SG.13).

\begin{tabular}{|c|c|cc|cc|}
\hline & \multirow{2}{*}{ TOTAL } & \multicolumn{2}{|c|}{ PIEZAS CON TALÓN } & \multicolumn{2}{c|}{ PIEZAS PREPARADAS } \\
\cline { 3 - 6 } & & $\mathrm{N}$ & $\%$ & $\mathrm{~N}$ & $\%$ \\
\hline GR-1 & 61 & 28 & 45,9 & 6 & 21,4 \\
GR-2 & 55 & 18 & 32,7 & 6 & 33,3 \\
GR-3 & 14 & 10 & 71,4 & 2 & 20,0 \\
GR-6 & 80 & 44 & 55 & 16 & 36,4 \\
\hline & 210 & 100 & 47,6 & 30 & 30,0 \\
\hline
\end{tabular}

Cuadro SG.13: piezas con talón y preparación relativa dentro de los distintos grupos tecnológicos.

En los tipos de preparación (cuadro SG.14) predomina el esquirlado (43\%) sobre el retoque (32\%) y la abrasión (25\%). En la representación del tipo de preparación por grupos tecnológicos y tipos de talón, no hay ninguna discrepancia respecto a esta tendencia general (cuadros SG.14, 15, 16).

\begin{tabular}{|l|cccc|cc|}
\hline & \multirow{2}{*}{ GR-1 } & GR-2 & \multirow{2}{*}{ GR-3 } & GR-6 & \multicolumn{2}{|c|}{ TOTAL } \\
\cline { 6 - 7 } & & & & & $\mathrm{N}$ & $\%$ \\
\hline Facetado & & & & & & \\
Abrasión & 1 & 1 & & 5 & 7 & 25,0 \\
Esquirlado & 5 & 1 & 1 & 5 & 12 & 42,9 \\
Retoque & 2 & 1 & & 6 & 9 & 32,1 \\
\hline & 8 & 3 & 1 & 16 & 28 & 100 \\
\hline
\end{tabular}

Cuadro SG.14: tipos de preparación según los distintos grupos tecnológicos. FAC: facetado, A: abrasión, E: esquirlado, R: retoque.

\begin{tabular}{|l|cccccccc|}
\hline & C & D & F & L & P & R & S & O \\
\hline PIEZAS CON TALÓN & & 4 & 13 & 34 & 16 & 14 & & \\
\hline PIEZAS PREPARADAS & & 2 & 6 & 15 & 4 & 1 & & \\
$\%$ & & 50 & 46,2 & 44,1 & 25 & 7,14 & & \\
\hline
\end{tabular}

Cuadro SG.15: porcentaje de preparación en los distintos tipos de talón disponibles. C: cortical, D: diedro, F: facetado, L: liso, O: sin talón, P: puntiforme, R: roto, S: suprimido. 


\begin{tabular}{|c|c|c|c|c|c|c|c|c|}
\hline & $\mathrm{C}$ & $\mathrm{D}$ & $\mathrm{F}$ & $\mathrm{L}$ & $\mathrm{P}$ & $\mathrm{R}$ & $S$ & $\mathrm{O}$ \\
\hline FAC & & & & & & & & \\
\hline A & & & 1 & 4 & 1 & 1 & & \\
\hline $\mathrm{E}$ & & 2 & 4 & 6 & & & & \\
\hline $\mathrm{R}$ & & & 1 & 5 & 3 & & & \\
\hline TOTAL & & 2 & 6 & 15 & 4 & 1 & & \\
\hline$\%$ & & 7,1 & 21,4 & 53,6 & 14,3 & 3,6 & & \\
\hline
\end{tabular}

Cuadro SG.16: tipos de preparación sobre los distintos tipos de talón. C: cortical, D: diedro, F: facetado, L: liso, O: sin talón, P: puntiforme, R: roto, S: suprimido.

\section{IV.4.1.8.- ÁNGULO DE PERCUSIÓN}

En el ángulo del frente de percusión predomina un ángulo abierto (cuadro SG.17), cercano a los $90^{\circ}$ y no hay demasiadas diferencias en los distintos grupos de soportes excepto en los debris, donde el ángulo más cerrado ( $\mathrm{Fa} / \mathrm{Db})$ es tan importante como el abierto. Aunque el número de piezas es muy escaso y por tanto su validez relativa, hay la misma tendencia en este tipo de sílex que la observada para el resto de las materias.

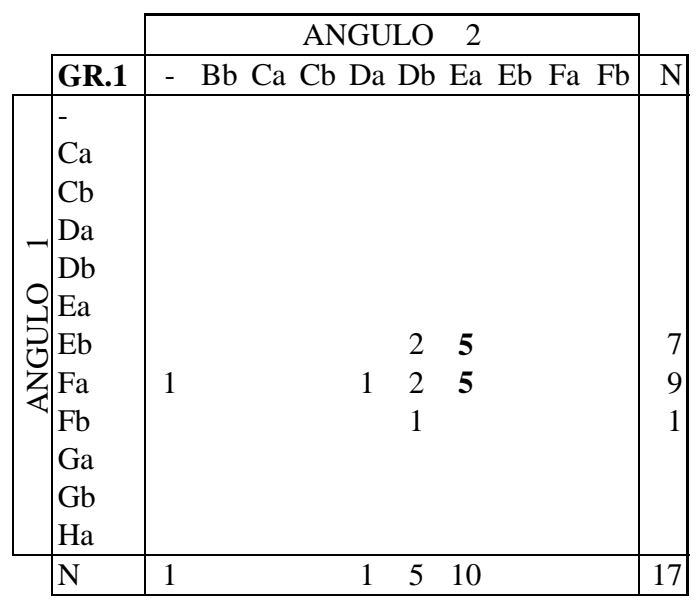

Cuadro SG.17: ángulos de percusión por grupos tecnológicos Angulo 1: ángulo interno (entre talón y el bulbo). Angulo 2: ángulo externo o de la cornisa (entre talón y la cara superior). $\mathrm{Bb}=30-40^{\circ}, \mathrm{Ca}=40-50^{\circ}, \mathrm{Cb}=50-60^{\circ}, \mathrm{Da}=60-70^{\circ}, \mathrm{Db}=70-80^{\circ}, \mathrm{Ea}=80-90^{\circ}, \mathrm{Eb}=90-100^{\circ}, \mathrm{Fa}=100-$ $110^{\circ}, \mathrm{Fb}=110-120^{\circ}, \mathrm{Ga}=120-130^{\circ}, \mathrm{Gb}=130-140^{\circ}, \mathrm{Ha}=140-150^{\circ}$. 

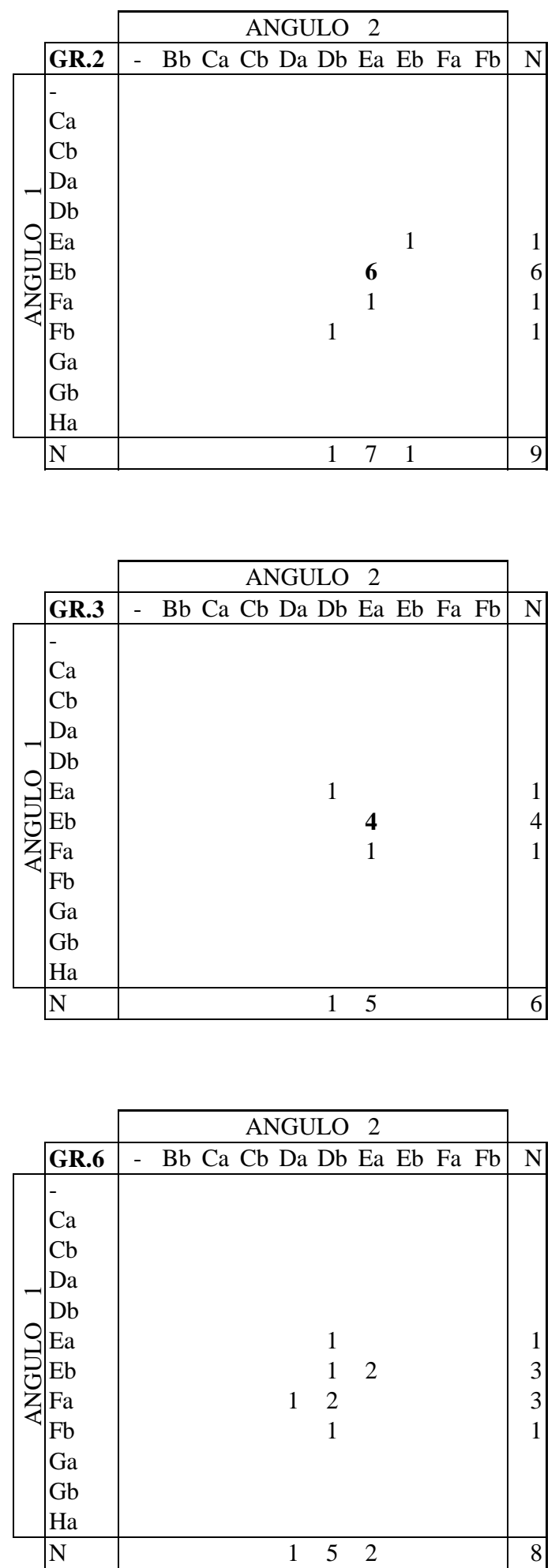

Cuadro SG.17 (continuación): ángulos de percusión por grupos tecnológicos. Angulo 1: ángulo interno (entre talón y el bulbo). Angulo 2: ángulo externo o de la cornisa (entre talón y la cara superior). $\mathrm{Bb}=30-40^{\circ}, \mathrm{Ca}=40-50^{\circ}, \mathrm{Cb}=50-60^{\circ}, \mathrm{Da}=60-70^{\circ}, \mathrm{Db}=70-80^{\circ}, \mathrm{Ea}=80-90^{\circ}, \mathrm{Eb}=90-100^{\circ}$, $\mathrm{Fa}=100-110^{\circ}, \mathrm{Fb}=110-120^{\circ}, \mathrm{Ga}=120-130^{\circ}, \mathrm{Gb}=130-140^{\circ}, \mathrm{Ha}=140-150^{\circ}$. 


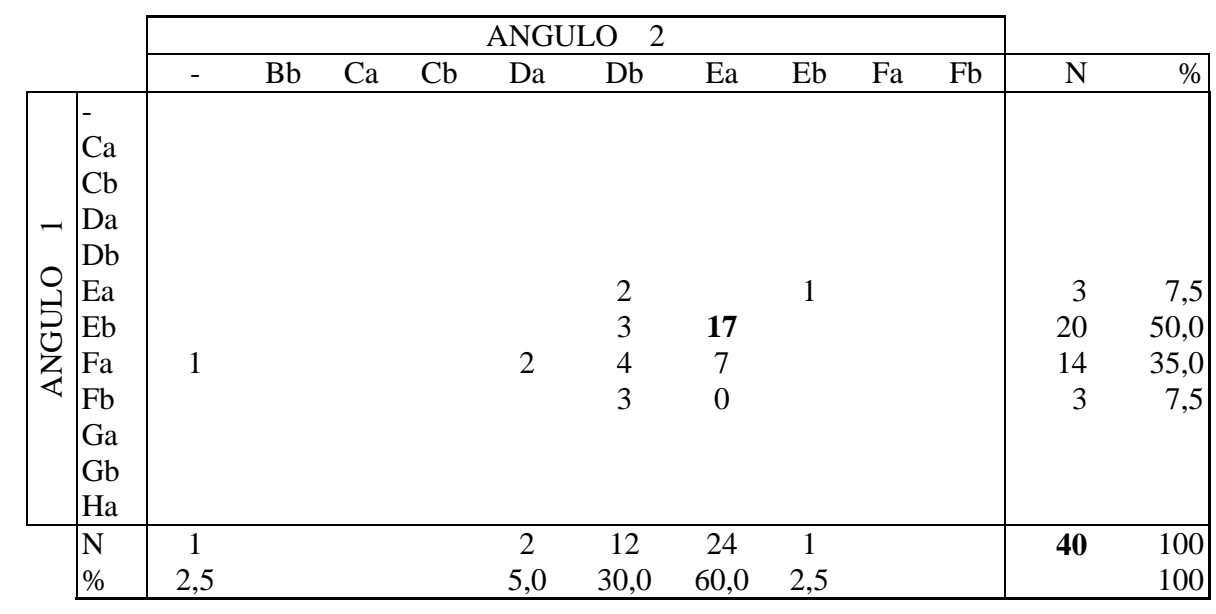

Cuadro SG.17 (continuación): ángulos de percusión en el sílex gris. Angulo 1: ángulo interno (entre talón y el bulbo). Angulo 2: ángulo externo o de la cornisa (entre talón y la cara superior). $\mathrm{Bb}=30-40^{\circ}, \mathrm{Ca}=40-50^{\circ}, \mathrm{Cb}=50-60^{\circ}, \mathrm{Da}=60-70^{\circ}, \mathrm{Db}=70-80^{\circ}, \mathrm{Ea}=80-90^{\circ}, \mathrm{Eb}=90-100^{\circ}, \mathrm{Fa}=100-$ $110^{\circ}, \mathrm{Fb}=110-120^{\circ}, \mathrm{Ga}=120-130^{\circ}, \mathrm{Gb}=130-140^{\circ}, \mathrm{Ha}=140-150^{\circ}$.

\section{IV.4.1.9.- ALTERACIONES}

No se ha apreciado la presencia de ningún tipo de alteración en el sílex gris.

\section{IV.4.1.10. MODO DE TALLA}

El modo de talla aplicado se ha identificado en muy pocas piezas y sin que se aprecien grandes diferencias en los distintos tipos de soportes. Parece que sí se ha utilizado el percutor blando y puede que la piedra blanda. Habría que recordar, como siempre, el tamaño del talón en los soportes laminares, que ha sido reducido como consecuencia de una preparación más intensa del punto de impacto; lo cual vendría a indicar un mayor cuidado y quizás algún cambio en los gestos de la percusión aplicada en la extracción de las hojas-hojitas.

\begin{tabular}{|l|ccc|c|}
\hline & PDD & PDDB & PDB & TOTAL \\
\hline GR.1 & & & & \\
GR.2 & & & 1 & 1 \\
GR.3 & 1 & & 1 & 2 \\
GR.6 & & 1 & 1 & 2 \\
\hline
\end{tabular}

Cuadro SG.18: modo de talla por grupos tecnológicos. PDD: percusión directa con percutor duro; PDDB: percusión directa con percutor de piedra blando; PDB: percusión directa con percutor blando. 


\section{IV.4.2. NÚCLEOS}

\section{IV.4.2.1. Atributos BÁsicos}

Hay tres núcleos de sílex gris (figura SG.1), todos se clasificarían como prismáticos con un plano de percusión (cuadro SG.19). Las últimas extracciones visibles son hojitas de dirección unipolar. Las medidas de los núcleos no son demasiado grandes: 30-40 mm. de longitud por 20-25 mm. de anchura. En dos casos se trata de núcleos con forma de prisma alargado y estrecho (en torno a $10 \mathrm{~mm}$ de grosor) bastante regular ya que tienen un plano natural de diaclasado como superficie posterior, paralela a la superficie de extracciones. El otro núcleo tiene restos de preparación sobre la superficie posterior y los laterales. En el atributo del córtex se expone la disposición de estos planos naturales en la conformación del volumen del núcleo.

En los tres casos la superficie de extracciones aparece sobre la superficie más ancha del volumen del núcleo, aspecto que es más acusado en los dos núcleos cuya parte posterior es un plano natural.

El abandono de los núcleos se debe posiblemente a su pequeño tamaño y un estado de agotamiento del volumen a explotar. En el primer núcleo los reflejados (posiblemente ocasionados por la pérdida de una carena correcta) son la causa del abandono directo, en los otros dos, más estrechos, posiblemente se trate de la pérdida de la carena. 

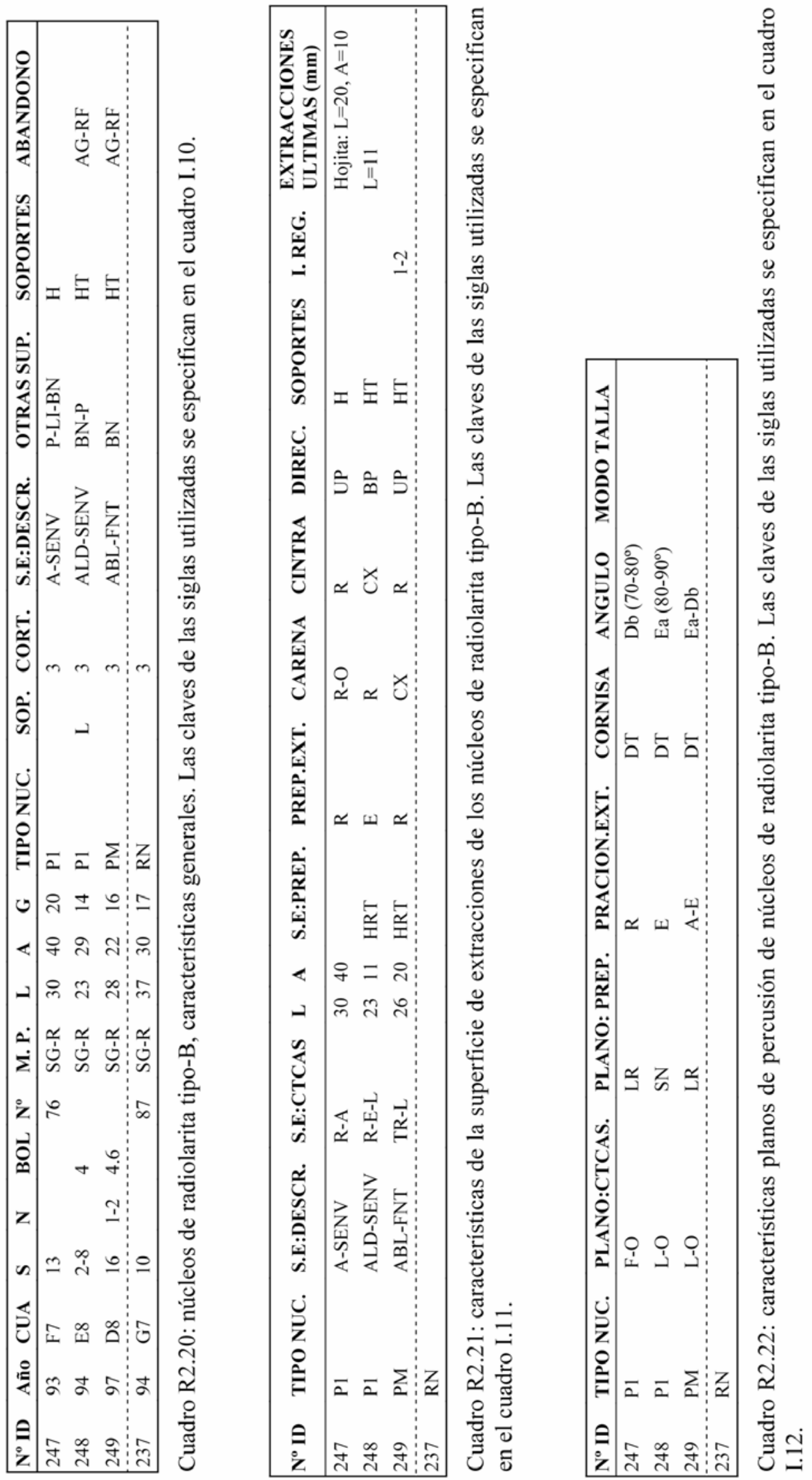


\section{IV.4.2.2. CARACTERÍSTICAS DE LA SUPERFICIE DE EXTRACCIONES}

En los tres núcleos el tipo de avance del débitage es frontal (cuadro SG.20), sobre una superficie de extracciones rectangular estrecha; estas características son típicas del esquema operativo de los núcleos prismáticos tipo-A descritos para el sílex negro, pero de tamaño más reducido en este caso.

Los procedimientos de reparación de la tabla laminar son los propios de un esquema unipolar prismático "estricto", con un mantenimiento de dicha superficie de forma perpendicular a los laterales del núcleo en el avance frontal del débitage. Se trata entonces de procurar que la tabla continúe teniendo esta estructura, mediante las extracciones axiales sobre los flancos del núcleo. Estas extracciones se pueden producir por medio de flancos longitudinales o bien mediante las hojas o "piezas con flanco".

La preparación de las extracciones propiamente dichas no se constata demasiado en los núcleos que tenemos, tan solo se puede ver restos de retoque en uno de ellos.

La carena es, en general, tendente a recta, al igual que la cintra.

La dirección del débitage es unipolar y los soportes son hojitas en general, puede que se obtengan algunas hojas algo más anchas. Hay que reseñar que la apariencia de los negativos laminares en los dos últimos núcleos refleja una regularidad bastante buena de las extracciones.

Las últimas extracciones se leen mejor en los dos últimos núcleos que en el primero, en uno de ellos hay una hojita de $23 \mathrm{~mm}$ de longitud por 9 de anchura; en el otro se ha encontrado el remontage de una "hoja con flanco" de $13 \mathrm{~mm}$ de anchura. En este último caso se puede observar cómo el método de débitage de tipo de frontal con la tabla ortogonal a los laterales se puede auto-mantener de forma efectiva a partir de este tipo de extracciones axiales que se llevan parte del flanco lateral del núcleo. 


\section{IV.4.2.3. CARACTERÍSTICAS DEL PLANO DE PERCUSIÓN}

Los planos de percusión son facetados en dos casos $\left(n^{0} 1\right.$ y 2$)$ y un plano natural en el $\mathrm{n}^{0} 3$; en el primer núcleo es un plano oblicuo respecto a la superficie de extracciones, mientras que en los otros dos es más recto (cuadro SG.21).

La reparación del plano de percusión se produce en forma de pequeñas lasquitas de reavivado, excepto en el caso del plano natural. Respecto a la preparación del punto de impacto sí hay constancia de un método de preparación que afecta al plano de percusión, con restos de retoque sobre dicho plano. Dicho procedimiento debe haber sido más o menos intenso, ya que en todos los casos la cornisa es continua.

Respecto al ángulo del frente de percusión, en el núcleo $\mathrm{n}^{\circ} 3$ es bastante abierto $\left(80-90^{\circ}\right)$, mientras que en los otros dos el ángulo es más cerrado (60-70 ). En los soportes extraídos se ha visto como hay un predominio de los ángulos abiertos, cercano a los $90^{\circ} \mathrm{y}$, de hecho, parece que esta tendencia también se observa en los núcleos, a pesar de que en principio hay más frentes de talla cerrados. Si se observa el núcleo con la "hoja con flanco" remontada (Figura SG.1: 2b), el ángulo de percusión varía dependiendo de si la pieza está remontada o no. En el núcleo abandonado el ángulo es cerrado, en cambio en la pieza remontada el ángulo es abierto, constatándose además el procedimiento de preparación del punto de impacto bastante intenso en torno al talón. 


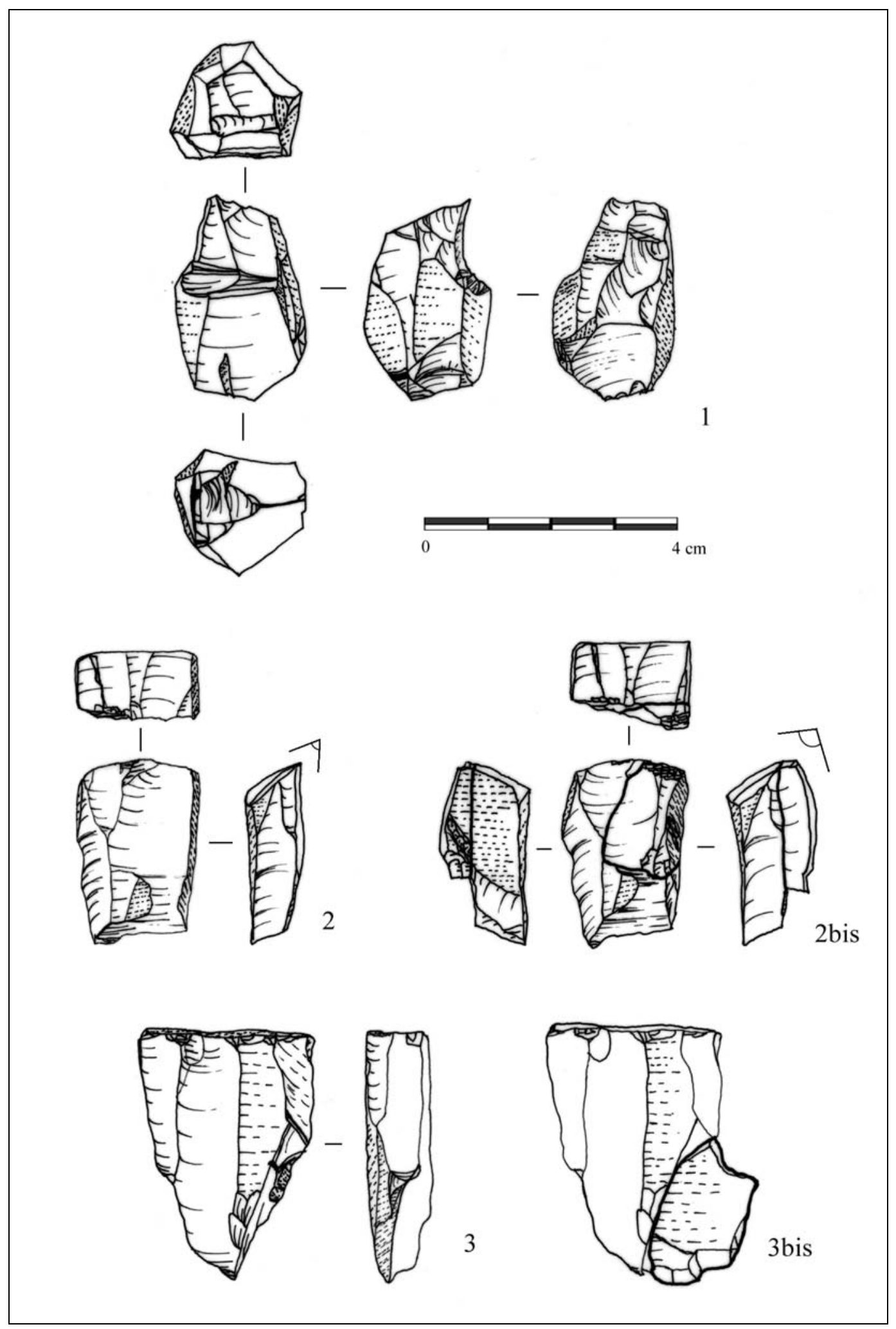

Figura SG.1: núcleos de hojitas de sílex gris. Todos son prismáticos unipolares. 2b: remontage de una "hoja con flanco" con el talón preparado; obsérvese el cambio en el ángulo del frente de percusión en la hoja preparada y en el núcleo restante. 3b: remontage de una lasca que tiene un perforador sobre la zona transversal-derecha (aprovechando la rotura distal). 


\section{IV.4.3. PRODUCTOS DE ACONDICIONAMIENTO}

Los productos de acondicionamiento suponen un 6\% del conjunto de sílex gris y contamos con cinco piezas con cresta, una semitableta de núcleo, cinco flancos de núcleo y tres aristas indeterminadas.

\section{IV.4.3.1. PIEZAS CON CRESTA}

De las cinco piezas con cresta cuatro son neo-crestas (en tres casos tienen extracciones transversales a lo largo de toda la longitud de la pieza y una es parcial) y tan solo una tiene extracciones hacia ambas vertientes. Predominan por tanto los procedimientos que recurren a crestas laterales a lo largo de la fase de producción, de forma que tales crestas pueden aparecer posteriormente en forma de neo-crestas, con una función similar a las "hojas con flanco" o algunos flancos longitudinales. El único ejemplo de cresta podría proceder también de estos procedimientos de mantenimiento del débitage más que de la fase de iniciación del mismo.

\section{IV.4.3.2. TABLETAS Y SEMITABLETAS DE NÚCLEO}

Solamente se ha localizado una semitableta de núcleo, al analizar los núcleos se pudo comprobar cómo el mantenimiento de los mismos se realizaba a partir de pequeñas lasquitas de reavivado del plano, más que en forma de tabletas o semitabletas.

\section{IV.4.3.3. FLANCOS DE NÚCLEO}

Hay cinco flancos de núcleo, cuatro de ellos son longitudinales unipolares, realizados desde el mimo plano de percusión principal, el último se han realizado a partir del plano opuesto. En otros dos flancos se constata también un débitage bipolar. Puede llamar la atención la presencia de estos flancos y huellas de un ritmo de talla bipolar, desde un segundo plano de percusión, cuando por el contrario, al examinar los núcleos no aparecía el recurso a un segundo plano de percusión, y en general, predomina un ritmo de talla unipolar. No obstante en el núcleo $\mathrm{n}^{\circ} 2$ aparece un negativo de un flanco de núcleo desde un plano opuesto, por lo que posiblemente habrían 
existido secuencias de producción y arreglo desde un plano de percusión opuesto al principal, pero no ha quedado constancia en los núcleos en su estado de abandono.

\section{IV.4.3.4. ARISTAS DE NÚCLEO Y OTROS PRODUCTOS DE ACONDICIONAMIENTO}

Hay, por último, tres piezas que se han denominado como aristas de núcleo sin que se pueda concretar más su función en el núcleo. Se trata de pequeñas productos, gruesos, que podrían corresponder con la eliminación de alguna esquina o borde anguloso del núcleo. Tienen unas dimensiones medias de $12 \mathrm{~mm}$ de longitud, 10 de anchura y 7 de grosor, destacando por tanto (dentro del conjunto de los productos de acondicionamiento) su escasa longitud y, por el contrario, su acentuado grosor.

\section{IV.4.4. SOPORTES: LASCAS, HOJAS Y HOJITAS}

\section{IV.4.4.1. LASCAS}

Las lascas tienen unas dimensiones medias de $13 \mathrm{~mm}$ de longitud, 11 de anchura y 3 de grosor (cuadro SG.9). La longitud tiene un máximo en los 11-12 mm y la anchura presenta también un máximo en este mismo intervalo (gráficos SG.5 y SG.6). 


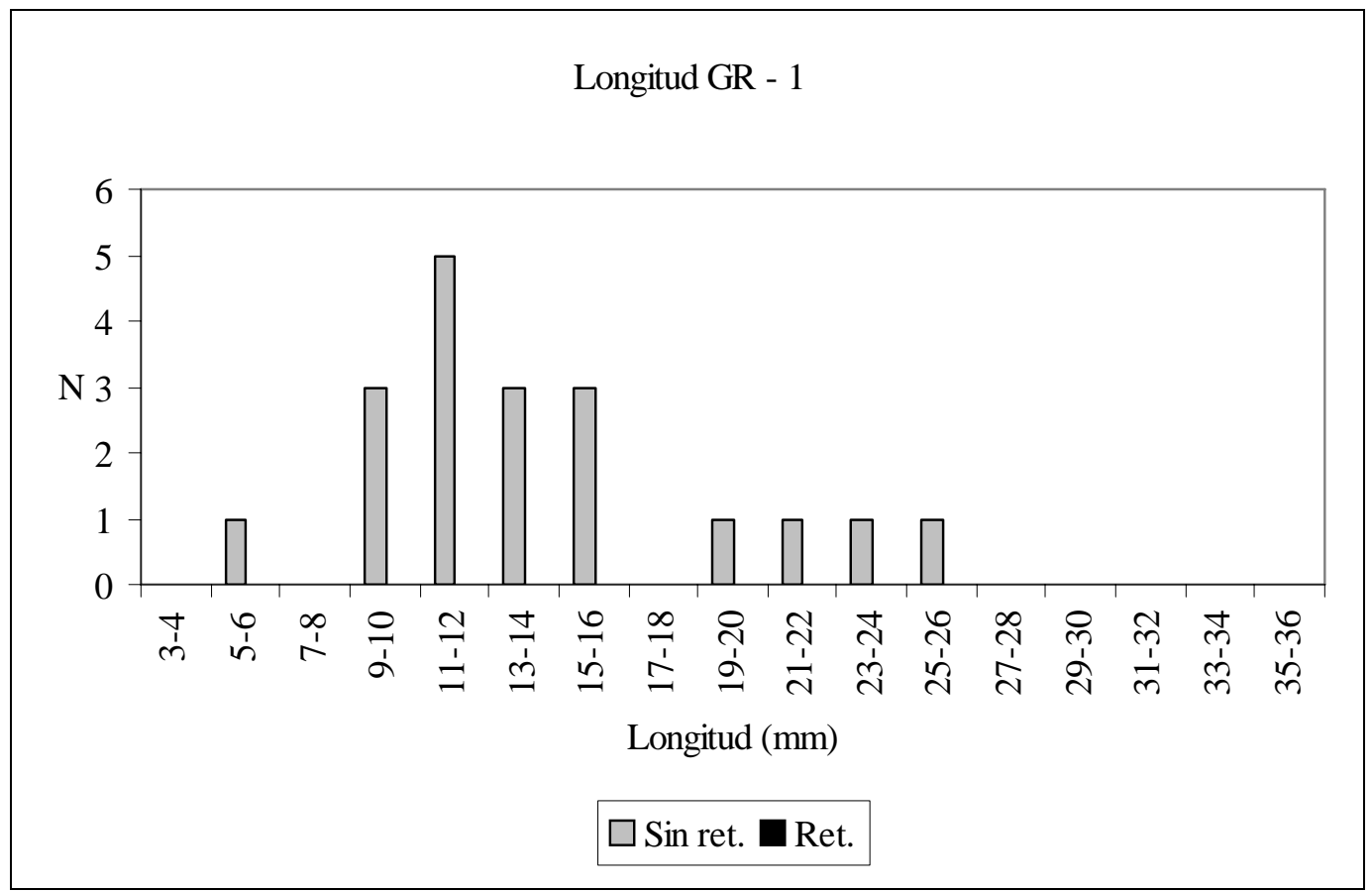

Gráfico SG.5: longitud de los soportes del grupo tecnológico 1 (lascas, lascas laminares). Sin retocar: $\mathrm{n}=19$. Retocados: $\mathrm{n}=0$.

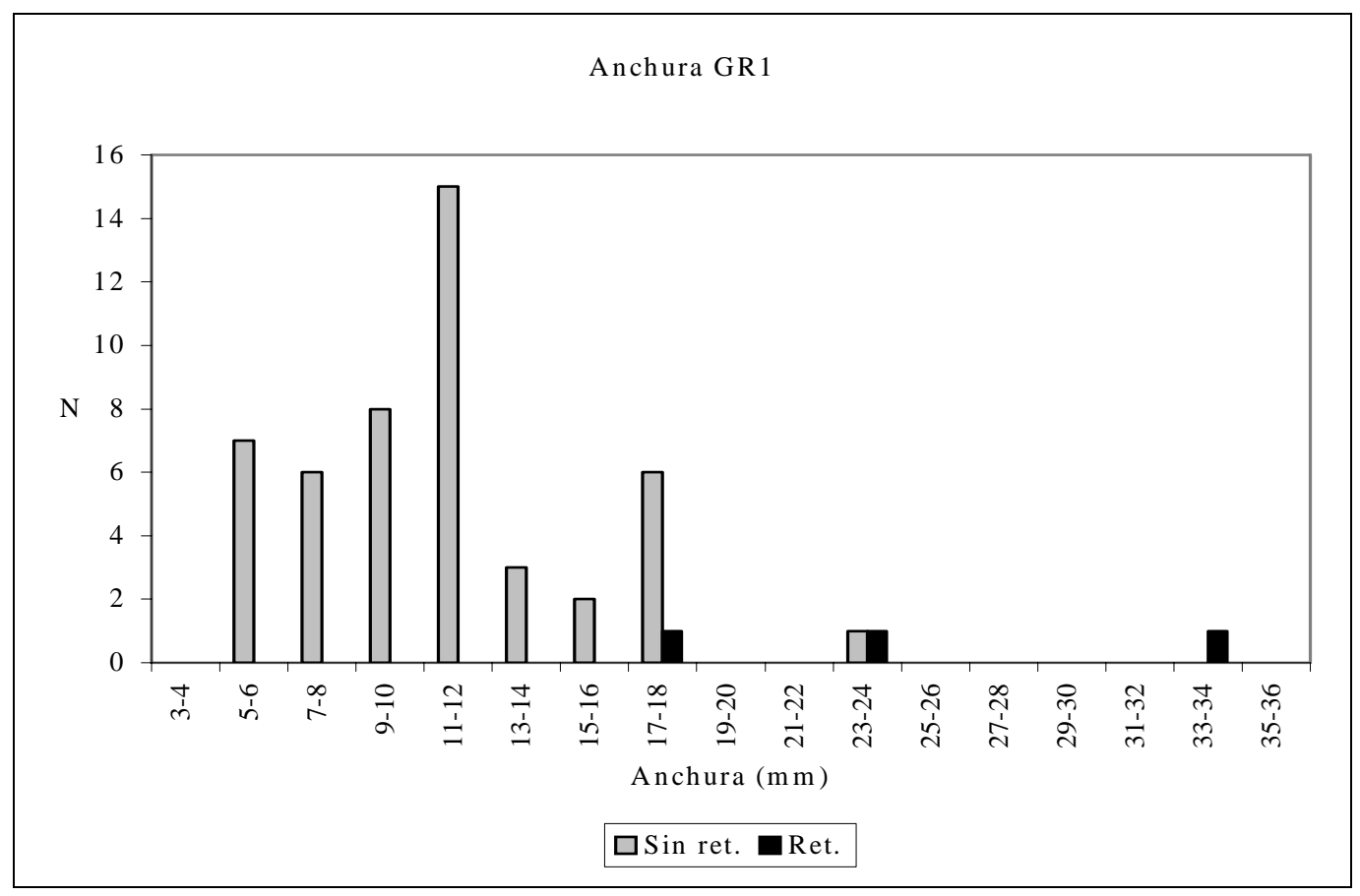

Gráfico SG.6: anchura de los soportes del grupo tecnológico 1 (lascas, lascas laminares). Sin retocar: $n=44$. Retocados: $n=3$. 


\section{IV.4.4.2. SOPORTES LAMINARES: HOJAS Y HOJITAS}

\section{IV.4.4.2.1. DATOS MÉTRICOS: LONGITUD Y ANCHURA}

Los soportes laminares tienen unas dimensiones medias de $14 \mathrm{~mm}$ de longitud, 9 de anchura y 2 de grosor (cuadro SG.9). Respecto a la longitud (gráfico SG.7), sólo hay 5 hojitas completas sin retocar, que miden de 12 a $18 \mathrm{~mm}$, y 2 retocadas (de 13, 14 $\mathrm{mm})$. Si se toma en consideración tanto los soportes completos como los fragmentados (gráfico SG.7), tienen una distribución entre los 9 y los 18 mm, concentrándose las retocadas entre los 9 y $14 \mathrm{~mm}$. Por su parte, las "hojas con flanco" se distribuyen entre los 18 y $26 \mathrm{~mm}$.

La anchura (gráfico SG.8) se distribuye de 5 a $11 \mathrm{~mm}$, siendo las retocadas ligeramente inferiores, con un máximo en los 5-6 mm. No obstante, teniendo en cuenta que la mayoría de las hojitas retocadas son dorsos, las hojitas de partida encajarían en los intervalos superiores. 


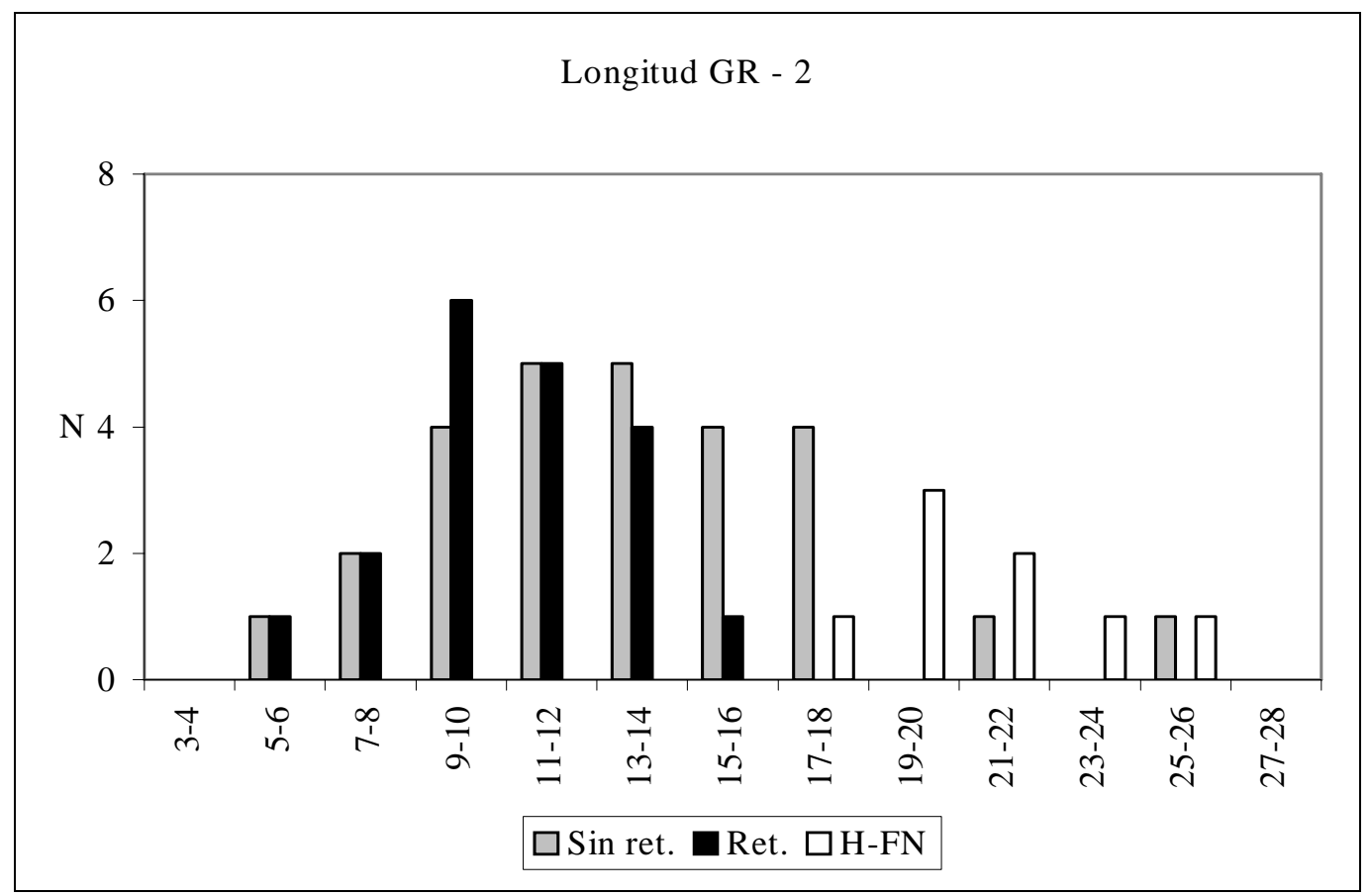

Gráfico SG.7: longitud de los soportes del grupo tecnológico 2 (hojas, hojitas), incluidos tanto las piezas completas como las fragmentadas. Sin retocar: $n=27$. Retocados: $n=19$. "Hojas con flanco": n=8, están todas retocadas excepto dos (de 19 y 25 mm).

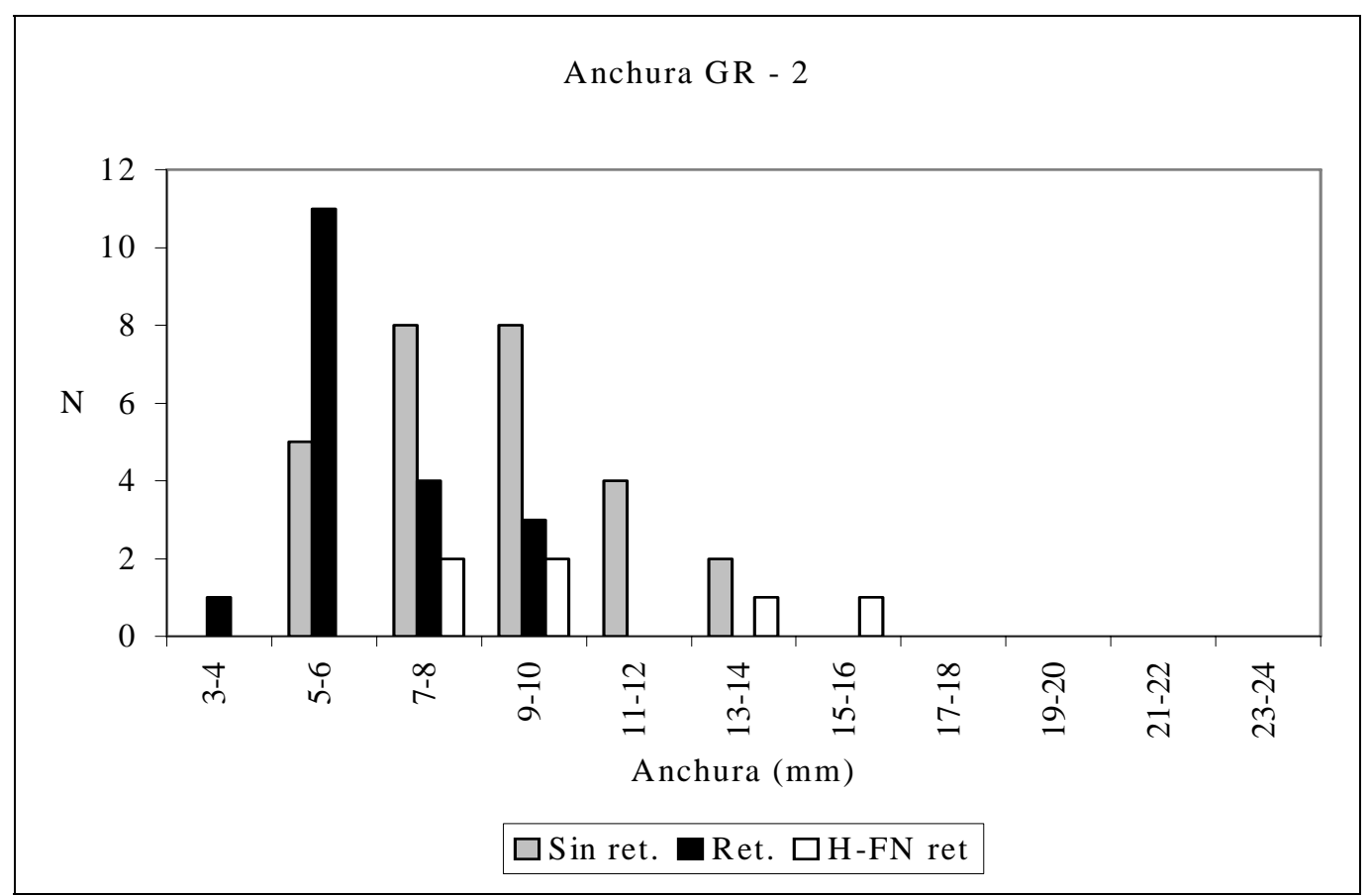

Gráfico SG.8: anchura de los soportes del grupo tecnológio 2 (hojas, hojitas). Sin retocar: n=27. Retocados: $\mathrm{n}=19$. Hojas con flanco retocadas: $\mathrm{n}=6$. 


\section{IV.4.4.2.2. DATOS TÉCNICOS}

La mayoría de las hojitas tienen una o dos nervaduras (cuadro SG.22). Frente a lo que sucede en el resto de los sílex, en esta materia son más abundantes las hojitas con dos nervaduras en las piezas sin retocar que en las retocadas. Casi todos son soportes con la dirección de los negativos unipolar (cuadro SG.23), lo cual está en consonancia con los esquemas técnicos de los núcleos. En la sección longitudinal predominan ampliamente las hojitas rectilíneas (con más del 60\%) sobre las cóncavas (cuadro SG.24). Este tipo de sección estaría también en consonancia con la carena rectilínea que predomina en los núcleos. Respecto a la sección transversal, predomina la triangular, pero en este tipo de materia alcanza una representación relativamente elevada la sección trapezoide, debido a que hay también un buen número de hojitas con dos nervaduras (cuadro SG.25).

Por último, el índice de regularidad de las hojitas sería medio, existiendo más hojitas de mejor calidad entre las piezas retocadas que sin retocar (cuadro SG.26).

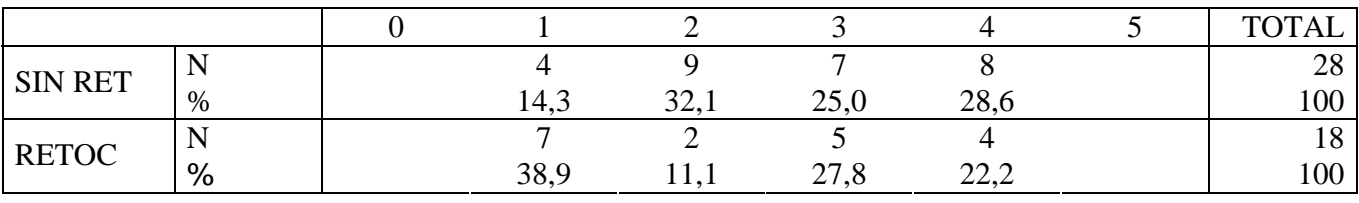

Cuadro SG.22: $\mathrm{N}^{\circ}$ de nervaduras en los soportes laminares.

\begin{tabular}{|l|cc|cc|}
\hline \multirow{2}{*}{} & \multicolumn{2}{|c|}{ SIN RET } & \multicolumn{2}{c|}{ RET } \\
\cline { 2 - 5 } & $\mathrm{N}$ & $\%$ & $\mathrm{~N}$ & $\%$ \\
\hline DP & & & 1 & 6,7 \\
PD & 19 & 76,0 & 12 & 80,0 \\
PD-DP & 4 & 16,0 & 2 & 13,3 \\
PD-ID & 2 & 8,0 & & \\
\hline
\end{tabular}

Cuadro SG.23: dirección de los negativos de los soportes laminares, según el número de nervaduras en su cara superior. DP: distal-proximal (opuesta); PD: proximal-distal (unipolar); PD-DP: proximal-distal y distal-proximal (bipolar). 


\begin{tabular}{|l|l|ccccc|r|}
\hline \multicolumn{2}{|c|}{} & Cn & Cx & R & S & T & TOTAL \\
\hline \multirow{2}{*}{ SIN RET } & N & 6 & 1 & 14 & & & 21 \\
& $\%$ & 28,6 & 4,8 & 66,7 & & 100 \\
\hline \multirow{2}{*}{ RET } & $\mathrm{N}$ & 4 & 1 & 10 & 1 & & 16 \\
& $\%$ & 25,0 & 6,3 & 62,5 & 6,3 & & 100 \\
\hline
\end{tabular}

Cuadro SG.24: perfil longitudinal de los soportes laminares. Cn: cóncavo, curvo; Cx: convexo; R: rectilíneo; S: sinuoso (cóncavo-convexo); T: torse (alabeado).

\begin{tabular}{|l|l|ccc|r|}
\hline \multicolumn{2}{|c|}{} & Bi-cX & TR & TZ & TOTAL \\
\hline \multirow{2}{*}{ SIN RET } & $\mathrm{N}$ & 17 & 8 & 25 \\
& $\%$ & 68,0 & 32,0 & 100 \\
\hline \multirow{2}{*}{ RET } & $\mathrm{N}$ & 10 & 8 & 18 \\
& $\%$ & & 55,6 & 44,4 & 100 \\
\hline
\end{tabular}

Cuadro SG.25: sección transversal de los soportes laminares. Bi-cx: biconvexa; TR: triangular; TZ: trapezoidal.

\begin{tabular}{|c|c|c|c|c|c|c|c|}
\hline & & 0 & $0-1$ & 1 & $1-2$ & 2 & TOTAL \\
\hline \multirow{2}{*}{ SIN RET } & $\mathrm{N}$ & 9 & & 9 & 1 & 2 & 21 \\
\hline & $\%$ & 42,9 & & 42,9 & 4,8 & 9,5 & 100 \\
\hline \multirow{2}{*}{ RET } & $\mathrm{N}$ & 6 & & 6 & 4 & 2 & 18 \\
\hline & $\%$ & 33,3 & & 33,3 & 22,2 & 11,1 & 100 \\
\hline
\end{tabular}

Cuadro SG.26: índice de regularidad de los soportes laminares. 0: mala calidad; 1: calidad media, aceptable; 2: buena calidad.

\section{IV.4.4.3. "HOJAS CON FLANCO"}

En la línea de los productos laminares están las que hemos clasificado como "hojas con flanco", de las cuales tenemos dos entre el conjunto sin retocar y seis entre las retocadas. Se trata de piezas de tendencia laminar, pero suelen ser bastante gruesas (4 mm de espesor) y su rasgo definitorio es que se llevan el borde lateral o flanco del núcleo. Este tipo de piezas está directamente relacionado con el método de débitage desarrollado sobre este tipo de materia. Al examinar los esquemas técnicos de los núcleos, hay dos de ellos que tienen una construcción volumétrica en forma de prisma aplanado, con la tabla de extracciones perfectamente delimitada entre los bordes laterales del núcleo, que enlazan con ella en forma de planos casi perpendiculares. Como es lógico, al avanzar la talla sobre estos bordes laterales, hay piezas que se llevan tanto parte de la tabla como del lateral del núcleo. Tales piezas las encontraremos en el 
conjunto industrial en forma de estas hojas con flanco, o también en forma de otros productos de acondicionamiento más centrados en estos laterales del núcleo (las neocrestas y los flancos de núcleo). Este tipo de piezas por tanto tendría un estatus que las situaría entre los productos o soportes "supuestamente buscados" (las hojas-hojitas) y los productos de acondicionamiento. Nos inclinamos por incluirlas dentro del conjunto de los productos laminares, aún más teniendo en cuenta que se han utilizado frecuentemente como soportes de útiles retocados. Por esta razón al presentar los datos se han incluido dentro del grupo de hojas-hojitas también estas piezas con flanco, si bien para la presentación de los datos métricos concretos de los soportes laminares, preferimos contar sólo con las hojas-hojitas estrictamente.

\section{IV.4.5. PIEZAS RETOCADAS}

A la hora de retocar, hay una selección neta de los soportes laminares, los cuales suponen el 66\% de los elementos retocados en sílex gris (cuadro SG.4). Casi la mitad de las hojas-hojitas del conjunto lítico se han retocado, por lo que se puede decir que sobre este tipo de materia hay una producción especializada de hojitas (cuadro SG.5).

\begin{tabular}{|c|c|c|c|c|c|c|c|c|c|c|}
\hline \multirow[b]{3}{*}{ TIPO RETOC. } & & & \multicolumn{8}{|c|}{ GRUPOS TEC. } \\
\hline & \multicolumn{2}{|c|}{ TOTAL } & 1 & \multicolumn{3}{|c|}{2} & \multicolumn{2}{|c|}{3} & \multirow{2}{*}{$\begin{array}{c}5 \\
\mathrm{CH} \\
\end{array}$} & \multirow{2}{*}{$\begin{array}{c}7 \\
\text { GB } \\
\end{array}$} \\
\hline & $\mathrm{N}$ & $\%$ & $\mathrm{~L}$ & H3 & H-FN & HT3 & SN & FN & & \\
\hline Raspador & 3 & 7,9 & 2 & & 1 & & & & & \\
\hline Buril & 1 & 2,6 & & & 1 & & & & & \\
\hline Perforador & 1 & 2,6 & 1 & & & & & & & \\
\hline U.compuesto & 2 & 5,3 & & & 1 & & & & 1 & \\
\hline Truncadura & 3 & 7,9 & 2 & & 1 & & & & & \\
\hline Raclette & 1 & 2,6 & & & & & 1 & & & \\
\hline Dorso & 22 & 57,9 & 2 & & 2 & 16 & & 1 & & 1 \\
\hline Diverso & 2 & 5,3 & 1. & & & & & & 1 & \\
\hline Escot./rot. & 3 & 7,9 & & 2 & & 1 & & & & \\
\hline TOTAL & 38 & 100 & 8 & 2 & 6 & 17 & 1 & 1 & 2 & 1 \\
\hline
\end{tabular}

Cuadro SG.27: piezas retocadas.

Las hojitas tienen un uso específico para las hojitas de dorso. Hay algunas hojas de anchura y grosor ligeramente mayor que se han utilizado para un raspador y un buril. También hay tres hojitas con una escotadura al lado de una rotura, dicho procedimiento, 
que podría relacionarse con la técnica de microburil, en cambio no tiene su correspondencia ni con geométricos ni con microburiles. Las hojas con flanco aparecen en dos piezas con dorso y una truncadura. Las lascas se utilizan para dos raspadores, una truncadura y un perforador. Hay otras lasquitas de pequeño tamaño que aparecen en un dorso y una truncadura. Por último los productos de acondicionamiento y los chunks aparecen en tipos dispersos. La pieza identificada como golpe de buril se ha utilizado para realizar un dorso, el soporte podría corresponder con algún tipo de procedimiento similar al de las "piezas con flanco".

Se puede afirmar que hay una producción laminar especializada en la fabricación de piezas con dorso, tipo que supone el 58\% de las piezas retocadas en sílex gris. El resto de los soportes que aparecen en este proceso de débitage se utilizan de forma más expeditiva, para fabricar tipos como raspadores. 


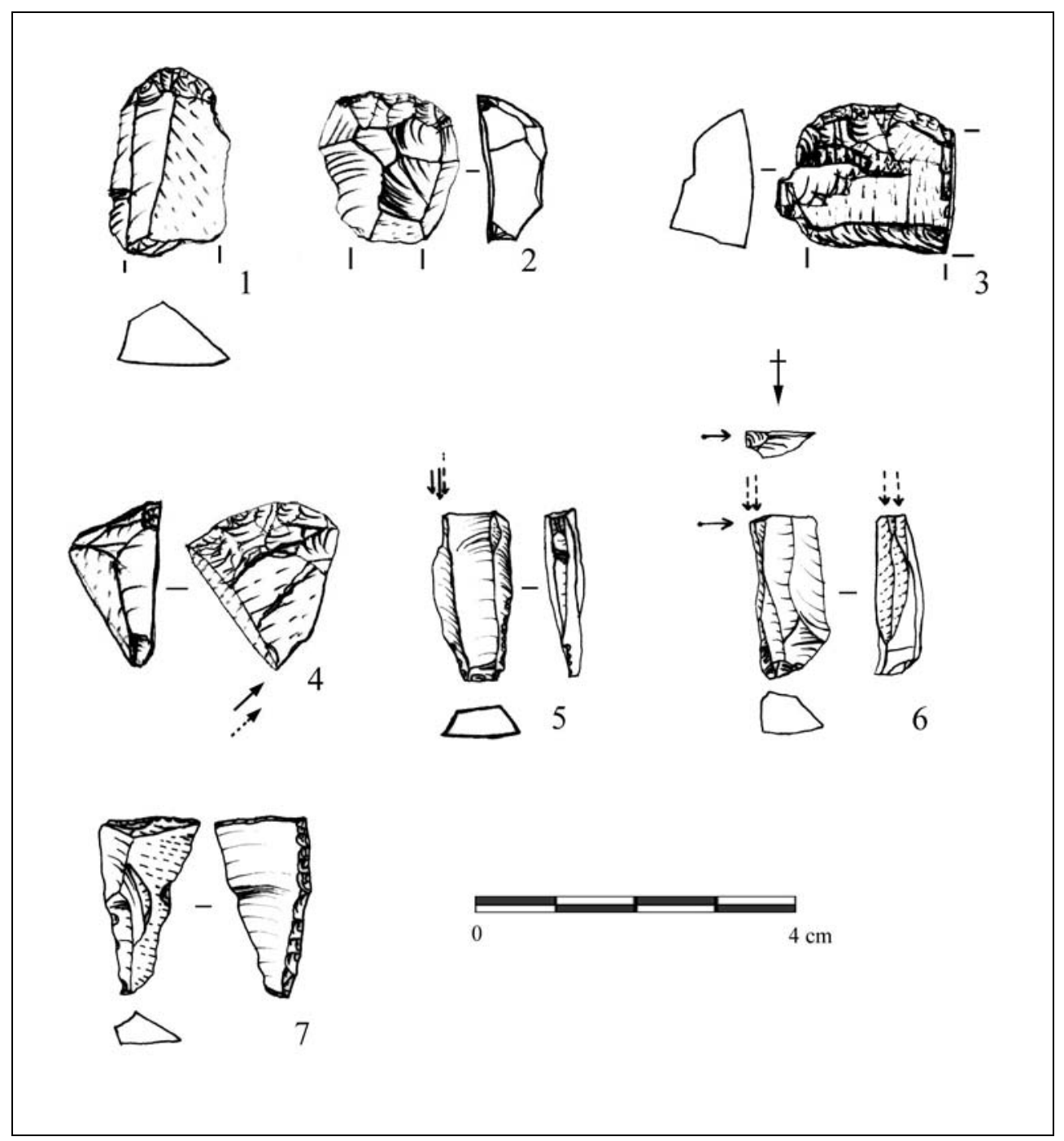

Figura SG.2: Piezas retocadas de sílex gris. Raspadores (1 a 3), útiles compuestos (raspadorburil [4] y buril-truncadura [5]), buril: 6. Hoja con dorso truncada: 7. Soportes: Hojas con flanco $(1,5,6,7)$, lascas $(2,3)$ y chunk (4). 


\section{IV.4.6. CADENA OPERATIVA}

A partir del análisis de los esquemas técnicos de los núcleos se deduce que hay una única cadena operativa sobre el sílex gris, se trata de una cadena de tipo prismático, que se podría incluir en el esquema operativo de los núcleos prismáticos tipo-A definido para el sílex negro. A partir del análisis de los distintos soportes se ha comprobado que dicha cadena está representada fundamentalmente en sus fases de producción plena y de retoque. El objetivo es la obtención de soportes microlaminares y el método de talla característico es unipolar, con un avance del débitage de tipo frontal. El estado final de las superficies es bastante "limpio", susceptible de producir soportes rectos y relativamente largos.

\section{FASE 0: ADQUISICIÓN DE LA MATERIA}

De la fase de adquisición de la materia prima podemos decir muy poco. Hay una representación de piezas de tercer orden fundamentalmente, pertenecientes en su gran mayoría a la fase de producción plena, tanto en la obtención de hojas-hojitas, como en secuencias de re-acondicionamiento o rectificación del proceso de talla y a la fase del retoque. El sílex gris está afectado por abundantes planos de rotura natural y quizás puedan ser muchas de éstas la zona externa de los bloques. Sólo podemos decir que las lascas y fragmentos presentes de este tipo de sílex no son de gran tamaño, el mayor es de $4 \mathrm{~cm}$. Muy probablemente la llegada de este tipo de sílex al yacimiento se produce en forma de pequeños bloques o fragmentos que habrían sido sometidos a algún tipo de preparación en el lugar de la adquisición de esta materia, ya que los bloques parece que tienen una conformación más o menos determinada del volumen.

\section{FASE 1: PREPARACIÓN DEL NÚCLEO}

Se puede constatar una fase de preparación o acondicionamiento del núcleo para adecuar la superficie de extracciones y el plano de percusión. Dicha fase posiblemente se realizara en el lugar de adquisición de la materia prima, ya que si bien contamos en el 
conjunto lítico con lascas y chunks que pudieran pertenecer a estas acciones, pueden asimismo corresponder a otras secuencias de reparación del núcleo. No obstante sí podemos decir algo al menos sobre las preferencias sobre la estructuración del volumen a talla.

Hay una preferencia por colocar la superficie de extracciones en una superficie relativamente ancha y alargada del volumen disponible. Dos núcleos ( $\mathrm{n}^{\circ} 2$ y 3 ) tienen unas características geométricas muy similares: en prisma alargado y plano $(1 \mathrm{~cm}$. de grosor) delimitado en la cara posterior del núcleo por un plano de diaclasa natural. Esto indica un aprovechamiento de las propias limitaciones de la materia prima (los abundantes planos naturales) en la conformación general del núcleo. También en el $n^{\circ} 3$ se utiliza una de estas superficies naturales como plano de percusión. En el núcleo ${ }^{\circ} 1$ se puede ver una preparación de las superficies posteriores y laterales, con restos de planos naturales en los flancos.

No podemos afirmar mucho más respecto a esta estructuración volumétrica y al modo como proceden a iniciar la talla. Se puede plantear como hipótesis, el aprovechamiento de las aristas naturales como guía para las primeras extracciones; cosa que no sería rara, habida cuenta, en primer lugar del aprovechamiento de tales superficies y diaclasas como partes estructurales del volumen a tallar y, en segundo lugar, del uso de tales aristas naturales en la fase de producción plena.

\section{FASE 2: PRODUCCIÓN PLENA DE SOPORTES}

El objetivo del débitage del sílex gris son las hojitas. Los productos sin retocar están entre los 6 y los $13 \mathrm{~mm}$, con un máximo en los 9-10 mm. Los soportes retocados tienen una distribución muy concentrada entre los 4 y 7 mm, con un máximo en los 5 mm. En todos estos casos se trata de hojitas con dorso. Hay también piezas retocadas en soportes de $10 \mathrm{~mm}$ de anchura, pero en este caso no se trata de dorsos, sino de hojas con escotadura al lado de una rotura. Podemos observar por tanto una distribución más o menos continua de los 6 a los $13 \mathrm{~mm}$. En consecuencia consideramos que este tipo de hojitas es el objetivo de la producción del sílex gris. 
La regularidad de los productos laminares se puede calificar en general de media y hay preferencia por los soportes con una regularidad aceptable a la hora de elegirlos para retocar. La mayoría de los soportes tienen una sección triangular y hay una tendencia al incremento de las secciones trapezoides en los soportes más regulares.

En resumen, los productos buscados en el débitage del sílex gris son hojitas de una anchura que oscila entre los 6 y los $13 \mathrm{~mm}$ y un grosor medio de $2 \mathrm{~mm}$. Estos soportes estarán destinados en su mayoría a la realización de hojitas con dorso, seleccionándose los soportes más regulares para ser retocados.

No poseemos datos para saber cómo se produce la iniciación del lascado pleno, posiblemente se utilicen aristas naturales como guía para la obtención de unas primeras nervaduras. Ya se ha señalado, que el sílex gris es una materia con abundantes planos naturales por lo que favorece más un tipo de aprovechamiento inmediato sobre las posibilidades de la propia materia, que una conformación cuidadosa, cosa que es más peligrosa por la existencia de esas irregularidades.

La extracción de los productos laminares es unipolar, sobre superficies de extracciones rectangulares alargadas. En algún caso hay negativos en dirección opuesta, pero han sido obtenidos a partir de un plano de percusión anterior, en una secuencia distinta a la última observada.

La carena es bastante rectilínea, en todos los casos con tendencia a "sobrepasarse". Si se observa el perfil longitudinal de los soportes laminares, también predominan los rectilíneos sobre los curvos. En consecuencia la talla se realiza sobre superficies con una carena poco acusada, con tendencia a que los soportes se sobrepasen. No obstante aparece la cuestión de si la rectitud de las superficies de extracciones que observamos en los núcleos, es el resultado de su explotación final o por el contrario una de las características de la talla de este sílex. Nos decantamos a favor de que esa carena tan poco acusada sea una elección a la hora de tallar, debido a dos razones. En primer lugar en el conjunto de los soportes laminares predomina ampliamente la sección longitudinal recta. Por otro lado, la tendencia a sobrepasarse parece ser una consecuencia de esta rectitud de la superficie de extracciones que, al mismo tiempo, es aprovechada para seguir manteniendo la carena. De hecho este tipo de 
accidente se puede observar tanto en los núcleos como en el conjunto de los soportes extraídos, especialmente en los productos de acondicionamiento.

Los procedimientos utilizados para la reparación del núcleo son los siguientes:

- Sobre el plano de percusión se realizan pequeñas extracciones desde la superficie de extracciones. Así se consigue una inclinación correcta del plano sobre la superficie a tallar.

- Sobre la superficie de extracciones podemos hacer dos grandes grupos de procedimientos:

1. Los que corrigen la conformación general del núcleo, desde los bordes laterales y de forma transversal.

2. Los que corrigen la superficie de extracciones en el curso del débitage. En este caso los productos de acondicionamiento son de eje, es decir se producen desde el mismo plano de percusión o desde un plano opuesto. Este tipo de extracciones va a tener dos objetivos principales.

- Eliminar accidentes (reflejados) o irregularidades de la materia prima mediante extracciones gruesas.

- Mantenimiento del débitage de extracciones laminares, ya que se aprovecha una arista natural lateral que sirva de nervadura-guía para retomar el débitage.

- Hay otro procedimiento o más bien gesto usado para corregir deformaciones o accidentes en la superficie de extracciones: la neo-cresta parcial, pero es un gesto poco sistemático, no se trata en ningún caso de una preparación cuidadosa de una arista.

Hay por último otros productos de acondicionamiento que hemos recogido bajo el nombre de "aristas de núcleo", ya que son piezas que eliminan una arista, pero no sabemos muy bien su ubicación en una determinada secuencia. Son productos pequeños gruesos y angulosos, parecen corresponder a una cornisa del núcleo ya que se ve una parte lisa, a modo de plano de percusión sobre la que se ha percutido hacia otra zona, pero las últimas extracciones visibles son pequeños levantamientos repetidos que embotan la zona. 


\section{FASE 3: RETOQUE}

Hay un número bastante elevado de elementos retocados (un 16\%) en relación con la escasez de material con que contamos en este tipo de materia prima. Más de la mitad de piezas retocadas son hojitas de dorso (55\%). Estarían seguidas por una serie de piezas que hemos reunido bajo el nombre de piezas con escotadura adyacente a una rotura, en la línea de los microburiles. También hay tres raspadores, una truncadura y una escotadura. Si nos detenemos en el tipo de soportes sobre los que se han fabricado los útiles retocados, predominan las hojitas (42\%) sobre las que aparecen los dorsos, así como algunas piezas con retoque adyacente a una rotura. Las lascas y chunks se han utilizado para hacer raspadores y una escotadura. Los productos de acondicionamiento también se aprovechan para hacer otros productos como una truncadura, una raclette y piezas con dorso.

Las características tipológicas del conjunto, con el amplio predominio de las hojitas de dorso, señalan perfectamente la orientación de la talla de esta variedad de materia prima, hacia la producción microlaminar. Paralelamente se aprovechan algunas lascas de la primera fase de la talla y también de las secuencias de acondicionamiento de la fase de producción plena para confeccionar otros útiles de fondo común como pueden ser raspadores. El aprovechamiento de los soportes de la fase de plena producción es predominante, ya que el 74\% de las piezas retocadas se han obtenido de esta fase de la cadena operativa. 


\section{IV.5.- SÍLEX VARIOS}

Los “sílex varios” reúnen varios tipos de materias del grupo de los sílex (tal y como se ha descrito en el capítulo sobre la materia prima), materias cuya procedencia es desconocida, foránea probablemente, varias de estas variedades están presentes tan solo en 3-4 ejemplos retocados. Se van a exponer las características técnicas de estos sílex en conjunto ya que constituyen un grupo muy pequeño de piezas ( $\mathrm{n}=70$, lo cual significa tan solo un $0,5 \%$ de la industria lítica). Una característica esencial de este conjunto sería la ruptura espacio-temporal existente en la cadena operativa de estas materias, el proceso de débitage en sus primeras fases (preparación y producción plena) se habría desarrollado en otro lugar fuera del yacimiento, donde se habrían retocado también las piezas (hojitas de dorso fundamentalmente) que luego vamos a encontrar en la cueva. Aquí aparecen sobre todo los útiles ya retocados por lo que se habrían desarrollado las últimas fases de la cadena (uso y abandono). No obstante hay algunas variedades de estos sílex de las que tenemos núcleos y otros restos de talla, parece que se habrían llevado ocasionalmente esos núcleos de sílex más o menos exóticos, de pequeño tamaño, para ser tallados en los puestos de caza o los lugares por donde se iban moviendo los grupos prehistóricos.

\section{IV.5.1.- CARACTERÍSTICAS GENERALES}

\section{IV.5.1.1.- LISTA TECNOLÓGICA, GRUPOS TECNOLÓGICOS}

Las 70 piezas de sílex varios se distribuyen a lo largo de varios tipos de soporte en las distintas secuencias de la cadena operativa, con excepción de los productos de acondicionamiento (cuadro SV.1). Un poco más de un tercio de los sílex varios son hojitas de tercer orden, que predominan, otro tercio son lascas de tercer orden, a las que seguirían las lasquitas de los debris, el resto de los tipos tienen porcentajes inferiores al $8 \%$. 


\begin{tabular}{|c|c|c|c|c|}
\hline \begin{tabular}{|l|} 
GRUPO \\
TECNOLÓGICO
\end{tabular} & $\mathrm{N}^{\circ}$ TEC. & SOPORTE & $\mathbf{N}$ & $\%$ \\
\hline GRUPO 0 (nódulos) & 0 & Nódulo & 1 & 1,43 \\
\hline \multirow{6}{*}{$\begin{array}{l}\text { GRUPO } 1 \\
\text { (lascas) }\end{array}$} & 1 & Lasca de primer orden & 1 & 1,43 \\
\hline & 2 & Lasca de segundo orden & 1 & 1,43 \\
\hline & $2-5$ & Lasca laminar de segundo orden & & \\
\hline & 3 & Lasca de tercer orden & 21 & 30,00 \\
\hline & $3-6$ & Lasca laminar & & \\
\hline & 4 & Hoja de primer orden & & \\
\hline \multirow{5}{*}{$\begin{array}{l}\text { GRUPO } 2 \\
\text { (soportes laminares) }\end{array}$} & 5 & Hoja de segundo orden & 1 & 1,43 \\
\hline & 6 & Hoja de tercer orden & 5 & 7,14 \\
\hline & 6-FN & Hoja de tercer orden con flanco & & \\
\hline & 7 & Hojita de segundo orden & & \\
\hline & 8 & Hojita de tercer orden & 22 & 31,43 \\
\hline \multirow{5}{*}{$\begin{array}{l}\text { GRUPO } 3 \text { (productos de } \\
\text { acondicionamiento) }\end{array}$} & 9 & Lámina cresta & & \\
\hline & 10 & Tableta de núcleo & & \\
\hline & 11 & Semitableta de núcleo & & \\
\hline & 12 & Flanco de núcleo & & \\
\hline & 13 & Arista de núcleo y otros & & \\
\hline \multirow{5}{*}{$\begin{array}{l}\text { GRUPO } 4 \\
\text { (núcleos) }\end{array}$} & 14 & Núcleo prismático con un plano & 1 & 1,43 \\
\hline & 15 & Núcleo prismático con dos planos & & \\
\hline & 16 & Núcleo sobre lasca & 1 & 1,43 \\
\hline & 17 & Núcleo globuloso & & \\
\hline & 18 & Resto de núcleo & 1 & 1,43 \\
\hline GRUPO 7 (golpes buril) & 19 & Golpe de buril & 2 & 2,86 \\
\hline \multirow{3}{*}{$\begin{array}{l}\text { GRUPO } 5 \\
\text { (indeterminados) }\end{array}$} & 23 & Astilla de talla & & \\
\hline & 24 & Chunk & 2 & 2,86 \\
\hline & 25 & Indeterminado & 1 & 1,43 \\
\hline \multirow{3}{*}{$\begin{array}{l}\text { GRUPO } 6 \\
\text { (debris) }\end{array}$} & DEB-LT & Debris: lasquita & 9 & 12,86 \\
\hline & DEB-AT & Debris: astilla e indeterminados & 1 & 1,43 \\
\hline & & & 70 & 100 \\
\hline
\end{tabular}

Cuadro SV.1: lista tecnológica de radiolarita tipo-B.

\begin{tabular}{|lcc|}
\hline GRUPOS TEC. & $\mathbf{N}$ & $\mathbf{\%}$ \\
\hline 0 & 1 & 1,4 \\
1 & 23 & 32,9 \\
2 & 28 & 40,0 \\
3 & & \\
4 & 3 & 4,3 \\
5 & 3 & 4,3 \\
6 & 10 & 14,3 \\
7 & 2 & 2,9 \\
\hline & 70 & 100 \\
\hline
\end{tabular}

Cuadro SV.2: grupos tecnológicos de radiolarita tipo-B. 


\begin{tabular}{|c|c|c|c|c|}
\hline \begin{tabular}{|l|} 
GRUPO \\
TECNOLÓGICO
\end{tabular} & No TEC. & SOPORTE & $\mathbf{N}$ & $\%$ \\
\hline $\begin{array}{l}\begin{array}{l}\text { GRUPO } 0 \\
\text { (nódulos) }\end{array} \\
\end{array}$ & 0 & Nódulo & & \\
\hline $\begin{array}{l}\text { GRUPO } 1 \\
\text { (lascas) }\end{array}$ & $\begin{array}{l}1 \\
2 \\
2-5 \\
3 \\
3-6 \\
4\end{array}$ & $\begin{array}{l}\text { Lasca de primer orden } \\
\text { Lasca de segundo orden } \\
\text { Lasca laminar de segundo orden } \\
\text { Lasca de tercer orden } \\
\text { Lasca laminar } \\
\text { Hoja de primer orden }\end{array}$ & 2 & 11,1 \\
\hline $\begin{array}{l}\text { GRUPO } 2 \\
\text { (soportes laminares) }\end{array}$ & $\begin{array}{l}5 \\
6 \\
6-\mathrm{FN} \\
7 \\
8\end{array}$ & $\begin{array}{l}\text { Hoja de segundo orden } \\
\text { Hoja de tercer orden } \\
\text { Hoja de tercer orden con flanco } \\
\text { Hojita de segundo orden } \\
\text { Hojita de tercer orden }\end{array}$ & 15 & 83,3 \\
\hline $\begin{array}{l}\text { GRUPO } 3 \text { (productos } \\
\text { de } \\
\text { acondicionamiento) }\end{array}$ & $\begin{array}{l}9 \\
10 \\
11 \\
12 \\
13\end{array}$ & $\begin{array}{l}\text { Lámina cresta } \\
\text { Tableta de núcleo } \\
\text { Semitableta de núcleo } \\
\text { Flanco de núcleo } \\
\text { Arista de núcleo y otros }\end{array}$ & & 0,0 \\
\hline $\begin{array}{l}\text { GRUPO } 4 \\
\text { (núcleos) }\end{array}$ & $\begin{array}{l}14 \\
15 \\
16 \\
17 \\
18\end{array}$ & $\begin{array}{l}\text { Núcleo prismático con un plano } \\
\text { Núcleo prismático con dos planos } \\
\text { Núcleo sobre lasca } \\
\text { Núcleo globuloso- } \\
\text { Resto de núcleo }\end{array}$ & & \\
\hline \begin{tabular}{|l|}
$\begin{array}{l}\text { GRUPO } 7 \\
\text { (golpes buril) }\end{array}$ \\
\end{tabular} & 19 & Golpe de buril & 1 & 5,6 \\
\hline $\begin{array}{l}\text { GRUPO } 5 \\
\text { (indeterminados) }\end{array}$ & $\begin{array}{l}23 \\
24 \\
25\end{array}$ & $\begin{array}{l}\text { Astilla de talla } \\
\text { Chunk } \\
\text { Indeterminado }\end{array}$ & & \\
\hline $\begin{array}{l}\text { GRUPO } 6 \\
\text { (debris) }\end{array}$ & $\begin{array}{l}\text { DEB-LT } \\
\text { DEB-AT }\end{array}$ & $\begin{array}{l}\text { Debris: lasquita } \\
\text { Debris: astilla e indeterminados }\end{array}$ & & \\
\hline
\end{tabular}

Cuadro SV.3: lista tecnológica de los soportes retocados de sílex negro.

\begin{tabular}{|lll|}
\hline GRUPOS TEC. & N & \% \\
\hline 0 & & \\
1 & 2 & 11,1 \\
2 & 15 & 83,3 \\
3 & & \\
4 & & \\
5 & & \\
6 & & \\
7 & 1 & 5,6 \\
\hline & 18 & 100 \\
\hline
\end{tabular}

Cuadro SV.4: grupos tecnológicos del sílex negro en las piezas retocadas. 
Por grupos tecnológicos (cuadro SV.2) predominan, con el 40\% del conjunto, las hojas-hojitas, seguidas por las lascas (33\%) y los debris (14\%). Es la única materia en la que los soportes laminares son los más abundantes. Destaca la ausencia de productos de acondicionamiento, sobre todo cuando sí hay constancia, aunque sea mínima, de secuencias de talla dentro del yacimiento a partir tanto de los núcleos, como de las piezas indeterminadas y debris. La explicación de esta ausencia de elementos relativos a fases de reparación/mantenimiento de la cadena operativa, puede ser el hecho de que no se realicen tales secuencias dentro del yacimiento porque el proceso de talla presente sea más simple que los esquemas conceptuales examinados sobre las otras materias. Los núcleos de sílex varios que se llevan al yacimiento son pequeños, ya están conformados o bien se trata de restos de núcleos de los que se obtienen unas pocas lascas sin recurrir a esquemas complejos.

\begin{tabular}{|l|c|cc|}
\hline \multirow{2}{*}{ GRUPO TEC. } & \multirow{2}{*}{ TOTAL } & \multicolumn{2}{|c|}{ RETOCADAS } \\
\cline { 3 - 4 } & & $\mathrm{N}$ & $\%$ \\
\hline 0 & 23 & 2 & 8,7 \\
1 & 28 & 15 & 53,6 \\
2 & & & \\
3 & 3 & & \\
4 & 3 & & \\
5 & 10 & & 50,0 \\
6 & 2 & 1 & 25,7 \\
7 & 70 & 18 & \\
\hline & & & \\
\hline
\end{tabular}

Cuadro SG.5: piezas retocadas relativamente al total de las disponibles y según los distintos grupos tecnológicos.

\section{IV.5.1.2.- ROTURAS}

\section{IV.5.1.2.1.- TIPOS DE SOPORTES ROTOS}

El 70\% de las piezas están rotas (cuadro SV.6), lo cual es similar al porcentaje de roturas presentes en el resto de las materias primas. Los soportes más afectados son las hojas-hojitas que están prácticamente todas fragmentadas. 


\begin{tabular}{|c|c|c|c|c|c|c|c|}
\hline \multirow{2}{*}{$\begin{array}{l}\text { GRUPO } \\
\text { TEC. }\end{array}$} & \multirow{2}{*}{ TIPO TEC. } & \multirow{2}{*}{ COMPLETOS } & \multicolumn{4}{|c|}{ FRAGMENTADOS } & \multirow{2}{*}{ TOTAL } \\
\hline & & & Distal & Mesial & Proximal & Rota & \\
\hline 1 & $\begin{array}{c}\mathrm{L} \\
\mathrm{L}-\mathrm{H} \\
\mathrm{H}\end{array}$ & 10 & 3 & 1 & 7 & 2 & 23 \\
\hline 2 & $\begin{array}{c}\mathrm{H} \\
\mathrm{H}-\mathrm{FN} \\
\mathrm{HT}\end{array}$ & $\begin{array}{l}1 \\
1\end{array}$ & $\begin{array}{l}1 \\
7\end{array}$ & $\begin{array}{l}3 \\
6\end{array}$ & $\begin{array}{l}1 \\
8\end{array}$ & & $\begin{array}{c}6 \\
22\end{array}$ \\
\hline 4 & $\mathrm{~N}$ & 3 & & & & & 3 \\
\hline 5 & IT & & & & & 3 & 3 \\
\hline 6 & $\begin{array}{l}\text { LT } \\
\text { IT }\end{array}$ & 5 & 2 & & 1 & $\begin{array}{l}1 \\
1\end{array}$ & $\begin{array}{l}9 \\
1 \\
\end{array}$ \\
\hline 7 & GB & 1 & 1 & & & & 2 \\
\hline & & 21 & 14 & 10 & 17 & 7 & 69 \\
\hline & & $21(30,4)$ & \multicolumn{4}{|c|}{$48(69,6)$} & \\
\hline
\end{tabular}

Cuadro SV.6: representación de los tipos de soportes enteros y fragmentados de radiolarita, teniendo en cuanta la totalidad de las piezas.

\section{IV.5.1.2.2.- TIPOS DE ROTURAS}

El tipo de rotura predominante es la distal (43\%) seguida por la proximal (26\%) y la próximo-distal (19\%), con menor porcentaje están los otros tipos de roturas, pero predominan claramente aquellas que afectan a las piezas de forma transversal (cuadro SV.7).

\begin{tabular}{|l|cccccccc|r|}
\hline & BL & DL & DP & DS & LT & PD & PL & PX & TOTAL \\
\hline GR.1:L & & 1 & & 8 & 1 & 1 & & 3 & 14 \\
GR.2:H & & & & 9 & & 6 & 1 & 7 & 23 \\
GR.6:DEB & & 1 & 1 & 1 & 1 & & 1 & 5 \\
\hline N & & 1 & 1 & 18 & 2 & 8 & 1 & 11 & 42 \\
$\%$ & & 2,4 & 2,4 & 42,9 & 4,8 & 19,0 & 2,4 & 26,2 & 100 \\
\hline
\end{tabular}

Cuadro SV.7: tipos de roturas en los distintos grupos tecnológicos.

En la forma como afectan los tipos de roturas a los distintos tipos de soportes se pueden tener en cuenta los siguientes aspectos (gráfico SV.1):

- los debris están afectados por los distintos tipos de rotura sin que predomine uno sobre otro; se trata de un tipo de representación similar a lo que ocurre en los debris de las restantes materias primas 
- las hojas-hojitas tienen roturas de tipo transversal, al igual que en el resto de los sílex

- las lascas tienen una sobrerrepresentación de las roturas distales

Los sílex varios tendrían un patrón de comportamiento respecto a las roturas muy similar al resto de los sílex, destacando tan solo la abundancia de fracturas distales.

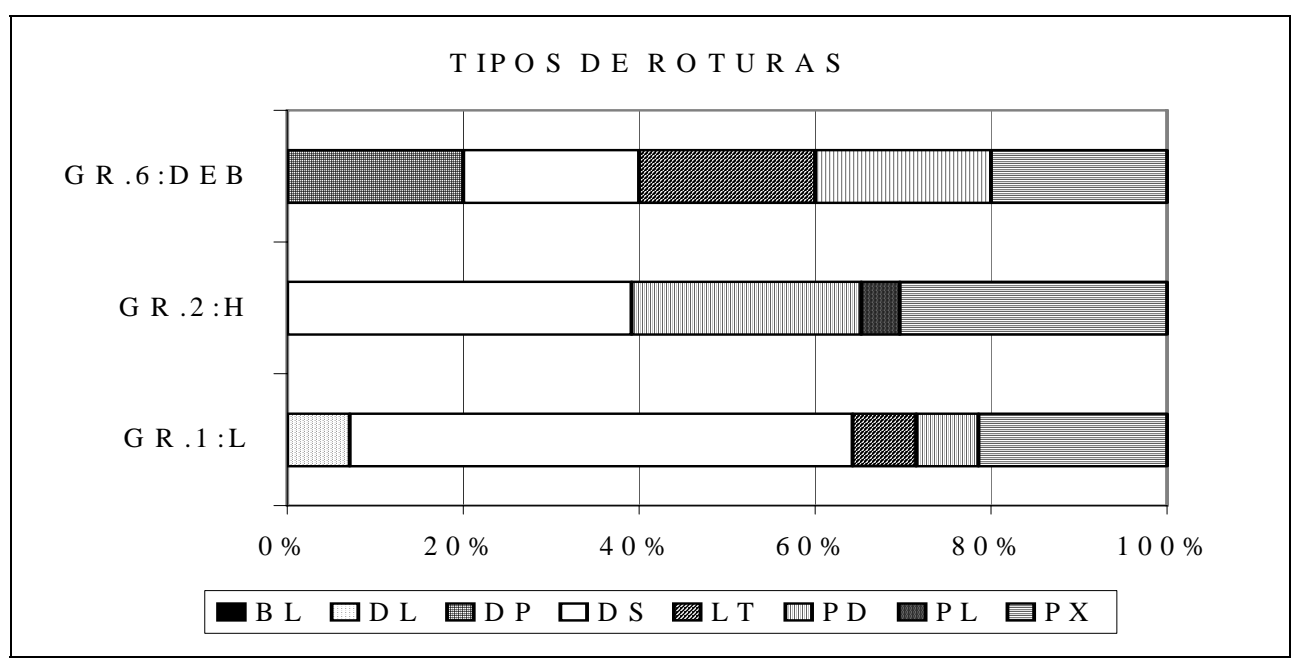

Gráfico SV.1: porcentaje de los tipos de roturas por grupos tecnológicos. Tipos de roturas: BL: bilateral, DL: distal-lateral, DP: distal-proximal-lateral, LT: lateral, PD: proximal-distal, PL: proximal-lateral, PX: proximal.

\section{IV.5.1.2.3.- CAUSA DE LA ROTURA}

La mayoría de las roturas fueron por percusión (45\%), mientras que las indeterminadas y las ocasionadas por flexión tienen unos porcentajes similares (cuadro SV.5), sin que se pueda comprobar ninguna tendencia clara en las causas de las roturas dependiendo del tipo de rotura y de soporte (gráfico SV.2).

\begin{tabular}{|l|ccc|cc|}
\hline & GR.1 & GR.2 & GR.6 & N & $\%$ \\
\hline F & 4 & 6 & 1 & 11 & 26,2 \\
I & 2 & 7 & 3 & 12 & 28,6 \\
P & 8 & 10 & 1 & 19 & 45,2 \\
\hline
\end{tabular}

Cuadro SV.8: causa rotura en los distintos grupos tecnológicos. F: flexión, I: indeterminada, P: percusión. 

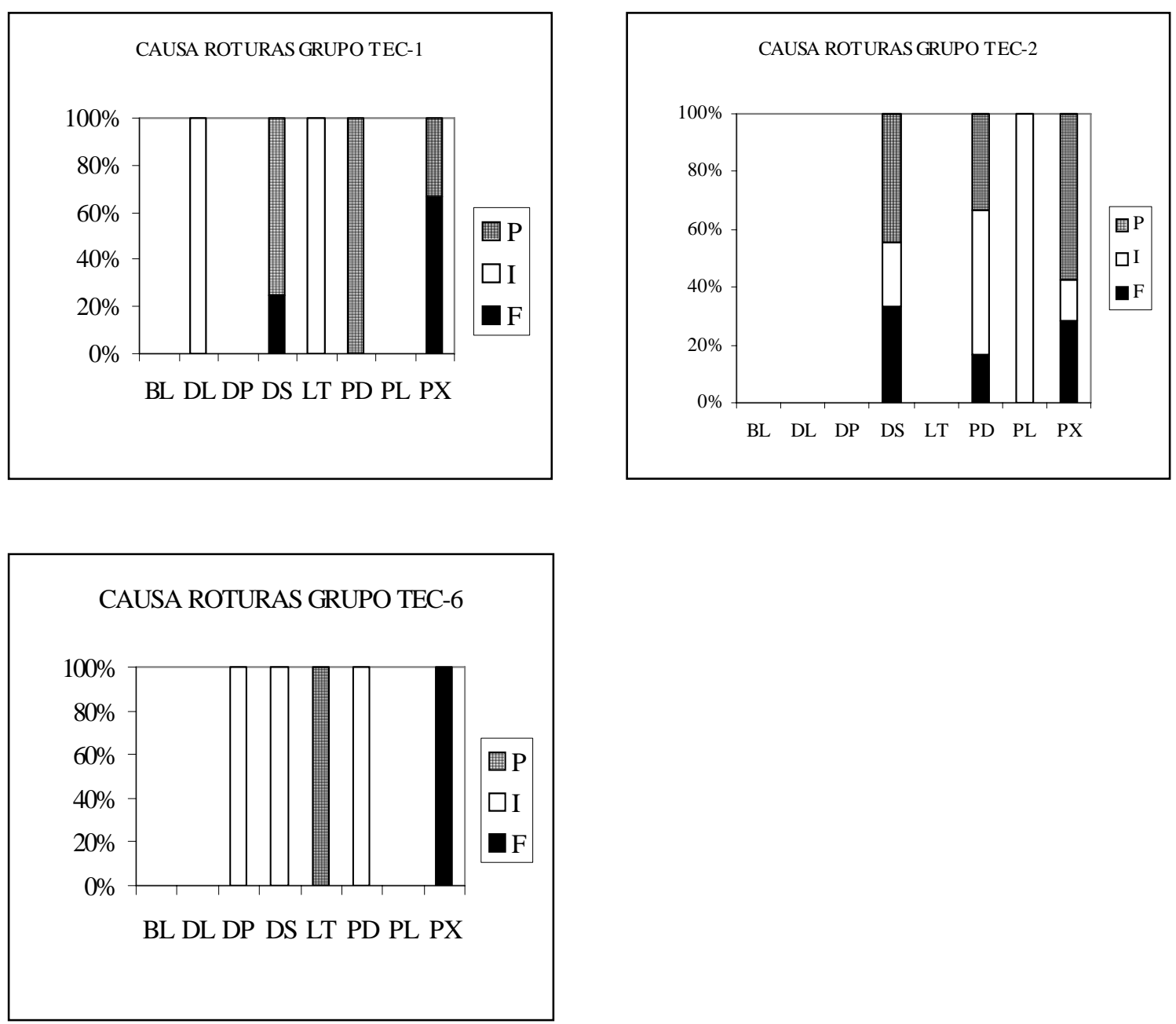

Gráfico SV.2: porcentaje de representación de las causas de la rotura según los distintos tipos de fracturas y por grupos tecnológicos. En el eje de abscisas los tipos de fracturas: BL: bilateral, DL: distal-lateral, DP: distal-proximal-lateral, LT: lateral, PD: proximal-distal, PL: proximallateral, PX: proximal. En el eje de ordenadas se sitúa el porcentaje de los tipos de roturas: P: percusión, I: indeterminada, F: por flexión.

\section{IV.5.1.3.- CÓRTEX}

Hay tan solo 6 piezas que presentan restos de córtex, lo cual supone en torno al 9\%. Cabría esperar una menor presencia cortical en una cadena rota como la presente aquí, en la que se producen fundamentalmente las últimas fases de tal cadena. No obstante, las piezas corticales procederían sobre todo de los pequeños núcleos que se llevan al yacimiento. 


\section{IV.5.1.4.- DATOS MÉTRICOS}

\section{IV.5.1.4.1.- TIPOS DE SOPORTES}

Las medidas mayores de estos sílex apenas sobrepasan los $3 \mathrm{~cm}$, tan solo una lasca alcanza los $31 \mathrm{~mm}$ de longitud y 34 de anchura, así como un núcleo, de $34 \mathrm{~mm}$ de anchura (cuadro SV.9). Las lascas tienen unas medias de $17 \mathrm{~mm}$ de longitud, 16 de anchura y 4 de grosor. Las hojas-hojitas sin retocar tienen una anchura de $8 \mathrm{~mm}$ y 2 de grosor. Los núcleos por su parte miden 25 mm de longitud, 24 de anchura y 14 de grosor. Los indeterminados 16 mm de longitud, 14 de anchura y 6 de grosor; los debris por último $7 \mathrm{~mm}$ tanto de longitud como de anchura y 2 de grosor.

\begin{tabular}{|c|c|c|c|c|c|c|c|}
\hline SIN REOCAR & & & & RETOCADAS & & & \\
\hline GR1:L & $\mathbf{L}$ & A & G & GR1:L & $\mathbf{L}$ & A & G \\
\hline $\mathrm{N}$ & 9 & 19 & 21 & $\mathrm{~N}$ & 1 & 2 & 2 \\
\hline Rango & 6-31 & $7-34$ & $1-20$ & Rango & 19 & $14-22$ & 4-5 \\
\hline Media & 16,89 & 15,84 & 4,45 & Media & & & \\
\hline Desviación & 8,43 & 7,78 & 4,30 & Desviación & & & \\
\hline GR2:H & $\mathbf{L}$ & A & G & GR2:H & $\mathbf{L}$ & A & $\mathbf{G}$ \\
\hline $\mathrm{N}$ & 2 & 13 & 13 & $\mathrm{~N}$ & - & 15 & 15 \\
\hline Rango & $18-21$ & $6-10$ & $1-6$ & Rango & & $4-16$ & $2-5$ \\
\hline Media & & 8,38 & 2,28 & Media & & 6,87 & 2,37 \\
\hline Desviación & & 1,45 & 1,62 & Desviación & & 3,18 & 0,90 \\
\hline GR4:N & $\mathbf{L}$ & A & G & GR4:N & $\mathbf{L}$ & A & $\mathbf{G}$ \\
\hline $\mathrm{N}$ & 3 & 3 & 3 & $\mathrm{~N}$ & - & - & - \\
\hline Rango & $24-26$ & $16-34$ & $12-15$ & Rango & & & \\
\hline Media & 25,0 & 23,67 & 14,0 & Media & & & \\
\hline Desviación & 1,0 & 9,29 & 1,73 & Desviación & & & \\
\hline GR5:IT & $\mathbf{L}$ & $\mathbf{A}$ & G & GR5:IT & $\mathbf{L}$ & A & G \\
\hline $\mathrm{N}$ & 3 & 3 & 3 & $\mathrm{~N}$ & - & - & - \\
\hline Rango & $10-24$ & $13-15$ & $5-8$ & Rango & & & \\
\hline Media & 16,0 & 14,0 & 6,33 & Media & & & \\
\hline Desviación & 7,21 & 1,0 & 1,53 & Desviación & & & \\
\hline GR6:DEB & $\mathbf{L}$ & $\mathbf{A}$ & G & GR6:DEB & $\mathbf{L}$ & A & G \\
\hline $\mathrm{N}$ & 10 & 10 & 10 & $\mathrm{~N}$ & - & - & - \\
\hline Rango & $5-9$ & $5-10$ & $1-5$ & Rango & & & \\
\hline Media & 7,5 & 7,5 & 2,1 & Media & & & \\
\hline Desviación & 1,51 & 1,84 & 1,48 & Desviación & & & \\
\hline
\end{tabular}

Cuadro SV.9: datos métricos de los sílex varios, por grupos tecnológicos. N: número de elementos. L: longitud, A: anchura, G: grosor. 
En las piezas retocadas, la anchura media de las hojitas es inferior a la de las piezas sin retocar $(7 \mathrm{~mm})$, pero hay que tener en cuenta que se trata de hojitas de dorso, por lo que su anchura está reducida por el retoque.

\section{IV.5.1.4.2.- TALÓN}

La dimensión del talón, respecto a su anchura es de 3 mm para las lascas y 2 para las hojas-hojitas (cuadro SV.10).

\begin{tabular}{|rcc|rcc|}
\hline SIN RETOCAR & & & RETOCADAS & \\
\hline GR1:L & L & A & GR1:L & L & A \\
N & 11 & 14 & N & - & 1 \\
Rango & $1,3-22,5$ & $0,4-9$ & Rango & $\mathbf{3}$ \\
Media & $\mathbf{6 , 4 2}$ & $\mathbf{2 , 5 7}$ & Media & \\
Desviación & 6,46 & 2,36 & Desviación & \\
& & & & & \\
GR2:H & L & A & GR2:H & L & A \\
N & 5 & 5 & N & - & 1 \\
Rango & $4-7,5$ & $1-3$ & Rango & & $\mathbf{1 , 2}$ \\
Media & $\mathbf{5 , 2}$ & $\mathbf{2 , 0}$ & Media & \\
Desviación & 1,35 & 0,71 & Desviación & \\
& & & & & \\
GR6:DEB & $\mathbf{L}$ & $\mathbf{A}$ & GR6:DEB & $\mathbf{L}$ & $\mathbf{A}$ \\
$\mathrm{N}$ & 1 & 1 & $\mathrm{~N}$ & - & - \\
Rango & $\mathbf{6}$ & $\mathbf{2}$ & Rango & \\
Media & & & Media & \\
Desviación & & & Desviación & \\
\hline
\end{tabular}

Cuadro SV.10: datos métricos de los talones de radiolarita tipo-B, por grupos tecnológicos. $\mathrm{N}$ : número de elementos. L: longitud, A: anchura, G: grosor.

\section{IV.5.1.5.- ACCIDENTES}

Solo hay tres piezas que presenten algún accidente de talla: 2 reflejados en sendas lascas y 1 pseudoburil en una lasquita de los debris. 


\section{IV.5.1.6.- TIPOS DE TALÓN}

Debido al alto porcentaje de roturas, casi la mitad de las piezas carecen de talón (cuadro SV.11) de las restantes, predominan los talones lisos (16\%) sobre los puntiformes $(11 \%)$, facetados $(10 \%)$, rotos $(6 \%)$, diedros, suprimidos y corticales. Si diferenciamos los tipos de soportes (gráfico SV.3), apenas contamos con talones en las hojas-hojitas, pero, como en el resto de las materias, son los talones lisos los más frecuentes.

\begin{tabular}{|l|cccccccc|r|}
\hline & C & D & F & L & O & P & R & S & TOTAL \\
\hline GR.1 & 1 & 3 & 4 & 5 & 6 & 2 & 2 & 1 & 24 \\
GR.2 & & & 2 & 4 & 17 & 2 & 1 & 2 & 28 \\
GR.6 & & & & 1 & 5 & 3 & 1 & & 10 \\
\hline N & 1 & 3 & 6 & 10 & 28 & 7 & 4 & 3 & 62 \\
$\%$ & 1,61 & 4,84 & 9,68 & 16,13 & 45,16 & 11,29 & 6,45 & 4,84 & 100 \\
\hline
\end{tabular}

Cuadro SV.11: tipos de talón por grupos tecnológicos. C: cortical, D: diedro, F: facetado, L: liso, O: sin talón, P: puntiforme, R: roto, S: suprimido.

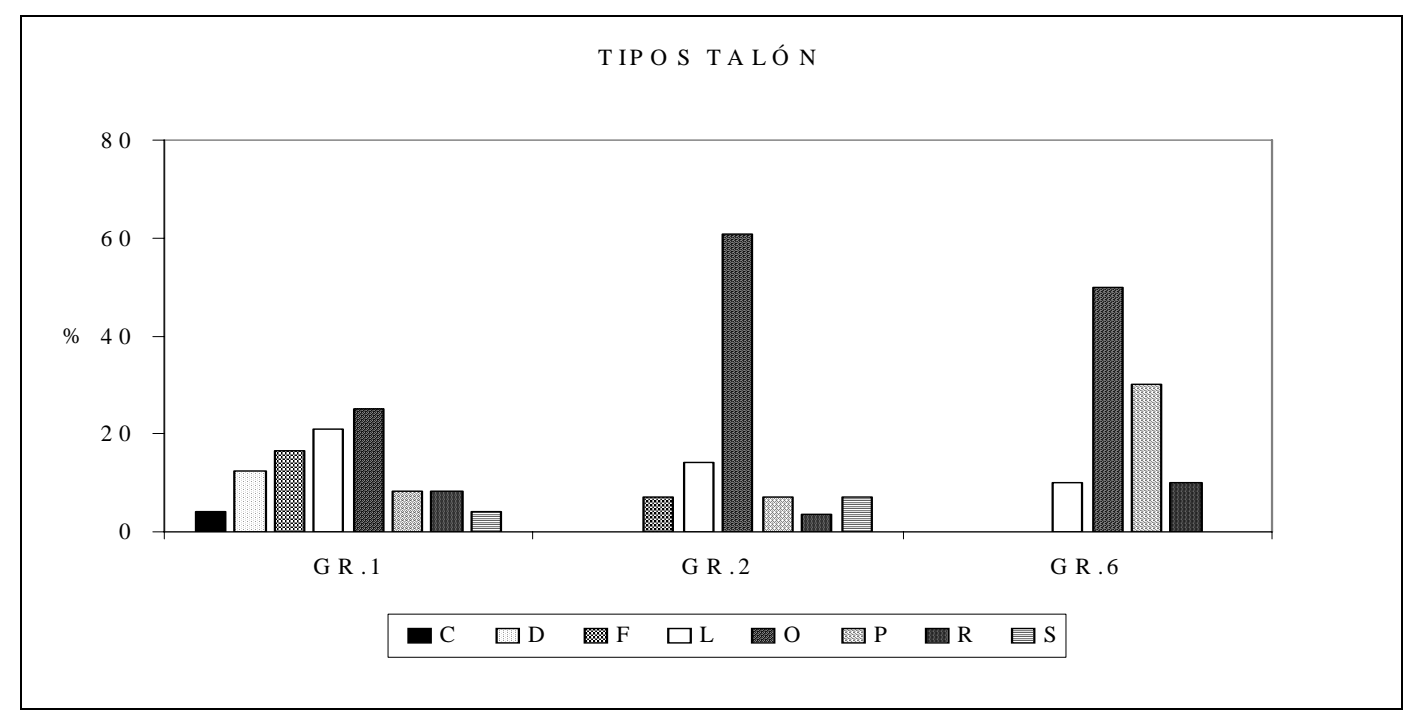

Gráfico SV.3: tipos de talón por grupos tecnológicos. C: cortical, D: diedro, F: facetado, L: liso, O: sin talón, P: puntiforme, R: roto, S: suprimido. 


\section{IV.5.1.7.- PREPARACIÓN DEL PUNTO DE IMPACTO}

El porcentaje de preparación del frente de talla es el más elevado de todas las materias (cuadro SV.12), superando en las hojitas y en los debris el 60\% de las piezas existentes.

\begin{tabular}{|c|c|cc|cc|}
\hline \multirow{2}{*}{} & \multirow{2}{*}{ TOTAL } & \multicolumn{2}{|c|}{ PIEZAS CON TALÓN } & \multicolumn{2}{c|}{ PIEZAS PREPARADAS } \\
\cline { 3 - 6 } & & $\mathrm{N}$ & $\%$ & $\mathrm{~N}$ & $\%$ \\
\hline GR-1 & 27 & 17 & 63 & 8 & 47,1 \\
GR-2 & 28 & 11 & 39,3 & 7 & 63,6 \\
GR-6 & 10 & 6 & 60 & 4 & 66,7 \\
\hline & 65 & 34 & 52,3 & 19 & 55,9 \\
\hline
\end{tabular}

Cuadro SV.12: piezas con talón y preparación relativa dentro de los distintos grupos tecnológicos.

El tipo de preparación que predomina es el esquirlado (47\%), seguido por la abrasión (26\%) y el retoque (21\%) (cuadro SV.13). Los tipos de talón más preparados son los puntiformes y los lisos (cuadro SV.14).

\begin{tabular}{|l|ccc|cc|}
\hline & \multirow{2}{*}{ GR-1 } & \multirow{2}{*}{ GR-2 } & \multirow{2}{*}{ GR-6 } & \multicolumn{2}{|c|}{ TOTAL } \\
\cline { 5 - 6 } & & & & $\mathrm{N}$ & $\%$ \\
\hline Facetado & 1 & & & 1 & 5,3 \\
Abrasión & 3 & 1 & 1 & 5 & 26,3 \\
Esquirlado & 3 & 4 & 2 & 9 & 47,4 \\
Retoque & 1 & 2 & 1 & 4 & 21,1 \\
\hline & 8 & 7 & 4 & 19 & 100 \\
\hline
\end{tabular}

Cuadro SV.13: tipos de preparación según los distintos grupos tecnológicos.

\begin{tabular}{|l|cccccccc|}
\hline & $\mathrm{C}$ & $\mathrm{D}$ & $\mathrm{F}$ & $\mathrm{L}$ & $\mathrm{P}$ & $\mathrm{R}$ & $\mathrm{S}$ & $\mathrm{O}$ \\
\hline PIEZAS CON TALÓN & 1 & 3 & 6 & 10 & 7 & 4 & 3 & 28 \\
\hline PIEZAS PREPARADAS & 1 & 2 & 3 & 7 & 6 & & & \\
$\%$ & 100 & 66,7 & 50 & 70 & 85,7 & & & \\
\hline
\end{tabular}

Cuadro SV.14: porcentaje de preparación en los distintos tipos de talón disponibles. C: cortical, D: diedro, F: facetado, L: liso, O: sin talón, P: puntiforme, R: roto, S: suprimido. 


\begin{tabular}{|c|c|c|c|c|c|c|c|c|}
\hline & $\mathrm{C}$ & $\mathrm{D}$ & $\mathrm{F}$ & $\mathrm{L}$ & $\mathrm{P}$ & $\mathrm{R}$ & $\mathrm{S}$ & $\mathrm{O}$ \\
\hline Facetado & 1 & & & & & & & \\
\hline Abrasión & & 1 & & 3 & 1 & & & \\
\hline Esquirlado & & & 2 & 3 & 4 & & & \\
\hline Retoque & & 1 & 1 & 1 & 1 & & & \\
\hline TOTAL & 1 & 2 & 3 & 7 & 6 & & & \\
\hline$\%$ & 5 & 10,5 & 15,8 & 36,8 & 31,6 & & & \\
\hline
\end{tabular}

Cuadro SV.15: tipos de preparación sobre los distintos tipos de talón. C: cortical, D: diedro, F: facetado, L: liso, O: sin talón, P: puntiforme, R: roto, S: suprimido.

\section{IV.5.1.8.- ÁNGULO DE PERCUSIÓN}

No son muchas las piezas sobre las que se ha podido tomar el ángulo del frente de talla en la muestra disponible (cuadro SV.16), respecto al ángulo entre el talón y la cara superior (ángulo 2) predomina el ángulo de $70-80^{\circ}$, con tendencia a un ángulo más cerrado, entre $60-70^{\circ}$. Por tanto destaca en esta materia esta tendencia a un frente más cerrado que en las otras materias primas.

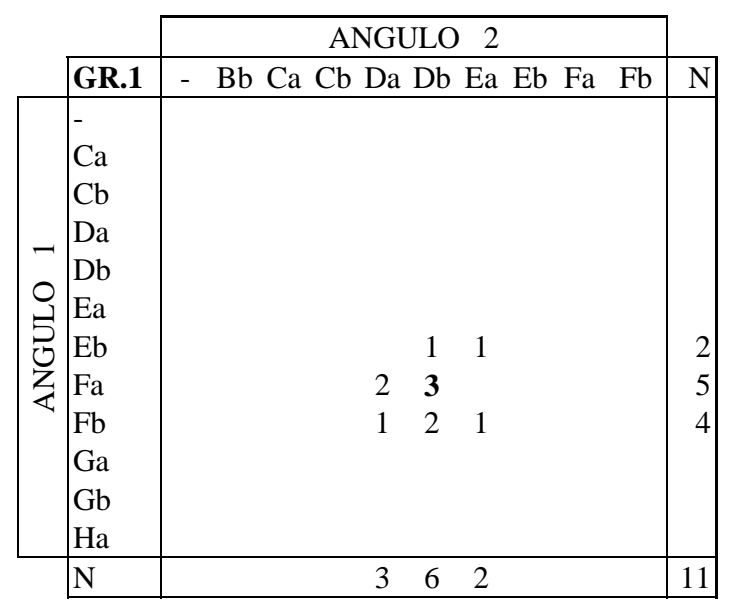

Cuadro SV.16: ángulos de percusión según los grupos tecnológicos. Angulo 1: ángulo interno (entre talón y el bulbo). Angulo 2: ángulo externo o cornisa (entre talón y la cara superior). $\mathrm{Bb}=30-40^{\circ}, \mathrm{Ca}=40-50^{\circ}, \mathrm{Cb}=50-60^{\circ}, \mathrm{Da}=60-70^{\circ}, \mathrm{Db}=70-80^{\circ}, \mathrm{Ea}=80-90^{\circ}, \mathrm{Eb}=90-100^{\circ}, \mathrm{Fa}=100-$ $110^{\circ}, \mathrm{Fb}=110-120^{\circ}, \mathrm{Ga}=120-130^{\circ}, \mathrm{Gb}=130-140^{\circ}, \mathrm{Ha}=140-150^{\circ}$. 

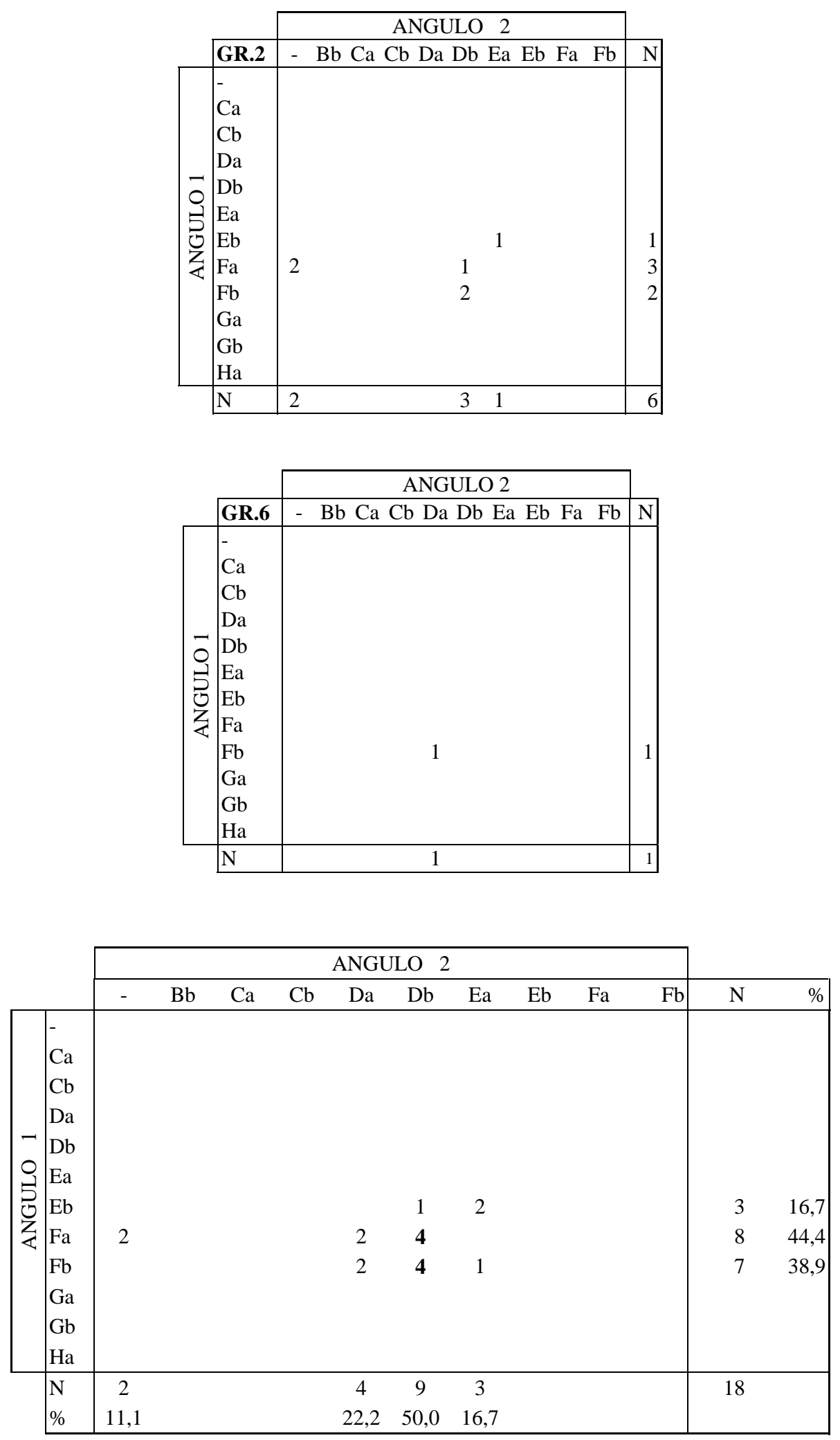

Cuadro SV.16 (continuación): ángulos de percusión en el grupo tecnológico 6 y en el total de los sílex varios. Angulo 1: ángulo interno (entre talón y el bulbo). Angulo 2: ángulo externo o cornisa (entre talón y la cara superior). 


\section{IV.5.1.9.- ALTERACIONES}

Hay 30 piezas afectadas por alguna alteración, cuatro tienen una alteración térmica y 26 tienen desilificación. Entre estas últimas hay tres que tienen un grado bajo de desilificación, mientras que las 23 restantes pertenecen a una de las variedades de sílex varios que se han diferenciado, la cual está afectada totalmente por esta alteración.

\section{IV.5.1.10.- MODO DE TALLA}

No se pueden decir mucho acerca del modo de talla adoptado en los sílex varios sobre todo porque la mayoría del proceso de débitage se habría desarrollado en otro lugar.

\section{IV.5.2.- NÚCLEOS}

Hay tres núcleos de sílex varios: uno prismático, otro sobre lasca y un resto de núcleo. Cada uno pertenece a distintas variedades de sílex y tan solo el primero tiene un esquema técnico que permite inscribirlo en un esquema más amplio, en concreto, dentro de las cadenas de núcleos prismáticos tipo-A. Los otros dos tienen una explotación de tipo anárquico y oportunista, parece que se han llevado fragmentos de núcleos o lascas más o menos grandes y que se han dado unos pocos golpes sin ninguna organización concreta del débitage.

El núcleo prismático es un pequeño núcleo de un sílex gris transparente (SV.3), con una morfología piramidal (ESP92/D7/S8/Lim.1; figura SV.1). La superficie de extracciones es triangular alargada, y está enmarcada ortogonalmente por los flancos laterales. La base del núcleo es una arista perpendicular a la superficie de extracciones. La explotación es unipolar frontal y las últimas extracciones son hojitas. Las características de este núcleo encajan plenamente en el esquema operativo de los núcleos prismáticos unipolares del grupo A definido para el sílex negro. 


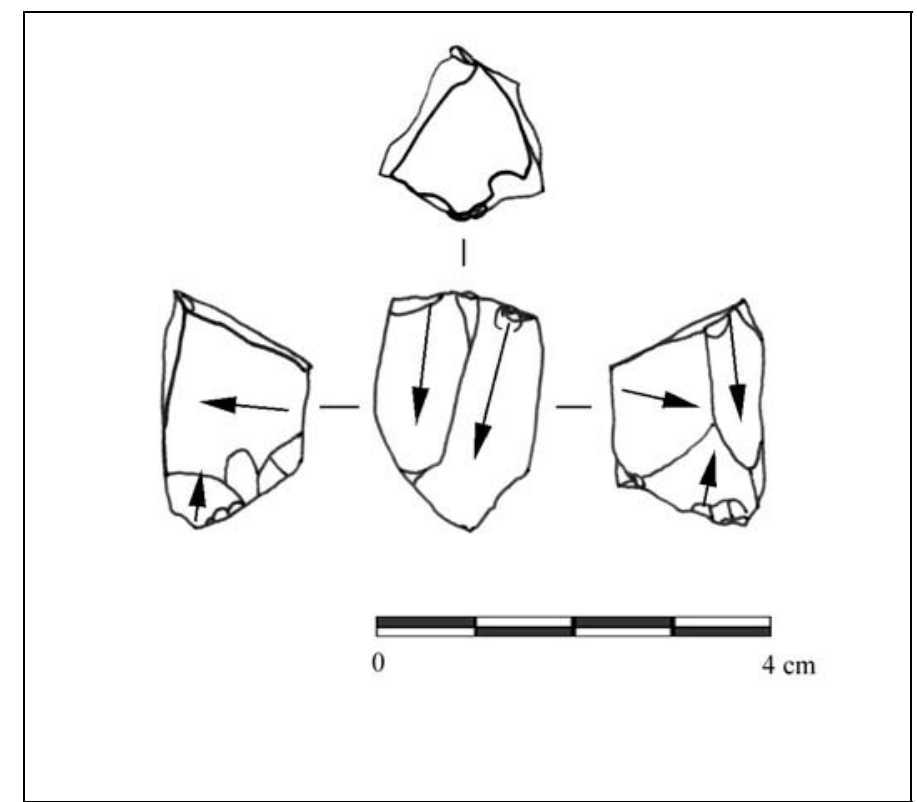

Figura SV.1: Núcleo de sílex varios, a partir del esquema prismático tipo-A (unipolarconvergente). 


\section{IV.5.3.- SOPORTES: HOJAS Y HOJITAS}

El pequeño número de elementos con los que contamos en los sílex varios no permite examinar demasiado bien las dimensiones de los distintos soportes, nos centraremos tan solo en las hojas-hojitas, ya que son los soportes más abundantes.

\section{IV.5.3.1.- SOPORTES LAMINARES: HOJAS Y HOJITAS}

\section{IV.5.3.1.1.- DATOS MÉTRICOS}

La longitud de las retocadas se encuentra entre 8 y 24 mm, pero la mayoría están de 11 a 18 mm (gráfico SV.4). En este gráfico se muestran el conjunto total de hojashojitas, tanto las rotas como las completas (de las que sólo hay dos). Esta distribución corresponde con la variación de las piezas de dorso. Las piezas sin retocar son todas hojitas de una anchura entre 6-10 mm, las retocadas se encuentran sobre todo en los 5-6 mm, la única hoja de mayor anchura corresponde al raspador doble, que mide $16 \mathrm{~mm}$ (gráfico SV.5). 


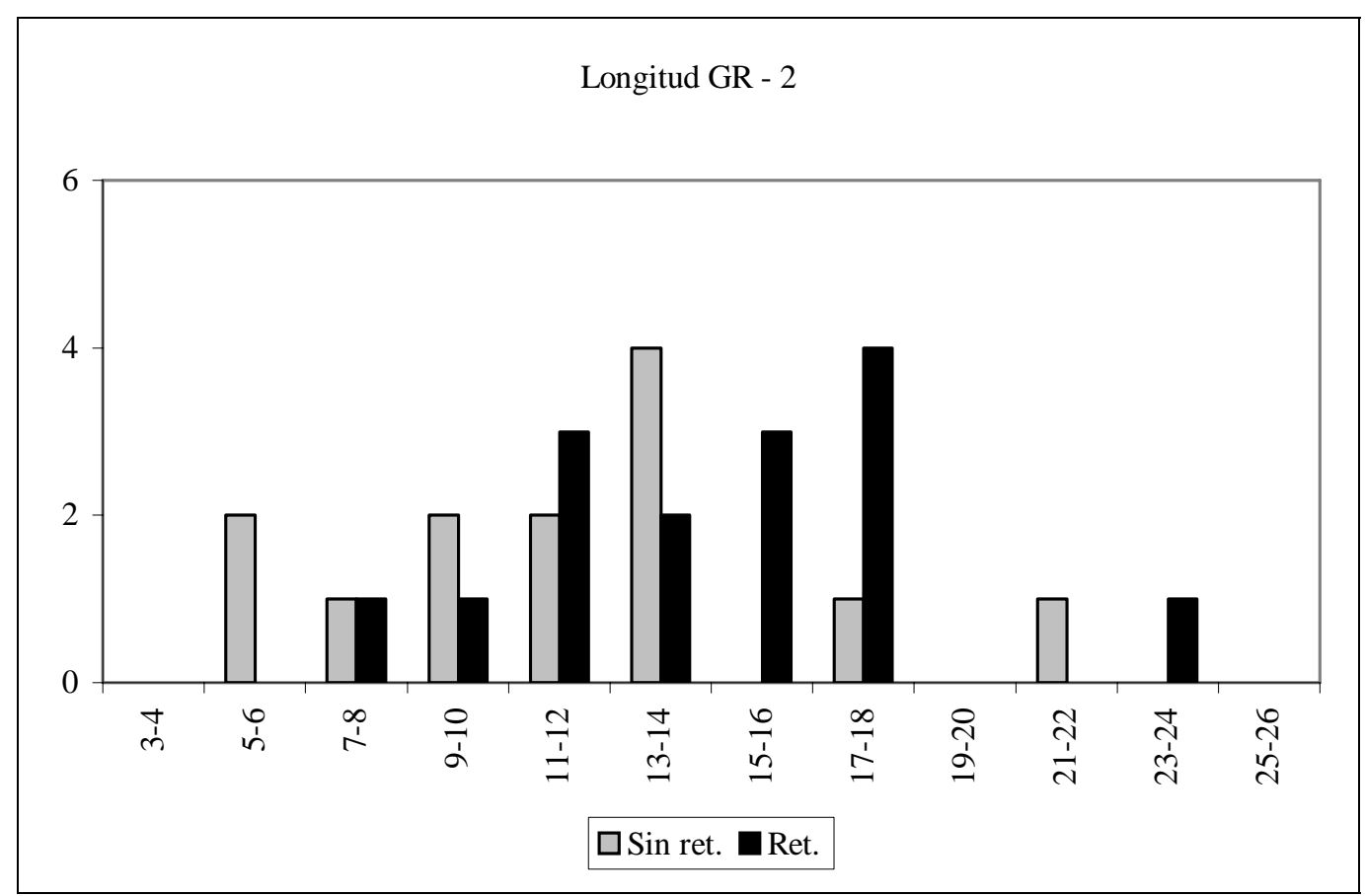

Gráfico SV.4: longitud de los soportes del grupo tecnológico 2 (hojas, hojitas). Sin retocar: $\mathrm{n}=13$. Retocados: $\mathrm{n}=15$. Se presentan tanto las piezas completas (de las que sólo hay 2 hojitas, sin retocar, de 18 y $21 \mathrm{~mm}$ ) como las rotas.

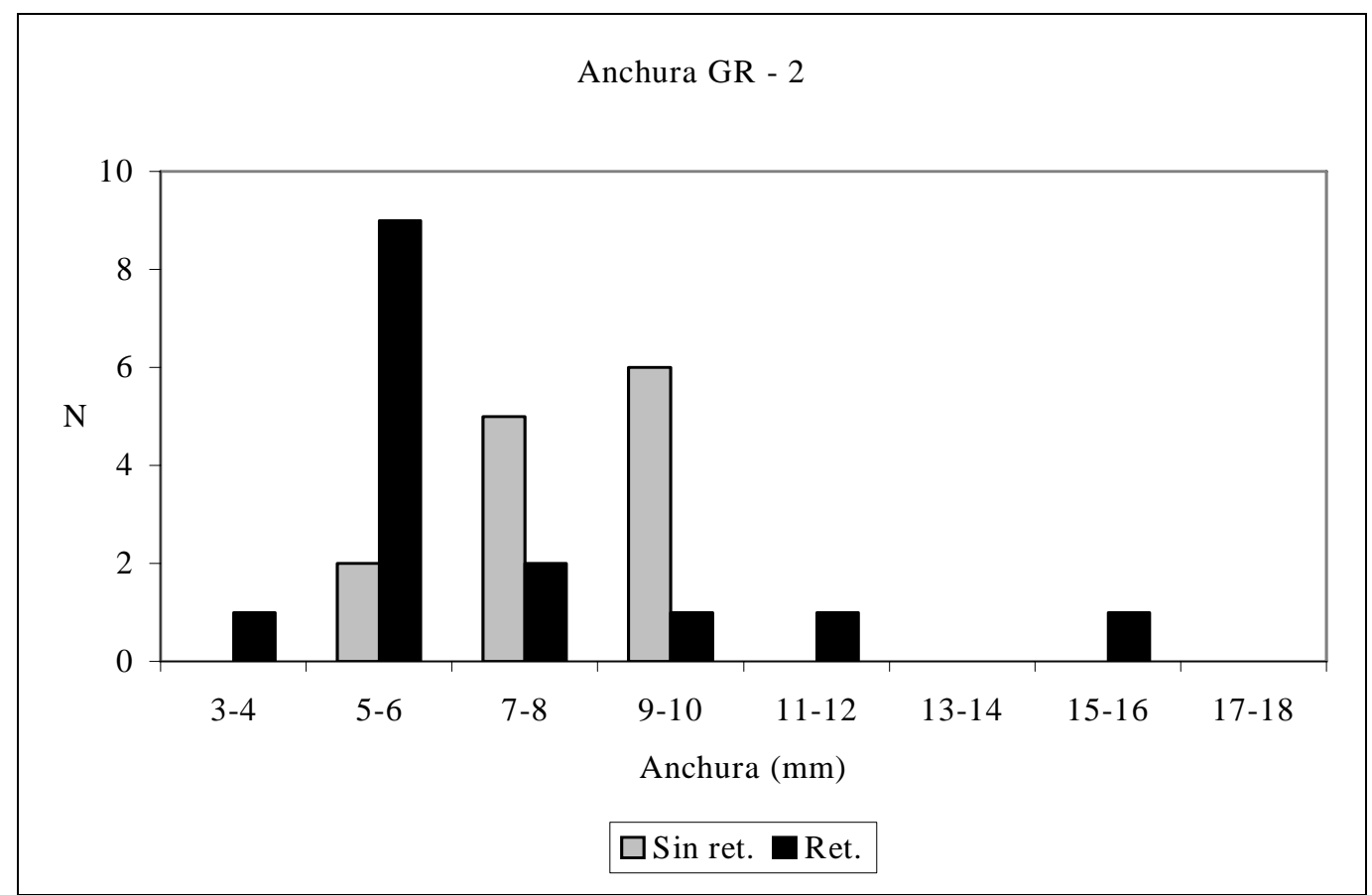

Gráfico SV.5: anchura de los soportes del grupo tecnológico 2 (hojas, hojitas). Sin retocar: $\mathrm{n}=13$. Retocados: $\mathrm{n}=15$. 


\section{IV.5.3.1.2.- DATOS TÉCNICOS}

El número de nervaduras difiere en las hojitas con y sin retoque, siendo más abundantes con una nervadura en las primeras y con dos en las segundas (cuadro SV.17). La dirección de los negativos es predominantemente unipolar, y la sección transversal triangular (cuadros SV.18 y SV.20). Respecto al perfil longitudinal, en las piezas sin retocar es más abundante el cóncavo, mientras que las retocadas tienen casi todas el perfil recto (cuadro SV.19). Por último en el índice de regularidad, tanto las retocadas como sin retocar se encuentran en un nivel de calidad medio-bueno, excepto porque las pocas hojas de mala calidad que hay están sin retocar; pero sorprende, frente a los otros otros sílex, que haya más hojitas de calidad óptima sin retocar con relación a las retocadas (cuadro SV.21).

\begin{tabular}{|l|l|lccccc|r|}
\hline \multicolumn{2}{|c|}{} & 0 & 1 & 2 & 3 & 4 & 5 & TOTAL \\
\hline \multirow{2}{*}{ SIN RET } & $\mathrm{N}$ & & 1 & 8 & 3 & & & 12 \\
& $\%$ & & 8,3 & 66,7 & 25,0 & & 100 \\
\hline \multirow{2}{*}{ RETOC } & $\mathrm{N}$ & 1 & 9 & 2 & 2 & & 14 \\
& $\%$ & 7,1 & 64,3 & 14,3 & 14,3 & & & 100 \\
\hline
\end{tabular}

Cuadro SV.17: $\mathrm{N}^{\mathrm{o}}$ de nervaduras en los soportes laminares

\begin{tabular}{|l|cc|cc|}
\hline \multirow{2}{*}{} & \multicolumn{2}{|c|}{ SIN RET } & \multicolumn{2}{c|}{ RET } \\
\cline { 2 - 5 } & $\mathrm{N}$ & $\%$ & $\mathrm{~N}$ & $\%$ \\
\hline PD & 7 & 70,0 & 6 & 75,0 \\
PD-DI & 1 & 10,0 & & \\
PD-DP & 1 & 10,0 & 1 & 12,5 \\
CI & 1 & 10,0 & 1 & 12,5 \\
\hline
\end{tabular}

Cuadro SV.18: dirección de los negativos de los soportes laminares, según el número de nervaduras en su cara superior. PD: proximal-distal (unipolar); PD-DP: proximal-distal y distalproximal (bipolar).

\begin{tabular}{|l|l|ccccc|r|}
\hline \multicolumn{2}{|c|}{} & Cn & Cx & R & S & T & TOTAL \\
\hline \multirow{2}{*}{ SIN RET } & $\mathrm{N}$ & 5 & & 3 & & & 8 \\
& $\%$ & 62,5 & & 37,5 & & & 100 \\
\hline \multirow{2}{*}{ RET } & $\mathrm{N}$ & & 1 & 10 & 1 & & 12 \\
& $\%$ & & 8,3 & 83,3 & 8,3 & & 100 \\
\hline
\end{tabular}

Cuadro SV.19: perfil longitudinal de los soportes laminares. Cn: cóncavo, curvo; Cx: convexo; R: rectilíneo; S: sinuoso (cóncavo-convexo); T: torse (alabeado). 


\begin{tabular}{|l|l|cccr|}
\hline \multicolumn{2}{|c|}{} & Bi-cX & TR & TZ & TOTAL \\
\hline \multirow{2}{*}{ SIN RET } & $\mathrm{N}$ & 5 & 7 & 12 \\
& $\%$ & 41,7 & 58,3 & 100 \\
\hline \multirow{2}{*}{ RET } & $\mathrm{N}$ & 13 & 1 & 14 \\
& $\%$ & 92,9 & 7,1 & 100 \\
\hline
\end{tabular}

Cuadro SV.20: sección transversal de los soportes laminares. Bi-cx: biconvexa; TR: triangular; TZ: trapezoidal.

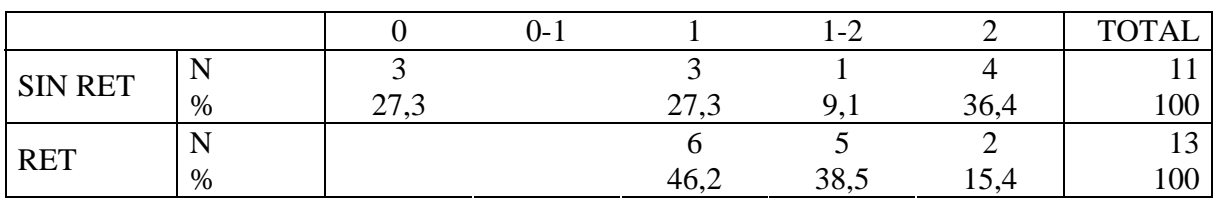

Cuadro SV.21: índice de regularidad de los soportes laminares. 0: mala calidad; 1: calidad media, aceptable; 2: buena calidad.

\section{IV.5.4.- PIEZAS RETOCADAS}

Hay 18 útiles retocados en estas variedades de sílex: 13 hojitas de dorso, un raspador doble, dos geométricos, un perforador y una punta con muesca (figura SV.1). Todas estos útiles tienen por soportes hojas-hojitas excepto los dos últimos tipos, fabricados sobre lascas. La especialización de los sílex varios en hojitas de dorso es, por tanto, muy evidente.

\begin{tabular}{|l|cc|c|cc|c|}
\cline { 2 - 7 } \multicolumn{1}{c}{} & \multicolumn{4}{c|}{} & \multicolumn{3}{c|}{ GRUPOS TEC. } \\
\cline { 2 - 8 } \multicolumn{1}{c|}{} & \multicolumn{2}{c|}{ TOTAL } & 1 & \multicolumn{2}{c|}{2} & 7 \\
\hline TIPO RETOC. & $\mathrm{N}$ & $\%$ & $\mathrm{~L}$ & H3 & HT3 & GB \\
\hline Raspador & 1 & 5,6 & & 1 & & \\
Perforador & 1 & 5,6 & 1 & & & \\
Punta & 1 & 5,6 & 1 & & & \\
Geométrico & 2 & 11,1 & & 2 & & \\
Dorso & 13 & 72,2 & & & 12 & 1 \\
\hline TOTAL & 18 & 100 & 2 & 3 & 12 & 1 \\
\hline
\end{tabular}

Cuadro SV.22: piezas retocadas en sílex varios. 


\section{IV.5.5.- CADENAS OPERATIVAS}

La/s cadena/s operativa/s de los sílex varios están rotas en el espacio, de manera que el proceso de talla que habría producido los soportes laminares no se ha realizado en nuestro yacimiento, las primeras fases de la cadena están ausentes (la de preparación, producción y retoque). Aquí se habrían traído los útiles retocados, dentro del “equipaje” de los grupos mesolíticos. De hecho, dicho bagaje se centra en elementos vinculados a útiles compuestos que se habrían utilizado posiblemente para armar las flechas u otros proyectiles, ya que se trata de hojitas y puntas de dorso, geométricos y una punta de muesca. Pertenecerían, por tanto, a actividades cinegéticas posiblemente, sólo hay dos piezas vinculadas a otro tipo de tareas más domésticas: el raspador y el perforador. Este último es además un útil de carácter oportunista en el sentido de que tiene una factura muy simple, ya que aprovecha la punta originada entre la rotura distal de una lasca y su borde izquierdo.

Además de este conjunto de útiles tan específicos, aparecen algunos elementos relacionados con el proceso de débitage propiamente dicho de estas materias (los soportes típicos de secuencias de producción), se trata de los tres núcleos, algunos chunks y varias lascas. Pero ni el escaso número de tales elementos, ni su tamaño permiten que sobre tales piezas se pueda aplicar algún esquema para la producción de las hojitas que están presentes en el conjunto. Hay que resaltar, no obstante, que el núcleo piramidal encaja totalmente en las cadenas desarrolladas por las personas que habitaron en la cueva. Parece que estos núcleos y restos de talla responden a un comportamiento distinto al que vemos en el resto de las materias, no se aprecia una intención de llevar nódulos para efectuar un débitage con los objetivos de los esquemas presentes en el resto de las materias, sino que más bien se trata de recoger algunas lascas gruesas, fragmentos informes o núcleos ya conformados y prácticamente agotados de estas materias "raras", que son tallados de forma esporádica, con una finalidad que desconocemos. Dicho comportamiento podría vincularse incluso a un gusto por tales materias, a modo de souvenirs o curiosidades. 
Estos sílex varios se podrían tildar por tanto de “materias exóticas”, cuyo origen desconocemos, pero que estaría vinculado a lugares distintos al área de captación inmediata de recursos minerales que explotan desde la cueva. El tipo de soportes en que aparecen son, por una parte, los útiles retocados y, por otra, algún núcleo y lascas de pequeño tamaño; serían soportes sin demasiada conexión entre sí. Los útiles retocados serían llevados lo más seguro en los utensilios fabricados y transportados por los grupos (útiles cinegéticos probablemente). Respecto a los núcleos, puede plantearse la posibilidad de que aparezcan esporádicamente en zonas de conglomerados algún núcleo de estas variedades “raras”, o también a lo largo de los desplazamientos de estos grupos; tales piezas serían recogidas quizás por la singularidad de la materia. Parece que tales elementos no se recogen con la misma intención práctica que los otros núcleos que se han visto en el yacimiento, no se aplica sobre ellos los esquemas desarrollados en el resto de las materias. Parece más bien que la intención es de tipo anecdótico, se recogen esas rocas y se prueban en el yacimiento. 


\section{IV.6.- CUARCITA}

La cuarcita es la segunda materia utilizada en El Espertín después del chert negro; con 2281 elementos supone, aproximadamente, el 18\% del conjunto lítico. Junto con el chert negro, es una roca de origen local y sobre ella se ha llevado a cabo un tipo de explotación intensiva en el yacimiento, ya que en él se encuentran elementos de todo el proceso de talla ejecutado.

\section{IV.6.1.- CARACTERÍSTICAS GENERALES}

\section{IV.6.1.1.- LISTA TECNOLÓGICA, GRUPOS TECNOLÓGICOS}

En cuarcita se encuentran representados casi todos los tipos de soportes de la lista tecnológica, dicho hecho viene a confirmar la ejecución de la talla de este tipo de materia en el yacimiento desde el comienzo mismo de la/s cadena/s operativas desarrolladas; no hay ninguna ruptura aparente de dicho proceso, encontrando desde nódulos fragmentados desechados, hasta las pequeñas astillas de talla. Los bloques se habrían seleccionado en un lugar no muy alejado de la cueva, y a ella se habrían llevado para ser transformados. Este comportamiento, típico de un modelo de adquisición de las materias autóctonas cercanas, es similar al desarrollado sobre el chert negro.

El tipo de soporte más abundante en cuarcita son las lascas de tercer orden (cuadro C.1), que constituyen casi la mitad de las piezas presentes (46\%), seguidas por las lasquitas de talla (26\%); los tipos de soportes restantes no llegan a un 5\% en su representación respecto al conjunto.

Por grupos tecnológicos genéricos (cuadro C.2) se observa claramente el peso predominante del conjunto de las lascas, que suponen la mitad de las piezas de cuarcita (54\%), seguidas por los debris, que agrupan un tercio (29\%). Con un $8 \%$ se encuentran las hojas-hojitas, a las que siguen los soportes indeterminados (7\%); por último, con una representación muy pequeña están los productos de acondicionamiento, núcleos, golpes de buril y nódulos. 


\begin{tabular}{|c|c|c|c|c|}
\hline $\begin{array}{l}\text { GRUPO } \\
\text { TECNOLÓGICO }\end{array}$ & $\mathbf{N}^{\circ}$ TEC. & SOPORTE & $\mathbf{N}$ & $\%$ \\
\hline GRUPO 0 (nódulos) & 0 & Nódulo & 2 & 0,1 \\
\hline \multirow{6}{*}{$\begin{array}{l}\text { GRUPO } 1 \\
\text { (lascas) }\end{array}$} & 1 & Lasca de primer orden & 31 & 1,4 \\
\hline & 2 & Lasca de segundo orden & 120 & 5,3 \\
\hline & $2-5$ & Lasca laminar de segundo orden & 3 & 0,1 \\
\hline & 3 & Lasca de tercer orden & 1061 & 46,5 \\
\hline & 3-6 & Lasca laminar & 7 & 0,3 \\
\hline & 4 & Hoja de primer orden & & \\
\hline \multirow{5}{*}{$\begin{array}{l}\text { GRUPO } 2 \\
\text { (soportes laminares) }\end{array}$} & 5 & Hoja de segundo orden & 11 & 0,5 \\
\hline & 6 & Hoja de tercer orden & 88 & 3,9 \\
\hline & 6-FN & Hoja de tercer orden con flanco & & \\
\hline & 7 & Hojita de segundo orden & 5 & 0,2 \\
\hline & 8 & Hojita de tercer orden & 73 & 3,2 \\
\hline \multirow{5}{*}{$\begin{array}{l}\text { GRUPO } 3 \text { (productos de } \\
\text { acondicionamiento) }\end{array}$} & 9 & Lámina cresta & 1 & 0,0 \\
\hline & 10 & Tableta de núcleo & & \\
\hline & 11 & Semitableta de núcleo & 2 & 0,1 \\
\hline & 12 & Flanco de núcleo & 6 & 0,3 \\
\hline & 13 & Arista de núcleo y otros & 23 & 1,0 \\
\hline \multirow{5}{*}{$\begin{array}{l}\text { GRUPO } 4 \\
\text { (núcleos) }\end{array}$} & 14 & Núcleo prismático con un plano & 2 & 0,1 \\
\hline & 15 & Núcleo prismático con dos planos & 1 & 0,0 \\
\hline & 16 & Núcleo sobre lasca & & \\
\hline & 17 & Núcleo globuloso & 4 & 0,2 \\
\hline & 18 & Resto de núcleo & 9 & 0,4 \\
\hline GRUPO 7 (golpes buril) & 19 & Golpe de buril & 11 & 0,5 \\
\hline \multirow{3}{*}{$\begin{array}{l}\text { GRUPO } 5 \\
\text { (indeterminados) }\end{array}$} & 23 & Astilla de talla & 100 & 4,4 \\
\hline & 24 & Chunk & 31 & 1,4 \\
\hline & 25 & Indeterminado & 24 & 1,1 \\
\hline \multirow{2}{*}{\begin{tabular}{|l}
$\begin{array}{l}\text { GRUPO } 6 \\
\text { (debris) }\end{array}$ \\
\end{tabular}} & DEB-LT & Debris: lasquita & 601 & 26,3 \\
\hline & DEB-AT & Debris: astilla e indeterminados & 65 & 2,8 \\
\hline & & & 2281 & 100 \\
\hline
\end{tabular}

Cuadro C.1: lista tecnológica de la cuarcita.

\begin{tabular}{|lcc|}
\hline GRUPOS TEC. & $\mathbf{N}$ & $\mathbf{\%}$ \\
\hline 0 & 2 & 0,1 \\
1 & 1222 & 53,6 \\
2 & 177 & 7,8 \\
3 & 32 & 1,4 \\
4 & 16 & 0,7 \\
5 & 155 & 6,8 \\
6 & 666 & 29,2 \\
7 & 11 & 0,5 \\
\hline & 2281 & 100 \\
\hline
\end{tabular}

Cuadro C.2: grupos tecnológicos de la cuarcita. 


\begin{tabular}{|c|c|c|c|c|}
\hline \begin{tabular}{|l|} 
GRUPO \\
TECNOLÓGICO
\end{tabular} & $\mathbf{N}^{\circ}$ TEC. & SOPORTE & $\mathbf{N}$ & $\%$ \\
\hline GRUPO 0 (nódulos) & 0 & Nódulo & & \\
\hline \multirow{6}{*}{$\begin{array}{l}\text { GRUPO } 1 \\
\text { (lascas) }\end{array}$} & 1 & Lasca de primer orden & 2 & 1,8 \\
\hline & 2 & Lasca de segundo orden & 10 & 9,0 \\
\hline & $2-5$ & Lasca laminar de segundo orden & 1 & 0,9 \\
\hline & 3 & Lasca de tercer orden & 67 & 60,4 \\
\hline & 3-6 & Lasca laminar & 1 & 0,9 \\
\hline & 4 & Hoja de primer orden & & \\
\hline \multirow{5}{*}{$\begin{array}{l}\text { GRUPO } 2 \\
\text { (soportes laminares) }\end{array}$} & 5 & Hoja de segundo orden & 2 & 1,8 \\
\hline & 6 & Hoja de tercer orden & 8 & 7,2 \\
\hline & 6-FN & Hoja de tercer orden con flanco & & \\
\hline & 7 & Hojita de segundo orden & & \\
\hline & 8 & Hojita de tercer orden & 12 & 10,8 \\
\hline \multirow{5}{*}{$\begin{array}{l}\text { GRUPO } 3 \text { (productos de } \\
\text { acondicionamiento) }\end{array}$} & 9 & Lámina cresta & & \\
\hline & 10 & Tableta de núcleo & & \\
\hline & 11 & Semitableta de núcleo & & \\
\hline & 12 & Flanco de núcleo & 3 & 2,7 \\
\hline & 13 & Arista de núcleo y otros & 3 & 2,7 \\
\hline \multirow{5}{*}{$\begin{array}{l}\text { GRUPO } 4 \\
\text { (núcleos) }\end{array}$} & 14 & Núcleo prismático con un plano & & \\
\hline & 15 & Núcleo prismático con dos planos & & \\
\hline & 16 & Núcleo sobre lasca & & \\
\hline & 17 & Núcleo globuloso & & \\
\hline & 18 & Resto de núcleo & & \\
\hline GRUPO 7 (golpes buril) & 19 & Golpe de buril & & \\
\hline \multirow{3}{*}{$\begin{array}{l}\text { GRUPO } 5 \\
\text { (indeterminados) }\end{array}$} & 23 & Astilla de talla & & \\
\hline & 24 & Chunk & 2 & 1,8 \\
\hline & 25 & Indeterminado & & \\
\hline \multirow{3}{*}{$\begin{array}{l}\text { GRUPO } 6 \\
\text { (debris) }\end{array}$} & DEB-LT & Debris: lasquita & & \\
\hline & DEB-AT & Debris: astilla e indeterminados & & \\
\hline & & & 111 & 100,0 \\
\hline
\end{tabular}

Cuadro C.3: lista tecnológica de los soportes retocados de sílex negro.

\begin{tabular}{|lcc|}
\hline $\begin{array}{l}\text { GRUPOS } \\
\text { TEC. }\end{array}$ & $\mathbf{N}$ & $\mathbf{\%}$ \\
\hline 0 & 81 & 73,0 \\
1 & 22 & 19,8 \\
2 & 6 & 5,4 \\
3 & & \\
4 & 2 & 1,8 \\
5 & & \\
6 & & 100 \\
7 & 111 & \\
\hline \multicolumn{2}{l}{} \\
\hline
\end{tabular}

Cuadro C.4: grupos tecnológicos del sílex negro en las piezas retocadas. 
A partir de estos tipos de soportes presentes en cuarcita se puede entrever que los esquemas conceptuales aplicados en su transformación son fundamentalmente de lascas, pero con la presencia de esquemas laminares. Estos últimos estarían encaminados a la obtención de hojas y hojitas, y su peso en el conjunto del débitage de la cuarcita parece, en principio, inferior al de las lascas, al menos en razón del elevado número de éstas. No obstante, habrá que valorar la importancia del débitage laminar no sólo sobre el número de lascas, sino sobre el tipo de núcleos y resto de soportes presentes en el conjunto.

En los tipos de soportes retocados predominan también las lascas (cuadro C.4), con el 60\%, pero en el conjunto de la cuarcita (cuadro C.5) los soportes laminares alcanzan una representación más evidente, suponiendo el 20\%.

Se constata también en cuarcita una selección preferente de las hojas y hojitas disponibles para ser retocadas (cuadro C.5), por encima incluso de las lascas.

\begin{tabular}{|l|c|cc|}
\hline \multirow{2}{*}{ GRUPOS TEC. } & \multirow{2}{*}{ TOTAL } & \multicolumn{2}{|c|}{ RETOCADAS } \\
\cline { 3 - 4 } & & $\mathrm{N}$ & $\%$ \\
\hline 0 & 2 & & \\
1 & 1222 & 81 & 6,6 \\
2 & 177 & 22 & 12,4 \\
3 & 32 & 6 & 18,8 \\
4 & 16 & & \\
5 & 155 & 2 & 1,3 \\
6 & 666 & & \\
7 & 11 & & \\
\hline & 2281 & 111 & 4,9 \\
\hline
\end{tabular}

Cuadro C.5: piezas retocadas relativamente al total de las disponibles en los distintos grupos tecnológicos.

\section{IV.6.1.2.- ROTURAS}

Como en la mayoría del resto de materias presentes en el yacimiento, hay un elevado número de elementos rotos, tan solo un tercio de ellos se encuentran completos. 
IV.6.1.2.1.- TIPOS DE SOPORTES ROTOS

En los cuadros C.6 y C.7 se especifica el estado de fragmentación en que se encuentran los principales tipos de soportes.

\begin{tabular}{|c|c|c|c|c|c|c|c|}
\hline \multirow{2}{*}{$\begin{array}{l}\text { GRUPO } \\
\text { TEC. }\end{array}$} & \multirow{2}{*}{ TIPO TEC. } & \multirow{2}{*}{ COMPLETOS } & \multicolumn{4}{|c|}{ FRAGMENTADOS } & \multirow{2}{*}{ TOTAL } \\
\hline & & & Distal & Mesial & Proximal & Roto & \\
\hline 0 & L-PL & 2 & & & & & 2 \\
\hline 1 & $\begin{array}{l}\mathrm{L} \\
\mathrm{L}-\mathrm{H} \\
\mathrm{H}\end{array}$ & $\begin{array}{c}449 \\
1\end{array}$ & $\begin{array}{c}220 \\
2\end{array}$ & $\begin{array}{c}67 \\
1\end{array}$ & $\begin{array}{c}300 \\
5\end{array}$ & $\begin{array}{c}176 \\
1\end{array}$ & $\begin{array}{r}1212 \\
10 \\
0\end{array}$ \\
\hline 2 & $\begin{array}{l}\mathrm{H} \\
\mathrm{H}-\mathrm{FN} \\
\mathrm{HT}\end{array}$ & $\begin{array}{l}22 \\
2\end{array}$ & $\begin{array}{l}13 \\
22\end{array}$ & $\begin{array}{l}23 \\
31\end{array}$ & $\begin{array}{l}37 \\
22\end{array}$ & $\begin{array}{l}4 \\
1\end{array}$ & $\begin{array}{l}99 \\
78\end{array}$ \\
\hline 3 & $\begin{array}{l}\text { LC } \\
\text { TN } \\
\text { SN } \\
\text { FN } \\
\text { AN }\end{array}$ & $\begin{array}{l}1 \\
2 \\
5 \\
6 \\
\end{array}$ & 9 & $\begin{array}{l}1 \\
5 \\
\end{array}$ & 3 & & $\begin{array}{r}1 \\
2 \\
6 \\
23 \\
\end{array}$ \\
\hline 4 & $\mathrm{~N}$ & 16 & & & & & 16 \\
\hline 5 & IT & & & & & 155 & 155 \\
\hline 6 & $\begin{array}{l}\text { LT } \\
\text { IT }\end{array}$ & 246 & 81 & 41 & 62 & $\begin{array}{c}171 \\
65\end{array}$ & $\begin{array}{r}601 \\
65 \\
\end{array}$ \\
\hline 7 & GB & 5 & 2 & 1 & 3 & & 11 \\
\hline & & & 349 & 170 & 432 & 573 & 2281 \\
\hline & & 757 (33,2\%) & & 1524 & $6,8 \%)$ & & \\
\hline
\end{tabular}

Cuadro C.6: representación de los tipos de soportes enteros y fragmentados de sílex negro, teniendo en cuanta la totalidad de las piezas.

\section{IV.6.1.2.2.- TIPOS DE ROTURAS}

El tipo de rotura más abundante (cuadro C.7) es la distal, que afecta a una cuarta parte de las piezas, seguida por las roturas por todos los lados (19\%) y la proximal (15\%); las roturas distales-laterales, laterales, próximo-distales y próximo-laterales tienen en torno al 10\% de representación, siendo las bilaterales las más escasas (2\%). 


\begin{tabular}{|l|cccccccc|r|}
\hline & BL & DL & DP & DS & LT & PD & PL & PX & TOTAL \\
\hline GR.1:L & 27 & 111 & 141 & 229 & 116 & 69 & 96 & 138 & 927 \\
GR.2:H & & 2 & 4 & 59 & & 54 & 1 & 35 & 155 \\
GR.3:P.A. & & & & 2 & 1 & 6 & & 9 & 18 \\
GR.6:DEB & 4 & 47 & 155 & 116 & 27 & 44 & 42 & 50 & 485 \\
GR.7:GB & & & & 3 & & 1 & & 3 & 7 \\
\hline N & 31 & 160 & 300 & 409 & 144 & 174 & 139 & 235 & 1592 \\
$\%$ & 1,9 & 10,1 & 18,8 & 25,7 & 9,0 & 10,9 & 8,7 & 14,8 & 100,0 \\
\hline
\end{tabular}

Cuadro C.7: tipos de roturas en los distintos tipos de soportes. BL: bilateral, DL: distal-lateral, DP: distal-lateral-proximal, DS: distal, LT: lateral, PD: proximal-distal, PL: proximal-lateral, PX: proximal.

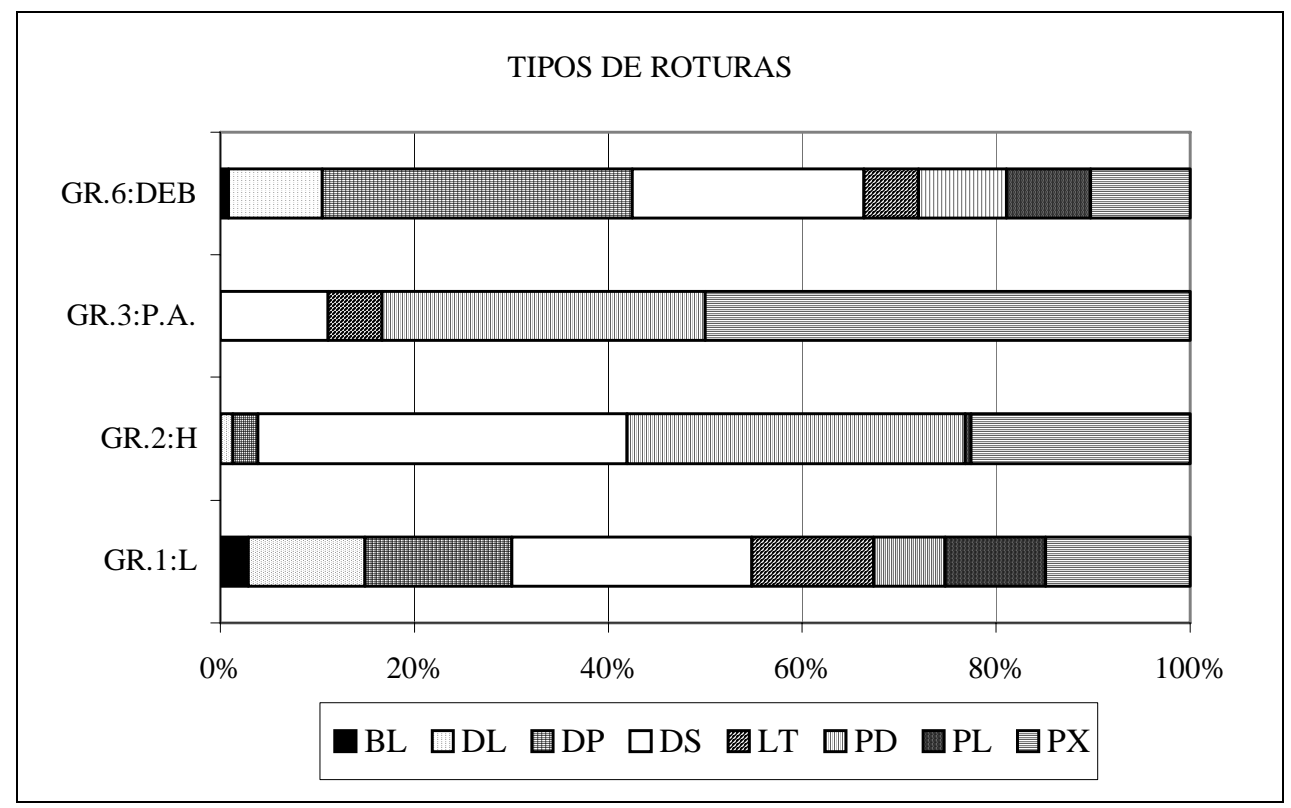

Gráfico C.1: porcentaje de los tipos de roturas por grupos tecnológicos. Tipos de roturas: BL: bilateral, DL: distal-lateral, DP: distal-proximal-lateral, LT: lateral, PD: proximal-distal, PL: proximal-lateral, PX: proximal.

Respecto a la representación de los tipos de roturas según los distintos soportes (gráfico C.1), en el grupo de las lascas y los debris están presentes todas las variantes de roturas, en cambio en el grupo de las hojas-hojitas y los productos de acondicionamiento predominan claramente las roturas de tipo transversal (proximales, distales y próximo-distales). Esta disparidad entre los productos pertenecientes a la fase de producción plena en un débitage laminar por un lado, y el resto de los productos (tanto los “soportes secundarios" de un débitage laminar, como las lascas de primera intención dentro de un débitage de lascas propiamente dicho) se ha visto para el resto de las materias que se han analizado. 
IV.6.1.2.3.- CAUSA DE LA ROTURA
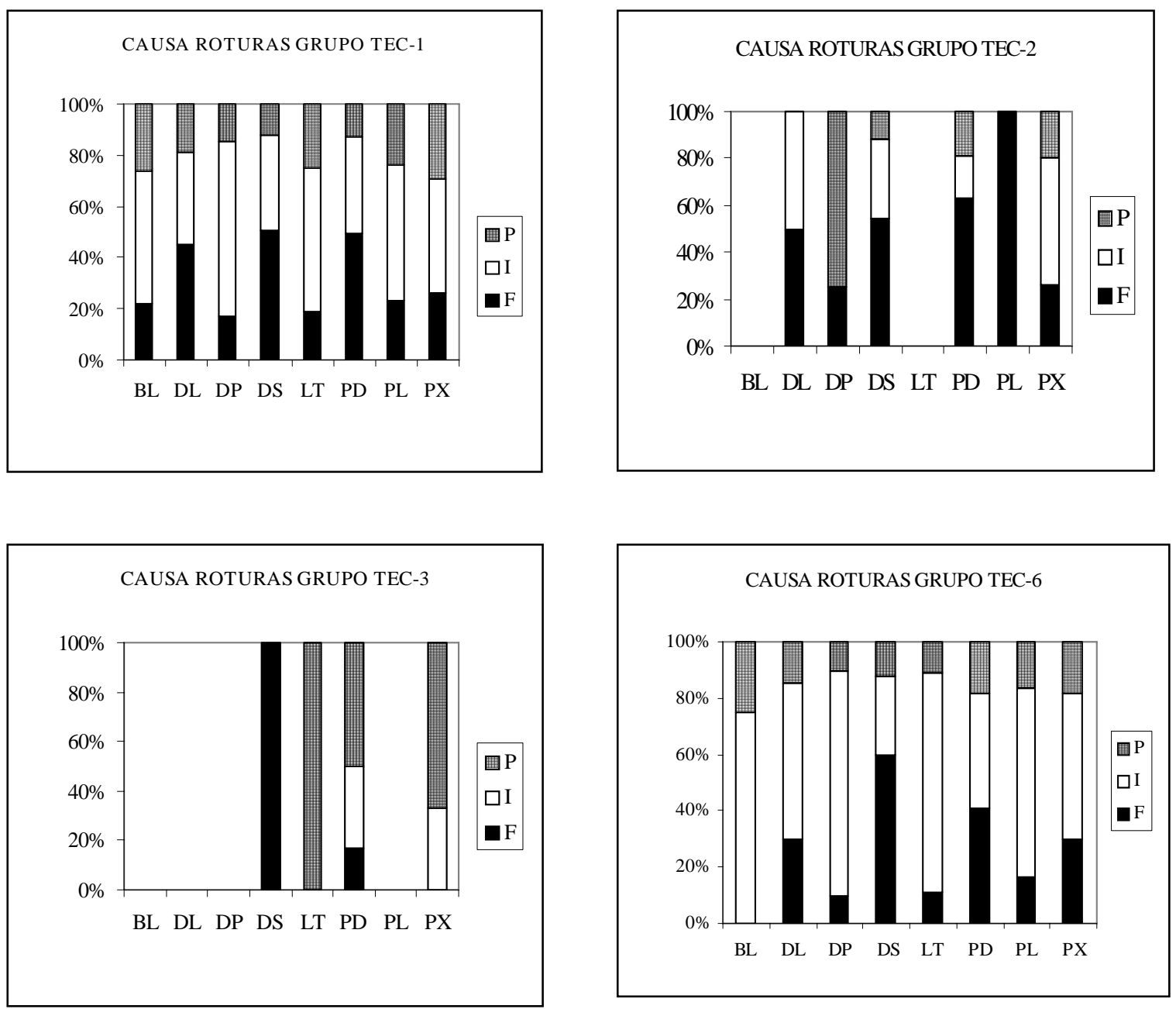

Gráfico C.2: porcentaje de representación de las causas de la rotura según los distintos tipos de fracturas y por grupos tecnológicos. En el eje de abscisas los tipos de fracturas: BL: bilateral, DL: distal-lateral, DP: distal-proximal-lateral, LT: lateral, PD: proximal-distal, PL: proximallateral, PX: proximal. En el eje de ordenadas se sitúa el porcentaje de los tipos de roturas: P: percusión, I: indeterminada, F: por flexión.

\begin{tabular}{|l|cccc|cc|}
\hline & GR.1 & GR.2 & GR.3 & GR.6 & N & $\%$ \\
\hline Flexión & 310 & 78 & 3 & 141 & 532 & 33,6 \\
Indeterminada & 439 & 50 & 5 & 279 & 773 & 48,8 \\
Percusión & 178 & 27 & 10 & 65 & 280 & 17,7 \\
\hline
\end{tabular}

Cuadro C.8: causa rotura en los distintos grupos tecnológicos.

En el motivo de la rotura (cuadro C.8), casi la mitad de las piezas tienen una causa indeterminada; en el resto es más frecuente la flexión (34\%) que la percusión 
(18\%). La representación de este atributo según los grupos de soportes genéricos (gráfico C.2) sigue la misma tendencia general, tan solo se podría señalar que las roturas indeterminadas tienen su mayor representación en los debris.

\section{IV.6.1.3.- CÓRTEX}

La cuarcita y el chert negro son las materias donde más presencia de piezas corticales hay del conjunto lítico, hecho que se explicaría por el tipo de adquisición local y explotación intensiva ejecutado sobre estas dos materias. En cuarcita hay un $11 \%$ de piezas con restos corticales, su representación en los distintos tipos de soportes se especifica en el cuadro C.9.

\begin{tabular}{|l|rccccc|r|}
\hline & \multicolumn{7}{|c}{ CÓRTEX } \\
\hline & 1 & $\%$ & 2 & $\%$ & 3 & $\%$ & TOTAL \\
\hline L-PL & & & & & 2 & 100,0 & 2 \\
L & 42 & 3,5 & 121 & 10,0 & 1049 & 86,6 & 1212 \\
L-H & & & 3 & 30,0 & 7 & 70,0 & 10 \\
H & & & 11 & 11,1 & 88 & 88,9 & 99 \\
H-FN & & & & & & & \\
HT & & & 5 & 6,4 & 73 & 93,6 & 78 \\
LC & & & 1 & 100,0 & & 0,0 & 1 \\
TN & & & & & & & \\
SN & & & & & 2 & 100,0 & 2 \\
FN & & & 1 & 16,7 & 5 & 83,3 & 6 \\
AN & & & 4 & 17,4 & 19 & 82,6 & 23 \\
Nuc. & & & 7 & 43,8 & 9 & 56,3 & 16 \\
GB & & & & & 11 & 100,0 & 11 \\
IT & 11 & 7,1 & 21 & 13,5 & 123 & 79,4 & 155 \\
DEB:LT & & & 24 & 4,0 & 577 & 96,0 & 601 \\
DEB:IT & & & 2 & 3,1 & 63 & 96,9 & 65 \\
\hline TOTAL & 53 & 2,3 & 200 & 8,8 & 2028 & 88,9 & 2281 \\
\hline
\end{tabular}

Cuadro C.9: presencia de córtex en los principales tipos tecnológicos, con sus respectivos porcentajes

\section{IV.6.1.4.- DATOS MÉTRICOS}

\section{IV.6.1.4.1.- TIPOS DE SOPORTES}

En el cuadro C.10 se presentan las dimensiones medias de los distintos tipos de soportes. Las mayores dimensiones corresponden a sendas lascas corticales que miden casi ocho centímetros, pertenecerían por tanto a la fase de preparación de los núcleos. 
Entre los productos de acondicionamiento se encuentran también piezas superiores a los siete centímetros, medida que es el límite mayor en los núcleos. Por tanto habría una coherencia respecto a las dimensiones a lo largo de los esquemas aplicados en la cuarcita, encontrándose tanto las lascas de conformación iniciales, de dimensiones considerables, como productos de acondicionamiento de tamaño intermedio en el proceso de débitage.

Como en las anteriores materias, hay una tendencia generalizada a seleccionar los soportes mayores, de entre los disponibles, para ser retocados. Las lascas tienen unas dimensiones medias de $20 \mathrm{~mm}$ de longitud, 17 de anchura y 5 de grosor, las lascas retocadas aumentan más de un centímetro las dimensiones principales.

Los soportes laminares miden 35 mm de longitud, 12 de anchura y 4 de grosor, en las piezas retocadas el tamaño aumenta casi un centímetro en la longitud y en el grosor, pero la anchura es prácticamente la misma o incluso ligeramente inferior. Estos datos de todas formas proceden de una muestra laminar bastante reducida por lo que puede que no sean demasiado representativos. De todos modos sorprende este hecho, ya que en algunas variedades de sílex también había un número reducido de piezas y siempre se veía una tendencia a un incremento en la anchura de las hojas-hojitas retocadas.

Los productos de acondicionamiento son bastante grandes, sus medias son: 37 mm de longitud, 22 de anchura y 11 de grosor; medidas que aumentan en las piezas retocadas a $41 \mathrm{~mm}$ de longitud, 34 de anchura y 16 de grosor. En este caso la longitud tiene una desviación relativamente reducida, constatando esta selección de piezas en torno a los $4 \mathrm{~cm}$. Los núcleos tienen unas dimensiones bastante variadas ya que en el conjunto hay tanto núcleos relativamente grandes como otros prácticamente agotados. Sus dimensiones medias están en $44 \mathrm{~mm}$ de longitud y anchura y 30 de grosor. Las piezas indeterminadas reflejan soportes alargados, estrechos y gruesos, de $17 \mathrm{~mm}$ de longitud, 10 de anchura y 6 de grosor; son por tanto, en general, inferiores al resto de soportes. Por último las medias de los debris reflejan unas piezas cuadrangulares de 8 mm de longitud, 7 de anchura y 2 de grosor. 


\begin{tabular}{|c|c|c|c|c|c|c|c|}
\hline \multicolumn{4}{|l|}{ SIN RETOCAR } & \multicolumn{4}{|l|}{ RETOCADAS } \\
\hline GR1:L & $\mathbf{L}$ & A & G & GR1:L & $\mathbf{L}$ & A & G \\
\hline $\mathrm{N}$ & 415 & 966 & 1135 & $\mathrm{~N}$ & 35 & 70 & 77 \\
\hline Rango & $6-67$ & $5-77$ & $1-30$ & Rango & $11-78$ & $8-55$ & $2-23$ \\
\hline Media & 19,68 & 16,69 & 4,77 & Media & 34,0 & 26,86 & 7,99 \\
\hline Desviación & 10,92 & 8,82 & 3,22 & Desviación & 14,75 & 11,29 & 4,38 \\
\hline GR1:L-H & $\mathbf{L}$ & A & G & GR1:L-H & $\mathbf{L}$ & A & G \\
\hline $\mathrm{N}$ & - & 7 & 8 & $\mathrm{~N}$ & 1 & 2 & 2 \\
\hline Rango & & $6-21$ & $2-5$ & Rango & 48 & $20-30$ & 8-11 \\
\hline Media & & 14,43 & 3,43 & Media & & & \\
\hline Desviación & & 5,44 & 0,91 & Desviación & & & \\
\hline GR2:H & $\mathbf{L}$ & A & G & GR2:H & $\mathbf{L}$ & A & G \\
\hline $\mathrm{N}$ & 21 & 151 & 155 & $\mathrm{~N}$ & 3 & 21 & 22 \\
\hline Rango & $14-66$ & $5-33$ & $1-14$ & Rango & $22-70$ & $5-28$ & $1-14$ \\
\hline Media & 35,0 & 11,59 & 3,60 & Media & 44,33 & 11,26 & 4,14 \\
\hline Desviación & 13,24 & 4,67 & 1,91 & Desviación & 24,17 & 6,27 & 3,23 \\
\hline GR3:P.A. & $\mathbf{L}$ & A & G & GR3:P.A. & $\mathbf{L}$ & A & G \\
\hline $\mathrm{N}$ & 11 & 26 & 26 & $\mathrm{~N}$ & 3 & 6 & 6 \\
\hline Rango & $24-77$ & $7-56$ & $4-23$ & Rango & $37-44$ & $21-70$ & $8-26$ \\
\hline Media & 37,0 & 21,94 & 11,35 & Media & 40,67 & 33,70 & 15,72 \\
\hline Desviación & 15,81 & 12,09 & 4,91 & Desviación & 3,51 & 18,46 & 6,22 \\
\hline GR4:N & $\mathbf{L}$ & A & G & GR4:N & $\mathbf{L}$ & A & G \\
\hline $\mathrm{N}$ & 16 & 16 & 16 & $\mathrm{~N}$ & - & - & - \\
\hline Rango & $22-70$ & $26-66$ & $14-60$ & Rango & & & \\
\hline Media & 43,69 & 43,69 & 29,50 & Media & & & \\
\hline Desviación & 14,64 & 10,81 & 10,49 & Desviación & & & \\
\hline GR5:IT & $\mathbf{L}$ & A & G & GR5:IT & $\mathbf{L}$ & A & G \\
\hline $\mathrm{N}$ & 152 & 152 & 152 & $\mathrm{~N}$ & 2 & 2 & 2 \\
\hline Rango & $7-68$ & $3-45$ & $1-22$ & Rango & $24-45$ & $32-37$ & $14-20$ \\
\hline Media & 17,43 & 10,32 & 6,06 & Media & & & \\
\hline Desviación & 8,17 & 6,90 & 4,85 & Desviación & & & \\
\hline GR6:DEB & $\mathbf{L}$ & A & G & GR6:DEB & $\mathbf{L}$ & A & G \\
\hline $\mathrm{N}$ & 663 & 663 & 663 & $\mathrm{~N}$ & 3 & 3 & 3 \\
\hline Rango & $4-10$ & $1-10$ & $1-6$ & Rango & $5-10$ & $7-10$ & $1-2$ \\
\hline Media & 7,94 & 7,23 & 2,09 & Media & 8,33 & 9,0 & 1,63 \\
\hline Desviación & 1,54 & 1,63 & 1,91 & Desviación & 2,89 & 1,73 & 0,21 \\
\hline
\end{tabular}

Cuadro C.10: datos métricos de la cuarcita, por grupos tecnológicos. N: número de elementos. L: longitud, A: anchura, G: grosor. 
IV.6.1.4.2.- TALÓN

Las dimensiones del talón (cuadro C.11) son relativas al tamaño del soporte en cuestión y, en cuarcita, tienen la particularidad de ser de mayores dimensiones que en el resto de las materias primas. Si nos fijamos en la anchura, las lacas tienen una media de $4 \mathrm{~mm}$, las hojas-hojitas de 3, los productos de acondicionamiento 7 e incluso los debris superan los $2 \mathrm{~mm}$. En las piezas retocadas estas dimensiones se incrementan, en correspondencia con el mayor tamaño general de dichos soportes seleccionados.

Estos talones de dimensión grande estarían relacionados con una percusión interna y con la preferencia del percutor duro como modo de talla de este tipo de materia.

\begin{tabular}{|c|c|c|c|c|c|}
\hline SIN RETOCAR & & & RETOCADAS & & \\
\hline GR1:L & $\mathbf{L}$ & A & GR1:L & $\mathbf{L}$ & A \\
\hline $\mathrm{N}$ & 394 & 548 & $\mathrm{~N}$ & 42 & 52 \\
\hline Rango & $0,5-53$ & $0,5-22$ & Rango & $2-50$ & $1-14$ \\
\hline Media & 12,72 & 4,28 & Media & 17,32 & 5,87 \\
\hline Desviación & 7,82 & 2,76 & Desviación & 10,41 & 3,41 \\
\hline GR1:L-H & $\mathbf{L}$ & A & GR1:L-H & $\mathbf{L}$ & $\mathbf{A}$ \\
\hline $\mathrm{N}$ & 4 & 4 & $\mathrm{~N}$ & 1 & 1 \\
\hline Rango & $6-16$ & $1,3-3$ & Rango & 15 & 3,5 \\
\hline Media & 9,75 & 2,33 & Media & & \\
\hline Desviación & 4,35 & 0,83 & Desviación & & \\
\hline GR2:H & $\mathbf{L}$ & $\mathbf{A}$ & GR2:H & $\mathbf{L}$ & $\mathbf{A}$ \\
\hline $\mathrm{N}$ & 56 & 60 & $\mathrm{~N}$ & 6 & 7 \\
\hline Rango & $2-19$ & $0,5-9$ & Rango & $6,4-20,5$ & $1,2-10$ \\
\hline Media & 8,78 & 3,13 & Media & 11,70 & 3,57 \\
\hline GR3:P.A. & $\mathbf{L}$ & $\mathbf{A}$ & GR3:P.A. & $\mathbf{L}$ & $\mathbf{A}$ \\
\hline $\mathrm{N}$ & 10 & 11 & $\mathrm{~N}$ & - & - \\
\hline Rango & $4-33$ & $2-15$ & Rango & & \\
\hline Media & 12,89 & 6,95 & Media & & \\
\hline Desviación & 8,89 & 4,63 & Desviación & & \\
\hline GR6:DEB & $\mathbf{L}$ & $\mathbf{A}$ & GR6:DEB & $\mathbf{L}$ & $\mathbf{A}$ \\
\hline $\mathrm{N}$ & 98 & 176 & $\mathrm{~N}$ & - & - \\
\hline Rango & $2,4-10$ & $0,4-5$ & Rango & & \\
\hline Media & 6,08 & 2,15 & Media & & \\
\hline Desviación & 1,72 & 1,09 & Desviación & & \\
\hline
\end{tabular}

Cuadro C.11: datos métricos de los talones de cuarcita, por grupos tecnológicos. N: número de elementos. L: longitud, A: anchura, G: grosor. 


\section{IV.6.1.5.- ACCIDENTES}

En el tipo de accidente que afecta a la cuarcita (cuadro C.12) predomina ampliamente el pseudoburil de Siret que está en un 70\% de las piezas afectadas por algún tipo de accidente. A continuación están los reflejados (20\%) y, con una presencia menor, los sobrepasados, los accidentes provocados por la existencia de planos internos que dificultan la talla, el doble bulbo y por último las lengüetas.

\begin{tabular}{|l|cccccc|r|}
\hline & DB & LG & PB & RF & SP & PN & TOTAL \\
\hline GR.1 & 7 & & 188 & 54 & 11 & 9 & 269 \\
GR.2 & 1 & & 3 & 5 & 6 & 3 & 18 \\
GR.3 & & & 2 & 3 & 1 & 1 & 7 \\
GR.6 & 2 & 1 & 79 & 13 & 2 & & 97 \\
\hline TOTAL & 10 & 1 & 272 & 75 & 20 & 13 & 391 \\
$\%$ & 2,56 & 0,26 & 69,57 & 19,18 & 5,12 & 3,32 & 100,00 \\
\hline
\end{tabular}

Cuadro C.12: accidentes de talla según los distintos grupos tecnológicos. DB: doble bulbo, LG: fragmento en lengüeta, PB: pseudoburil de Siret, RF: reflejado, SP: sobrepasado, PN: plano natural.

En la representación de los distintos accidentes dependiendo de los tipos de soportes (gráfico C.3) se puede observar cómo el pseudoburil predomina totalmente en los grupos de las lascas y los debris. En cambio, este accidente no es principal en las hojas-hojitas y los productos de acondicionamiento, siendo en estos grupos los reflejados y los sobrepasados los más abundantes.

La preeminencia del pseudoburil de Siret en la cuarcita está ocasionada muy probablemente por los gestos ejecutados en el modo de talla requerido por este tipo de materia. Las características físicas de la cuarcita difieren en cierto grado de las del sílex y, a la hora de su talla intencional, necesita de una habilidad concreta adaptada a estas condiciones. Parece que es necesario, en particular, una mayor fuerza en la percusión, al menos eso es lo indican las huellas del impacto que quedan en las lascas y núcleos (puntos de impacto visibles, talones grandes, bulbos pronunciados,...). El pseudoburil parece ser una consecuencia de este fuerte impacto y, su frecuencia, sería un índice del hecho de que la talla de este tipo de materia necesita de estos gestos enérgicos. 


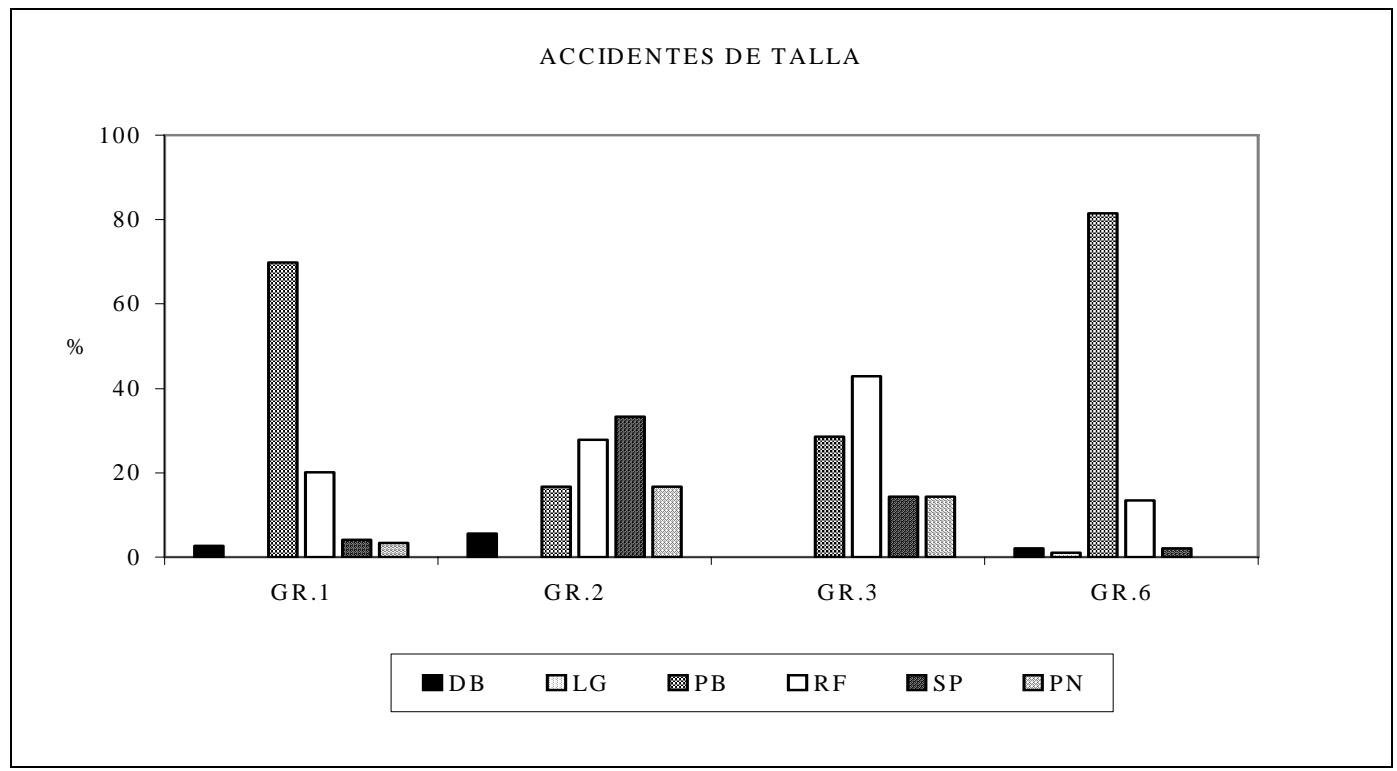

Gráfico C.3: accidentes de talla por grupos tecnológicos. DB: dobre bulbo, LG: fragmento en lengüeta, PB: pseudoburil de Siret, RF: reflejado, SP: sobrepasado, PN: plano natural

\section{IV.6.1.6.- TIPOS DE TALÓN}

Como en el resto de las materias, son las piezas sin talón las predominantes en el conjunto lítico (cuadro C.13), seguidas por los talones lisos (25\%), los rotos (9\%), los corticales (7\%), puntiformes (6\%), facetados (4\%), diedros (4\%) y suprimidos (1\%).

\begin{tabular}{|l|cccccccc|r|}
\hline & $\mathrm{C}$ & $\mathrm{D}$ & $\mathrm{F}$ & $\mathrm{L}$ & $\mathrm{O}$ & $\mathrm{P}$ & $\mathrm{R}$ & $\mathrm{S}$ & TOTAL \\
\hline GR.1 & 122 & 62 & 71 & 346 & 464 & 46 & 99 & 12 & 1222 \\
GR.2 & 7 & 5 & 6 & 42 & 95 & 10 & 10 & 2 & 177 \\
GR.3 & 3 & 1 & 2 & 6 & 18 & 2 & & & 32 \\
GR.6 & 19 & 9 & 10 & 134 & 356 & 59 & 79 & & 666 \\
\hline TOTAL & 151 & 77 & 89 & 528 & 933 & 117 & 188 & 14 & 2097 \\
$\%$ & 7,20 & 3,67 & 4,24 & 25,18 & 44,49 & 5,58 & 8,97 & 0,67 & 100,00 \\
\hline
\end{tabular}

Cuadro C.13: tipos de talón por grupos tecnológicos. C: cortical, D: diedro, F: facetado, L: liso, O: sin talón, P: puntiforme, R: roto, S: suprimido.

En la representación de los tipos de talón respecto a los distintos tipos de soportes (gráfico C.4) la pauta seguida por la cuarcita es similar al resto de las materias primas, con un predominio general de los talones lisos, pero en este caso hay un mayor número de este tipo talón, que constituyen una cuarta parte del conjunto, mientras el resto de los tipos de talones tienen una presencia más dispar. Los corticales en este caso 
son más abundantes en el grupo de las lascas y los productos de acondicionamiento, además es la cuarcita donde hay mayor proporción de talones corticales.

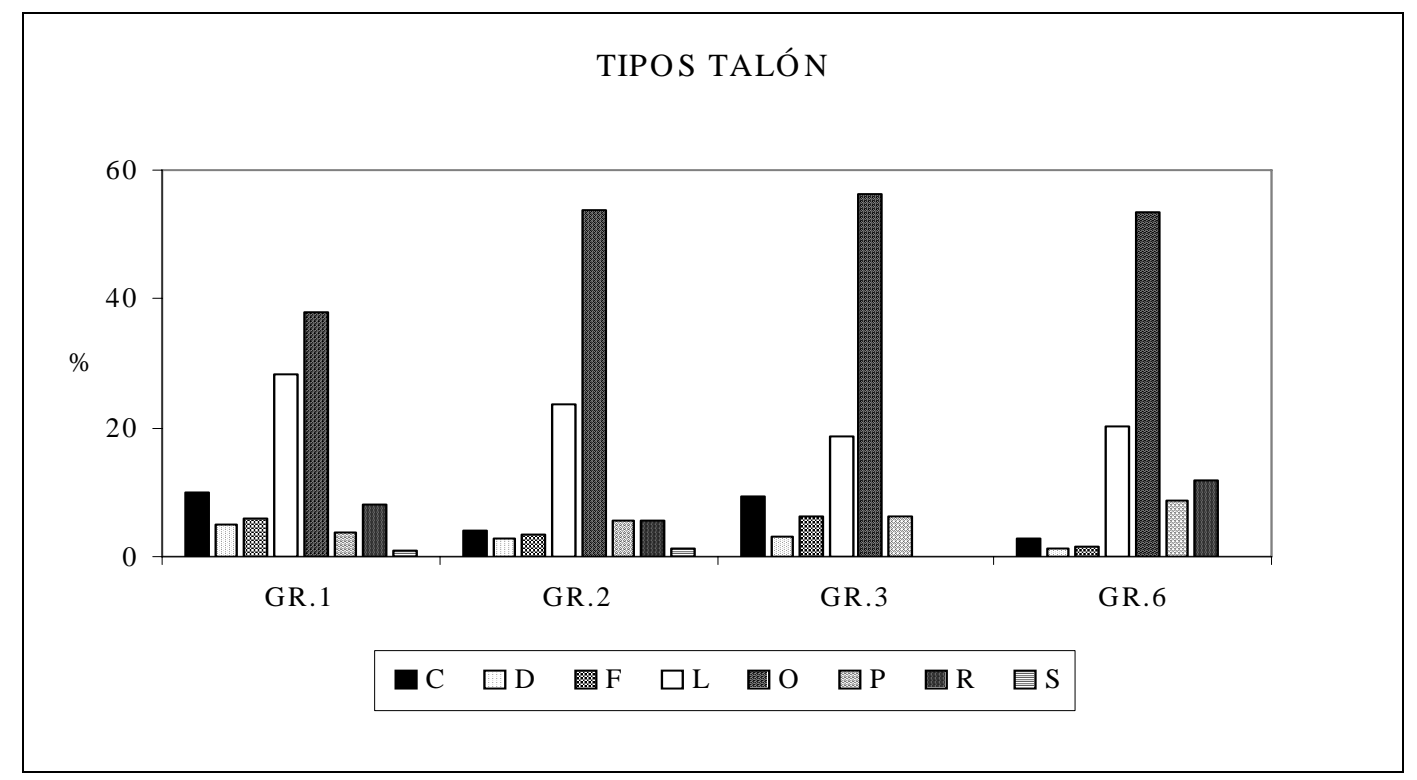

Gráfico C.4: tipos de talón por grupos tecnológicos. C: cortical, D: diedro, F: facetado, L: liso, O: sin talón, P: puntiforme, R: roto, S: suprimido.

\section{IV.6.1.7.- PREPARACIÓN DEL PUNTO DE IMPACTO}

La cuarcita tiene un índice de preparación inferior a las materias silíceas anteriores, tan solo una cuarta parte de las piezas tienen huellas de preparación en torno al talón (cuadro C.14), mientras que para las anteriores hay, al menos, un tercio preparadas. No obstante, siguiendo la misma pauta que en las materias anteriores, son las hojas-hojitas las más preparadas (más del 40\%), así como los productos de acondicionamiento, es decir, serían las piezas procedentes de la fase de producción.

\begin{tabular}{|c|c|cc|cc|}
\hline \multirow{2}{*}{ TOTAL } & \multicolumn{2}{|c|}{ PIEZAS CON TALÓN } & \multicolumn{2}{c|}{ PIEZAS PREPARADAS } \\
\cline { 3 - 6 } & & $\mathrm{N}$ & $\%$ & $\mathrm{~N}$ & $\%$ \\
\hline GR-1 & 1222 & 755 & 61,8 & 212 & 28,1 \\
GR-2 & 177 & 83 & 46,9 & 36 & 43,4 \\
GR-3 & 32 & 17 & 53,1 & 6 & 35,3 \\
GR-6 & 666 & 308 & 46,2 & 42 & 13,6 \\
\hline & 2097 & 1163 & 55,5 & 296 & 25,5 \\
\hline
\end{tabular}

Cuadro C.14: piezas con talón y preparación relativa dentro de los distintos grupos tecnológicos 
En el tipo de preparación (cuadro C.15) predomina netamente el retoque (65\%), seguido por el esquirlado (28\%) y, con menor representación, el facetado (5\%) y la abrasión (2\%). Esta última apenas si está presente. Respecto al tipo de talones, son los facetados y los puntiformes los que más se han preparado (cuadro C.16). En todos ellos el retoque es el tipo de preparación más abundante, excepto en los puntiformes y los rotos, que es el esquirlado el más frecuente (cuadro C.17).

\begin{tabular}{|l|cccc|cc|}
\hline & \multirow{2}{*}{ GR-1 } & \multirow{2}{*}{ GR-2 } & \multirow{2}{*}{ GR-3 } & \multirow{2}{*}{ GR-6 } & \multicolumn{2}{|c|}{ TOTAL } \\
\cline { 5 - 7 } & & & & $\mathrm{N}$ & $\%$ \\
\hline Facetado & 9 & 4 & & 1 & 14 & 4,7 \\
Abrasión & 2 & & & 4 & 6 & 2,0 \\
Esquirlado & 55 & 13 & & 14 & 82 & 27,7 \\
Retoque & 146 & 19 & 6 & 23 & 194 & 65,5 \\
\hline & 212 & 36 & 6 & 42 & 296 & 100 \\
\hline
\end{tabular}

Cuadro C.15: tipos de preparación según los distintos grupos tecnológicos.

\begin{tabular}{|l|ccccccc|}
\hline & $\mathrm{C}$ & $\mathrm{D}$ & $\mathrm{F}$ & $\mathrm{L}$ & $\mathrm{P}$ & $\mathrm{R}$ & $\mathrm{S}$ \\
\hline PIEZAS CON TALÓN & 151 & 77 & 89 & 528 & 117 & 188 & 14 \\
\hline PIEZAS PREPARADAS & 34 & 22 & 38 & 141 & 42 & 17 & 2 \\
$\%$ & 22,5 & 28,6 & 42,7 & 26,7 & 35,9 & 9,04 & 14,3 \\
\hline
\end{tabular}

Cuadro C.16: porcentaje de preparación en los distintos tipos de talón disponibles. C: cortical, D: diedro, F: facetado, L: liso, O: sin talón, P: puntiforme, R: roto, S: suprimido.

\begin{tabular}{|l|ccccccc|}
\hline & $\mathrm{C}$ & $\mathrm{D}$ & $\mathrm{F}$ & $\mathrm{L}$ & $\mathrm{P}$ & $\mathrm{R}$ & $\mathrm{S}$ \\
\hline Facetado & & 2 & 9 & 2 & & 1 & \\
Abrasión & & 1 & & 4 & 1 & & \\
Esquirlado & 12 & 7 & 2 & 29 & 23 & 9 & \\
Retoque & 22 & 12 & 27 & 106 & 18 & 7 & 2 \\
\hline TOTAL & 34 & 22 & 38 & 141 & 42 & 17 & 2 \\
$\%$ & 11,5 & 7,4 & 12,8 & 47,6 & 14,2 & 5,7 & 0,7 \\
\hline
\end{tabular}

Cuadro C.17: tipos de preparación sobre los distintos tipos de talón. C: cortical, D: diedro, F: facetado, L: liso, O: sin talón, P: puntiforme, R: roto, S: suprimido. 


\begin{tabular}{|l|cccccccc|r|}
\hline GR-1 & C & D & F & L & P & R & S & O & N \\
\hline Facetado & & 1 & 6 & 2 & & & & & 9 \\
Abrasión & & & & 2 & & & & & 2 \\
Esquirlado & 9 & 6 & 1 & 25 & 7 & 6 & & 1 & 55 \\
Retoque & 19 & 12 & 21 & $\mathbf{7 7}$ & 10 & 5 & 2 & & 146 \\
\hline & 28 & 19 & 28 & 106 & 17 & 11 & 2 & 1 & $\mathbf{2 1 2}$ \\
\hline
\end{tabular}

\begin{tabular}{|l|rccccccc|r|}
\hline GR-2 & C & D & F & L & P & R & S & O & $\mathrm{N}$ \\
\hline Facetado & & 1 & 3 & & & & & & 4 \\
Abrasión & & & & & & & & & 0 \\
Esquirlado & & 1 & 3 & 2 & 4 & 3 & & & 13 \\
Retoque & & & 1 & $\mathbf{1 5}$ & 1 & 1 & & 1 & 19 \\
\hline & & 2 & 7 & 17 & 5 & 4 & & 1 & $\mathbf{3 6}$ \\
\hline
\end{tabular}

\begin{tabular}{|l|rlllllll|r|}
\hline GR-3 & C & D & F & L & P & R & S & O & N \\
\hline Facetado & & & & & & & & & \\
Abrasión & & & & & & & & & \\
Esquirlado & & & & & & & & & \\
Retoque & 1 & & $\mathbf{2}$ & $\mathbf{2}$ & 1 & & & & 6 \\
\hline & 1 & & 2 & 2 & 1 & & & & 6 \\
\hline
\end{tabular}

\begin{tabular}{|l|cccccccc|r|}
\hline GR-6 & C & D & F & L & P & R & S & O & N \\
\hline Facetado & & & & & & 1 & & & 1 \\
Abrasión & & 1 & & 2 & 1 & & & & 4 \\
Esquirlado & & & & 2 & $\mathbf{1 2}$ & & & & 14 \\
Retoque & 2 & & 3 & $\mathbf{1 2}$ & 5 & 1 & & & 23 \\
\hline & 2 & 1 & 3 & 16 & 18 & 2 & & & 42 \\
\hline
\end{tabular}

Cuadro C.18: tipos de talón con los distintos tipos de preparación y separado por grupos tecnológicos. C: cortical, D: diedro, F: facetado, L: liso, O: sin talón, P: puntiforme, R: roto, S: suprimido.

\section{IV.6.1.8.- ÁNGULO DE PERCUSIÓN}

El ángulo de talla de la cuarcita es cerrado lo más frecuentemente, en el ángulo formado entre el talón y la cara superior (ángulo 2) el más abundante es de $60-70^{\circ}$, seguido por $70-80^{\circ}$, quedando el ángulo más abierto, en torno a los $90^{\circ}$ en tercer lugar (cuadro C.19). Esta pauta general se cumple en los distintos grupos tecnológicos, aunque quizás habría que matizar que en las hojas-hojitas el ángulo más abundante no es de $60-70^{\circ}$ sino de $70-80^{\circ}$, invirtiéndose así los dos ángulos predominantes a favor del que tiende a ser más abierto. 


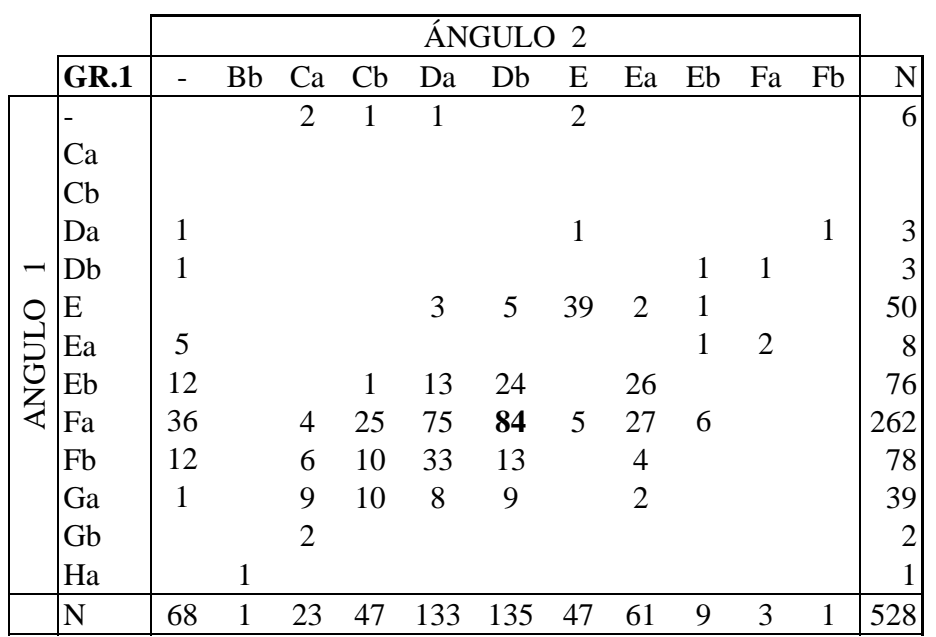
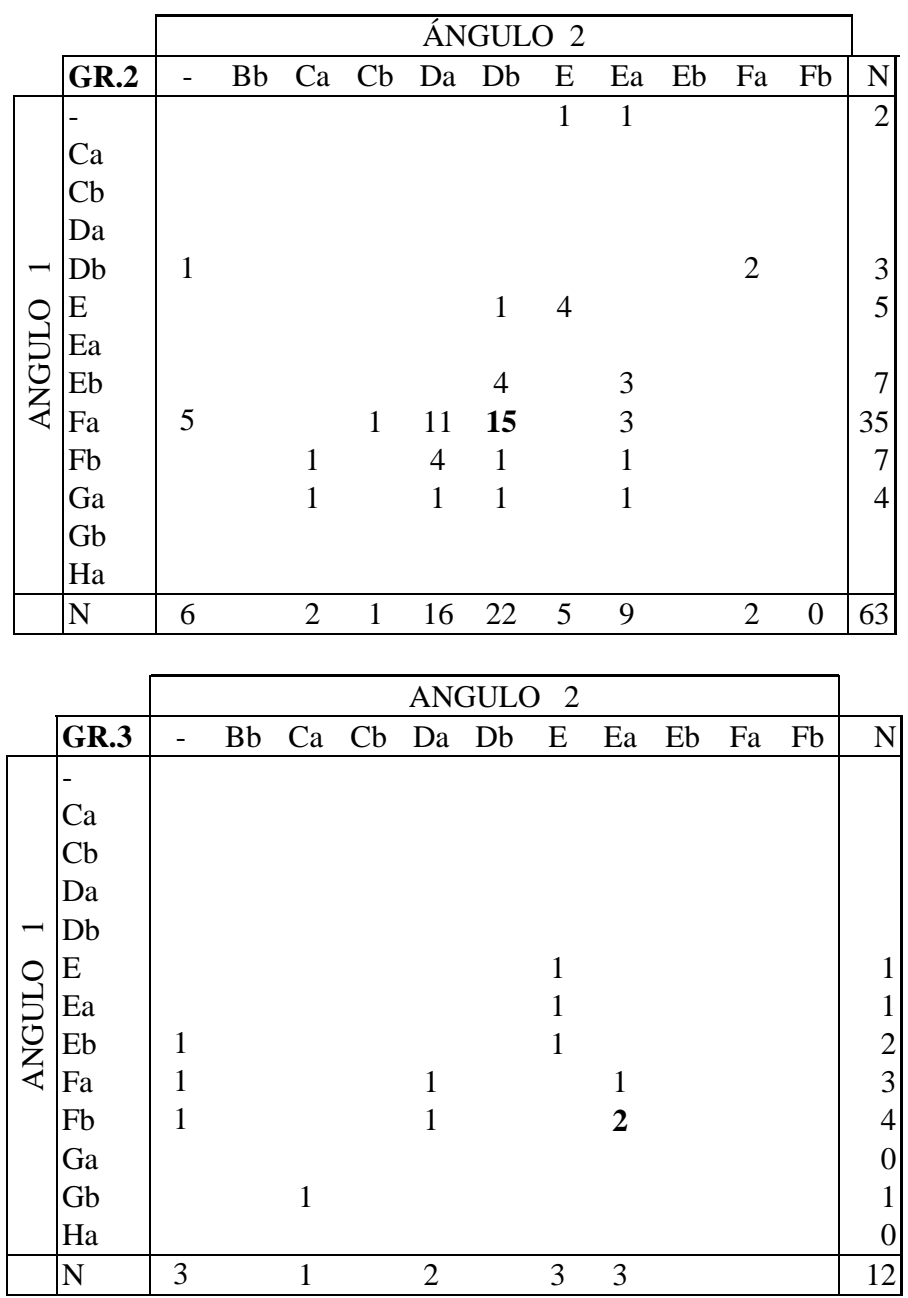

Cuadro C.19: ángulos de percusión según los grupos tecnológicos. Angulo 1: ángulo interno (entre talón y el bulbo). Angulo 2: ángulo externo o cornisa (entre talón y la cara superior). $\mathrm{Bb}=30-40^{\circ}, \mathrm{Ca}=40-50^{\circ}, \mathrm{Cb}=50-60^{\circ}, \mathrm{Da}=60-70^{\circ}, \mathrm{Db}=70-80^{\circ}, \mathrm{Ea}=80-90^{\circ}, \mathrm{Eb}=90-100^{\circ}, \mathrm{Fa}=100-$ $110^{\circ}, \mathrm{Fb}=110-120^{\circ}, \mathrm{Ga}=120-130^{\circ}, \mathrm{Gb}=130-140^{\circ}, \mathrm{Ha}=140-150^{\circ}$. 


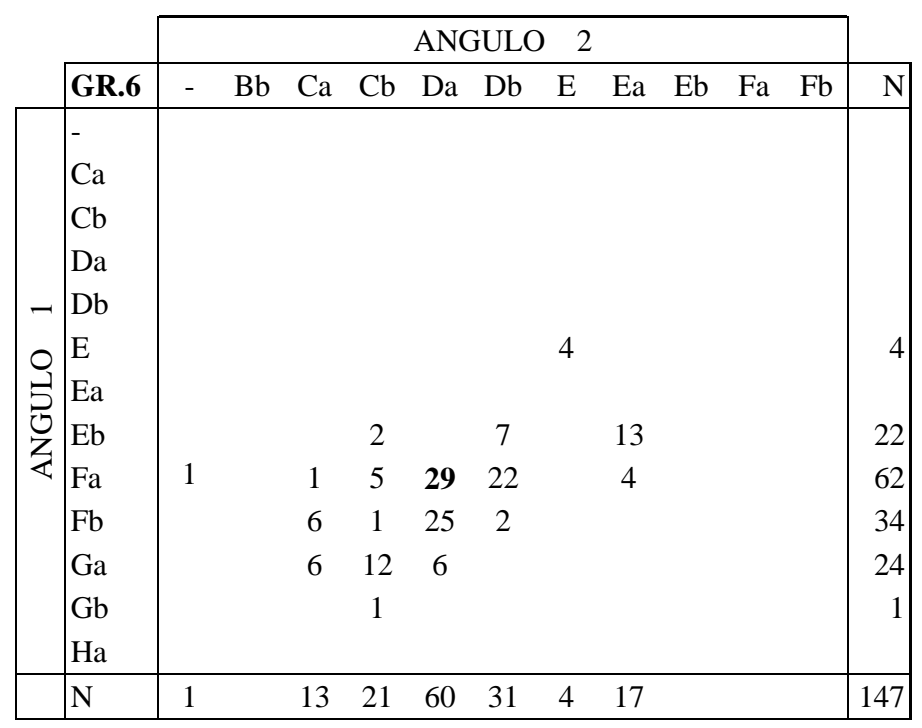

\begin{tabular}{|c|c|c|c|c|c|c|c|c|c|c|c|c|c|}
\hline & \multicolumn{11}{|c|}{ ANGULO 2} & \multirow[b]{2}{*}{$\mathrm{N}$} & \multirow[b]{2}{*}{$\%$} \\
\hline & - & $\mathrm{Bb}$ & $\mathrm{Ca}$ & $\mathrm{Cb}$ & $\mathrm{Da}$ & $\mathrm{Db}$ & $\mathrm{E}$ & Ea & Eb & $\mathrm{Fa}$ & $\mathrm{Fb}$ & & \\
\hline - & & & 2 & 1 & 1 & & 3 & 1 & & & & 8 & 1,1 \\
\hline $\begin{array}{l}\mathrm{Ca} \\
\mathrm{Cb}\end{array}$ & & & & & & & & & & & & & \\
\hline $\begin{array}{l}\mathrm{Cb} \\
\mathrm{Da}\end{array}$ & & & & & & & & & & & & & \\
\hline Da & 1 & & & & & & 1 & & & & 1 & 3 & 0,4 \\
\hline$\dashv \mathrm{Db}$ & 2 & & & & & & & & 1 & 3 & & 6 & 0,8 \\
\hline o $\mathrm{E}$ & & & & & 3 & 6 & 48 & 2 & 1 & & & 60 & 8,0 \\
\hline $\mathrm{Ea}$ & 5 & & & & & & 1 & 0 & 1 & 2 & & 9 & 1,2 \\
\hline 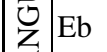 & 13 & & & 3 & 13 & 35 & 1 & 42 & & & & 107 & 14,3 \\
\hline $4 \mathrm{Fa}$ & 43 & & 5 & 31 & 116 & 121 & 5 & 35 & 6 & & & 362 & 48,3 \\
\hline $\mathrm{Fb}$ & 13 & & 13 & 11 & 63 & 16 & & 7 & & & & 123 & 16,4 \\
\hline Ga & 1 & & 16 & 22 & 15 & 10 & & 3 & & & & 67 & 8,9 \\
\hline $\mathrm{Gb}$ & & & 3 & 1 & & & & & & & & 4 & 0,5 \\
\hline На & & 1 & & & & & & & & & & 1 & 0,1 \\
\hline $\mathrm{N}$ & 78 & 1 & 39 & 69 & 211 & 188 & 59 & 90 & 9 & 5 & 1 & 750 & 100 \\
\hline$\%$ & 10,4 & 0,1 & 5,2 & 9,2 & 28,1 & 25,1 & 7,9 & 12,0 & 1,2 & 0,7 & 0,1 & 100 & \\
\hline
\end{tabular}

Cuadro C.19 (continuación): ángulos de percusión en grupo tecnológico 6 y en el total de la cuarcita. Angulo 1: ángulo interno (entre talón y el bulbo). Angulo 2: ángulo externo o cornisa (entre talón y la cara superior). $\mathrm{Bb}=30-40^{\circ}, \mathrm{Ca}=40-50^{\circ}, \mathrm{Cb}=50-60^{\circ}, \mathrm{Da}=60-70^{\circ}, \mathrm{Db}=70-80^{\circ}$, $\mathrm{Ea}=80-90^{\circ}, \mathrm{Eb}=90-100^{\circ}, \mathrm{Fa}=100-110^{\circ}, \mathrm{Fb}=110-120^{\circ}, \mathrm{Ga}=120-130^{\circ}, \mathrm{Gb}=130-140^{\circ}, \mathrm{Ha}=140-$ $150^{\circ}$. 


\section{IV.6.1.9.- AlTERACIONES}

No se ha constatado ninguna alteración que afecte a la cuarcita.

\section{IV.6.1.10.- MODO DE TALLA}

En el modo de talla se ha observado una abundancia de percusión directa con percutor duro, cosa bastante lógica teniendo en cuenta las características de la propia materia. En los accidentes de talla se había observado también que el predominio del pseudoburil de Siret podría estar relacionado con este tipo de percusión. No obstante hay que hacer notar que en algunas piezas se ha anotado la presencia de los estigmas característicos de una percusión más blanda.

\begin{tabular}{|l|ccc|}
\hline & PDD & PDDB & PDB \\
\hline GR.1 & 64 & & 8 \\
GR.2 & 3 & & 3 \\
GR.3 & 2 & & \\
GR.6 & & & \\
\hline
\end{tabular}

Cuadro C.20: modo de talla por grupos tecnológicos. PDD: percusión directa con percutor duro; PDDB: percusión directa con percutor de piedra blando; PDB: percusión directa con percutor blando.

Respecto al cambio de los gestos en los modos de talla a lo largo del proceso operativo, no se ve tan claramente como en los sílex; al menos el tipo de percusión en las hojas-hojitas no es tan tangencial, ya que el tamaño del talón no disminuye en la misma proporción que se había constatado en el anterior grupo de materias. Lo que sí se constata, de la misma manera que en los sílex, es un mayor cuidado en la preparación del punto de impacto en las piezas del grupo 2. 


\section{IV.6.2.- NÚCLEOS}

Hay 16 núcleos de cuarcita, la segunda materia con más núcleos después del chert negro. Su clasificación es más compleja que para las materias silíceas que se han analizado previamente, el esquema técnico de éstos no se lee de forma tan fácil como para los sílex y, de hecho, resulta complicado el análisis de dichos núcleos a partir de la plantilla con la que se han recogido los atributos de los ejemplos de las materias anteriores, incluso hay muchos de estos atributos que no han podido ser anotados. La causa de esta dificultad radica en las propias características de la cuarcita, en la medida que se trata de un tipo de roca con unas condiciones para la talla que difieren en cierto grado de las rocas “tipo-sílex”, en especial por su dureza y el tamaño del grano, lo cual le otorgan a la cuarcita una textura y unas condiciones para la talla intencional un poco diferentes respecto al sílex. Estas peculiaridades de la materia no suponen en ningún caso una limitación para su talla, tan solo habría que tener en cuenta que los esquemas aplicados a esta materia requieren quizás de unas adaptaciones particulares para que se puedan ejecutar con éxito. Surge, de todas formas, el problema de si los esquemas aplicados a la cuarcita se pueden encuadrar en las mismas cadenas operativas aplicadas en los sílex, o si, por el contrario, el cambio en las características genéricas de la materia impone un cambio también en los esquemas conceptuales. Parece que la respuesta a esta duda se decanta por la primera opción, es decir la cuarcita se talla a partir de los mismos esquemas que el sílex, al menos se pueden encontrar varios esquemas operativos que han sido definidos ya para el chert negro; no obstante, sí hay peculiaridades en la manera como se adaptan tales esquemas a la cuarcita.

\section{IV.6.2.1.- ATRIBUTOS BÁSICOS}

En el cuadro C.21 se presentan las características generales de los núcleos de cuarcita, hay once que se han podio encuadrar en seis esquemas operativos, mientras que los cinco restantes se han clasificado como restos de núcleo, si bien tienen aveces esquemas técnicos que quizás remitan a alguno de los esquemas operativos determinados. 


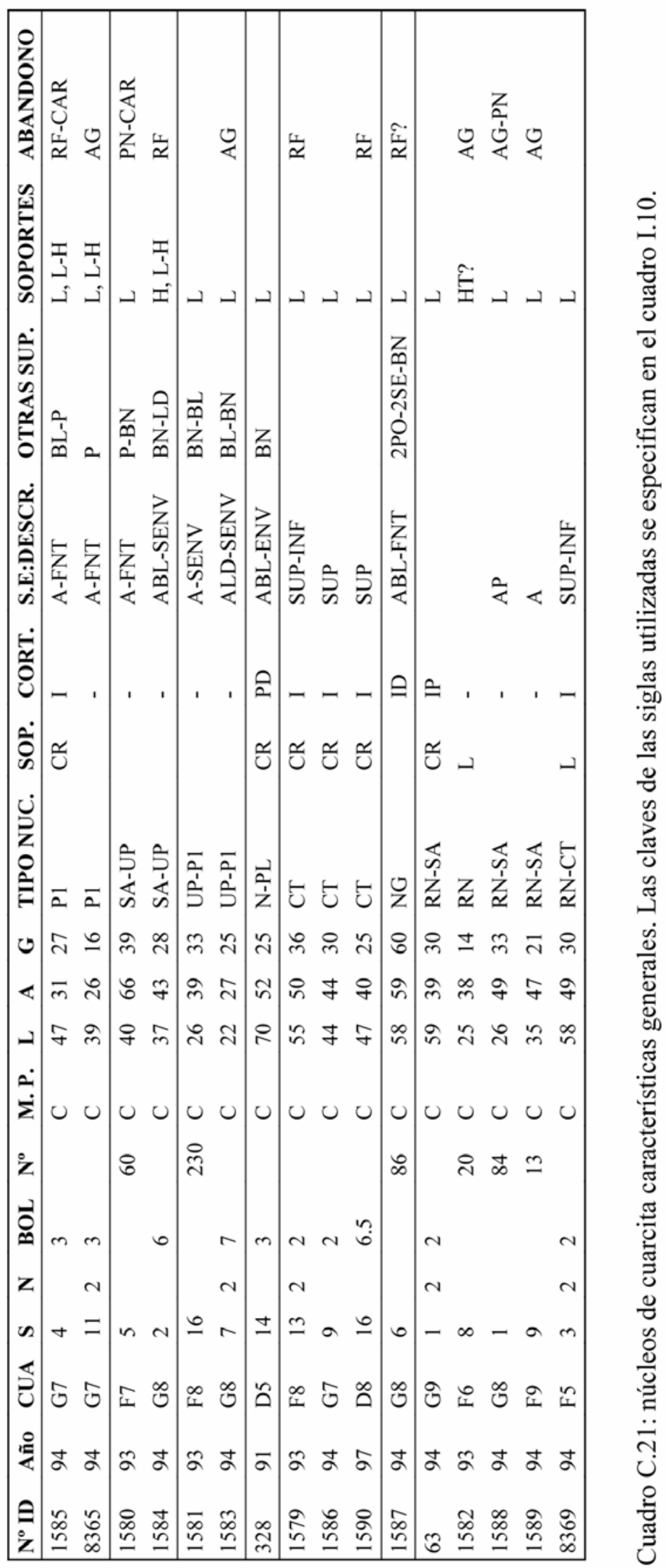




\section{Tipo de núcleo}

Se podrían hacer dos grandes grupos en los esquemas técnicos esbozados por los núcleos de cuarcita: por un lado los que pertenecen a cadenas operativas de lascas y por otro los que tienen unos esquemas que pueden haber originado extracciones laminares, aunque en la mayoría de los casos las últimas extracciones son de lascas. Estos últimos pertenecerían a una cadena operativa de tipo prismático y unipolar genérico. El término unipolar lo utilizamos en este caso para matizar el tipo de esquema aplicado, el cual podría encuadrarse dentro de los prismáticos pero con una mayor flexibilidad que estos últimos. De este grupo de los prismáticos-unipolares se han diferenciado tres esquemas operativos:

Núcleos Prismáticos (P1): hay dos núcleos (1585, 8365) con una conformación prismática más o menos “clásica”, sus características son las siguientes:

- La fase de preparación de dicho volumen ha incidido sobre las superficies laterales y la superficie posterior además del plano de percusión y la superficie de extracciones.

- Superficie de extracciones rectangular, estrecha, alargada (5 cm de longitud por 3 de anchura en el primer núcleo, 4 cm por 2 en el segundo)

- Débitage unipolar frontal, con la carena y la cintra bastante rectos

- Extracciones de lascas predominantes aunque se pueden obtener también lascas-laminares o "piezas con flanco” como en el caso del núcleo nº 8365, en el cual remonta una de estas piezas.

- En el mantenimiento del débitage estos dos núcleos adoptan dos métodos distintos; en el primero se recurre a extracciones longitudinales desde la superficie cortical inferior en dirección opuesta al débitage principal, se producen extracciones grandes y contundentes. En el segundo se recurre a una cresta sobre el lateral izquierdo con la que se corrige la cintra; dicha cresta sigue hacia la base del núcleo, rectificando así la carena en la zona inferior del núcleo. En este segundo núcleo se producen por tanto extracciones más pequeñas y cuidadosas. Estos dos métodos en el tratamiento de los volúmenes responden a las características de la cuarcita, 
ya que en el primer núcleo el tamaño del grano de la materia es mayor que en el segundo. Como consecuencia de ello en este último núcleo es posible realizar un débitage más cuidadoso y más “laminar”.

- El plano de percusión también se arregla por métodos distintos, de forma paralela al arreglo de la superficie de extracciones, en el primer núcleo a partir de semitabletas desde la superficie posterior y lateral; en el segundo a partir de lascas de reavivado desde la superficie de extracciones, de forma más cuidada.

- Como la superficie de extracciones está enmarcada por los flancos laterales, sin que exista una transición de tipo "semi-envolvente”, cuando el débitage se produce sobre los laterales del núcleo, se realizan extracciones del tipo “piezas con flanco” o bien flancos de núcleo.

Estos dos núcleos se podrían clasificar dentro de los esquemas operativos prismáticos que se han visto en los sílex. La diferencia en el tratamiento de ambos radica fundamentalmente en que la calidad de la cuarcita permite en el segundo núcleo un tratamiento más cuidadoso (recuerda incluso los núcleos de sílex gris) que en el primero, cuya gestión es más contundente.

Núcleos de superficie ancha-unipolar (SA-UP), hay dos ejemplos $(1580,1584)$ y sus características son las siguientes:

- En la fase de preparación las superficies posterior e inferior juegan un papel importante en la conformación del bloque, sobre ellos se producirán extracciones amplias en dirección a la superficie de extracciones.

- La superficie posterior y uno de las laterales forman un ángulo diedro abierto opuesto a la superficie de extracciones, por tanto la sección transversal del núcleo es triangular.

- El plano de percusión es liso y bastante grande.

- La dirección del débitage es unipolar semi-envolvente, avanzando hacia uno de los laterales del núcleo.

- Sobre el otro lateral hay una cresta sobre la que se producen extracciones transversales que rectifican la cintra. 
- La carena se corrige a partir de extracciones que parten de la superficie posterior, rectificando la base del núcleo.

- Las extracciones son lascas en el primer núcleo (se ha encontrado una de ellas que remonta, de $34 \mathrm{~mm}$ de longitud y 34 de anchura), en el otro núcleo hay extracciones más laminares, aunque las últimas son lascas.

Núcleos unipolares-prismáticos (UP-P1), hay otros dos núcleos en este esquema (1583, 1581), el cual recuerda al que se analizó en el chert negro, pero en el caso de la cuarcita el tamaño de los núcleos es inferior. Las características de este esquema son las siguientes:

- Conformación general del núcleo de tipo prismática, su principal rasgo es su base, paralela al plano de percusión.

- La superficie de extracciones es corta (no llega a los $3 \mathrm{~cm}$ ), delimitada por la base del núcleo, que al mismo tiempo controla la carena.

- El débitage es unipolar convergente y semi-envolvente, expandiéndose hacia ambos laterales.

- Dicho débitage contribuye al mantenimiento de la carena, aunque existe también el recurso a una cresta lateral en uno de los ejemplos.

- Plano de percusión liso y bastante grande, con eventuales arreglos puntuales por lasquitas de reavivado.

- Las extracciones son lascas cortas (unos $2 \mathrm{~cm}$ de longitud) y puede que eventualmente se haya obtenido alguna hojita, sobre todo en el núcleo $\mathrm{n}^{\circ}$ 1583.

- En este núcleo se produce un último aprovechamiento del volumen, abriendo una superficie de extracciones sobre la cara posterior, utilizando una de las aristas, pero dicho intento no consigue extracciones exitosas, de hecho el núcleo estaba ya bastante agotado.

En las cadenas operativas más puramente de lascas hay otros tres esquemas: núcleo-placa, centrípeto y uno de tipo globuloso.

Dentro del esquema que se definió para el chert negro como "núcleo-placa” (UP-PL) encontramos en cuarcita otro ejemplo (328), la síntesis de dicho esquema sería la siguiente: 
- Selección de un soporte tipo-placa, en este caso se trata de un canto rodado de cuarcita afectado por sendas superficies de diaclasado interno.

- Dicha placa, es decir un volumen paralelepípedo muy alargado, se orienta de forma que la superficie delimitada por los planos naturales va a ser la superficie de extracciones, tomando como orientación su eje menor.

- Las superficies naturales serán el plano de percusión y la base del núcleo.

- El débitage se produce de forma envolvente, desarrollándose por el contorno de la placa-soporte.

- La dirección de las extracciones es alternante; si bien en este caso hay una dirección unipolar predominante, ésta se desarrolla en la medida que las características del núcleo permitan progresar el débitage; cuando esta condición no se cumple, hay un giro del núcleo, utilizando la base del núcleo como plano de percusión, produciendo así extracciones alternas a lo largo del contorno del núcleo.

- Las condiciones técnicas del débitage se auto-mantienen fácilmente en este tipo de esquema ya que, por un lado, la carena está totalmente controlada por la escasa longitud de la superficie de extracciones (poco más de $2 \mathrm{~cm}$ ), por otro lado la cintra se va rectificando al avanzar de esta forma envolvente. Tan solo sería necesario un ángulo de talla y un gesto adecuado a la hora de producir la extracción.

Núcleos centrípetos (CT), con tres ejemplos (1579, 1586, 1590):

- En todos los casos se trata de cantos rodados que se han tallado a partir de una arista periférica en el contorno del nódulo, hacia las dos superficies secantes, de forma centrípeta y alterna.

- En dos de los núcleos se ha privilegiado una de estas superficies como superficie de extracciones preferente, quedando en la opuesta, que ha servido como plano de percusión, restos abundantes de córtex. En el otro (nº 1579) las dos superficies se han utilizado de forma alterna.

- Los soportes extraídos son lascas de unos $3 \mathrm{~cm}$ de longitud.

- El ángulo de percusión es bastante cerrado $\left(60-70^{\circ}\right)$ y la arista en general bastante sinuosa, señalando tanto el empleo de un percutor duro, como la 
rapidez en la gestión de estos núcleos, sin que exista un acondicionamiento de dicha arista en el proceso de talla.

- No se produce una fase de preparación elaborada en el débitage de estos núcleos, tan solo cabría considerar una cierta preparación en los núcleos con superficie de extracciones predominante, pero ni siquiera en ellos se constata la existencia de gestos de organización cuidadosos

El esquema operativo aquí esbozado estaría en la tradición de los esquemas conceptuales de débitage de lascas centrípetos, en este caso se desarrolla de una forma que se podría tildar de rápida y sencilla (no hay una preparación desarrollada, sino que la extracción de los soportes se produce prácticamente desde el principio) con el objetivo de obtener una serie de lascas fácilmente.

El último esquema técnico identificado y que podríamos otorgarle cierta entidad, es el del núcleo globuloso (NG). Los núcleos globulosos, tal y como se han definido de forma tradicional, suelen ser el resto de un esquema conceptual poco elaborado, basado en la obtención de lascas a largo de un bloque que no tiene mayor organización que la búsqueda de las condiciones de talla mínimas (es decir, un ángulo propicio, inferior a $90^{\circ}$, entre dos superficies y unas curvaturas adecuadas en la superficie sobre la que se va a producir la extracción). Estas extracciones se prolongan a largo del volumen, intercambiando las funciones de plano de percusión y superficie de extracciones por las distintas superficies del núcleo, así se va conformando una estructura más o menos anárquica.

El núcleo de cuarcita calificado como globuloso (1587) tiene una forma cúbica (de casi $6 \mathrm{~cm}$ de lado) en la que hay extracciones por todas sus caras. En principio parece que podría verse un esquema prismático, con un plano de percusión principal en la parte superior y una superficie de extracciones unipolar en la anterior, la base es una superficie paralela al plano de percusión y las superficies laterales y posterior han recibido un tratamiento bastante intenso, hasta el punto que se ha eliminado todo el córtex prácticamente. Puede que haya sido éste el esquema inicial en el tratamiento de este núcleo, con la extracción de grandes lascas, pero la cornisa superior de dicho núcleo ha sufrido una serie de gestos cuyos restos son un esquirlado sumamente intenso a lo largo de la arista superior, extendiéndose hacia ambos laterales, sobre todo en la 
parte derecha. A partir de dicha arista, que comienza en la parte anterior del núcleo y avanza hacia la posterior, se producen varias extracciones, en la medida que es posible aprovechar unas condiciones favorables del volumen para obtener lascas.

Este núcleo, por tanto, parece que tendría una posible conformación inicial de tipo prismático, pero es posible que la gestión de dicho esquema sea más compleja en la cuarcita que en el sílex, sobre todo por las características de la propia materia. Además es un volumen bastante grande y grueso, las extracciones se han realizado a partir de golpes intensos a juzgar por los contrabulbos y las estrías marcadas de los negativos. Quizás por estas dificultades de la materia se ha optado por seguir una de las aristas del núcleo a partir de la cual obtener una serie de lascas a lo largo del núcleo. Lo que no se explica demasiado bien es el motivo por el que la arista de la cornisa se sometió a un esquirlado tan intenso, visible sobre la superficie anterior y lateral izquierdo.

Por último hay cinco piezas clasificadas como restos de núcleo (RN) debido a que es difícil encuadrar sus esquemas técnicos en esquemas operativos más amplios.

Uno de ellos (8369) está fabricado sobre una lasca grande de talón cortical sobre la que puede que se haya desarrollado una explotación de tipo centrípeta, ya que hay una obtención de lascas hacia ambas superficies de la primitiva lasca a partir de la arista de su contorno, excepto en la zona del talón.

Otros tres núcleos $(1589,1588,63)$ podrían incluirse quizás dentro de los núcleos de superficie ancha-unipolar. El último (1582) es un núcleo sobre lasca estrecho, sobre el que hay alguna extracción laminar sobre uno de sus bordes estrechos, recordando en cierto grado el esquema prismático de hojitas.

En todos estos casos, no obstante, se produce más bien una explotación de los núcleos de tipo oportunista, que si bien podría corresponder a alguno de los esquemas determinados, en cambio no tienen algunas de las características definidas en dichos esquemas. 


\section{Datos métricos}

Las dimensiones medias de los núcleos de cuarcita dan como resultado piezas bastantes grandes: $44 \mathrm{~mm}$ de longitud, 44 de anchura y 30 de grosor, con rangos que llegan hasta los 7 cm (cuadro C.10). Dentro de cada tipo de núcleo las medidas son más homogéneas, así por ejemplo los más pequeños son los núcleos unipolares-prismáticos (2-3 cm de longitud, 3-4 de anchura y 3 de grosor) y algunos restos de núcleos. Los núcleos centrípetos tienen una forma más o menos circular de unos $5 \mathrm{~cm}$ de diámetro y 2-3 cm de grosor.

\section{Tipo de soporte}

El soporte de la cuarcita son cantos rodados de río, su morfología esférica y córtex típicamente fluvial se ve claramente en algunos núcleos.

\section{Córtex}

Hay restos de córtex en ocho de los dieciséis núcleos, en la mayoría esta presencia está muy reducida, lo cual es indicativo de que tales núcleos han estado sometidos a un proceso de talla bastante intenso, con la excepción de los núcleos centrípetos, cuyo esquema rápido de obtención de lascas hace que una de las superficies conserve abundantes restos corticales.

\section{Descripción de la superficie de extracciones}

Los núcleos prismáticos tienen un avance del débitage frontal sobre la superficie anterior, en cambio en los unipolares-prismáticos el avance de las extracciones se produce de forma envolvente tendiendo entonces a abarcar uno de los laterales del núcleo. Los núcleos de superficie ancha tendrían un estado intermedio entre los anteriores. Por su parte, el núcleo-placa tiene un tipo de avance de tendencia envolvente, hacia todo el contorno del volumen. En el resto de los núcleos la superficie de extracciones no se puede describir tan bien como en estos esquemas, fundamentalmente porque los esquemas a los que pertenecen no encajan demasiado 
bien en el núcleo prismático-modelo sobre el que se diseñó este atributo. Por esta razón en los núcleos centrípetos se describe tan solo si la superficie de extracciones afecta a una o las dos superficies del volumen.

\section{Preparación de otras superficies}

Los núcleos que pertenecen a la cadena operativa genérica de los prismáticosunipolares, así como el núcleo-placa tienen todos una preparación más o menos intensa de su estructura, es decir posiblemente la fase de preparación del núcleo haya sido más o menos elaborada.

La zona de la base del núcleo es una superficie sobre la que se incide bastante, de hecho forma parte estructural del esquema del núcleo-placa y del unipolarprismático. En ambos casos la base es una superficie paralela al plano de percusión, delimita la longitud la superficie de extracciones y controla la carena. En los núcleos de superficie ancha la base del núcleo necesita ser tratada para controlar la carena, pero su tratamiento se efectúa en forma de diversas extracciones desde la superficie posterior del núcleo, sin que se produzca esa superficie paralela al plano de percusión. Quizás este último procedimiento de truncar la parte inferior del núcleo sea demasiado costoso en cuanto a la longitud de la superficie de extracciones.

\section{Soportes}

Los soportes extraídos son mayoritariamente lascas, aunque parece que sí se han extraído hojas-hojitas o lascas laminares a partir de los núcleos prismáticos y los de superficie ancha. Incluso se ha señalado la posibilidad de la obtención de alguna hojita en uno de los restos de núcleo, mediante un esquema del tipo de los núcleos de hojitas sobre el borde de una lasca.

\section{Abandono}

La causa del abandono de los núcleos es fundamentalmente por agotamiento del volumen y también por accidentes de talla, sobre todo reflejados, existiendo asimismo 
varios núcleos en los que la presencia de planos de diaclasado naturales han impedido la continuación del débitage.

\section{IV.6.2.2.- CARACTERÍSTICAS DE LA SUPERFICIE DE EXTRACCIONES}

\section{Características: morfología superficie de extracciones}

En las características de la superficie de extracciones (cuadro C.22) se reflejan en cierta medida los distintos tipos de núcleos que se han distinguido, los núcleos prismáticos tienen una superficie rectangular estrecha alargada, los de superficie ancha, los unipolares-prismáticos y el núcleo placa, por el contrario tienen una superficie ancha, más corta que los primeros.

\section{Preparación/reparación de la superficie de extracciones}

Se constata el empleo de crestas laterales para la reforma de la superficie de extracciones, sobre todo la cintra, tanto en los núcleos prismáticos como en los de superficie ancha. En estos últimos habría también el recurso a los flancos de núcleo longitudinales o "piezas con flanco" para avanzar sobre uno de los laterales en el proceso de débitage.

\section{Preparación de las extracciones}

En torno a la cornisa se observan restos de preparación del frente de percusión que han quedado en forma de retoque en tres casos y esquirlado en dos. No hay huellas claras de una abrasión más intensa, pero los núcleos han sido abandonados tras las últimas secuencias de talla o bien porque están agotados, por lo que no contienen los últimos gestos previos a la secuencia de extracción propiamente dicha. 


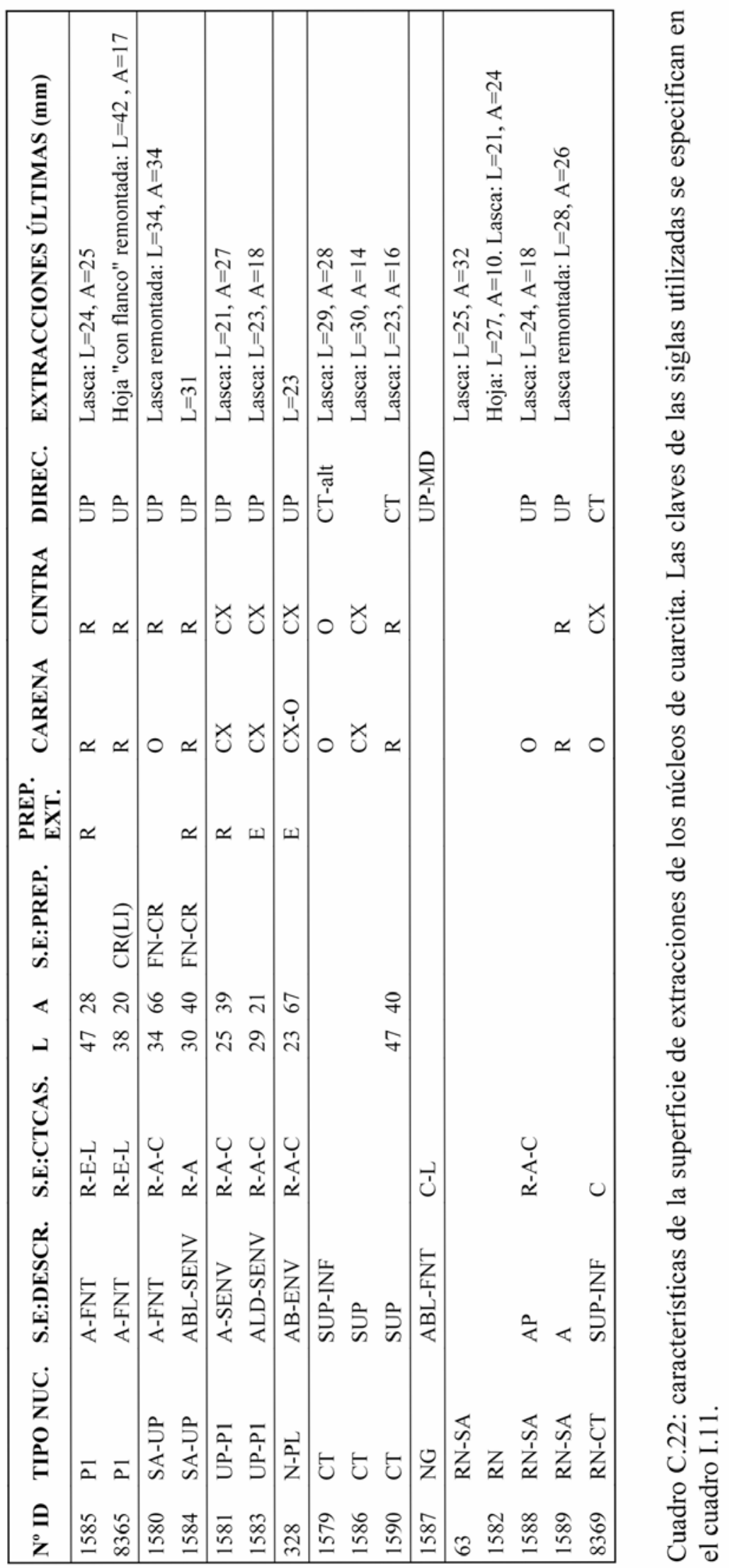




\section{Carena}

La carena se presenta en todas sus variantes dependiendo de los distintos tipos de núcleo. En los prismáticos es recta; oblicua en los de superficie ancha; convexa en los unipolares-prismáticos y también en el núcleo-placa; y, por último, en los centrípetos no tiene ninguna tendencia marcada.

\section{Cintra}

En la curvatura transversal sucede parecido a la carena, pero con unas tendencias más marcadas. En los núcleos prismáticos y los de superficie ancha es tendente a recta, mientras en los unipolares-primáticos y en el núcleo-placa es convexa. En los centrípetos sucede lo mismo que en la carena, es decir no tiene un estado fijo.

\section{Dirección}

La dirección del débitage sobre cuarcita es unipolar predominante, excepto en los núcleos centrípetos y cuando hay una explotación del núcleo expeditiva y rápida, como el caso del núcleo globuloso y alguno de los restos de núcleo, en los cuales se sigue una arista o una superficie apta para proseguir la talla.

\section{Últimas extracciones}

Hay varios núcleos en los que se ha encontrado el remontage de la última lasca extraída. Tanto estas extracciones como los negativos de los últimos levantamientos no suelen superar en longitud los tres centímetros, con la excepción de una lasca de 34 mm y una "hoja con flanco" de $42 \mathrm{~mm}$, ambas remontadas. 


\section{IV.6.2.3.- CARACTERÍSTICAS DEL PLANO DE PERCUSIÓN}

\section{Características del plano de percusión}

La mayoría de los planos de percusión (cuadro C.23) son lisos y cóncavos, en dos casos se ha aprovechado una superficie natural del núcleo como plano de percusión y otro es facetado.

\begin{tabular}{|c|c|c|c|c|c|c|c|}
\hline $\mathbf{N}^{\circ}$ ID & $\begin{array}{l}\text { TIPO } \\
\text { NUC. }\end{array}$ & $\begin{array}{l}\text { PLANO: } \\
\text { CTCAS }\end{array}$ & $\begin{array}{l}\text { PLANO: } \\
\text { PREP. }\end{array}$ & $\begin{array}{l}\text { PREP. } \\
\text { EXT. }\end{array}$ & CORNISA & ANGULO & $\begin{array}{l}\text { MODO } \\
\text { TALLA }\end{array}$ \\
\hline 1585 & P1 & L-CN & SN & & CNT & $70^{\circ}$ & \\
\hline 8365 & $\mathrm{P} 1$ & F-O & LR & $\mathrm{R}$ & CNT & 80 & \\
\hline 1580 & SA-UP & PN-R & & & DT & $70^{\circ}$ & PDD \\
\hline 1584 & SA-UP & L-CN & LR & & DT & $80^{\circ}$ & PDD \\
\hline 1581 & UP-P1 & L-CN & LR & & DT & $70-80^{\circ}(\mathrm{Db})$ & \\
\hline 1583 & UP-P1 & L-CN & LR & & DT & $70-80^{\circ}(\mathrm{Db})$ & \\
\hline 328 & N-PL & PN-R & & $\mathrm{R}$ & CNT & & \\
\hline 1579 & CT & & & & DT & $70^{\circ}$ & PDD \\
\hline 1586 & $\mathrm{CT}$ & & & $\mathrm{R}$ & DT & $60^{\circ}$ & \\
\hline 1590 & CT & & & & DT & $70^{\circ}$ & PDD \\
\hline 1587 & NG & L-CN & & & DT & $80-90^{\circ}(\mathrm{Ea})$ & PDD \\
\hline 63 & RN-SA & & & & & & \\
\hline 1582 & $\mathrm{RN}$ & & & & & & \\
\hline 1588 & RN-SA & L-CN & SN-LR & & DT & $60-70^{\circ}(\mathrm{Da})$ & \\
\hline 1589 & RN-SA & & & & & & \\
\hline 8369 & RN-CT & & & & DT & & \\
\hline
\end{tabular}

Cuadro C.23: características planos de percusión de núcleos de cuarcita. Las claves de las siglas utilizadas se especifican en el cuadro 12.

\section{Preparación/reparación del plano}

Para arreglar el plano de percusión se recurre sobre todo a las lasquitas de retoque para acondicionar de forma puntual el punto de impacto.

\section{Preparación de las extracciones}

Hay restos de preparación del punto de impacto en tres casos, todos en forma de retoque. 


\section{Cornisa}

La morfología de la cornisa en los núcleos prismáticos y en el núcleo-placa es continua; en el resto de los núcleos es denticulada. Esta irregularidad del frente de talla viene a reflejar los contrabulbos marcados de los negativos de lascas en la mayoría de los casos, aunque no hay que olvidar que son núcleos abandonados después de una última secuencia de extracciones, por lo que conservan la preparación previa a ella.

\section{Ángulo}

La mayoría de los ángulos del frente de percusión están entre los 70-80ª es decir ángulos con tendencia a ser cerrados, tan solo el núcleo globuloso presente un frente de talla cercano al ángulo recto.

\section{Modo de talla}

En todos los núcleos sobre los que se ha determinado el modo de talla se trata de percusión directa con percutor duro. 

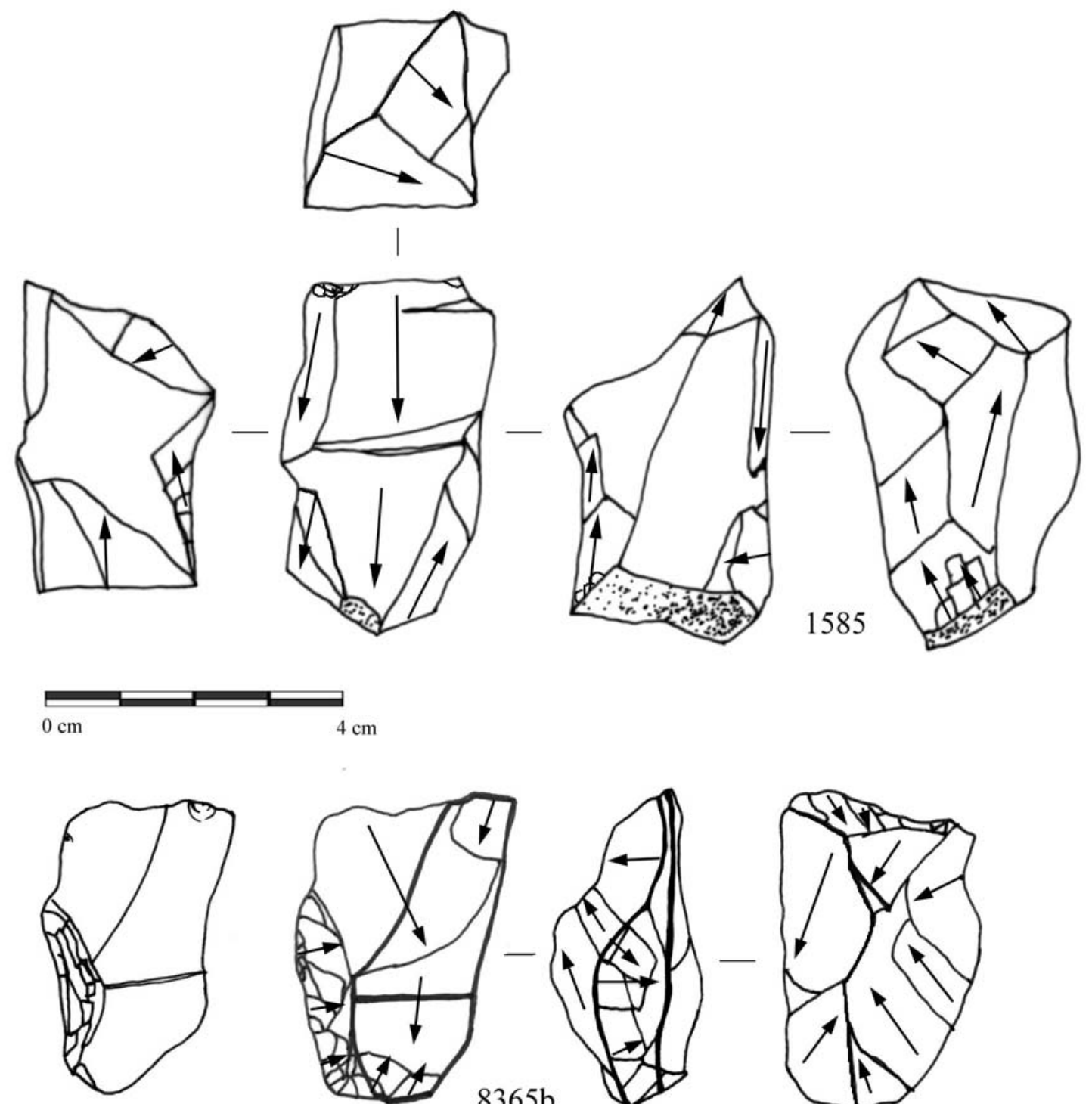

$8365 \mathrm{a}$
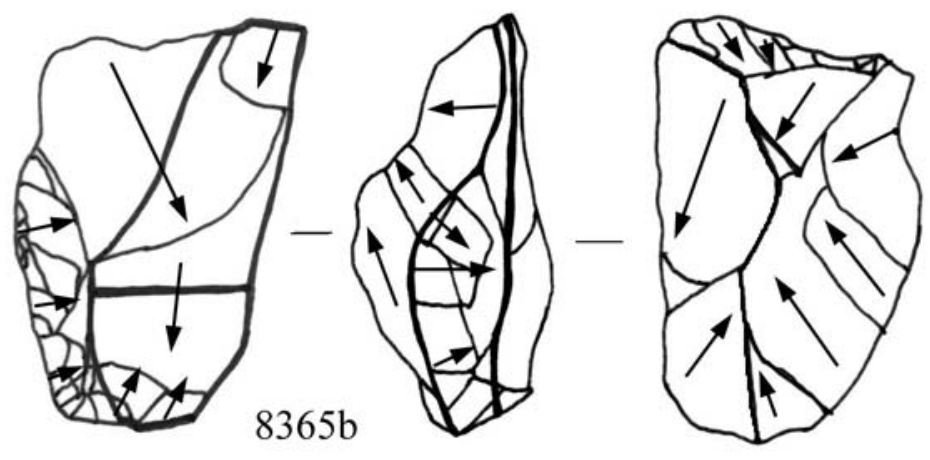

Figura C.1: núcleos de cuarcita. Esquema prismático. En $n^{0}$ 8365b tiene el remontage de una "hoja con flanco". 

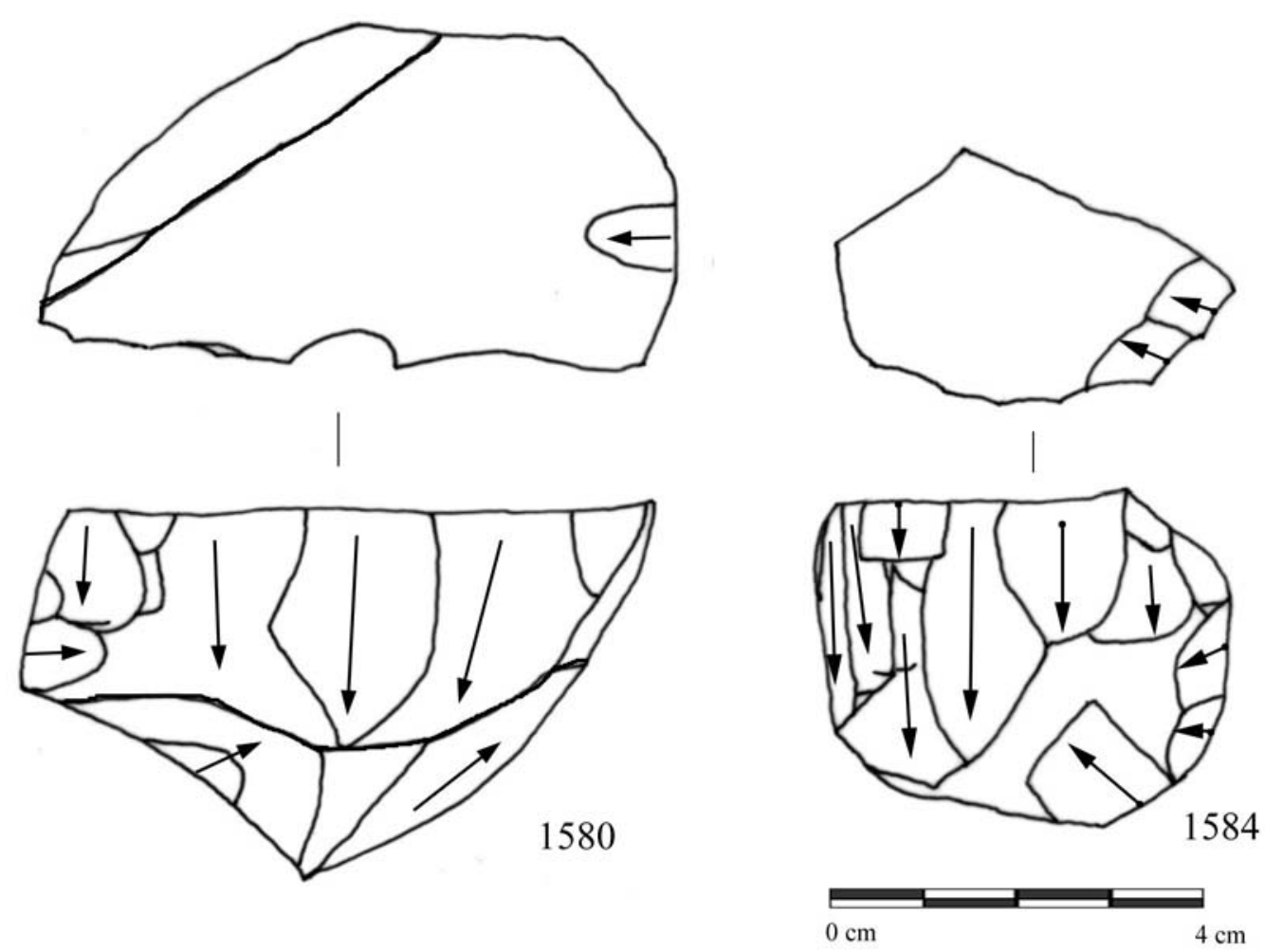

Figura C.2: Núcleos de cuarcita. Esquema prismático de superficie ancha.

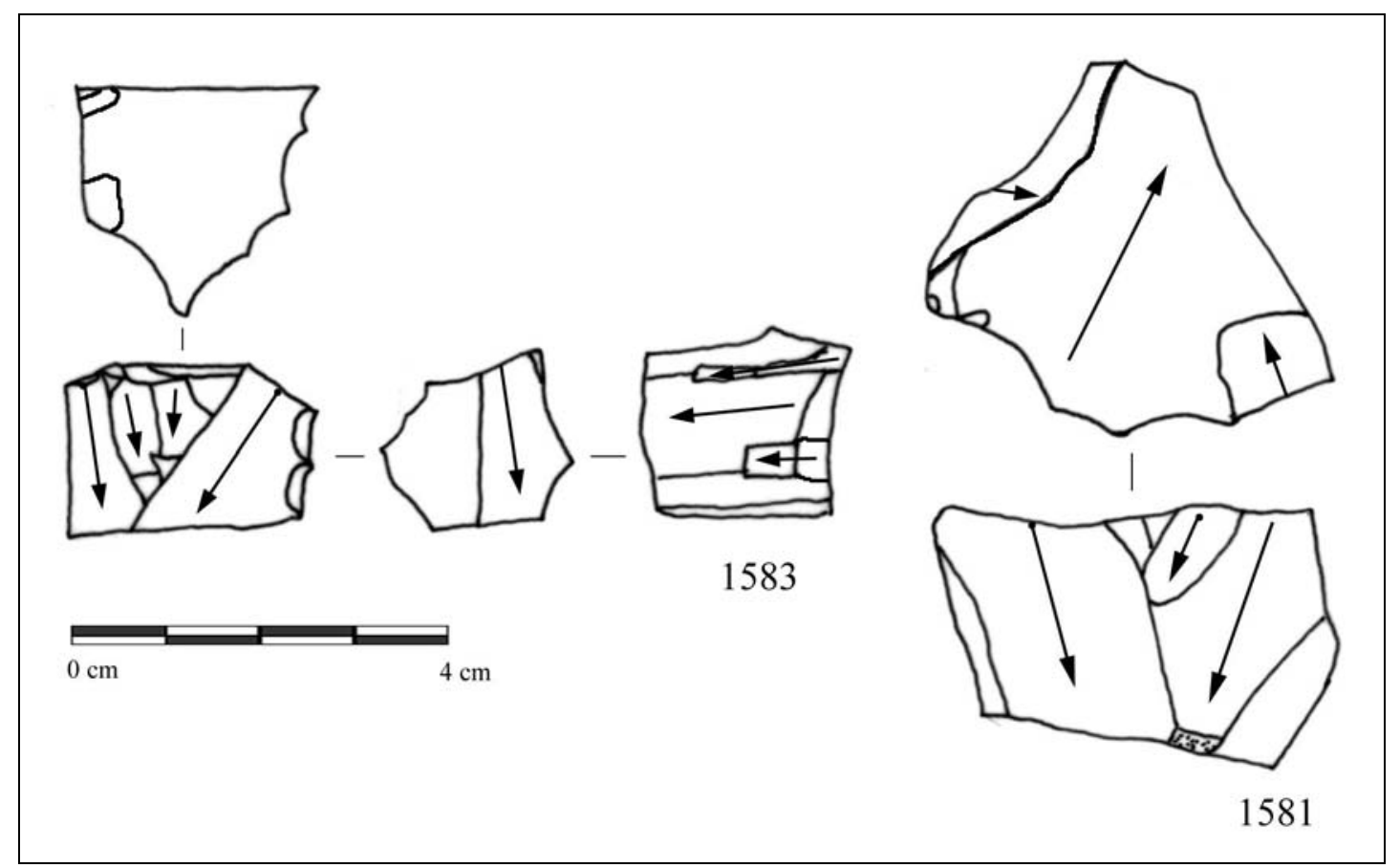

Figura C.3: núcleos de cuarcita. Esquema unipolar-prismático. 


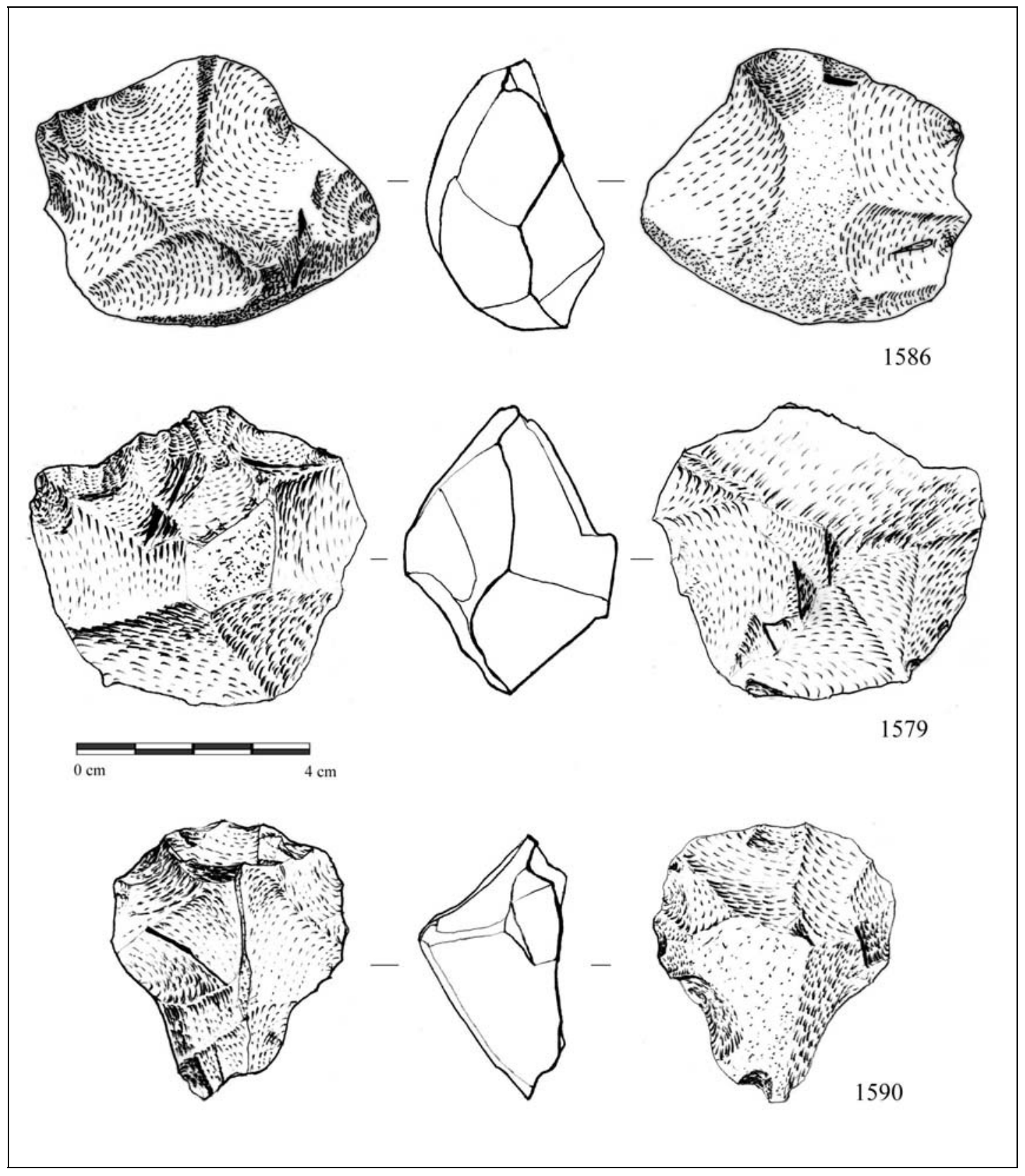

Figura C.4: núcleos de cuarcita. Cadena operativa centrípeta/discoide. 


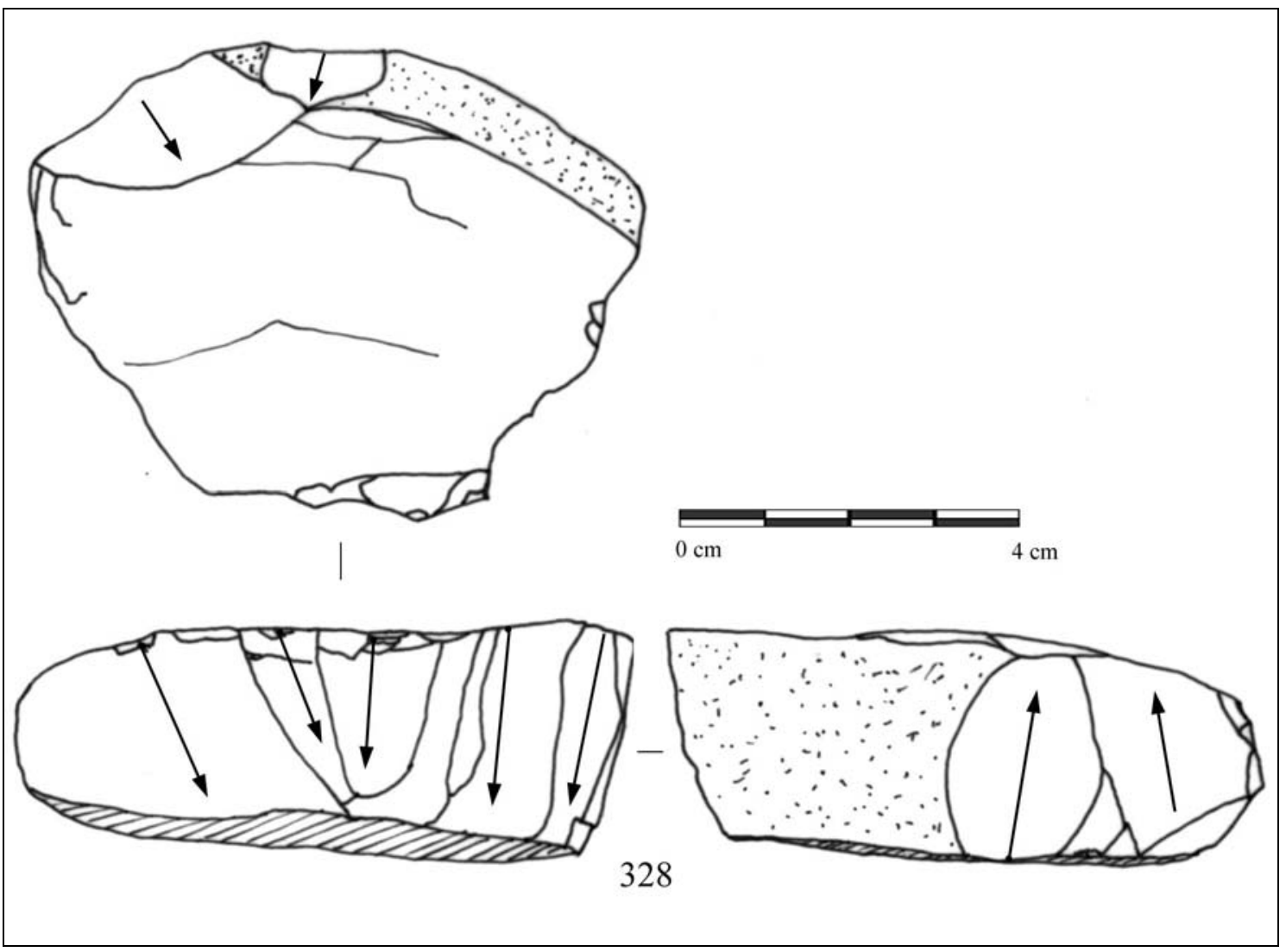

Figura C.5: núcleo de cuarcita, cadena operativa tipo nódulo-placa.

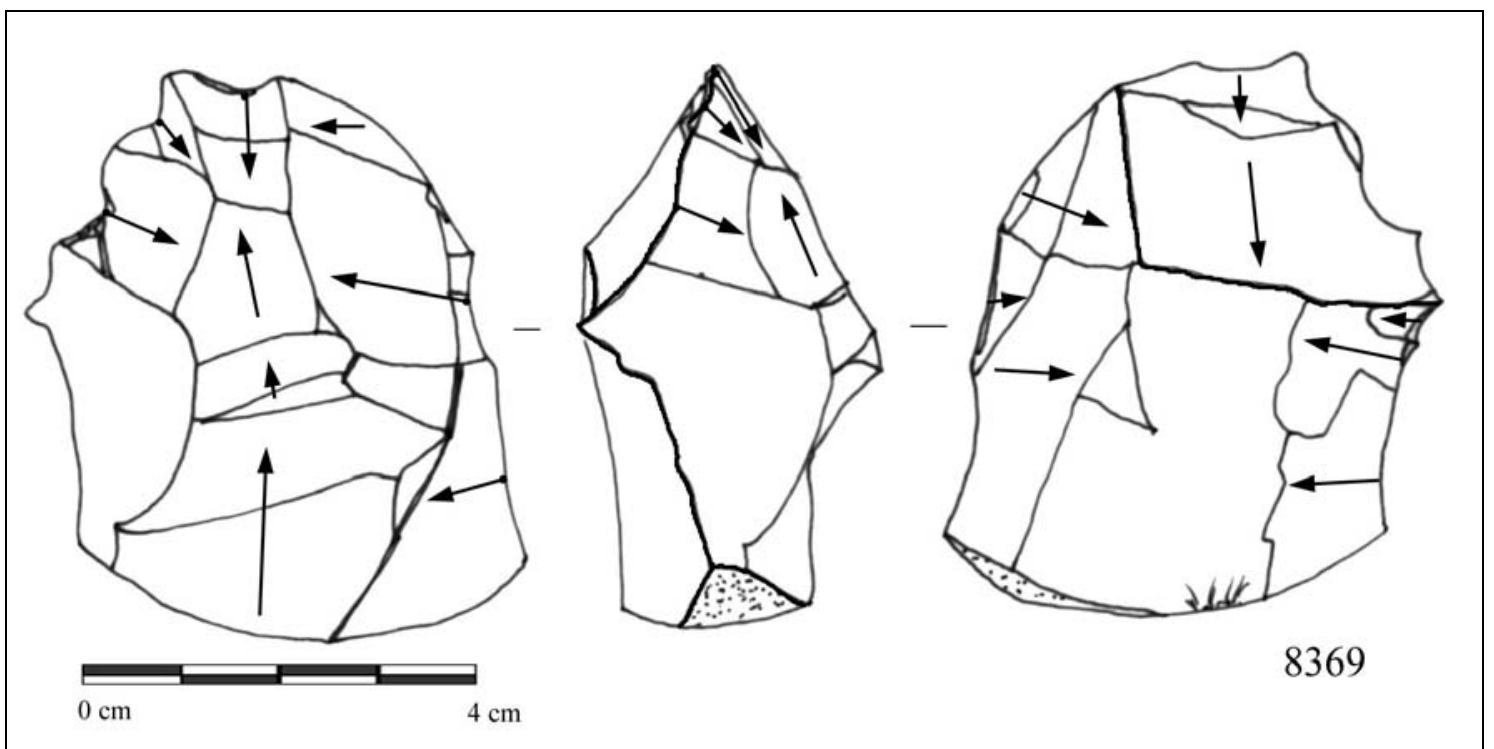

Figura C.6: núcleo de cuarcita, sobre lasca. Esquema no estandarizado. 


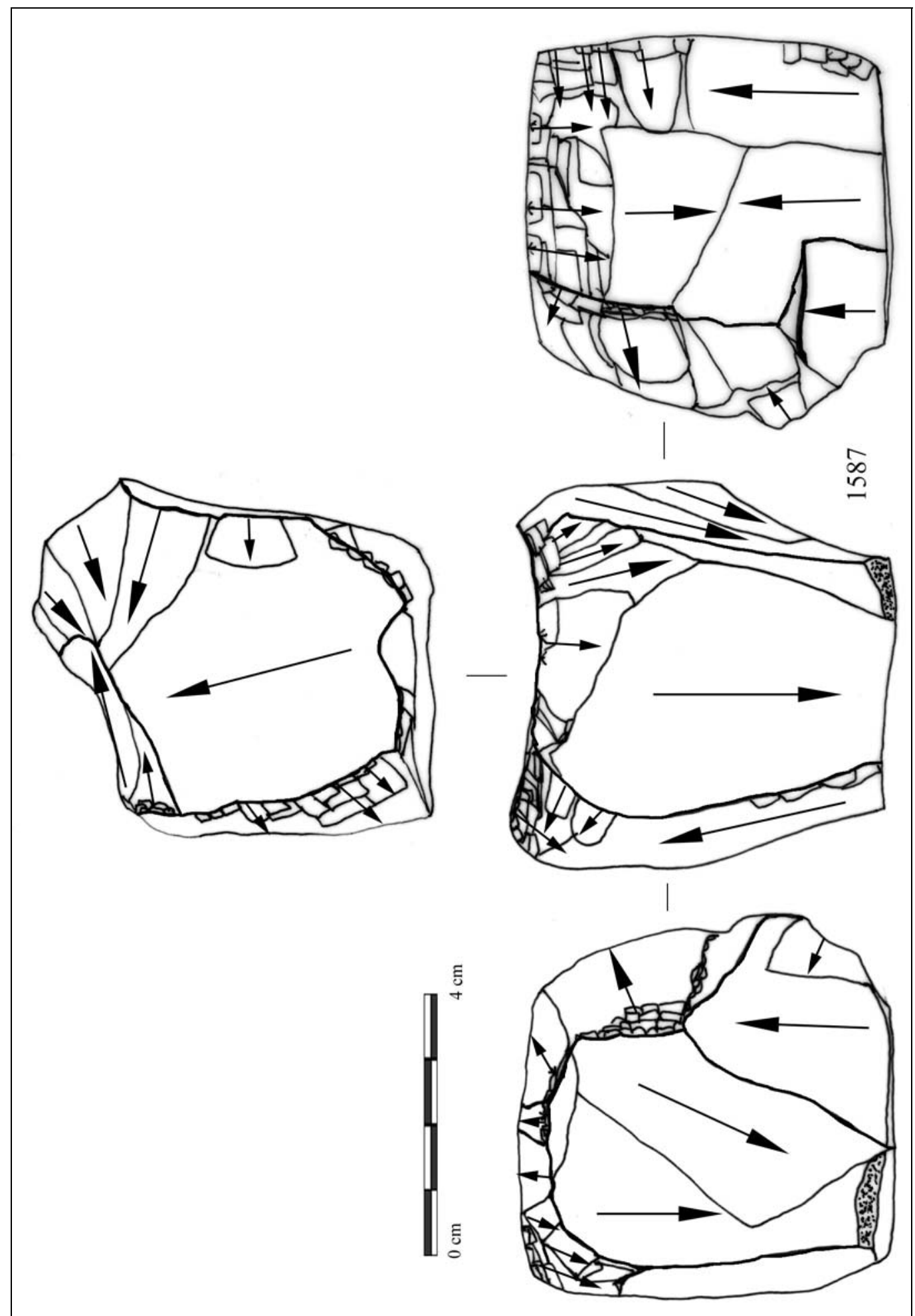

Figura C.7: núcleo de cuarcita. Esquema no estandarizado (núcleo globuloso). 

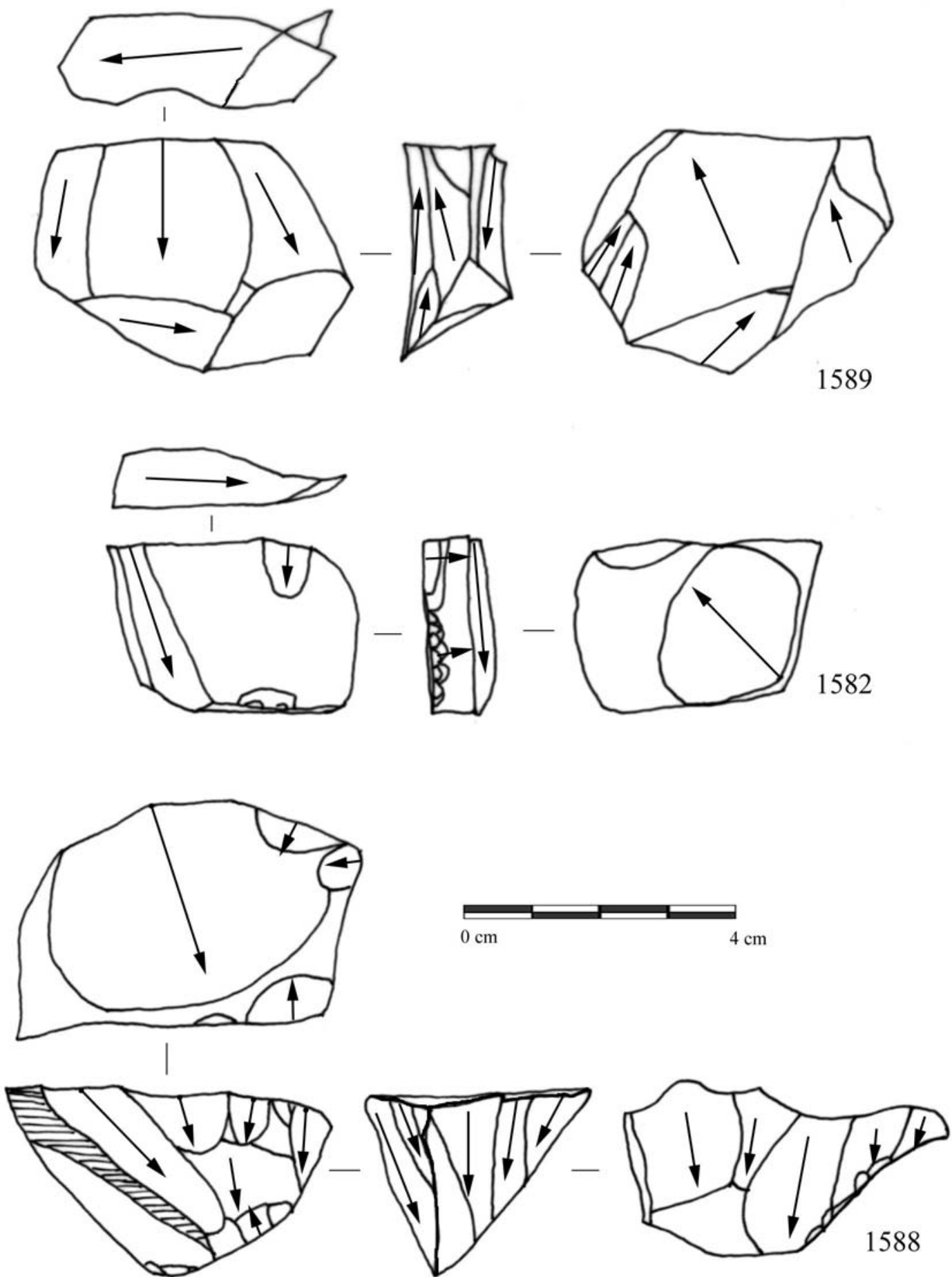

Figura C.8: núcleos de cuarcita. Esquemas no estandarizados. 


\section{IV.6.3. PRODUCTOS DE ACONDICIONAMIENTO}

Hay 32 piezas definidas como productos de acondicionamiento, tan solo una pieza con cresta, dos semitabletas, seis flancos y veintitrés productos de acondicionamiento indeterminados. El pequeño número de piezas cuya función ha podido ser identificada hace que no sea muy útil separar las medidas de estos distintos tipos de soportes (tabletas, flancos de núcleo y piezas con cresta). La existencia de numerosas piezas “indeterminadas” está explicada quizás por las características peculiares de este tipo de materia, los gestos necesarios para su gestión hacen que sean más complicados de interpretar que en el caso del sílex.

Solamente hay una pieza con cresta, el motivo de la escasez de este tipo de soporte, en relación sobre todo con el resto de materias primas, en las cuales hay una presencia moderada, sobre todo de las "piezas con neo-cresta"; puede deberse a que no se apliquen en cuarcita los mismos métodos en la gestión de los núcleos. No hay constancia de la presencia del método de la cresta anterior para la apertura de la superficie de extracciones. Sin embargo sí aparece en los núcleos el recurso a la cresta lateral como un método útil, especialmente en los esquemas de tendencia más laminar, por lo que sí cabría esperar que encontráramos alguna pieza con neo-cresta. Quizás dichas crestas no se eliminaran de los núcleos, o bien no las hemos localizado. 


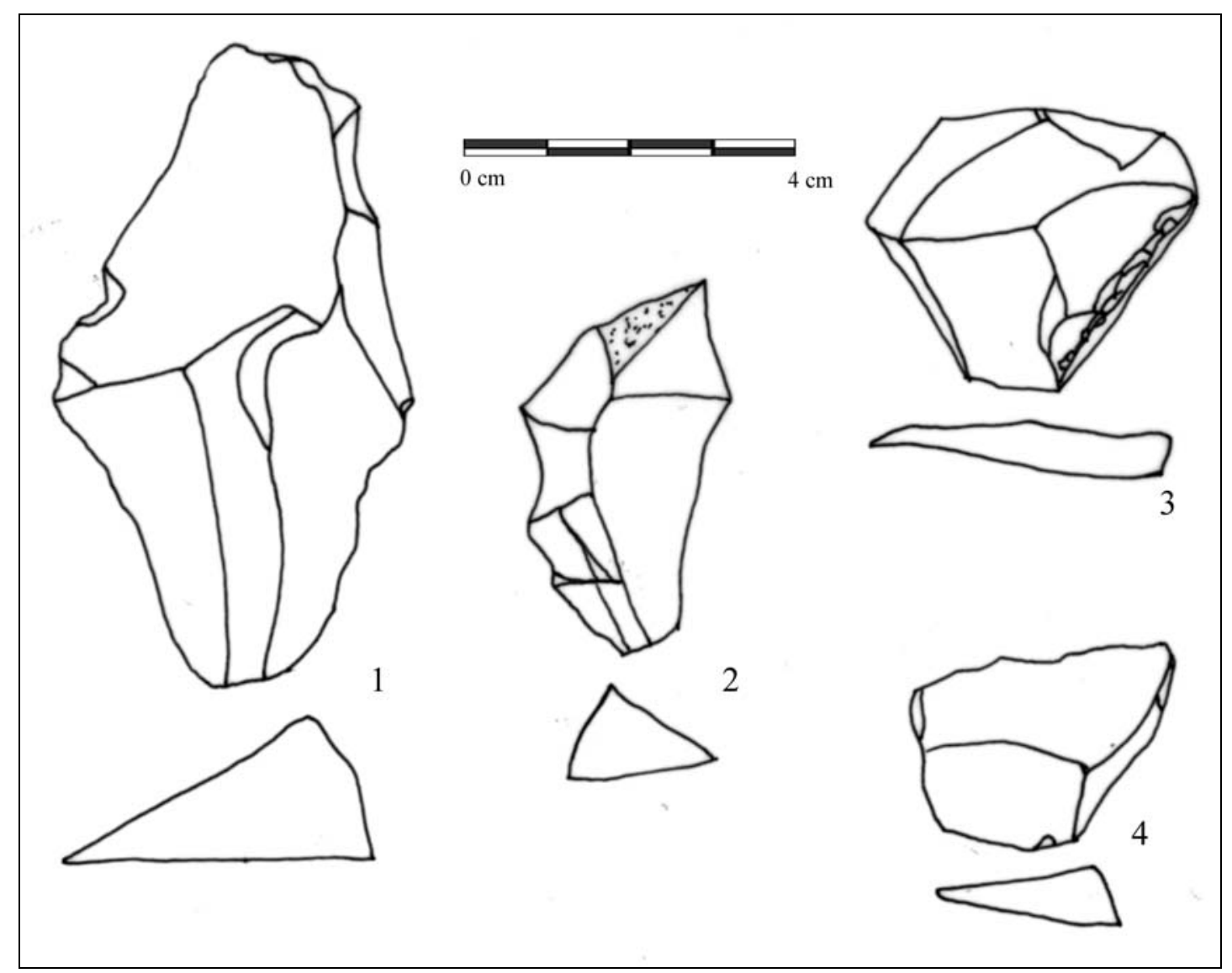

Figura C.9: productos de acondicionamiento de cuarcita. Flancos de núcleo: 1, 2. Semitabletas de núcleo: 3, 4.

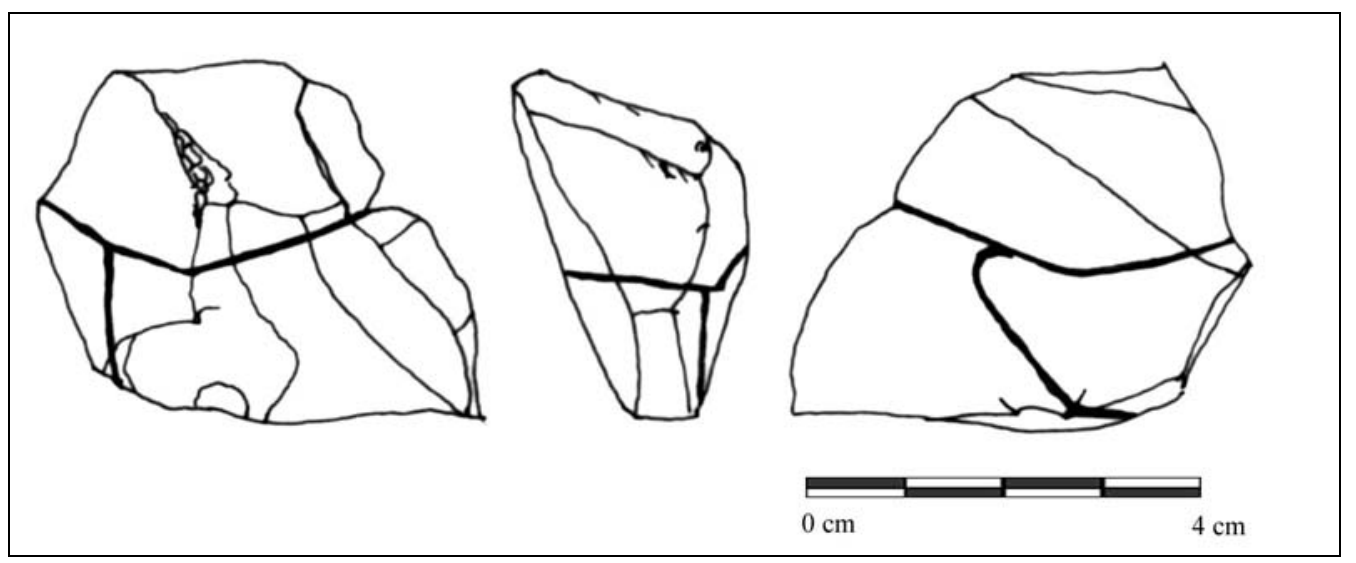

Figura C.10: producto de acondicionamiento de cuarcita, roto en tres fragmentos. 


\section{IV.6.4.- SOPORTES: LASCAS, HOJAS Y HOJITAS}

\section{IV.6.4.1.- LASCAS}

Las dimensiones medias de las lascas se situaban (cuadro C.10) en los $20 \mathrm{~mm}$ de longitud, 17 de anchura y 5 de grosor. Si observamos el gráfico de barras de sus longitudes y anchuras estas medias se matizan (gráfico C.5 y C6), en la longitud hay un máximo de lascas de 11-12 mm, y continúan siendo abundantes hasta los $18 \mathrm{~mm}$, a partir del cual disminuyen paulatinamente. En la anchura hay también un máximo en los 11-12 mm, decreciendo hasta los $30 \mathrm{~mm}$.

\section{IV.6.4.2.- SOPORTES LAMINARES: HOJAS Y HOJITAS}

\section{IV.6.4.2.1.- DATOS MÉTRICOS: LONGITUD Y ANCHURA}

Las dimensiones medias de los soportes laminares son (cuadro C.10): 35 mm de longitud, 12 de anchura y 4 de grosor. Los gráficos de barras de la anchura y grosor muestran la distribución de estas medidas. En la longitud no hay demasiados elementos completos, pero la media en los $35 \mathrm{~mm}$ sería una representación bastante adecuada. No obstante hay dos piezas de casi $7 \mathrm{~cm}$ de longitud que no parecen estar en correlación con esta distribución. En la anchura hay un máximo entre los 7-8 mm, decreciendo moderadamente el número de piezas hasta los $16 \mathrm{~mm}$; de nuevo hay una pieza superior a los $3 \mathrm{~cm}$ de anchura que no encaja demasiado bien en esta distribución.

La existencia de soportes laminares de dimensiones mayores al conjunto laminar existente en el yacimiento plantea la posibilidad de que tales soportes hayan sido llevados al yacimiento y no tallados allí. Hay que tener en cuenta además que el débitage laminar en cuarcita no es demasiado abundante, además las evidencias de este tipo de explotación en los núcleos con que contamos refleja que se obtendrían unos soportes de dimensiones moderadas. A esto hay que añadir el hecho de que el tipo de cuarcita de estas hojas grandes es una materia de color claro (blanco-rosáceo, la variedad C3) que no es demasiado abundante en el conjunto. 


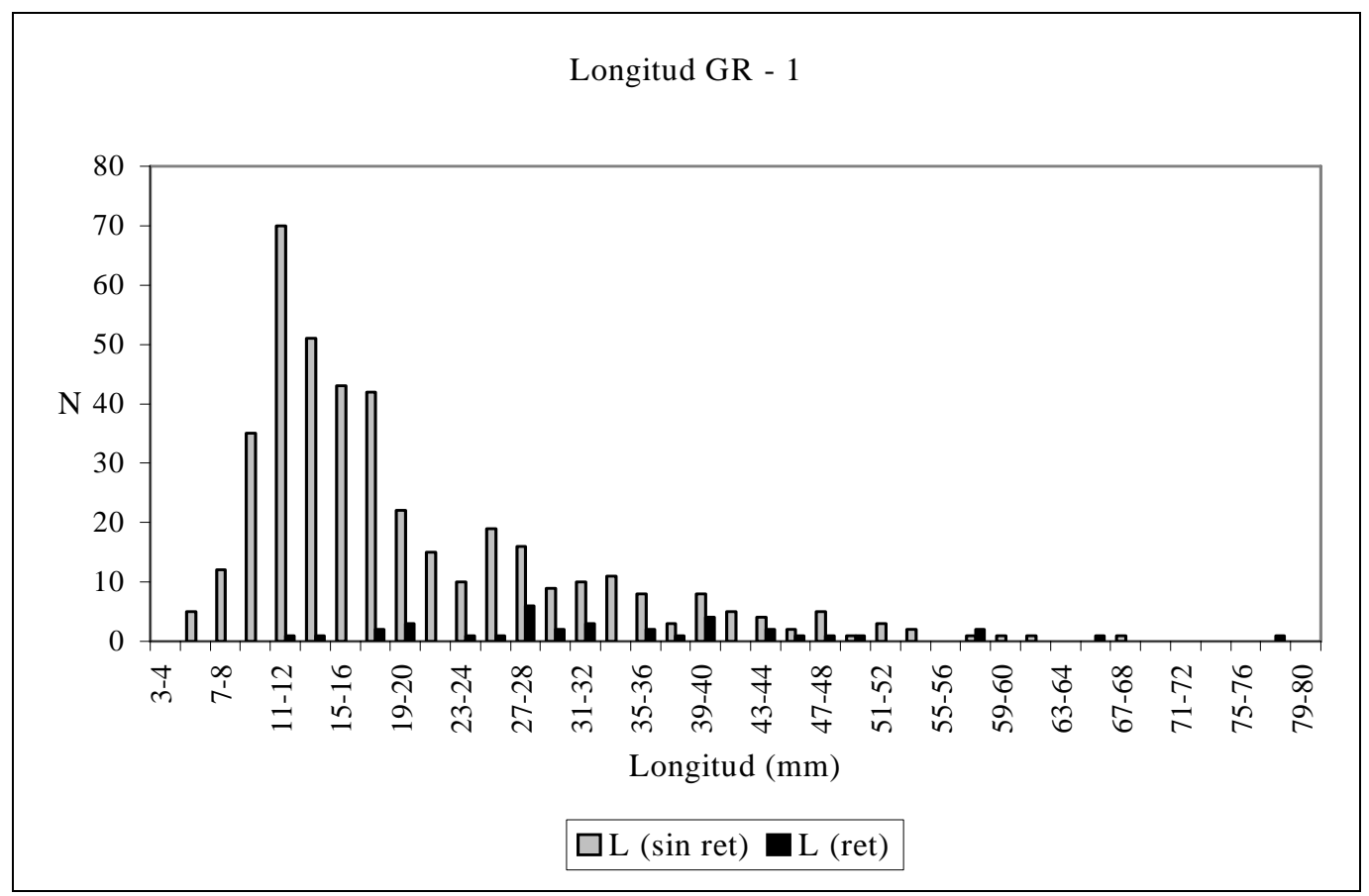

Gráfico C.5: longitud de los soportes del grupo tecnológico 1 (lascas, lascas laminares). Sin retocar: $n=415$. Retocados: $n=36$.

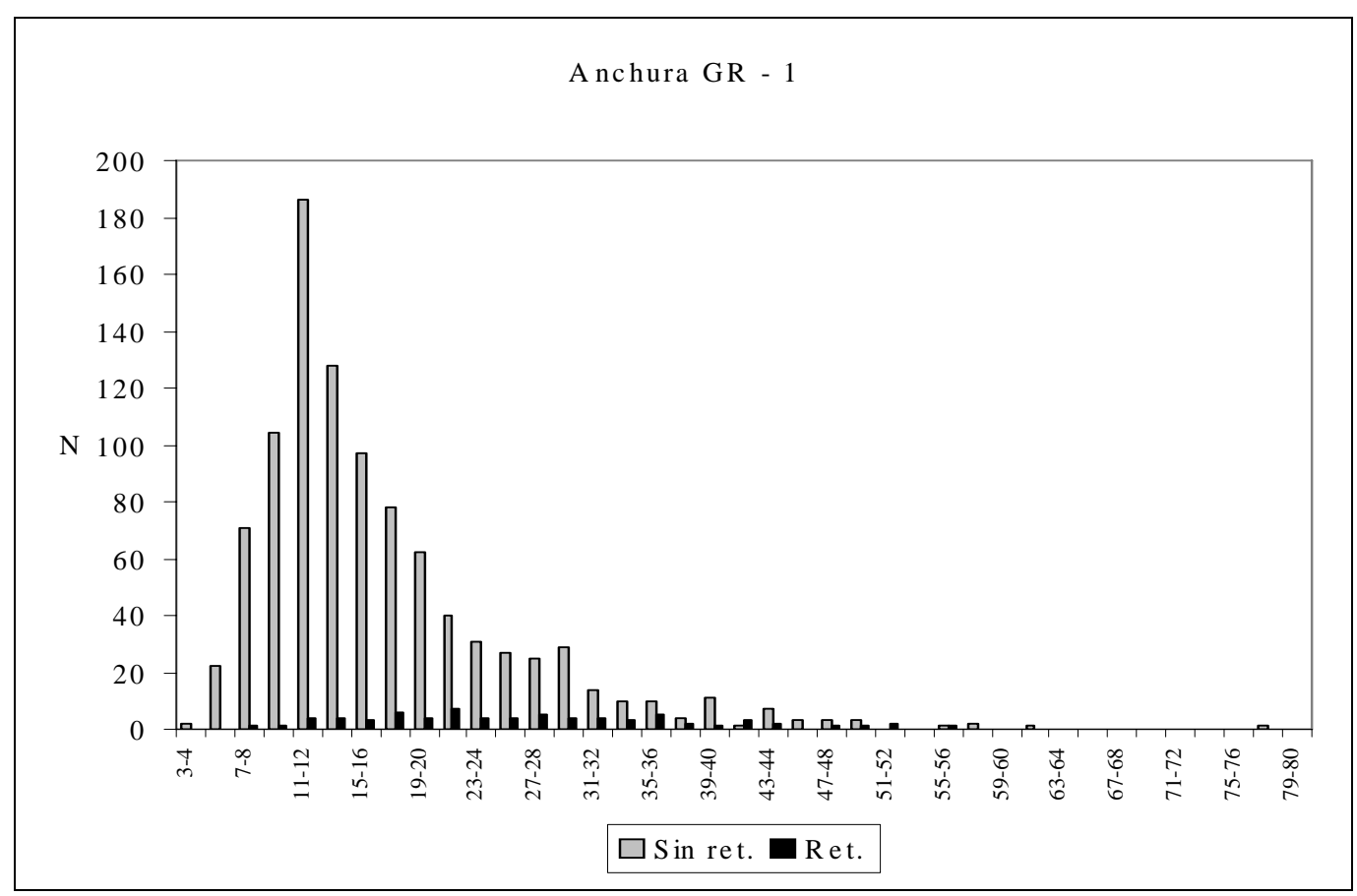

Gráfico C.6: anchura de los soportes del grupo tecnológico 1 (lascas, lascas laminares). Sin retocar: $\mathrm{n}=973$. Retocados: $\mathrm{n}=72$. 


\section{Longitud GR - 2}

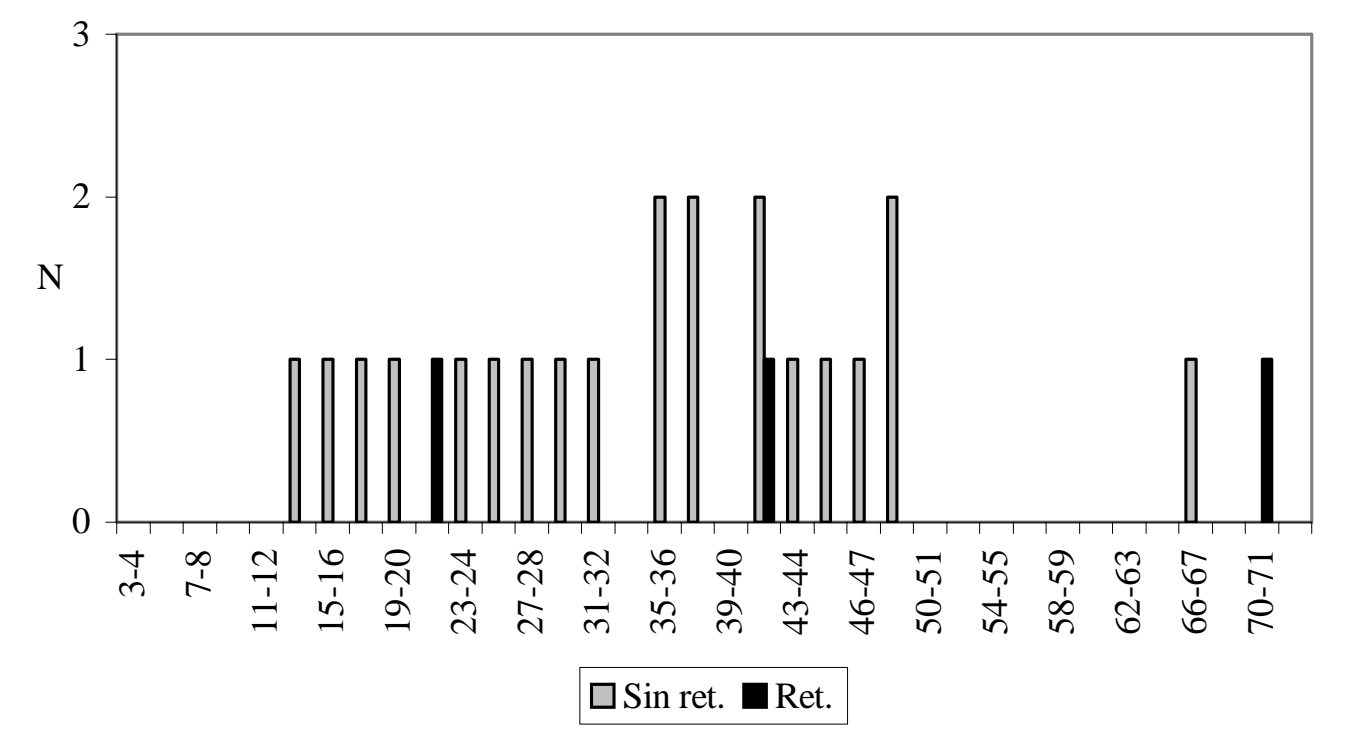

Gráfico C.7: longitud de los soportes del grupo tecnológico 2 (hojas, hojitas). Sin retocar: $n=21$. Retocados: $\mathrm{n}=3$.

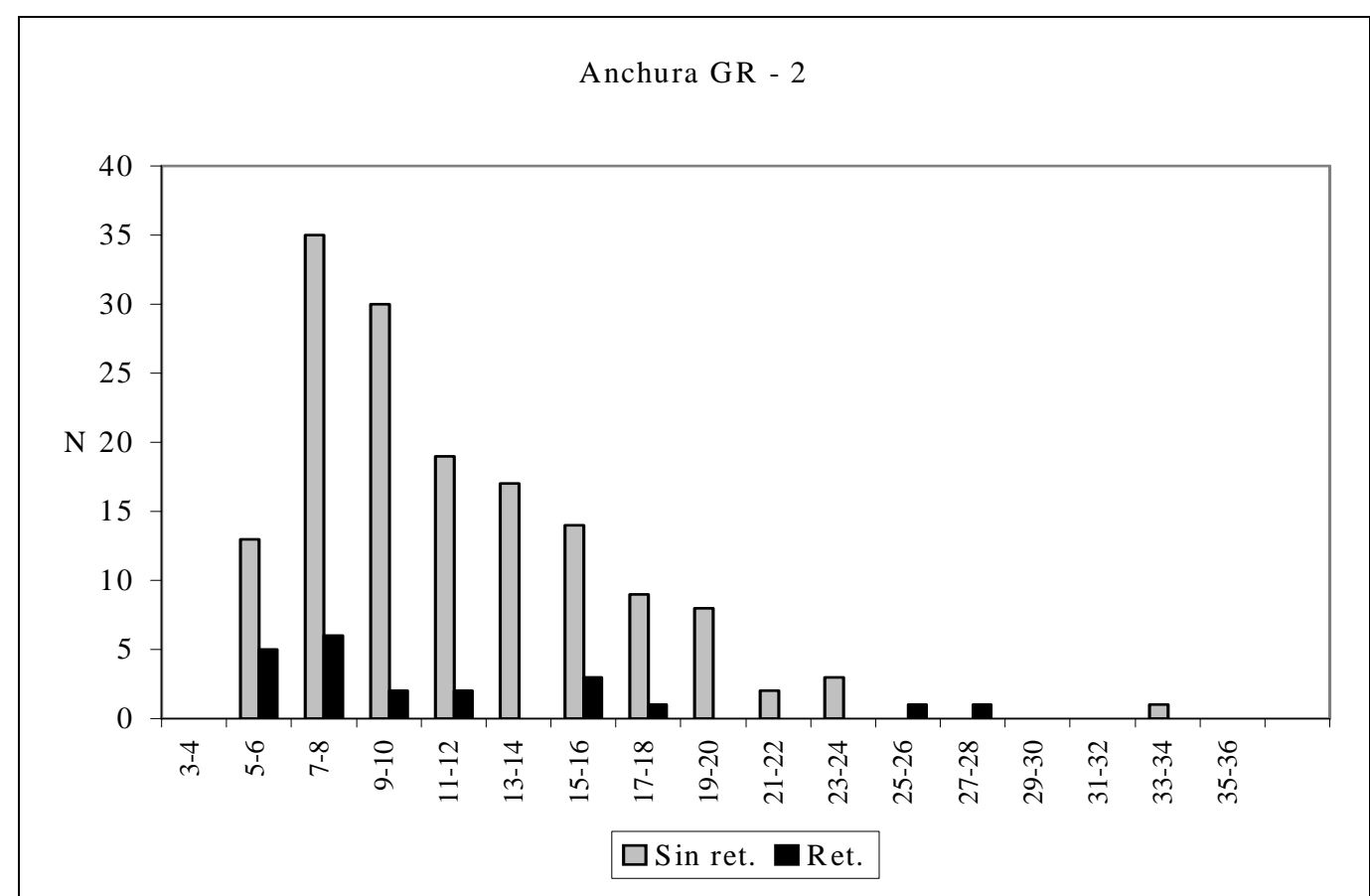

Gráfico C.8: anchura de los soportes del grupo tecnológico 2 (hojas, hojitas). Sin retocar: $n=$ 151. Retocados: $n=21$. 


\section{IV.6.4.2.2.- DATOS TÉCNICOS}

El número de negativos de las hojas de cuarcita suele ser uno en la mayoría de los casos, pero también hay un buen número de piezas con dos y tres negativos (cuadro C.24). Como en el resto de las materias la dirección de los levantamientos es unipolar y el perfil longitudinal más cóncavo que recto (cuadros C.25, 26). En este atributo hay que reseñar el hecho de que en las piezas retocadas se prefieren los perfiles rectos. La sección transversal es triangular en casi todos los casos (cuadro 27) y, por último, el índice de regularidad es medio o malo en las piezas sin retocar, sin que varíe demasiado en las piezas retocadas (cuadro 28). Este último atributo sería por tanto distinto a lo que sucedía en los sílex, donde se veía una tendencia clara a seleccionar las hojas de mayor regularidad. En este caso quizás estas últimas no sean demasiado abundantes.

\begin{tabular}{|l|l|cccccc|r|}
\hline \multicolumn{2}{|c|}{} & 0 & 1 & 2 & 3 & 4 & 5 & TOTAL \\
\hline \multirow{2}{*}{ SIN RET } & $\mathrm{N}$ & 3 & 77 & 53 & 18 & 2 & 2 & 155 \\
& $\%$ & 1,9 & 49,7 & 34,2 & 11,6 & 1,3 & 1,3 & 100 \\
\hline \multirow{2}{*}{ RETOC } & $\mathrm{N}$ & 6 & 6 & 9 & 1 & & & 22 \\
& $\%$ & 27,3 & 27,3 & 40,9 & 4,5 & & & 100 \\
\hline
\end{tabular}

Cuadro C.24: $\mathrm{N}^{\circ}$ de nervaduras en los soportes laminares.

\begin{tabular}{|l|cc|cc|}
\hline \multirow{2}{*}{} & \multicolumn{2}{|c|}{ SIN RET } & \multicolumn{2}{c|}{ RET } \\
\cline { 2 - 5 } & $\mathrm{N}$ & $\%$ & $\mathrm{~N}$ & $\%$ \\
\hline DP & 2 & 1,7 & 1 & 7,1 \\
PD & 98 & 83,8 & 12 & 85,7 \\
PD-DP & 16 & 13,7 & 1 & 7,1 \\
PD-ID & 1 & 0,9 & & \\
\hline
\end{tabular}

Cuadro C.25: dirección de los negativos de los soportes laminares, según el número de nervaduras en su cara superior. DP: distal-proximal (opuesta al sentido de la extracción misma); PD: proximal-distal (unipolar); PD-ID: proximal-distal y transversal en sentido izquierdo-distal; PD-DP: proximal-distal y distal-proximal (bipolar).

\begin{tabular}{|l|l|ccccc|r|}
\hline \multicolumn{2}{|c|}{} & $\mathrm{Cn}$ & $\mathrm{Cx}$ & $\mathrm{R}$ & $\mathrm{S}$ & $\mathrm{T}$ & $\mathrm{N}$ \\
\hline \multirow{2}{*}{ SIN RET } & $\mathrm{N}$ & 54 & 19 & 39 & 4 & 1 & 117 \\
& $\%$ & 46,2 & 16,2 & 33,3 & 3,4 & 0,9 & 100 \\
\hline \multirow{2}{*}{ RET } & $\mathrm{N}$ & 6 & 2 & 9 & & & 17 \\
& $\%$ & 35,3 & 11,8 & 52,9 & & & 100 \\
\hline
\end{tabular}

Cuadro C.26: perfil longitudinal de los soportes laminares. Cn: cóncavo, curvo; Cx: convexo; R: rectilíneo; S: sinuoso (cóncavo-convexo); T: torse (alabeado). 


\begin{tabular}{|l|l|ccr|}
\hline \multicolumn{2}{|c|}{} & TR & TZ & N \\
\hline \multirow{2}{*}{ SIN RET } & $\mathrm{N}$ & 110 & 23 & 133 \\
& $\%$ & 82,7 & 17,3 & 100 \\
\hline \multirow{2}{*}{ RET } & $\mathrm{N}$ & 14 & 2 & 16 \\
& $\%$ & 87,5 & 12,5 & 100 \\
\hline
\end{tabular}

Cuadro C.27: sección transversal de los soportes laminares. Bi-cx: biconvexa; TR: triangular; TZ: trapezoidal.

\begin{tabular}{|l|l|ccccc|r|}
\hline \multicolumn{2}{|c|}{} & 0 & $0-1$ & 1 & $1-2$ & 2 & $\mathrm{~N}$ \\
\hline \multirow{2}{*}{ SIN RET } & $\mathrm{N}$ & 49 & 4 & 56 & 4 & 5 & 118 \\
& $\%$ & 41,5 & 3,4 & 47,5 & 3,4 & 4,2 & 100 \\
\hline \multirow{2}{*}{ RET } & $\mathrm{N}$ & 3 & 1 & 6 & & 2 & 12 \\
& $\%$ & 25,0 & 8,3 & 50,0 & 0,0 & 16,7 & 100 \\
\hline
\end{tabular}

Cuadro C.28: índice de regularidad de los soportes laminares. 0: mala calidad; 1: calidad media, aceptable; 2: buena calidad. 


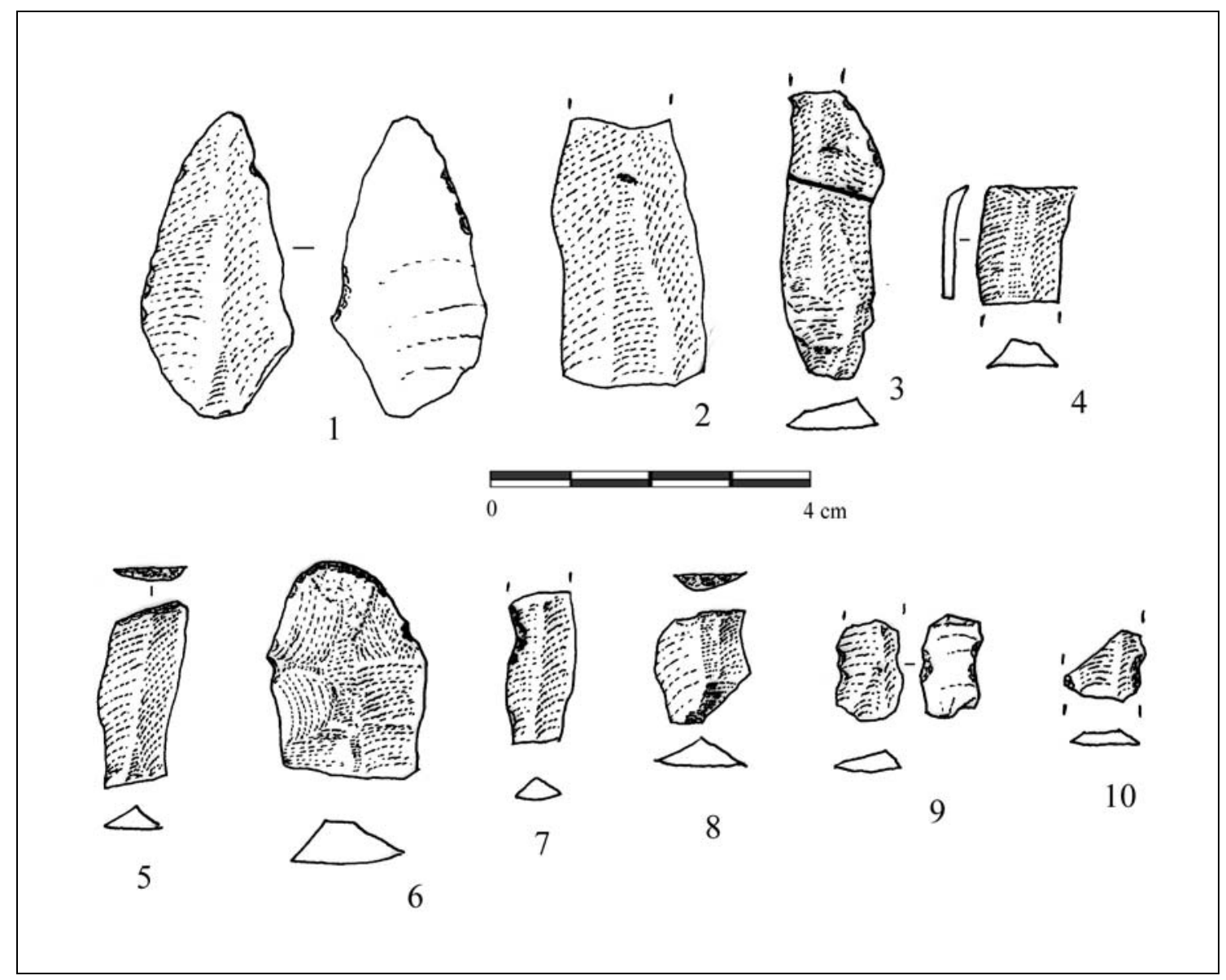

Figura C.11: soportes laminares y microlaminares de cuarcita. 1: lasca-laminar apuntada con retoque marginal sobre ambos laterales. 2 a 4 hojas sin retocar. 5, 6, 8: truncaduras. 7, 9 y 10: hojitas con escotadura. 


\section{IV.6.5.- PIEZAS RETOCADAS}

En cuarcita se van a seleccionar sobre todo lascas, casi las tres cuartas partes del conjunto retocado utilizan este tipo de soporte (cuadro C.4). Las hojas y hojitas serían el siguiente soporte utilizado, con el $20 \% \mathrm{y}$, por último, los productos de acondicionamiento e indeterminados. De todas formas hay un empleo relativo mayor de los soportes laminares que de las lascas, ya que, dentro de las hojas-hojitas disponibles, se retocan un $12 \%$, mientras que de las lascas se retocan en torno al $7 \%$, pero el número de lascas existente en cuarcita es muy elevado (cuadro C.5).

Las lascas tienen un uso bastante diversificado en los distintos tipos de útiles retocados, pero sobre todo aparecen en escotaduras y denticulados así como otras piezas del conjunto de los “útiles de fondo común” tales como raspadores, raederas, buriles y perforadores (cuadro C.29). Las hojas no son muy abundantes, pero se utilizan también en diversos tipos: en piezas de retoque continuo, una truncadura, un buril, un dorso y una escotadura. Las hojitas por su parte tienen un uso específico para las piezas con dorso y escotaduras. Por último los productos de acondicionamiento y chunks se utilizan sobre todo en escotaduras y denticulados.

Dentro del conjunto retocado de cuarcita son las escotaduras y denticulados los tipos más abundantes, suponiendo casi la mitad de las piezas retocadas en esta materia (el 46\%). El siguiente tipo en importancia son las piezas de dorso, con un 13\%, seguido por los buriles, que tienen en torno al 6\%; el resto de los tipos tienen una representación inferior al 5\%. Hay que remarcar la presencia de dos triángulos realizados sobre fragmentos de lascas, así como de la presencia de dos microburiles y tres piezas que pueden proceder de una “técnica de microburil” defectuosa (las piezas con escotadura o retoque al lado de una rotura). Tanto los microburiles como dos de las piezas con “escotadura/rotura adyacente a una rotura” tienen hojas-hojitas como soporte, por lo que hay un desequilibrio entre los geométricos y esta técnica de microburil. Quizás se hayan fabricado más geométricos sobre hoja-hojita, pero o bien no se han encontrado en la superficie excavada, o bien fueron llevados fuera por los grupos prehistóricos. 


\begin{tabular}{|c|c|c|c|c|c|c|c|c|c|}
\hline \multirow[b]{3}{*}{ TIPO RETOC. } & & & \multicolumn{7}{|c|}{ GRUPOS TEC. } \\
\hline & \multicolumn{2}{|c|}{ TOTAL } & \multicolumn{2}{|c|}{1} & \multicolumn{2}{|c|}{2} & \multicolumn{2}{|c|}{3} & \multirow{2}{*}{\begin{tabular}{|c|}
5 \\
$\mathrm{CH}$
\end{tabular}} \\
\hline & $\mathrm{N}$ & $\%$ & $\mathrm{~L}$ & L-H & H3 & HT3 & FN & AN & \\
\hline Raspador & 4 & 3,6 & 3 & & & & 1 & & \\
\hline Buril & 7 & 6,3 & 6 & & 1 & & & & \\
\hline Perforador & 3 & 2,7 & 3 & & & & & & \\
\hline Ret.continuo & 5 & 4,5 & 4 & & 1 & & & & \\
\hline Ret.cont. M, Pa & 4 & 3,6 & 1 & 1 & 2 & & & & \\
\hline Truncadura & 4 & 3,6 & 3 & & & & & 1 & \\
\hline Escotadura & 29 & 26,1 & 22 & & 1 & 4 & 1 & 1 & \\
\hline Denticulado & 22 & 19,8 & 17 & 1 & & & 1 & 1 & 2 \\
\hline Raedera & 5 & 4,5 & 5 & & & & & & \\
\hline Raclette & 1 & 0,9 & 1 & & & & & & \\
\hline Astillada & 1 & 0,9 & 1 & & & & & & \\
\hline Dorso & 14 & 12,6 & 5 & & 1 & 8 & & & \\
\hline Geométricos & 2 & 1,8 & 2 & & & & & & \\
\hline Diverso & 4 & 3,6 & 4 & & & & & & \\
\hline Microburil & 2 & 1,8 & & & 1 & 1 & & & \\
\hline Picante triédrico & 1 & 0,9 & 1 & & & & & & \\
\hline Ret./rotura & 1 & 0,9 & & & 1 & & & & \\
\hline Escot./rot. & 2 & 1,8 & 1 & & 1 & & & & \\
\hline TOTAL & 111 & 100 & 79 & 2 & 9 & 13 & 3 & 3 & 2 \\
\hline
\end{tabular}

Cuadro C.29: tipología de piezas retocadas en cuarcita 


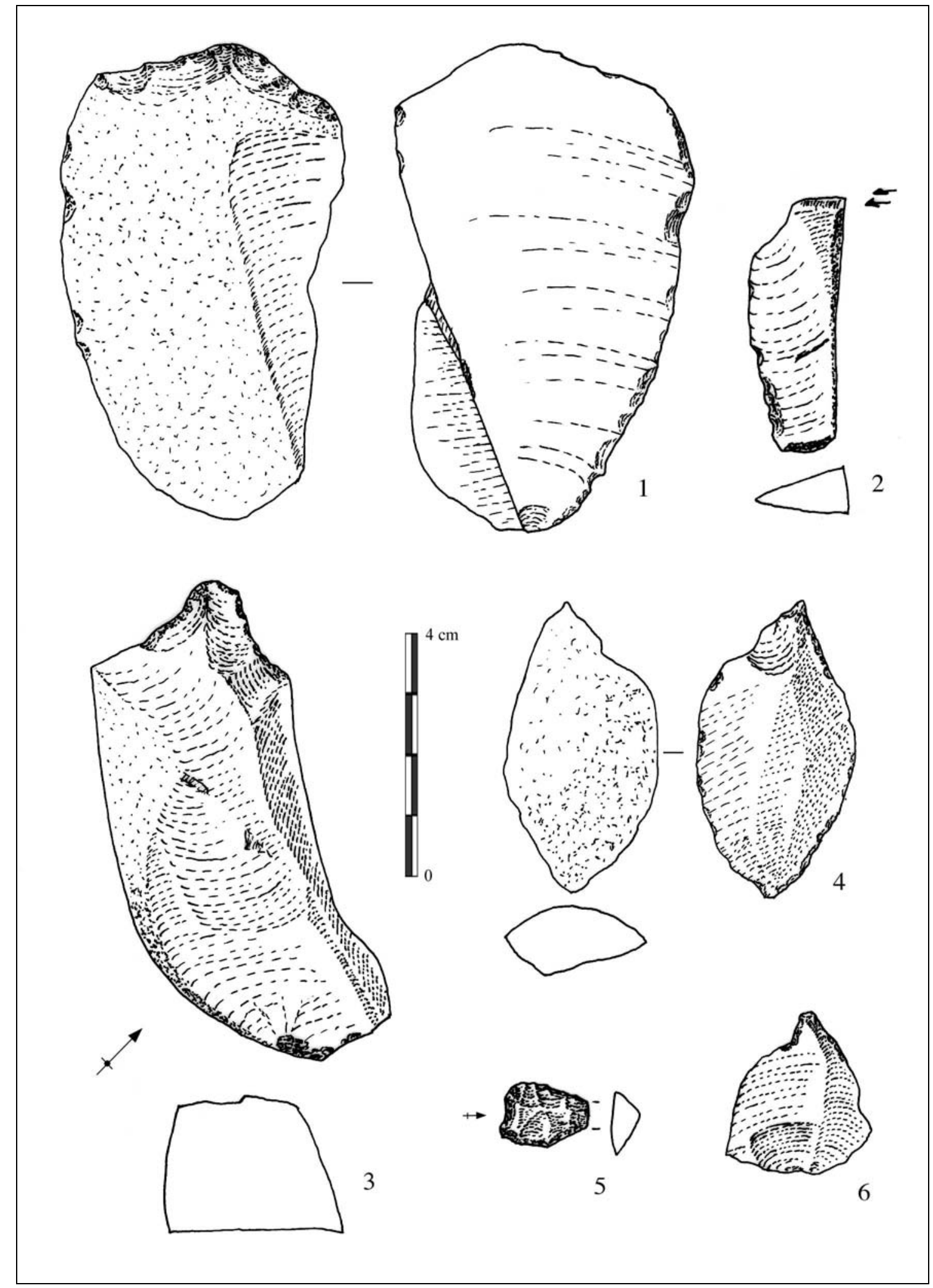

Figura C.12: Piezas retocadas de cuarcita: Raspadores (1, 3, 5), buril (2) y perforadores $(4,6)$. 


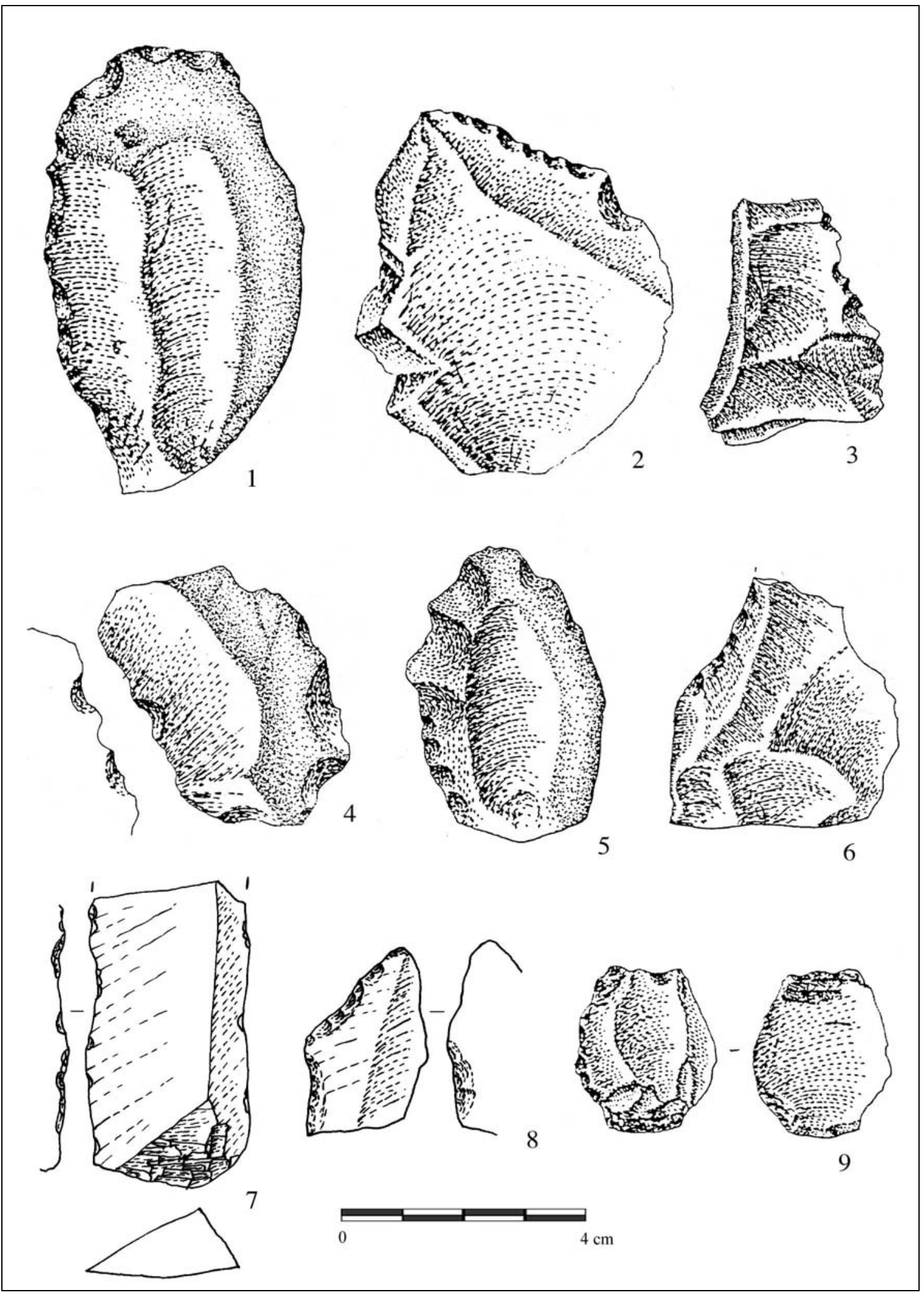

Figura C.13: Piezas retocadas de cuarcita: denticulados-escotaduras (1 a 6), retoque continuo (7), pieza retocada y apuntada (8) y astillada (9). Dibujos 1 a 6 y 9 realizados por R. M ${ }^{a}$ Yágüez. 


\section{IV.6.6.- CADENAS OPERATIVAS}

Las cadenas operativas presentes en cuarcita, a partir de los esquemas operativos identificados, son principalmente tres: la prismática-unipolar, la del núcleo-placa y la centrípeta. A éstas habría que sumar los esquemas técnicos que pertenecen a cadenas no estandarizadas o que no se han podido encuadrar en un esquema más genérico y el esquema más o menos oportunista que se ha determinado en el núcleo globuloso. La primera cadena tendría tres esquemas operativos o variantes, a partir de ella se han obtenido soportes laminares y lascas; las otras dos son exclusivamente de lascas. De estos tres esquemas conceptuales básicos, tan solo el centrípeto aparece exclusivamente en la cuarcita, los restantes son esquemas que se desarrollan también en las otras materias primas. Hay que añadir que en la cuarcita aparecen además otros esquemas más oportunistas en la gestión de los núcleos.

\begin{tabular}{|c|c|c|c|c|}
\hline CADENAS OPERATIVAS & \multicolumn{2}{|c|}{ ESQUEMA OPERATIVO } & $\mathrm{N}$ & ID n $^{\circ}$ \\
\hline PRISMÁTICA-UNIPOLAR & $\begin{array}{l}\text { Prismáticos } \\
\text { Superficie ancha } \\
\text { Unipolar-prismático }\end{array}$ & $\begin{array}{l}\text { P1 } \\
\text { SA-UP } \\
\text { UP-P1 }\end{array}$ & $\begin{array}{l}2 \\
2 \\
2\end{array}$ & $\begin{array}{l}1585,8365 \\
1580,1584 \\
1581,1583\end{array}$ \\
\hline NÓDULO TIPO-PLACA & & UP-PL & 1 & 328 \\
\hline CENTRÍPETA & & CT & 3 & $\begin{array}{r}1579,1586, \\
1590\end{array}$ \\
\hline NO ESTANDARIZADA & $\begin{array}{l}\text { Núcleo globuloso } \\
\text { Indeterminados }\end{array}$ & $\begin{array}{l}\text { NG } \\
\text { RN }\end{array}$ & $\begin{array}{l}1 \\
5\end{array}$ & $\begin{array}{r}1587 \\
63,1582, \\
1588,1589, \\
8369\end{array}$ \\
\hline & & & 16 & \\
\hline
\end{tabular}

Cuadro C.30: cadenas operativas y esquemas operativos de cuarcita.

\section{IV.6.6.1.- FASE 0}

La fase de adquisición de la materia prima sería, en principio, la misma para todas las cadenas operativas desarrolladas. Como se ha indicado en el capítulo sobre la materia prima, la cuarcita es una materia de origen local, cuyo lugar de adquisición estaría muy cercano al mismo yacimiento arqueológico. Esta materia se presenta en forma de cantos rodados y la mayoría procederían del entorno próximo, no obstante puede que haya alguna variante que provenga de otros lugares de adquisición. Los 
cantos serían llevados al yacimiento, donde se desarrollaría toda el proceso de la cadena operativa correspondiente.

\section{IV.6.6.2.- CADENA OPERATIVA PRISMÁTICA UNIPOLAR}

Se ha recogido bajo esta denominación los esquemas operativos que tienen una configuración del volumen de estructura prismática, cuyas principales partes son la superficie de extracciones y el plano de percusión, mientras el resto del núcleo (flancos, superficie posterior y base) juega un papel importante en la conformación y mantenimiento de la gestión del mismo, de modo que las características de la superficie de extracciones dependen de la gestión que se realice sobre los laterales, base o superficie posterior del núcleo. En cada uno de los esquemas operativos diferenciados dichas partes juegan un papel ligeramente diferente, pero en todos los casos es necesaria la realización de extracciones sobre esas zonas para el mantenimiento de la superficie de extracciones.

Una cadena con semejante conformación ha requerido necesariamente de una fase de preparación elaborada, de hecho en las otras cadenas la fase de preparación es muy corta o bien está ausente. Las primeras secuencias de preparación del núcleo están también presentes en el yacimiento, en el cual se ha desarrollado todo el proceso de talla de la cuarcita de forma completa. Tanto los nódulos fragmentados a consecuencia de secuencias se pruebas de los cantos recogidos, como las grandes lascas corticales, serían testimonio de esta fase de preparación. Asimismo la presencia de productos de acondicionamiento de gran tamaño vendría a reflejar el desarrollo del proceso de talla desde el inicio, pasando por las sucesivas secuencias de la gestión de los núcleos.

El estado de abandono en que se encuentran los núcleos no permiten diferenciar demasiado bien lo que habría sido la fase de preparación inicial, así que los distintos esquemas operativos corresponden a la síntesis de los métodos de preparación y explotación aplicados. Los esquemas operativos diferenciados son los siguientes:

1. Esquema operativo de los núcleos prismáticos (P1). La superficie de extracciones se sitúa sobre una superficie alargada del nódulo, los flancos y la base tienen una colocación ortogonal respecto a ella. El avance del 
débitage se produce de forma frontal y la carena y cintra se mantienen por esa conformación de los flancos. En uno de los núcleos uno de los flancos y la base son aristas que servirán de apoyo a crestas mediante las cuales se rectifica la carena y cintra del núcleo.

2. Esquema operativo de los núcleos de superficie ancha (SA-UP). La superficie de extracciones se sitúa sobre una superficie ancha del núcleo, empleando un plano de percusión bastante amplio, la parte posterior del núcleo forma un diedro opuesto a la superficie de extracciones. La explotación se produce de forma frontal o semi-envolvente, avanzando hacia uno de los laterales con la ayuda a veces de "piezas con flanco". Sobre el otro lateral se recurre al método de la cresta sobre esa arista, para rectificar la cintra de la superficie de extracciones. La base por su parte será controlada desde la superficie posterior mediante extracciones que tienden a truncarla. Las extracciones son lascas en uno de los núcleos y hojas en otro ejemplar.

3. Esquema operativo tipo unipolar-prismático (UP-P1). La superficie de extracciones está enmarcada por un plano de percusión amplio y una base paralela a él, conformada a partir de una gran extracción que trunca el núcleo. La longitud de las extracciones está por tanto delimitada entre estos dos planos, permitiendo un auto-mantenimiento de la carena. El proceso de débitage avanza de forma semi-envolvente, con tendencia a que las extracciones sean convergentes. Se obtienen así lascas y quizás hojitas.

El primer esquema operativo encaja en el esquema prismático tipo-B identificado en el chert negro y sería un esquema prismático más o menos “clásico” que no se adapta demasiado bien a este tipo de materia. El segundo y tercer esquema también aparecen en el chert negro y parecen ser esquemas que se adecuan mejor a la obtención de soportes laminares en cuarcita. A partir de los núcleos presentes en el conjunto se podría decir que los esquemas de orientación laminar que mejor funcionan en cuarcita son aquellos que utilizan una superficie de extracciones ancha, con un plano de percusión muy amplio; el inconveniente de esta conformación es que la longitud de las extracciones es escasa. 


\section{IV.6.6.3.- CADENA OPERATIVA DEL NÓDULO TIPO-PLACA}

Como se explicó para el chert negro, este esquema conceptual es muy simple ya que se aprovechan las características morfológicas de un tipo de nódulo (en forma de placa) para adaptar de forma rápida, casi sin preparación, un método de explotación de lascas. Estas características básicas, resumidas en una superficie estrecha y larga delimitada por sendos planos naturales, se adaptan para aprovechar al máximo sus características técnicas. Dicha superficie se va a explotar a partir de su eje menor y mediante un avance de la talla de tipo periférico, aprovechando todo el contorno del nódulo. La carena se puede controlar bastante bien debido a la escasa longitud de la superficie de extracciones. En cuanto a la cintra, el propio avance de la talla puede ir corrigiendo los defectos de su curvatura, y en todo caso, existe el recurso al cambio del plano de percusión, volteando el núcleo e invirtiendo las funciones del plano de percusión y la base del núcleo.

Se consigue así una explotación rápida de lascas por el contorno del núcleo, el único problema es que la longitud de las mimas está delimitada a unos tres centímetros como máximo.

\section{IV.6.6.4.- CADENA OPERATIVA CENTRÍPETA}

Este esquema conceptual sería de los más “clásicos” presentes en el yacimiento, en el sentido de que se encuadraría dentro de la tradición de los métodos centrípetos de explotación de un núcleo, cuya presencia en los esquemas de débitage se remonta prácticamente al Paleolítico inferior.

El método que aparece en El Espertín no es demasiado complejo, las fases de preparación y explotación del núcleo estarían muy cercanas y se basarían en la explotación de cantos rodados de río a partir de la arista periférica del núcleo. Sobre dicha arista se producen las extracciones de tendencia centrípeta sobre las superficies que conforma el núcleo. En dos de los núcleos parece que hay una superficie preferente sobre la otra, de forma que la segunda (con restos de córtex) podría considerarse como plano de percusión. El perfil de ambos núcleos refleja también el desequilibrio entre ambas superficies. El otro núcleo en cambio tiene un perfil con la arista más centrada 
entre ambas caras, sobre él se habría llevado a cabo un tipo de explotación alterno de sendas superficies. No obstante las zonas de explotación de las superficies no se superponen, es decir la cara superior se explota sobre todo en su parte distal, mientras que la inferior en su zona proximal; de este modo este núcleo puede haber seguido el mismo esquema de explotación privilegiando una de las superficies.

El resultado de este esquema son lascas, extraídas de forma bastante rápida, ya que si bien podría considerar un cierto grado de preparación de la superficie que actuará como plano de percusión, dicha conformación no es demasiado elaborada.

\section{IV.6.6.5.- CADENAS OPERATIVAS MÁS OPORTUNISTAS}

Tanto el núcleo globuloso como los restos de núcleo tienen unos esquemas de explotación basados sobre todo en la explotación de superficies aptas para ello a partir de un ángulo también favorable. Es una forma de obtener lascas de forma rápida, tanto a partir de nódulos fragmentos de forma más o menos amorfa, como de núcleos explotados mediante otros esquemas.

\section{IV.6.6.6.- FASE DE RETOQUE - USO}

La mayor parte de las piezas retocadas en cuarcita se realizan sobre lasca (las tres cuartas partes), seguido por los soportes laminares (20\%) y los productos de acondicionamiento. A pesar del pequeño número de hojas-hojitas retocadas, hay una selección evidente de este tipo de soportes para ser retocados, dentro de la también escasez de soportes laminares con que contamos en cuarcita. De hecho hay un uso especializado de las hojitas para las piezas de dorso, como en el resto de las materias del yacimiento.

Las lascas por su parte tienen un uso diversificado en los distintos tipos de útiles retocados, especialmente en los “útiles de fondo común” (raspadores, raederas, perforadores, buriles), pero hay que reseñar la abundancia de escotaduras y denticulados en lascas de cuarcita, de hecho estos dos tipos suponen casi la mitad de los retocados en esta materia. 
Hay que reseñar la presencia no solo de los útiles más típicos de la tradición paleolítica, sino también de tipos "novedosos”, como son los geométricos. A este respecto destaca el hecho de que no solo aparecen dos triángulos propiamente dichos, sino que también hay huellas de uno de los procesos de fabricación identificados en el yacimiento, la "técnica de microburil”, sobre hojitas de cuarcita. Se ha planteado la posibilidad por tanto de la existencia de más geométricos de este tipo de materia pero en hojas-hojitas, sin que se hayan encontrado en la colección disponible. 


\section{IV.7.- CUARZO}

El cuarzo tiene una representación muy pequeña dentro del conjunto de El Espertín; con 147 elementos ni siquiera llega a un 2\% del material lítico. Como se indicó en el capítulo sobre materias primas, hay un cuarzo lechoso y otro más hialino, no obstante ambas variedades pueden corresponder a un mismo tipo de afloramiento de cuarzo, con un grado de cristalización diferente.

\section{IV.7.1.- CARACTERÍSTICAS GENERALES}

\section{IV.7.1.1.- LISTA TECNOLÓGICA, GRUPOS TECNOLÓGICOS}

La lista tecnológica del cuarzo no tiene demasiados tipos de soportes (cuadro Q.1), de hecho las piezas se distribuyen en unos pocos tipos, los más abundantes son las lasquitas de los debris (con un 38\%) y las lascas de tercer orden (32\%), teniendo el resto una representación muy pequeña.

En la representación de los grupos tecnológicos (cuadro Q.2) se observa mucho mejor cómo el cuarzo se resume en dos grupos básicamente: el de los debris, que casi supone la mitad de este tipo de materia (48\%), y el de las lascas (37\%), completado por los indeterminados (14\%) y la presencia prácticamente anecdótica de un resto de núcleo. 


\begin{tabular}{|c|c|c|c|c|}
\hline GRUPO TECNOLÓGICO & $N^{\circ}$ TEC. & SOPORTE & $\mathbf{N}$ & $\%$ \\
\hline GRUPO 0 (nódulos) & 0 & Nódulo & & \\
\hline $\begin{array}{l}\text { GRUPO } 1 \\
\text { (lascas) }\end{array}$ & $\begin{array}{l}1 \\
2 \\
2-5 \\
3 \\
3-6 \\
4\end{array}$ & $\begin{array}{l}\text { Lasca de primer orden } \\
\text { Lasca de segundo orden } \\
\text { Lasca laminar de segundo orden } \\
\text { Lasca de tercer orden } \\
\text { Lasca laminar } \\
\text { Hoja de primer orden }\end{array}$ & $\begin{array}{l}3 \\
4\end{array}$ & \begin{tabular}{r|}
2,0 \\
2,7 \\
32,7
\end{tabular} \\
\hline $\begin{array}{l}\text { GRUPO } 2 \\
\text { (soportes laminares) }\end{array}$ & $\begin{array}{l}5 \\
6 \\
6-\mathrm{FN} \\
7 \\
8\end{array}$ & $\begin{array}{l}\text { Hoja de segundo orden } \\
\text { Hoja de tercer orden } \\
\text { Hoja de tercer orden con flanco } \\
\text { Hojita de segundo orden } \\
\text { Hojita de tercer orden }\end{array}$ & & \\
\hline $\begin{array}{l}\text { GRUPO } 3 \text { (productos de } \\
\text { acondicionamiento) }\end{array}$ & $\begin{array}{l}9 \\
10 \\
11 \\
12 \\
13\end{array}$ & $\begin{array}{l}\text { Lámina cresta } \\
\text { Tableta de núcleo } \\
\text { Semitableta de núcleo } \\
\text { Flanco de núcleo } \\
\text { Arista de núcleo y otros }\end{array}$ & & \\
\hline $\begin{array}{l}\text { GRUPO } 4 \\
\text { (núcleos) }\end{array}$ & $\begin{array}{l}14 \\
15 \\
16 \\
17 \\
18\end{array}$ & $\begin{array}{l}\text { Núcleo prismático con un plano } \\
\text { Núcleo prismático con dos planos } \\
\text { Núcleo sobre lasca } \\
\text { Núcleo globuloso } \\
\text { Resto de núcleo } \\
\end{array}$ & 1 & 0,7 \\
\hline GRUPO 7 (golpes buril) & 19 & Golpe de buril & & \\
\hline $\begin{array}{l}\text { GRUPO } 5 \\
\text { (indeterminados) }\end{array}$ & $\begin{array}{l}23 \\
24 \\
25\end{array}$ & $\begin{array}{l}\text { Astilla de talla } \\
\text { Chunk } \\
\text { Indeterminado }\end{array}$ & $\begin{array}{l}9 \\
5 \\
7 \\
\end{array}$ & $\begin{array}{l}6,1 \\
3,4 \\
4,8 \\
\end{array}$ \\
\hline $\begin{array}{l}\text { GRUPO } 6 \\
\text { (debris) }\end{array}$ & $\begin{array}{l}\text { DEB-LT } \\
\text { DEB-AT }\end{array}$ & $\begin{array}{l}\text { Debris: lasquita } \\
\text { Debris: astilla e indeterminados }\end{array}$ & $\begin{array}{l}56 \\
14\end{array}$ & $\begin{array}{r}38,1 \\
9,5\end{array}$ \\
\hline & & & 147 & 100,0 \\
\hline
\end{tabular}

Cuadro Q.1: lista tecnológica de la cuarzo.

\begin{tabular}{|llr|}
\hline GRUPOS TEC. & N & \% \\
\hline 0 & & \\
1 & 55 & 37,4 \\
2 & & \\
3 & & \\
4 & 1 & 0,7 \\
5 & 21 & 14,3 \\
6 & 70 & 47,6 \\
7 & & \\
\hline & 147 & 100 \\
\hline
\end{tabular}

Cuadro Q.2: grupos tecnológicos de la cuarzo. 
El cuarzo, por tanto, ha sido objeto de un proceso de talla bastante restringido, limitado a la obtención de unas pocas lascas. El elevado número de debris indica que el débitage se realizó dentro del yacimiento, incluso resulta bastante llamativo el porcentaje de debris respecto al resto de soportes, ya que curiosamente es la materia con más debris del yacimiento. Esto plantea la duda de si estos debris realmente son producto del proceso de talla desarrollado en esta reducida muestra de cuarzo, o si se puede plantear la hipótesis de que esta materia haya sido objeto de un débitage más intenso o secuencias de retoque de las que no han quedado más huellas. En este planteamiento hay que sumar el hecho de que prácticamente no hay núcleos, tan solo se ha clasificado un resto de núcleo de tamaño muy pequeño que además tiene un tratamiento un tanto peculiar, ya que presenta una morfología piramidal con un esquirlado en la arista opuesta al plano de percusión. Esta ausencia de núcleos podría explicarse, en parte, porque el cuarzo tiene unas características para la talla ligeramente diferentes al sílex, lo cual implica que los esquemas, así como los gestos adoptados en su talla, no van a dejar las mismas características que en las otras materias. En fin, se trata de una materia cuya “lectura tecnológica” resulta bastante difícil y algunos de los chunks y piezas indeterminadas pueden corresponder a núcleos fragmentados que no se reconocen demasiado bien.

\section{IV.7.1.2.- ROTURAS}

IV.7.1.2.1.- TIPOS DE SOPORTES ROTOS

\begin{tabular}{|c|c|c|c|c|c|c|c|}
\hline \multirow{2}{*}{$\begin{array}{l}\text { GRUPO } \\
\text { TEC. }\end{array}$} & \multirow{2}{*}{ TIPO TEC. } & \multirow{2}{*}{ COMPLETOS } & \multicolumn{4}{|c|}{ FRAGMENTADOS } & \multirow{2}{*}{ TOTAL } \\
\hline & & & Distal & Mesial & Proximal & Roto & \\
\hline 1 & $\mathrm{~L}$ & 18 & 5 & 6 & 4 & 22 & 57 \\
\hline 4 & $\mathrm{~N}$ & 1 & & & & & \\
\hline 5 & IT & & & & & 21 & 21 \\
\hline \multirow[t]{3}{*}{6} & $\begin{array}{l}\text { LT } \\
\text { IT }\end{array}$ & 22 & 7 & 7 & 1 & $\begin{array}{l}19 \\
14\end{array}$ & $\begin{array}{l}56 \\
14\end{array}$ \\
\hline & & 41 & 12 & 13 & 5 & 76 & 147 \\
\hline & & $41(27,9)$ & \multicolumn{4}{|c|}{$106(72,1 \%)$} & \\
\hline
\end{tabular}

Cuadro Q.3: representación de los tipos de soportes enteros y fragmentados de cuarzo, teniendo en cuenta la totalidad de las piezas. 
La mayoría de las piezas de cuarzo están rotas (72\%), lo cual es similar a lo que sucede en el resto de las materias, tanto la cuarcita como el sílex. En el cuadro Q.3 se muestran los distintos fragmentos de lascas presentes en el conjunto.

\section{IV.7.1.2.2.- TIPOS DE ROTURAS}

El tipo de rotura predominante en el cuarzo es aquella que afecta a todos los lados (DP), con un 23\%, seguida por la rotura distal, la próximo-distal y la proximallateral, con el 15\% cada una, a continuación están las roturas proximales y laterales, y con menor representación, las distales-laterales y las bilaterales (cuadro Q.4).

\begin{tabular}{|l|cccccccc|r|}
\hline & BL & DL & DP & DS & LT & PD & PL & PX & TOTAL \\
\hline GR.1:L & 3 & 1 & 5 & 6 & 7 & 6 & 10 & 4 & 42 \\
GR.6:DEB & & 3 & 15 & 7 & 2 & 7 & 3 & 6 & 43 \\
\hline N & 3 & 4 & 20 & 13 & 9 & 13 & 13 & 10 & 85 \\
$\%$ & 3,5 & 4,7 & 23,5 & 15,3 & 10,6 & 15,3 & 15,3 & 11,8 & 100 \\
\hline
\end{tabular}

Cuadro Q.4: tipos de roturas por grupos tecnológicos. BL: bilateral, DL: distal-lateral, DP: distal-lateral-proximal, DS: distal, LT: lateral, PD: proximal-distal, PL: proximal-lateral, PX: proximal.

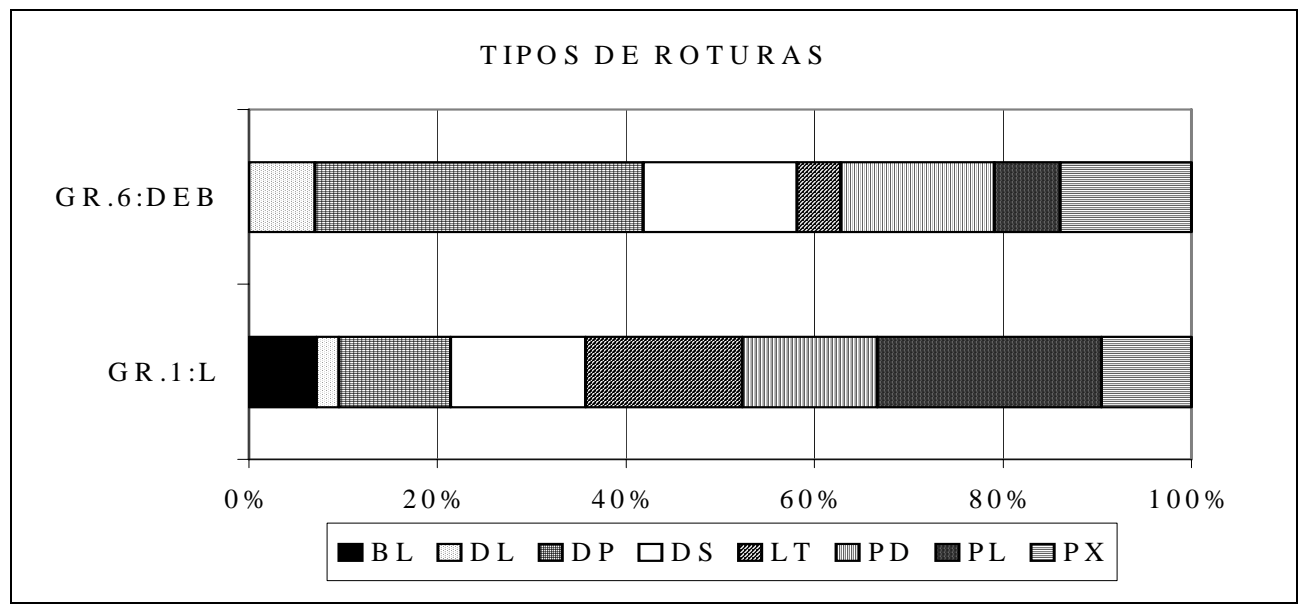

Gráfico Q.1: porcentaje de los tipos de roturas por grupos tecnológicos. Tipos de roturas: BL: bilateral, DL: distal-lateral, DP: distal-proximal-lateral, LT: lateral, PD: proximal-distal, PL: proximal-lateral, PX: proximal. 
Si observamos cómo afectan estas roturas separando las lascas y los debris (gráfico Q.1), las primeras tienen una representación de los distintos tipos de rotura más o menos equilibrada, pero predomina la proximal-lateral; en cambio los debris tienen una sobrerrepresentación de la rotura por todos lados, suponiendo un 35\% del total de las roturas. Es, por tanto, este alto porcentaje de fragmentos indeterminados inferiores a un centímetro el causante del predominio de este tipo de rotura en el conjunto del cuarzo. De nuevo aparece el grupo de los debris en un aspecto que sobresale respecto al resto de las materias.

IV.7.1.2.3.- CAUSA DE LA ROTURA

\begin{tabular}{|l|cc|cc|}
\hline & GR.1 & GR.6 & N & $\%$ \\
\hline Flexión & 4 & 10 & 14 & 16,5 \\
Indeterminada & 15 & 14 & 29 & 34,1 \\
Percusión & 23 & 19 & 42 & 49,4 \\
\hline \multicolumn{2}{l}{} & & 85 & 100 \\
\hline
\end{tabular}

Cuadro Q.5: causa de las roturas del cuarzo, por grupos tecnológicos.
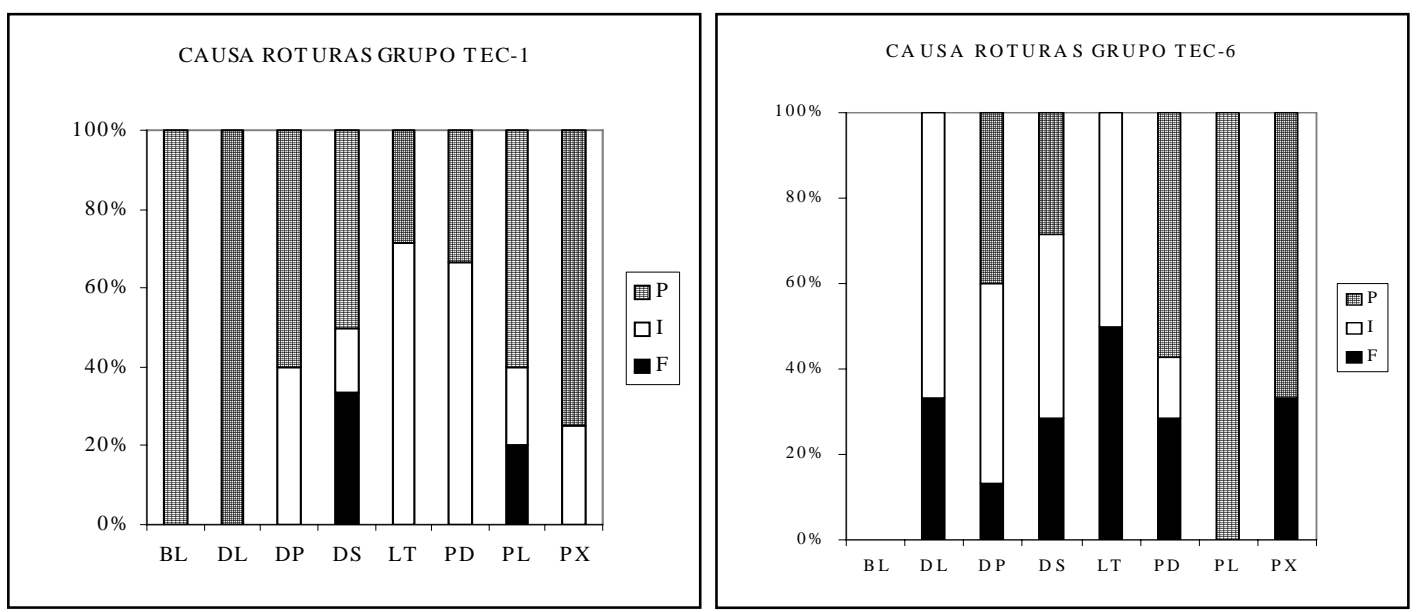

Gráfico Q.2: porcentaje de representación de las causas de la rotura según los distintos tipos de fracturas y por grupos tecnológicos. En el eje de abscisas se colocan los tipos de fracturas recogidos: BL: bilateral, DL: distal-lateral, DP: distal-proximal-lateral, LT: lateral, PD: proximal-distal, PL: proximal-lateral, PX: proximal. En el eje de ordenadas se situa el porcetaje de los tipos de roturas: P: percusión, I: indeterminada, F: por flexión.

La causa mayoritaria de rotura (cuadro Q.5) es por percusión (49\%), seguida por la indeterminada (34\%) y la flexión (16\%). Respecto a cómo afecta estas distintas 
causas dependiendo de los tipos de soportes, la flexión es más frecuente en los debris que en las lascas (gráfico Q.2).

\section{IV.7.1.3.- CÓRTEX}

La presencia de córtex se reduce al 7\% del conjunto de cuarzo (cuadro Q.6).

\begin{tabular}{|l|rrrrrr|r|}
\hline & \multicolumn{7}{|c}{ CÓRTEX } \\
\hline & 1 & $\%$ & 2 & $\%$ & 3 & $\%$ & TOTAL \\
\hline L & 3 & & 4 & & 50 & & 57 \\
Nuc. & & & & & & & \\
IT & & & & & 20 & & 20 \\
DEB:LT & 1 & & 2 & & 53 & & 56 \\
DEB:IT & & & & & 14 & & 14 \\
\hline TOTAL & 4 & 2,7 & 6 & 4,1 & 137 & 93,2 & 147 \\
\hline
\end{tabular}

Cuadro Q.6: presencia de córtex en los principales tipos tecnológicos, con sus respectivos porcentajes.

\section{IV.7.1.4.- DATOS MÉTRICOS}

Las medidas de los soportes de cuarzo son bastante reducidas, ninguno de ellos alcanza los tres centímetros de longitud (cuadro Q.7).

\section{IV.7.1.4.1.- TIPOS DE SOPORTES}

Las lascas tienen una media de $14 \mathrm{~mm}$ de longitud, 11 de anchura y 5 de grosor. El resto de núcleo ni siquiera llega a un centímetro y medio en sus dimensiones mayores, los chunks e indeterminados tienen 15 mm de longitud, 9 de anchura y 6 de grosor; por último los debris tienen unas medias de $8 \mathrm{~mm}$ de longitud, 7 de anchura y 3 de grosor. Lo único reseñable de estas medidas, aparte de su pequeña dimensión, es su grosor, elevado en comparación al tamaño general. 


\begin{tabular}{|rccc|}
\hline GR1:L & L & A & G \\
N & 16 & 30 & 52 \\
Rango & $6-25$ & $6-20$ & $1-11$ \\
Media & $\mathbf{1 3 , 3 1}$ & $\mathbf{1 1 , 0}$ & $\mathbf{4 , 9 8}$ \\
Desviación & 4,56 & 3,88 & 2,58 \\
& & & \\
GR4: N & L & A & G \\
N & 1 & 1 & 1 \\
Rango & $\mathbf{1 4}$ & $\mathbf{1 4}$ & $\mathbf{1 0}$ \\
Media & & & \\
Desviación & & & \\
& & & \\
GR5: IT & L & $\mathbf{A}$ & $\mathbf{G}$ \\
N & 20 & 20 & 20 \\
Rango & $9-28$ & 14,8 & 4,12 \\
Media & $\mathbf{1 4 , 8}$ & $\mathbf{8 , 6 0}$ & $\mathbf{5 , 5 2}$ \\
Desviación & 4,12 & 3,83 & 3,87 \\
& & & \\
GR6: DEB & $\mathbf{L}$ & $\mathbf{A}$ & $\mathbf{G}$ \\
$\mathrm{N}$ & 71 & 71 & 71 \\
Rango & $5-10$ & $3-10$ & $1-6$ \\
Media & $\mathbf{7 , 9 0}$ & $\mathbf{6 , 9 3}$ & $\mathbf{2 , 7 1}$ \\
Desviación & 1,52 & 1,65 & 1,08 \\
\hline & & &
\end{tabular}

Cuadro Q.7: datos métricos de la radiolarita, por grupos tecnológicos. N: número de elementos. L: longitud, A: anchura, G: grosor.

IV.7.1.4.2.- TALÓN

\begin{tabular}{|rcc|}
\hline GR1: L & L & A \\
N & 5 & 9 \\
Rango & $2,3-15,5$ & $1-7,7$ \\
Media & $\mathbf{1 0 , 1 0}$ & $\mathbf{5 , 6 2}$ \\
Desviación & 4,99 & 2,09 \\
& & \\
GR6: DEB & $\mathbf{L}$ & $\mathbf{A}$ \\
$\mathrm{N}$ & 3 & 5 \\
Rango & $3-8$ & $1,5-4,2$ \\
Media & $\mathbf{5 , 8 7}$ & $\mathbf{2 , 2 8}$ \\
Desviación & 2,58 & 1,09 \\
\hline
\end{tabular}

Cuadro Q.8: datos métricos de los talones de cuarzo, por grupos tecnológicos. N: número de elementos. L: longitud, A: anchura, G: grosor. 
La dimensión del talón es, al igual que el grosor general, bastante grande en comparación con el pequeño tamaño de las lascas. Su anchura es de 6 mm en las lascas y 2 en los debris (cuadro Q.8). La explicación de estos datos es que el modo de percusión es de tipo interno y muy posiblemente mediante percusión directa con percutor duro.

\section{IV.7.1.5.- ACCIDENTES}

Solo hay 17 piezas afectadas por algún tipo de accidente, en todos los casos, excepto un reflejado, se trata de pseudoburiles de Siret (cuadro Q.9). Como en la cuarcita, la relativa abundancia de este tipo de accidente está muy probablemente relacionada con el modo de talla y los gestos necesarios para la percusión del cuarzo. El tamaño del talón se relacionaba ya con la percusión directa con percutor duro; la intensidad necesaria para aplicar la fuerza es, seguramente, la causante de este tipo de accidente, que se produce en el momento del impacto del percutor.

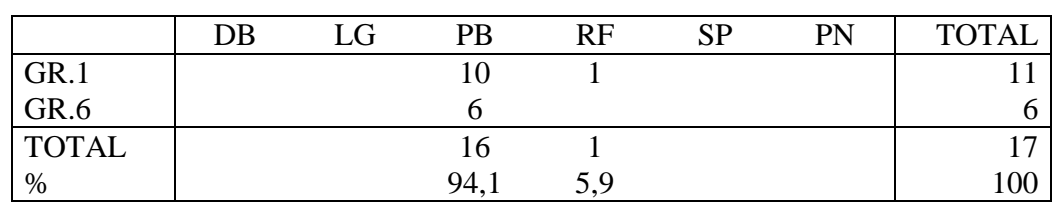

Cuadro Q.9: accidentes de talla según los distintos grupos tecnológicos. DB: dobre bulbo, LG: fragmento en lengüeta, PB: pseudoburil de Siret, RF: reflejado, SP: sobrepasado, PN: plano natural

\section{IV.7.1.6.- TIPOS DE TALÓN}

Más de la mitad de las piezas no tienen talón y, en las restantes, predominan los talones rotos (22\%) sobre los lisos (11\%), apareciendo también en menor número los puntiformes y los diedros (cuadro Q.3). El cuarzo es la única materia en la que no son los talones lisos los más predominantes, este hecho posiblemente tenga relación con el tipo de materia y de nuevo la gestión peculiar que hay que realizar sobre ella. 


\begin{tabular}{|c|c|c|c|c|c|c|c|}
\hline & $\mathrm{C}$ & $\mathrm{F}$ & $\mathrm{L}$ & $\mathrm{O}$ & $\mathrm{P}$ & $\begin{array}{ll}\mathrm{R} & \mathrm{S}\end{array}$ & TOTAL \\
\hline GR.1 & 2 & & 10 & 30 & 3 & 12 & 57 \\
\hline GR.6 & 2 & & 4 & 46 & 2 & 16 & 70 \\
\hline $\mathrm{N}$ & 4 & & 14 & 76 & 5 & 28 & 127 \\
\hline$\%$ & 3,15 & & 11,02 & 59,84 & 3,94 & 22,05 & 100 \\
\hline
\end{tabular}

Cuadro Q.10: tipos de talón por grupos tecnológicos. C: cortical, D: diedro, F: facetado, L: liso, O: sin talón, P: puntiforme, R: roto, S: suprimido.

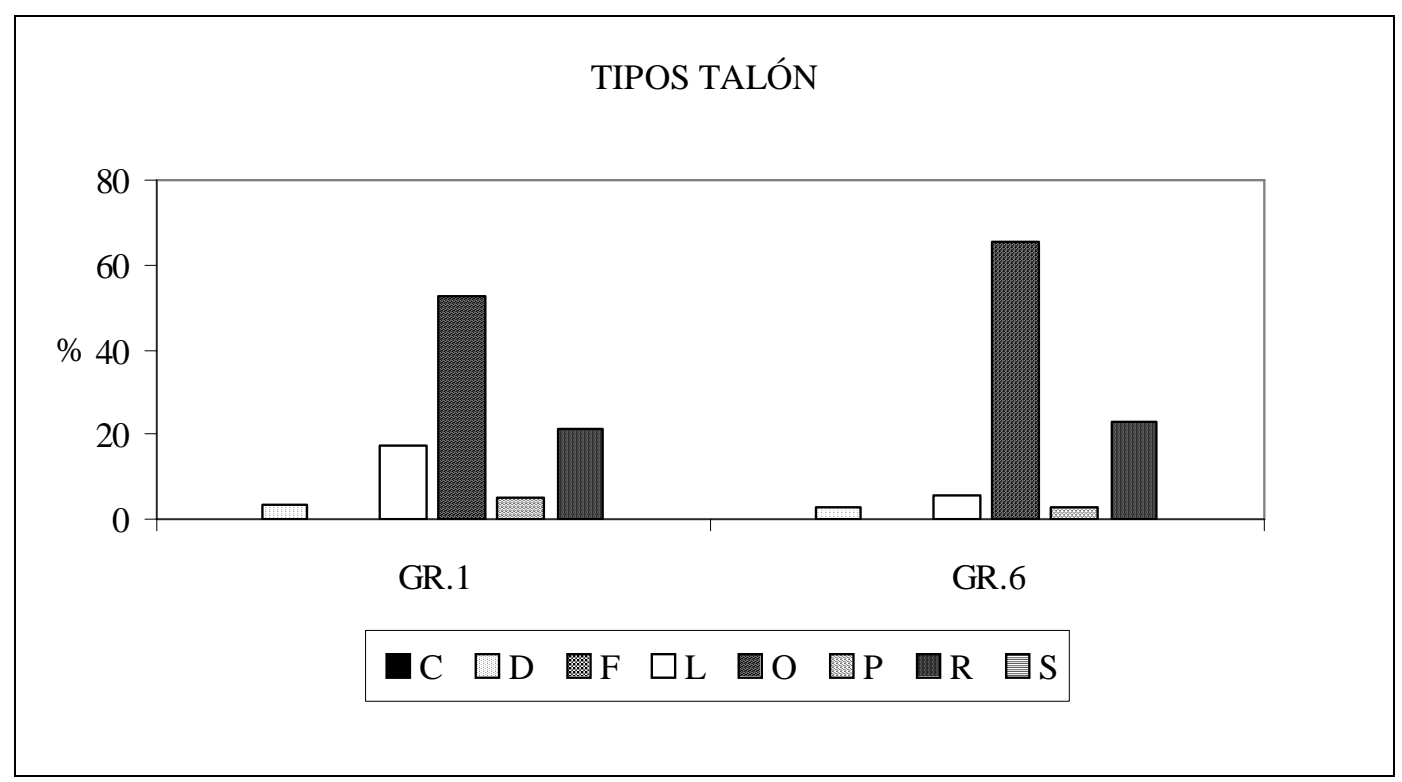

Gráfico Q.3: tipos de talón por grupos tecnológicos. C: cortical, D: diedro, F: facetado, L: liso, O: sin talón, P: puntiforme, R: roto, S: suprimido.

\section{IV.7.1.7.- PREPARACIÓN DEL PUNTO DE IMPACTO}

El porcentaje de preparación del punto de impacto es muy bajo en el cuarzo, se limita al 14\% (cuadro Q.11), constituyendo la materia que presenta una menor preparación del frente de talla. Esta preparación está presente sobre todo en las lascas, mientras que en los debris apenas hay restos de preparación.

\begin{tabular}{|c|c|cc|cc|}
\hline \multirow{2}{*}{ TOTAL } & \multicolumn{2}{|c|}{ PIEZAS CON TALÓN } & \multicolumn{2}{c|}{ PIEZAS PREPARADAS } \\
\cline { 3 - 6 } & & $\mathrm{N}$ & $\%$ & $\mathrm{~N}$ & $\%$ \\
\hline GR-1 & 57 & 23 & 40,4 & 8 & 34,8 \\
GR-6 & 70 & 46 & 65,7 & 2 & 4,3 \\
\hline & 127 & 69 & 54,3 & 10 & 14,5 \\
\hline
\end{tabular}

Cuadro Q.11: piezas con talón y preparación relativa dentro de los distintos grupos tecnológicos. 
En el tipo de preparación predomina el esquirlado sobre el retoque, mientras que la abrasión prácticamente no existe ya que solo hay un caso (cuadro Q.12). Dentro de los tipos de talón los que más se preparan son los puntiformes y los diedros (cuadro Q.13), los lisos son los que tienen más variantes en cuanto al tipo de preparación (cuadro Q.14).

\begin{tabular}{|l|cc|cc|}
\hline & \multirow{2}{*}{ GR-1 } & \multirow{2}{*}{ GR-6 } & \multicolumn{2}{|c|}{ TOTAL } \\
\cline { 4 - 5 } & & \multicolumn{2}{|c|}{$\mathrm{N}$} & $\%$ \\
\hline Facetado & & & & \\
Abrasión & 1 & & 1 & 10,0 \\
Esquirlado & 5 & 2 & 7 & 70,0 \\
Retocado & 2 & & 2 & 20,0 \\
\hline & 8 & 2 & 10 & 100 \\
\hline
\end{tabular}

Cuadro Q.12: tipos de preparación según los distintos grupos tecnológicos.

\begin{tabular}{|c|c|c|c|c|c|c|c|}
\hline & $\mathrm{C}$ & $\mathrm{D}$ & $\mathrm{F}$ & $\mathrm{L}$ & $\mathrm{P}$ & $\mathrm{R}$ & $\mathrm{S}$ \\
\hline PIEZAS CON TALÓN & & 4 & & 14 & 5 & 28 & \\
\hline PIEZAS PREPARADAS & & 2 & & 5 & 3 & & \\
\hline$\%$ & & 50 & & 35,7 & 60 & & \\
\hline
\end{tabular}

Cuadro Q.13: porcentaje de preparación en los distintos tipos de talón disponibles. C: cortical, D: diedro, F: facetado, L: liso, O: sin talón, P: puntiforme, R: roto, S: suprimido.

\begin{tabular}{|c|c|c|c|c|c|c|c|}
\hline & $\mathrm{C}$ & $\mathrm{D}$ & $\mathrm{F}$ & $\mathrm{L}$ & $P$ & $\mathrm{R}$ & $\mathrm{S}$ \\
\hline \multicolumn{8}{|l|}{ Facetado } \\
\hline Abrasión & & & & 1 & & & \\
\hline Esquirlado & & 2 & & 2 & 3 & & \\
\hline Retocado & & & & 2 & & & \\
\hline TOTAL & & 2 & & 5 & 3 & & \\
\hline$\%$ & & 20,0 & & 50,0 & 30,0 & & \\
\hline
\end{tabular}

Cuadro Q.14: tipos de preparación sobre los distintos tipos de talón. C: cortical, D: diedro, F: facetado, L: liso, O: sin talón, P: puntiforme, R: roto, S: suprimido.

\section{IV.7.1.8.- ÁNGULO DE PERCUSIÓN}

En el ángulo del frente de talla predomina un ángulo de tipo medio (70-80²), tendente a recto. En el ángulo entre el talón y la cara superior (ángulo 2) predomina el situado entre $70-80^{\circ}$, y en segundo lugar entre 80-90 (cuadro Q. 15). 

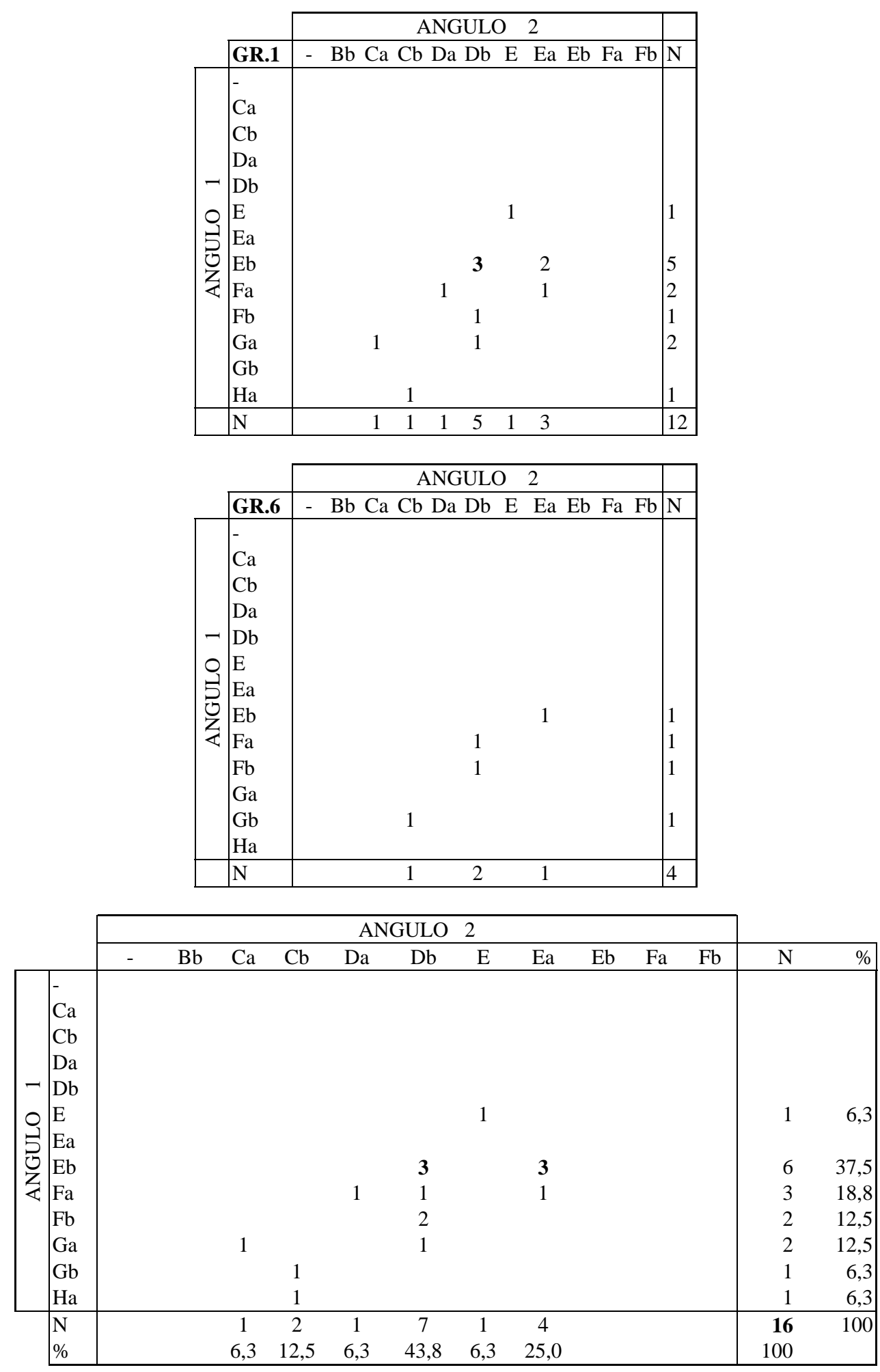

Cuadro Q.15: ángulos de percusión por grupos tecnológicos (en los dos primeros cuadros) y en el conjunto del cuarzo (en el tercero). Angulo 1: ángulo interno (entre talón y el bulbo). Angulo 2: ángulo externo o la cornisa (entre talón y la cara superior). $\mathrm{Bb}=30-40^{\circ}, \mathrm{Ca}=40-50^{\circ}, \mathrm{Cb}=50$ $60^{\circ}, \mathrm{Da}=60-70^{\circ}, \mathrm{Db}=70-80^{\circ}, \mathrm{Ea}=80-90^{\circ}, \mathrm{Eb}=90-100^{\circ}, \mathrm{Fa}=100-110^{\circ}, \mathrm{Fb}=110-120^{\circ}, \mathrm{Ga}=120-$ $130^{\circ}, \mathrm{Gb}=130-140^{\circ}, \mathrm{Ha}=140-150^{\circ}$. 


\section{IV.7.1.9.- ALTERACIONES}

No se han observado alteraciones en cuarzo.

\section{IV.7.1.10.- MODO DE TALLA}

El modo de talla aplicado en la gestión del cuarzo es muy probablemente la percusión directa con percutor duro a lo largo de todo el proceso de débitage, sin que existan cambios a lo largo de dicho proceso, así cabe deducir de los siguientes aspectos:

- dimensión del talón bastante grande en los distintos tipos de soporte, incluso en los debris

- grosor de los soportes

- abundancia de los pseudoburiles de Siret

- $\quad$ se ha reconocido en el conjunto alguna lasca cuyo modo de talla ha sido con percutor duro

\section{IV.7.2.- NÚCLEOS}

Tan solo hay una pieza que se ha definido como resto de núcleo, se trata de una pieza de pequeño tamaño, cuyo esquema técnico no se aprecia demasiado bien. La apariencia que tiene es la de un núcleo piramidal, cuyas últimas extracciones han sido pequeñas lascas de forma unipolar y semi-envolvente. Pero dicho núcleo presenta la peculiaridad de un esquirlado en la arista opuesta al plano de percusión, por lo que puede haberse utilizado para algún tipo de trabajo. 


\section{IV.7.3.- SOPORTES}

En cuarzo no hay productos de acondicionamiento, tan solo lascas, debris y piezas indeterminadas. Las lascas son de pequeño tamaño, su media está en $13 \mathrm{~mm}$ de longitud, 11 de anchura y 5 de grosor (cuadro Q.7). Respecto a la longitud (gráfico Q.4), la mayoría de las lascas son inferiores a la media, existiendo un máximo en los 11$12 \mathrm{~mm}$, no obstante hay un fragmento mesial de lasca cuya longitud es la mayor dimensión de todo el conjunto de cuarzo, llegando casi a los 4 cm (37 mm en concreto). En la anchura no obstante la media es bastante ajustada (gráfico Q.5), ya que la mayoría de las lascas oscilan entre los 9-12 mm, si bien existe también un buen número de ellas en torno a los 17-18 mm. 


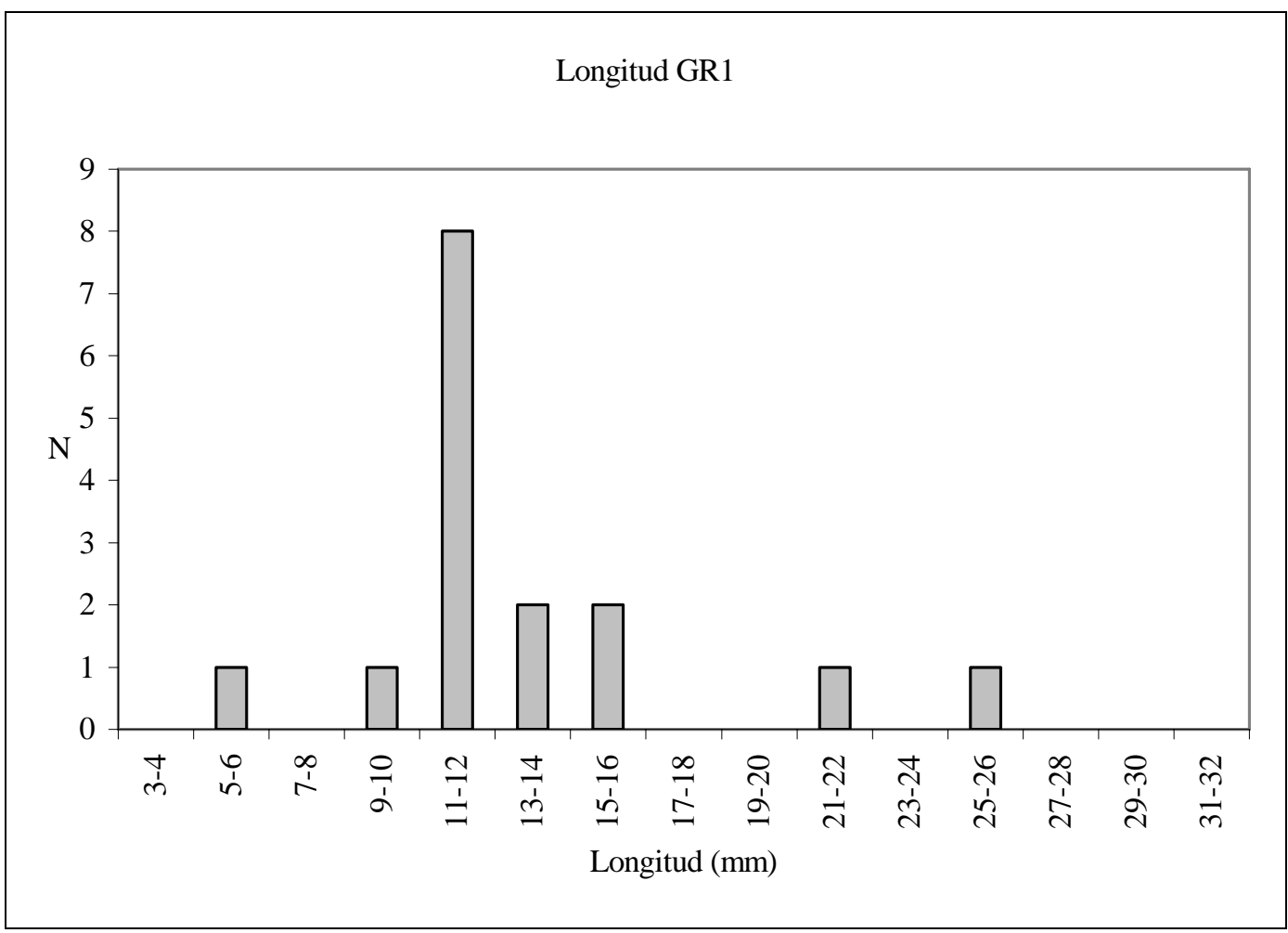

Gráfico Q.4: Longitud lascas (grupo tecnológico 1) de cuarzo, n=18.

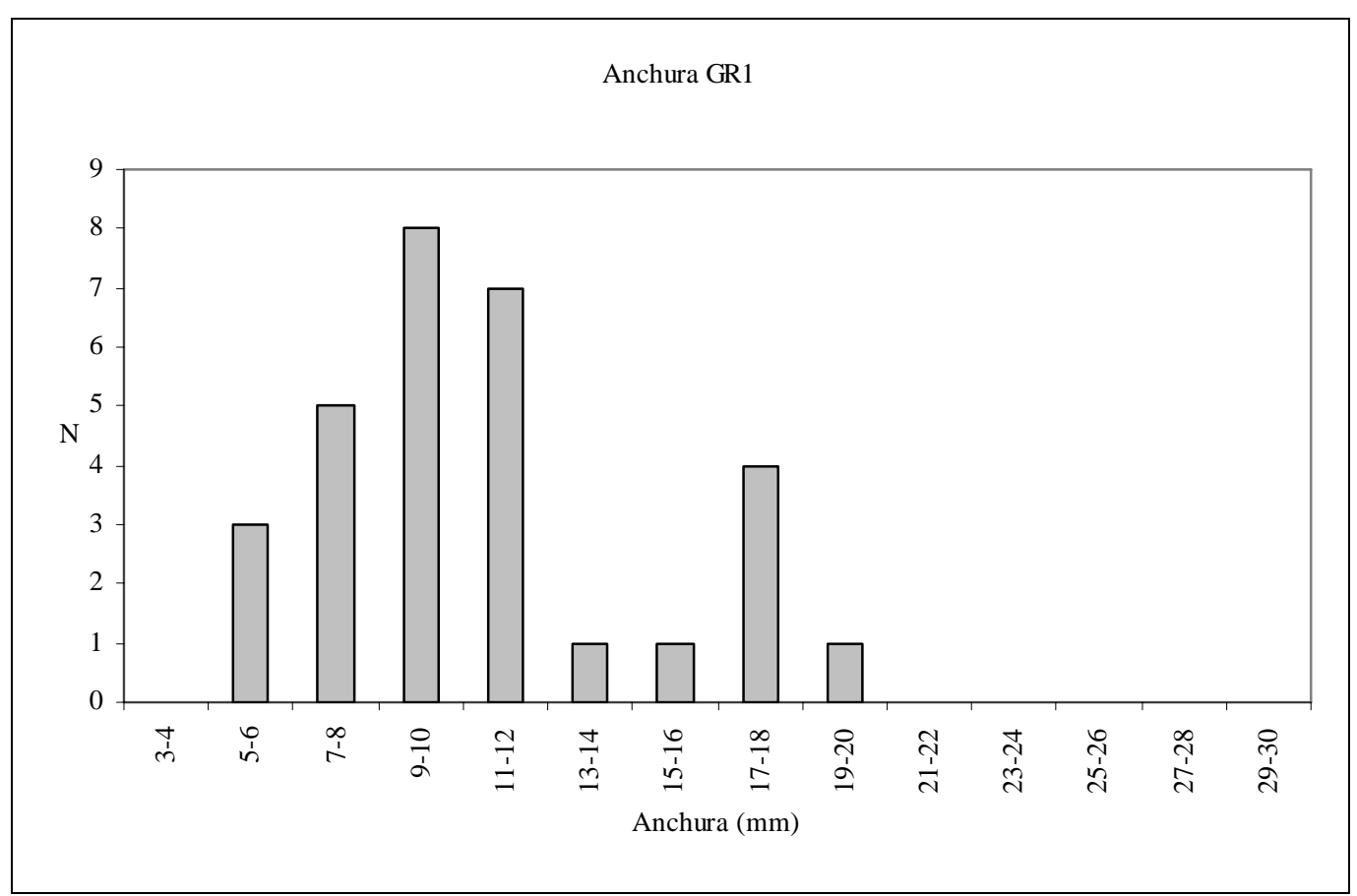

Gráfico Q.5: Anchura lascas (grupo tecnológico 1) de cuarzo, n=33. 


\section{IV.7.4.- PIEZAS RETOCADAS}

Se ha identificado un buril y un raspador atípico sobre lascas de cuarzo transparente en ambos casos. El buril es diedro recto y el raspador tiene un frente muy corto sobre la zona distal izquierda de la lasca. En ambos casos son lascas que superan las medidas medias del conjunto (el buril es un fragmento distal de $19 \mathrm{~mm}$ de longitud, 12 de anchura y 4 de grosor; el raspador es una lasca de $13 \mathrm{~mm}$ de longitud, $18 \mathrm{de}$ anchura y 5 de grosor), por lo que existe al parecer la misma tendencia a seleccionar los soportes mayores para ser retocados.

\section{IV.7.5.- CADENAS OPERATIVAS}

El proceso de talla presente en el cuarzo es difícil de precisar en un esquema conceptual amplio. Parece que hay una única cadena operativa que sería bastante simple ya que no aparecen productos de acondicionamiento que revelen una gestión compleja del proceso, ni tampoco hay una gran variedad de soportes representados. De hecho no contamos con demasiados elementos para concretar dicha cadena, la ausencia sobre todo de núcleos impide que se puedan apreciar los esquemas técnicos desarrollados.

Se podría plantear incluso la existencia de una ruptura en la cadena del cuarzo, a partir de los siguientes aspectos:

- $\quad$ poca variedad de tipos de soportes (lascas y chunks)

- $\quad$ ausencia de núcleos

- $\quad$ elevado número de debris

Se plantea la hipótesis de que estos tres aspectos se expliquen porque falta parte del conjunto lítico de cuarzo (núcleos y otros soportes, puede que piezas retocadas incluso), que se habría llevado fuera del yacimiento. Aquí se habría producido entonces un proceso de talla (del cual serían testimonio las lascas, chunks y debris) más amplio de lo que cabría suponer, y parte de sus elementos habrían sido llevados por los grupos prehistóricos al abandonar el yacimiento. 
No se puede concretar la cadena operativa que dirige la talla del cuarzo, tan solo se puede decir, a partir del conjunto con que contamos, que se trata de una cadena de carácter simple, mediante percusión directa con percutor duro, encaminada a la obtención de lascas pequeñas, existiendo la posibilidad de que parte del conjunto lítico (sobre todo las piezas retocadas, a juzgar por el alto porcentaje de debris presentes) no se encuentre en el yacimiento. 
CAPÍTULO V -

EL PROCESO DE TALLA

PRESENTE EN “EL ESPERTÍN” 



\section{V.1.- ESTRATEGIAS DE APROVISIONAMIENTO Y REPRESENTACIÓN DEL PROCESO TÉCNICO}

La estrategia de adquisición de las materias primas es de tipo intensivo y local, produciéndose un aprovechamiento de los recursos disponibles en el entorno inmediato del yacimiento. Se ha deducido este modelo de adquisición a partir de varios aspectos del conjunto lítico, pero sobre todo, en función del volumen de materia local explotada. Tanto el número de elementos de materia prima local como su tamaño y las técnicas de talla aplicadas indican un tratamiento intensivo de tal materia.

Los datos que mejor nos pueden servir para valorar el tipo de explotación de las distintas variedades líticas son los siguientes:

- la disponibilidad de las materias primas presentes

- el número de elementos de cada materia

- el tamaño de las piezas de cada materia

- representación del proceso operativo en las distintas materias

\section{V.1.1.- DISPONIBILIDAD DE MATERIAS PRIMAS Y REPRESENTACIÓN DE LAS DISTINTAS MATERIAS}

En el capítulo sobre materias primas se han descrito, por una parte, las variedades de materias presentes en El Espertín y, por otra, algunos de los tipos de materias disponibles en el contexto geológico del yacimiento.

Respecto a los tipos de materias que se encuentran en el conjunto lítico del yacimiento, hay dos grandes grupos, el sílex en primer lugar y, por otra parte, la cuarcita y el cuarzo (Gráfico V.1).

En cuanto al contexto litológico del yacimiento, se ha comprobado cómo presenta una estructura geomorfológica sumamente compleja. En ella se han localizado varias formaciones que pueden haber sido fuentes potenciales de dos materias: el chert negro y la radiolarita. La suma de estas variedades líticas del yacimiento (chert negro y 
radiolarita) que, a su vez están presentes en la litología del entorno, supone el 78,8\% del conjunto lítico (Cuadro V.1). A ellas se podría añadir la cuarcita que, si bien no se ha localizado de forma efectiva en el contexto geológico, hay varias formaciones que contienen cuarcitas. Si añadimos la cuarcita, se obtiene que el 96,5\% de las materias talladas en el Espertín procederían de un entorno cercano al yacimiento.

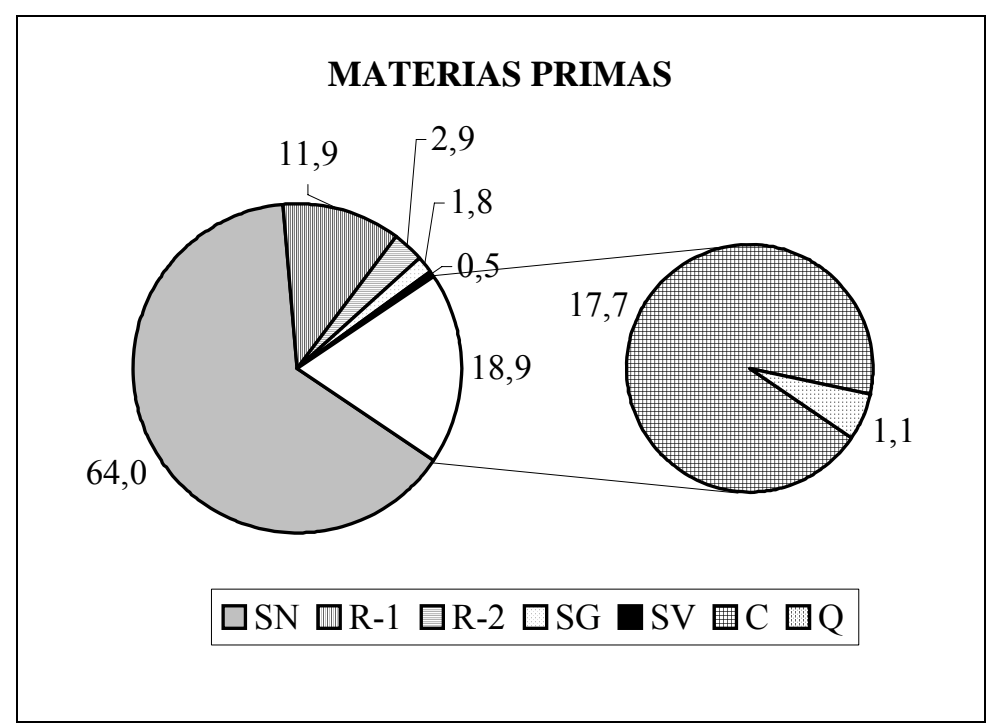

Gráfico V.1: porcentaje de las distintas materias primas de la industria lítica de El Espertín; en el gráfico circular mayor está el conjunto de los sílex, en el menor la cuarcita y el cuarzo. SN: sílex/chert negro, R-1: radiolarita-1, R-2: radiolarita-2, $\mathrm{SG}$ : sílex gris, $\mathrm{SV}$ : sílex varios, $\mathrm{C}$ : cuarcita, Q: cuarzo.

\begin{tabular}{|l|c|c|}
\hline MP & Entorno geológico cercano & \% en El Espertín \\
\hline Sílex/chert negro & Sí & 64,0 \\
Radiolarita & Sí & 14,8 \\
Sílex gris & ¿? & 1,8 \\
Sílex varios & No & 0,5 \\
Cuarcita & Sí (pero no localizado) & 17,7 \\
Cuarzo & $¿ ?$ & 1,1 \\
\hline
\end{tabular}

Cuadro V.1: presencia de los distintos tipos de materias primas en El Espertín y en su entorno geológico

Hay que tener en cuenta, además, que de las materias que no podemos relacionar con dicho entorno inmediato hay una al menos (el sílex gris, que supone un $2 \%$ del conjunto) que podría encontrarse en este contexto litológico, ya que esta variedad silícea aparece en forma de cantos fluviales en posición derivada en las terrazas del río Esla. 
Como resultado del análisis de las materias potenciales en el entorno del yacimiento, tenemos que hay tan solo un 1,5\% de dichas materias (los sílex varios y el cuarzo) que no se encuentran en dicho contexto y que al menos un 97\% de ellas proceden de dicho entorno local.

La precisión de lo que se puede definir como "local", "foráneo" o "exótico" es un poco controvertida ya que es complicado valorar la lejanía o cercanía de los yacimientos. Se ha partido del examen de los mapas geológicos fundamentalmente el primero a escala 1:200.000 (Julivert et al., 1981) y el segundo de escala más reducida, de 1:50.000 (Heredia et al., 1991). En un radio de $20 \mathrm{Km}$ de la cueva hay tanto radiolarita como formaciones susceptibles de contener chert. Como se puede observar en tales mapas, la complejidad de las formaciones en que aparecen estas materias, dificulta en gran medida la localización de afloramientos. No obstante, a partir de la presencia de este tipo de formaciones litológicas en el entorno de El Espertín, se puede decir que tanto el chert como la radiolarita son materias de origen local. Esta clasificación de "local" se puede extender probablemente a la cuarcita, ya que la localización de sus fuentes de aprovisionamiento es también complicada, pero en el contexto geológico son susceptibles de aparecer.

\section{V.1.2.- DIMENSIONES DE LAS MATERIAS PRIMAS}

Para tener una visión de conjunto del tamaño de las series líticas en las distintas materias primas se reflejan en los gráficos V.2 y V.3 las áreas de dispersión de la longitud, anchura y grosor según las materias. Del examen de dichos gráficos podemos destacar los siguientes aspectos:

- El chert negro y la cuarcita son las materias que tienen piezas de mayor tamaño, siendo el límite máximo $10 \mathrm{~cm}$ para el chert y $8 \mathrm{~cm}$ para la cuarcita.

- La radiolarita estaría a continuación de las materias anteriores, alcanzando unas dimensiones máximas de $6 \mathrm{~cm}$ en la radiolarita-1, y $5 \mathrm{~cm}$ en la radiolarita-2. 

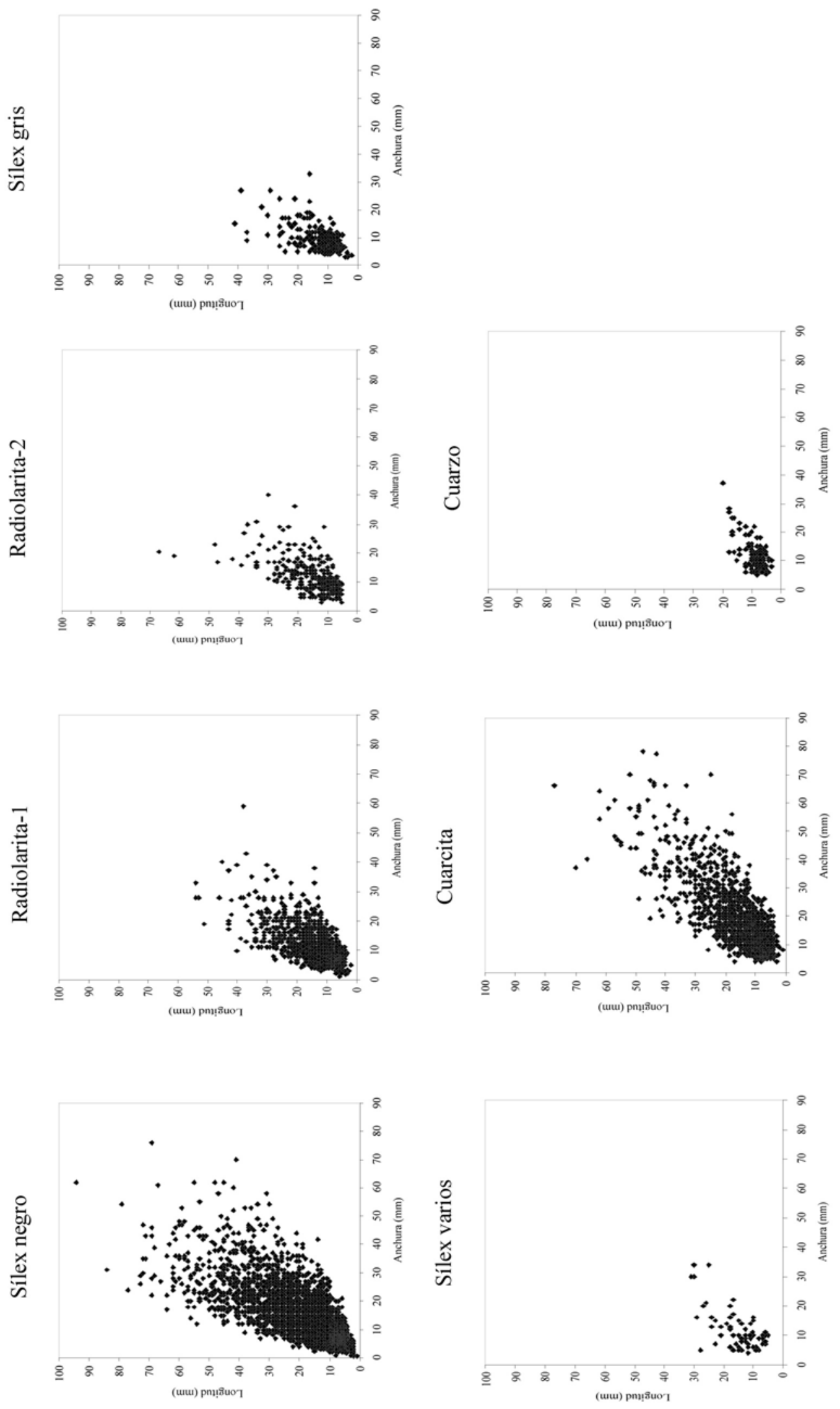

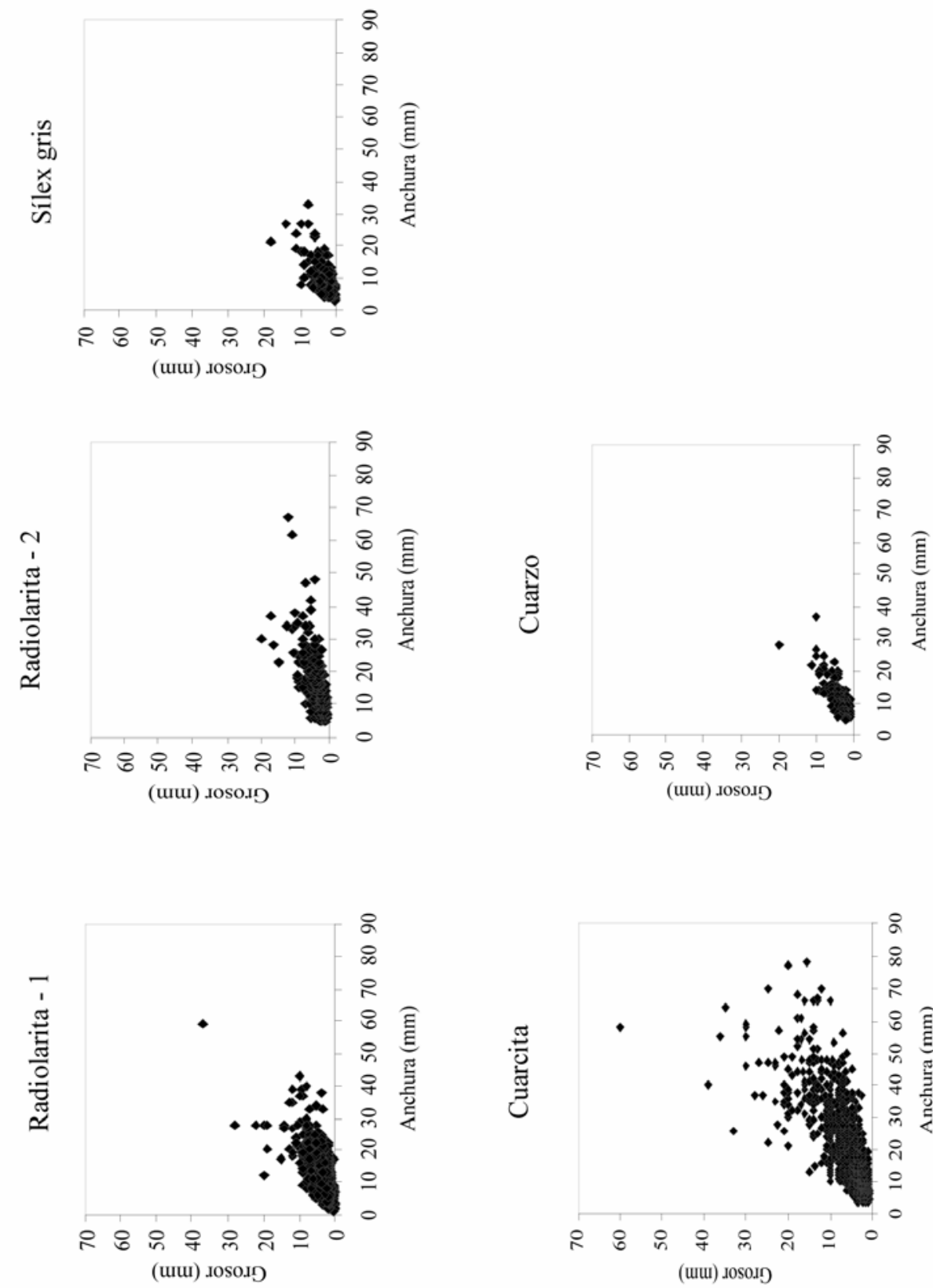

章
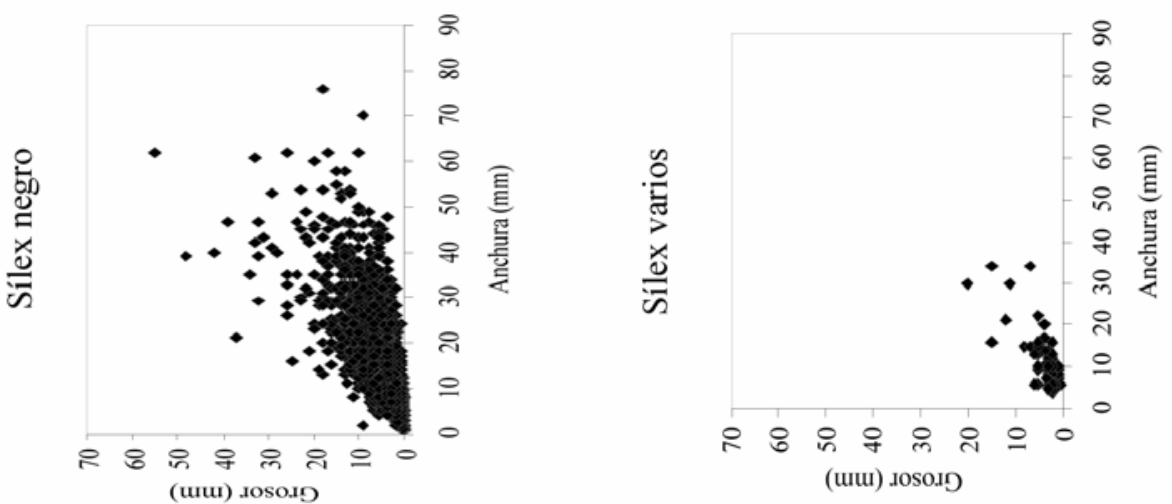

:0 
En la radiolarita tipo 2 hay dos elementos cuya longitud alcanza casi $7 \mathrm{~cm}$, sobresaliendo por tanto de la representación del conjunto. Al analizar las características técnicas de dichos elementos se ha planteado la posibilidad de que tales piezas hayan sido introducidas en el yacimiento procedente de una fase de débitage previa al proceso ejecutado en la cueva.

- Las materias que tienen una menor representación en el conjunto tienen unas dimensiones muy reducidas: el sílex gris apenas alcanza los $4 \mathrm{~cm}$; los sílex varios que superan los $3 \mathrm{~cm}$ corresponden a los núcleos; y el cuarzo sólo sobrepasa los $3 \mathrm{~cm}$ en una pieza.

\section{V.1.3.- REPRESENTACIÓN DEL PROCESO OPERATIVO}

\section{V.1.3.1.- PROCESOS OPERATIVOS Y MATERIAS PRIMAS: ESTRATEGIAS DE PRODUCCIÓN DIVERSIFICADAS}

Para tener una idea general del significado del proceso operativo presente en cada una de las materias trabajadas, se va a tener en cuenta la representación de los distintos grupos tecnológicos a lo largo de estas materias. En el gráfico V.4 se presenta el porcentaje de cada grupo tecnológico en cada una de las materias, en él se pueden observar dos comportamientos, que estarían relacionados con la abundancia de la materia correspondiente.

A. Las materias más abundantes, que son además las de origen local (chert negro, radiolarita y cuarcita), se caracterizan por:

- predominio del grupo tecnológico 1 (lascas), que supone en torno al $40 \%$ del material en los sílex y sobrepasa el $50 \%$ de la cuarcita

- alta representación de los debris (grupo 6), significando en torno al 30\%

- el grupo de los soportes laminares es el que más difiere en estas materias locales, suponen un $8 \%$ en la cuarcita, un $12 \%$ en el sílex negro y un $20 \%$ aproximadamente en la radiolarita. La causa de esta divergencia está en la especialización en la producción laminar de la radiolarita, frente a una producción mixta (de hojas y lascas) en las dos primeras. 

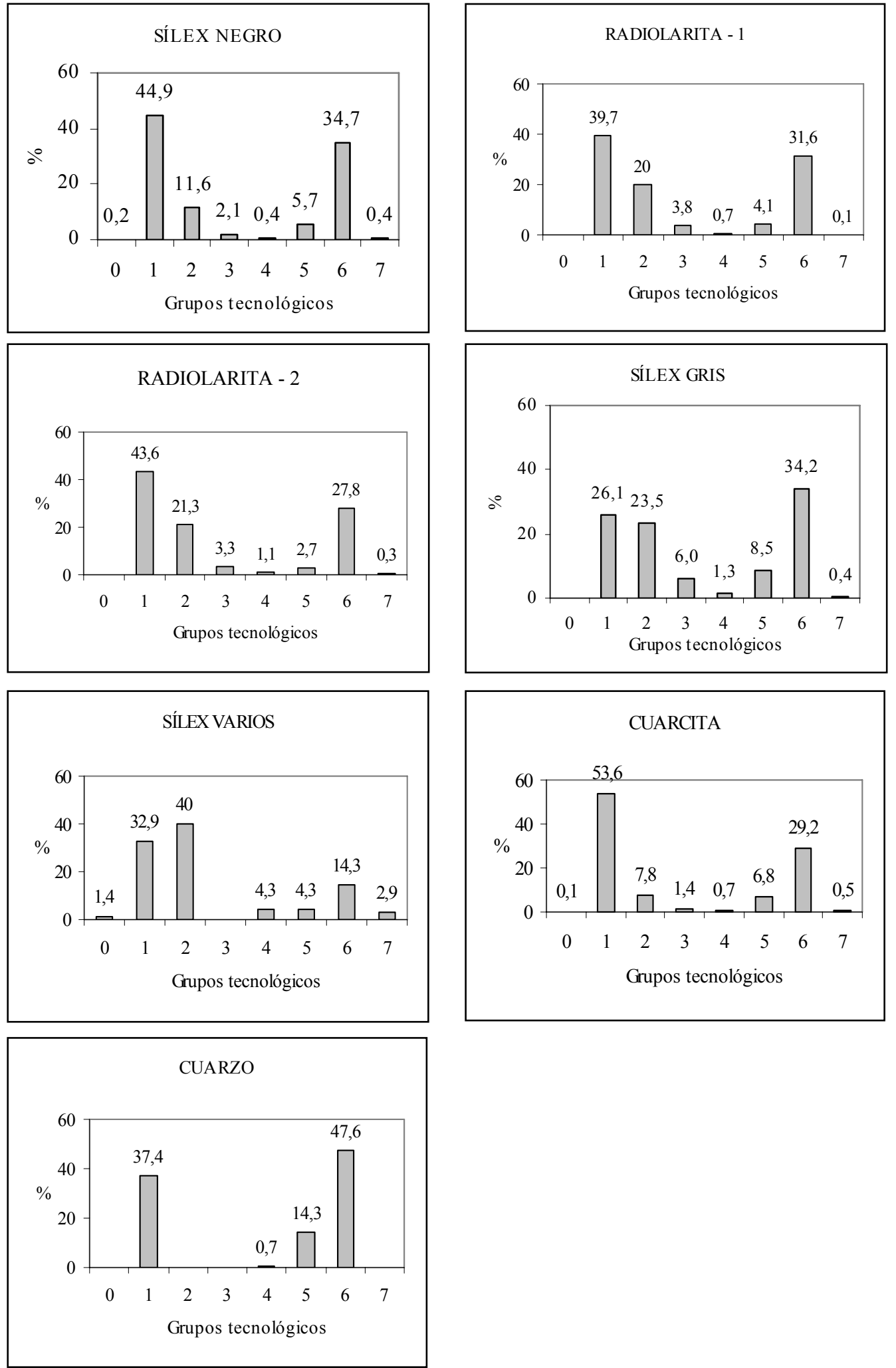

Gráfico V.4: porcentaje de los distintos grupos tecnológicos, según las materias primas. Grupo 0: nódulos, grupo 1: lascas, grupo 2: hojas y hojitas, grupo 3: productos de acondicionamiento, grupo 4: núcleos, grupo 5: piezas indeterminadas, grupo 6: debris, grupo 7: golpes de buril. 
B. Las materias primas con menor representación tienen un comportamiento más anómalo:

En el sílex gris:

- el grupo 2 alcanza casi la misma representación (23\%) que el grupo 1 (26\%), marcando una producción especializada de hojitas en esta variedad lítica

- el grupo 6 (debris) sigue teniendo una presencia importante, en torno al 30\%, como en las materias anteriores

En los sílex varios:

- los soportes laminares suponen el 40\% del conjunto, lo cual significa que se trata de la materia con mayor especialización laminar, superando en gran medida al grupo $1(30 \%)$

- los debris constituyen tan solo el $14 \%$ del conjunto, siendo la materia en la que menos están representados. Este dato se puede interpretar en el sentido de que se trata de la materia que menos se ha tallado en el yacimiento. En ella sólo se habrían llevado a cabo pequeñas secuencias de talla, sin que se encuentre representado todo el proceso operativo de las mismas ya que hay una ruptura de la cadena operativa

En el cuarzo:

- Sólo están representados tres grupos (lascas, indeterminados y debris), sin que haya presencia de un débitage laminar. En consecuencia el proceso operativo de esta materia difiere totalmente del resto.

- los debris alcanzan un 48\% del conjunto, siendo la materia con mayor representación de este grupo

A partir de esta representación de las distintas categorías de soportes, se puede constatar la existencia de un comportamiento operativo diferente según las materias. Estas diferencias en función de la abundancia de los distintos materiales, se pueden interpretar como consecuencia de la aplicación de distintas estrategias de explotación en relación con la cercanía de sus fuentes de aprovisionamiento. Esta explotación sería más diversificada en las materias locales y más especializada en las materias de origen 
desconocido. Incluso se puede observar una gradación en el nivel de especialización dentro de las mismas materias locales y en relación con el número de restos con que contamos; de manera que a mayor abundancia de la materia (chert negro y cuarcita), hay una producción mixta (lascas y hojas), mientras que sobre materias menos abundantes (radiolaritas), la producción es más especializada.

Se puede plantear la hipótesis de que este modelo de explotación diversificada de las materias está en relación con la lejanía del lugar de aprovisionamiento. De este modo, dentro de las materias disponibles en el entorno, se explotan más extensivamente y en mayor cantidad aquéllas más cercanas.

No obstante, en este tipo de comportamiento, podría influir también otro factor, relacionado con la abundancia de los recursos líticos. Si tenemos en cuenta esta variable, el hecho de que se exploten de forma muy abundante el sílex negro y la cuarcita puede deberse a que son las materias más abundantes (además de las más cercanas). Las radiolaritas, por su parte, puede que no se encuentren de forma tan habitual como las anteriores.

Teniendo en cuenta estos dos aspectos, se podría establecer el siguiente esquema para caracterizar las distintas materias que aparecen en el yacimiento:

- El sílex negro y la cuarcita: Son materias locales, las más numerosas del yacimiento (en conjunto suponen el $82 \%$ del conjunto lítico) y también las de mayor dimensión del conjunto. Cabe suponer que los lugares de adquisición de dicha materia no estén demasiado alejados del yacimiento y también que son las más abundantes en dicho contexto.

- La radiolarita: Es una materia local pero no es tan abundante como las anteriores, su tamaño es también menor y en ellas hay una mayor especialización en la producción laminar; además en la radiolarita-2 la cadena operativa está rota. Quizás las fuentes de aprovisionamiento de la radiolarita estén un poco más alejadas que el sílex negro y la cuarcita.

- El sílex gris: Tiene unas características que lo colocarían a medio camino entre la radiolarita y los sílex varios. De forma similar al sílex de radiolarios, tiene una elevada presencia de debris y predomina el grupo 1; en cambio la representación del grupo de los soportes laminares es muy elevada, 
indicando una mayor especialización. Siguiendo el esquema anterior, se podría plantear que es posible que la adquisición de este tipo de materia se encuentre más lejos que la radiolarita, o bien que su disponibilidad en el contexto geográfico sea menor.

- Los sílex varios: Tienen una representación del proceso operativo apropiada para un tipo de materias exógenas, sus rasgos característicos son una especialización total en los soportes laminares, superando a los soportes genéricos del grupo 1, y un bajo porcentaje de los debris.

\section{V.1.3.2.- SIGNIFICADO DE LA REPRESENTACIÓN DE LOS GRUPOS TECNOLÓGICOS}

Teniendo en cuenta el proceso operativo descrito a lo largo de las distintas materias; cabe extraer una serie de conclusiones de índole tecnológica a partir de la representación por grupos tecnológicos y su significado en el modelo de explotación desarrollado:

- El grupo 1 (grupo genérico de lascas) no es demasiado discriminante, parece reflejar la intensidad del proceso de talla desarrollado (en los sílex varios, que no se han tallado en el yacimiento, el grupo 1 no es el predominante), pero también objetivos de talla diferentes (en el cuarzo tampoco es el predominante) o producciones mixtas (su representación -sobre todo con relación al grupo 2- es más importante en el sílex negro y la cuarcita)

- El grupo 2 (soportes laminares) sería indicativo de la presencia de un débitage laminar. Su representación, en relación con el grupo 1, indicaría el grado de especialización en este tipo de producción. De este modo, en las materias con producción laminar especializada, el grupo 2 alcanza al menos el $20 \%$ del conjunto lítico (llegando hasta el $40 \%$ en las materias donde hay una sobrerrepresentación de este grupo debido a que se aportan artefactos retocados), en cambio, en las materias con explotación mixta, el porcentaje desciende al $12 \%$ en el sílex negro y el $8 \%$ en la cuarcita.

- El grupo 3 (productos de acondicionamiento) no es muy abundante porcentualmente (en ninguna materia supera el 6\%), pero su presencia es indicativa, como el grupo 6 , de cadenas continuas y procesos de talla más o menos intensos. Por esta razón están ausentes en los sílex varios, que tienen 
una representación parcial de la cadena operativa. Hay que reseñar que la ausencia de productos de acondicionamiento en el cuarzo se debe probablemente a que el proceso de talla de esta materia no tiene los mismos objetivos que las materias anteriores, ya se ha indicado que el cuarzo tiene unas singularidades propias.

- El grupo 4 (núcleos) y el 5 (indeterminados) no aportan ningún dato respecto a las características más genéricas del tipo de talla realizada, ya que aparecen, siempre con un porcentaje bajo (en especial los núcleos), en todas ellas, ya sean materias locales o exógenas o bien se hayan tallado de una forma más intensa o somera. Quizás una presencia relativamente alta de los indeterminados, como en el cuarzo, venga a indicar, bien un proceso peculiar de talla del que no se pueden reconocer con detalle sus soportes, o bien las dificultades de la talla de una materia dada.

- El grupo 6 (debris) parece constituir un índice del grado de intensidad de la talla in situ y de la representación de las distintas fases de la cadena operativa, de modo que tiene una importancia relevante en aquellas materias que han sufrido un proceso de talla intenso en el yacimiento, con una representación continua de la/s cadena/s ejecutada/s. En todas las materias los debris superan el 30\%, la única excepción son los sílex varios, en los que no llegan al 15\%. Recordemos que éstos tienen la cadena operativa rota, ya que en el yacimiento aparecen mayoritariamente las piezas retocadas y no hay constancia de su proceso de débitage.

\section{V.1.4.- ROTURAS E INTENSIDAD DEL PROCESO DE TALLA}

\section{V.1.4.1.- PORCENTAJE DE PIEZAS COMPLETAS}

El número de piezas rotas es bastante elevado en el conjunto lítico de El Espertín (Gráfico V.5). Son las materias locales (sílex negro y cuarcita) las que tienen más elementos completos, suponiendo un tercio del total; pero realmente tampoco hay demasiadas diferencias con materias más lejanas, como los sílex varios, que cuentan también con el 30\% de piezas completas. Es la radiolarita, en sus dos variedades, la 
materia que más roturas presenta, estando tan solo una cuarta parte de las piezas completas. El cuarzo se instala en una posición intermedia, con el $28 \%$ de elementos completos.

En consecuencia el índice de roturas de la industria lítica de este yacimiento se cifra en torno al 70\%, existiendo una mayor fragmentación en la radiolarita, debido posiblemente a la propia estructura heterogénea de la materia y sus abundantes planos de rotura internos. Quizás sea este factor relativo a la homogeneidad en la estructura de la materia (la "fábrica", tal y como se ha especificado en el capítulo sobre las materias primas), uno de los determinantes en este atributo, de forma que las materias con mayor número de irregularidades en su composición, se fracture más frecuentemente en el propio proceso de talla.

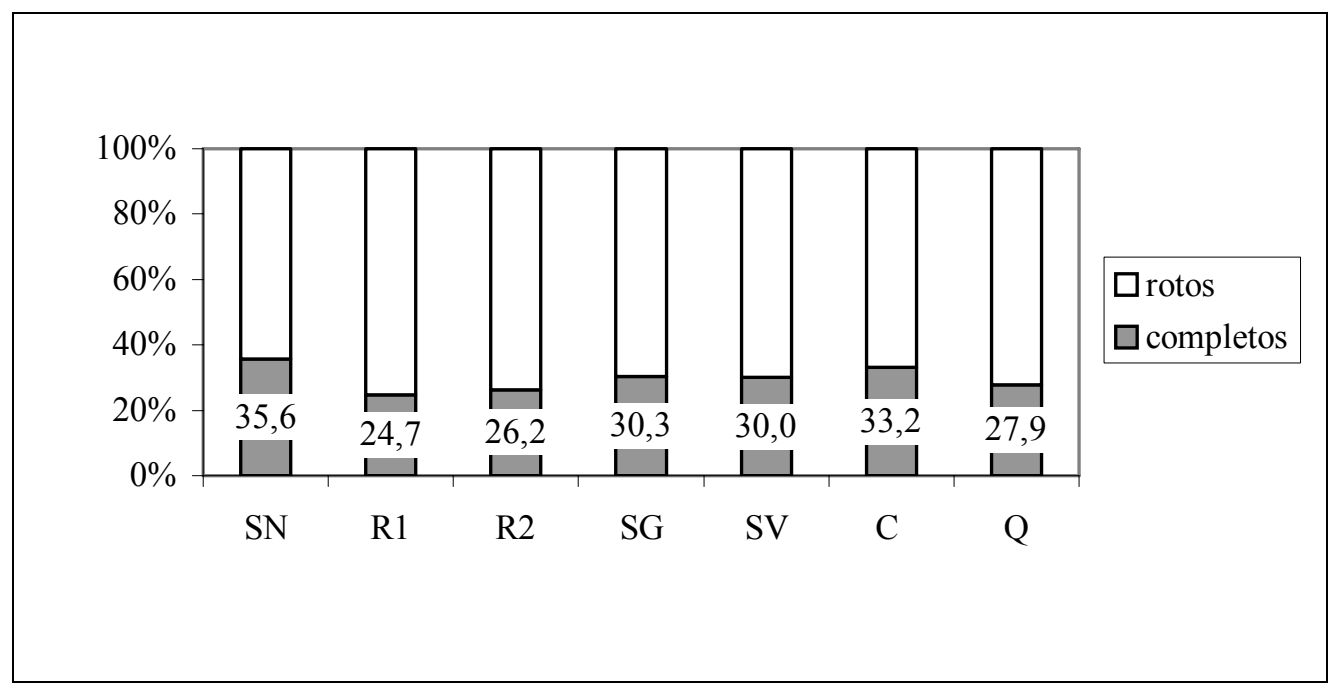

Gráfico V.5: porcentaje de piezas completas y rotas. SN: sílex negro, R1: radiolarita-1, R2: radiolarita-2, SG: sílex gris, SV: sílex varios, C: cuarcita, Q: cuarzo.

\section{V.1.4.2.- TIPOS DE ROTURAS}

Respecto a los tipos de roturas presentes en las distintas materias primas cabe destacar los siguientes aspectos (Gráfico V.6):

- Hay un predominio de la rotura distal en todas las materias excepto en el cuarzo. 
- En las materias locales más talladas en el yacimiento (sílex negro y cuarcita) el orden de presencia de los tipos de roturas, de mayor a menor importancia, es: rotura distal, rotura "por todos los lados" (DP: distal-lateral-proximal) y, por último, roturas de tipo transversal (proximal y próximo-distal).

- En las materias de origen más alejado o con procesos de talla laminares especializados (radiolarita, sílex gris y sílex varios) las roturas de tipo transversal predominan sobre las roturas "por todos los lados".

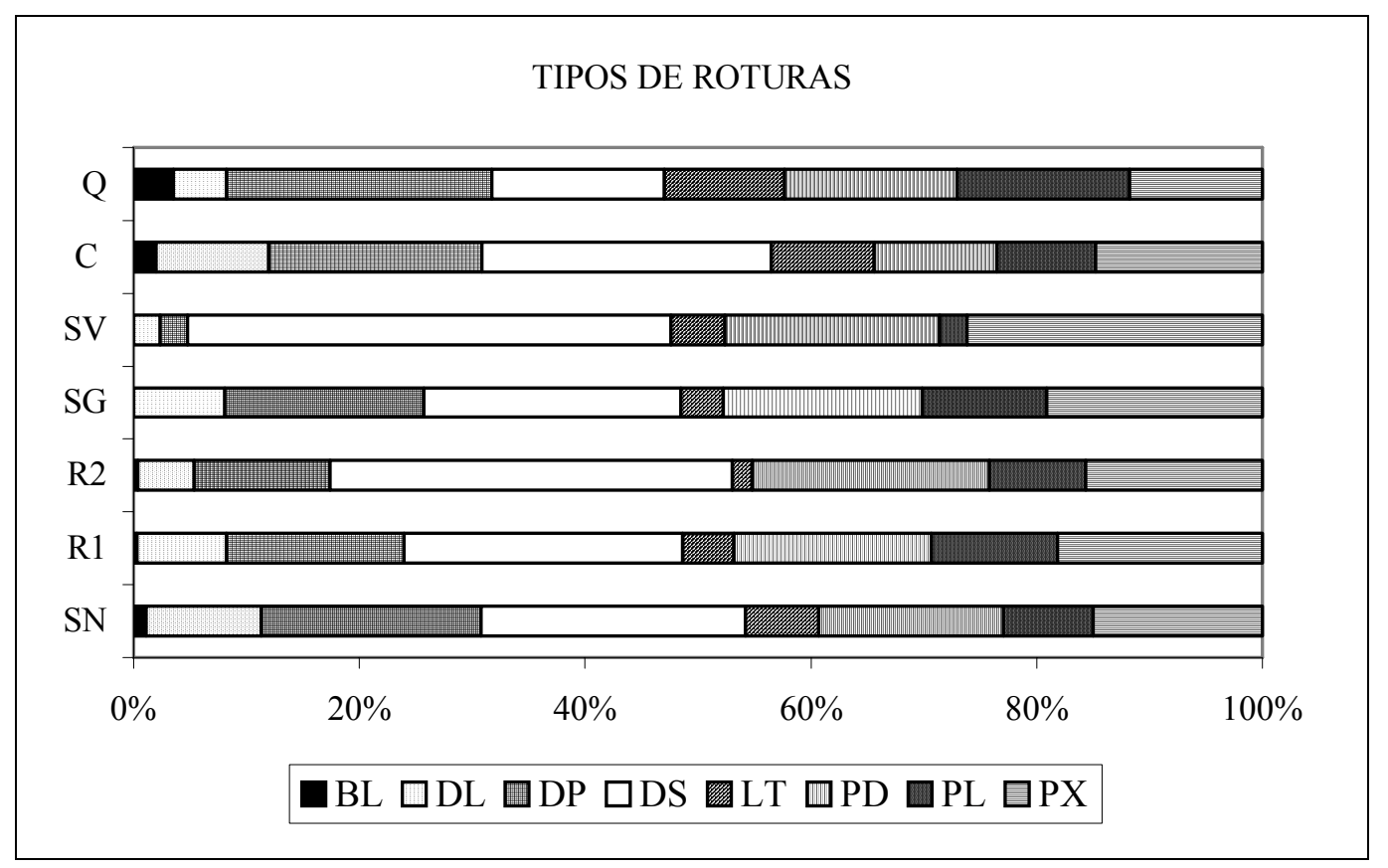

Gráfico V.6: tipos de roturas por materias. BL: bilateral, DL: distal-lateral, DP: distal-lateralproximal ("por todos los lados"), DS: distal, LT: lateral, PD: próximo-distal, PL: próximolateral, PX: proximal. SN: sílex negro, R1: radiolarita-1, R2: radiolarita-2, SG: sílex gris, SV: sílex varios, C: cuarcita, Q: cuarzo.

Se puede plantear la posibilidad de que la rotura "por todos los lados" esté relacionada con un proceso de talla más intenso realizado en el yacimiento, ya que aparece más abundantemente en las materias cuya cadena operativa está presente de forma total en el yacimiento. Ya se ha comentado a este respecto que la radiolarita, el sílex gris y los sílex varios tienen la cadena rota en mayor o menor medida.

Otro aspecto que se ha comentado al examinar cada materia de forma individual, es que parece haber una diferente representación de los tipos de rotura según los grupos 
tecnológicos, de forma que los grupos 1 y 6 son los que más variedad de tipos de rotura presentan (con un aumento significativo de la presencia de las roturas "por todos los lados"), mientras que el 2 y el 3 tienen una mayor proporción de roturas transversales. Se ha planteado la hipótesis de que el patrón de roturas del grupo 2 sea debido a causas de tipo cultural, relacionadas con fracturas intencionales de soportes laminares, especialmente en las hojitas de dorso. Por el contrario, los grupos tecnológicos 1 y 6 , afectados en mayor medida por toda la variedad de tipos de roturas, parecen pertenecer a un patrón de fracturas más relacionadas quizás con circunstancias vinculadas a la ejecución de la talla. El grupo 6, el de los debris, se define especialmente como el conjunto más indicativo en este sentido, de modo que tanto el número de elementos que lo integran, como este tipo de patrón de roturas variadas, se pueden considerar como un índice de la intensidad del proceso de talla desarrollada.

Siguiendo este planteamiento (es decir el hecho de que una presencia de roturas variadas pueda ser indicio de un proceso de talla intenso en el yacimiento), vamos a dejar a un lado las materias de forma individual para realizar una valoración de las materias primas en conjunto. Desde este punto de vista, el sílex negro, la radiolarita-1, el sílex gris, la cuarcita y el cuarzo son las materias que más variedad de tipos de roturas presentan; en consecuencia se pueden considerar como las materias que han sufrido un proceso de talla más intenso en el yacimiento. Esta circunstancia ha sido, de hecho, puesta ya de relieve cuando se han presentado los procesos de talla realizados en cada una de ellas. Por el contrario, la radiolarita-2 y los sílex varios, con una mayor representación relativa de las roturas de tipo transversal, son las materias con menor intensidad de débitage del yacimiento; circunstancia que se corresponde con lo observado al examinar las cadenas operativas de estas materias, ya que en ambos casos existe una ruptura importante, con ausencia al menos de la fase de preparación y de las primeras secuencias de producción.

\section{V.1.4.3.- CAUSA DE LA ROTURA}

En la causa de las roturas, la flexión supone al menos un 40\% en el grupo de los sílex (llega casi al 60\% en el sílex gris), excepto en los sílex varios, que sólo alcanza un 26\% (Gráfico V.7). En la cuarcita y el cuarzo, por su parte, la flexión es menos 
frecuente, en la primera supone un 34\%, mientras que en el cuarzo sólo un $16 \%$. La percusión alcanza porcentajes importantes tan solo en dos materias, ambas un tanto anómalas por su escasa presencia o por su proceso peculiar: los sílex varios y el cuarzo, en ambos casos llega a ser la causa de casi la mitad de las roturas.

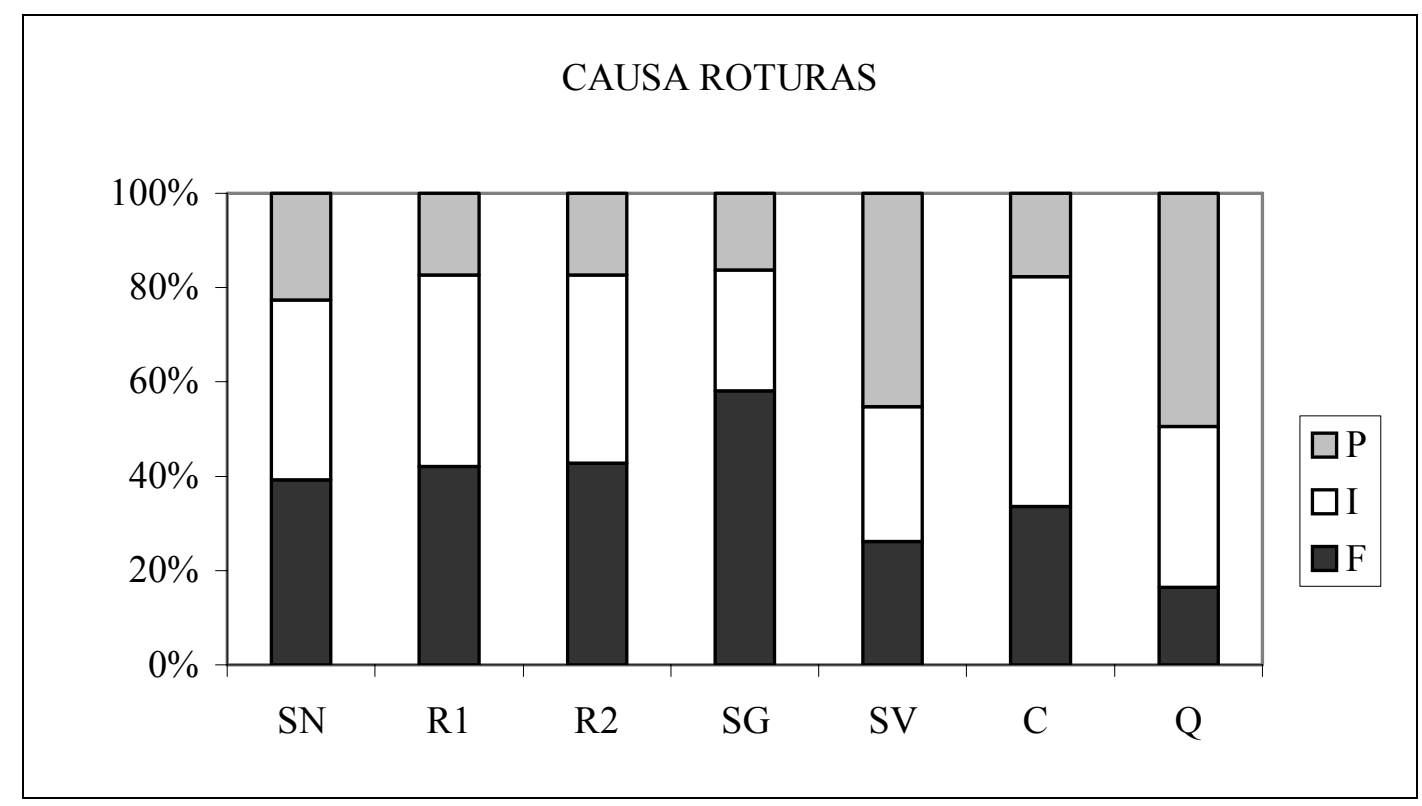

Gráfico V.7: causa de las roturas por materias primas. P: percusión, I: indeterminada, F: flexión. $\mathrm{SN}$ : sílex negro, R1: radiolarita-1, R2: radiolarita-2, SG: sílex gris, SV: sílex varios, C: cuarcita, Q: cuarzo.

\section{V.1.5.- ESTRATEGIA DE EXPLOTACIÓN DE LAS MATERIAS PRIMAS}

A partir de la disponibilidad de las materias en el entorno y de la representación del proceso operativo en el conjunto lítico, se puede establecer el siguiente esquema relativo al aprovechamiento de las materias primas líticas:

- Materias locales: proceso de talla in situ y cadenas continuas (alto porcentaje de los debris, al menos un 30\%)

- Sílex negro y cuarcita: Débitage intenso de estas materias, que son las más abundantes y posiblemente más cercanas (cadena completa desde el inicio) y explotación con objetivo mixto (hojas-hojitas y lascas). 
- Radiolarita y sílex gris: Débitage especializado (hojas-hojitas) de materias quizás un poco más alejadas (radiolarita) o más escasas en el entorno (sílex gris).

- Cuarzo: proceso de talla peculiar, con objetivos distintos a las materias anteriores.

- Materias exógenas (sílex varios): cadena rota, representación parcial del proceso operativo (los debris no llegan al 15\%), especialización total en productos laminares (que suponen el $40 \%$ del conjunto).

La gestión de las materias primas en el yacimiento de El Espertín es de carácter local, con tan solo un $0,5 \%$ de materias exóticas. El origen local de las materias se ha determinado a partir de dos indicios; en primer lugar la constatación de la presencia de materias en el contexto geológico análogas a las que aparecen en la cueva, tales materias son el sílex/chert negro y la radiolarita. Por otra parte, a partir de la representación del proceso operativo (el porcentaje de los distintos grupos tecnológicos) de las distintas materias se puede observar que hay algunas características del sílex negro y la radiolarita (fundamentalmente el porcentaje de los debris) que también se producen en el sílex gris, la cuarcita y el cuarzo, a partir de lo cual se propone la hipótesis de que estas ultimas materias tengan también un origen local. Esta hipótesis estaría reforzada por el hecho de que en el contexto geológico de la cueva la cuarcita y el cuarzo pueden estar presentes, sin que sea posible adscribirlos a una formación concreta. Del mismo modo, el sílex gris puede encontrarse en dicho contexto, habida cuenta que es una materia que se encuentra en forma de canto rodado en posición derivada dentro de las terrazas formadas por el río Esla. A este respecto no hay que olvidar tampoco las formaciones de conglomerados.

La estrategia de adquisición, por tanto, privilegia la captación de los recursos de origen local, con un comportamiento de carácter doble, patente en el proceso de explotación peculiar de cada materia. Por un lado se explotan de forma extensiva las materias más abundantes y seguramente más cercanas; por otra parte, hay un aprovechamiento más especializado de las materias que están quizás ligeramente más distantes y/o menos abundantes; sobre ellas se habrían producido las primeras secuencias de talla en el lugar de adquisición. Las materias exógenas son muy escasas y 
aparecen sobre todo en forma de elementos retocados, formado parte probablemente de los útiles que portan estos grupos en sus desplazamientos. No parece en todo caso que carguen con demasiado "equipaje", limitándose a lo más utilitario y prefiriendo el aprovechamiento intensivo de los recursos locales. 


\section{V.2.- LAS DIFICULTADES DE LAS MATERIAS PRIMAS Y LOS MODOS DE TALLA}

Las características de las materias primas en cuanto a su facilidad para la talla pueden afectar en un doble aspecto a los modos y técnicas de talla empleadas. Por un lado materias de carácter duro y tamaño de grano medio o grueso pueden exigir modos de talla contundentes y técnicas más expeditivas. Por otro lado materias más blandas y de grano fino pueden facilitar técnicas más versátiles. A esto hay que añadir otro factor determinante en la calidad de las materias para la talla, que es su fábrica, es decir si son rocas homogéneas o heterogéneas, si hay abundantes superficies naturales, de diaclasado, fisuras, etc., que entorpezcan la ejecución de la talla.

Teniendo en cuenta estos factores, los modos de talla aplicados pueden variar en mayor o menor grado dependiendo tanto del tipo de materia propiamente dicho, como del desarrollo de la cadena operativa. Al examinar detalladamente los distintos tipos de materias se ha observado que se podían apreciar indicios de cambios en los modos de talla adoptados a lo largo de las distintas fases de la cadena operativa, fundamentalmente en la fase de producción plena para la obtención de soportes laminares. Tales indicios se ponen de manifiesto al analizar los siguientes atributos: accidentes de talla, tipo de talón, preparación del punto de impacto, ángulo del frente de percusión y modo de talla.

\section{V.2.1.- LOS ACCIDENTES DE TALLA}

Este atributo es el que más información aporta relativamente a la dicotomía planteada en esta apartado; es decir, por una parte la incidencia de las características de la materia prima y, en segundo lugar, el modo de talla adoptado. Al examinar por separado las distintas materias se ha observado que hay una serie de tipos de accidentes que están ligados, por un lado, a modos de talla concretos y, por otro, a las dificultades de las materias primas. Se podría realizar el siguiente esquema: 
- El doble bulbo aparece en un porcentaje muy pequeño y se ha planteado su relación con la percusión directa con percutor duro a partir de su mayor presencia en las lascas del grupo 1.

- La fractura en lengüeta aparece (también en porcentajes reducidos) de forma más frecuente en la fase de producción, en las hojas y hojitas, por lo que estaría más relacionada con los modos de talla específicos adoptados en estas secuencias.

- El pseudoburil de Siret es un accidente más frecuente que los anteriores e incide de forma mayoritaria en las lascas del grupo 1 y también en el grupo 6. Se ha planteado su relación con una percusión con percutor duro en secuencias de conformación de los núcleos y con gestos de talla enérgicos, necesarios sobre todo en la manipulación de materias de grano grueso como la cuarcita y el cuarzo.

- Los reflejados son también bastante abundantes, sobre todo en la fase de producción.

- Los sobrepasados no son demasiado frecuentes y, a veces, se relacionan con secuencias de reforma del núcleo, en los productos de acondicionamiento.

- Los accidentes ocasionados por la presencia de planos de rotura natural de las materias son indicios claros de las dificultades relacionadas directamente con la heterogeneidad de las rocas empleadas. A este respecto, el alto porcentaje de este tipo de accidente en la radiolarita, el sílex gris y, en menor medida, el sílex negro pone de manifiesto las características muchas veces mediocres de estas materias en cuanto a su calidad para la talla.

Si se toma en consideración el conjunto de la totalidad de las materias (Gráfico V.8), en cada una predominan distintos accidentes, poniendo en evidencia distintos aspectos:

- En el conjunto de los sílex predominan accidentes vinculados a la fase de producción (reflejados) excepto en la radiolarita y el sílex gris donde, por delante de los reflejados, están los accidentes ocasionados por las dificultades de la materia prima.

- En el cuarzo y la cuarcita predomina el pseudoburil de Siret, poniendo de relieve por tanto la contundencia necesaria en la percusión de estas materias 
En el grupo de los sílex el tipo de accidentes que están presentes se relaciona más con la fase de producción, haciendo también hincapié por tanto en la importancia de la obtención de los soportes laminares, sobre todo en los sílex varios. La cuarcita y el cuarzo presentan una sobrerrepresentación de los pseudoburiles de Siret que puede estar relacionada con el modo de talla necesario en la percusión de estas materias, pero también enmascara en cierto grado los cambios en los modos de talla a lo largo de sus cadenas operativas, especialmente en el caso de la cuarcita.

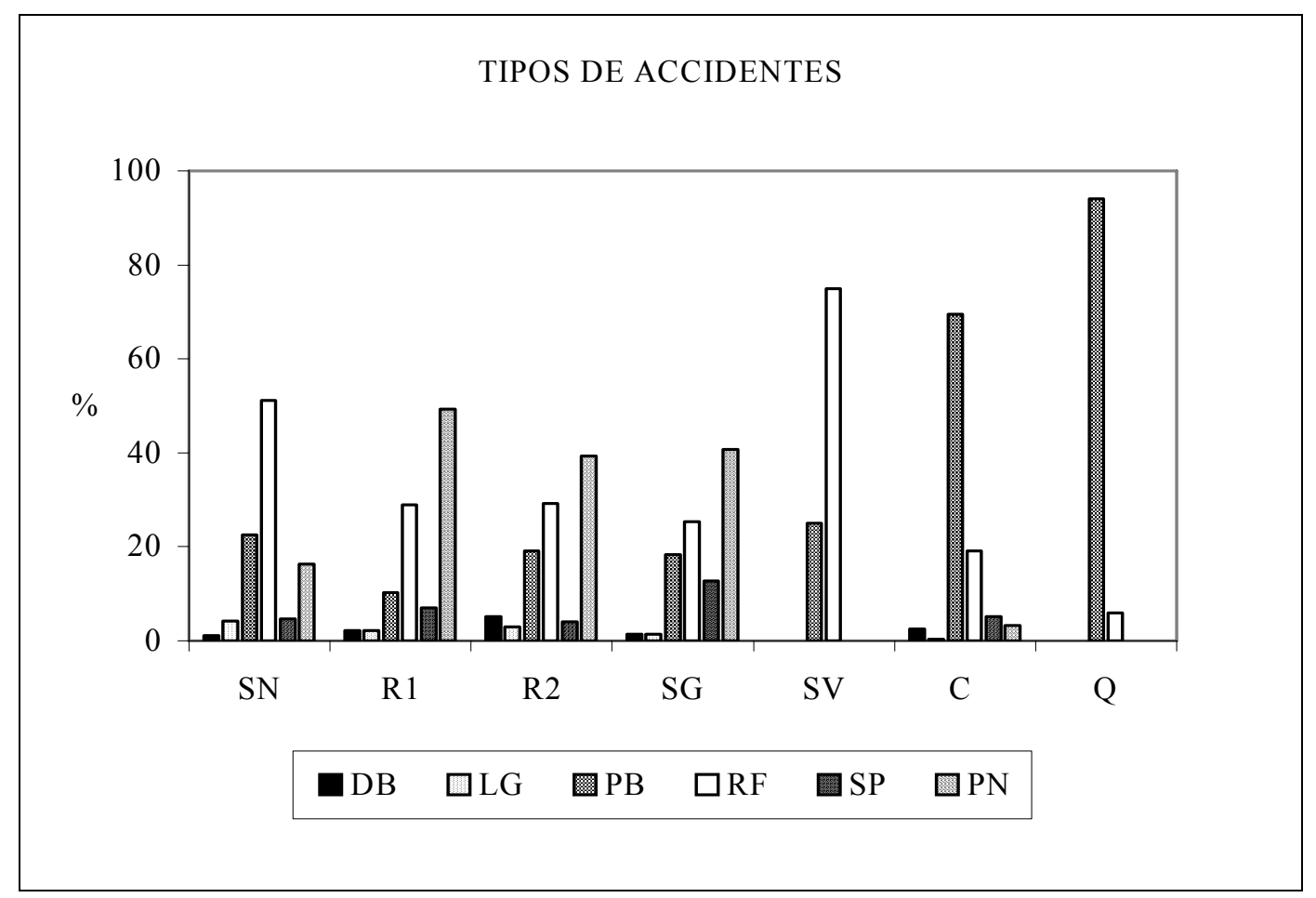

Gráfico V.8: tipos de accidentes en las distintas materias primas. DB: doble bulbo, LG: fractura en lengüeta, PB: pseudoboril de Siret, RF: reflejado, SP: sobrepasado, PN: planos naturales. SN: sílex/chert negro, R-1: radiolarita-1, R-2: radiolarita-2, SG: sílex gris, $\mathrm{SV}$ : sílex varios, C: cuarcita, Q: cuarzo.

\section{V.2.2.- EL MODO DE TALLA}

Para valorar este aspecto es interesante tener en cuenta no solo el modo de talla observado directamente, sino también el tipo de talón, la preparación del punto de 
impacto y el ángulo; incluso también podríamos añadir la dimensión del talón y los accidentes de talla.

\section{V.2.2.1.- EL MODO DE TALLA A LO LARGO DEL PROCESO OPERATIVO}

La problemática del modo de talla tiene más relevancia al valorar los cambios de este atributo a lo largo de la cadena operativa, ya que está generalmente admitido el hecho de que el uso de los instrumentos y técnicas de talla van variando a lo largo del proceso operativo en función de las necesidades de los bloques líticos y los objetivos perseguidos. A este respecto, en el análisis diferenciado de cada materia se ha constatado la presencia de variaciones en estos atributos de los soportes a lo largo de las distintas fases de la cadena operativa. Se puede realizar el siguiente esquema, válido, sobre todo, para los sílex:

- El grupo 1 (lascas en general) se caracteriza por un tamaño del talón relativamente grande ( $3 \mathrm{~mm}$ de anchura), relacionándose, por tanto, con un tipo de percusión interna (Boëda, 1997). Suele haber una mayor proporción del pseudoburil de Siret y del doble bulbo y hay una mayor presencia de percusión directa con percutor duro. Se plantea por tanto la posibilidad del empleo de este tipo de percusión en las primeras fases del débitage

- En el grupo 2 (soportes laminares) el tamaño del talón es inferior (2 mm como máximo), por tanto la percusión se realiza de forma más tangencial, lo cual está relacionado, necesariamente, con una preparación cuidadosa del frente de percusión. A este respecto, en todas las materias, las hojas-hojitas constituyen el grupo de soportes más preparados. En los sílex el porcentaje de preparación supera el 50\%, a excepción del sílex gris (que sólo presenta un $33 \%$ ); en la cuarcita por su parte alcanza el $43 \%$. El tipo de preparación suele ser bastante cuidadoso, con frecuente presencia de abrasión. En el modo de talla concreto aparecen las características diagnósticas de la percusión directa con percutor blando, al menos en un cierto número de elementos de este grupo.

- En el grupo 3 (productos de acondicionamiento) el tamaño del talón suele ser mayor incluso que en el grupo 1 (3-4 $\mathrm{mm})$ en tanto que el modo de talla 
también se asemeja a la utilizada en el citado grupo, es decir percusión directa con percutor duro.

- El grupo 6 (debris) presenta unas características peculiares, por un lado hay un conjunto de piezas que tienen características cercanas al grupo 1 (presencia de pseudoburil y doble bulbo, percusión directa con percutor duro), tales elementos corresponderían sin duda a fragmentos proximales de lascas de las primeras fases de la talla o de secuencias de reparación. Las lasquitas procedentes de las fases de retoque, en cambio, tendrían características más acordes con este estatus: tamaño del talón muy pequeño, talones puntiformes, etc. A esto habría que añadir una peculiaridad que se ha constatado en todas las materias, se trata de una mayor presencia de un ángulo de talla más cerrado que en el resto de los soportes.

En esta diferenciación de los modos de talla a lo largo de la cadena operativa se constata, por tanto, un cambio en la secuencia de producción plena, correspondiente a la obtención de las hojas-hojitas, con el probable empleo de la percusión directa con percutor blando. Tal aspecto es bastante lógico, habida cuenta que los soportes laminares son aquellos artefactos que se han calificado como "de primera intención".

\section{V.2.2.2.- EL MODO DE TALLA EN LAS DISTINTAS MATERIAS}

\section{V.2.2.2.1.- ACCIDENTES DE TALLA Y PREPARACIÓN}

Respecto a los atributos que intervienen en el modo de talla, vamos a tener en cuenta, en primer lugar, tres de ellos: los accidentes de talla, la presencia de preparación y el tipo de preparación. Sobre ellos se individualizan dos grupos: el de los sílex, por un lado, y el de la cuarcita más el cuarzo, por otro.

El grupo de los sílex tiene las siguientes características:

- Mayor presencia de los accidentes (reflejados) más frecuentes en la secuencia de producción de soportes laminares.

- Preparación del punto de impacto en, al menos, un tercio del total de las piezas (Gráfico V.9). 
- Los tipos de preparación del punto de impacto son variados (presencia de retoque, esquirlado y abrasión en distinta proporción, sobre todo de los dos últimos) (Gráfico V.10).

$\underline{\text { La cuarcita y el cuarzo, }}$, por su parte, presentan las siguientes características:

- Presencia importante de pseudoburil de Siret.

- Preparación del punto de impacto en menor proporción, una cuarta parte de las piezas en la cuarcita y tan solo un $15 \%$ en el cuarzo (Gráfico V.9).

- Los tipos de preparación no son tan variados como en los sílex; hay una sobrerrepresentación del retoque o del esquirlado (Gráfico V.10).

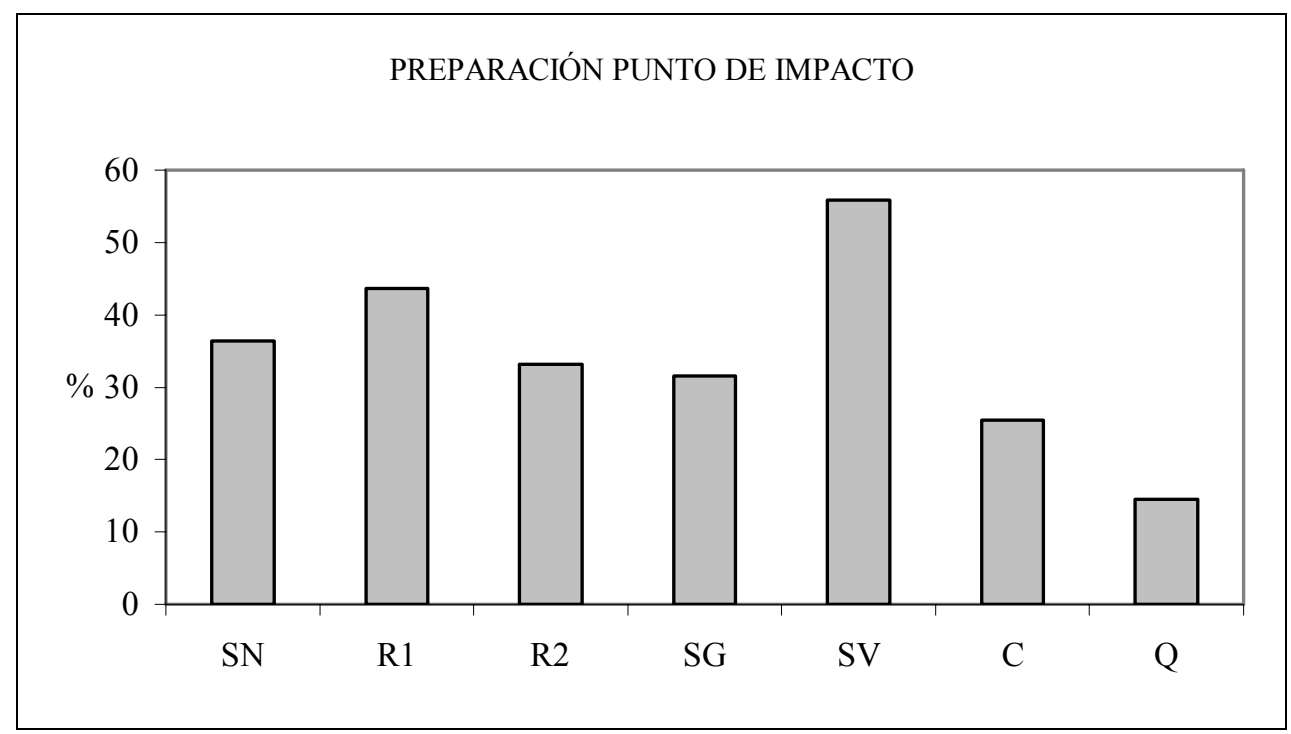

Gráfico V.9: porcentaje de preparación del punto de impacto por materias primas. SN: sílex/chert negro, R-1: radiolarita-1, R-2: radiolarita-2, SG: sílex gris, SV: sílex varios, C: cuarcita, Q: cuarzo.

Como consecuencia de estas diferencias, se puede plantear la utilización de técnicas en cierto grado divergentes, debidas, seguramente, a la adaptación de los métodos de talla a las características materiales peculiares de estos dos grupos litológicos. En los sílex se constataría el empleo, al menos parcial, del percutor blando; mientras que en el cuarzo y la cuarcita hay un mayor uso de la percusión dura. 


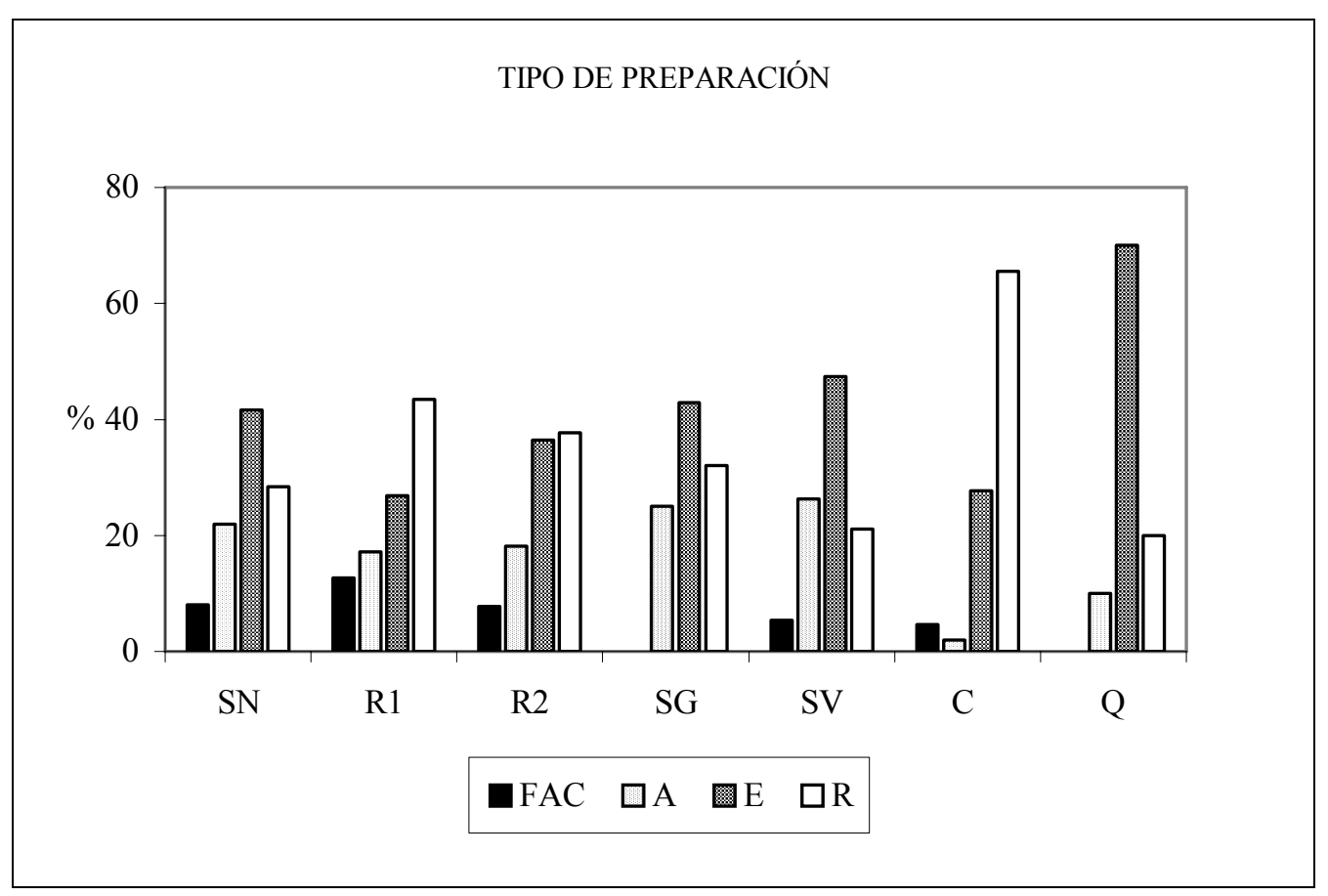

Gráfico V.10: tipos de preparación por materias primas. FAC: facetado, A: abrasión, E: esquirlado, R: retoque. SN: sílex/chert negro, R-1: radiolarita-1, R-2: radiolarita-2, SG: sílex gris, SV: sílex varios, C: cuarcita, Q: cuarzo.

\section{V.2.2.2.2.- EL TIPO DE TALÓN}

Hay otro atributo que no se ha mencionado de forma específica, que es el tipo de talón. En todos los casos predomina el talón liso (siempre por detrás de las piezas “sin talón”), por lo que no es una característica demasiado definitoria, tan solo en el cuarzo hay un tipo de talón que está por delante del liso, que es el roto (Gráfico V.11). Este aspecto es un dato que vendría a corroborar el carácter peculiar del proceso de talla aplicado sobre el cuarzo. 


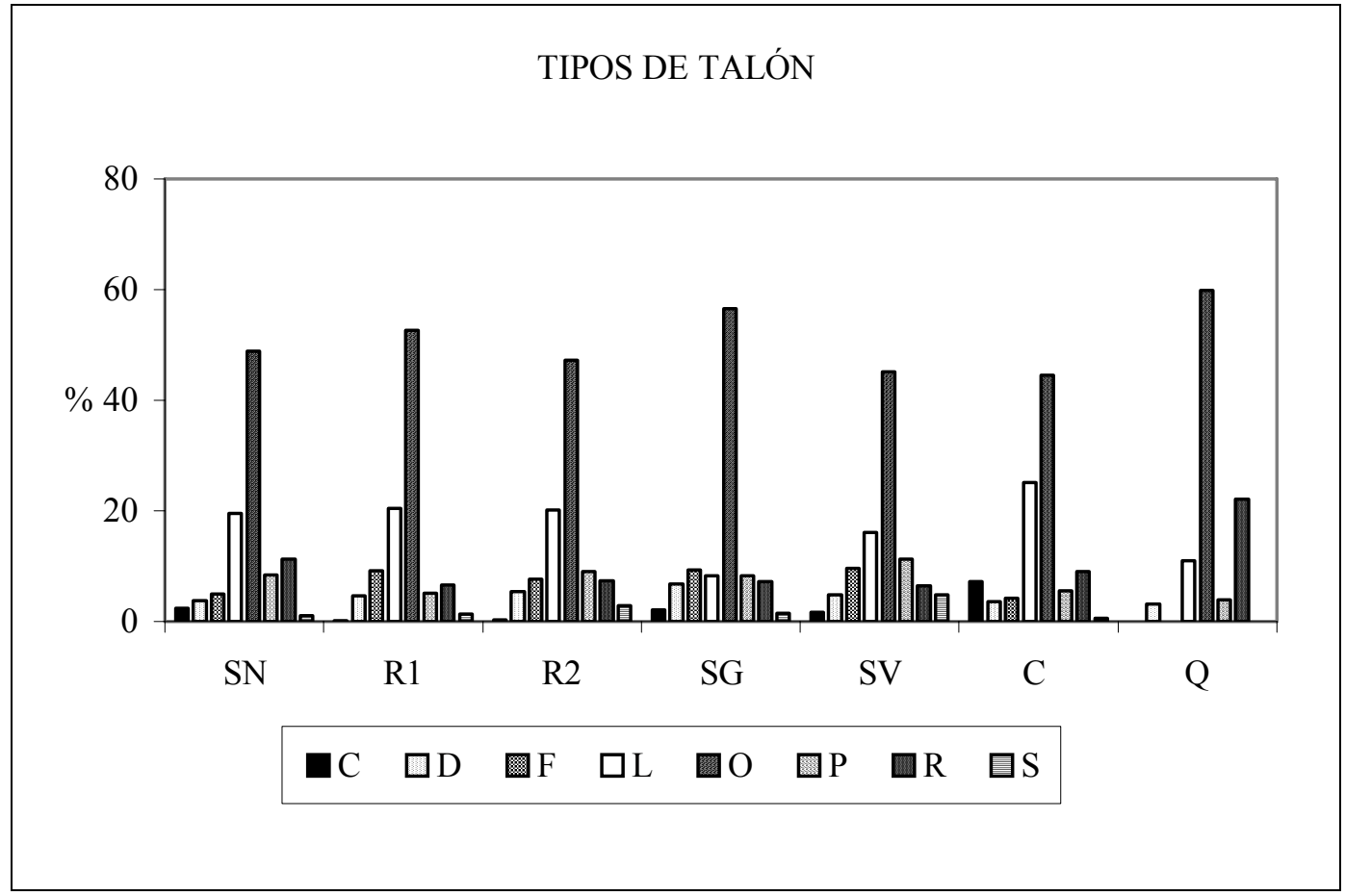

Gráfico V.11: tipos de talón en las distintas materias primas. C: cortical, D: diedro, F: facetado, L: liso, O: sin talón, P: puntiforme, R: roto, S: suprimido. $\mathrm{SN}$ : sílex/chert negro, R-1: radiolarita-1, R-2: radiolarita-2, SG: sílex gris, SV: sílex varios, C: cuarcita, Q: cuarzo.

\section{V.2.2.2.3.- EL ÁNGULO DE PERCUSIÓN}

En el ángulo de percusión, nos vamos a centrar en el ángulo formado por el talón y la cara superior (el que se ha denominado “ángulo 2"). Lo más interesante es la forma en que cambia el ángulo respecto a los tipos de soportes a lo largo del proceso de talla, ya que así se puede intuir también una variación en el modo de talla en las distintas fases de la cadena operativa (Gráfico V.12). Las principales características en el ángulo de talla de los distintos grupos tecnológicos y por materias primas son las siguientes:

- Los sílex en general tienen unos ángulos más abiertos (más cercanos al ángulo recto) que la cuarcita y el cuarzo.

- Dentro de los sílex, en las materias con especialización laminar predominan los ángulos de $80-90^{\circ}$, con la excepción de los sílex varios, que tienen su máximo en los $70-80^{\circ}$.

- En las materias más abundantes y más talladas en el yacimiento (sílex negro, cuarcita, radiolarita-1) los soportes del grupo 1 no tienen un ángulo que 
predomine de forma clara, sino que hay tres intervalos que tienen una representación destacada: $80-90^{\circ}, 70-80^{\circ}$ y $60-70^{\circ}$. En el sílex negro y la radiolarita-1 está en primer lugar el intervalo de ángulos más abiertos, más cercanos al ángulo recto; mientras que en la cuarcita son más abundantes los más cerrados.

- En estas materias, el grupo 2 tiene también unos ángulos que oscilan en torno a los intervalos del grupo 1, con el matiz de que (frente a lo que cabría esperar) en el sílex negro los soportes laminares no son más abundantes en torno al ángulo recto, sino en los $70-80^{\circ}$. La radiolarita-1 en cambio tiene estos ángulos de los soportes laminares en los $80-90^{\circ}$, aspecto que se repite en la cuarcita, en la que son más abundantes las hojas-hojitas con un ángulo relativamente abierto $\left(70-80^{\circ}\right)$.

- En el resto de los sílex, el ángulo de los soportes del grupo 1 tiene un máximo claro, que coincide también con el grupo 2 y el 3. En la radiolarita-2 y el sílex gris es un ángulo muy abierto $\left(80-90^{\circ}\right)$, mientras que en los sílex varios es más cerrado $\left(70-80^{\circ}\right)$.

- El grupo tecnológico 6 es el que tiene unos ángulos más peculiares, y en todas las materias se distancian del resto de los soportes. Como pauta general el ángulo tiende a ser cerrado, igual o menor a $\operatorname{los} 70-80^{\circ}$, y siempre es inferior a los predominantes en el conjunto lítico de la materia en cuestión.

- El cuarzo tiene una representación particular; en este caso el grupo de los debris tiene un máximo que coincide con el grupo 1 , en los $70-80^{\circ}$, y tiene también otro máximo en un ángulo muy cerrado, $50-60^{\circ}$. Se acentúa así de nuevo el carácter peculiar del proceso de talla de esta materia.

A partir de los indicios obtenidos en el examen de otros atributos, cabría esperar, respecto al ángulo, que hubiera unas diferencias más claras en los distintos tipos de soportes. No hay demasiadas variaciones en el ángulo de las hojas-hojitas y las lascas, a no ser por algunos matices suaves. Donde sí se establecen las variaciones mayores es entre las siguientes agrupaciones:

- Entre el grupo de los sílex por un lado y la cuarcita por otro; en los primeros el ángulo es más abierto que en la segunda. 
- Entre las materias más talladas en el yacimiento (sílex negro, radiolarita-1 y cuarcita) y el resto (radiolarita-2, sílex gris y sílex varios). En las primeras los ángulos tienen una mayor variedad, mientras que las segundas se polarizan más claramente hacia un intervalo concreto.

- Entre los debris y el resto de los soportes. Los primeros presentan un ángulo que tiende a ser más cerrado que en el resto de artefactos.

Sin duda el ángulo peculiar de los debris se debe a las técnicas de retoque ejecutadas, que difieren lógicamente del proceso de débitage del que se obtienen el resto de los soportes.

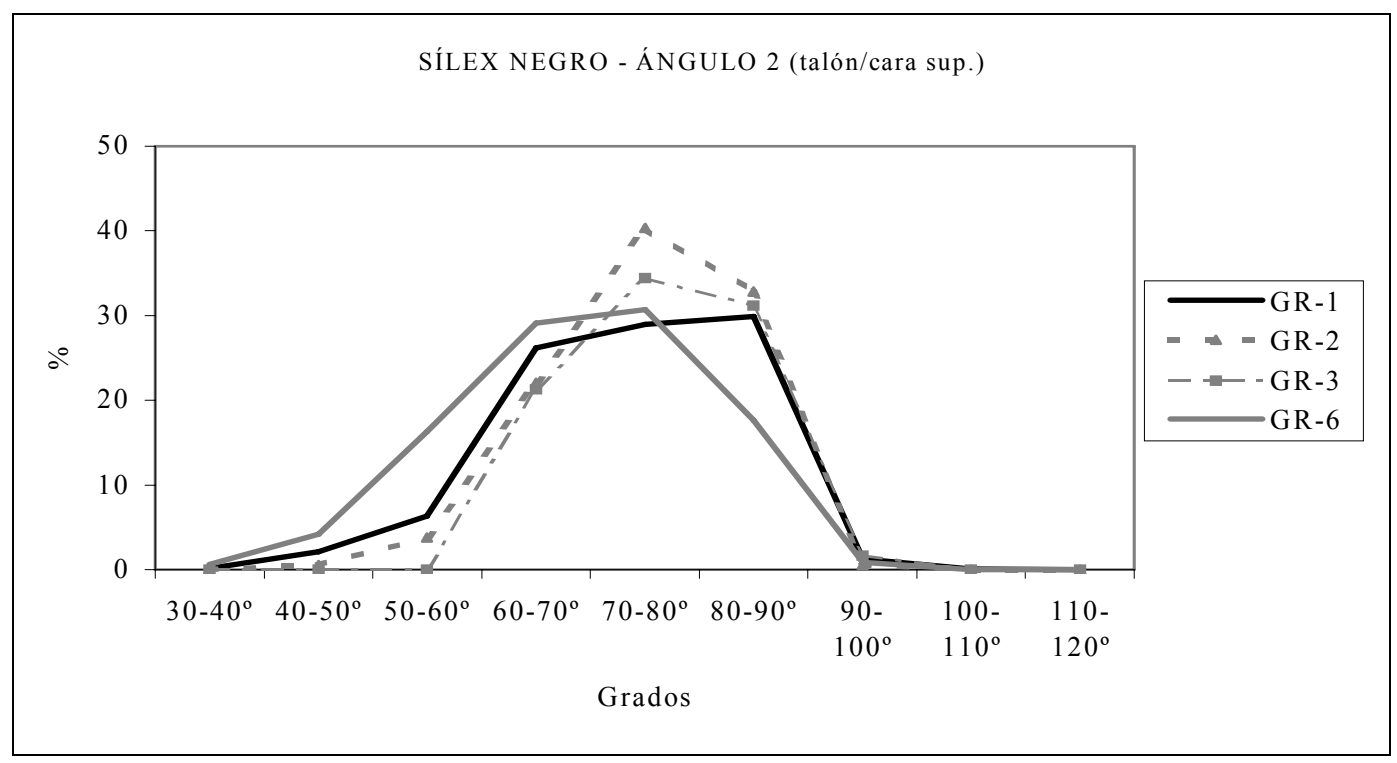

Gráfico V.12: ángulo del frente de percusión (ángulo 2: entre el talón y la cara superior) en las distintas materias y diferenciando por los grupos tecnológicos. GR-1: grupo 1, lascas; GR-2: hojas-hojitas; GR-3: productos de acondicionamiento; GR-6: debris. 

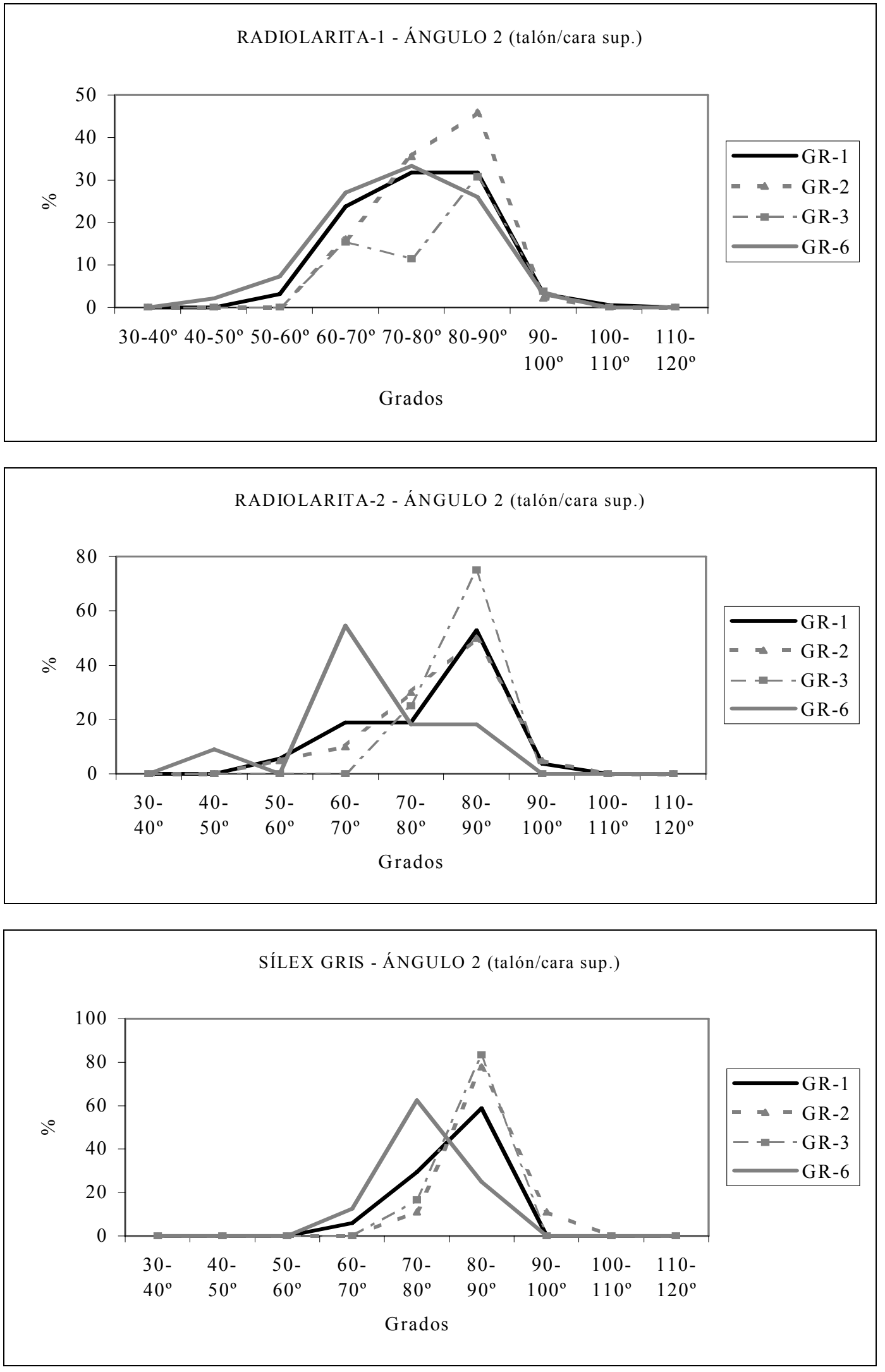

Gráfico V.12 (continuación): ángulo del frente de percusión (ángulo 2: entre el talón y la cara superior). 
SÍLEX VARIOS - ÁNGULO 2 (talón/cara sup.)
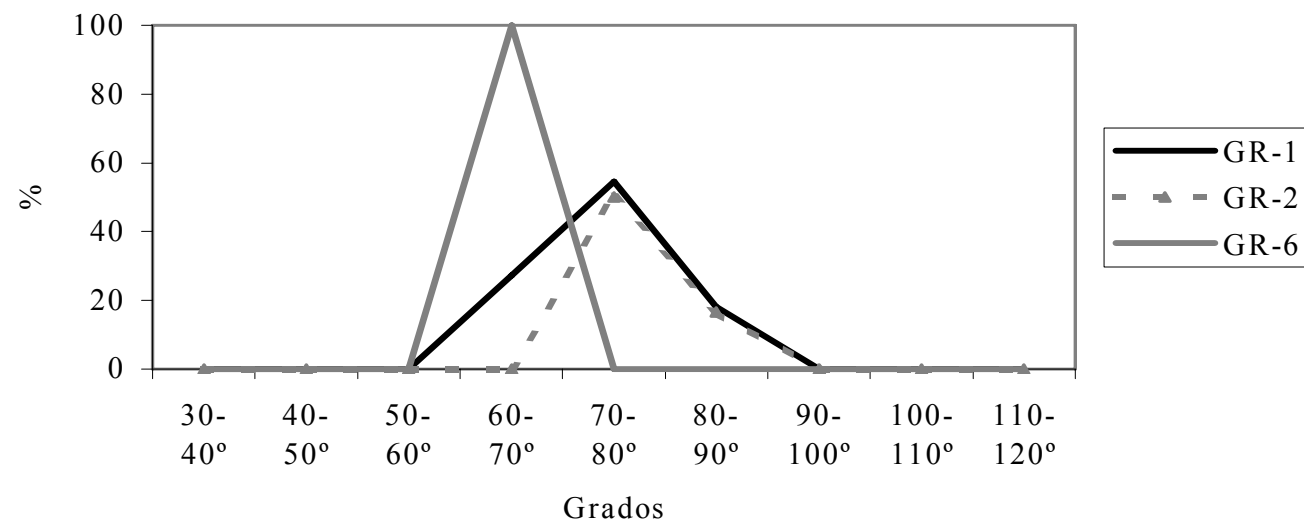

CUARCITA - ÁNGULO 2 (talón/cara sup.)

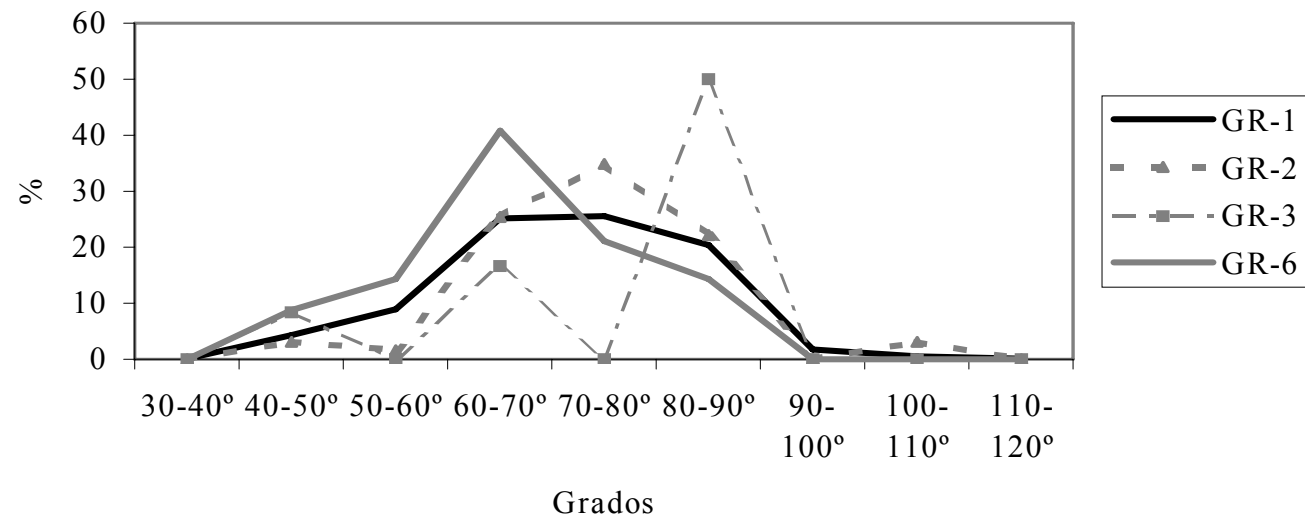

CUARZO - ÁNGULO 2 (talón/cara sup.)

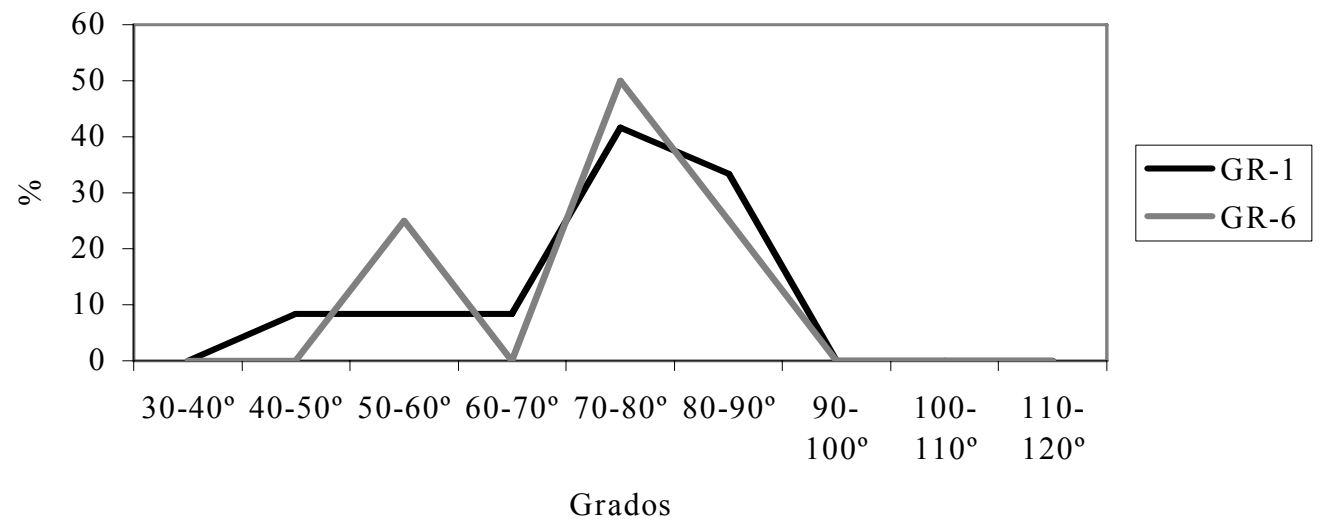

Gráfico V.12 (continuación): ángulo del frente de percusión (ángulo 2). 


\section{V.3.- LOS OBJETIVOS DEL DÉBITAGE: LOS SOPORTES EXTRAÍDOS Y LAS PIEZAS RETOCADAS}

\section{V.3.1.- PROCESO DE DÉBITAGE: REPRESENTACIÓN DE LOS GRUPOS TECNOLÓGICOS}

En el capítulo sobre la metodología se ha tratado adecuadamente y de forma extensa acerca de los soportes extraídos a lo largo de un proceso de débitage. En todo proceso de talla hay unos objetivos concretos, los considerados como "soportes de primera intención" (que pueden ser tanto lascas como hojas y hojitas o puntas); pero también se obtienen una serie de elementos a lo largo de la cadena operativa, que son los productos de acondicionamiento y los que se han denominado "soportes de segunda intención” o "soportes secundarios" (Cuadro I.5). A ellos habría que añadir además los debris y otros fragmentos informes que se desprenden normalmente en la ejecución de la talla y en distintos procedimientos de preparación, reforma, retoque, etc.

Los soportes "de segunda intención" constituyen, a veces, una categoría de difícil tratamiento ya que en ella se incluyen el conjunto de las lascas, grupo que puede ser muy heterogéneo. No obstante, en caso de que el conjunto lítico tenga una producción de tipo laminar único, estos soportes "de segunda intención" se pueden considerar como un índice de la intensidad y desarrollo de la cadena operativa. En efecto, dentro de estos soportes, se agrupan tanto las lascas que proceden de las primeras secuencias de la cadena (la fase de conformación del núcleo), como aquéllas derivadas de secuencias de reparación y reacondicionamiento sucesivas.

En cambio, si en la producción hay objetivos mixtos, con la presencia de cadenas operativas laminares y de lascas, lógicamente el grupo de las lascas adquiere un significado distinto al caso anterior. Hay que tener en cuenta que el estudio analítico se ha realizado partiendo de un proceso operativo laminar-modelo, que es el que guía la ordenación de los artefactos. En consecuencia, a la hora de clasificar las categorías tecnológicas de los soportes, dentro del grupo 1 (el correspondiente a los soportes “de 
segunda intención", tal y como se ha explicado en el capítulo sobre la metodología) se incluirían, además de las lascas correspondientes a las cadenas laminares, las "lascas de primera intención" de las cadenas de objetivo-tipo-lasca.

Por tanto, en las materias con objetivo mixto, el grupo tecnológico de las lascas, o al menos, la relación entre éste y el grupo laminar, tendrá un significado e importancia distinta a las materias con objetivo único de hojas-hojitas.

En El Espertín están presentes estas dos posibilidades; en el sílex negro y la cuarcita hay una explotación de objetivo mixto, mientras que en el resto de los sílex hay una única producción laminar. Estas dos categorías de producción lítica (laminar y mixta) e incluso una tercera, la desarrollada sobre el cuarzo, se ponen de manifiesto cuando se observan los gráficos relativos a la representación de las categorías tecnológicas. Es conveniente que nos detengamos en dos gráficos, en primer lugar el que muestra el porcentaje bruto de representación de los distintos grupos tecnológicos por materias primas (Gráfico V.4); teniendo en cuenta sobre todo la relación existente entre el grupo tecnológico 1 y 2. Por otro lado, hay que tener en cuenta también el gráfico de representación por grupos tecnológicos incluyendo las piezas retocadas (Gráfico V.13).

En el primer gráfico (Gráfico V.4; p. 539) se observa, en primer lugar, que en todas las materias el grupo predominante es el 1, con la única excepción de los sílex varios. Una segunda constatación es que, excepto en el cuarzo, los soportes laminares están siempre presentes, y precisamente el distinto porcentaje de hojas y hojitas es indicativo del grado de especialización en este tipo de objetivo. En aquellas materias que tienen una producción especializada de hojas-hojitas, el valor de este grupo es igual o superior al 20\% (radiolarita, sílex gris y sílex varios). Se puede incluso ir más allá en el examen de este conjunto de rocas silíceas, ya que en aquéllas que se han tallado en el yacimiento, con la presencia de una cadena más o menos completa (radiolarita-1), o al menos una fase de producción in situ (radiolarita-2 y sílex gris), el porcentaje del grupo 2 se mantiene en torno a un 20-23\%. En cambio, en el caso de los sílex varios, este valor está sobrerrepesentado, alcanzando el 40\% (es la única materia en la que el grupo 2 es el predominante), lo cual pone en evidencia, no sólo la especialización en hojitas de 
esta materia, sino, sobre todo, la ruptura existente en su proceso operativo, con la incorporación de esas hojitas al yacimiento, sin que hayan sido obtenidas aquí.

En las materias con producción mixta (sílex negro y cuarcita), por su parte, el grupo 2 no supera el 12\%, poniéndose en evidencia, por tanto, que el objetivo de su explotación no es únicamente laminar.

Al examinar el gráfico en el que se muestran las categorías de soportes diferenciando las piezas con y sin retoque, se observa de forma aún más clara los distintos objetivos del débitage (Gráfico V.13). En estos gráficos se ha eliminado el cuarzo debido al escaso número de piezas retocadas. En este tipo de presentación se pone de manifiesto los soportes que han sido seleccionados directamente para confeccionar los útiles retocados $\mathrm{y}$, en este caso, los porcentajes del grupo laminar ascienden de forma importante.

La preferencia por los soportes laminares para el conjunto retocado es muy marcada, especialmente en las materias de objetivo laminar especializado, en las cuales el grupo 2 es siempre el predominante. De nuevo los porcentajes varían en función del grado de especialización y la existencia de rupturas en la cadena operativa. En las materias talladas in situ los elementos retocados sobre hojas-hojitas superan el $60 \%$, a excepción de la radiolarita-2, en la que, curiosamente, el porcentaje se sitúa en torno al $50 \%$. La explicación de esta anomalía en esta variedad de radiolarita quizás esté vinculada con la existencia de una ruptura parcial en el proceso operativo presente en esta materia, con la presencia de elementos incorporados de fuera y un débitage parcial en el yacimiento. Por su parte, en los sílex varios, el valor de los soportes microlaminares retocados superan el $80 \%$ del conjunto de piezas retocadas, poniéndose una vez más en evidencia el carácter especializado e importado de estos elementos. 

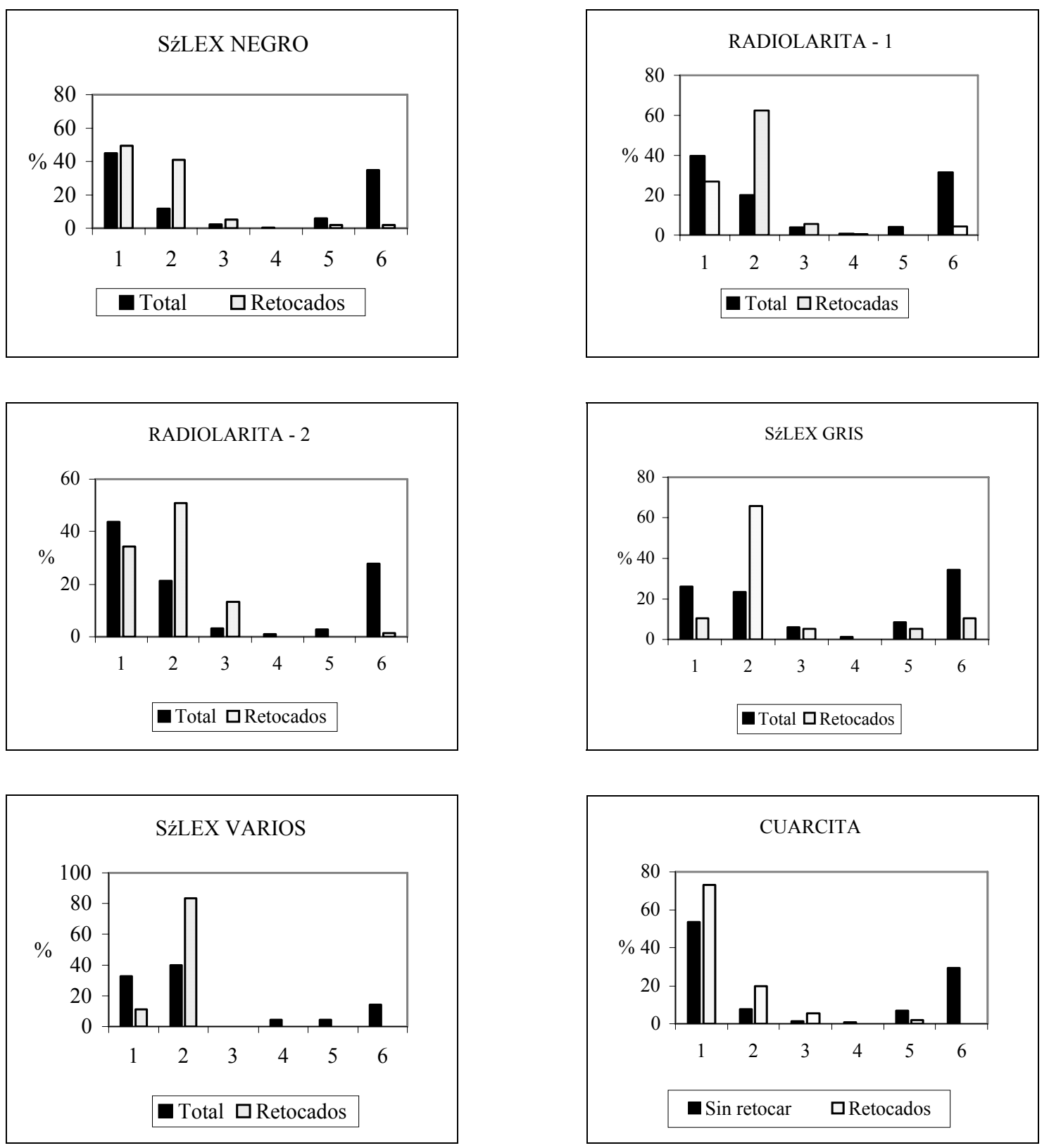

Gráfico V.13: porcentajes de representación de los distintos grupos tecnológicos por materias primas, diferenciando los soportes retocados y sin retocar. 1: grupo 1, lascas; 2: hojas-hojitas; 3 : productos de acondicionamiento; 6: debris. 
En las materias de producción mixta hay un predominio de las piezas del grupo 1 dentro de las retocadas, pero en este caso se constata una gestión diferente de los soportes de sílex negro, por un lado, y los de cuarcita, por otro. En los primeros, los soportes laminares alcanzan casi un $40 \%$ del total de retocadas, mientras que en la cuarcita tan solo suponen el $20 \%$. En consecuencia, la producción de lascas es mucho más importante en la cuarcita, mientras que en el sílex negro sería un complemento de la producción laminar. 


\section{V.3.2.- LAS PIEZAS RETOCADAS}

Las piezas retocadas se pueden considerar como los objetivos del débitage lítico desarrollado en el yacimiento, o, al menos, una parte esencial de dichos objetivos. No se van a abordar aspectos sobre las retocadas relativos a las implicaciones funcionales de estos elementos, en el sentido, por ejemplo, de que pueden ser útiles únicos per se o compuestos, las formas en que se habrían utilizado, lo tipos de enmangues, o el tipo de soportes utilizados (bien sabido es que los artefactos sin retocar habrían sido frecuentemente utilizados). Lógicamente este tipo de consideraciones sólo se podrán abordar cuando se realicen los análisis de tipo traceológico pertinentes.

Dado que todo este trabajo se ha centrado en el análisis de la tecnología lítica presente en el conjunto lítico retocado de El Espertín, en este apartado se seguirá manteniendo este punto de vista, de modo que nos centraremos en el análisis de las piezas retocadas desde un punto de vista esencialmente técnico. Por esta razón, la tipología expuesta se basa en grupos tipológicos amplios (raspadores, buriles, etc.), si bien a la hora de abordar cada grupo, en ocasiones, se describirá eventualmente la existencia de tipos retocados concretos de forma más detallada. Para ello, se hará alusión tanto a la tipología de Sonneville-Bordes y Perrot del Paleolítico Superior (1954, 1955, 1956a, 1956b), como a la de Fortea (1973) sobre el Epipaleolítico de la vertiente mediterránea $\mathrm{y}$, ocasionalmente, a otras tipologías del Epipaleolítico / Mesolítico europeo, fundamentalmente la del "Groupe d'Etude de l'EpipaléolithiqueMesolithique" (GEEM, 1969; 1972; 1975), en la que estaría incluida la de Rozoy (1978), así como otras aplicaciones y adaptaciones más recientes de estas últimas (Valdeyron, 1994; Bobeuf, 1998).

Se prestará una atención especial a los tipos de soportes seleccionados para confeccionar las piezas retocadas (Cuadro V.2), así como a las materias primas (Cuadro V.3); con el fin de determinar tanto los objetivos concretos del débitage, como la selección y gestión de los distintos soportes. 


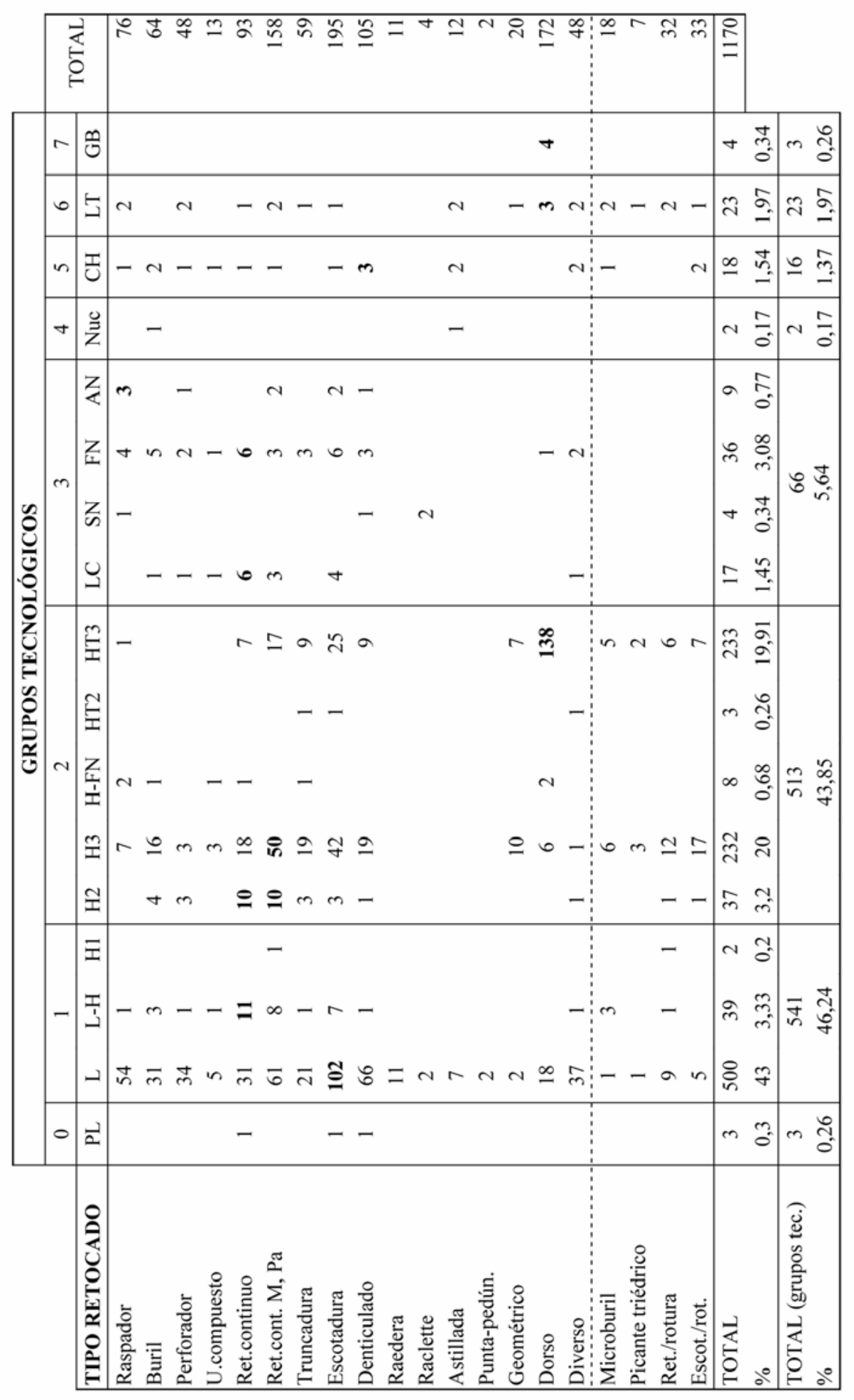

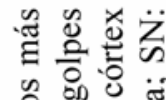
क品品号

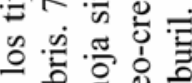
흐웡

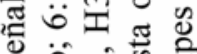
के

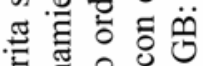

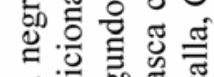
斗 它

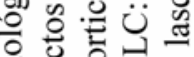
氮 흥.

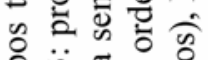

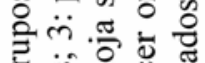
5n î. 它: $\lambda$ 它政

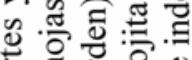

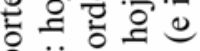
응 o 命言焉 象要要

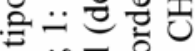
ㅎํ용

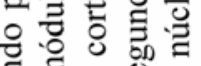

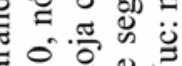

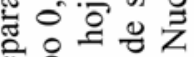

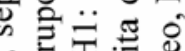
of 50 : : 政 言言泀 o 80.

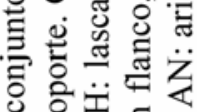

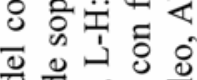

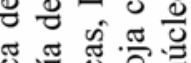

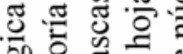
然品 워요용

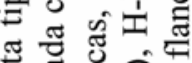
总 ते $>$ 这

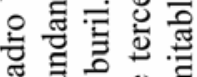

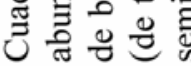




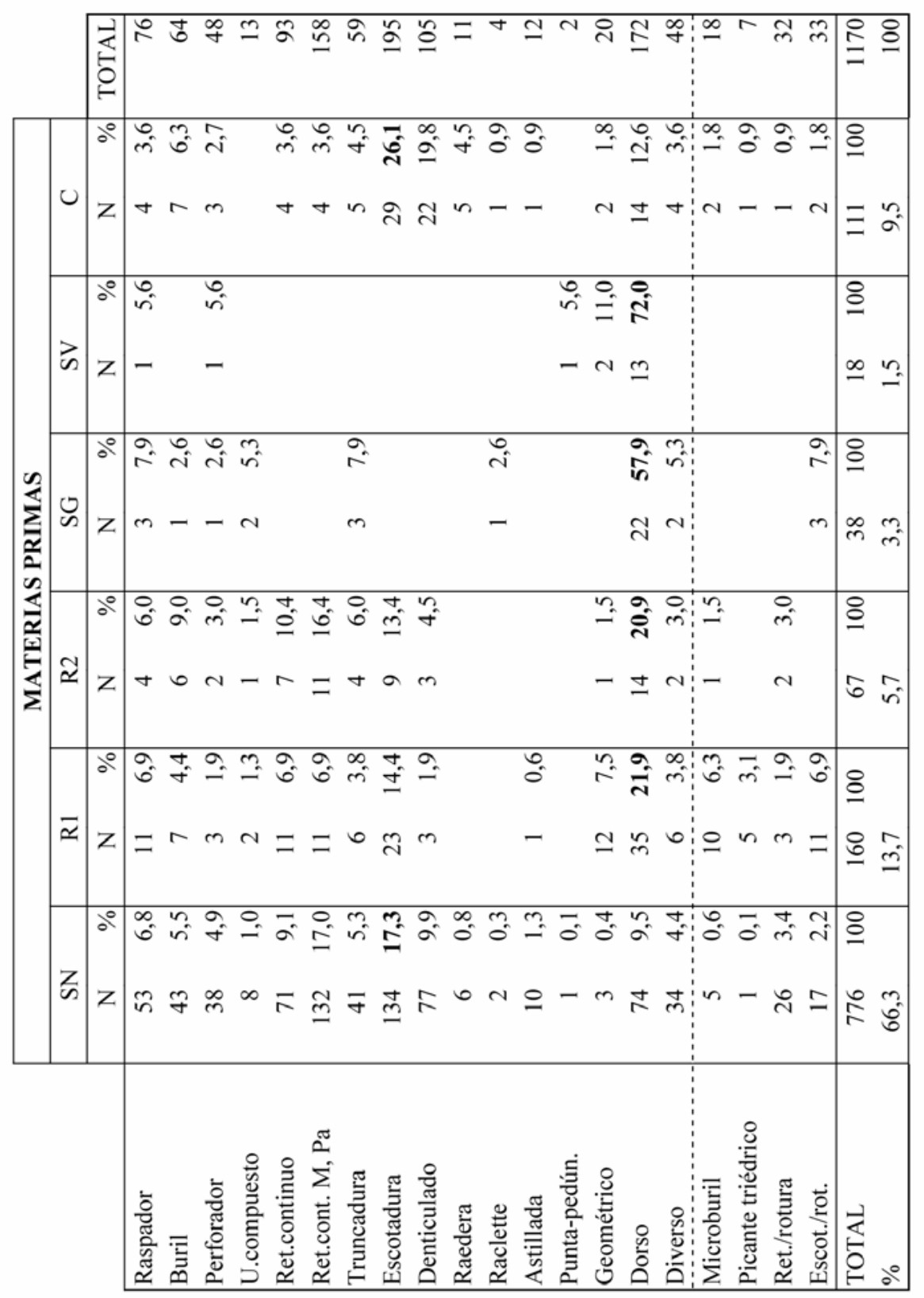

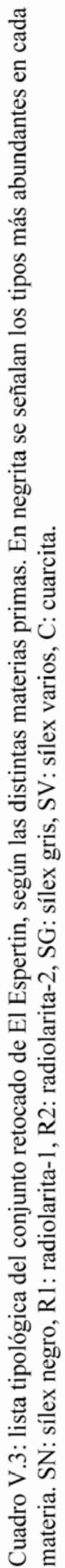




\section{V.3.2.1.- TIPOS DE SOPORTES SELECCIONADOS}

En el cuadro V.2 se pueden observar los distintos tipos de soportes elegidos para confeccionar los tipos retocados. La mayoría de las piezas se han retocado sobre el grupo de las lascas (el 46\%), seguido, muy de cerca, por el grupo de las hojas-hojitas (44\%). Con una presencia mucho menos importante están los productos de acondicionamiento y el resto de soportes del proceso operativo.

La pauta de selección de los soportes para retocar que se refleja sería propia de un proceso de talla laminar realizado in situ; de forma que hay un aprovechamiento extensivo de las lascas que se producen a lo largo de esta cadena de hojas-hojitas. Este cuadro por tanto es un resumen del comportamiento técnico que se ha observado, pero deja encubiertas las distintas formas en que se han tratado las materias primas; en particular, se pierde, en esta visión de conjunto, los distintos grados de especialización laminar revelados en las radiolaritas, el sílex gris y los sílex varios. Como es lógico, en este cuadro-resumen prevalecen, sobre todo, las características de las materias más abundantes del yacimiento, fundamentalmente el sílex negro y la cuarcita, pero tampoco permite acceder al carácter mixto que tiene el proceso operativo en ellas y la presencia de cadenas de objetivo tipo-lasca.

Por tanto este cuadro sobre la elección de los distintos soportes para los tipos retocados nos proporciona una visión genérica de la composición de la industria retocada de El Espertín, con un equilibrio entre el uso de lascas y soportes laminares, siendo interesante centrarnos quizás en el análisis de estos distintos tipos y sobre qué soportes se han retocado.

Hay algunos soportes que tienen un uso que se podría calificar de diversificado, frente a otros que lo tienen más especializado. La pauta seguida a la hora de retocar los distintos tipos de soportes se podría esquematizar del siguiente modo:

- Las lascas se utilizan sobre todo para escotaduras y denticulados, así como para piezas con retoque continuo, raspadores, perforadores y buriles. Se seleccionan por tanto para diversos tipos, especialmente aquellos "de fondo común”. 
- Los soportes que aportan un filo largo, es decir las hojas, las lascas laminares, láminas de cresta y algunos flancos de núcleo (los longitudinales), se vinculan con bastante frecuencia a las piezas con retoque continuo, aprovechando uno de los bordes largos como parte activa de la función ejecutada.

- Las hojas tendrían, además de lo anterior, una utilización de carácter "diversificado moderado", ya que aparecen en escotaduras, denticulados, buriles y truncaduras, además de los geométricos. Las escotaduras podrían estar en relación con la realización de los geométricos, por lo que las principales aplicaciones de las hojas serían: piezas de retoque continuo, denticulados, buriles, truncaduras y geométricos.

- Las hojitas, por su parte, tienen un uso específico para la fabricación de piezas de dorso, y aparecen en menor medida con escotaduras y con retoque continuo marginal sobre alguno de sus bordes. En este último uso se incluirían, al lado de los dorsos, como piezas pertenecientes a útiles compuestos.

- Las semitabletas de núcleo y las aristas de núcleo en general no son muy abundantes y se habrían utilizado de una forma similar a las lascas, para escotaduras y denticulados, raspadores, etc. Lo mismo se podría decir de otras piezas procedentes de otras fases de la cadena operativa (chunks y núcleos), que se habrían seleccionado eventualmente para la confección de algún útil retocado.

- Las piezas retocadas pertenecientes al grupo 6, es decir el de los debris, tendrían un patrón de aprovechamiento difícil de valorar, ya que aparecen en una gran variedad de tipos retocados. Sin duda muchas de estas piezas no son solamente lasquitas utilizadas como hojitas de dorso, también estarían incluidas en este grupo fragmentos de otras piezas de mayor tamaño, las cuales han sido reavivadas o han resultado rotas.

- Por último, los golpes de buril tienen un uso totalmente específico para las hojitas de dorso. 
Se podría decir, a modo de conclusión, que hay tres grandes grupos de categorías de soportes con unas características morfológicas y métricas determinadas, que tienen una utilización peculiar a la hora de ser retocados:

1.- Grupo de las lascas (uso diversificado privilegiando las "piezas de fondo común")

Este grupo está integrado por los elementos pertenecientes al grupo tecnológico 1, el de las lascas propiamente dichas, y también por otros soportes de los grupos tecnológicos 3, 4 y 5, de características cercanas a ellas (las tabletas y semitabletas de núcleo, las aristas de núcleo, los chunks y los núcleos). Se trata de un grupo de soportes de distinto tamaño, pero con una relación entre su anchura y longitud muy pequeña, y con un grosor elevado. Este grupo aportaría los soportes aptos para fabricar el grueso de los útiles denominados frecuentemente como "de fondo común", es decir, las escotaduras, denticulados, raspadores, buriles, perforadores, raederas, etc.

2.- Grupo de las hojas y soportes alargados en general (uso diversificado moderado)

El atributo fundamental en este grupo es que se trata de soportes "largos", con uno o más bordes de una longitud importante. Aquí se incluyen, además de las hojas propiamente dichas, las lascas laminares, las "hojas con flanco", las láminas con cresta y algunos de los flancos longitudinales. Este tipo de soportes va a tener una utilización diversificada de tipo "moderado" centrada en el aprovechamiento de este módulo morfométrico. Se van a utilizar sobre todo para tres objetivos:

- Piezas de retoque continuo, sobre uno o dos bordes y con un retoque más o menos intenso. Este tipo de piezas retocadas aprovecharía las características métricas de este grupo.

- Geométricos. La mayoría de los geométricos, tanto los tipos reconocibles como las piezas interpretadas como intentos fallidos en su fabricación, aparecen sobre hojas de una anchura mayor a un centímetro, por lo que se deduce que se prefieren los soportes laminares para su fabricación. Además hay un buen número de piezas que serían elementos secundarios en la fabricación de los geométricos: los microburiles, los picantes triédricos, las 
escotaduras y piezas retocadas que tienen una rotura justo al lado de tal retoque, e incluso podríamos apuntar que algunas de las escotaduras fueran también intentos de fabricar geométricos.

- Algunos de los tipos del "fondo común", en concreto escotaduras, buriles y algunos raspadores. En el caso de las escotaduras se ha indicado ya cómo muchas de ellas podrían constituir el primer paso en la confección de un geométrico. Para la fabricación de algunos buriles se han seleccionado este tipo de piezas alargadas porque aportan un soporte muy apto para este útil, que frecuentemente se fabrica a partir de los gestos más simples, por ejemplo sobre el talón de una hoja.

\section{3.- Grupo de las hojitas (uso específico)}

Este grupo tiene una función totalmente específica para las piezas de dorso, tanto hojitas de dorso propiamente dichas, como puntas. De forma secundaria podemos encontrar hojitas que habrían sido utilizadas también como elementos compuestos, insertadas en astiles (las hojitas con retoque continuo), así como hojitas con escotaduras y geométricos. De nuevo hay que recordar, como en las hojas, que algunas de las escotaduras pueden estar relacionadas con la fabricación de geométricos.

\section{V.3.2.2.- TIPOS RETOCADOS POR MATERIAS PRIMAS}

En el cuadro V.3 se expone la distribución de los tipos retocados según las materias primas. En él se puede apreciar el patrón de utilización de las distintas rocas según los distintos tipos. El sílex negro y la cuarcita se han retocado en una gran variedad de grupos tipológicos, aunque el tipo más predominante es el de las escotaduras. No obstante, en estas dos materias (las más abundantes del conjunto) tienen una gestión de los soportes que difiere en cierto grado entre sí, ya que mientras el sílex negro ha servido para un buen número de piezas con retoque continuo, la cuarcita se ha utilizado especialmente en denticulados.

Los otros sílex (radiolaritas, sílex gris y sílex varios) han tenido un uso más específico, no tienen tanta diversificación en útiles retocados como en las materias anteriores. Destaca en ellos especialmente la producción de piezas de dorso, en todos 
ellos éste es el grupo retocado predominante. De este modo, el carácter del débitage de este tipo de materias, especializadas en la producción laminar y microlaminar, se matiza aún más, ya que tales hojas y hojitas van a tener una aplicación bastante concreta, en especial las hojitas, centrada en la fabricación de las piezas de dorso. Incluso el elevado porcentaje de este tipo retocado en el sílex gris (58\%) y los sílex varios (72\%), permite decir que estas materias tienen una utilización totalmente específica, cuyo objetivo son hojitas para la fabricación de elementos de dorso.

El sílex negro es la materia que cuenta con un mayor número de piezas retocadas (el $66 \%$ del conjunto), ya se ha comentado que esta materia local es la más abundante del yacimiento, y sobre ella se ha desarrollado un proceso de talla extenso y con objetivos de tipo mixto; por tanto es bastante lógico que sea también la materia con más elementos retocados. A la hora de retocar el chert negro hay una diversificación tanto en los tipos de soportes seleccionados, como en la variedad de tipos que se retocan. De hecho, el sílex negro es la materia predominante en los distintos grupos tipológicos, con la excepción de los geométricos y restos de la técnica de microburil (microburiles propiamente dichos y picantes triédricos), en los cuales es la radiolarita-1 la materia más abundante (Cuadro V.4). En consecuencia, la radiolarita resalta como una materia que se ha utilizado para realizar dos tipos retocados que podrían considerarse como objetivos privilegiados de su débitage, aunque no exclusivos: las piezas de dorso $(22 \%$ de las piezas retocadas de radiolarita-1) y los geométricos (7\%). Aunque el porcentaje de estos últimos es ciertamente modesto, podemos tener en cuenta que el conjunto de microburiles y restos de la técnica de microburil suponen un $18 \%$, y que hay un $14 \%$ de escotaduras, algunas de las cuales pueden haber sido efectuadas para la fabricación de estos microlitos.

La materia más retocada después del sílex negro es la radiolarita-1 (14\% del conjunto), cosa que puede llamar la atención, ya que la segunda materia más tallada en el yacimiento es la cuarcita, pero se ha seleccionado menos a la hora de retocar (9\%). En consecuencia se acentúa el carácter más específico del débitage de la radiolarita frente a las materias de objetivo mixto (sílex negro y cuarcita) talladas en el yacimiento. 


\begin{tabular}{|c|c|c|c|c|c|c|c|}
\hline & \multicolumn{6}{|c|}{ MATERIAS PRIMAS } & \multirow[b]{2}{*}{ TOTAL } \\
\hline & $\mathrm{SN}$ & $\mathrm{R} 1$ & R2 & SG & $\mathrm{SV}$ & $\mathrm{C}$ & \\
\hline Raspador & 69,7 & 14,5 & 5,3 & 3,9 & 1,3 & 5,3 & 100 \\
\hline Buril & 67,2 & 10,9 & 9,4 & 1,6 & & 10,9 & 100 \\
\hline Perforador & 79,2 & 6,3 & 4,2 & 2,1 & 2,1 & 6,3 & 100 \\
\hline U.compuesto & 61,5 & 15,4 & 7,7 & 15,4 & & & 100 \\
\hline Ret.continuo & 76,3 & 11,8 & 7,5 & & & 4,3 & 100 \\
\hline Ret.cont. M, Pa & 83,5 & 7,0 & 7,0 & & & 2,5 & 100 \\
\hline Truncadura & 69,5 & 10,2 & 6,8 & 5,1 & & 8,5 & 100 \\
\hline Escotadura & 68,7 & 11,8 & 4,6 & & & 14,9 & 100 \\
\hline Denticulado & 73,3 & 2,9 & 2,9 & & & 21,0 & 100 \\
\hline Raedera & 54,5 & & & & & 45,5 & 100 \\
\hline Raclette & 50,0 & & & 25,0 & & 25,0 & 100 \\
\hline Astillada & 83,3 & 8,3 & & & & 8,3 & 100 \\
\hline Punta-pedún. & 50,0 & & & & 50,0 & & 100 \\
\hline Geométrico & 15,0 & 60,0 & 5,0 & & 10,0 & 10,0 & 100 \\
\hline Dorso & 43,0 & 20,3 & 8,1 & 12,8 & 7,6 & 8,1 & 100 \\
\hline Diverso & 70,8 & 12,5 & 4,2 & 4,2 & & 8,3 & 100 \\
\hline Microburil & 27,8 & 55,6 & 5,6 & & & 11,1 & 100 \\
\hline Picante triédrico & 14,3 & 71,4 & & & & 14,3 & 100 \\
\hline Ret./rotura & 81,3 & 9,4 & 6,3 & & & 3,1 & 100 \\
\hline Escot./rot. & 51,5 & 33,3 & & 9,1 & & 6,1 & 100 \\
\hline
\end{tabular}

Cuadro V.4: porcentaje de la lista tipológica del conjunto de El Espertín, por materias primas. En negrita se señalan los tipos más abundantes. $\mathrm{SN}$ : sílex negro, R1: radiolarita-1, R2: radiolarita-2, $\mathrm{SG}$ : sílex gris, $\mathrm{SV}$ : sílex varios, C: cuarcita.

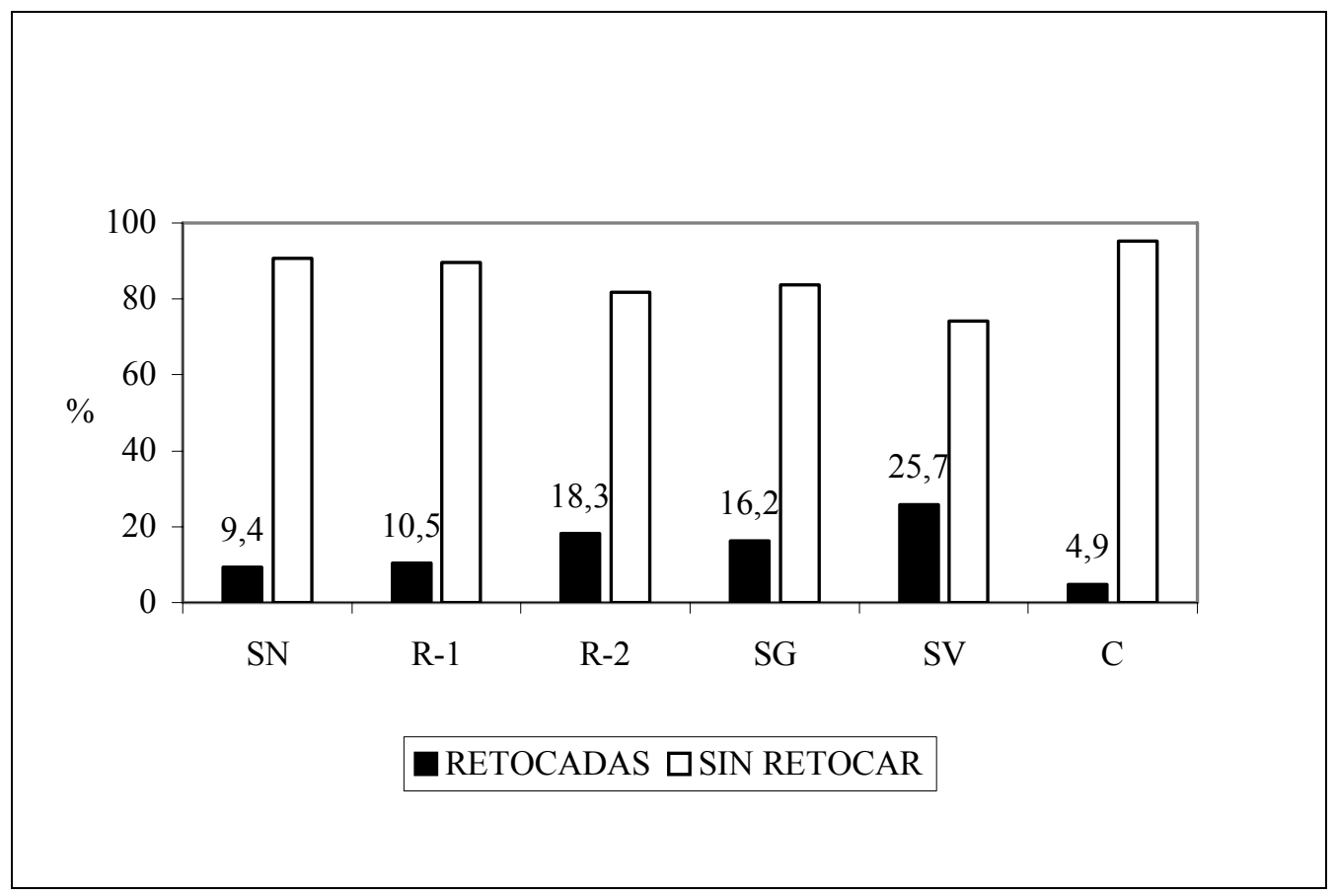

Gráfico V.14: porcentaje de representación de las distintas materias primas, con y sin retoque. $\mathrm{SN}$ : sílex negro, R1: radiolarita-1, R2: radiolarita-2, SG: sílex gris, SV: sílex varios, C: cuarcita. 
Si se tiene en cuenta las piezas retocadas respecto al número de elementos de cada materia, se pone también de relieve el carácter diversificado de la explotación según las materias. Las materias que más se han retocado, en relación al número de elementos presentes de cada materia, son aquellas que tienen un carácter especializado; de más a menos retocadas son: sílex varios, sílex gris, radiolarita-2, radiolarita-1, sílex negro y cuarcita (Gráfico V.14).

\section{V.3.2.3.- TIPOLOGÍA}

En el cuadro V.5 se presentan los distintos tipos retocados con el número total de piezas y el porcentaje relativo de cada uno. El tipo más abundante es el de las escotaduras, con un $17 \%$, seguido por los dorsos, con un $15 \%$ y por las piezas con retoque continuo marginal, con un $13 \%$. Si tomamos en conjunto algunos de estos grupos tipológicos, el grupo más abundante sería el de las escotaduras y denticulados, que constituyen en torno a la cuarta parte del conjunto (26\%), seguido por las piezas con retoque continuo, con un $21 \%$, quedando en tercer lugar los dorsos. Los raspadores suponen el $6 \%$, los buriles y las truncaduras el 5\% y los perforadores el 4\%. Los geométricos representarían tan solo el $2 \%$ del conjunto, y el resto de los tipos suponen un porcentaje igual o inferior a un 1\% (útiles compuestos, raederas, raclettes, astilladas, así como dos puntas un tanto peculiares con un pedúnculo).

En las filas inferiores del cuadro se han incluido los microburiles, picantes triédricos y piezas con una rotura o una escotadura adyacente a una rotura; se tratarían, todas, de piezas que pertenecerían a una secuencia previa al retoque del tipo propiamente dicho, y se relacionan con la fabricación de geométricos, más concretamente serían las huellas de fases de rotura de los soportes. Este tipo de elementos se han incluido dentro del cuadro que especifica los tipos de piezas retocadas ya que, tradicionalmente, se ha realizado así en la descripción de las industrias líticas del Epipaleolítico/Mesolítico (por ejemplo las listas-tipo expuestas en: GEEM, 1969 y Valdeyron, 1994). No obstante, hay que resaltar que no se trataría de útiles retocados sensu estricto, sino que son restos de la secuencia de retoque en un sentido más amplio. En total suponen en torno al $8 \%$ del conjunto retocado, por lo cual este tipo de piezas, 
que evidencian una secuencia peculiar de rotura de un soporte, tiene una presencia interesante en este conjunto.

\begin{tabular}{|l|rr|}
\hline TIPO RETOCADO & $\mathrm{N}$ & $\%$ \\
\hline Raspador & 76 & 6,50 \\
Buril & 64 & 5,47 \\
Perforador & 48 & 4,10 \\
Útil compuesto & 13 & 1,11 \\
Retoque continuo & 93 & 7,95 \\
Ret.cont. marginal o parcial & 158 & 13,50 \\
Truncadura & 59 & 5,04 \\
Escotadura & 195 & 16,67 \\
Denticulado & 105 & 8,97 \\
Raedera & 11 & 0,94 \\
Raclette & 4 & 0,34 \\
Astillada & 12 & 1,03 \\
Punta con muesca/pedúnculo & 2 & 0,17 \\
Geométrico & 20 & 1,71 \\
Dorso & 172 & 14,70 \\
Diverso & 48 & 4,10 \\
\hline Microburil & 18 & 1,54 \\
Picante triédrico & 7 & 0,60 \\
Retoque/rotura & 32 & 2,74 \\
Escotadura/rotura & 33 & 2,82 \\
\hline TOTAL & 1170 & 100,00 \\
\hline
\end{tabular}

Cuadro V.5: lista tipológica del total de las materias de El Espertín.

En el cuadro V.6 se expone el porcentaje de los distintos tipos retocados según el grupo tecnológico sobre el que se fabrican, con el fin de aportar una visión genérica de los soportes seleccionados en los distintos útiles. Es patente el predominio de las lascas en la mayoría de los tipos, excepto en las piezas con retoque continuo, truncadas, geométricos y dorsos, para los que se han preferido los soportes laminares. 


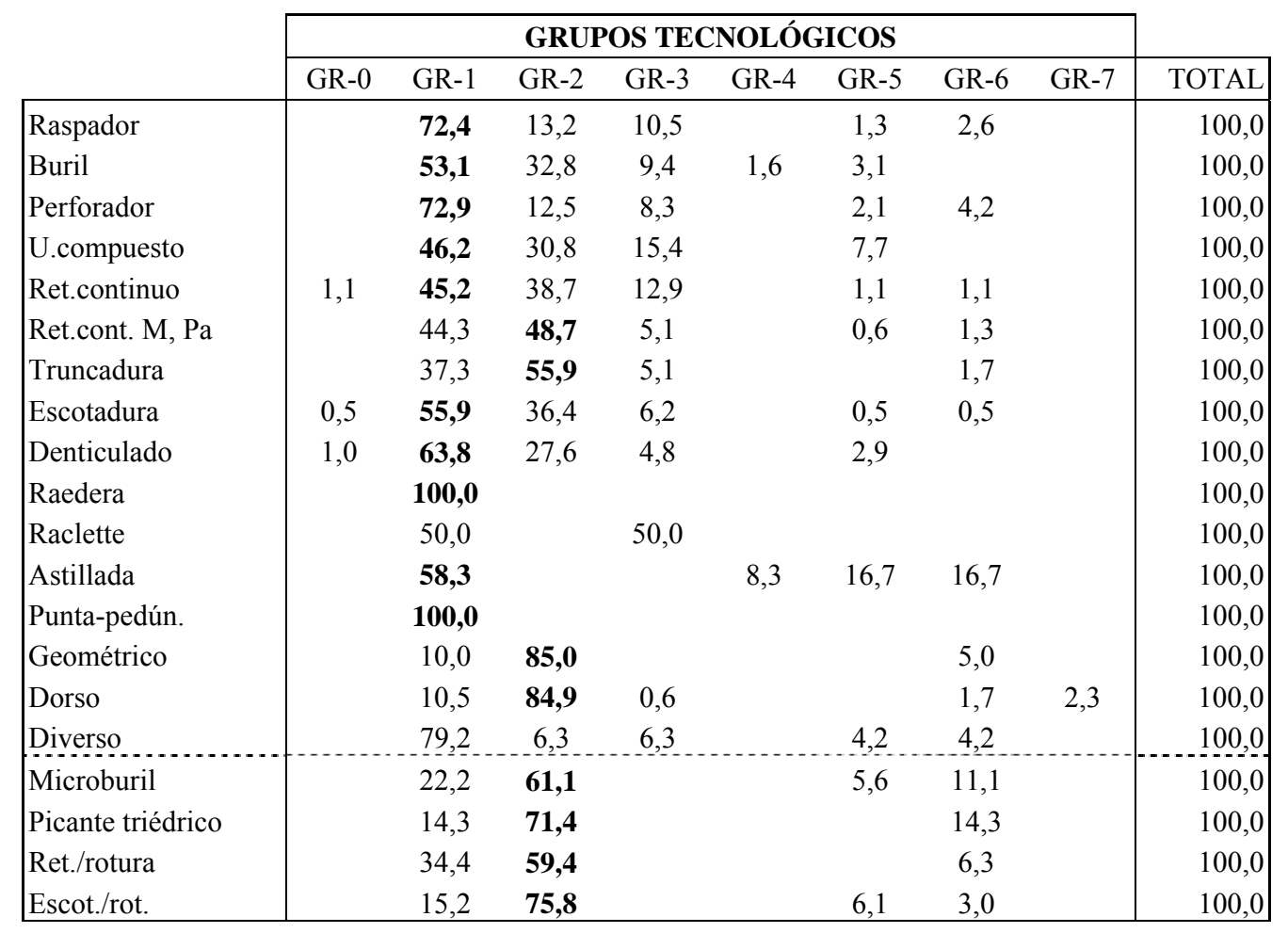

Cuadro V.6: porcentaje de la lista tipológica según los grupos tecnológicos. En negrita se señalan los tipos más abundantes, remarcando así el grupo tecnológico seleccionado.

\section{Raspadores}

Hay 76 raspadores, la gran mayoría (casi las tres cuartas partes) se han fabricado sobre lasca, aunque hay un pequeño número de ellos para los que se han utilizado hojas, en este último caso, tales soportes laminares son de calidad media o media-buena. Dentro de este grupo tipológico se han incluido tres frentes de raspador (dos de sílex negro y uno de radiolarita-1) lo cual indicaría que en la cueva se habría desarrollado las actividades funcionales relacionadas con este útil, no sólo su fabricación, sino también su utilización, con los consiguientes reavivados del frente útil de la pieza.

La mayoría de los raspadores se sitúan entre 1-3 cm de longitud, 1-3 de anchura y 4-8 mm de grosor, los de mayor módulo (de 4 a $6 \mathrm{~cm}$ de longitud y 3-4 $\mathrm{cm}$ de anchura) son de sílex negro exclusivamente; también destacan dos raspadores de cuarcita, los cuales llegan a alcanzar los 7-8 cm de dimensión máxima (ver Gráfico MP.15 para la dispersión de la longitud y anchura). Por materias primas, hay una preferencia absoluta por el sílex negro $(n=53)$ al que le sigue muy de lejos la radiolarita 
(con 11 ejemplares de la radiolarita-1 y 4 de la radiolarita-2). Sorprende el hecho de que tan solo hay 4 raspadores de cuarcita, dos de los cuales son una lasca y un flanco de núcleo, ambos corticales y de gran tamaño, como se ha indicado.

Respecto a la tipología más detallada de los raspadores, hay un buen número de raspadores unguiformes (que supondrían un poco más de un tercio del conjunto), algunos de tamaño microlítico (inferior a $1 \mathrm{~cm}$ ). Hay también algún ejemplar de raspador cuyo retoque conforma un frente con morfología denticulada. Hay dos raspadores dobles, uno sobre una hoja de un sílex afectado totalmente por deshidratación y otro con retoque alterno. Este último tiene una morfología un tanto peculiar, ya que está fabricado sobre una placa de chert negro, fracturada como consecuencia de planos de diaclasado interno paralelos, que son aprovechados en sus bordes cortos para confeccionar sendos frentes de raspador. Este tipo de soporte puede tener ciertas similitudes morfológicas con los raspadores alternos mencionados por Merino (1994: 103), los cuales aprovechan tabletas de reavivado del núcleo.

\section{Buriles}

Hay 64 buriles, la mitad de ellos se han fabricado sobre lascas, incrementándose en este tipo los soportes de módulo más largo, tanto hojas, como hojas con flanco y lascas laminares. Esto se observa bastante bien en las dimensiones medias de los buriles, que tienen, en general, mayor longitud que los raspadores (Gráfico MP.15). Se han aprovechado, no obstante, a veces soportes tipo-placa, o fragmentos de lascas rotas por planos naturales, utilizando los bordes de esos fragmentos para confeccionar el bisel.

En la tipología interna de los buriles, predominan los de factura sencilla, especialmente los buriles de ángulo sobre rotura o paño natural, destacando algunos fabricados sobre el talón de hojas y lascas laminares. Además predominan los buriles con un solo paño de buril, por lo que su fabricación es muy rápida. Los buriles sobre truncadura no son demasiado abundantes y sobresalen algunos porque son de muy buena factura, por ejemplo un buril sobre truncadura recta en radiolarita-2, en una hoja de buena calidad (su sigla es: ESP97/C8/S9/N3B/B2.12). Se ha hecho ya mención a esta pieza porque no encaja en el conjunto de este tipo de materia presente en el conjunto 
material, por lo que se ha planteado que pertenecería a una fase de débitage anterior, realizada fuera del yacimiento.

\section{Perforadores}

Hay 48 perforadores, la gran mayoría sobre lasca, destacando algunos ejemplos de microperforadores sobre lasquitas.

En la tipología interna de este grupo, hay perforadores de eje rectos, pero también hay un buen número de perforadores desviados, situados sobre la zona distal derecha/izquierda, sobre una esquina distal del soporte. Como en el caso de los buriles, se trataría de una factura muy simple del tipo, aprovechando la morfología del soporte para la fabricación del perforador, cuya punta estaría entre el borde transversal (que puede ser la parte distal natural de la pieza o bien una rotura) y el lateral. Así a partir de unos pocos retoques sobre estos bordes se confecciona una punta robusta, normalmente dichos retoques llegan a realizar una escotadura sobre algunos de estos bordes, quedando el otro con una amplitud de menor intensidad. Incluso hay algunos ejemplos en los que el borde lateral tiene una escotadura más o menos marcada, mientras que el borde transversal tiene apenas retoque.

\section{Piezas con retoque continuo}

Las piezas con retoque continuo son bastante abundantes en el conjunto lítico (21\% del total), se han hecho dos grandes grupos dependiendo de la amplitud del retoque, de modo que se han separado por un lado las piezas con retoque normal o profundo $\mathrm{y}$, por otro, las piezas con retoque marginal y/o con una morfología del retoque irregular. Este segundo grupo podría corresponder a las piezas "con huellas de uso", pero en todo caso se han incluido las piezas que, aunque marginal, tienen un retoque continuo a lo largo de uno o dos bordes. Este segundo subconjunto es el más abundante (13\%) y posiblemente sea indicio de una utilización muy intensiva de los soportes con un borde largo y afilado para distintas labores.

Los soportes utilizados son, como en casi todos los tipos, predominantemente lascas, pero en este grupo tipológico el uso de las lascas ronda aproximadamente un tercio del conjunto, es decir, habría una menor presencia de este tipo de soporte y un 
incremento de los soportes laminares. En las piezas con retoque continuo y amplitud normal el grupo tecnológico 1 constituiría el 46\% del conjunto, mientras que el grupo 2 supone el 38\%; por su parte en las piezas con retoque continuo marginal se constata un incremento de los soportes laminares, tanto hojas como hojitas, de forma que el grupo 1 constituye un $45 \%$, pero el grupo 2 asciende al 49\%. Respecto a las características cualitativas de los soportes laminares, hay una tendencia a seleccionar los de una regularidad media-buena, siendo el sílex negro la materia donde más se aprovechan también las hojas de carácter mediocre.

Las dimensiones medias son unos 3 centímetros de longitud, por 2 de anchura y 5 milímetros de grosor, no obstante varían también dependiendo de las materias, de manera que las piezas de cuarcita son las de mayor tamaño (36 $\mathrm{mm}$ de longitud de media, por 22 de anchura y 8 de grosor), seguidas por las de sílex negro ( $29 \mathrm{~mm}$ por 20 y por 6) y por último las de radiolarita (22-25 mm de longitud, 15 de anchura y 5 de grosor). Hay que reseñar que en cuarcita y sílex negro se llegan a alcanzar los $7 \mathrm{~cm}$ de longitud (Gráfico V.15).

Respecto a la tipología interna de este grupo, hay prácticamente el mismo número de piezas con un borde retocado que con dos, siendo más interesantes los atributos relativos a la morfología e intensidad del propio retoque. Dentro de las piezas con retoque continuo se dividió en un primer momento aquellas con un retoque normal, de aquellas con un retoque marginal. En ambas hay que reseñar que hay una serie de ellas que tienen una delineación del retoque denticulada o festoneada, es decir, el retoque no conforma una línea recta y homogénea a lo largo del borde, sino que es un poco irregular, pero sin llegar a considerarse como un denticulado estrictamente. Quizás exista una gradación en la intensidad de este tipo de retoque continuo de morfología denticulada (o más bien microdenticulada)/festoneada y el denticulado propiamente dicho, de forma que dicha gradación corresponda a la intensidad del trabajo realizado.

Entre las hojitas hay un mayor número con un retoque marginal que normal; las primeras podrían corresponder al conjunto de las hojitas del tipo de las Dufour.

Hay que reseñar la presencia de 7 piezas que se podrían considerar como puntas, con retoque continuo convergente sobre ambos laterales. Cinco están realizadas sobre 
sílex negro, una sobre radiolarita-2 y la última en cuarcita. Sus dimensiones medias son: $35 \mathrm{~mm}$ de longitud, 22 de anchura y 7 de grosor, pero dos ejemplos que están completos (una hoja con arista natural de sílex negro y una hoja con flanco de radiolarita-2) llegan a alcanzar prácticamente los $5 \mathrm{~cm}$ de longitud (Gráfico V.15).

Este tipo de piezas podría encajar en el tipo "hojas retocadas apuntadas", definido por Sonneville-Bordes y Deffarge (1975) y añadido a la lista tipológica del Paleolítico Superior (Sonneville-Bordes y Perrot, 1954 a 1956), con el número 93. Sonneville-Bordes y Deffarge señalan que este tipo aparece de forma frecuente en varios niveles de cuevas francesas del Magdaleniense final, y que pueden considerarse como una pieza característica de este periodo.

Las piezas con retoque continuo han sido a veces un grupo tipológico difícil de interpretar, en primer lugar porque puede estar muy cercano a otras categorías tipológicas, especialmente las raederas y, en segundo, porque puede haber algunas de ellas cuyo retoque no corresponda a un gesto técnico intencional, sino que sea la consecuencia de su utilización ${ }^{25}$. En el caso de El Espertín, se han incluido en este grupo aquellos soportes retocados cuyos atributos del retoque son, aproximadamente, los siguientes: retoque simple, sobreelevado u oblicuo, normal o marginal y continuo, sobre uno o ambos bordes laterales. En ocasiones la morfología del borde retocado en lugar de ser continua es más irregular; variante que se ha calificado de festoneada o microdenticulada. Aparte de estas piezas, hay otras que quizás correspondan a las "piezas con huellas de uso", con un retoque, discontinuo, parcial o menos uniforme.

\section{Truncaduras}

Hay 59 truncaduras en el conjunto; en ellas se han incluido no sólo las truncaduras más "convencionales”, sobre los distintos soportes, especialmente hojas, sino que también hay unos tipos un tanto peculiares, en concreto 6 piezas con truncadura y retoque continuo sobre el resto de los bordes y una pieza con retoque continuo como las anteriores, si bien la truncadura, oblicua, parece conformar un

\footnotetext{
${ }^{25}$ Respecto a la problemática en torno a las hojas con retoques continuos, cabe mencionar que ha sido un tema tratado por ejemplo por A. Cava, quien las denomina: "láminas retocadas y/o con estigmas", y son muy frecuentes en la industria lítica de los niveles neolíticos de la cueva de Chaves (Huesca) y, en general, en el Neolítico antiguo mediterráneo (Cava, 2000: 117).
} 
perforador (sigla: ESP94/G8/S5/nº88). Estas siete piezas con retoque prácticamente por todos lados (a excepción del talón) están fabricadas sobre sílex negro y, como soporte, se han seleccionado cinco hojas, una lasca y una "lasca con flanco"; se trata de soportes de un módulo bastante alargado (longitudes que oscilan de 3 a $6 \mathrm{~cm}$ ) y grueso (de 3 a 13 $\mathrm{mm}$ ), en concreto sus dimensiones medias son: $41 \mathrm{~mm}$ de longitud, 21 de anchura y 6 de grosor.

Estas piezas quizás haya que incluirlas de forma más adecuada entre las de retoque continuo, como "hojas retocadas truncadas", definidas junto con las "hojas retocadas apuntadas" (Sonneville-Bordes y Deffarge, 1975), e incluidas asimismo en la lista del Paleolítico superior con el número 94. De la misma manera que las anteriores, fueron consideradas como artefactos retocados típicos del Magdaleniense final. Además las características técnicas de los soportes seleccionados siguen los mismos criterios que en el caso de las "hojas retocadas apuntadas", con la salvedad de que en "las hojas retocadas truncadas" la longitud es ligeramente superior $(3,5 \mathrm{~cm}$ para las primeras y 4 $\mathrm{cm}$ para las segundas). En ambos casos, estas piezas sobrepasan la longitud media tanto de las piezas con retoque continuo, como de las truncaduras.

Respecto a los tipos concretos de soportes seleccionados para el conjunto de las truncaduras, predominan de nuevo las lascas, con el 36\%, pero las hojas de tercer orden alcanzan el 32\%. De hecho, se constata ya en el grupo tipológico de las truncaduras una preferencia por los soportes laminares, ya que el grupo tecnológico 2 supone el 56\% del total (frente al 37\% del grupo 1), y en este incremento en la selección de soportes laminares hay que tener en cuenta no solo las hojas, sino también las hojitas (hay 14 piezas que se clasificarían como hojitas con truncadura).

Las dimensiones medias de las truncaduras son 23 milímetros de longitud, 15 de anchura y 4 de grosor; estos datos no corresponden a soportes de tipo alargado, como se ha observado al examinar los distintos soportes seleccionados, sino que tales medidas se refieren al tamaño de los útiles una vez retocados y/o reavivados (Gráfico V.15). 

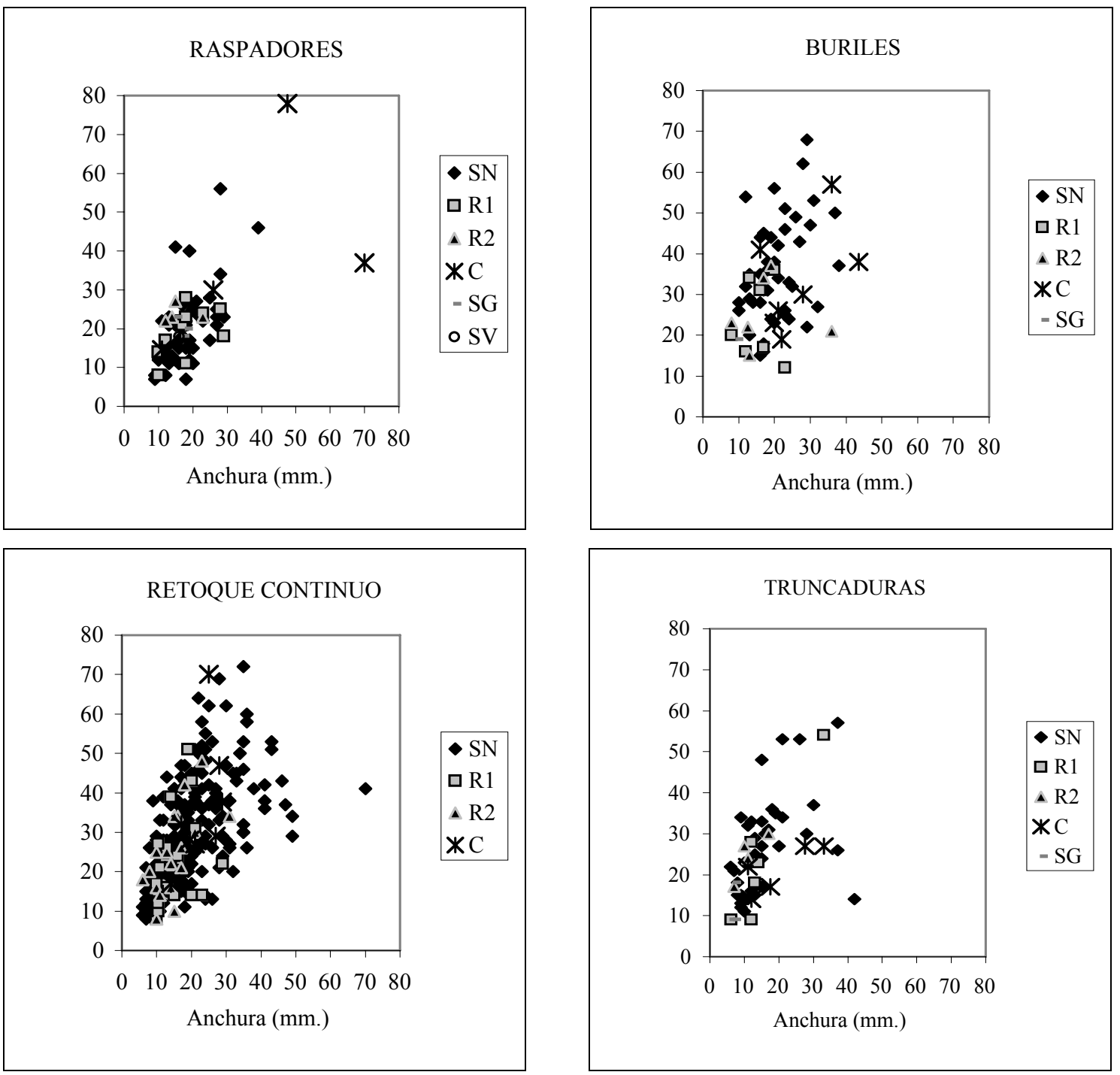

Gráfico V.15: gráfico de dispersión de los raspadores, buriles, piezas de retoque continuo y truncaduras; según su longitud y anchura, y señalando las distintas materias primas. SN: sílex negro, R1: radiolarita, R2: radiolarita-2, C: cuarcita, SG: sílex gris, SV: sílex varios. 


\section{Escotaduras y denticulados}

Las materias más abundantes en estos tipos son el sílex negro y sobre todo la cuarcita; en esta última casi la mitad de los elementos retocados son escotaduras y denticulados. Se utiliza también la radiolarita para estos tipos, aunque en un porcentaje muy escaso (16\% en escotaduras y tan solo un $6 \%$ en denticulados). Respecto a las materias más "exóticas” y menos abundantes como son el sílex gris y los sílex varios, no se han documentado estos tipos "de fondo común".

En los soportes seleccionados predominan ampliamente las lascas (52\% en escotaduras y $63 \%$ en denticulados) y, si tenemos en cuenta los grupos tecnológicos, el grupo 1 es el más abundante, con un $56 \%$ en las escotaduras y un $64 \%$ en los denticulados; por el contrario el grupo 2 alcanza solo un $28 \%$ en los denticulados y asciende al $34 \%$ en las escotaduras. En consecuencia parece que para los denticulados se prefieren sobre todo las lascas de cuarcita, mientras que las escotaduras aparecen en mayor proporción en radiolarita, así como en hojas/hojitas; de hecho en esta materia prima, y a diferencia de lo que sucede en este grupo tipológico, la mitad de las piezas con escotadura son hojas y hojitas.

El tamaño de las piezas con escotaduras no es demasiado grande, la mayoría se encuentran en unas dimensiones de 1 a 4-5 centímetros de longitud y una anchura de 1 a 3-4 centímetros (Gráfico V.16). La media aritmética se halla en una longitud de 24 milímetros, 18 de anchura y 5 de grosor. Se trataría por tanto de elementos de tamaño medio, de morfología cuadrangular o rectangular y de un cierto grosor; son características por tanto que encajan en la morfología prototípica de los soportes-tipolasca. Las mayores piezas se encuentran en el sílex negro, llegando a aparecer una lasca de $9 \mathrm{~cm}$ de longitud por 6 de anchura (sigla: ESP94/E5/S9/nº42); por el contrario, la radiolarita-1 y la cuarcita tendrían un tamaño más cercano a la media general, sin apenas sobrepasar los 4 centímetros de longitud máxima. En cuarcita, las piezas, dado que se trata casi siempre de lascas, son de morfología más cuadrangular, con un tamaño de unos 2 centímetros de lado y, en general, tienen un mayor grosor (en torno a los 7 $\mathrm{mm}$ ). En radiolarita-2 sucede algo curioso, ya que aparecen, de nuevo en esta materia, rasgos que apuntan a la presencia de una ruptura en la cadena operativa. En este caso se 
trata de la presencia de una lámina con cresta que mide 6 centímetros de longitud, además de otras dos hojas de 15 milímetros de anchura, soportes que en conjunto no encajan en las características técnicas y métricas que se han observado en la materia. Se podría considerar por tanto que estas piezas son testimonio de la existencia de fases de débitage desarrolladas fuera del yacimiento, con la fabricación de unos útiles retocados que son transportados por los grupos prehistóricos.

Respecto a la tipología interna del grupo de las escotaduras, tenemos que reseñar que hay tres piezas de sílex negro (una lasca-laminar, una lasca y una neo-cresta) que podrían considerarse como un tipo intermedio hacia un perforador, ya que la escotadura está realizada sobre una esquina de la pieza.

Hay, también en sílex negro, siete soportes (cuatro lascas y tres hojas) que además de la concavidad que da lugar a la escotadura tienen retoque en el resto del borde afectado por dicha escotadura, de forma que podría considerarse como una pieza a medio camino entre una escotadura y una pieza de retoque continuo. El hecho de que el retoque realice una amplitud bastante acusada en la conformación de la escotadura es lo que nos ha decantado por incluirla en esta última categoría tipológica.

Hay otras cuatro piezas de sílex negro (todas sobre lascas) que tienen la escotadura en el borde transversal, por lo que podrían ser un tipo tangencial con las truncaduras cóncavas. De nuevo la morfología cóncava muy acusada del retoque, así como el módulo general de dichos elementos, con una morfología cuadrangular y un tamaño reducido, de 20 milímetros de longitud, por 18 de anchura y 2 de grosor; nos ha inclinado a incluir estas piezas "con escotadura-truncadura" entre las escotaduras.

En cuanto a los soportes laminares con escotadura, habría que hacer dos matizaciones. En primer lugar la escotadura puede estar relacionada con una función específica concreta (tratamiento de materias blandas como la madera, asta, etc.), pero por otra parte, la escotadura también puede estar relacionada no con una acción directa, sino con un paso técnico en una fase de retoque ${ }^{26}$. Esta segunda posibilidad se refiere a

${ }^{26}$ Es característico de conjuntos del Epipaleolítico y Mesolítico que el grupo de los denticulados y escotaduras sea muy abundante. En el caso de las escotaduras se suele relacionar, en particular las escotaduras sobre soportes laminares, con la presencia de geométricos (Cava, 1989: 121). 
que, en la realización de un útil retocado, hay ocasiones en las que es necesario, además de la selección del soporte adecuado, una preparación o adecuación de tal soporte, previamente al retoque propiamente dicho. Dicha adecuación puede ser más o menos larga en la secuencia de gestos técnicos, por ejemplo en algunos buriles se hace una truncadura previa al golpe de buril; pero hay ocasiones en las que es necesario realizar una fractura intencional del soporte para darle una morfología o un módulo métrico adecuado para el tipo de útil que se quiere conseguir. El caso de la "técnica de microburil" sería paradigmático de este tipo de técnicas, centrado en fracturar de una determinada manera la hoja-soporte y retocar el geométrico. Dado que esta técnica necesita la realización de una escotadura sobre la hoja-soporte, puede ser que algunas de las escotaduras sobre soporte laminar hayan tenido por objetivo la realización de geométricos. Esta posibilidad estaría reforzada por el hecho de que en radiolarita, que es la materia donde más geométricos aparecen, hay un buen número de hojas con escotadura.

En los denticulados se podrían hacer dos grandes grupos a partir del soporte seleccionado: por un lado los denticulados sobre soportes tipo-lasca (piezas de los grupos tecnológicos 1,3 y 5) y por otro los que tienen por soporte hojas u hojitas. Los primeros son piezas robustas, con unas dimensiones medias aproximadas (Gráfico MP.16) de 3-4 centímetros de longitud, por 3 de anchura y un grosor de 7 milímetros para el sílex negro y la radiolarita-2, y 11 milímetros en la cuarcita; en la radiolarita-1 el grosor es inferior, unos 5 milímetros.

En segundo lugar los denticulados sobre soporte laminar; en este caso aparecen sólo en sílex negro y en una hoja mesial de radiolarita. El límite entre hojas y hojitas, respecto a la longitud, parece encontrarse en los 3 centímetros. En cuanto a la anchura, para las hojas la media está en los 16 milímetros y para las hojitas en 8 milímetros; y su grosor está en una media de $4 \mathrm{~mm}$ para las hojas y 2 para las hojitas. En el criterio para la selección de este tipo de soportes, sigue primando una preferencia por los soportes de mejor calidad dentro de los disponibles.

Respecto a la tipología interna del grupo de denticulados, habría que destacar la citada diferencia en el módulo de las piezas, que separa en cierto grado los denticulados sobre soporte tipo-lasca de los de soporte laminar. Los primeros son piezas bastante 
gruesas ( $7 \mathrm{~mm}$ de espesor medio), sobre todo aquellas fabricadas en cuarcita (que llegan a los $11 \mathrm{~mm}$ ), mientras que los segundos, lógicamente, son piezas de un módulo más alargado y un grosor inferior al conjunto anterior, pero aun así robusto, ya que alcanzan los 4 milímetros.

Con relación a los denticulados sobre este tipo de soportes alargados, hay que señalar que en algunos casos la morfología y amplitud del retoque no es demasiado acusada, siendo por tanto tipos intermedios hacia las piezas de retoque continuo. Al examinar estas últimas, ya se hizo mención a la presencia de una serie de ellas que presentaban una morfología del retoque denticulada o festoneada, siendo piezas intermedias entre las piezas de retoque continuo y los denticulados. En el caso de los denticulados, vuelve a surgir algunos cuyo retoque se halla en cierto grado en una posición intermedia, en transición entre ambos tipos ${ }^{27}$. En particular hay 7 piezas (3 hojas y 4 lascas) que podrían corresponder a unas piezas de retoque continuodenticulado, cuya función concreta quizás habría que poner en relación con los elementos de retoque continuo, tan abundantes en este conjunto lítico.

Al igual que pasaba con las piezas con retoque continuo, hay algunos denticulados que presentan unas características de transición hacia otros tipos, como son los "denticulados-perforador", de los que contamos con cuatro (tres sobre lasca y uno sobre una semitableta), además de una lasca cuyo retoque convergente sobre ambos laterales hace una punta.

${ }^{27}$ Este tipo de piezas con retoque de morfología irregular quizás se pueden relacionar con las "hojas y hojitas Montbani" definidas en el Epipaleolítico/ Mesolítico europeo (Rozoy, 1968: 360), las cuales tienen un retoque irregular, de distinta intensidad, que pueden ser piezas con escotadura, denticuladas u hojas/hojitas con retoque de menor amplitud. 

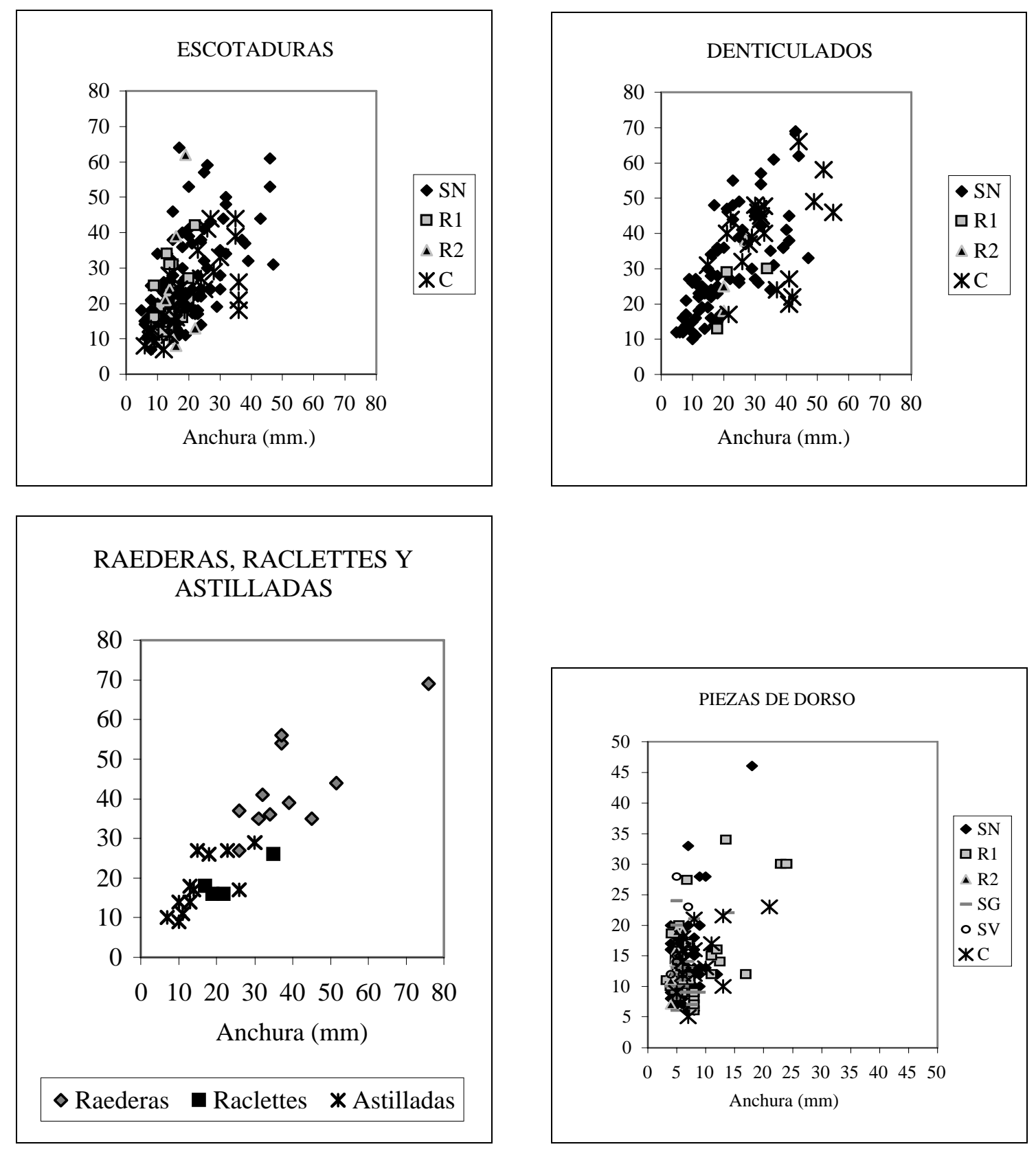

Gráfico V.16: gráfico de dispersión de las escotaduras, denticulados y piezas de dorso; según su longitud y anchura, y separando las materias primas. Las raederas, raclettes y astilladas se presentan en otro gráfico de dispersión, sin separar en este caso las materias debido al escaso número de piezas incluidas en estos tipos. SN: sílex negro, R1: radiolarita, R2: radiolarita-2, C: cuarcita, SG: sílex gris, SV: sílex varios. 


\section{Raederas}

Hay 11 raederas, todas sobre lasca, fabricadas solamente en las dos materias más abundantes del yacimiento, sílex negro y cuarcita (Figura V.1). Se trata de piezas grandes y gruesas, con unas dimensiones medias (Gráfico V.16) aproximadas de 4 centímetros de longitud, 4 de anchura y 1,4 de grosor, siendo las de cuarcita de un mayor espesor (1,5 cm frente a 1,3 del sílex negro). La mayor raedera no obstante se ha realizado en sílex negro, sobre una lasca de segundo orden de aproximadamente 7 centímetros de longitud por casi 8 de anchura (sigla: ESP93/F8/S3/n ${ }^{\circ} 52$, Figura V.1, $\mathrm{n}^{\mathrm{o}}$ 1).

\section{Raclettes}

Sólo hay cuatro raclettes, dos en sílex negro, una en sílex gris y una en cuarcita. Como soportes se han utilizado dos lascas y dos semitabletas de núcleo. Tres de ellas tienen un tamaño muy similar, con una morfología cuadrangular de dos centímetros de lado, aunque tienden a ser más anchas que largas. La excepción sería una raclette de sílex negro de casi 3 centímetros de longitud por 3,5 de anchura. 


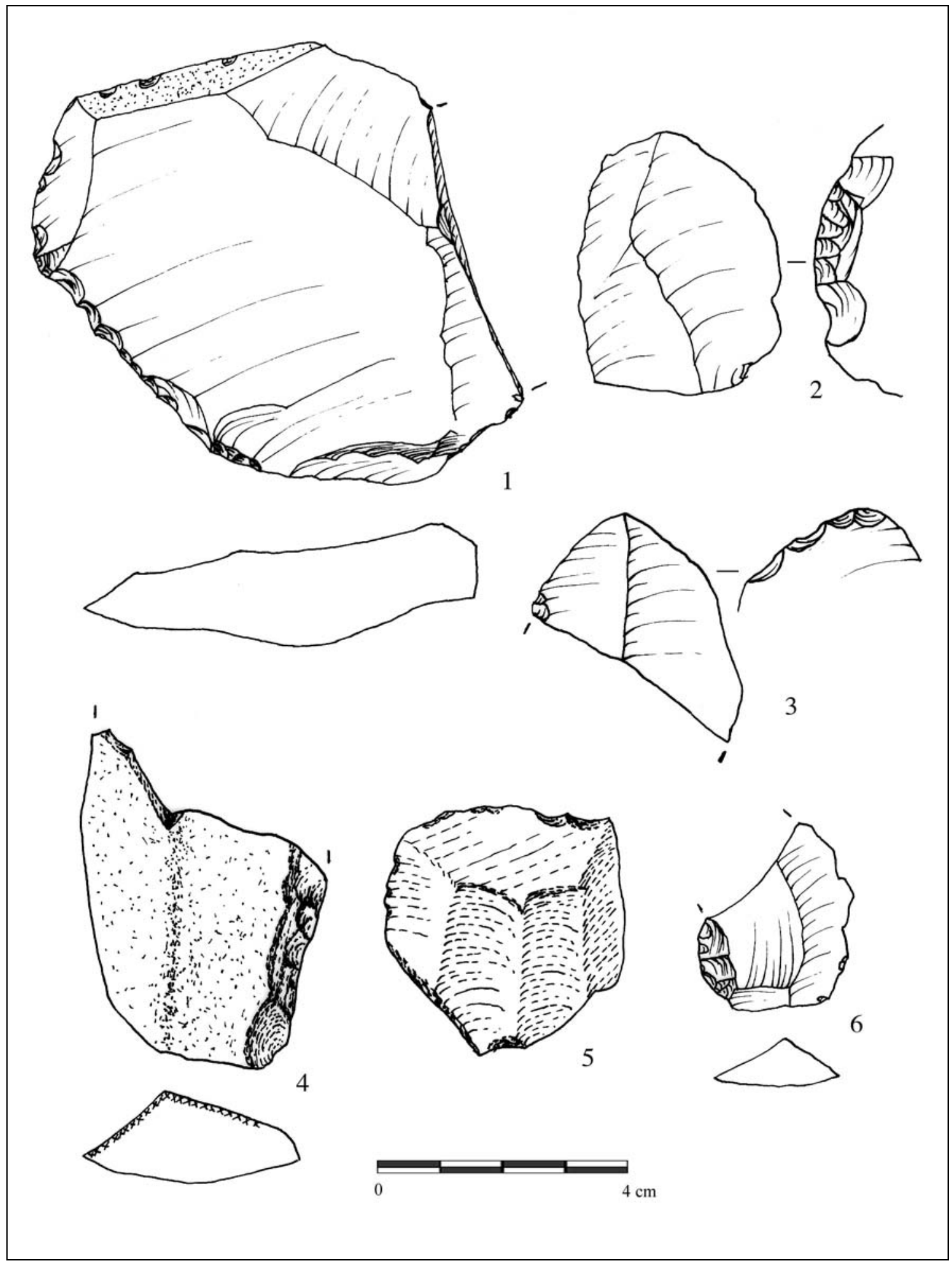

Figura V.1: Raederas de sílex negro $(1,2,3,6)$ y cuarcita $(4,5)$. 


\section{Astilladas}

Hay 12 piezas astilladas, 10 en sílex negro, una en radiolarita-1 y otra en cuarcita. Como soportes se han utilizado 9 lascas, 2 chunks y un resto de núcleo (la de radiolarita). Si tomamos en conjunto este grupo tipológico, las astilladas tienen unas dimensiones medias de 1,5 centímetros de longitud por 1,6 de anchura y 0,6 de grosor. No obstante, si tenemos en cuenta la distribución de las medidas de estas piezas se observan dos grupos, diferenciados sobre todo en su longitud (Gráfico V.16).

Por un lado un subconjunto de 4 astilladas relativamente grandes, con un tamaño de 2,5 a $3 \mathrm{~cm}$ de longitud y de 1,5 a $3 \mathrm{~cm}$ de anchura; por otro lado otro subconjunto de astilladas "pequeñas" con una longitud de 0,9 a $2 \mathrm{~cm}$ de longitud y 0,7 a $1,4 \mathrm{~cm}$ de anchura. En consecuencia el límite entre ambos subconjuntos estaría aproximadamente en los $2 \mathrm{~cm}$ de longitud y 1,5 cm de anchura. Hay que resaltar, por tanto, la presencia de una serie de astilladas de tamaño pequeño, incluso hay algunas que apenas alcanzan el centímetro de longitud, que podrían clasificarse como microlíticas. Además esta variedad en el tamaño de este tipo aparece tan solo en el sílex negro, incluso destaca el hecho de que dos astilladas microlíticas se encuentran sobre una variedad de sílex negro de color grisáceo (sílex gris-negro.2), lo que podría indicar la presencia de algún tipo de función específica en este tipo de materia concreta.

\section{Geométricos}

Hay 14 geométricos propiamente dichos, pero se han incluido en este grupo seis piezas que se han considerado como geométricos en fase de fabricación o bien como tipos anómalos. En un trabajo anterior se ha realizado un análisis exhaustivo de la fabricación de los geométricos (Fuertes, 2000-01), destacando por una parte la peculiaridad de la presencia de esta categoría tipológica, así como el hecho de que su fabricación encaja totalmente en el proceso técnico presente en el yacimiento.

En relación con los microlitos geométricos, hay una serie de aspectos que conviene reseñar. En primer lugar se trata de tipos un tanto curiosos a nivel cronocultural, ya que si bien hay geométricos desde finales del Paleolítico superior (su presencia en la lista-tipo del Paleolítico Superior de Sonneville-Bordes y Perrot [1954 a 
1956], no es caprichosa), son tipos característicos de momentos epipaleolíticos y mesolíticos. En la Cornisa Cantábrica, en concreto, no son tipos "raros", ya que hay geométricos en el Aziliense ${ }^{28}$, y se van constatando también a lo largo del Epipaleolítico/Mesolítico cantábrico, tanto en yacimientos con niveles mesolíticos ${ }^{29}$ como en el Asturiense ${ }^{30}$.

Respecto a los tipos concretos documentados, los triángulos son más abundantes que los trapecios, de los que tan solo hay cuatro (Figura V.2: $\mathrm{n}^{\mathrm{o}} 1$ a 14). Para describir sus características tipológicas nos hemos ayudado de la tipología desarrollada por el G.E.E.M (1969, 1972), además de la tipología existente para el EpipaleolíticoMesolítico de la Península Ibérica (Fortea, 1973). No obstante, especialmente en el caso de los triángulos, los ejemplares con que contamos no encajan demasiado bien en esta última, seguramente debido a que fue creada para un ámbito geográfico alejado del nuestro (Cuadro V.7).

\begin{tabular}{|l|l|r|}
\hline GEOMÉTRICOS & DESCRIPCIÓN & $\mathbf{N}$ \\
\hline \multirow{2}{*}{ TRAPECIOS } & Trapecio asimétrico corto & 3 \\
& Trapecio de Vieille (trapecio rectángulo) & 1 \\
\hline \multirow{3}{*}{ TRIÁNGULOS } & Triángulo escaleno & 3 \\
& Triángulo isósceles corto (con los dos lados cóncavos) & 2 \\
& Triángulo de Chateneuf (similar al anterior, pero con la truncadura mayor & \\
\hline PUUNTĀAS DE & más grande que el borde sin retocar) & 1 \\
BASE TRANSVERSAL & Punta triangular corta (triángulo de Coincy corto) & 2 \\
\hline TOTAL & Punta triangular corta/base cóncava (triáng. Coincy corto/b. cónc.) & 2 \\
\hline
\end{tabular}

Cuadro V.7: tipología de los microlitos geométricos.

${ }^{28}$ Por ejemplo aparecen en Piélago (Mirones, Cantabria), nivel 1-2 (García Guinea, 1985) y en Ekain (Deba, Guipúzcoa), nivel II, ambos considerados como Aziliense evolucionado (Merino y Altuna, 1984; Fernández-Tresguerres, 1995), aunque hay discordancia entre algunos autores, de modo que estos dos niveles han sido caracterizados también como pertenecientes a un Epipaleolítico Aziloide (Arias, 1991). Otros ejemplos son: Atxeta (Forua, Vizcaya), nivel D, aunque sólo hay un trapecio (Arias, 1991); Cueva del Valle, donde aparecen 15 triángulos y 6 segmentos (Fernández-Tresguerres, 1980), etc.

${ }^{29}$ La presencia de geométricos, no obstante, no es demasiado abundante en la Región Cantábrica, incluso hay ocasiones en las que se han caracterizado algunos niveles como pertenecientes a un Epipaleolítico Geométrico (Arias 1991) cuando en realidad la presencia de estos microlitos es muy pequeña. Así sucede, por ejemplo, con El Tarrerón (Soba, Cantabria), nivel III, donde hay un solo segmento de círculo; en el conchero del nivel IV de Santimamiñe (Cortézubi, Vizcaya), hay seis microlitos; y dos en el nivel IIA de Arenaza (San Pedro de Galdames, Vizcaya) .

${ }^{30}$ En el Asturiense se ha constatado un único geométrico, se trata de un trapecio hallado en Mazaculos II (La Franca, Ribadedeva, Asturias), en el nivel 1 (Arias, 1991). 
Todos estos microlitos se realizan mediante retoque abrupto. Podemos decir como característica general que se trata de piezas "cortas", es decir, no son ejemplares estilizados (el índice de alargamiento, Long/Anch no llega nunca a 1,5), y de carácter microlítico puesto que en ningún caso la dimensión mayor supera los $15 \mathrm{~mm}$ (Cuadro V.8).

\begin{tabular}{|l|ccc|}
\hline & $\mathrm{L}$ & $\mathrm{A}$ & $\mathrm{G}$ \\
\hline Rango & $9-15$ & $7-14$ & $1,4-3,2$ \\
Media & 11,9 & 9,7 & 2,1 \\
Desviación típica & 2,0 & 2,0 & 0,5 \\
\hline
\end{tabular}

Cuadro V.8: media (en $\mathrm{mm}$.) de las medidas de los geométricos en radiolarita $(\mathrm{n}=14)$. N: número de ejemplares, L: longitud, A: anchura, G: grosor.

Dentro de los triángulos hay tres subconjuntos que se han individualizado a partir de su morfología, fundamentalmente con relación a su índice de alargamiento:

A. Triángulos isósceles cuyos lados iguales corresponden al borde sin retocar y a un borde abatido, se trata de puntas triangulares (puntas de base transversal); contamos con cuatro ejemplares (Figura V.2: $\mathrm{n}^{\circ} 1$ a 4 ).

B. Triángulos escalenos con la truncadura menor convexa y la otra oblicua o cóncava, con tres piezas (Figura V.2: $\mathrm{n}^{\mathrm{0}} 5$ a 7).

C. Triángulos isósceles/escalenos cortos con las dos truncaduras cóncavas, con otros tres ejemplares (Figura V.2: $\mathrm{n}^{\circ} 8$ a 10); uno de ellos, debido a que tiene la truncadura mayor más grande que el borde sin retocar, sería similar a los triángulos tipo "Chateneuf” ( $\mathrm{n}^{\circ}$ 9). 


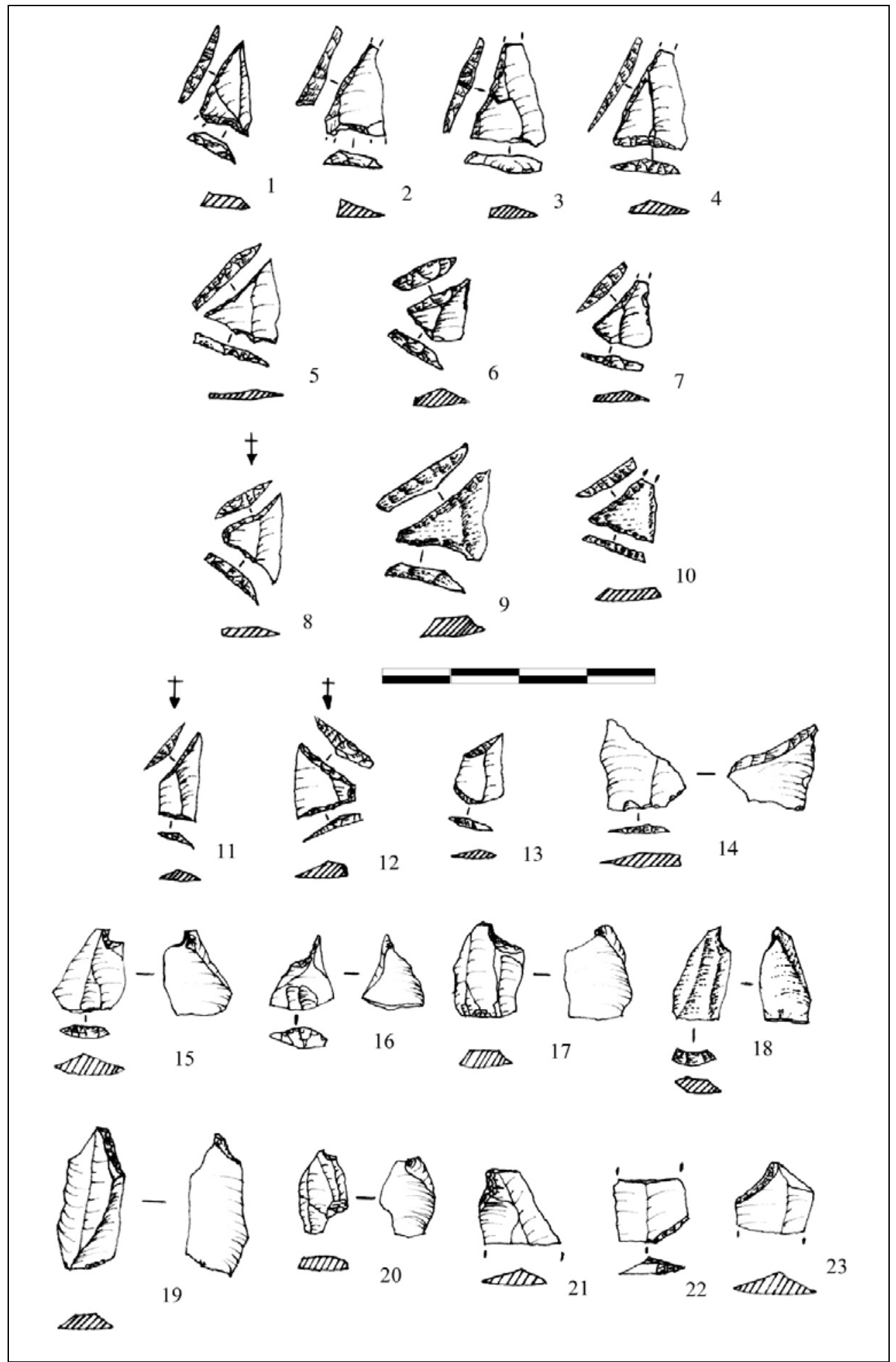

Figura V.2: Microlitos geométricos (1 a 14), microburiles (15 a 20) y hojas con una rotura al lado de una escotadura (21 a 23). Puntas triangulares: 1 a 4; triángulos, grupo B: 5 a 7; triángulos, grupo C: 8 a 10. Trapecios: 11 a 14. Radiolarita-1: 2, 4, 6, 7, 8, 11, 15, 21, 22. Radiolarita-2: 3, 19. Sílex negro: 1, 13, 14, 16, 17, 20, 23. Sílex "vario": 5, 12. Cuarcita: 9, 10, 18. 
Desde un punto de vista genérico, la tipología de los geométricos de este yacimiento corresponde a un conjunto de carácter mesolítico. Los tipos concretos que aparecen son habituales en otros yacimientos peninsulares de cronología Epipaleolítica / Mesolítica, excepto las puntas de base transversal. De hecho, este último grupo es el único que no encajaría en la tipología de geométricos definida por Fortea para el Mediterráneo. No obstante hay presencia de este tipo de puntas, siempre en número escaso, en niveles mesolíticos de yacimientos situados en la parte oriental de la Región Cantábrica, en concreto en dos yacimientos de la zona alavesa ${ }^{31}$ : Montico de Charratu (Albaina, Treviño), nivel II (Baldeón, Berganza y García, 1983) y Kukuma (Araia, Alava) (Baldeón y Berganza, 1997).

Respecto a las características estrictamente tecnológicas de los geométricos, hay que reseñar tres aspectos fundamentalmente:

i) Carácter laminar de estas piezas, que encaja plenamente dentro de la cadena operativa laminar presente en el yacimiento

ii) La fase de retoque de estos elementos tiene una secuencia larga de gestos previos a la ejecución del retoque del geométrico propiamente dicho.

iii) La gran mayoría de los geométricos (6 de 14) se han realizado en radiolarita-1, de forma que se puede afirmar que hay una preferencia en esta materia prima para la realización de los geométricos.

Los soportes de los geométricos son laminares a excepción de dos fragmentos de lasca con los que se han realizado sendos triángulos de cuarcita. Para los geométricos de sílex negro, radiolarita y sílex varios se han utilizado soportes laminares de una regularidad destacable, al menos en radiolarita se ha constatado que hay una preferencia por aquellos productos de mejor calidad.

${ }^{31}$ En Montico de Charratu hay una punta triangular corta y una punta de Tardenois. En Kukuma hay un punta triangular corta con base natural cóncava. En ambos casos la presencia de geométricos es más bien discreta, al igual que sucede en El Espertín, ya que dicho grupo tipológico constituye en torno al $6 \%$ de sendos conjuntos líticos. 
En cuanto al tipo de materias, hay que remarcar que los geométricos constituyen el único tipo (al lado de los microburiles y picantes triédricos, que son restos de la fabricación de los mismos) en el que no predomina el sílex negro, sino que es la radiolarita-1 la más abundante (Cuadro V.6). En consecuencia se puede hablar de una preferencia sobre esta materia para los geométricos, aunque no se llegaría quizás a tratar de una gestión diferencial de la materia (Perlès, 1991), ya que hay presencia de geométricos y de los restos de su fabricación en otras materias, incluida la cuarcita.

La secuencia de fabricación de los geométricos es un aspecto que abordaremos al lado de los microburiles y el resto de los desechos de su fabricación, en el siguiente apartado.

\section{Microburiles, picantes triédricos y piezas con escotadura o retoque adyacente a una rotura}

En este grupo se incluye el conjunto de piezas que constituyen desechos de la factura de los microlitos geométricos. Los microburiles y picantes triédricos son desechos característicos de la "técnica de microburil", de la que ha quedado constancia en el conjunto analizado. Hay microburiles en las materias que más se han tallado en el yacimiento: sílex negro, radiolarita y cuarcita (Figura V.2: $\mathrm{n}^{\mathrm{o}} 15$ a 20). Destaca, de hecho, el ejemplar fabricado en cuarcita (Figura V.2: $\mathrm{n}^{\mathrm{o}}$ 18; sigla: ESP97/D8/S7/N3B/B3), ya que a pesar de ser una materia con un tamaño de grano mayor que el grupo de los sílex, se ha aplicado sobre ella la técnica del microburil de una manera totalmente "típica". Por tanto, el proceso de fabricación de los geométricos está presente en su totalidad; la única materia para la que no tenemos evidencias de fabricación son los sílex varios, de los que hay dos geométricos, pero ningún microburil ni otro desecho de la fase de retoque. Tales piezas habrían sido llevadas al yacimiento como elementos ya fabricados, posiblemente enmangados en los útiles correspondientes, de la misma manera que las hojitas de dorso. En el resto de las materias sobre las que aparecen geométricos hay también restos de la secuencia de su fabricación; en consecuencia, se puede hablar de una flexibilidad operativa tanto en la gestión de las materias como de los procedimientos aplicados.

Respecto a la secuencia del retoque de los geométricos, hay que tener en cuenta que previamente a los gestos de retoque propiamente dichos, este tipo de elementos 
necesita que el soporte de origen (normalmente una hoja u hojita) sea fracturado de forma intencional para proporcionar una conformación de la morfología del elemento que facilite su fabricación. La "técnica de microburil" es de las más comunes para estos geométricos ya que facilita una fracturación intencional de la hoja-soporte de forma muy controlada a partir de una escotadura. Además esta fractura controlada es oblicua, respecto a la vista frontal del soporte y también a su vista de perfil (Tixier et al., 1980), por lo que la morfología del geométrico en cuestión se consigue fácilmente. No obstante, a veces esta técnica no tiene una ejecución correcta, de forma que la faceta de rotura no resulta con esa doble oblicuidad y por tanto el desecho no es un microburil "típico" sino una hoja/hojita con restos de una escotadura o un retoque al lado de una rotura transversal. Esta ejecución irregular de la técnica de microburil se ha constatado tanto en el ámbito experimental (Tixier et al., 1980) como en conjuntos líticos arqueológicos; debido a ello, en las listas tipológicas del Epipaleolítico/Mesolítico, se han incluido este tipo de piezas que pueden resultar de una ejecución mediocre de la técnica de microburil, bajo la denominación de "lamelle cassée dans une encoche" (GEEM, 1969; Valdeyron, 1994; Boboeuf, 1998).

En el conjunto de El Espertín hay constancia por tanto de los geométricos propiamente dichos, así como de restos que podrían corresponder a secuencias de una técnica de fractura "tipo-microburil" errónea; tales restos serían las piezas con un retoque o escotadura al lado de una rotura, que aparecen sobre el mismo tipo de soportes que los microburiles (Figura V.2: n $^{\mathrm{o}} 21$ a 23). 

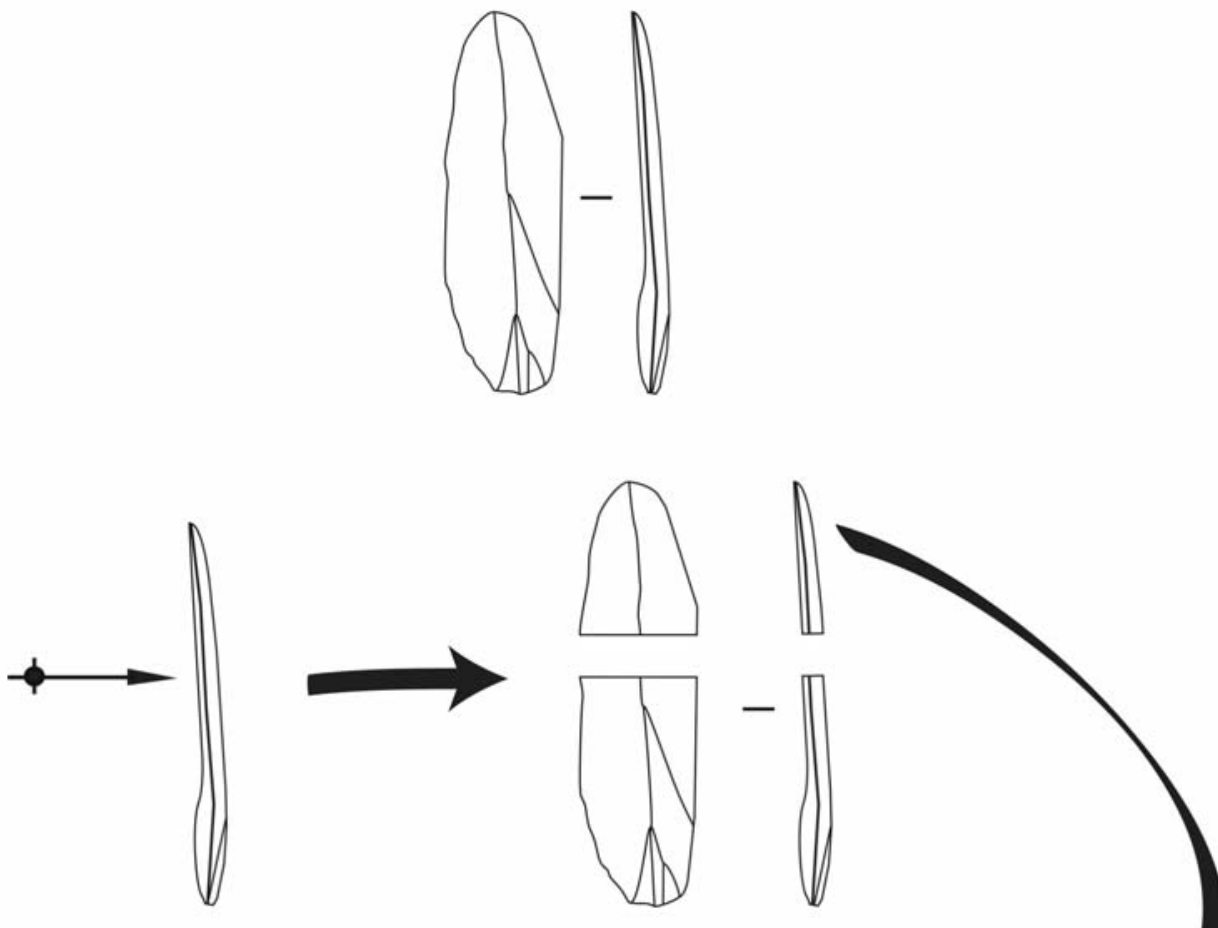

1: "Técnica de rotura transversal": fracturación de una hoja por percusión sobre su cara inferior
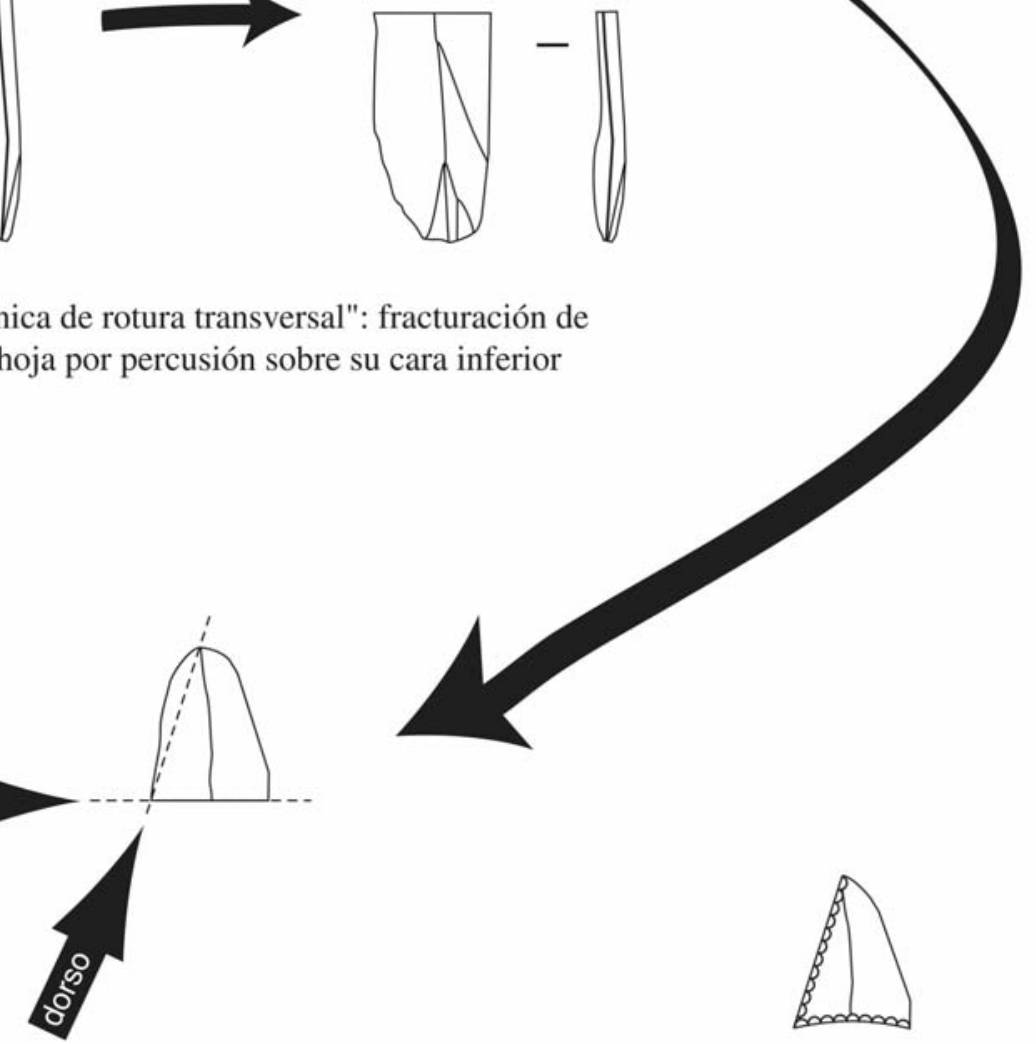

2: Retoque sobre la parte distal de la hoja fracturada

Punta triangular

Figura V.3: esquema de la "técnica de rotura transversal". 
Pero además de la técnica de microburil, se ha constatado en El Espertín otro procedimiento de fractura intencional de una hoja para la fabricación de geométricos, es la que hemos denominado como "técnica de rotura transversal" 32 (Fuertes, 2000-2001). Se trata de una técnica muy simple, requiere menos gestos técnicos que la anterior y consiste en fracturar la hoja-soporte mediante un golpe en la mitad de la cara inferior (ver esquema en figura V.3). Se obtiene así el fragmento distal de la hoja, con la longitud deseada y, por otro lado, la parte proximal de la hoja, con una rotura distal por percusión. Este tipo de desecho no se reconoce demasiado bien en el conjunto de restos de talla, ya que se puede confundir con otras hojas con rotura distal. Lo que sí se puede reconocer es en algunos geométricos, sobre el borde proximal, la faceta de fractura intencional. Este tipo de procedimiento se relaciona además, en este conjunto, con un tipo de geométrico específico, las puntas triangulares. En concreto la faceta de rotura se ha visto en una punta triangular de radiolarita-2 (Figura V.2: $\mathrm{n}^{\mathrm{o}} 3$ ), pero hay otras dos puntas triangulares en radiolarita-1 y una en sílex negro, sobre las que no es posible apreciar esta característica porque tienen una truncadura retocada sobre el borde proximal (Figura V.2: $\mathrm{n}^{\mathrm{o}} 1,2 \mathrm{y} 4$ ).

La fabricación de los geométricos se ha realizado por tanto en el yacimiento, como la mayoría de los útiles de las principales materias talladas (todas excepto los sílex varios), incluida la cuarcita. En esta materia los geométricos se han fabricado sobre fragmentos de lasca, pero hay un microburil proximal sobre una hojita de buena calidad que probaría la presencia de esta técnica sobre cuarcita, aunque no se han recuperado los geométricos sobre hojita. Además de esta adaptabilidad de los procedimientos técnicos a las distintas materias, hay también una flexibilidad práctica a la hora de aplicar dos procedimientos para fabricar tipos de geométricos con unas características tipológicas diferentes.

\footnotetext{
${ }^{32}$ Respecto a las secuencias de rotura de hojas, A. Cava aborda "las técnicas de troceado" de los soportes laminares al analizar las dimensiones de las "hojas con retoque continuo y/o con estigmas" fragmentadas del conjunto industrial neolítico de la cueva de Chaves (Cava, 2000:120-123). Se plantea en este trabajo el uso de dos técnicas, básicamente, para conseguir una rotura transversal a la hoja: la flexión y la "fractura por percusión apoyada sobre yunque". Aunque se plantean las lógicas dudas respecto a la intencionalidad de las roturas de los soportes, el último procedimiento se correspondería con nuestra "técnica de rotura transversal".
} 


\section{Piezas con dorso}

Hay un total de 172 piezas con dorso, el 43\% en sílex negro, el $28 \%$ en radiolarita, el $13 \%$ en sílex gris y, por último, el $8 \%$ en sílex varios y otro tanto en cuarcita. A pesar de esta abundancia relativa del sílex negro, si tenemos en cuenta las distintas materias primas, el grupo de los dorsos es el tipo retocado mayoritario en las materias foráneas y en aquellas que no se encuentran en el entorno inmediato del yacimiento, es decir todos los sílex (radiolarita, sílex gris y sílex varios) excepto el chert negro. Parece existir una cierta relación entre la lejanía/escasez de las materias y el grado de especialización en la producción de piezas de dorso, de forma que a mayor lejanía/escasez/especialización laminar hay mayor porcentaje de dorsos y por tanto una mayor especialización en la producción de este tipo de elementos. Esta circunstancia es máxima por tanto en los sílex varios, que tienen un 72\% de dorsos y en el sílex gris, con un $58 \%$; en cambio desciende a un $21-22 \%$ en las radiolaritas, pero aún así siguen siendo el tipo más abundante en el sílex de radiolarios. Por el contrario, en las materias más abundantes del yacimiento, es decir sílex negro y cuarcita, el grupo de los dorsos no constituyen el tipo dominante, suponiendo un 9 y 13\% respectivamente (Cuadro V.3).

\begin{tabular}{|c|c|c|c|c|c|c|c|c|c|}
\hline \multirow{2}{*}{\multicolumn{2}{|c|}{ SOPORTE }} & \multirow{2}{*}{ SN } & \multirow{2}{*}{$\mathrm{R} 1$} & \multirow{2}{*}{$\mathrm{R} 2$} & \multirow{2}{*}{ SG } & \multirow{2}{*}{ SV } & \multirow{2}{*}{$\mathrm{C}$} & \multicolumn{2}{|c|}{ TOTAL } \\
\hline & & & & & & & & $\mathrm{N}$ & $\%$ \\
\hline \multicolumn{2}{|l|}{ Lasca } & 10 & 4 & & 2 & & 5 & 21 & 12,2 \\
\hline \multicolumn{2}{|c|}{ Hoja con flanco } & 1 & 1 & & 2 & & & 4 & 2,3 \\
\hline \multicolumn{2}{|c|}{ Hoja } & 4 & 3 & & & & 2 & 9 & 5,2 \\
\hline \multicolumn{2}{|l|}{ Hojita } & 57 & 27 & 14 & 16 & 12 & 7 & 133 & 77,3 \\
\hline \multicolumn{2}{|c|}{ Golpe buril } & 2 & & & 2 & 1 & & 5 & 2,9 \\
\hline TOTAL & $\begin{array}{l}\mathrm{N} \\
\%\end{array}$ & $\begin{array}{c}74 \\
43,0\end{array}$ & $\begin{array}{c}35 \\
20,3\end{array}$ & $\begin{array}{l}14 \\
8,1\end{array}$ & $\begin{array}{c}22 \\
12,8\end{array}$ & $\begin{array}{c}13 \\
7,6\end{array}$ & $\begin{array}{l}14 \\
8,1\end{array}$ & $\begin{array}{c}172 \\
100,0\end{array}$ & 100,0 \\
\hline
\end{tabular}

Cuadro V.9: dorsos retocados, distribución por materias primas y por tipos de soportes.

El tipo de soporte seleccionado para la confección de dorsos es laminar, esencialmente las hojitas, lo cual es bastante lógico, habida cuenta que las hojitas de dorso constituyen el tipo más común (Cuadro V.9). Para los elementos de dorso de pequeño tamaño (hojitas y puntas) se utilizan también ocasionalmente golpes de buril y lascas o fragmentos de lascas de pequeña dimensión, dado que tal módulo sería equivalente al de las hojitas. No obstante hay algún soporte de mayor tamaño para 
fabricar piezas de dorso más robustas, tanto hojas propiamente dichas como hojas con flanco.

\begin{tabular}{|c|c|c|c|c|c|c|c|}
\hline \multirow{2}{*}{ TIPOLOGÍA } & \multicolumn{6}{|c|}{ MATERIAS PRIMAS } & \multirow{2}{*}{ TOTAL } \\
\hline & SN & R1 & R2 & SG & SV & C & \\
\hline Dorso (hoja) & & 7 & & 1 & & 2 & 10 \\
\hline Dorso parcial (hoja) & 1 & 1 & & & & & 2 \\
\hline Dorso (hojita) & 59 & 18 & 11 & 20 & 10 & 7 & 125 \\
\hline Dorso (hojita) con escotadura & 1 & 1 & & & & & 2 \\
\hline Dorso (hojita) con truncadura & 2 & 1 & 1 & & & & 4 \\
\hline Dorso (hojita) con denticulado & 1 & & & & 1 & & 2 \\
\hline Punta-Dorso & 10 & 7 & 2 & & 2 & 5 & 26 \\
\hline
\end{tabular}

Cuadro V.10: tipología de las piezas con dorso y distribución por materias primas

En la tipología de las piezas de dorso, hay alguna hoja con dorso continuo o parcial, pero la mayoría son hojitas de dorso $(n=125)$. Algunas de ellas tienen una escotadura $(n=2)$ o denticulado $(n=2)$ en el borde opuesto y en cuatro casos tienen una truncadura (Cuadro V.10). Respecto a las piezas con dorso apuntado, hay 26 ejemplares de puntas con dorso tanto rectilíneo como curvo. Dado que el presente trabajo se centra fundamentalmente en un análisis tecnológico, no se ha profundizado en las características tipológicas concretas de estas puntas. Ello es debido, asimismo, a que la definición de este tipo de elementos es a veces conflictiva, tanto por el problema de las piezas de dorso fragmentadas que pueden corresponder a puntas, como por las propias dificultades de la adscripción a un tipo concreto de los ejemplos existentes ${ }^{33}$.

Respecto a las dimensiones de las hojitas de dorso, la mayoría se encuentran entre los 5 y 20 milímetros de longitud, y 4 a 9 milímetros de anchura; su grosor se sitúa entre 1 y 3,5 milímetros (Gráfico V.16).

Las puntas de dorso tienen una longitud similar, pero más restringida hacia los módulos mayores, encontrándose la mayoría entre los 10 y 20 milímetros de longitud, excepto un grupo de tres puntas de casi 30 milímetros (Gráfico V.17). La anchura es similar a las hojitas de dorso, hallándose entre los 3 y los 9 milímetros, a excepción de

${ }^{33}$ Respecto a la problemática en torno a la tipología de las piezas de dorso y, sobre todo, de las puntas de dorso, se puede mencionar lo señalado por J. M. Merino (1984) respecto a Ekain, así como el análisis tecnológico más reciente de M. Lloret (2001: 556-558) sobre la serie Magdaleniense Superior/Final- Azilinse de La Pila. 
otros tres ejemplares, que miden de 11 a 13. El grosor de las puntas es también más restringido que las hojitas, encontrándose entre los 2 y 3 milímetros.
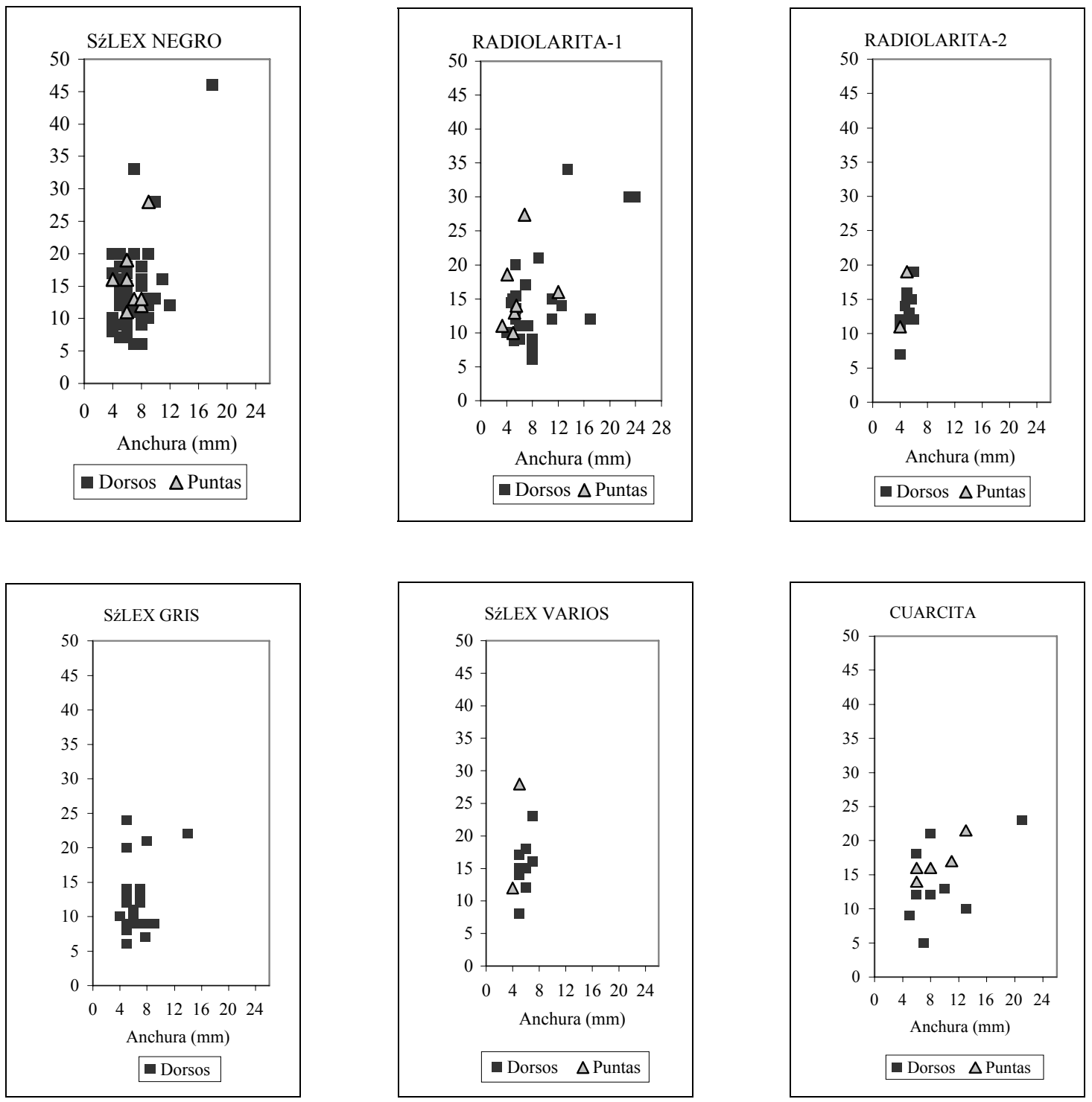

Gráfico V.17: gráficos de dispersión de las hojitas de dorso y las puntas de dorso, por materias primas.

En cuanto a las hojitas de dorso, hay que tener en cuenta que la mayoría de estas piezas están rotas de forma transversal, por lo que esta longitud recurrente entre 0,5 y 2 centímetros parece responder a un patrón más o menos fijo, quizás buscado intencionalmente para facilitar el enmangue de estos elementos múltiples. Respecto a la anchura, en la mayoría de ellas es inferior a un centímetro, si bien la amplitud del retoque habría reducido en algún milímetro la anchura de la hojita-soporte seleccionada. Teniendo en cuenta esta corrección, la distribución de la anchura de estos dorsos 
encajaría en la de las hojitas sin retocar, que se encuentra mayoritariamente de 8 a 10 milímetros, o quizás hasta los 12 . 


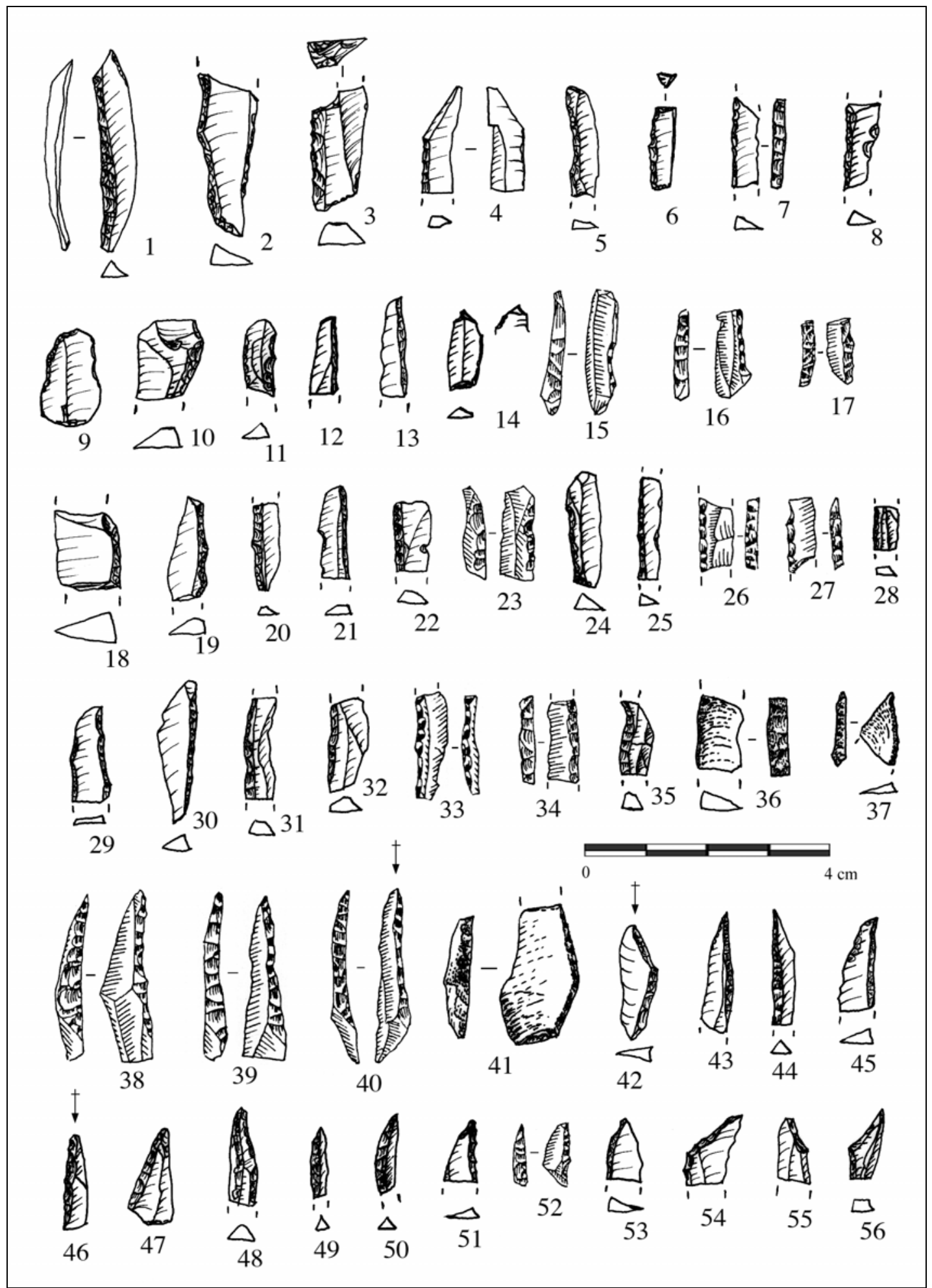

Figura V.4: Piezas de dorso. Hojitas de dorso: 1 a 36 (hojita de dorso truncada: 3, 6; hojita con doble dorso: 29). Puntas de dorso: 37 a 56. Sílex negro: 1 a 17, 38, 42, 43, 45, 46, 48, 53 a 56. Radiolarita-1: 18 a 23, 39, 44, 47, 49, 51. Radiolarita-2: 24 a 28, 52. Sílex varios: 29 a 35, 40, 50. Cuarcita: 36, 37, 41. Dibujos 15 a 17, 23, 26, 27, 33, 34, 38, 39, 40 y 52 realizados por R. $\mathrm{M}^{\mathrm{a}}$ Yágüez. 


\section{Punta con muesca / pedúnculo}

Hay dos puntas con unas características curiosas en la colección, la primera es una punta con muesca de sílex varios, en concreto es un sílex de color beige claro y translúcido en los bordes, afectado por deshidración/desilificación (sigla: ESP97/D7/Lim.94). Sus medidas son 19 milímetros de longitud por 14 de anchura y 4 de grosor, tiene por tanto una anchura relativamente grande y es una pieza también robusta por su grosor, de hecho el soporte de esta punta es una lasca. Su morfología es triangular, con los bordes laterales convexos, convergentes en la zona distal, aunque la punta no es demasiado aguda. Esta forma está conseguida a partir de un retoque continuo sobre ambos bordes laterales y el proximal, de tipo escamoso y sobrelevado/abrupto. La muesca se ha fabricado a partir de un retoque profundo y amplio en la parte inferior derecha. El extremo distal tiene una rotura con un esquirlado, que puede haber estado provocada por un impacto de tipo axial.

La otra pieza es una punta de sílex negro (sigla: ESP94/G8/S1/N2/B4), sus características en cuanto al soporte técnico seleccionado son similares a la punta de muesca anterior, ya que se trata de un fragmento de lasca y sus dimensiones son 15 milímetros de longitud, 13 de anchura y 4 de grosor. Sin embargo las características tipológicas y el retoque difieren del ejemplo anterior. Se trata de una punta corta con cabeza triangular y pedúnculo muy corto conseguido por sendas muescas en la zona proximal. El retoque se limita a las muescas y a la zona distal, quedando los bordes laterales sin retocar. En la zona distal el retoque es marginal, inverso y plano. 


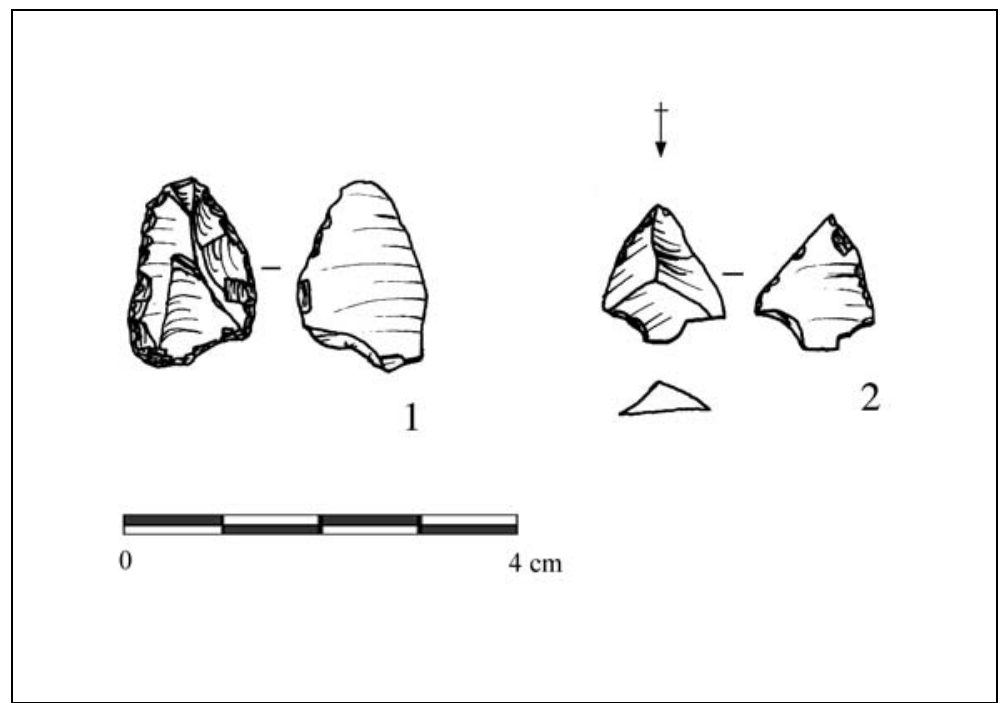

Figura V.5: Punta con muesca en sílex varios $\left(\mathrm{n}^{\mathrm{o}} 1\right)$ y punta con pedúnculo en sílex negro $\left(\mathrm{n}^{\mathrm{o}} 2\right)$. 


\section{V.4.- LAS CADENAS OPERATIVAS}

En el conjunto lítico de El Espertín se han determinado tres cadenas operativas o esquemas conceptuales básicos: una cadena de concepción prismática-unipolar, otra que explota nódulos en forma de placa y una última centrípeta. Se podría añadir otro esquema que recogemos bajo la denominación de cadena no estandarizada, que incluiría aquellos núcleos explotados de forma oportunista, así como aquellos cuyo esquema técnico no permite encuadrarlos en alguna de las cadenas determinadas. Estos últimos parecen proceder en ocasiones de alguno de los esquemas anteriores, pero han sido sometidos a una gestión un tanto anómala (explotación muy intensa, anárquica, etc.) cuyo motivo podría estar vinculado no tanto a aspectos productivos de la talla, sino a razones más prácticas: pruebas de los talladores, familiarización con la materia, con los gestos de percusión, etc.; incluso podría estar relacionado con tareas de enseñanza / práctica de la talla (Ploux, 1991).

\begin{tabular}{|c|c|c|c|c|c|c|c|c|}
\hline & & & & $\overline{M A}$ & ERI & $\overline{S P R}$ & $\overline{\mathrm{MAS}}$ & \\
\hline CADENAS OPERATIVAS & ESQUEMAS OPE & ATIVOS & $\mathrm{SN}$ & R-1 & $\mathrm{R}-2$ & SG & SV & $\mathrm{C}$ \\
\hline & & P Tipo-A (piramidal) & 7 & & 2 & 2 & 1 & \\
\hline & Prismático "típico" & P Tipo-B & 7 & 4 & $\mathrm{FN}$ & 1 & & 2 \\
\hline & & P Genérico & 2 & 3 & & & & \\
\hline PRISMÁTICA- & & $\mathrm{SA}$ unipolar & 3 & & 1 & & & \\
\hline UNIPOLAR & Superficie ancha & SA bipolar & 4 & & & & & \\
\hline & & SA genérico & & & & & & 2 \\
\hline & $\begin{array}{l}\text { Unipolar- } \\
\text { Prismático }\end{array}$ & & 2 & & & & & 2 \\
\hline TIPO NÓDULO-PLACA & & & 1 & & & & & 1 \\
\hline CENTRÍPETA & & & & & & & & 3 \\
\hline NO ESTANDARIZADA & & & 11 & 3 & 1 & & 2 & 6 \\
\hline & & & 37 & 10 & 4 & 3 & 3 & 16 \\
\hline
\end{tabular}

Cuadro V.11: cadenas operativas con sus correspondientes esquemas operativos. Se señalan por cada materia prima el número de núcleos que se podría adscribir a cada esquema, así como la presencia de otros elementos (como flancos de núcleo) que permitan intuir algunos de estos esquemas.

La primera cadena engloba un amplio conjunto de núcleos que se han reunido bajo un mismo esquema conceptual, el prismático-unipolar, con tres esquemas operativos básicos (Cuadro V.11): i) el esquema prismático que se podría calificar como "más clásico o típico"; ii) el esquema de núcleos que explotan una superficie ancha; y, 
por último, iii) el esquema que hemos denominado como "unipolar-prismático". Frente a la complejidad y variabilidad de esta primera cadena operativa, la cadena del nóduloplaca y la centrípeta son esquemas más sencillos, los cuales tienen una aplicación inmediata más rápida.

Puede resultar llamativo el desequilibrio entre la primera cadena y las dos restantes, tanto por la variedad de modalidades que tiene, como por el número de núcleos. Incluso puede surgir la duda de si los esquemas operativos diferenciados son realmente modalidades pertenecientes a una única cadena, o bien constituyen por sí mismos cadenas independientes. En el capítulo sobre metodología se apuntó este tipo de problemática $\mathrm{y}$, en este caso, se ha optado por adoptar un punto de vista amplio y sintético, reuniendo los esquemas más cercanos y tomando en consideración algunas de las características más globales para realizar dichas agrupaciones. Estas características se basan en la conformación del volumen del núcleo, de modo que se han diferenciado esencialmente tres maneras de explotar un volumen:

- Concepción prismática: gestión de un volumen con una estructura prismática básica (tetragonal casi siempre); sobre una de las caras del prisma se sitúa la superficie de extracciones, que está más o menos encajada entre los flancos del núcleo y un plano de percusión que se une a ella de forma aproximadamente perpendicular. La disposición de los laterales del núcleo y de la base, así como la anchura de la superficie de extracciones van a determinar las distintas modalidades.

- Concepción del núcleo-tipo-placa: aprovechamiento de un volumen en forma de placa de manera que se explota la superficie existente entre los planos que delimitan dicha placa a partir de su eje corto.

- Concepción centrípeta: gestión de un núcleo a partir de su arista periférica mediante extracciones centrípetas sobre una o las dos superficies.

Desde este punto de vista tan amplio y básico consideramos que es factible esta asociación de esquemas. La primera cadena encierra la estructura que más variabilidad puede tener desde un punto de vista técnico; por el contrario las otras dos están quizás más ceñidas a la morfología inicial de los bloques y esta limitación material puede ocasionar una reducción de las modalidades posibles. La cadena de concepción 
prismática está también muchas veces favorecida por la morfología inicial de la materia prima, pero es una estructura sobre la que se pueden aplicar más variedad de soluciones.

La primera cadena es la predominante en el conjunto lítico y aparece en todas las materias primas. Si nos fijamos en la representación de sus distintas modalidades, la cuarcita es la única materia sobre la que se han aplicado toda la variedad de esquemas presentes, seguida por el sílex negro, que carece de la cadena centrípeta. La radiolarita y el resto de los sílex sólo se han gestionado mediante el esquema prismático, especialmente en la modalidad más "clásica".

Respecto a los tipos de soportes que se pueden obtener de estas cadenas, la cadena prismática va a aportar fundamentalmente hojas y hojitas, pero también lascas laminares e incluso en algún caso lascas. La cadena tipo placa y la centrípeta son esquemas de débitage de lascas exclusivamente y por tanto sólo aparecen en las materias que han tenido un tipo de producción mixta (soportes laminares y lascas): sílex negro y cuarcita. Al examinar el proceso operativo de las distintas materias se comprobó cómo había una mayor especialización laminar sobre la radiolarita, el sílex gris y los sílex varios; estas hojas y hojitas se van a obtener, fundamentalmente, a partir del esquema prismático. 


\section{V.4.1.- CADENA DE CONCEPCIÓN PRISMÁTICA}

En esta cadena hay dos esquemas operativos básicos (prismático-unipolar y de superficie ancha), que se han dividido en tres para facilitar su descripción (separando el primero en prismático y en unipolar-prismático; ver cuadro V.11).

El esquema operativo primero, el prismático "típico", sería el más "clásico", aquí encajarían algunos de los núcleos prismáticos y núcleos piramidales más "típicos" (Bordes, 1979: 89; Brézillon, 1977: 92-93; Laplace, 1966: 32; Rozoy, 1968: 378), desarrollados sobre todo a lo largo del Paleolítico superior, aunque no circunscritos a él exclusivamente. Este esquema genérico se ha dividido a su vez en dos modalidades básicas:

- El esquema operativo prismático-A o prismático de tendencia piramidal.

- El esquema prismático-B, que podría asimilarse grosso modo a los núcleos prismáticos unipolares o bipolares.

El esquema operativo de superficie ancha tiene dos métodos que se diferencian tan solo en la dirección de la talla, es decir puede ser unipolar o bipolar.

Por último, el esquema unipolar-prismático parece corresponder a una aplicación rápida del prismático- $\mathrm{B}$, sobre núcleos gruesos. 


\section{CADENA OPERATIVA PRISMÁTICA - UNIPOLAR}

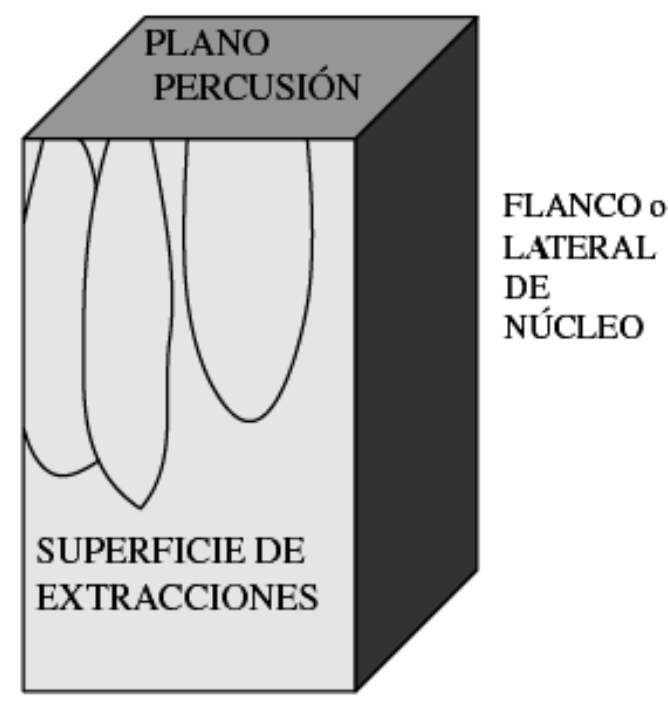

FASE 0: Selección de nódulos con morfología adecuada para los distintos métodos (por ejemplo: bloques prismáticos, con aristas naturales que facilitan el inicio de la talla o también algunas lascas grandes).

FASE 1: Preparación / conformación: Estructura prismática.

Superficie de extracciones delimitada por los flancos del núcleo.

La base del núcleo puede ser una superficie paralela al plano de percusión o una arista.

FASE 2: Débitage de soportes alargados (hojas, hojitas, lascas laminares).

Los método de talla varían depediendo del esquema operativo, pueden ser de forma: unipolar, convergente, unipolar alterna o bipolar.

$\mathrm{El}$ avance de la talla puede ser frontal o semi-envolvente.

Figura V.6: cadena operativa prismática - unipolar 


\section{V.4.1.1.- ESQUEMA OPERATIVO PRISMÁTIO-A O PRISMÁTICO CON TENDENCIA A PIRAMIDAL}

En este esquema se incluirían algunos de los núcleos prismáticos unipolares y piramidales (desde un punto de vista "clásico" de clasificación de los núcleos). Sus características básicas se fundamentan en una construcción del volumen estructurada en un prisma tetragonal o trigonal alargado. La tabla laminar está en el cuerpo del prisma, constreñida entre los flancos del núcleo; el plano de percusión está situado en la parte superior del prisma y es una superficie más o menos ortogonal a la tabla; mientras que la base es una arista perpendicular a la tabla, con una dirección aproximadamente antero-posterior.

El avance del débitage se produce de forma unipolar, con tendencia a ser convergente, y frontal. Para la extracción de los soportes es necesaria una preparación del frente de percusión (abrasión) previa, el ángulo del frente de talla es abierto y el plano de percusión es liso. Este esquema se va a aplicar sobre todo para la obtención de hojitas, aunque también hay ejemplos de hojas de mayor calibre.

El mantenimiento de este ritmo de talla se produce a partir de dos recursos:

- Auto-mantenimiento del propio avance de talla facilitado por la construcción volumétrica del núcleo, que permite, mediante ese avance unipolarconvergente y frontal, el control de la carena y la cintra. Este automantenimiento se ve favorecido también por el hecho de que la longitud de las extracciones no es demasiado elevada. En este proceso hay que destacar también la obtención de las que hemos denominado "hojas con flanco", es decir aquellas piezas que están en la intersección entre la tabla laminar y un flanco, y que contribuyen tanto a la conservación de los flancos (cuya intersección con la tabla ha de ser aproximadamente perpendicular), como al avance frontal del débitage.

- Fases de reparación del núcleo independientes de la producción, a lo largo del proceso de talla. En estas secuencias se procede a arreglar por ejemplo la tabla para reavivar la ortogonalidad de la misma con los laterales del núcleo 
mediante flancos longitudinales; o también se puede corregir la carena a partir de pequeñas extracciones desde la arista basal (que se convierte frecuentemente en una cresta inferior) del núcleo. El plano de percusión se suele arreglar a partir de tabletas o semitabletas que reavivan totalmente el frente de talla.

Los nódulos seleccionados para este tipo de esquema son tanto bloques más o menos conformados, como lascas grandes. En el caso de núcleos sobre nódulos, la fase de preparación/conformación es bastante importante, ya que hay que realizar una preparación correcta de los flancos de núcleo y sobre todo de la arista basal. Asimismo requiere un cuidado de los flancos a lo largo del débitage para conservar la cintra, así como de la carena a partir de la cresta inferior.

Cuando estos núcleos se realizan sobre una lasca, la conformación inicial está facilitada por las características morfológicas de este soporte, ya que la arista basal sería uno de los bordes laterales de la lasca, mientras la cara superior e inferior servirían de flancos. La tabla laminar se sitúa sobre otro de los bordes de la lasca, de modo que tan solo hay que conformar el plano de percusión. El avance de las extracciones y el proceso de auto-mantenimiento es, en este caso, más inmediato, ya que la ortogonalidad de los flancos está asegurada por las superficies de la lasca, así como el débitage unipolar-convergente; incluso se evitaría el arreglo de la arista basal. 


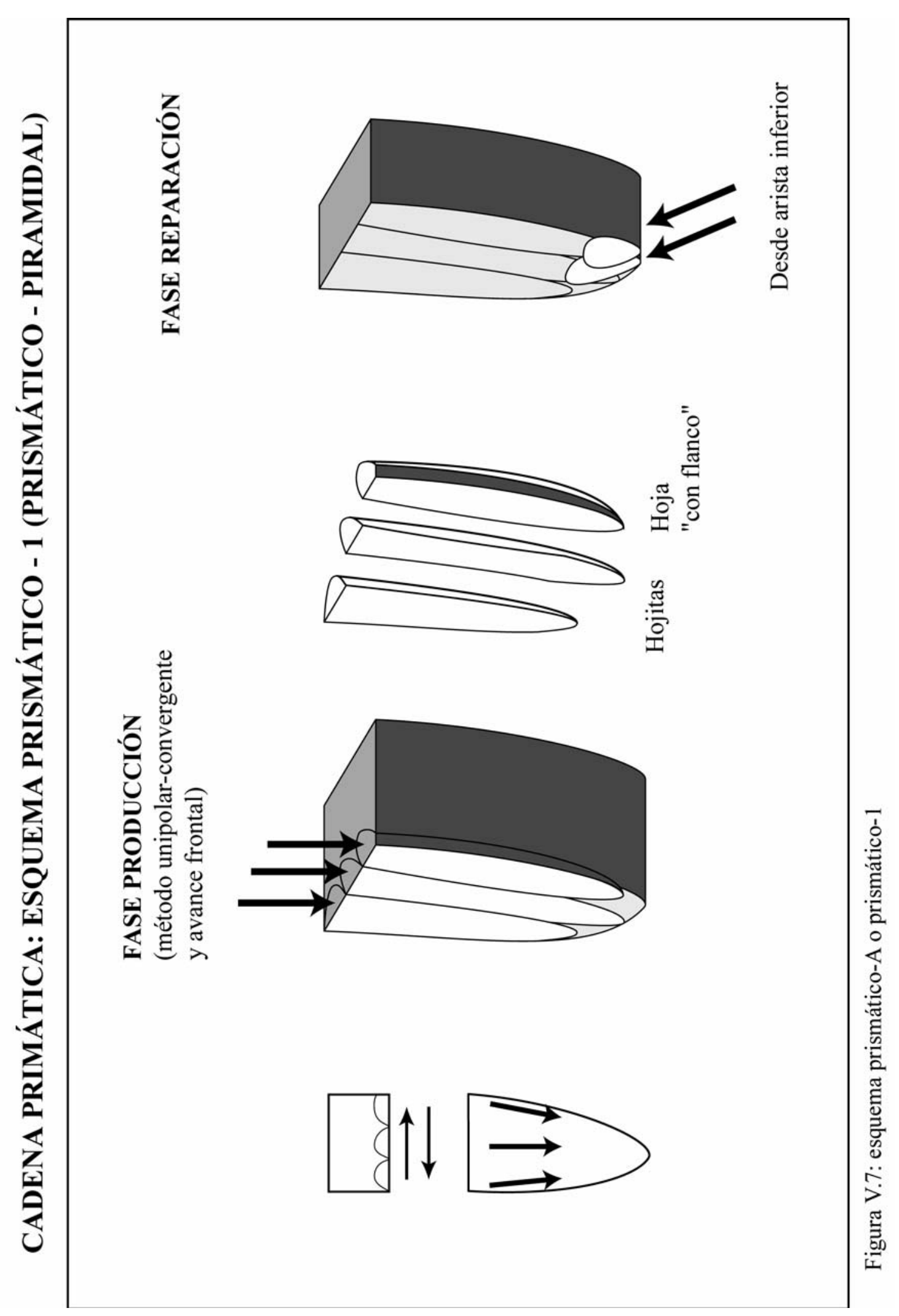


En este tipo de explotación, el débitage se produce, por tanto, sobre uno de los bordes la lasca primitiva, lo cual estaría en la línea del débitage tipo buril-núcleo. Este tipo de explotación se ha analizado sobre todo en contextos del Paleolítico Superior Inicial, interpretando algunos buriles como núcleos de hojitas. No obstante, esta modalidad operativa de los buriles-núcleos (y también los raspadores carenadosnúcleos) $)^{34}$ para débitage microlaminar se encuentra también en otros contextos cronológicos y tecnológicos (por ejemplo en el Magdaleniense Inferior [Cazals, 2000]), debido posiblemente a una convergencia técnica (Le Brun-Ricalens et Brou, 2003).

En El Espertín la modalidad de explotación del núcleo prismático-A sobre lasca no parece corresponder de forma directa a la de los buriles carenados-núcleo, al menos tal y como es analizado por ejemplo por F. Le Brun-Ricalens y L. Brou (2003), las principales diferencias con éstos son las siguientes:

- carena muy rectilínea (mientras que en los buriles parece que existe una curvatura más acusada, con una tendencia muchas veces a tener una dirección longitudinal de tipo alabeada o helicoidal [torses en terminología francesa])

- avance del débitage frontal (en los buriles tiende a ser semi-envolvente, aunque también hay en estos un reavivado de los flancos laterales)

- el tamaño de la lasca seleccionada es bastante grande

Se pueden resumir estas diferencias en que la modalidad aplicada en El Espertín está plenamente en relación con el esquema prismático-A, sigue los mismos presupuestos técnicos que éste; mientras que los buriles carenados-núcleos parecen pertenecer a un método ligeramente distinto, sin descartar que ambos puedan encajar en un mismo esquema conceptual. No obstante, hay que recordar que en El Espertín tan

${ }^{34}$ Respecto al problema de este tipo de útiles retocados / lascas-núcleo, tan solo queremos hacer mención a la controversia que rodea a este tipo de "piezas nucleiformes y carenadas", ya que últimamente hay una cierta tendencia hacia la interpretación de algunas de estas piezas (tanto buriles como raspadores) como núcleos de hojitas, a partir de análisis tecnológicos. Así sucede en algunos estudios realizados por ejemplo en conjuntos auriñacienses, con el buril busqué (Bordes et Lenoble, 2002), o en el Gravetiense con el buril de Raysse (Lucas, 2002; Klaric et al., 2002) y también en otros momentos con el buril carenado (Le Brun-Ricalens et Brou, 2003). No se pretende, no obstante, ahondar en esta temática, ya que se sitúa fuera de la problemática presente en la industria lítica de El Espertín. 
solo hay un ejemplo de lasca-núcleo con explotación sobre el borde de la lasca, por lo que hay que guardar cautela sobre su significado.

\section{V.4.1.2.- ESQUEMA OPERATIVO PRISMÁTICO-B}

Este esquema es el característico de los núcleos prismáticos unipolares y bipolares y se utiliza sobre todo en la producción de hojas. Como en el esquema anterior, la estructura volumétrica es un prisma alargado y la tabla está delimitada perfectamente por al menos uno de los flancos de núcleo. La diferencia fundamental con el esquema precedente es que la base del núcleo no es una arista antero-posterior perpendicular a la tabla, sino que se trata de una superficie paralela a la tabla o, en caso de que se trate de una arista, ésta tiene una dirección transversal. Otra diferencia es que el avance del débitage se produce de forma unipolar, como en el caso anterior, pero con un progreso que tiene más tendencia a ser semi-envolvente, sobre todo cuando se adapta a las dificultades ocasionadas por los abundantes planos de fisura internos. De todas formas, en caso de que se pueda proseguir un avance frontal, éste se ejecuta, como lo atestiguan algunos flancos longitudinales que reavivan totalmente una tabla laminar frontal.

En este esquema se hace patente el aprovechamiento de las superficies naturales existentes en la materia, de manera que es muy frecuente que se tome una de estas superficies del nódulo original colocándola como uno de los flancos, de forma longitudinal. La arista existente entre dicho flanco y la tabla de extracciones servirá como guía para la apertura de la talla, con la obtención de hojas de encetadura, continuando el débitage hacia el flanco opuesto. El flanco de partida suele conservarse perpendicular a la tabla, permitiendo así retomar sobre él las extracciones, mientras que la serie de extracciones suele seguir un progreso semi-envolvente hacia el flanco opuesto.

El mantenimiento de este débitage se produce a partir de varios procedimientos, por ejemplo flancos longitudinales, extracciones desde la base del núcleo, etc. Hay que destacar que en este esquema las extracciones desde la base del núcleo, es decir desde el plano opuesto, son más importantes y más frecuentes que en el esquema anterior. Hay 
constancia tanto de flancos longitudinales desde el plano opuesto con el fin de "limpiar" la tabla, como de cambios del sentido del débitage, con un volteo del núcleo, para explotar la superficie de extracciones desde el plano opuesto. Hay que destacar, no obstante, que no se produce un ritmo de talla bipolar estricto, sino que se trata de secuencias de extracciones de sentido unipolar que explotan la tabla desde planos distintos. Además de estos recursos que juegan de forma bastante flexible con la estructura del volumen, hay que mencionar el empleo de crestas laterales para arreglar la cintra del núcleo. En cuanto al plano de percusión, son más frecuentes en este esquema los arreglos mediante pequeñas lascas de reavivado del frente de talla, más que reavivados totales del plano de percusión propiamente dichos.

Este esquema se define bastante bien sobre los núcleos, y hay que desatacar la adaptabilidad de dicha estructura sobre los nódulos disponibles, aunque con las dificultades de la ejecución de la talla debido a las características de la materia prima. Los soportes seleccionados para este esquema son bloques de las distintas materias, no se han utilizado lascas-núcleo. La fase de conformación del núcleo no es tan importante como en el esquema anterior, ya que hay un aprovechamiento y/o adaptación a las características peculiares de las materias disponibles. Hay que recordar que muchos nódulos de chert negro y sobre todo los de radiolarita se presentan con una morfología prismática, que es bastante cercana a la estructura volumétrica requerida para este esquema.

También se puede rastrear esta modalidad en la presencia de algunos elementos de reavivado de la superficie de extracciones, sobre todo de flancos longitudinales opuestos. Así por ejemplo en la radiolarita-2 no hay núcleos característicos de este esquema, pero sí hay flancos que atestiguarían su aplicación en secuencias de débitage anteriores a las presentes en el conjunto (hay que recordar que la cadena operativa estaría rota en esta materia). 


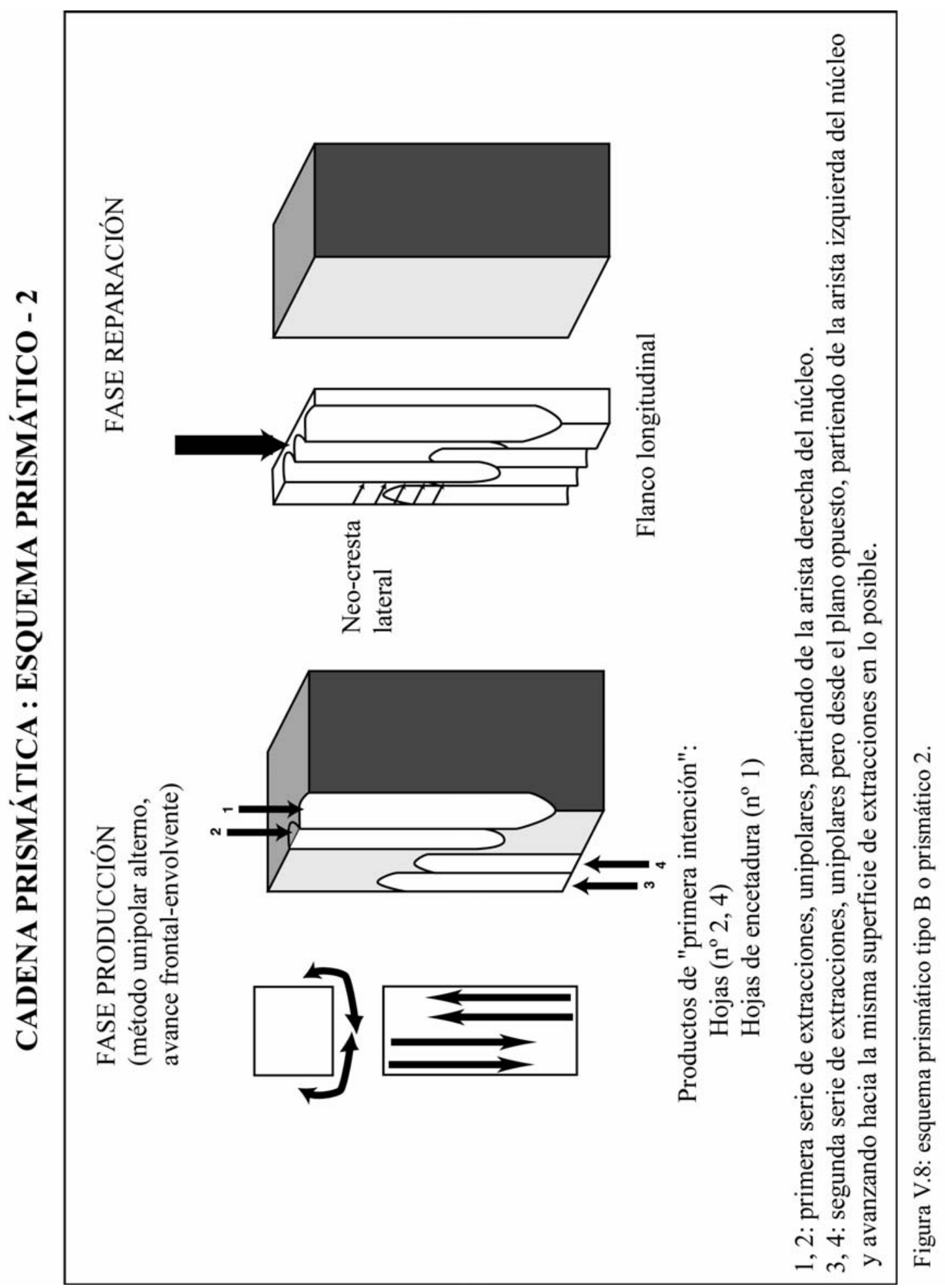




\section{V.4.1.3. ESQUEMA OPERATIVO DE SUPERFICIE ANCHA}

Esta construcción suele aparecer sobre bloques de grosor considerable y su característica esencial es, como se destaca en su propia definición, la explotación de una tabla de extracciones bastante ancha. La morfología de dicha tabla suele ser cuadrangular, más que rectangular alargada como en los esquemas anteriores. Las extracciones son hojas anchas o más bien lascas laminares, se trata en general de extracciones más anchas que en los esquemas anteriores, pero buscando la mayor longitud posible aunque se trate de piezas gruesas. El modo de talla, a partir de los contrabulbos de los núcleos, parece ser percusión dura y el avance del débitage frontal. Al igual que en el esquema anterior, se aprovecha una de las aristas naturales de forma longitudinal para abrir la superficie de extracciones. También suele ser importante uno de los flancos del núcleo, sobre el cual se instala una cresta lateral sobre la que se producen extracciones transversales que permitirán el control de la cintra. Otra característica de este esquema es que la base del núcleo se mantiene como una superficie paralela al plano de percusión.

Se documentan dos métodos de explotación a partir de la orientación de las extracciones, de forma que hay un esquema unipolar y otro bipolar. Este último sí se define como un avance bipolar estricto, ya que, al contrario que en el esquema operativo prismático anterior, la superficie de extracciones se explota a partir de dos planos opuestos, desde cada uno de los cuales se alcanza aproximadamente la mitad de la longitud de la tabla, dando como resultado una carena en diedro. 


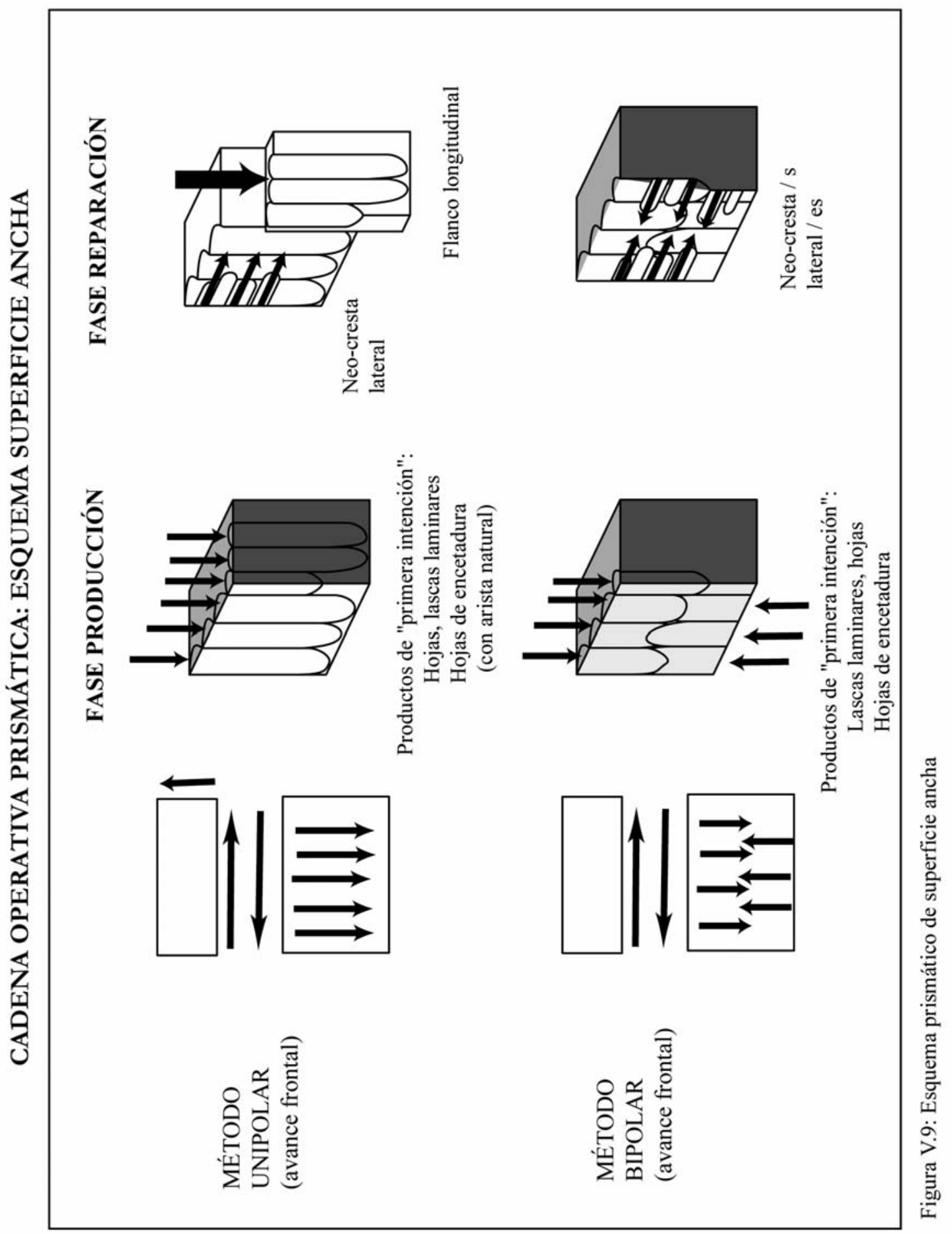


Para la aplicación de este esquema de superficie ancha se seleccionan bloques gruesos, como se ha indicado, muchos de los cuales tienen una estructura en prisma tetragonal de base rectangular. Sobre ellos la apertura de la superficie de extracciones se realiza a partir de hojas de encetadura. También se ha constatado un procedimiento de conformación del núcleo que consiste en fracturar en dos partes el nódulo disponible, de modo que se obtiene así una cara ancha sobre la que instalar la superficie de extracciones. Por último, también se han utilizado en este esquema operativo las lascas grandes pero, en este caso y a diferencia de lo que sucedía en el esquema prismático-A, la superficie de extracciones del núcleo se coloca sobre la cara inferior de la lasca, no sobre uno de sus bordes. De este modo se obtiene la superficie ancha requerida en esta modalidad.

Como se puede observar, la fase de selección y conformación del núcleo en este esquema es bastante variada y flexible y aprovecha también de forma ventajosa las características morfológicas iniciales del núcleo.

El aprovechamiento de las lascas como núcleos para la obtención de lascas y lascas laminares, es un tipo de gestión de la lasca-núcleo distinta a la que estaba presente en el esquema prismático-A Esta explotación de la cara inferior de la lasca se podría incluir, dentro de la clasificación de las lascas-núcleo realizada por J. Tixier y A. Turq (1999), en el denominado "mode 1", con la salvedad de que no se trataría del método kombewa, sino que en nuestro caso el tipo de tratamiento del volumen encaja totalmente en el esquema operativo prismático de superficie ancha. A este respecto, sí hay en el conjunto alguna lasca o lasca laminar de tipo "lasca-Kombewa", en el sentido de que su cara superior es la cara bulbar de la lasca-núcleo de origen. No obstante, su número es muy escaso, aspecto que concuerda con la aparición esporádica de este tipo de núcleos.

La principal diferencia entre el esquema desarrollado en las lascas-núcleo de El Espertín y el método kombewa es que en este último se explota la lasca a partir de sus bordes laterales o distal para obtener unas pocas lascas de morfología frecuentemente subcircular (Newcomer \& Hivernel-Gerre, 1974: 123-124; Inizian et al, 1995: 71). No hay una jerarquización estricta del plano de percusión utilizado, sino que se suele 
conformar un retoque parcial en el borde sobre el que se va a percutir. En nuestro caso la construcción del volumen de la lasca está determinada totalmente por la estructura prismática de superficie ancha a la que está circunscrita.

\section{V.4.1.4.- ESQUEMA UNIPOLAR-PRISMÁTICO}

Este esquema podría incluirse en el esquema prismático-B; como en éste la utilización de las aristas y planos naturales de la materia se optimizan para el inicio de la talla y la estructuración del volumen. Las características más llamativas de este esquema son que aparece en nódulos de longitud escasa con relación a su grosor, además la base es una superficie lisa paralela al plano de percusión. Esta escasa longitud de la tabla permite un control directo de la carena, y el avance del débitage se produce de forma semi-envolvente sobre ambos flancos a partir de una arista natural en la parte frontal. El inicio de la talla se produce a partir de piezas de encetadura que abren la superficie de extracciones, facilitando así la explotación en dirección antero-posterior del grosor del núcleo.

Este esquema no requiere demasiadas complicaciones en secuencias de reparación y conformación, se trataría de una forma rápida de conseguir hojitas y lascas de forma unipolar y con una longitud que abarca toda la superficie de extracciones disponible. 


\section{V.4.2.- CADENA OPERATIVA TIPO NÓDULO-PLACA}

La estructura de este esquema está determinada por el tipo de nódulo que se selecciona y la forma como se gestiona tal nódulo. Sobre un bloque-placa, es decir un nódulo delimitado por sendas superficies naturales paralelas, la superficie de extracciones se orienta según su eje menor, en consecuencia se extraen lascas cortas, cuyo eje tecnológico está enmarcado por las superficies. La longitud escasa de la superficie de extracciones permite el control de la carena; el avance del débitage se produce de forma envolvente, y el plano de percusión no tiene una posición fija, sino que se sitúa sobre las superficies naturales, intercambiando la función de plano de percusión y de base del núcleo conforme lo requiera el avance del débitage.

Se trata por tanto de un esquema de producción de lascas de carácter simple y rápido, que permite una optimización de las características de la materia prima sobre los aparentes inconvenientes que presenta ésta (los abundantes planos naturales), para un proceso de talla inmediato y eficaz. 


\section{CADENA OPERATIVA TIPO NÓDULO-PLACA}

FASE 0: nódulos

en forma de placas, delimitadas por sendos

planos naturales.

FASE 1: preparación

La superficie de extracciones es la delimitada por los planos naturales, tomando como eje de talla el lado corto.

Los planos naturales serán los planos de percusión

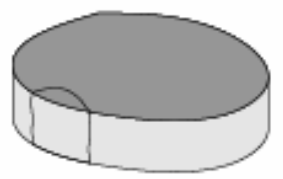

FASE 2: producción

Débitage de lascas

Método de avance envolvente

Extracciones alternantes
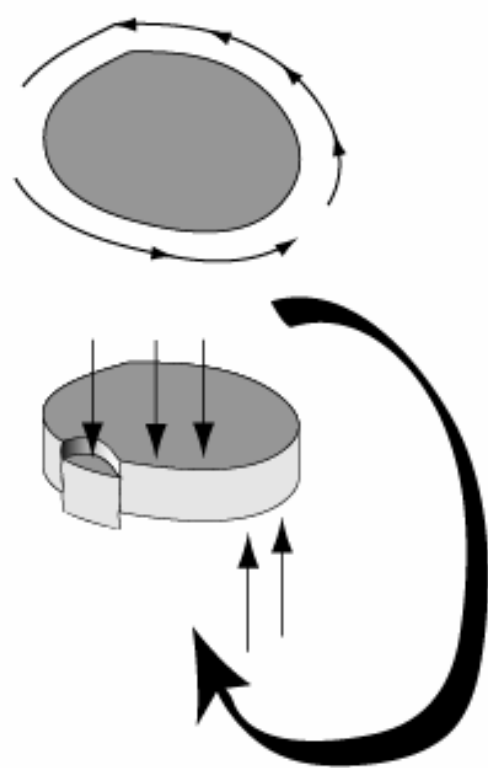

Soportes "de primera intención":

Lascas (pequefnas y cuadrangulares)

Figura V.10: cadena operativa tipo nódulo-placa 


\section{V.4.3.- CADENA OPERATIVA CENTRÍPETA}

Este esquema conceptual se encuentra dentro de la tradición de los esquemas de débitage de tipo centrípeto/discoide, que aprovechan un núcleo estructurado en dos superficies secantes, de forma que la explotación de dichas superficies se produce desde la arista del contorno. En este caso se trata de un método muy sencillo de explotación de cantos rodados sin fases de conformación o preparación elaboradas; la fase de producción se centra en obtener soportes de la superficie que tiene las condiciones técnicas más aptas, más que en un juego de explotación bifacial alternante propiamente dicho. La dirección de la talla es centrípeta porque se intenta extraer las lascas de dicha superficie de forma rápida, mediante golpes contiguos que van contorneando el nódulo. Se trata por tanto de un esquema simple y rápido adaptado también a un tipo de nódulos (los cantos rodados) para la obtención de lascas de forma inmediata. 


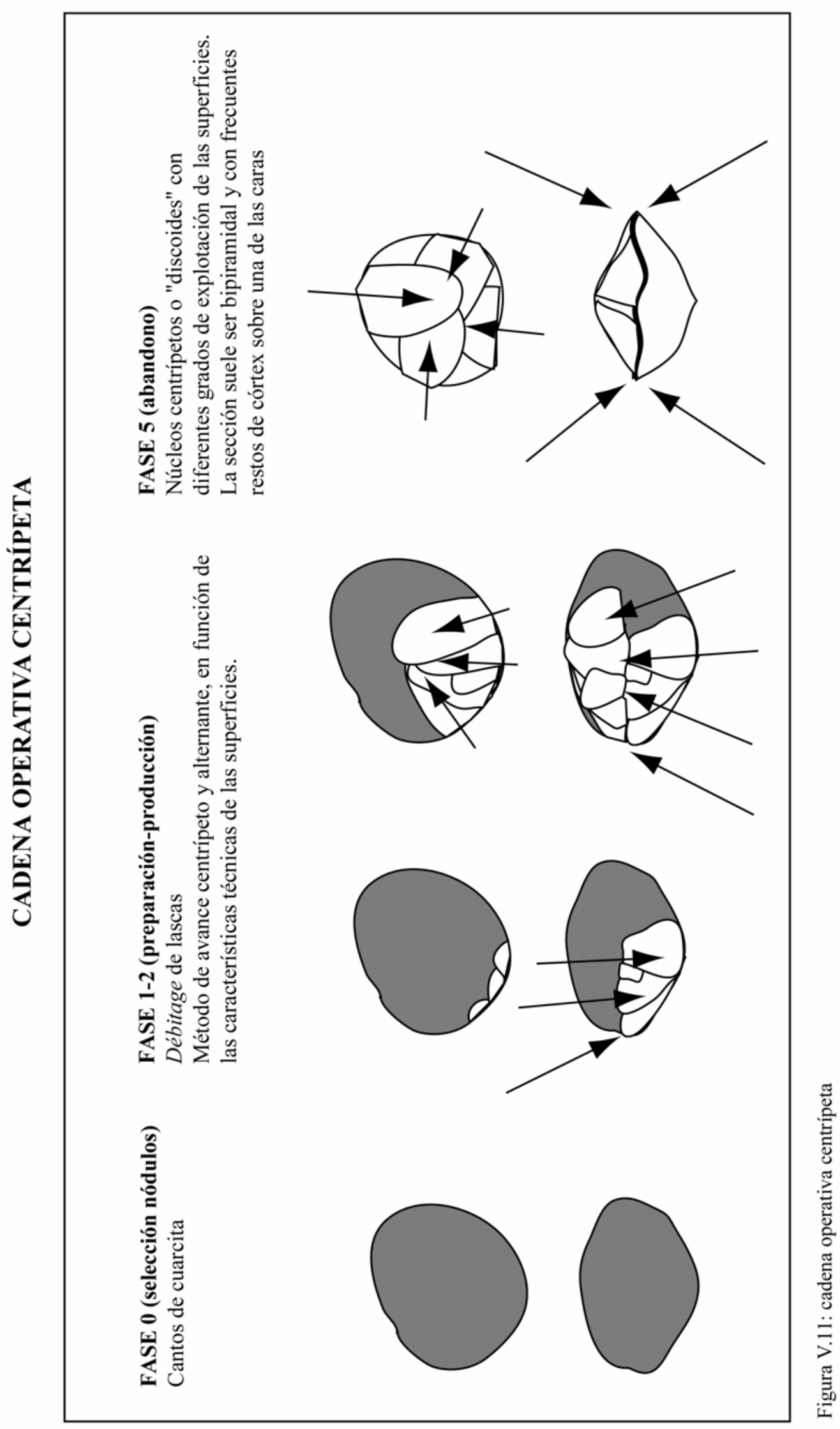




\section{V.4.4.- RELACIÓN DE LAS CADENAS OPERATIVAS PRESENTES EN “EL ESPERTÍN” CON OTROS PROCESOS OPERATIVOS}

Como se indicó en el capítulo sobre metodología, el principal objetivo de un análisis tecnológico consiste en determinar los esquemas conceptuales presentes en una industria lítica y las relaciones de tales esquemas con el resto de los sistemas técnicos, económicos o sociales del grupo. Esta segunda parte es, sin duda, una tarea compleja, que habría que abordar desde un punto de vista más interdisciplinar. En este trabajo nos conformamos con un objetivo más inmediato, dedicado exclusivamente a la tecnología lítica. Teniendo en cuenta esta intención, nos hemos centrado en describir esas cadenas, así como los esquemas operativos en que se pueden diversificar. No obstante, se intentará realizar una exposición de la problemática que existe a la hora de intentar realizar esta contextualización del proceso técnico, especialmente respecto al entorno crono-cultural.

\section{V.4.4.1.- DIFICULTADES PARA UNA TECNOLOGÍA COMPARATIVA: ESCASEZ DE DATOS SOBRE LOS PROCESOS OPERATIVOS EN EL EPIPALEOLÍTICO/MESOLÍTICO DE LA CORNISA CANTÁBRICA}

Una segunda parte de este estudio sería encajar los esquemas así definidos dentro de un contexto crono-cultural preciso, o, al menos, relacionarlos con tradiciones culturales de mayor o menor alcance en el tiempo o en el espacio. Sin duda este objetivo sólo se podrá alcanzar cuando los análisis sobre tecnología lítica se extiendan sobre otros conjuntos industriales y, así, poder hacer una tecnología comparativa que permita sintetizar las diferencias y similitudes entre los procesos técnicos de los distintos yacimientos. Lamentablemente contamos con muy pocos análisis de tipo tecnológico en yacimientos de la Cornisa Cantábrica, al menos monográficos amplios ${ }^{35}$, además los existentes (Cazals, 2000; Lloret, 2001; Maíllo, 2003) abordan períodos cronológicos

${ }^{35} \mathrm{Si}$ bien sí es cierto que existen algunos análisis realizados en la zona oriental de la Cornisa, sobre yacimientos vascos (González Urquijo e Ibáñez Estévez, 1991; 1998; Ibáñez Estévez y González Urquijo, 1994; 1998). 
anteriores al Mesolítico (el Magdaleniense Inferior-Medio, el Magdaleniense Superior/Final-Aziliense y la transición Paleolítico Medio-Superior respectivamente).

Se da la circunstancia, por tanto, de que para el contexto crono-cultural de El Espertín, el Mesolítico/Epipaleolítico, no contamos con otros análisis de tipo tecnológico aparte del nuestro. A esto habría que añadir la dificultad que supone el hecho de que el propio Epipaleolítico/Mesolítico no está demasiado bien conocido en la parte centro-occidental de la Cornisa Cantábrica, por lo que incluso carecemos de unos rasgos generales de este periodo en un contexto cercano ${ }^{36}$. Tendríamos el Asturiense (González Morales, 1982; Arias Cabal, 1991; Fano, 1998), como facies costera del mesolítico cantábrico ${ }^{37}$, pero las características de su industria lítica son un tanto peculiares y distan de las que tenemos en El Espertín. Hay otra serie de yacimientos mesolíticos en un contexto interior ${ }^{38}$, no obstante, también es cierto que muchas veces hay dificultades para hacer una comparativa, debido a dos razones fundamentales:

i) Las propias características arqueológicas de algunos yacimientos a veces complican la valoración de su industria lítica. Por ejemplo la cueva de Los Canes (Arangas, Cabrales, Asturias) tiene la dificultad de que, además de las tumbas mesolíticas, hay otras estructuras posteriores que complican su estratigrafía (Arias Cabal y Pérez Suárez, 1990, 1992, 1995). Se podría también citar el caso del nivel III de la cueva de Tarrerón (Soba, Cantabria), para el que se duda entre su adscripción a una fase final del Mesolítico (Mesolítico final según Apellániz, 1975 o Epipaleolítico geométrico según Arias, 1991) o un Mesolítico en fase de neolitización (Arias, 1997).

${ }^{36}$ En la última década han aparecido varias síntesis sobre el Epipaleolítico/Mesolítico, pero afectan, sobre todo, a la cuenca del Ebro (Cava, 1994; Utrilla et al., 1998; Utrilla, 2002; Alday Ruiz, 2002) y zona vasca (Alday Ruiz, 1999; 2000); o bien son de carácter muy amplio (González Morales, 1995) o están centradas en la Neolitización (Arias Cabal et al., 1999; 2000; Juan-Cabanilles \& Martí Oliver, 2002).

${ }^{37}$ Además de los concheros asturienses hay otros yacimientos mesolíticos costeros con conchero en la zona centro-oriental cantábrica (González Morales, 1992, 1995, 1996); por ejemplo en el nivel 1 del abrigo de La Peña del Perro (Santoña, Cantabria [González Morales y Díaz Casado 1991-92]), sin olvidar otros yacimientos más clásicos como Santimamiñe (Cortézubi, Vizcaya), nivel IV, ya en el País Vasco (Arias, 1991, 1992).

${ }^{38}$ Por ejemplo la cueva de Cubío Redondo (Matienzo, Ruesga, Cantabria [Ruiz Cobo \& Smith, 2001]) y se podrían nombrar también algunos yacimientos al aire libre mesolíticos, como Sierra Plana (Asturias [Arias, 1991]), Hayas y Peña Oviedo (ambos en Cantabria [González Morales, 1999]). 
ii) Hay yacimientos que aún están en fase de análisis debido a que han sido objeto de una excavación reciente. De ellos contamos con datos respecto a la adscripción mesolítica de algunos de sus niveles, incluso con dataciones radiocarbónicas, pero aún no conocemos las características de su industria lítica; es el caso por ejemplo de la cueva de Arangas (Arangas, Cabrales, Asturias), que se localiza muy cerca de los Canes, o La Garma (Ribamontán del Monte, Cantabria) (Arias et al., 1999).

Hay que citar también, para un contexto interior cantábrico, la existencia de un yacimiento en un valle no muy alejado del entorno de El Espertín, en la Liébana, ya en Cantabria, pero también inmediato a Picos de Europa; se trata del abrigo de La Mina (Dobarganes, Vega de Liébana, Cantabria), cuya industria lítica ha sido revisada por P. Arias (1996), quien la adscribe a un momento epipaleolítico/mesolítico.

Por lo que respecta a la zona occidental de la Cordillera Cantábrica, hacia Galicia, apenas si contamos tampoco con datos para el Epipaleolítico/Mesolítico, a excepción del yacimiento de Xestido III (Abadín, Lugo), que tiene una datación del $7310 \pm 160$ BP (Ramil Rego, 1995; Ramil Soneira y Villar Quinteiro, 1995).

\section{V.4.4.2.- RELEVANCIA DE LAS CARACTERÍSTICAS TÉCNICAS: CADENAS CON “MARCADOR CULTURAL” INTENSO Y CADENAS - ARQUETIPOS}

Un aspecto importante, en este objetivo de más largo alcance relativo a la relación entre las características tecnológicas de este yacimiento y otros, tanto en el ámbito sincrónico como diacrónico; sería la determinación de aquellos rasgos de tipo cultural que se puedan poner en relación con grupos culturales o tradiciones determinadas. A este respecto, parece que la cadena de tipo prismático-unipolar es la que contiene un "marcador cultural" de mayor intensidad.

Habría que incidir de todos modos, como se explicó también en la metodología, en el hecho de que es importante delimitar los rasgos de tipo cultural de aquellos otros que están determinados por factores técnicos o materiales. En este sentido, puede que las cadenas de tipo más sencillo estén relacionadas con formas de ejecutar un proceso de débitage de una manera rápida y práctica, adaptada a las características de las materias 
primas en cuestión. Con el término "sencillo" nos referimos a que son esquemas con un pequeño número de gestos, sin una preparación elaborada o un desarrollo extenso del proceso de talla; no queriendo dotar a tal término de ninguna connotación peyorativa ni juicio de valor. Se han planteado dudas incluso sobre la categoría tecnológica de este tipo de cadenas, en el sentido de que se vacila a la hora de considerar como esquemas conceptuales con entidad a unos esquemas de tipo sencillo, repetitivo y adaptados casi siempre a las características de la materia prima. Entonces se emplean términos como "fórmula" o "algoritmo" para hacer referencia a estos esquemas (Pelegrin, citado por Cazals, 2000: 105). Nuestra opinión a este respecto está más a favor de la consideración de estos tipos de explotación como esquemas conceptuales (o cadenas operativas propiamente dichas) con entidad plena.

Como ejemplo de este tipo de cadenas tenemos en El Espertín los procesos de débitage de lascas (la cadena centrípeta y la del nódulo-placa). Estas cadenas parecen responder a las características morfológicas y técnicas de las materias en cuestión. Este tipo de cadenas simples, aptas para una explotación eficaz de unos nódulos determinados, podría considerarse como una especie de arquetipos de explotación de nódulos con una estructura volumétrica determinada. No obstante este concepto de arquetipo habría que aplicarlo cuando, una vez ejecutado el análisis de conjuntos industriales de distintos contextos y cronología, se comprobara que existen, efectivamente, unos procesos recurrentes con relación a la explotación también de unas estructuras volumétricas y/o materias primas concretas. Tales arquetipos podrían responder, por tanto, a un fenómeno de convergencia técnica, más que a tradiciones culturales. No deja de ser curioso, no obstante, que en un contexto cronológico no muy lejano, en concreto el IX milenio BP, hay también unos procesos técnicos de débitage de lascas, de tipo sencillo y vinculados a las características de la materia prima. Este tipo de cadenas aparece en varios yacimientos mesolíticos de los Pirineos orientales (Terradas, e.p.). En consecuencia, puede que quizás una explotación intensiva de los recursos del entorno en el Mesolítico lleve a la presencia de este tipo de cadenasarquetipo adaptadas perfectamente a la explotación de las materias disponibles. 


\section{V.4.4.3.- CADENA PRISMÁTICA-UNIPOLAR}

La cadena prismática podría considerarse como la más representativa desde un punto de vista "cultural". Habría que hacer, no obstante, algunas matizaciones para centrar el tratamiento de esta cadena:

- Desde un punto de vista tecnológico, la cadena prismática-unipolar es una estructura volumétrica determinada, que consiste, esencialmente, en un prisma tetragonal. Esta estructura se va explotar a partir del principio de "gestión del volumen del núcleo", no "de una superficie", según la terminología de E. Boëda (1990).

- Esta estructura se va a utilizar para procesos de débitage laminar y microlaminar sobre todo, aunque también se pueden producir soportes tipolasca o lasca laminar, pero siempre intentando obtener extracciones alargadas.

- Este esquema conceptual se puede desarrollar en varios esquemas operativos, pero hay que tener siempre en cuenta la estructura básica, sobre todo el principio de "gestión del volumen del núcleo".

- Desde un punto de vista tipológico, los núcleos prismáticos unipolares y bipolares y los núcleos piramidales son de sobra reconocidos a lo largo del Paleolítico, y son muy abundantes en conjuntos del Paleolítico superior y Epipaleolítico; muchos de ellos encajarían en alguno de los esquemas operativos descritos en El Espertín, en concreto dentro del primero: el "prismático típico".

De los esquemas operativos de la cadena prismática-unipolar definidos en El Espertín, tan solo el "prismático típico" puede rastrearse de forma más o menos factible en otros conjuntos. Los otros dos esquemas, el de superficie ancha, y el unipolarprismático, no son susceptibles de identificarse de una manera tan inmediata como el primero. Esto no significa que no exista en otros yacimientos, pero al no poder identificarlos correctamente, no podemos ahondar demasiado, por el momento, en el 
significado e implicaciones de dichos esquemas, bien sea exclusivamente a un nivel técnico solamente o también cultural.

El esquema de superficie ancha sería adecuado para la obtención de hojas anchas o más bien lascas laminares. El esquema unipolar-prismático parece ser una solución rápida a unos nódulos cortos y gruesos, los cuales se explotan a partir de una aplicación de la estructura genérica de la cadena prismática.

Hay que destacar el hecho de que esta estructura prismática tiene una gama variada de modalidades de aplicación, incluso se dibuja una cierta tendencia hacia el uso de esquemas específicos para soportes más o menos concretos. En consecuencia la flexibilidad que hemos constatado en la gestión de las materias primas se extendería hacia una flexibilidad técnica a la hora de aplicar esquemas variados para obtener una gama de soportes amplia, tanto hojas y hojitas como lascas laminares y lascas de tamaño variado.

\section{V.4.4.3.1.- ¿EL ESQUEMA OPERATIVO “PRISMÁTICO TÍPICO” SE CORRESPONDE DE FORMA UNÍVOCA CON LOS NÚCLEOS PRISMÁTICOS Y PIRAMIDALES “TÍPICOS O CLÁSICOS”?}

Las modalidades prismáticas-A y $\mathrm{B}$ son las que más se podrían encontrar en otros conjuntos líticos, pero para poder realizar una equiparación entre estos esquemas y aquellos que se pueden intuir a partir de los núcleos prismáticos y piramidales “clásicos” (Bordes, 1979: 89; Brézillon, 1977: 92-93; Laplace, 1966: 32; Rozoy, 1968: 378), hay que hacer una serie de puntualizaciones en el ámbito técnico:

- La estructura volumétrica es esencialmente prismática en el cuerpo del núcleo (nunca cilíndrica), su proyección en visión frontal es de forma rectangular/subrectangular o subtriangular en el caso de los núcleos piramidales, y su sección transversal es también subrectangular o subtriangular (no circular).

- La tabla laminar está encajada entre los flancos laterales, al menos uno de ellos se mantiene de forma perpendicular a ella. Los flancos así conformados juegan un papel importante en el mantenimiento de la cintra. 
- La explotación puede ser unipolar (que es la que está presente en E1 Espertín) o bipolar. Esta última no aparece en nuestro conjunto, pero es un esquema que se puede encontrar en distintos momentos del Paleolítico Superior $^{39}$.

- El avance de la explotación suele ser frontal, pero también puede convertirse en semi-envolvente, e incluso envolvente. En este último caso, no obstante, el avance del débitage se produce a partir de tablas yuxtapuestas consecutivas, una al lado de la otra, hasta expandir la superficie de extracciones por todo el contorno, sin perder la estructura volumétrica prismática, con su sección subrectangular.

- En los núcleos piramidales la arista presente en su base es un factor estructural importante en la conformación del volumen. Otra característica esencial es la explotación unipolar con tendencia a convergente.

- En los núcleos piramidales el avance suele ser frontal, pero también puede ser ocasionalmente semi-envolvente; en este caso no se llega a una explotación de todo el contorno, lo cual parece que es debido a que se necesitan los flancos para apoyar el proceso de talla.

Se ha insistido bastante en el hecho de que, en este esquema operativo "prismático clásico", el avance del débitage se produce a partir de la explotación de tablas laminares que pueden expandir en mayor o menor grado la superficie de extracciones a lo largo del contorno del núcleo. Es importante destacar que se intenta mantener la estructura prismática de inicio. De este modo quedarían fuera de este esquema operativo aquellos núcleos que tienen una explotación envolvente-circular, más propia de estructuras cilíndricas o cónicas. Este último tipo de explotación daría lugar por ejemplo a los núcleos "en mitra" o "en bala de fusil", que se producen, además, a partir de modos de talla peculiares, en concreto mediante presión (VVAA, 1984; Pelegrin, 1988; Inizian et al, 1995: 77-80), técnica que en Europa aparece (según los autores que analizan los distintos modos de talla, por ejemplo: Tixier, 1984: 62; Pelegrin, 1988) a partir de un momento avanzado del Mesolítico, desarrollándose en gran medida a lo largo del Neolítico y Calcolítico.

${ }^{39}$ Por ejemplo en el Gravetiense (Bordes, 1968; Airvaux et Bouchet, 2001) o en el Tardiglaciar de la Cuenca de París para la producción de hojas rectilíneas (Valentin, 1995; Valentin et Pigeot, 2000). 


\section{V.4.4.3.2.- ¿CUÁNDO APARECEN LOS ESQUEMAS PRISMÁTICOS LAMINARES /} MICROLAMINARES TIPO ESQUEMA-A O ESQUEMA-B?

Los esquemas prismáticos-A y $\mathrm{B}$ serían los que proporcionan los productos laminares de forma más sistemática; el primero (con tendencia a piramidal) es más indicado para las hojitas mientras que el segundo lo es para las hojas. En El Espertín hay, en principio, una producción independiente de estos soportes a partir de ambos esquemas, pero en algún caso se ha comprobado una producción continua de hojas y luego hojitas por reducción de tamaño del núcleo; lo que no se ha constatado es una producción intercalada de hojas y hojitas.

Hoy en día no es necesario incidir en el hecho de que la producción de soportes laminares está verificada desde al menos el Paleolítico Medio, si bien es cierto que es a partir del Paleolítico Superior cuando se va a producir un mayor desarrollo y diversificación de los métodos de obtención de hojas y hojitas. La obtención de soportes laminares se puede producir a partir de varios procedimientos, tanto métodos Levallois, como "no-Levallois" y “de estilo Paleolítico Superior". Estas tres variantes aparecen mencionadas en conjuntos del Paleolítico Medio y desde fases antiguas (estados isotópicos 8 a 4) en distintos conjuntos musterienses (Révillion, 1994). Uno de los principales problemas del análisis de las cadenas operativas laminares es sin duda la definición o, mejor, el acuerdo en la definición de lo que es ese "estilo Paleolítico Superior”. Dicho “estilo", que se puede resumir en algunos de los núcleos prismáticos y piramidales "clásicos", parece pertenecer a una categoría estructural de los volúmenes (de estructura prismática), que se capta frecuentemente de forma intuitiva. Pero surge la duda: ¿los núcleos de "estilo Paleolítico Superior" que se pueden observar en distintos conjuntos del Paleolítico Medio, se corresponden realmente con los núcleos "típicos del Paleolítico Superior" en cuanto a su cadena operativa?. Esta cuestión se sitúa sobre todo en el terreno relativo al débitage laminar, y algunos investigadores llegan al extremo de afirmar que el "estilo Paleolítico Superior" no se ve de forma clara hasta el Gravetiense (Pigeot, 1991). Sin duda este debate sobrepasa con creces nuestro trabajo, aunque sí es cierto se nos han planteado abundantes dudas en torno a esta controversia, debido fundamentalmente a la ausencia de una definición tecnológica clara del estatus de los núcleos prismáticos y piramidales, así como sus variantes. Esto dificulta la labor de 
efectuar una relación más o menos directa de las cadenas identificadas en nuestro yacimiento con los esquemas prismáticos de tradición supero-paleolítica.

Por tanto el debate que nos preocupa es el relativo a las cadenas prismáticas laminares, que son las que tienen un mayor desarrollo y diversificación en el Paleolítico Superior, pero no vamos a desarrollar de forma más detallada la problemática de esta discusión. Tan solo se puede indicar que en fechas recientes se ha comprobado la existencia de un débitage prismático de hojitas en conjuntos del Musteriense Final (por ejemplo en los niveles 20, 21 de la cueva de El Castillo [Cabrera et al., 2000]). Estos métodos de producción microlaminar parecen además jugar un papel interesante en la transición Paleolítico Medio-Paleolítico Superior, ya que se han constatado también en el Auriñaciense de transición (en el nivel 18 de Castillo [Cabrera et al., 2001]).

Son muchas las preguntas acerca de las características concretas de las cadenas de tipo prismático, y de cuándo pueden aparecer de forma clara. Pero estos planteamientos no se restringen solamente a la aparición de estas estructuras, bien sea en el Musteriense o a principios del Paleolítico Superior, sino también a su desarrollo. Es decir, habría una problemática en dos niveles respecto al débitage prismático laminar/microlaminar:

i) A nivel "conceptual”: la definición clara del esquema prismático y cuándo aparece.

ii) A nivel "estructural": la definición de las variantes o modalidades que pueden existir, y si dichas variantes pueden ser de tipo cultural o cronológico (por ejemplo, si se puede determinar un débitage prismático laminar auriñaciense característico, gravetiense, magdaleniense, etc.) o bien de tipo más morfotécnico (características de las materias primas).

\section{V.4.4.3.3.- AlgUNOS EJEMPLOS DE CADENAS PRISMÁTICAS EN LA REGIÓN CANTÁBRICA}

Aparte de estas dificultades de tipo general para un encuadre técnico amplio de las cadenas prismáticas, existen otros inconvenientes de tipo más inmediato para una contextualización más cercana. Se trata, como se ha indicado previamente, de que son muy escasos los análisis tecnológicos con que contamos de zonas más o menos 
próximas. Como estos estudios tecnológicos están en una fase muy incipiente, corren el riesgo añadido de que pueden surgir problemas relativos a los criterios tecnológicos con los que se analizan las distintas series, así como a las peculiaridades intrínsecas de los distintos conjuntos.

Para la Región Cantábrica, tenemos dos estudios tecnológicos amplios de momentos avanzados del Paleolítico Superior a los que podemos aludir, uno sobre el Magdaleniense Inferior-Medio (Cazals, 2000) y otro sobre el Magdaleniense Final/Aziliense (Lloret, 2001).

En el análisis realizado por N. Cazals sobre el Magdaleniense Inferior-Medio cantábrico, no se habla de la estructura prismática como tal, pero dicho esquema, conforme lo hemos definido en nuestro caso, estaría implícito en las producciones de hojas y hojitas. En este trabajo se definen especialmente dos tipos de débitage, que quizás puedan corresponder grosso modo a algunas modalidades identificadas en El Espertín.

a) El débitage semi-tournant (semi-envolvente) aparece en explotaciones de lascas-núcleo tipo raspador o buril en el Magdaleniense Inferior, para la obtención de hojitas curvas de pequeño tamaño. También se utiliza en este periodo para hojitas de mayor tamaño. En el Magdaleniense Medio este débitage se aplica en la fabricación de hojas y hojitas, en un proceso continuo.

b) El débitage convergente se emplea en el Magdaleniense Inferior para las hojitas grandes y rectilíneas. En el Magdaleniense Medio es un método de obtención tanto de hojas (aunque sólo se ha constatado en un conjunto: Abauntz, nivel E) como de hojitas de distinto tamaño.

En ambos casos se trata de una explotación unipolar, con un plano de percusión que es muy oblicuo en el débitage convergente. Este último se caracteriza además porque tiene un volumen piramidal, con la tabla de extracciones bastante estrecha, aspecto que se conserva a lo largo del proceso de talla mediante un auto-mantenimiento del débitage a partir del plano de percusión. En el transcurso de este mantenimiento se 
pueden extraer "hojas de flanco", así como hojas unipolares y convergentes; la preparación de las extracciones es cuidadosa, procediéndose a una regularización frecuente del frente de percusión. Este tipo de explotación permite la obtención de hojas y hojitas rectilíneas y de gran regularidad. Se podría decir que es el método más cuidadoso y útil para la producción de soportes laminares de buena factura.

Este débitage convergente nos recuerda bastante al esquema prismático-A definido para El Espertín, especialmente por el volumen piramidal del núcleo, la tendencia convergente del sentido de las extracciones, la preparación cuidadosa prestada a la preparación del núcleo y de las extracciones, el avance frontal, y la obtención de hojas y hojitas de buena regularidad.

Con relación al débitage semi-envolvente, en algunos casos nos recuerda a una variante de nuestro esquema primático-A cercana al prismático-B, ya que los núcleos son de tendencia piramidal, pero con la diferencia de que los flancos no juegan un papel restrictivo, sino que el progreso de las extracciones, al ser envolvente, tiende a avanzar hacia los laterales del núcleo, aunque en forma de tablas yuxtapuestas. En otros casos podría estar más cercano al esquema prismático-B (prismático unipolar), especialmente en los núcleos de hojas. Recordemos, a este respecto, que este esquema no tiene la rigidez técnica del anterior, aspecto que también comparte con el semi-envolvente.

En el estudio realizado por M. Lloret (2001) sobre la secuencia del Magdaleniense Superior/Final-Aziliense de la cueva de La Pila, no se menciona tampoco de forma específica la estructura prismática, pero este esquema se sobreentiende de forma tácita para el débitage de hojitas y hojas medianas. En la producción de estos soportes se utilizan volúmenes piramidales con una dirección de talla unipolar predominante. Un aspecto muy interesante en este trabajo es que se produce a lo largo de esta secuencia un cambio en los métodos de producción laminares, ya que aparece en el Magdaleniense Final el denominado débitage tournante (lo cual podría equipararse a nuestro envolvente o semi-envolvente).

Este esquema definido por Lloret (2001), de una estructura con volumen piramidal, unipolar y con avance frontal en el Magdaleniense Superior/Final y semienvolvente en el Aziliense; puede recordarnos al esquema prismático-A determinado en 
nuestro yacimiento. Parece que esta estructura es muy apropiada, como también se ha identificado en El Espertín, para la producción de hojitas y hojas pequeñas, rectilíneas, de calidad bastante buena, especialmente en el método frontal.

\section{V.4.4.4.- LAS CADENAS DE LASCAS}

En el Paleolítico Superior y en épocas posteriores sigue existiendo una producción de lascas al lado de la explotación laminar (Cazals, 1999), si bien su estudio y tratamiento ha sido muchas veces obviado. No es raro encontrar en el inventario de los conjuntos líticos de los yacimientos de estos períodos la presencia de núcleos caracterizados como discoides, amorfos, etc. que bien pudieran corresponder a esquemas de producción específica de lascas ${ }^{40}$. Además, en los tipos de útiles fabricados se utilizan, en distinto grado, lascas como soporte. No obstante está presente siempre el problema de que tales lascas pueden pertenecer a procesos laminares, por lo que habría que valorar en cada caso si existe en el conjunto una producción laminar exclusiva o una producción mixta.

La escasa entidad o importancia que a veces se le concede a las cadenas operativas de objetivo-tipo-lasca, en los conjuntos líticos posteriores al Paleolítico Medio, puede deberse al hecho, que se ha comentado ya, de que frecuentemente son esquemas de estructura "simple", adaptados a las características morfotécnicas de los bloques disponibles. Desde luego, parece que el nivel de complejidad y variedad operativa en relación con los esquemas de débitage de lascas desarrollados en el Paleolítico Medio, no está presente en épocas posteriores, si bien este factor no es suficiente para negar la presencia de estos esquemas de lascas acompañando frecuentemente a las cadenas laminares (que son las que se van a sufrir un desarrollo y diversificación más importante). Incluso existe la controversia de si los esquemas de

${ }^{40}$ En la Cornisa Cantábrica especialmente parece que la producción de lascas ha sido bastante importante a lo largo de todo el Paleolítico Superior, al lado de una producción de hojitas y hojas pequeñas, más que de hojas incluso. Se ha constatado la presencia de una producción independiente de lascas a partir de análisis tecnológicos desarrollados en estos últimos años en varios periodos superopaleolíticos, así por ejemplo en el Auriñaciense (en la cueva del Castillo [Cabrera et al., 1997; Cabrera et al., 2001]), en el Magdaleniense Inferior (Cazals, 2000) o en el Magdaleniense Superior, Final y Aziliense (Lloret, 2001). 
estructura "simple" han de considerarse como esquemas en el ámbito conceptual con entidad plena.

Se ha esbozado también que, algunos de estos métodos al menos, podrían considerarse como arquetipos de explotación de unos volúmenes o materias concretos. Una explotación de este estilo podría tildarse, por tanto, de oportunista, en tanto que aprovecha de forma inmediata y rápida unas formas determinadas.

Como consecuencia de este planteamiento, hay que observar dos aspectos en torno a los débitages de lascas de estructura simple:

i) Pueden ser arquetipos de explotación de una materia con una morfología concreta (por ejemplo cantos rodados, placas, etc.), y por tanto es factible que aparezcan en distintos contextos crono-culturales, por un fenómeno de convergencia técnica.

ii) Una presencia intensa de este tipo de explotación puede ser indicio de un comportamiento de tipo oportunista, y este rasgo sí puede conllevar una implicación de carácter cultural más fuerte que el aspecto anterior.

En relación con este último punto, y centrándonos en el Epipaleolítico / Mesolítico, hay que hacer notar que a veces aparecen cadenas de explotación de lascas de estructura simple en este tipo de conjuntos. No hay que olvidar que es un periodo caracterizado (sobre todo en sus fases iniciales) por una intensificación del aprovechamiento de los recursos locales. Por tanto este tipo de comportamiento oportunista encajaría dentro del carácter general de esta época.

Dentro de los esquemas de lascas, uno de los más habituales es el centrípeto/discoide, pero también hay otros, tanto de tipo más expeditivo u oportunista, como más elaborados.

\section{V.4.4.4.1.- CADENA CENTRÍPETA/DISCOIDE}

Tal y como se ha comentado, el esquema centrípeto/discoide está presente no solo en el Paleolítico Medio, sino que perdura a lo largo del Paleolítico Superior y 
posteriormente. No se va a abordar la problemática en torno a los métodos centrípeto/discoide ya que tan solo se pretende exponer el tipo de método presente en este yacimiento.

La cadena centrípeta documentada en El Espertín se concreta en un esquema que explota dos superficies secantes a partir de la arista del contorno, el avance del débitage se produce de forma centrípeta y alternando las superficies de aprovechamiento según las necesidades del propio avance de la talla. No habría una preparación concienzuda de una de las superficies para que tenga una función preponderante. Una cadena así estaría en la línea de los esquemas discoides de Boëda, aunque no vamos a abordar el complejo tema de los débitages discoide y Levallois centrípeto porque no tendría ninguna relación con nuestro caso concreto. Lo que sí querríamos que quedase claro es que el esquema que se ha localizado en nuestro yacimiento entroncaría con este tipo de esquemas que tienen una amplia tradición en el Paleolítico y que tienen por objetivo la explotación de un núcleo estructurado en forma de dos superficies más o menos convexas que convergen en una arista, y que dicha arista circundante es el frente de percusión. Sería distinto a los esquemas Levallois, ya que éstos tienen una preparación cuidadosa de una de estas superficies, que será la preferente; y se trataría por tanto de una forma de débitage de tipo simple, rápido y normalmente adaptado al volumen del nódulo de origen.

Un esquema así planteado ha tenido problemas para su definición, o más bien para su denominación, debido al desarrollo que este tipo de cadenas ha alcanzado en el Paleolítico Medio. También parece a veces arriesgado utilizar el nombre de esquemas definidos sobre industrias determinadas en culturas o tecno-complejos (o la categoría de entidad que tratemos) de una cronología y ubicación determinados para otras industrias que pertenezcan a grupos cronológicamente posteriores.

El esquema centrípeto determinado en nuestro yacimiento pertenece al grupo de las cadenas que explotan un núcleo construido sobre dos superficies secantes, a partir de la arista del contorno. Entronca a su vez con la tradición de esquemas de débitage de lascas desarrollado a lo largo de todo el Paleolítico y, desde este punto de vista, dado que parece que es una manera de débitage más o menos recurrente a lo largo del tiempo, 
quizás se trate de un arquetipo operativo a la hora de explotar fácilmente unos nódulos a partir de la arista de su contorno.

El "débitage facial" (con dos modalidades) determinado por N. Cazals (2000) en el Magdaleniense Inferior podría corresponderse, al menos en alguno de métodos, al presente en "El Espertín", ya que consiste en la explotación de la superficie de un núcleo a partir de la arista de su contorno. El denominado "débitage de grandes lascas yuxtapuestas", identificado en Las Caldas y aplicado además en cuarcita, es el que podría estar más cercano al esquema de nuestro yacimiento, ya que es más expeditivo que la otra modalidad, denominada "débitage de lascas finas superpuestas" hacer notar además, que no hay en El Espertín una intencionalidad determinada hacia un tipo de soporte concreto, el esquema centrípeto es simple, encaminado a la obtención rápida e inmediata de algunas lascas cuyo uso no es específico (al menos no para la realización de tipos demasiado elaborados).

M. Lloret (2001) también identifica en La Pila una cadena centrípeta para la producción de lascas de cuarcita en el Magdaleniense Superior.

Hay más ejemplos de esquemas de tipo centrípeto/discoide en otros contextos de cronología mesolítica, los ya mencionados de los yacimientos Mesolíticos de los Pirineos orientales, datados en torno al IX milenio BP (Terradas, 1995; e.p.) así como en la Cornisa Cantábrica (Arias, 1991).

\section{V.4.4.4.2.- OTROS PROCESOS OPERATIVOS PARA LA OBTENCIÓN DE LASCAS}

Aparte del esquema centrípeto/discoide, la producción de lascas se puede ejecutar mediante otros esquemas, muchos de los cuales son de tipo más expeditivo. En la bibliografía suelen denominarse bajo términos genéricos, que describen muchas veces, más la morfología del soporte obtenida (por ejemplo: “método para la obtención de lascas grandes y gruesas" [Cazals, 2000]) que el esquema de talla propiamente dicho. Es cierto también que muchas veces este tipo de procesos es de carácter muy inmediato

${ }^{41}$ Identificada en este caso en Erralla, nivel V. Se trata de un esquema más elaborado, sobre nódulos de sílex, su objetivo es producir lascas finas, sobre una superficie aplanada que permita una pequeña serie de extracciones superpuestas. 
y oportunista, como sucede también en El Espertín. En estos casos es cuando más se aplica el concepto de "fórmulas" inmediatas aplicadas a casos más o menos concretos, ya que es difícil determinar el concepto volumétrico del bloque.

Si nos centramos en la Cordillera Cantábrica, en el Magdaleniense Inferior la producción de lascas tiene un gran peso en el proceso de talla al lado de la de hojitas (por el contrario la presencia de hojas es muy escasa). N. Cazals (2000) ha identificado varios esquemas de producción de lascas, incluso con objetivos distintos: un débitage poliédrico para la obtención de lascas gruesas, un débitage facial (de tipo centrípeto o discoide) para lascas finas, además de otras modalidades o fórmulas más difíciles de concretar. En los periodos en los que la producción de lascas no es definitoria (Magdaleniense Medio, Superior, etc.), siguen apareciendo ocasionalmente núcleos de lascas.

Un rasgo que llama la atención en el Epipaleolítico/Mesolítico es la frecuente presencia de una producción de lascas en conjuntos donde este tipo de soportes va a tener una presencia bastante destacada. No cabe duda de que para la Cornisa Cantábrica el ejemplo más claro a este respecto lo aporta el Asturiense; en esta facies litoral del Mesolítico, la presencia de hojas y hojitas es muy baja, mientras que los artefactos retocados sobre lasca, así como los útiles nucleares, la mayoría en cuarcita, van a ser los elementos más abundantes. Desde el análisis realizado por G. A. Clark (1976), pasando por el de M. R. González Morales (1982), hasta el de P. Arias (1991) sobre varias series de conjuntos líticos asturienses, se observa un predominio de las lascas en los productos de talla, así como de los núcleos de lascas (discoides, indeterminados, mixtos, etc.), restringiéndose las hojas y hojitas a aparecer de forma testimonial y, sobre todo, entre las piezas retocadas. P. Arias (1987) identifica un tipo de núcleo en unas piezas tradicionalmente definidas como cantos tallados unifaciales (choppers), se trata del que denomina "núcleo unidireccional con plano de percusión cortical” (NUPC), que es el más abundante en los yacimientos asturienses que analiza. Se trataría de un método muy expeditivo e inmediato sobre una superficie natural (cortical), características que se corresponderían con la gran abundancia de lascas con talón cortical que aparecen entre los restos de talla. 
En los Pirineos Orientales hay una serie de yacimientos en el IX milenio BP en los que la producción de lascas es el aspecto básico en la producción lítica (por ejemplo en Font del Ros, Berga, Barcelona [Terradas, 1995]) o al menos una parte relevante del conjunto industrial, al lado de algunas hojas-hojitas (Terradas, e.p.). Los modelos de explotación de lascas reconocidos en estos yacimientos son tres: i) explotación unipolar de una superficie de extracciones a partir de un único plano de percusión, ii) explotación unipolar alternante de varias superficies de extracciones a partir de varios planos de percusión, y iii) explotación discoide. El segundo podría definirse como una intensificación del modelo primero y en ambos casos se trata de un método muy variable, en función del bloque de materia.

Cabe citar también en este apartado, respecto al Mesolítico de la Península Ibérica septentrional, la presencia del denominado "Mesolítico macrolítico" o "Mesolítico de denticulados", localizado en torno al Valle del Ebro (Cava, 1994; Utrilla et al., 1998; García Martínez de Lagrán, 2001; Alday Ruiz, 2002; Utrilla, 2002). Aunque carecemos de análisis tecnológicos estrictos, las características tipológicas de la industria indican una ausencia de elementos laminares, y por el contrario, un elevado uso de las lascas, especialmente de gran grosor, para la realización de las piezas retocadas, con una gran abundancia en el conjunto retocado de escotaduras y denticulados, así como del retoque denominado "campiñense". Este mesolítico "macrolítico" es una fase del Mesolítico que se ha determinado en la cuenca del Ebro, tanto en su cuenca baja, como en la alta, hacia la zona alavesa, sin que haya aparecido, hasta ahora, en la Cornisa Cantábrica centro-occidental. Se desarrolla en la segunda mitad del IX milenio BP y se trata de una fase que sigue a un mesolítico de carácter "microlítico" entroncado con el aziliense.

Lo que resulta curioso de esta fase macrolítica es el aparente corte que representa en la tradición laminar anterior (caracterizada normalmente como un Epipaleolítico microlítico o Aziloide) y posterior (el Epipaleolítico/Mesolítico Geométrico, que entronca con el Epipaleolítico Geométrico de la vertiente mediterránea definido sobre el modelo de Cocina [Fortea, 1973]). Aún no contamos con estudios tecnológicos de este Mesolítico macrolítico, pero los indicios de su tecnología a partir de sus características tipológicas indican una producción de soportes bastantes gruesos, 
sobre todo lascas, aunque no sabemos a partir de qué tipo de esquemas operativos. Es llamativo también el hecho de que después de esta fase (y coincidiendo también en parte con ella), a partir del 8000 BP aproximadamente aparece el Mesolítico Geométrico, cuya tecnología, a partir de nuevo de los indicios tipológicos, se centra fundamentalmente en una producción laminar elaborada, encaminada a la obtención de hojas que permitan realizar los geométricos.

\section{V.4.4.5.- LAS LASCAS-NÚCLEO}

En el yacimiento de El Espertín aparecen algunas lascas-núcleo, aunque en un pequeño número de ejemplares. La presencia de este tipo de soportes es relativamente común en distintos conjuntos industriales, pero en nuestro caso concreto no constituyen per se una cadena operativa diferenciada ni ningún esquema peculiar. El uso de las lascas como núcleos en este yacimiento se inscribe totalmente dentro de las cadenas determinadas y hay que resaltar el hecho de que aparecen dos formas de explotación, en dos esquemas operativos distintos: el prismático-A y el de superficie ancha.

El uso de lascas (normalmente de buen tamaño) como núcleos para la obtención de otros elementos de débitage se produce de forma recurrente en distintos contextos cronológicos y culturales, y su presencia parece que se debe a un aprovechamiento de las características técnicas de las lascas para unos fines inmediatos variados (lascas y hojitas fundamentalmente) y por un fenómeno de convergencia técnica (Newcomer \& Hivernel-Gerre, 1974; Tixier \& Turq, 1999).

Siguiendo la clasificación de Tixier y Turq (1999), en nuestro yacimiento los modos de explotación de lascas-núcleo presentes son el "mode 1", o explotación del volumen inferior, y el "mode 4", o explotación del espesor (tipo buril). En ambos casos sin embargo la modalidad operativa presente en El Espertín no se adscribe estrictamente a los métodos empleados de forma más común en estos “modes". En el "mode 1" el método paradigmático es el kombewa, y en el "mode 4" la explotación tipo buril. Lo que es importante en este yacimiento es que el tratamiento de estas lascas-núcleo encaja totalmente en los esquemas presentes, no constituyendo una forma particular de explotación de dichas lascas. 
La presencia de estas lascas-núcleo, en dos esquemas distintos, se adecua dentro del comportamiento operativo con el que se aborda la industria lítica en este yacimiento en general. En efecto aquí los bloques, soportes o, en general, el material disponible, son aprovechados de forma inmediata y eficaz, pero dentro de los parámetros técnicos establecidos. Las dos modalidades en que aparecen las lascas-núcleo se articulan en sus esquemas operativos respectivos, por lo que no hay una voluntad previa de una producción de lascas grandes para un tratamiento específico en la producción de ciertos soportes, sino que la presencia de dichas lascas de módulo grande es aprovechada ocasionalmente para aplicar las distintas modalidades operativas.

Esta ausencia de una modalidad operativa peculiar en el tratamiento de las lascas-núcleo quizás pueda ponerse en relación con un aspecto observado por M. Lloret (2001) respecto al paso entre el Magdaleniense Superior/Final y el Aziliense. Esta investigadora observa que en el Magdaleniense Superior están presentes las lascasnúcleo (para la producción de lasquitas), pero tienden a desaparecer en el Aziliense (donde los ejemplos observados son para la producción de hojitas).

En cuanto al motivo de la existencia de estas lascas grandes, no hay constancia de su producción intencional. Es posible que sean el resultado de secuencias de prueba de bloques de gran tamaño o bien de un fraccionamiento de tales nódulos con el fin de facilitar su talla, o también cabe la posibilidad de que pertenezcan a una fase de conformación de otros núcleos (serían entonces lascas de preparación, pertenecientes a la fase 1 de una cadena laminar). 
CAPÍTULO VI -

CONCLUSIONES 

Las características de índole técnica de la industria lítica de El Espertín constituyen el propósito fundamental de este análisis. En el capítulo precedente se han expuesto en detalle los principales resultados a este respecto, ahora se van a esquematizar los rasgos más genéricos de la industria lítica:

- La estrategia de adquisición de las materias líticas es mayoritariamente de tipo local e intensivo (las materias locales más abundantes en el entorno son las más numerosas en el yacimiento: el chert negro y la cuarcita).

- La estrategia de explotación de las distintas materias varía en función de la abundancia y/o cercanía de éstas:

a) En las materias locales más abundantes (chert negro, cuarcita) se produce una explotación de tipo extensivo y con objetivo mixto (lascas y hojas/hojitas).

b) En las materias autóctonas menos numerosas (radiolarita y sílex gris, seguramente localizadas a mayor distancia que las anteriores) se produce una explotación de tipo intensivo y especializado en la producción laminar tanto de hojas como de hojitas.

c) En las materias más alejadas y/o de carácter “exótico” (sílex varios) la especialización microlaminar es más acusada, existiendo una ruptura en la cadena operativa, de manera que sólo aparece en el yacimiento la fase de uso y abandono de los útiles (sobre todo elementos de dorso y geométricos); es decir serían el testimonio de útiles que se habrían fabricado en otro lugar y que llegarían como productos acabados (posiblemente enmangados en puntas de proyectil, flechas, etc.).

d) Sobre el cuarzo hay un proceso de talla peculiar y distinto al resto de las materias. Es poco abundante, con huellas de haber sufrido un proceso de transformación y retoque, pero con ausencia del grueso de esas piezas retocadas o conformadas. No tenemos reflejadas todas las fases del proceso, estando ausente el uso y abandono de los soportes retocados. 
- Se constata una actividad de talla abundante en el yacimiento, con tres cadenas operativas identificadas, una de objetivo laminar y las otras dos con objetivo tipolasca:

- Las cadenas de lascas (un esquema conceptual centrípeto y otro que hemos denominado de tipo-nódulo-placa) se aplican sobre las materias que han sufrido un proceso más extenso y que son más abundantes, es decir el chert negro y la cuarcita.

- La cadena laminar es el esquema operativo prismático-unipolar y se aplica sobre todas las materias (con la excepción que ya se ha comentado del cuarzo), por tanto tiene una gran flexibilidad, que se concreta en tres procesos operativos.

- Las cadenas de lascas tienen unas estructuras de explotación muy simples, vinculadas a la morfología del nódulo en cuestión. Este tipo de explotación podría calificarse de oportunista, debido a que se trata de un aprovechamiento inmediato y rápido de unos volúmenes concretos y sobre unas materias muy numerosas en el entorno inmediato.

- Tales cadenas de lascas podrían corresponder a ARQUETIPOS de explotación de unos núcleos con una morfología determinada (cantos fluviales y nódulos en forma de placas).

- La cadena operativa de estructura prismática-unipolar tiene tres modalidades: i) esquema operativo de tipo prismático “típico” propiamente dicho, ii) de superficie ancha y iii) unipolar-prismático.

- A pesar de ser una cadena elaborada, la cadena prismática tiene un matiz oportunista, visible sobre todo en la fase de selección y preparación del núcleo, ya que hay un aprovechamiento recurrente de la morfología original de los nódulos, tanto para la orientación del núcleo, como para el inicio del débitage, en el que se suelen utilizar las aristas naturales de los bloques de origen (las hojas de encetadura con arista natural por ejemplo). 
- El primer esquema operativo podría corresponder a algunos de los núcleos prismáticos “clásicos” del Paleolítico Superior y se incluyen dos variantes: el esquema prismático-A (de débitage unipolar convergente y frontal, cuyos núcleos característicos son los de tendencia piramidal) y el esquema prismáticoB (de débitage unipolar semi-envolvente, a veces desde dos planos opuestos pero sobre superficies alternas, con unos núcleos prismáticos unipolares o bipolares).

- El esquema prismático-A (de tendencia piramidal) se emplea sobre todo en la producción de hojitas, mientras que el prismático-B aparece más frecuentemente en hojas.

- El esquema operativo de superficie ancha es muy útil para obtener hojas gruesas y lascas laminares de distinto tamaño. Este esquema tiene dos métodos: unipolar y bipolar.

- El esquema operativo unipolar-prismático tiene una estructura prismática y unos objetivos laminares, pero es más oportunista que los anteriores. De hecho podría considerarse como una aplicación rápida del esquema prismático genérico sobre unos nódulos gruesos y cortos. El carácter más oportunista de este esquema recuerda en cierto grado a la cadena de nódulo-placa, y, de hecho, como en esta última, se aplica en las materias más abundantes del conjunto (chert negro y cuarcita).

- En la selección de los soportes para retocar hay, como es lógico, distintos grados de especialización con relación a los distintos tipos de soportes:

- Las hojitas se utilizan casi exclusivamente para los elementos de dorso (hojas y puntas).

- Las hojas tienen un uso diversificado moderado: para piezas de retoque continuo, buriles, truncaduras, geométricos y los restos de la secuencia de retoque de éstos (microburiles, picantes, piezas con escotadura o retoque adyacente a una rotura, quizás algunas escotaduras). 
- Las lascas tienen un uso diversificado más amplio, aparecen en mayor variedad de piezas retocadas y son fundamentales para las piezas “de fondo común”: raspadores, perforadores, buriles, raederas, denticulados, escotaduras, etc.

- Se podría resaltar también que hay unas preferencias dentro de algunas materias primas para tipos retocados concretos, pero sin llegar a hablar de una "gestión de materias primas” estricta:

- La cuarcita para escotaduras, denticulados y raederas

- La radiolarita-1 en los geométricos

- La radiolarita, el sílex gris y los sílex varios en las piezas con dorso

- Respecto a la tipología de las piezas retocadas, predominan las piezas con retoque sobre uno o dos bordes, aunque entre ellas, la mayoría tienen un retoque marginal. A continuación estarían las escotaduras y denticulados, seguidos por los elementos de dorso. Los raspadores son de módulo corto, fabricados sobre lasca la mayoría y hay un buen número de unguiformes. En los buriles predominan los que tienen una confección simple, especialmente los de ángulo sobre rotura. Destaca la presencia de 14 geométricos (6 triángulos, 4 puntas triangulares y 4 trapecios), todos con retoque abrupto. También es reseñable una punta de muesca y una pequeña punta con pedúnculo muy corto.

- En la fabricación de los geométricos hay que destacar, dentro de la fase de retoque, la presencia de dos procedimientos de fractura de la hoja-soporte:

- La técnica de microburil

- La "técnica de rotura transversal”

Como resumen de estas características técnicas, podemos resaltar un rasgo de tipo económico-estratégico, que es la explotación intensiva de las materias locales. Además esta explotación se ejecuta a partir de unos procesos operativos que son a la vez flexibles y eficaces. Flexibles tanto en la variedad de materias que explotan, como en las cadenas operativas desarrolladas, las cuales son aplicadas a tal heterogeneidad material (tanto un chert o radiolarita de una calidad a veces mediocre, como la cuarcita). La eficacia se manifiesta no sólo en la habilidad en el ámbito de capacidad técnica manual (savoir-faire) de los talladores mesolíticos, sino también en la facilidad para 
obtener una serie de soportes predeterminados por los objetivos marcados por su idiosincrasia cultural. Y otro carácter importante de esta tradición cultural es la adaptabilidad y oportunismo con que son capaces de gestionar los objetos líticos de una forma inmediata y práctica, a partir de una variada panoplia de esquemas operativos. 
BIBLIOGRAFÍA 

(1945). Mapa E: 1:50.000, Hoja $n^{o}$ 54, Rioseco. Dirección general del Instituto Geográfico y Catastral.

Águeda Villar, J.; Anguita Virella, F.; Araña Saavedra, V.; López Ruiz, J. y Sánchez de la Torre, L. (1983). Geología (2ª edición). Madrid, Editorial Rueda.

Aime, G. et Thevenin, A. (Dir.) (1989). Epipaléolithique et Mésolithique entre Ardennes et Massif Alpin. Table Ronde de Besançon. Mémoire de la Société d'Agriculture, Lettres, Sciences et Arts de la Haute-Saône.

Alday Ruiz, A. (1997). "El yacimiento prehistórico de Kanpanoste Goikoa (Alava). Análisis industrial de los útiles sobre sílex y caracterización cronológicocultura”. Munibe, 49: 3-50.

Alday Ruiz, A. (1998). El depósito prehistórico de Kanpanoste Goikoa (Vírgala. Alava). Memoria de las actuaciones arqueológicas. 1992 y 1993. Vitoria, Diputación Foral de Alava.

Alday Ruiz, A. (1999). "Dudas, manipulaciones y certezas para el Mesoneolítico vasco.” Zephyrus, 52: 129-174.

Alday Ruiz, A. (2000). “El Neolítico en el País Vasco: pensando la marginalidad”. Neolitizaçao e Megalitismo da Península Ibérica. Actas do $3^{\circ}$ Congresso de Arqueologia Peninsular (Vila Real, Portugal, setembro de 1999), volumen III. Porto, ADECAP: 97-113.

Alday Ruiz, A. (2002a). "Las unidades industriales mesolíticas en la alta-media cuenca del Ebro.” Complutum, 13: 19-50.

Alday Ruiz, A. (2002b). "Los últimos cazadores-recolectores de la Iberia interior: La Alta-Media Cuenca del Ebro y la Meseta Norte”. Munibe, 54: 79-101.

Alix, P.; Pelegrin, J. et Deloge, H. (1995). "Un débitage original de lamelles par pression au Magdalenien du Rocher-de-la-Caille (Loire, France)”. Paléo, 7: 187199.

Alonso Herrero, E. (1995). “Litología y Geomorfología”. En Atlas del medio natural de la provincia de León. Madrid, ITGE y Diputación de León: 11-18.

Alvargonzález Rodríguez, R. (1997). "El medio natural de Asturias”. En Asturias, Montes y Valles. Agedime S.L., Editorial Mediterráneo: 9-20.

Apellániz, J. M. y Altuna, J. (1975). “Excavaciones en la Cueva de Arenaza I ( S. Pedro de Galdames, Vizcaya). $1^{\text {a }}$ campaña, 1972. Neolítico y Mesolítico Final”. Noticiario Arqueológico Hispánico. Prehistoria, 4: 121-146.

Aramburu, C. y Bastida, F. (Eds.) (1995). Geología de Asturias. Gijón, Ediciones Trea, S.L. 
Arias Cabal, P. (1987). “Acerca de la clasificación de un tipo de cantos tallados postpaleolíticos de la Región Cantábrica”. Veleia, 4: 99-118.

Arias Cabal, P. (1990). "Utilisation diffèrentiale des variétes de silex au Chalcolothique dans les Asturias Orientales (Espagne)”. En L. Sèronie-Vivien et M. Lenoir (Ed.): Le silex, de sa genèse à l'outil. Cahiers du Quaternaire $n^{0} 17$. Tome II. Paris, Editions du CNRS. Centre régional de publication de Bordeaux: 449-452.

Arias Cabal, P. (1991a). De cazadores a campesinos. La transición al Neolítico en la región cantábrica. Santander, Servicio de publicaciones de la Universidad de Cantabria - Asamblea Regional de Cantabria. 371 p.

Arias Cabal, P. (1991b). "Estrategias de aprovechamiento de las materias primas líticas en la costa oriental de Asturias (VIII-VII milenio a.C.)”. En R. Mora, X. Terradas, A. Parpal y C. Plana (Eds.): Tecnología y cadenas operativas líticas. Reunión Internacional, 15-18 enero de 1991. Treballs d'Arqueologia, 1. Bellaterra (Barcelona), Universidad Autónoma de Barcelona: 37-55.

Arias Cabal, P. (1992). "Estrategias económicas de las poblaciones del Epipaleolítico avazado y el Neolítico en la Región Cantábrica”. En A. Moure (Ed.): Elefantes, ciervos y ovicaprinos: economía y aprovechamiento del medio en la prehistoria de España y Portugal. Santander, Universidad de Cantabria: 163-184.

Arias Cabal, P. (1996). "La comarca de los Picos de Europa en la Prehistoria”. En M. Estrada Sánchez y M. A. Sánchez Gómez (Eds.): La Liébana. Una aproximación Histórica: 33-58.

Arias Cabal, P. (1997). “¿Nacimiento o consolidación?. El papel del fenómeno megalítico en los procesos de Neolitización de la Región Cantábrica”. En A. Rodríguez Casal (Ed.): O Neolítico Atlántico e as orixes do Megalitismo. Actas do Coloquio internacional, Santiago de Compostela, 1-6 de Abril de 1996: 371389.

Arias Cabal, P. (1999). "La colonisation Holocène des Monts Cantabriques (Espagne): Le cas de la Région des Picos de Europa”. En P. Bintz et A. Thevenin: L'Europe des derniers chasseurs, Epipaléolithique et Mésolithique. $5^{\circ}$ Colloque international UISPP, Grenoble, 18-23 septembre 1995. CTHS: 18-23.

Arias Cabal, P., Altuna, J.; Armendáriz, A.; González Urquijo, J.E.; Ibáñez Estévez, J.J.; Ontañón Peredo, R. y Zapata, L. (1999). "Nuevas aportaciones al conocimiento de las primeras sociedades productoras en la región Cantábrica”. En II Congrés del Neolític a la Península Ibèrica, Valencia 7-9 abril 1999. Saguntum, PLAV-extra 2: 549-557.

Arias Cabal, P., Altuna, J.; Armendáriz, A.; González Urquijo, J.E.; Ibáñez Estévez, J.J.; Ontañón Peredo, R. \& Zapata, L. (2000). "La transición al Neolítico en la región cantábrica. Estado de la cuestión”. Neolitizaçao e Megalitismo da Península Ibérica. Actas do $3^{\circ}$ Congresso de Arqueologia Peninsular (Vila Real, Portugal, setembro de 1999), volumen III. Porto, ADECAP: 115-133. 
Arias Cabal, P. y Pérez Suárez, C. (1990). "Las excavaciones en la cueva de Los Canes y otros trabajos en la Depresión Prelitoral del Oriente de Asturias (1981-1986)”. Excavaciones Arqueológicas en Asturias 1983-1986: 135-141.

Arias Cabal, P. y Pérez Suárez, C. (1990). "Investigaciones prehistóricas en la Sierra Plana de la Borbolla (1979-1986)”. Excavaciones Arqueológicas en Asturias 1983-186: 143-151.

Arias Cabal, P. y Pérez Suárez, C. (1992). "Las excavaciones arqueológicas de la Cueva de los Canes (Arangas, Cabrales). Campañas de 1987 a 1990”. Excavaciones Arqueológicas en Asturias 1987-1990: 95-101.

Arias Cabal, P. y Pérez Suárez, C. (1992). "Sondeo estratigráfico en la Cueva del Tiu LLines (Arangas, Cabrales)”. Excavaciones Arqueológicas en Asturias 19871990: 103-104.

Arias Cabal, P. y Pérez Suárez, C. (1995). "Excavaciones arqueológicas en Arangas, Cabrales (1991-1994). Las cuevas de los Canes, El Tiu Llines y Arangas”. Excavaciones Arqueológicas en Asturias 1991-1994: 79-92.

Audouze, F.; Karlin, C.; Cahen, D.; de Croisset, D., Coudret, P.; Larrierre, M.; Massob, P.; Mauger; Olive, M.; Pelegrin, J.; Pigeot, N.; Plisson, H.; Schmider, B.; Taborin, Y. (1988). "Taille du silex et finalité du débitage dans le Magdalenien du Bassin parisien”. De la Loire à l'Oder. Les civilisations du Paléolithique final dans le nord-ouest européen. Actes du Colloque de Liège, décembre 1985, vol. I. BAR International Series 444(i): 55-84.

Aura Tortosa, J. E. y Pérez Ripoll, M. (1995). "El Holoceno inicial en el Mediterráneo español (11.000-7.000 BP). Características culturales y económicas”. En V. Villaverde Bonilla (Ed.): Los últimos cazadores. Transformaciones culturales y económicas durante el Tardiglaciar y el inicio del Holoceno en el ámbito mediterráneo. Alicante, Instituto de Cultura Juan Gil Albert: 119-146.

Balfet, H. (1991). “Des chaînes opératoires, pour quoi faire?”. En H. Balfet (Ed.): Observer l'action techniques des chaînes opèratoires, pour quoi faire?. Paris, CNRS: 11-19.

Barandiarán Maestu, I. y Cava, A. (1985). “Las industrias líticas del epipaleolítico y del neolítico en el Bajo Aragón”. Bajo Aragón, Prehistoria, V: 49-85.

Barandiarán, I. y Cava, A. (1989). "The Evolution of the Mesolithic in the North East of the Iberian Peninsula”. En C. Bonsall (Ed.): The Mesolithic in Europe. Papers presented at the third International Symposium, Edinburgh. J. Donald publ.: $572-581$

Barandiarán, I. y Cava, A. (1989). El yacimiento prehistórico de Zatoya (Navarra). Trabajos de Arqueología Navarra, 8. Pamplona, Dirección General de Cultura, Institución Príncipe de Viana. 
Barandiarán, I. y Cava, A. (1989). La ocupación prehistórica del Abrigo de Costalena (Maella, Zaragoza). Colección Arqueología y Paleontología, 6. Serie Arqueología aragonesa, monografías 1. Diputación General de Aragón.

Barandiarán, I. y Cava, A. (1992). “Caracteres industriales del Epipaleolítico y Neolítico en Aragón: su referencia a los yacimientos levantinos”. En P. Utrilla (Coord.): Aragón/Litoral Mediterráneo: Intercambios culturales durante la Prehistoria. Zaragoza, Institución Fernando el Católico: 181-196.

Barandiarán, I.; Freeman, L. G.; González Echegaray, J. y Klein, R. G. (1985). Excavaciones en la cueva del Juyo. Centro de Investigación y Museo de Altamira, Monografías n ${ }^{0} 14$. Madrid, Ministerio de Cultura. 224 p.

Barba, P.; Bahamonde, J.R.; Rodríguez Fernández, L.R.; Colmenero, J.R. y Fernández, L.P. (1991). "Estratigrafía”. En Memoria explicativa del Mapa Geológico de España, E. 1:50.000 n 80 (Burón). Madrid, ITGE: 10-70.

Barbaza, M.; Valdeyron, N.; Andre, J.; Briois, F.; Martin, H.; Philibert, S.; Allios, D. et Lignon, E. (1991). Fontfaurès en Quercy. Contribution à l'étude du sauveterrien. Toulouse, Ecole des Hautes Etudes en Sciences Sociales.

Barbaza, M. (1999). Les civilisations postglaciaires. La vie dans la grande forêt tempérée. Coll. Histoire de la France Préhistorique. De -10.000 à -5.000 ans. Paris, La Maison des Roches.

Basalla, G. (1994). La evolución de la tecnología. De los útiles de piedra al molino hidráulico; de la máquina de vapor al turborreactor: un estudio de los factores que han generado el cambio tecnológico en la histoira. Barcelona, RBA editores.

Bastida, F. y Aller, J (1995). “Rasgos geológicos generales”. En C. Aramburu y F. Bastida (Eds.): Geología de Asturias. Gijón, Ediciones Trea, S.L.: 27-34.

Berganza, E. (1990). “El Epipaleolítico en el País Vasco”. Munibe, 42: 81-89.

Bergman, C. A.; Barton, R. N. E.; Collcutt, S. N. and Morris, G. (1987). "Intentional breakage in a late Upper Palaeolithic assemblage from southern England”. En The human use of flint and chert. Proceedings of the fourth international flint Symposium. Cambridge University Press: 21-32.

Bernabeu, J.; Orozco, T. y Terradas, X. (eds.) (1998). Los recursos abióticos en la prehistoria. Caracterización, aprovisionamiento e intercambio. Col.lecció Oberta. Sèrie Història. 2. Universitat de València. 188 p.

Bernaldo de Quirós, F. (1980). Notas sobre la economía del Paleolítico Superior. Centro de Investigación y Museo de Altamira, Monografías $\mathrm{n}^{\circ} 1$. Santander, Ministerio de Cultura. 44 p. 
Bernaldo de Quirós, F. (1982). Los inicios del Paleolítico Superior Cantábrico. Centro de Investigación y Museo de Altamira, Monografías $n^{\circ}$ 8. Madrid, Ministerio de Cultura. 347 p.

Bernaldo de Quirós, F. (1995). “Tecnología”. En J. González Echegaray (Ed.): 10 palabras clave en Prehistoria. Estella, Editorial Verbo Divino: 135-166.

Bernaldo de Quirós, F.; Cabrera, V.; Cacho, C. y Vega, L. G. (1981). "Proyecto de análisis técnico para las industria líticas”. Trabajos de Prehistoria, 38: 9-37.

Bernaldo de Quirós, F. y Cabrera Valdés, V. (1996). "Raw material in the Palaeolithic of Cueva del Castillo and in the Cantabrian region”. En Moloney, N.; Raposo, L. \& Santonja, M. (Eds.): Non-Flint Stone Tools and the Palaeolithic Occupation of the Iberian Peninsula. BAR International Series, 649. Oxford: 37-41.

Bernaldo de Quirós, F. y Neira, A. (1992). "Mountain occupation sites in the Cantabrian Range (Spain)”. Preistoria Alpina, 28: 49-58.

Bernaldo de Quirós, F. y Neira, A. (1993). "Paleolítico Superior Final de Alta Montaña en la Cordillera Cantábrica (noreste de León)”. Pyrenae, 24: 17-22.

Bernaldo de Quirós, F. y Neira Campos, A. (1999). “Prehistoria”. En VVAA: La Historia de León. Volumen I. León, Universidad de León y Diario de León: 15114.

Bernaldo de Quirós, F.; Neira Campos, A. y Fernández Rodríguez, C. (1997). "Panorama del Paleolítico Superior y Epipaleolítico en el Norte de la Cuenca del Duero”. En: II Congreso de Arqueología Peninsular, Zamora, del 24 al 27 de Septiembre de 1996. Tomo I: Paleolítico y Epipaleolítico. Fundación Rei Afonso Henriques: 367-382.

Binder, D. (1984). "Systèmes de débitage laminaire par pression: exemples chasséens provençaux”. En Préhistoire de la pierre taillée, 2: économie du débitage laminaire: technologie et expérimentation. III table ronde de technologie lithique, Meudon-Bellevue, octobre 1982. Paris, CREP: 71-84.

Binder, D. (1986). "Economie des matiéres dans le néolothique moyen de Giribaldi (Nice).” BSPF, 83(3): 71.

Bintz, P. et Thevenin, A. (Eds.) (1999). L'Europe des derniers chasserus. Epipaléolithique et Mésolithique. Actes du 5e Colloque International UISPP, Commission XII, Grenoble, 18-23 septembre 1995. CTHS.

Boboeuf, M. (1998). "Les Mésolithiques sauveterriens de la Vayssière (Aveyron). Production lithiques et comportements”. B.S.P.F., 95(4): 475-503.

Boëda, E. (1988). "Le concept laminaire: rupture et filiation avec le concept Levallois”. En L'Homme de Néandertal. 8, La Mutation. Actes du Colloque, Liège, 1988: 41-59. 
Boëda, E. (1990). "De la surface au volumen. Analyse des conceptions des débitages levallois et laminaire”. En C. Farizy (Dir.): Paléolithique moyen récent et Paléolithique supérieur ancien en Europe. Actes du colloque international de Nemours, 9-11 mai 1988. Mémoires du Musée de Préhistoire d'Ile-de-France, 3: 63-68.

Boëda, E. (1991a). “Approche de la variabilité des systèmes de production lithique des industries du Paléolithique inférieur et moyen: chronique d'une variablité attendue”. Tecniques et Culture, 17/18: 37-79.

Boëda, E. (1991b). “Le débitage discoide et le débitage Levallois Récurrent cetripète”. B.S.P.F. 90(6): 392-404.

Boëda, E. (1994). Le concept Levallois: variabilité des méthodes. Paris, CNRS Éditions.

Boëda, E. (1997). Technogenèse de systèmes de production lithique au Paléolithique inférieur et moyen en Europe Occidentale et au Proche-Orient. 2 vol. Habilitation à diriger des recherches. Université de Paris-X-Nanterre.

Boëda, E., Geneste, J.-M. \& Meignen, L. (1990). "Identification de chaines operatoires lithiques du Paleolithique ancien et moyen”. Paléo, 2: 43-80.Boëda, E. (1991). "Approche de la variabilité des systèmes de production lithique des industries du Paléolithique inférieur et moyen: chronique d'une variablité attendue.” Tecniques et Culture, 17/18: 37-79.

Bon, F. (1998). "Réflexions sur les productions laminaires et lamellaires aurignaciennes à travers l'étude de quelques séries des Pyrénées françaises”. En N. Cazals (Dir.): Comportements techiques et éconimiques des sociétés au Paléolthique Supérieur dans le contexte pyrénéen. Apports de la technologie lithique (Production laminaire et lamellaire), Rapport du P.C.R. N. D. Cazals, SRA Midi-Pyrénées et UMR ArScAn: 20-31.

Bonsall, C. (Ed.) (1989). The Mesolithic in Europe. Papers presented at the third International Symposium, Edinburgh.

Bordes, F. (1947). "Etude comparative des différentes techniques de taille du silex et des roches dures”. L'Atrhropologie, 51: 1-29.

Bordes, F. (1967). "Considerations sur la typologie et les techniques dans le Paléolithique”. Quartär, 18: 25-55.

Bordes, F. (1968). La question périgordienne. En La Préhistoire: problèmes et tendances. Paris, Éditions du CNRS: 59-70.

Bordes, F. (1979). Typologie du Paleolithique Ancien et Moyen. Cahiers du Quaternaire, 1. Paris, Éditions du C.N.R.S. $3^{\text {a }}$ edición.

Bordes, F. (1980). “Question de contemporanéité: l'illusion des remontages.” B.S.P.F., 77(5): 132-133. 
Bordes, F. et Crabtree, D. (1969). "The Corbiac blade technique and other experiments”. Tebiwa, 12(2): 1-21.

Bordes, J.-G. et Lenoble, A. (2002). "La "lamelle Caminade": un nouvel outil lithique aurignacien?”. BSPF, 99(4): 735-749.

Bosch, J.; Terradas, X. i Orozco, T. (1998). Actes de la $2^{a}$ Reunió de Treball sobre Aprovisionament de Recursos Lítics a la Prehistòria. Barcelona, Gavà, 26- 28 novembre de 1997. Rubricatum, Revista del Museu de Gavà, $\mathrm{n}^{\circ} 2$.

Bracco, J.-P. (1997). “L’utilisation du quartz au Paléolithique Superieur”, Préhistoire et Anthropologie Méditerranéennes, 6 (Première table ronde, Aix-en-Provence, 1819 avril 1996): 285-288.

Bradley, B. A. (1975). “Lithic Reduction Sequences: A Glossary and Discussion”. En E. Swanson (Ed.): Lithic technology. Making and using stone tools. Chicago, World Anthropology/Mouton Publishers: 5-13.

Brézillon, M.N. (1977). La dénomination des objets de pierre taillée. Materiaux pour un vocabulaire des préhistoriens de langue française. IV Supplément à Gallia Préhistoire. Paris, CNRS. 425 p.

Cabrera Valdés, V. (1984). El Yacimiento de la cueva de "El Castillo" (Puente Viesgo, Santander). Madrid, Bibliotheca Praehistorica Hispana, 22. 485 p.

Cabrera Valdés, V.; Lloret, M.; Bernaldo de Quirós, F. y Hoyos, M. (1997). "El Auriñaciense arcaico de la Cueva del Castillo”. En: II Congreso de Arqueología Peninsular, Zamora, del 24 al 27 de Septiembre de 1996. Tomo I: Paleolítico y Epipaleolítico. Fundación Rei Afonso Henriques: 133-140.

Cabrera Valdés, V.; Maíllo, J.M.; Bernaldo de Quirós, F. (2000). “Esquemas operativos laminares en el Musteriense Final de la Cueva del Castillo (Puente Viesgo, Cantabria)”. Espacio, Tiempo y Forma, 13: 51-78.

Cabrera, V.; Maíllo, J.M.; Lloret, M.; Bernaldo de Quirós, F. (2001). “La transition vers le Paléolithique supérieur dans la grotte du Castillo (Cantabrie, Espagne): la couche 18”. L'Anthropologie, 105: 505-532.

Cahen, D. et Karlin, C. (1980). “Nouvelles voies pour l'etude des pierres taillees”. En J. Tixier (Dir.): Prèhistoire et technologie lithique. Journées du 11-13 mai 1979. Publications de l'URA 28: cahier $n^{\circ} 1$. Valbonne, CNRS: 24-27.

Cahen, D.; Karlin, C.; Keeley, L. H. \& Van Noten, F. (1980). "Mèthodes d'analyse tèchnique, spatiale et fonctionnelle d'ensembles litiques.” Helinium, XX: 209259.

Cailleux, A. (1948). Code des couleurs des sols. Boubée.

Calderón, S. (1910). Los minerales de España. Tomo I. Madrid, Junta para la ampliación de estudios e investigaciones científicas. 
Cava, A. (1975). "La industria lítica de los niveles postazilienses de Santimamiñe (Vizcaya)”. Sautuola, I: 53-73.

Cava, A. (1989). “La industria lítica: los utensilios”. En I. Barandiarán y A. Cava: El yacimiento prehistórico de Zatoya (Navarra). Trabajos de Arqueología Navarra, $n^{\circ}$ 8. Pamplona, Dirección General de Cultura, Institución Príncipe de Viana: 37-136.

Cava, A. (1990). “El Neolítico en el País Vasco”. Munibe, 42: 97-106.

Cava, A. (1994). "El Mesolítico en la Cuenca del Ebro. Un estado de la cuestión”. Zephyrus, XLVII: 65-91.

Cava, A. (1997). "L'Abri l'Aizpea. Un facies a trapezes et son evolution a la fin du Mesolitique sur le versant sud des Pyrenees”, Préhistoire Européene, 10: 151171.

Cava, A. (2000). "La industria lítica del neolítico en Chaves, Huesca”. Saldvie, 1: 77164.

Cava, A. y Beguiristain, A. M. (1991-1992). "El yacimiento prehistórico del abrigo de la Peña (Marañón, Navarra)”. Trabajos de Arqueología Navarra, 10: 69-135.

Cazals, N. (Dir.) (1998). Comportements techiques et économiques des sociétés au Paléolthique Supérieur dans le contexte pyrénéen. Apports de la technologie lithique (Production laminaire et lamellaire), Rapport du P.C.R. SRA MidiPyrénées et UMR ArScAn. 123 p.

Cazals, N. (Dir.) (1999). Comportements techiques et économiques des sociétés au Paléolthique Supérieur dans le contexte pyrénéen. Apports de la technologie lithique (Production d'éclats), Rapport du P.C.R. SRA Midi-Pyrénées et UMR ArScAn. 95 p.

Cazals, N. (2000). Constantes et variations des traits techniques et économiques entre le Magdalénien "inferieur" et "moyen": analyse des productions lithiques du nord de la Peninsule Iberique. Thèse de doctorat. Université de Paris I. 2 vol., $590 \mathrm{p}$.

Cazals, N. (Dir.) (2000). Comportements techiques et économiques des sociétés au Paléolthique Supérieur dans le contexte pyrénéen. Apports de la technologie lithique (Analyses sur l'outillage). Rapport du P.C.R. SRA Midi-Pyrénées et UMR ArScAn.

Chadelle, J.-P. (1983). Technologie et utilisation du silex du Perigordien Superieur. Exemple de la couche VII du Flageolet I. Mémoire en vue de l'obtention du diplôme de L'Ecole des Hautes en Sciences Sociales.

Cheynier, A. \& Barnes, A. S. (1937). "Les lames à section triangulaire et les pièces à crête”. En Congrès Préhistorique de France, $12^{\circ}$ sess., Toulouse-Foix. Paris: 630-637. 
Clark, G. A. (1976). El Asturiense Cantábrico. Bibliotheca Praehistorica Hispana, vol. XIII. Madrid, CSIC, Instituto Español de Prehistoria e Instituto de Estudios Asturianos. 370 p.

Clarke, D. L. (1984). Arqueología analítica (2ª ed.). Barcelona, Ediciones Bellaterra, S.A. 470 p.

Collins, M. B. (1975). "Lithic technology as a Means of Processual Inference”. En E. Swanson (Ed.): Lithic technology. Making and using stone tools. Chicago, World Anthropology/Mouton Publishers: 15-34.

Corchón Rodríguez, M. S. (1995). “El Magdaleniense Medio cantábrico: nuevas evidencias”. En A. Moure Romanillo y C. González Sainz (Eds.): El Final del Paleolítico Cantábrico. Santander, Servicio de Publicaciones de la Universidad de Cantabria: 119-158.

Corchón Rodríguez, M. S. (2002). "El Tardiglaciar y la transición al Postglaciar en la Meseta Norte española: una visión de síntesis”. Zephyrus, 55: 85-142.

Corchón Rodríguez, M. S. y Hoyos Gómez, M. (1972-1973). “La cueva de Sofoxó (Las Regueras, Asturias)”. Zephyrvs, XXIII-XXIV: 39-100.

Crabtree, D. E. (1967). "Notes on experimentes in Flintknapping: 4. Tools used for making flaked stone artifacts”. Tebiwa, 10(1): 60-73.

Crabtree, D. E. (1968). “Mesoamerican polyhedral cores and prismatic blades”. American Antiquity, 33(4): 446-478.

Crabtree, D. E. (1972). “The cone fracture principle and the manufacture of lithic materials”. Tebiwa, 15(2): 29-42.

Cresswell, R. (1996). “Tecnología”. En P. Bonte, P. y M. Izard (Eds.): Diccionario de Etnología y Antropología. Madrid, Akal: 692-695.

Dauvois, M. (1976). Precis de dessin dynamique et structural des industries lithiques préhistoriques. Périgueux, Pierre FANLAC avec le concours du C.N.R.S. 263 p.

Demars, P.-Y. (1982). L'utilisation du silex au Paléolithique Superieur: choix, approvisionment, circulation. L'exemple du Bassin de Brive. Cahiers du Quaternaire, $\mathrm{n}^{\circ}$ 5. Paris, CNRS.

Desrosiers, S. (1991). "Sur le concept de chaîne opératoire”. En H. Balfet (Ed.): Observer l'action techniques des chaînes opèratoires, pour quoi faire?. Paris, CNRS: 21-25.

Heredia, N.; Rodríguez Fernández, L. R.; Suárez Rodríguez, A. y Alvarez Marrón, J. (1991). Mapa Geológico de España, E. 1:50.000 nº 80 (Burón). Madrid, ITGE. 
Hofman, J. L. (1992). "Putting the pieces together: an introduction to refitting”. En J. L. Hofman \& J.G. Enloe (Eds.): Piecing toghether the Past: Applications of Refiting Studies in Archaeology. BAR International Series, 578. Oxford: 1-20.

Hofman, J. L. \& Enloe, J.G. (Eds.) (1992). Piecing toghether the Past: Applications of Refiting Studies in Archaeology. BAR International Series, 578. Oxford.

Fano Martínez, M. A. (1996). "El Mesolítico en Asturias: delimitación cronológica y espacial”. Complutum, 7: 51-62.

Fano Martínez, M. A. (1998). El Hábitat Mesolítico en el Cantábrico Occidental. Trasformaciones Ambientales y Medio Físico durante el Holoceno Antiguo. BAR International Series, 732. 145 p.

Farias, P. y. Marquínez, J. (1995). “El relieve”. En C. Aramburu y F. Bastida (Eds.): Geología de Asturias. Gijón, Ediciones Trea, S.L.: 163-172.

Féblot-Augustin, J. (1997). La circulation des mtières premières au Paléolithique. Liège, ERAUL, $\mathrm{N}^{0} 75$.

Fernández-Tresguerres Velasco, J. A. (1980). El Aziliense en la Provincia de Asturias y Santander. Centro de Investigación y Museo de Altamira, Monografías $n^{\circ} 2$. Santander, Ministerio de Cultura.

Fernández-Tresguerres Velasco, J. A. (1995). “El Aziliense de la Región Cantábrica”. En A. Moure Romanillo y C. González Sainz (Eds.): El Final del Paleolítico Cantábrico. Santander, Servicio de Publicaciones de la Universidad de Cantabria: 199-224.

Fortea, F. J. (1973). Los complejos microlaminares y geométricos del Epipaleolítico mediterráneo español. Memorias del Seminario de Prehistoria y Arqueología de la Universidad de Salamanca, $\mathrm{n}^{\circ}$ 4. Universidad de Salamanca.

Fuertes Prieto, N. (2000). "Les géométriques d'El Espertin (Leon, Espagne) dans l'ensemble de son indsutrie lithique”. En N. Cazals (Dir.) Comportements techiques et économiques des sociétés au Paléolthique Supérieur dans le contexte pyrénéen. Apports de la technologie lithique (Analyses sur l'outillage). Rapport du P.C.R. SRA Midi-Pyrénées et UMR ArScAn: 36-50.

Fuertes Prieto, N. (2000-2001). "El modo de producción de los microlitos geométricos: el caso de la cueva de "El Espertín"”. Lancia, 4: 51-70.

G.E.E.M. (Groupe d’Etude de l'Epipaléolithique-Mésolithique) (1969). “Epipaléolithique-Mésolithique. Les microlithes géométriques”. B.S.P.F., 66(1): 355-366.

G.E.E.M. (1972). “Epipaléolithique-Mésolithique. Les armatures non geometriques. 1”. B.S.P.F., 69(1): 364-375. 
G.E.E.M. (1975). "Epipaléolithique-Mésolithique. L'outillage du fonds commun”. B.S.P.F,. 72(1): 319-332.

García Guinea, M. A. (1985). “Las cuevas azilienses de El Piélago (Mirones, Cantabria) y sus excavaciones de 1967-1969”. Sautuola, IV: 13-154.

García Martínez de Lagrán, I. (2001). “Los complejos mesolíticos de muescas y denticulados: estado de la cuestión en la Cuenca del Ebro". Cuadernos de Arqueología, Universidad de Navarra, 9: 7-110.

Geneste, J.-M. (1988). "Systèmes d'approvisionnement en matières premières au Paléolithique moyen at au Paléolithique supérieur en Aquitaine”. En M. Otte (ed.) L'Homme de Néandertal. Actes du colloque international de Liège (4-7 décembre,1986). Vol.8, La Mutation. ERAUL, 35: 61-66.

Geneste, J.-M. (1991a). “L'approvisionnement en matieres premieres dans les systemes de production lithique: la dimension spatiale de la technologie”. En R. Mora, X. Terradas, A. Parpal y C. Plana (Eds.): Tecnología y cadenas operativas líticas. Reunión Internacional, 15-18 enero de 1991. Treballs d’Arqueologia, 1. Bellaterra (Barcelona), Universidad Autónoma de Barcelona: 1-36.

Geneste, J.-M. (1991b). "Systémes techniques de production lithique: variations technoéconomiques dans les processus de réalisation des outillages paléolithiques”. Techniques et culture, 17/18: 1-35.

González Echegaray, J. \& Freeman, L.G. (1971). Cueva Morín: Excavaciones 19661968. Santander, Patronato de las Cuevas Prehistóricas.

González Echegaray, J. \& Freeman, L.G. (1973). Cueva Morín: Excavaciones 1969. Santander, Patronato de las Cuevas Prehistóricas.

González Morales, M. R. (1982). El Asturiense y otras culturas locales. Monografías del Museo de Altamira. Santander, Ministerio de Cultura. 295 p.

González Morales, M. R. (1990). "La Prehistoria de las Marismas: excavaciones en el Abrigo de la Peña del Perro (Santoña, Cantabria). Campañas de 1985 a 1988”. Cuadernos de Trasmiera, 2: 13-28.

González Morales, M. R. (1992). “Mesolíticos y megalíticos: la evidencia arqueológica de los cambios en las formas productivas en el paso al megalitismo en la costa cantábrica”. En A. Moure (Ed.): Elefantes, ciervos y ovicaprinos: economía y aprovechamiento del medio en la prehistoria de España y Portugal. Santander, Universidad de Cantabria: 185-202.

González Morales, M. R. (1995). “La transición al Holoceno en la Región Canatábrica: el contraste con el modelo del mediterráneo español”. En V. Villaverde Bonilla (Ed.): Los últimos cazadores. Transfomaciones culturales y económicas durante el Tardiglaciar y el inicio del Holoceno en el ámbito mediterráneo. Alicante, Instituto de Cultura Juan Gil Albert: 63-78. 
González Morales, M. R. (1996). "La transición al Neolítico en la costa cantábrica: la evidencia arqueológica”. En Actes I Congrès del Neolític a la Península Ibèrica. Gavà-Bellaterra, 27 a 29 de març de 1995. Rubricatum, 1(vol. 2): 879-885.

González Morales, M. R. (1999). "Costa e interior: algunas observaciones sobre el uso de las cuevas durante el Mesolítico”. De Oriente a Occidente. Homenaje al Dr. Emilio Olávarri. Salamanca, Publicaciones Universidad Pontificia: 237-246.

González Morales, M. R. y Díaz Casado, Y. (1991-1992). “Excavaciones en los Abrigos de La Peña del Perro (Santoña, Cantabria). Estratigrafía, cronología y comentario preliminar de sus industrias”. Veleia, 8-9: 43-64.

González-Morales, M.; García-Codrón, J.C. \& Morales-Muñiz, A. (1992). "El Bajo Asón del X al V milenio BP: cambios ambientales, económicos y sociales en el paso a la Prehistoria Reciente”. En A. Cearreta and F. M. Ugarte (Ed.): The late quaternary in the western Pyrnean Region. Proceedings of the International Conference on the Environment and the Human Society in the Western Pyrenees and the Basque Mountains during the upper Plesitocen and the Holocene. Vitoria, May 3-5, 1990. Bilbao, Servicio editorial Universidad del País Vasco: 333-342.

González Sáinz, C. (1989). El Magdaleniense Superior-Final de la Región Cantábrica. Santander, Editorial Tantín y Universidad de Cantabria. 317 p.

González Sainz, C. (1991). “Algunas reflexiones sobre las materias primas líticas y la variabilidad técnica y tipológica al término del Paleolítico Superior de la región cantábrica”. En R. Mora, X. Terradas, A. Parpal y C. Plana (Eds.): Tecnología y cadenas operativas líticas. Reunión Internacional, 15-18 enero de 1991. Treballs d’Arqueologia, 1. Bellaterra (Barcelona), Universidad Autónoma de Barcelona: 57-72.

González Sainz, C. (1995). “13000-11000 BP. El Final de la época Magdaleniense en la Región Cantábrica”. En A. Moure Romanillo y C. González Sainz (Eds.): El Final del Paleolítico Cantábrico. Santander, Servicio de Publicaciones de la Universidad de Cantabria: 159-197.

González Urquijo, J. E. e Ibáñez Estévez, J. J. (1991). "La tecnología de talla laminar en la ocupación epipaleolítica de Berniollo (Subijana-Morrillas, Alava)”. En R. Mora, X. Terradas, A. Parpal y C. Plana (Eds.): Tecnología y cadenas operativas líticas. Reunión Internacional, 15-18 enero de 1991. Treballs d’Arqueologia, 1. Bellaterra (Barcelona), Universidad Autónoma de Barcelona: 201-222.

González Urquijo, J.-E. e Ibáñez Estévez, J.-J. (1998). "La production de lamelles et de l'outillage à dos à la fin du Paléolithique et à l'Epipaléolithique de quelques gisements du Pays Basque”. En N. Cazals (Dir.): Comportements techiques et économiques des sociétés au Paléolthique Supérieur dans le contexte pyrénéen. Apports de la technologie lithique (Production laminaire et lamellaire), Rapport du P.C.R. SRA Midi-Pyrénées et UMR ArScAn: 80-88. 
González Urquijo, J. E. e Ibáñez Estévez, J. J. (1999). "Fabrication et utilisation de l'outillage à dos à la fin du Paléolithique Supérieur au Pays Basque”. En P. Bintz et A. Thevenin: L'Europe des derniers chasseurs, Epipaléolithique et Mésolithique. $5^{\circ}$ Colloque international UISPP, Grenoble, 18-23 septembre 1995. CTHS: 109-113.

Guilaine, J. (Dir.) (1993). Dourgne. Derniers chasseurs-collecteurs et premiers éleveurs de la Haute-Vallée de l'Aude. Centre d'Anthropologie des Sociétés Rurales, Toulouse; Archéologie en Terre d'Aude, Carcassone.

Gutiérrez Elorza, M. (Coord.) (1994): Geomorfología de España. Madrid, Editorial Rueda.

Hahn, J. \& Owen, L.R. (1985). "Blade technology in the Aurignacian and Gravettian of Geissenklösterle Cave, Southwest Germany”. World Archaeology, 17(1): 61-75.

Heredia, N.; Rodríguez Fernández, L.R..; Suárez Rodríguez y Álvarez Marrón, J. (1991): Mapa geológico de España, E. 1:50.000 nº 80 (Burón). Segunda Serie (MAGNA). Madrid, ITGE.

Heredia, N. Rodríguez Fernández, L.R. y Suárez, A. (1994). “Tectónica”. En: Memoria explicativa del mapa geológico de la provincia de León. E: 1:200.000. León, ITGT. Diputación de León.: 91-132.

Hofman, J. L. (1992). "Putting the pieces together: an introduction to refitting”. En J. L. Hofman \& J.G. Enloe (Ed): Piecing toghether the Past: Applications of Refiting Studies in Archaeology. BAR International Series, 578. Oxford: 1-20.

Hofman, J.L \& Enloe, J.G. (Ed.) (1992). Piecing toghether the Past: Applications of Refiting Studies in Archaeology. BAR International Series, 578. Oxford.

Ibáñez Estévez, J. J. y González Urquijo, J.E. (1994). “La fabricación del utillaje lítico tallado en Laminak II”. Kobie, XXI: 85-110.

Ibáñez Estévez, J. J. y González Urquijo, J.E. (1997). “Diversidad funcional de los asentamientos en el final del Paleolítico Superior. Una perpectiva desde el utillaje lítico. En: II Congreso de Arqueología Peninsular, Zamora, del 24 al 27 de Septiembre de 1996. Tomo I: Paleolítico y Epipaleolítico. Fundación Rei Afonso Henriques: 287-296.

Ibáñez Estévez, J. J. y González Urquijo, J.E. (1998). “The production and use of lithic tools at the end of the Upper Palaeolithic in the Basque Country”. En S. Milliken (Ed.): The Organization of lithic tecnology in the late glacial and Early Postglacial Europe. BAR International Series, 700: 17-37.

Inizian, M.-L. Roche, M.; Roche, H. \& Tixier, J. (Eds.) (1995). Technologie de la pierre taillée. Préhistoire de la pierre taillée. Meudon, CREP (Cercle de Recherches et d'Etudes Préhistoriques), con el concours de CNRS. 
Julien, M. (1992). "Interrogation directe et indirecte: mèthodes et concepts. La technologie et la typologie. Du fossile directeur à la chaîne opératoire”. En J. Garanger (Ed.) La Préhistoire dans le monde. Nouvelle édition de La Préhistoire d’André Leroi-Gourhan. Paris, Presses Universitaires de France: 163-193.

Julivert, M.; Truyols, J. y García-Alcalde, J (1981). Memoria explicativa del Mapa Geológico de España, E. 1: 200.000, no 10 (Mieres). Segunda Edición. Madrid, IGME.

Juan-Cabanilles, J. M.; Martí Oliver, B. (2002). "Poblamiento y procesos culturales en la Península Ibérica del VII al V milenio A.C. (8000-5500 BP). Una cartografía de la neolitización”. En E. Badal, J. Bernabeu y B. Martí (Eds.): El Paisaje en el Neolítico mediterráneo, Saguntum (PLAV), Extra-5: 45-87.

Karlin, C. (1991a). "Connaissances et savoir-faire: comment analyser un processus technique en Prehistoires. Introduction”. En R. Mora, X. Terradas, A. Parpal y C. Plana (Eds.): Tecnología y cadenas operativas líticas. Reunión Internacional, 15-18 enero de 1991. Treballs d'Arqueologia, 1. Bellaterra (Barcelona), Universidad Autónoma de Barcelona: 99-124.

Karlin, C. (1991b). “Analyse d'un processus technique: le débitage laminaire des magdaleniens de Pincevent (Seine et Marne)”. En R. Mora, X. Terradas, A. Parpal y C. Plana (Eds.): Tecnología y cadenas operativas líticas. Reunión Internacional, 15-18 enero de 1991. Treballs d'Arqueologia, 1. Bellaterra (Barcelona), Universidad Autónoma de Barcelona: 125-162.

Karlin, C. (1999). “À coté d'un savoir-faire stéreotypé, un savoir-faire adaptatif. La taille des matériaux lithiques par les occupants de l'abri de Tomayoc (Phase II, 3900-3500 B.P., Puna de Jujuy - Argentine)”. En J.-L. Jamard, A. Montigny and F.-R. Picon (Eds.): Dans le sillage des techniques. Hommage à Robert Creswell. Paris, L'Harmattan: 225-257.

Karlin, C.; Bodu, P. et Pelegrin, J. (1991). Processus techniques et chaînes opératoires. Comment les préhistoriens s'approprient un concept élaboré par les ethnologues”. En H. Balfet (Ed.): Observer l'action techniques des chaînes opèratoires, pour quoi faire?. Paris, CNRS: 101-117.

Karlin, C., Pelegrin, J. \& Bodu, P. (1986). "Processus techniques et chaîne opératoires: un outil pour le Préhistoiren.” B.S.P.F., 83(3): 66-67.

Klaric, L; Aubry, T. et Walter, B. (2002). "Un nouveau type d'armature en contexte gravettien et son mode de production sur les burins du Raysse (la Picardie, commune de Preuilly-sur-Claise, Indre-et-Loire)”. B.S.P.F., 99(4): 751-764.

Klein, C. \& Hurlbut, C.S. (1997). Manual de mineralogía. Basado en la obra de J.Dana. Barcelona, Editorial Reverté.

Laplace, G. (1966). Recherches sur l'origine et l'évolution des complexes leptolithiques. Paris, École Française de Rome. 
Le Brun-Ricalens, F. et Brou, L. (2003). "Burins carénés-nucléus à lamelles: identification d'une chaîne opératoire particulière à Thèmes (Yonne) et implications”. B.S.P.F., 100(1): 67-83.

Lemonnier, P. (1976). "La description des chaînes operaoires: contribution a l'analyse des systemes techniques.” Techniques et Culture, 1: 100-151.

Lemonnier, P. (1983). "L’étude des systèmes techniques, une urgence en technologie culturelle”. Techniques et Culture (nueva serie), 1: 11-26

Lemonnier, P. (1991). "De la culture matérielle à la culture? Ethnologie des techniques et Préhistoire”. 25 ans d'etudes technologiques en Préhistoire. Bilan et perspectives. Juan-les-Pins, APDCA: 15-20.

Lemonnier, P. (1996). “Técnico (sistema)”. En P. Bonte, y M. Izard (Eds.): Diccionario de Etnología y Antropología. Madrid, Akal: 691-692.

Lemonnier, P. (1996). “Técnico (sistema)”. En P. Bonte y M. Izard (Eds.): Diccionario de Etnología y Antropología. Madrid, Akal: 691-692.

Lenoir, M. (1975). “Remarks on Fragments with Languette Fractures”. En E. Swanson (Ed.): Lithic technology. Making and using stone tools. Chicago, World Anthropology/Mouton Publishers: 129-132.

Lenoir, M. (1980). “Quelques remarques sur l'Economie de la Matiere premiere dans les industries paleolithiques des Basses Vallees de la Dordogne et de la Garonne”. En J. Tixier (ed.) Prèhistoire et technologie lithique. Journées du 11-13 mai 1979. Valbonne, C.N.R.S.: 31.

Leroi-Gourhan, A. (1971a). El gesto y la palabra. Caracas, Universidad Central de Venezuela. (1 ${ }^{\mathrm{a}}$ ed., 1964).

Leroi-Gourhan, A. (1971b): Evolution et Techniques, 1: L'Homme et la matière. $2^{\mathrm{a}}$ ed. Paris, Albin Michel. 348 p. (1 ${ }^{\mathrm{a}}$ ed., 1943).

Leroi-Gourhan, A. (1973): Evolution et Techniques, 2: Milieu et Techniques. $2^{\mathrm{a}}$ ed. Paris, Albin Michel. 471 p. (1 ${ }^{\text {a }}$ ed., 1945).

Lloret, M. (1995). “Análisis tecnológico de los núcleos de la cueva de La Pila (Magdaleniense Superior: Nivel V y IV.4)”. Espacio, Tiempo y Forma, Serie I, Prehistoria y Arqueología, 8: 11-32.

Lloret, M. (1997). "El proceso tecnológico en el Magdaleniense Superior de la Cueva de la Pila (Cuchía, Cantabria)”. En: II Congreso de Arqueología Peninsular. Tomo I: Paleolítico y Epipaleolítico. Zamora, Fundación Rei Afonso Henriques: 141-146.

Lloret Martínez de la Riva, Ma . M. (2001). Los procesos operativos en la transición magdaleniense superior/final-aziliense de la cornisa cantábrica. Tesis doctoral inédita. Madrid, U.N.E.D. 
Lucas, G. (2002). “À propos des burins du Raysse du Flageolet I (Dordogne, France)”. Paléo, 14: 63-76.

Maíllo Fernández, J. M. (2003). La transición Paleolítico Medio en Cantabria: análisis tecnológico de la industria lítica de Cueva Morín. Tesis doctoral inédita. Madrid, UNED. 547 p.

Mangado, J. (2002). La caracterización y el aprovisionamiento de los recursos abióticos en la Prehistoria de Cataluña: las materias primas silíceas del Paleolítico Superior Final y el Epipaleolítico. Tesis doctoral inédita. Universidad de Barcelona. 425 p.

Marín Ramos, M.; Pérez Cueva, A.; Sanz Donaire, J. y Segura Beltrán, F. (1997). Geografía de España. 3. Geografía Física. Barcelona, Océano-Instituto Gallach.

Marquínez, J. (1992): “Tectónica y relieve en la Cornisa Cantábrica”. En A. Cearreta and F.M. Ugarte (Eds.): The Late Quaternary in the Western Pyrenean Region. Proceedings of the International Conferecne on the Environment and the Human Society in the Western Pyrenees and the Basque Mountains during the upper Pleistocene and the Holocene, Vitoria, May 3-5, 1990. Bilbao, Servicio Editorial Universidad del País Vasco: 143-159.

Martín-Serrano, A. (1994): “Macizo Hespérico Septentrional”. En M. Gutiérrez Elorza (Coord.): Geomorfología de España. Madrid, Editorial Rueda: 25-62.

Mazo, C. y Montes, L. (1992): "La transición Epipaleolítico-Neolítico antiguo en el abrigo de El Pontet (Maella, Zaragoza)”. En P. Utrilla (Coord.): Aragón-Litoral mediterráneo: intercambios culturales durante la prehistoria. Zaragoza, Institución Fernando el Católico: 243-254.

Merino, J. M. (1984). “Industria lítica del yacimiento de Ekain”. En J. Altuna y J. M. Merino: El yacimiento prehistórico de la cueva de Ekain (Deba, Guipúzcoa). Guipúzcoa, Sociedad de Estudios Vascos.

Merino, J. M. (1994). Tipología lítica. Munibe, Suplemento $n^{0}$ 9. $3^{\mathrm{a}}$ edición. San Sebastián, Sociedad de Ciencias Aranzadi.

Mohen, J.-P. (1988). “Grand-Pressigny (Le)”. En A. Leroi-Gourhan (Dir.): Dictionnaire de la Préhistoire. Paris, Presses Universitaires de France: 442.

Mollfulleda Borrell, J. (1999). Minerales de España. Barcelona, Carroggio, S.A. de ediciones.

Montes, Ma L. (2001-2003). "El abrigo epipaleolítico de Peña 14 (Biel, Zaragoza). Excavaciones 1999 y 2000”. Saldvie, 2: 291-306.

Montes, M ${ }^{\mathrm{a}}$ L. y Domingo, R. (2001-2002). "Epipaleolítico y Neolítico en las sierras exteriores de Aragón. Prospecciones, sondeos y excavaciones. 2001”. Saldvie, 2: 323-336. 
Mora, R.; Terradas, X.; Pampal, A. y Plana, C. (Ed.) (1991). Tecnología y cadenas operativas líticas. Reunión Internacional, 15-18 enero de 1991. Treballs d'Arqueología, 1. Bellaterra (Barcelona), Universidad Autónoma de Barcelona.

Morala, A. et Turq, A. (1991). "Relations entre matières premières litihiques et technologíe: l'exemple du Paléolithique entre Dordogne et Lot”. En VVAA 25 ans d'etudes technologiques en Préhistoire. Bilan et perspectives. Juan-les-Pins, APDCA: 159-168.

Moure Romanillo, A. y González Sáinz, C. (Ed.) (1995). El Final del Paleolítico Cantábrico. Santander, Servicio de Publicaciones de la Universidad de Cantabria.

Mourre, V. (1997). “Industries en quartz: Précisions terminologiques dans les domaines de la pétrographie et de la technologie”. Préhistoire et Anthropologie Méditerranéennes, 6 (L'explotation du quartz au Paléolithique. Première table ronde, Aix-en-Provence, 18-19 avril 1996): 201-210.

Neira Campos, A. (1985). Evidencias de Paleolítico Superior en la Provincia de León. Memoria de licenciatura. Universidad de León.

Neira Campos, A. (1987). “Nuevas evidencias de Paleolítico Superior en la provincia de León.” Tierras de León, 69: 107-125.

Neira Campos, A. (1993). Análisis matemáticos aplicados al Paleolítico. Tesis doctoral. Universidad de León. 2 tomos. 778 p.

Neira Campos, A. (1997). "Prehistoria”. En VVAA: Historia de León. Volumen I. León, La Crónica de León: 1-155.

Neira Campos, A. y Bernaldo de Quirós, F. (1996). "El Paleolítico en la Provincia de León”. En: ArqueoLeón. Historia de León a través de la Arqueología. León, Junta de Castilla y León y Diputación Provincial de León.

Neira Campos, A. y Mallo, F. (1990). “Análisis estadístico de materiales líticos paleolíticos: la Cueva de la Cantera (Alcedo, León)”. Trabajos de Prehistoria, 47: 321-338.

Neira Campos, A.; Fernández Rodríguez, C.; Bernaldo de Quirós, F.; Fuertes Prieto, N. y Yágüez Juárez, R.Ma (1997). “Avance al estudio de la cueva de La Uña (La Uña, Acebedo, León)”. Lancia, 2: 47-81.

Neira-Campos, A; Fuertes-Prieto, N.; Fernández-Rodríguez, C.; Bernaldo de Quirós, F. (en prensa). "Le gisement mésolithique de la " cueva del Espertin », León, Espagne”. En Actes du XIV Congrès de l'UISPP, Liège, septembre 2001.

Newcomer, M. H. (1975a). "Punch Technique" and Upper Paleolithic Blades. En E. Swanson (Ed.): Lithic technology. Making and using stone tools. Chicago, World Anthropology/Mouton Publishers: 97-102. 
Newcomer, M. H. (1975b). “Spontaneous Retouch”. Second International Symposium on Flint. Maastricht. Staringia, $n^{\circ}$ 3: 62-64.

Nozal, F. (1994). “Cuaternario y Geomorfología”. En Memoria explicativa del Mapa Geológico de la Provincia de León, E. 1:200.000. Madrid, ITGME y Diputación de la Provincia de León: 79-90.

Olive, M. (1988). Une habitation Magdalénienne d'Etiolles: L'Unité P15. Mémoires de la Société Préhistorique Française. Tome 20. CNRS et Ministére de la Culture.

Olive, M. (1988). “Une forme particulière d'économie de débitage à Etiolles”. En J. Tixier (Ed.): Technologie préhistorique. Notes et Monographies, 25. C.N.R.S: 27-36.

Pelegrin, J. (1984). “Approche technologique expérimentale de la mise en forme de nucléus pour le débitage systématique par pression”. En: Préhistoire de la pierre taillée, 2: économie du débitage laminaire: technologie et expérimentation. III table ronde de technologie lithique, Meudon-Bellevue, octobre 1982. Paris, CREP: 93-103.

Pelegrin, J. (1988a). “Pression”. En A. Leroi-Gourhan (Dir.): Dictionnaire de la Préhistoire. Paris, Presses Universitaires de France: 865.

Pelegrin, J. (1988b). “Taille”. En A. Leroi-Gourhan (Dir.): Dictionnaire de la Préhistoire. Paris, Presses Universitaires de France: 1019-1020.

Pelegrin, J. (1990). "Prehistoric lithic technology: some aspects of research". Archaeological Review from Cambridge, 9(1): 116-125.

Pelegrin, J. (1991a). “Les savoir-faire: une très longue histoire”. Terrain, 16: 106-113.

Pelegrin, J. (1991b). “Aspects de démarche expérimentale en technologie lithique”. En VVAA: 25 ans d'études techologiques en Préhistoire. Bilan et perspectives. Juan-les-Pins, APDCA: 57-62.

Pelegrin, J. (1993). “A framework for analysing prehistoric stone tool manufacture and a tentative application to some early stone industries”. En A. Berthelet and J. Chavaillon (Eds.): The Use of tools by Human and Non-human Primates. Oxford, Claredon Press: 302-314.

Pelegrin, J. (1995). Technologie lithique: le châtelperronien de Roc-de-Combe (Lot) et de La Côte (Dordogne). Cahiers du Quaternaire, n 20. Paris, CNRS. 297 p.

Pelegrin, J. (2000). "Les techniques de débitage laminaire au Tardiglaciaire: critères de diagnose et quelques réflexions". En L'Europe Centrale et Septentrionale au Tardiglaciaire. Table-ronde de Nemours, 13-16 mai 1997. Mémoires du Musée de Préhistorire d'Ilde de France, 7: 73-86. 
Pelegrin, J.; Karlin, C. et Bodu, P. (1988). "Chaînes opératoires: un outil pour le préhistorien”. En J. Tixier (dir.) Journée d'études technologiques en préhistoire. Notes et monographies techniques du CRA, $\mathrm{n}^{\circ}$ 25. Paris, CNRS: 55-62.

Perlès, C. (1980). "Economie de la matière premiere et economie de débitage: deux exemples grecs”. En J. Tixier: Prèhistoire et technologie lithique. Journées du 11-13 mai 1979. Valbonne, CNRS: 37-41.

Perlès, C. (1991). "Économie des matiéres premières et économie du débitage: deux conceptions opposées?”. En VVAA: 25 ans d'études techologiques en Préhistoire. Bilan et perspectives. Juan-les-Pins, APDCA: 35-45.

Perlès, C. (1993). "Ecological determinism, group strategies, and individual decisions in the conception of prehistoric stone assemblages”. En A. Berthelet and J. Chavaillon (Eds.): The Use of tools by Human and Non-human Primates. Oxford, Claredon Press: 267-277.

Pigeot, N. (1987). Magdaléniens d'Etiolles: économie de débitage et organisation sociale (l'unité d'Habitation U5). Supplément à Gallia Préhistoire, XXV. Paris, CNRS.

Pigeot, N. (1988). “Apprendre à débiter des lames: un cas d'éducation technique chez des magdaléniens d'Etiolles”. En J. Tixier (Ed.): Technologie préhistorique. Notes et Monographies techniques, 25. CNRS: 63-70.

Pigeot, N. (1990). "Technical and Social Actors: Flintknapping Specialists at Magdalenian Etiolles”. Archaeological Review from Cambridge, 9(1): 126-141.

Pigeot, N. (1991). “Reflexions sur l'Histoire technique de l'Homme: de l'evolution cognitive a l'evolution culturelle”. Paléo, 3: 167-200.

Ploux, S. (1991). “Tecnhologie, Technicité, Techniciens: méthode de détermination d'auteurs et comportementes tedhniques individuels". En VVAA: 25 ans d'études techologiques en Préhistoire. Bilan et perspectives. Juan-les-Pins, APDCA: 201-214.

Ploux, S.; Karlin, C \& Bodu, P. (1991). "D'une chaine à l'autre: normes et variations dans le débitage laminaire magdalénien.” Techniques et culture, 17/18: 81-113.

Ploux, S. et Karlin, C. (1993). "Fait technique et degré de sens dans l'analyse d'un processus de débitage magdalénien.” Techniques et Culture, 21: 61-78.

Poplin, F. (1979). "Les chasse-lame néolithiques en bois de cerf”. En H. Camps-Fabrer (org.) L'industrie en os et bois de cervidé durant le Néolithique et l'Âge des Métaux. Première réunion du groupe de travail n ${ }^{\circ} 3$ sur l'industrie de l'os préhistorique. Paris, CNRS: 87-91.

Ramil Rego, E. (1995). "El poblamiento en la Sierra del Xistral (Lugo) a finales del Paleolítico”. En Actas del XXI Congreso Nacional de Arqueología, Teruel. Colección Actas, 29. Zaragoza: 545-554. 
Ramil Soneira, J. y Villar Quinteiro, R. (1995). "El yacimiento epipaleolítico de Xestido III (Abadín, Lugo). Comentario a la industria lítica”. Actas del XXI Congreso Nacional de Arqueología, Teruel. Colección Actas, 29. Zaragoza: 569-587.

Ramil Soneira, J. y Ramil Rego, E. (1997). "La talla del cristal de roca: una primera aproximación experimental”. Lancia, 2: 11-22.

Révillon, S. (1994). Les industries laminaires du Paléolithique moyen en Europe septentrionale. L'exemple des gisementes de Saint-Germain-des-Vaux/PortRacine (Manche), de Seclin (Nord) et de Riencourt-les-Bapaume (Pas-deCalais). Publications du CERP, $\mathrm{n}^{\mathrm{o}}$ 5. Centres d'Études et de Recherches Préhistoriques, Université des Sciences et Technologies de Lille.

Roche, J. et Tixier, J. (1982). “Les accidents de taille.” Studia Praehistorica Belgica, 2: 65-76.

Rodriguez Fernández, L. R. (1991). “Introducción”. En Memoria explicativa del Mapa Geológico de España, E. 1:50.000 nº 80 (Burón). Madrid, ITGE: 7-10.

Rodríguez Fernández, L.R. (1994): “Introducción”. En Memoria explicativa del Mapa Geológico de la Provincia de León, E. 1:200.000. Madrid, ITGME y Diputación de la Provincia de León: 9-12.

Rodríguez Fernández, L. R. y Heredia, N. (1994). Mapa geológico de la provincia de León. E: 1:200.000. León, ITGT. Diputación de León.

Roux, V. (1991). "Peut-on interpréter les activités lithiques préhistoirques en termes de durée d'apprentissage?. Apport d'ethnologie et de la psychologie aux études technologiques”. En VVAA: 25 ans d'études techologiques en Préhistoire. Bilan et perspectives. Juan-les-Pins, APDCA: 47-56.

Rozoy, J.-G. (1968). “L'étude du matériel brut et des microburins”. BSPF, LXL(1): 365390.

Rozoy, J.-G. (1978). “Typologie de l'Epipaléolithique (Mésolithique) franco-belge”. Bulletin de la Société archéologique champenoise, № espécial.

Rozoy, J.-G. (1978). Les derniers chasseurs. L'Epipaléolithique en France et en Belgique. Essai de synthèse. Bulletin de la Société Archéologique Champennoise, 3 vol., 1256 p.

Rozoy, J.-G. (1992). "L'évolution en mosaïque. Les changementes à l'Epipaléolithique (Mésolithique).” B.S.P.F., 89(1): 19-25.

Ruiz Cobo, J. y Smith, P. (2001). "El yacimiento del Cubío Redondo (Matienzo, Ruesga): Una estación mesolítica de montaña en Cantabria”. Munibe, 53: 31-55.

Sanmartín, J. (1987). Los nuevos redentores. Reflexiones sobre la ingeniería genética, la sociobiología y el mundo feliz que nos prometen. Barcelona, Anthropos. 
Sanmartín, J. (1990). Tecnología y futuro humano. Barcelona, Anthropos.

Sarabia Rogina, P. M. (1990). “Approche de l'etude de la distribution stratigraphique du silex de la province de Cantabria (Espagne du Nord)”. En L. Sèronie-Vivien et M. Lenoir (Ed.): Le silex, de sa genèse à l'outil. Actes du V Colloque international sur le silex (Bordeaux, 1987). Cahiers du Quaternaire ${ }^{\circ} 17$. Tome I. Paris, Editions du CNRS. Centre régional de publication de Bordeaux: 141147.

Sarabia Rogina, P. M. (1999). "Notas sobre los modelos de aprovisionamiento de materias primas líticas en le Paleolítico Superior de Cueva Morín (vbillanueva de Villaescusa, Cantabria)”. Sautuola, VI: 145-154.

Sarabia Rogina, P. M. (2002). "La utilización de rocas del grupo radiolarita en las industrias paleolíticas de Cantabria”. Sautuola, VIII: 11-25.

Sellet, F. (1993). "Chaîne opératoire; the concept and its applications”. Lithic technology, 18(1-2): 106-112.

Sigaut, F. (1985). "Ethnoscience et technologie: les taches de la technologie. Un exemple, l'identification des formes de consommation de céréales”. Techniques et Culture, 5: 1-18.

Sigaut, F. (1993). "How can we analyse and describe technical actions?”. En A. Berthelet and J. Chavaillon (Eds.): The Use of tools by Human and Non-human Primates. Oxford, Claredon Press: 381-397.

Sonneville-Bordes, D. de et Perrot, J. (1954). "Lexique typologique du Paléolithique Supérieur. Outillage lithique. I. Grattoirs. II. Outils Solutréens.” B.S.P.F., LI: 327-335.

Sonneville-Bordes, D. de et Perrot, J. (1955). "Lexique typologique du Paléolithique Supérieur. Outillage lithique. III. Outils composites. Perçoirs.” B.S.P.F., LII: 7679.

Sonneville-Bordes, D. de et Perrot, J. (1956a). "Lexique typologique du Paléolithique Supérieur. Outillage lithique. IV. Burins.” B.S.P.F., LIII: 408-412.

Sonneville-Bordes, D. de et Perrot, J. (1956b). "Lexique typologique du Paléolithique Supérieur. Outillage lithique (suite et fin). V. Outillage à bord abattu. VI. Piéces tronquées. VII. Lames retouches. VIII. Piéces variées. IX. Outillage lamellaire. Pointe Azilienne”. B.S.P.F., LIII: 547-559.

Sonneville-Bordes, D. et Deffarge, R. (1974). "Lames Retouchées Magdaléniennes du Morin (Gironde)”. Zephyrus, XXV: 95-105.

Straus, L. G. (1996). The use of quartzite in the Upper Palaeolithic of Cantabrian Spain. En N. Moloney; L. Raposo \& M. Santonja (Eds.): Non-Flint Stone Tools and the Palaeolithic Occupation of the Iberian Peninsula. BAR International Series, 649. Oxford: 37-41. 
Straus, L. G. (2002). "Tardiglaciar Lithic Raw Material Utilization in Vasco-Cantabria (Spain) and Gascony (France)”. En L. E. Fisher \& B. V. Eriksen (eds.) Lithic Raw Material Economies in Late Glacial and Early Postglacial Europe. British Archeological Reports S1093: 133-145.

Straus, L.G.; Clark, G.A.; Ordaz, J.; Suárez, L.; Esbert, R. (1986). "Patterns of lithic raw material variation at La Riera”. En L.G. Straus \& G.A. Clark (Eds.): $L a$ Riera Cave. Stone age hunter-gatherer adptations in northern Spain. Anthropological Research Papers No. 36. Arizona State University: 189-208.

Straus, L. G. \& Clark, G.A. (Ed.) (1986). La Riera Cave. Stone age hunter-gatherer adptations in northern Spain. Anthropological Research Papers No. 36. Arizona State University.

Suárez, A.; Barba, P.; Heredia, N.; Rodríguez fernández, L.R.; Fernández, L.P. y Herrero, A. (1994): Mapa Geológico de la Provincia de León, E. 1:200.000. Madrid, ITGE y Diputación de León.

Tarriño Vinagre, A. (1998). "Rocas silíceas sedimentarias. Su composición mineralógica y terminología”. Krei, 3: 143-161.

Tarriño Vinagre, A. (2001). El sílex en la cuenca vasco-cantábrica y Pirineo navarro: caracterización y su aprovechamiento en la Prehistoria. Tesis doctoral. Universidad del País Vasco.

Terradas, X. (1995). Las estrategias de gestión de los recursos líticos del Prepirineo catalán en el IX milenio BP: el asentamiento prehistórico de la Font del Ros (Berga, Barcelona). Bellaterra, Universitat Autònoma de Barcelona.

Terradas, X. (1998a). "From raw material procurement to tool production: reconstruction of the lithic production process durin the late glacial period in the eastern Pyrenees”. En S. Milliken (Ed.): The Organization of Lithic Technology in Late Glacial and Early Postglacial Europe. BAR International Series, 700: 116.

Terradas Batlle, X. (1998b). "Estado actual de las investigaciones sobre el aprovisionamiento de materias primas líticas entre grupos cazadores-recoletores prehistóricos en el estado español”. En J. Bernabeu, T. Orozco y X. Terradas (eds.) Los recursos abióticos en la prehistoria. Universitat de València: 73-82.

Terradas, X. (1999). "La producción de lascas en el Epipaleolítico de los Pirineos Orientales”. En N. Cazals (Dir.): Comportements techiques et économiques des sociétés au Paléolthique Supérieur dans le contexte pyrénéen. Apports de la technologie lithique (Production d'éclats), Rapport du P.C.R. SRA MidiPyrénées et UMR ArScAn: 7-16.

Terradas, X. (2001). La gestión de los recursos minerales en las sociedades cazadorasrecolectoras. Treballs d'Etnoarqueologia, $\mathrm{n}^{\circ}$ 4. Madrid, CSIC. $177 \mathrm{p}$. 
Terradas, X. (en prensa). "La production de l'outillage lithique dans le Mésolithique des Pyrénées orientales: contrainte environnementale ou choix fonctionnelle?”. En J.-P. Bracco \& Montoya (Eds.): Les systèmes techniques lithiques pendant le Tardiglaciaire autour de la Méditerranée nord-occidentale. Éditions du CNRS.

Terradas, X.; Mora, R.; Plana, C.; Parpal, A. y Martínez, J. (1992). “Estudio preliminar de las ocupaciones del yacimiento al aire libre de la Font del Ros (Berga, Barcelona)”. En P. Utrilla (Coord.): Aragón/Litoral mediterráneo: intercambios culturales durante la Prehistoria. Zaragoza, Institución Fernando el Católico: 285-296.

Tixier, J. (1967). "Procedes d'analyse et questions de terminologie concernant l'etude des ensembles industriels du Paleolithique Recent et de l'Epipaleolithique dans l'Afrique du Nord-ouest”. En W.W. Bishop et J. D. Clark (Eds.): Background to evolution in Africa. The University of Chicago Press: 771-820.

Tixier, J. (1978). Notice su les travaux scientifiques. Presentée en vue du grade de docteur és lettres. Université de Paris X-Nanterre. 117 p.

Tixier, J. (Ed.) (1980a). Prèhistoire et technologie lithique. Journées du 11-13 mai 1979. Publications de l'URA 28: cahier $n^{0}$ 1. Valbonne, C.N.R.S.

Tixier, J. (1980b). “Raccords et remontages”. En J. Tixier (Dir.): Prèhistoire et technologie lithique. Journées du 11-13 mai 1979. Publications de l'URA 28: cahier $\mathrm{n}^{0} 1$. Valbonne, CNRS: 50-55.

Tixier, J. (1980c). Expériences de taille. En J. Tixier (Ed.): Prèhistoire et technologie lithique. Journées du 11-13 mai 1979. Publications de l'URA 28: cahier $\mathrm{n}^{\circ} 1$. Valbonne, C.N.R.S.: 47-49.

Tixier, J.; Inizian, M.-L. \& Roche, H. (Eds.) (1980). Préhistoire de la pierre taillée. 1 Terminologie et technologie. Valbonne, CREP.

Tixier, J. (1982). “Techniques de débitage: osons ne plus affirmer”. En D. Cahen (Ed.): Tailler! pour quoi faire: Préhistoire et technologie lithique: Recent progress in microwear studies. URA 28 du CRA: 13-22.

Tixier, J. (1984). "Le débitage par pression”. En: Préhistoire de la pierre taillée, 2: économie du débitage laminaire: technologie et expérimentation. III table ronde de technologie lithique, Meudon-Bellevue, octobre 1982. Paris, CREP: 57-70.

Tixier, J. (Ed.) (1988). Technologie Préhistorique. Notes et Monographies, 25. C.N.R.S.

Tixier, J. (1991). “Cogitations non conclusives”. En VVAA: 25 ans d'études techologiques en Préhistoire. Bilan et perspectives. Juan-les-Pins, APDCA: 391394.

Tixier, J. et Turq, A. (1999). “Kombewa et alii”. Paléo, 11: 135-143. 
Turq, A. (1990). "Exploitation du milieu minéral: technologie, économie et circulation du silex”. En J. Jaubert et al. Les chasseurs d'Aurochs de La Borde. Un site du Paléolothique moyen (Livernon, Lot). Documents d'Archeologie Française (DAF), n ${ }^{\circ} 27$. Paris, Editions de la Maison des sciences de l'Homme: 103-115.

Turq, A. (1992). Le Paléolithique inferieur et moyen entre les valles de la Dordogne et du Lot. Tesis doctoral. Bordeaux, Université de Bordeaux I. 2 vol. 782 p.

Turq, A.; Detrain, L.; Vigier, S. (2000). "L'importance de l'accessibilité des gîtes dans l'étude de l'approvisionnement en matières premières lithiques: l'exemple du Haut-Agenais (Lot-en-Garonne)". Les derniers chasseurs-cueilleurs d'Europe occidentale. Actes du colloque international de Besançon (Doubs, France), 2325 octobre 1998. Annales Littéraires, 699; Série "Environnement, sociétés et archéologie", 1. Presses Universitaires Franc-Comtoises: 267-276.

Ugarte, F. M. (1994): "Montes Vasco-cantábricos". En M. Gutiérrez Elorza (Coord.) Geomorfología de España. Madrid, Editorial Rueda: 227-250.

Utrilla Miranda, P. (1981). El Magdaleniense Inferior y Medio en la Cornisa Cantábrica. Centro de Investigación y Museo de Altamira, Monografías $n^{0} 4$. Santander, Ministerio de Cultura. 335 p.

Utrilla Miranda, P. (1995). "El valle del Ebro durante el Tardiglaciar y comienzos del Holoceno. Las relaciones con el Magdaleniense cantábrico”. En A. Moure Romanillo y C. González Sainz (Eds.): El Final del Paleolítico Cantábrico. Santander, Servicio de Publicaciones de la Universidad de Cantabria: 281-311.

Utrilla, P. (2002). "Epipaleolíticos y neolíticos del Valle del Ebro”. En E. Badal, J. Bernabeu y B. Martí (Eds.): El Paisaje en el Neolítico mediterráneo, Saguntum (PLAV), Extra-5: 179-208.

Utrilla Miranda, P. (2002). "Paleolítico y Epipaleolítico en Aragón”. Caesaraugusta, 75: $115-158$.

Utrilla, P.; Cava, A.; Alday, A.; Baldellou, V.; Barandiarán, I.; Mazo, C. et Montes, L. (1998). "Le passage du Mésolithique au Néolithique ancien dans le Bassin de l'Ebre (Espagne) d'apres les datations C14”. Préhistoire Européenne, 12: 171194.

Utrilla, P. y Domingo, R. (2001-2002). “ Excavaciones en el Arenal de Fonseca (Ladruñán, Teruel)”. Saldvie, 2: 337-354.

Utrilla, P.; Domingo, R. y Martínez Bea, M. (2003). "La campaña del año 2002 en el Arenal de Fonseca (Ladruñán, Teruel)”. Saldvie, 3: 301-311.

Utrilla, P. y Mazo, C. (1996). "La transición del Tardiglaciar al Holoceno en el Alto Aragón: los abrigos de Las Forcas (Graus, Huesca)”. En XXV Congreso de Arqueología Nacional, vol I: 349-365. 
Utrilla, P. y Rodanés, J.M. (2001-2002). “El yacimiento epipaleolítico de los Baños (Ariño, Teruel)”. Saldvie, 2: 307-322.

Valdeyron, N. (1994). Le Sauveterrien. Culture et societés mésolithiques dans la France du sud durant les Xe et IXe millenaires B.P. Thèse de doctorat. 2 tomes. Toulouse, Université Toulouse-Le Mirail.

Valdeyron, N. (2000). "Géographie culturelle du Mésolithique récent/final dans le sudouest de la France”. Rencontres méridionales de Préhistoire récente. Troisième session, Toulouse, 1998. Éditions Archives d'Ecologie Préhistorique: 23-34.

Valentin, B. (1995). Les groupes humains et leurs traditions au Tardiglaciaire dans le Bassin Parisien. Apports de la technologie comparée. Thèse de doctorat. Université de Paris I. 3 vol., 1106 p.

Valentin, B. et Pigeot, N. (2000). "Éléments pour une chronologie des occupations magdaléniennes dans le Bassin parisien". En L'Europe Centrale et Septentrionale au Tardiglaciaire. Table-ronde de Nemours, 13-16 mai 1997. Mémoires du Musée de Préhistorire d'Ilde de France, 7: 129-138.

Vermeersch, P.-M. et Van Peer, P. (Eds.) (1990). Contributions to the Mesolithic in Europe. Actes du Colloque UISPP, Leuven. Leuven University Press.

Villaverde Bonilla, V. (Ed.) (1995). Los últimos cazadores. Transfomaciones culturales y económicas durante el Tardiglaciar y el inicio del Holoceno en el ámbito mediterráneo. Alicante, Instituto de Cultura Juan Gil Albert.

VVAA (1984). Préhistoire de la pierre taillée, 2: économie du débitage laminaire: technologie et expérimentation. III table ronde de technologie lithique, MeudonBellevue, octobre 1982. Paris, CREP.

VVAA (1991). 25 ans d'études techologiques en Préhistoire. Bilan et perspectives. Actes des rencontres 18-19-20 octobre 1990. XI ${ }^{\circ}$ Rencontres Internationales d'Archéologie et d'Histoire d'Antibes. Juan-les-Pins, APDCA.

VVAA (2003). Les matières premières lithiques en Préhistoire. Table ronde internationale organisée à Aurillac (Cantal), du 20 au 22 juin 2002. Service régional de l'archéologie d'Auvergne, UMR 5808 du CNRS "Milieux, techniques et cultures de la préhistoire", Musée national de préhistoire des Eyzies-de-Tayac (Dordogne). 
ÍNDICES :

CUADROS, GRÁFICOS, FIGURAS Y LÁMINAS 



\section{ÍNDICE DE CUADROS}

\section{CAPÍTULO I}

Cuadro I.1: fases teóricas de un análisis tecnológico y potencialidad de líneas de investigación de cada una de ellas.

Cuadro I.2: esquema-resumen de los distintos términos utilizados por los principales autores a la hora de conceptualizar las distintos niveles de análisis tecnológicos.

Cuadro I.3: propuesta del significado de los términos para la descripción de los distintos niveles de

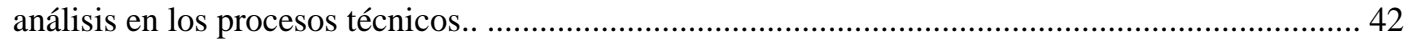

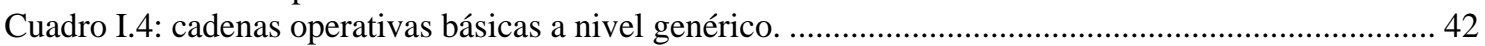

Cuadro I.5: diagrama ideal de una cadena operativa laminar. ......................................................... 44

Cuadro I.6: modelo hipotético de una cadena operativa laminar con las secuencias y procedimientos en que se puede dividir y las piezas líticas que corresponderían a cada segmento. .......................... 45

Cuadro I.7: Procedimientos y secuencias posibles en la fase de preparación (fase 1)........................... 47

Cuadro I.8: tipos de soportes según su número técnico y sus agrupaciones correspondientes en los grupos técnicos más amplios.

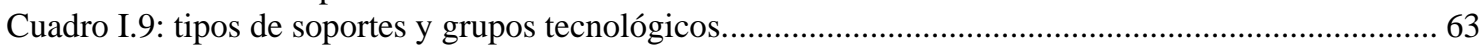

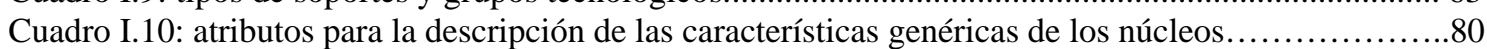

Cuadro I.11: atributos para la descripción de la superficie de extracciones. .............................80

Cuadro I.12: atributos para la descripción del plano de percusión. ..............................80

\section{CAPÍTULO III}

Cuadro III.1: plantilla para la descripción macroscópica de las materias primas. A partir del esquema proporcionado por J. Féblot-Agustins.

Cuadro III.2: Descripción macroscópica de las materias primas 167-169

\section{CAPÍTULO IV.1}

Cuadro SN.1: lista tecnológica del sílex negro........................................................................ 174

Cuadro SN.2: grupos tecnológicos del sílex negro. ....................................................................... 174

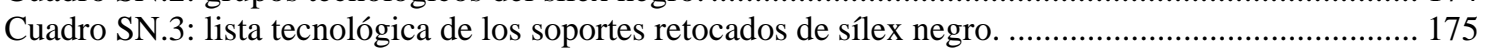

Cuadro SN.4: grupos tecnológicos del sílex negro en las piezas retocadas. ........................................ 175

Cuadro SN.5: piezas retocadas relativamente al total de las disponibles y según los distintos grupos

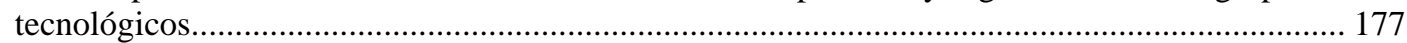

Cuadro SN.6: representación de los tipos de soportes enteros y fragmentados de sílex negro, teniendo en

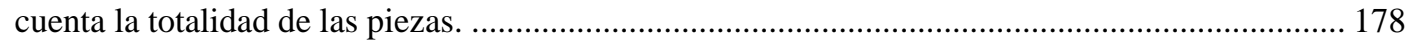

Cuadro SN.7: tipos de roturas en los distintos grupos tecnológicos. ................................................ 179

Cuadro SN.8: causa rotura en los distintos grupos tecnológicos. ...................................................... 181

Cuadro SN.9: presencia de córtex en los principales tipos tecnológicos, con sus respectivos porcentajes.

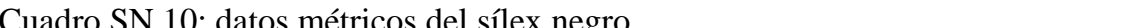

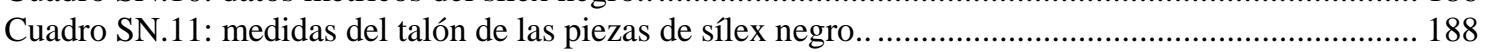

Cuadro SN.12: accidentes de talla según los distintos grupos tecnológicos. ........................................ 190

Cuadro SN.13: tipos de talón por grupos tecnológicos..................................................................... 193

Cuadro SN.14: piezas con talón y preparación relativa dentro de los distintos grupos tecnológicos. .... 195

Cuadro SN.15: tipos de preparación según los distintos grupos tecnológicos. ....................................... 195

Cuadro SN.16: tipos de preparación sobre los distintos tipos de talón. ................................................. 195

Cuadro SN.17: porcentaje de preparación en los distintos tipos de talón disponibles............................ 196

Cuadro SN.18: porcentaje de tipo de preparación por tipos de talón, separando por grupos tecnológicos.

Cuadro SN.19: ángulo externo o de la cornisa (ángulo 2) e interno (ángulo 1) por grupos tecnológicos...

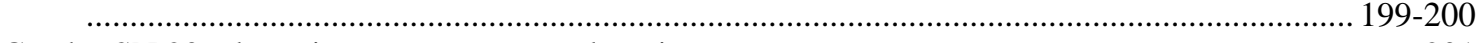

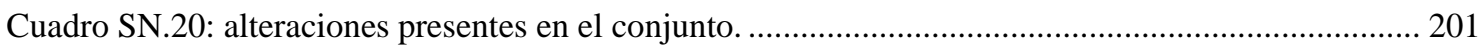

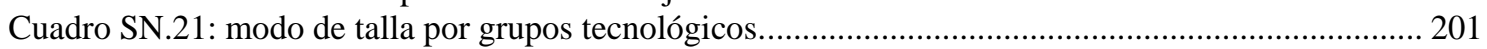

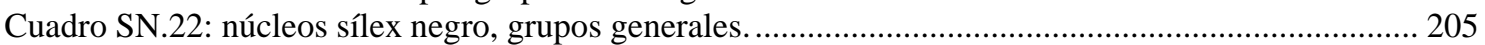

Cuadro SN.24: núcleos de sílex negro, características generales................................................... 206 
Cuadro SN.25: características de la superficie de extracciones de los núcleos de sílex negro................. 207

Cuadro SN.26: características planos de percusión de núcleos de sílex negro....................................... 208

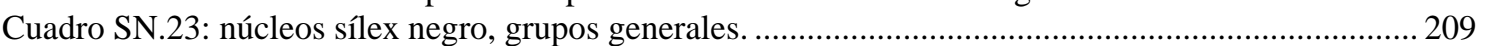

Cuadro SN.27: preparación o acondicionamiento de otras superficies del núcleo..................................212

Cuadro SN.28: características morfológicas de la superficie de extracciones. ..................................... 215

Cuadro SN.29: preparación/reparación/mantenimiento de la superficie de extracciones. ....................... 216

Cuadro SN.30: carena, cintra y dirección de las extracciones en los núcleos de sílex negro................... 218

Cuadro SN.31: preparación de las extracciones sobre la cornsisa e índice de regularidad ...................... 219

Cuadro SN.32: longitud de las últimas extracciones en los núcleos ................................................... 221

Cuadro SN.33: características del plano de percusión de los núcleos de sílex negro.............................. 222

Cuadro SN.34: reparación / acondicionamiento del plano de percusión, preparación del frente de percusión y morfología de la cornisa...................................................................................... 223

Cuadro SN.35: ángulo del frente de talla de los núcleos de sílex negro . .......................... 225

Cuadro SN.19: ángulo de la cornisa (ángulo 2) y ángulo interno (ángulo 1) por grupos tecnológicos.

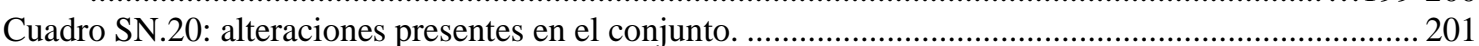

Cuadro SN.21: modo de talla por grupos tecnológicos................................................................... 201

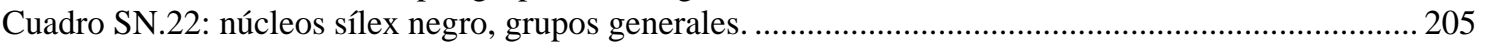

Cuadro SN.25: características de la superficie de extracciones de los núcleos de sílex negro................. 207

Cuadro SN.26 características planos de percusión de núcleos de sílex negro....................................... 208

Cuadro SN.23: núcleos sílex negro, grupos generales.. ................................................................ 209

Cuadro SN.27: preparación o acondicionamiento de otras superficies del núcleo................................. 212

Cuadro SN.28: características morfológicas de la superficie de extracciones. ..................................... 215

Cuadro SN.29: preparación/reparación/mantenimiento de la superficie de extracciones........................ 216

Cuadro SN.30: carena, cintra y dirección de las extracciones en los núcleos de sílex negro................... 218

Cuadro SN.31: preparación de las extracciones visible sobre la superficie de extracciones (sobre la cornsisa) e índice de regularidad de los negativos laminares. ................................................... 219

Cuadro SN.32: longitud de las últimas extracciones en los núcleos que se ha aprovechado toda la longitud de la superficie de extracciones en el estado de abandono. ...................................................... 221

Cuadro SN.33: características del plano de percusión de los núcleos de sílex negro.............................. 222

Cuadro SN.34: reparación / acondicionamiento del plano de percusión, preparación del frente de percusión morfología de la cornisa....................................................................................... 223

Cuadro SN.35: ángulo del frente de talla de los núcleos de sílex negro. ............................................ 225

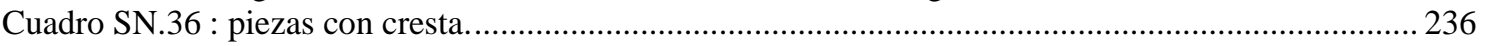

Cuadro SN.37: datos métricos de las piezas con cresta y de las tabletas y semitabletas de núcleo. ........ 238

Cuadro SN.38: datos métricos de los flancos de núcleo. ............................................................... 239

Cuadro SN.39: representación de piezas con arista natural ............................................................ 248

Cuadro SN.40: No de nervaduras en los soportes laminares .......................................................... 251

Cuadro SN.41: dirección de los negativos de los soportes laminares. ................................................ 252

Cuadro SN.42: perfil longitudinal de los soportes laminares........................................................... 253

Cuadro SN.43: sección transversal de los soportes laminares.......................................................... 254

Cuadro SN.44: índice de regularidad de los soportes laminares. ....................................................... 255

Cuadro SN.45: piezas retocadas de sílex negro, por tipos de soporte y por grupos tecnológicos............ 257

Cuadro SN.46: cadenas operativa y esquemas operativos presentes en el sílex negro ................. 274

\section{CAPÍTULO IV.2}

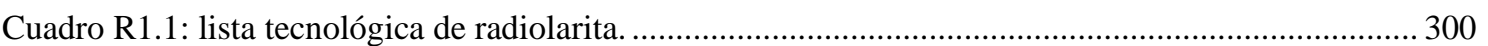

Cuadro R1.2: grupos tecnológicos de radiolarita. ......................................................................... 300

Cuadro R1.3: lista tecnológica de los soportes retocados de radiolarita. ............................................. 301

Cuadro R1.4: grupos tecnológicos de radiolarita en las piezas retocadas. ........................................... 301

Cuadro R1.5: piezas retocadas relativamente al total de las disponibles en los distintos grupos tecnológicos.

Cuadro R1.6: representación de los tipos de soportes enteros y fragmentados de radiolarita, teniendo en

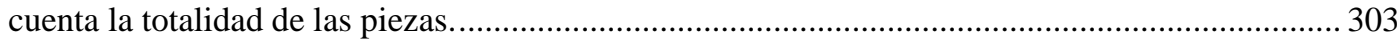

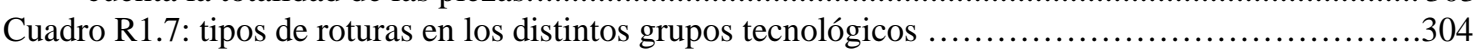

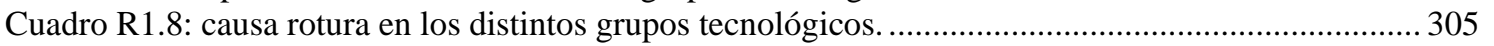

Cuadro R1.9: presencia de córtex en los principales tipos tecnológicos .............................................. 307 
Cuadro R1.10: datos métricos de la radiolarita, por grupos tecnológicos........................................... 309

Cuadro R1.11: datos métricos del talón de radiolarita ....................................................................... 310

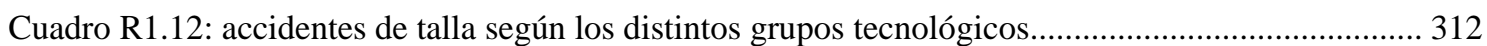

Cuadro R1.13: tipos de talón por grupos tecnológicos. ................................................................ 313

Cuadro R1.14: piezas con talón y preparación relativa dentro de los distintos grupos tecnológicos...... 315

Cuadro R1.15: tipos de preparación según los grupos tecnológicos................................................... 316

Cuadro R1.16: porcentaje de preparación en los distintos tipos de talón disponibles.............................. 316

Cuadro R1.17: tipos de preparación sobre los distintos tipos de talón.................................................. 316

Cuadro R1.18: porcentaje de tipo de preparación en los tipos de talón y por grupos tecnológicos. ........ 317

Cuadro R1.19: ángulos de percusión según los distintos grupos tecnológicos ............................... 319-320

Cuadro R1.20: alteraciones presentes en el conjunto...................................................................... 321

Cuadro R1.21: modo de talla por grupos tecnológicos. .................................................................. 321

Cuadro R1.22: núcleos de sílex negro, características generales...................................................... 327

Cuadro R1.23: núcleos de sílex negro, características de la superficie de extracciones ......................... 327

Cuadro R1.24: características de los planos de percusión de núcleos de radiolarita............................... 331

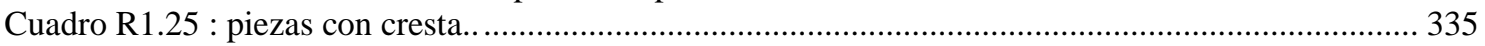

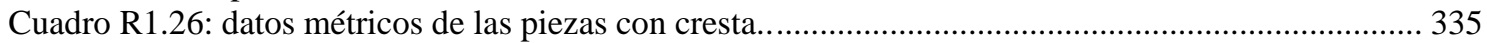

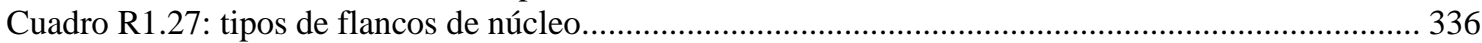

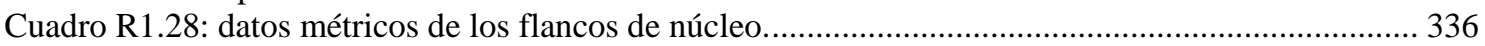

Cuadro R1.29: No de nervaduras en los soportes laminares............................................................. 344

Cuadro R1.30: dirección de los negativos de los soportes laminares ............................................... 344

Cuadro R1.31: perfil longitudinal de los soportes laminares. ....................................................... 345

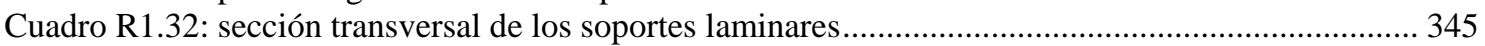

Cuadro R1.33: índice de regularidad de los soportes laminares ...................................................... 346

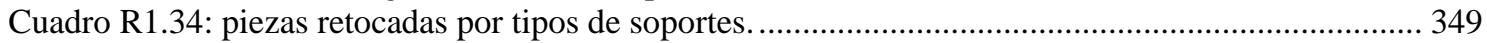

\section{CAPÍTULO IV.3}

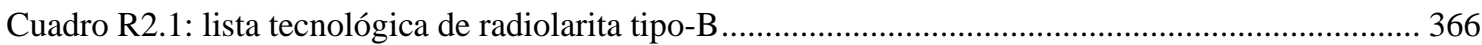

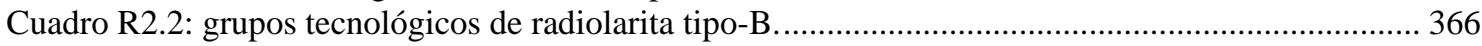

Cuadro R2.3: lista tecnológica de los soportes retocados de sílex negro............................................ 367

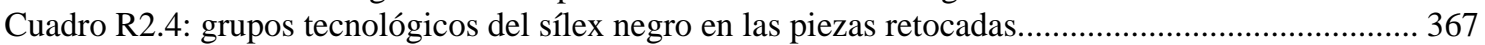

Cuadro R2.5: piezas retocadas respecto al total de las disponibles y por grupos tecnológicos. .............. 368

Cuadro R2.6: representación de los tipos de soportes enteros y fragmentados de radiolarita, teniendo en

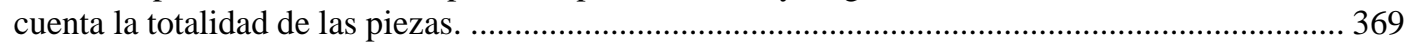

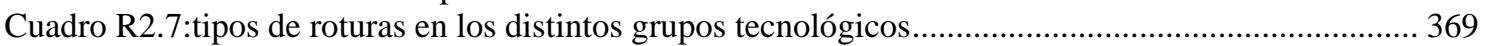

Cuadro R2.8: causa rotura en los distintos grupos tecnológicos....................................................... 371

Cuadro R2.9: presencia de córtex en los principales tipos tecnológicos.......................................... 372

Cuadro R2.10: datos métricos de la radiolarita, por grupos tecnológicos........................................... 373

Cuadro R2.11: datos métricos de los talones de radiolarita tipo-B, por grupos tecnológicos.................. 375

Cuadro R2.12: accidentes de talla según los distintos grupos tecnológicos.......................................... 376

Cuadro R2.13 tipos de talón por grupos tecnológicos ................................................................. 377

Cuadro R2.14: piezas con talón y preparación relativa dentro de los distintos grupos tecnológicos ...... 378

Cuadro R2.15: tipos de preparación según los distintos grupos tecnológicos. ........................................ 378

Cuadro R2.16: porcentaje de preparación en los distintos tipos de talón disponibles.............................. 379

Cuadro R2.17: tipos de preparación sobre los distintos tipos de talón................................................... 379

Cuadro R1.18: porcentaje de tipo de preparación en los tipos de talón y por grupos tecnológicos .......... 380

Cuadro R2.19: ángulos de percusión según los distintos grupos tecnológicos. ................................ 381-382

Cuadro R2.20: núcleos de radiolarita tipo-B, características generales ............................................... 387

Cuadro R2.21: características de la superficie de extracciones de los núcleos de radiolarita tipo-B ....... 387

Cuadro R2.22: características planos de percusión de núcleos de radiolarita tipo-B............................ 387

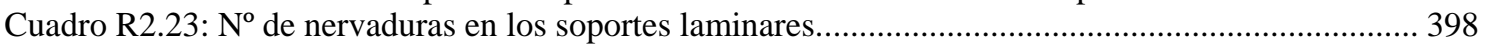

Cuadro R2.24: dirección de los negativos de los soportes laminares ................................................. 398

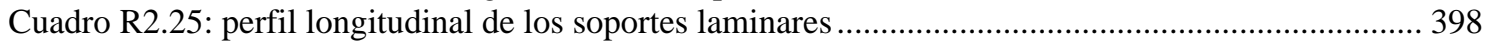

Cuadro R2.26: sección transversal de los soportes laminares.............................................................. 399

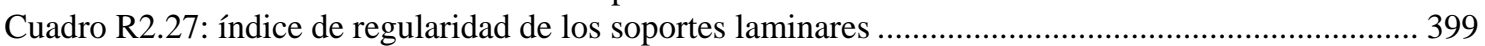

Cuadro R2.28: piezas retocadas por tipos de soportes. ................................................................... 400 


\section{CAPÍTULO IV.4}

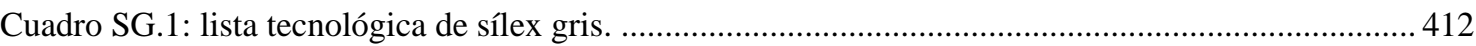

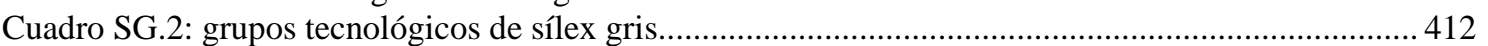

Cuadro SG.3: lista tecnológica de los soportes retocados de sílex gris.................................................... 413

Cuadro SG.4: grupos tecnológicos del sílex gris en las piezas retocadas. .................................................. 413

Cuadro SG.5: piezas retocadas relativamente al total de las disponibles y por grupos tecnológicos........ 414

Cuadro SG.6: representación de los tipos de soportes enteros y fragmentados de sílex gris, teniendo en cuenta la totalidad de las piezas.

Cuadro SG.7: tipos de roturas en los distintos grupos tecnológicos ............................................................ 415

Cuadro SG.8: causa rotura en los distintos grupos tecnológicos................................................................. 416

Cuadro SG.9: datos métricos de los talones de radiolarita tipo-B, por grupos tecnológicos..................... 419

Cuadro SG.10: datos métricos de los talones de radiolarita tipo-B, por grupos tecnológicos................... 420

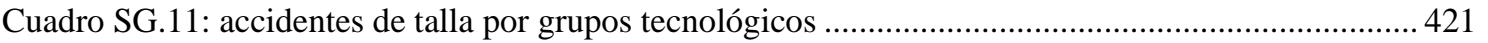

Cuadro SG.12: tipos de talón por grupos tecnológicos .............................................................................. 422

Cuadro SG.13: piezas con talón y preparación relativa dentro de los distintos grupos tecnológicos........ 423

Cuadro SG.14: tipos de preparación según los distintos grupos tecnológicos ............................................. 423

Cuadro SG.15: porcentaje de preparación en los distintos tipos de talón disponibles ................................. 423

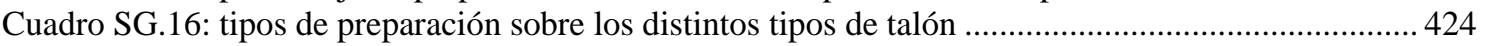

Cuadro SG.17: ángulos de percusión por grupos tecnológicos ......................................................... 424-426

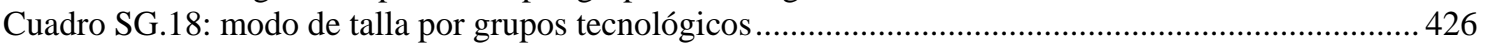

Cuadro SG.19: núcleos de sílex gris, características generales................................................................. 428

Cuadro SG.20: características de la superficie de extracciones de los núcleos de sílex gris...................... 428

Cuadro SG.21: características planos de percusión de núcleos de sílex gris.............................................. 428

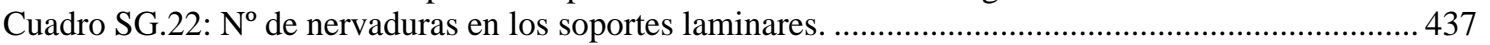

Cuadro SG.23: dirección de los negativos de los soportes laminares ...........................................................437

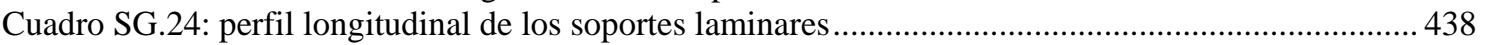

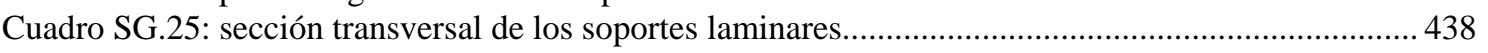

Cuadro SG.26: índice de regularidad de los soportes laminares .................................................................. 438

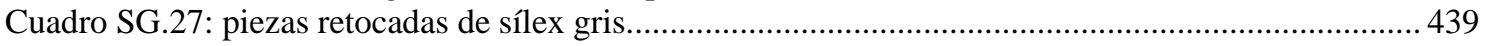

\section{CAPÍTULO IV.5}

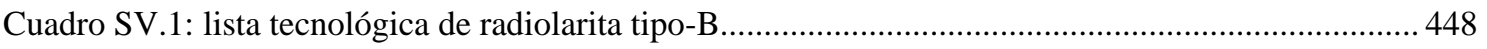

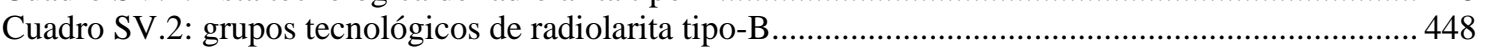

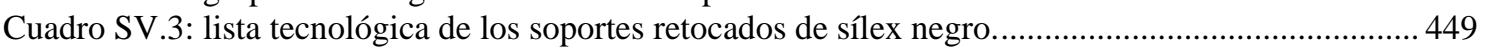

Cuadro SV.4: grupos tecnológicos del sílex negro en las piezas retocadas. .............................................. 449

Cuadro SG.5: piezas retocadas relativamente al total de las disponibles y por grupos tecnológicos........ 450

Cuadro SV.6: representación de los tipos de soportes enteros y fragmentados de radiolarita, teniendo en

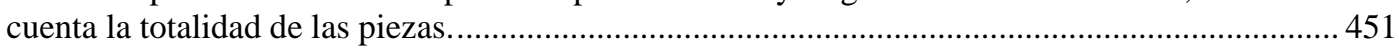

Cuadro SV.7: tipos de roturas en los distintos grupos tecnológicos. ........................................................... 451

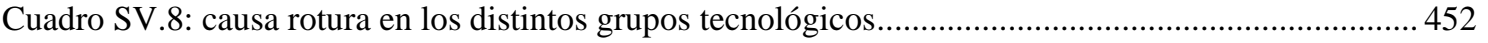

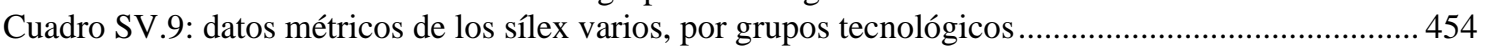

Cuadro SV.10: datos métricos de los talones de radiolarita tipo-B, por grupos tecnológicos................... 455

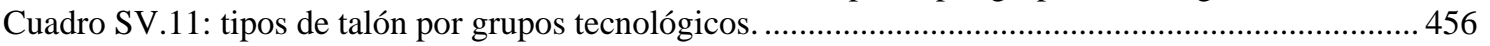

Cuadro SV.12: piezas con talón y preparación relativa dentro de los distintos grupos tecnológicos....... 457

Cuadro SV.13: tipos de preparación según los distintos grupos tecnológicos. .............................................457

Cuadro SV.14: porcentaje de preparación en los distintos tipos de talón disponibles .................................457

Cuadro SV.15: tipos de preparación sobre los distintos tipos de talón ..........................................................45

Cuadro SV.16: ángulos de percusión según los grupos tecnológicos. ................................................458-459

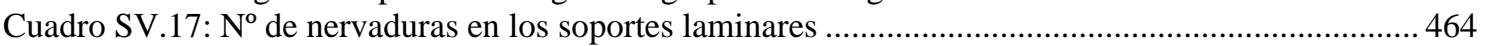

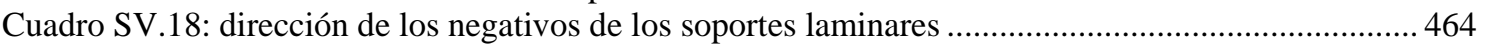

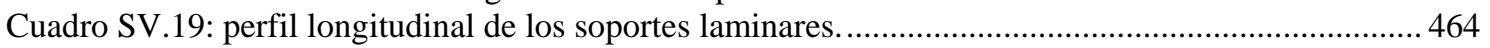

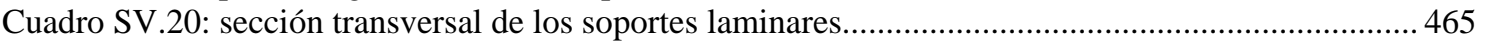

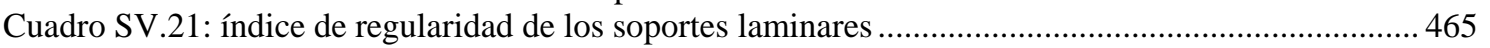

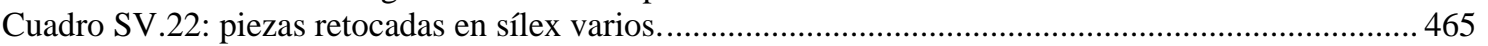




\section{CAPÍTULO IV.6}

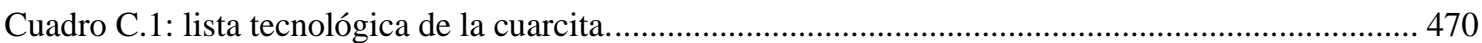

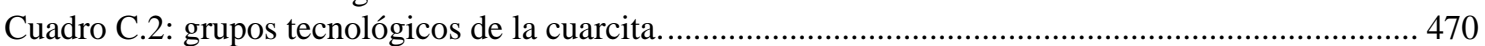

Cuadro C.3: lista tecnológica de los soportes retocados de sílex negro.................................................. 471

Cuadro C.4: grupos tecnológicos del sílex negro en las piezas retocadas.....................................................47 471

Cuadro C.5: piezas retocadas relativamente al total de las disponibles por grupos tecnológicos ............. 472

Cuadro C.6: representación de los tipos de soportes enteros y fragmentados de sílex negro, teniendo en cuenta la totalidad de las piezas.

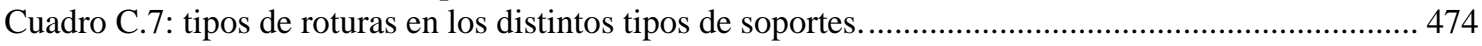

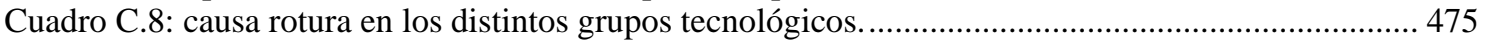

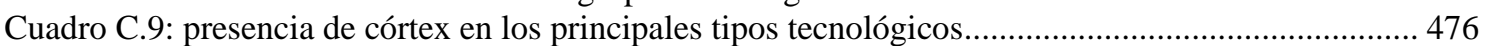

Cuadro C.10: datos métricos de la cuarcita, por grupos tecnológicos ........................................................... 478

Cuadro C.11: datos métricos de los talones de cuarcita, por grupos tecnológicos....................................... 479

Cuadro C.12: accidentes de talla según los distintos grupos tecnológicos ................................................... 480

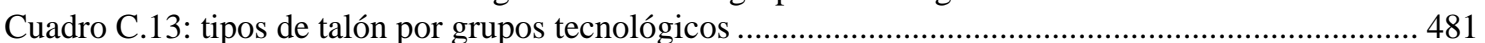

Cuadro C.14: piezas con talón y preparación relativa dentro de los distintos grupos tecnológicos......... 482

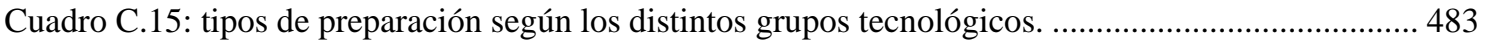

Cuadro C.16: porcentaje de preparación en los distintos tipos de talón disponibles................................... 483

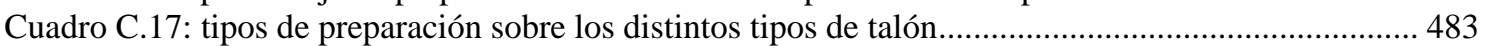

Cuadro C.18: tipos de talón con los tipos de preparación y por grupos tecnológicos....................................4 484

Cuadro C.19: ángulos de percusión según los grupos tecnológicos...................................................... 485-486

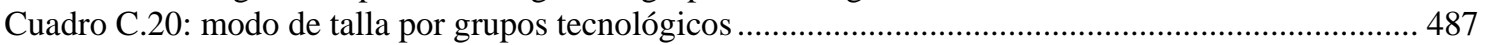

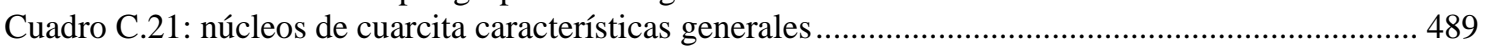

Cuadro C.22: características de la superficie de extracciones de los núcleos de cuarcita.......................... 499

Cuadro C.23: características planos de percusión de núcleos de cuarcita...................................................... 501

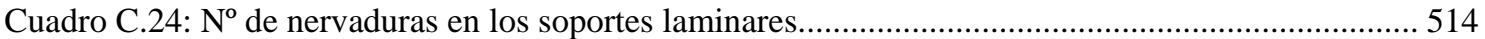

Cuadro C.25: dirección de los negativos de los soportes laminares. .......................................................... 514

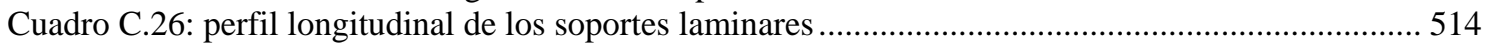

Cuadro C.27: sección transversal de los soportes laminares...................................................................... 515

Cuadro C.28: índice de regularidad de los soportes laminares ............................................................ 515

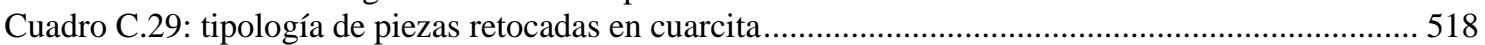

Cuadro C.30: cadenas operativas y esquemas operativos de cuarcita......................................................... 521

\section{CAPÍTULO IV.7}

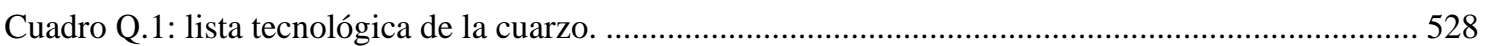

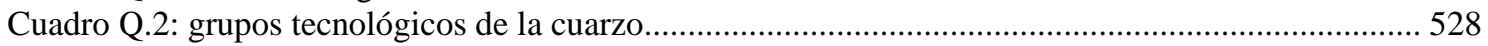

Cuadro Q.3: representación de los tipos de soportes enteros y fragmentados de cuarzo, teniendo en cuenta

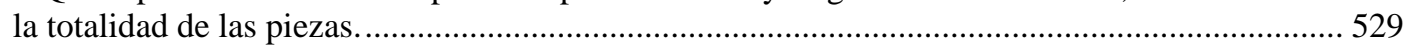

Cuadro Q.4: tipos de roturas por grupos tecnológico ...................................................................... 530

Cuadro Q.5: causa de las roturas del cuarzo, por grupos tecnológicos...................................................... 531

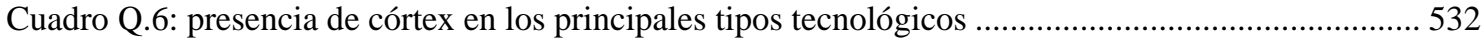

Cuadro Q.7: datos métricos de la radiolarita, por grupos tecnológicos .................................................... 533

Cuadro Q.8: datos métricos de los talones de cuarzo, por grupos tecnológicos ...................................... 533

Cuadro Q.9: accidentes de talla según los distintos grupos tecnológicos .................................................. 534

Cuadro Q.10: tipos de talón por grupos tecnológicos ............................................................................... 535

Cuadro Q.11: piezas con talón y preparación relativa dentro de los distintos grupos tecnológicos......... 535

Cuadro Q.12: tipos de preparación según los distintos grupos tecnológicos. ............................................ 536

Cuadro Q.13: porcentaje de preparación en los distintos tipos de talón disponibles. ................................ 536

Cuadro Q.14: tipos de preparación sobre los distintos tipos de talón .......................................................... 536

Cuadro Q.15: ángulos de percusión por grupos tecnológicos .................................................................. 537

\section{CAPÍTULO V}

Cuadro V.1: presencia de los distintos tipos de materias primas en El Espertín y en su entorno geológico

Cuadro V.2: lista tipológica del conjunto retocado, separando por tipos de soportes y por grupos tecnológicos. 
Cuadro V.4: porcentaje de la lista tipológica del conjunto de El Espertín, por materias primas.............. 587

Cuadro V.5: lista tipológica del total de las materias de El Espertín. .................................................. 589

Cuadro V.6: porcentaje de la lista tipológica según los grupos tecnológicos. ......................................590

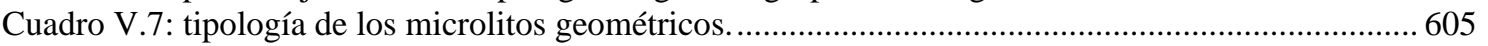

Cuadro V.8: media (en mm.) de las medidas de los geométricos en radiolarita ................................... 606

Cuadro V.9: dorsos retocados, distribución por materias primas y por tipos de soportes...................... 613

Cuadro V.10: tipología de las piezas con dorso y distribución por materias primas.............................. 614

Cuadro V.11: cadenas operativas con sus correspondientes esquemas operativos. ...............................620 


\section{ÍNDICE DE FIGURAS}

\section{CAPÍTULO I}

Figura I.1: Atributos métricos del talón. 54

Figura I.2: Ejemplo de operaciones de preparación de la extracción laminar....................................... 56

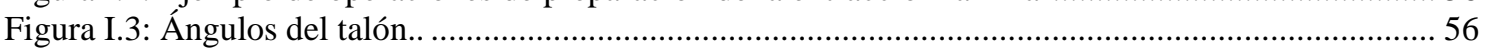

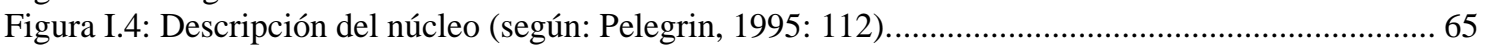

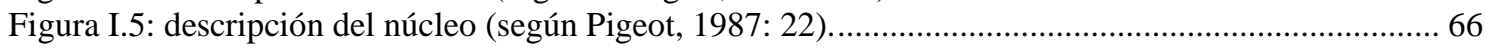

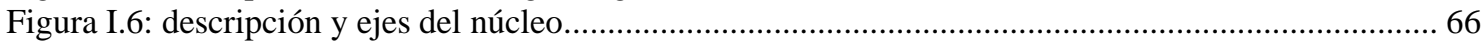

Figura I.7: avance del débitage en tablas a través de la superficie de extracciones (según Valentin, 1995: anexos, p.4).

Figura I.8: relación entre el ángulo de percusión y los reavivados del frente de talla (según Valentin, 1995: anexos, p.16).

Figura I.9: neo-cresta. Reavivado de la cintra del núcleo a partir de extracciones transversales anteroposterioes (cresta), con la extracción de la neo-cresta (Según: Pelegrin, 1995: p. 140).................. 84

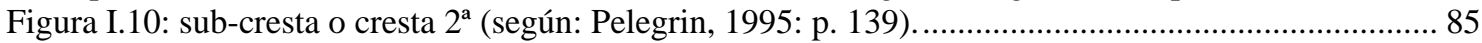

Figura I.11: crestas sobre el núcleo, hojas con neo-cresta, con neo-cresta parcial y hojas con flanco. ..... 85

Figura I.12: procesos de arreglo de la superficie de extracciones: los flancos de núcleo. ........................86

Figura I.13: procedimientos de reforma / acondicionamiento del plano de percusión. ...................89

\section{CAPÍTULO II}

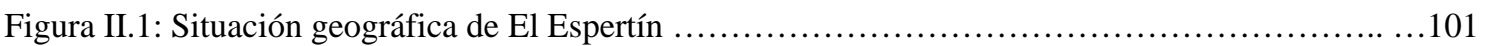

Figura II.2: Planta de la cueva de El Espertín ............................................... 101

Figura II.3: Esquema geológico de la Cornisa Cantábrica . ...................................110

Figura II.4: La Zona Cantábrica con la situación de la Hoja de Burón .............................111

Figura II.5: Esquema de las unidades geológicas de la Zona Cantábrica y corte geológico ..............112

Figura II.6: Columnas estratigráficas de las principales unidades litológicas de la Zona Cantábrica......117

\section{CAPÍTULO IV.1}

Figura SN.1: núcleos de sílex negro a partir del esquema prismático “clásico” tipo A.......................... 226

Figura SN.2: núcleos de sílex negro a partir del esquema prismático tipo-B. .................................... 227

Figura SN.3: núcleos de sílex negro, a partir del esquema prismático tipo-B. .................................... 2228

Figura SN.4: núcleos de sílex negro a partir del esquema prismático tipo-B. ..................................... 229

Figura SN.5: núcleos de sílex negro, a partir del esquema prismático genérico................................... 230

Figura SN.6: núcleos de sílex negro, a partir del esquema prismático de superficie ancha, unipolar...... 231

Figura SN.7: núcleos de sílex negro, a partir del esquema prismático de superficie ancha, bipolar........ 232

Figura SN.8: núcleos de sílex negro, a partir del esquema unipolar - prismático. ............................... 233

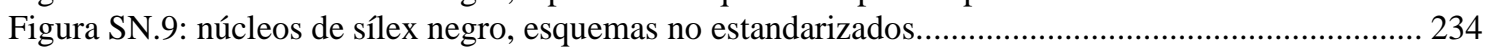

Figura SN.10: núcleo de sílex negro, a partir del esquema tipo “nódulo-placa”. ................................. 235

Figura SN.11: productos de acondicionamiento de sílex negro. ...................................................... 245

Figura SN.12: productos de acondicionamiento de sílex negro: piezas con cresta................................ 242

Figura SN.13: productos de acondicionamiento de sílex negro: flancos de núcleo ................................ 243

Figura SN.14: piezas retocadas de sílex negro: raspadores. ............................................................ 259

Figura SN.15: piezas retocadas de sílex negro: raspadores. ......................................................... 260

Figura SN.16: piezas retocadas de sílex negro: buriles................................................................ 261

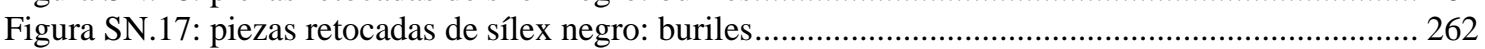

Figura SN.18: piezas retocadas de sílex negro: buriles, raclette y útil compuesto ............................... 263

Figura SN.19: piezas retocadas de sílex negro: buriles y perforadores ............................................. 264

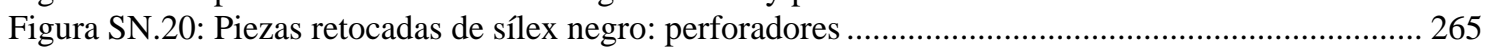

Figura SN.21: Piezas retocadas de sílex negro: truncaduras, raclette y astilladas. ............................... 266

Figura SN.22: Piezas retocadas de sílex negro: piezas con retoque continuo..................................... 267

Figura SN.23: Piezas retocadas de sílex negro: piezas de retoque continuo..................................... 268

Figura SN.24: Piezas retocadas de sílex negro: piezas de retoque continuo........................................ 269

Figura SN.25: Piezas retocadas de sílex negro: escotaduras sobre soporte tipo-lasca............................ 270

Figura SN.26: Piezas retocadas de sílex negro: escotaduras.......................................................... 271 
Figura SN.27: Piezas retocadas de sílex negro: denticulados sobre soporte tipo-lasca. 272

Figura SN.28: Piezas retocadas de sílex negro: denticulados sobre soporte laminar y microlaminar y

fragmentos mesiales de hojitas con escotadura

\section{CAPÍTULO IV.2}

Figura R1.1: núcleos de hojas de radiolarita-1, a partir del esquema prismático tipo-B, unipolar........... 332

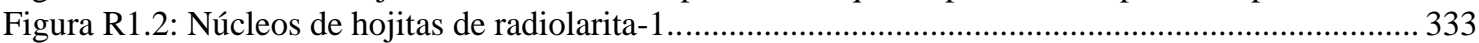

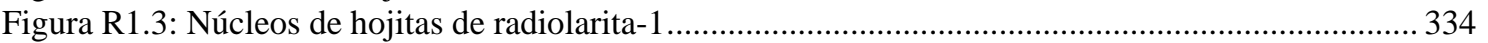

Figura R1.4: productos de acondicionamiento de radiolarita-1. Hojas con neo-cresta parcial y semitabletas de núcleo......

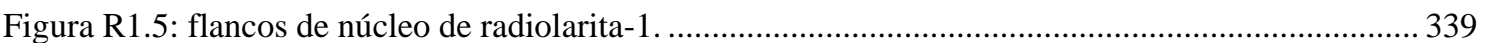

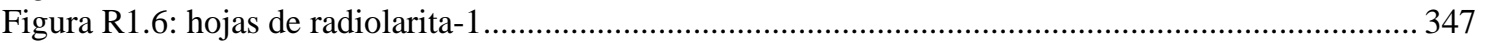

Figura R1.7: Hojas y hojitas fragmentadas de radiolarita-1 ....................................................... 348

Figura R1.8: Piezas retocadas de radiolarita-1................................................................................ 352

\section{CAPÍTULO IV.3}

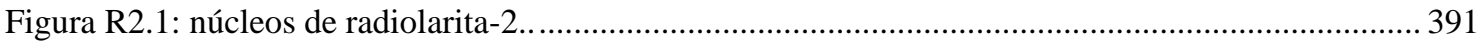

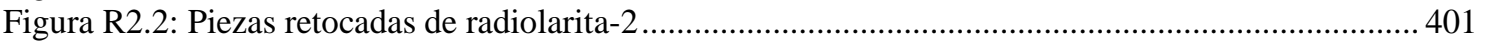

\section{CAPÍTULO IV.4}

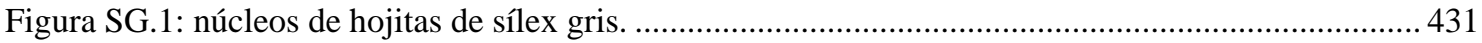

Figura SG.2: Piezas retocadas de sílex gris $\ldots \ldots \ldots \ldots \ldots \ldots \ldots \ldots \ldots \ldots \ldots \ldots \ldots \ldots \ldots \ldots \ldots \ldots \ldots \ldots, 441$

\section{CAPÍTULO IV.5}

Figura SV.1: Núcleo de sílex varios, a partir del esquema prismático tipo-A (unipolar-convergente).... 461

\section{CAPÍTULO IV.6}

Figura C.1: núcleos de cuarcita. Esquema prismático....................................................................503

Figura C.2: Núcleos de cuarcita. Esquema prismático de superficie ancha. ........................................504

Figura C.3: núcleos de cuarcita. Esquema unipolar-prismático..................................................... 504

Figura C.4: núcleos de cuarcita. Cadena operativa centrípeta/discoide. ..............................................505

Figura C.5: núcleo de cuarcita, cadena operativa tipo nódulo-placa................................................5 506

Figura C.6: núcleo de cuarcita, sobre lasca. Esquema no estandarizado............................................ 506

Figura C.7: núcleo de cuarcita. Esquema no estandarizado (núcleo globuloso). ..................................507

Figura C.8: núcleos de cuarcita. Esquemas no estandarizados......................................................... 508

Figura C.9: productos de acondicionamiento de cuarcita. Flancos y semitabletas de núcleo .................. 510

Figura C.10: producto de acondicionamiento de cuarcita, roto en tres fragmentos. .............................. 510

Figura C.11: soportes laminares y microlaminares de cuarcita........................................................ 516

Figura C.12: Piezas retocadas de cuarcita: Raspadores, buril y perforadores ..................................... 519

Figura C.13: Piezas retocadas de cuarcita: denticulados-escotaduras, retoque continuo, pieza retocada y

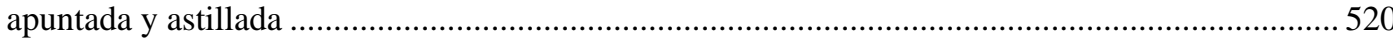

\section{CAPÍTULO V}

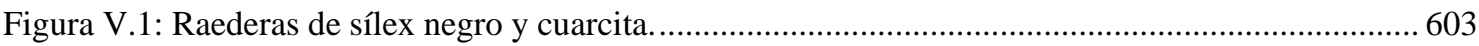

Figura V.2: Microlitos geométricos, microburiles y hojas con una rotura al lado de una escotadura...... 607

Figura V.3: esquema de la “técnica de rotura transversal”. ............................................................ 611

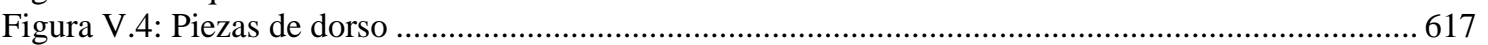

Figura V.5: Punta con muesca en sílex varios y punta con pedúnculo en sílex negro ............................ 619

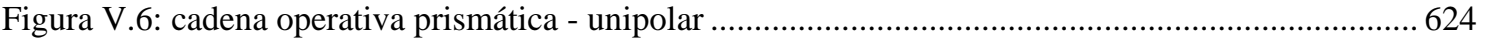

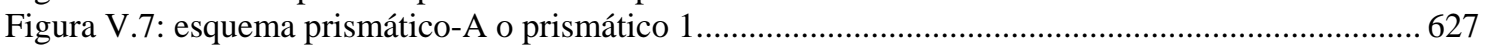

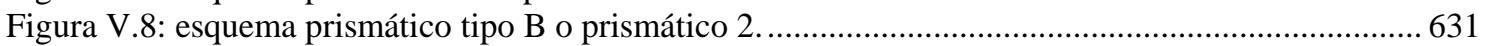

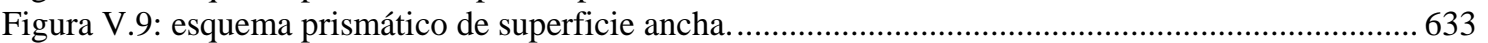

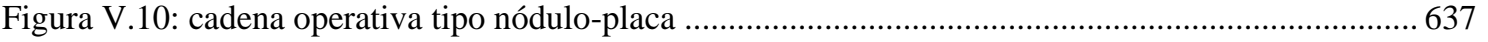

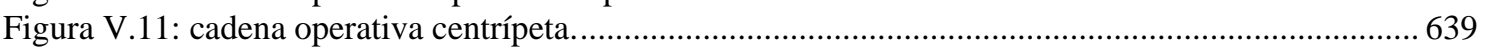




\section{ÍNDICE DE GRÁFICOS}

\section{CAPÍTULO IV.1}

Gráfico SN.1: porcentaje de los tipos de roturas por grupos tecnológicos. ......................................... 180

Gráfico SN.2: porcentaje de representación de las causas de la rotura según los distintos tipos de fracturas y por grupos tecnológicos.

Gráfico SN.3: accidentes de talla por grupos tecnológicos............................................................... 190

Gráfico SN.4: tipos de talón por grupos tecnológicos .................................................................... 193

Gráfico SN.5: longitud de los soportes del grupo tecnológio 1 ...................................................... 247

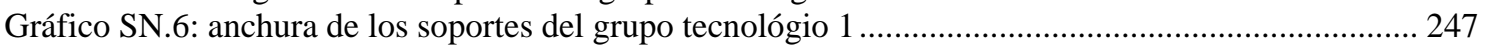

Gráfico SN.7: longitud de los soportes del grupo tecnológico 2 ....................................250

Gráfico SN.8: anchura de los soportes del grupo tecnológico 2 .................................250

\section{CAPÍTULO IV.2}

Gráfico R1.1: porcentaje de los tipos de roturas por grupos tecnológicos.

304

Gráfico R1.2: porcentaje de representación de las causas de la rotura según los distintos tipos de fracturas

y por grupos tecnológicos.

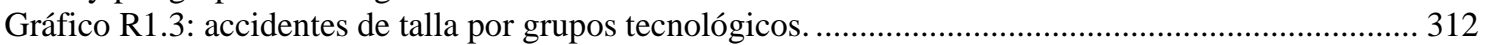

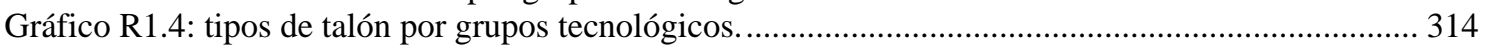

Gráfico R1.5 : longitud de los soportes de radiolarita-1 del grupo tecnológio 1 ................................. 341

Gráfico R1.6: anchura de los soportes de radiolarita-1del grupo tecnológio 1 .................................... 341

Gráfico R1.7: longitud de los soportes del grupo tecnológio 2 (hojas, hojitas). ................................... 343

Gráfico R1.8: anchura de los soportes del grupo tecnológio 2 (hojas, hojitas).................................... 343

\section{CAPÍTULO IV.3}

Gráfico R2.1: porcentaje de los tipos de roturas por grupos tecnológicos

Gráfico R2.2: porcentaje de representación de las causas de la rotura según los distintos tipos de fracturas

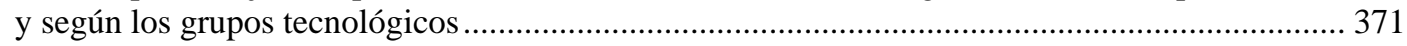

Gráfico R2.3: accidentes de talla por grupos tecnológicos ......................................................... 376

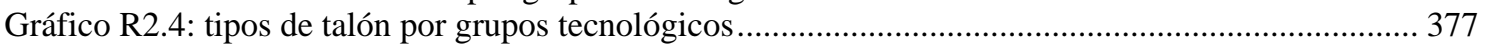

Gráfico R2.5 : longitud de los soportes de radiolarita-1 del grupo tecnológio 1 ................................. 394

Gráfico R2.6: anchura de los soportes de radiolarita-1del grupo tecnológio 1 .................................... 395

Gráfico R2.7: longitud de los soportes del grupo tecnológio 2 (hojas, hojitas) ................................... 397

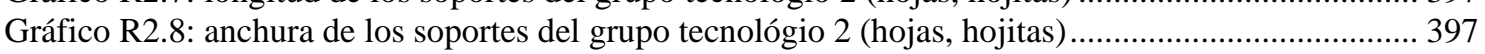

\section{CAPÍTULO IV.4}

Gráfico SG.1: porcentaje de los tipos de roturas por grupos tecnológicos.

Gráfico SG.2: porcentaje de representación de las causas de la rotura según tipos de fracturas y por grupos tecnológicos.

Gráfico SG.3: accidentes de talla por grupos tecnológicos.......................................................... 421

Gráfico SG.4: tipos de talón por grupos tecnológicos ..................................................................422

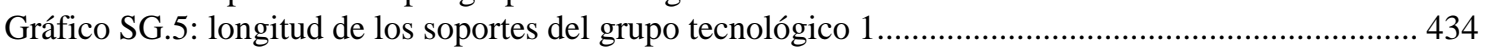

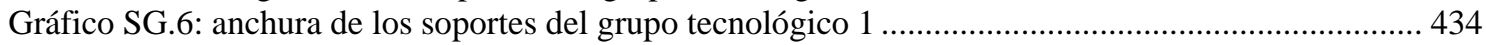

Gráfico SG.7: longitud de los soportes del grupo tecnológico 2 (hojas, hojitas) .................................. 436

Gráfico SG.8: anchura de los soportes del grupo tecnológio 2 (hojas, hojitas) ................................... 436

\section{CAPÍTULO IV.5}

Gráfico SV.1: porcentaje de los tipos de roturas por grupos tecnológicos. ..........................452

Gráfico SV.2: porcentaje de representación de las causas de la rotura según los tipos de fracturas y por grupos tecnológicos

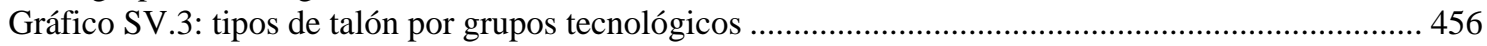

Gráfico SV.4: longitud de los soportes del grupo tecnológico 2 (hojas, hojitas)................................. 463

Gráfico SV.5: anchura de los soportes del grupo tecnológico 2 (hojas, hojitas)................................... 463 


\section{CAPÍTULO IV.6}

Gráfico C.1: porcentaje de los tipos de roturas por grupos tecnológicos

Gráfico C.2: porcentaje de representación de las causas de la rotura según tipos de fracturas y por grupos tecnológicos.......

Gráfico C.3: accidentes de talla por grupos tecnológicos ................................................................... 481

Gráfico C.4: tipos de talón por grupos tecnológicos ............................................................................. 482

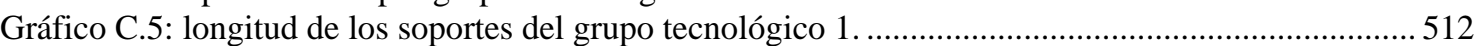

Gráfico C.6: anchura de los soportes del grupo tecnológico 1 ............................................................. 512

Gráfico C.7: longitud de los soportes del grupo tecnológico 2 ........................................................ 513

Gráfico C.8: anchura de los soportes del grupo tecnológico 2 ......................................................... 513

\section{CAPÍTULO IV.7}

Gráfico Q.1: porcentaje de los tipos de roturas por grupos tecnológicos.

Gráfico Q.2: porcentaje de representación de las causas de la rotura según los tipos de fracturas y por grupos tecnológicos

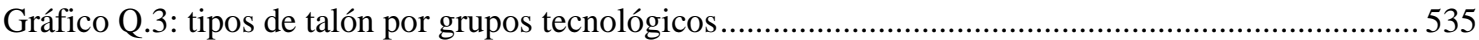

Gráfico Q.4: Longitud lascas (grupo tecnológico 1) de cuarzo..........................................................540

Gráfico Q.5: Anchura lascas (grupo tecnológico 1) de cuarzo..............................................................5 540

\section{CAPÍTULO V}

Gráfico V.1: gráfico circular con el porcentaje de las distintas materias de la industria lítica de El Espertín

Gráfico V.3: gráficos de dispersión del grosor y anchura de los artefactos líticos, según las distintas materias primas

546

Gráfico V.6: tipos de roturas por materias

Gráfico V.7: causa de las roturas por materias primas ................................................................... 559

Gráfico V.8: tipos de accidentes en las distintas materias primas.....................................................564

Gráfico V.9: porcentaje de preparación del punto de impacto por materias primas ..............................567

Gráfico V.10: tipos de preparación por materias primas.....................................................................5 568

Gráfico V.11: tipos de talón en las distintas materias primas .......................................................... 569

Gráfico V.12: ángulo del frente de percusión (ángulo 2: entre el talón y la cara superior) en las materias y por los grupos tecnológicos 571-573

Gráfico V.13: porcentajes de representación de los grupos tecnológicos por materias primas, diferenciando los soportes retocados y sin retocar..

Gráfico V.14: porcentaje de representación de las distintas materias primas, con y sin retoque .............587

Gráfico V.15: gráfico de dispersión de los raspadores, buriles, piezas de retoque continuo y truncaduras; según su longitud y anchura, y por materias primas....

Gráfico V.16: gráfico de dispersión de las escotaduras, denticulados y piezas de dorso; según su longitud y anchura, y separando las materias primas. Las raederas, raclettes y astilladas se presentan en otro gráfico de dispersión, sin separar en este caso las materias

Gráfico V.17: gráficos de dispersión de las hojitas y las puntas de dorso, por materias primas. 


\section{ÍNDICE DE LÁMINAS}

Lámina 1: Situación de El Espertín en el mapa geológico E. 1:200.000 (Julivert et al., 1981) 159

Lámina 2: Afloramientos de chert y radiolarita

160 
APÉNDICE :

TRADUCCIÓN FRANCÉS 



\section{INTRODUCTION}

L'objectif principal de cette étude est celui d'élaborer une analyse technologique du matériel lithique d'un gisement préhistorique. Cet objectif est matérialisé par la mise en place des structures opératoires fondamentales réalisées par le groupe préhistorique concret, avec les implications qu'elles englobent par rapport à des espaces socioéconomiques, et en définitive culturels, par exemple, les méthodes d'exploitation du matériel lithique du milieu.

Dans un tout premier moment, notre étude s'est appuyée sur un cadre d'analyse plus ample, en relation avec le matériel lithique du gisement fin du Paléolithique Supérieur-Épipaléolithique situé dans le bassin du Duero. Ce projet initial a dû être modifié afin d'atteindre des objectifs beaucoup plus concrets et spécifiques pour des raisons méthodologiques. Le type d'analyse que nous voulions mettre en place dans chaque série lithique était de type technologique, ce qui nous obligeait, nécessairement, à tenir en compte, tout un ensemble d'éléments lithiques taillés provenant de chaque gisement archéologique. Cette activité d'analyse doit être complétée, logiquement, dans chaque cas, avec une synthèse de tout le processus technique développé par le groupe préhistorique sur le matériel lithique.

À cause de ces besoins méthodologiques, et puisque nous ne comptions, dans ce cadre géographique d'étude, que d'un seul gisement qui réunissait les conditions idéales afin de mener à bien cette analyse, nous avons décidé de cadrer notre étude sur le gisement de El Espertín. D’un point de vue géographique, cette petite grotte est située dans le bassin du Duero. Cependant nous devons tenir compte de son emplacement dans un milieu de montagne, aux portes de Picos de Europa et tout près de la zone qui divise les deux versants; ce qui correspond à une surface marginale de ce bassin, caractérisée par un relief avec une prédominance plate. Le gisement est exceptionnel, non seulement par sa propre position géographique, situé à une altitude qui surpasse les 1200 mètres ce qui indique une connexion avec le versant septentrional de la corniche Cantabrique; mais surtout parce que la période à laquelle elle appartient, le Mésolithique, est mal connue dans ce milieu. Par conséquent le choix de cette étude, n'a pas été aléatoire, puisque ces circonstances le justifient pleinement. 


\section{LES RAISONS D’UNE ÉTUDE TECHNOLOGIQUE.}

L'intérêt majeur au tout début de ce travail est focalisé dans l'élaboration d'une étude de type technologique sur le matériel lithique préhistorique. De cette façon, nous voulions aborder ce type de matériel, primordial dans ce contexte Paléolithique, d'un point de vue de celui qui était en train de s'étendre tout au long de ces deux dernières décades dans d'autres régions européennes. Ce type de rapprochement répond à une volonté constante d'extraire le plus possible d'information, à partir de plusieurs focalisations, d'une série de données matérielles qui ont toujours été traitées traditionnellement à partir de perspectives plus immédiates (typologiques principalement).

Aujourd'hui ce type d'analyse est considéré comme très utile selon divers objectifs (économique, spatial, cognitif, etc...) et spécialement afin de contribuer à une meilleure caractérisation des modèles économiques utilisés par les différents groupes humains, et de même pour un rapprochement de ses caractéristiques culturelles plus immédiates. Ce type d'études technologique est ainsi encadré, en conjonction avec le reste des analyses interdisciplinaires, dans une perspective d'études du matériel lithique qui prétend apporter des synthèses économico-stratégiques, lesquelles vont nous permettre de comprendre les groupes préhistoriques, en relation, non seulement avec le contexte de l’environnement, mais aussi avec ses caractéristiques culturelles.

\section{LA GROTTE DE « EL ESPERTÍN »}

Comme nous l'avons dit précédemment, nous avons commencé a appliquer ce type d'analyse technologique l'ensemble lithique d'un gisement fouillé dans la montagne au nord-ouest de León, la grotte de El Espertín, gisement captivant pour deux raisons :

i) sa particulière situation géographique, déjà mentionnée

ii) les caractéristiques archéologiques du même gisement, avec une seule période représenté, apte pour appliquer l’analyse de type technologique. 
El Espertín, situé dans une vallée secondaire de la source du fleuve Esla à plus de 1200 mètres d'altitude, constitue un des rares gisements connus à l'intérieur de la Cordillère Cantabrique à cette altitude. Les seules exceptions sont la grotte de La Uña (Burón, León), située très près de El Espertín à une altitude similaire avec un niveau Azilien (Neira et al., 1997) et l'abri de La Mina (Dobarganes, Vega de Liébana, Cantabria), à 1000 mètres d'altitude, enclavée à l'intérieur des Picos de Europa, dans une vallée non loin de El Espertín avec un gisement Mésolithique (Arias, 1996). Voilà pourquoi notre gisement présente des données primordiales, à la fois, pour la compréhension du territoire fréquenté par les groupes préhistoriques et pour la communication entre le versant septentrional et méridional de la Cordillère. Lors des premières phases des premières fouilles et en fonction du matériel lithique récupéré, il avait été établi comme une possibilité, le fait qu'il puisse s'agir d'un gisement du Paléolithique Supérieur, mais des analyses ultérieures ont permis de vérifier sa désignation à certaines périodes du Mésolithique. Par conséquent, ceci est très important lors de l’appréciation du territoire fréquenté par des groupes holocènes dans ce contexte montagneux.

Par rapport à ce thème, il semble que la relation du groupe occupationnel du gisement ce soit établi avec le versant nord de la cordillère, dans la tradition des groupes Paléolithiques qui ont peuplé la zone asturienne et de façon parallèle à l'Asturien. Par conséquent, il faudra mettre en évidence la présence de ces groupes Mésolithiques autant dans la zone côtière comme dans la zone de montagne, atteignant même le versant méridional de la Corniche Cantabrique. Ces contacts dans la voie nord-sud, à travers les réseaux hydrographiques, sont très intéressants, mais il faudra de même évaluer la relation de ces groupes avec l'axe est-ouest.

Un autre des aspects intéressant que renferme El Espertín, afin de mettre en place l'analyse technologique, c'est qu'il s'agit d'un gisement avec une seule période représentée, le Mésolithique, du moins son industrie lithique taillée peut être considéré comme un ensemble unitaire en ce qui concerne sa tradition culturelle, et qui provient de ce moment unique. Cependant, il est certain, qu'il y a un déplacement ultérieur dans le gisement (écoulements, modifications anthropiques plus récentes, etc.) qui a provoqué que la situation spatiale des objets lithiques a été modifié à certains endroits 
de la grotte; ce qui, d'un autre côté, n'empêche pas son attachement à un ensemble unitaire. Cette caractéristique nous donne la possibilité de développer l'analyse de type technologique d'une façon plus ample.

En conséquence nous avons décidé de focaliser l'analyse technologique sur ce gisement et essayer de concrétiser les processus techniques mis en place par le groupe ou groupes mésolithiques qui ont habité la grotte. Il faudra aussi évaluer ultérieurement la signification de ces processus à l’intérieur de la tradition Paléolithique de la Corniche Cantabrique en relation avec les possibles modifications par rapport à l'instant de l'environnement où il se développent et à l'accroissement du territoire fréquentée pendant l’Holocène

\section{STRUCTURE DU TRAVAIL DE RECHERHE}

La structure de cette recherche comprend six chapitres. Le premier chapitre énonce la méthodologie appliquée, en deux parties :

i) Un tableau complet des principes généraux de la technologie qui a pour cadre les Sciences Humaines et, concrètement, appliqué à la Préhistoire et à l'industrie lithique. Dans cet chapitre nous allons, avant tout, parler des concepts généraux, basiques lors des analyses technologiques afin de délimiter leur signification; spécialement dans les termes suivants: chaîne opératoire (schéma conceptuel), schéma opérationnel et schéma technique

ii) Un tableau de la méthodologie concrète employée pour l'étude analytique du matériel (avec les différentes caractéristiques observées). Nous décrivons l'examen concret de chaque élément lithique, à partir duquel nous allons synthétiser les schémas techniques, opératoires et, enfin conceptuels. Nous allons suivre un discours exposition qui va de l'universel au plus concret, en commençant par des concepts plus amples (chaîne opératoire laminaire) aux plus concrets (par exemple la dénomination de quelques supports comme les pièces à crête). Nous choisissons comme chaîne opératoire idéale une qui comporte une 
structure laminaire, car la production de lames et lamelles est celle qui prédomine dans l'ensemble lithique. Cette chaîne opératoire se divise dans les différentes phases et processus techniques dans lesquels s'insèrent les éléments lithiques successifs. Afin de structurer ce processus, il est primordial de classifier non seulement ses éléments dans les catégories de supports techniques (par exemple lame corticale, lame d'entame, éclat laminaire de deuxième catégorie, semitablette de ravivage), mais aussi surtout, l'agroupement de ces supports dans des « groupes technologiques » plus amples, lesquels englobent rapidement le processus opératoire d'un ensemble lithique (le groupe 1 correspond aux éclats, le groupe 2 aux lames/lamelles, le groupe 3 aux produits de conditionnement, le groupe 4 aux nucléus, le groupe 5 aux chunks et en général des supports informes et, finalement, le groupe 6 aux débris).

Dans le deuxième chapitre nous allons présenter la provenance du matériel examiné, qui est l'ensemble lithique de El Espertín, avec une contextualisation du matériel à partir de deux points de vue :

i) D’un point de vue archéologique. Nous décrivons l'emplacement du site archéologique, de son fouille et les caractéristiques des matériaux récupérés (faune, charbons, etc.).

ii) D'un point de vue géographique. Nous consacrons une large étude au contexte géologique dans lequel se trouve cette grotte, afin d'effectuer ultérieurement une analogie des niveaux lithologiques qui peuvent, éventuellement, contenir des sources de matériaux qui sont employés dans cet ensemble.

L'analyse concrète du matériel est structurée à partir des différentes matières. Par conséquent le troisième chapitre est dédié à la description des différentes matières lithiques qui se trouvent dans l'ensemble. Ce chapitre comporte deux parties :

i) Description du matériel lithique en établissant les principaux 
ii) Groupes de silex, quartzite et quartz. Bien que cette description soit du type macroscopique, nous considérons qu'elle est utile et nécessaire afin de connaître le type de matière qui a été utilisé.

iii) Relation entre les matières présentes dans l'ensemble lithique et les niveaux lithologiques qui se trouvent présent dans le contexte géologique de la grotte, qui pourraient contenir les principaux groupes lithiques reconnus : le chert noir et la radiolarite. Lors de cette connexion nous observons que ces deux variétés de roches siliceuses se trouvent, effectivement, dans un environnement plus ou moins proche de la grotte.

Dans le quatrième chapitre nous allons développer l'analyse technologique concrète des diverses matières premières (le silex/chert noir, les deux variétés de radiolarite, le silex gris, les silex variés, la quartzite et le quartz), à partir du schéma technologique établi dans la méthodologie, avec l'examen des diverses propriétés spécifiées. De telles propriétés vont être résumées dans une série de tableaux et de graphiques en distinguant les groupes technologiques, pour essayer de constater des variations tout au long du processus opératoire effectué dans chaque matière. Premièrement nous allons exposer les caractéristiques plus générales de l'ensemble lithique (par exemple la présence de cortex, les mesures, les types de talon, les cassures, etc.); deuxièmement nous allons analyser les différentes catégories de support afin d'extraire les lignes techniques sommaires du processus (nucléus, produits de conditionnement); ensuite nous allons considérer aussi les supports récupérés, aussi bien ceux à caractère secondaire (les éclats en général) que ceux de «premier projet» (lames, lamelles). Ultérieurement, nous allons présenter les pièces retouchées, en essayant de déterminer s’il existe une quelconque préférence dans les supports sélectionnés. Finalement, nous allons décrire les chaînes opératoires présentes dans la matière, avec leurs particularités.

Le cinquième chapitre présente la synthèse du processus opératoire total, effectué dans l'ensemble lithique taillé de El Espertín, en employant pour cela les différentes caractéristiques étudiées. À partir de ces données synthétiques on peut arriver à diverses conclusions, par exemple : 
- les stratégies d'acquisition et les objectifs de production dans les différentes matières

- l'influence des caractéristiques des différentes matières en appliquant le processus de débitage

- le degré de définition dans l'utilisation de supports concrets, c'est-à-dire s'il existe des supports spécialisés dans des types concrets d'outils ou bien s’il y a des supports avec une utilité plus ample

- les chaînes opératoires génériques et leurs schémas opératifs particuliers, développés.

Sans aucun doute, ces chaînes constituent un des objectifs premiers de tout cette étude. Ainsi, nous allons essayer de mettre en rapport ces structures avec celles définies dans s'autres contextes culturels. Et même, il serait possible que quelques uns des ces schémas puissent devenir des archétypes, c'est-à-dire des manières de tailler un nodule d'une façon élémentaire, pouvant apparaître dans différents contextes culturels et qui peuvent être la conséquence d'un phénomène d'une convergence technique.

Enfin, dans le sixième chapitre nous donnons les conclusions les plus génériques de toute cette analyse technologique, dans lequel nous allons essayer de schématiser les caractéristiques les plus importantes de l’industrie lithique. 


\section{RÉSUMÉ}

Étant donné que l'objectif principal de cette étude est celui de concrétiser le processus technique dans le gisement mésolithique de la grotte de El Espertín, nous allons orienter notre étude sur les aspects techniques exprimés dans le chapitre cinq.

\section{1 - STRATÉGIES D’ACQUISITION ET D’EXPLOITATION DES MATIÈRES PREMIÈRES}

Les matières premières présentes dans l'ensemble lithique de El Espertín sont (Graphique V.1, p. 546): le silex /chert noir (64\%), la radiolarite (avec deux variétés : radiolarite-1 [12\%] et radiolarite-2 [3\%]), le silex gris (2\%), ceux que l'on a nommé silex variés (qui réunissent un petit nombre de roches siliceuses de bonne qualité [0,5\%], presque toutes retouchées), quartzite (18\%) et quartz (1\%). Entre ce groupe nous avons localisé, dans le contexte lithologique dans lequel se situe la grotte, deux d'entre elles: le silex/chert noir (dans la Formation Escalada, Carbonifère MoyenSuperieur) et la radiolarite (dans la Formation Alba, Carbonifère Inférieur). On a trouvé deux affleurements de ces niveaux lithologiques, qui fournissent des matières que nous pourrions considérer analogues à celles qui apparaissent dans le site (Planche 1 et 2, pp. 159-160). Par conséquent, 79\% des matières de l'ensemble proviennent d'un environnement qui pourrait être local. On pourrait aussi ajouter la quartzite, qui, bien qu'il n’a pas été localisé de manière effective dans le contexte géologique, dans ce dernier il existe plusieurs formations qui contiennent de la quartzite. Si nous ajoutons la quartzite, on obtient que 96,5\% des matières taillées dans El Espertín proviendraient d'un contexte proche du gisement (Table V.1, p. 546).

Afin d'analyser la manière dont on a traité les diverses matières premières et vérifié s'il existe une gestion différente par matières, on a étudié une série de propriétés, afin de concrétiser la stratégie d'exploitation par matières. Les caractéristiques observées sont, à part la disponibilité lithologique: le nombre d'élément de chaque matière, leur représentation par groupes technologiques (Graphique V.4, p. 551), la taille des pièces (Graphiques V.2 et V.3, pp. 548-549) et les cassures (Graphique V.5 et V.6, pp. 556-557). À partir de la disposition des matières dans l'environnement et de la 
représentation du processus opératoire dans l'ensemble lithique, il est possible d'établir le schéma suivant :

- Matériaux locaux : processus de taille in situ et chaînes opératoires continues (pourcentage élevé du groupe des débris, qui comprend au mois $30 \%$ de l'ensemble)

o Silex noir et quartzite : débitage intense de ces matières, qui sont les plus nombreuses et vraisemblablement les plus proches (chaîne complète dès le commencement) et exploitation avec un objectif mixte (lames/lamelles et éclats).

o Radiolarite et silex gris : Débitage spécialisé (lames/lamelles) de matières vraisemblablement plus éloignées (radiolarite) ou moins nombreuses dans l’environnement (silex gris).

o Quartz : processus de taille particulier, avec des objectifs différents aux matières précédentes.

- Matières exogènes (Silex variés) : chaîne opératoire brisée, représentation partielle du processus opératoire (les débris ne dépassent pas 15\%), spécialisation totale dans les produits laminaires (qui représentent $40 \%$ de l'ensemble).

La gestion des matières premières dans le gisement de El Espertín est à caractère local, avec seulement $0,5 \%$ de matières exotiques. L'origine locale des matières a été déterminé à partir de deux indices ; premièrement on a décelé la présence de matériaux dans le contexte géologique, analogues à ceux trouvés dans la grotte, tel que le silex /chert noir et la radiolarite. D’autre part, à partir de le représentation du processus opératoire (le pourcentage des divers groupes technologiques) des divers matériaux, on peut constater qu'il existe certaines caractéristiques du silex noir et de la radiolarite (surtout en ce qui concerne le pourcentage des débris) qui se répètent dans le silex gris, la quartzite et le quartz, à partir de ces données on propose l’hypothèse que ces derniers matériaux soient aussi d’origine locale. Cette hypothèse serait renforcée par le fait que, dans le contexte géologique de la grotte, la quartzite et le quartz pourraient être présents, sans pour cela les intégrer dans une formation concrète. De même, le silex gris pourrait se trouver dans le contexte cité, car c'est un matériau qui se trouve sous la 
forme de galet, en position dérivée dans les terrasses façonnées par le fleuve Esla. À ce propos il ne faut oublier, non plus, les formations de conglomérats.

La stratégie d'acquisition, privilégie, par conséquent, la captation des ressources d'origine locale, avec un comportement à double caractère, évident dans le processus d'exploitation particulier de chaque matière. D'un côté, on exploite sous une forme extensive les matériaux les plus abondants et sans doute les plus proches (silex noir et quartzite) ; d’un autre côté, on discerne une utilisation beaucoup plus spécialisée des matières qui sont peut-être plus lointaines et/ou moins abondantes (radiolarite et silex gris) ; c'est dans ces matières que l'on aurait effectué les premières séquences de taille à l'endroit même de son acquisition. Les matières exogènes (silex divers) sont très peu nombreuses et elles apparaissent surtout sous la forme d'éléments retouchés, et elles font partie, probablement, des outils que transportent ces groupes dans leurs déplacements. Il n'apparaît nulle part que ces groupes se déplacent trop chargés, se limitant au strict minimum, ils préféreraient, par contre, les ressources locales.

\section{2 - LES DIFFICULTÉS DES MATIÈRES ET DES MODES DE TAILLE}

Les caractéristiques des matières premières, en ce qui concerne leur facilité pour le taille, peuvent concerner, sous un double aspect, les modes et les techniques de taille employées. D’un côté, les matériaux résistants et de taille de grain moyen ou gros, peuvent exiger des modes de taille et des techniques plus expéditives. D’un autre côté, des matières plus douces et de grain fin, peuvent exiger des techniques plus versatiles. Il faut ajouter aussi, une autre donnée décisive, en ce qui concerne la qualité des matériaux pour le taille, qui est sa structure, c'est-à-dire, si ce sont des roches homogènes ou bien hétérogènes, s’il existe d’abondantes surfaces naturelles, diaclasées, fissures, etc., qui puissent nuire au taille.

\section{1 - LES MODES DE TAILLE TOUT AU LONG DU PROCESSUS OPÉRATOIRE}

La problématique des modalités de taille est mis en relief lorsque l'on tient en compte les modifications de cette propriété tout au long de la chaîne opératoire, car il est admis le fait que l'emploi des instruments et des techniques de taille, varient tout au 
long du processus opératoire, en fonction des besoins des blocs lithiques et des objectifs visés. En ce qui concerne ce dernier point, dans l'analyse de chaque matière, nous avons constaté la présence de variations dans ces propriétés des supports tout au long des diverses phases de la chaîne opératoire. Nous pouvons, dès lors, présenter le schéma suivant, uniquement valide, surtout, pour les silex.

- Le groupe 1 (éclats en général) se caractérise par la dimension du talon relativement grand (3mm en largeur), ce qui le met en rapport avec un type de percussion interne (Boëda, 1997). Il existe une plus ample proportion du pseudoburin de Siret et du double bulbe (Graphique V.8, p. 564) et il existe une présence plus importante de percussion directe avec percuteur dur. Par conséquent, on peut établir l'emploi de ce type de percussion dans les premières phases du débitage.

- Dans le groupe 2 (supports laminaires) la taille du talon est inférieure (2 mm maximum), par conséquent, la frappe s'effectue d'une manière plus tangente, ce qui permet d'établir avec une préparation plus soignée de la ligne de frappe. À ce propos, dans tous les matériaux, les lames/lamelles constituent le groupe de supports les mieux préparés. Dans les silex, le pourcentage de préparation dépasse $50 \%$ sauf le silex gris (qui ne présente que 33\%); la quartzite parvient à 43\% (Graphique V.9, p. 567). Le genre de préparation est assez soigné, avec une présence d'abrasion (Graphique V.10, p. 568). Dans le mode de taille concrète, apparaissent les caractéristiques de diagnostic de la percussion directe avec un percuteur tendre (Pelegrin, 2000), au moins en ce qui concerne un certain nombre d'éléments de ce groupe.

- Dans le groupe 3 (produits de conditionnement) les dimensions du talon sont souvent plus grandes que dans le groupe 1 (3-4 mm) d'autant plus, que le mode de taille śassimile aussi à celui qui est utilisé dans le groupe en question, c'est-à-dire percussion directe avec un percuteur dur.

- $\quad$ Le groupe 6 (débris) présente des caractéristiques singulières, d’un côté il y existe un ensemble de débris qui possèdent des caractéristiques proches au groupe 1 (présence de pseudoburin et double bulbe, percussion directe avec percuteur dur), ces éléments pourraient correspondre, sans doute, à des 
fragments proximales des éclats de la première phase du taille ou bien à des séquences de réparation. Par contre, les petits éclats qui proviennent des phases de retouche, auraient des caractéristiques plus en accord avec ce statut: petite taille du talon, talons punctiformes, etc. Il faudrait ajouter une spécificité qui a été observée dans toutes les matières, il s'agit d'une plus grande présence d'un angle de taille plus fermée que le reste des supports (Graphique V.12, pp. 571-573).

Par conséquent, dans la différenciation des modes de taille, tout au long de la chaîne opératoire, on constate, une modification dans la séquence de la production pleine, qui correspond à l'obtention des lames/lamelles, avec une probable utilisation de la percussion directe avec un percuteur tendre. Cet aspect est assez logique, étant donné que les supports laminaires appartiennent aux outils qualifiés comme « de première intention $"$.

\section{2 - LE MODE DE TAILLE DANS LES DIVERS MATÉRIAUX.}

En ce qui concerne les propriétés qui interviennent dans le mode de taille, en prenant en compte les accidents, la présence de préparation ainsi que le type de préparation. On peut distinguer deux groupes: d'un côté celui du silex et de l'autre, celui de la quartzite et du quartz.

Le groupe des silex renferme les caractéristiques suivantes :

- Une plus ample présence des accidents (réfléchissements) les plus fréquents dans la séquence de production des supports laminaires.

- Préparation du point d'impact dans, au moins, un tiers du total des pièces (Graphique V. 9, p. 567).

- Les catégories de préparation du point d’impact sont variées (retouche, esquillement et abrasion dans différentes proportions, surtout les deux dernières; Graphique V.10, p. 568).

La quartzite et le quartz, présentent las caractéristiques suivantes :

- Importante présence de pseudoburin de Siret. 
- Préparation du point d'impact dans une moindre proportion, un quart des pièces dans la quartzite et seulement 15\% dans le quartz (Graphique V.9, p. 567).

- Les catégories de préparation ne sont pas aussi variées que dans les silex ; il existe une présentation beaucoup plus importante de la retouche ou bien de l'esquillement (Graphique V.10, p. 568).

Aux vues de ces différences, on peut préconiser l'utilisation de techniques, à un certain degré divergentes dues, sûrement, à l'adaptation des méthodes de taille aux caractéristiques matérielles particulières de ces deux groupes lithologiques. Dans les silex, on pourrait constater l'emploi, du moins partiel, du percuteur tendre; tandis que dans le quartz et la quartzite il existe un plus grande utilisation du percuteur dur.

\section{3 - LES OBJECTIFS DU DÉBITAGE : LES SUPPORTS EXTRAITS ET LES PIÈCES RETOUCHÉES}

\section{1 - PROCESSUS DU DÉBITAGE: REPRESENTATIVITÉ DES GROUPES TECHNOLOGIQUES}

Dans l'ensemble de El Espertín il existe deux types de productions, avec des objectifs de débitage différents : i) fabrication de lames et de lamelles, et ii) fabrication d'éclats. On pourrait ajouter une troisième catégorie, attaché au traitement du quartz, qui n'est pas très bien défini à cause de la légère présence de cette matière, mais qui se caractérise par : une plus grande représentation des débris (48\%), absence de production laminaire et foisonnement d'instruments avec une forme indéterminée. Nous avons même formulé l'hypothèse d'un processus de taille particulier, adapté à certaines retouches ou bien à un façonnage d'instruments qui n’ont pas été trouvés dans la série analysée.

En ce qui concerne les objectifs essentiels de taille (laminaire et d'éclats), nous avons organisé les matériaux en deux catégories. Il existe des matériaux avec un traitement qui se caractérise comme étant du type mixte, ćest-à-dire que les deux objectifs ont été utilisés ; il s'agit des matériaux les plus nombreux de l'ensemble, le silex noir et la quartzite, les deux à caractère local. En ce qui concerne le reste de roches 
silices (radiolarites, silex gris et autres silex) nous avons accompli un débitage à caractère spécialisé, strictement laminaire et microlaminaire. Dans ces dernières catégories, il existe différents degrés de spécialisation, en fonction de sa profusion dans l'ensemble (Graphique V.4, p. 551). De cette façon, dans celles taillées sur le gisement, avec présence d'une chaîne plus ou moins complète (radiolarite-1), ou au moins une phase de production in situ (radiolarite-2 et silex gris), le pourcentage du groupe 2 (lames et lamelles) se maintient aux alentours de 20-23\%. Par contre, dans les cas des silex variés, cette donnée est très importante, atteignant $40 \%$ (c'est la seule matière dans laquelle le groupe 2 est prédominante), ce qui met en évidence non seulement la spécialisation en lamelles de ce matériel, mais surtout, la rupture qui existe lors de son processus opératoire, avec l'incorporation de ces lamelles au gisement, sans pour cela avoir été taillées sur place.

Dans les matériaux à production mixte (silex noir et quartzite), le groupe 2 ne dépasse pas 12\%, par conséquent, il est évident, que l'objectif de son exploitation n'est pas seulement laminaire.

Si l'on tient compte du type de support sélectionné pour retoucher, on observe d'une manière encore plus évidente, les différents objectifs du débitage (Graphique V.13, p. 577) car les pourcentages du groupe laminaire augmentent d'une manière évidente dans tous les matériaux, spécialement dans ceux avec un objectif laminaire spécialisé. À nouveau, les pourcentages varient en fonction du degré de spécialisation et l'existence de fractures dans la chaîne opératoire. Dans les matériaux taillées in situ , les éléments retouchés sur lames/lamelles dépassent 60\%, à l'exception de la radiolarite-2, dans laquelle, curieusement, le pourcentage se situe aux environ de 50\%. L'explication de cette anomalie dans cette variété de radiolarite, est peut-être lié avec l'existence d'une rupture partielle dans le processus opératoire présent dans cette matière, avec la présence d'éléments extérieurs et avec un débitage partiel dans le gisement. D’un autre côté, dans les silex diversifiés, la valeur des supports microlaminaires retouchés dépassent $80 \%$ de l'ensemble des pièces retouchés, confirmant à nouveau le caractère spécialisé et implanté de ces éléments. 


\section{2 - LES PIÈCES RETOUCHÉS}

On peut considérer les pièces retouchés comme les objectifs du débitage lithique développé dans le gisement ou, du moins, une part essentielle de ces objectifs. Nous allons focaliser notre étude sur l'analyse des pièces retouchés, d'un point de vue essentiellement technique. Pour cette raison, la typologie énoncé est basée sur des groupes typologiques amples (grattoirs, burins, etc).

\subsection{1 - TYPES DE SUPPORTS SÉLECTIONNÉS}

Dans le tableau V.2 (p. 580) nous pouvons remarquer les divers types de supports choisis afin de confectionner les types retouchés. La majorités des pièces ont été retouchées sur le groupe des éclats (46\%), suivi de très près par le groupe des lames/lamelles (44\%). Avec une présence plus petite, se trouvent les produits de conditionnement et le reste des supports du processus opératoire.

La mode de sélection des supports, afin de retoucher, serait propre d'un processus de taille laminaire accompli in situ; par conséquent, il existe un profit extensif des éclats qui s'établissent tout au long de cette chaîne de lames/lamelles. Cependant, lors de cette vision de l'ensemble on perd les divers degrés de spécialisation laminaire dévoilés dans les radiolarites, le silex noir et les silex variés. Logiquement, ce sont surtout les caractéristiques des matières les plus abondantes du gisement qui excellent, essentiellement le silex noir et la quartzite.

Certains supports renferment une utilité que l’on pourrait qualifier de diversifiée, par contre, d'autres sont plus spécialisées. On pourrait affirmer qu'il y a trois grands groupes de catégories de supports avec des caractéristiques morphologiques et métriques déterminées, qui ont une utilisation particulière lors de leur retouche.

1.- Groupes d'éclats (utilité diversifiée en favorisant les "pièces de fond commun")

Ce groupe est composé par les éléments appartenant au groupe technologique 1, celui des éclats et aussi par d'autres supports des groupes technologiques 3, 4 et 5, avec des caractéristiques proches de celles-ci (les tablettes et semitablettes de ravivage, les 
arêtes de nucléus, les chunks et les nucléus). Il s'agit d'un groupe de supports de différentes tailles, mais avec une corrélation entre sa largeur et sa longueur très réduite, et avec une épaisseur élevée. Ce groupe pourrait apporter les supports aptes à fabriquer la plupart des outils dénommés habituellement de «fond commun», c'est-à-dire, les encoches, denticulés, grattoirs, burins, perçoirs, racloirs, etc.

\section{2.- Groupe de lames et supports étirées (emploi diversifiée modérée)}

La qualité fondamentale dans ce groupe c'est qu'il s'agit de supports «longs», avec un ou plusieurs bords d'une longueur importante. On peut inclure ici, en plus des lames, les éclats laminaires, les «lames avec flanc», les lames à crêtes et quelques uns des flancs longitudinaux. Cette variété de supports va avoir une utilisation diversifiée de type «modérée» cadrée dans l'utilisation de ce module morphométrique. Ils vont être utilisés pour trois objectifs essentiels :

- Pièces de retouche continue, sur un ou deux bords et avec une retouche plus ou moins intense. Ce type de pièces retouchées, utiliserait les caractéristiques métriques de ce groupe.

- Géométriques. La plupart des géométriques, les variétés reconnaissables comme les variétés étant des projets ratés dans leur facture; apparaissent sur des lames de plus d'un centimètre de largeur, de là, on peut déduire la préférence des supports laminaires à leur fabrication. En plus, il y a un bon nombre de pièces qui pourraient être des éléments secondaires dans la fabrication des éléments géométriques: les microburins, les piquants-trièdres, les encoches et pièces retouchées qui ont une fracture juste à côté de l'encoche, et même on pourrait ajouter que quelques unes des encoches pourraient être des tentatives de fabrication d'éléments géométriques.

- Quelques-unes des variétés du «fond commun», concrètement des encoches, burins et quelques grattoirs. En ce qui concernes les encoches, plusieurs d'entre elles pourraient former le premier maillon dans la création d'un élément géométrique. Pour la fabrication de certains burins, on a sélectionner ce type de pièces étirées, car elles proportionnent un support plus apte pour 
cet outil, qui se fabrique fréquemment à partir des gestes les plus simples, par exemple sur le talon d'une lame.

\section{3.- Groupe de lamelles (utilisation spécifique)}

Ce groupe a une fonction totalement spécifique pour les pièces à dos, autant pour les lamelles à dos, comme pour les pointes. D'une manière secondaire, nous pouvons trouver des lamelles qui auraient pu être utilisées aussi comme éléments composés, enchâssés sur des manches (les lamelles avec des retouches continues), et de même des lamelles avec des encoches et géométriques. Il faut à nouveau avertir que, d'une façon analogue aux les lames, certaines des encoches peuvent être en rapport avec la création d'éléments géométriques.

\subsection{2 - TYPES RETOUCHÉES PAR DES MATIÈRES PREMIÈRES}

Dans le tableau V.3 (p. 581) nous présentons la distribution des variétés retouchées selon les matières premières. Le silex noir et la quartzite ont été retouchés dans une grande variété de groupes typologiques, même si le type le plus abondant sont les encoches. Les autres silex (radiolarite, silex gris et silex variés) ont eu une utilisation plus spécifique, en remarquant spécialement la production d'éléments à dos.

Le silex noir est la matière qui a le plus grand nombre de pièces retouchées (66\% de l'ensemble), nous avons déjà expliqué que cette matière locale est la plus abondante du gisement, et l'on a effectué sur elle un processus de taille abondant avec des objectifs de type mixte ; par conséquent il est assez logique que ce soit aussi la matière avec le plus d'éléments retouchés. Lors des retouches du chert noir, il existe une diversification, autant dans les types de support sélectionnés, comme dans la diversité des variétés retouchées. D’ailleurs, le silex noir est la matière prépondérante dans les divers groupes typologiques, avec l'exception des groupes géométriques et les déchets de la technique du microburins (microburins et piquants-trièdres), dans lesquels ćest la radiolarite-1 qui prédomine (Tableau V.4, p. 587). Par conséquent, la radiolarite se distingue comme une matière qui a été utilisée pour réaliser deux variétés retouchées que l'on pourrait considérer comme des objets privilégiés de leur débitage, même s'il n'est pas spécifique: les pièces à dos (22\% des pièces retouchées de radiolarite-1) et 
celles géométriques (7\%). Même si le pourcentage des ces dernières est discret, nous pouvons tenir compte que l'ensemble des micro burins et les débris de la technique des microburins supposent un $18 \%$, et il y a un $14 \%$ des encoches, quelques-unes d'entre elles, auraient pu être faites pour fabriquer ces microlithes.

La matière la plus retouchée après le silex noir est la radiolarite-1 (14\% de l'ensemble), ce qui est extraordinaire, car la deuxième matériau le plus taillé sur le gisement est la quartzite, cependant, moins sélectionnée lors des retouches (9\%). Par conséquent le caractère plus spécifique du débitage de la radiolarite s’intensifie face aux matériaux à objectif mixte (silex noir et quartzite) taillés dans le gisement.

\subsection{3 - TYPOLOGIE}

Dans le tableau V.5 (p. 589) on expose les différents variétés retouchées avec le nombre total des pièces et le pourcentage relatif à chacun d'entre elles. Le groupe typologique le plus abondant est celui des encoches et denticulés, qui composent presque le quart de l'ensemble (26\%), suivie des pièces avec retouche continue, avec $21 \%$, les pièces à dos apparaissent en troisième position. Les grattoirs supposent $16 \%$, les burins et les truncatures $5 \%$ et les perçoirs $14 \%$. Les géométriques représenteraient seulement 2\% de l'ensemble, et le reste des variétés suppose un pourcentage égal ou inférieur à un 1\% (outils composés, racloirs, raclettes, pièces esquilles, et deux pointes un peu singulières: une avec un cran et l'otre avec un pédoncule court, respectivement).

Dans la liste des variétés retouchées, nous avons inséré aussi les microburins, piquants-trièdres et les pièces cassées dans une encoche; il s'agirait de pièces qui pourraient appartenir à une séquence antérieure à la retouche, et elles correspondent avec la fabrication d'éléments géométriques. Ce type d’éléments, ont été inclus dans le tableau qui précisent les types de pièces retouchées, car traditionnellement il a été effectué ainsi lors de la description des industries lithiques du Epipaléolithique / Mésolithique (par exemple les listes-type exposées dans: GEEM, 1969 et Valdeyron, 1994). Cependant, il faut remarquer qu'il ne s'agirait pas d'outils retouchés sensu stricto, mais plutôt des débris de la séquence de la retouche dans un sens plus large. Dans l'ensemble cela suppose, plus ou moins, 8\% de l'ensemble retouché, et par 
conséquent, cette variété de pièces, qui illustrent une séquence particulière de fracture d'un support, occupe une place singulière dans l'ensemble.

\section{4 - LES CHAÎNES OPÉRATOIRES}

Dans l'ensemble lithique de El Espertín nous avons spécifié trois chaînes opératoires ou trois schémas conceptuels sommaires: une chaîne de conception prismatique-unipolaire, une autre qui exploite des nodules de forme de plaque et une dernière, centripète. On pourrait ajouter un autre schéma que nous formulons sous la dénomination de chaîne non standardisé, qui pourrait inclure certains nucléus exploités d'une façon opportuniste, de même, ceux dont leur schéma technique ne nous permettent pas de les encadrer dans les chaînes citées auparavant. Ces derniers proviennent, sans doute, de quelques-uns des schémas cités, mais ils ont été soumis à une gestion un peu singulière (production très intense, désordonnée, etc.) dont la motivation pourrait être attachée non pas à des aspects de production de taille, mais à des raisons plus pratiques: démonstrations de tailleurs, familiarisation avec la matière, avec les gestes de percussion, etc., il pourrait même être mis en relation avec des thèmes d'éducation / coutume de taille (Ploux, 1991).

La première chaîne englobe un vaste ensemble de nucléus réunis sous un même schéma conceptuel, le prismatique-unipolaire, avec trois schémas opératoires de base (Tableau V.11, p. 620): i) le schéma prismatique que l'on pourrait qualifier comme étant «plus classique ou typique »; ii) le schéma de nucléus qui exploitent une large surface; et, finalement, iii) le schéma que nous avons désigné sous le nom de «unipolaire-prismatique». Vis-à-vis de la complexité et variabilité de la première chaîne opératoire, la chaîne du nodule-plaque et la centripète sont des schémas plus sommaires, qui ont une application immédiate plus rapide.

Le fait de l'instabilité qui existe entre la première chaîne et les deux autres, par la variété des modalités qu'elle a et, aussi, par le nombre de nucléus, peut être curieux. Il arrive même de douter sur le fait que les schémas opératoires dissociés soient réellement des modalités qui appartiennent à une seule chaîne, ou bien qu'ils constituent, par eux-mêmes des chaînes indépendantes. Dans le chapitre sur la méthodologie nous avons argué sur ce type de problématique et nous avons adopté, à ce 
sujet, un point de vue vaste et synthétique, intégrant les schémas les plus proches et en prenant en compte quelques-unes des caractéristiques les plus globales afin de réaliser ces groupes. Ces caractéristiques reposent sur l'aspect du volume du nucléus, et ainsi on distingue essentiellement trois façons d'exploiter un volume:

- Une structure prismatique: gestion d'un volume avec une structure prismatique basique (presque toujours en forme de tétragone); sur une des flancs du prisme, on localise la surface d'enlèvement, qui se trouve, plus ou moins, enchâssée entre les côtés du nucléus et un plan de frappe qui la relie perpendiculairement (Figure V.6, p. 624). La disposition des latéraux du nucléus et de la base, ainsi comme la largeur de la surface des extractions, vont définir las différentes modalités.

- Une structure du nodule-type-plaque: utilisation d'un volume en forme de plaque dont on exploite la surface présente entre deux plans qui délimitent cette plaque à partir de son axe court.

- Une structure centripète: gestion d'un nucléus à partir de son arête extérieure à l'aide d'enlèvementes centripètes sur une ou sur les deux surfaces.

D'un point de vue aussi vaste, nous considérons que cette association de schémas est possible. La première chaîne renferme la structure qui possède le plus de fluctuations d'un point de vue technique; cependant les deux autres sont, peut-être, plus ajustées à la morphologie première des blocs et cette limitation matérielle peut provoquer une réduction des modalités éventuelles. La chaîne de création prismatique est souvent favorisé par la morphologie initiale de la matière première, mais c'est une structure sur laquelle on peut appliquer un abondant éventail de solutions.

En ce qui concerne les supports que l'on peut obtenir de ces chaînes, la chaîne prismatique va produire fondamentalement des lames et des lamelles, mais aussi des éclats laminaires et même, dans certains cas, des éclats. La chaîne de type plaque et la centripète sont des schémas de débitage d'éclats exclusivement et, par conséquent, elles apparaissent dans les matériaux de variété de production mixte (supports laminaires et éclats): silex noir et quartzite. Si l'on étudie le processus opératoire des différents 
matériaux, nous avons constaté une plus grande spécialisation laminaire (à l’aide du schéma prismatique) sur la radiolarite, le silex gris et les silex variés.

\section{1 - CHAÎNE DE CONCEPTION PRISMATIQUE}

Dans cette chaîne (Figure V.6, p. 624) il existe deux schémas opératoires de base (prismatique - unipolaire et de surface large), divisés en trois afin de faciliter leur description (en séparant le premier en prismatique et en unipolaire-prismatique; voir table V.11, p. 620).

Le schéma opératoire premier, le prismatique «typique », pourrait être le plus « classique », où l'on pourrait enchâsser quelques-uns des nucléus prismatiques les plus « typiques» (Bordes, 1979 : 89 ; Brezillon, 1977 : 92-93 ; Laplace, 1966 : 32 ; Rozoy, 1968 : 378), développé surtout tout au long du Paléolithique supérieur, bien que non délimités exclusivement. Ce schéma générique a été divisé en deux modalités basiques :

- Le schéma opératoire prismatique-A ou prismatique à tendance pyramidale.

- Le schéma prismatique-B, qui pourrait être intégré grosso modo aux nucléus prismatiques unipolaires ou bipolaires.

Le schéma opératoire de superficie large, connaît deux méthodes qui se différentient uniquement par le sens du débitage, c'est-à-dire, il peut être unipolaire ou bien bipolaire.

Finalement, le schéma unipolaire-prismatique, semble correspondre à une application rapide du prismatique-B, sur de nucléus épais.

\subsection{1 - SCHÉMA OPÉRATOIRE PRISMATIQUE-A OU PRISMATIQUE AVEC TENDANCE PYRAMIDALE}

Dans ce schéma nous allons inclure quelques-uns des nucléus prismatiques unipolaires et pyramidaux (d'un point de vue «classique » de classification des nucléus). Leurs caractéristiques primordiales ont pour base une construction du volume structurée dans un prisme en forme de tétragone, ou dans un trigone étiré. La table 
laminaire se trouve à l'intérieur du prisme, enchâssée entre les flancs du nucléus; le plan de frappe est situé dans la partie supérieure du prisme et c'est une surface plus ou moins orthogonale, vis-à-vis de la table; tandis que la base est une arête perpendiculaire à la tabla, avec une direction approximativement antéro-postérieure (Figure V.7, p. 627).

La progression du débitage s'effectue de manière unipolaire, avec une tendance convergente, et frontale. Afin d'enlever les supports, on doit préparer le front de percusión (abrasion) préalable, l'angle du ce front de taille est ouvert et le plan de frappe est lisse. Nous allons appliquer ce schéma surtout pour l'obtention de lamelles, même s'il existe certains cas de lames de plus gros calibre.

Le maintient de ce rythme de taille se réalise à partir de deux ressources:

- Auto-maintien de l'avance du débitage facilité par la construction volumétrique du nucléus, ce qui permet, à l'aide de la progression unipolaire convergente et frontale, le contrôle du carenage e du cintrage. Cet automaintient est favorisé aussi par le fait que la longueur des extractions n'est pas trop élevée. Dans ce processus, il faut remarquer, l'obtention occasionelle de ce qu l’on a appelé « lame à flanc ».

- Phases de réparation du nucléus afin de réparer, par exemple, la table et raviver sa orthogonalité avec les latéraux du nucléus (à l'aide de flancs longitudinaux); ou bien, on peut aussi réformer la carène à partir de petites extractions à partir de l'arête de la base (qui devient fréquemment une crête inférieure). Le plan de frappe peut être maintenu à l’aide de tablettes ou bien de demi-tablettes qui ravivent totalement le front de percussion.

Les nodules sélectionnés, pour cette variété de schéma sont des blocs plus ou moins conformés et d'éclats grandes. Dans le cas de nucléus sur des nodules, la phase de mise en forme est assez importante, car il faut réaliser une préparation appropriée des flancs du nucléus et surtout de l'arête de la base. De même, cela requiert une attention particulière des flancs du débitage afin de préserver le cintre, et aussi de la carène à partir de la crête inférieure. 
Lorsque ces nucléus se conçoivent sur un éclat, la configuration initiale est facilitée par les caractéristiques morphologiques de ce support, car l'arête de base serait un des bords latéraux de l'éclat. La table laminaire est située sur un autre des bords de l'éclat (il s'agit d'une production «type-burin " d'un éclat), de manière qu'il ne faut configurer que le plan de frappe. La progression des enlèvements et le processus d'automaintient est, dans ce cas précis, plus immédiat.

\subsection{2 - SCHÉMA OPÉRATOIRE PRISMATIQUE-B}

Ce schéma est caractéristique des nucléus prismatiques unipolaires et bipolaires, surtout utilisé dans la production de lames. De même que dans le précédent, la structure volumétrique est un prisme allongée et la table est parfaitement délimitée dans au moins un des côtés du nucléus (Tableau V.8, p. 631). La différence fondamentale avec le schéma précédant, c'est que la base du nucléus n’est pas une arête antéro-postérieure perpendiculaire à la table, mais qu'il s'agit d'une surface parallèle au plan de frappe. Une autre différence, c'est que l'avancée du débitage s'effectue d'une manière unipolaire, comme dans l'exemple précédant, mais avec une progression à tendance semi-tournante, surtout lorsqu'elle s'adapte aux difficultés occasionnées par les nombreuses surfaces de fissure internes. De toute façon, dans l'éventualité que l'on puisse maintenir une progression frontale, celle-ci s'accomplit, comme le prouvent certains flancs longitudinaux qui font raviver totalement une table laminaire frontale.

Ce schéma nous prouve l'utilisation des surfaces naturelles qui existent dans la matière, par conséquent, il est très fréquent que l'on prenne une de ces surfaces du nucléus originaire comme flanc latéral. L'arête qui se trouve entre le flanc cité et la table laminaire, sera utilisée pour ouvrir le débitage, avec l'obtention de lames d’entame, en poursuivant le débitage vers le flanc opposé.

Le maintient de ce débitage s'effectue à partir de plusieurs procédés, par exemple des flancs longitudinaux, des extractions à partir de la base de nucléus, etc. Il faut mettre en relief que, dans ce schéma, les extractions à partir de la base du nucléus sont plus importantes et plus fréquentes que dans le schéma précédant. Nous pouvons discerner des flancs longitudinaux à partir de la surface opposée afin de «nettoyer » la 
table; de même, nous pouvons discerner des modifications de la direction du débitage, avec un renversement du nucléus, afin d'exploter la surface d'enlèvement à partir du plan opposé. Cependant, il faut remarquer que le rythme de la taille bipolaire strict ne se présenté pas, tout au plus, il s'agit de séquences d'extractions à sens unipolaire qui exploitent la surface d'enlèvements à partir de deux plans de frappe. En plus de ces ressources, qui modulent d'une façon assez flexible la structure du volume, il faut remarquer l'usage de neo-crêtes latérales afin d'arranger le cintre du nucléus. En ce qui concerne le plan de frappe, les réparations à l'aide de petits éclats de ravivage sur le front de taille sont plus fréquents dans ce schéma, beaucoup plus que les ravivage complets du plan de frappe.

Ce schéma est assez visible dans les nucléus et il faut remarquer l'adaptabilité de cette structure sur les nodules disponibles, mais en tenant compte les difficultés d' exécution de la taille, dues aux caractéristiques de la matière première. Le supports choisis pour ce schéma sont des blocs des différentes matières, on n'a pas utilisé des éclats-nucléus. La phase de mise en forme du nucléus n’est pas aussi importante comme dans le schéma précédant, car il y a une utilité et/ou une adaptation aux caractéristiques particulières des matières disponibles. Il faut rappeler que des nodules de chert noir et surtout ceux de radiolarite ont une morphologie en forme de prisme qui est assez proche de la structure volumétrique requise pour ce schéma.

\subsection{3 - SCHÉMA OPÉRATOIRE À LARGE SURFACE}

Cette construction apparaît parfois dans des blocs de taille importants et leur caractéristique essentielle, comme il est dit dans leur propre définition, est l'exploitation d'une table d'enlèvement assez large, avec une morphologie carrée (Figure V.9, p. 633). Les extractions sont de lames larges ou plutôt d'éclats laminaires; habituellement il s'agit de supports plus larges que dans les schémas précédents, mais en cherchant des pièces les plus longilignes possible même s'il śagit de grosses produits. Le mode de taille, à partir des contrabulbes des nucléus, semble présenter une percussion dure, et la progression du débitage est frontal. De même que dans le schéma précédent, on utilise une des arêtes naturelles en configuration longitudinale afin d'ouvrir la surface d'enlèvements. Un des flancs du nucléus devient très important, car c'est ici que l'on 
place une des crêtes pour observer le cintre. Une autre caractéristique de ce schéma, c'est que la base du nucléus se maintient comme une surface parallèle au plan de frappe.

On remarque deux méthodes de production à partir de l'orientation des extractions, c'est ainsi qu'il existe un schéma unipolaire et un autre bipolaire. En ce qui concerne ce dernier, il s'agit réellement d'une progression bipolaire stricte, car, à l' opposé du schéma opératoire en forme de prisme précédent, la surface d’enlèvements est exploitée par deux plans opposés, à partir desquels on atteint à peu près la moitié de la longueur de la table, ce qui donne comme résultat une carène en dièdre.

En ce qui concerne l'application de ce schéma de large surface, on sélectionne de larges blocs, dont certains d'entre eux possèdent une structure en forme de tétragone avec une base rectangulaire. L'ouverture de la surface d'enlèvement s'effectue sur eux à partir de lames d'entame. Pour ce schéma nous avons utilisé aussi les grandes éclats mais, dans ce cas précis et à l'opposé de ce qui survenait dans le schéma prismatique-A, la surface d'enlèvements se place sur la face inférieure de l'éclat, et non pas sur un de ses bords. De cette façon on obtient la superficie large requise pour cette modalité.

Comme nous pouvons observer, la phase de sélection et de mise en forme du nucléus dans ce schéma est assez variée et souple, et elle utilise, aussi favorablement, les caractéristiques morphologiques originaires du nucléus.

L'utilisation des éclats comme des nucléus pour le débitage des éclats et des éclats laminaires est un type de gestion de l'éclat-nucléus différente à celle qui était présente dans le schéma prismatique-A. Cette exploitation de la face inférieure de l'éclat pourrait être insérée, dans la classification des éclats-nucléus réalisé par J. Tixier et A. Turq (1999), dans le « mode 1 », mais il ne s’agirait pas de la méthode Kombewa, mais en ce qui nous concerne, le traitement du volume concorde totalement avec le schéma opératoire prismatique à large surface.

\subsection{4 - SCHÉMA UNIPOLAIRE-PRISMATIQUE}

On pourrait inclure ce schéma dans celui prismatique-B ; de même que dans ce dernier, l'utilisation des arêtes et plans naturels de la matière śaméliorent au début de la 
taille et de la structuration du volume. Les caractéristiques les plus importantes de ce schéma c'est qu'ils se présentent en forme de nodules de longueur réduite en relation avec leur épaisseur, en plus, la base est une surface lisse, parallèle au plan de frappe. Cette longueur réduite de la table permet un contrôle direct de la carène, et la progression du débitage s'effectue d'une façon semi-tournante, sur les deux côtés, à partir d'une arête naturelle sur la partie frontale. Le début du débitage s'effectue à partir de pièces d'entame qui ouvrent la surface d'enlèvements, en facilitant ainsi la production dans la direction antéro postérieure de la dimension du nucléus.

Ce schéma n'est pas trop complexe en ce qui concerne les séquences de réparation, il s'agirait d'une forme rapide d'obtenir des lamelles et des éclats d'un aspect unipolaire et d'une longueur qui englobe toute la surface des extractions disponible.

\section{2 - CHAÎNE OPÉRATOIRE DE TYPE NODULE-PLAQUE}

La structure de ce schéma est déterminée par le type de bloc qui est sélectionné et par la configuration de la gestion du nodule. Sur un bloc-plaque, c'est-à-dire, un nodule délimité par deux surfaces naturelles et parallèles, la surface d'enlèvements s'oriente selon son axe secondaire, par conséquent on ne peut qu'extraire des petits éclats, dont l'axe technologique est enchâssé dans les plans naturels (Figure V.10, p. 637). La longueur limitée de la surface d'enlèvement permet le contrôle de la carène; la progression du débitage s'effectue d'une manière tournante et le plan de frappe n'a pas une position fixe, par contre il se trouve sur las surfaces naturelles, en modifiant la fonction du plan de frappe et de la base du nucléus selon les besoins de la progression du débitage.

Par conséquent, il s’agit d’un schéma de production d'éclats rapide et simple, ce qui permet une optimisation des caractéristiques de la matière première sur les contraintes qu'elle présente (les nombreux plans naturels), pour un processus de taille efficace et immédiat. 


\section{3 - CHAÎNE OPÉRATOIRE CENTRIPÈTE}

Ce schéma conceptuel s'implante dans la tradition des schémas de débitage de type centripète-discoïde, qui profitent d'un nucléus structuré en deux surfaces secantes, de façon à ce que la production de ces surfaces s'exécute à partir de l'arête du contour. Dans ce cas précis, il s'agit d'un procédé très simple d'exploitation de galets sans phases de mise en forme ou de préparation recherchée; la phase de production se limite à l'obtention de supports de la surface qui possède les conditions techniques les plus aptes, plus que d'une activité de production bifaciale alternante (Figure V.11, p. 639). Le sens de la taille est centripète car on essaye d'extraire les éclats de cette surface d'une façon rapide, à l'aide de coups contigus qui contournent le nodule. Il s'agit d'un schéma simple et rapide adapté à un type de nodule (les galets) pour l'obtention d'éclats de forme immédiate.

\section{4 - RELATION DES CHAÎNES OPÉRATOIRES REPÉRÉES DANS « EL ESPERTÍN » AVEC D’AUTRES PROCESSUS OPÉRATOIRES}

Dans une deuxième section de cette étude, nous essayons d'insérer ces schémas étudiés dans un contexte chrono-culturel précis, ou du moins, les rattacher avec des traditions culturelles situées dans le temps et dans l'espace. Bien entendu, nous ne pourrons atteindre cet objectifs que lorsque les études sur les technologies lithiques puissent se divulguer, ainsi, on pourra mettre en place une technologie comparative. Aujourd'hui, nous ne possédons que très peu d'études de type technologique sur des gisements de la Corniche Cantabrique, du moins des analyses étendues; les travaux disponibles actuellement (par exemple: Cazals, 2000; Lloret, 2001; Maíllo, 2003) contemplent des périodes chronologiques antérieures au Mésolithique (Magdalénien Inferiéur - Moyen; Magdalénien Supérieur/Final-Azilien et la transition au Paléolithique Supérieur respectivement).

Par conséquent, nous nous trouvons dans une conjoncture particulière car, afin d'étudier le contexte chrono culturel de El Espertín, le Mésolithique / Epipaléolithique, nous ne trouvons aucune autre analyse, de type technologique, que la nôtre. Il faudrait ajouter aussi, dans l'énumération des diverses difficultés, le fait que le 
Epipaléolithique/Mésolithique n'est pas encore très connu dans la zone centra occidentale de la Corniche Cantabrique, nous n'avons même pas accès à un répertoire des caractéristiques générales de cette époque dans un contexte proche. Nous pouvons disposer de l'Asturien (González Morales, 1982; Arias Cabral, 1991; Fano, 1998), comme facies maritime du Mésolithique Cantabrique, mais les caractéristiques de sa production lithique sont assez particulières et elles s'écartent de celles que nous avons dans El Espertín. Il existe aussi une autre série de gisements Mésolithiques dans un contexte interne (par exemple Los Canes [Arias Cabal et Pérez Suárez, 1990, 1992, 1995; Arias, 1991], Arangas, La Garma [Arias et al., 1990], Tarrerón [Apellániz, 1975, Arias, 1991], Cubío Redondo [Ruiz Cobo et Smith, 2001], etc.), mais il est vrai qu'ils incarnent des exemples clairs de cette occupation Mésolithique qui se répand vers l'intérieur de la Corniche Cantabrique, cependant nous ne pouvons pas très bien connaître les caractéristiques concrètes de cette production lithique.

Un aspect très important, en ce qui concerne un objectif beaucoup plus ample, celui de la relation entre les caractéristiques technologiques de ce gisement avec d'autres gisements, dans un contexte synchronique et diachronique; serait l'étude des traits culturels que l'on peut mettre en rapport avec les groupes culturels ou traditions délimitées. Il semble que la chaîne de type prysmatique-unipolaire est celle qui contient un « marqueur culturel » plus intense.

Il faudrait expliquer d'une façon plus accentuée, de même que nous l'avons fait dans la méthodologie, qu'il est important de délimiter les traits culturels de ceux qui sont déterminés par des éléments techniques ou matériels. Il se peut que les chaînes de type plus simples soient en relation avec des façons de créer un processus de débitage d'une façon rapide et pratique, adapté aux caractéristiques des matières premières en question. Sous l'appellation « simple » nous voulons dire que ce sont des schémas avec un nombre réduits de gestes, sans une mise en forme élaborée ou bien avec un développement ample du processus de taille; sans aucune signification dépréciative. Il y a même eu des controverses, en ce qui concerne la catégorie technologique de ce type de chaînes, car on hésite à considérer comme des schémas conceptuels des schémas simples, adaptés presque toujours aux caractéristiques de la matière première. Pour caractériser ce type de processus on emploi des termes comme «formule » ou bien 
« algorithme » (Pelegrin, cité avec Cazals, 2000: 105). Notre avis, est plus en faveur de la considération de ces types de production comme étant des schémas conceptuels, (ou chaînes opératoires) avec des caractéristiques spécifiques.

Pour donner un exemple de ce type de chaînes, nous avons dans El Espertín les différents processus de débitage d'éclats (la chaîne centripète et celle du nodule-plaque). Ces chaînes semblent correspondre avec les caractéristiques morphologiques et techniques des matières en question. Ces chaînes simples, aptes à une production efficace de nodules déterminés, pourraient être considérées comme une espèce d’archétypes de production de nodules avec une structure volumétrique déterminée. Ces archétypes pourraient correspondre, à un événement de convergence technique, plus qu'à des traditions culturelles. Cependant, il est curieux que dans un contexte chronologique pas très éloigné, le IXème millénaire BP, il existe aussi tout un processus technique de débitage d'éclats, de type simple et lié aux caractéristiques de la matière première. Nous pouvons trouver ce type de chaînes dans plusieurs gisements mésolithiques des Pyrénées orientaux (Terradas, e.p.). Par conséquent, il est tout à fait possible qu'une exploitation intense des ressources locaux dans le Mésolithique, nous mette en présence de ce type de chaînes-archétypes, parfaitement adaptées à la production des matières disponibles.

\subsection{1 - CHAÎNE PRISMATIQUE-UNIPOLAIRE}

Nous pourrions considérer la chaîne prismatique comme étant la plus représentative d'un point de vue «culturel ». Cependant, il serait souhaitable de faire quelques considérations, afin de définir le fonction de cette chaîne :

- D'un point de vue technologique, la chaîne prismatique-unipolaire est une structure volumétrique en forme de prisme quadratique. Cette structure va être exploitée à partir du système de "gestion du volume » du nucléus, et non pas « de surface », selon la terminologie de E. Boëda (1990).

- Cette structure va être utilisée pour des processus de débitage laminaire et surtout microlaminaire, même s'il est possible de debiter des supports de 
type éclat ou éclat laminaire, mais toujours avec une volonté d’obtenir des productions allongées.

- Nous pouvons développer ce schéma conceptuel en plusieurs schémas opératoires, mais il faut toujours tenir compte de la structure fondamentale, surtout le principe de « gestion des volumes du nucléus ».

- D’un point de vue typologique, les nucléus prismatiques unipolaires et bipolaires et les nucléus pyramidaux sont très connus tout au long du Paléolithique, et sont très abondantes dans des ensembles du Paléolithique supérieur et Epipaléolithique ; dans cet ensemble, beaucoup d'entre eux pourraient se cataloguer dans certains schémas opératoires décrits dans El Espertín, concrètement dans le premier: le « prismatique typique ».

De tous les schémas opératoires de la chaîne prismatique-unipolaire détaillés dans El Espertín, uniquement le «prismatique typique » peut se suivre à la trace d'une façon plus ou moins vraisemblable dans d'autres ensembles. Les autres deux schémas, celui à surface ample, et celui unipolaire, ne sont pas susceptibles d'être identifiés d'une façon aussi immédiate comme le premier. Cela ne veut pas dire qu'il ne puisse pas exister dans d'autres gisements, mais en ne pouvant pas les identifier correctement, nous ne sommes pas en mesure de mettre en place une étude exhaustive du sens et des implications de ces schémas, autant à un niveau technique comme culturel.

Il faut mettre en relief, le fait que cette structure prismatique possède une gamme variée de modalités d'application. Il existe une certaine tendance vers l'utilisation des schémas spécifiques pour des supports plus ou moins concrets. Par conséquent, la flexibilité que nous avons constaté dans la gestion des matières premières pourrait s'étendre vers une flexibilité technique lors de l'application de schémas variés, afin d'obtenir une gamme de supports plus ample, autant pour des lames et lamelles ou pour des éclats laminaires et des éclats de dimensions variées.

Les modalités prismatiques-A et B sont celles que l'on pourrait trouver le plus dans des ensembles lithiques, mais afin d'effectuer une comparaison entre ces schémas et ceux que l'on peut deviner à partir des nucléus prismatiques et pyramidaux 
« classiques » (Bordes, 1979: 89; Brézillon, 1977: 92-93; Laplace, 1966: 32; Rozoy, 1968: 378), il est nécessaire d'énoncer certaines précisions d'ordre techniques:

- La structure volumétrique est essentiellement prismatique dans le corps du nucléus (jamais cylindrique) et sa section transversale est sous rectangulaire ou sous triangulaire (jamais circulaire).

- La table laminaire est encaissé dans les flanc latéraux, cependant un des deux est toujours perpendiculaire. Les flancs ainsi conformés, jouent un rôle important dans le maintient du cintre.

- La production peut être unipolaire (c'est celle que l'on remarque dans El Espertín) ou bien bipolaire. Cette dernière n'est pas visible dans notre ensemble, mais c'est un schéma que l'on peut trouver à différents moments du Paléolithique Supérieur.

- La progression de l'exploitation est souvent frontale, mais elle peut aussi devenir semi-tournante, et même tournante. Cependant, dans cette dernière modalité la progression du débitage se manifeste à partir de tables juxtaposées consécutives, l'une à côté de l'autre, jusqu'à dilater la surface d'enlèvement dans tout le contour, sans pour cela perdre la structure volumétrique prismatique, avec sa section sous-rectangulaire.

- Dans les nucléus pyramidaux l'arête qui se trouve dans sa base, est un élément structurel important lors de la configuration du volume. Une autre caractéristique essentielle est la production unipolaire, convergente et, très souvent, frontale.

Nous avons assez insisté sur le fait que, dans ce schéma opératoire « prismatique classique », la progression du débitage s'effectue à partir de l'exploitation de tables laminaires qui peuvent se dilater plus ou moins la surface d'enlèvement, tout au long du contour du nucléus. Il faut souligner que l'on essaye de maintenir la structure prismatique du début. Ainsi, les nucléus qui possèdent une production tournantecirculaire, plus appropriée des structures cylindriques ou coniques, resteraient en dehors de ce schéma opératoire. Ce dernier type de production, fournirait des nucléus en forme de «mitre » ou de «balle de fusil », qui se forment, à partir de modes de taille 
spécifiques, concrètement par pression (VVAA, 1984; Pelegrin, 1988; Inizian et al., 1995: 77-80), technique qui apparaît en Europe à partir d'un période avancée du Mésolithique (selon les auteurs qui analysent les différents mode de taille, par exemple: Tixier, 1984: 62; Pelegrin, 1988), se développant en grande partie tout au long du Néolithique et du Chalcolithique.

Les schémas prismatiques-A et B livrent les produits laminaires d'une façon systématique ; le premier (vers une tendance pyramidale) est le plus indiqué pour les lamelles, tandis que le deuxième, l'est pour les lames. Dans El Espertín, il existe, en principe, une production indépendante de ces supports, à partir des deux schémas, mais on a vérifié, dans certains cas, une production continue de lames et ensuite des lamelles, à cause de la diminution des nucléus. Par contre, on n’a pas constaté de production intercalée de lames et lamelles.

\section{QUELQUES EXEMPLES DE CHAÎNES PRISMATIQUES DANS LA RÉGION CANTABRIQUE}

Comme nous l'avons dit précédemment, les analyses technologiques dont nous sommes en possession, en ce qui concerne les zones plus ou moins proches, sont très peu nombreuses. Étant donné que les études technologiques débutent, des problèmes en relation à des critères technologiques avec lesquels nous analysons les différentes séries, et aussi aux particularités inhérentes aux différents ensembles, peuvent surgir. En ce qui concerne la Région Cantabrique, nous disposons de deux études technologiques étendus de périodes avancés du Paléolithique Supérieur, l'une du Magdalénien Inférieur Moyen (Cazals, 2000) et l'autre du Magdalénien Final/Azilien (Lloret, 2001). Dans les deux travaux, on définie des schémas qui peuvent évoquer le schéma prismatique-A (pyramidal) explicitée dans El Espertín. Dans le Magdalénien Inférieur et Moyen, N. Cazals énonce un débitage convergeant, avec un volume pyramidal du nucléus, caractérisé par une importante préparation du nucléus et des enlèvements et progression frontale. Pour le Magdalénien Supérieur/Final-Azilien, M. Lloret définie un schéma avec volume pyramidal, dont le sens de la taille est unipolaire et dont la progression est frontale dans le Magdalénien Supérieur/Final et semi-tournant dans le Azilien. Dans les deux cas de figure, il s'agit de schémas élaborés, aptes à la production de lames et de lamelles rectilignes d'une bonne regularité. 


\subsection{2 - LES CHAÎNES D’ÉCLATS}

Dans le Paléolithique Supérieur et dans les périodes suivantes il subsiste une production d'éclats en même temps que la production laminaire (Cazals, 1999), dont l'application et le traitement, ont souvent été oubliés. Il n’est pas impossible de trouver, dans le catalogue des formations lithiques des gisements de ces périodes, la présence de nucléus caractérisés comme étant discoïdes, amorphes, etc. qui pourraient correspondre à des schémas de production spécifiques d'éclats. En plus, dans les types d'outils exécutés, on utilise, à différents niveaux, des éclats comme support. Cependant, il faut toujours évoquer le fait que, ces éclats pourraient appartenir à des processus laminaires, et dans ce cas, il faudrait évaluer, à chaque fois, s'il existe une production laminaire exclusive ou bien une production mixte dans l'ensemble.

Nous avons aussi constaté le fait que, quelques-unes de ces méthodes pourraient être considérées comme étant des archétypes d'exploitation de volumes ou de matières concrètes. De cette façon, une exploitation de ce type, pourrait être désigné comme opportuniste, car elle utilise d'une façon immédiate et rapide des formes prédéterminées.

Suite à cette analyse, il faut considérer deux tendances, en ce qui concerne les débitages d'éclats à structure simple:

i) Ce sont peut-être des archétypes d'exploitation avec une morphologie concrète (par exemple des galets, plaques, etc.), par conséquent, il est possible qu'elles apparaissent dans différents contextes chrono-culturels, à cause d'une manifestation de convergence technique.

ii) Une présence intense de ce type d'exploitation, peut être une indication d'un comportement opportuniste, et cette donnée peut renfermer une implication culturelle plus importante que l’idée précédente.

En ce qui concerne ce dernier sujet, et en nous ajustant dans le Epipaléolithique / Mésolithique, il faut préciser que, parfois, des chaînes d'exploitation d'éclats à structure simple apparaissent dans ces ensembles. Il ne faut pas oublier que c'est une période 
caractérisée par un accroissement des ressources locales. Par conséquent, cette attitude opportuniste correspondrait à un trait fréquent de cette période.

Le schéma centripète/discoïde, est un des plus traditionnels, des schéma d'éclats, mais il en existe d'autres, de type expéditif ou opportuniste, comme les plus élaborés.

La caractéristique qui frappe le plus dans le Epipaléolithique/Mésolithique, est la traditionnelle présence d'une production d'éclats dans des ensembles où ce type de supports va avoir une présence assez notable. Un des exemples les plus évidents, de cette présence dans la Corniche Cantabrique est l'Asturien. Dans cette facies littorale du Mésolithique, la présence de lames et de lamelles est très restreint, tandis que les outils retouchés sur les éclats, ainsi que les outils nucléaires, la plupart d'entre eux de quartzite, vont être les éléments les plus nombreux. En partant de l'étude réalisée par G. A Clark (1976), en continuant avec celle de M. R. González Morales (1982), et en arrivant à celle de P. Arias (1991) sur plusieurs séries d'ensembles lithiques asturiens, on observe une prépondérance des éclats dans les produits de taille, de même que dans les nucléus d'éclats (discoïdes, mixtes, etc.), c'est ainsi que les lames et les lamelles n’apparaissent que très peu, et, surtout, entre les pièces retouchées. P. Arias (1987) identifie un type de nucléus dans des pièces traditionnellement définies comme étant des galets taillés unifacials (choppers), il s’agit du «nucléus unidirectionnel avec un plan de frappe cortical » (NUPC), qui est le plus nombreux dans les gisements asturiens qu'il étudie. Il s'agit d’un procédé très expéditif et immédiat sur une surface naturelle (corticale), caractéristiques qui peuvent correspondre avec l'abondance d'éclats avec talon cortical qui apparaissent entre les déchets de la taille.

Dans les Pyrénées Orientaux, il existe une série de gisements, au IXème millénaire BP dont la production d'éclats est l'aspect essentiel de la production lithique (par exemple à Font del Ros, Berga, Barcelona [Terradas, 1995]) ou du moins une partie importante de l'ensemble industriel, à côté de quelques lames-lamelles (Terradas, e.p.). Il existe trois modèles d'exploitation des éclats identifiés dans ces gisements : i) exploitation unipolaire d'une surface d'enlèvement, à partir d'un seul plan de frappe, ii) exploitation unipolaire alternante de plusieurs surfaces d'enlèvement, à partir de plusieurs plans de frappe, et iii) exploitation discoïde. On pourrait définir le deuxième 
comme un accroissement du premier modèle, mais dans les deux cas, il s'agit d'une méthode très variable, en fonction du bloc de matière.

Il faut citer aussi dans ce chapitre, en ce qui concerne le Mésolithique de la Péninsule Ibérique septentrionale, la présence du dénommé « Mésolithique macro lithique » ou bien " Mésolithique à denticulés », situé aux alentours de la Vallée de l’Èbre (Cava, 1994 ; Utrilla et al., 1998; García Martínez de Lagrán, 2001; Alday Ruiz, 2002; Utrilla, 2002). Même si nous ne disposons pas d'études technologiques rigoureuses, les caractéristiques typologiques de l'industrie, indiquent une absence d'éléments laminaires et, au contraire, un nombre élevé d'utilisation d'éclats, surtout de grande dimension, pour la réalisation des pièces retouchées, avec une richesse dans l'ensemble retouché d'encoches et de denticulés, et aussi dans la retouche définie sous le nom de «campignien». Ce mésolithique “macrolithique” est une phase du Mésolithique située dans le bassin de l’Èbre (aussi bien dans son bassin basse, comme dans la haute, vers la zone de Alava), sans qu'il se soit manifesté, jusqu'à ce jour, dans la Corniche Cantabrique centro-occidentale. Elle se développe dans la deuxième moitié du IX ème millénaire BP et il s'agit d'une phase qui suit une époque mésolithique à caractère « microlitique » rattachée à l’Azilien.

Ce qui est curieux, dans cette phase macrolitique, c'est l'apparente coupure que représente, dans la tradition laminaire précédente (normalement caractérisée comme un Épipaléolithique microlithique ou aziloïde) et postérieure (l’Épipaléolithique / Mésolithique Géométrique sur le modèle de Cocina [Fortea, 1973]). Nous ne possédons pas encore d'études technologiques de ce Mésolithique macrolithique, mais les indices de sa technologie, à partir de ses caractéristiques typologiques, indiquent une production de supports assez groses, surtout des éclats, même si nous ne connaissons pas à partir de quelle catégorie de schémas opératoires. De même, il faut remarquer qu'après cette phase (en coïncidant en partie avec elle), à partir du 8000 BP à peu près, apparaît le Mésolithique Géométrique, dont la technologie, à partir à nouveau des indices typologiques, se focalise fondamentalement dans une production laminaire élaborée, portée vers l'obtention de lames, qui puissent permettre réaliser les géométriques. 


\section{CONCLUSIONS}

Les caractéristiques techniques de l’industrie lithique de El Espertín constituent l'objectif le plus important de cette étude. Lors du chapitre cinq nous avons énoncé en détail, les résultats les plus significatif de cette étude. Nous allons maintenant schématiser les éléments les plus génériques de cette industrie lithique.

- $\quad$ La stratégie d'acquisition des matériaux lithiques est en majorité de type local et intensif (les matériaux locaux les plus abondants aux abords, sont les plus nombreuses dans le gisement : le chert noir et la quartzite).

- La stratégie d'exploitation des diferentes matières premières dépend de son abondance et/ou proximité:

a) Dans les matériaux locaux plus abondants (chert noir, quartzite) il existe une production de type extensif avec un objectif mixte (éclats et lames/lamelles).

b) Dans les matières autochtones moins nombreuses (radiolarite et silex gris, localisées probablement à une plus grande distance que les précédentes), il existe une production de type intensif et spécialisé dans la production laminaire de lames et de lamelles.

c) Dans les matériaux les plus éloignés et/ou bien à caractère « exotique » (divers silex ) la spécialisation microlaminaire est plus soulignée, ce qui produit une rupture dans la chaîne opératoire, de sorte que la phase d'utilisation et abandon des outils apparaissent uniquement dans le gisement (surtout les éléments à dos et les géométriques); c'est-à-dire, qu'il s’agirait de témoins d'outils qui auraient été fabriqués ailleurs et qui seraient arrivé comme des produits finis (sans doute emmanchés sur des pointes de projectiles, des flèches, etc.).

d) Sur le quartz, il existe tout un processus de taille particulier et différent des autres matériaux. Il est très peu abondant, avec des traces d'avoir subi un processus de modification et de retouche, mais avec une carence du gros des 
pièces retouchés ou façonnées. Nous n’avons pas indiqué toutes les phases du processus, il manque l’usage et abandon des supports retouchés.

- On constate une abondante activité de taille dans le gisement, avec trois chaînes opératoires identifiées, une d'entre elles avec un objectif laminaire et les autres deux avec un objectif de type d'éclats.

o Les chaînes d'éclats (un schéma conceptuel centripète et un autre que nous avons appelé de type-nodule-plaque) s’appliquent sur les matériaux qui ont souffert un processus plus ample et qui sont plus abondants, c'est-à-dire le chert noir et la quartzite.

o La chaîne laminaire est le schéma opératoire en forme de prismeunipolaire et on l'applique sur toutes les matières (avec l'exception que nous avons déjà commentée du quartz), par conséquent il possède une grande flexibilité, qui se concrète en trois processus opératoires.

- Les chaînes d'éclats ont une structure d'exploitation très simples, reliées à la morphologie du nodule en question. Ce type d'exploitation pourrait être qualifié d'opportuniste, car il s'agit d'une utilisation immédiate et rapide sur des volumes concrets et sur des matériaux très nombreux dans l'entourage immédiat.

o Ces chaînes d'éclats pourraient correspondre à des archétypes d'exploitation de nucléus avec une morphologie déterminée ( galets fluviaux et des nodules en forme de plaques).

- La chaîne opératoire de structure en forme de prisme-unipolaire possède trois modalités : i) schéma opératoire prismatique «typique », ii) de surface ample et iii) unipolaire prismatique.

o Même s’il s'agit d'une chaîne élaborée, la chaîne prismatique possède une nuance opportuniste, surtout visible lors de la phase de sélection et de mise en forme du nucléus, car il y a une utilisation récurrente de la morphologie originelle des nodules, aussi bien par l'orientation du nucléus, que pour la genèse du débitage, dans lequel on utilise d'habitude les arêtes naturelles des blocs originaux (les lames d'entame avec une arête naturelle). 
o Le premier schéma opératoire pourrait correspondre avec certains des nucléus en prismatique «classiques » du Paléolithique Supérieur, avec deux subdivisions: le schéma prismatique-A (de débitage unipolaire convergeant et frontal, dont les nucléus particuliers sont de tendance pyramidale) et le schéma prismatique-B (de débitage unipolaire demi tournante, parfois à partir de deux plans opposés mais sur des surfaces alternes, avec des nucléus prismatiques unipolaires ou bipolaires).

o Le schéma prismatique-A (pyramidal) surtout employé dans la production de lamelles, tandis que le prismatique-B apparaît plus souvent en lames.

o Le schéma opératoire à large surface est très utile afin d'obtenir d'épaisses lames et d'éclats laminaires de différente taille. Ce schéma dispose de deux méthodes : unipolaire et bipolaire.

o Le schéma opératoire unipolaire prismatique possède une structure en forme de prisme et des objectifs laminaires, mais il est plus opportuniste que les précédents. On pourrait même le considérer comme une application rapide du schéma en forme de prisme générique sur des nodules épais et courts. La propriété la plus opportuniste de ce schéma rappelle, à un certain degré, la chaîne de nodule-plaque et, de même que dans la précédente, on l'applique dans les matériaux les plus abondants de l'ensemble (chert noir et quartzite).

- Dans le choix des supports dans le but de retoucher il existe, normalement, plusieurs degrés de spécialisation en relation aux différents types de supports:

o On utilise, presque exclusivement, les lamelles pour des éléments à dos (lames et pointes).

o Les lames renferment une utilité diversifiée modérée: pour des pièces de retouche continue, burins, truncatures, géométriques et ce qui reste de la séquence de retouche de ces derniers (microburins, piquantstrièdres, morceaux d'encoche ou de retouche proche d'une encoche, peut-être quelques encoches). 
o Les éclats, d'une utilité diversifiée plus ample, se trouvent dans une plus grande variété de pièces retouchées et elles sont primordiales pour les pièces de «fond commun »: grattoirs, perçoirs, burins, racloirs, denticulés, encoches, etc.

- De même, on pourrait mettre en relief qu'il existe des préférences dans certaines matières premières pour types retouchés concrets, mais sans pour cela parler d'une « gestion des matières premières » stricte:

o La quartzite pour des encoches, denticulés et racloirs.

o La radiolarite-1 dans les géométriques.

o La radiolarite, le silex gris et les silex variés dans les pièces à dos.

- En ce qui concerne la typologie des pièces retouchées, ce sont les pièces avec des retouches sur un ou deux côtés qui prédominent, même si entre elles la plupart possèdent une modification marginale. Ensuite, on trouverait les encoches et les denticulés, après les éléments à dos. Les grattoirs possèdent des modules courts, fabriqués sur des éclats dans la plupart des cas et il existe une grande quantité de unguiformes. Dans les burins, prédominent ceux qui possèdent une facture simple, spécialement ceux d'angle sur cassure. Il faut remarquer la présence de 14 géométriques (6 triangles, 4 pointes triangulaires et 4 trapèzes), tous avec une retouche abrupte. Il faut aussi distinguer une pointe de cran et une petite pointe avec un pédoncule très court.

- Il faut distinguer lors de la fabrication de ceux géométriques, lors de la phase de retouche, la présence de deux procédés de cassure de la lame-support.

o La technique du microburin.

o La « technique de fracture transversale ».

Pour résumer les caractéristiques techniques, nous pouvons mettre en relief une caractéristique économico-stratégique, c’est l'exploitation intensive des matériaux locaux. En plus, cette exploitation est exécutée à partir de procédés opératoires qui sont à la fois flexible set efficaces. Flexibles dans la variété des matériaux qu'ils exploitent, 
mais aussi dans les chaînes opératoires développées, lesquelles sont appliquées pour cette différence matérielle ( aussi bien un chert ou radiolarite d'une qualité parfois médiocre, comme la quartzite). L'efficacité se manifeste, non seulement, dans le savoirfaire des tailleurs du mésolithique, mais aussi dans la facilité afin d’obtenir une série de supports prédéterminés par les objetives marqués par les propres valeurs culturelles. Une autre caractéristique importante de cette tradition culturelle c'est l'adaptabilité et l'opportunisme qu'ils possèdent afin de gestionner les objets lithiques d'une façon immédiate et pratique, à partir d'une panoplie variée de schémas opératoires. 